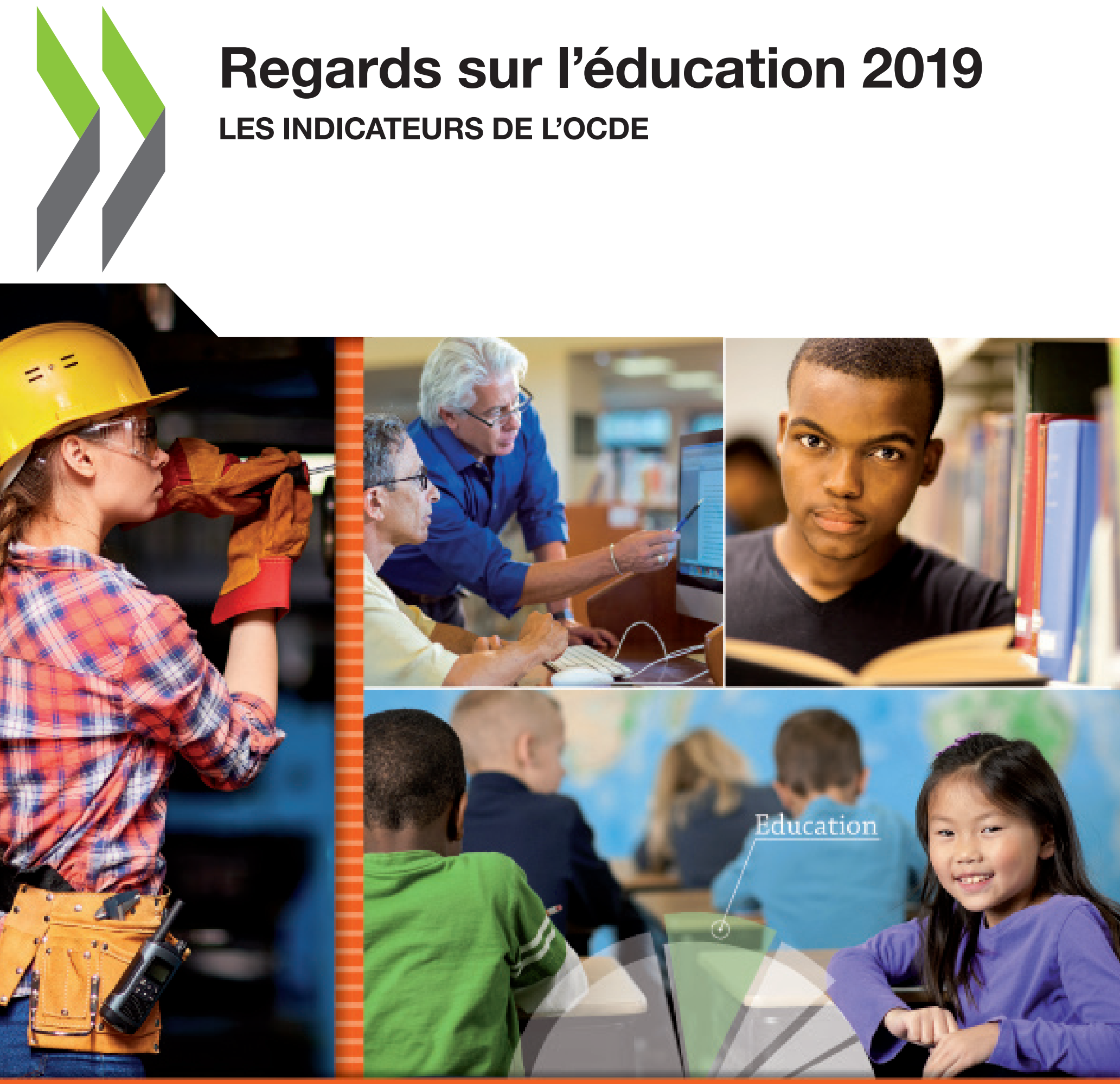

Q 8 OCDE 


\section{Regards sur l'éducation 2019}

LES INDICATEURS DE L'OCDE

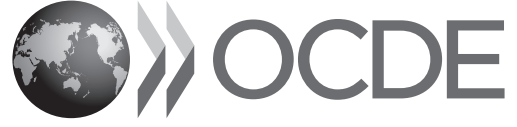


Cet ouvrage est publié sous la responsabilité du Secrétaire général de l'OCDE. Les opinions et les arguments exprimés ici ne reflètent pas nécessairement les vues officielles des pays membres de l'OCDE.

Ce document, ainsi que les données et cartes qu'il peut comprendre, sont sans préjudice du statut de tout territoire, de la souveraineté s'exerçant sur ce dernier, du tracé des frontières et limites internationales, et du nom de tout territoire, ville ou région.

\section{Merci de citer cet ouvrage comme suit :}

OCDE (2019), Regards sur l'éducation 2019 : Les indicateurs de l'OCDE, Éditions OCDE, Paris, https://doi.org/10.1787/6bcf6dc9-fr.

ISBN 978-92-64-67749-4 (imprimé)

ISBN 978-92-64-85387-4 (pdf)

Regards sur l'éducation

ISSN 1563-0528 (imprimé)

ISSN 1999-1495 (en ligne)

Les données statistiques concernant Israël sont fournies par et sous la responsabilité des autorités israéliennes compétentes. L'utilisation de ces données par l'OCDE est sans préjudice du statut des hauteurs du Golan, de Jérusalem-Est et des colonies de peuplement israéliennes en Cisjordanie aux termes du droit international.

Crédits photo : Couverture $\odot$ Christopher Futcher/iStock; @ Marc Romanelli/Gettyimages; @ michaeljung/ Shutterstock; $\odot$ Pressmaster/Shutterstock.

Les corrigenda des publications de l'OCDE sont disponibles sur : www.oecd.org/about/publishing/corrigenda.htm.

La copie, le téléchargement ou l'impression du contenu OCDE pour une utilisation personnelle sont autorisés. Il est possible d'inclure des extraits de publications, de bases de données et de produits multimédia de l'OCDE dans des documents, présentations, blogs, sites internet et matériel pédagogique, sous réserve de faire mention de la source et du copyright. Toute demande en vue d'un usage public ou commercial ou concernant les droits de traduction devra être adressée à rights@oecd.org. Toute demande d'autorisation de photocopier une partie de ce contenu à des fins publiques ou commerciales devra être soumise au Copyright Clearance Center (CCC), info@copyright.com, ou au Centre français d'exploitation du droit de copie (CFC), contact@cfcopies.com. 


\section{Avant-propos}

Les pouvoirs publics s'intéressent de plus en plus aux analyses comparatives internationales des possibilités d'apprentissage et des résultats de l'éducation lorsqu'ils doivent élaborer des politiques visant à améliorer les perspectives économiques et sociales des individus, à promouvoir une gestion plus efficace des systèmes scolaires et à mobiliser des ressources pour répondre à une demande croissante. La Direction de l'éducation et des compétences de l'OCDE concourt à ces efforts grâce à l'élaboration et à l'analyse d'indicateurs quantitatifs, comparables à l'échelle internationale, qu'elle publie chaque année dans Regards sur l'éducation. Associés aux examens des politiques nationales menés par l'OCDE, ces indicateurs peuvent aider les pouvoirs publics à améliorer l'efficacité et l'équité de leur système d'éducation.

Regards sur l'éducation répond aux besoins d'un large éventail de lecteurs : des décideurs soucieux de tirer des enseignements politiques aux chercheurs en quête de données pour approfondir leurs analyses, en passant par l'opinion publique désireuse de savoir dans quelle mesure les établissements d'enseignement de son pays réussissent à former des élèves et des étudiants de classe internationale. Cette publication analyse la qualité des résultats de l'éducation, les leviers politiques et les facteurs contextuels qui conditionnent ces résultats, ainsi que les diverses formes de rendement privé et social générées par les investissements dans l'éducation.

Regards sur l'éducation est le fruit d'une longue et intense collaboration entre les gouvernements des pays de I'OCDE, les experts et institutions qui participent au Programme des indicateurs des systèmes d'enseignement de l'OCDE (INES), et le Secrétariat de l'OCDE. La Division Innovation et mesure du progrès de la Direction de l'éducation et des compétences de l'OCDE s'est chargée de la rédaction de la présente publication, sous la responsabilité de Deborah Roseveare et de Marie-Hélène Doumet et en collaboration avec Étienne Albiser, Majda Benzidia, Andrea Borlizzi, Éric Charbonnier, Manon Costinot, Gillian Golden, Bruce Golding, Fatine Guedira, Corinne Heckmann, Karinne Logez, Camila de Moraes, Simon Normandeau, Gara Rojas González, Daniel Sánchez Serra, Markus Schwabe, Giovanni Maria Semeraro et Choyi Whang. Valérie Forges s'est chargée du soutien administratif et Vanessa Denis, Majda Eddaifi, Yanjun Guo, Julia Himstedt et Hajar Sabrina Yassine ont fourni un soutien analytique ainsi que des conseils supplémentaires. Marilyn Achiron, Cassandra Davis et Sophie Limoges ont apporté une précieuse contribution au processus éditorial et à la production de cet ouvrage. La préparation de ce rapport a été dirigée par les pays membres au travers du Groupe de travail INES et facilitée par les réseaux INES. Les membres des différents organismes et les experts qui ont contribué à cette publication en particulier et aux travaux du réseau INES en général sont cités en fin d'ouvrage.

Même si de nombreux progrès ont été accomplis ces dernières années, les pays membres et l'OCDE continuent de renforcer l'adéquation entre les besoins politiques et les données disponibles les plus comparables à l'échelle internationale. La poursuite de ce dessein passe par de nombreux défis et compromis. Premièrement, les indicateurs doivent aborder des questions sur l'éducation qui comptent parmi les priorités politiques des pays et dont l'étude comparative dans une perspective internationale peut utilement compléter les analyses et les évaluations réalisées à l'échelle nationale. Deuxièmement, si les indicateurs doivent se prêter autant que possible aux comparaisons internationales, ils doivent néanmoins laisser ressortir les spécificités nationales, de façon à pouvoir tenir compte des différences historiques, systémiques et culturelles entre les pays. Troisièmement, la présentation des indicateurs doit être aussi concise que possible, mais assez détaillée pour éviter de simplifier outre mesure les réalités complexes de l'éducation. Enfin, le souhait général est de limiter le 


\section{4 | AVANT-PROPOS}

plus possible la panoplie d'indicateurs, pour autant qu'elle demeure suffisamment étoffée pour servir de base de travail aux décideurs politiques de pays qui font face à des enjeux différents dans le domaine de l'éducation.

L'OCDE continuera non seulement de relever ces défis avec détermination et d'élaborer des indicateurs dans des domaines où la collecte de données est réalisable et prometteuse, mais aussi d'étendre ses recherches à des domaines qui requièrent encore des travaux conceptuels importants. Le Programme international pour le suivi des acquis des élèves (PISA) de l'OCDE et son prolongement par le biais du Programme pour l'évaluation internationale des compétences des adultes (Évaluation des compétences des adultes [PIAAC]), ainsi que l'Enquête internationale sur l'enseignement et l'apprentissage (TALIS) de l'OCDE, sont autant d'initiatives majeures sur la voie de l'accomplissement de cet objectif. 


\section{Table des matières}

Avant-propos 3

Éditorial

$\begin{array}{ll}\text { Introduction : les indicateurs et leur structure } & 15\end{array}$

$\begin{array}{ll}\text { Guide du lecteur } & 21\end{array}$

$\begin{array}{ll}\text { Résumé } & 29\end{array}$

Les jeunes dans l'Objectif de développement durable relatif à l'éducation 34

Chapitre A. Résultats des établissements d'enseignement et impact de l'apprentissage 45

Indicateur A1. Quel est le niveau de formation de la population adulte ? 46

Indicateur A2. Transition entre les études et la vie active : Où en sont les jeunes d'aujourd'hui ? 62

Indicateur A3. Dans quelle mesure le niveau de formation affecte-t-il le taux d'emploi ? $\quad 74$

Indicateur A4. Quel avantage salarial le niveau de formation procure-t-il ? 94

Indicateur A5. Quels sont les facteurs financiers qui incitent à investir dans l'éducation ? 108

Indicateur A6. En quoi les retombées sociales sont-elles liées à l'éducation ? 128

Indicateur A7. Dans quelle mesure les adultes participent-ils équitablement à des activités de formation?

Chapitre B. Accès à l'éducation, participation et progression 161

Indicateur B1. Quels sont les effectifs scolarisés? 162

Indicateur B2. En quoi les systèmes d'éducation de la petite enfance se différencient-ils dans le

monde? 176

Indicateur B3. Quel est le profil des diplômés du deuxième cycle de l'enseignement secondaire ?196

Indicateur B4. Quel est le profil des nouveaux inscrits dans l'enseignement tertiaire ? $\quad 210$

Indicateur B5. Combien d'étudiants terminent-ils leurs études tertiaires ?

Indicateur B6. Quel est le profil des étudiants en mobilité internationale ? 250

Indicateur B7. Quels sont le profil et les perspectives professionnelles des titulaires d'un doctorat ?268

Chapitre C. Ressources financières et humaines investies dans l'éducation 283

Indicateur C1. Quel est le montant des dépenses par élève / étudiant ? 286

Indicateur C2. Quelle part de leur richesse nationale les pays consacrent-ils à l'éducation ? 300

Indicateur C3. Quelle est la répartition entre les investissements publics et privés au titre des établissements d'enseignement? 312

Indicateur C4. Quel est le montant total des dépenses publiques d'éducation ? 324 
Indicateur C5. Combien les étudiants paient-ils et quelles aides publiques reçoivent-ils dans l'enseignement tertiaire?

Indicateur C6. À quelles catégories de services et de ressources les dépenses d'éducation sont-elles affectées?

\section{Chapitre D. Enseignants, environnement d'apprentissage et organisation scolaire}

\section{TABLEAUX}

Tableau A1.1. Niveau de formation des adultes âgés de 25 à 64 ans (2018)

Tableau A1.2. Évolution du niveau de formation des adultes âgés de 25 à 34 ans, selon le sexe (2008 et 2018)

Tableau A1.3. Domaines d'études des diplômés de l'enseignement tertiaire âgés de 25 à 64 ans (2018)

Tableau A2.1. Pourcentage de 18-24 ans scolarisés ou non, selon leur situation au regard de l'emploi (2018)

Tableau A2.2. Évolution du pourcentage de jeunes adultes scolarisés ou non, occupant un emploi ou non, selon le groupe d'âge (2008 et 2018)

Tableau A2.3. Pourcentage de 18-24 ans scolarisés ou non, selon leur situation au regard de l'emploi et la durée de la période de chômage (2018)

Tableau A3.1. Taux d'emploi des adultes âgés de 25 à 64 ans, selon le niveau de formation (2018)

Tableau A3.2. Évolution des taux d'emploi des adultes âgés de 25 à 34 ans, selon le niveau de formation et le sexe (2008 et 2018)

Tableau A3.3. Taux d'emploi, de chômage et d'inactivité des adultes âgés de 25 à 34 ans, selon le niveau de formation (2018)

Tableau A3.4. Taux d'emploi des adultes diplômés de l'enseignement tertiaire, selon le domaine d'études (2018)

Tableau A3.5. Taux de chômage des adultes âgés de 25 à 64 ans, selon la durée de la période de chômage et le niveau de formation (2018)

Tableau A4.1. Revenus du travail relatifs des actifs occupés, selon le niveau de formation (2017)

Tableau A4.2. Comparaison du niveau de revenus par rapport au revenu médian, selon le niveau de formation (2017)

Tableau A4.3. Différences de revenus du travail entre les femmes et les hommes travaillant à temps plein, selon le niveau de formation et le groupe d'âge (2017

Tableau A4.4. Revenus du travail relatifs des adultes diplômés de l'enseignement tertiaire, selon le domaine d'études (2017)

Tableau A5.1a. Coûts et bénéfices privés de l'obtention d'un diplôme de l'enseignement tertiaire chez les individus de sexe masculin (2016)

Tableau A5.1b. Coûts et bénéfices privés de l'obtention d'un diplôme de l'enseignement tertiaire chez les 
individus de sexe féminin (2016)

Tableau A5.2a. Coûts et bénéfices publics de l'obtention d'un diplôme de l'enseignement tertiaire chez les individus de sexe masculin (2016)

Tableau A5.2b. Coûts et bénéfices publics de l'obtention d'un diplôme de l'enseignement tertiaire chez les individus de sexe féminin (2016)

Tableau A5.3a. Coûts et bénéfices privés/publics de l'obtention d'un diplôme de l'enseignement tertiaire chez les individus de sexe masculin, selon le niveau de l'enseignement tertiaire (2016)

Tableau A5.3b. Coûts et bénéfices privés/publics de l'obtention d'un diplôme de l'enseignement tertiaire chez les individus de sexe féminin, selon le niveau de l'enseignement tertiaire (2016) 121 Tableau A6.1. Liens sociaux, selon le niveau de formation (2015 ou 2017) 145 Tableau A6.2a. Équilibre entre vie professionnelle et vie privée, selon le niveau de formation (2015 ou 2016) 146 Tableau A6.2b. Intensité et flexibilité du travail, selon le niveau de formation (2012 ou 2015)

Tableau A7.1. Participation à des activités formelles et/ou non formelles de formation, selon le sexe, le groupe d'âge et le niveau d'enseignement (2016)

Tableau A7.2a. Répartition des activités non formelles de formation, selon le sexe, le groupe d'âge et le niveau d'enseignement (2016)

Tableau A7.3. Scolarisation dans l'enseignement formel, selon le groupe d'âge, et répartition par niveau d'enseignement (2017)

Tableau B1.1. Taux de scolarisation, par groupe d'âge (2005, 2010 et 2017)

Tableau B1.2. Taux de scolarisation dans l'enseignement tertiaire, selon le groupe d'âge et le niveau d'enseignement (2017)

Tableau B1.3. Profil des effectifs scolarisés dans l'enseignement tertiaire (2017)

Tableau B2.1. Taux de scolarisation des enfants de moins de 3 ans dans les structures d'éducation et d'accueil de la petite enfance, selon le type de service et l'âge (2005, 2010 et 2017)

Tableau B2.2 Taux de scolarisation dans les structures d'éducation et d'accueil des jeunes enfants (EAJE) et l'enseignement primaire, selon l'âge (2005, 2010 et 2017)

Tableau B2.3. Taux de scolarisation des enfants dans les structures privées d'éducation et d'accueil des jeunes enfants (CITE 0), taux d'encadrement et qualifications minimales (2017)

Tableau B2.4. Financement des structures d'éducation et d'accueil des jeunes enfants (CITE 0) et évolution des dépenses en pourcentage du PIB (2012 et 2016)

Tableau B3.1. Profil des diplômés de la filière professionnelle du deuxième cycle du secondaire (2017) 207

Tableau B3.2. Profil des diplômés de la filière professionnelle de l'enseignement post-secondaire non tertiaire (2017)

Tableau B3.3. Évolution des taux d'obtention d'un premier diplôme du deuxième cycle du secondaire ou de

l'enseignement post-secondaire non tertiaire (2005, 2010 et 2017)

Tableau B4.1. Profil des nouveaux inscrits (première inscription) dans l'enseignement tertiaire (2017)

Tableau B4.2. Répartition des nouveaux inscrits selon le domaine d'études, le sexe et le niveau de

l'enseignement tertiaire (2017)

Tableau B4.3. Taux de premier accès, selon le niveau de l'enseignement tertiaire (2017)

Tableau B5.1. Taux de réussite des étudiants de l'enseignement tertiaire scolarisés à plein temps, selon le niveau d'enseignement et le sexe (2017)

Tableau B5.2. Taux de réussite des étudiants de l'enseignement tertiaire scolarisés à plein temps, selon le niveau d'enseignement et la filière suivie dans le deuxième cycle du secondaire (2017)

Tableau B5.3. Situation des étudiants de licence scolarisés à plein temps à différents délais après leur inscription (2017)

Tableau B6.1. Étudiants étrangers/en mobilité internationale scolarisés dans l'enseignement tertiaire (2010, 2013 et 2017)

Tableau B6.2 Répartition des étudiants étrangers/en mobilité internationale, selon le domaine d'études et la région d'origine (2017)

Tableau B6.3. Profil de mobilité des étudiants étrangers/en mobilité internationale (2017)

Tableau B7.1. Profil des diplômés à l'issue d'un doctorat (2017)

Tableau B7.2. Répartition des diplômés à l'issue d'un doctorat, selon le domaine d'études (2017)

Tableau B7.3. Niveau de formation et taux d'emploi des adultes âgés de 25 à 64 ans titulaires d'un master ou d'un doctorat (2018)

Tableau C1.1. Dépenses totales au titre des établissements d'enseignement par élève/étudiant en équivalents temps plein, sources finales de financement (2016)

Tableau C1.2. Dépenses totales au titre des établissements d'enseignement par élève/étudiant en équivalents temps plein pour les services d'éducation, les services auxiliaires et la R-D (2016)

Tableau C1.3. Indice de variation des dépenses totales au titre des établissements d'enseignement par élève/étudiant en équivalents temps plein (2005, 2011 et 2016) 
Tableau C2.1. Dépenses totales au titre des établissements d'enseignement en pourcentage du PIB (2016) 309 Tableau C2.2. Dépenses totales au titre des établissements d'enseignement en pourcentage du PIB, selon la source finale des financements (2016)

Tableau C2.3. Évolution des dépenses totales au titre des établissements d'enseignement en pourcentage du PIB (2005, 2011 et 2016)

Tableau C3.1. Part relative des dépenses publiques, privées et internationales au titre des établissements d'enseignement, source finale de financement (2016)

Tableau C3.2. Part relative des dépenses publiques, privées et internationales au titre des établissements d'enseignement, source initiale de financement (2016)

Tableau C3.3. Évolution de la part des dépenses publiques, privées et internationales au titre des établissements d'enseignement (2005, 2010 et 2016)

Tableau C4.1. Dépenses publiques totales d'éducation en pourcentage des dépenses publiques totales (2016)

Tableau C4.2. Dépenses publiques totales d'éducation en pourcentage des dépenses publiques totales, selon la provenance des financements (2016)

Tableau C4.3. Évolution des dépenses publiques totales d'éducation en pourcentage des dépenses publiques totales (2005, 2010 et 2016)

Tableau C5.1. Frais de scolarité annuels moyens (ou les plus courants) demandés par les établissements d'enseignement tertiaire aux étudiants nationaux et étrangers (2017/18)

Tableau C5.2. Frais de scolarité demandés par les établissements d'enseignement aux étudiants scolarisés à temps plein, en équivalents USD convertis sur la base des PPA, et pourcentage d'étudiants nationaux bénéficiant d'une aide financière $(2017 / 18)$

Tableau C5.3. Prêts publics aux étudiants, remboursement et allègement de la dette dans l'enseignement tertiaire $(2017 / 18)$

Tableau C5.4. Évolution des politiques de frais de scolarité et de l'aide publique aux étudiants (2007/08 à 2017/18)

Tableau C6.1. Part des dépenses de fonctionnement et des dépenses en capital, selon le niveau d'enseignement (2016)

Tableau C6.2. Dépenses de fonctionnement, selon la catégorie de ressources (2016)

Tableau C6.3. Part des dépenses de fonctionnement, selon la catégorie de ressources et le type d'établissement (2016)

Tableau C7.1. Coût salarial des enseignants par élève, selon le niveau d'enseignement (2017)

Tableau C7.2. Contribution de divers facteurs au coût salarial des enseignants par élève dans l'enseignement primaire (2017)

Tableau C7.3. Contribution de divers facteurs au coût salarial des enseignants par élève dans le premier cycle de l'enseignement secondaire (2017)

Tableau D1.1. Temps d'instruction en filière générale de l'enseignement obligatoire1 (2019)

Tableau D1.2. Organisation de la filière générale de l'enseignement obligatoire (2019)

Tableau D1.3a. Temps d'instruction par matière dans l'enseignement primaire (2019)

Tableau D1.3b. Temps d'instruction par matière en filière générale du premier cycle de l'enseignement secondaire (2019)

Tableau D2.1. Taille moyenne des classes, selon le type d'établissement (2017) et indice de variation entre 2005 et 2017

Tableau D2.2. Taux d'encadrement dans les établissements d'enseignement, selon le niveau d'enseignement (2017)

Tableau D2.3. Taux d'encadrement, selon le type d'établissement d'enseignement (2017)

Tableau D3.1a. Salaire statutaire des enseignants (sur la base des qualifications les plus courantes) à différentes étapes de leur carrière (2018)

Tableau D3.2a. Salaire effectif des enseignants et des chefs d'établissement par comparaison avec les revenus d'autres actifs occupés diplômés de l'enseignement tertiaire (2017)

Tableau D3.4. Salaire effectif moyen des enseignants et des chefs d'établissement, selon le groupe d'âge et le sexe (2017)

Tableau D3.10 Salaire statutaire minimum/maximum des chefs d'établissement, sur la base des qualifications minimales (2018)

Tableau D4.1a. Organisation du temps d'enseignement des enseignants (2018)

Tableau D4.1b. Organisation du temps de travail des enseignants (2018)

Tableau D4.2. Nombre annuel d'heures d'enseignement (2000, 2005 à 2018)

Tableau D4.3b. Autres responsabilités assignées aux enseignants, selon le niveau d'enseignement (2018)

Tableau D5.1. Pyramide des âges des enseignants (2017) 
Tableau D5.2. Répartition des enseignants selon le sexe (2017)

Tableau D5.3. Répartition des enseignants par sexe selon le groupe d'âge (2017) et pourcentage de femmes parmi les enseignants, tous groupes d'âge confondus (2005 et 2017)

Tableau D6.1a. Organisation du système d'admission et du processus de candidature pour un premier cursus tertiaire dans un établissement public (2017)

Tableau D6.2a. Examens et autres critères utilisés pour l'admission en premier cursus tertiaire dans un établissement public (2017)

Tableau D6.3. Niveau minimal de qualification et de performance académique requis à l'accès à

l'enseignement tertiaire (selon les autorités) (2017)

\section{Suivez les publications de l'OCDE sur:}

http://twitter.com/OECD_Pubs

f $h t t p: / / w w w$. facebook.com/OECDPublications

in. http://www.linkedin.com/groups/OECD-Publications-4645871

- http://www.youtube.com/oecdilibrary

OECD

http://www.oecd.org/oecddirect/

\section{Ce livre contient des...}

En bas des tableaux ou graphiques de cet ouvrage, vous trouverez des StatLinks. Pour télécharger le fichier Excel ${ }^{\circledR}$ correspondant, il vous suffit de retranscrire dans votre navigateur internet le lien commençant par : https://doi.org, ou de cliquer sur le lien depuis la version PDF de l'ouvrage.
StatLinks 켄ㄴ

Acœédez aux fichiers Excel $^{\boxplus}$ à partir des livres imprimés ! 



\section{Éditorial}

Le capital intellectuel est l'atout le plus précieux à l'heure où les pays s'emploient avec détermination à relever les défis que leur lancent les transformations économiques, environnementales et sociales, liées notamment au progrès technologique, au changement climatique et aux migrations. Le savoir est à la base du capital humain, et son enrichissement et sa transmission sont au cœur de la mission de l'enseignement supérieur. L'enseignement tertiaire est essentiel pour aider les individus et les sociétés à faire face à ces changements profonds.

La demande de connaissances et de compétences d'ordre supérieur a une portée tant économique que sociale. Le taux d'emploi des adultes diplômés de l'enseignement tertiaire est supérieur d'environ 9 points de pourcentage à celui des adultes titulaires uniquement d'un diplôme de l'enseignement secondaire, et les premiers gagnent en moyenne $57 \%$ de plus que les seconds. Les adultes diplômés de l'enseignement tertiaire sont également davantage susceptibles d'être en bonne santé, d'agir pour la protection de l'environnement ou de prendre part à la vie publique.

Ces grandes avancées vont de pair avec une incertitude accrue. Les progrès de l'intelligence artificielle devraient doper la productivité dans un certain nombre de secteurs, mais ils modifient aussi fondamentalement la façon de travailler dans certaines branches. Avec l'accès généralisé à l'information, il est plus facile que jamais d'apprendre, mais le rythme du changement s'est accéléré, de sorte que beaucoup se demandent comment s'adapter ou luttent pour ne pas perdre pied. La mondialisation ouvre de nouvelles voies, certes, mais elle est également à l'origine d'une concurrence féroce en quête de talents.

Les pays ont amélioré l'accès à l'enseignement et à l'apprentissage pour relever ces défis. Les dispositifs de soutien financier réduisent le poids de la poursuite des études, un investissement payant sur le marché du travail, et sont assortis d'options souples de remboursement. Le parcours scolaire linéaire traditionnel, de l'enseignement primaire à l'enseignement tertiaire, cède progressivement la place à une approche plus holistique de l'apprentissage tout au long de la vie. Comme l'évolution de la demande de compétences sur le marché du travail est trop rapide pour que certains établissements d'enseignement puissent l'anticiper, bon nombre de ceux-ci s'emploient à promouvoir des parcours flexibles dans l'enseignement tertiaire et à établir des partenariats avec d'autres acteurs, dont des entreprises et des organismes de formation. Un nombre croissant d'adultes sont séduits par l'enseignement tertiaire grâce à ces politiques, mais les établissements d'enseignement doivent concilier l'accroissement de leur effectif et la nécessité de maîtriser leurs coûts, tout en veillant à la pertinence et à la qualité des formations qu'ils proposent.

\section{Répondre à la demande de compétences d'ordre supérieur}

Dans ce contexte, la présente édition de Regards sur l'éducation accorde la priorité à l'enseignement tertiaire. Elle montre que la demande de compétences tertiaires reste forte sur le marché du travail malgré la hausse de l'effectif diplômé et que l'avantage salarial des diplômés de l'enseignement tertiaire augmente avec l'âge et l'expérience professionnelle. La licence reste la voie royale d'entrée dans l'enseignement tertiaire : les jeunes diplômés de ce niveau d'enseignement n'ont jamais été aussi nombreux (24\%).

C'est un défi de taille que de garantir une offre adéquate de compétences dans un monde aussi évolutif. Le taux de participation des adultes peu instruits à des activités d'éducation ou de formation - soit les individus en ayant 
le plus besoin - est en moyenne inférieur de 40 points de pourcentage à celui des adultes très instruits. Pourtant, moins de $15 \%$ des nouveaux inscrits en licence ont choisi l'ingénierie, les industries de transformation et la construction, et moins de $5 \%$ d'entre eux ont opté pour les technologies de l'information et de la communication - alors que ces domaines d'études sont les plus couramment associés au progrès technologique et à de meilleurs débouchés sur le marché du travail.

Le pourcentage de diplômés à l'issue d'un master ou d'un doctorat n'a guère évolué entre les générations. Ces niveaux de formation restent très demandés et l'investissement initial procure un rendement attractif. Le coût annuel moyen de ces formations est similaire à celui enregistré en licence dans plus de la moitié des pays de l'OCDE, mais les diplômés gagnent en moyenne $32 \%$ de plus.

Les systèmes d'admission sont essentiels pour que les diplômés du deuxième cycle de l'enseignement secondaire passent sans heurts dans l'enseignement tertiaire. Le régime d'admission dans l'enseignement tertiaire public est ouvert dans plus de la moitié des pays et économies, mais est sélectif dans d'autres pays, avec des critères portant sur les résultats durant la scolarité et à des examens d'entrée et, parfois, sur la filière suivie dans le deuxième cycle de l'enseignement secondaire. Les régimes sélectifs semblent mieux réussir à faire en sorte que les étudiants terminent leur formation puisqu'ils autorisent uniquement l'admission des étudiants ayant les compétences requises. Toutefois, les taux de réussite sont parfois très similaires entre des pays dont le régime d'admission est très différent. En moyenne, $39 \%$ des individus titulaires d'une licence ont obtenu leur diplôme sans dépasser la durée théorique de leur formation et 28 \% d'entre eux l'ont décroché dans les trois années suivantes dans les pays dont les données sont disponibles.

Tout cela a un coût. Entre 2005 et 2016, les dépenses au titre de l'enseignement tertiaire ont augmenté à un rythme plus de deux fois plus soutenu que l'effectif scolarisé et s'élèvent à 15600 USD par étudiant en moyenne, dans les pays de l'OCDE. Dans la majorité des pays de l'OCDE, le secteur privé a été mis à contribution, car les frais de scolarité ont augmenté ou ont été instaurés. L'essentiel de cette hausse des dépenses a financé les services d'éducation proprement dits; dans l'enseignement tertiaire, le corps académique a augmenté en moyenne de $1 \%$ durant cette période, soit presque au même rythme que l'effectif scolarisé.

\section{Des parcours scolaires inédits ou adaptés}

L'école aide les individus à acquérir les compétences dont ils ont besoin pour participer à la vie de la société, mais le développement de l'enseignement tertiaire n'est durable que si l'offre de diplômés est en adéquation avec la demande sur le marché du travail. L'accès aisé au financement et les régimes ouverts d'admission risquent de promouvoir l'enseignement tertiaire au détriment d'autres formations plus professionnelles dont les diplômés sont très demandés, mais qui semblent moins attractifs.

L'objectif de développement durable relatif à l'éducation nous rappelle l'importance de l'accès de tous, sur un pied d'égalité, à un enseignement de qualité et à des possibilités d'apprentissage tout au long de la vie. Cet objectif reconnaît la diversité des parcours que les jeunes et les adultes peuvent emprunter afin d'acquérir les compétences nécessaires pour faciliter leur entrée sur le marché du travail et vivre une vie meilleure. La cible 4.3 de cet objectif est de faire en sorte que « d'ici à 2030, les femmes et les hommes aient tous accès dans des conditions d'égalité à un enseignement technique, professionnel ou tertiaire, y compris universitaire, de qualité et d'un coût abordable ». L'objectif de développement durable relatif à l'éducation est assorti d'une série d'indicateurs qui permettent de mesurer les compétences acquises par les individus au fil de leur existence lors de la scolarité obligatoire et dans d'autres contextes, dans un large éventail de cursus ou d'activités d'apprentissage dans le cadre institutionnel ou non.

Dans cette édition, le chapitre sur les objectifs de développement durable décrit les parcours que les jeunes suivent jusqu'à l'âge adulte ainsi que pendant la transition entre l'enseignement secondaire et les niveaux supérieurs d'enseignement et le passage de l'école à la vie active. II révèle qu'en moyenne, environ un sixième des 15-24 ans suivent une formation en filière professionnelle dans les pays de l'OCDE. L'écart entre le niveau de formation des jeunes adultes diplômés de l'enseignement tertiaire et ceux diplômés de l'enseignement 
secondaire s'est atténué. En 2018, le pourcentage de diplômés du deuxième cycle de l'enseignement secondaire ou de l'enseignement post-secondaire non tertiaire ( $41 \%)$ était presque équivalent au pourcentage de diplômés de l'enseignement tertiaire (44\%).

Chacun espère pouvoir choisir entre des débouchés prometteurs et rémunérateurs sur le marché du travail, enchaîner les promotions sans heurts et trouver un sens à sa vie. Nous avons le devoir en tant que responsables de l'éducation d'aider les jeunes à faire le tri dans l'éventail des possibilités et à prendre des décisions engageant leur avenir en toute connaissance de cause. Nous avons aussi le devoir de proposer un large éventail de parcours intéressants aux yeux des jeunes, à qui nous devons inculquer les compétences requises pour évoluer dans un monde imprévisible en constante mutation. Pour y parvenir, nous devons multiplier les possibilités d'apprentissage, élargir l'éventail des formations et établir de meilleurs liens avec le marché du travail. II nous faut aussi investir dans l'orientation des jeunes pour que chacun d'entre eux trouve sa place dans la société et exploite pleinement son potentiel. C'est uniquement si ces conditions sont réunies que les jeunes peuvent acquérir les connaissances qui leur permettent d'aller de l'avant, le genre de connaissances qui peuvent changer leur vie.

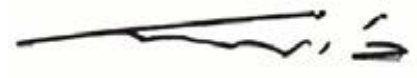

Angel Gurría

Secrétaire général de l'OCDE 



\section{Introduction: les indicateurs et}

\section{leur structure}

\section{Structure}

Regards sur l'Éducation 2019 : Les indicateurs de l'OCDE présente un jeu étoffé d'indicateurs actualisés et comparables qui montrent la situation présente de l'éducation à l'échelle internationale sur la base d'une méthode validée par tous les experts concernés. Ces indicateurs rendent compte des moyens humains et financiers mobilisés en faveur de l'éducation, du fonctionnement et de l'évolution des systèmes d'éducation et d'apprentissage et du rendement des investissements consentis dans l'éducation. Ils sont agencés de manière thématique, et chacun d'entre eux est assorti de la description du contexte de l'action publique et de l'interprétation des données.

\section{Graphique A. Structure des indicateurs dans Regards sur l'éducation}

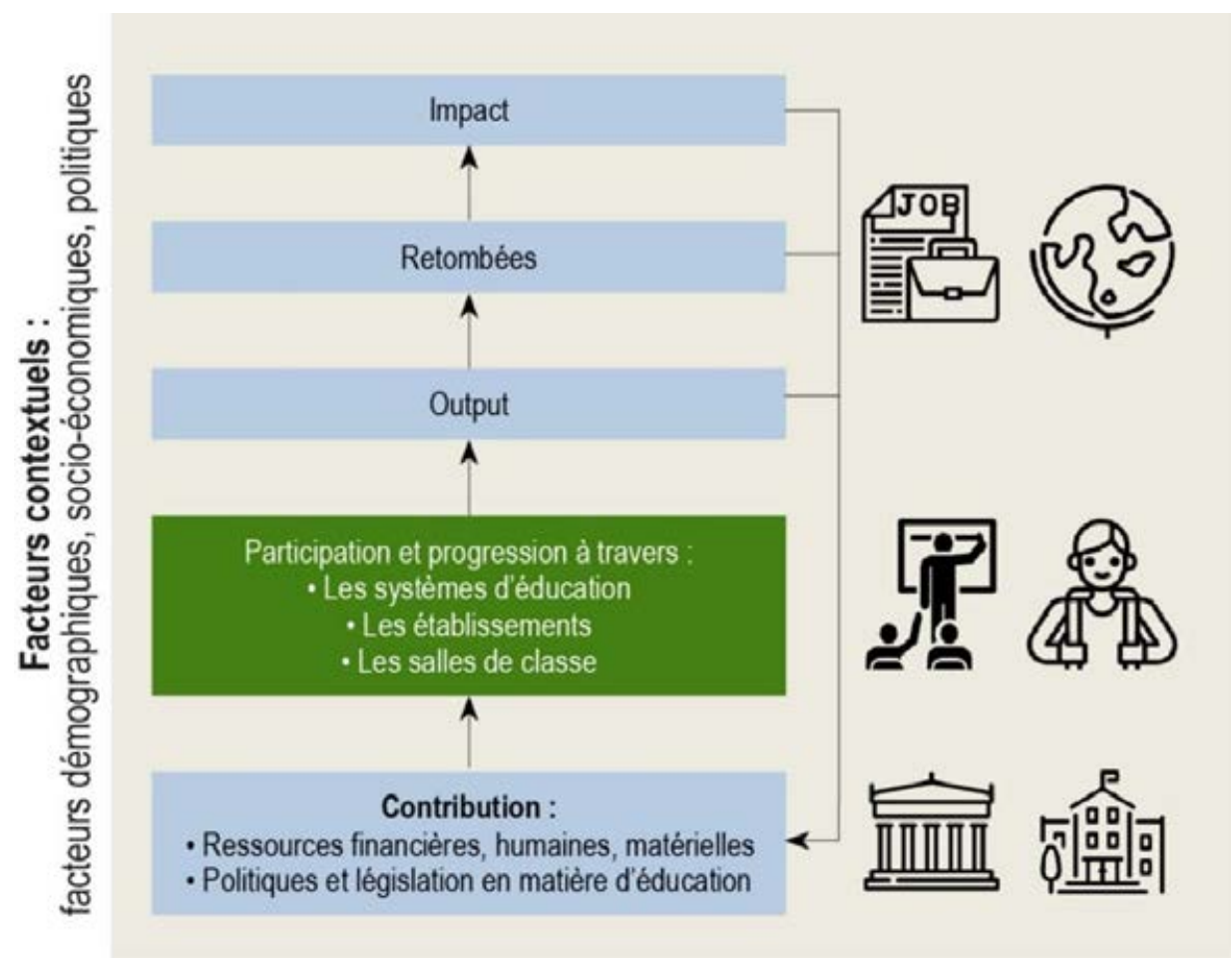

Les indicateurs de l'éducation s'intègrent dans une structure qui fait la distinction entre les acteurs des systèmes d'éducation, regroupe les indicateurs en fonction des domaines dont ils traitent et analyse les facteurs contextuels qui influent sur l'action publique (voir le graphique A). Outre ces dimensions, l'évolution de la situation dans le temps permet de décrire certains aspects de la dynamique de développement des systèmes d'éducation. 


\section{Acteurs des systèmes d'éducation}

Les indicateurs de l'éducation de l'OCDE visent davantage à évaluer les performances globales des systèmes d'éducation des pays qu'à comparer les différents établissements ou les entités infranationales. Il est cependant de plus en plus communément admis qu'il faut bien comprendre le rendement de l'apprentissage et sa corrélation avec les moyens mobilisés et les mécanismes à l'œuvre au niveau individuel et à l'échelle des établissements d'enseignement pour évaluer de nombreuses caractéristiques importantes du développement, du fonctionnement et de l'impact des systèmes d'éducation.

Pour en tenir compte, la première dimension de la structure du présent rapport fait la distinction entre les trois types d'acteurs des systèmes d'éducation :

- les systèmes d'éducation dans leur ensemble

- les prestataires de services d'éducation (établissements d'enseignement) et leur cadre pédagogique (classes, enseignants)

- les individus en formation, c'est-à-dire les enfants et les jeunes scolarisés durant leur formation initiale et les adultes pratiquant l'apprentissage tout au long de la vie.

\section{Groupes d'indicateurs}

La deuxième dimension du cadre structurel répartit les indicateurs entre trois catégories :

- Les indicateurs sur la production, les retombées et les impacts des systèmes d'éducation : les indicateurs sur la production analysent les caractéristiques des individus en fin de cursus, par exemple leur niveau de formation. Les indicateurs sur les retombées analysent les effets directs de la production des systèmes d'éducation, par exemple l'amélioration des perspectives professionnelles et salariales résultant de l'élévation du niveau de formation. Les indicateurs sur les impacts analysent les effets indirects à long terme de la production des systèmes d'éducation, par exemple les connaissances et les compétences acquises, la contribution à la croissance économique et au bien-être sociétal, la cohésion sociale et l'équité.

- Les indicateurs sur la scolarisation et les parcours scolaires : ces indicateurs évaluent la probabilité que les individus accèdent à différents niveaux d'enseignement, s'y inscrivent et les réussissent et décrivent les divers parcours suivis entre les types de formation et les niveaux d'enseignement.

- Les indicateurs sur les intrants des systèmes d'éducation et des environnements d'apprentissage : ces indicateurs décrivent les leviers politiques dont résultent les taux de scolarisation et les parcours scolaires ainsi que la production et les retombées des systèmes d'éducation à chaque niveau d'enseignement. Ces leviers politiques portent sur les ressources investies dans l'éducation, dont les moyens financiers, humains (enseignants et autres personnels de l'éducation) et matériels (bâtiments et infrastructures). Ces indicateurs portent aussi sur les orientations politiques, notamment l'environnement d'apprentissage en classe, les matières enseignées et les méthodes pédagogiques. Enfin, ils analysent l'organisation des établissements d'enseignement et des systèmes d'éducation, notamment la gouvernance et l'autonomie, et des politiques spécifiques visant à réguler l'accès à certaines formations.

\section{Facteurs contextuels influant sur l'action publique}

Les leviers politiques ont généralement des antécédents, c'est-à-dire des facteurs externes qui conditionnent ou limitent l'action publique, mais qui ne sont pas en lien direct avec la thématique politique à l'étude. Les facteurs démographiques, socio-économiques et politiques sont autant de caractéristiques nationales dont il est important de tenir compte lors de l'interprétation des indicateurs. La récente crise financière a par exemple été lourde de conséquences pour le budget public de l'éducation. 
Les caractéristiques des individus scolarisés, notamment leur sexe, leur âge et leur milieu socio-économique ou culturel, sont également des facteurs contextuels qui influent dans une grande mesure sur les résultats de la politique de l'éducation.

\section{Cadre d'analyse des indicateurs}

Ce cadre multidimensionnel permet de comparer le fonctionnement de toute entité à vocation pédagogique, du système d'éducation dans son ensemble à l'entité la plus petite du système, la classe, en passant par des niveaux d'enseignement ou des formations spécifiques.

Il est important que ce cadre soit multidimensionnel, car de nombreuses caractéristiques des systèmes d'éducation ont des effets qui varient entre les différents niveaux des systèmes. Dans l'analyse de la situation des élèves en classe, la relation entre les résultats des élèves et la taille des classes peut par exemple être négative si les interactions entre élèves et enseignants sont de meilleure qualité dans les classes moins denses. En revanche, à l'échelle des classes ou des établissements, les élèves sont souvent regroupés à dessein de sorte que les élèves plus faibles ou issus de milieux défavorisés se retrouvent dans des classes plus petites, où un soutien plus personnalisé peut leur être accordé. À ce niveau, la relation entre les deux mêmes variables est donc souvent positive, ce qui suggère que les résultats des élèves sont meilleurs dans les classes à effectif important que dans les classes à effectif réduit. À des niveaux supérieurs d'agrégation, la relation entre les résultats des élèves et la taille des classes dépend aussi du niveau socio-économique de l'effectif des établissements d'enseignement ou de facteurs liés à la culture d'apprentissage propre à chaque pays. II est donc important de bien comprendre les relations entre tous ces aspects pour interpréter les indicateurs.

L'analyse de chacun des éléments du cadre et des interactions entre ces éléments permet de cerner un large éventail d'aspects de l'action publique :

- la qualité de l'offre d'enseignement et du rendement de l'apprentissage

- l'égalité des chances dans l'éducation et l'équité du rendement de l'apprentissage

- l'adéquation des ressources investies dans l'éducation et l'efficacité et l'efficience de leur affectation

- la pertinence des mesures prises par les pouvoirs publics pour améliorer le rendement de l'apprentissage.

\section{Structure des chapitres et des indicateurs dans Regards sur l'éducation}

Les indicateurs publiés dans la présente édition de Regards sur l'éducation ont été élaborés dans ce cadre. Les chapitres portent sur les systèmes d'éducation, mais les indicateurs sont désagrégés entre différents éléments des systèmes ou environnements d'apprentissage, de sorte qu'ils peuvent porter sur plus d'une dimension du cadre.

Le chapitre A, Résultats des établissements d'enseignement et impact de l'apprentissage, regroupe les indicateurs sur la production, le rendement et les impacts des systèmes d'éducation, à savoir ceux sur le niveau global de formation de la population, sur le rendement de l'apprentissage et sur les retombées économiques et sociales de l'éducation (voir le graphique A). Grâce à cette analyse, les indicateurs de ce chapitre permettent de cerner les orientations de la politique relative à l'apprentissage tout au long de la vie. Ils décrivent aussi les leviers politiques à actionner pour améliorer la situation dans des domaines où le rendement et les impacts ne sont pas à la hauteur d'objectifs stratégiques nationaux.

Le chapitre B, Accès à l'éducation, participation et progression, porte sur tous les niveaux d'enseignement, de l'éducation de la petite enfance à l'enseignement tertiaire, et regroupe des indicateurs sur l'enchaînement des niveaux d'enseignement ainsi que sur leurs taux de scolarisation et de réussite (voir le graphique A). Ces indicateurs portent sur des aspects combinant production et rendement, dans la mesure où la production de 
chaque niveau d'enseignement est l'intrant du niveau suivant et que la progression de niveau en niveau est le fruit des politiques et pratiques en classe, dans les établissements d'enseignement et dans les systèmes d'éducation. Ils permettent aussi d'identifier des domaines dans lesquels les pouvoirs publics doivent prendre des mesures par exemple pour remédier à des inégalités ou encourager la mobilité internationale.

Les chapitres $C$ et $D$ portent sur les intrants des systèmes d'éducation (voir le graphique $A$ ) :

- Le chapitre C, Ressources financières investies dans l'éducation, regroupe les indicateurs sur l'investissement dans l'éducation et les établissements d'enseignement et indique les parts publique et privée de cet investissement. Ces indicateurs portent essentiellement sur des leviers politiques, mais ils contribuent aussi à expliquer des aspects spécifiques du rendement de l'apprentissage. Les dépenses unitaires au titre des établissements d'enseignement sont par exemple un levier politique majeur : elles ont un impact on ne peut plus direct au niveau individuel, mais elles sont aussi des contraintes pour l'environnement d'apprentissage dans les établissements et les conditions d'apprentissage en classe.

- Le chapitre D, Enseignants, environnement d'apprentissage et organisation scolaire, regroupe les indicateurs sur le temps d'instruction, le temps de travail des enseignants et le salaire des enseignants et des chefs d'établissement. Ces indicateurs portent sur des leviers politiques qu'il est possible d'actionner et décrivent de surcroît des facteurs contextuels liés à la qualité de l'enseignement et aux résultats des apprenants. Enfin, ce chapitre décrit le profil des enseignants et les systèmes d'admission dans l'enseignement tertiaire.

En plus de cette série habituelle d'indicateurs et de données statistiques, Regards sur l'éducation propose des encadrés sur des recherches qui permettent de mieux comprendre des indicateurs ou sur des analyses relatives à des groupes plus restreints de pays qui viennent compléter les constats plus généraux.

\section{Le quatrième objectif de développement durable}

En septembre 2015, les dirigeants du monde entier se sont réunis afin de fixer des objectifs ambitieux pour l'avenir de l'humanité. Le quatrième des objectifs de développement durable est " d'assurer l'accès de tous à une éducation de qualité, sur un pied d'égalité, et de promouvoir les possibilités d'apprentissage tout au long de la vie ». Chaque cible de ce quatrième objectif est associée à au moins un indicateur mondial et à plusieurs indicateurs thématiques connexes conçus pour compléter l'analyse et l'évaluation de la cible.

L'UNESCO supervise le programme de ce quatrième objectif relatif à l'éducation dans le cadre établi sous l'égide des Nations Unies. En tant qu'organisme responsable de la plupart des indicateurs du quatrième objectif de développement durable, l'Institut de statistique (ISU) de I'UNESCO coordonne les efforts consentis à l'échelle mondiale pour élaborer le cadre de suivi des progrès par cible. L'ISU recueille des données et élabore avec des partenaires de nouveaux indicateurs, de nouvelles approches statistiques et de nouveaux instruments de suivi pour mieux évaluer les progrès réalisés dans les cibles relatives à l'éducation.

Dans ce cadre, les programmes de l'OCDE sur l'éducation ont un rôle clé à jouer dans les initiatives à prendre pour atteindre le quatrième objectif et ses cibles ainsi que dans l'évaluation des progrès accomplis en ce sens. Il existe une forte complémentarité entre le programme d'action du quatrième objectif et les outils, instruments, données et plateformes de dialogue proposés par l'OCDE dans le domaine de l'éducation. L'OCDE travaille avec I'ISU, le Comité directeur « Éducation 2030 » responsable du quatrième objectif de développement durable et les groupes techniques mis en place par I'UNESCO et ses partenaires pour élaborer un système global de données qui permette de rendre compte de la situation dans le monde et convenir des sources de données et des méthodes à retenir dans le suivi des indicateurs mondiaux du quatrième objectif et d'un ensemble d'indicateurs thématiques dans les pays membres et partenaires de l'OCDE.

Dans le cadre de ces efforts consentis à l'échelle mondiale pour alimenter le dialogue et améliorer le suivi du quatrième objectif, Regards sur l'éducation consacre de nouveau un chapitre à ce programme mondial en faveur de l'éducation. Ce chapitre montre où les pays membres et partenaires de l'OCDE se situent par rapport aux 
cibles des objectifs de développement durable. Selon la priorité thématique de chaque édition, les indicateurs mondiaux et thématiques relatifs au quatrième objectif présentés varieront parfois d'une année à l'autre. Le chapitre sur le quatrième objectif de développement durable suit le cadre général de Regards sur l'éducation.

\section{Tableau A. Indicateurs analysant l'enseignement tertiaire dans Regards sur l'éducation 2019}

\begin{tabular}{|c|c|c|c|}
\hline Chapitre & $\begin{array}{l}\text { Numéro } \\
\text { d'indicateur }\end{array}$ & Indicateur & $\begin{array}{c}\text { Aspects } \\
\text { analysés dans } \\
\text { l'enseignement } \\
\text { tertiaire }\end{array}$ \\
\hline \multirow{7}{*}{$\begin{array}{l}\text { Chapitre A: Résultats des } \\
\text { établissements } \\
\text { d'enseignement et impact de } \\
\text { l'apprentissage }\end{array}$} & A1 & Quel est le niveau de formation de la population adulte? & $\mathrm{x}$ \\
\hline & A2 & Transition entre les études et la vie active : Où en sont les jeunes d'aujourd'hui ? & $\mathrm{x}$ \\
\hline & A3 & Dans quelle mesure le niveau de formation affecte-t-il le taux d'emploi? & $\mathrm{x}$ \\
\hline & A4 & Quel avantage salarial le niveau de formation procure-t-il ? & $\mathrm{x}$ \\
\hline & A5 & Quels sont les facteurs financiers qui incitent à investir dans l'éducation? & $\mathrm{x}$ \\
\hline & A6 & En quoi les retombées sociales sont-elles liées à l'éducation? & $x$ \\
\hline & A7 & $\begin{array}{l}\text { Dans quelle mesure les adultes participent-ils sur un pied d'égalité à des activités de } \\
\text { formation? }\end{array}$ & $\mathrm{x}$ \\
\hline \multirow{7}{*}{$\begin{array}{l}\text { Chapitre B: Accès à } \\
\text { l'éducation, participation et } \\
\text { progression }\end{array}$} & B1 & Quels sont les effectifs scolarisés? & $x$ \\
\hline & B2 & $\begin{array}{l}\text { En quoi les systèmes d'éducation de la petite enfance se différencient-ils dans le } \\
\text { monde? }\end{array}$ & \\
\hline & B3 & Quel est le profil des diplômés du deuxième cycle de l'enseignement secondaire? & \\
\hline & B4 & Quel est le profil des nouveaux inscrits dans l'enseignement tertiaire? & $x$ \\
\hline & B5 & Combien d'étudiants terminent-ils leurs études tertiaires? & $\mathrm{x}$ \\
\hline & B6 & Quel est le profil des étudiants en mobilité internationale? & $\mathrm{x}$ \\
\hline & B7 & Quelles sont les caractéristiques des doctorants et leur situation une fois diplômés? & $\mathrm{x}$ \\
\hline \multirow{7}{*}{$\begin{array}{l}\text { Chapitre C: Ressources } \\
\text { financières et humaines } \\
\text { investies dans l'éducation }\end{array}$} & $\mathrm{C} 1$ & Quel est le montant des dépenses par élève/étudiant? & $\mathrm{x}$ \\
\hline & $\mathrm{C} 2$ & Quelle part de leur richesse nationale les pays consacrent-ils à l'éducation? & $x$ \\
\hline & $\mathrm{C} 3$ & $\begin{array}{l}\text { Quelle est la répartition entre les investissements publics et privés au titre des } \\
\text { établissements d'enseignement? }\end{array}$ & $\mathrm{x}$ \\
\hline & $\mathrm{C} 4$ & Quel est le montant total des dépenses publiques d'éducation? & $\mathrm{x}$ \\
\hline & $\mathrm{C} 5$ & $\begin{array}{l}\text { Combien les étudiants paient-ils et quelles aides publiques reçoivent-ils dans } \\
\text { l'enseignement tertiaire? }\end{array}$ & $\mathrm{x}$ \\
\hline & $\mathrm{C} 6$ & $\begin{array}{l}\text { À quelles catégories de services et de ressources les dépenses d'éducation sont-elles } \\
\text { affectées? }\end{array}$ & $\mathrm{x}$ \\
\hline & $\mathrm{C} 7$ & Quels facteurs influent sur le coût salarial des enseignants? & \\
\hline \multirow{6}{*}{$\begin{array}{l}\text { Chapitre D: Enseignants, } \\
\text { environnement } \\
\text { d'apprentissage } \\
\text { organisation scolaire }\end{array}$} & D1 & Combien de temps les élèves passent-ils en classe? & \\
\hline & D2 & Quels sont le taux d'encadrement et la taille des classes? & $\mathrm{x}$ \\
\hline & D3 & Quel est le niveau de salaire des enseignants et des chefs d'établissement? & $\mathrm{x}$ \\
\hline & D4 & Quel est le temps de travail des enseignants? & \\
\hline & D5 & Qui sont les enseignants? & $\mathrm{x}$ \\
\hline & D6 & Quels sont les systèmes d'admission dans l'enseignement tertiaire? & $\mathrm{x}$ \\
\hline
\end{tabular}

\section{L'enseignement tertiaire dans l'édition de 2019 de Regards sur l'éducation}

L'enseignement tertiaire est le thème central de l'édition de 2019 de Regards sur l'éducation. L'enseignement tertiaire s'est développé à un rythme sans précédent durant la dernière décennie et est l'une des voies susceptibles de mener les jeunes à la réussite. Les responsables politiques s'intéressent de plus en plus à l'analyse comparative du parcours des jeunes et des diplômés et des moyens mobilisés. C'est pourquoi cette édition fait une large place aux indicateurs relatifs aux taux de scolarisation et à l'enchaînement des cursus dans l'enseignement tertiaire ainsi qu'aux retombées financières, professionnelles et sociales des diplômes de ce niveau d'enseignement. Des indicateurs sur les moyens, tant financiers qu'humains, investis dans l'enseignement tertiaire sont également présentés. Cette année, trois nouveaux indicateurs viennent s'ajouter à 
l'ensemble d'indicateurs : ils analysent les taux de réussite dans l'enseignement tertiaire, notamment en doctorat, les débouchés des diplômés de l'enseignement tertiaire sur le marché du travail et les systèmes d'admission dans l'enseignement tertiaire.

En adéquation avec le thème central de cette édition, le chapitre sur les objectifs de développement durable porte sur les parcours d'apprentissage des jeunes pour alimenter et éclairer le débat sur les perspectives et l'emploi des jeunes dans les pays membres et partenaires de l'OCDE compte tenu du Programme de développement durable. Ce chapitre se base sur deux des objectifs de développement durable, le quatrième (enseignement de qualité) et le huitième (travail décent et croissance économique), pour décrire les parcours que les jeunes peuvent emprunter, à commencer par l'enseignement secondaire, puis l'enchaînement des niveaux de l'enseignement supérieur et, enfin, leur entrée sur le marché du travail au sortir des études.

Le tableau A résume les chapitres et les indicateurs qui analysent l'enseignement tertiaire dans l'édition de cette année. 


\section{Guide du lecteur}

\section{Champ couvert par les données}

Bien que restant limités dans de nombreux pays faute de données suffisantes, les indicateurs portent en principe sur le système d'éducation dans son ensemble (sur le territoire national), quels que soient le statut ou le mode de financement des établissements d'enseignement à l'étude et les mécanismes selon lesquels l'enseignement est dispensé. À une exception près (décrite ci-dessous), les catégories d'élèves et étudiants et les groupes d'âge sont en principe tous inclus : les enfants (y compris les enfants ayant des besoins spécifiques d'éducation), les adultes, les ressortissants nationaux, les ressortissants étrangers, ainsi que les individus en formation à distance, inscrits dans l'enseignement spécialisé ou adapté ou suivant une formation organisé par un ministère autre que le ministère de l'Éducation, à condition que l'enseignement dispensé ait pour principal objectif de former les individus. Les données sur les dépenses de formation initiale et les effectifs scolarisés excluent l'enseignement technique et la formation professionnelle dispensés en entreprise, sauf s'il s'agit de formations en alternance considérées comme faisant explicitement partie du système d'éducation.

Les formations qui s'adressent aux "adultes » ou qui sont de type "non traditionnel » sont prises en considération pour autant qu'elles comportent des cours ou des matières analogues à ceux de l'enseignement « ordinaire » ou qu'elles soient sanctionnées par des diplômes équivalents à ceux délivrés à l'issue de formations relevant de l'enseignement ordinaire.

Sont exclues les formations que les adultes suivent essentiellement par intérêt personnel, dans un souci d'épanouissement ou à des fins récréatives.

Pour de plus amples informations sur le champ couvert par les indicateurs de Regards sur l'éducation, consulter l'ouvrage Guide de l'OCDE pour l'établissement de statistiques internationalement comparables dans le domaine de l'éducation 2018 (OCDE, 2019[1]).

\section{Comparabilité au fil du temps}

Les indicateurs de Regards sur l'éducation sont le fruit d'un processus d'amélioration méthodologique continu qui vise à accroître la durabilité et la comparabilité internationale desdits indicateurs. En conséquence, afin d'effectuer une analyse des indicateurs au fil du temps, il est fortement recommandé de s'appuyer uniquement sur l'édition la plus récente de Regards sur l'éducation, plutôt que de comparer les données des différentes éditions. Les comparaisons dans le temps présentées dans ce rapport se fondent toutes sur des révisions annuelles de données historiques ainsi que sur les améliorations méthodologique mises en œuvre dans la présente édition.

\section{Représentativité}

La présente publication contient des données sur l'éducation provenant de tous les pays membres de l'OCDE ${ }^{1}$, de deux pays partenaires qui participent au Projet de l'OCDE sur les indicateurs des systèmes d'enseignement (INES) - le Brésil et la Fédération de Russie - et des autres pays partenaires du G20 ou des pays en passe d'accéder à l'OCDE qui ne sont pas membres des réseaux INES - l'Afrique du Sud, l'Arabie saoudite, l'Argentine, 
le Costa Rica, l'Inde, l'Indonésie et la République populaire de Chine. Les données des pays ne participant pas au projet INES peuvent provenir des collectes régulières de données de I'INES, de I'Institut de statistique de I'UNESCO ou d'Eurostat.

Dans certains cas, les données des pays portent sur des entités infranationales ou des régions.

Les données statistiques concernant Israël sont fournies par et sous la responsabilité des autorités israéliennes compétentes. L'utilisation de ces données par l'OCDE est sans préjudice du statut des hauteurs du Golan, de Jérusalem-Est et des colonies de peuplement israéliennes en Cisjordanie aux termes du droit international.

\section{Remarque sur les entités infranationales}

II y a lieu de tenir compte de la taille de la population et de la superficie des entités infranationales lors de l'interprétation des résultats les concernant. Au Canada par exemple, il y avait en 201737996 habitants sur une superficie de 1.9 million de $\mathrm{km}^{2}$ au Nunavut, mais 14.2 millions d'habitants sur une superficie de $909000 \mathrm{~km}^{2} \mathrm{en}$ Ontario (OCDE, 2019[2] $)$. En outre, les disparités régionales tendent à être plus fortes lorsque les entités infranationales sont plus nombreuses, comme dans les grands pays tels que le Canada, les États-Unis et la Fédération de Russie.

\section{Dénomination des entités territoriales}

Par souci d'uniformisation, les entités nationales et infranationales sont désignées respectivement par les termes " pays » et " économies » dans cette publication. Les entités territoriales et infranationales sont suivies de leur pays, par exemple « Angleterre (Royaume-Uni) ». Par souci de cohérence avec d'autres indicateurs de Regards sur l'éducation, la dénomination "Flandre (Belgique)» utilisée dans le Programme pour l'évaluation internationale des compétences des adultes (Évaluation des compétences des adultes [PIAAC]) et l'Enquête internationale sur l'enseignement et l'apprentissage (TALIS) est remplacée dans cet ouvrage par celle de "Communauté flamande de Belgique ». Dans les tableaux et graphiques, les abréviations "Comm. flamande (Belgique) » et "Comm. française (Belgique)» désignent respectivement les Communautés flamande et française de Belgique.

\section{Calcul des moyennes internationales}

Regards sur l'éducation a pour principal objectif de fournir une compilation de référence des comparaisons internationales clés en matière de statistiques dans le domaine de l'éducation. Les valeurs globales des pays sont présentées dans ces comparaisons, mais il ne faut pas en déduire que la situation est homogène à l'échelle nationale. Les moyennes nationales occultent en effet des différences significatives entre entités infranationales, tout comme la moyenne des pays de l'OCDE occulte des différences entre les pays.

La moyenne de l'OCDE est indiquée dans de nombreux indicateurs, et le total de l'OCDE l'est aussi dans certains d'entre eux. La moyenne de l'OCDE est la moyenne non pondérée de tous les pays de l'OCDE ${ }^{2}$ dont les données sont disponibles ou peuvent être estimées. La moyenne des pays de l'OCDE correspond donc à la moyenne des valeurs de tous les systèmes d'éducation à l'étude et peut être utilisée pour comparer l'indicateur d'un pays avec celui du pays « type » ou moyen. Elle est calculée abstraction faite de la taille, en valeur absolue, du système d'éducation de chaque pays.

Le total de I'OCDE est la moyenne pondérée de tous les pays de l'OCDE ${ }^{3}$ dont les données sont disponibles ou peuvent être estimées. II correspond donc à la valeur de l'indicateur dans toute la zone de l'OCDE. II permet par exemple de comparer le montant des dépenses de divers pays à celui de toute la zone de l'OCDE, une entité unique constituée de tous les pays de l'OCDE dont les données disponibles sont fiables. 
Dans les tableaux qui contiennent des séries chronologiques, une moyenne supplémentaire est calculée sur la base des pays dont les données de chaque année de référence sont disponibles. Cette méthode permet de comparer l'évolution de la moyenne de l'OCDE pendant la période de référence, abstraction faite de la variation due à l'exclusion de pays dont les données de certaines années ne sont pas disponibles.

La moyenne de I'UE23 est également indiquée dans un grand nombre d'indicateurs. Elle correspond à la moyenne non pondérée des 23 pays à la fois membres de l'Union européenne et de l'OCDE dont les données sont disponibles ou peuvent être estimées. Ces 23 pays sont : l'Allemagne, l'Autriche, la Belgique, le Danemark, l'Espagne, l'Estonie, la Finlande, la France, la Grèce, la Hongrie, l'Irlande, l'Italie, la Lettonie, la Lituanie, le Luxembourg, les Pays-Bas, la Pologne, le Portugal, la République slovaque, la République tchèque, le RoyaumeUni, la Slovénie et la Suède. La moyenne du G20 est indiquée dans certains indicateurs. Elle correspond à la moyenne non pondérée des valeurs des pays du G20 dont les données sont disponibles ou peuvent être estimées (l'Afrique du Sud, l'Allemagne, l'Arabie saoudite, l'Argentine, l'Australie, le Brésil, le Canada, la Chine, la Corée, les États-Unis, la Fédération de Russie, la France, l'Inde, l'Indonésie, l'Italie, le Japon, le Mexique, le Royaume-Uni et la Turquie ; l'Union européenne est le $20^{\circ}$ membre du G20, mais n'est pas prise en compte dans ces calculs). La moyenne du G20 n'est pas calculée lorsque les données de la Chine et de l'Inde ne sont pas disponibles.

Les données manquantes peuvent avoir une incidence significative sur les moyennes et totaux de l'OCDE, de I'UE23 et du G20. Il arrive que les données relatives à des indicateurs ne soient pas disponibles ou que des catégories soient sans objet dans certains pays. Le lecteur doit donc garder à l'esprit que les moyennes de I'OCDE, de l'/UE23 et G20 » se rapportent aux pays de l'OCDE, de l'UE23 ou du G20 retenus dans les comparaisons. Les moyennes ne sont pas calculées si les données ne sont pas disponibles ou portent sur des catégories différentes dans plus de $40 \%$ des pays.

Une moyenne est indiquée dans certains indicateurs. Elle correspond à la moyenne arithmétique des estimations relatives aux entités nationales et infranationales présentées dans les tableaux et graphiques.

\section{Classification des niveaux d'enseignement}

Les niveaux d'enseignement sont classés en fonction de la Classification internationale type de l'éducation (CITE). La CITE est un instrument permettant de produire des statistiques de l'éducation comparables à l'échelle internationale. À la suite de la récente révision de la CITE 97, la nouvelle Classification internationale type de l'éducation (CITE 2011) a été officiellement adoptée en novembre 2011. Cette nouvelle classification est utilisée dans le présent ouvrage, sauf dans les tableaux présentant des données provenant de l'Évaluation des compétences des adultes (PIAAC), lesquelles portent sur la classification de la CITE 97.

Certains indicateurs portent sur des niveaux de formation intermédiaires. Ces niveaux de formation correspondent à des cursus relevant d'un niveau d'enseignement de la CITE 2011, mais considérés comme insuffisants pour achever ce niveau, de sorte qu'ils sont classés à un niveau inférieur de la CITE 2011.

Le tableau B présente les niveaux de la CITE 2011 utilisés dans cette publication (OCDE/Eurostat/Institut de statistique de l'UNESCO, 2016[3]). L'enseignement tertiaire, le thème central de cette édition, propose des activités d'apprentissage dans des domaines spécialisés et s'appuie sur les acquis de l'enseignement secondaire. II propose des formations « académiques » ainsi que des formations techniques et professionnelles de haut niveau. Il est constitué des niveaux 5 (formation de cycle court), 6 (licence), 7 (master) et 8 (doctorat) de la CITE. II faut être diplômé du deuxième cycle de l'enseignement secondaire pour accéder à l'enseignement tertiaire, où les étudiants peuvent commencer leur parcours par une formation de cycle court, une licence ou un premier master de type long (voir le graphique B). Le niveau 4 de la CITE (enseignement post-secondaire non tertiaire y donne également accès dans certains cas. 


\section{Tableau B. Niveaux d'enseignement de la CITE 2011}

\begin{tabular}{|c|c|}
\hline Termes utilisés dans cette publication & Classification CITE \\
\hline $\begin{array}{l}\text { Éducation de la petite enfance } \\
\text { Ce niveau englobe les programmes de la petite enfance ayant une composante éducative intentionnelle et } \\
\text { visant à développer les compétences cognitives, motrices et socio-émotionnelles nécessaires à la participation } \\
\text { à la vie scolaire et à la société. Les programmes de ce niveau se différencient souvent en fonction de l'âge. }\end{array}$ & $\begin{array}{l}\text { CITE } 0 \text { (scindé en deux catégories : d'une } \\
\text { part, le développement éducatif de la } \\
\text { petite enfance [niveau 01] et, d'autre part, } \\
\text { l'enseignement préprimaire [niveau 02]) }\end{array}$ \\
\hline $\begin{array}{l}\text { Enseignement primaire } \\
\text { À ce niveau d'enseignement, les élèves acquièrent des compétences fondamentales en lecture, en expression } \\
\text { écrite et en mathématiques et sont amenés à découvrir quelques autres matières et à en comprendre des } \\
\text { concepts de base. Âge de début : entre } 5 \text { et } 7 \text { ans. Durée habituelle : six ans. }\end{array}$ & CITE 1 \\
\hline $\begin{array}{l}\text { Premier cycle de l'enseignement secondaire } \\
\text { Ce niveau d'enseignement consolide les savoirs et savoir-faire fondamentaux acquis, généralement dans le } \\
\text { cadre de cours plus différenciés par matière et dispensés par des professeurs plus spécialisés. Les cours de ce } \\
\text { niveau se différencient parfois par leur orientation (générale ou professionnelle), mais moins souvent que dans } \\
\text { le deuxième cycle de l'enseignement secondaire. Ce niveau débute à la fin de l'enseignement primaire et dure } \\
\text { d'ordinaire trois ans. Dans certains pays, la fin de ce niveau d'enseignement marque la fin de la scolarité } \\
\text { obligatoire. }\end{array}$ & CITE 2 \\
\hline $\begin{array}{l}\text { Deuxième cycle de l'enseignement secondaire } \\
\text { Ce niveau d'enseignement est plus spécialisé que le premier cycle de l'enseignement secondaire. Il existe deux } \\
\text { filières d'enseignement à ce niveau : la filière générale et la filière professionnelle. Durée habituelle : trois ans. }\end{array}$ & CITE 3 \\
\hline $\begin{array}{l}\text { Enseignement post-secondaire non tertiaire } \\
\text { Ce niveau vise à élargir plutôt qu'à approfondir les connaissances, aptitudes et compétences acquises dans le } \\
\text { deuxième cycle de l'enseignement secondaire. Il est conçu pour multiplier les débouchés sur le marché du travail } \\
\text { ou pour préparer l'entrée dans l'enseignement tertiaire. En règle générale, il a une orientation plus } \\
\text { professionnelle. }\end{array}$ & CITE 4 \\
\hline $\begin{array}{l}\text { Enseignement tertiaire de cycle court } \\
\text { Ce niveau d'enseignement vise souvent à enseigner des connaissances, aptitudes et compétences } \\
\text { professionnelles. En règle générale, les cours sont pratiques et axés sur une profession et préparent à entrer } \\
\text { directement dans la vie active. Ce niveau peut également servir de passerelle vers d'autres niveaux de } \\
\text { l'enseignement tertiaire (niveaux } 6 \text { et } 7 \text { de la CITE). La durée minimale est de deux ans. }\end{array}$ & CITE 5 \\
\hline $\begin{array}{l}\text { Licence (ou formation équivalente) } \\
\text { Ce niveau d'enseignement vise à inculquer des connaissances, aptitudes et compétences académiques ou } \\
\text { professionnelles intermédiaires et est sanctionné par un premier diplôme (ou titre équivalent). Durée habituelle : } \\
\text { trois à quatre années d'études à temps plein. }\end{array}$ & CITE 6 \\
\hline $\begin{array}{l}\text { Master (ou formation équivalente) } \\
\text { Ce niveau d'enseignement est plus spécialisé et le contenu des cours est plus complexe qu'en licence. II est } \\
\text { conçu pour enseigner des connaissances académiques ou professionnelles d'ordre supérieur. La composante } \\
\text { de recherche peut être importante à ce niveau. } \\
\text { Les premières formations de type long, d'une durée minimale de cinq ans, relèvent de ce niveau si leur contenu } \\
\text { est d'une complexité comparable à celle des autres masters. }\end{array}$ & CITE 7 \\
\hline $\begin{array}{l}\text { Doctorat (ou formation équivalente) } \\
\text { Les doctorats sont sanctionnés par un titre de chercheur hautement qualifié. } \\
\text { Ils sont consacrés à des études approfondies et à des travaux de recherche originaux et existent aussi bien } \\
\text { dans des domaines académiques que professionnels. }\end{array}$ & CITE 8 \\
\hline
\end{tabular}

\section{Domaines d'études et de formation}

Dans la CITE, les cursus et les titres qui les sanctionnent peuvent être classés par domaine d'études et de formation et par niveau. À la suite de l'adoption de la CITE 2011, un processus d'analyse séparée et de consultation mondiale a été mené sur les domaines d'études de la CITE. Les domaines d'études de la CITE ont été révisés et la Conférence générale de I'UNESCO a adopté la Classification des domaines d'études et de formation de la CITE 2013 (CITE-F 2013) (UNESCO-ISU, 2014[4] $)$ en novembre 2013 lors de sa 37e session. Le présent rapport porte sur les grands domaines d'études de la CITE-F suivants : éducation ; lettres et arts ; sciences sociales, journalisme et information; commerce, administration et droit; sciences naturelles, mathématiques et statistiques ; technologies de l'information et de la communication (TIC) ; ingénierie, industries de transformation et construction ; et santé et bien-être. Dans le présent rapport, le concept de « domaine d'études » désigne les différents domaines répertoriés dans cette classification. 


\section{Graphique B. Niveaux de l'enseignement tertiaire}

CITE 8

CITE 7

CITE 6

CITE 5

Seconde licence ou autre diplôme à la suite d'une licence
Tertiaire de cycle court
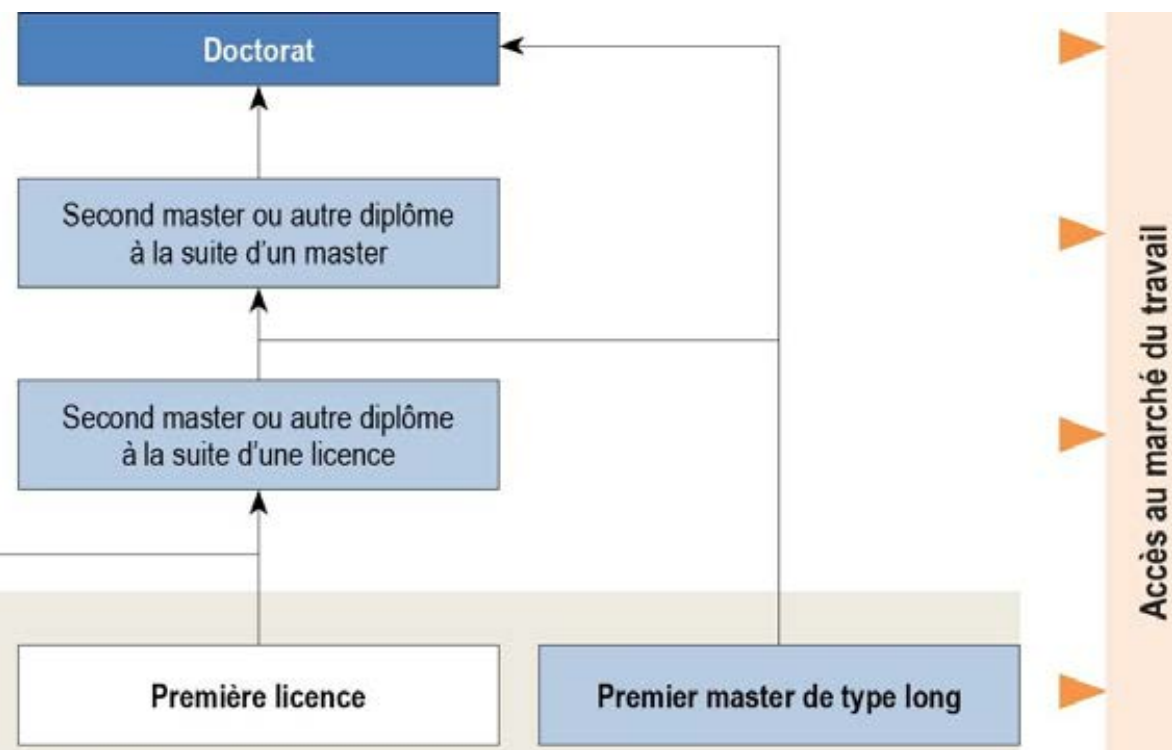

Première licence

\section{Nouveaux inscrits dans l'enseignement tertiaire}

Source : (OCDE/Eurostat/Institut de statistique de I'UNESCO, 2016[3]), Guide opérationnel CITE 2011 : Directives pour la classification des programmes éducatifs nationaux et des certifications correspondantes, https://dx.doi.org/10.1787/9789264228368-en.

\section{Erreur-type (Er.-T.)}

Comme les estimations statistiques présentées dans ce rapport sont dérivées d'échantillons d'adultes, elles ne correspondent pas aux chiffres réels qui seraient obtenus si tous les individus de la population cible étaient interrogés. II s'ensuit que les estimations sont entourées d'un degré d'incertitude qui est lié aux erreurs d'échantillonnage et de mesure et qui peut être exprimé sous la forme d'une erreur-type. L'utilisation d'intervalles de confiance permet de faire des inférences sur les moyennes et les pourcentages, compte tenu de l'incertitude propre aux estimations basées sur des échantillons. Dans ce rapport, les intervalles de confiance ont un seuil de confiance de $95 \%$. Autrement dit, les résultats obtenus dans une population donnée se situeront dans cet intervalle de confiance 95 fois sur 100 dans différents échantillons de cette population.

Dans les tableaux qui présentent des erreurs-types, la colonne « \% » indique le pourcentage moyen et la colonne «Er.-T. », l'erreur-type. Avec cette méthode, les pourcentages calculés (\%) comportent une incertitude d'échantillonnage égale à deux erreurs-types (Er.-T.). Par exemple, si le pourcentage (\%) est égal à 10 et que l'erreur-type (Er.-T.) est égale à 2.6, la valeur $10 \%$ est entourée d'une incertitude (1.96) équivalant à deux erreurs-types (2.6) dans l'hypothèse d'un risque d'erreur de $5 \%$. Le pourcentage réel devrait donc se situer entre $5 \%$ et $15 \%$ ( « intervalle de confiance ») dans l'hypothèse d'un risque d'erreur de $5 \%$. L'intervalle de confiance est calculé comme suit: $\%+/-1.96 *$ Er.-T., soit, dans cet exemple, $5 \%=10 \%-1.96{ }^{*} 2.6$ et $15 \%=10 \%+1.96 * 2.6$.

\section{Symboles remplaçant les données manquantes et abréviations}

Les symboles et abréviations suivants sont utilisés dans les tableaux et graphiques :

a Les données de la catégorie sont sans objet. 
b Rupture des séries chronologiques, notamment lorsque les données de la dernière année disponible se rapportent à la CITE 2011 et celles de l'année précédente, à la CITE 97.

c Nombre trop limité d'observations pour garantir la fiabilité des estimations.

d Les données d'une autre catégorie sont incluses.

m Les données ne sont pas disponibles - soit les données sont manquantes, soit l'indicateur n'a pas pu être calculé en raison du nombre limité de répondants..

$r \quad$ Les valeurs se situent en dessous d'un certain seuil de fiabilité et doivent être interprétées avec prudence.

q Les données ont été exclues à la demande du pays concerné.

X Les données sont incluses dans une autre catégorie ou colonne du tableau (« x(2) » signifie par exemple que les données sont incluses dans la colonne no 2).

\section{Autres références}

Le site www.oecd.org/education/education-at-a-glance-19991487.htm décrit de manière détaillée les méthodes utilisées pour calculer les valeurs des indicateurs, explique comment interpréter ces valeurs dans les différents contextes nationaux et donne des renseignements sur les sources de données sollicitées. Les données sur lesquelles se fondent les indicateurs et le glossaire détaillé des termes techniques utilisés dans cette publication peuvent également être consultés sur ce site.

Tous les changements intervenus après la production de ce rapport sont indiqués sur les pages suivantes: www.oecd.org/publishing/corrigenda (corrections) et http://dx.doi.org/10.1787/eag-data-fr (mises à jour).

Regards sur l'éducation propose le service "StatLinks » de l'OCDE. Sous chaque tableau et graphique de cette édition de Regards sur l'éducation se trouve un lien hypertexte (URL) qui donne accès à un classeur au format Excel $\circledast$ contenant les données de référence de l'indicateur concerné (en anglais). Ces liens sont stables et ne seront pas modifiés à l'avenir. De plus, il suffit aux lecteurs de la version électronique de Regards sur l'éducation de cliquer sur ces liens pour ouvrir les classeurs correspondants dans une autre fenêtre.

La base de données de Regards sur l'éducation disponible sur le site OECD.Stat (http://stats.oecd.org/) regroupe les données brutes et les indicateurs présentés dans Regards sur l'éducation ainsi que les métadonnées permettant de contextualiser et de comprendre les données nationales. Cette base de données permet aux utilisateurs de ventiler les données en fonction de variables bien plus nombreuses que ne le permet le format de cette publication et, donc, d'effectuer leur propre analyse des systèmes d'éducation des pays participants. La base de données de Regards sur l'éducation peut être consultée sur le site OECD.Stat sous la rubrique «Éducation et formation ».

\section{Présentation des tableaux}

Dans tous les tableaux, les chiffres entre parenthèses sous le titre des colonnes servent uniquement de référence. Si ce chiffre entre parenthèses n'est pas suivi d'un autre chiffre, cela signifie que les colonnes correspondantes peuvent uniquement être consultées en ligne.

\section{Abréviations utilisées dans cet ouvrage}

TIC Technologies de l'information et de la communication

CITE Classification internationale type de l'éducation 
PIAAC Programme pour l'évaluation internationale des compétences des adultes

PPP Parités de pouvoir d'achat

Er.-T. Erreur-type

STIM Sciences, technologie, ingénierie et mathématiques

ISU Institut de statistique de I'UNESCO

UOE UNESCO, OCDE et Eurostat, les trois organisations responsables de la collecte de données

\section{Références}

OCDE (2019), Base de données régionales de l'OCDE, http://stats.oecd.org/Index.aspx?DataSetCode=REGION DEMOGR.

OCDE (2019), Guide de l'OCDE pour l'établissement de statistiques internationalement comparables dans le domaine de l'éducation 2018 : Concepts, normes, définitions et classifications, Éditions OCDE, Paris, https://dx.doi.org/10.1787/9789264305380-fr.

OCDE/Eurostat/Institut de statistique de I'UNESCO (2016), Guide opérationnel CITE 2011: Directives pour la classification des programmes éducatifs nationaux et des certifications correspondantes, Institut de statistique de l'UNESCO, Paris, https://dx.doi.org/10.1787/9789264248823-fr.

UNESCO-ISU (2014), Domaines d'études et de formation de la CITE 2013 (CITE-F) : Manuel accompagnant la Classification internationale type de l'éducation 2011, Institut de statistique de I'UNESCO, Montréal,, http://uis.unesco.org/sites/default/files/documents/isced-fields-of-educationand-training-2013-fr.pdf (consulté le 18 avril 2018).

\section{Notes}

${ }^{1}$ Le 25 mai 2018, le Conseil de l'OCDE a invité la Colombie à adhérer à l'OCDE. La Colombie est incluse dans les moyennes de l'OCDE présentées dans cette publication, mais n'avait ni achevé le processus national de ratification, ni déposé son instrument d'adhésion à la Convention relative à l'OCDE au moment de la rédaction de ce rapport.

2 Voir la note 1.

3 Voir la note 1. 



\section{Résumé}

\section{La demande de profils tertiaires reste forte malgré l'accroissement de l'effectif diplômé}

Dans les pays de l'OCDE, $44 \%$ des 25-34 ans étaient diplômés de l'enseignement tertiaire en 2018, contre $35 \%$ en 2008. C'est l'augmentation de l'effectif des titulaires d'une licence qui a le plus contribué à cette croissance. Chez les jeunes, l'avantage des diplômés de l'enseignement tertiaire par rapport aux diplômés du deuxième cycle de l'enseignement secondaire est resté relativement stable sur le marché du travail au cours de la dernière décennie. Les adultes diplômés de l'enseignement tertiaire sont moins vulnérables au chômage de longue durée et affichaient en 2018 un taux d'emploi supérieur de 9 points de pourcentage à celui des diplômés du deuxième cycle de l'enseignement secondaire. Ils sont aussi mieux rémunérés dans l'ensemble, même si l'avantage salarial varie entre les domaines d'études. Leur avantage augmente aussi avec l'âge : chez les 25-34 ans, les diplômés de l'enseignement tertiaire gagnent environ $38 \%$ de plus que les diplômés du deuxième cycle de l'enseignement secondaire, un pourcentage qui atteint $70 \%$ chez les $45-54$ ans.

\section{L'enseignement tertiaire est plus accessible, mais il reste des défis à relever}

Les dispositifs de soutien financier ont contribué à améliorer l'accessibilité de l'enseignement tertiaire à un plus grand nombre. Dans les pays où les frais de scolarité sont les plus élevés, $70 \%$ au moins des étudiants bénéficient d'allocations ou de prêts d'études. L'effectif passant en master et en doctorat n'a guère évolué entre les générations malgré le rendement attractif de l'investissement initial. Ces cursus coûtent plus au moins autant par an que la licence dans plus de la moitié de pays de l'OCDE ayant des données, mais la rémunération qui y est associée est supérieure de $32 \%$ en moyenne.

Certains secteurs peinent toujours à recruter les profils qualifiés dont ils ont besoin. L'ingénierie, les industries de transformation et la construction et les technologies de l'information et de la communication sont les deux domaines d'études associés aux meilleurs débouchés sur le marché du travail, mais les diplômés en 2017 sont seulement $14 \%$ à avoir opté pour le premier et $4 \%$ à avoir opté pour le second. Les femmes sont particulièrement sous-représentées : elles représentent en moyenne moins de $25 \%$ des nouveaux inscrits dans ces domaines dans les pays de l'OCDE.

\section{Le deuxième cycle de l'enseignement secondaire et le système d'admission dans l'enseignement tertiaire influent sur le parcours des jeunes}

Dans près de la moitié des pays de l'OCDE, plus de $40 \%$ des 19-20 ans sont en formation dans l'enseignement tertiaire et l'âge moyen en début de licence varie entre 18 ans au Japon et 25 ans en Suisse. Dans les pays où l'effectif scolarisé en filière générale dans le deuxième cycle de l'enseignement secondaire est plus élevé, l'effectif de nouveaux inscrits dans l'enseignement tertiaire est dans l'ensemble plus élevé et plus jeune. L'accès à l'enseignement tertiaire est libre dans plus de la moitié des pays et économies, mais est sélectif en fonction de critères tels que les résultats durant la scolarité et aux examens d'entrée, voire la filière dans le deuxième cycle de l'enseignement secondaire dans d'autres pays. Dans les pays de l'OCDE, le pourcentage de nouveaux inscrits (première inscription) en formation tertiaire de cycle court s'élève en moyenne à $17 \%$, contre $76 \%$ en 
licence et $7 \%$ en master. En moyenne, $12 \%$ des nouveaux inscrits en licence ne sont plus en formation dans l'enseignement tertiaire au début de la deuxième année d'études. En moyenne, $39 \%$ des étudiants en licence sont diplômés à la fin de la durée théorique de leur formation et $28 \%$ d'entre eux le sont dans les trois ans qui suivent. Les hommes et les élèves scolarisés en filière professionnelle dans le deuxième cycle de l'enseignement secondaire sont dans l'ensemble moins susceptibles d'entamer une formation tertiaire et de la réussir. L'enseignement tertiaire est important dans l'apprentissage tout au long de la vie : en moyenne, plus de trois 30-39 ans sur quatre en formation suivent un cursus tertiaire dans les pays de l'OCDE.

\section{L'augmentation des budgets a contribué au développement de l'enseignement tertiaire}

Entre 2005 et 2016, les dépenses au titre de l'enseignement tertiaire ont en moyenne augmenté de $28 \%$, soit plus du double du taux de croissance de l'effectif scolarisé (12\%), dans les pays de l'OCDE. Toutefois, l'effectif scolarisé et le budget total ont augmenté à un rythme moins soutenu depuis 2010. Selon les chiffres de 2016, les dépenses par étudiant dans l'enseignement tertiaire s'élèvent à 15556 USD, dont un tiers environ est affecté à la recherche-développement. Le secteur privé finance plus de $30 \%$ du budget, et les frais de scolarité en licence ont augmenté de plus de $20 \%$ entre 2007 et 2017 dans la moitié des pays dont les données sont disponibles. Le personnel en poste dans l'enseignement tertiaire s'est également étoffé dans la plupart des pays. Entre 2005 et 2017, le corps académique a augmenté à un taux moyen de $1 \%$ par an dans les pays de l'OCDE, un taux comparable à celui de l'effectif en formation dans l'enseignement tertiaire.

\section{Les taux d'obtention d'un diplôme du deuxième cycle de l'enseignement secondaire ont augmenté au cours des dix dernières années}

L'effectif diplômé du deuxième cycle de l'enseignement secondaire a augmenté de 6 points de pourcentage entre 2005 et 2017, mais en moyenne, 15 \% des 25-34 ans n'ont pas décroché de diplôme de ce niveau en 2018 dans les pays de l'OCDE. Dans certains pays, la filière professionnelle est très importante dans le deuxième cycle de l'enseignement secondaire. Dans les pays de l'OCDE, 40 \% des diplômés du deuxième cycle de l'enseignement secondaire en 2017 étaient en filière professionnelle ; ce pourcentage est supérieur à $66 \%$ en Autriche, en République slovaque, en République tchèque et en Slovénie. En 2016, les pays de l'OCDE ont consacré en moyenne $3.5 \%$ de leur PIB à l'enseignement primaire, secondaire et post-secondaire non tertiaire ; le budget public de ces niveaux d'enseignement a augmenté de $18 \%$ depuis 2005. La diminution de l'effectif des classes et l'augmentation du salaire des enseignants ont contribué à cette augmentation. Dans le premier cycle de l'enseignement secondaire, la taille moyenne des classes a diminué de $6 \%$, tandis que le salaire des enseignants a augmenté de $8 \%$ en moyenne entre 2005 et 2017 dans les pays de l'OCDE.

\section{L'enseignement peine toujours à attirer de nouvelles recrues}

Dans la plupart des pays de l'OCDE, le pourcentage d'enseignants en poste dans l'enseignement primaire et secondaire est plus élevé chez les 50-59 ans que chez les 25-34 ans, ce qui peut faire craindre des pénuries d'enseignants à l'avenir. En moyenne, dans les pays de l'OCDE, environ $10 \%$ des enseignants ont moins de 30 ans dans l'enseignement primaire et l'enseignement secondaire. Le salaire des enseignants tend à augmenter avec le niveau d'enseignement, mais les enseignants gagnent entre $78 \%$ et $93 \%$ de la rémunération des diplômés de l'enseignement tertiaire qui travaillent à temps plein. Par contraste, les chefs d'établissement gagnent au moins $25 \%$ de plus que les diplômés de l'enseignement tertiaire. Dans les pays de l'OCDE, le nombre annuel d'heures de cours diminue dans l'ensemble de niveau d'enseignement en niveau d'enseignement, une tendance qui ne s'est pas démentie entre 2000 et 2018 dans la plupart des pays dont les données sont disponibles. 


\section{Autres faits marquants}

En 2017, plus d'un enfant de 3 ans sur trois fréquentait une structure d'accueil et d'éducation de la petite enfance en moyenne dans les pays de l'OCDE, soit une augmentation de 7 points de pourcentage depuis 2010.

En moyenne, dans les pays de l'OCDE, $14 \%$ des individus âgés de 18 à 24 ans sont sans emploi et ne sont ni scolarisés, ni en formation (neither employed nor in education or training, NEET). En Afrique du Sud, au Brésil, en Colombie, au Costa Rica, en Italie et en Turquie, plus de $25 \%$ des individus âgés de 18 à 24 ans sont dans cette situation.

Les adultes dont le niveau de formation est plus élevé ont davantage tendance à participer à des activités culturelles ou sportives : plus de $90 \%$ des diplômés de l'enseignement tertiaire prennent en effet part à de telles activités, contre moins de $60 \%$ des adultes dont le niveau de formation est inférieur au deuxième cycle de l'enseignement secondaire. 
ENSEIGNEMENT TERTIAIRE

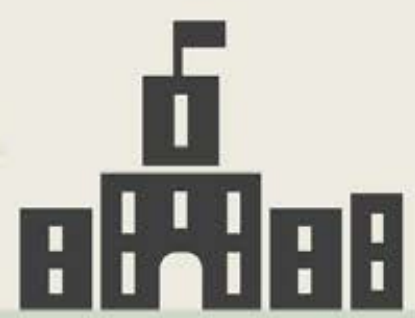

\section{Accès à l'enseignement} tertiaire

Parmi les nouveaux inscrits dans fenseignement tertiaire:

$17 \%$ entament une formation tertiaire
de cycle court

$76 \%$ entament une licence

$7 \%$ entament un master<smiles>C=CC(F)=CC(F)F</smiles>

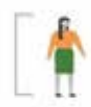

Les secteurs fortement demandés peuvent éprouver des difficultés à trouver les compétences dont ils ont besoin

Seuls $14 \%$ des étudiants
obtiennent un diplöme en ingénierie,
en industries de transformation ou
en construction

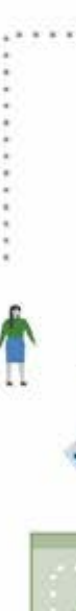

\section{...}

Parmi les étudiants de licence:

Chronologie des études en licence (en années)

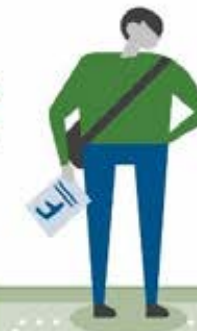

Au moins

$12 \%$ de plus abandonneront leurs études plus tard
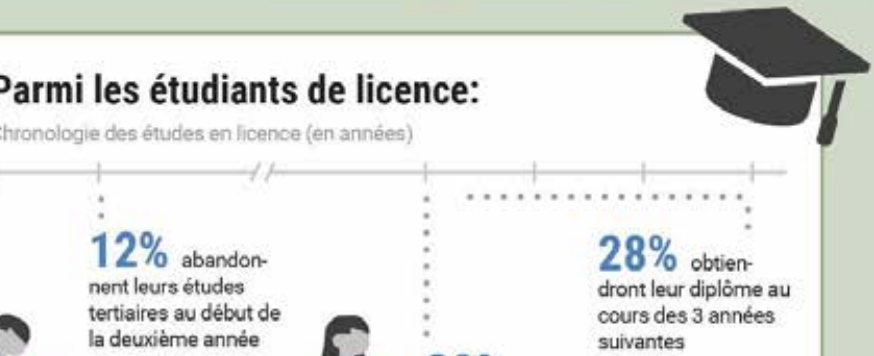

$39 \%$ obtiendront leur diplöme à la fin de la durée théorique du programme

\section{Laccroissement du financement a soutenu le développement de l'enseignement tertiaire}

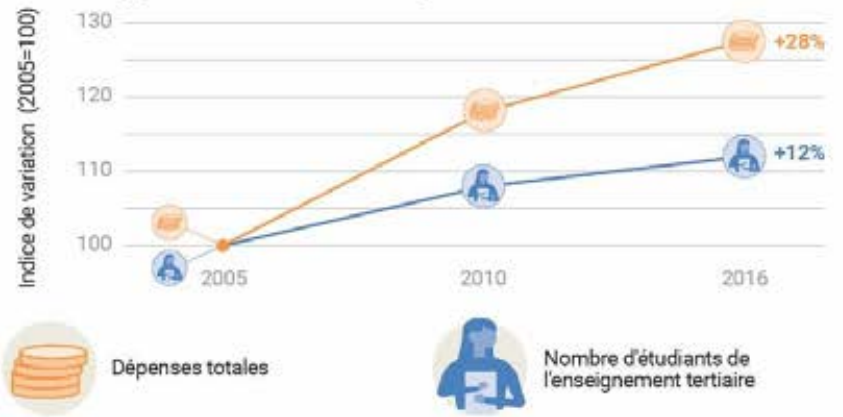

\section{Bénéfices de l'enseignement tertiaire}

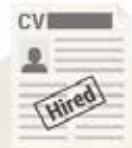

des taux d'emploi supérieurs

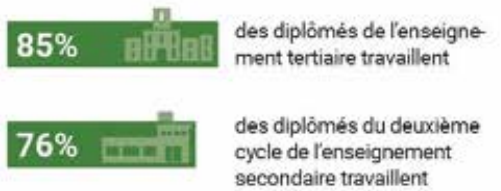

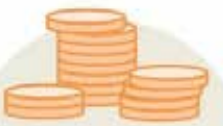

- des revenus plus élevés

avantage salarial par rapport aux diplómés du deuxième cycle de l'enseignement secondaire $38 \%$ les $25-34$ ans gagnent
$38 \%$ de plus

$70 \%$

\section{les $45-54$ ans gagnent} $70 \%$ de plus

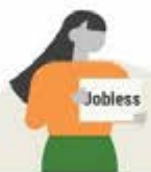

- une plus grande résilience au chômage de longue durée

\% de chômeurs de longue durèe, parmi les adultes au chômage, selon le niveau de formation Enseignement 29\% tertiaire: Deuxième cycle de
lenseignement secondaire $36 \%$ 


\section{ENSEIGNEMENT PRIMAIRE ET SECONDAIRE}

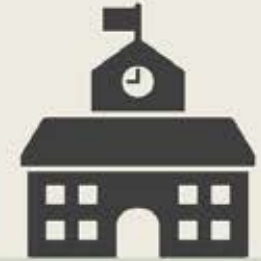

\section{Niveau de formation}

Diplôme du deuxième cycle de l'enseignement secondaire

En 2018, $15 \%$ secondaire

Les taux d'obtention dún diplôme du deuxième cycle de lenseignement secondaire sont passés de:

$80 \%$ on 2005 a $: \vdots$

$86 \%$ en 2017 :

$40 \%$ des titulaires dun premier diplôme du deuxième cycle de l'enseignement secondaire ont opté pour une formation professionnelle en 2017

Un plus grand nombre d'étudiants obtiennent un diplôme tertiaire après le deuxième cycle de

l'enseignement secondaire qu'il y a dix ans

25-34 ans diplômés de l'enseignement tertiaire:

$$
44 \% \text { en } 2018
$$

$35 \%$ en 2008

\section{Les dépenses augmentent}

Dépenses publiques

au titre des établissements denseignement primaire, secondaire et post-secondaire non tertiaire, entre 2005 et 2016 :

$+18 \%$

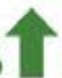

\section{Le corps enseignant vieillit}

Áge des enseignants dans le primaire et le secondaire

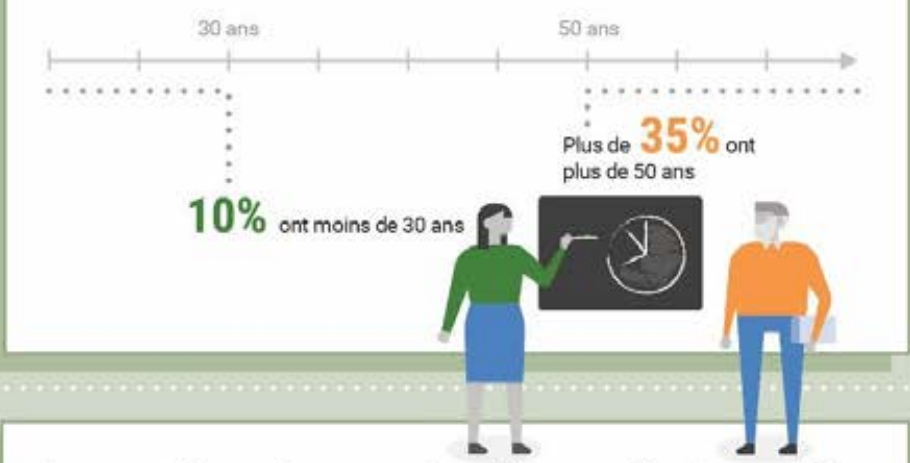

Les enseignants gagnent moins que d'autres actifs occupés diplômés de l'enseignement tertiaire

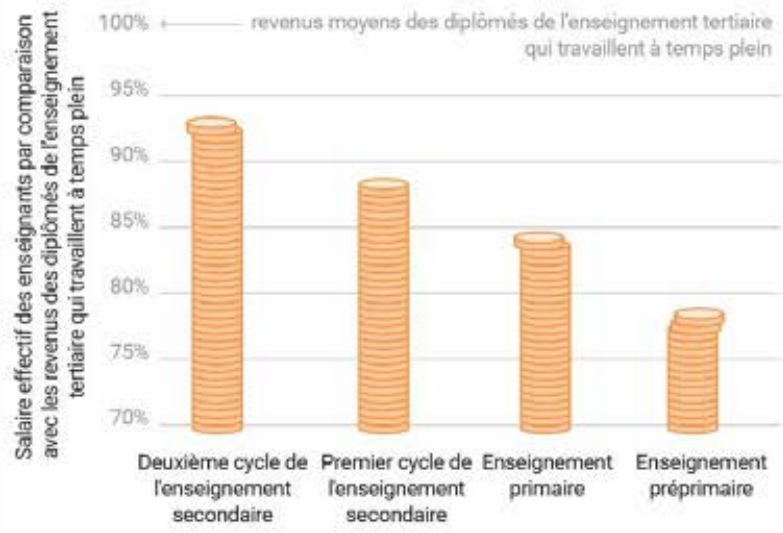

La hausse des coûts s'explique par (premier cycle de lenseignement secondaire, 2005-2017)

Des salaires statutaires plus élevés:

Des classes plus petites :
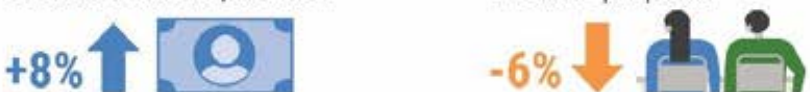


\section{Les jeunes dans l'Objectif de développement durable relatif à l'éducation}

\section{Faits marquants}

- Le $4^{e}$ Objectif de développement durable (ODD 4) relatif à l'éducation aborde ce thème dans une perspective d'apprentissage tout au long de la vie et met l'enseignement professionnel et tertiaire à l'ordre du jour mondial. Avec le $8^{\mathrm{e}}$ Objectif de développement durable (ODD 8) dédié au travail décent et à la croissance économique, ces deux objectifs incluent suffisamment d'indicateurs pour suivre le parcours des jeunes de l'éducation jusqu'au marché du travail.

- Dans plus d'un quart des pays membres ou partenaires de l'OCDE, les jeunes non scolarisés (ODD 4.1.5) représentent encore plus de $10 \%$ de la population de la tranche d'âge officielle du deuxième cycle de l'enseignement secondaire. Certains pays sont toutefois parvenus à réduire sensiblement leur proportion de jeunes non scolarisés. C'est par exemple le cas de la Fédération de Russie et du Mexique, où cette proportion a diminué d'au moins 18 points de pourcentage depuis 2005.

- En moyenne, dans les pays de l'OCDE, $18 \%$ des $15-24$ ans suivent un programme professionnel (niveaux 2 à 5 de la CITE ; indicateur 4.3.3 des ODD). La plupart d'entre eux sont scolarisés dans l'enseignement secondaire.

Graphique 1. Taux de non-scolarisation dans le deuxième cycle de l'enseignement secondaire (2005 et 2017) Indicateur 4.1.5 des ODD

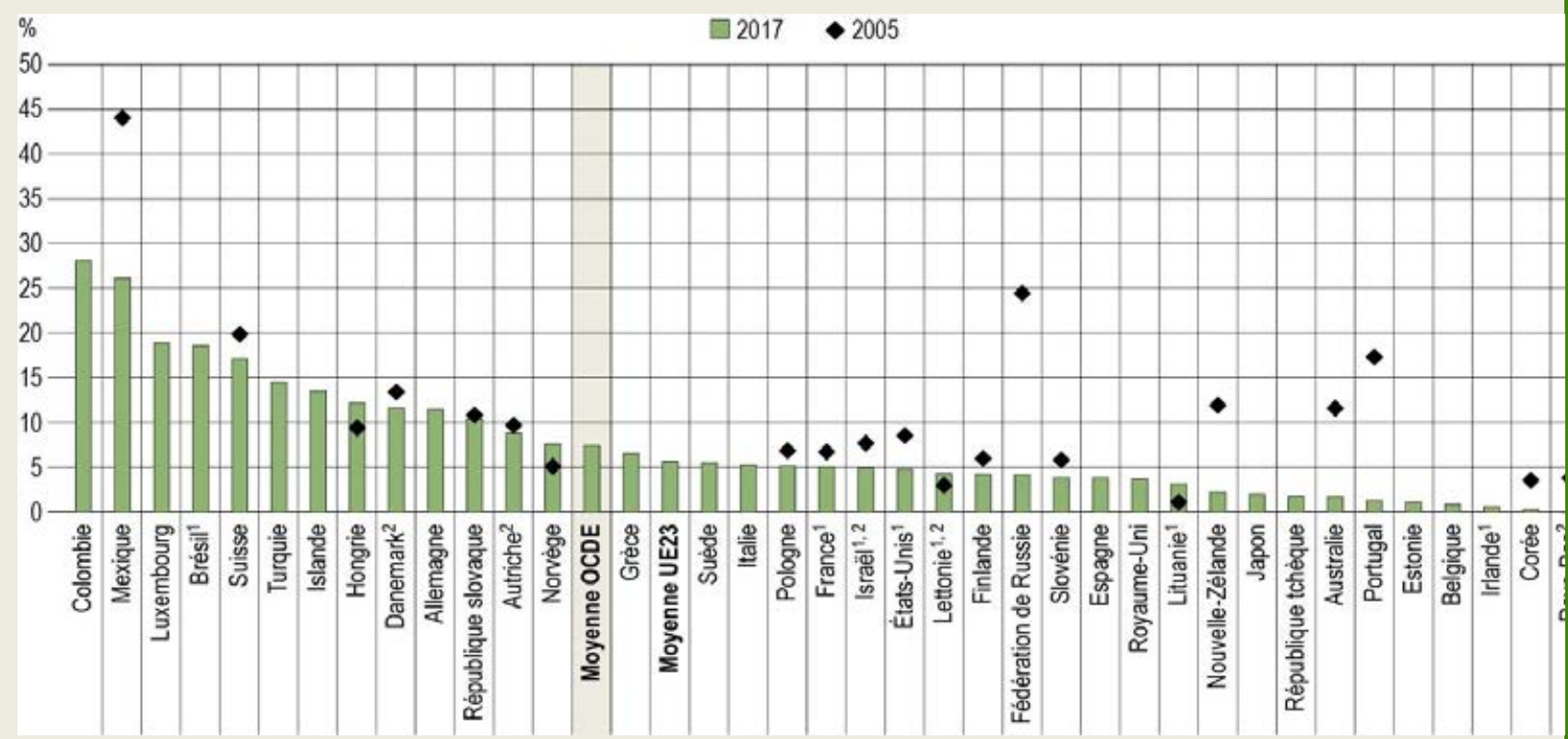

Remarque : Le taux de non-scolarisation est calculé en prenant le nombre d'étudiants dans la tranche d' âge du deuxième cycle de l'enseignement secondaire et qui sont inscrits dans l'enseignement primaire, secondaire ou à des niveaux plus élevés que l'on a soustrait à la population totale du même âge (numérateur), divisé par la population totale du même âge (dénominateur)

1. Les données démographiques proviennent de l'exercice UOE de collecte de données démographiques (Eurostat/DEM), et non de la Division de la population de I'Organisation des Nations Unies (UNPD).

2. Année de référence : 2010 , et non 2005.

Les pays sont classés par ordre décroissant du taux de non-scolarisation dans le deuxième cycle de l'enseignement secondaire en 2017.

Source : OCDE (2019). Les sources de données officielles de cet indicateur sont : la collecte de données UOE pour les données sur la scolarisation ; et la Division de la population de l'Organisation des Nations Unies (UNPD) pour les données démographiques. Consulter la section « Source » pour tout complément d'information et l'annexe 3 pour les notes (https://doi.org/10.1787/f8d7880d-en). 


\section{Contexte}

Contrairement aux Objectifs antérieurs du Millénaire pour le développement (OMD 2000-2015), fixés pour les pays à revenu faible ou intermédiaire, l'Agenda 2030 pour le développement durable est à vocation universelle. Fort de 17 objectifs ambitieux et de grande envergure, il enjoint chaque pays à travers le monde à éradiquer la pauvreté et à favoriser un développement prospère et durable à l'horizon 2030.

Le $4^{\mathrm{e}}$ Objectif de développement durable (ODD 4) relatif à l'éducation vise à « assurer l'accès de tous à une éducation de qualité, sur un pied d'égalité, et à promouvoir les possibilités d'apprentissage tout au long de la vie » d'ici à 2030. Pour réaliser cet objectif, il s'agit d'atteindre dix cibles qui constituent le programme d'action le plus complet et le plus ambitieux jamais adopté en faveur de l'éducation dans le monde. Se démarquant des OMD, qui mettaient l'accent sur l'enseignement primaire universel, l'ODD 4 conçoit l'apprentissage comme un processus continu, commençant dès la naissance pour se poursuivre au fil de l'ensemble des étapes de l'existence. Ce faisant, le programme d'action de l'ODD 4 envisage les trajectoires individuelles d'apprentissage dans toute leur diversité et leur flexibilité. L'enseignement tertiaire, thème central de cette édition de Regards sur l'éducation, joue aussi un rôle dans ce cadre et apparaît comme l'une des voies susceptibles de mener les jeunes à la réussite (voir l'encadré 1).

Ce chapitre se propose d'explorer les trajectoires d'apprentissage des jeunes et de contribuer à éclairer le débat sur les perspectives et l'emploi des jeunes dans les pays membres ou partenaires de l'OCDE, à la lumière de l'Agenda pour le développement durable. S'appuyant non seulement sur l'ODD 4 (éducation de qualité), mais aussi sur l'ODD 8 (travail décent et croissance économique), ce chapitre s'attachera à décrire les trajectoires que les jeunes peuvent emprunter au fil de leur parcours : du secondaire aux niveaux supérieurs d'enseignement (dont l'enseignement tertiaire) ; d'un niveau supérieur d'enseignement à un autre ; et des études au marché du travail.

\section{Autres faits marquants}

- Les jeunes sont plus exposés au risque de la précarité de l'emploi que les adultes plus âgés. En moyenne, dans les pays de l'OCDE, le taux de chômage des $25-34$ ans $(7 \%)$ est supérieur de 2 points de pourcentage à celui des 35-44 ans (5\%) (voir l'indicateur A3, utilisé comme variable indicative pour l'indicateur 8.5.2 des ODD).

- En moyenne, dans les pays de l'OCDE, $11 \%$ des 15-24 ans sont sans emploi et ne sont ni scolarisés, ni en formation (neither in employment, nor in education or training, NEET) (voir l'indicateur A2, utilisé comme variable indicative pour l'indicateur 8.6.2 des ODD).

\section{Remarque}

Dans le cadre de suivi de l'ODD 4, chaque cible est associée à au moins un indicateur mondial et à plusieurs indicateurs thématiques connexes conçus pour compléter l'analyse et l'évaluation de la cible. Au total, 11 indicateurs mondiaux et 32 indicateurs thématiques sont retenus pour suivre l'évolution des progrès relatifs à l'ODD4. La liste de tous ces indicateurs, accompagnés de leur méthodologie, peut être consultée sur le site de l'UNESCO (http://SDG4monitoring.uis.unesco.org.).

Les graphiques de ce chapitre présentent quelques indicateurs convenus par cible, choisis en fonction de leur pertinence pour les pays membres ou partenaires de l'OCDE, et des données disponibles. Certains indicateurs de l'ODD 4 correspondent à des indicateurs déjà publiés dans d'autres chapitres de Regards sur l'éducation. Dans ce cas, un lien renvoie à l'indicateur correspondant.

Les données présentées dans ce chapitre ne suivent pas l'évolution d'une seule cohorte dans le temps. Elles décrivent et analysent plutôt les trajectoires éducatives et professionnelles des jeunes à un moment déterminé, dans différents groupes d'âge. 


\section{Analyse}

\section{Encadré 1. Les trajectoires d'apprentissage dans le cadre des ODD}

Parmi les 17 Objectifs de développement durable et leurs cibles, plusieurs mentionnent explicitement les jeunes femmes et les jeunes hommes. L'ODD 4, relatif à l'égalité d'accès à une éducation de qualité, et I'ODD 8, dédié au travail décent, sont ceux qui concernent le plus directement les jeunes. Parmi les autres objectifs particulièrement pertinents à cet égard, citons I'ODD 10 (inégalités) et l'ODD 16 (paix et justice).

L'Objectif de développement durable relatif à l'éducation (ODD 4) insiste sur l'importance de l'accès de tous, sur un pied d'égalité, à une éducation de qualité et à des possibilités d'apprentissage tout au long de la vie. Pour suivre ce processus continu d'apprentissage, le programme d'action de I'ODD 4 propose une série d'indicateurs afin de mesurer la participation et les compétences des individus au fil de leur existence, couvrant les niveaux d'enseignement obligatoires ou non, ainsi qu'un large éventail de programmes (dont l'éducation formelle, mais aussi non formelle).

\section{Graphique 2. Trajectoires des jeunes de l'éducation à l'emploi}

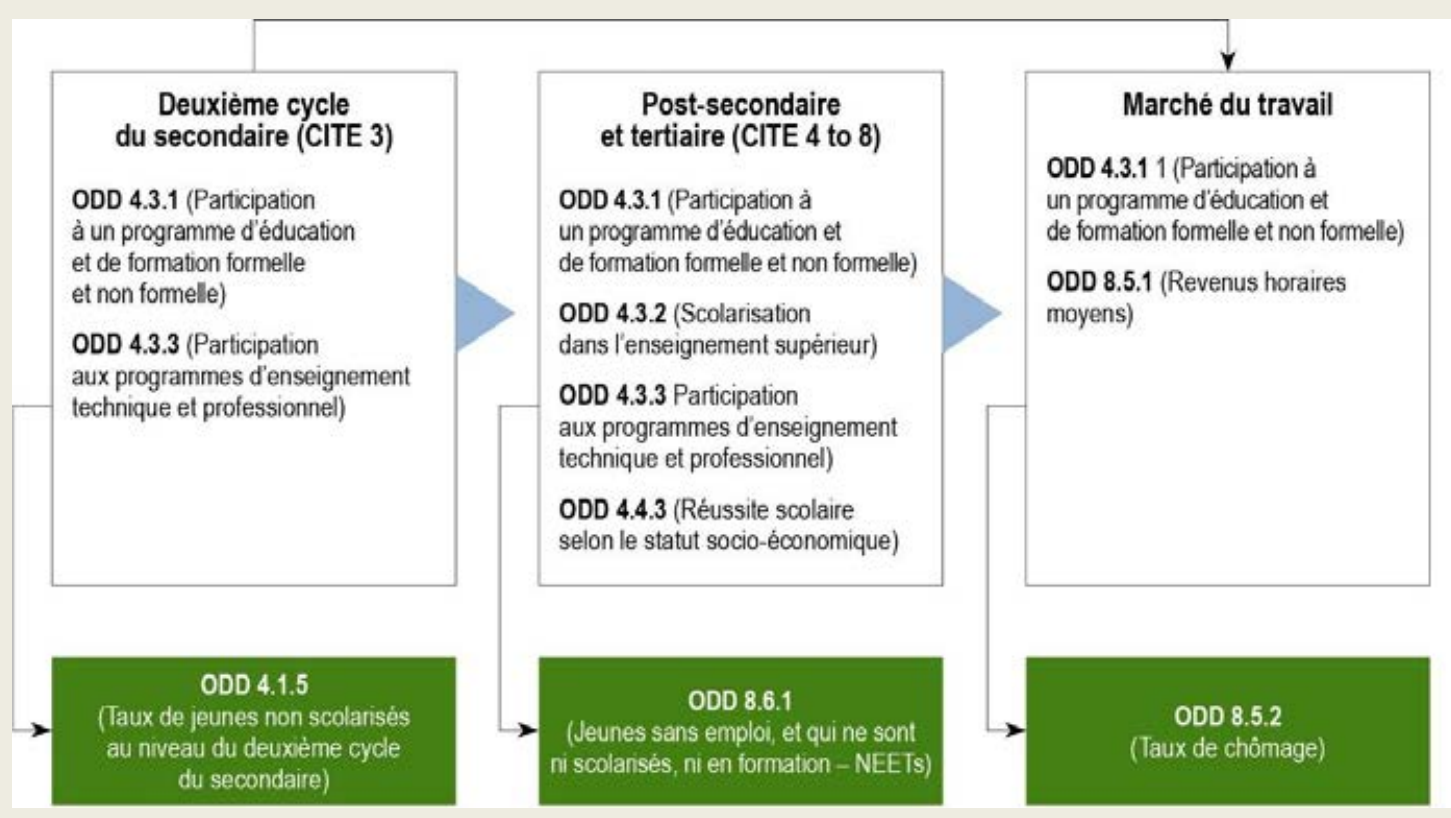

Parmi les cibles de l'ODD 4, I'ODD 4.1 et l'ODD 4.2 soulignent l'importance de la participation, mais aussi de la qualité, dans l'enseignement préprimaire (ODD 4.2), l'enseignement primaire et l'enseignement secondaire (ODD 4.1), tandis que I'ODD 4.3 s'attache à la participation aux niveaux supérieurs d'enseignement. L'ODD 4.3 vise à « faire en sorte, d'ici à 2030, que les femmes et les hommes aient tous accès dans des conditions d'égalité à un enseignement technique, professionnel ou tertiaire, y compris universitaire, de qualité et d'un coût abordable ». Cette cible est étroitement liée aux ODD 4.4 et 4.6, qui mesurent tous deux les compétences essentielles que les jeunes et les adultes peuvent acquérir dans le cadre de l'enseignement professionnel ou tertiaire, ou de la formation pour adultes, notamment celles en littératie, en numératie, en culture numérique et en technologies de l'information et de la communication (TIC). Elle est également en lien étroit avec I'ODD 4.7, qui vise à faire en sorte que les élèves acquièrent les connaissances et compétences nécessaires pour promouvoir le développement durable. 
L'ODD 4.3 inclut un indicateur mondial sur le taux de participation des jeunes et des adultes à l'éducation et la formation formelles ou non formelles, et deux indicateurs thématiques sur le taux brut de scolarisation dans l'enseignement tertiaire et le taux de participation à l'enseignement professionnel. La formulation de cette cible, ainsi que les indicateurs qu'elle comprend, reconnaissent la diversité des trajectoires que les jeunes et les adultes peuvent emprunter afin d'acquérir les compétences nécessaires pour faciliter leur entrée sur le marché du travail et vivre une vie meilleure.

Le graphique 2 décrit la façon dont les indicateurs des ODD 4 et 8 suivent la progression des jeunes depuis l'enseignement secondaire jusqu'au marché du travail, en évaluant leur participation (flèches bleues) et la proportion de ceux quittant le système éducatif et/ou le marché du travail (rectangles rouges).

Avec ses cibles, le $4^{\mathrm{e}}$ Objectif de développement durable propose un programme d'action ambitieux qui englobe la qualité de l'apprentissage et l'équité dans l'éducation, à côté des concepts plus traditionnels d'accès et de scolarisation à tous les niveaux d'enseignement. En fait, il engage chaque pays du monde à améliorer son système d'éducation et se démarque sensiblement des objectifs et cibles antérieurs dans le domaine de l'éducation, tels que les Objectifs du Millénaire pour le développement, qui n'étaient pas d'une aussi grande portée et se concentraient davantage sur l'accès et la scolarisation dans l'enseignement primaire. Les analyses ci-après tiennent compte de cette dimension continue de l'apprentissage tout au long de la vie et examinent les trajectoires empruntées par les jeunes au fil de leur parcours, des études jusqu'au marché du travail.

\section{Réussite du deuxième cycle de l'enseignement secondaire}

La réussite du deuxième cycle de l'enseignement secondaire est une étape importante, qui permet aux jeunes de mieux s'intégrer sur le marché du travail. Les personnes non diplômées du deuxième cycle de l'enseignement secondaire sont plus susceptibles d'être sans emploi (voir l'indicateur A3) et d'avoir des revenus moins élevés (voir l'indicateur A4) que celles diplômées de ce niveau ou d'un niveau supérieur d'enseignement.

Comme le confirme le programme d'action des ODD, l'éducation joue aussi un rôle décisif pour amener les jeunes à devenir des citoyens engagés, qui participent à la vie de la société. Dans cette perspective, la cible 4.7 des ODD vise à « faire en sorte que tous les élèves acquièrent les connaissances et compétences nécessaires pour promouvoir le développement durable, notamment par l'éducation en faveur du développement et de modes de vie durables, des droits de l'homme, de l'égalité des sexes, de la promotion d'une culture de paix et de nonviolence, de la citoyenneté mondiale et de l'appréciation de la diversité culturelle et de la contribution de la culture au développement durable ». Les données nécessaires au bon suivi de la cible 4.7 des ODD sont encore limitées, mais cette cible reconnaît les multiples fonctions de l'éducation, au nombre desquelles la formation de citoyens plus éclairés.

L'obtention d'un diplôme de l'enseignement secondaire ne mène pas nécessairement à la poursuite des études, les trajectoires variant sensiblement entre les pays à l'issue du secondaire. Ainsi, dans certains pays, les jeunes souhaitant suivre une formation tertiaire peuvent devoir au préalable passer un examen d'entrée centralisé (voir l'indicateur D6). Dans d'autres pays, les jeunes diplômés de l'enseignement secondaire peuvent avoir de bonnes chances de réussite s'ils entrent directement sur le marché du travail. Le pourcentage de jeunes diplômés de l'enseignement secondaire ne reflète donc pas toujours celui des jeunes qui poursuivront leurs études au-delà de ce niveau d'enseignement. Toutefois, dans l'ensemble des pays, les jeunes non diplômés du deuxième cycle de l'enseignement secondaire sont moins susceptibles de poursuivre leurs études, et plus susceptibles d'être sans emploi ou inactifs.

L'indicateur 4.1.5 des ODD mesure le taux de non-scolarisation dans le deuxième cycle de l'enseignement secondaire, c'est-à-dire le pourcentage de jeunes appartenant à la tranche d'âge officielle du deuxième cycle du secondaire qui ne sont scolarisés ni dans l'enseignement primaire, ni dans l'enseignement secondaire, ni dans un autre niveau supérieur d'enseignement. En moyenne, dans les pays de l'OCDE, près de $7 \%$ des jeunes de la tranche d'âge du deuxième cycle de l'enseignement secondaire n'étaient pas scolarisés en 2017 ; ce 
pourcentage est toutefois égal ou inférieur à $5 \%$ de ce groupe d'âge dans plus de la moitié des pays dont les données sont disponibles (voir le graphique 1). En d'autres termes, si la majorité des pays sont parvenus à limiter le pourcentage de jeunes non scolarisés (avec des taux inférieurs à $5 \%$ ), ceux-ci restent nombreux (plus de $10 \%$ ) dans environ un quart des pays membres ou partenaires de l'OCDE. Parmi tous les pays membres ou partenaires de l'OCDE, ce sont la Colombie et le Mexique qui présentent les taux les plus élevés de jeunes non scolarisés : plus de $25 \%$ des jeunes de la tranche d'âge du deuxième cycle de l'enseignement secondaire ne sont pas scolarisés dans ces pays; suivent le Luxembourg (19\%), le Brésil (19\%) et la Suisse (17\%). Au Luxembourg, le taux élevé de redoublement dans l'enseignement primaire et l'enseignement secondaire peut contribuer à un taux de décrochage scolaire plus important (OCDE, 2016[1] $)$.

Ces dix dernières années, certains pays ont réalisé des progrès considérables dans la réduction du nombre de jeunes non scolarisés. Le graphique 1 montre une diminution de 20 points de pourcentage du taux de nonscolarisation en Fédération de Russie, de 18 points de pourcentage au Mexique, de 16 points de pourcentage au Portugal et de 10 points de pourcentage en Australie et en Nouvelle-Zélande entre 2005 et 2017. L'ampleur de ces réductions reflète les efforts politiques consentis pour maintenir dans le système scolaire les élèves de la tranche d'âge du deuxième cycle de l'enseignement secondaire.

Les taux de non-scolarisation dans le deuxième cycle de l'enseignement secondaire restent à peu près similaires entre les sexes dans la plupart des pays. La différence de taux de non-scolarisation entre les jeunes femmes et les jeunes hommes reste égale ou inférieure à 4 points de pourcentage dans la quasi-totalité des pays, à l'exception du Luxembourg, où ce taux est supérieur de 5 points de pourcentage chez les jeunes hommes, et en Suède, où il est supérieur de 11 points de pourcentage chez les jeunes femmes.

\section{Transition entre l'enseignement secondaire et les niveaux supérieurs d'enseignement}

À l'issue du deuxième cycle de l'enseignement secondaire, la poursuite du parcours éducatif peut prendre des formes très diverses. Une fois obtenu leur diplôme du secondaire, les jeunes peuvent opter, selon les pays, pour une formation post-secondaire non tertiaire, une formation tertiaire de cycle court, une licence ou une première formation tertiaire de type long.

La cible 4.3 des ODD vise à « faire en sorte, d'ici à 2030, que les femmes et les hommes aient tous accès dans des conditions d'égalité à un enseignement technique, professionnel ou tertiaire, y compris universitaire, de qualité et d'un coût abordable ». Elle reconnaît la diversité des trajectoires que les jeunes et les adultes peuvent emprunter afin d'acquérir les compétences nécessaires pour faciliter leur entrée sur le marché du travail, devenir des citoyens engagés et vivre une vie meilleure. Bien que la cible 4.3 s'attache uniquement à la participation, elle est étroitement liée aux cibles 4.4 et 4.6, qui mesurent certaines des compétences pouvant être acquises dans le cadre d'un enseignement ou d'une formation professionnels ou tertiaires.

La cible 4.3 met en outre fortement l'accent sur le principe d'équité, en préconisant que « les femmes et les hommes aient tous accès dans des conditions d'égalité " à ce type d'enseignement. Les parcours à disposition des jeunes peuvent varier, mais le plus important reste que chacun ait les mêmes chances d'y accéder. En outre, le suivi des différentes trajectoires permet de prendre la mesure de la perméabilité du système d'éducation, également liée à l'équité : les apprenants doivent avoir la possibilité de passer facilement d'un niveau/type de programme à un autre (par exemple, d'une filière professionnelle à une filière générale). Enfin, la cible 4.3 souligne l'importance de la qualité comme du coût abordable de l'enseignement professionnel et tertiaire ; pour le moment, toutefois, aucun indicateur n'a été proposé pour évaluer l'une et/ou l'autre de ces deux dimensions (UNESCO, 2016[2]).

\section{Enseignement et formation professionnels}

L'enseignement et la formation professionnels peuvent jouer un rôle décisif dans la lutte contre le chômage des jeunes. Durant les phases de ralentissement économique, comme lors de la récession de 2008 , ils se sont avérés un puissant outil pour faire face à ce problème dans des pays comme l'Allemagne, l'Autriche et la Suisse. Ces 
trois pays ont tous utilisé les programmes de formation professionnelle avec grande efficacité, en ciblant en particulier les élèves susceptibles de décrocher du système scolaire (Dolado, 2015 ${ }_{[3]}$ ).

L'indicateur thématique 4.3.3 des ODD mesure le taux de participation des 15-24 ans aux programmes techniques et professionnels, que ce soit dans un cadre éducatif formel, professionnel ou autre. Cet indicateur cible ce large groupe d'âge et un vaste éventail de niveaux d'enseignement (enseignement secondaire, enseignement post-secondaire non tertiaire et enseignement tertiaire de cycle court) ; il entend mesurer la participation aux programmes de formation à visée professionnelle, conçus pour accéder à un emploi (UNESCO, 2017[4]]). En moyenne dans les pays de l'OCDE, $18 \%$ des 15-24 ans étaient scolarisés en 2017 dans un programme d'enseignement professionnel (enseignement secondaire, enseignement post-secondaire non tertiaire et enseignement tertiaire de cycle court confondus), avec des pourcentages allant de $3 \%$ au Brésil à $35 \%$ en Slovénie (voir le graphique 4). Les taux de scolarisation dans ce type de programmes restent plus élevés chez les jeunes hommes que chez les jeunes femmes dans la quasi-totalité des pays dont les données sont disponibles (voir le graphique 3). En moyenne dans les pays de l'OCDE, les jeunes femmes (âgées de 15 à 24 ans) représentent $16 \%$ des effectifs totaux en filière professionnelle mais ce pourcentage passe à $19 \%$ pour les hommes.

La ventilation de l'indicateur 4.3.3 des ODD par niveau d'enseignement indique que dans la quasi-totalité des pays, la plupart des jeunes âgés de 15 à 24 ans suivant un programme professionnel sont scolarisés dans l'enseignement secondaire (voir le graphique 4). En d'autres termes, la grande majorité des élèves suivant un programme professionnel le feront dans la tranche d'âge correspondant au deuxième cycle de l'enseignement secondaire, c'està-dire entre 15 et 19 ans (voir l'indicateur B1). Il est donc possible que le groupe d'âge élargi de l'indicateur 4.3.3 des ODD (15-24 ans) sous-estime les taux de participation à ces programmes dans les pays de l'OCDE.

\section{Graphique 3. Participation des 15-24 ans à l'enseignement et la formation professionnels, selon le sexe (2017)}

Indicateur 4.3.3 des ODD

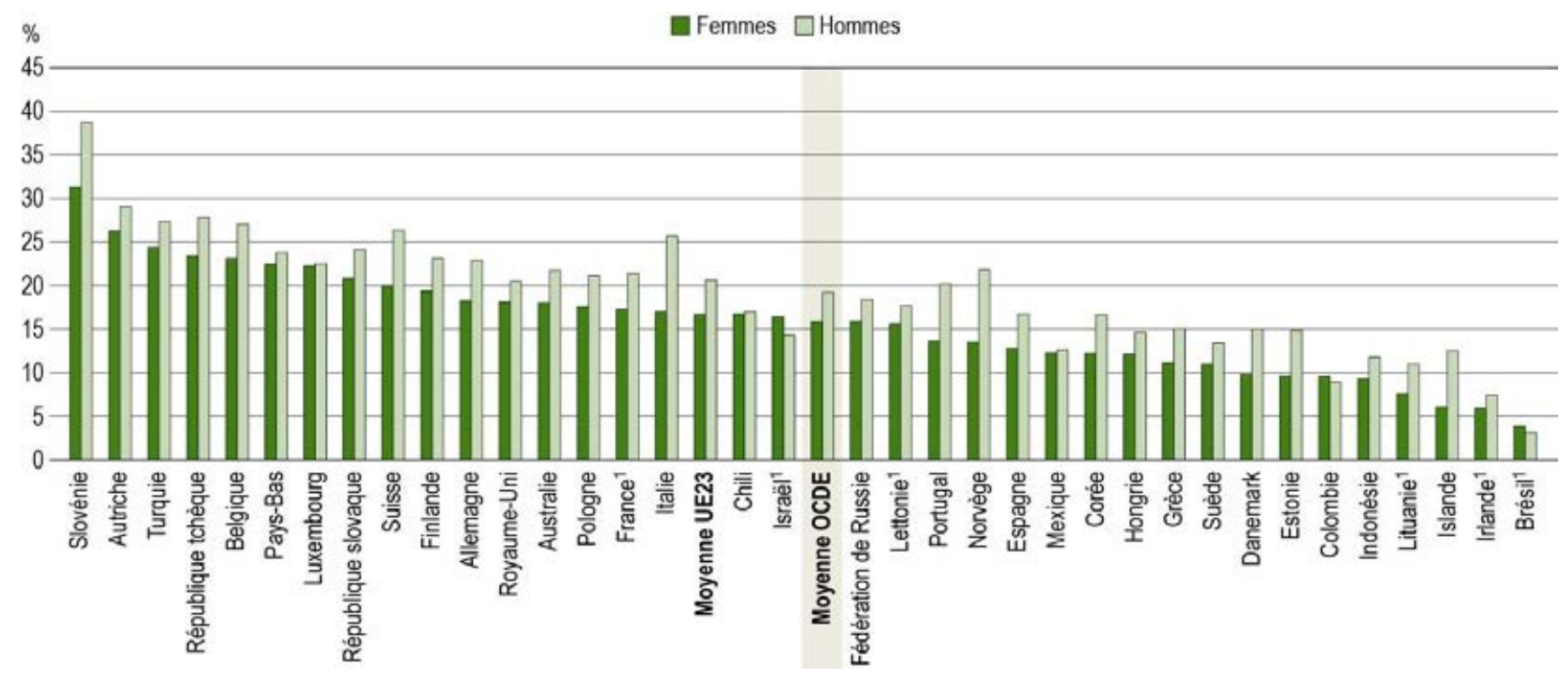

1. Les données démographiques proviennent de l'exercice UOE de collecte de données démographiques (Eurostat/DEM), et non de la Division de la population de l'Organisation des Nations Unies (UNPD).

Les pays sont classés par ordre décroissant du taux de scolarisation des femmes âgées de 15 à 24 ans dans des programmes d'enseignement et de formation professionnels en 2017.

Source : OCDE (2019). Les sources de données officielles de cet indicateur sont : la collecte de données UOE pour les données sur la scolarisation ; et la Division de la population de l'Organisation des Nations Unies (UNPD) pour les données démographiques. Consulter la section « Source » pour tout complément d'information et l'annexe 3 pour les notes (https://doi.org/10.1787/f8d7880d-en). 
L'expérience professionnelle reste l'une des principales caractéristiques d'un enseignement et d'une formation professionnels réussis (OCDE, 2014[5]). Les données disponibles ne permettent toutefois pas de rendre compte de toute la diversité des programmes professionnels proposés dans les différents pays. Plus spécifiquement, le suivi des systèmes existants de formation en alternance (enseignement professionnel combinant cadre éducatif formel et immersion en milieu de travail) permettrait de mieux comprendre le rôle de l'enseignement et de la formation professionnels dans la limitation des taux de décrochage scolaire et l'offre de voies alternatives aux jeunes désengagés (voir l'encadré A5.1 dans (OCDE, 2017[6])).

L'enseignement et la formation professionnels peuvent également permettre d'accéder à l'enseignement tertiaire. Des pays comme la Finlande et les Pays-Bas ont par exemple renforcé la perméabilité de leur système éducatif et mis en place des « passerelles » entre formation professionnelle et enseignement tertiaire.

\section{Enseignement tertiaire}

Le nombre d'étudiants suivant une formation tertiaire n'a cessé d'augmenter dans le monde au cours des 20 dernières années, croissance qui devrait se poursuivre à l'horizon 2030 (OCDE, 2018[7]). Dans les pays de l'OCDE, le pourcentage de jeunes adultes (âgés de 25 à 34 ans) diplômés de l'enseignement tertiaire a ainsi progressé, passant de $35 \%$ en 2008 à $44 \%$ en 2018 (voir l'indicateur A1). Cette augmentation pourrait refléter une hausse de la demande de main-d'œuvre qualifiée, de la demande de formations tertiaires, de la richesse et du nombre de politiques d'aide financière visant à promouvoir l'accès à ce niveau d'enseignement (OCDE, 2018[7] ; Owens, 2017[8]).

\section{Graphique 4. Participation des 15-24 ans à l'enseignement et la formation professionnels, selon le niveau d'enseignement (2017)}

Indicateur 4.3.3 des ODD

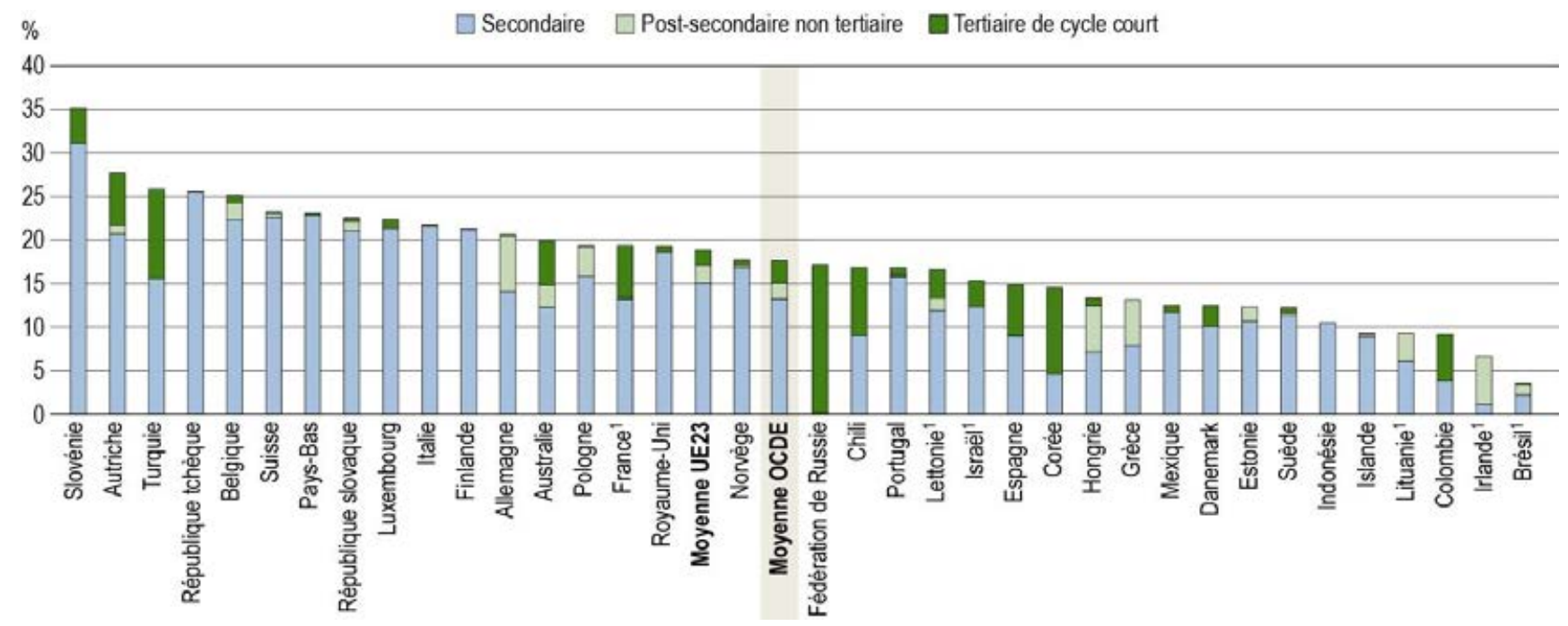

1. Les données démographiques proviennent de l'exercice UOE de collecte de données démographiques (Eurostat/DEM), et non de la Division de la population de l'Organisation des Nations Unies (UNPD).

Les pays sont classés par ordre décroissant du taux de scolarisation des 15-24 ans dans des programmes d'éducation et de formation professionnelles en 2017.

Source : OCDE (2019). Les sources de données officielles de cet indicateur sont : la collecte de données UOE pour les données sur la scolarisation ; et la Division de la population de l'Organisation des Nations Unies (UNPD) pour les données démographiques. Consulter la section « Source » pour tout complément d'information et l'annexe 3 pour les notes (https://doi.org/10.1787/f8d7880d-en). 
Le programme d'action des ODD reconnaît l'importance croissante de l'enseignement tertiaire dans le monde et inclut un indicateur dédié à ce niveau. L'indicateur 4.3.2 mesure ainsi le taux brut de scolarisation dans l'enseignement tertiaire, soit le nombre total d'étudiants scolarisés à ce niveau d'enseignement, quel que soit leur âge, en pourcentage de la population de la tranche d'âge de cinq ans suivant immédiatement la fin du deuxième cycle de l'enseignement secondaire (typiquement, 18-22 ans). II est toutefois possible que cette définition sousestime les taux de scolarisation des pays où les étudiants suivent principalement des programmes de courte durée par rapport à ceux où ils suivent des programmes plus longs. D'autres facteurs de confusion s'observent dans les pays de l'OCDE où les longues périodes de scolarisation à temps partiel sont courantes.

Comme mentionné précédemment, la cible 4.3 des ODD est étroitement liée aux cibles 4.4, 4.6 et 4.7, qui visent à accroître le nombre de jeunes et d'adultes dotés des compétences nécessaires pour réussir sur le marché du travail et s'engager dans la société au sens plus large. À cette fin, l'indicateur 4.4.3 des ODD mesure le « niveau de formation des jeunes selon le groupe d'âge, la situation au regard de l'activité économique et l'orientation du programme ». En moyenne, dans les pays de l'OCDE, le niveau de formation le plus élevé atteint est le deuxième cycle de l'enseignement secondaire ou le post-secondaire non tertiaire pour $41 \%$ des jeunes adultes (âgés de 25 à 34 ans), et l'enseignement tertiaire pour $44 \%$ de ce même groupe d'âge (voir l'indicateur A1). L'indicateur 4.4.3 reconnaît aussi l'importance d'explorer le lien entre niveau de formation et situation au regard de l'activité économique, thème qui fera l'objet de la section suivante.

\section{Entrée sur le marché du travail}

La transition entre l'école et le monde du travail est un moment éprouvant pour de nombreux jeunes. Le risque de chômage, la précarité résultant des emplois mal rémunérés ou des contrats de courte durée et les aléas du début de l'autonomie sont autant de difficultés que les jeunes peuvent rencontrer (OCDE, 2018[9]).

Dans les pays de l'OCDE, les jeunes restent davantage exposés que les adultes au risque du chômage et de l'emploi précaire (voir l'indicateur A3). Ils sont en général moins spécialisés et plus susceptibles d'être licenciés lorsque les entreprises sont en difficulté, et peuvent en outre se retrouver piégés dans le cercle vicieux de l'expérience, les employeurs privilégiant les travailleurs expérimentés et les jeunes étant ainsi dans l'impossibilité de développer leur propre expérience (Dolado, 2015[3]). Sur le plan de l'offre de travail, la rotation des travailleurs est plus forte chez les jeunes que chez les adultes, leurs premiers emplois pouvant ne pas correspondre à leurs compétences et préférences (Blanchflower et Bell, 2011 [10]).

Le $8^{e}$ Objectif de développement durable (ODD 8) vise à « promouvoir une croissance économique soutenue, partagée et durable, le plein emploi productif et un travail décent pour tous ». À cet égard, il recoupe la cible 4.4, qui souligne l'impératif de disposer des compétences nécessaires "à l'emploi [et] à l'obtention d'un travail décent ». L'ODD 8 reconnaît également la vulnérabilité relative des jeunes sur le marché du travail et leur consacre deux cibles dédiées. La cible 8.6 vise ainsi, d'ici à 2020, à réduire considérablement la proportion de jeunes sans emploi ne suivant ni études ni formation, et la cible 8.B, à élaborer et mettre en œuvre une stratégie mondiale en faveur de l'emploi des jeunes, et à appliquer le Pacte mondial pour l'emploi de l'Organisation internationale du travail. La cible 8.5 , visant à garantir un emploi productif et un travail décent à toutes les femmes et à tous les hommes, confirme également la vulnérabilité relative des jeunes, en les mentionnant spécifiquement comme un groupe potentiellement désavantagé.

L'indicateur 8.5.2 des ODD mesure le taux de chômage selon le sexe, l'âge et la situation au regard du handicap. L'indicateur A3 de cette publication permet la comparaison des taux de chômage des jeunes et des adultes plus âgés. En moyenne, dans les pays de l'OCDE, le taux de chômage des 25-34 ans (7 \%) est supérieur de 2 points de pourcentage à celui des 35-44 ans (5\%). L'indicateur A3 met également au jour le lien net entre le niveau de formation des jeunes et leur situation au regard de l'activité. En moyenne, dans les pays de l'OCDE, le taux de chômage est ainsi près de deux fois plus élevé chez les jeunes (âgés de 25 à 34 ans) non diplômés du deuxième cycle de l'enseignement secondaire (14\%) que chez ceux diplômés de ce niveau d'enseignement ou de l'enseignement post-secondaire non tertiaire (7\%) ou chez ceux diplômés de l'enseignement tertiaire (6 \%) (voir l'indicateur A3). 
Pour suivre les progrès réalisés par les pays sur la voie de l'emploi productif et du travail décent, la cible 8.5 inclut également un indicateur de la rémunération horaire moyenne selon la profession, le sexe, l'âge et la situation au regard du handicap (indicateur 8.5.1 des ODD). Bien que l'indicateur A4 de la présente publication évalue quant à lui la rémunération annuelle moyenne relative, il peut toutefois permettre de comparer les revenus des jeunes dans les pays de l'OCDE. II montre qu'à l'instar de la situation au regard de l'activité professionnelle, les revenus sont aussi en corrélation étroite avec le niveau de formation : en moyenne, dans les pays de l'OCDE, chez les 25-34 ans, les diplômés de l'enseignement tertiaire ont ainsi des revenus supérieurs de $38 \%$ à ceux des diplômés du deuxième cycle de l'enseignement secondaire (voir l'indicateur A4). En raison de l'absence de ventilation des données selon la situation au regard du handicap, cette dimension des indicateurs 8.5.1 et 8.5.2 ne peut pas encore faire l'objet d'un suivi.

Le pourcentage de jeunes sans emploi ne suivant ni études ni formation (neither in employment nor in education or training, NEET) reste un indicateur plus pertinent de la participation des jeunes au marché du travail que le taux de chômage, car un pourcentage important d'individus du groupe d'âge considéré sont encore scolarisés, et cet indicateur couvre non seulement les jeunes sans emploi, mais aussi les inactifs (Dolado, 2015[3]). II s'agit d'un indicateur clé de la performance des jeunes sur le marché du travail, ce groupe étant exposé à un fort risque de marginalisation et d'exclusion sociale. L'indicateur 8.6.1 des ODD mesure le pourcentage de jeunes (âgés de 15 à 24 ans) ne participant à aucune forme d'éducation - qu'elle soit formelle ou non formelle -, n'occupant aucun emploi et ne suivant aucune formation. Si l'on utilise l'indicateur A2 de cette publication comme variable indicative (dans la mesure où il ne couvre que les jeunes participant à des programmes formels d'éducation), en moyenne, dans les pays de l'OCDE, 11 \% des 15-24 ans étaient NEET en 2017.

\section{Définitions}

Par inactifs, on entend les individus qui n'étaient ni occupés, ni au chômage (qui n'étaient pas à la recherche d'un emploi) durant la semaine de référence.

L'expression « enseignement et formation techniques et professionnels » (EFTP) est l'expression générique communément employée par l'Institut de statistique de l'UNESCO pour désigner l'enseignement, la formation et le développement de compétences dans un large éventail de domaines professionnels, de secteurs de production, de services et de moyens de subsistance. Ces cursus peuvent comporter un volet pratique en entreprise (par exemple, les formations sous contrat d'apprentissage ou les formations en alternance). La réussite de ces formations donne lieu à la délivrance de diplômes certifiant des qualifications professionnelles utilisables sur le marché du travail et reconnues comme telles par les autorités nationales compétentes ou le marché du travail.

\begin{tabular}{ll}
\hline Indicateur des ODD & \multicolumn{1}{c}{ Définition } \\
\hline 4.1.5 & Taux de non-scolarisation dans le deuxième cycle de l'enseignement secondaire \\
4.3.2 & Taux brut de scolarisation dans l'enseignement tertiaire, selon le sexe \\
4.3.3 & Taux de participation à des programmes techniques et professionnels (jeunes âgés de 15 à 24 ans), selon le sexe \\
4.4.3 & $\begin{array}{l}\text { Niveau de formation des jeunes, selon le groupe d'âge, la situation au regard de l'activité économique, le niveau d'enseignement et } \\
\text { l'orientation du programme }\end{array}$ \\
\hline 8.5.1 & $\begin{array}{l}\text { Rémunération horaire moyenne des salariés de sexe féminin et de sexe masculin, selon la profession, l'âge et la situation au } \\
\text { regard du handicap }\end{array}$ \\
\hline 8.5.2 & Taux de chômage, selon le sexe, l'âge et la situation au regard du handicap \\
\hline 8.6.1 & Pourcentage de jeunes (âgés de 15 à 24 ans) sans emploi ne suivant ni études ni formation \\
\hline
\end{tabular}

\section{Méthodologie}

Les indices de parité sont calculés avec pour numérateur le groupe vraisemblablement le plus défavorisé et pour dénominateur le groupe vraisemblablement le plus favorisé. L'indice de parité entre les sexes correspond au ratio de la valeur de l'indicateur pour les femmes par rapport à la valeur pour les hommes. 
Tous les indicateurs présentés dans ce chapitre suivent la méthodologie convenue à propos des objectifs de développement durable, notamment au sujet des sources de données recommandées ; ils peuvent donc différer dans certains cas d'autres indicateurs publiés dans Regards sur l'éducation.

Voir les notes spécifiques aux pays à l'annexe 3 (https://doi.org/10.1787/f8d7880d-en).

\section{Source}

\begin{tabular}{ll}
\hline \multicolumn{1}{c}{ Indicateur } & \multicolumn{1}{c}{ Source } \\
\hline 4.1.5 & Collecte de données UOE 2018 et UNPD (sauf mention contraire) \\
4.3 .3 & Collecte de données UOE 2018 et UNPD (sauf mention contraire) \\
\hline
\end{tabular}

\section{Note concernant les données d'Israël}

Les données statistiques concernant Israël sont fournies par et sous la responsabilité des autorités israéliennes compétentes. L'utilisation de ces données par l'OCDE est sans préjudice du statut des hauteurs du Golan, de Jérusalem-Est et des colonies de peuplement israéliennes en Cisjordanie aux termes du droit international.

\section{Références}

Blanchflower, D. et D. Bell (2011), "Young people and the Great Recession », Oxford Review of Economic Policy, vol. 27/2, pp. 241-267.

Dolado, J. (2015), No Country for Young People? Youth Labour Market Problems in Europe, Centre for Economic Policy Research, http://www.cepr.org.

OCDE (2018), « Diplômés de l'enseignement tertiaire: Quelles évolutions ? », Les indicateurs de l'éducation à la loupe, $\mathrm{n}^{\circ} 61$, https://dx.doi.org/10.1787/1a4e9f01-fr.

OCDE (2018), Regards sur l'éducation 2018: Les indicateurs de l'OCDE, Éditions OCDE, Paris, https://dx.doi.org/10.1787/eag-2018-fr.

OCDE (2017), Regards sur l'éducation 2017: Les indicateurs de l'OCDE, Éditions OCDE, Paris, https://dx.doi.org/10.1787/eag-2017-fr.

OCDE (2016), Education Policy Outlook : Luxembourg, OCDE, Paris, https://www.oecd.org/luxembourg/Education-Policy-Outlook-Country-Profile-Luxembourg.pdf.

OCDE (2014), Skills beyond School: Synthesis Report, OECD Reviews of Vocational Education and Training, Éditions OCDE, Paris, https://dx.doi.org/10.1787/9789264214682-en.

Owens, T. (2017), « Higher education in the sustainable development goals framework », European Journal of Education, http://dx.doi.org/10.1111/ejed.12237.

UNESCO (2017), Global Education Monitoring Report: Accountability in education: meeting our commitments, UNESCO, Paris.

UNESCO (2016), Global Education Monitoring Report 2016: Education for People and Planet: Creating Sustainable Futures for All, UNESCO, Paris. 



\section{Chapitre A. Résultats des établissements d'enseignement et impact de l'apprentissage}

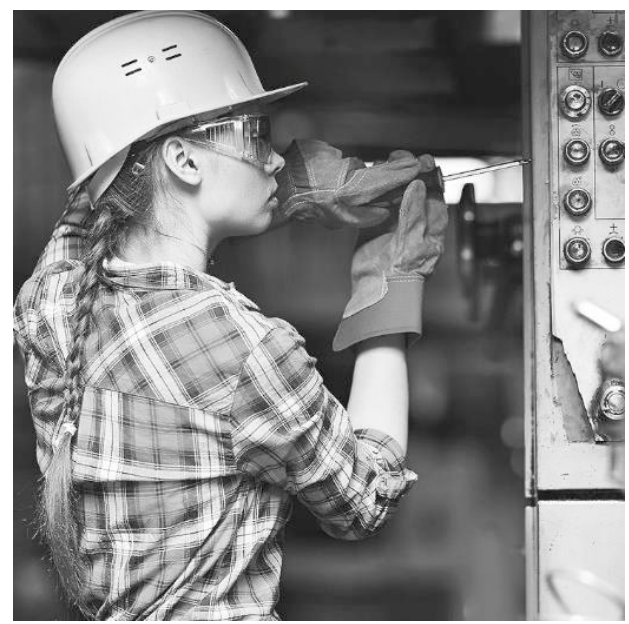

Indicateur A1 Quel est le niveau de formation de la population adulte?

Statlink : https://doi.org/10.1787/888933980792

Indicateur A2 Transition entre les études et la vie active : Où en sont les jeunes

d'aujourd'huil?

Statlink : https://doi.org/10.1787/888933980811

Indicateur A3 Dans quelle mesure le niveau de formation affecte-t-il le taux d'emploi ?

Statlink : https://doi.org/10.1787/888933980830

Indicateur A4 Quel avantage salarial le niveau de formation procure-t-il ?

Statlink : https://doi.org/10.1787/888933980849

Indicateur A5 Quels sont les facteurs financiers qui incitent à investir dans l'éducation ?

Statlink : https://doi.org/10.1787/888933980868

Indicateur A6 En quoi les retombées sociales sont-elles liées à l'éducation ?

Statlink : https://doi.org/10.1787/888933980887

Indicateur A7 Dans quelle mesure les adultes participent-ils équitablement à des activités de formation?

Statlink : https://doi.org/10.1787/888933980906 


\section{Indicateur A1. Quel est le niveau de formation de la population adulte?}

\section{Faits marquants}

- En moyenne, dans les pays de l'OCDE, environ 25 \% des diplômés de l'enseignement tertiaire âgés de 25 à 64 ans ont suivi une formation en commerce, en administration ou en droit, mais au plus $5 \%$ d'entre eux, une formation en rapport avec les technologies de l'information et de la communication (TIC), les sciences naturelles, les mathématiques ou les statistiques.

- Le pourcentage de diplômés de l'enseignement tertiaire âgés de 25 à 64 ans a augmenté de 9 points de pourcentage en moyenne dans les pays de l'OCDE entre 2008 et 2018, tandis que le pourcentage d'adultes non diplômés du deuxième cycle de l'enseignement secondaire a diminué, passant de $19 \%$ à $15 \%$.

- Dans tous les groupes d'âge, mais surtout parmi les jeunes, les femmes sont maintenant plus nombreuses que les hommes parmi les diplômés de l'enseignement tertiaire dans la quasi-totalité des pays de l'OCDE. Dans certains pays, le défaut de parité s'est inversé entre les générations plus âgées et plus jeunes.

Graphique A1.1. Domaines d'études des diplômés de l'enseignement tertiaire âgés de 25 à 64 ans (2018)

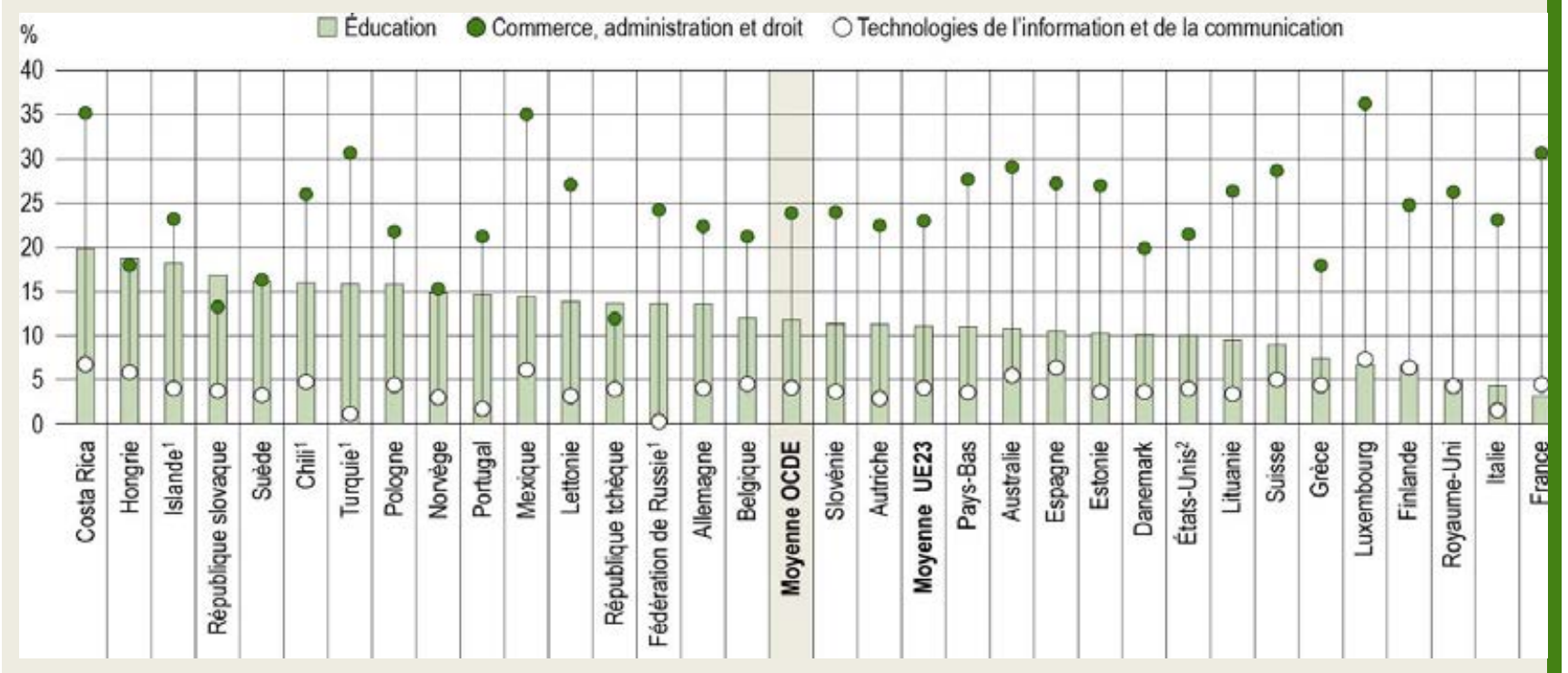

1. L'année de référence n'est pas 2018. Consulter le tableau source pour de plus amples informations.

2. Les données se rapportent au domaine d'études choisi en licence, même pour les adultes titulaires d'autres diplômes de l'enseignement tertiaire. Les pays sont classés par ordre décroissant du pourcentage d'adultes âgés de 25 à 34 ans diplômés de l'enseignement tertiaire ayant choisi le domaine d'études.

Source: OCDE (2019), tableau A1.3. Consulter la section «Source » pour tout complément d'information et l'annexe 3 pour les notes (https://doi.org/10.1787/f8d7880d-en). 


\section{Contexte}

Offrir à tous la possibilité de suivre un enseignement de haute qualité est une composante fondamentale du contrat social. II est absolument essentiel d'éliminer l'inégalité des chances dans l'éducation pour améliorer la mobilité sociale et les retombées socio-économiques. Une population hautement qualifiée dans un éventail de domaines d'études promeut la croissance inclusive, car elle alimente le vivier de personnes susceptibles d'occuper des postes qui requièrent de grandes compétences.

L'indicateur du niveau de formation correspond au pourcentage d'individus officiellement diplômés d'un certain niveau d'enseignement dans la population. Le niveau de formation sert souvent d'indicateur pour juger des compétences des individus et rendre compte du capital humain - c'est-à-dire du niveau de compétence associé à un certain niveau de formation dans la population et la main-d'œuvre.

Des niveaux de formation plus élevés sont associés à plusieurs retombées sociales et économiques positives pour les individus (voir les indicateurs A2, A3, A4, A5 et A6). Les individus très instruits tendent dans l'ensemble à être plus engagés dans la vie sociale et à afficher des revenus relatifs et des taux d'emploi supérieurs. Une meilleure performance en littératie et en numératie est également en forte corrélation avec des niveaux de formation plus élevés (OCDE, 2016[1]).

Les individus sont donc incités à poursuivre leurs études tandis que les gouvernements sont eux incités à fournir les infrastructures appropriées pour favoriser l'élévation du niveau de formation de la population et à prévoir l'organisation requise pour ce faire. Au cours des dernières décennies, le niveau de formation de la population, en particulier des jeunes et des femmes, a sensiblement augmenté dans la quasi-totalité des pays de l'OCDE.

Pour les employeurs, les qualifications certifient et décrivent les connaissances et les compétences que des personnes qu'ils envisagent d'engager ont acquises dans le cadre institutionnel. Cela peut les aider à choisir des candidats, voire l'endroit où s'implanter pour accéder aux profils les plus qualifiés. Il faut aussi être diplômé dans un domaine d'études spécifique pour exercer certaines professions ou accéder à certains secteurs. L'analyse des qualifications par domaine d'études peut donc donner des informations sur l'offre et la demande dans différentes catégories de professions dans les pays de l'OCDE.

\section{Autres faits marquants}

- Entre 2008 et 2018, le pourcentage de jeunes diplômés de l'enseignement tertiaire a augmenté dans tous les pays membres et partenaires de l'OCDE, tandis que le pourcentage de jeunes au plus diplômés du deuxième cycle de l'enseignement secondaire ou de l'enseignement post-secondaire non tertiaire a augmenté en Afrique du Sud, au Brésil, au Costa Rica, en Indonésie, au Mexique et au Portugal.

- Entre 2008 et 2018 , le pourcentage de jeunes diplômés de l'enseignement tertiaire a augmenté chez les hommes et chez les femmes dans les pays de d'OCDE, mais les femmes ont creusé leur avance, de 9 points de pourcentage en 2008 à 12 points de pourcentage en 2018.

- Le pourcentage de diplômés de l'enseignement tertiaire dans le domaine de l'éducation varie fortement : il est de l'ordre de $20 \%$ au Costa Rica, en Hongrie et en Islande, mais est inférieur ou égal à $5 \%$ en France, en Italie et au Royaume-Uni.

- En moyenne, dans les pays de l'OCDE, 14 \% des adultes ont obtenu leur diplôme à l'issue d'un master ou d'un doctorat. Ce pourcentage dépasse les $20 \%$ en Estonie, en Fédération de Russie, au Luxembourg, en Pologne, en République slovaque et en Suisse, mais est de l'ordre de $2 \%$ seulement en Afrique du Sud, en Arabie saoudite, en Argentine, au Brésil, au Chili, en Chine, au Costa Rica, en Indonésie, au Mexique et en Turquie. 


\section{Analyse}

\section{Niveau de formation inférieur au deuxième cycle de l'enseignement secondaire}

Le deuxième cycle de l'enseignement secondaire est à présent le niveau minimum requis pour évoluer dans l'économie et la société modernes. II s'ensuit que les jeunes qui arrêtent leurs études avant d'avoir terminé le deuxième cycle de l'enseignement secondaire peinent à trouver leur place sur le marché du travail et sont de surcroît deux fois plus susceptibles d'être peu performants en numératie que ceux qui sont diplômés de ce niveau d'enseignement (OCDE, 2015[2]). Dans la plupart des pays de l'OCDE, la grande majorité des jeunes adultes (les 25-34 ans) sont au moins diplômés du deuxième cycle de l'enseignement secondaire selon les chiffres de 2018, tandis que le pourcentage moyen de jeunes non diplômés de ce niveau d'enseignement s'établit à $15 \%$ (voir le graphique A1.2).

\section{Graphique A1.2. Niveau de formation des adultes âgés de 25 à 64 ans (2018)}

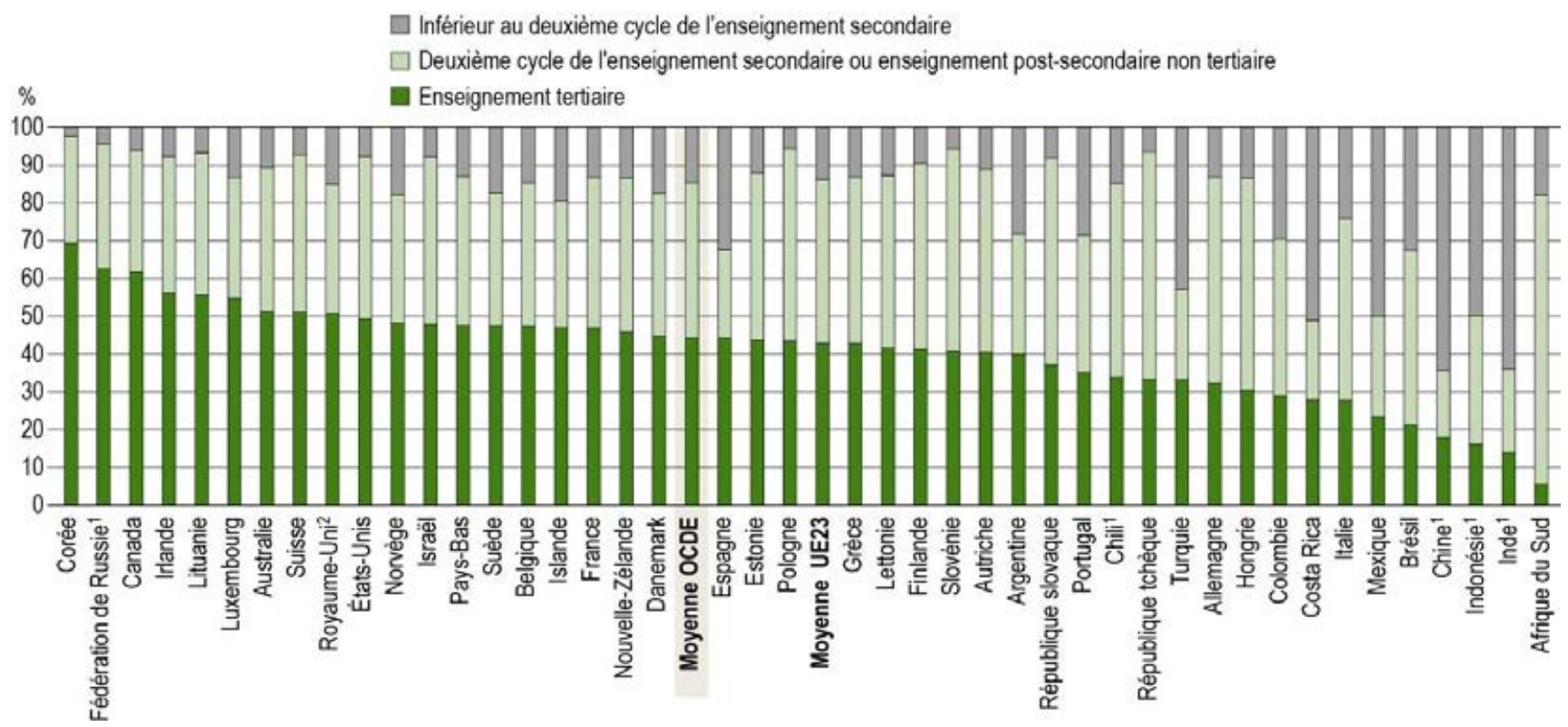

1. L'année de référence n'est pas 2018. Consulter le tableau A1.1 pour de plus amples informations.

2. Les données concernant les diplômés du deuxième cycle du secondaire incluent la réussite d'un volume et d'un niveau suffisant de programmes qui seraient classés individuellement dans la catégorie réussite d'une formation intermédiaire du deuxième cycle du secondaire ( $13 \%$ des adultes âgés de 25 à 64 ans se classent dans cette catégorie).

Les pays sont classés par ordre décroissant du pourcentage d'adultes âgés de 25 à 34 ans diplômés de l'enseignement tertiaire.

Source : OCDE (2019), Base de données de Regards sur l'éducation, http://stats.oecd.org. Consulter la section "Source » pour tout complément d'information et l'annexe 3 pour les notes (https://doi.org/10.1787/f8d7880d-en).

StatLink : तils https://doi.org/10.1787/888933976422

Le pourcentage de jeunes non diplômés du deuxième cycle de l'enseignement secondaire varie toujours sensiblement entre les pays membres et partenaires de l'OCDE. Chez les 25-34 ans, il est inférieur à $10 \%$ dans 13 pays (au Canada, en Corée, aux États-Unis, en Fédération de Russie, en Finlande, en Irlande, en Israël, en Lituanie, en Pologne, en République slovaque, en République tchèque, en Slovénie et en Suisse), mais égal ou supérieur à $50 \%$ au Costa Rica, en Inde, en Indonésie et en République populaire de Chine. En Corée, le pourcentage de femmes et d'hommes âgés de 25 à 34 ans qui ne sont pas diplômés du deuxième cycle de l'enseignement secondaire s'établit à $2 \%$ seulement, le pourcentage le moins élevé chez les femmes et chez les hommes de tous les pays membres et partenaires de l'OCDE, alors qu'en Chine et en Inde, le pourcentage de jeunes au plus diplômés du premier cycle de l'enseignement secondaire s'établit à $64 \%$ (voir le graphique A1.2 et le tableau A1.2). 
Chez les jeunes adultes, l'effectif non diplômé du deuxième cycle de l'enseignement secondaire a diminué, passant de $19 \%$ en 2008 à $15 \%$ en 2018, en moyenne, dans les pays de l'OCDE, signe de l'élévation globale du niveau de formation dans les pays de l'OCDE. Dans certains pays, le pourcentage de jeunes adultes non diplômés du deuxième cycle de l'enseignement secondaire a diminué dans une mesure nettement plus importante. Parmi les pays de l'OCDE dont les données de 2008 et de 2018 sont comparables, c'est au Portugal que le pourcentage de jeunes adultes non diplômés du deuxième cycle de l'enseignement secondaire ou de l'enseignement post-secondaire non tertiaire a le plus diminué : il a chuté de 25 points de pourcentage durant cette période. Le pourcentage de jeunes adultes non diplômés du deuxième cycle de l'enseignement secondaire a diminué sensiblement au Mexique aussi, de 15 points de pourcentage au moins entre 2008 et 2018. Dans ces deux pays, la diminution du pourcentage de jeunes adultes non diplômés du deuxième cycle de l'enseignement secondaire est allée de pair avec une augmentation du pourcentage de jeunes adultes diplômés du deuxième cycle de l'enseignement secondaire, de l'enseignement post-secondaire non tertiaire et de l'enseignement tertiaire (voir le tableau A1.2).

À l'inverse, le pourcentage de jeunes non diplômés du deuxième cycle de l'enseignement secondaire n'a pas varié de plus de 1 point de pourcentage entre 2008 et 2018 en Autriche, en Finlande et en Hongrie. La Norvège est le seul pays parmi ceux dont les données de 2008 et 2018 sont comparables où le pourcentage de jeunes adultes non diplômés du deuxième cycle de l'enseignement secondaire a augmenté (voir le tableau A1.2).

Dans la plupart des pays, le pourcentage de jeunes adultes non diplômés du deuxième cycle de l'enseignement secondaire est plus élevé chez les hommes ( $17 \%$ en moyenne dans les pays de l'OCDE) que chez les femmes (14\%). La différence de pourcentage entre les sexes représente au moins 5 points de pourcentage dans un quart environ des pays membres et partenaires de l'OCDE : l'Afrique du Sud, l'Argentine, le Brésil, la Colombie, le Costa Rica, le Danemark, l'Espagne, l'Estonie, l'Inde, l'Islande, l'Italie, la Lettonie, la Norvège, le Portugal et la Turquie. Cette différence représente au moins 10 points de pourcentage en Espagne, en Inde, en Islande et au Portugal. La différence est favorable aux jeunes hommes en Inde et en Turquie, mais aux jeunes femmes dans tous les autres pays. Le pourcentage de jeunes adultes non diplômés du deuxième cycle de l'enseignement secondaire est similaire chez les femmes et chez les hommes en Autriche, en Corée, en Hongrie, au Luxembourg, en République slovaque et en République tchèque (voir le tableau A1.2).

\section{Niveau de formation égal au deuxième cycle de l'enseignement secondaire et à l'enseignement post-secondaire non tertiaire}

En moyenne, dans les pays de l'OCDE, $42 \%$ des individus âgés de 25 à 64 ans sont au plus diplômés du deuxième cycle de l'enseignement secondaire ou de l'enseignement post-secondaire non tertiaire : $37 \%$ d'entre eux sont au plus diplômés du deuxième cycle de l'enseignement secondaire et $6 \%$, au plus diplômés de l'enseignement post-secondaire non tertiaire. Le pourcentage d'adultes au plus diplômés de l'enseignement post-secondaire non tertiaire est particulièrement élevé en Allemagne, au Canada, en Fédération de Russie, en Grèce, en Irlande, en Lettonie, en Lituanie et en Nouvelle-Zélande : il est égal ou supérieur à $10 \%$ (voir le tableau A1.1).

Parmi les pays membres et partenaires de l'OCDE, le pourcentage de jeunes adultes (les 25-34 ans) au plus diplômés du deuxième cycle de l'enseignement secondaire ou de l'enseignement post-secondaire non tertiaire représente $18 \%$ seulement en Chine, mais atteint $77 \%$ en Afrique du Sud (voir le graphique A1.3).

Le pourcentage de jeunes adultes au plus diplômés du deuxième cycle de l'enseignement secondaire ou de l'enseignement post-secondaire non tertiaire a diminué, passant de $46 \%$ en 2008 à $41 \%$ en 2018, en moyenne dans les pays de l'OCDE. Cette évolution s'inscrit dans le contexte de la diminution du pourcentage de jeunes adultes non diplômés du deuxième cycle de l'enseignement secondaire (de $19 \%$ en 2008 à $15 \%$ en 2018) et de l'augmentation du pourcentage de jeunes diplômés de l'enseignement tertiaire (de $35 \%$ à $44 \%$ ) (voir le tableau A1.2). 
La situation n'a pas évolué partout de la même façon. Parmi les pays de l'OCDE, le pourcentage de jeunes adultes au plus diplômés du deuxième cycle de l'enseignement secondaire ou de l'enseignement post-secondaire non tertiaire a par exemple augmenté de 8 points de pourcentage au Mexique et de 13 points de pourcentage au Portugal entre 2008 et 2018. Dans la plupart des autres pays de l'OCDE, le pourcentage de jeunes au plus diplômés du deuxième cycle de l'enseignement secondaire ou de l'enseignement post-secondaire non tertiaire a diminué, tandis que le pourcentage de jeunes diplômés de l'enseignement tertiaire a augmenté. En Autriche par exemple, le pourcentage de jeunes diplômés de l'enseignement tertiaire a augmenté de 7 points de pourcentage (passant de $33 \%$ à $40 \%$ ), tandis que le pourcentage de jeunes au plus diplômés du deuxième cycle de l'enseignement secondaire ou de l'enseignement post-secondaire non tertiaire a diminué dans la même mesure (de $55 \%$ à $48 \%$ ) (voir le tableau A1.2).

\section{Niveau de formation égal à l'enseignement tertiaire}

En moyenne, dans les pays de l'OCDE, 39 \% des adultes (les 25-64 ans) sont diplômés de l'enseignement tertiaire selon les chiffres de 2018. L'enseignement tertiaire s'est fortement développé au cours des dernières décennies dans les pays de l'OCDE. En moyenne, dans les pays de l'OCDE, les jeunes adultes (les 25-34 ans) diplômés de l'enseignement tertiaire sont plus nombreux que les jeunes adultes au plus diplômés du deuxième cycle de l'enseignement secondaire selon les chiffres de 2018. Le pourcentage de diplômés de l'enseignement tertiaire est nettement plus élevé chez les jeunes adultes, $44 \%$ en moyenne dans les pays de l'OCDE, que chez les 55-64 ans (27\%), signe de l'amélioration de l'accessibilité de l'enseignement tertiaire ces toutes dernières décennies dans les pays de l'OCDE. Dans tous les pays de l'OCDE, le pourcentage de jeunes diplômés de l'enseignement tertiaire a augmenté entre 2008 et 2018 (voir le tableau A1.2 et (OCDE, 2019[3])).

Chez les 25-34 ans, le pourcentage de diplômés de l'enseignement tertiaire est égal ou supérieur à $60 \%$ au Canada, en Corée, en Fédération de Russie et au Japon. Au Canada, en Corée et en Fédération de Russie, ce pourcentage élevé de diplômés de l'enseignement tertiaire va de pair avec un pourcentage peu élevé (moins de 7 \%) d'adultes non diplômés du deuxième cycle de l'enseignement secondaire. Parmi les pays membres et partenaires de l'OCDE, c'est en Afrique du Sud, en Inde et en Indonésie que le pourcentage de jeunes adultes diplômés de l'enseignement tertiaire est le moins élevé (16 \% ou moins). En Inde et en Indonésie, le niveau de formation le plus courant des 25-34 ans est inférieur au deuxième cycle de l'enseignement secondaire, tandis qu'en Afrique du Sud, il correspond au deuxième cycle de l'enseignement secondaire ou à l'enseignement post-secondaire non tertiaire (voir le tableau A1.2).

La majorité des 25-34 ans diplômés de l'enseignement tertiaire ont opté pour une licence (ou formation équivalente) dans la plupart des pays membres et partenaires de l'OCDE, même s'ils sont nombreux aussi à avoir choisi une formation tertiaire de cycle court dans certains pays. Les 25-34 ans diplômés à l'issue d'une formation tertiaire de cycle court représentent par exemple plus d'un cinquième de l'effectif diplômé de l'enseignement tertiaire dans ce groupe d'âge au Canada, en Corée et en Fédération de Russie et le pourcentage le plus élevé de cet effectif en Autriche et en Chine. À l'inverse, il n'y a pratiquement aucun jeune adulte diplômé à l'issue d'une formation tertiaire de cycle court dans plus de 15 pays (voir le graphique A1.3).

Les diplômés à l'issue d'un master (ou formation équivalente) sont les plus nombreux dans l'effectif diplômé de l'enseignement tertiaire en Espagne, en Fédération de Russie, en France, en Hongrie, en Italie, au Luxembourg, en Pologne, au Portugal, en République slovaque, en République tchèque et en Slovénie. Cela peut refléter des tendances différentes dans l'organisation de l'enseignement tertiaire entre les pays ; la tradition des premiers cursus de type long sanctionnés par un diplôme de master est par exemple plus fortement ancrée dans certains pays. En moyenne, dans les pays de l'OCDE, $1 \%$ environ des jeunes adultes sont titulaires d'un doctorat (ou titre équivalent), un pourcentage qui est toutefois de l'ordre de $2 \%$ aux États-Unis, au Luxembourg et en Suisse. C'est en Slovénie que le pourcentage de titulaires d'un doctorat (ou titre équivalent) est le plus élevé, $5 \%$ environ (voir le graphique A1.3). 
Graphique A1.3. Répartition des adultes âgés de 25 à 34 ans diplômés de l'enseignement tertiaire, selon le niveau de l'enseignement tertiaire (2018)

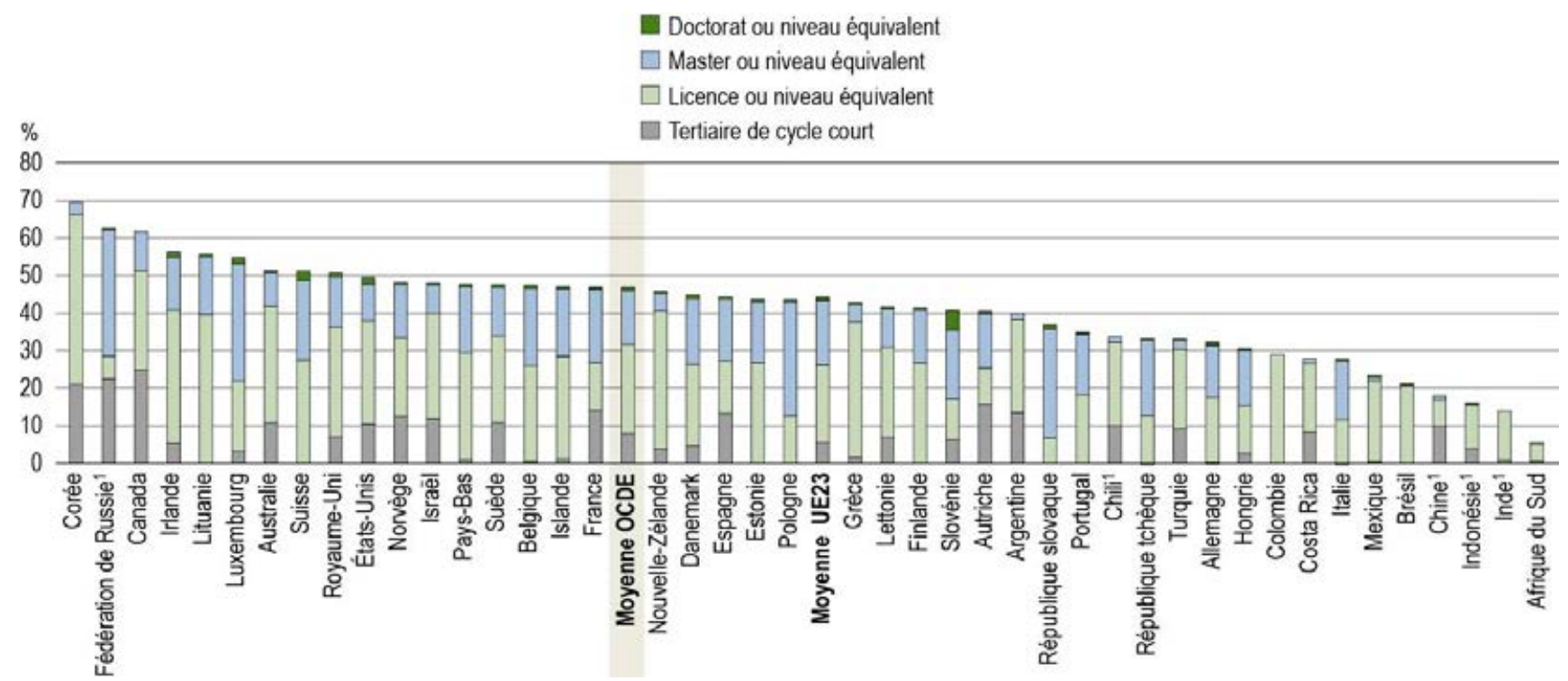

Remarque: Certaines catégories peuvent être incluses dans d'autres. Veuillez consulter la Base de données de Regards sur l'Éducation (http://stats.oecd.org) pour de plus amples informations.

1. L'année de référence n'est pas 2018. Consulter le tableau A1.1 pour de plus amples informations.

Les pays sont classés par ordre décroissant du pourcentage total d'adultes âgés de 25 à 34 ans diplômés de l'enseignement tertiaire.

Source : OCDE (2019), Base de données de Regards sur l'éducation, http://stats.oecd.org. Consulter la section " Source » pour tout complément d'information et l'annexe 3 pour les notes (https://doi.org/10.1787/f8d7880d-en).

StatLink 제대 https://doi.org/10.1787888933976441

\section{Différences entre les hommes et les femmes dans l'effectif diplômé de l'enseignement tertiaire}

Dans les pays de l'OCDE, le défaut de parité dans l'effectif de jeunes diplômés de l'enseignement tertiaire a augmenté, passant de 9 points de pourcentage en 2008 à 12 points de pourcentage en 2018. Dans la quasitotalité des pays de l'OCDE, les femmes sont plus nombreuses que les hommes parmi les 25-64 ans diplômés de l'enseignement tertiaire. Leur pourcentage représente au moins $50 \%$ de plus que celui des hommes dans l'effectif diplômé de l'enseignement tertiaire en Estonie, en Islande, en Lettonie et au Portugal, tandis que les hommes ne sont plus nombreux qu'elles dans cet effectif que dans neuf pays seulement. En Inde, les femmes représentent moins de $60 \%$ du pourcentage d'hommes dans l'effectif diplômé de l'enseignement tertiaire (voir le graphique A1.4 et le tableau A1.2).

Le défaut de parité qui s'observe dans l'effectif diplômé de l'enseignement tertiaire est dans l'ensemble plus important chez les jeunes adultes que chez les adultes plus âgés, sauf en Estonie, en Fédération de Russie, en Islande, en Lituanie et en Suède. Le défaut de parité s'est inversé entre les adultes plus jeunes et plus âgés dans certains pays. En Corée par exemple, les femmes diplômées de l'enseignement tertiaire représentent $50 \%$ du pourcentage d'hommes diplômés du même niveau d'enseignement chez les 55-64 ans, mais en représentent $18 \%$ de plus chez les 25-34 ans (voir le graphique A1.4).

\section{Domaines d'études des diplômés de l'enseignement tertiaire}

Certains domaines d'études sont plus courants chez les diplômés de l'enseignement tertiaire. En moyenne, dans les pays de l'OCDE dont les données sont disponibles, 24 \% des 25-64 ans diplômés de l'enseignement tertiaire 
ont suivi une formation en commerce, en administration ou en droit, le domaine d'études le plus courant. Ce pourcentage s'établit à $12 \%$ en République tchèque, mais à plus de $30 \%$ au Costa Rica, en France, au Luxembourg, au Mexique et en Turquie. Dans la plupart des pays dont les données désagrégées de ce domaine d'études sont disponibles, les diplômés sont plus nombreux à avoir opté pour le commerce ou l'administration que pour le droit (voir le graphique A1.1 et le tableau A1.3)

\section{Graphique A1.4. Pourcentage de femmes diplômées de l'enseignement tertiaire rapporté au pourcentage} d'hommes diplômés de l'enseignement tertiaire, selon le groupe d'âge (2018)

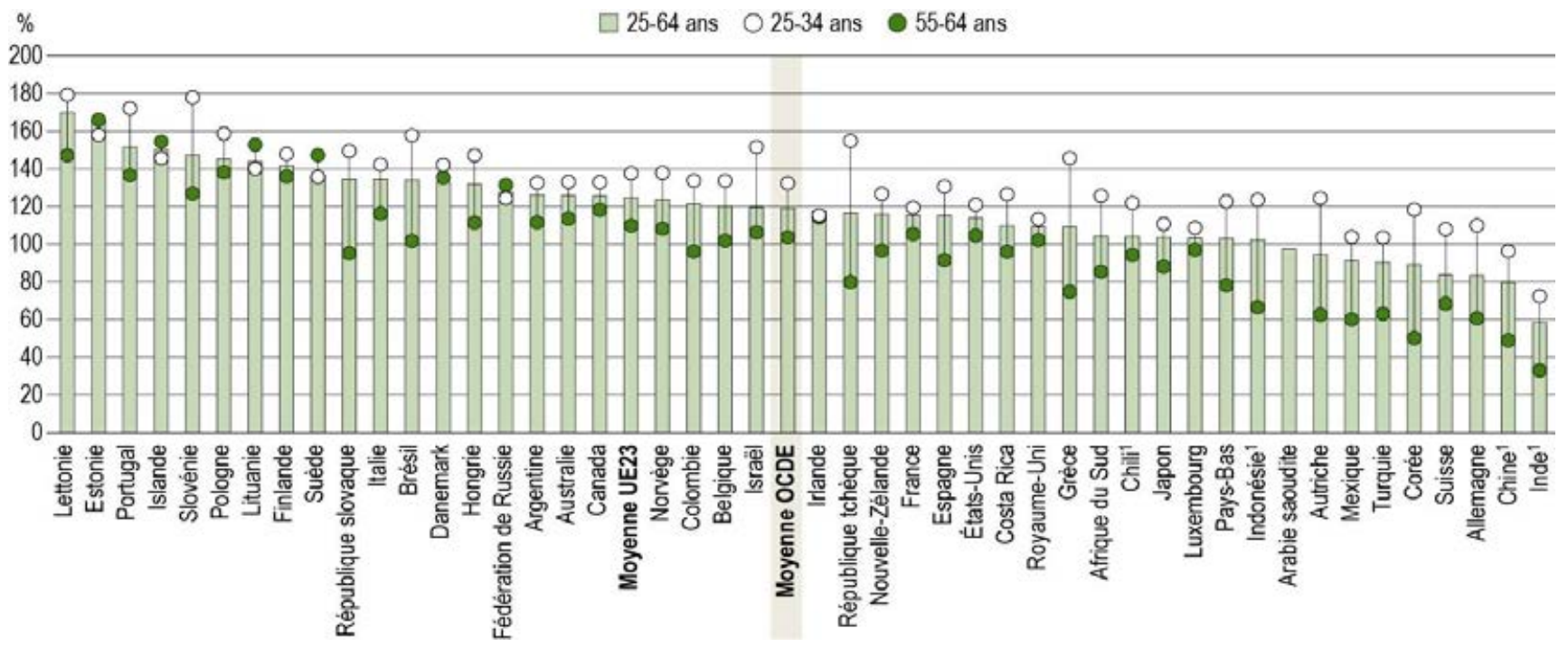

1. L'année de référence n'est pas 2018. Consulter le tableau A1.1 pour de plus amples informations.

Les pays sont classés par ordre décroissant de la différence de points de pourcentage pour le groupe d'âge des 25-64 ans.

Source : OCDE (2019), Base de données de Regards sur l'éducation, http://stats.oecd.org. Consulter la section " Source » pour tout complément d'information et l'annexe 3 pour les notes (https://doi.org/10.1787/f8d7880d-en).

StatLink त्ता st https://doi.org/10.1787/888933976460

En Belgique, aux États-Unis, en Grèce, en Hongrie, en Islande, en Italie, en Pologne et en République tchèque, les lettres et arts, les sciences sociales, le journalisme et l'information sont les domaines d'études les plus prisés. Chez les diplômés de l'enseignement tertiaire, le domaine d'études le plus populaire est celui de l'ingénierie, des industries de transformation et de la construction en Allemagne, en Autriche en Fédération de Russie et en République slovaque, mais celui de la santé et de la protection sociale au Danemark, en Norvège et en Suède (voir le tableau A1.3).

En dépit des excellents débouchés qui s'offrent sur le marché du travail aux diplômés en technologies de l'information et de la communication (TIC) (voir les indicateurs A3 et A4), le pourcentage d'étudiants qui optent pour une formation dans ce domaine est relativement peu élevé dans les pays de l'OCDE. En moyenne, $4 \%$ des diplômés de l'enseignement tertiaire ont suivi une formation dans ce domaine, et leur pourcentage varie nettement moins entre les pays que dans de nombreux autres domaines d'études. Parmi les pays membres et partenaires de I'OCDE, le pourcentage de diplômés en TIC atteint $6 \%$ environ en Espagne, en Finlande, en Hongrie et au Mexique ; c'est au Costa Rica et au Luxembourg qu'il est le plus élevé : $7 \%$. À l'inverse, au plus $1 \%$ seulement des diplômés de l'enseignement tertiaire ont opté pour une formation en rapport avec les TIC en Fédération de Russie et en Turquie (voir le tableau A1.3).

Le pourcentage de diplômés dans des matières en rapport avec les services sociaux (l'éducation, la santé et la protection sociale, par exemple) donne un aperçu de l'offre potentielle de travailleurs à même de fournir ces services essentiels à la population. Ainsi, de nombreux pays en proie à une pénurie d'enseignants et de 
professionnels de la santé ces dernières années ont adopté des politiques visant à accroître les effectifs dans ces domaines et à rendre ces professions plus attractives.

En moyenne, dans les pays de l'OCDE, 12 \% des 25-64 ans diplômés de l'enseignement tertiaire ont suivi une formation dans le domaine de l'éducation, mais ce pourcentage varie énormément entre les pays : il est inférieur ou égal à $5 \%$ en France, en Italie et au Royaume-Uni, mais est égal ou supérieur à $18 \%$ au Costa Rica, en Hongrie et en Islande. Le pourcentage de diplômés dans des matières en rapport avec la santé et la protection sociale varie autant entre les pays dont les données sont disponibles. Le pourcentage de diplômés de l'enseignement tertiaire dans ces matières s'établit par exemple à $27 \%$ au Danemark, mais à $6 \%$ seulement en Turquie (voir le tableau A1.3).

\section{Encadré A1.1. Évolution des domaines d'études les plus prisés}

Le niveau de formation est un indicateur du niveau global des qualifications de la population, tandis que l'effectif diplômé correspond au nombre d'individus qui ont obtenu leur diplôme une année donnée (en 2017 en l'espèce). Toutefois, la comparaison de la répartition des domaines d'études entre l'effectif total de diplômés et les étudiants qui viennent d'être diplômés donne des indications sur l'évolution des préférences au fil du temps.

\section{Graphique A1.a. Répartition des jeunes diplômés de l'enseignement tertiaire selon le domaine d'études, par comparaison avec les domaines d'études de l'ensemble des diplômés de l'enseignement tertiaire âgés de 25-64 ans (2017 et 2018)}

En moyenne dans les pays de l'OCDE

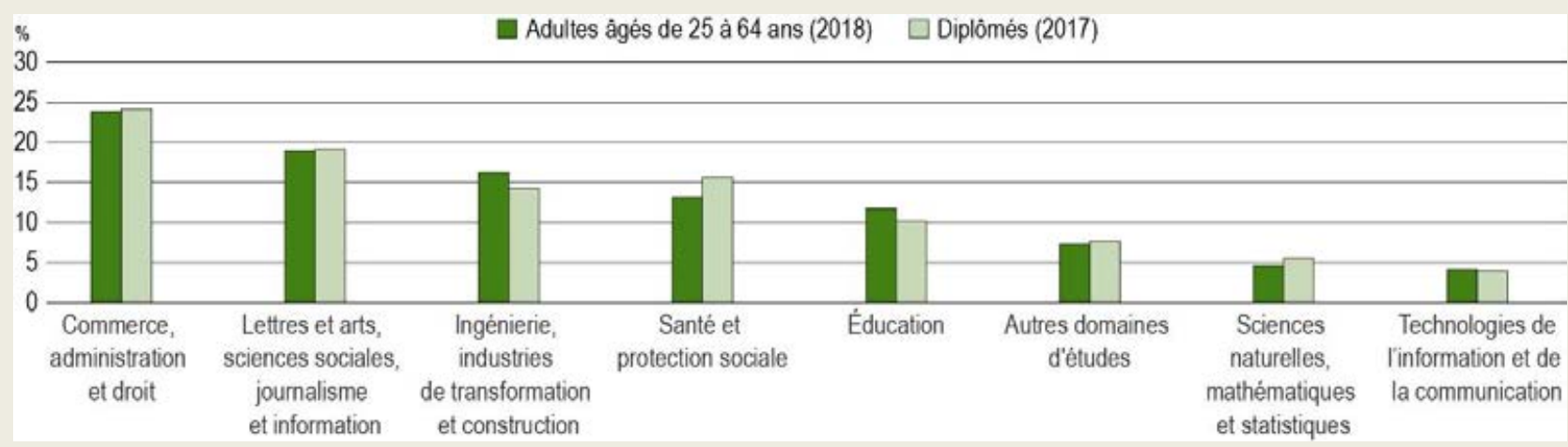

Les domaines d'études sont classés par ordre décroissant de la répartition de l'ensemble des diplômés de l'enseignement tertiaire âgés de 25 à 64 ans.

Source : OCDE/ISU/Eurostat (2019) et OCDE/OIT/ISU (2019). Consulter la section « Source » pour tout complément d'information et l'annexe 3 pour les notes (https://doi.org/10.1787/f8d7880d-en).

StatLink त्ता ज्ञ https://doi.org/10.1787/888933976479

Le commerce, l'administration et le droit, les lettres et arts, les sciences sociales, le journalisme et l'information sont les grands domaines d'études les plus souvent choisis dans l'enseignement tertiaire par les jeunes diplômés et l'effectif total de diplômés, même si les jeunes tendent à avoir un léger penchant pour le commerce, l'administration et le droit. Ce penchant est particulièrement marqué en Hongrie, au Luxembourg, en République slovaque et en République tchèque : le pourcentage de jeunes diplômés dans ce domaine est supérieur de 6 points de pourcentage au moins à celui qui s'observe dans l'effectif total de diplômés de l'enseignement tertiaire (voir le graphique A1.a). 
La différence est plus importante dans le domaine de la santé et de la protection sociale. Le pourcentage de diplômés dans ce domaine en 2017 s'établit à $16 \%$, soit 3 points de pourcentage de plus que dans l'effectif total de diplômés de l'enseignement tertiaire. Cette différence représente plus de 7 points de pourcentage en Belgique, aux États-Unis, en Lettonie et en Lituanie. Cette variation peut s'expliquer par un changement dans les préférences des étudiants, mais aussi par les qualifications supérieures désormais exigées pour travailler dans ce domaine (voir le graphique A1.a et le tableau A1.3).

Par contraste, les jeunes diplômés ont semblé légèrement moins attirés par l'ingénierie, les industries de transformation et la construction. Le pourcentage de diplômés de l'enseignement tertiaire dans ce domaine s'établit à $16 \%$ chez les $25-64$ ans en 2017 , mais à $14 \%$ seulement chez les jeunes diplômés cette année-là (voir le graphique A1.a et le tableau A1.3).

\section{Graphique A1.b. Pourcentage de diplômés en ingénierie, en industries de transformation et en construction parmi l'ensemble des 25-64 ans diplômés de l'enseignement tertiaire et des jeunes diplômés (2017 et 2018)}

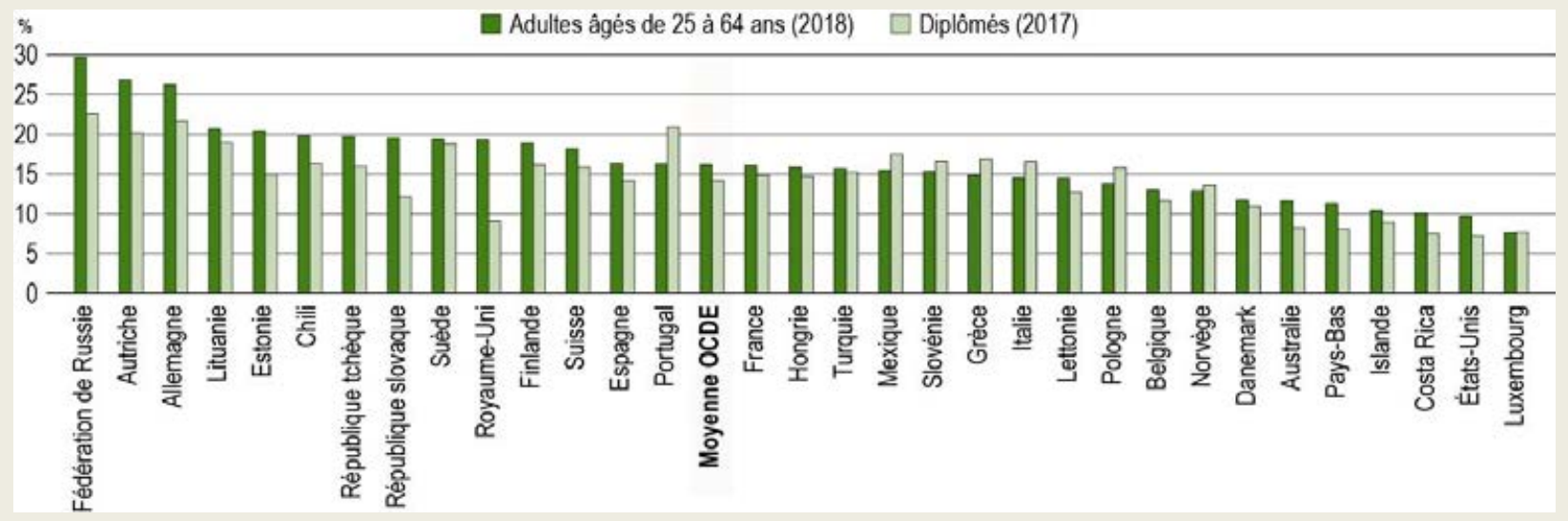

Les pays sont classés par ordre décroissant du pourcentage de diplômés en ingénierie, en industries de transformation et en construction parmi l'ensemble des 25-64 ans diplômés de l'enseignement tertiaire (2018).

Source : OCDE/ISU/Eurostat (2019) et OCDE/OIT/ISU (2019). Consulter la section « Source » pour tout complément d'information et l'annexe 3 pour les notes (https://doi.org/10.1787/f8d7880d-en).

StatLink 슈

Les profils spécialisés en TIC et en ingénierie sont très demandés sur le marché du travail et sont appelés à le rester à l'avenir sous l'effet du progrès technologique. Dans la plupart des pays toutefois, la popularité de ces domaines parmi les étudiants est soit stable, soit en recul. Parmi les pays de l'OCDE, le pourcentage de 25-64 ans diplômés de l'enseignement tertiaire dans le domaine de l'ingénierie, des industries de transformation et de la construction est par exemple inférieur à $10 \%$ aux États-Unis, mais égal ou supérieur à $20 \%$ en Allemagne, en Autriche, en Estonie, en Fédération de Russie et en Lituanie. Toutefois, le pourcentage de jeunes diplômés dans le domaine de l'ingénierie, des industries de transformation et de la construction est inférieur dans tous les pays, sauf en Grèce, en Italie, au Mexique, en Norvège, en Pologne, au Portugal et en Slovénie (voir le graphique A1.b).

Le pourcentage de diplômés de l'enseignement tertiaire dans le domaine de l'ingénierie, des industries de transformation et de la construction varie sensiblement (de plus de 6 points de pourcentage) entre les 25-64 ans et les 25-34 ans en Autriche, en Fédération de Russie, en République slovaque et au RoyaumeUni. Le Royaume-Uni se caractérise par un pourcentage de jeunes diplômés dans ce domaine inférieur de plus de moitié à celui qui s'observe dans l'effectif total de diplômés et connaît une forte pénurie de travailleurs spécialisés dans ce domaine (voir le graphique A1.b). 


\section{Variation infranationale du niveau de formation}

Les données nationales occultent souvent de fortes inégalités régionales. Dans l'ensemble, les inégalités régionales relatives au niveau de formation se sont en partie comblées ces dernières années, en particulier grâce à l'embellie dans les régions accusant les niveaux de formation les moins élevés (OCDE, 2018[4]). Toutefois, des différences sensibles de niveau de formation s'observent toujours entre les régions dans de nombreux pays. Selon les données les plus récentes, le pourcentage de 25-64 ans diplômés de l'enseignement tertiaire varie au moins du simple au triple dans les régions les mieux loties et les régions les plus mal loties au Brésil, en Italie, en République tchèque et en Turquie. De nombreux pays où l'effectif diplômé de l'enseignement tertiaire est relativement élevé dans la population accusent aussi de fortes inégalités régionales. À titre d'exemple, en Fédération de Russie (85 régions) l'effectif diplômé de l'enseignement tertiaire en 2016 atteint $53 \%$ à l'échelle nationale, mais varie entre $26 \%$ et $75 \%$ selon les régions. La situation est la même au Canada : $57 \%$ des adultes sont diplômés de l'enseignement tertiaire, mais la différence entre les provinces les mieux loties et les plus mal loties atteint 28 points de pourcentage (OCDE $\left.\left(2019_{[5]}\right)\right)$.

À l'inverse, dans de nombreux autres pays, le niveau de formation varie nettement moins entre les régions. Les différences les plus ténues tendent à s'observer dans les pays où les régions sont moins nombreuses. Les différences les moins importantes (moins de 1.5 point de pourcentage) entre les régions où l'effectif diplômé de l'enseignement tertiaire est le plus élevé et le moins élevé s'observent en Belgique, en Finlande, en Hongrie, en Irlande, en Pologne, en Slovénie et Suisse, des pays principalement constitués de petites régions. En Belgique par exemple, l'effectif de diplômés de l'enseignement tertiaire ne varie pas de plus de 10 points de pourcentage entre les trois régions. En Hongrie, qui compte huit régions, l'effectif de diplômés de l'enseignement tertiaire varie de moins de 4 points de pourcentage entre la région la mieux lotie et la région la plus mal lotie (OCDE, 2019[5]).

\section{Définitions}

Groupes d'âge : le terme "adultes » désigne la population âgée de 25 à 64 ans ; l'expression " jeunes (adultes) », la population âgée de 25 à 34 ans ; et l'expression " (adultes) plus âgés », la population âgée de 55 à 64 ans.

Par formations intermédiaires, on entend au sens de la Classification internationale type de l'éducation (CITE 2011) les formations reconnues relevant d'un niveau d'enseignement qui sont toutefois insuffisantes pour que les individus qui les ont réussies soient considérés comme diplômés de ce niveau d'enseignement ; c'est pourquoi ces formations se classent au niveau d'enseignement inférieur. De plus, la réussite d'une formation intermédiaire ne donne pas directement accès à un niveau d'enseignement supérieur.

Le niveau de formation correspond au plus haut niveau d'enseignement dont les individus sont diplômés.

Les domaines d'études sont dérivés des domaines d'études et de formation de la CITE 2013 (CITE-F 2013). La liste de tous les domaines d'études à l'étude dans ce rapport figure dans le Guide du lecteur.

Niveaux de formation : les niveaux de la CITE 2011 sont tous décrits dans le Guide du lecteur, au début du présent rapport.

\section{Méthodologie}

Les niveaux de formation sont établis à partir des données annuelles sur le pourcentage de la population adulte (les 25-64 ans) diplômé d'un niveau spécifique de formation dans chaque groupe d'âge.

Dans les statistiques de l'OCDE, les qualifications obtenues à l'issue de formations relevant du niveau 3 de la CITE 2011 dont la durée est insuffisante pour que les individus concernés puissent être considérés comme diplômés du niveau 3 de la CITE 2011 sont classées au niveau 2 de la CITE 2011 (voir le Guide du lecteur). 
Dans les pays qui ont pu démontrer l'équivalence, en termes de valeur sur le marché du travail, des qualifications officiellement délivrées à l'issue de formations intermédiaires relevant du deuxième cycle de l'enseignement secondaire (par exemple, le fait d'obtenir cinq bonnes notes au General Certificate of Secondary Education [GCSE] au Royaume-Uni) et le diplôme du deuxième cycle de l'enseignement secondaire, les diplômés à l'issue de ces formations intermédiaires sont inclus dans la catégorie des diplômés du niveau 3 de la CITE 2011 dans les tableaux sur les trois niveaux de formation agrégés (Institut de statistique de l'UNESCO, 2013[6]).

La plupart des pays de l'OCDE classent les individus sans formation formelle au niveau 0 de la CITE 2011. Les moyennes relatives au niveau de formation inférieur à l'enseignement primaire en subissent donc vraisemblablement l'influence.

Voir le Guide de l'OCDE pour l'établissement de statistiques internationalement comparables dans le domaine de l'éducation 2018 (OCDE, 2019[7]) pour de plus amples informations. Voir les notes spécifiques aux pays à l'annexe 3 (https://doi.org/10.1787/f8d7880d-en).

\section{Source}

Dans la plupart des pays, les données démographiques et les chiffres sur le niveau de formation proviennent des bases de données de l'OCDE et d'Eurostat qui ont été compilées à partir d'enquêtes nationales sur la population active par le Réseau LSO (Network on Labour Market and Social Outcomes of Learning) de l'OCDE, chargé d'élaborer les données relatives aux retombées de l'éducation sur l'économie, le marché du travail et la société. Les données relatives au niveau de formation proviennent de la base de données de l'Organisation internationale du travail (OIT) en Arabie saoudite et en Indonésie et de la base de données de l'Institut de statistique de l'UNESCO (ISU) en Chine.

Les données infranationales de certains indicateurs sont disponibles dans la Base de données régionales de I'OCDE (OCDE, 2019 $[5])$.

\section{Note concernant les données d'Israël}

Les données statistiques concernant Israël sont fournies par et sous la responsabilité des autorités israéliennes compétentes. L'utilisation de ces données par l'OCDE est sans préjudice du statut des hauteurs du Golan, de Jérusalem Est et des colonies de peuplement israéliennes en Cisjordanie aux termes du droit international.

\section{Références}

Institut de statistique de l'UNESCO (2013), Classification internationale type de l'éducation CITE 2011, UNESCO-UIS, Montréal, http://uis.unesco.org/sites/default/files/documents/international-standardclassification-of-education-isced-2011-fr.pdf.

OCDE (2019), Base de données de Regards sur l'éducation - Niveau de formation et situation au regard de l'emploi, http://stats.oecd.org/Index.aspx?datasetcode=EAG NEAC.

OCDE (2019), Base de données des statisques régionales - Niveau d'éducation par groupe d'âge, http://stats.oecd.org/Index.aspx?datasetcode=REGION EDUCAT. 
OCDE (2019), Guide de l'OCDE pour l'établissement de statistiques internationalement comparables dans le domaine de l'éducation 2018 : Concepts, normes, définitions et classifications, Éditions

OCDE, Paris, https://dx.doi.org/10.1787/9789264305380-fr.

OCDE (2018), OECD Regions and Cities at a Glance 2018, Éditions OCDE, Paris, https://dx.doi.org/10.1787/reg cit glance-2018-en.

OCDE (2016), Regards sur l'éducation 2016: Les indicateurs de l'OCDE, Éditions OCDE, Paris, https://dx.doi.org/10.1787/eag-2016-fr.

OCDE (2015), « Quels avantages offre aujourd'hui un diplôme du deuxième cycle du secondaire ? ", Les indicateurs de l'éducation à la loupe, $\mathrm{n}^{\circ} 34$, Éditions OCDE, Paris, https://dx.doi.org/10.1787/5jirts3mv6llp-fr.

\section{Tableaux de l'indicateur A1}

Tableau A1.1

Tableau A1.2

Tableau A1.3
Niveau de formation des adultes âgés de 25 à 64 ans (2018)

Évolution du niveau de formation des adultes âgés de 25 à 34 ans, selon le sexe (2008 et 2018)

Domaines d'études des diplômés de l'enseignement tertiaire âgés de 25 à 64 ans (2018)

Date butoir pour les données : 19 juillet 2019. Les mises à jour peuvent être consultées en ligne sur : http://dx.doi.org/10.1787/eag-data-en. D'autres données désagrégées sont également disponibles dans la Base de données de Regards sur l'éducation (http://stats.oecd.org/).

StatLink : https://doi.org/10.1787/888933980792 
Tableau A1.1. Niveau de formation des adultes âgés de 25 à 64 ans (2018)

Pourcentage d'adultes par niveau de formation (niveau le plus élevé atteint)

\begin{tabular}{|c|c|c|c|c|c|c|c|c|c|c|c|c|}
\hline & \multicolumn{5}{|c|}{ Inférieur au deuxième cycle du secondaire } & \multicolumn{2}{|c|}{$\begin{array}{c}\text { Deuxième cycle } \\
\text { du secondaire ou post- } \\
\text { secondaire non tertiaire }\end{array}$} & \multicolumn{4}{|c|}{ Tertiaire } & \multirow[b]{2}{*}{ 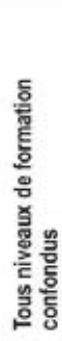 } \\
\hline & 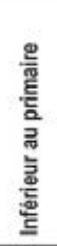 & 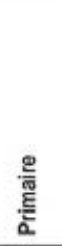 & 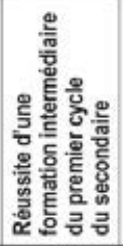 & 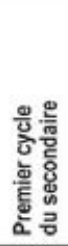 & 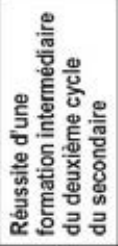 & 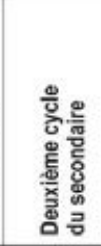 & 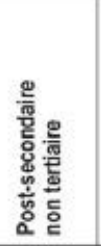 & 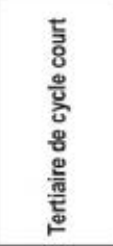 & 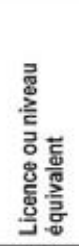 & 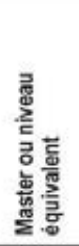 & 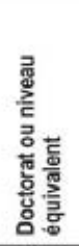 & \\
\hline & (1) & (2) & (3) & (4) & (5) & (6) & (n) & (8) & (9) & (10) & (11) & (12) \\
\hline \multicolumn{13}{|l|}{ w Pays } \\
\hline Oustralie & 0 & 4 & a & 14 & a & 31 & 5 & 12 & 26 & 7 & 1 & 100 \\
\hline${ }^{\circ}$ Autriche & $x(2)$ & $1^{\circ}$ & a & 14 & a & 50 & 3 & 15 & 4 & 13 & 1 & 100 \\
\hline Belgique & 3 & 5 & a & 14 & a & 36 & 1 & 1 & 23 & 17 & 1 & 100 \\
\hline Canada & $x(2)$ & $2^{\circ}$ & a & 6 & a & 23 & 10 & 26 & 22 & $10^{\circ}$ & $x(10)$ & 100 \\
\hline Chili' & 7 & 5 & a & 21 & a & 42 & a & 9 & 15 & $2^{\circ}$ & $x(10)$ & 100 \\
\hline Colombie & $x(4)$ & $x(4)$ & a & $40^{4}$ & 5 & $32^{\circ}$ & $x(6)$ & $x(9)$ & $23^{4}$ & $x(9)$ & $x(9)$ & 100 \\
\hline Rèpublique tchèque & 0 & 0 & a & 6 & a & $70^{\circ}$ & $x(6)$ & 0 & 6 & 17 & 1 & 100 \\
\hline Danemark & $x(2)$ & $3^{\mathrm{d}}$ & a & 16 & a & 43 & 0 & 5 & 18 & 13 & 1 & 100 \\
\hline Estonie & 0 & 0 & a & 10 & a & 39 & 9 & 6 & 13 & 21 & 1 & 100 \\
\hline Finlande & $x(2)$ & $2^{\mathrm{d}}$ & a & 9 & a & 43 & 1 & 11 & 17 & 15 & 1 & 100 \\
\hline France & 2 & 5 & a & 14 & a & 42 & 0 & 14 & 10 & 11 & 1 & 100 \\
\hline Allemagne & $x(2)$ & $4^{\mathrm{d}}$ & a & 10 & a & 45 & 12 & 1 & 15 & 12 & 1 & 100 \\
\hline Gréce & 1 & 13 & 0 & 12 & 0 & 32 & 10 & 2 & 26 & 4 & 1 & 100 \\
\hline Hongrie & 0 & 1 & a & 14 & a & 51 & 8 & 1 & 13 & 10 & 1 & 100 \\
\hline Islande & $x(2)$ & $0^{d}$ & a & 22 & a & 27 & 7 & 2 & 23 & 18 & 1 & 100 \\
\hline Irlande & 0 & 5 & a & 12 & a & 21 & 15 & 7 & 27 & 12 & 1 & 100 \\
\hline Israë| & 2 & 4 & a & 7 & a & 36 & a & 14 & 23 & 12 & 1 & 100 \\
\hline Italie & 1 & 5 & a & 33 & a & 42 & 1 & 0 & 4 & 14 & 1 & 100 \\
\hline Japon & $x(6)$ & $x(6)$ & a & $x(6)$ & a & $48^{\circ}$ & $x(8)$ & $21^{4}$ & $31^{\circ}$ & $x(9)$ & $x(9)$ & 100 \\
\hline Corée & $x(2)$ & $4^{\circ}$ & a & 8 & a & 39 & a & 14 & 31 & $5^{6}$ & $x(10)$ & 100 \\
\hline Lettonie & 0 & 0 & a & 9 & 3 & 44 & 10 & 4 & 17 & 13 & 0 & 100 \\
\hline Lituanie & 0 & 0 & 0 & 4 & 2 & 32 & 19 & a & 27 & 14 & 1 & 100 \\
\hline Luxembourg & c & 7 & a & 16 & a & 31 & 2 & 4 & 15 & 22 & 2 & 100 \\
\hline Mexique & 12 & 17 & 2 & 27 & 4 & 21 & a & 0 & 16 & 2 & 0 & 100 \\
\hline Pays-Bas & 1 & 5 & a & 15 & a & 40 & 0 & 2 & 22 & 13 & 1 & 100 \\
\hline Nouvelle-Zélande & $x(4)$ & $x(4)$ & a & $20^{\circ}$ & a & 27 & 14 & 4 & 29 & 5 & 1 & 100 \\
\hline Norvège & $\mathrm{m}$ & 1 & a & 17 & a & 37 & 2 & 12 & 19 & 11 & 1 & 100 \\
\hline Pologne & 0 & 6 & a & 1 & a & 58 & 3 & 0 & 7 & 23 & 1 & 100 \\
\hline Portugal & 2 & 28 & a & 20 & a & 24 & 1 & c & 6 & 18 & 1 & 100 \\
\hline République slovaque & 0 & 0 & 0 & 7 & 0 & 65 & 2 & 0 & 3 & 20 & 1 & 100 \\
\hline Slovénic & 0 & 0 & a & 11 & a & 56 & a & 8 & 7 & 14 & 4 & 100 \\
\hline Espagne & 3 & 7 & a & 30 & a & 23 & 0 & 11 & 10 & 15 & 1 & 100 \\
\hline Suede & $x(2)$ & $3^{\mathrm{a}}$ & a & 12 & 2 & 32 & 7 & 10 & 18 & 14 & 2 & 100 \\
\hline Suisse & 0 & 2 & a & 9 & a & $45^{d}$ & $x(6)$ & $\times(9,10,11)$ & $22^{d}$ & $19^{\circ}$ & $3^{\circ}$ & 100 \\
\hline Turquie & 5 & 39 & a & 15 & a & 19 & a & 6 & 13 & 2 & 0 & 100 \\
\hline Royaume-Uni & 0 & 0 & a & 20 & 13 & 21 & a & 10 & 23 & 12 & 1 & 100 \\
\hline Etats-Unis & 1 & 3 & a & 6 & a & $43^{\circ}$ & $x(6)$ & 11 & 24 & 11 & 2 & 100 \\
\hline Moyenne OCDE & 2 & 5 & $\mathrm{~m}$ & 14 & $\mathrm{~m}$ & 38 & 6 & 7 & 17 & 13 & 1 & 100 \\
\hline Moyenne UE23 & 1 & 4 & m & 13 & $\mathrm{~m}$ & 41 & 5 & 5 & 14 & 15 & 1 & 100 \\
\hline Argentine & 5 & 17 & 7 & 5 & 3 & 28 & $a$ & 14 & $20^{\circ}$ & $1^{\circ}$ & $x(10)$ & 100 \\
\hline Brésil & 14 & 20 & a & 14 & a & 35 & a & $x(9)$ & $17^{\circ}$ & 1 & 0 & 100 \\
\hline E. Chine ${ }^{2}$ & 3 & 25 & a & 47 & a & $15^{\circ}$ & $x(6)$ & 6 & 3 & $0^{\circ}$ & $x(10)$ & 100 \\
\hline Costa Rica & 12 & 29 & 9 & 8 & 2 & 17 & 0 & 5 & 15 & 2 & 0 & 100 \\
\hline${ }^{2}$ Inde & 46 & 14 & a & 11 & a & 18 & 0 & 1 & $10^{d}$ & $x(9)$ & $x(9)$ & 100 \\
\hline Indonèsie' & 17 & 27 & a & 18 & a & 26 & 0 & 3 & 8 & 1 & 0 & 100 \\
\hline Fédération de Russie' & $x(2)$ & $1^{\circ}$ & a & 4 & a & 19 & 20 & 25 & 2 & 29 & 0 & 100 \\
\hline Arabie saoudite $^{4}$ & 12 & 14 & a & 18 & a & 27 & 6 & 0 & $24^{d}$ & 0 & $x(10)$ & 100 \\
\hline Afrique du Sud & $x(2)$ & $14^{\circ}$ & a & 12 & a & 59 & 8 & 1 & 5 & 10 & $x(10)$ & 100 \\
\hline
\end{tabular}

\begin{tabular}{l|l|l|l|l|l|l|l|l|l|l|l|l|l|} 
Moyenne G20 & 9 & 12 & $m$ & 16 & $m$ & 32 & $m$ & 9 & 16 & 7 & $m$ & 100 \\
\hline
\end{tabular}

Remarques : Dans la plupart des pays, les données se rapportent à la classification CITE 2011. Pour l'Arabie saoudite et l'Indonésie, elles se rapportent à la classification CITE 97. Pour de plus amples informations, consulter les sections « Définitions » et « Méthodologie ». Les données et d'autres types de ventilations peuvent être consultés sur http://stats.oecd.org/, Base de données de Regards sur l'éducation.

1. Année de référence : 2017.

2. Année de référence : 2010 .

3. Année de référence : 2011.

4. Année de référence : 2016.

Source : OCDE / OIT / ISU (2019). Consulter la section « Source » pour tout complément d'information et l'annexe 3 pour les notes (https://doi.org/10.1787/f8d7880d-en). Les symboles représentant les données manquantes et les abréviations figurent dans le Guide du lecteur. 
Tableau A1.2. Évolution du niveau de formation des adultes âgés de 25 à 34 ans, selon le sexe (2008 et 2018)

Pourcentage d'adultes par niveau de formation (niveau le plus élevé atteint) parmi les adultes âgés de 25 à 34 ans

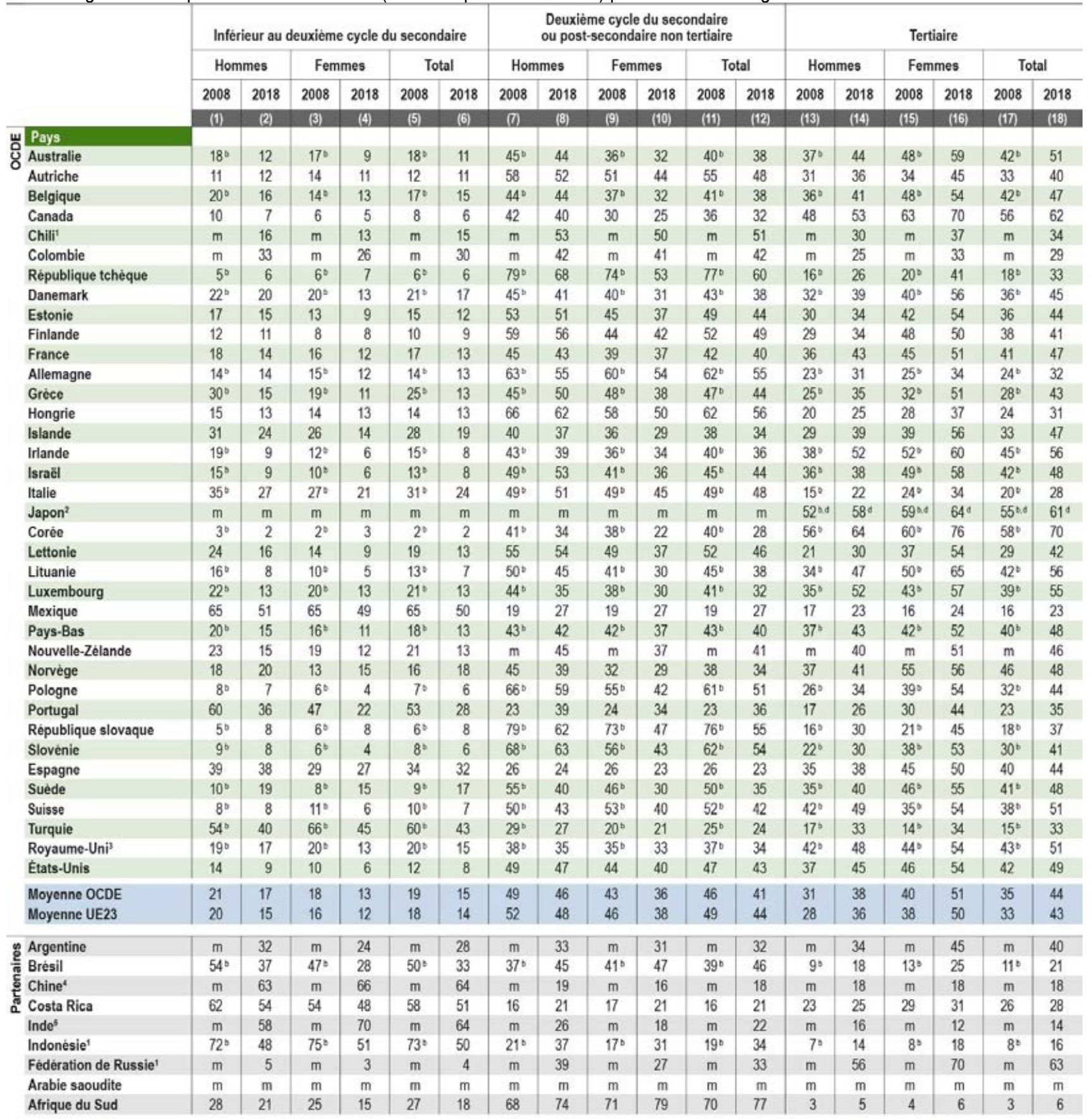

\begin{tabular}{|l|l|l|l|l|l|l|l|l|l|l|l|l|l|l|l|l|l|l|} 
Moyenne $\mathrm{G} 20$ & $\mathrm{~m}$ & 27 & $\mathrm{~m}$ & 25 & $\mathrm{~m}$ & 26 & $\mathrm{~m}$ & 40 & $\mathrm{~m}$ & 34 & $\mathrm{~m}$ & 37 & $\mathrm{~m}$ & 35 & $\mathrm{~m}$ & 41 & $\mathrm{~m}$ & 38 \\
\hline
\end{tabular}

Remarques : Dans la plupart des pays, on observe une rupture des séries chronologiques (indiquée par le code « $b$ »), les données de 2018 se rapportant à la classification CITE 2011, tandis que celles de 2008 se rapportent à la classification CITE 97. Pour l'Arabie saoudite et l'Indonésie, elles se rapportent à la classification CITE 97 . Consulter les sections "Définitions » et "Méthodologie " pour de plus amples informations. Les données et d'autres types de ventilations peuvent être consultés sur http://stats.oecd.org/, Base de données de Regards sur l'éducation.

1. Année de référence : 2017, et non 2018.

2. Les données relatives au niveau de formation tertiaire incluent les programmes du deuxième cycle du secondaire et de l'enseignement post-secondaire non tertiaire (moins de $5 \%$ de la population adulte se classent dans cette catégorie).

3. Les données concernant les diplômés du deuxième cycle du secondaire incluent la réussite d'un volume et d'un niveau suffisant de programmes qui seraient classés individuellement dans la catégorie réussite d'une formation intermédiaire du deuxième cycle du secondaire ( $13 \%$ des adultes âgés de 25 à 64 ans se classent dans cette catégorie) .

4. Année de référence : 2010 , et non 2018.

5. Année de référence : 2011 , et non 2018

Source : OCDE / OIT / ISU (2019). Consulter la section « Source » pour tout complément d'information et l'annexe 3 pour les notes (https://doi.org/10.1787/f8d7880d-en). Les symboles représentant les données manquantes et les abréviations figurent dans le Guide du lecteur. 
Tableau A1.3. Domaines d'études des diplômés de l'enseignement tertiaire âgés de 25 à 64 ans (2018) Pourcentage d'adultes diplômés de l'enseignement tertiaire

\begin{tabular}{|c|c|c|c|c|c|c|c|c|c|c|c|c|c|c|}
\hline & \multirow[b]{2}{*}{ 흘 } & \multicolumn{2}{|c|}{$\begin{array}{l}\text { Lettres et arts (excepté } \\
\text { langues étrangères), } \\
\text { sciences sociales, } \\
\text { journalisme } \\
\text { et information }\end{array}$} & \multirow{2}{*}{ 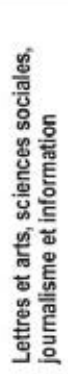 } & \multicolumn{2}{|c|}{$\begin{array}{l}\text { Commerce, } \\
\text { administration } \\
\text { ou droit }\end{array}$} & \multirow{2}{*}{ 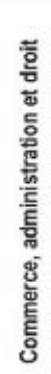 } & \multirow{2}{*}{ 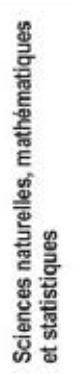 } & \multirow{2}{*}{ 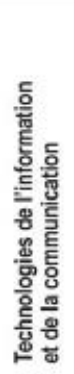 } & \multirow{2}{*}{ 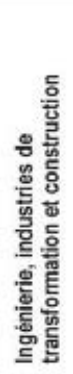 } & \multicolumn{2}{|c|}{ Santé } & \multirow[b]{2}{*}{ 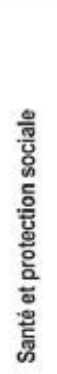 } & \multirow[b]{2}{*}{ 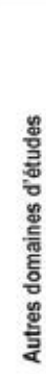 } \\
\hline & & 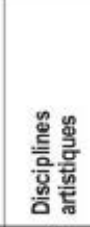 & 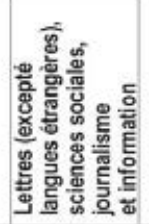 & & 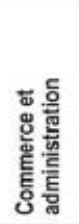 & 홓 & & & & & 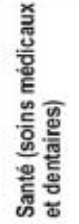 & 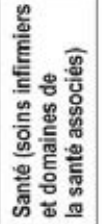 & & \\
\hline & (1) & (2) & (3) & (4) & (5). & (6) & (7) & (8) & (9) & (10) & (11) & (12) & (13) & (14) \\
\hline \multicolumn{15}{|l|}{ س Pays } \\
\hline Oustralie & 11 & $x(4)$ & $x(4)$ & 16 & $x(7)$ & $x(7)$ & 29 & 4 & 5 & 12 & $x(13)$ & $x(13)$ & 18 & 6 \\
\hline Autriche & 11 & 4 & 7 & 14 & $\times(7)$ & $\times(7)$ & 22 & 4 & 3 & 27 & 4 & 4 & 9 & 10 \\
\hline Belgique & 12 & $x(4)$ & 12 & 22 & $x(7)$ & $x(7)$ & 21 & 5 & 5 & 13 & $x(13)$ & $x(13)$ & 17 & 5 \\
\hline Canada & $\mathrm{m}$ & $\mathrm{m}$ & $\mathrm{m}$ & $\mathrm{m}$ & $\mathrm{m}$ & $\mathrm{m}$ & $\mathrm{m}$ & $\mathrm{m}$ & $\mathrm{m}$ & $\mathrm{m}$ & $\mathrm{m}$ & $\mathrm{m}$ & $\mathrm{m}$ & $\mathrm{m}$ \\
\hline Chili' & 16 & 3 & 4 & 8 & 23 & 3 & 26 & 1 & 5 & 20 & 3 & 11 & 17 & 8 \\
\hline Colombie & $\mathrm{m}$ & $\mathrm{m}$ & $\mathrm{m}$ & $\mathrm{m}$ & $\mathrm{m}$ & m & $\mathrm{m}$ & $\mathrm{m}$ & $\mathrm{m}$ & $\mathrm{m}$ & $\mathrm{m}$ & $\mathrm{m}$ & m & $\mathrm{m}$ \\
\hline République tchèque & 14 & 3 & 17 & 22 & 9 & 2 & 12 & 5 & 4 & 20 & 4 & 6 & 12 & 11 \\
\hline Danemark & 10 & 4 & 12 & 21 & 18 & $x(7)$ & 20 & 4 & 4 & 12 & 5 & 9 & 27 & 3 \\
\hline Estonie & 10 & 4 & 9 & 16 & 23 & 4 & 27 & 4 & 4 & 20 & 3 & 4 & 9 & 10 \\
\hline Finlande & 7 & $x(4)$ & 5 & 15 & $x(7)$ & $x(7)$ & 25 & 4 & 6 & 19 & $x(13)$ & $x(13)$ & 18 & 7 \\
\hline France & 3 & $x(4)$ & 9 & 19 & $x(7)$ & $x(7)$ & 31 & 5 & 4 & 16 & $x(13)$ & $x(13)$ & 14 & 7 \\
\hline Allemagne & 14 & 4 & 7 & 14 & 8 & 3 & 22 & 5 & 4 & 26 & 4 & 2 & 9 & 6 \\
\hline Grèce & 7 & $x(4)$ & 13 & 26 & $x(7)$ & $x(7)$ & 18 & 5 & 4 & 15 & $x(13)$ & $x(13)$ & 12 & 12 \\
\hline Hongrie & 19 & $x(4)$ & 16 & 22 & $\times(7)$ & $x(7)$ & 18 & 2 & 6 & 16 & $x(13)$ & $x(13)$ & 8 & 9 \\
\hline Islande ${ }^{2}$ & 18 & $x(4)$ & $x(4)$ & 23 & $x(7)$ & $x(7)$ & 23 & 4 & 4 & 10 & $x(13)$ & $x(13)$ & 13 & 4 \\
\hline Irlande & $\mathrm{m}$ & $\mathrm{m}$ & $\mathrm{m}$ & $\mathrm{m}$ & $\mathrm{m}$ & $\mathrm{m}$ & $\mathrm{m}$ & $\mathrm{m}$ & $\mathrm{m}$ & $\mathrm{m}$ & $\mathrm{m}$ & $\mathrm{m}$ & $\mathrm{m}$ & $\mathrm{m}$ \\
\hline Israë| & $\mathrm{m}$ & m & $\mathrm{m}$ & m & $\mathrm{m}$ & $\mathrm{m}$ & m & m & $\mathrm{m}$ & m & m & $m$ & $\mathrm{~m}$ & m \\
\hline Italie & 4 & 4 & 20 & 29 & 13 & 10 & 23 & 8 & 2 & 15 & $x(13)$ & $x(13)$ & 15 & 4 \\
\hline Japon & $\mathrm{m}$ & $\mathrm{m}$ & $\mathrm{m}$ & $\mathrm{m}$ & $\mathrm{m}$ & $\mathrm{m}$ & $\mathrm{m}$ & m & $\mathrm{m}$ & $\mathrm{m}$ & $\mathrm{m}$ & $\mathrm{m}$ & $\mathrm{m}$ & $\mathrm{m}$ \\
\hline Corée & $\mathrm{m}$ & $\mathrm{m}$ & $\mathrm{m}$ & $\mathrm{m}$ & $\mathrm{m}$ & $\mathrm{m}$ & $\mathrm{m}$ & $\mathrm{m}$ & $\mathrm{m}$ & m & $\mathrm{m}$ & m & m & $\mathrm{m}$ \\
\hline Lettonie & 14 & 2 & 18 & 23 & 20 & 7 & 27 & 3 & 3 & 14 & 5 & 1 & 7 & 8 \\
\hline Lituanie & 9 & 3 & 14 & 20 & 21 & $x(7)$ & 26 & 4 & 3 & 21 & 4 & 4 & 9 & 7 \\
\hline Luxembourg & 7 & $x(4)$ & 14 & 25 & $x(7)$ & $x(7)$ & 36 & 5 & 7 & 8 & $x(13)$ & $x(13)$ & 8 & 4 \\
\hline Mexique & 14 & 3 & 10 & 13 & 26 & 9 & 35 & 3 & 6 & 15 & 5 & 5 & 9 & 4 \\
\hline Pays-Bas & 11 & 4 & 12 & 18 & 23 & 5 & 28 & 4 & 4 & 11 & 3 & 7 & 17 & 7 \\
\hline Nouvelle-Zélande & $\mathrm{m}$ & $\mathrm{m}$ & $\mathrm{m}$ & $\mathrm{m}$ & $\mathrm{m}$ & $\mathrm{m}$ & $\mathrm{m}$ & $\mathrm{m}$ & $\mathrm{m}$ & m & $\mathrm{m}$ & m & $\mathrm{m}$ & $\mathrm{m}$ \\
\hline Norvège & 15 & 2 & 14 & 19 & 13 & 3 & 15 & 7 & 3 & 13 & 3 & 13 & 20 & 8 \\
\hline Pologne & 16 & $x(4)$ & 17 & 24 & $x(7)$ & $x(7)$ & 22 & 5 & 4 & 14 & $x(13)$ & $x(13)$ & 8 & 7 \\
\hline Portugal & 15 & $x(4)$ & 11 & 20 & $x(7)$ & $x(7)$ & 21 & 4 & 2 & 16 & $\mathrm{x}(13)$ & $x(13)$ & 15 & 7 \\
\hline République slovaque & 17 & 1 & 15 & 18 & 10 & 3 & 13 & 5 & 4 & 20 & 3 & 5 & 14 & 10 \\
\hline Slovènie & 11 & $x(4)$ & 15 & 21 & $x(7)$ & $\times(7)$ & 24 & 4 & 4 & 15 & $x(13)$ & $x(13)$ & 9 & 12 \\
\hline Espagne & 10 & $x(4)$ & 5 & 14 & $x(7)$ & $x(7)$ & 27 & 6 & 6 & 16 & $x(13)$ & $x(13)$ & 13 & 7 \\
\hline Suéde & 16 & 3 & 10 & 15 & 13 & 3 & 16 & 5 & 3 & 19 & 4 & 10 & 20 & 5 \\
\hline Suisse & 9 & 3 & 7 & 12 & 25 & 4 & 29 & 5 & 5 & 18 & 3 & 8 & 14 & 8 \\
\hline Turquie $^{2}$ & 16 & $x(4)$ & $x(4)$ & 18 & $x(7)$ & $\times(7)$ & 31 & 5 & 1 & 16 & $x(13)$ & $x(13)$ & 6 & 7 \\
\hline Royaume-Uni & 5 & $x(4)$ & 4 & 13 & $x(7)$ & $\times(7)$ & 26 & 3 & 4 & 19 & $x[13)$ & $x(13)$ & 17 & 12 \\
\hline Etats-Unis ${ }^{1,3}$ & 10 & 6 & 20 & 30 & $x(7)$ & $x(7)$ & 21 & 10 & 4 & 10 & $x(13)$ & $x(13)$ & 9 & 6 \\
\hline Moyenne OCDE & 12 & $\mathrm{~m}$ & 12 & 19 & $\mathrm{~m}$ & $\mathrm{~m}$ & 24 & 5 & 4 & 16 & $\mathrm{~m}$ & $\mathrm{~m}$ & 13 & 7 \\
\hline Moyenne UE23 & 11 & m & 12 & 20 & m & m & 23 & 5 & 4 & 17 & m & $\mathrm{m}$ & 13 & 8 \\
\hline Ig Argentine & $\mathrm{m}$ & $\mathrm{m}$ & $\mathrm{m}$ & $\mathrm{m}$ & $\mathrm{m}$ & $\mathrm{m}$ & $\mathrm{m}$ & $\mathrm{m}$ & $\mathrm{m}$ & $\mathrm{m}$ & $\mathrm{m}$ & $\mathrm{m}$ & $\mathrm{m}$ & $\mathrm{m}$ \\
\hline Brésil & $\mathrm{m}$ & $\mathrm{m}$ & $\mathrm{m}$ & $\mathrm{m}$ & $\mathrm{m}$ & $\mathrm{m}$ & $\mathrm{m}$ & $\mathrm{m}$ & $\mathrm{m}$ & $\mathrm{m}$ & $\mathrm{m}$ & $\mathrm{m}$ & $\mathrm{m}$ & $\mathrm{m}$ \\
\hline Chine & $\mathrm{m}$ & m & $\mathrm{m}$ & $\mathrm{m}$ & $\mathrm{m}$ & $\mathrm{m}$ & $\mathrm{m}$ & m & m & $\mathrm{m}$ & $\mathrm{m}$ & m & m & $\mathrm{m}$ \\
\hline 苋 Costa Rica & 20 & 2 & 7 & 10 & 30 & 5 & 35 & 2 & 7 & 10 & $\mathrm{x}(13)$ & $x(13)$ & 11 & 5 \\
\hline Inde & $\mathrm{m}$ & $\mathrm{m}$ & $\mathrm{m}$ & $\mathrm{m}$ & $\mathrm{m}$ & $\mathrm{m}$ & $\mathrm{m}$ & $\mathrm{m}$ & m & $\mathrm{m}$ & $\mathrm{m}$ & $\mathrm{m}$ & $\mathrm{m}$ & $\mathrm{m}$ \\
\hline Indonèsie & $\mathrm{m}$ & $\mathrm{m}$ & $\mathrm{m}$ & $\mathrm{m}$ & $\mathrm{m}$ & $\mathrm{m}$ & $\mathrm{m}$ & $\mathrm{m}$ & m & $\mathrm{m}$ & $\mathrm{m}$ & $\mathrm{m}$ & m & $\mathrm{m}$ \\
\hline Fédération de Russie' & 14 & $x(4)$ & 1 & 11 & $x(7)$ & $x(7)$ & 24 & 3 & 0 & 30 & $x(13)$ & $x(13)$ & 10 & 8 \\
\hline Arabie saoudite & $\mathrm{m}$ & $\mathrm{m}$ & $\mathrm{m}$ & $\mathrm{m}$ & $\mathrm{m}$ & $\mathrm{m}$ & $\mathrm{m}$ & $\mathrm{m}$ & $\mathrm{m}$ & $\mathrm{m}$ & $\mathrm{m}$ & $\mathrm{m}$ & $\mathrm{m}$ & $\mathrm{m}$ \\
\hline Afrique du Sud & $\mathrm{m}$ & $\mathrm{m}$ & $\mathrm{m}$ & $\mathrm{m}$ & $\mathrm{m}$ & $\mathrm{m}$ & $\mathrm{m}$ & $\mathrm{m}$ & m & $\mathrm{m}$ & $\mathrm{m}$ & m & $\mathrm{m}$ & m \\
\hline
\end{tabular}

\begin{tabular}{l|c|c|c|c|c|c|c|c|c|c|c|c|c|c|} 
Moyenne G20 & $\mathrm{m}$ & $\mathrm{m}$ & $\mathrm{m}$ & $\mathrm{m}$ & $\mathrm{m}$ & $\mathrm{m}$ & $\mathrm{m}$ & $\mathrm{m}$ & $\mathrm{m}$ & $\mathrm{m}$ & $\mathrm{m}$ & $\mathrm{m}$ & $\mathrm{m}$ & $\mathrm{m}$ \\
\hline arque : Les données relatives aux domaines d'étude agrégés peuvent ne pas être équivalentes à la somme des sous-catégories en raison de la catégorie inconnue.
\end{tabular} Remarque : Les données relative

2. Année de référence : 2016.

3. Les données se rapportent au domaine d'études choisi en licence, même pour les adultes titulaires d'autres diplômes de l'enseignement tertiaire.

Source : OCDE / OIT / ISU (2019). Consulter la section « Source » pour tout complément d'information et l'annexe 3 pour les notes (https://doi.org/10.1787/f8d7880d-en). Les symboles représentant les données manquantes et les abréviations figurent dans le Guide du lecteur. 



\section{Indicateur A2. Transition entre les études et la vie active : Où en sont les jeunes d'aujourd'hui ?}

\section{Faits marquants}

- En moyenne, dans les pays de l'OCDE, $14.3 \%$ des individus âgés de 18 à 24 ans sont sans emploi et ne sont ni scolarisés, ni en formation (neither employed nor in education or training, NEET). Le pourcentage de NEET est supérieur à $25 \%$ chez les 18-24 ans en Afrique du Sud, au Brésil, en Colombie, au Costa Rica, en Italie et en Turquie.

- La longueur de la période pendant laquelle les jeunes sont NEET varie selon les pays. En moyenne dans les pays de l'OCDE, $1.5 \%$ des 18-24 ans sont non scolarisés et sont au chômage depuis plus d'un an. Ce pourcentage est égal ou supérieur à $3.0 \%$ en Argentine, au Brésil, en Espagne, en Grèce, en Italie, au Portugal et en République slovaque ; c'est en Grèce qu'il est le plus élevé (7.9 \%).

- Dans les pays de l'OCDE, le pourcentage de jeunes adultes non scolarisés à la recherche d'un emploi s'établit en moyenne à $1.9 \%$ chez les 15-19 ans ; le pourcentage de NEET au chômage est nettement plus élevé chez les $20-24$ ans (6.2\%) et le reste chez les $25-29$ ans.

Graphique A2.1. Pourcentage de 18-24 ans non scolarisés, selon leur situation au regard de l'emploi (2018)

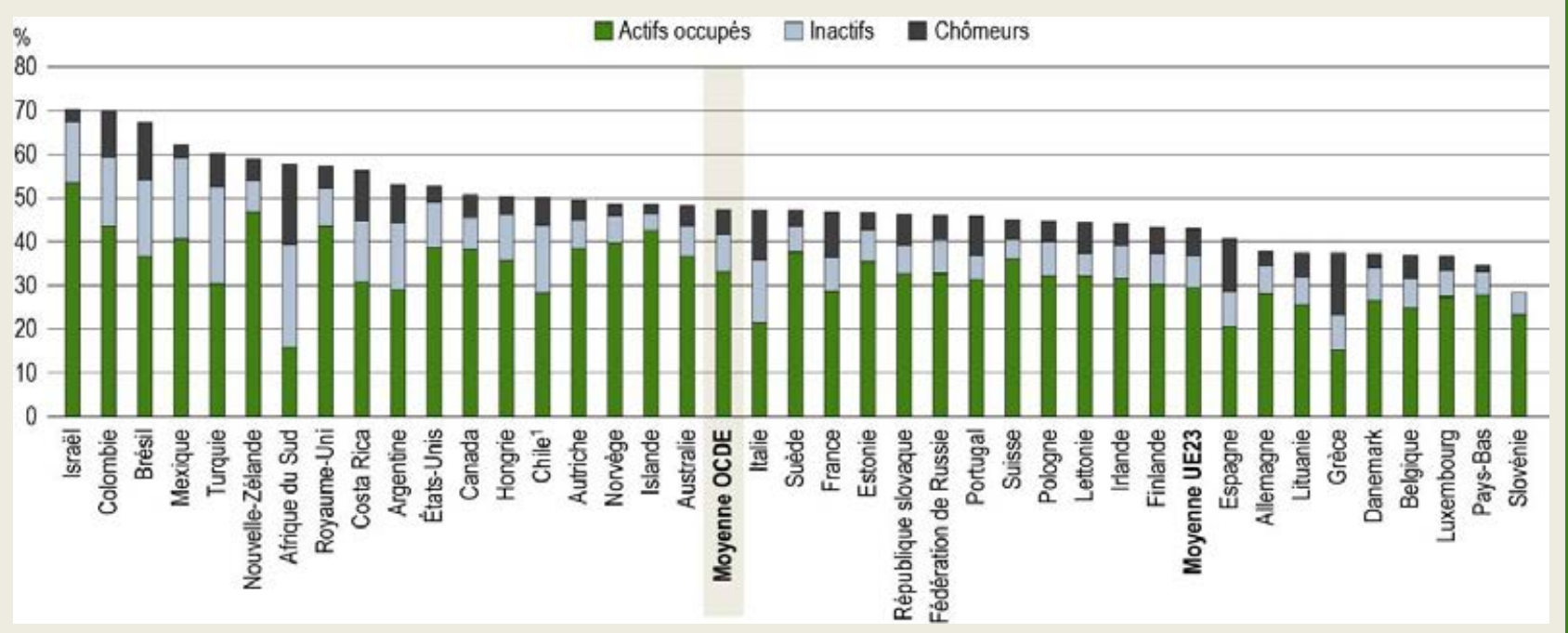

1. L'année de référence n'est pas 2018. Consulter le tableau source pour de plus amples informations.

Les pays sont classés par ordre décroissant du pourcentage total de 18-24 ans non scolarisés.

Source: OCDE (2019), tableau A2.1. Consulter la section «Source» pour tout complément d'information et l'annexe 3 pour les notes (https://doi.org/10.1787/f8d7880d-en). 


\section{Contexte}

La longueur et la qualité de l'instruction ont un impact sur la transition des individus entre les études et la vie active, au même titre que la situation sur le marché du travail, la conjoncture économique et le contexte culturel. II est par exemple d'usage que les jeunes terminent leurs études avant de chercher du travail dans certains pays, alors que formation et emploi sont souvent concomitants dans d'autres pays. Dans certains pays, la transition des jeunes entre l'école et la vie active ne diffère guère entre les femmes et les hommes, alors que dans d'autres, les femmes sont nombreuses à se consacrer à temps plein à leur famille dès la fin de leurs études, sans incursion sur le marché du travail. Lorsque le marché du travail est morose, les jeunes ont souvent tendance à prolonger leurs études, car des taux de chômage élevés diminuent le coût d'opportunité de l'éducation, et ils peuvent améliorer leurs compétences en attendant que la situation s'améliore.

Pour améliorer la transition entre l'école et la vie active, quelle que soit la conjoncture économique, les systèmes d'éducation doivent transmettre aux individus les compétences demandées sur le marché du travail. Pour les pouvoirs publics, investir dans l'éducation peut être un moyen sensé de lutter contre le chômage et de produire les compétences requises en vue de la reprise économique. De plus, les investissements publics peuvent cibler des employeurs potentiels pour les encourager à recruter de jeunes adultes.

Rester sans-emploi peut être lourd de conséquences à long terme, en particulier lorsque les périodes de chômage sont longues et que le découragement gagne. Le problème des jeunes NEET est une préoccupation majeure des responsables politiques, d'autant qu'il peut avoir des implications importantes à l'avenir pour les individus et la société si aucune mesure n'est prise pour y remédier.

\section{Autres faits marquants}

- Dans tous les pays de l'OCDE, le pourcentage de NEET diminue sous l'effet de l'élévation du niveau de formation. En moyenne, le pourcentage de NEET dans l'effectif des $25-29$ ans est de $40.1 \%$ si le niveau de formation est inférieur au deuxième cycle de l'enseignement secondaire, contre $16.8 \%$ s'il est égal au deuxième cycle de l'enseignement secondaire ou à l'enseignement post-secondaire non tertiaire et $10.8 \%$ s'il est égal à l'enseignement tertiaire.

- Entre 2008 et 2018, les taux d'accès des jeunes adultes à l'enseignement tertiaire ont augmenté. Dans la plupart des pays, cet accès à des possibilités supplémentaires de formation est allé de pair avec une diminution du pourcentage de jeunes actifs occupés. En Espagne par exemple, le taux de scolarisation a augmenté de $18 \%$ environ, tandis que le pourcentage d'actifs occupés non scolarisés a diminué de 21 points de pourcentage depuis 2008 chez les 20-24 ans.

- Dans la plupart des pays, les NEET sont en majorité inactifs chez les femmes et chômeurs chez les hommes. En moyenne, chez les NEET non scolarisés de 18 à 24 ans, $10.8 \%$ des femmes sont inactives, contre $6.5 \%$ seulement des hommes, et 5.0 \% des femmes sont au chômage, contre 6.4 \% des hommes, dans les pays de l'OCDE.

\section{Remarque}

Cet indicateur analyse la situation des jeunes à l'âge de la transition entre l'école et le monde du travail : certains d'entre eux sont encore scolarisés, d'autres travaillent déjà et d'autres encore sont sans emploi et ne sont ni scolarisés, ni en formation (neither employed nor in education or training, NEET). Les NEET regroupent à la fois ceux qui ne réussissent pas à trouver du travail (les chômeurs) et ceux qui n'en recherchent pas activement (les inactifs). Une partie des analyses proposées ici se concentre sur les individus âgés de 18 à 24 ans car, bien qu'arrivés au terme de la scolarité obligatoire, nombre d'entre eux poursuivront leurs études. 


\section{Analyse}

\section{La situation des jeunes adultes sur le marché du travail au sortir de l'école}

La scolarité de nombreux jeunes prend fin entre l'âge de 18 et 24 ans. En moyenne, dans les pays de l'OCDE, près de la moitié (47\%) des 18-24 ans ne sont plus scolarisés. Le pourcentage de 18-24 ans non scolarisés est égal ou supérieur à $60 \%$ en Colombie, en Israël, au Mexique et en Turquie, mais n'atteint pas $40 \%$ en Allemagne, en Belgique, au Danemark, en Grèce, en Lituanie, au Luxembourg, aux Pays-Bas et en Slovénie (voir le graphique A2.1).

En moyenne, dans les pays de l'OCDE, $16 \%$ seulement des 25-29 ans sont encore scolarisés. Ce pourcentage de 25-29 ans encore en formation est toutefois supérieur à $25 \%$ au Danemark, en Finlande, en Islande et en Israël (OCDE, 2019[1]).

Les jeunes adultes qui ne sont plus scolarisés se répartissent entre actifs occupés, chômeurs et inactifs. En moyenne, dans les pays de l'OCDE, $33 \%$ des 18-24 ans travaillent et ne sont plus scolarisés ; en d'autres termes, la plupart des 18-24 ans qui ne sont plus scolarisés travaillent. Le pourcentage d'actifs occupés dans l'effectif total de 18-24 ans non scolarisés est égal ou supérieur à $80 \%$ en Islande, en Norvège, en Nouvelle-Zélande, aux Pays-Bas, en Suède et en Suisse. Les jeunes éprouvent plus de difficultés à entrer dans la vie active au sortir de l'école dans d'autres pays. En Afrique du Sud et en Grèce par exemple, plus de $30 \%$ des 18-24 ans qui ne sont plus scolarisés sont au chômage (voir le graphique A2.1).

\section{Graphique A2.2. Pourcentage de jeunes adultes non scolarisés et au chômage, selon le groupe d'âge (2018)}

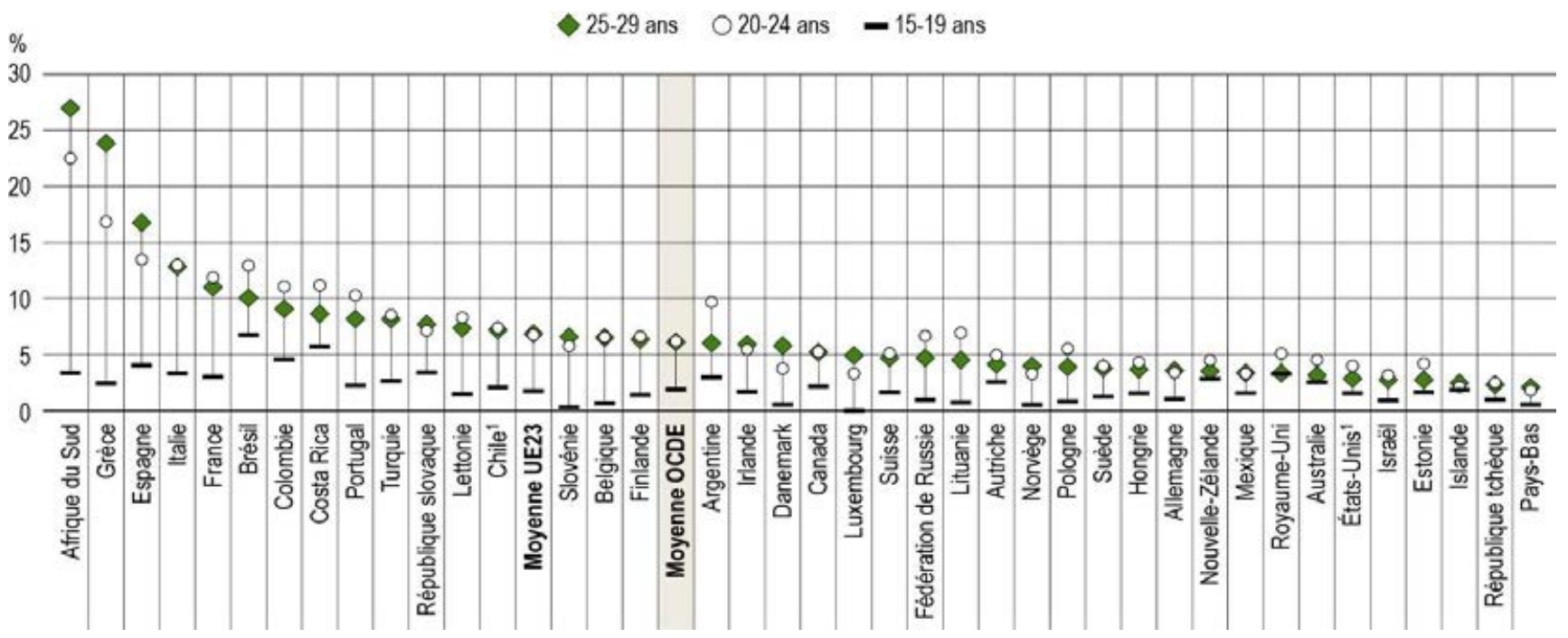

1. L'année de référence n'est pas 2018. Consulter le tableau A2.1 pour de plus amples informations.

Les pays sont classés par ordre décroissant du pourcentage de 25-29 ans non scolarisés et au chômage.

Source : OCDE (2019), Base de données de Regards sur l'éducation, http://stats.oecd.org. Consulter la section « Source » pour tout complément d'information et l'annexe 3 pour les notes (https://doi.org/10.1787/f8d7880d-en).

Les jeunes adultes sans emploi au sortir de l'école sont dits "NEET » (de l'anglais neither employed nor in education or training). En moyenne, dans les pays de l'OCDE, le pourcentage de NEET s'établit à $14.3 \%$ dans le groupe d'âge des 18-24 ans. II est inférieur à $10 \%$ en Allemagne, en Islande, au Luxembourg, en Norvège, aux Pays-Bas, en Slovénie, en Suède et en Suisse, mais égal ou supérieur à $20 \%$ en Afrique du Sud, en Argentine, au Brésil, au Chili, en Colombie, au Costa Rica, en Espagne, en Grèce, en Italie, au Mexique et en 
Turquie. Dans la plupart des pays, les NEET sont plus souvent inactifs que chômeurs : en moyenne, $8.6 \%$ de NEET sont inactifs et 5.7 \% d'entre eux sont au chômage chez les 18-24 ans dans les pays de l'OCDE. Le pourcentage de NEET au chômage est toutefois supérieur au pourcentage de NEET inactifs en Espagne, en France, en Grèce, en Lettonie, au Portugal et en République slovaque (voir le tableau A2.1).

\section{Variation des pourcentages de NEET au chômage entre les groupes d'âge}

Le pourcentage de jeunes adultes non scolarisés à la recherche d'un emploi augmente avec l'âge. En moyenne, dans les pays de l'OCDE, il s'établit à $1.9 \%$ dans le groupe d'âge des 15-19 ans. Ce pourcentage peu élevé s'explique en partie par le fait que la scolarité obligatoire prend généralement fin entre l'âge de 16 et 18 ans (voir le tableau X1.3). Le pourcentage de NEET au chômage augmente considérablement chez les $20-24$ ans (6.2 \%) et ne diminue pas chez les $25-29$ ans (6.1\%).

Le pourcentage de NEET au chômage est le moins élevé parmi les plus jeunes (les 15-19 ans) dans tous les pays membres et partenaires de l'OCDE. La situation est moins uniforme entre les pays chez les 20-24 ans et les 25-29 ans : le pourcentage de NEET au chômage est supérieur de 2 points de pourcentage au moins chez les 20-24 ans en Argentine, au Brésil, en Colombie, au Costa Rica, en Fédération de Russie, en Lituanie et au Portugal, mais chez les 25-29 ans en Afrique du Sud, au Danemark, en Espagne et en Grèce (voir le graphique A2.2).

\section{Durée du chômage des NEET chômeurs}

Les jeunes au chômage au sortir de l'école sont plus susceptibles de revivre cette situation plus tard dans leur carrière et d'être moins bien rémunérés - le scarring effect en anglais, ou séquelle durable d'une entrée « ratée » sur le marché du travail (Eurofound, 2017[2]). La durée de la période de chômage a des effets sensibles sur l'évolution de la vie professionnelle. Le scarring effect est négligeable chez les jeunes peu de temps au chômage (moins de 3 mois), mais il s'amplifie progressivement chez ceux qui restent au chômage plus longtemps (entre 3 et 12 mois) ainsi que chez les chômeurs de longue durée (plus de 12 mois) (OCDE, 2015[3]).

En moyenne, dans les pays de l'OCDE, 2 \% des NEET âgés de 18 à 24 ans sont au chômage depuis moins de 3 mois, $2.8 \%$ d'entre eux depuis 3 à 12 mois, et $1.5 \%$ d'entre eux depuis au moins 12 mois. En d'autres termes, chez un pourcentage important de NEET, le chômage n'est pas temporaire - un intermède entre deux postes mais s'inscrit dans la durée (voir le tableau A2.3).

C'est en Grèce et en Italie que les chômeurs de longue durée sont les plus nombreux parmi les NEET au chômage dans le groupe d'âge des 18-24 ans : plus d'un sur deux est au chômage depuis au moins un an. Par contraste, les chômeurs de longue durée sont proportionnellement les moins nombreux parmi les NEET au chômage au Canada, au Chili, en Colombie, au Costa Rica, aux États-Unis, au Mexique et en Nouvelle-Zélande, où moins de $10 \%$ d'entre eux sont au chômage depuis au moins un an (voir le graphique A2.3).

\section{Variation du pourcentage de NEET inactifs entre les hommes et les femmes}

Les NEET sont en majorité inactifs chez les femmes et chômeurs chez les hommes. En moyenne, chez les 18-24 ans non scolarisés, $10.8 \%$ des femmes sont inactives, contre $6.5 \%$ seulement des hommes, et $5.0 \%$ des femmes sont au chômage, contre 6.4 \% des hommes, dans les pays de l'OCDE (OCDE, 2019[1]).

Différents facteurs contribuent à l'inactivité, c'est-à-dire le fait de ne pas travailler et de ne pas être activement à la recherche d'un emploi. Les principales causes de l'inactivité sont liées aux responsabilités familiales chez les femmes, mais aux problèmes de santé et autres chez les hommes (OCDE, 2017[4]). Lors de l'interprétation du pourcentage de NEET, il convient de garder à l'esprit le fait que certains, peu nombreux, d'entre eux le sont temporairement et reprendront rapidement une activité professionnelle ou des études. Un petit nombre d'entre eux peuvent également se décourager et cesser de chercher du travail, persuadés qu'il n'y a pas d'offres d'emploi pour eux (Eurofound, 2016[5]). 
Graphique A2.3. Pourcentage de 18-24 ans non scolarisés au chômage, selon la durée de leur période de chômage (2018)

Rapporté au pourcentage de l'ensemble de la population âgée de 18 à 24 ans

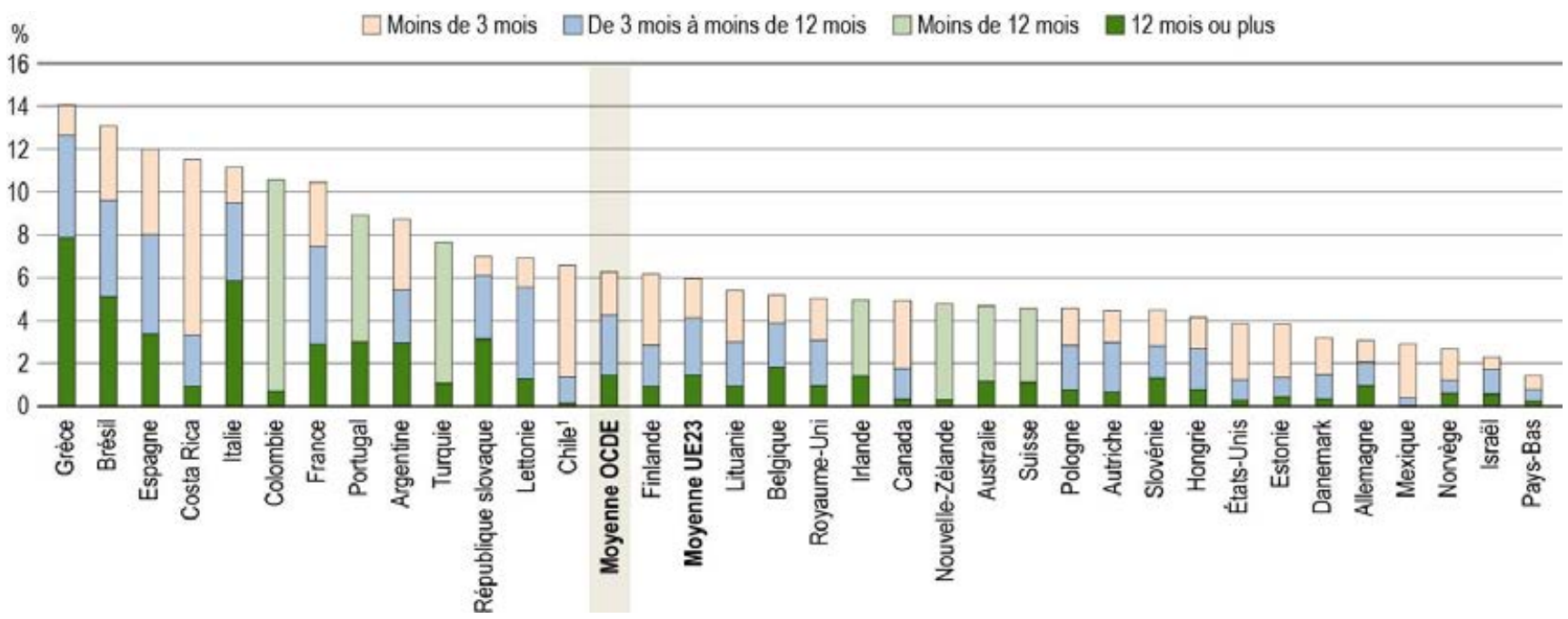

Remarque : La répartition de la durée du chômage ne correspond pas nécessairement au pourcentage de chômeurs, car ces données ont été recueillies séparément.

1. L'année de référence n'est pas 2018. Consulter le tableau source pour de plus amples informations. Les pays sont classés par ordre décroissant du pourcentage de 18-24 ans au chômage.

Source : OCDE (2019), tableau A2.3. Consulter la section «Source» pour tout complément d'information et l'annexe 3 pour les notes (https://doi.org/10.1787/f8d7880d-en).

StatLink 젶ㄴ https://doi.org/10.1787/888933976612

Le pourcentage de NEET inactifs augmente avec l'âge chez les femmes, mais tend à rester plus ou moins stable chez les hommes. Chez les NEET âgés de 15 à 19 ans, $5.5 \%$ des femmes et $4.3 \%$ des hommes sont inactifs en moyenne, dans les pays de l'OCDE, soit une différence de moins de 2 points de pourcentage entre les sexes. Ce pourcentage d'inactifs augmente dans le groupe d'âge des 20-24 ans et des 25-29 ans et passe respectivement à $11.6 \%$ et à $16.5 \%$ chez les femmes et à $6.5 \%$ et à $5.6 \%$ chez les hommes, soit une différence de plus de 10 points de pourcentage entre les sexes (OCDE, 2019 $9_{[1]}$ ).

Chez les 25-29 ans, l'effectif d'inactifs varie de 20 points de pourcentage au moins entre les sexes en Colombie, au Costa Rica, au Mexique, en République slovaque, en République tchèque et en Turquie. Le Mexique et la Turquie sont les deux seuls pays de l'OCDE où il varie de plus de 35 points de pourcentage entre les sexes. Dans ces deux pays, comme dans bien d'autres, l'effectif important de NEET dans l'ensemble s'explique par le pourcentage élevé de NEET inactifs chez les femmes (OCDE, 2019[1]).

\section{Niveau de formation et exposition au risque de devenir NEET}

À l'âge de 25 ans, la plupart des jeunes adultes ne sont plus scolarisés et, s'ils le sont encore, ils ont déjà décroché un premier diplôme tertiaire. L'âge typique d'obtention d'un diplôme de licence (ou formation équivalente) varie entre 21 et 24 ans (voir le tableau X.1a). Les jeunes adultes sont plus exposés au risque de devenir NEET s'ils ne sont pas diplômés de l'enseignement tertiaire que s'ils le sont. En moyenne, le pourcentage de NEET chez les 25-29 ans s'établit à $10.8 \%$ si le niveau de formation est égal à l'enseignement tertiaire, contre $16.8 \%$ s'il est égal au deuxième cycle de l'enseignement secondaire ou à l'enseignement post-secondaire non tertiaire et $40.1 \%$ environ s'il est inférieur au deuxième cycle de l'enseignement secondaire. La situation est particulièrement grave pour les 25-29 ans dont le niveau de formation est inférieur au deuxième cycle de 
l'enseignement secondaire en Afrique du Sud, en Lituanie et en République slovaque, où le pourcentage de NEET passe la barre des $60 \%$ chez ces jeunes adultes non diplômés du deuxième cycle de l'enseignement secondaire. Le pourcentage de NEET est également très élevé en France, en Grèce, en Irlande, en Italie, en Pologne, en République tchèque et en Slovénie, où la moitié au moins des 25-29 ans sont concernés (voir le graphique A2.4).

Être diplômé du deuxième cycle de l'enseignement secondaire réduit sensiblement le risque d'être NEET. L'impact positif de l'élévation du niveau de formation sur le risque de devenir NEET est particulièrement important en Allemagne, en Autriche, au Danemark, en Lituanie, au Luxembourg, en République slovaque, en République tchèque, en Slovénie, en Suède et en Suisse. Dans tous ces pays, le pourcentage de NEET diplômés du deuxième cycle de l'enseignement secondaire ou de l'enseignement post-secondaire non tertiaire représente un tiers environ du pourcentage de NEET dont le niveau de formation est inférieur chez les 25-29 ans (voir le graphique A2.4).

Le pourcentage de NEET est supérieur à $20 \%$ chez les $25-29$ ans quel que soit leur niveau de formation en Afrique du Sud, en Grèce, en Italie et en Turquie. Toutefois, même dans ces pays, l'élévation du niveau de formation est bénéfique et réduit sensiblement le risque de devenir NEET (voir le graphique A2.4).

\section{Graphique A2.4. Pourcentage de NEET parmi les 25-29 ans, selon le niveau de formation (2018)}

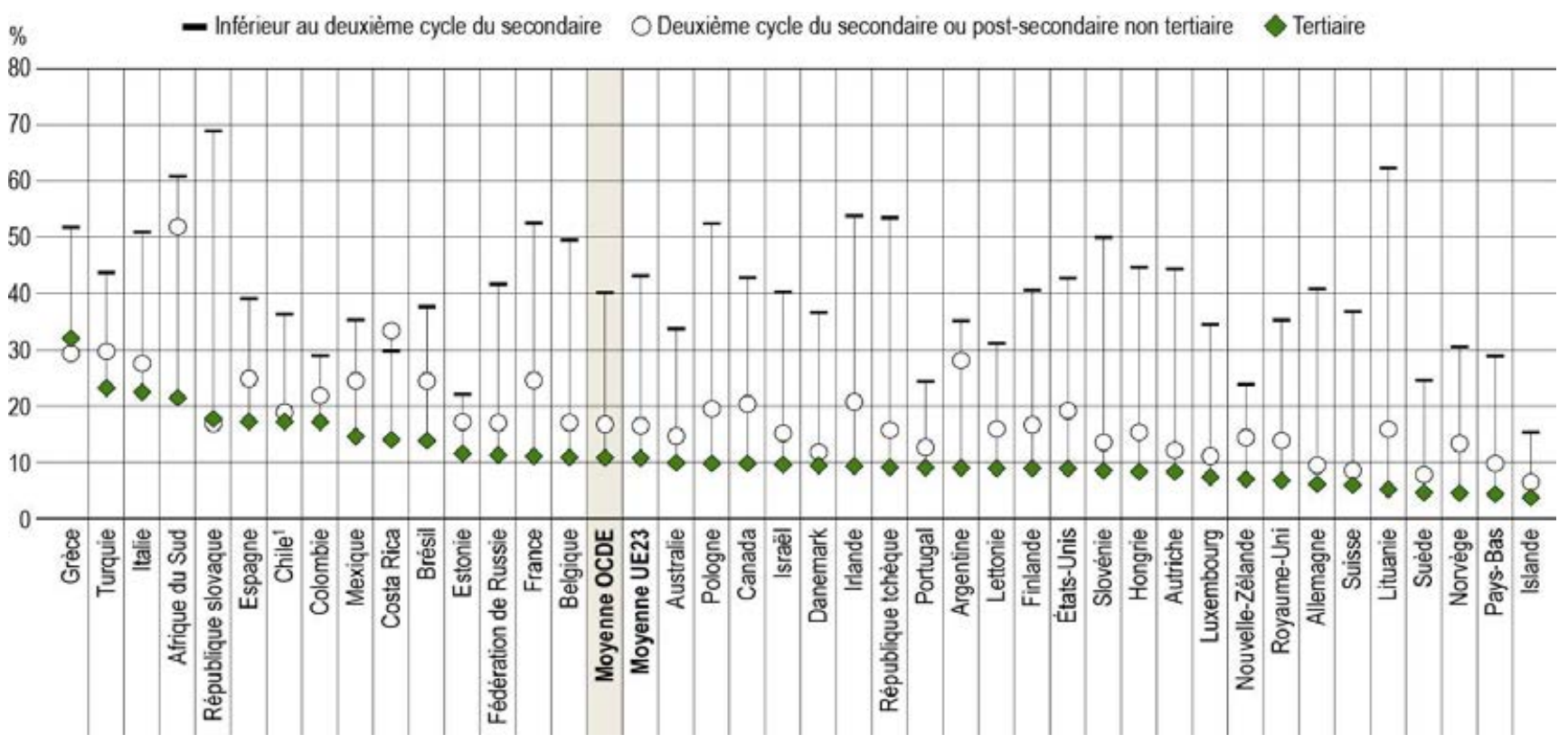

Remarque : Par NEET, on entend les jeunes sans emploi ne suivant ni études ni formation (de l'anglais neither employed nor in education or training). 1. L'année de référence n'est pas 2018. Consulter le tableau A2.1 pour de plus amples informations.

Les pays sont classés par ordre décroissant du pourcentage de NEET parmi les adultes âgés de 25 à 34 ans diplômés de l'enseignement tertiaire.

Source : OCDE (2019), Base de données de Regards sur l'éducation, http://stats.oecd.org. Consulter la section " Source » pour tout complément d'information et l'annexe 3 pour les notes ((https://doi.org/10.1787/f8d7880d-en).

StatLink 젶ㄴ https://doi.org/10.1787/888933976631

\section{Évolution de la transition entre les études et la vie active}

En 2008, l'année où la crise financière et économique a éclaté dans de nombreux pays, le pourcentage de jeunes adultes non scolarisés sans emploi avait atteint un niveau des moins élevés de la première décennie du XXIe siècle. En moyenne, dans les pays de l'OCDE, le pourcentage de NEET âgés de 20 à 24 ans, $15.3 \%$ en 2008, a fortement augmenté dans les années qui ont suivi la crise et a atteint un niveau sans précédent en 
2010/11 en de nombreux endroits. Entre 2010 et 2018, le pourcentage de sans-emploi ni scolarisés, ni en formation a diminué de 4 points de pourcentage chez les 20-24 ans en moyenne, dans les pays de l'OCDE : il est passé de $19.0 \%$ en 2010 à $15.3 \%$ en 2018, un pourcentage du même ordre que dix ans auparavant (voir le tableau A2.2 et OCDE (2019[1])).

Le pourcentage de NEET enregistré en 2018 est plus élevé qu'en 2008 chez les 20-24 ans dans la plupart des pays de l'OCDE, mais a sensiblement diminué dans un certain nombre de pays. Parmi les pays dont les données de 2008 et de 2018 sont comparables, c'est en Hongrie qu'il a le plus diminué en valeur relative, passant de $18.4 \%$ à $15.4 \%$ (soit une diminution de $16 \%$ ). Les États-Unis affichent également une évolution significative : le pourcentage de NEET a chuté de $14 \%$ (voir le tableau A2.2).

Au cours des dix dernières années, la tendance à l'amélioration de l'accès des jeunes adultes à l'enseignement tertiaire ne s'est pas démentie (voir l'indicateur B1). En Espagne, le taux de scolarisation des 20-24 ans a augmenté de 18 points de pourcentage, passant de $34 \%$ en 2008 à $52 \%$ en 2018, la progression la plus forte durant cette période. En Autriche, le pourcentage de jeunes adultes toujours scolarisés a augmenté de près de 10 points de pourcentage entre 2008 et 2018 (voir le tableau A2.2).

Dans la plupart des pays, l'amélioration de l'accès à l'enseignement est allée de pair avec une diminution du pourcentage de jeunes actifs occupés. Parmi les pays de l'OCDE dont les données de 2008 et de 2018 sont comparables, cette diminution représente au moins 10 points de pourcentage en Autriche, en Espagne, en Norvège et au Portugal chez les 20-24 ans. En Espagne, le pourcentage d'actifs occupés non scolarisés en 2018 est inférieur de près de 20 points de pourcentage à celui enregistré en 2008, tandis que le taux de scolarisation a augmenté de 18 points de pourcentage chez les 20-24 ans. L'inverse s'observe dans certains pays : le pourcentage d'actifs occupés non scolarisés a augmenté, alors que le taux de scolarisation a diminué chez les 20-24 ans entre 2008 et 2018 en Hongrie et en Nouvelle-Zélande (voir le tableau A2.2).

\section{Variation infranationale du pourcentage de NEET chez les jeunes}

Le pourcentage de jeunes sans-emploi ni scolarisés, ni en formation varie sensiblement entre les entités infranationales, comme entre les pays de l'OCDE. Parmi les régions de l'OCDE, le pourcentage de NEET âgés de 18 à 24 ans s'établit à $2.1 \%$ seulement dans une région du Japon, mais atteint $48.8 \%$ dans une région de Turquie. Les moyennes nationales peuvent aussi occulter le fait que le pourcentage de NEET peut être nettement plus élevé ou moins élevé dans certaines régions, qui font dès lors figure d'exception (OCDE, 2019[6]).

Dans 18 pays membres et partenaires de l'OCDE, le pourcentage de NEET chez les 18-24 ans varie au moins du simple au double entre les entités infranationales les mieux loties et les plus mal loties. En Fédération de Russie, le ratio entre les régions où ce pourcentage est respectivement le plus et le moins élevé est égal à 12 , tandis qu'en Espagne, il y a environ trois fois plus de NEET dans la région la plus mal lotie $(30.7 \%)$ que dans la région la mieux lotie (9.9\%) (OCDE, 2019[6]).

À l'autre extrême, c'est au Danemark, en Slovénie et en Suède, parmi les pays membres et partenaires de I'OCDE, que l'effectif de NEET varie le moins entre les régions : la différence entre les régions où l'effectif de NEET est respectivement le plus et le moins élevé est inférieure à 3 points de pourcentage. Ces trois pays comptent au plus huit entités infranationales. En Finlande, aux Pays-Bas et en Norvège, le pourcentage de NEET varie également peu entre les régions : dans ces trois pays, la différence entre les régions est inférieure à 4 points de pourcentage (OCDE, 2019[6]).

Dans les pays de l'OCDE, l'activité économique et l'emploi tendent à se concentrer dans les villes (OCDE, 2018[7]). Toutefois, des tendances différentes s'observent quant au pourcentage de NEET dans les capitales des pays de l'OCDE. La région de la capitale affiche le pourcentage de NEET le moins élevé dans de nombreux pays, notamment au Chili, au Danemark, en Finlande et en République tchèque, mais se situe au premier rang en Allemagne, en Autriche et en Belgique du classement des régions en fonction de l'importance du pourcentage de NEET (OCDE, 2019[6]). 


\section{Définitions}

Le niveau de formation correspond au plus haut niveau d'enseignement dont les individus sont diplômés.

Actifs occupés, chômeurs et inactifs : voir la section « Définitions » de l'indicateur A3.

Par individus scolarisés, on entend les individus scolarisés ou en formation dans le cadre institutionnel durant les quatre semaines précédant l'enquête.

Niveaux de formation : les niveaux de la CITE 2011 sont tous décrits dans le Guide du lecteur, au début du présent rapport.

Par NEET (de l'anglais employed nor in education or training), on entend les jeunes sans emploi qui ne sont ni scolarisés, ni en formation.

\section{Méthodologie}

Les données se rapportent dans l'ensemble au deuxième trimestre de l'année scolaire, car c'est la période la plus probante pour déterminer si les jeunes sont encore scolarisés ou s'ils ont arrêté leurs études pour entrer dans la vie active. Le deuxième trimestre de l'année scolaire correspond au premier trimestre de l'année civile (janvier, février et mars) dans la plupart des pays, mais au deuxième trimestre de l'année civile (mars, avril et mai) dans quelques pays.

Comme le fait d'être scolarisé ou en formation implique ici de l'être dans le cadre institutionnel, les sans-emploi qui suivent une formation en dehors du cadre institutionnel sont classés dans la catégorie des NEET.

Voir l'indicateur A1 pour des informations sur la méthodologie concernant les variations infranationales.

Voir le Guide de l'OCDE pour l'établissement de statistiques internationalement comparables dans le domaine de l'éducation 2018 (OCDE, 2019[8] $)$ pour de plus amples informations. Voir les notes spécifiques aux pays à l'annexe 3 (https://doi.org/10.1787/f8d7880d-en).

\section{Source}

Voir les sources de l'indicateur A1.

\section{Note concernant les données d'Israël}

Les données statistiques concernant Israël sont fournies par et sous la responsabilité des autorités israéliennes compétentes. L'utilisation de ces données par l'OCDE est sans préjudice du statut des hauteurs du Golan, de Jérusalem-Est et des colonies de peuplement israéliennes en Cisjordanie aux termes du droit international.

\section{Références}

Eurofound (2017), Long term unemployed youth - Characteristics and policy responses, https://www.eurofound.europa.eu/publications/report/2017/long-term-unemployed-youth.

Eurofound (2016), Exploring the diversity of NEETs, Publications Office of the European Union, Luxembourg, http://dx.doi.org/10.2806/62307. 
OCDE (2019), Base de données de Regards sur l'éducation - Transition de l'école au travail, http://stats.oecd.org/lndex.aspx?datasetcode=EAG TRANS.

OCDE (2019), Guide de l'OCDE pour l'établissement de statistiques internationalement comparables dans le domaine de l'éducation 2018: Concepts, normes, définitions et classifications, Éditions OCDE, Paris, https://dx.doi.org/10.1787/9789264305380-fr.

OCDE (2019), Statistiques régionales - Education au niveau régional, http://stats.oecd.org/Index.aspx?datasetcode=REGION EDUCAT.

OCDE (2018), OECD Regions and Cities at a Glance 2018, Éditions OCDE, Paris, https://dx.doi.org/10.1787/reg cit glance-2018-en.

OCDE (2017), Panorama de la société 2016: Les indicateurs sociaux de l'OCDE, Éditions OCDE, Paris, https://dx.doi.org/10.1787/soc glance-2016-fr.

OCDE (2015), Perspectives de l'OCDE sur les compétences 2015: Les jeunes, les compétences et l'employabilité, Éditions OCDE, Paris, https://dx.doi.org/10.1787/9789264235465-fr.

\section{Tableaux de l'indicateur A2}

Tableau A2.1

Tableau A2.2

Tableau A2.3
Pourcentage de 18-24 ans scolarisés ou non, selon leur situation au regard de l'emploi (2018)

Évolution du pourcentage de jeunes adultes scolarisés ou non, occupant un emploi ou non, selon le groupe d'âge (2008 et 2018)

Pourcentage de 18-24 ans scolarisés ou non, selon leur situation au regard de l'emploi et la durée de leur période de chômage (2018)

Date butoir pour les données : 19 juillet 2019. Les mises à jour peuvent être consultées en ligne sur : http://dx.doi.org/10.1787/eag-data-en. D'autres données désagrégées sont également disponibles dans la Base de données de Regards sur l'éducation (http://stats.oecd.org/).

StatLink : https://doi.org/10.1787/888933980811 
Tableau A2.1. Pourcentage de 18-24 ans scolarisés ou non, selon leur situation au regard de l'emploi (2018)

\begin{tabular}{|c|c|c|c|c|c|c|c|c|c|c|c|c|}
\hline & \multicolumn{6}{|c|}{ Scolarisés } & \multicolumn{5}{|c|}{ Non scolarisés } & \multirow[b]{3}{*}{ 哭 } \\
\hline & \multicolumn{3}{|c|}{ Actifs occupès } & \multirow[b]{2}{*}{ 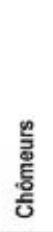 } & \multirow[b]{2}{*}{$\begin{array}{l}\text { 总 } \\
\text { 总 }\end{array}$} & \multirow[b]{2}{*}{ 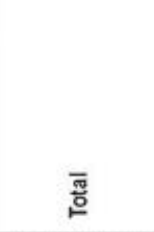 } & \multirow[b]{2}{*}{ 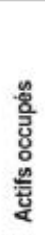 } & \multicolumn{3}{|c|}{ NEET } & \multirow[b]{2}{*}{ হ } & \\
\hline & 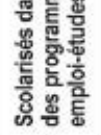 & 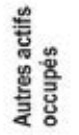 & $\begin{array}{l}\text { 푱 } \\
\text { }\end{array}$ & & & & & 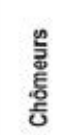 & 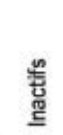 & 푱 & & \\
\hline & (1) & (2) & $(3)=(1)+(2)$ & (4) & (5) & $(6)=(3)+(4)+(5)$ & (7) & (8) & (9) & $(10)=(8)+(9)$ & $(11)=(7)+(10)$ & $(12)=(6)+(11)$ \\
\hline \multicolumn{13}{|c|}{ (c) } \\
\hline Oustralie & 5 & 28 & 33 & 29 & 16 & 52 & 37 & 4.6 & 7.0 & 11.6 & 48 & 100 \\
\hline Autriche & 7 & 13 & 20 & 1.8 & 29 & 50 & 38 & 4.5 & 6.7 & 11.1 & 50 & 100 \\
\hline Belgique & 0 & 5 & 6 & 1.0 & 56 & 63 & 25 & 5.2 & 6.9 & 12.1 & 37 & 100 \\
\hline Canada & $x(2)$ & $23^{\circ}$ & 23 & 20 & 25 & 49 & 38 & 5.1 & 7.4 & 12.5 & 51 & 100 \\
\hline Chili" & $x(2)$ & $9^{d}$ & 9 & 3.0 & 38 & 50 & 28 & 6.6 & 15.3 & 21.9 & 50 & 100 \\
\hline Colombie & a & 10 & 10 & 3.0 & 17 & 30 & 43 & 10.6 & 15.9 & 26.5 & 70 & 100 \\
\hline Republique tchèque & $\mathrm{m}$ & $\mathrm{m}$ & $\mathrm{m}$ & $\mathrm{m}$ & $\mathrm{m}$ & $\mathrm{m}$ & $\mathrm{m}$ & $\mathrm{m}$ & $\mathrm{m}$ & $\mathrm{m}$ & $\mathrm{m}$ & $\mathrm{m}$ \\
\hline Danemark & $x(2)$ & $35^{\circ}$ & 35 & 3.2 & 25 & 63 & 27 & 3.1 & 75 & 10.7 & 37 & 100 \\
\hline Estonie & c & 22 & 22 & 29 & 28 & 53 & 35 & 3.8 & 7.4 & 112 & 47 & 100 \\
\hline Finlande & $x(2)$ & $20^{\circ}$ & 20 & 6.0 & 31 & 57 & 30 & 6.0 & 7.1 & 13.1 & 43 & 100 \\
\hline France & 7 & 5 & 12 & 0.9 & 41 & 53 & 29 & 10.4 & 7.8 & 18.2 & 47 & 100 \\
\hline Allemagne & 16 & 16 & 32 & 1.0 & 30 & 62 & 28 & 3.1 & 6.5 & 9.6 & 38 & 100 \\
\hline Grèce & a & 5 & 5 & 17 & 56 & 63 & 15 & 14.0 & 82 & 223 & 37 & 100 \\
\hline Hongrie & a & 2 & 2 & c & 47 & 50 & 36 & 4.2 & 10.5 & 14.6 & 50 & 100 \\
\hline Islande & a & 37 & 37 & 23 & 12 & 51 & 43 & 22 & 3.7 & 59 & 49 & 100 \\
\hline Irlande & a & 20 & 20 & 1.9 & 34 & 56 & 32 & 5.0 & 7.6 & 12.5 & 44 & 100 \\
\hline Israël & $x(2)$ & $10^{\circ}$ & 10 & 0.6 & 19 & 30 & 53 & 28 & 14.0 & 16.9 & 70 & 100 \\
\hline Italie & a & 3 & 3 & 0.7 & 49 & 53 & 22 & 11.5 & 14.3 & 25.7 & 47 & 100 \\
\hline Japon & $\mathrm{m}$ & $\mathrm{m}$ & $\mathrm{m}$ & m & $\mathrm{m}$ & $\mathrm{m}$ & m & $\mathrm{m}$ & $\mathrm{m}$ & $\mathrm{m}$ & $\mathrm{m}$ & $\mathrm{m}$ \\
\hline Corée & $\mathrm{m}$ & $\mathrm{m}$ & $\mathrm{m}$ & $\mathrm{m}$ & $\mathrm{m}$ & $\mathrm{m}$ & $\mathrm{m}$ & $\mathrm{m}$ & $\mathrm{m}$ & $\mathrm{m}$ & $\mathrm{m}$ & m \\
\hline Lettonic & a & 14 & 14 & c & 41 & 56 & 32 & 7.1 & 5.1 & 122 & 44 & 100 \\
\hline Lituanie & a & 14 & 14 & 1.0 & 47 & 63 & 26 & 5.4 & 6.5 & 11.9 & 37 & 100 \\
\hline Luxembourg & a & 14 & 15 & 24 & 46 & 63 & 27 & 3.4 & 6.0 & 9.3 & 37 & 100 \\
\hline Mexique & a & 10 & 10 & 0.8 & 27 & 38 & 41 & 3.1 & 18.5 & 21.6 & 62 & 100 \\
\hline Pays-Bas & $x(2)$ & $41^{\circ}$ & 41 & 28 & 22 & 65 & 28 & 1.6 & 5.3 & 6.9 & 35 & 100 \\
\hline Nouvelle-Zélande & a & 22 & 22 & 1.8 & 18 & 41 & 47 & 4.9 & 7.1 & 11.9 & 59 & 100 \\
\hline Norvège & 1 & 20 & 21 & 2.5 & 28 & 51 & 40 & 2.7 & 6.0 & 8.8 & 49 & 100 \\
\hline Pologne & a & 10 & 10 & 1.0 & 44 & 55 & 32 & 4.6 & 7.9 & 12.5 & 45 & 100 \\
\hline Portugal & a & 6 & 6 & 1.4 & 47 & 54 & 31 & 8.9 & 5.6 & 14.5 & 46 & 100 \\
\hline Rèpublique slovaque & c & 3 & 3 & c & 51 & 54 & 33 & 7.0 & 6.6 & 13.6 & 46 & 100 \\
\hline Slovénie & $x(2)$ & $22^{\circ}$ & 22 & 1.3 & 43 & 67 & 23 & 4.5 & 5.0 & 9.5 & 33 & 100 \\
\hline Espagne & $x(2)$ & $8^{\circ}$ & 8 & 3.7 & 48 & 59 & 21 & 12.0 & 8.2 & 20.2 & 41 & 100 \\
\hline Suéde & a & 17 & 17 & 6.1 & 30 & 53 & 38 & 3.7 & 59 & 9.6 & 47 & 100 \\
\hline Suisse & 19 & 15 & 34 & 1.8 & 19 & 55 & 36 & 4.6 & 4.4 & 9.0 & 45 & 100 \\
\hline Turquie & a & 14 & 14 & 3.3 & 23 & 40 & 30 & 7.6 & 22.2 & 29.8 & 60 & 100 \\
\hline Royaume-Uni & 5 & 14 & 18 & 1.5 & 23 & 43 & 44 & 5.0 & 8.8 & 13.8 & 57 & 100 \\
\hline États-Unis & $x(2)$ & $20^{\circ}$ & 20 & 1.3 & 26 & 47 & 39 & 3.9 & 10.3 & 142 & 53 & 100 \\
\hline Moyenne OCDE & m & 15 & 17 & 22 & 33 & 53 & 33 & 5.7 & 8.6 & 14.3 & 47 & 100 \\
\hline Moyenne UE23 & m & 14 & 16 & 22 & 39 & 57 & 30 & 6.1 & 7.3 & 13.4 & 43 & 100 \\
\hline \& Argentine & a & 12 & 12 & 4.3 & 31 & 47 & 29 & 8.8 & 15.3 & 24.1 & 53 & 100 \\
\hline 旅 Brèsil & a & 14 & 14 & 5.2 & 14 & 33 & 37 & 13.1 & 17.6 & 30.6 & 67 & 100 \\
\hline Shine & $\mathrm{m}$ & $\mathrm{m}$ & $\mathrm{m}$ & $\mathrm{m}$ & $\mathrm{m}$ & m & m & $\mathrm{m}$ & $\mathrm{m}$ & $\mathrm{m}$ & $\mathrm{m}$ & $\mathrm{m}$ \\
\hline aj Costa Rica & a & 12 & 12 & 4.2 & 27 & 44 & 31 & 11.5 & 14.1 & 25.6 & 56 & 100 \\
\hline Inde & $\mathrm{m}$ & $\mathrm{m}$ & $\mathrm{m}$ & $\mathrm{m}$ & $\mathrm{m}$ & $\mathrm{m}$ & $\mathrm{m}$ & $\mathrm{m}$ & $\mathrm{m}$ & $\mathrm{m}$ & $\mathrm{m}$ & m \\
\hline Indonésie & $\mathrm{m}$ & $\mathrm{m}$ & $\mathrm{m}$ & $\mathrm{m}$ & $\mathrm{m}$ & $\mathrm{m}$ & $\mathrm{m}$ & $\mathrm{m}$ & $\mathrm{m}$ & $\mathrm{m}$ & $\mathrm{m}$ & $\mathrm{m}$ \\
\hline Fédération de Russie & $\mathrm{m}$ & 6 & 6 & 20 & 46 & 54 & 33 & 56 & 7.6 & 132 & 46 & 100 \\
\hline Arabie saoudite & $\mathrm{m}$ & $\mathrm{m}$ & $\mathrm{m}$ & $\mathrm{m}$ & $\mathrm{m}$ & $\mathrm{m}$ & $\mathrm{m}$ & $\mathrm{m}$ & $\mathrm{m}$ & $\mathrm{m}$ & $\mathrm{m}$ & $\mathrm{m}$ \\
\hline Afrique du Sud & a & 1 & 1 & 0.8 & 41 & 42 & 16 & 18.3 & 236 & 41.9 & 58 & 100 \\
\hline
\end{tabular}

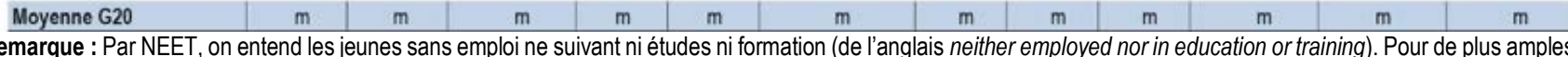
informations, consulter les sections « Définitions » et « Méthodologie ». Les données et d'autres types de ventilations peuvent être consultés sur http://stats.oecd.org/, Base de données de Regards sur l'éducation.

1. Année de référence : 2017.

Source : OCDE (2019) Consulter la section « Source » pour tout complément d'information et l'annexe 3 pour les notes (https://doi.org/10.1787/f8d7880d-en). Les symboles représentant les données manquantes et les abréviations figurent dans le Guide du lecteur. 
Tableau A2.2. Évolution du pourcentage de jeunes adultes scolarisés ou non, occupant un emploi ou non, selon le groupe d'âge (2008 et 2018)

\begin{tabular}{|c|c|c|c|c|c|c|c|c|c|c|c|c|}
\hline & \multicolumn{6}{|c|}{$20-24$ ans } & \multicolumn{6}{|c|}{$15-29$ ans } \\
\hline & \multicolumn{3}{|c|}{2008} & \multicolumn{3}{|c|}{2018} & \multicolumn{3}{|c|}{2008} & \multicolumn{3}{|c|}{2018} \\
\hline & \multirow[b]{2}{*}{ Scolarisés } & \multicolumn{2}{|c|}{ Non scolarisès } & \multirow[b]{2}{*}{ Scolarisés } & \multicolumn{2}{|c|}{ Non scolarisés } & \multirow[b]{2}{*}{ Scolarisés } & \multicolumn{2}{|c|}{ Non scolarisès } & \multirow[b]{2}{*}{ Scolarisés } & \multicolumn{2}{|c|}{ Non scolarisès } \\
\hline & & $\begin{array}{c}\text { Actifs } \\
\text { occupes }\end{array}$ & NEET & & $\begin{array}{c}\text { Actifs } \\
\text { occupés }\end{array}$ & NEET & & $\begin{array}{l}\text { Actifs } \\
\text { occupés }\end{array}$ & NEET & & $\begin{array}{c}\text { Actifs } \\
\text { occupés }\end{array}$ & NEET \\
\hline & (1) & (2) & (3) & (4) & (5) & (6) & (7) & (8) & (9) & (10) & (ii) & (12) \\
\hline ш Pays & & & & & & & & & & & & \\
\hline Australie & $39^{\circ}$ & $50^{t}$ & $10.7^{\circ}$ & 46 & 42 & 11.9 & $44^{\circ}$ & $45^{b}$ & $10.4^{\circ}$ & 47 & 42 & 10.8 \\
\hline Autriche & 33 & 55 & 120 & 42 & 45 & 12.5 & 43 & 46 & 10.7 & 46 & 43 & 11.1 \\
\hline Belgique & $41^{\circ}$ & $44^{\circ}$ & $14.1^{\circ}$ & 53 & 33 & 14.6 & $46^{\circ}$ & $42^{b}$ & $12.1^{\mathrm{b}}$ & 50 & 37 & 128 \\
\hline Canada & 39 & 48 & 13.3 & 43 & 44 & 13.4 & 44 & 44 & 11.9 & 43 & 45 & 11.9 \\
\hline Chili' & $\mathrm{m}$ & $\mathrm{m}$ & $\mathrm{m}$ & 44 & 34 & 21.8 & $\mathrm{~m}$ & $\mathrm{~m}$ & m & 46 & 35 & 18.4 \\
\hline Colombie & $\mathrm{m}$ & $\mathrm{m}$ & $\mathrm{m}$ & 24 & 49 & 26.3 & $\mathrm{~m}$ & $\mathrm{~m}$ & $\mathrm{~m}$ & 34 & 44 & 22.7 \\
\hline République tchèque & $45^{\circ}$ & $45^{\circ}$ & $10.6^{\circ}$ & 49 & 42 & 8.8 & $47^{\circ}$ & $43^{\circ}$ & $10.9^{\circ}$ & 46 & 44 & 10.0 \\
\hline Danemark & $51^{\circ}$ & $41^{\circ}$ & $8.2^{\circ}$ & 57 & 31 & 11.9 & $54^{\circ}$ & $39^{\circ}$ & $6.9^{\circ}$ & 57 & 33 & 10.8 \\
\hline Estonie & 47 & 43 & 10.7 & 44 & 44 & 122 & 50 & 39 & 11.3 & 44 & 43 & 12.7 \\
\hline Finlande & 50 & 38 & 12.0 & 50 & 36 & 14.2 & 56 & 34 & 9.9 & 54 & 34 & 11.9 \\
\hline France & 42 & 41 & 16.6 & 42 & 37 & 20.3 & 46 & 40 & 14.0 & 48 & 36 & 16.1 \\
\hline Allemagne & $47^{\circ}$ & $39^{\mathrm{b}}$ & $14.0^{\circ}$ & 55 & 35 & 10.4 & $52^{\circ}$ & $36^{\circ}$ & $11.6^{b}$ & 53 & 38 & 9.2 \\
\hline Grèce & $49^{b}$ & $34^{b}$ & $16.7^{b}$ & 58 & 19 & 22.9 & $45^{\circ}$ & $39^{\mathrm{b}}$ & $16.0^{\mathrm{b}}$ & 53 & 25 & 21.5 \\
\hline Hongrie & 48 & 33 & 18.4 & 40 & 45 & 15.4 & 47 & 37 & 16.3 & 42 & 44 & 13.5 \\
\hline Islande & 48 & 46 & 52 & 45 & 49 & 6.5 & 48 & 46 & 5.6 & 47 & 47 & 6.1 \\
\hline Irlande & $30^{b}$ & $55^{\circ}$ & $14.6^{\circ}$ & 46 & 41 & 13.6 & $36^{\circ}$ & $51^{\mathrm{b}}$ & $128^{\circ}$ & 51 & 38 & 11.7 \\
\hline Israë| & $29^{\circ}$ & $34^{\circ}$ & $37.5^{\circ}$ & 28 & 55 & 17.0 & $42^{\circ}$ & $30^{\mathrm{b}}$ & $27.5^{\circ}$ & 43 & 43 & 13.4 \\
\hline Italie & $43^{b}$ & $35^{\circ}$ & $22.0^{\circ}$ & 44 & 27 & 28.4 & $45^{\circ}$ & $36^{b}$ & $19.2^{b}$ & 48 & 28 & 23.8 \\
\hline Japon & $32^{\circ}$ & $57^{\circ}$ & $11.1^{\circ}$ & $\mathrm{m}$ & $\mathrm{m}$ & m & $40^{\circ}$ & $49^{\circ}$ & $113^{b}$ & $\mathrm{~m}$ & $\mathrm{~m}$ & m \\
\hline Corée & $\mathrm{m}$ & $\mathrm{m}$ & $\mathrm{m}$ & $\mathrm{m}$ & $\mathrm{m}$ & $\mathrm{m}$ & $\mathrm{m}$ & $\mathrm{m}$ & $\mathrm{m}$ & $\mathrm{m}$ & $\mathrm{m}$ & $\mathrm{m}$ \\
\hline Lettonie & 39 & 47 & 14.0 & 44 & 42 & 14.0 & 47 & 41 & 12.0 & 44 & 45 & 11.2 \\
\hline Lituanic $^{2}$ & $51^{\circ}$ & $33^{\circ}$ & $15.9^{\circ}$ & 51 & 34 & 14.6 & $56^{\circ}$ & $33^{\mathrm{b}}$ & $11.4^{5}$ & 50 & 40 & 10.5 \\
\hline Luxembourg & $56^{\circ}$ & $34^{\circ}$ & $98^{\circ}$ & 58 & 32 & 10.1 & $52^{\circ}$ & $40^{b}$ & $85^{\circ}$ & 53 & 39 & 8.4 \\
\hline Mexique & 25 & 49 & 25.9 & 31 & 46 & 23.2 & 33 & 43 & 23.4 & 38 & 41 & 20.9 \\
\hline Pays-Bas & $52^{\circ}$ & $42^{\circ}$ & $56^{\circ}$ & 58 & 34 & 7.7 & $54^{\circ}$ & $41^{\mathrm{b}}$ & $5.1^{\circ}$ & 56 & 37 & 7.0 \\
\hline Nouvelle-Zélande & 40 & 46 & 14.1 & 35 & 52 & 124 & 46 & 42 & 12.1 & 43 & 47 & 10.2 \\
\hline Norvège & 39 & 54 & 7.0 & 46 & 44 & 10.3 & 44 & 49 & 6.7 & 47 & 45 & 8.7 \\
\hline Pologne & $57^{b}$ & $28^{\circ}$ & $15.6^{\circ}$ & 43 & 42 & 14.5 & $53^{\circ}$ & $34^{\mathrm{b}}$ & $13.7^{\circ}$ & 43 & 44 & 127 \\
\hline Portugal & 37 & 50 & 13.5 & 44 & 40 & 16.8 & 40 & 48 & 12.2 & 49 & 39 & 11.6 \\
\hline République slovaque & $39^{\circ}$ & $44^{\circ}$ & $16.6^{\circ}$ & 44 & 41 & 14.7 & $43^{\circ}$ & $41^{\mathrm{b}}$ & $16.2^{b}$ & 42 & 43 & 15.1 \\
\hline Slovénie & $61^{\mathrm{B}}$ & $29^{\circ}$ & $10.3^{\circ}$ & 59 & 29 & 12.0 & $57^{\circ}$ & $34^{\mathrm{b}}$ & $8.5^{b}$ & 55 & 36 & 9.7 \\
\hline Espagne & 34 & 47 & 19.0 & 52 & 26 & 22.0 & 36 & 48 & 16.7 & 51 & 30 & 19.1 \\
\hline Suede & $40^{\circ}$ & $48^{\circ}$ & $12.9^{\circ}$ & 46 & 44 & 10.0 & $51^{\circ}$ & $40^{\mathrm{b}}$ & $8.7^{\circ}$ & 49 & 42 & 8.9 \\
\hline Suisse & $43^{b}$ & $48^{\circ}$ & $9.1^{\circ}$ & 45 & 45 & 10.0 & $46^{\circ}$ & $44^{\mathrm{b}}$ & $9.6^{\circ}$ & 48 & 44 & 8.1 \\
\hline Turquie & $20^{\circ}$ & $34^{\circ}$ & $46.1^{\circ}$ & 35 & 34 & 31.2 & $23^{\circ}$ & $35^{\circ}$ & $42.0^{\circ}$ & 42 & 31 & 26.5 \\
\hline Royaume-Uni & $28^{\circ}$ & $53^{\circ}$ & $18.3^{\circ}$ & 34 & 51 & 14.2 & $38^{\circ}$ & $47^{\circ}$ & $14.8^{\circ}$ & 36 & 51 & 126 \\
\hline Etats-Unis & 37 & 46 & 172 & 39 & 47 & 14.8 & 45 & 40 & 14.7 & 44 & 43 & 127 \\
\hline Moyenne OCDE & 42 & 43 & 15.3 & 45 & 40 & 15.3 & 46 & 41 & 13.4 & 47 & 40 & 13.2 \\
\hline Moyenne UE23 & 44 & 42 & 14.0 & 48 & 37 & 14.6 & 48 & 40 & 12.1 & 49 & 39 & 12.7 \\
\hline \& Argentine & $\mathrm{m}$ & $\mathrm{m}$ & $\mathrm{m}$ & 41 & 34 & 25.0 & $\mathrm{~m}$ & m & m & 48 & 32 & 20.4 \\
\hline Brésil & 24 & 54 & 22.5 & 28 & 42 & 29.8 & 35 & 46 & 19.0 & 38 & 37 & 24.9 \\
\hline Shine & $\mathrm{m}$ & $\mathrm{m}$ & $\mathrm{m}$ & $\mathrm{m}$ & $\mathrm{m}$ & $\mathrm{m}$ & $\mathrm{m}$ & $\mathrm{m}$ & $\mathrm{m}$ & $\mathrm{m}$ & $\mathrm{m}$ & $\mathrm{m}$ \\
\hline a Costa Rica & $\mathrm{m}$ & $\mathrm{m}$ & $\mathrm{m}$ & 37 & 38 & 24.9 & $\mathrm{~m}$ & m & $\mathrm{m}$ & 44 & 33 & 23.1 \\
\hline Inde & $\mathrm{m}$ & $\mathrm{m}$ & $\mathrm{m}$ & $\mathrm{m}$ & $\mathrm{m}$ & $\mathrm{m}$ & $\mathrm{m}$ & $\mathrm{m}$ & $\mathrm{m}$ & $\mathrm{m}$ & $\mathrm{m}$ & $\mathrm{m}$ \\
\hline Indonésie & $\mathrm{m}$ & $\mathrm{m}$ & $\mathrm{m}$ & $\mathrm{m}$ & $\mathrm{m}$ & $\mathrm{m}$ & $\mathrm{m}$ & $\mathrm{m}$ & $\mathrm{m}$ & $\mathrm{m}$ & $\mathrm{m}$ & $\mathrm{m}$ \\
\hline Fédération de Russie & $\mathrm{m}$ & $\mathrm{m}$ & $\mathrm{m}$ & 45 & 41 & 14.7 & $\mathrm{~m}$ & $\mathrm{~m}$ & $\mathrm{~m}$ & 38 & 50 & 12.2 \\
\hline Arabie saoudite & $\mathrm{m}$ & $\mathrm{m}$ & $\mathrm{m}$ & $\mathrm{m}$ & $\mathrm{m}$ & $\mathrm{m}$ & $\mathrm{m}$ & $\mathrm{m}$ & $\mathrm{m}$ & $\mathrm{m}$ & $\mathrm{m}$ & $\mathrm{m}$ \\
\hline Afrique du Sud & $\mathrm{m}$ & $\mathrm{m}$ & $\mathrm{m}$ & 31 & 20 & 48.6 & $\mathrm{~m}$ & $\mathrm{~m}$ & $\mathrm{~m}$ & 41 & 22 & 37.7 \\
\hline
\end{tabular}

\begin{tabular}{c|c|c|c|c|c|c|c|c|c|c|c|c|c|c|c|c|} 
Moyenne G20 & $m$ & $m$ & $m$ & $m$ & $m$ & $m$ & $m$ & $m$ & $m$ & $m$ & $m$
\end{tabular}

Remarque : Par NEET, on entend les jeunes sans emploi ne suivant ni études ni formation (de l'anglais neither employed nor in education or training). Voir les sections " Définitions » et « Méthodologie » pour de plus amples informations. Les données et d'autres types de ventilations peuvent être consultés sur http://stats.oecd.org/, Base de données de Regards sur l'éducation.

1. Année de référence : 2017 , et non 2018

2. Année de référence : 2005 , et non 2008.

Source : OCDE (2019) Consulter la section « Source » pour tout complément d'information et l'annexe 3 pour les notes (https://doi.org/10.1787/f8d7880d-en). Les symboles représentant les données manquantes et les abréviations figurent dans le Guide du lecteur. 
Tableau A2.3. Pourcentage de 18-24 ans scolarisés ou non, selon leur situation au regard de l'emploi et la durée de la période de chômage (2018)

\begin{tabular}{|c|c|c|c|c|c|c|}
\hline & \multirow[b]{3}{*}{ Scolarisés } & \multirow[b]{3}{*}{ Non scolarisés } & \multicolumn{4}{|c|}{ Non scolarisés } \\
\hline & & & \multirow[b]{2}{*}{ Chòmeurs } & \multicolumn{3}{|c|}{ Chōmeurs } \\
\hline & & & & Moins de 3 mois & $\begin{array}{l}\text { De } 3 \text { mois à moins } \\
\text { de } 12 \text { mois }\end{array}$ & 12 mois ou plus \\
\hline & (1) & (2) & (3) & (4) & (5) & (6) \\
\hline \multicolumn{7}{|l|}{ س Pays } \\
\hline Australie & 52 & 48 & 4.6 & $x(5)$ & $3.5^{\mathrm{d}}$ & 1.1 \\
\hline Autriche & 50 & 50 & 4.5 & 1.5 & 2.3 & 0.7 \\
\hline Belgique & 63 & 37 & 5.2 & 13 & 2.1 & 18 \\
\hline Canada & 49 & 51 & 5.1 & 32. & 1.4 & 0.3 \\
\hline Chili' & 50 & 50 & 6.6 & 5.2 & 12 & 02 \\
\hline Colombie & 30 & 70 & 10.6 & $x(5)$ & $9.9^{\circ}$ & 0.7 \\
\hline Rèpublique tchèque & m & $\mathrm{m}$ & $\mathrm{m}$ & $\mathrm{m}$ & m & $\mathrm{m}$ \\
\hline Danemark & 63 & 37 & 3.1 & 1.7 & 1.1 & 0.4 \\
\hline Estonie & 53 & 47 & 3.8 & 2.5 & 0.9 & 0.5 \\
\hline Finlande & 57 & 43 & 6.0 & 3.3 & 1.9 & 1.0 \\
\hline France & 53 & 47 & 10.4 & 3.0 & 4.6 & 2.9 \\
\hline Allemagne & 62 & 38 & 3.1 & 1.0 & 1.1 & 1.0 \\
\hline Grèce & 63 & 37 & 14.0 & 1.4 & 4.8 & 7.9 \\
\hline Hongrie & 50 & 50 & 4.2 & 1.5 & 1.9 & 0.8 \\
\hline Islande & 51 & 49 & 22 & $\mathrm{~m}$ & $\mathrm{~m}$ & $\mathrm{~m}$ \\
\hline Irlande & 56 & 44 & 5.0 & $x(5)$ & $3.5^{\mathrm{d}}$ & 1.4 \\
\hline Israël & 30 & 70 & 28 & 0.6 & 1.1 & 0.6 \\
\hline Italie & 53 & 47 & 11.5 & 1.7 & 3.6 & 5.9 \\
\hline Japon & $\mathrm{m}$ & $\mathrm{m}$ & $\mathrm{m}$ & $\mathrm{m}$ & $\mathrm{m}$ & $\mathrm{m}$ \\
\hline Corée & $\mathrm{m}$ & $\mathrm{m}$ & $\mathrm{m}$ & $\mathrm{m}$ & $\mathrm{m}$ & $\mathrm{m}$ \\
\hline Lettonie & 56 & 44 & 7.1 & 1.4 & 4.3 & 1.3 \\
\hline Lituanie & 63 & 37 & 5.4 & 2.4 & 2.1 & 1.0 \\
\hline Luxembourg & 63 & 37 & 3.4 & $\mathrm{~m}$ & $\mathrm{~m}$ & $\mathrm{~m}$ \\
\hline Mexique & 38 & 62 & 3.1 & 2.5 & 0.4 & 0.0 \\
\hline Pays-Bas & 65 & 35 & 1.6 & 0.7 & 0.5 & 0.2 \\
\hline Nouvelle-Zèlande & 41 & 59 & 4.9 & $x(5)$ & $4.5^{\circ}$ & 0.3 \\
\hline Norvège & 51 & 49 & 2.7 & 1.5 & 0.6 & 0.6 \\
\hline Pologne & 55 & 45 & 4.6 & 1.7 & 2.1 & 0.8 \\
\hline Portugal & 54 & 46 & 89 & $x(5)$ & $59^{\circ}$ & 30 \\
\hline République slovaque & 54 & 46 & 7.0 & 0.9 & 3.0 & 3.1 \\
\hline Slovénie & 67 & 33 & 4.5 & 1.7 & 1.5 & 13 \\
\hline Espagne & 59 & 41 & 120 & 4.0 & 4.6 & 3.4 \\
\hline Suède & 53 & 47 & 3.7 & 1.8 & 1.2 & c \\
\hline Suisse & 55 & 45 & 4.6 & $x(5)$ & $3.5^{d}$ & 1.1 \\
\hline Turquie & 40 & 60 & 7.6 & $x(5)$ & $6.6^{d}$ & 1.1 \\
\hline Royaume-Uni & 43 & 57 & 5.0 & 1.9 & 2.1 & 1.0 \\
\hline États-Unis & 47 & 53 & 3.9 & 2.6 & 1.0 & 0.3 \\
\hline Moyenne OCDE & 53 & 47 & 5.7 & 2.0 & 28 & 1.5 \\
\hline Moyenne UE23 & 57 & 43 & 6.1 & 1.9 & 26 & 1.5 \\
\hline Is Argentine & 47 & 53 & 8.8 & 3.3 & 2.5 & 3.0 \\
\hline Brèsil & 33 & 67 & 13.1 & 3.5 & 4.5 & 5.1 \\
\hline Shine & $\mathrm{m}$ & $\mathrm{m}$ & $\mathrm{m}$ & $\mathrm{m}$ & $\mathrm{m}$ & $\mathrm{m}$ \\
\hline Costa Rica & 44 & 56 & 11.5 & 8.2 & 2.4 & 0.9 \\
\hline Inde & $\mathrm{m}$ & $\mathrm{m}$ & $\mathrm{m}$ & $\mathrm{m}$ & m & $\mathrm{m}$ \\
\hline Indonésie & $\mathrm{m}$ & $\mathrm{m}$ & $\mathrm{m}$ & $\mathrm{m}$ & $\mathrm{m}$ & $\mathrm{m}$ \\
\hline Fédération de Russie & 54 & 46 & 5.6 & c & c & c \\
\hline Arabie saoudite & $\mathrm{m}$ & $\mathrm{m}$ & m & m & $\mathrm{m}$ & $m$ \\
\hline Afrique du Sud & 42 & 58 & 18.3 & m & m & m \\
\hline Moyenne G20 & $\mathrm{m}$ & $\mathrm{m}$ & m & $\mathrm{m}$ & m & m \\
\hline
\end{tabular}

Remarque : Les données sur la durée de la période de chômage ne correspondent pas nécessairement aux totaux des individus au chômage en raison de certaines données manquantes.

1. Année de référence : 2017.

Source : OCDE (2019) Consulter la section « Source » pour tout complément d'information et l'annexe 3 pour les notes (https://doi.org/10.1787/f8d7880d-en).

Les symboles représentant les données manquantes et les abréviations figurent dans le Guide du lecteur. 


\section{Indicateur A3. Dans quelle mesure le niveau de formation affecte-t-il le taux d'emploi ?}

\section{Faits marquants}

- Les taux d'emploi moyens des diplômés de l'enseignement tertiaire varient entre les pays de l'OCDE dans une mesure pouvant aller jusqu'à 7 points de pourcentage selon les domaines d'études, mais une forte variation s'observe parfois aussi dans les mêmes domaines d'études entre les pays.

- Les taux de chômage de longue durée diminuent sous l'effet de l'élévation du niveau de formation dans la plupart des pays de l'OCDE. Dans la plupart des pays, le pourcentage de chômeurs de longue durée, 12 mois au moins, est moins élevé chez les diplômés de l'enseignement tertiaire que chez les adultes dont le niveau de formation est inférieur.

- Dans la majorité des pays membres et partenaires de l'OCDE, les diplômés de l'enseignement tertiaire affichent des taux d'emploi supérieurs s'ils sont plus âgés que s'ils sont plus jeunes. En moyenne, dans les pays de l'OCDE, le taux d'emploi des 45-54 ans est supérieur de 4 points de pourcentage à celui des 25-34 ans, mais cette différence représente plus de 10 points de pourcentage dans certains pays.

Graphique A3.1. Taux d'emploi des adultes diplômés de l'enseignement tertiaire, selon le domaine d'études (2018)

Pourcentage d'actifs occupés âgés de 25 à 64 ans dans l'ensemble de la population âgée de 25 à 64 ans

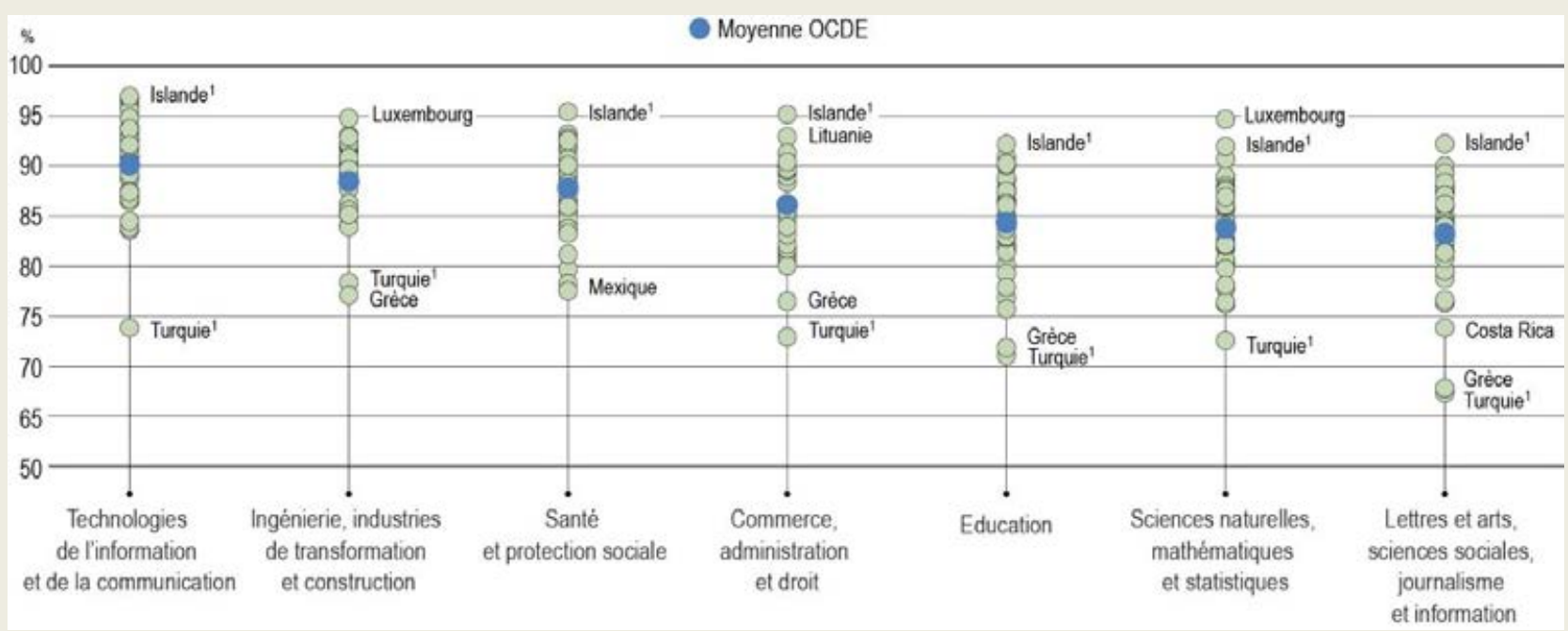

1. L'année de référence n'est pas 2018. Consulter le tableau source pour de plus amples informations.

Les domaines d'études sont classés par ordre décroissant des taux d'emploi pour la moyenne OCDE.

Source : OCDE (2019), tableau A3.4. Consulter la section «Source » pour tout complément d'information et l'annexe 3 pour les notes (https://doi.org/10.1787/f8d7880d-en). 


\section{Contexte}

Les économies des pays de l'OCDE sont tributaires d'une offre suffisante de travailleurs hautement qualifiés. La multiplication des possibilités de formation a accru la réserve de profils compétents dans l'ensemble des pays et les individus plus qualifiés sont plus susceptibles de trouver un emploi. À l'autre extrême, il reste des débouchés pour les individus moins qualifiés, mais leurs perspectives sont relativement moins prometteuses sur le marché du travail. Les individus les moins instruits gagnent moins bien leur vie (voir l'indicateur A4) et occupent souvent des emplois aux tâches routinières plus susceptibles d'être automatisées et, donc, sont exposés à un plus grand risque de chômage (Arntz, Gregory et Zierahn, 2016[1] $)$. Ces différences sur le marché du travail peuvent exacerber les inégalités dans la société.

Les systèmes d'éducation ont des défis à relever pour faire face à l'évolution des compétences demandées sur le marché du travail. Les adultes dont le niveau de formation est moins élevé tendent à être moins bien lotis sur le marché du travail, mais dans certains secteurs, la forte demande de profils qualifiés peut réduire les différences de taux d'emploi entre les niveaux de formation si les individus acquièrent les compétences pertinentes. Comme le progrès technologique a transformé les besoins du marché du travail mondial, les individus plus qualifiés, en particulier dans les technologies de l'information et de la communication (TIC), et ceux à l'aise en résolution de problèmes au moyen des TIC ont par exemple souvent les meilleurs débouchés sur le marché du travail. Dans certains cas, de bonnes compétences en TIC peuvent totalement compenser le handicap lié à des niveaux de formation inférieurs sur le marché du travail (Lane et Conlon, 2016[2]).

La comparaison des indicateurs relatifs au marché du travail entre les pays peut aider les gouvernements à mieux comprendre les tendances mondiales et à anticiper l'évolution possible des économies dans les prochaines années. Ces informations permettent de concevoir en meilleure connaissance de cause les politiques d'éducation, dont l'objectif est de faire en sorte que les étudiants d'aujourd'hui soient bien préparés au marché du travail de demain.

\section{Autres faits marquants}

- Les diplômés de l'enseignement tertiaire affichent des taux d'emploi plus élevés s'ils ont opté pour un master (ou formation équivalente) plutôt que pour une licence (ou formation équivalente). Dans l'ensemble, les taux d'emploi les plus élevés s'observent chez les titulaires d'un doctorat, mais ce constat général souffre quelques exceptions.

- Les taux d'inactivité varient fortement entre les pays et tendent à être supérieurs à la moyenne lorsque les taux d'emploi sont inférieurs à la moyenne.

- Dans les pays de l'OCDE, le taux d'emploi moyen des diplômés de l'enseignement tertiaire est le plus élevé après une formation en technologies de l'information et de la communication (TIC), mais le moins élevé après une formation en rapport avec les lettres et arts, les sciences sociales, le journalisme ou l'information.

- Dans la quasi-totalité des pays de l'OCDE, le taux de chômage est aussi peu élevé, voire moins élevé chez les diplômés de l'enseignement tertiaire que chez les diplômés du deuxième cycle de l'enseignement secondaire ou de l'enseignement post-secondaire non tertiaire. 


\section{Analyse}

\section{Niveau de formation et taux d'emploi}

Dans les pays de l'OCDE, le deuxième cycle de l'enseignement secondaire est généralement considéré comme le niveau de formation minimum pour réussir à entrer sur le marché du travail. Tous groupes d'âge confondus, les adultes qui ne sont pas diplômés de ce niveau d'enseignement sont pénalisés sur le marché du travail. En moyenne, dans les pays de l'OCDE, le taux d'emploi des adultes (âgés de 25 à 64 ans) est égal à $85 \%$ chez les diplômés de l'enseignement tertiaire et à $76 \%$ chez les diplômés du deuxième cycle de l'enseignement secondaire ou de l'enseignement post-secondaire non tertiaire, mais est égal à $59 \%$ chez ceux qui ne sont pas diplômés du deuxième cycle de l'enseignement secondaire (voir le tableau A3.1).

Dans tous les pays membres et partenaires de l'OCDE, les jeunes adultes (soit les adultes âgés de 25-34 ans) sont plus instruits que leurs aînés (voir l'indicateur A1). Les taux d'emploi des jeunes adultes sont comparables à ceux de l'effectif des 25-64 ans; en moyenne, dans les pays de l'OCDE, $84 \%$ des jeunes diplômés de l'enseignement tertiaire travaillent, comme $78 \%$ des jeunes diplômés du deuxième cycle de l'enseignement secondaire ou de l'enseignement post-secondaire non tertiaire, et $60 \%$ des jeunes adultes dont le niveau de formation est inférieur au deuxième cycle de l'enseignement secondaire (voir le tableau A3.2).

Chez les jeunes, les femmes sont en moyenne plus instruites que les hommes (voir l'indicateur A1), mais elles accusent des taux d'emploi inférieurs à tous les niveaux de formation. En moyenne, dans les pays de l'OCDE, le taux d'emploi des 25-34 ans dont le niveau de formation est inférieur au deuxième cycle de l'enseignement secondaire s'établit à $45 \%$ chez les femmes, mais à $72 \%$ chez les hommes. L'écart favorable aux hommes se réduit de 8 points de pourcentage chez les diplômés de l'enseignement tertiaire (voir le tableau A3.2).

Les taux d'emploi varient sensiblement par niveau de formation entre les pays. C'est en Lituanie et en Pologne que les diplômés de l'enseignement tertiaire l'emportent le plus largement sur les diplômés du deuxième cycle de l'enseignement secondaire ou de l'enseignement post-secondaire non tertiaire : la différence de taux d'emploi représente plus de 16 points de pourcentage. À l'inverse, la différence de taux d'emploi favorable aux diplômés de l'enseignement tertiaire par rapport aux diplômés du deuxième cycle de l'enseignement secondaire ou de l'enseignement post-secondaire non tertiaire représente au plus 5 points de pourcentage au Danemark, en Estonie, en Islande, en Nouvelle-Zélande, au Portugal, en République tchèque, au Royaume-Uni et en Suède (voir le tableau A3.1).

Des différences plus ténues de taux d'emploi entre les niveaux de formation s'observent dans certains pays, par exemple ceux en proie à des pénuries de main-d'œuvre ou ceux où le deuxième cycle de l'enseignement secondaire et l'enseignement post-secondaire non tertiaire font la part belle à la filière professionnelle. En Allemagne et en Suisse par exemple, une majorité des diplômés de la filière professionnelle ont suivi des programmes « emploi-études », qui facilitent la transition entre l'école et le monde du travail (OCDE, 2019 $9_{[3]}$ ).

\section{Niveau de formation et taux de chômage selon la durée des périodes de chômage}

Dans de nombreux pays membres et partenaires de l'OCDE, les taux de chômage sont particulièrement élevés chez les 25-34 ans. En moyenne, dans les pays de l'OCDE, le taux de chômage est deux fois plus élevé chez les jeunes dont le niveau de formation est inférieur au deuxième cycle de l'enseignement secondaire : $14 \%$, contre $7 \%$ chez les diplômés du deuxième cycle de l'enseignement secondaire ou de l'enseignement postsecondaire non tertiaire. Le taux de chômage des jeunes diplômés de l'enseignement tertiaire s'établit à $6 \%$ seulement (voir le tableau A3.3).

Les taux de chômage des jeunes dont le niveau de formation est inférieur au deuxième cycle de l'enseignement secondaire sont particulièrement élevés en Afrique du Sud et en République slovaque, deux pays où ils sont supérieurs à $35 \%$. Ils sont très élevés aussi en Espagne, en France, en Grèce et en Italie, où $25 \%$ environ de ces jeunes sont sans-emploi (voir le tableau A3.3). 
L'impact positif du deuxième cycle de l'enseignement secondaire et de l'enseignement post-secondaire non tertiaire est particulièrement important en Allemagne, en Australie, en Autriche, en Hongrie, en République slovaque, en République tchèque et en Suède. Dans tous ces pays, le taux de chômage des jeunes diplômés du deuxième cycle de l'enseignement secondaire ou de l'enseignement post-secondaire non tertiaire représente au plus un tiers de celui des jeunes dont le niveau de formation est inférieur au deuxième cycle de l'enseignement secondaire (voir le tableau A3.3).

Graphique A3.2. Pourcentage de chômeurs de longue durée âgés de 25 à 64 ans, selon le niveau de formation (2018)

Adultes ayant connu une période de chômage d'au moins 12 mois, en pourcentage des chômeurs âgés de 25 à 64 ans

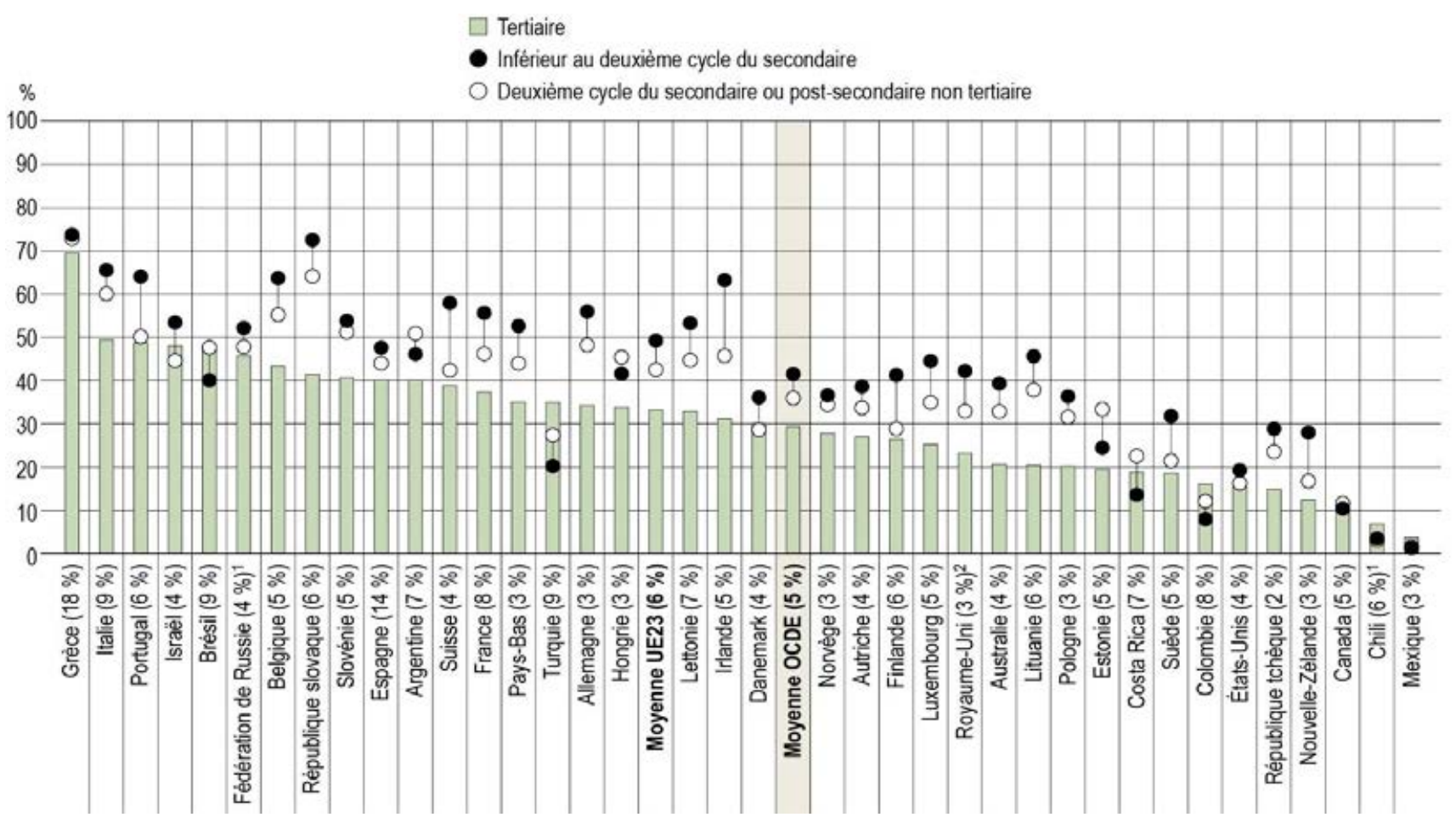

Remarque : Le pourcentage entre parenthèses représente le taux de chômage de l'ensemble des 25-64 ans.

1. Les données concernant les diplômés du deuxième cycle du secondaire incluent la réussite d'un volume et d'un niveau suffisant de programmes qui seraient classés individuellement dans la catégorie réussite d'une formation intermédiaire du deuxième cycle du secondaire (13\% des adultes âgés de 25 à 64 ans se classent dans cette catégorie).

2. L'année de référence n'est pas 2018. Consulter le tableau source pour de plus amples informations.

Les pays sont classés par ordre décroissant du pourcentage d'adultes âgés de 25 à 64 ans diplômés de l'enseignement tertiaire ayant connu une période de chômage d'au moins 12 mois.

Source: OCDE (2019), tableau A3.5. Consulter la section «Source» pour tout complément d'information et l'annexe 3 pour les notes (https://doi.org/10.1787/f8d7880d-en).

StatLink 겦ㄴ https://doi.org/10.1787/888933976764

L'élévation du niveau de formation tend à réduire la durée des périodes de chômage. En moyenne, dans les pays de l'OCDE, 29 \% des diplômés de l'enseignement tertiaire ont été au chômage pendant au moins 12 mois, contre $36 \%$ des diplômés du deuxième cycle de l'enseignement secondaire ou de l'enseignement postsecondaire non tertiaire, et $41 \%$ des adultes dont le niveau de formation est inférieur au deuxième cycle de l'enseignement secondaire. Le chômage de longue durée touche moins les diplômés de l'enseignement tertiaire que ceux dont le niveau de formation est inférieur dans tous les pays membres et partenaires de l'OCDE dont 
les données sont disponibles, sauf au Brésil, au Canada, au Chili, en Colombie, au Costa Rica, au Danemark, en Israël, au Mexique et en Turquie (voir le graphique A3.2 et le tableau A3.5).

Le pourcentage de chômeurs de longue durée (12 mois au moins) n'est supérieur à $40 \%$ que dans 9 pays chez les diplômés de l'enseignement tertiaire, mais l'est dans 18 pays chez les diplômés du deuxième cycle de l'enseignement secondaire et dans 22 pays chez les adultes dont le niveau de formation est inférieur au deuxième cycle de l'enseignement secondaire. Les taux de chômage de longue durée associés au niveau de formation inférieur au deuxième cycle de l'enseignement secondaire sont particulièrement élevés en Belgique, en Grèce, en Irlande, en Italie, au Portugal et en République slovaque, où ils atteignent au moins $60 \%$. Toutefois, le taux de chômage de longue durée à ce niveau de formation représente plus du double de celui des diplômés de l'enseignement tertiaire en Irlande, alors que la différence de taux avec les diplômés de l'enseignement tertiaire est inférieure à 5 points de pourcentage en Grèce (voir le graphique A3.2).

\section{Niveau de formation et inactivité}

Dans les pays de l'OCDE, le pourcentage d'inactifs (soit les sans-emploi qui ne cherchent pas de travail activement) tend à être plus élevé parmi les individus peu instruits. En moyenne, dans les pays de l'OCDE, $30 \%$ des 25-34 ans dont le niveau de formation est inférieur au deuxième cycle de l'enseignement secondaire sont inactifs, contre $16 \%$ des diplômés du deuxième cycle de l'enseignement secondaire ou de l'enseignement post-secondaire non tertiaire et $11 \%$ des diplômés de l'enseignement tertiaire selon les chiffres de 2018 (voir le tableau A3.3).

\section{Graphique A3.3. Taux d'emploi et d'inactivité des diplômés de l'enseignement tertiaire âgés de 25 à} 34 ans (2018)

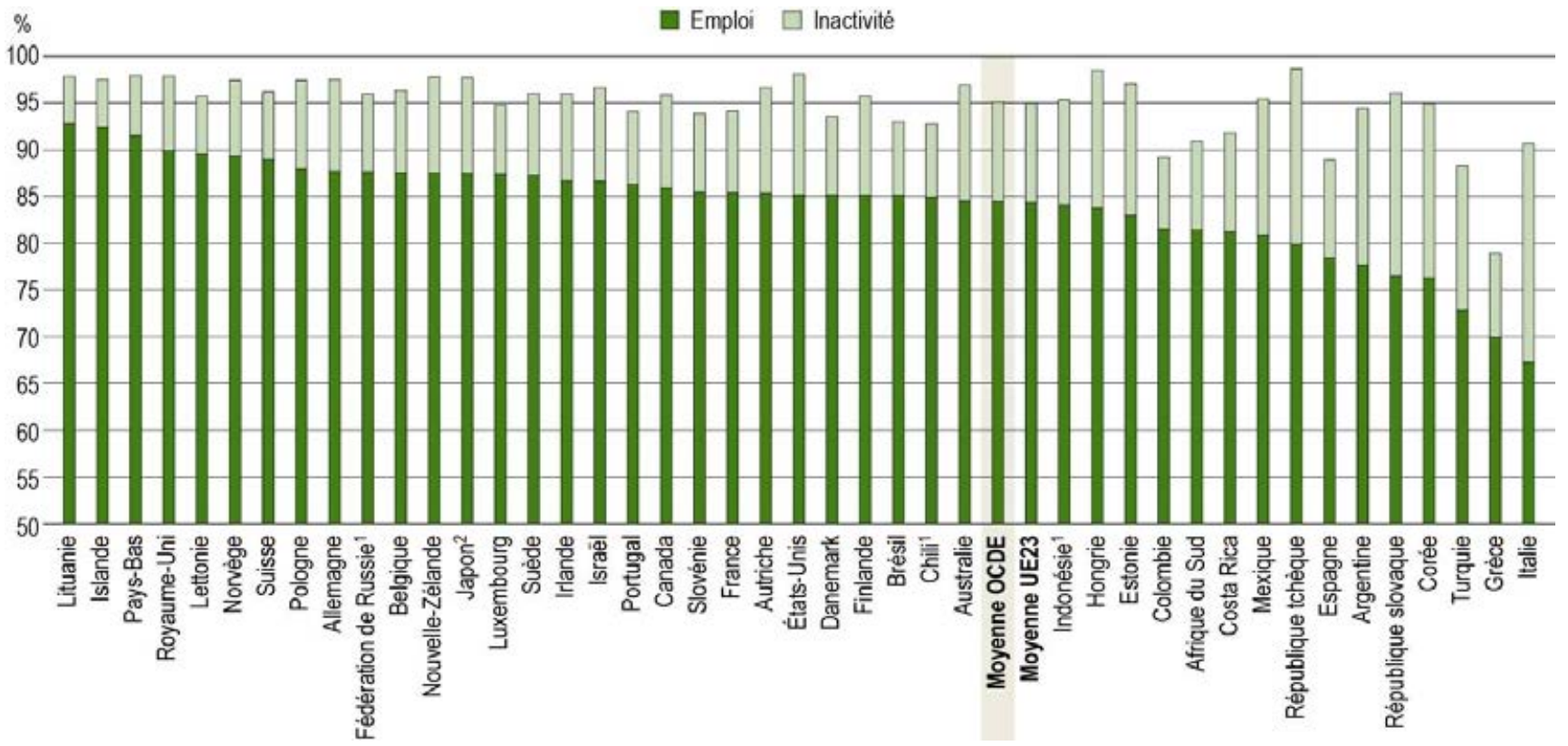

1. L'année de référence n'est pas 2018. Consulter le tableau source pour de plus amples informations.

2. Les données de l'enseignement tertiaire comprennent les programmes du deuxième cycle de l'enseignement secondaire et de l'enseignement postsecondaire non tertiaire (moins de $5 \%$ d'adultes sont dans ce cas).

Les pays sont classés par ordre décroissant du taux d'emploi des diplômés de l'enseignement tertiaire âgés de 25 à 34 ans.

Source: OCDE (2019), tableau A3.3. Consulter la section «Source» pour tout complément d'information et l'annexe 3 pour les notes (https://doi.org/10.1787/f8d7880d-en). 
Les taux d'inactivité des jeunes diplômés de l'enseignement tertiaire sont particulièrement élevés en Italie, où ils sont supérieurs à $20 \%$. Par contraste, les diplômés de l'enseignement tertiaire affichent les taux d'emploi les plus élevés et les taux d'inactivité les moins élevés dans certains pays. Chez les 25-34 ans diplômés de l'enseignement tertiaire, les taux d'emploi sont supérieurs à $90 \%$ et les taux d'inactivité inférieurs ou égaux à $6 \%$ en Islande, en Lituanie et aux Pays-Bas (voir le graphique A3.3).

Les taux d'inactivité sont systématiquement plus élevés chez les femmes que chez les hommes à tous les niveaux de formation, mais ils sont particulièrement élevés chez celles dont le niveau de formation est inférieur au deuxième cycle de l'enseignement secondaire. En moyenne, dans les pays de l'OCDE, près de la moitié (46 \%) des jeunes femmes qui ne sont pas diplômées du deuxième cycle de l'enseignement secondaire sont inactives, contre moins d'un cinquième des jeunes hommes (18\%). La différence de taux d'inactivité entre les jeunes femmes et les jeunes hommes est la plus importante au Mexique (56 \%, contre $5 \%$ ) et en Turquie (69 \%, contre $6 \%)$. Le Portugal est le seul pays où l'écart entre les sexes est presque comblé : le taux d'inactivité des jeunes adultes moins instruits s'établit à $17 \%$ chez les femmes et à $9 \%$ chez les hommes. Au Portugal, l'écart entre les sexes chez les individus les plus instruits est l'un des plus ténus parmi les pays de l'OCDE (OCDE, $\left.2019_{[3]}\right)$.

\section{Graphique A3.4. Taux d'emploi des adultes diplômés de l'enseignement tertiaire, selon l'âge (2018)}

25-34 ans et 45-54 ans

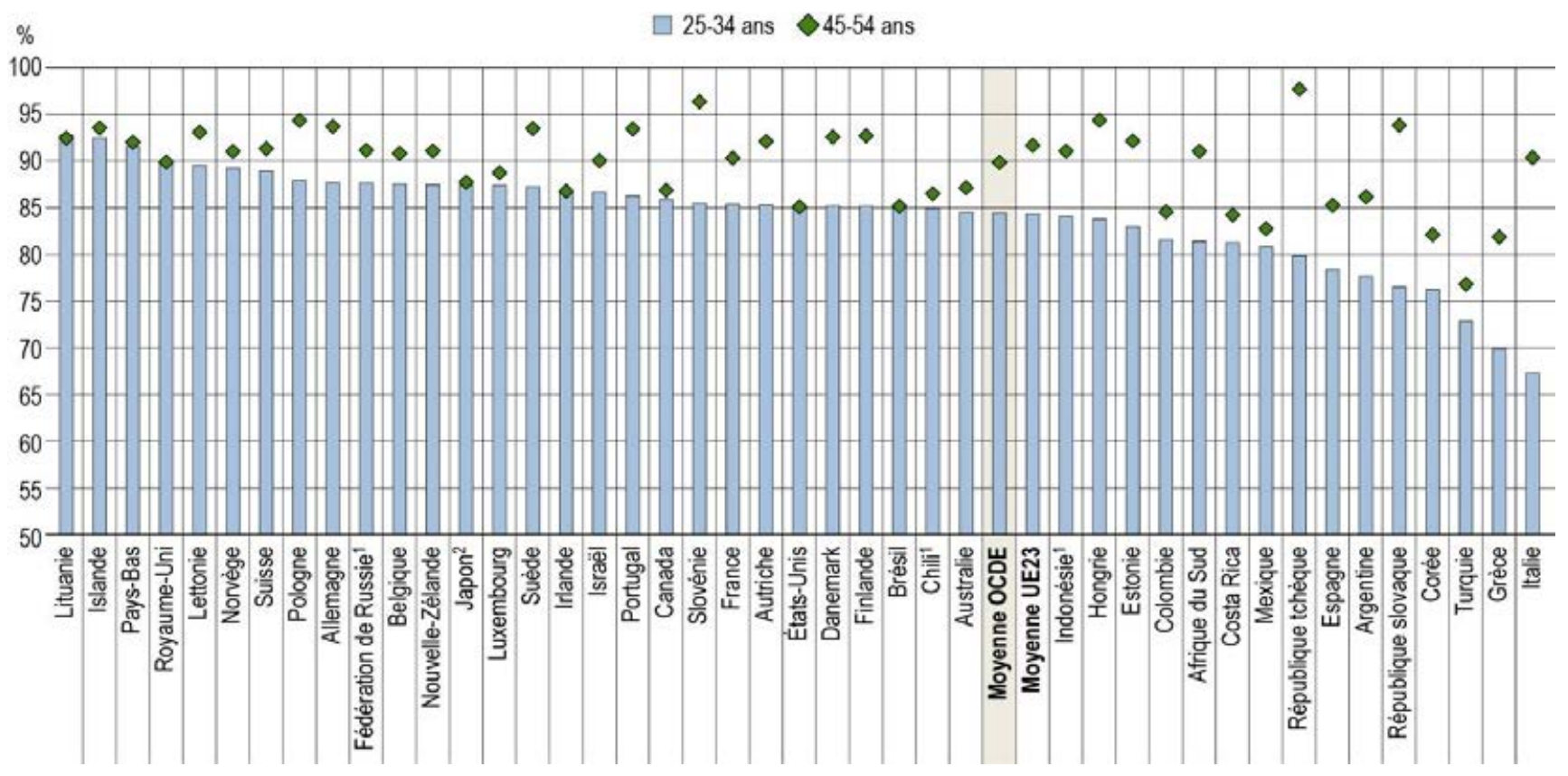

1. L'année de référence n'est pas 2018. Consulter le tableau source pour de plus amples informations.

2. Les données de l'enseignement tertiaire comprennent les programmes du deuxième cycle de l'enseignement secondaire et de l'enseignement postsecondaire non tertiaire (moins de $5 \%$ d'adultes sont dans ce cas).

Les pays sont classés par ordre décroissant du taux d'emploi des diplômés de l'enseignement tertiaire âgés de 25 à 34 ans.

Source : OCDE (2019), tableau A3.3 et Base de données de Regards sur l'éducation, http://stats.OCDE.org/. Consulter la section « Source » pour tout complément d'information et l'annexe 3 pour les notes (https://doi.org/10.1787/f8d7880d-en). 


\section{Taux d'emploi selon le groupe d'âge}

En moyenne, dans les pays de l'OCDE, un diplôme de l'enseignement tertiaire accroît le taux d'emploi des jeunes de 25 points de pourcentage environ, par rapport à ceux qui ne sont pas diplômés du deuxième cycle de l'enseignement secondaire. Toutefois, dans la majorité des pays de l'OCDE, le taux d'emploi des diplômés de l'enseignement tertiaire est moins élevé chez les 25-34 ans que chez les 45-54 ans. Cette différence peut indiquer que les jeunes diplômés ont moins de débouchés sur le marché du travail dans certains pays, mais qu'ils sont nombreux à être encore scolarisés dans d'autres pays (voir l'indicateur A2). La différence de taux d'emploi favorable aux aînés (les 45-54 ans) représente 6 points de pourcentage en moyenne, dans les pays de I'OCDE. Le taux d'emploi des jeunes est toutefois inférieur de plus de 10 points de pourcentage à celui de leurs aînés en Grèce, en Italie, en République slovaque, en République tchèque et en Slovénie (voir le graphique A3.4 et le tableau A3.2).

Les taux d'emploi ne varient guère, voire pas du tout (moins de 1 point de pourcentage) entre les 25-34 ans et les 45-54 ans dans huit pays, à savoir le Brésil, le Canada, les États-Unis, le Japon, l'Irlande, la Lituanie, les Pays-Bas et le Royaume-Uni. Dans tous les autres pays, la différence de taux d'emploi entre les groupes d'âge est favorable aux 45-54 ans (voir le graphique A3.4).

\section{Taux d'emploi selon le niveau de l'enseignement tertiaire}

Le taux d'emploi continue généralement à augmenter avec les niveaux de l'enseignement tertiaire. En moyenne, dans les pays de l'OCDE, le taux d'emploi des diplômés de l'enseignement tertiaire s'établit à $82 \%$ après une formation de cycle court et atteint $84 \%$ après une licence (ou formation équivalente), $88 \%$ après un master (ou formation équivalente) et $92 \%$ après un doctorat (ou formation équivalente) (voir le tableau A3.1).

Dans la plupart des pays, les taux d'emploi des diplômés de l'enseignement tertiaire sont moins élevés à l'issue d'une formation tertiaire de cycle court qu'à l'issue d'une licence (ou formation équivalente). Certains pays font toutefois figure d'exception, notamment ceux où les formations tertiaires de cycle court sont particulièrement prisées. En Autriche par exemple, les taux d'emploi des diplômés de l'enseignement tertiaire sont relativement élevés après une formation de cycle court [ $87 \%$, contre $79 \%$ après une licence (ou formation équivalente)] et l'effectif de 25-34 ans diplômés à l'issue d'une formation de cycle court s'établit à $15 \%$ (voir l'indicateur A1). À l'inverse, en Pologne, les jeunes diplômés de l'enseignement tertiaire à l'issue d'une formation de cycle court sont extrêmement peu nombreux et peinent à trouver du travail par comparaison avec les jeunes diplômés d'un niveau supérieur de l'enseignement tertiaire et même avec les jeunes diplômés du deuxième cycle de l'enseignement secondaire ou de l'enseignement post-secondaire non tertiaire (voir le tableau A3.1).

Les jeunes les plus diplômés, c'est-à-dire ceux qui ont fait un master ou un doctorat (ou formation équivalente), ont généralement les meilleures perspectives professionnelles. Dans la plupart des pays dont les données sont disponibles, les 25-34 ans diplômés à l'issue d'un master (ou formation équivalente) affichent des taux d'emploi au moins aussi élevés que ceux diplômés à l'issue d'une licence (ou formation équivalente). Le master (ou formation équivalente) procure un avantage considérable sur le marché du travail dans certains pays. Cet avantage atteint au moins 10 points de pourcentage en Argentine, au Chili, au Luxembourg, en République slovaque et en Turquie. Les jeunes titulaires d'un doctorat se distinguent également par de belles perspectives sur le marché du travail : leurs taux d'emploi sont égaux ou supérieurs à $90 \%$ dans 16 des 26 pays dont les données sont disponibles (voir le graphique A3.5).

Le doctorat requiert un investissement important de la part tant des doctorants que des gouvernements et est la voie royale vers un poste dans la recherche académique. Les doctorants tendent aussi à se spécialiser davantage dans de nombreux domaines d'études scientifiques et technologiques très demandés sur le marché du travail (voir l'indicateur B7). Leur évolution sur le marché du travail une fois diplômés suscite de plus en plus l'intérêt des responsables politiques. De nouvelles sources de données au sujet des titulaires d'un doctorat permettent d'analyser leur situation de manière plus détaillée que sur la seule base des taux d'emploi (voir l'encadré A3.1). 
Graphique A3.5. Taux d'emploi des jeunes diplômés de l'enseignement tertiaire, selon le niveau de l'enseignement tertiaire (2018)

25-34 ans

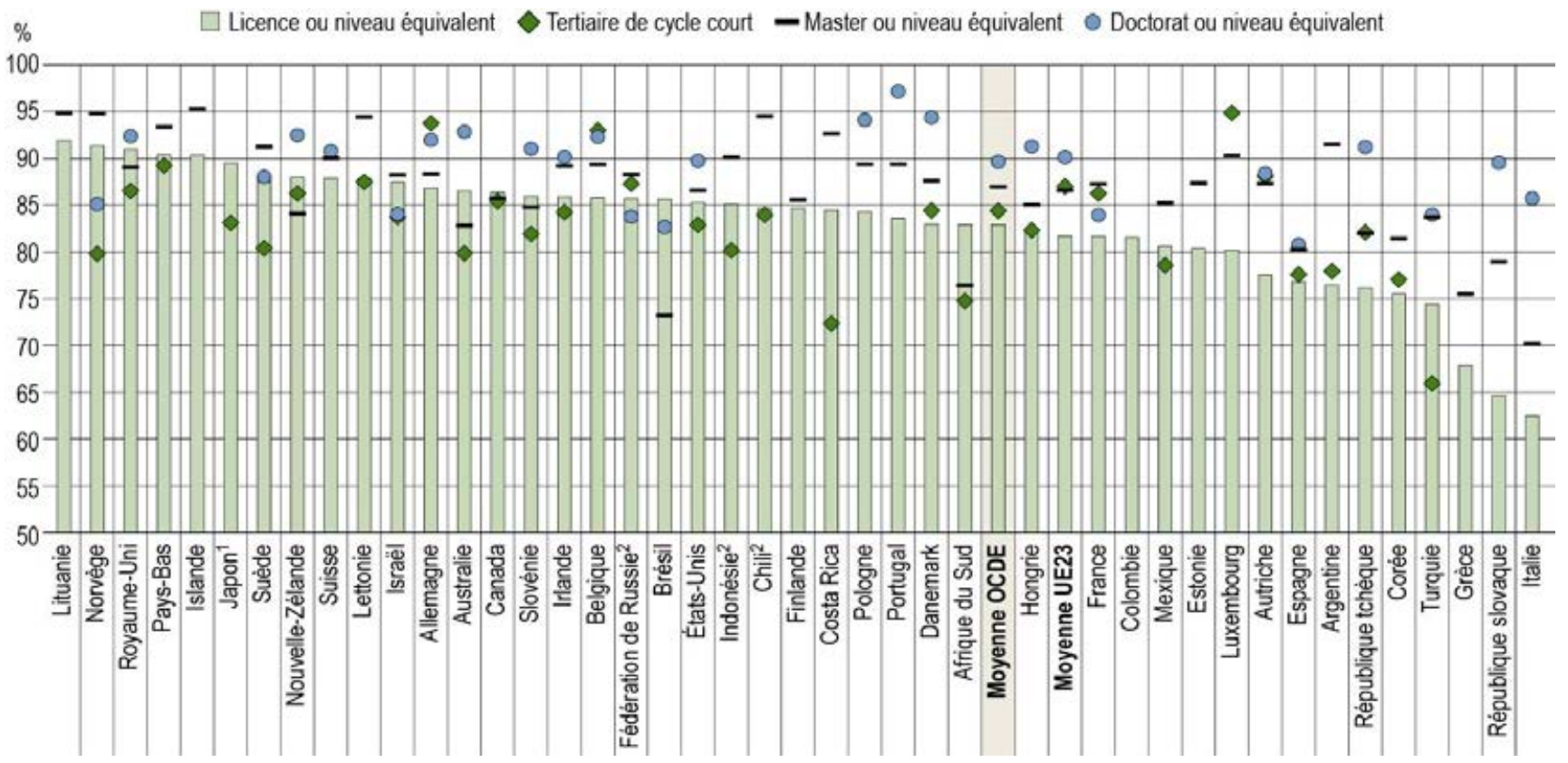

1. Les données de l'enseignement tertiaire comprennent les programmes du deuxième cycle de l'enseignement secondaire et de l'enseignement postsecondaire non tertiaire (moins de $5 \%$ d'adultes sont dans ce cas).

2. L'année de référence n'est pas 2018. Consulter le tableau A3.1 pour de plus amples informations.

Les pays sont classés par ordre décroissant du taux d'emploi des jeunes adultes titulaires d'une licence ou d'un diplôme équivalent.

Source : OCDE (2019), base de données de Regards sur l'éducation, http://stats.oecd.org. Consulter la section "Source » pour tout complément d'information et l'annexe 3 pour les notes (https://doi.org/10.1787/f8d7880d-en).

StatLink 제요 https://doi.org/10.1787/888933976821

\section{Variation du taux de chômage selon le domaine d'études}

Dans les pays de l'OCDE, les diplômés de l'enseignement tertiaire affichent les taux d'emploi les plus élevés, mais ceux-ci varient considérablement selon les domaines d'études. En moyenne, dans les pays de l'OCDE, le taux d'emploi des diplômés de l'enseignement tertiaire (les 25-64 ans) varie entre $83 \%$ après une formation en rapport avec les lettres et arts, les sciences sociales, le journalisme et l'information et $90 \%$ après une formation en TIC (voir le graphique A3.1 et le tableau A3.4).

Chez les diplômés de l'enseignement tertiaire, les différences les plus importantes de taux d'emploi entre les domaines d'études s'observent au Costa Rica, en Estonie, en Fédération de Russie, en Grèce, en Italie et en République slovaque, où elles représentent au moins 15 points de pourcentage. Les différences sont nettement plus ténues entre les domaines d'études dans d'autres pays. En Australie, en Islande et aux Pays-Bas par exemple, des pays où le taux d'emploi est relativement élevé dans l'ensemble, les différences de taux d'emploi entre les domaines d'études ne représentent pas plus de 5 points de pourcentage (voir le tableau A3.4).

Les taux d'emploi des diplômés à l'issue d'une formation tertiaire en rapport avec l'éducation, la santé ou la protection sociale varient sensiblement aussi entre les pays. Les débouchés sur le marché du travail, les perspectives salariales et la perception du rôle des enseignants dans la société sont quelques-uns des facteurs dont les jeunes peuvent tenir compte lorsqu'ils choisissent leur domaine d'études (voir l'indicateur B4). Les taux d'emploi des diplômés à l'issue d'une formation tertiaire dans le domaine de l'éducation sont égaux ou supérieurs 
à $90 \%$ au Danemark, en Islande, en Lettonie, en Lituanie et en Suède. Les diplômés en médecine ou en dentisterie sont aussi promis à un bel avenir professionnel dans de nombreux pays. Les taux d'emploi sont plus élevés dans ce domaine d'études que dans tout autre au Chili, au Danemark et en Lituanie (voir le tableau A3.4).

\section{Encadré A3.1. Profil et activités professionnelles des titulaires d'un doctorat}

Les débouchés sur le marché du travail varient après un doctorat. Les diplômés de ce niveau d'enseignement peuvent s'orienter vers une carrière académique, mais sont aussi demandés dans l'industrie et d'autres secteurs d'activité. II apparaît que de nombreux doctorants fraîchement émoulus ne parviennent pas à trouver d'emploi stable dans le monde académique; la précarisation accrue des postes d'enseignants et de chercheurs dans l'enseignement supérieur pourrait les inciter à renoncer au monde académique pour se tourner vers d'autres secteurs (voir l'indicateur B7 et OCDE (2019[4])).

\section{Graphique A3.a. Pourcentage de titulaires d'un doctorat travaillant dans le secteur de l'éducation (2016)}

En pourcentage de l'ensemble des titulaires d'un doctorat

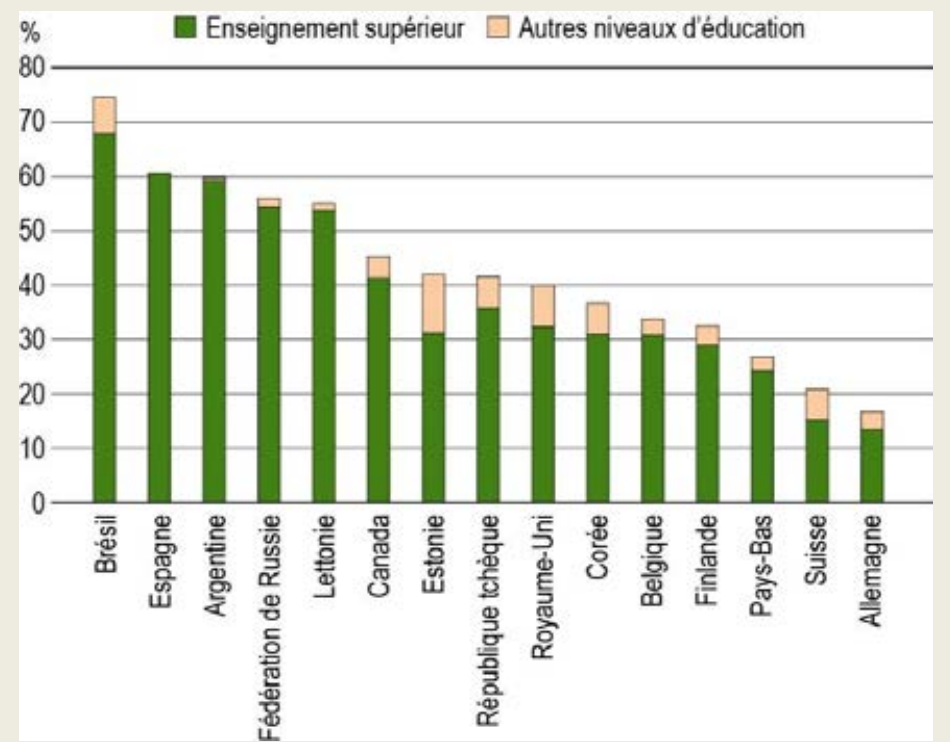

Source: Enquête de l'OCDE sur les carrières des titulaires de doctorat (2017), https://www.oecd.org/innovation/inno/careers-of-doctorateholders.htm.

StatLink त्ता जी https://doi.org/10.1787/888933976859

II peut être difficile de compiler des données comparatives sur les titulaires d'un doctorat en raison des échantillons réduits ; les diplômés de ce niveau ne représentent en moyenne que $1 \%$ environ de la population dans les pays de l'OCDE (voir l'indicateur A1). Toutefois, comme l'effectif de diplômés de ce niveau d'enseignement augmente dans la population, il est désormais possible de décrire leur profil et leur évolution en tant que groupe distinct. L'OCDE a entamé en 2011 une collecte de données sur la carrière des titulaires d'un doctorat pour enrichir les informations sur le profil et l'évolution de la carrière de ce groupe spécifique de la population. Cette collecte de données a lieu tous les deux ans dans des pays membres et partenaires de I'OCDE. Les résultats proviennent d'une série de collectes nationales de données, dont des enquêtes sur les titulaires d'un doctorat, des enquêtes auprès de la population active et des registres de la population (OCDE, 2018[5]). 
Les résultats de la collecte de données de 2017 sur la carrière des titulaires d'un doctorat révèlent certaines des différences dans le profil et la situation professionnelle de ces diplômés entre les 15 pays membres et partenaires de l'OCDE dont les données sont disponibles et comparables. Le graphique A3.a indique le pourcentage de titulaires d'un doctorat en poste dans le secteur de l'éducation dans les pays de l'OCDE. Le pourcentage de titulaires d'un doctorat en poste dans l'enseignement supérieur est de l'ordre de $15 \%$ seulement en Allemagne et en Suisse. Ce pourcentage peut être le signe d'un manque de débouchés pour les docteurs dans le monde académique ou de conditions de travail plus attractives dans d'autres secteurs. Par contraste, au Brésil, près de $70 \%$ des docteurs travaillent dans l'enseignement supérieur.

En outre, chez les titulaires d'un doctorat, le pourcentage de travailleurs indépendants varie fortement parmi les pays membres et partenaires de l'OCDE dont les données sont disponibles. Ce pourcentage est faible dans certains pays, comme en Fédération de Russie et au Portugal, où il est inférieur à $5 \%$. À l'autre extrême, le pourcentage de travailleurs indépendants est supérieur à $25 \%$ en Allemagne (voir le graphique A3.b).

\section{Graphique A3.b. Pourcentage de travailleurs indépendants dans l'effectif de titulaires d'un doctorat, selon le sexe (2016)}

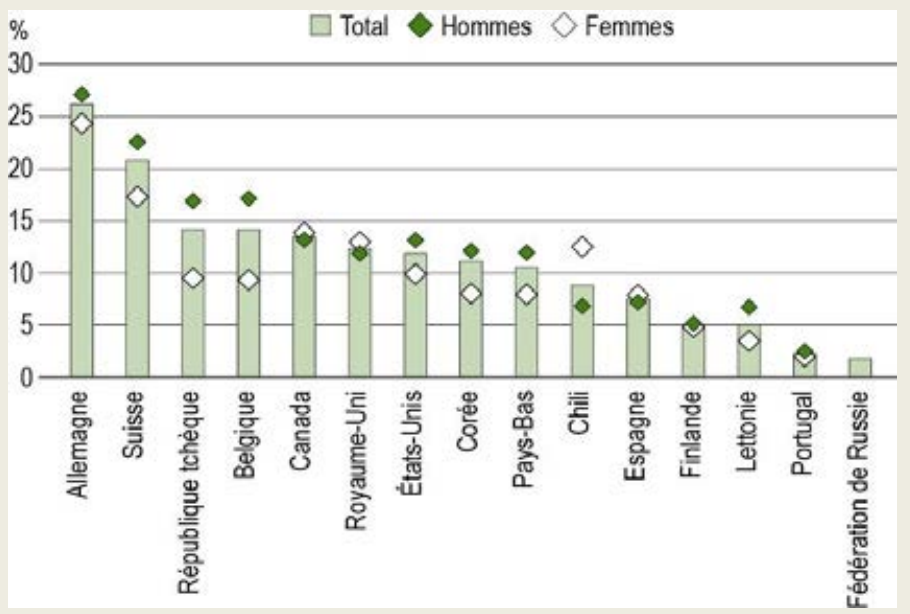

Source: Enquête de I'OCDE sur les carrières des titulaires de doctorat (2017), https://www.oecd.org/innovation/inno/careers-of-doctorateholders.htm.

Le pourcentage de travailleurs indépendants dans l'effectif de titulaires d'un doctorat est plus élevé chez les hommes que chez les femmes dans la plupart des pays, mais il ne varie guère entre les sexes au Canada, en Finlande en Espagne, au Portugal et au Royaume-Uni, et est supérieur chez les femmes au Chili (voir le graphique A3.b).

Par ailleurs, de nombreux pays réussissent moins bien à réunir les conditions propres à attirer des titulaires d'un doctorat de l'étranger ou à retenir les doctorants étrangers après l'obtention de leur diplôme. Ce constat indique que ces diplômés forment un groupe qui tend à être plus mobile et plus désireux d'aller à l'étranger pour suivre leur formation et trouver des débouchés sur le marché du travail. Le pourcentage de ressortissants étrangers dans l'effectif de titulaires d'un doctorat est de l'ordre de $40 \%$ en Norvège et en Suisse, mais est égal ou inférieur à $5 \%$ en Argentine, en Finlande, en Lettonie, au Portugal et en République tchèque (voir le graphique A3.c et l'indicateur B7). 


\section{Graphique A3.c. Pourcentage de titulaires d'un doctorat nés à l'étranger ou ressortissants étrangers (2016)}

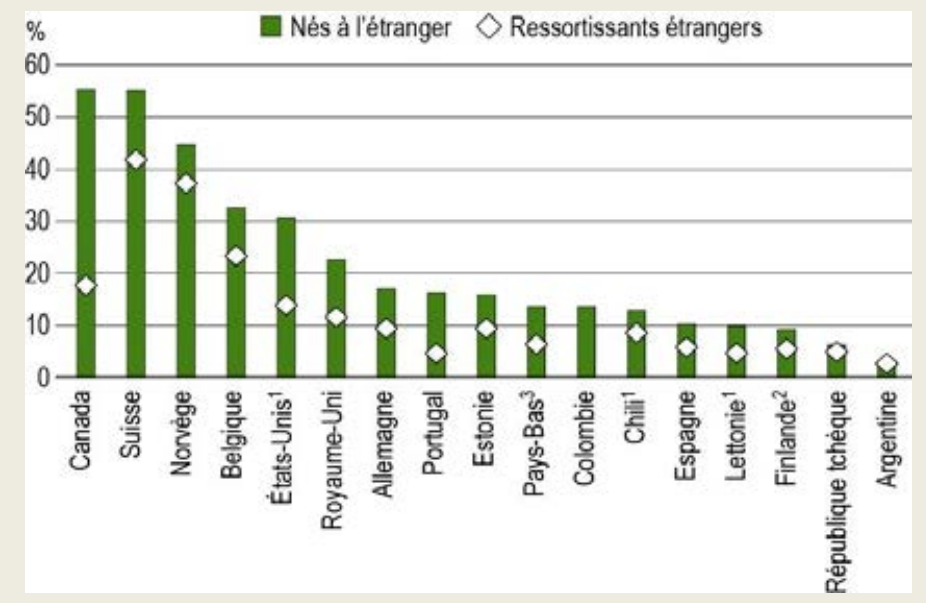

1. Les données se rapportent à 2015 .

2. Les données se rapportent à 2014 .

3. Les données se rapportent à 2013.

Source: Enquête de I'OCDE sur les carrières des titulaires de doctorat (2017), https://www.oecd.org/innovation/inno/careers-of-doctorateholders.htm.

StatLink त्ञात https://doi.org/10.1787/888933976897

\section{Variation infranationale de la situation au regard de l'emploi, selon le niveau de formation}

En moyenne, dans les pays membres et partenaires de l'OCDE dont les données infranationales sur la situation au regard de l'emploi sont disponibles, les taux d'emploi varient davantage entre les régions chez les moins instruits. Aux États-Unis par exemple, le taux d'emploi varie entre les États de $30 \%$ à $70 \%$ chez les adultes qui ne sont pas diplômés du deuxième cycle de l'enseignement secondaire, mais de $77 \%$ à $90 \%$ chez les diplômés de l'enseignement tertiaire. II en va de même en Italie, où le taux d'emploi des adultes dont le niveau de formation est inférieur au deuxième cycle de l'enseignement secondaire passe du simple à plus du double entre les régions, de $35 \%$ à $74 \%$, tandis que celui des diplômés de l'enseignement tertiaire ne varie pas de plus de 25 points de pourcentage environ entre les régions (de $64 \%$ à $89 \%$ ) (OCDE, 2019[6]).

Dans de nombreux pays, les taux d'emploi des diplômés de l'enseignement tertiaire varient très peu entre les régions. Ils varient de moins de $5 \%$ entre les régions en Hongrie, en Irlande, en Lettonie, aux Pays-Bas, au Portugal, en Slovénie et en Suède. Ils varient davantage entre les régions dans d'autres pays. La différence la plus importante s'observe en Estonie, où le taux d'emploi des diplômés de l'enseignement tertiaire varie de près de 35 points de pourcentage entre les régions (de $57 \%$ à $92 \%$ ). Les autres pays où le taux d'emploi des diplômés de l'enseignement varie sensiblement entre les régions sont le Canada, le Chili, la Colombie, la Fédération de Russie, l'Espagne, les États-Unis, la Grèce, Israël, l'Italie et la Turquie. Dans tous ces pays, la différence de taux d'emploi entre la région la mieux lotie et la région la plus mal lotie représente au moins 10 points de pourcentage (voir le graphique A3.6 et (OCDE, 2019[6])).

Les diplômés de l'enseignement tertiaire tendent à afficher des taux d'emploi supérieurs à la moyenne dans la région de la capitale. En Colombie par exemple, leur taux d'emploi s'établit à $86 \%$ dans la région de la capitale, contre $83 \%$ en moyenne dans le pays. Dans d'autres pays, le taux d'emploi de la région de la capitale ne s'écarte guère de la moyenne nationale. Toutefois, la région de la capitale n'est bien souvent pas la région où le taux d'emploi des diplômés de l'enseignement tertiaire est le plus élevé dans les pays de l'OCDE. Au Chili par 
exemple, la région de la capitale affiche un taux d'emploi supérieur à la moyenne nationale, mais se classe au troisième rang seulement des régions du pays (voir le graphique A3.6 et (2019[6])).

\section{Graphique A3.6. Variation infranationale du taux d'emploi des diplômés de l'enseignement tertiaire, par entité infranationale (2018)}

Pourcentage d'actifs occupés âgés de 25 à 64 ans dans l'ensemble de la population âgée de 25 à 64 ans

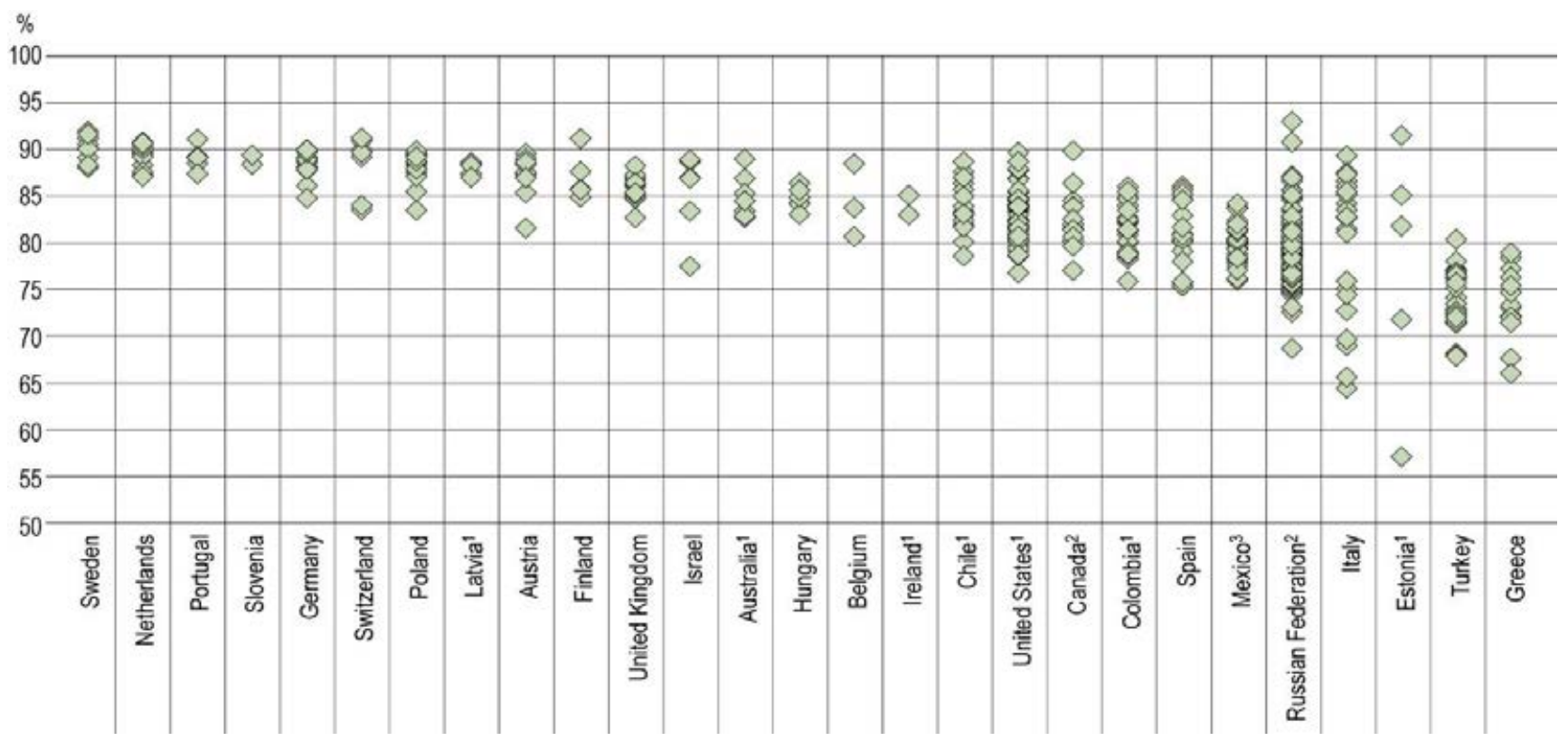

1. Année de référence : 2017.

2. Année de référence : 2016.

3. Année de référence : 2015.

Les pays sont classés par ordre décroissant du taux national d'emploi des adultes diplômés de l'enseignement tertiaire (moyenne non pondérée des régions).

Source : Collecte de données infranationales OCDE INES/CFE. Consulter la section « Source » pour tout complément d'information et l'annexe 3 pour les notes (https://doi.org/10.1787/f8d7880d-en).

StatLink 제프 https://doi.org/10.1787/888933976840

\section{Définitions}

Par population active (main-d'œuvre), on entend le nombre total d'actifs occupés et au chômage, conformément à la définition de l'Enquête sur les forces de travail.

Groupes d'âge : le terme "adultes » désigne la population âgée de 25 à 64 ans ; l'expression " jeunes (adultes) ", la population âgée de 25 à 34 ans ; et l'expression " (adultes) plus âgés ", la population âgée de 55 à 64 ans.

Le niveau de formation correspond au plus haut niveau d'enseignement dont les individus sont diplômés.

Les actifs occupés sont les individus qui, durant la semaine de référence, ont effectué un travail d'une durée d'une heure au moins moyennant un salaire ou un bénéfice ou avaient un emploi, mais étaient temporairement absents de leur travail. Le taux d'emploi correspond au pourcentage d'actifs occupés dans la population en âge de travailler. 
Les domaines d'études sont dérivés des domaines d'études et de formation de la CITE 2013 (CITE-F 2013). La liste de tous les domaines d'études cités dans ce rapport figure dans le Guide du lecteur.

Par inactifs, on entend les individus qui n'étaient ni occupés, ni au chômage (qui n'étaient pas à la recherche d'un emploi) durant la semaine de référence. Le taux d'inactivité correspond au pourcentage d'individus inactifs dans la population en âge de travailler (le nombre d'inactifs est divisé par le nombre total d'individus en âge de travailler).

Niveaux de formation : les niveaux de la CITE 2011 sont tous décrits dans le Guide du lecteur, au début du présent rapport.

Par chômeurs, on entend les individus qui, durant la semaine de référence, n'ont pas travaillé et ont activement cherché un emploi et étaient disponibles pour commencer à travailler. Le taux de chômage correspond au pourcentage de chômeurs dans la population active (c'est-à-dire le nombre de chômeurs divisé par la somme des actifs occupés et des chômeurs).

Par population en âge de travailler, on entend les individus âgés de 25 à 64 ans.

\section{Méthodologie}

Voir l'indicateur A1 pour des informations sur la méthodologie.

Voir le Guide de l'OCDE pour l'établissement de statistiques internationalement comparables dans le domaine de l'éducation 2018 (OCDE, 2019[7]) pour de plus amples informations. Voir les notes spécifiques aux pays à l'annexe 3 (https://doi.org/10.1787/f8d7880d-en).

\section{Source}

Voir l'indicateur A1 pour des informations sur les sources.

Les données infranationales de certains indicateurs sont disponibles dans la Base de données régionales de I'OCDE (OCDE, 2019[8]).

\section{Remarque concernant les données fournies par Israël}

Les données statistiques concernant Israël sont fournies par et sous la responsabilité des autorités israéliennes compétentes. L'utilisation de ces données par l'OCDE est sans préjudice du statut des hauteurs du Golan, de Jérusalem-Est et des colonies de peuplement israéliennes en Cisjordanie aux termes du droit international.

\section{Références}

Arntz, M., T. Gregory et U. Zierahn (2016), « The risk of automation for jobs in OECD countries: A comparative analysis ", Documents de travail de l'OCDE sur les questions sociales, l'emploi et les migrations, $\mathrm{n}^{\circ}$ 189, Éditions OCDE, Paris, http://dx.doi.org/10.1787/5j|z9h56dvq7-en.

Lane, M. et G. Conlon (2016), « The impact of literacy, numeracy and computer skills on earnings and employment outcomes ", Documents de travail de l'OCDE sur l'éducation, n 129, Éditions OCDE, Paris, http://dx.doi.org/10.1787/5jm2cv4t4gzs-en. 
OCDE (2019), Base de données de Regards sur l'éducation - Niveau de formation et situation au regard de l'emploi, http://stats.oecd.org/Index.aspx?datasetcode=EAG NEAC.

OCDE (2019), Base de données de statistiques régionales - Niveau d'éducation par groupe d'âge, http://stats.oecd.org/Index.aspx?datasetcode=REGION EDUCAT.

OCDE (2019), Base de données de statistiques régionales - Taux d'emploi par niveau d'éducation et groupe d'âge, http://stats.oecd.org/lndex.aspx?datasetcode=REGION EDUCAT.

OCDE (2019), Benchmarking Higher Education System Performance, Éditions OCDE, Paris, https://doi.org/10.1787/be5514d7-en.

OCDE (2019), Guide de l'OCDE pour l'établissement de statistiques internationalement comparables dans le domaine de l'éducation 2018 : Concepts, normes, définitions et classifications, Éditions OCDE, Paris, https://dx.doi.org/10.1787/9789264305380-fr.

OCDE (2018), Science, technologie et industrie : Tableau de bord de l'OCDE 2017: La transformation numérique, Éditions OCDE, Paris, https://dx.doi.org/10.1787/sti scoreboard-2017-fr.

\section{Tableaux de l'indicateur A3}

Tableau A3.1

Tableau A3.2

Tableau A3.3

Tableau A3.4

Tableau A3.5
Taux d'emploi des adultes âgés de 25 à 64 ans, selon le niveau de formation (2018) Évolution des taux d'emploi des adultes âgés de 25 à 34 ans, selon le niveau de formation et le sexe (2008 et 2018)

Taux d'emploi, de chômage et d'inactivité des adultes âgés de 25 à 34 ans, selon le niveau de formation (2018)

Taux d'emploi des adultes diplômés de l'enseignement tertiaire, selon le domaine d'études (2018)

Taux de chômage des adultes âgés de 25 à 64 ans, selon la durée de la période de chômage et le niveau de formation (2018)

Date butoir pour les données : 19 juillet 2019. Les mises à jour peuvent être consultées en ligne à l'adresse : http://dx.doi.org/10.1787/eag-data-en. D'autres données désagrégées sont également disponibles dans la Base de données de Regards sur l'éducation (http://stats.oecd.org/).

StatLink : https://doi.org/10.1787/888933980830 
Tableau A3.1. Taux d'emploi des adultes âgés de 25 al 64 ans, selon le niveau de formation (2018)

Pourcentage d'actifs occupés âgés de 25 à 64 ans dans l'ensemble de la population âgée de 25 à 64 ans

\begin{tabular}{|c|c|c|c|c|c|c|c|c|c|c|}
\hline & \multirow{2}{*}{$\begin{array}{l}\text { Inférieur } \\
\text { au deuxième } \\
\text { cycle du } \\
\text { secondaire }\end{array}$} & \multicolumn{3}{|c|}{$\begin{array}{l}\text { Deuxième cycle du secondaire } \\
\text { ou post-secondaire non tertiaire }\end{array}$} & \multicolumn{5}{|c|}{ Tertiaire } & \multirow[b]{2}{*}{$\begin{array}{l}\text { Tous niveaux } \\
\text { de formation } \\
\text { confondus }\end{array}$} \\
\hline & & $\begin{array}{l}\text { Deuxième } \\
\text { cycle du } \\
\text { secondaire }\end{array}$ & $\begin{array}{c}\text { Post- } \\
\text { secondaire } \\
\text { non tertiaire }\end{array}$ & Total & $\begin{array}{c}\text { Tertiaire } \\
\text { de cycle court }\end{array}$ & $\begin{array}{l}\text { Licence } \\
\text { ou niveau } \\
\text { equivalent }\end{array}$ & $\begin{array}{c}\text { Master } \\
\text { ou niveau } \\
\text { equivalent }\end{array}$ & $\begin{array}{l}\text { Doctorat } \\
\text { ou niveau } \\
\text { equivalent }\end{array}$ & Total & \\
\hline & (i) & (2) & (3) & (4) & (5) & (6) & (7) & (8) & (9) & (10) \\
\hline \multicolumn{11}{|l|}{ س Pays } \\
\hline Ô Australie & 60 & 77 & 81 & 77 & 81 & 85 & 86 & 89 & 84 & 77 \\
\hline Autriche & 55 & 77 & 83 & 78 & 87 & 79 & 88 & 90 & 86 & 77 \\
\hline Belgique & 46 & 74 & 86 & 74 & 84 & 85 & 87 & 90 & 86 & 73 \\
\hline Canada & 56 & 72 & 80 & 74 & 81 & 84 & $85^{\circ}$ & $x(7)$ & 83 & 78 \\
\hline Chili' & 62 & 72 & a & 72 & 81 & 85 & $93^{\circ}$ & $\times(\pi)$ & 84 & 72 \\
\hline Colombie & 71 & $75^{d}$ & $x(2)$ & 75 & $x(6)$ & $82^{\circ}$ & $x(6)$ & $x(6)$ & 82 & 75 \\
\hline République tchèque & 52 & $84^{\circ}$ & $x(2)$ & 84 & 89 & 83 & 88 & 93 & 87 & 83 \\
\hline Danemark & 65 & 83 & 93 & 83 & 87 & 86 & 90 & 96 & 88 & 82 \\
\hline Estonie & 65 & 80 & 79 & 80 & 80 & 84 & 87 & 91 & 85 & 80 \\
\hline Finlande & 55 & 75 & 97 & 76 & 84 & 86 & 88 & 97 & 87 & 78 \\
\hline France & 53 & 74 & 64 & 73 & 83 & 83 & 88 & 91 & 85 & 73 \\
\hline Allemagne & 61 & 81 & 87 & 82 & 90 & 89 & 89 & 93 & 89 & 81 \\
\hline Grèce & 50 & 60 & 63 & 61 & 67 & 73 & 82 & 90 & 74 & 62 \\
\hline Hongrie & 57 & 77 & 84 & 78 & 83 & 84 & 87 & 96 & 86 & 77 \\
\hline Islande & 77 & 86 & 93 & 87 & 89 & 90 & 95 & 96 & 92 & 87 \\
\hline Irlande & 52 & 71 & 77 & 74 & 80 & 85 & 88 & 91 & 85 & 75 \\
\hline Israël & 52 & 74 & a & 74 & 84 & 87 & 90 & 93 & 87 & 78 \\
\hline Italie & 53 & 71 & 75 & 71 & c & 73 & 83 & 93 & 81 & 66 \\
\hline Japon $^{2}$ & $x(2)$ & $81^{\circ}$ & $x(5)$ & $\mathrm{m}$ & $81^{\circ}$ & $88^{\circ}$ & $x(6)$ & $x(6)$ & 85 & 83 \\
\hline Corèe & 65 & 72 & a & 72 & 77 & 77 & $85^{\circ}$ & $x(7)$ & 78 & 74 \\
\hline Lettonie & 62 & 75 & 76 & 75 & 90 & 88 & 90 & 95 & 89 & 78 \\
\hline Lituanie & 55 & 74 & 77 & 75 & a & 90 & 92 & 99 & 91 & 80 \\
\hline Luxembourg & 62 & 75 & 75 & 75 & 80 & 81 & 89 & 92 & 86 & 77 \\
\hline Mexique & 65 & 71 & a & 71 & 72 & 79 & 84 & 91 & 80 & 69 \\
\hline Pays-Bas & 63 & 81 & 88 & 81 & 88 & 89 & 91 & 96 & 90 & 81 \\
\hline Nouvelle-Zélande & 72 & 82 & 87 & 83 & 88 & 88 & 88 & 92 & 88 & 83 \\
\hline Norvège & 61 & 80 & 88 & 81 & 82 & 91 & 94 & 91 & 89 & 81 \\
\hline Pologne & 43 & 70 & 73 & 70 & 67 & 86 & 90 & 96 & 89 & 74 \\
\hline Portugal & 70 & 84 & 86 & 84 & c & 82 & 90 & 94 & 88 & 78 \\
\hline République slovaque & 38 & 77 & 83 & 77 & 81 & 76 & 83 & 86 & 83 & 75 \\
\hline Slovénie & 51 & 76 & a & 76 & 84 & 90 & 89 & 93 & 89 & 77 \\
\hline Espagne & 57 & 71 & 81 & 71 & 80 & 80 & 84 & 89 & 82 & 70 \\
\hline Suede & 67 & 87 & 84 & 87 & 85 & 91 & 92 & 93 & 90 & 85 \\
\hline Suisse & 69 & $82^{\circ}$ & $x(2)$ & 82 & $x(6,7,8)$ & $88^{\circ}$ & $88^{\circ}$ & $92^{\circ}$ & 89 & 83 \\
\hline Turquie & 52 & 63 & a & 63 & 66 & 76 & 85 & 92 & 74 & 59 \\
\hline Royaume-Uni' & 66 & 83 & a & 81 & 83 & 87 & 87 & 90 & 86 & 80 \\
\hline Etats-Unis & 57 & $70^{4}$ & $x(2)$ & 70 & 78 & 82 & 85 & 88 & 82 & 75 \\
\hline Moyenne OCDE & 59 & 76 & 82 & 76 & 82 & 84 & 88 & 92 & 85 & 77 \\
\hline Moyenne UE23 & 56 & 76 & 80 & 77 & 82 & 84 & 88 & 93 & 86 & 77 \\
\hline Argentine & 64 & 74 & $a$ & 74 & 79 & $82^{\circ}$ & 94 & $x(6)$ & 81 & 73 \\
\hline$\frac{2}{\pi}$ Brésil & 59 & 72 & a & 72 & $x(6)$ & $82^{\circ}$ & 84 & 91 & 83 & 68 \\
\hline Shine & $\mathrm{m}$ & $\mathrm{m}$ & $\mathrm{m}$ & $\mathrm{m}$ & $\mathrm{m}$ & $\mathrm{m}$ & $\mathrm{m}$ & $\mathrm{m}$ & $\mathrm{m}$ & $\mathrm{m}$ \\
\hline Costa Rica & 65 & 70 & c & 70 & 73 & 83 & 86 & c & 81 & 70 \\
\hline Inde & $\mathrm{m}$ & $\mathrm{m}$ & $\mathrm{m}$ & $\mathrm{m}$ & $\mathrm{m}$ & $\mathrm{m}$ & $\mathrm{m}$ & $\mathrm{m}$ & $\mathrm{m}$ & $\mathrm{m}$ \\
\hline Indonésié' & 73 & $74^{\circ}$ & $x(2)$ & 74 & 78 & 87 & 94 & 98 & 85 & 75 \\
\hline Fédération de Russie' & 54 & 68 & 77 & 73 & 78 & 88 & 86 & 89 & 83 & $\pi 7$ \\
\hline Arabie saoudite 4 & 62 & 61 & 82 & 65 & c & $74^{\circ}$ & c & c & 74 & 66 \\
\hline Afrique du Sud & 44 & 55 & 75 & 57 & 80 & 85 & $88^{\circ}$ & $x(6)$ & 85 & 56 \\
\hline Moyenne G20 & $\mathrm{m}$ & $\mathrm{m}$ & $\mathrm{m}$ & $\mathrm{m}$ & $\mathrm{m}$ & $\mathrm{m}$ & $\mathrm{m}$ & $\mathrm{m}$ & $\mathrm{m}$ & $\mathrm{m}$ \\
\hline
\end{tabular}

Remarque : Dans la plupart des pays, les données se rapportent à la classification CITE 2011. Pour l'Arabie saoudite et l'Indonésie, elles se rapportent à la classification CITE 97. Pour de plus amples informations, consulter les sections « Définitions » et « Méthodologie ». Les données et d'autres types de ventilations peuvent être consultés sur http://stats.oecd.org/, Base de données de Regards sur l'éducation.

1. Année de référence : 2017.

2. Les données relatives au niveau de formation tertiaire incluent les programmes du deuxième cycle du secondaire et de l'enseignement post-secondaire non tertiaire (moins de $5 \%$ de la population adulte se classent dans cette catégorie).

3. Les données concemant les diplômés du deuxième cycle du secondaire incluent la réussite d'un volume et d'un niveau suffisant de programmes qui seraient classés individuellement dans la catégorie réussite d'une formation intermédiaire du deuxième cycle du secondaire ( $13 \%$ des adultes âgés de 25 à 64 ans se classent dans cette catégorie) .

4. Année de référence : 2016

Source : OCDE / OIT (2019). Consulter la section « Source » pour tout complément d'information et l'annexe 3 pour les notes (https://doi.org/10.1787/f8d7880d-en). Les symboles représentant les données manquantes et les abréviations figurent dans le Guide du lecteur. 
Tableau A3.2. Évolution des taux d'emploi des adultes âgés de 25 å 34 ans, selon le niveau de formation et le sexe (2008 et 2018) Pourcentage d'actifs occupés âgés de 25 à 34 ans dans l'ensemble de la population âgée de 25 à 34 ans

\begin{tabular}{|c|c|c|c|c|c|c|c|c|c|c|c|c|c|c|c|c|c|c|}
\hline & \multicolumn{6}{|c|}{ Inférieur au deuxième cycle du secondaire } & \multicolumn{6}{|c|}{$\begin{array}{l}\text { Deuxiẻme cycle du secondaire } \\
\text { ou post-secondaire non tertiaire }\end{array}$} & \multicolumn{6}{|c|}{ Tertiaire } \\
\hline & \multicolumn{2}{|c|}{ Hommes } & \multicolumn{2}{|c|}{ Femmes } & \multicolumn{2}{|c|}{ Total } & \multicolumn{2}{|c|}{ Hommes } & \multicolumn{2}{|c|}{ Femmes } & \multicolumn{2}{|c|}{ Total } & \multicolumn{2}{|c|}{ Hommes } & \multicolumn{2}{|c|}{ Femmes } & \multicolumn{2}{|c|}{ Total } \\
\hline & 2008 & 2018 & 2008 & 2018 & 2008 & 2018 & 2008 & 2018 & 2008 & 2018 & 2008 & 2018 & 2008 & 2018 & 2008 & 2018 & 2008 & 2018 \\
\hline & (1) & (2) & (3) & (4) & (5) & (6) & (I) & (8) & (9) & (10) & (11) & (12) & (13) & (14) & (15) & (16) & (17) & (18) \\
\hline шаys & & & & & & & & & & & & & & & & & & \\
\hline Australie & $81^{\circ}$ & 69 & $46^{\circ}$ & 43 & $64^{\circ}$ & 57 & $92^{\circ}$ & 86 & $69^{\circ}$ & 69 & $82^{\circ}$ & 79 & $94^{\circ}$ & 91 & $80^{\circ}$ & 80 & $86^{\circ}$ & 85 \\
\hline Autriche & 74 & 67 & 50 & 49 & 61 & 58 & 90 & 88 & 77 & 81 & 84 & 85 & 91 & 89 & 85 & 82 & 88 & 85 \\
\hline Belgique & $71^{\circ}$ & 62 & $43^{\circ}$ & 35 & $59^{\circ}$ & 50 & $90^{\circ}$ & 84 & $74^{\circ}$ & 71 & $83^{\circ}$ & 78 & $92^{\circ}$ & 89 & $90^{\circ}$ & 87 & $91^{\circ}$ & 88 \\
\hline Canada & 68 & 70 & 49 & 40 & 61 & 58 & 86 & 84 & 72 & 70 & 80 & 78 & 89 & 89 & 82 & 84 & 85 & 86 \\
\hline Chili' & $\mathrm{m}$ & 77 & $\mathrm{~m}$ & 48 & $\mathrm{~m}$ & 64 & $\mathrm{~m}$ & 80 & m & 59 & m & 69 & $\mathrm{~m}$ & 88 & $\mathrm{~m}$ & 83 & m & 85 \\
\hline Colombie & $\mathrm{m}$ & 90 & m & 49 & $\mathrm{~m}$ & 72 & $\mathrm{~m}$ & 88 & m & 61 & m & 75 & $\mathrm{~m}$ & 89 & m & 76 & $\mathrm{~m}$ & 82 \\
\hline République tchèque & $62^{\circ}$ & 69 & $38^{\circ}$ & 36 & $50^{\circ}$ & 52 & $93^{\circ}$ & 95 & $62^{\mathrm{b}}$ & 65 & $79^{\circ}$ & 82 & $91^{\circ}$ & 94 & $69^{\circ}$ & 70 & $79^{\circ}$ & 80 \\
\hline Danemark & $81^{\circ}$ & 67 & $69^{\circ}$ & 49 & $75^{\circ}$ & 63 & $92^{\circ}$ & 84 & $82^{b}$ & 73 & $88^{\circ}$ & 81 & $91^{\circ}$ & 88 & $89^{\circ}$ & 82 & $90^{\circ}$ & 85 \\
\hline Estonic & 79 & 84 & 59 & 57 & 71 & 75 & 94 & 91 & 72 & 67 & 84 & 81 & 96 & 94 & 71 & 75 & 82 & 83 \\
\hline Finlande & 75 & 63 & 58 & 30 & 69 & 49 & 86 & 82 & 70 & 69 & 79 & 76 & 95 & 92 & 82 & 81 & 87 & 85 \\
\hline France & 77 & 64 & 46 & 37 & 62 & 51 & 89 & 83 & 73 & 68 & 82 & 76 & 92 & 88 & 86 & 84 & 89 & 85 \\
\hline Allemagne & $70^{b}$ & 68 & $41^{\mathrm{b}}$ & 45 & $55^{\circ}$ & 57 & $83^{b}$ & 87 & $72^{b}$ & 80 & $78^{\circ}$ & 84 & $93^{b}$ & 91 & $83^{b}$ & 84 & $88^{b}$ & 88 \\
\hline Gréce & $89^{\circ}$ & 71 & $43^{\circ}$ & 31 & $71^{\circ}$ & 54 & $87^{\circ}$ & 71 & $63^{\circ}$ & 50 & $75^{\circ}$ & 62 & $84^{\circ}$ & 79 & $78^{\circ}$ & 64 & $80^{\circ}$ & 70 \\
\hline Hongrie & 60 & 75 & 32 & 39 & 47 & 57 & 86 & 91 & 61 & 67 & 75 & 81 & 93 & 94 & 75 & 76 & 82 & 84 \\
\hline Islande & 91 & 82 & 74 & 75 & 84 & 80 & 88 & 89 & 76 & 78 & 83 & 84 & 95 & 93 & 88 & 92 & 91 & 92 \\
\hline Irlande & $67^{\circ}$ & 63 & $43^{\circ}$ & 34 & $57^{\circ}$ & 50 & $87^{\circ}$ & 83 & $70^{\circ}$ & 76 & $79^{\circ}$ & 75 & $91^{\circ}$ & 89 & $85^{\circ}$ & 85 & $88^{\circ}$ & 87 \\
\hline |sraë| & $63^{\circ}$ & 74 & $22^{\circ}$ & 44 & $47^{\circ}$ & 62 & $75^{\circ}$ & 74 & $60^{\circ}$ & 66 & $68^{\circ}$ & 71 & $87^{\circ}$ & 90 & $82^{\circ}$ & 84 & $84^{\circ}$ & 87 \\
\hline Italie & $79^{\circ}$ & 66 & $42^{b}$ & 35 & $63^{2}$ & 53 & $83^{\circ}$ & 72 & $64^{\circ}$ & 53 & $74^{\circ}$ & 63 & $76^{b}$ & 70 & $69^{\circ}$ & 66 & $72^{\circ}$ & 67 \\
\hline Japon $^{2}$ & $m$ & $\mathrm{~m}$ & $\mathrm{~m}$ & $\mathrm{~m}$ & $\mathrm{~m}$ & $\mathrm{~m}$ & $x(13)$ & $x(14)$ & $x(15)$ & $x(16)$ & $x(17)$ & $x(18)$ & $92^{\circ b}$ & $94^{\circ}$ & $690=$ & $81^{\circ}$ & $80^{40}$ & $87^{\circ}$ \\
\hline Corée & $72^{\circ}$ & 76 & $48^{\circ}$ & 55 & $63^{2}$ & 65 & $74^{\circ}$ & 71 & $50^{\mathrm{b}}$ & 54 & $63^{5}$ & 65 & $84^{b}$ & 82 & $65^{\circ}$ & 71 & $74^{\circ}$ & 76 \\
\hline Lettonie & 74 & 69 & 52 & 54 & 66 & 64 & 88 & 85 & 72 & 67 & 81 & 78 & 93 & 92 & 85 & 88 & 88 & 90 \\
\hline Lituanie & $59^{\circ}$ & 63 & $58^{\mathrm{b}}$ & 27 & $59^{\circ}$ & 50 & $81^{\circ}$ & 86 & $71^{\mathrm{b}}$ & 71 & $76^{\circ}$ & 80 & $94^{\circ}$ & 95 & $86^{\circ}$ & 91 & $90^{\circ}$ & 93 \\
\hline Luxembourg & $88^{\circ}$ & 81 & $59^{\circ}$ & 55 & $75^{\circ}$ & 67 & $85^{\circ}$ & 85 & $71^{\circ}$ & 83 & $78^{\circ}$ & 84 & $87^{\circ}$ & 89 & $83^{\circ}$ & 86 & $85^{\circ}$ & 87 \\
\hline Mexique & 92 & 92 & 40 & 42 & 64 & 66 & 89 & 89 & 56 & 55 & 71 & 71 & 90 & 88 & 78 & 75 & 83 & 81 \\
\hline Pays-Bas & $87^{\circ}$ & 76 & $60^{\circ}$ & 50 & $75^{\circ}$ & 65 & $95^{\circ}$ & 89 & $85^{\circ}$ & 80 & $90^{\circ}$ & 85 & $97^{\circ}$ & 93 & $92^{\circ}$ & 91 & $94^{\circ}$ & 92 \\
\hline Nouvelle-Zélande & 79 & 80 & 56 & 57 & 68 & 70 & 91 & 91 & 69 & 71 & 81 & 82 & 92 & 93 & 77 & 83 & 83 & 87 \\
\hline Norvège & 75 & 67 & 62 & 55 & 70 & 62 & 92 & 87 & 84 & 75 & 89 & 82 & 89 & 89 & 90 & 89 & 89 & 89 \\
\hline Pologne & $65^{\circ}$ & 59 & $41^{\mathrm{b}}$ & 28 & $55^{\circ}$ & 48 & $87^{\circ}$ & 90 & $64^{\circ}$ & 60 & $76^{\circ}$ & 78 & $92^{\circ}$ & 94 & $84^{\circ}$ & 84 & $88^{\circ}$ & 88 \\
\hline Portugal & 88 & 84 & 72 & 74 & 81 & 80 & 81 & 85 & 79 & 83 & 80 & 84 & 90 & 86 & 84 & 87 & 87 & 86 \\
\hline République slovaque & $34^{\circ}$ & 43 & $25^{\circ}$ & 26 & $30^{\circ}$ & 35 & $89^{\circ}$ & 91 & $65^{\circ}$ & 66 & $78^{\circ}$ & 80 & $93^{\circ}$ & 91 & $74^{b}$ & 67 & $82^{\circ}$ & 77 \\
\hline Slovènie & $78^{\circ}$ & 74 & $56^{b}$ & 31 & $70^{\circ}$ & 61 & $90^{\circ}$ & 88 & $83^{\circ}$ & 79 & $87^{\circ}$ & 85 & $94^{b}$ & 91 & $89^{\circ}$ & 82 & $91^{\circ}$ & 85 \\
\hline Espagne & 77 & 72 & 58 & 52 & 69 & 63 & 84 & 73 & 73 & 65 & 78 & 69 & 87 & 81 & 81 & 76 & 84 & 78 \\
\hline Suède & $76^{6}$ & 74 & $52^{b}$ & 55 & $65^{\circ}$ & 66 & $89^{b}$ & 88 & $79^{b}$ & 81 & $84^{\circ}$ & 85 & $90^{b}$ & 89 & $86^{b}$ & 86 & $88^{\circ}$ & 87 \\
\hline Suisse & $85^{\circ}$ & 76 & $61^{\mathrm{D}}$ & 56 & $71^{\circ}$ & 67 & $91^{\circ}$ & 89 & $80^{\circ}$ & 81 & $85^{\circ}$ & 86 & $96^{\circ}$ & 92 & $87^{\circ}$ & 86 & $92^{\circ}$ & 89 \\
\hline Turquie & $82^{\circ}$ & 84 & $20^{\circ}$ & 27 & $49^{\circ}$ & 54 & $86^{\circ}$ & 87 & $33^{b}$ & 35 & $65^{\circ}$ & 65 & $86^{b}$ & 84 & $70^{\circ}$ & 62 & $79^{\circ}$ & 73 \\
\hline Royaume-Uni' & $75^{\circ}$ & 77 & $45^{b}$ & 50 & $60^{\circ}$ & 66 & $89^{\circ}$ & 92 & $73^{\circ}$ & 75 & $81^{\circ}$ & 84 & $91^{\circ}$ & 93 & $85^{\circ}$ & 87 & $88^{\circ}$ & 90 \\
\hline Etats-Unis & 73 & 73 & 42 & 41 & 60 & 59 & 81 & 79 & 67 & 65 & 75 & 73 & 90 & 89 & 82 & 82 & 86 & 85 \\
\hline Moyenne OCDE & 75 & 72 & 49 & 45 & 63 & 60 & 87 & 85 & 70 & 68 & 79 & 78 & 91 & 89 & 81 & 81 & 86 & 84 \\
\hline Moyenne UE23 & 73 & 69 & 50 & 43 & 63 & 58 & 88 & 85 & 72 & 70 & 80 & 79 & 91 & 89 & 82 & 81 & 86 & 84 \\
\hline Argentine & $\mathrm{m}$ & 82 & $\mathrm{~m}$ & 40 & $\mathrm{~m}$ & 64 & $\mathrm{~m}$ & 91 & $\mathrm{~m}$ & 58 & $\mathrm{~m}$ & 75 & $\mathrm{~m}$ & 83 & $\mathrm{~m}$ & 74 & $\mathrm{~m}$ & 78 \\
\hline Bresil & $89^{\circ}$ & 76 & $56^{\circ}$ & 45 & $73^{\circ}$ & 62 & $91^{\circ}$ & 84 & $70^{\circ}$ & 63 & $80^{\circ}$ & 73 & $94^{\circ}$ & 89 & $86^{\circ}$ & 82 & $89^{\circ}$ & 85 \\
\hline Chine & $\mathrm{m}$ & $\mathrm{m}$ & m & m & m & m & $\mathrm{m}$ & $\mathrm{m}$ & $\mathrm{m}$ & $\mathrm{m}$ & $\mathrm{m}$ & $\mathrm{m}$ & $\mathrm{m}$ & $\mathrm{m}$ & $\mathrm{m}$ & $\mathrm{m}$ & $\mathrm{m}$ & m \\
\hline Costa Rica & 92 & 86 & 45 & 43 & 70 & 66 & 96 & 85 & 69 & 57 & 82 & 72 & 92 & 88 & 83 & 76 & 87 & 81 \\
\hline Inde & $\mathrm{m}$ & $\mathrm{m}$ & $\mathrm{m}$ & $\mathrm{m}$ & $\mathrm{m}$ & $\mathrm{m}$ & $\mathrm{m}$ & $\mathrm{m}$ & $\mathrm{m}$ & $\mathrm{m}$ & $\mathrm{m}$ & $\mathrm{m}$ & $\mathrm{m}$ & $\mathrm{m}$ & $\mathrm{m}$ & $\mathrm{m}$ & m & $\mathrm{m}$ \\
\hline Indonésie' & $89^{\circ}$ & 91 & $47^{\circ}$ & 47 & $67^{\circ}$ & 68 & $86^{\circ}$ & 90 & $46^{\circ}$ & 49 & $67^{\circ}$ & 71 & $82^{\circ}$ & 91 & $64^{\circ}$ & 79 & $73^{\circ}$ & 84 \\
\hline Fédération de Russie' & $\mathrm{m}$ & 69 & $\mathrm{~m}$ & 48 & $\mathrm{~m}$ & 60 & $\mathrm{~m}$ & 88 & $\mathrm{~m}$ & 67 & $\mathrm{~m}$ & 80 & $\mathrm{~m}$ & 95 & $\mathrm{~m}$ & 82 & m & 88 \\
\hline Arabie saoudite & $\mathrm{m}$ & $\mathrm{m}$ & $\mathrm{m}$ & $\mathrm{m}$ & $\mathrm{m}$ & $\mathrm{m}$ & $\mathrm{m}$ & $\mathrm{m}$ & m & m & m & $\mathrm{m}$ & $\mathrm{m}$ & $\mathrm{m}$ & $\mathrm{m}$ & $\mathrm{m}$ & $\mathrm{m}$ & $\mathrm{m}$ \\
\hline Afrique du Sud & 59 & 49 & 31 & 30 & 46 & 41 & 71 & 56 & 50 & 43 & 60 & 49 & 87 & 83 & 87 & 80 & 87 & 81 \\
\hline
\end{tabular}

\begin{tabular}{|l|l|l|l|l|l|l|l|l|l|l|l|l|l|l|l|l|l|l|} 
Moyenne $\mathrm{G} 20$ & $\mathrm{~m}$ & $\mathrm{~m}$ & $\mathrm{~m}$ & $\mathrm{~m}$ & $\mathrm{~m}$ & $\mathrm{~m}$ & $\mathrm{~m}$ & $\mathrm{~m}$ & $\mathrm{~m}$ & $\mathrm{~m}$ & $\mathrm{~m}$ & $\mathrm{~m}$ & $\mathrm{~m}$ & $\mathrm{~m}$ & $\mathrm{~m}$ & $\mathrm{~m}$ & $\mathrm{~m}$ & $\mathrm{~m}$ \\
\hline
\end{tabular}

Remarque : Dans la plupart des pays, on observe une rupture des séries chronologiques (indiquée par le code « $b$ »), les données de 2018 se rapportant à la classification CITE 2011, tandis que celles de 2008 se rapportent à la classification CITE 97. Pour de plus amples informations, consulter les sections « Définitions » et « Méthodologie ». Les données et d'autres types de ventilations peuvent être consultés sur http://stats.oecd.org/, Base de données de Regards sur l'éducation.

1. Année de référence : 2017 , et non 2018.

2. Les données relatives au niveau de formation tertiaire incluent les programmes du deuxième cycle du secondaire et de l'enseignement post-secondaire non tertiaire (moins de $5 \%$ de la population adulte se classent dans cette catégorie).

3. Les données concernant les diplômés du deuxième cycle du secondaire incluent la réussite d'un volume et d'un niveau suffisant de programmes qui seraient classés individuellement dans la catégorie réussite d'une formation intermédiaire du deuxième cycle du secondaire ( $13 \%$ des adultes âgés de 25 à 64 ans se classent dans cette catégorie).

Source : OCDE / OIT (2019). Consulter la section « Source » pour tout complément d'information et l'annexe 3 pour les notes (https://doi.org/10.1787/f8d7880d-en)

Les symboles représentant les données manquantes et les abréviations figurent dans le Guide du lecteur. 
Tableau A3.3. Taux d'emploi, de chômage et d'inactivité des adultes âgés de 25 å 34 ans, selon le niveau de formation (2018) Les taux d'emploi et d'inactivité sont calculés en pourcentage de l'ensemble de la population âgée de 25 à 34 ans, et les taux de chômage, en pourcentage de la population active âgée de 25 à 34 ans

\begin{tabular}{|c|c|c|c|c|c|c|c|c|c|c|}
\hline & \multicolumn{3}{|c|}{ Taux d'emploi } & \multicolumn{3}{|c|}{ Taux de chómage } & \multicolumn{3}{|c|}{ Taux d'inactivité } \\
\hline & & $\begin{array}{l}\text { Inférieur } \\
\text { au deuxième } \\
\text { cycle du } \\
\text { secondaire }\end{array}$ & $\begin{array}{l}\text { Deuxième } \\
\text { cycle du } \\
\text { secondaire } \\
\text { ou post- } \\
\text { secondaire } \\
\text { non tertiaire }\end{array}$ & Tertiaire & $\begin{array}{l}\text { Inférieur } \\
\text { au deuxième } \\
\text { cycle du } \\
\text { secondaire }\end{array}$ & $\begin{array}{l}\text { Deuxième } \\
\text { cycle du } \\
\text { secondaire } \\
\text { ou post- } \\
\text { secondaire } \\
\text { non tertiaire }\end{array}$ & Tertiaire & $\begin{array}{l}\text { Inférieur } \\
\text { au deuxième } \\
\text { cycle du } \\
\text { secondaire }\end{array}$ & $\begin{array}{l}\text { Deuxième } \\
\text { cycle du } \\
\text { secondaire } \\
\text { ou post- } \\
\text { sccondaire } \\
\text { non tertiaire }\end{array}$ & Tertiaire \\
\hline & & (1) & (2) & (3) & (4) & (5) & (6) & (n) & (8) & (9) \\
\hline \multicolumn{11}{|c|}{ w Pays } \\
\hline 응 & Australie & 57 & 79 & 85 & 15 & 5 & 4 & 31 & 17 & 12 \\
\hline & Autriche & 58 & 85 & 85 & 16 & 5 & 4 & 30 & 11 & 11 \\
\hline & Belgique & 50 & 78 & 88 & 20 & 8 & 4 & 38 & 15 & 9 \\
\hline & Canada & 58 & 78 & 86 & 11 & 7 & 5 & 35 & 16 & 10 \\
\hline & Chili' & 64 & 69 & 85 & 11 & 10 & 8 & 29 & 23 & 8 \\
\hline & Colombie & 72 & 75 & 82 & 8 & 11 & 12 & 22 & 16 & 8 \\
\hline & République tchèque & 52 & 82 & 80 & 13 & 3 & 2 & 40 & 16 & 19 \\
\hline & Danemark & 63 & 81 & 85 & 10 & 5 & 7 & 30 & 15 & 8 \\
\hline & Estonie & 75 & 81 & 83 & 7 & 5 & 3 & 20 & 14 & 14 \\
\hline & Finlande & 49 & 76 & 85 & 16 & 9 & 5 & 42 & 16 & 11 \\
\hline & France & 51 & 76 & 85 & 25 & 12 & 6 & 32 & 14 & 9 \\
\hline & Allemagne & 57 & 84 & 88 & 13 & 3 & 3 & 34 & 13 & 10 \\
\hline & Gréce & 54 & 62 & 70 & 27 & 25 & 23 & 26 & 17 & 9 \\
\hline & Hongrie & 57 & 81 & 84 & 13 & 4 & 2 & 34 & 16 & 15 \\
\hline & Islande & 80 & 84 & 92 & 6 & 3 & 3 & 15 & 13 & 5 \\
\hline & Irlande & 50 & 75 & 87 & 15 & 7 & 4 & 41 & 19 & 9 \\
\hline & |sraêl| & 62 & 71 & 87 & 5 & 6 & 4 & 35 & 25 & 10 \\
\hline & Italie & 53 & 63 & 67 & 22 & 15 & 12 & 33 & 26 & 23 \\
\hline & Japon $^{2}$ & $\mathrm{~m}$ & $x(3)$ & $87^{\circ}$ & $m$ & $x(6)$ & $3^{d}$ & $\mathrm{~m}$ & $\times(9)$ & $10^{\circ}$ \\
\hline & Coree & 65 & 65 & 76 & 6 & 8 & 6 & 32 & 30 & 19 \\
\hline & Lettonie & 64 & 78 & 90 & 19 & 10 & 5 & 22 & 14 & 6 \\
\hline & Lituanic & 50 & 80 & 93 & 18 & 7 & 2 & 39 & 13 & 5 \\
\hline & Luxembourg & 67 & 84 & 87 & 13 & 5 & 6 & 23 & 11 & 7 \\
\hline & Mexique & 66 & 71 & 81 & 3 & 4 & 5 & 32 & 26 & 15 \\
\hline & Pays-Bas & 65 & 85 & 92 & 7 & 3 & 2 & 30 & 13 & 6 \\
\hline & Nouvelle-Zélande & 70 & 82 & 87 & 7 & 4 & 2 & 25 & 14 & 10 \\
\hline & Norvège & 62 & 82 & 89 & 10 & 4 & 3 & 31 & 14 & 8 \\
\hline & Pologne & 48 & 78 & 88 & 13 & 5 & 3 & 45 & 18 & 9 \\
\hline & Portugal & 80 & 84 & 86 & 8 & 8 & 6 & 12 & 9 & 8 \\
\hline & République slovaque & 35 & 80 & 77 & 37 & 7 & 5 & 45 & 14 & 20 \\
\hline & Slovénic & 61 & 85 & 85 & 17 & 8 & 7 & 26 & 8 & 8 \\
\hline & Espagne & 63 & 69 & 78 & 25 & 18 & 12 & 16 & 16 & 11 \\
\hline & Suède & 66 & 85 & 87 & 17 & 5 & 4 & 20 & 11 & 9 \\
\hline & Suisse & 67 & 86 & 89 & 13 & 5 & 4 & 23 & 10 & 7 \\
\hline & Turquie & 54 & 65 & 73 & 12 & 11 & 14 & 39 & 27 & 15 \\
\hline & Royaume-Uni ${ }^{3}$ & 66 & 84 & 90 & 8 & 4 & 2 & 29 & 13 & 8 \\
\hline & Etats-Unis & 59 & 73 & 85 & 9 & 6 & 2 & 35 & 22 & 13 \\
\hline & Moyenne OCDE & 60 & 78 & 84 & 14 & 7 & 6 & 30 & 16 & 11 \\
\hline & Moyenne UE23 & 58 & 79 & 84 & 16 & 8 & 6 & 31 & 14 & 11 \\
\hline 8 & Argentine & 64 & 75 & 78 & 12 & 9 & 7 & 27 & 18 & 17 \\
\hline$\frac{2}{\pi}$ & Brésil & 62 & 73 & 85 & 14 & 13 & 8 & 27 & 16 & 8 \\
\hline 들 & Chine & $\mathrm{m}$ & m & m & m & m & $\mathrm{m}$ & m & m & m \\
\hline$\frac{5}{g}$ & Costa Rica & 66 & 72 & 81 & 10 & 13 & 9 & 26 & 18 & 11 \\
\hline & Inde & $\mathrm{m}$ & $\mathrm{m}$ & $\mathrm{m}$ & $\mathrm{m}$ & m & $\mathrm{m}$ & $\mathrm{m}$ & $\mathrm{m}$ & m \\
\hline & Indonésié & 68 & 71 & 84 & 3 & 5 & 5 & 30 & 25 & 11 \\
\hline & Fédération de Russie' & 60 & 80 & 88 & 15 & 8 & 4 & 29 & 13 & 8 \\
\hline & Arabie saoudite & $m$ & $\mathrm{~m}$ & m & $\mathrm{m}$ & $\mathrm{m}$ & $\mathrm{m}$ & $m$ & m & m \\
\hline & Afrique du Sud & 41 & 49 & 81 & 37 & 35 & 10 & 35 & 24 & 10 \\
\hline
\end{tabular}

\begin{tabular}{l|l|l|l|l|l|l|l|l|l|} 
Moyenne $\mathbf{G 2 0}$ & $\mathrm{m}$ & $\mathrm{m}$ & $\mathrm{m}$ & $\mathrm{m}$ & $\mathrm{m}$ & $\mathrm{m}$ & $\mathrm{m}$ & $\mathrm{m}$ & $\mathrm{m}$
\end{tabular}

Remarque : Dans la plupart des pays, les données se rapportent à la classification CITE 2011. Pour l'Arabie saoudite et l'Indonésie, elles se rapportent à la classification CITE 97. Pour de plus amples informations, consulter les sections « Définitions » et « Méthodologie ». Les données et d'autres types de ventilations peuvent être consultés sur http://stats.oecd.org/, Base de données de Regards sur l'éducation.

1. Année de référence : 2017.

2. Les données relatives au niveau de formation tertiaire incluent les programmes du deuxième cycle du secondaire et de l'enseignement post-secondaire non tertiaire (moins de $5 \%$ de la population adulte se classent dans cette catégorie).

3. Les données concernant les diplômés du deuxième cycle du secondaire incluent la réussite d'un volume et d'un niveau suffisant de programmes qui seraient classés individuellement dans la catégorie réussite d'une formation intermédiaire du deuxième cycle du secondaire ( $13 \%$ des adultes âgés de 25 à 64 ans se classent dans cette catégorie).

Source : OCDE / OIT (2019). Consulter la section « Source » pour tout complément d'information et l'annexe 3 pour les notes (https://doi.org/10.1787/f8d7880d-en). Les symboles représentant les données manquantes et les abréviations figurent dans le Guide du lecteur. 
Tableau A3.4. Taux d'emploi des adultes diplômés de l'enseignement tertiaire, selon le domaine d'études (2018)

Pourcentage d'actifs occupés âgés de 25 à 64 ans dans l'ensemble de la population âgée de 25 à 64 ans

\begin{tabular}{|c|c|c|c|c|c|c|c|c|c|c|c|c|c|c|}
\hline & \multirow[b]{2}{*}{ 읋 } & \multicolumn{2}{|c|}{$\begin{array}{l}\text { Lettres et arts (excepté } \\
\text { langues étrangères), } \\
\text { sciences sociales, } \\
\text { journalisme et } \\
\text { information }\end{array}$} & \multirow{2}{*}{ 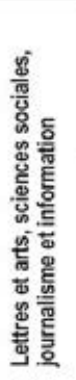 } & \multicolumn{2}{|c|}{$\begin{array}{l}\text { Commerce, } \\
\text { administration } \\
\text { ou droit }\end{array}$} & \multirow{2}{*}{ 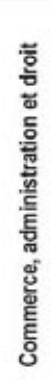 } & \multirow{2}{*}{ 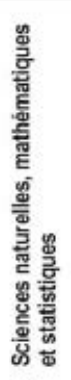 } & \multirow{2}{*}{ 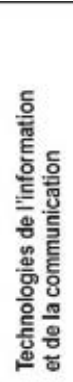 } & \multirow{2}{*}{ 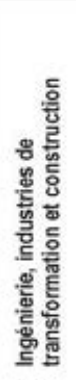 } & \multicolumn{2}{|c|}{ Santé } & \multirow[b]{2}{*}{ 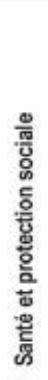 } & \multirow[b]{2}{*}{ 慇 } \\
\hline & & 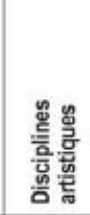 & 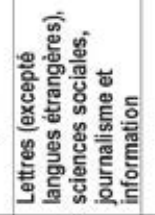 & & 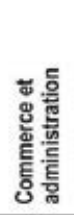 & "홍 & & & & & 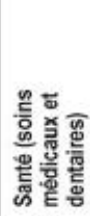 & 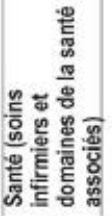 & & \\
\hline & (1) & (2) & (3) & (4) & (5) & (6) & (7) & (8) & (9) & (10) & (11) & (12) & (13) & (14) \\
\hline \multicolumn{15}{|l|}{ س } \\
\hline Oustralie & 84 & $x(4)$ & $x(4)$ & 81 & $x(7)$ & $x(7)$ & 84 & 82 & 84 & 85 & $x(13)$ & $x(13)$ & 86 & 84 \\
\hline Autriche & 86 & 83 & 82 & 81 & $x(7)$ & $x(7)$ & 86 & 82 & 90 & 88 & 90 & 84 & 86 & 86 \\
\hline Belgique & 85 & $x(4)$ & 86 & 84 & $x(7)$ & $x(7)$ & 86 & 82 & 90 & 90 & $x(13)$ & $x(13)$ & 88 & 86 \\
\hline Canada & $\mathrm{m}$ & $\mathrm{m}$ & $\mathrm{m}$ & $\mathrm{m}$ & m & $\mathrm{m}$ & $\mathrm{m}$ & $\mathrm{m}$ & m & $\mathrm{m}$ & $\mathrm{m}$ & m & $\mathrm{m}$ & 83 \\
\hline Chili' & 83 & 84 & 89 & 86 & 83 & 85 & 83 & 78 & 90 & 89 & 92 & 83 & 83 & 84 \\
\hline Colombie & $\mathrm{m}$ & $\mathrm{m}$ & $\mathrm{m}$ & $\mathrm{m}$ & $\mathrm{m}$ & $\mathrm{m}$ & $\mathrm{m}$ & $\mathrm{m}$ & $\mathrm{m}$ & $\mathrm{m}$ & $\mathrm{m}$ & $\mathrm{m}$ & $\mathrm{m}$ & 82 \\
\hline République tchèque & 83 & 85 & 82 & 82 & 85 & 88 & 85 & 84 & 92 & 91 & 90 & 82 & 84 & 87 \\
\hline Danemark & 90 & 83 & 85 & 83 & 90 & $x(7)$ & 90 & 80 & 87 & 90 & 93 & 92 & 90 & 88 \\
\hline Estonie & 86 & 79 & 85 & 84 & 81 & 87 & 82 & 87 & 94 & 86 & 94 & 86 & 88 & 85 \\
\hline Finlande & 88 & $x(4)$ & 90 & 87 & $x(7)$ & $x(7)$ & 86 & 86 & 95 & 91 & $x(13)$ & $x(13)$ & 89 & 87 \\
\hline France & 81 & $x(4)$ & 82 & 81 & $x(7)$ & $x(7)$ & 85 & 86 & 87 & 89 & $\times(13)$ & $x(13)$ & 85 & 85 \\
\hline Allemagne & 87 & 87 & 86 & 86 & 89 & 89 & 90 & 87 & 92 & 91 & 90 & 88 & 89 & 89 \\
\hline Grèce & 72 & $x(4)$ & 72 & 68 & $x(7)$ & $x(7)$ & 76 & 76 & 84 & 77 & $x(13)$ & $x(13)$ & 81 & 74 \\
\hline Hongrie & 84 & $x(4)$ & 83 & 84 & $\times(7)$ & $\times(7)$ & 85 & 88 & 93 & 88 & $\times(13)$ & $x(13)$ & 87 & 86 \\
\hline Islande ${ }^{2}$ & 92 & $x(4)$ & $x(4)$ & 92 & $x(7)$ & $x(7)$ & 95 & 92 & 97 & 93 & $x(13)$ & $x(13)$ & 95 & 92 \\
\hline Irlande & $\mathrm{m}$ & $\mathrm{m}$ & $\mathrm{m}$ & $\mathrm{m}$ & $\mathrm{m}$ & $\mathrm{m}$ & $\mathrm{m}$ & $\mathrm{m}$ & $\mathrm{m}$ & $\mathrm{m}$ & $\mathrm{m}$ & $\mathrm{m}$ & $\mathrm{m}$ & 85 \\
\hline Israēl & $\mathrm{m}$ & $\mathrm{m}$ & $\mathrm{m}$ & $\mathrm{m}$ & $\mathrm{m}$ & $\mathrm{m}$ & $\mathrm{m}$ & $\mathrm{m}$ & m & m & $\mathrm{m}$ & m & $\mathrm{m}$ & 87 \\
\hline Italie & 82 & 72 & 78 & 77 & 83 & 80 & 82 & 78 & 87 & 85 & $x(13)$ & $x(13)$ & 87 & 81 \\
\hline Japon ${ }^{3}$ & $\mathrm{~m}$ & $\mathrm{~m}$ & $\mathrm{~m}$ & $\mathrm{~m}$ & $\mathrm{~m}$ & $\mathrm{~m}$ & $\mathrm{~m}$ & $\mathrm{~m}$ & $\mathrm{~m}$ & $\mathrm{~m}$ & $\mathrm{~m}$ & $\mathrm{~m}$ & $\mathrm{~m}$ & $85^{\circ}$ \\
\hline Coree & $\mathrm{m}$ & $\mathrm{m}$ & m & $\mathrm{m}$ & $\mathrm{m}$ & $\mathrm{m}$ & $\mathrm{m}$ & $\mathrm{m}$ & $\mathrm{m}$ & $\mathrm{m}$ & $\mathrm{m}$ & $\mathrm{m}$ & $\mathrm{m}$ & 78 \\
\hline Lettonic & 90 & 91 & 90 & 88 & 90 & 90 & 90 & 91 & 92 & 86 & 92 & 97 & 93 & 89 \\
\hline Lituanie & 91 & 87 & 91 & 90 & 93 & $x(7)$ & 93 & 89 & 94 & 90 & 94 & 92 & 93 & 91 \\
\hline Luxembourg & 89 & $x(4)$ & 93 & 89 & $x(7)$ & $x(7)$ & 90 & 95 & 89 & 95 & $x(13)$ & $x(13)$ & 89 & 86 \\
\hline Mexique & 78 & 83 & 74 & 76 & 79 & 82 & 80 & 76 & 84 & 84 & $79^{\circ}$ & 76 & 78 & 80 \\
\hline Pays-Bas & 88 & 89 & 89 & 88 & 92 & 88 & 91 & 88 & 93 & 92 & 89 & 90 & 88 & 90 \\
\hline Nouvelle-Zèlande & m & $\mathrm{m}$ & $\mathrm{m}$ & $\mathrm{m}$ & $\mathrm{m}$ & $\mathrm{m}$ & $\mathrm{m}$ & $\mathrm{m}$ & $\mathrm{m}$ & $\mathrm{m}$ & $\mathrm{m}$ & $\mathrm{m}$ & $\mathrm{m}$ & 88 \\
\hline Norvège & 89 & 88 & 87 & 86 & 91 & 94 & 91 & 87 & 91 & 91 & 89 & 92 & 91 & 89 \\
\hline Pologne & 85 & $x(4)$ & 88 & 88 & $\times(7)$ & $\times(7)$ & 89 & 88 & 96 & 92 & $x(13)$ & $x(13)$ & 92 & 89 \\
\hline Portugal & 86 & $x(4)$ & 86 & 85 & $x(7)$ & $x(7)$ & 90 & 89 & 91 & 89 & $x(13)$ & $x(13)$ & 92 & 88 \\
\hline Republique slovaque & 82 & 77 & 81 & 80 & 79 & 86 & 80 & 81 & 93 & 86 & 90 & 84 & 83 & 83 \\
\hline Slovénie & 87 & $x(4)$ & 89 & 88 & $x(7)$ & $x(7)$ & 90 & 89 & 97 & 93 & $x(13)$ & $x(13)$ & 93 & 89 \\
\hline Espagne & 76 & $x(4)$ & 80 & 79 & $x(7)$ & $x(7)$ & 81 & 80 & 86 & 85 & $x(13)$ & $x(13)$ & 85 & 82 \\
\hline Suede & 90 & 88 & 90 & 88 & 90 & 88 & 90 & 86 & 94 & 92 & 88 & 94 & 92 & 90 \\
\hline Suisse & 87 & 82 & 86 & 84 & 89 & 85 & 88 & 86 & 93 & 92 & 92 & 90 & 90 & 89 \\
\hline Turquie? ${ }^{2}$ & 71 & $x(4)$ & $x(4)$ & 67 & $x(7)$ & $x(7)$ & 73 & 73 & 74 & 78 & $x(13)$ & $x(13)$ & 78 & 74 \\
\hline Royaume-Uni & 79 & $x(4)$ & 84 & 84 & $x(7)$ & $\times(7)$ & 85 & 80 & 87 & 88 & $\times(13)$ & $x(13)$ & 83 & 86 \\
\hline Etats-Unis ${ }^{1,4}$ & 80 & 81 & 84 & 83 & $x(7)$ & $x(7)$ & 86 & 85 & 87 & 88 & $x(13)$ & $x(13)$ & 85 & 82 \\
\hline Moyenne OCDE & 84 & $\mathrm{~m}$ & 85 & 83 & m & $\mathrm{m}$ & 86 & 84 & 90 & 89 & $\mathrm{~m}$ & m & 87 & 85 \\
\hline Moyenne UE23 & 85 & $\mathrm{~m}$ & 85 & 84 & $\mathrm{~m}$ & $\mathrm{~m}$ & 87 & 85 & 91 & 89 & $\mathrm{~m}$ & $\mathrm{~m}$ & 88 & 86 \\
\hline
\end{tabular}

\begin{tabular}{|c|c|c|c|c|c|c|c|c|c|c|c|c|c|c|}
\hline Argentine & $\mathrm{m}$ & $\mathrm{m}$ & $\mathrm{m}$ & $\mathrm{m}$ & $\mathrm{m}$ & m & $\mathrm{m}$ & $\mathrm{m}$ & $\mathrm{m}$ & $\mathrm{m}$ & $\mathrm{m}$ & $\mathrm{m}$ & $\mathrm{m}$ & 81 \\
\hline Brésil & $\mathrm{m}$ & $\mathrm{m}$ & $\mathrm{m}$ & $\mathrm{m}$ & $\mathrm{m}$ & $\mathrm{m}$ & $\mathrm{m}$ & $\mathrm{m}$ & $\mathrm{m}$ & $\mathrm{m}$ & $\mathrm{m}$ & m & $\mathrm{m}$ & 83 \\
\hline Chine & m & $\mathrm{m}$ & $\mathrm{m}$ & $\mathrm{m}$ & $\mathrm{m}$ & $\mathrm{m}$ & $\mathrm{m}$ & $\mathrm{m}$ & m & $\mathrm{m}$ & $\mathrm{m}$ & $\mathrm{m}$ & m & $\mathrm{m}$ \\
\hline Costa Rica & 77 & c & 74 & 74 & 81 & 82 & 81 & 82 & 89 & 89 & $x(13)$ & $x(13)$ & 80 & 81 \\
\hline Inde & m & $\mathrm{m}$ & $\mathrm{m}$ & $\mathrm{m}$ & $\mathrm{m}$ & $\mathrm{m}$ & $\mathrm{m}$ & $\mathrm{m}$ & $\mathrm{m}$ & $\mathrm{m}$ & $\mathrm{m}$ & $\mathrm{m}$ & m & $\mathrm{m}$ \\
\hline Indonésie' & $\mathrm{m}$ & $\mathrm{m}$ & $\mathrm{m}$ & $\mathrm{m}$ & $\mathrm{m}$ & $\mathrm{m}$ & $\mathrm{m}$ & $\mathrm{m}$ & $\mathrm{m}$ & $\mathrm{m}$ & m & $\mathrm{m}$ & $\mathrm{m}$ & 85 \\
\hline Fédération de Russie' & 82 & $\mathrm{~m}$ & 84 & 85 & $x(7)$ & $x(7)$ & 81 & 83 & 96 & 84 & $x(13)$ & $x(13)$ & 84 & 83 \\
\hline Arable saoudite ${ }^{2}$ & $\mathrm{~m}$ & $\mathrm{~m}$ & $\mathrm{~m}$ & $\mathrm{~m}$ & $\mathrm{~m}$ & $\mathrm{~m}$ & $\mathrm{~m}$ & $\mathrm{~m}$ & $\mathrm{~m}$ & $\mathrm{~m}$ & $\mathrm{~m}$ & $\mathrm{~m}$ & $\mathrm{~m}$ & 74 \\
\hline Afrique du Sud & $\mathrm{m}$ & $\mathrm{m}$ & $\mathrm{m}$ & & & & & & & $m$ & & & $m$ & 85 \\
\hline
\end{tabular}

\begin{tabular}{c|c|c|c|c|c|c|c|c|c|c|c|c|c|c|c|} 
Moyenne G20 & $m$ & $m$ & $m$ & $m$ & $m$ & $m$ & $m$ & $m$ & $m$ & $m$ & $m$ & $m$ & $m$ & $m$ & $m$
\end{tabular}

Remarque : Pour de plus amples informations, consulter les sections " Définitions » et « Méthodologie ». Les données et d'autres types de ventilations peuvent être consultés sur http://stats.oecd.org/, Base de données de Regards sur l'éducation.

1. Année de référence : 2017.

2. Année de référence : 2016 .

3. Les données relatives au niveau de formation tertiaire incluent les programmes du deuxième cycle du secondaire et de l'enseignement post-secondaire non tertiaire (moins de $5 \%$ de la population adulte se classent dans cette catégorie).

4. Les données se rapportent au domaine d'études choisi en licence, même pour les adultes titulaires d'autres diplômes de l'enseignement tertiaire.

Source : OCDE (2019). Consulter la section « Source » pour tout complément d'information et l'annexe 3 pour les notes (https://doi.org/10.1787/f8d7880d-en).

Les symboles représentant les données manquantes et les abréviations figurent dans le Guide du lecteur. 
Tableau A3.5. Taux de chômage des adultes âgés de 25 à 64 ans, selon la durée de la période de chômage et le niveau de formation (2018)

Pourcentage de chômeurs âgés de 25 à 64 ans dans l'ensemble de la population active âgée de 25 à 64 ans

\begin{tabular}{|c|c|c|c|c|c|c|c|c|c|c|c|c|}
\hline & \multicolumn{4}{|c|}{ Inférieur au deuxième cycle du secondaire } & \multicolumn{4}{|c|}{$\begin{array}{l}\text { Deuxième cycle du secondaire } \\
\text { ou post-secondaire non tertiaire }\end{array}$} & \multicolumn{4}{|c|}{ Tertiaire } \\
\hline & \multirow{2}{*}{ 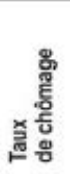 } & \multicolumn{3}{|c|}{$\begin{array}{l}\text { Répartition selon la duree } \\
\text { de la période de chómage }\end{array}$} & \multirow{2}{*}{ 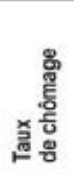 } & \multicolumn{3}{|c|}{$\begin{array}{l}\text { Répartition selon la durèe } \\
\text { de la période de chómage }\end{array}$} & \multirow{2}{*}{ 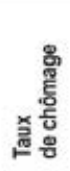 } & \multicolumn{3}{|c|}{$\begin{array}{l}\text { Répartition selon la durée } \\
\text { de la periode de chómage }\end{array}$} \\
\hline & & $\begin{array}{c}\text { Moins } \\
\text { de } 3 \text { mois }\end{array}$ & $\begin{array}{l}\text { De } 3 \text { mois } \\
\text { a moins } \\
\text { de } 12 \text { mois }\end{array}$ & $\begin{array}{l}12 \text { mois } \\
\text { ou plus }\end{array}$ & & $\begin{array}{c}\text { Moins } \\
\text { de } 3 \text { mois }\end{array}$ & $\begin{array}{l}\text { De } 3 \text { mois } \\
\text { a moins } \\
\text { de } 12 \text { mois }\end{array}$ & $\begin{array}{l}12 \text { mois } \\
\text { ou plus }\end{array}$ & & $\begin{array}{c}\text { Moins } \\
\text { de } 3 \text { mois }\end{array}$ & $\begin{array}{l}\text { De } 3 \text { mois } \\
\text { a moins } \\
\text { de } 12 \text { mois }\end{array}$ & $\begin{array}{l}12 \text { mois } \\
\text { ou plus }\end{array}$ \\
\hline & (1) & (2) & (3) & (4) & (5) & (6) & (7) & (8) & (9) & (10) & (11) & (12) \\
\hline \multicolumn{13}{|l|}{ w Pays } \\
\hline Oustralie & 7 & $x(3)$ & $61^{4}$ & 39 & 4 & $x(8)$ & $67^{\circ}$ & 33 & 3 & $x(13)$ & $80^{4}$ & 20 \\
\hline Autriche & 11 & 25 & 37 & 39 & 4 & 32 & 34 & 34 & 3 & 36 & 37 & 27 \\
\hline Belgique & 12 & 13 & 24 & 64 & 5 & 17 & 28 & 55 & 3 & 26 & 31 & 43 \\
\hline Canada & 9 & 55 & 35 & 10 & 6 & 56 & 32 & 11 & 4 & 55 & 33 & 11 \\
\hline Chili' & 6 & 73 & 23 & 3 & 7 & 73 & 24 & 3 & 6 & 68 & 25 & 7 \\
\hline Colombie & 6 & $x(3)$ & $92^{\mathrm{d}}$ & 8 & 9 & $x(8)$ & $88^{\circ}$ & 12 & 9 & $x(13)$ & $84^{d}$ & 16 \\
\hline Republique tchèque & 9 & 21 & 50 & 29 & 2 & 32 & 45 & 23 & 1 & 48 & 37 & 15 \\
\hline Danemark & 6 & 31 & 33 & 36 & 3 & 34 & 37 & 29 & 4 & 29 & 41 & 30 \\
\hline Estonie & 8 & 41 & 35 & 24 & 5 & 33 & 34 & 33 & 4 & 39 & 42 & 19 \\
\hline Finlande & 12 & 35 & 24 & 41 & 7 & 39 & 32 & 29 & 4 & 34 & 39 & 26 \\
\hline France & 14 & 16 & 28 & 56 & 8 & 19 & 35 & 46 & 5 & 26 & 37 & 37 \\
\hline Allemagne & 9 & 19 & 25 & 56 & 3 & 24 & 28 & 48 & 2 & 33 & 33 & 34 \\
\hline Grèce & 22 & 9 & 17 & 74 & 20 & 9 & 18 & 73 & 14 & 11 & 20 & 69 \\
\hline Hongric & 9 & 23 & 35 & 41 & 3 & 23 & 31 & 45 & 1 & 33 & 33 & 34 \\
\hline Islande & 3 & $\mathrm{~m}$ & $\mathrm{~m}$ & $\mathrm{~m}$ & 2 & $\mathrm{~m}$ & $\mathrm{~m}$ & $\mathrm{~m}$ & 2 & $\mathrm{~m}$ & $\mathrm{~m}$ & $\mathrm{~m}$ \\
\hline Irlande & 8 & $x(3)$ & $37^{\circ}$ & 63 & 5 & $x(8)$ & $54^{\circ}$ & 46 & 4 & $x(13)$ & $69^{4}$ & 31 \\
\hline Israël & 5 & 13 & 33 & 53 & 4 & 13 & 43 & 45 & 3 & 10 & 42 & 48 \\
\hline Italie & 13 & 13 & 21 & 66 & 8 & 16 & 24 & 60 & 6 & 23 & 28 & 49 \\
\hline Japon $^{2}$ & m & $\mathrm{m}$ & $\mathrm{m}$ & $\mathrm{m}$ & $\mathrm{m}$ & $\mathrm{m}$ & $\mathrm{m}$ & $\mathrm{m}$ & $2^{d}$ & $\mathrm{~m}$ & $\mathrm{~m}$ & $\mathrm{~m}$ \\
\hline Corée & 3 & $\mathrm{~m}$ & $\mathrm{~m}$ & $\mathrm{~m}$ & 4 & $\mathrm{~m}$ & $\mathrm{~m}$ & $\mathrm{~m}$ & 3 & $\mathrm{~m}$ & $\mathrm{~m}$ & m \\
\hline Lettonic & 15 & 16 & 30 & 53 & 8 & 19 & 36 & 45 & 4 & 31 & 36 & 33 \\
\hline Lituanie & 16 & 20 & 34 & 46 & 8 & 24 & 38 & 38 & 3 & 28 & 52 & 20 \\
\hline Luxembourg & 6 & 20 & 36 & 44 & 5 & 31 & 34 & 35 & 4 & 34 & 41 & 25 \\
\hline Mexique & 2 & 89 & 10 & 1 & 3 & 81 & 17 & 1 & 4 & 74 & 23 & 4 \\
\hline Pays-Bas & 5 & 22 & 25 & 53 & 3 & 23 & 34 & 44 & 2 & 32 & 33 & 35 \\
\hline Nouvelle-Zélande & 5 & $x(3)$ & $72^{\circ}$ & 28 & 3 & $x(8)$ & $83^{\circ}$ & 17 & 2 & $x(13)$ & $88^{4}$ & 12 \\
\hline Norvège & 6 & 28 & 35 & 37 & 3 & 31 & 35 & 34 & 2 & 33 & 40 & 28 \\
\hline Pologne & 9 & 26 & 38 & 36 & 4 & 30 & 39 & 31 & 2 & 35 & 45 & 20 \\
\hline Portugal & 7 & $x(3)$ & $36^{d}$ & 64 & 7 & $x(8)$ & $50^{d}$ & 50 & 5 & $x(13)$ & $51^{4}$ & 49 \\
\hline Republique slovaque & 27 & 9 & 18 & 72 & 5 & 13 & 23 & 64 & 3 & 28 & 31 & 41 \\
\hline Slovénie & 9 & 20 & 26 & 54 & 5 & 18 & 31 & 51 & 4 & 26 & 34 & 41 \\
\hline Espagne & 21 & 25 & 27 & 48 & 14 & 28 & 29 & 44 & 8 & 29 & 31 & 40 \\
\hline Suede & 15 & 23 & 45 & 32 & 3 & 33 & 45 & 21 & 3 & 36 & 46 & 18 \\
\hline Suisse & 8 & $x(3)$ & $42^{4}$ & 58 & 4 & $x(8)$ & $58^{d}$ & 42 & 4 & $x(13)$ & $61^{4}$ & 39 \\
\hline Turquie & 9 & $x(3)$ & $80^{\mathrm{d}}$ & 20 & 9 & $\times(8)$ & $73^{\mathrm{d}}$ & 27 & 10 & $\times(13)$ & $65^{\circ}$ & 35 \\
\hline Royaume-Uni' & 5 & 25 & 33 & 42 & 3 & 36 & 31 & 33 & 2 & 46 & 31 & 23 \\
\hline Etats-Unis & 7 & 54 & 27 & 19 & 5 & 55 & 29 & 16 & 2 & 55 & 30 & 15 \\
\hline Moyenne OCDE & 10 & 28 & 30 & 41 & 6 & 31 & 32 & 36 & 4 & 35 & 35 & 29 \\
\hline Moyenne UE23 & 12 & 22 & 31 & 49 & 6 & 25 & 33 & 42 & 4 & 32 & 36 & 33 \\
\hline Argentine & 8 & 34 & 20 & 46 & 7 & 30 & 20 & 51 & 5 & 36 & 24 & 40 \\
\hline 旅 Bresil & 10 & 33 & 27 & 40 & 10 & 22 & 30 & 48 & 6 & 23 & 30 & 47 \\
\hline है Chine & $\mathrm{m}$ & $\mathrm{m}$ & $\mathrm{m}$ & $\mathrm{m}$ & $\mathrm{m}$ & $\mathrm{m}$ & $\mathrm{m}$ & $\mathrm{m}$ & $\mathrm{m}$ & $\mathrm{m}$ & $\mathrm{m}$ & $\mathrm{m}$ \\
\hline Costa Rica & 8 & 65 & 21 & 14 & 9 & 54 & 23 & 22 & 6 & 54 & 27 & 19 \\
\hline Inde & $\mathrm{m}$ & $\mathrm{m}$ & $\mathrm{m}$ & $\mathrm{m}$ & $\mathrm{m}$ & $\mathrm{m}$ & $\mathrm{m}$ & $\mathrm{m}$ & $\mathrm{m}$ & $\mathrm{m}$ & $\mathrm{m}$ & m \\
\hline Indonésie' & 2 & m & $\mathrm{m}$ & $\mathrm{m}$ & 3 & $\mathrm{~m}$ & $\mathrm{~m}$ & $\mathrm{~m}$ & 3 & $\mathrm{~m}$ & $\mathrm{~m}$ & m \\
\hline Fédèration de Russie ${ }^{t}$ & 12 & 18 & 30 & 52 & 6 & 20 & 32 & 48 & 3 & 22 & 33 & 46 \\
\hline Arabie saoudite ${ }^{4}$ & 0 & $\mathrm{~m}$ & $\mathrm{~m}$ & $\mathrm{~m}$ & 4 & $\mathrm{~m}$ & $\mathrm{~m}$ & $\mathrm{~m}$ & 10 & $\mathrm{~m}$ & $\mathrm{~m}$ & m \\
\hline Afrique du Sud & 25 & m & m & m & 26 & $\mathrm{~m}$ & $\mathrm{~m}$ & $\mathrm{~m}$ & 6 & m & $\mathrm{m}$ & $\mathrm{m}$ \\
\hline
\end{tabular}

\begin{tabular}{|l|l|l|l|l|l|l|l|l|l|l|l|l|l|l|} 
Moyenne & G20 & $m$ & $m$ & $m$ & $m$ & $m$ & $m$ & $m$ & $m$ & $m$ & $m$ & $m$ & $m$ \\
\hline
\end{tabular}

Remarque : Pour de plus amples informations, consulter les sections " Définitions » et « Méthodologie ». Les données et d'autres types de ventilations peuvent être consultés sur http://stats.oecd.org/, Base de données de Regards sur l'éducation.

1. Année de référence : 2017.

2. Les données relatives au niveau de formation tertiaire incluent les programmes du deuxième cycle du secondaire et de l'enseignement post-secondaire non tertiaire (moins de $5 \%$ de la population adulte se classent dans cette catégorie).

3. Les données concemant les diplômés du deuxième cycle du secondaire incluent la réussite d'un volume et d'un niveau suffisant de programmes qui seraient classés individuellement dans la catégorie réussite d'une formation intermédiaire du deuxième cycle du secondaire ( $13 \%$ des adultes âgés de 25 à 64 ans se classent dans cette catégorie).

4. Année de référence : 2016.

Source : OCDE (2019). Consulter la section « Source » pour tout complément d'information et l'annexe 3 pour les notes (https://doi.org/10.1787/f8d7880d-en).

Les symboles représentant les données manquantes et les abréviations figurent dans le Guide du lecteur. 



\section{Indicateur A4. Quel avantage salarial le niveau de formation procure-t-il ?}

\section{Faits marquants}

- En moyenne, dans les pays de l'OCDE, les diplômés de l'enseignement tertiaire après une formation de cycle court gagnent $20 \%$ de plus que les diplômés du deuxième cycle de l'enseignement secondaire. Leur avantage salarial augmente et atteint $44 \%$ après une licence et $91 \%$ après un master ou un doctorat.

- Un différentiel salarial persiste entre les sexes à tous les niveaux de formation ; il est plus important au niveau de formation égal à l'enseignement tertiaire. Les femmes gagnent moins que les hommes même si elles sont diplômées de l'enseignement tertiaire dans le même domaine d'études qu'eux.

- Les grands domaines d'études les plus rémunérateurs sont l'ingénierie, les industries de transformation et la construction, et les technologies de l'information et de la communication (TIC).

Graphique A4.1. Revenus du travail relatifs des adultes diplômés de l'enseignement tertiaire, selon le niveau de formation (2017)

Actifs occupés (à temps plein ou partiel) âgés de 25 à 64 ans ; deuxième cycle du secondaire $=100$

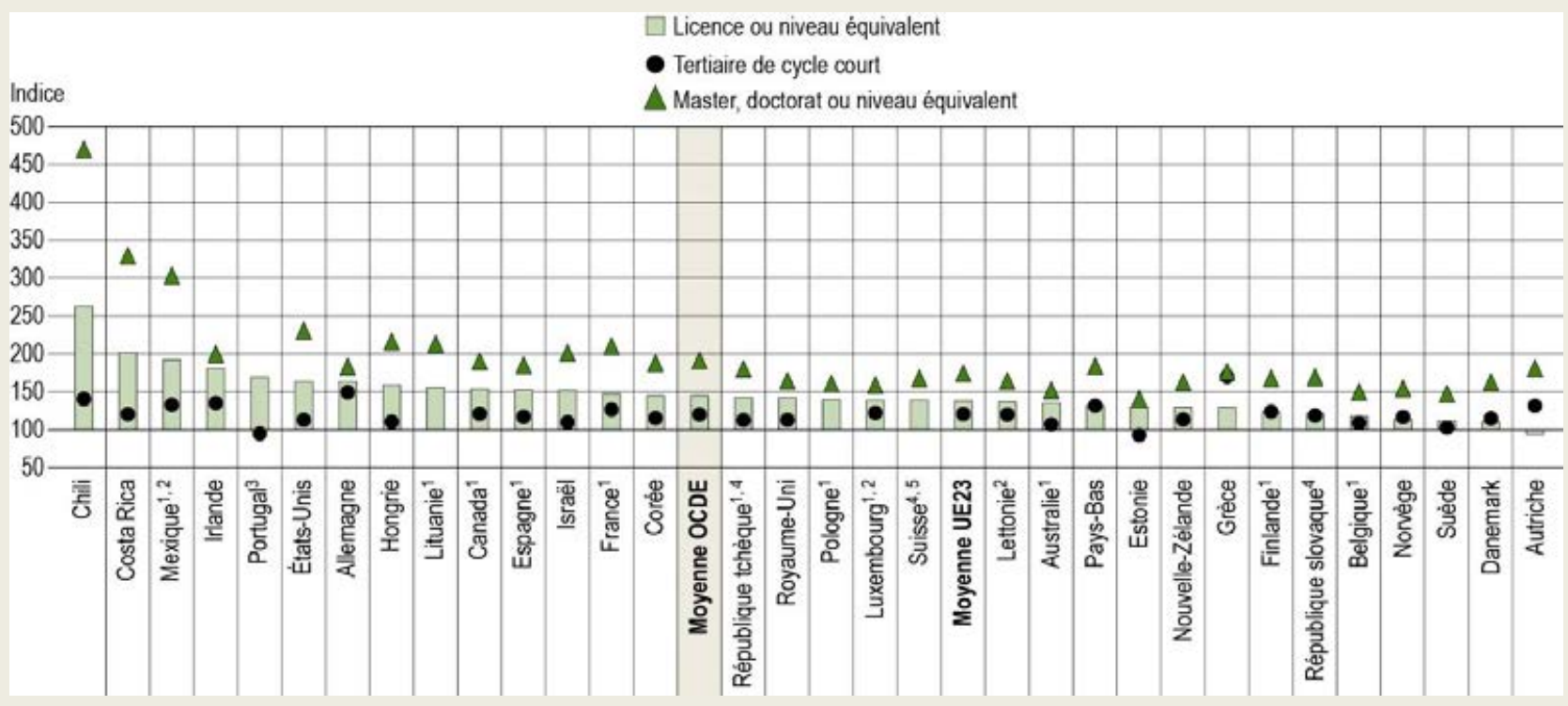

1. L'année de référence n'est pas 2017. Consulter le tableau source pour de plus amples informations.

2. Revenus nets d'impôts sur le revenu.

3. Le niveau licence ou équivalent inclut les niveaux master, doctorat ou équivalents.

4. L'indice 100 se rapporte à la combinaison des niveaux 3 et 4 dans la classification CITE 2011 des niveaux de formation.

5. Les niveaux licence, master, doctorat ou équivalents incluent l'enseignement tertiaire de cycle court.

Les pays sont classés par ordre décroissant des revenus relatifs des actifs rémunérés âgés de 25 à 64 ans titulaires d'une licence ou d'un diplôme équivalent.

Source: OCDE (2019), tableau A4.1. Consulter la section «Source » pour tout complément d'information et l'annexe 3 pour les notes (https://doi.org/10.1787/f8d7880d-en). 


\section{Contexte}

Dans l'ensemble, l'élévation du niveau de formation entraîne l'amélioration des débouchés sur le marché du travail (voir l'indicateur A3) et l'augmentation des rémunérations. La perspective de percevoir une rémunération plus élevée et de la voir de surcroît augmenter au fil du temps est, avec d'autres avantages sociaux, un aiguillon important qui incite les individus à faire des études et parfaire leur formation.

Un diplôme de l'enseignement tertiaire est en particulier associé à une rémunération plus élevée dans tous les pays de l'OCDE. Toutefois, cet avantage varie parfois selon l'âge, le sexe, le niveau de l'enseignement tertiaire et le domaine d'études. Les individus plus qualifiés et plus expérimentés sont plus susceptibles de gagner davantage. Toutefois, la rémunération varie toujours selon le sexe indépendamment de l'âge, du niveau de formation et du domaine d'études dans de nombreux pays.

Des facteurs autres que ceux liés à la formation, dont la demande de compétences sur le marché du travail, l'offre de main-d'œuvre aux divers niveaux de formation, la législation sur le salaire minimal et le droit du travail, les structures et les usages professionnels (dont la puissance des syndicats, le champ d'application des conventions collectives et la qualité des conditions de travail) interviennent aussi dans la rémunération des travailleurs. Ces facteurs contribuent aussi aux différences dans la répartition des rémunérations.

\section{Autres faits marquants}

- Dans l'ensemble, la probabilité de gagner plus que le revenu médian augmente avec l'élévation du niveau de formation. En moyenne, dans les pays de l'OCDE, environ deux diplômés de l'enseignement tertiaire sur trois gagnent plus que le revenu médian calculé sur la base de tous les actifs occupés, qu'ils travaillent à temps plein ou à temps partiel ; à titre de comparaison ce n'est le cas que d'environ un individu sur quatre chez ceux qui ne sont pas diplômés du deuxième cycle de l'enseignement secondaire.

- L'avantage salarial des diplômés de l'enseignement tertiaire augmente avec l'âge. Les 25-34 ans diplômés de l'enseignement tertiaire gagnent près de $40 \%$ de plus que ceux diplômés du deuxième cycle de l'enseignement secondaire et leurs aînés (les 45-54 ans) gagnent 70 \% de plus.

- Dans la plupart des pays dont les données sont disponibles, le différentiel salarial entre les sexes est moins important après une formation en rapport avec l'éducation ou les TIC et plus important après une formation en commerce, en administration ou en droit.

\section{Remarque}

Cet indicateur présente deux types de rémunération relative. Dans le premier, la rémunération de référence est celle des adultes au plus diplômés du deuxième cycle de l'enseignement secondaire. Les comparaisons montrent les écarts de rémunération entre les diplômés du deuxième cycle de l'enseignement secondaire et ceux ayant un niveau de formation différent. Dans le second, qui est utilisé pour rendre compte des écarts de rémunération entre les sexes, la rémunération de référence est celle des hommes. Dans les deux cas, l'accent est mis sur la rémunération relative, de sorte que l'augmentation ou la diminution des écarts peut refléter un changement dans le groupe à l'étude (le numérateur) ou le groupe de référence (le dénominateur). La rémunération relative plus élevée des diplômés de l'enseignement tertiaire peut par exemple refléter la rémunération plus élevée de cette catégorie ou la rémunération moins élevée des diplômés du deuxième cycle de l'enseignement secondaire. 


\section{Analyse}

\section{Rémunération relative, selon le niveau de formation}

La rémunération tend à augmenter avec le niveau de formation. En moyenne, dans les pays de l'OCDE, les 25-64 ans actifs occupés à temps plein ou à temps partiel gagnent $21 \%$ de moins que les diplômés du deuxième cycle de l'enseignement secondaire s'ils ne sont pas diplômés de ce niveau d'enseignement, mais en gagnent 57 \% de plus s'ils sont diplômés de l'enseignement tertiaire (voir le tableau A4.1).

Un diplôme tertiaire procure en effet un avantage salarial important dans la plupart des pays membres et partenaires de l'OCDE. L'avantage salarial relatif des travailleurs à temps plein et à temps partiel est le plus important au Chili, en Colombie et au Costa Rica, où les diplômés de l'enseignement tertiaire gagnent plus de deux fois plus que les diplômés du deuxième cycle de l'enseignement secondaire. Dans ces trois pays, le pourcentage de diplômés de l'enseignement tertiaire compte parmi les moins élevés des pays membres et partenaires des pays de l'OCDE (moins de $25 \%$ ), ce qui explique en partie leur avantage salarial relatif (OCDE, $\left.2017_{[1]}\right)$.

L'avantage salarial des diplômés de l'enseignement tertiaire varie toutefois sensiblement entre les niveaux de l'enseignement tertiaire. Dans la plupart des pays membres et partenaires de l'OCDE, les actifs occupés gagnent plus après un master ou un doctorat qu'après une licence et après une licence qu'après une formation tertiaire de cycle court. En moyenne, dans les pays de l'OCDE, les travailleurs gagnent $20 \%$ de plus après une formation tertiaire de cycle court que s'ils sont au plus diplômés du deuxième cycle de l'enseignement secondaire. L'avantage salarial augmente pour atteindre $44 \%$ après une licence et près de $91 \%$ après un master ou un doctorat (voir le graphique A4.1).

Ce constat général souffre quelques exceptions importantes. En Estonie et au Portugal, les actifs occupés gagnent moins s'ils ont suivi une formation tertiaire de cycle court que s'ils sont diplômés du deuxième cycle de l'enseignement secondaire. En Autriche, ce constat vaut pour les licenciés. Dans ces trois pays, ces groupes représentent toutefois un pourcentage peu élevé de l'effectif diplômé de l'enseignement tertiaire. De plus, la rémunération des travailleurs est plus élevée après une formation tertiaire de cycle court qu'après une licence en Autriche, au Danemark, en Finlande et en Norvège, contrairement à ce qui s'observe dans la plupart des pays. Tous ces pays, sauf le Danemark, comptent parmi ceux où le pourcentage de diplômés à l'issue d'une formation tertiaire de cycle court est le plus élevé : $10 \%$ au moins des adultes sont diplômés de ce niveau (voir l'indicateur A1).

\section{Variation de la rémunération des diplômés de l'enseignement tertiaire, selon le groupe d'âge et dans le temps}

L'élévation du niveau de formation entraîne l'augmentation de la rémunération durant toute la vie active ; cet avantage est particulièrement élevé chez les travailleurs plus âgés. En moyenne, dans les pays de l'OCDE, les jeunes (les 25-34 ans) gagnent près de 40 \% de plus s'ils sont diplômés de l'enseignement tertiaire que s'ils sont diplômés du deuxième cycle de l'enseignement secondaire. Quant à leurs aînés (les 45-54 ans), ils en gagnent $70 \%$ de plus. L'avantage salarial augmente avec l'âge dans tous les pays membres et partenaires de l'OCDE, mais son ampleur varie sensiblement : il est supérieur à 70 points de pourcentage au Chili, en Colombie et en Irlande, mais inférieur à 10 points de pourcentage en Estonie, aux États-Unis et en Nouvelle-Zélande (voir le graphique A4.2).

L'avantage salarial plus élevé des aînés signifie soit que cet avantage augmente avec l'expérience, soit qu'il est moins élevé chez les jeunes (ou que les deux effets se conjuguent). L'âge est un indicateur de l'expérience professionnelle dans le premier cas, mais de l'évolution au fil du temps dans le second cas. II n'est pas possible d'identifier le facteur le plus déterminant des résultats de chaque pays dans le graphique A4.2, mais l'analyse de l'évolution de l'avantage salarial au cours de la dernière décennie permet de mieux cerner le phénomène. 
Dans la plupart des pays de l'OCDE, l'avantage salarial des diplômés de l'enseignement tertiaire n'a pas sensiblement évolué entre 2007 et 2017. Dans au moins 20 pays membres et partenaires de l'OCDE, l'avantage salarial des diplômés de l'enseignement tertiaire a varié de moins de 10 points de pourcentage au cours des dix dernières années ; la différence est même inférieure à 5 points de pourcentage dans de nombreux cas. Cette évolution ne porte que sur une décennie, mais elle montre que dans de nombreux pays de l'OCDE, l'avantage salarial des travailleurs plus âgés s'explique essentiellement par la relation positive entre la rémunération relative et l'expérience professionnelle.

L'augmentation de l'avantage salarial des diplômés de l'enseignement tertiaire au fil de leur carrière peut notamment s'expliquer par le fait que les individus plus instruits sont plus susceptibles de trouver un emploi et de le garder et ont davantage la possibilité d'acquérir de l'expérience dans le cadre professionnel.

\section{Graphique A4.2. Revenus du travail relatifs des adultes diplômés de l'enseignement tertiaire, selon le groupe d'âge (2017)}

Actifs occupés (à temps plein ou partiel) âgés de 25 à 34 ans et de 45 à 54 ans ; deuxième cycle du secondaire $=100$

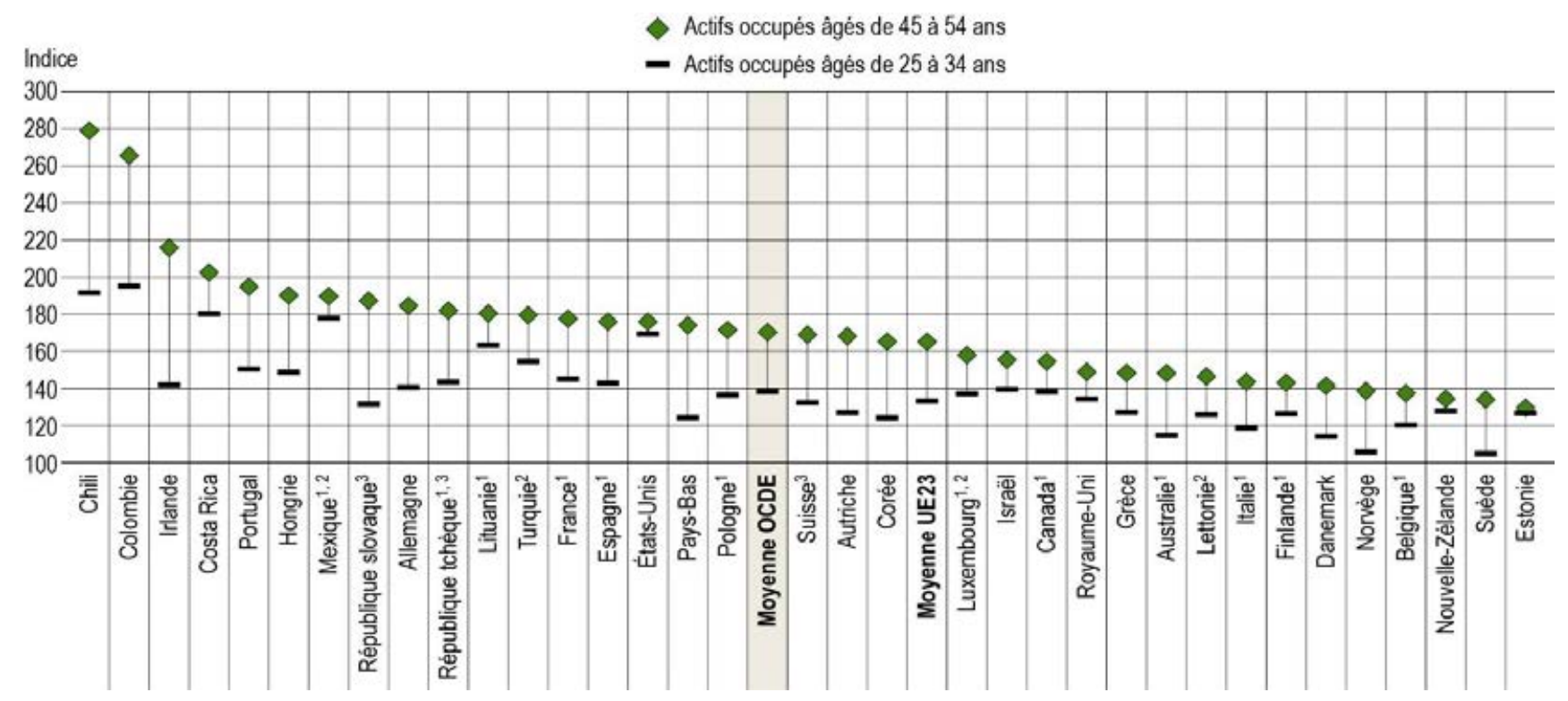

1. L'année de référence n'est pas 2017. Consulter le tableau source pour de plus amples informations.

2. Revenus nets d'impôts sur le revenu.

3. L'indice 100 se rapporte à la combinaison des niveaux 3 et 4 dans la classification CITE 2011 des niveaux de formation.

Les pays sont classés par ordre décroissant des revenus du travail relatifs des diplômés de l'enseignement tertiaire âgés de 45 à 54 ans.

Source : OCDE (2019), base de données de Regards sur l'éducation, http://stats.oecd.org/ Consulter la section " Source » pour tout complément d'information et l'annexe 3 pour les notes (https://doi.org/10.1787/f8d7880d-en).

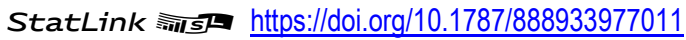

\section{Écart de la rémunération relative par rapport au revenu médian}

Une asymétrie importante de la répartition des travailleurs entre les catégories de revenus est le signe d'inégalités de revenus, qui peuvent affecter la cohésion sociale des communautés et influer fortement sur la croissance économique. Les chiffres sur la répartition des rémunérations entre les niveaux de formation indiquent dans quelle mesure les rémunérations se concentrent autour du revenu médian dans un pays. Le " revenu médian » est calculé sur la base de la rémunération de tous les actifs occupés, sans contrôle des différences de temps de travail. 
Dans les pays membres et partenaires de l'OCDE, la probabilité de gagner plus que le revenu médian augmente avec l'élévation du niveau de formation. En moyenne, dans les pays de l'OCDE, $68 \%$ des diplômés de l'enseignement tertiaire gagnent plus du double du revenu médian calculé sur la base de tous les actifs occupés, qu'ils travaillent à temps plein ou à temps partiel, contre $26 \%$ seulement des adultes dont le niveau de formation est inférieur au deuxième cycle de l'enseignement secondaire. La différence est plus frappante encore si l'analyse porte sur les actifs qui gagnent plus de deux fois plus que le revenu médian. En moyenne, dans les pays de l'OCDE, le pourcentage d'actifs dont la rémunération représente plus du double du revenu médian s'établit à $23 \%$ chez les diplômés de l'enseignement tertiaire, mais à $7 \%$ seulement chez les diplômés du deuxième cycle de l'enseignement secondaire ou de l'enseignement post-secondaire non tertiaire et à $3 \%$ seulement chez ceux dont le niveau de formation est inférieur au deuxième cycle de l'enseignement secondaire (voir le tableau A4.2).

La répartition des travailleurs entre les catégories de revenus est plus asymétrique dans certains pays que dans d'autres. Plus de $80 \%$ des diplômés de l'enseignement tertiaire gagnent plus que le revenu médian au Chili, en Colombie, au Costa Rica, en Hongrie, au Mexique et au Portugal. De surcroît, la moitié d'entre eux gagnent plus de deux fois plus que le revenu médian au Costa Rica et au Mexique. Les pays où les inégalités de revenus sont relativement fortes tendent aussi à compter parmi ceux où l'effectif non diplômé de l'enseignement tertiaire, voire du deuxième cycle de l'enseignement secondaire est le plus élevé (OCDE, 2018[2]).

\section{Graphique A4.3. Pourcentage d'adultes diplômés de l'enseignement tertiaire dont les revenus sont} supérieurs à deux fois le revenu médian, selon le niveau de l'enseignement tertiaire (2017)

Actifs occupés (à temps plein ou partiel) âgés de 25 à 64 ans

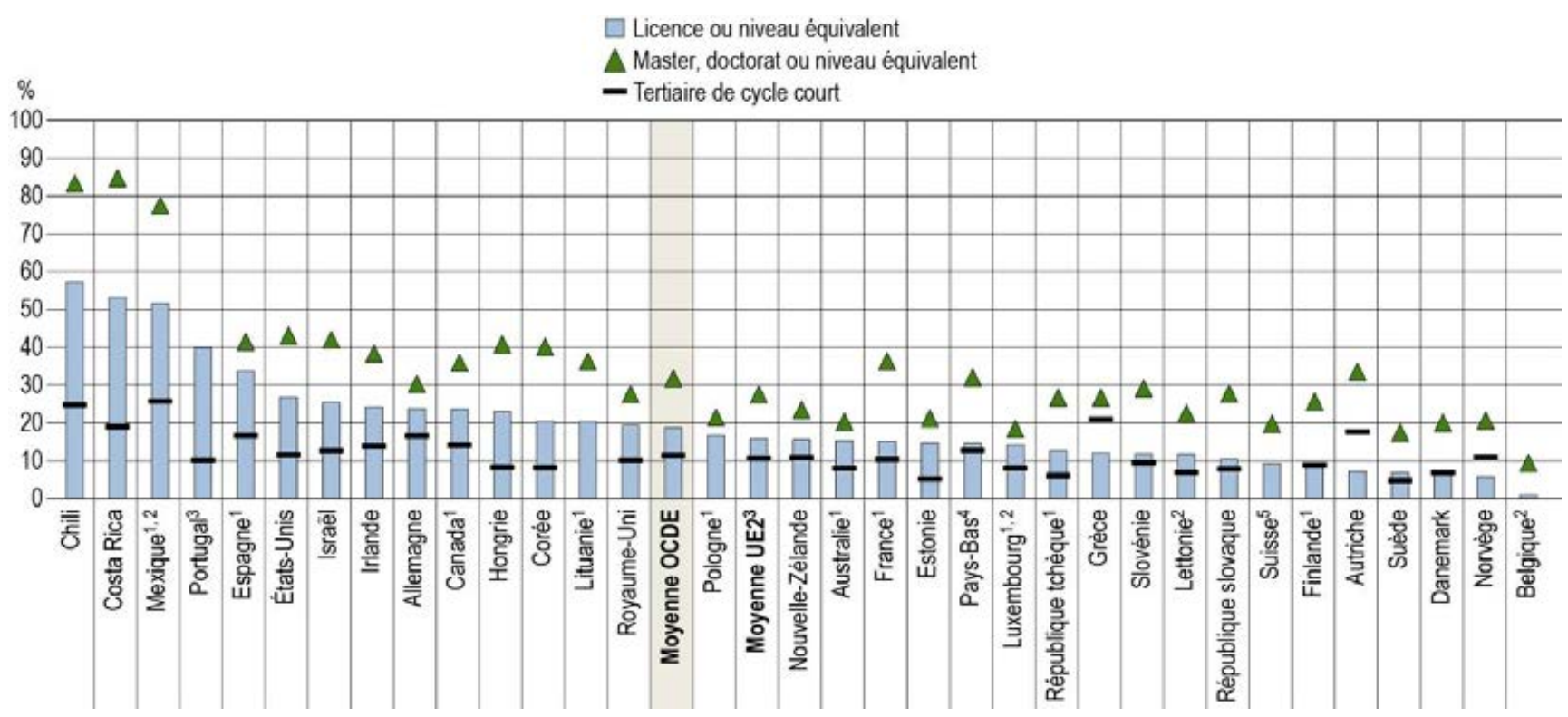

1. L'année de référence n'est pas 2017. Consulter le tableau source pour de plus amples informations.

2. Revenus nets d'impôts sur le revenu.

3. Le niveau licence ou équivalent inclut les niveaux master, doctorat ou équivalents.

4. Les données concernent uniquement les actifs occupés à plein temps toute l'année.

5. Les niveaux licence, master, doctorat ou équivalents incluent l'enseignement tertiaire de cycle court.

Les pays sont classés par ordre décroissant du pourcentage de 25-64 ans titulaires d'une licence ou d'un diplôme équivalent et dont les revenus sont supérieurs à deux fois le revenu médian.

Source : OCDE (2019), base de données de Regards sur l'éducation, http://stats.oecd.org/ Consulter la section " Source » pour tout complément d'information et l'annexe 3 pour les notes (https://doi.org/10.1787/f8d7880d-en). 
La répartition des diplômés de l'enseignement tertiaire entre les catégories de revenus varie parfois sensiblement selon les niveaux de l'enseignement tertiaire. Dans la quasi-totalité des pays de l'OCDE, le pourcentage de travailleurs gagnant plus de deux fois le revenu médian augmente de niveau en niveau dans l'enseignement tertiaire : formation de cycle court, licence, master et, enfin, doctorat. En moyenne, dans les pays de l'OCDE, le pourcentage d'actifs occupés gagnant plus de deux fois le revenu médian s'établit à $11 \%$ après une formation tertiaire de cycle court, À $19 \%$ après une licence et à $32 \%$ après un master ou un doctorat (voir le graphique A4.3).

\section{Revenus du travail relatifs des adultes diplômés de l'enseignement tertiaire, selon le domaine d'études}

L'avantage salarial des diplômés de l'enseignement tertiaire varie aussi en fonction de leur domaine d'études. Dans les 14 pays membres de l'OCDE dont les données sont disponibles, les grands domaines d'études les plus rémunérateurs sont l'ingénierie, les industries de transformation et la construction (6 pays) et les TIC (4 pays). En moyenne, dans les pays de l'OCDE, le pourcentage de diplômés de l'enseignement tertiaire en 2017 s'établit seulement à $14 \%$ dans le domaine de l'ingénierie, des industries de transformation et de la construction et à $4 \%$ dans le domaine des TIC. Avec les rémunérations comme indicateur de la demande sur le marché du travail, ces chiffres suggèrent l'existence d'un déséquilibre entre les diplômés les plus demandés sur le marché et les diplômés présents actuellement sur le marché dans certains pays. Ce déséquilibre pourrait en effet contribuer à expliquer l'avantage salarial important observé dans certains domaines d'études dans quelques-uns de ces pays (voir l'encadré A1.1 dans l'indicateur A1).

Dans certains pays, l'avantage salarial varie peu entre les domaines d'études. C'est le cas en Australie et en Finlande, où le diplôme le plus rémunérateur procure un avantage salarial de $30 \%$ à $40 \%$ plus élevé que le diplôme le moins rémunérateur. Dans d'autres pays, par exemple aux États-Unis et au Royaume-Uni, les diplômés des branches les plus rémunératrices gagnent presque deux fois plus que les diplômés des branches les moins rémunératrices (voir le tableau A4.4). La différence de rémunération entre les domaines d'études peut en partie s'expliquer par l'importance variable du travail à temps plein ou à temps partiel.

Dans certains pays, des domaines d'études sont associés à un désavantage salarial dans l'enseignement tertiaire, par comparaison avec les adultes au plus diplômés du deuxième cycle de l'enseignement secondaire. Au Royaume-Uni par exemple, les diplômés en lettres et arts, en sciences sociales, en journalisme ou en information gagnent moins en moyenne si la formation qu'ils sont suivie relève de l'enseignement tertiaire plutôt que du deuxième cycle de l'enseignement secondaire. Dans le même pays, les diplômés de l'enseignement tertiaire en ingénierie, en industries de transformation ou en construction ou en sciences naturelles, en mathématiques ou en statistiques gagnent $60 \%$ de plus que les diplômés du deuxième cycle de l'enseignement secondaire (voir le graphique A4.4).

Les données des quelques pays capables de désagréger les rémunérations par discipline sont révélatrices des différences marquées qui existent parfois entre les disciplines du même grand domaine d'études. Dans le domaine de la santé par exemple, les diplômés gagnent environ deux fois plus en médecine ou en dentisterie qu'en soins infirmiers et autres disciplines proches dans la quasi-totalité des pays dont les données sont disponibles (voir le tableau A4.4).

\section{Différences de rémunération entre les femmes et les hommes, selon le niveau de formation}

Les femmes ne gagnent autant que les hommes dans aucun pays membre ou partenaire de l'OCDE. Dans les pays de l'OCDE, les diplômées de l'enseignement tertiaire qui travaillent à temps plein ne gagnent que $75 \%$ de la rémunération de leurs homologues masculins. L'écart salarial défavorable aux femmes s'établit à $25 \%$ au niveau de formation égal à l'enseignement tertiaire et est légèrement supérieur à celui qui s'observe aux niveaux de formation inférieurs au deuxième cycle de l'enseignement secondaire (22\%) et égal au deuxième cycle de 
l'enseignement secondaire ou à l'enseignement post-secondaire non tertiaire (également $22 \%$ ) (voir le tableau A4.3).

\section{Graphique A4.4. Revenus du travail relatifs des adultes diplômés de l'enseignement tertiaire, selon le domaine d'études (2017)}

Diplômés de l'enseignement tertiaire (actifs occupés à temps plein ou partiel) âgés de 25 à 64 ans ; deuxième cycle du secondaire (tous domaines d'études confondus) $=100$

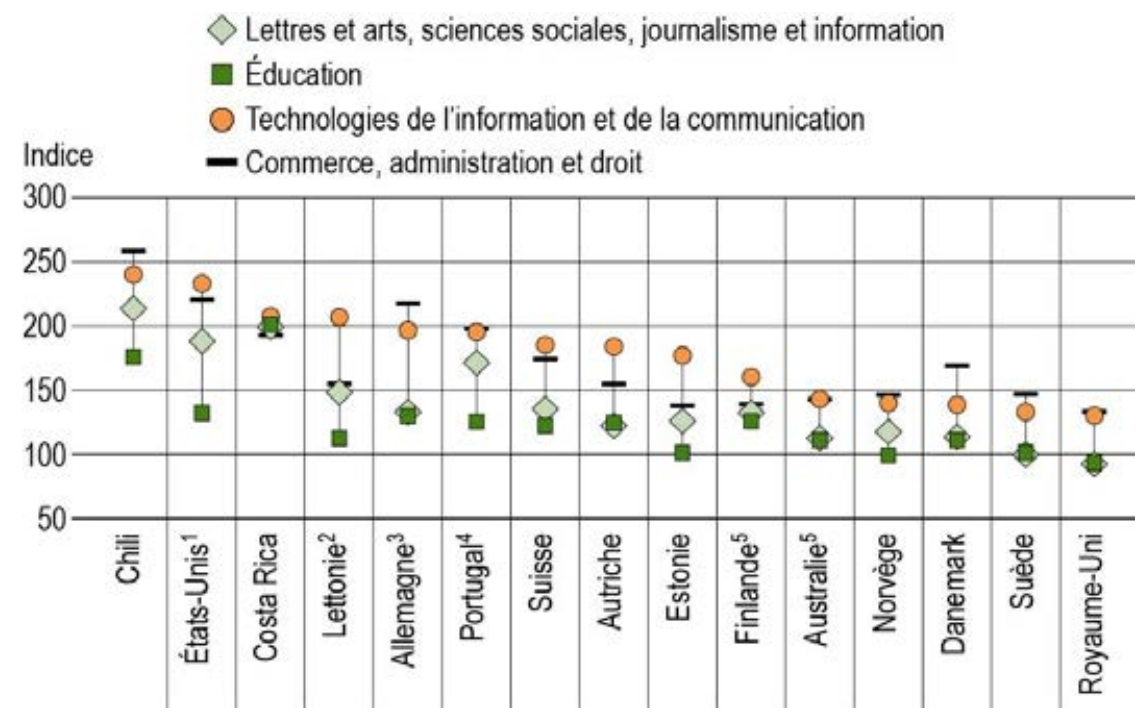

1. Les données se rapportent aux domaines d'études au niveau de la licence.

2. Revenus nets d'impôts sur le revenu.

3. Les revenus se rapportent aux programmes universitaires uniquement.

4. Lettres et arts, sciences sociales, journalisme et information ne comprennent pas le sous-domaines des langues étrangères.

5. L'année de référence n'est pas 2017. Consulter le tableau source pour de plus amples informations.

Les pays sont classés par ordre décroissant des revenus du travail relatifs des adultes âgés de 25 à 64 ans titulaires d'un diplôme tertiaire en technologies de l'information et de la communication.

Source: OCDE (2019), tableau A4.4. Consulter la section "Source» pour tout complément d'information et l'annexe 3 pour les notes (https://doi.org/10.1787/f8d7880d-en).

StatLink 제패 https://doi.org/10.1787/888933977049

Comme les femmes sont plus susceptibles que les hommes de travailler à temps partiel, l'écart de rémunération moyenne (calculée sur la base des travailleurs à temps plein et à temps partiel) est encore plus important entre les sexes. Chez les diplômés de l'enseignement tertiaire, les femmes qui travaillent à temps plein ou à temps partiel ne gagnent en moyenne que $69 \%$ de la rémunération des hommes dans les pays de l'OCDE (OECD, 2019[3]).

Les raisons qui expliquent ces écarts entre les sexes résident dans les stéréotypes sexistes, les conventions sociales et la discrimination envers les femmes (OCDE, 2018[4]), mais également dans les différences de domaines d'études entre les hommes et les femmes. Les hommes sont plus nombreux que les femmes à avoir opté pour des domaines d'études plus rémunérateurs comme l'ingénierie, les industries de transformation et la production ou les TIC, alors que les femmes sont plus nombreuses à avoir choisi des domaines d'études moins rémunérateurs comme l'éducation et les lettres et arts (voir l'indicateur B4).

Le graphique A4.5 montre toutefois que les femmes gagnent moins que les hommes même si elles ont choisi le même domaine d'études qu'eux. II apparaît en effet que les femmes ne gagnent plus que les hommes dans aucun des domaines d'études dont les données sont disponibles - même si l'écart salarial est plus ténu dans 
certains domaines que dans d'autres. Dans la plupart des pays dont les données sont disponibles, l'écart salarial est moins important dans le domaine de l'éducation et des TIC et plus important dans le domaine du commerce, de l'administration et du droit, par comparaison avec l'écart tous domaines d'études confondus. D'autres facteurs peuvent contribuer à expliquer l'écart salarial entre hommes et femmes dans le même domaine d'études, notamment la différence entre les secteurs d'activité, l'évolution de la carrière, le type de professions et le type de contrat.

Graphique A4.5. Revenus des femmes en pourcentage de ceux des hommes, selon le domaine d'études (2017)

\section{Diplômés de l'enseignement tertiaire âgés de 25 à 64 ans qui travaillent à temps plein}

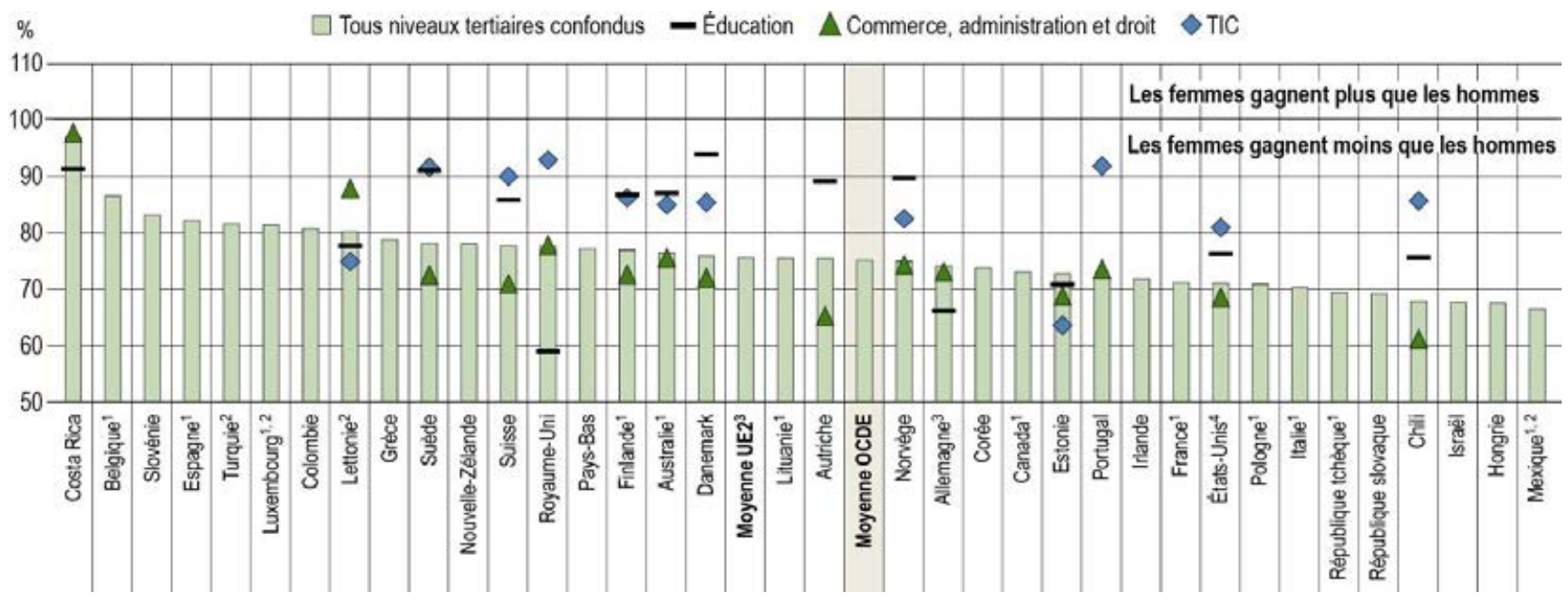

1. L'année de référence n'est pas 2017. Consulter le tableau source pour de plus amples informations.

2. Revenus nets d'impôts sur le revenu.

3. Les revenus se rapportent aux programmes universitaires uniquement.

4. Les données se rapportent aux domaines d'études au niveau de la license.

Les pays sont classés par ordre décroissant des revenus des femmes en pourcentage de ceux des hommes.

Source : OCDE (2019), base de données de Regards sur l'éducation, http://stats.oecd.org/ Consulter la section « Source » pour tout complément d'information et l'annexe 3 pour les notes (https://doi.org/10.1787/f8d7880d-en).

Depuis quelques années, les gouvernements se préoccupent davantage des écarts salariaux entre les sexes. De nombreux pays ont adopté de nouvelles politiques visant à réduire les écarts de rémunération entre les hommes et les femmes. Certains pays ont pris des mesures concrètes, notamment au sujet de la transparence des rémunérations, pour améliorer l'égalité salariale entre les hommes et les femmes (OCDE, 2018[4]). Dans la plupart des pays dont les données sont disponibles, l'écart salarial entre les diplômées et diplômés de l'enseignement tertiaire a diminué entre 2010 et 2017. En moyenne, dans les pays de l'OCDE dont les données des deux années de référence sont disponibles, l'écart s'est réduit d'environ 1.5 point de pourcentage pour s'établir à un peu plus de 5 points de pourcentage en Autriche, en Corée et en Estonie (OECD, 2019[3]).

\section{Définitions}

Le terme « adultes » désigne la population âgée de 25 à 64 ans.

Le niveau de formation correspond au plus haut niveau d'enseignement dont les individus sont diplômés. 
Les domaines d'études sont dérivés des domaines d'études et de formation de la CITE 2013 (CITE-F 2013). La liste de tous les domaines d'études cités dans ce rapport figure dans le Guide du lecteur.

Niveaux de formation : les niveaux de la CITE 2011 sont tous décrits dans le Guide du lecteur, au début du présent rapport.

\section{Méthodologie}

L'analyse de la rémunération relative de la population par niveau de formation et de la répartition des revenus est basée sur les travailleurs à temps plein et à temps partiel. Le temps de travail n'est pas contrôlé, alors qu'il peut influer sur la rémunération en général et sur la répartition en particulier. L'analyse des écarts de rémunération entre les hommes et les femmes porte uniquement sur les travailleurs à temps plein. Concernant la rémunération des travailleurs à temps plein, les pays ont précisé s'ils se sont basés sur une définition spécifique de la condition de travailleur à temps plein ou sur le temps de travail hebdomadaire minimal.

Les données sur les rémunérations se basent sur une période de référence annuelle, mensuelle ou hebdomadaire, selon les pays. La longueur de la période de référence des rémunérations varie aussi. Pour la plupart des pays, les données se rapportent aux revenus avant impôts. Les rémunérations des travailleurs indépendants sont exclues des chiffres de nombreux pays ; il n'existe pas de méthode simple et comparable qui permette de faire la distinction entre les revenus du travail et le rendement du capital investi dans l'entreprise.

Cet indicateur ne tient pas compte de l'impact des revenus effectifs générés par les services publics gratuits. En conséquence, bien que les rémunérations puissent être inférieures dans certains pays que dans d'autres, les soins de santé et l'enseignement, par exemple, peuvent être gratuits.

La rémunération moyenne des hommes et des femmes n'est pas la moyenne simple de la rémunération des hommes et des femmes, mais est calculée sur la base de la rémunération de l'ensemble de la population. Pour calculer cette moyenne globale, la rémunération moyenne des hommes et des femmes est pondérée en fonction du pourcentage d'hommes et de femmes à chaque niveau de formation.

Voir le Guide de l'OCDE pour l'établissement de statistiques internationalement comparables dans le domaine de l'éducation 2018 (OCDE, 2019[5]) pour de plus amples informations. Voir les notes spécifiques aux pays à l'annexe 3 (https://doi.org/10.1787/f8d7880d-en).

\section{Source}

Cet indicateur est basé sur la collecte de données sur l'enseignement et les rémunérations du réseau LSO (Labour Market and Social Outcomes of Learning) de l'OCDE qui est chargé d'élaborer les données relatives aux retombées de l'éducation sur l'économie, le marché du travail et la société. La collecte de données prend en compte la rémunération des actifs occupés durant la période de référence qui travaillent à temps plein ou à temps partiel toute l'année ou pendant une partie de l'année. Cette base de données contient des données sur la dispersion des rémunérations ainsi que sur la rémunération des actifs scolarisés et non scolarisés. Les données de la plupart des pays proviennent d'enquêtes nationales auprès des ménages, telles que les enquêtes sur la population active, les Statistiques communautaires sur le revenu et les conditions de vie (SILC) de I'Union européenne et d'autres collectes de données spécifiques sur les niveaux de rémunération. Un quart environ des pays utilisent les données fiscales ou autres. Voir les remarques spécifiques aux pays sur les sources nationales à l'annexe 3 (https://doi.org/10.1787/f8d7880d-en). 


\section{Remarque concernant les données fournies par Israël}

Les données statistiques concernant Israël sont fournies par et sous la responsabilité des autorités israéliennes compétentes. L'utilisation de ces données par l'OCDE est sans préjudice du statut des hauteurs du Golan, de Jérusalem-Est et des colonies de peuplement israéliennes en Cisjordanie aux termes du droit international.

\section{Références}

OCDE (2019), Guide de l'OCDE pour l'établissement de statistiques internationalement comparables dans le domaine de l'éducation 2018 : Concepts, normes, définitions et classifications, Éditions OCDE, Paris, https://dx.doi.org/10.1787/9789264305380-fr.

OCDE (2018), Atteindre l'égalité femmes-hommes: Un combat difficile, Éditions OCDE, Paris, https://dx.doi.org/10.1787/9789264203426-fr.

OCDE (2018), Regards sur l'éducation 2018 : Les indicateurs de l'OCDE, Éditions OCDE, Paris, https://dx.doi.org/10.1787/eag-2018-fr.

OCDE (2017), Regards sur l'éducation 2017 : Les indicateurs de l'OCDE, Éditions OCDE, Paris, http://dx.doi.org/10.1787/eag-2017-fr.

OECD (2019), Base de données de Regards sur l'éducation - Éducation et revenus, http://stats.oecd.org/Index.aspx?datasetcode=EAG EARNINGS.

\section{Tableaux de l'indicateur A4}

Tableau A4.1

Tableau A4.2

Tableau A4.3

Tableau A4.4
Revenus du travail relatifs des actifs occupés, selon le niveau de formation (2017)

Comparaison du niveau de revenus par rapport au revenu médian, selon le niveau de formation (2017)

Différences de revenus du travail entre les femmes et les hommes travaillant à temps plein, selon le niveau de formation et le groupe d'âge (2017)

Revenus du travail relatifs des adultes diplômés de l'enseignement tertiaire, selon le domaine d'études (2017)

Date butoir pour les données : 19 juillet 2019. Les mises à jour peuvent être consultées en ligne sur : http://dx.doi.org/10.1787/eag-data-en. D'autres données désagrégées sont également disponibles dans la Base de données de Regards sur l'éducation (http://stats.oecd.org/).

StatLink : https://doi.org/10.1787/888933980849 
Tableau A4.1. Revenus du travail relatifs des actifs occupés, selon le niveau de formation (2017)

Adultes âgés de 25 à 64 ans percevant des revenus du travail (actifs occupés à temps plein ou partiel) ; deuxième cycle du secondaire $=100$

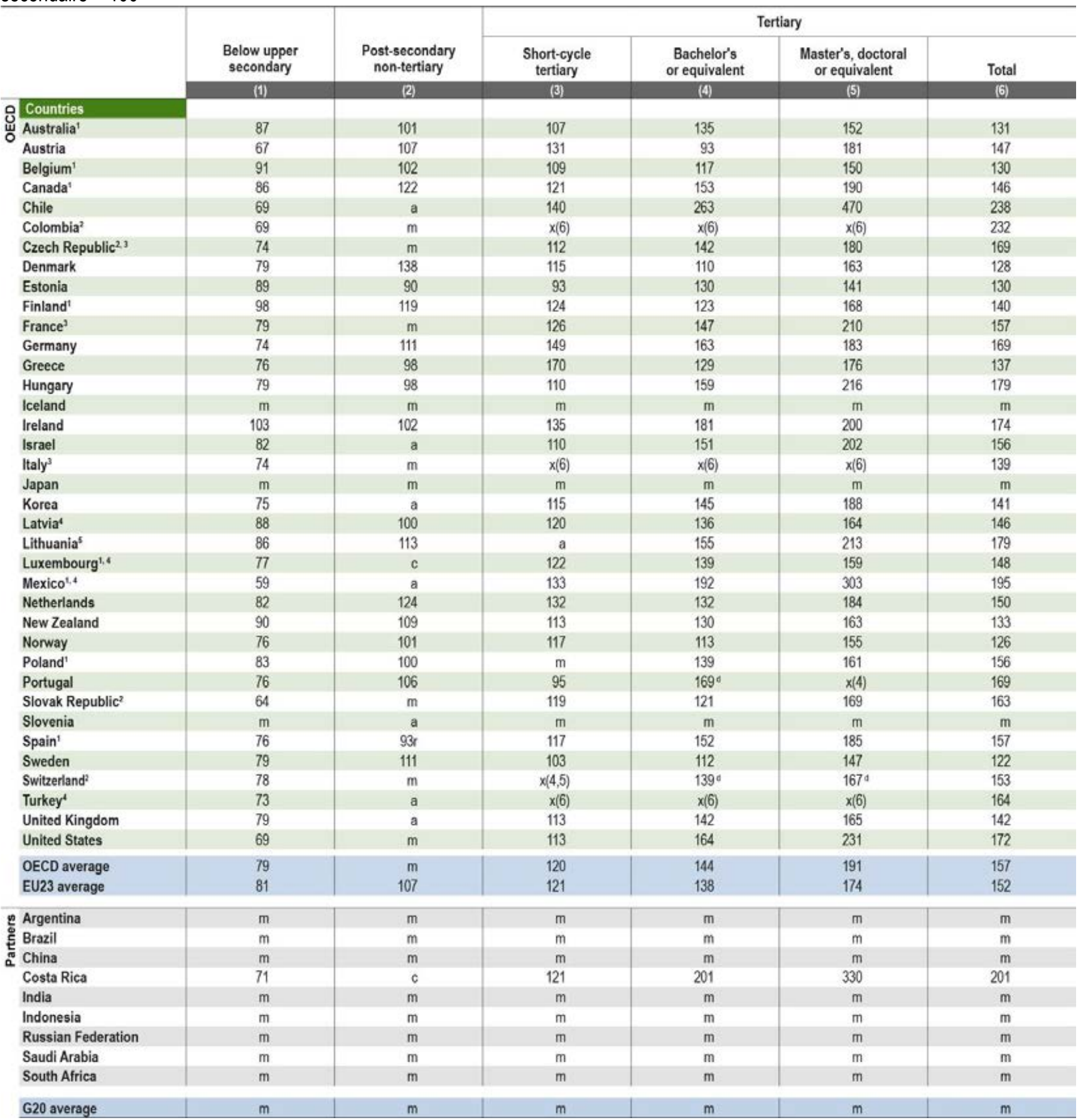

Remarque : Consulter les sections « Définitions » et « Méthodologie » pour de plus amples informations. Les données et d'autres types de ventilations peuvent être consultés sur http://stats.oecd.org/, Base de données de Regards sur l'éducation.

1. Année de référence : 2016.

2. L'indice 100 se rapporte à la combinaison des niveaux 3 et 4 dans la classification CITE 2011 des niveaux de formation.

3. Année de référence : 2015

4. Revenus nets d'impôts sur le revenu.

5. Année de référence : 2014.

Source : OCDE (2019). Consulter la section « Source » pour tout complément d'information et l'annexe 3 pour les notes (https://doi.org/10.1787/f8d7880d-en). Les symboles représentant les données manquantes et les abréviations figurent dans le Guide du lecteur. 
Tableau A4.2. Comparaison du niveau de revenus par rapport au revenu médian, selon le niveau de formation (2017)

Revenu médian des adultes âgés de 25 à 64 ans percevant des revenus du travail (actifs occupés à temps plein ou partiel), tous niveaux de formation confondus

\begin{tabular}{|c|c|c|c|c|c|c|c|c|c|c|c|c|c|c|c|}
\hline & \multicolumn{5}{|c|}{ Below upper secondary } & \multicolumn{5}{|c|}{ Upper secondary or post-secondary non-tertiary } & \multicolumn{5}{|c|}{ Tertiary } \\
\hline & $\begin{array}{l}\text { At or } \\
\text { below } \\
\text { half } \\
\text { of the } \\
\text { median }\end{array}$ & $\begin{array}{c}\text { More } \\
\text { than } \\
\text { half the } \\
\text { median } \\
\text { but at or } \\
\text { below the } \\
\text { median }\end{array}$ & $\begin{array}{l}\text { More } \\
\text { than the } \\
\text { median } \\
\text { but at or } \\
\text { below } 1.5 \\
\text { times the } \\
\text { median }\end{array}$ & $\begin{array}{l}\text { More } \\
\text { than } 1.5 \\
\text { times the } \\
\text { median } \\
\text { but at or } \\
\text { below } \\
\text { twice the } \\
\text { median }\end{array}$ & $\begin{array}{l}\text { More } \\
\text { than } \\
\text { twice the } \\
\text { median }\end{array}$ & $\begin{array}{l}\text { At or } \\
\text { below } \\
\text { half } \\
\text { of the } \\
\text { median }\end{array}$ & $\begin{array}{c}\text { More } \\
\text { than } \\
\text { half the } \\
\text { median } \\
\text { but at or } \\
\text { below the } \\
\text { median }\end{array}$ & $\begin{array}{l}\text { More } \\
\text { than the } \\
\text { median } \\
\text { but at or } \\
\text { below } 1.5 \\
\text { times the } \\
\text { median }\end{array}$ & $\begin{array}{l}\text { More } \\
\text { than } 1.5 \\
\text { times the } \\
\text { median } \\
\text { but at or } \\
\text { below } \\
\text { twice the } \\
\text { median }\end{array}$ & $\begin{array}{l}\text { More } \\
\text { than } \\
\text { twice the } \\
\text { median }\end{array}$ & $\begin{array}{l}\text { At or } \\
\text { below } \\
\text { half } \\
\text { of the } \\
\text { median }\end{array}$ & $\begin{array}{l}\text { More } \\
\text { than } \\
\text { half the } \\
\text { median } \\
\text { but at or } \\
\text { below the } \\
\text { median }\end{array}$ & $\begin{array}{l}\text { More } \\
\text { than the } \\
\text { median } \\
\text { but at or } \\
\text { below } 1.5 \\
\text { times the } \\
\text { median }\end{array}$ & $\begin{array}{l}\text { More } \\
\text { than } 1.5 \\
\text { times the } \\
\text { median } \\
\text { but at or } \\
\text { below } \\
\text { twice the } \\
\text { median }\end{array}$ & $\begin{array}{l}\text { More } \\
\text { than } \\
\text { twice the } \\
\text { median }\end{array}$ \\
\hline & (i) & (2) & (3) & (4) & (5) & (6) & (7) & (8) & (9) & (10) & (11) & (12) & (13) & (14) & (15) \\
\hline \multicolumn{16}{|l|}{ Countries } \\
\hline Australia' & 13 & 57 & 22 & 4 & 4 & 8 & 50 & 29 & 8 & 6 & 5 & 31 & 36 & 14 & 14 \\
\hline Austria & 37 & 42 & 16 & 4 & 1 & 21 & 32 & 30 & 11 & 6 & 16 & 19 & 23 & 18 & 23 \\
\hline Belgium $^{2}$ & 10 & 65 & 24 & c & c & 5 & 59 & 33 & 3 & c & 2 & 30 & 50 & 14 & 4 \\
\hline Canada' & 38 & 33 & 16 & 6 & 7 & 29 & 28 & 21 & 11 & 11 & 21 & 22 & 21 & 15 & 22 \\
\hline Chile & 25 & 50 & 18 & 4 & 3 & 13 & 41 & 26 & 10 & 10 & 4 & 16 & 18 & 14 & 48 \\
\hline Colombia & 36 & 36 & 21 & 5 & 3 & 18 & 28 & 35 & 10 & 9 & 7 & 12 & 22 & 14 & 45 \\
\hline Czech Republic' & 22 & 58 & 17 & 2 & 0 & 10 & 47 & 32 & 8 & 4 & 3 & 18 & 37 & 18 & 23 \\
\hline Denmark & 29 & 40 & 24 & 4 & 2 & 17 & 38 & 34 & 8 & 4 & 14 & 24 & 38 & 13 & 11 \\
\hline Estonia & 21 & 47 & 18 & 9 & 5 & 14 & 48 & 19 & 10 & 8 & 9 & 31 & 26 & 17 & 17 \\
\hline Finland' & 29 & 36 & 25 & 6 & 3 & 22 & 38 & 30 & 7 & 3 & 14 & 22 & 33 & 17 & 15 \\
\hline France $^{3}$ & 34 & 40 & 18 & 5 & 3 & 22 & 37 & 28 & 8 & 5 & 10 & 21 & 32 & 18 & 19 \\
\hline Germany & 40 & 36 & 17 & 5 & 2 & 22 & 35 & 27 & 10 & 5 & 12 & 18 & 25 & 20 & 25 \\
\hline Greece & 33 & 39 & 19 & 4 & 4 & 18 & 36 & 30 & 10 & 6 & 10 & 23 & 33 & 20 & 14 \\
\hline Hungary & 0 & 80 & 15 & 3 & 1 & 0 & 60 & 26 & 8 & 6 & 0 & 18 & 32 & 20 & 29 \\
\hline Iceland & $\mathrm{m}$ & $\mathrm{m}$ & $\mathrm{m}$ & m & $\mathrm{m}$ & $\mathrm{m}$ & $\mathrm{m}$ & $\mathrm{m}$ & $\mathrm{m}$ & m & $\mathrm{m}$ & $\mathrm{m}$ & $\mathrm{m}$ & $\mathrm{m}$ & $\mathrm{m}$ \\
\hline Ireland & 40 & 29 & 20 & 6 & 6 & 29 & 33 & 22 & 8 & 7 & 16 & 20 & 21 & 18 & 25 \\
\hline Israel & 23 & 54 & 14 & 5 & 4 & 20 & 44 & 20 & 8 & 9 & 10 & 26 & 22 & 14 & 27 \\
\hline Italy' & 31 & 34 & 25 & 7 & 3 & 18 & 29 & 30 & 12 & 10 & 15 & 20 & 27 & 15 & 23 \\
\hline Japan & $\mathrm{m}$ & m & $\mathrm{m}$ & m & m & $\mathrm{m}$ & $\mathrm{m}$ & $\mathrm{m}$ & $\mathrm{m}$ & $\mathrm{m}$ & $\mathrm{m}$ & $\mathrm{m}$ & $\mathrm{m}$ & $\mathrm{m}$ & $\mathrm{m}$ \\
\hline Korea & 31 & 51 & 14 & 3 & c & 16 & 46 & 23 & 8 & 6 & 7 & 28 & 29 & 16 & 19 \\
\hline Latvia ${ }^{2}$ & 12 & 71 & 13 & 2 & 3 & 10 & 63 & 20 & 3 & 4 & 3 & 41 & 32 & 9 & 15 \\
\hline Lithuania $^{4}$ & 31 & 44 & 13 & 8 & 3 & 20 & 43 & 19 & 11 & 7 & 15 & 22 & 20 & 17 & 27 \\
\hline Luxembourg', & 20 & 65 & 11 & 4 & 1 & 12 & 52 & 20 & 12 & 3 & 3 & 30 & 30 & 21 & 16 \\
\hline Mexico, & 29 & 38 & 21 & 8 & 6 & 12 & 26 & 25 & 15 & 21 & 5 & 11 & 15 & 17 & 52 \\
\hline Netherlands $\mathrm{s}^{5}$ & 33 & 36 & 24 & 5 & 2 & 22 & 35 & 27 & 10 & 5 & 15 & 21 & 26 & 18 & 21 \\
\hline New Zealand & 24 & 41 & 24 & 7 & 5 & 19 & 35 & 26 & 12 & 8 & 14 & 25 & 27 & 18 & 16 \\
\hline Norway & 31 & 41 & 21 & 5 & 2 & 15 & 39 & 32 & 9 & 4 & 12 & 23 & 39 & 14 & 11 \\
\hline Poland' & 0 & 73 & 20 & 5 & 2 & 0 & 58 & 28 & 9 & 5 & 0 & 28 & 34 & 17 & 20 \\
\hline Portugal & 9 & 55 & 25 & 6 & 5 & 6 & 40 & 29 & 10 & 14 & 3 & 14 & 23 & 20 & 40 \\
\hline Slovak Republic & 37 & 45 & 14 & 3 & 1 & 18 & 36 & 29 & 11 & 6 & 12 & 17 & 28 & 19 & 25 \\
\hline Slovenia & 0 & 84 & 14 & 1 & 0 & 0 & 64 & 28 & 6 & 2 & 0 & 22 & 33 & 25 & 21 \\
\hline Spain' & 39 & 29 & 20 & 8 & 5 & 27 & 28 & 22 & 13 & 11 & 16 & 17 & 19 & 16 & 32 \\
\hline Sweden & 26 & 44 & 26 & 4 & 1 & 16 & 36 & 36 & 9 & 4 & 15 & 25 & 37 & 14 & 10 \\
\hline Switzerland & 29 & 51 & 18 & 1 & c & 21 & 40 & 30 & 6 & 3 & 10 & 23 & 33 & 19 & 15 \\
\hline Turkey ${ }^{2}$ & 30 & 46 & 18 & 5 & 1 & 16 & 36 & 27 & 14 & 7 & 11 & 13 & 17 & 26 & 33 \\
\hline United Kingdom & 28 & 43 & 20 & 5 & 3 & 21 & 39 & 25 & 10 & 6 & 11 & 24 & 27 & 18 & 20 \\
\hline United States & 42 & 40 & 11 & 4 & 3 & 26 & 38 & 20 & 9 & 8 & 13 & 22 & 22 & 15 & 28 \\
\hline $\mathrm{OECD}$ average & 26 & 48 & 19 & 5 & 3 & 16 & 41 & 27 & 9 & 7 & 10 & 22 & 28 & 17 & 23 \\
\hline EU23 average & 24 & 49 & 19 & 5 & 3 & 15 & 43 & 27 & 9 & 6 & 9 & 23 & 30 & 17 & 21 \\
\hline
\end{tabular}

\begin{tabular}{|c|c|c|c|c|c|c|c|c|c|c|c|c|c|c|c|}
\hline e Argentina & $\mathrm{m}$ & m & m & $\mathrm{m}$ & $\mathrm{m}$ & $\mathrm{m}$ & $\mathrm{m}$ & $\mathrm{m}$ & $\mathrm{m}$ & $\mathrm{m}$ & $\mathrm{m}$ & $\mathrm{m}$ & $\mathrm{m}$ & $\mathrm{m}$ & $\mathrm{m}$ \\
\hline §. Brazil & $\mathrm{m}$ & m & $\mathrm{m}$ & $\mathrm{m}$ & m & $\mathrm{m}$ & $\mathrm{m}$ & $\mathrm{m}$ & $\mathrm{m}$ & $\mathrm{m}$ & m & $\mathrm{m}$ & $\mathrm{m}$ & $\mathrm{m}$ & $\mathrm{m}$ \\
\hline China & $\mathrm{m}$ & $\mathrm{m}$ & $\mathrm{m}$ & $\mathrm{m}$ & $\mathrm{m}$ & $\mathrm{m}$ & $\mathrm{m}$ & $\mathrm{m}$ & $\mathrm{m}$ & m & $\mathrm{m}$ & $\mathrm{m}$ & $\mathrm{m}$ & $\mathrm{m}$ & $\mathrm{m}$ \\
\hline Costa Rica & 22 & 50 & 21 & 5 & 3 & 10 & 37 & 31 & 11 & 11 & 3 & 12 & 20 & 15 & 50 \\
\hline India & $\mathrm{m}$ & $\mathrm{m}$ & $\mathrm{m}$ & $\mathrm{m}$ & $\mathrm{m}$ & $\mathrm{m}$ & $\mathrm{m}$ & $\mathrm{m}$ & $\mathrm{m}$ & $\mathrm{m}$ & $\mathrm{m}$ & $\mathrm{m}$ & $\mathrm{m}$ & $\mathrm{m}$ & $\mathrm{m}$ \\
\hline Indonesia & $\mathrm{m}$ & $\mathrm{m}$ & $\mathrm{m}$ & $\mathrm{m}$ & $\mathrm{m}$ & m & $\mathrm{m}$ & $\mathrm{m}$ & $\mathrm{m}$ & $\mathrm{m}$ & $\mathrm{m}$ & $\mathrm{m}$ & $\mathrm{m}$ & $\mathrm{m}$ & $\mathrm{m}$ \\
\hline Russian Federation & $m$ & $m$ & $\mathrm{~m}$ & $\mathrm{~m}$ & m & $\mathrm{m}$ & $m$ & $\mathrm{~m}$ & m & $m$ & $\mathrm{~m}$ & $m$ & $m$ & m & $\mathrm{m}$ \\
\hline Saudi Arabia & $\mathrm{m}$ & $\mathrm{m}$ & $\mathrm{m}$ & $\mathrm{m}$ & $\mathrm{m}$ & $\mathrm{m}$ & $\mathrm{m}$ & $\mathrm{m}$ & $\mathrm{m}$ & $\mathrm{m}$ & $\mathrm{m}$ & $\mathrm{m}$ & $\mathrm{m}$ & $\mathrm{m}$ & $\mathrm{m}$ \\
\hline South Africa & $\mathrm{m}$ & $\mathrm{m}$ & m & $\mathrm{m}$ & $\mathrm{m}$ & $\mathrm{m}$ & m & $\mathrm{m}$ & $\mathrm{m}$ & $\mathrm{m}$ & $\mathrm{m}$ & $m$ & $\mathrm{~m}$ & $\mathrm{~m}$ & $\mathrm{~m}$ \\
\hline
\end{tabular}

\begin{tabular}{l|c|c|c|c|c|c|c|c|c|c|c|c|c|c|c|} 
G20 average & $m$ & $m$ & $m$ & $m$ & $m$ & $m$ & $m$ & $m$ & $m$ & $m$ & $m$ & $m$ & $m$ & $m$ & $m$ \\
\hline
\end{tabular}

Remarque : Consulter les sections " Définitions » et « Méthodologie » pour de plus amples informations. Les données et d'autres types de ventilations peuvent être consultés sur http://stats.oecd.org/, Base de données de Regards sur l'éducation.

1. Année de référence : 2016.

2. Revenus nets d'impôts sur le revenu.

3. Année de référence : 2015.

4. Année de référence : 2014.

5. Les données concernent uniquement les actifs occupés à plein temps toute l'année.

Source : OCDE (2019). Consulter la section « Source » pour tout complément d'information et l'annexe 3 pour les notes (https://doi.org/10.1787/f8d7880d-en). Les symboles représentant les données manquantes et les abréviations figurent dans le Guide du lecteur. 
Tableau A4.3. Différences de revenus du travail entre les femmes et les hommes travaillant à temps plein, selon le niveau de formation et le groupe d'âge (2017

Population adulte percevant des revenus du travail (actifs occupés à temps plein) ; revenus du travail annuels moyens des femmes en pourcentage de ceux des hommes

\begin{tabular}{|c|c|c|c|c|c|c|c|c|c|c|c|c|c|c|c|}
\hline & \multicolumn{5}{|c|}{ Below upper secondary } & \multicolumn{5}{|c|}{ Upper secondary or post-secondary non-tertiary } & \multicolumn{5}{|c|}{ Tertiary } \\
\hline & $\begin{array}{l}\text { At or } \\
\text { below } \\
\text { half } \\
\text { of the } \\
\text { median }\end{array}$ & $\begin{array}{c}\text { More } \\
\text { than } \\
\text { half the } \\
\text { median } \\
\text { but at or } \\
\text { below the } \\
\text { median }\end{array}$ & $\begin{array}{l}\text { More } \\
\text { than the } \\
\text { median } \\
\text { but at or } \\
\text { below } 1.5 \\
\text { times the } \\
\text { median }\end{array}$ & $\begin{array}{l}\text { More } \\
\text { than } 1.5 \\
\text { times the } \\
\text { median } \\
\text { but at or } \\
\text { below } \\
\text { twice the } \\
\text { median }\end{array}$ & $\begin{array}{l}\text { More } \\
\text { than } \\
\text { twice the } \\
\text { median }\end{array}$ & $\begin{array}{c}\text { At or } \\
\text { below } \\
\text { half } \\
\text { of the } \\
\text { median }\end{array}$ & $\begin{array}{c}\text { More } \\
\text { than } \\
\text { half the } \\
\text { median } \\
\text { but at or } \\
\text { below the } \\
\text { median }\end{array}$ & $\begin{array}{l}\text { More } \\
\text { than the } \\
\text { median } \\
\text { but at or } \\
\text { below } 1.5 \\
\text { times the } \\
\text { median }\end{array}$ & $\begin{array}{l}\text { More } \\
\text { than } 1.5 \\
\text { times the } \\
\text { median } \\
\text { but at or } \\
\text { below } \\
\text { twice the } \\
\text { median }\end{array}$ & $\begin{array}{l}\text { More } \\
\text { than } \\
\text { twice the } \\
\text { median }\end{array}$ & $\begin{array}{l}\text { At or } \\
\text { below } \\
\text { half } \\
\text { of the } \\
\text { median }\end{array}$ & $\begin{array}{l}\text { More } \\
\text { than } \\
\text { half the } \\
\text { median } \\
\text { but at or } \\
\text { below the } \\
\text { median }\end{array}$ & $\begin{array}{l}\text { More } \\
\text { than the } \\
\text { median } \\
\text { but at or } \\
\text { below } 1.5 \\
\text { times the } \\
\text { median }\end{array}$ & $\begin{array}{l}\text { More } \\
\text { than } 1.5 \\
\text { times the } \\
\text { median } \\
\text { but at or } \\
\text { below } \\
\text { twice the } \\
\text { median }\end{array}$ & $\begin{array}{c}\text { More } \\
\text { than } \\
\text { twice the } \\
\text { median }\end{array}$ \\
\hline & (i) & (2) & (3) & (4) & (5) & (6) & (7) & (8) & (9) & (10) & (11) & (12) & (13) & (14) & (15) \\
\hline \multicolumn{16}{|l|}{ Countries } \\
\hline 㞻 Australia ${ }^{2}$ & 13 & 57 & 22 & 4 & 4 & 8 & 50 & 29 & 8 & 6 & 5 & 31 & 36 & 14 & 14 \\
\hline Austria & 37 & 42 & 16 & 4 & 1 & 21 & 32 & 30 & 11 & 6 & 16 & 19 & 23 & 18 & 23 \\
\hline Belgium $^{2}$ & 10 & 65 & 24 & c & c & 5 & 59 & 33 & 3 & c & 2 & 30 & 50 & 14 & 4 \\
\hline Canada' & 38 & 33 & 16 & 6 & 7 & 29 & 28 & 21 & 11 & 11 & 21 & 22 & 21 & 15 & 22 \\
\hline Chile & 25 & 50 & 18 & 4 & 3 & 13 & 41 & 26 & 10 & 10 & 4 & 16 & 18 & 14 & 48 \\
\hline Colombia & 36 & 36 & 21 & 5 & 3 & 18 & 28 & 35 & 10 & 9 & 7 & 12 & 22 & 14 & 45 \\
\hline Czech Republic' & 22 & 58 & 17 & 2 & 0 & 10 & 47 & 32 & 8 & 4 & 3 & 18 & 37 & 18 & 23 \\
\hline Denmark & 29 & 40 & 24 & 4 & 2 & 17 & 38 & 34 & 8 & 4 & 14 & 24 & 38 & 13 & 11 \\
\hline Estonia & 21 & 47 & 18 & 9 & 5 & 14 & 48 & 19 & 10 & 8 & 9 & 31 & 26 & 17 & 17 \\
\hline Finland' & 29 & 36 & 25 & 6 & 3 & 22 & 38 & 30 & 7 & 3 & 14 & 22 & 33 & 17 & 15 \\
\hline France ${ }^{3}$ & 34 & 40 & 18 & 5 & 3 & 22 & 37 & 28 & 8 & 5 & 10 & 21 & 32 & 18 & 19 \\
\hline Germany & 40 & 36 & 17 & 5 & 2 & 22 & 35 & 27 & 10 & 5 & 12 & 18 & 25 & 20 & 25 \\
\hline Greece & 33 & 39 & 19 & 4 & 4 & 18 & 36 & 30 & 10 & 6 & 10 & 23 & 33 & 20 & 14 \\
\hline Hungary & 0 & 80 & 15 & 3 & 1 & 0 & 60 & 26 & 8 & 6 & 0 & 18 & 32 & 20 & 29 \\
\hline Iceland & $\mathrm{m}$ & $\mathrm{m}$ & $\mathrm{m}$ & $\mathrm{m}$ & $\mathrm{m}$ & $\mathrm{m}$ & $\mathrm{m}$ & $\mathrm{m}$ & $\mathrm{m}$ & $\mathrm{m}$ & $\mathrm{m}$ & $\mathrm{m}$ & $\mathrm{m}$ & m & $\mathrm{m}$ \\
\hline Ireland & 40 & 29 & 20 & 6 & 6 & 29 & 33 & 22 & 8 & 7 & 16 & 20 & 21 & 18 & 25 \\
\hline Israel & 23 & 54 & 14 & 5 & 4 & 20 & 44 & 20 & 8 & 9 & 10 & 26 & 22 & 14 & 27 \\
\hline Italy & 31 & 34 & 25 & 7 & 3 & 18 & 29 & 30 & 12 & 10 & 15 & 20 & 27 & 15 & 23 \\
\hline Japan & $\mathrm{m}$ & $\mathrm{m}$ & m & m & $\mathrm{m}$ & m & m & $\mathrm{m}$ & $\mathrm{m}$ & m & m & m & m & m & $\mathrm{m}$ \\
\hline Korea & 31 & 51 & 14 & 3 & c & 16 & 46 & 23 & 8 & 6 & 7 & 28 & 29 & 16 & 19 \\
\hline Latvia ${ }^{2}$ & 12 & 71 & 13 & 2 & 3 & 10 & 63 & 20 & 3 & 4 & 3 & 41 & 32 & 9 & 15 \\
\hline Lithuania & 31 & 44 & 13 & 8 & 3 & 20 & 43 & 19 & 11 & 7 & 15 & 22 & 20 & 17 & 27 \\
\hline Luxembourg't.2 & 20 & 65 & 11 & 4 & 1 & 12 & 52 & 20 & 12 & 3 & 3 & 30 & 30 & 21 & 16 \\
\hline Mexico & 29 & 38 & 21 & 8 & 6 & 12 & 26 & 25 & 15 & 21 & 5 & 11 & 15 & 17 & 52 \\
\hline Netherlands ${ }^{8}$ & 33 & 36 & 24 & 5 & 2 & 22 & 35 & 27 & 10 & 5 & 15 & 21 & 26 & 18 & 21 \\
\hline New Zealand & 24 & 41 & 24 & 7 & 5 & 19 & 35 & 26 & 12 & 8 & 14 & 25 & 27 & 18 & 16 \\
\hline Norway & 31 & 41 & 21 & 5 & 2 & 15 & 39 & 32 & 9 & 4 & 12 & 23 & 39 & 14 & 11 \\
\hline Poland' & 0 & 73 & 20 & 5 & 2 & 0 & 58 & 28 & 9 & 5 & 0 & 28 & 34 & 17 & 20 \\
\hline Portugal & 9 & 55 & 25 & 6 & 5 & 6 & 40 & 29 & 10 & 14 & 3 & 14 & 23 & 20 & 40 \\
\hline Slovak Republic & 37 & 45 & 14 & 3 & 1 & 18 & 36 & 29 & 11 & 6 & 12 & 17 & 28 & 19 & 25 \\
\hline Slovenia & 0 & 84 & 14 & 1 & 0 & 0 & 64 & 28 & 6 & 2 & 0 & 22 & 33 & 25 & 21 \\
\hline Spain' & 39 & 29 & 20 & 8 & 5 & 27 & 28 & 22 & 13 & 11 & 16 & 17 & 19 & 16 & 32 \\
\hline Sweden & 26 & 44 & 26 & 4 & 1 & 16 & 36 & 36 & 9 & 4 & 15 & 25 & 37 & 14 & 10 \\
\hline Switzerland & 29 & 51 & 18 & 1 & c & 21 & 40 & 30 & 6 & 3 & 10 & 23 & 33 & 19 & 15 \\
\hline Turkey $^{2}$ & 30 & 46 & 18 & 5 & 1 & 16 & 36 & 27 & 14 & 7 & 11 & 13 & 17 & 26 & 33 \\
\hline United Kingdom & 28 & 43 & 20 & 5 & 3 & 21 & 39 & 25 & 10 & 6 & 11 & 24 & 27 & 18 & 20 \\
\hline United States & 42 & 40 & 11 & 4 & 3 & 26 & 38 & 20 & 9 & 8 & 13 & 22 & 22 & 15 & 28 \\
\hline $\mathrm{OECD}$ average & 26 & 48 & 19 & 5 & 3 & 16 & 41 & 27 & 9 & 7 & 10 & 22 & 28 & 17 & 23 \\
\hline EU23 average & 24 & 49 & 19 & 5 & 3 & 15 & 43 & 27 & 9 & 6 & 9 & 23 & 30 & 17 & 21 \\
\hline e Argentina & $\mathrm{m}$ & $\mathrm{m}$ & $\mathrm{m}$ & $\mathrm{m}$ & $\mathrm{m}$ & $\mathrm{m}$ & $\mathrm{m}$ & $\mathrm{m}$ & $\mathrm{m}$ & $\mathrm{m}$ & $\mathrm{m}$ & $\mathrm{m}$ & $\mathrm{m}$ & $\mathrm{m}$ & $\mathrm{m}$ \\
\hline Brazil & $\mathrm{m}$ & $\mathrm{m}$ & $\mathrm{m}$ & $\mathrm{m}$ & $\mathrm{m}$ & $\mathrm{m}$ & $\mathrm{m}$ & $\mathrm{m}$ & $\mathrm{m}$ & $\mathrm{m}$ & $\mathrm{m}$ & $\mathrm{m}$ & $\mathrm{m}$ & $\mathrm{m}$ & $\mathrm{m}$ \\
\hline China & m & $\mathrm{m}$ & $\mathrm{m}$ & m & m & $\mathrm{m}$ & $\mathrm{m}$ & $\mathrm{m}$ & m & $\mathrm{m}$ & m & $\mathrm{m}$ & $\mathrm{m}$ & m & $\mathrm{m}$ \\
\hline Costa Rica & 22 & 50 & 21 & 5 & 3 & 10 & 37 & 31 & 11 & 11 & 3 & 12 & 20 & 15 & 50 \\
\hline India & $\mathrm{m}$ & $\mathrm{m}$ & $\mathrm{m}$ & $\mathrm{m}$ & $\mathrm{m}$ & $\mathrm{m}$ & $\mathrm{m}$ & $\mathrm{m}$ & $\mathrm{m}$ & m & $\mathrm{m}$ & $\mathrm{m}$ & $\mathrm{m}$ & $\mathrm{m}$ & $\mathrm{m}$ \\
\hline Indonesia & $\mathrm{m}$ & $\mathrm{m}$ & $\mathrm{m}$ & $\mathrm{m}$ & $\mathrm{m}$ & $\mathrm{m}$ & $\mathrm{m}$ & $\mathrm{m}$ & $\mathrm{m}$ & $\mathrm{m}$ & $\mathrm{m}$ & $\mathrm{m}$ & $\mathrm{m}$ & $\mathrm{m}$ & $\mathrm{m}$ \\
\hline Russian Federation & $\mathrm{m}$ & $\mathrm{m}$ & $\mathrm{m}$ & $\mathrm{m}$ & $\mathrm{m}$ & $\mathrm{m}$ & m & $\mathrm{m}$ & m & $\mathrm{m}$ & $\mathrm{m}$ & $\mathrm{m}$ & $\mathrm{m}$ & m & $\mathrm{m}$ \\
\hline Saudi Arabia & $\mathrm{m}$ & $\mathrm{m}$ & $\mathrm{m}$ & $\mathrm{m}$ & $\mathrm{m}$ & $\mathrm{m}$ & $\mathrm{m}$ & $\mathrm{m}$ & $\mathrm{m}$ & $\mathrm{m}$ & $\mathrm{m}$ & $\mathrm{m}$ & $\mathrm{m}$ & $\mathrm{m}$ & $\mathrm{m}$ \\
\hline South Africa & $\mathrm{m}$ & $\mathrm{m}$ & $\mathrm{m}$ & $\mathrm{m}$ & $\mathrm{m}$ & m & $\mathrm{m}$ & $\mathrm{m}$ & $\mathrm{m}$ & m & m & m & $\mathrm{m}$ & $\mathrm{m}$ & m \\
\hline
\end{tabular}

G20 average

Remarque : Consulter les sections « Définitions » et « Méthodologie » pour de plus amples informations. Les données et d'autres types de ventilations peuvent être consultés sur http://stats.oecd.org/, Base de données de Regards sur l'éducation.

1. Année de référence : 2016 .

2. Année de référence : 2015

3. Revenus nets d'impôts sur le revenu.

4. Année de référence : 2014.

Source : OCDE (2019). Consulter la section « Source » pour tout complément d'information et l'annexe 3 pour les notes (https://doi.org/10.1787/f8d7880d-en).

Les symboles représentant les données manquantes et les abréviations figurent dans le Guide du lecteur. 
Tableau A4.4. Revenus du travail relatifs des adultes diplômés de l'enseignement tertiaire, selon le domaine d'études (2017) Adultes âgés de 25 à 64 ans percevant des revenus du travail (actifs occupés à temps plein ou partiel) ; deuxième cycle du secondaire (tous domaines) $=100$

\begin{tabular}{|c|c|c|c|c|c|c|c|c|c|c|c|c|c|c|}
\hline & \multirow[b]{2}{*}{ 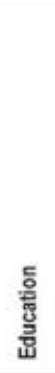 } & \multicolumn{2}{|c|}{$\begin{array}{c}\text { Arts or humanities } \\
\text { (except languages), } \\
\text { social sciences, } \\
\text { journalism and } \\
\text { information }\end{array}$} & \multirow{2}{*}{ 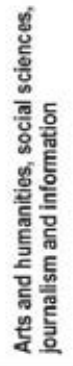 } & \multicolumn{2}{|c|}{$\begin{array}{c}\text { Business } \\
\text { and administration } \\
\text { or law }\end{array}$} & \multirow{2}{*}{ 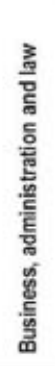 } & \multirow{2}{*}{ 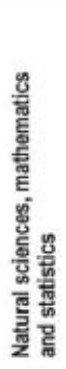 } & \multirow{2}{*}{ 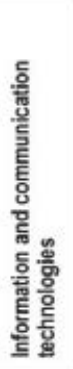 } & \multirow{2}{*}{ 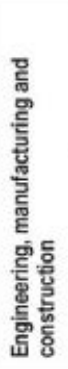 } & \multicolumn{2}{|c|}{ Health } & \multirow[b]{2}{*}{ 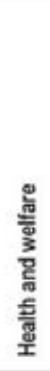 } & \multirow[b]{2}{*}{ 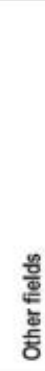 } \\
\hline & & $\frac{2}{2}$ & 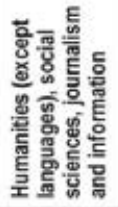 & & 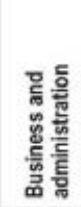 & 㞼 & & & & & 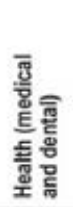 & 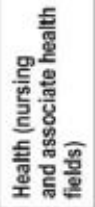 & & \\
\hline & (1) & (2) & (3) & (4) & (5) & (6) & (7) & (8) & (9) & (10) & (i1) & (12) & $(13)$ & (19) \\
\hline \multicolumn{15}{|l|}{ Countries } \\
\hline 㟧 Australia' & 111 & $\mathrm{~m}$ & $\mathrm{~m}$ & 113 & $\mathrm{~m}$ & m & 143 & 140 & 143 & 151 & m & $\mathrm{m}$ & 128 & 100 \\
\hline$\overline{0}_{\text {Austria }}$ & 125 & $\mathrm{~m}$ & m & 122 & $\mathrm{~m}$ & $\mathrm{~m}$ & 155 & 164 & 184 & 167 & $\mathrm{~m}$ & $\mathrm{~m}$ & 168 & 100 \\
\hline Belgium & m & $\mathrm{m}$ & $\mathrm{m}$ & $m$ & $\mathrm{~m}$ & $m$ & $m$ & $m$ & m & $m$ & $m$ & $\mathrm{~m}$ & $\mathrm{~m}$ & m \\
\hline Canada & m & m & $\mathrm{m}$ & m & $\mathrm{m}$ & $\mathrm{m}$ & $\mathrm{m}$ & $\mathrm{m}$ & $\mathrm{m}$ & $\mathrm{m}$ & $\mathrm{m}$ & m & $\mathrm{m}$ & m \\
\hline Chile & 176 & $\mathrm{~m}$ & $\mathrm{~m}$ & 214 & $m$ & $\mathrm{~m}$ & 259 & 252 & 240 & 300 & $\mathrm{~m}$ & $\mathrm{~m}$ & 241 & 183 \\
\hline Colombia & m & $\mathrm{m}$ & $\mathrm{m}$ & m & m & $m$ & m & $\mathrm{m}$ & $\mathrm{m}$ & $\mathrm{m}$ & $\mathrm{m}$ & m & $\mathrm{m}$ & m \\
\hline Czech Republic & m & $m$ & $\mathrm{~m}$ & $m$ & $\mathrm{~m}$ & $\mathrm{~m}$ & $\mathrm{~m}$ & $m$ & $\mathrm{~m}$ & $m$ & $\mathrm{~m}$ & $\mathrm{~m}$ & $\mathrm{~m}$ & m \\
\hline Denmark & 111 & $m$ & $\mathrm{~m}$ & 114 & $\mathrm{~m}$ & $m$ & 169 & 145 & 139 & 151 & $\mathrm{~m}$ & $\mathrm{~m}$ & 110 & 131 \\
\hline Estonia & 101 & 105 & 136 & 126 & 130 & 166 & 138 & 136 & 177 & 132 & 200 & 110 & 132 & 120 \\
\hline Finland' & 126 & 109 & 143 & 132 & 134 & 213 & 139 & 150 & 160 & 163 & 221 & 110 & 126 & 128 \\
\hline France & m & $m$ & m & $\mathrm{m}$ & $m$ & $\mathrm{~m}$ & $\mathrm{~m}$ & $\mathrm{~m}$ & m & m & m & $\mathrm{m}$ & $\mathrm{m}$ & m \\
\hline Germany ${ }^{2}$ & 130 & 111 & 145 & 133 & 209 & 256 & 218 & 163 & 197 & 216 & 284 & 152 & 171 & 170 \\
\hline Greece & m & $\mathrm{m}$ & $\mathrm{m}$ & $\mathrm{m}$ & $\mathrm{m}$ & $\mathrm{m}$ & m & $\mathrm{m}$ & m & $\mathrm{m}$ & $m$ & $\mathrm{~m}$ & $\mathrm{~m}$ & $\mathrm{~m}$ \\
\hline Hungary & $\mathrm{m}$ & $\mathrm{m}$ & $\mathrm{m}$ & $\mathrm{m}$ & m & $\mathrm{m}$ & $\mathrm{m}$ & $\mathrm{m}$ & $\mathrm{m}$ & $\mathrm{m}$ & $\mathrm{m}$ & $\mathrm{m}$ & $\mathrm{m}$ & $\mathrm{m}$ \\
\hline Iceland & m & $m$ & $m$ & $m$ & $m$ & $m$ & $m$ & $\mathrm{~m}$ & $\mathrm{~m}$ & $m$ & $\mathrm{~m}$ & m & $\mathrm{m}$ & m \\
\hline Ireland & m & $\mathrm{m}$ & m & m & $\mathrm{m}$ & $\mathrm{m}$ & $\mathrm{m}$ & $\mathrm{m}$ & $\mathrm{m}$ & $\mathrm{m}$ & $\mathrm{m}$ & $\mathrm{m}$ & $\mathrm{m}$ & m \\
\hline Israel & $m$ & $\mathrm{~m}$ & $\mathrm{~m}$ & $m$ & $\mathrm{~m}$ & $\mathrm{~m}$ & $\mathrm{~m}$ & $\mathrm{~m}$ & $m$ & $\mathrm{~m}$ & $\mathrm{~m}$ & $m$ & $\mathrm{~m}$ & m \\
\hline Italy & $m$ & $\mathrm{~m}$ & $\mathrm{~m}$ & $m$ & $\mathrm{~m}$ & $m$ & $\mathrm{~m}$ & $\mathrm{~m}$ & $\mathrm{~m}$ & $\mathrm{~m}$ & $\mathrm{~m}$ & $\mathrm{~m}$ & $\mathrm{~m}$ & m \\
\hline Japan & $m$ & $\mathrm{~m}$ & m & m & $\mathrm{m}$ & $m$ & $m$ & $m$ & $\mathrm{~m}$ & $m$ & $\mathrm{~m}$ & $m$ & m & m \\
\hline Korea & m & m & m & $\mathrm{m}$ & m & m & $\mathrm{m}$ & m & $\mathrm{m}$ & m & m & $\mathrm{m}$ & m & m \\
\hline Latvia & 113 & 123 & 154 & 148 & 151 & 166 & 155 & 147 & 207 & 146 & 145 & 134 & 136 & 146 \\
\hline Lithuania & m & $\mathrm{m}$ & $\mathrm{m}$ & m & $\mathrm{m}$ & m & $\mathrm{m}$ & $\mathrm{m}$ & m & $\mathrm{m}$ & m & $\mathrm{m}$ & $\mathrm{m}$ & $\mathrm{m}$ \\
\hline Luxembourg & $m$ & $\mathrm{~m}$ & $\mathrm{~m}$ & $m$ & $\mathrm{~m}$ & $m$ & $\mathrm{~m}$ & $\mathrm{~m}$ & $\mathrm{~m}$ & $\mathrm{~m}$ & $m$ & $\mathrm{~m}$ & $m$ & m \\
\hline Mexico & m & $\mathrm{m}$ & m & m & m & m & m & $\mathrm{m}$ & m & $m$ & m & m & m & m \\
\hline Netherlands & m & $\mathrm{m}$ & $\mathrm{m}$ & $\mathrm{m}$ & $\mathrm{m}$ & $m$ & m & $\mathrm{m}$ & $\mathrm{m}$ & $\mathrm{m}$ & $m$ & $\mathrm{~m}$ & $\mathrm{~m}$ & m \\
\hline New Zealand & $\mathrm{m}$ & $\mathrm{m}$ & $\mathrm{m}$ & $\mathrm{m}$ & $\mathrm{m}$ & $\mathrm{m}$ & $\mathrm{m}$ & $\mathrm{m}$ & $\mathrm{m}$ & $\mathrm{m}$ & $\mathrm{m}$ & $\mathrm{m}$ & $\mathrm{m}$ & $\mathrm{m}$ \\
\hline Norway & 99 & 79 & 125 & 118 & 139 & 180 & 146 & 138 & 140 & 157 & 196 & 103 & 116 & 130 \\
\hline Poland & $\mathrm{m}$ & $\mathrm{m}$ & $\mathrm{m}$ & m & $\mathrm{m}$ & $\mathrm{m}$ & $\mathrm{m}$ & $\mathrm{m}$ & $\mathrm{m}$ & $\mathrm{m}$ & m & m & $\mathrm{m}$ & m \\
\hline Portugal ${ }^{4}$ & 125 & 118 & 165 & 158 & 197 & 208 & 198 & 179 & 195 & 194 & m & m & 163 & 141 \\
\hline Slovak Republic & m & m & $\mathrm{m}$ & $\mathrm{m}$ & $\mathrm{m}$ & $\mathrm{m}$ & $\mathrm{m}$ & $\mathrm{m}$ & $\mathrm{m}$ & $\mathrm{m}$ & $m$ & m & m & m \\
\hline Slovenia & m & $\mathrm{m}$ & m & m & $\mathrm{m}$ & $\mathrm{m}$ & $\mathrm{m}$ & $\mathrm{m}$ & $\mathrm{m}$ & m & $\mathrm{m}$ & m & m & m \\
\hline Spain & m & $\mathrm{m}$ & $\mathrm{m}$ & $\mathrm{m}$ & $\mathrm{m}$ & $m$ & $\mathrm{~m}$ & $\mathrm{~m}$ & $m$ & $\mathrm{~m}$ & $\mathrm{~m}$ & $\mathrm{~m}$ & $\mathrm{~m}$ & $\mathrm{~m}$ \\
\hline Sweden & 101 & 82 & 108 & 100 & 123 & 152 & 147 & 117 & 133 & 147 & 172 & 106 & 117 & 116 \\
\hline Switzerland & 122 & 107 & 152 & 135 & 170 & 204 & 174 & 167 & 185 & 163 & 214 & 110 & 133 & 127 \\
\hline Turkey & m & m & $\mathrm{m}$ & m & m & $\mathrm{m}$ & m & m & $\mathrm{m}$ & $\mathrm{m}$ & $\mathrm{m}$ & $\mathrm{m}$ & m & m \\
\hline United Kingdom & 93 & $\mathrm{~m}$ & $\mathrm{~m}$ & 92 & m & $\mathrm{m}$ & 133 & 181 & 130 & 160 & $\mathrm{~m}$ & m & 100 & 105 \\
\hline United States ${ }^{5}$ & 132 & 149 & 200 & 188 & $m$ & $\mathrm{~m}$ & 220 & 250 & 233 & 260 & $\mathrm{~m}$ & $\mathrm{~m}$ & 180 & 161 \\
\hline $\begin{array}{l}\text { OECD average } \\
\text { EU } 23 \text { average }\end{array}$ & $\mathrm{m}$ & $\begin{array}{l}\mathrm{m} \\
\mathrm{m}\end{array}$ & $\begin{array}{l}m \\
m\end{array}$ & $\begin{array}{l}m \\
m\end{array}$ & $\begin{array}{l}m \\
m\end{array}$ & $\begin{array}{l}m \\
m\end{array}$ & $\begin{array}{l}\mathrm{m} \\
\mathrm{m}\end{array}$ & $\begin{array}{l}\mathrm{m} \\
\mathrm{m}\end{array}$ & $\begin{array}{l}m \\
m\end{array}$ & $\begin{array}{l}m \\
m\end{array}$ & $\begin{array}{l}m \\
m\end{array}$ & $\begin{array}{l}m \\
m\end{array}$ & $\mathrm{~m}$ & $\begin{array}{l}\mathrm{m} \\
\mathrm{m}\end{array}$ \\
\hline
\end{tabular}

\begin{tabular}{|c|c|c|c|c|c|c|c|c|c|c|c|c|c|c|}
\hline Argentina & $\mathrm{m}$ & $\mathrm{m}$ & $\mathrm{m}$ & m & m & m & $\mathrm{m}$ & $\mathrm{m}$ & $\mathrm{m}$ & m & m & m & m & m \\
\hline E Brazil & $\mathrm{m}$ & m & $\mathrm{m}$ & $\mathrm{m}$ & $\mathrm{m}$ & $\mathrm{m}$ & $\mathrm{m}$ & m & $\mathrm{m}$ & $\mathrm{m}$ & m & m & m & m \\
\hline China & m & $\mathrm{m}$ & $\mathrm{m}$ & m & $\mathrm{m}$ & $m$ & m & $\mathrm{m}$ & m & m & m & m & $\mathrm{m}$ & m \\
\hline Costa Rica & 201 & c & 202 & 199 & 187 & 232 & 193 & c & 207 & 204 & $\mathrm{~m}$ & m & 210 & 193 \\
\hline India & m & m & m & m & m & m & m & m & m & m & m & m & $\mathrm{m}$ & m \\
\hline Indonesia & $\mathrm{m}$ & m & $\mathrm{m}$ & m & m & $\mathrm{m}$ & $\mathrm{m}$ & m & $\mathrm{m}$ & m & m & m & $\mathrm{m}$ & $\mathrm{m}$ \\
\hline Russian Federation & m & $\mathrm{m}$ & $\mathrm{m}$ & m & m & $\mathrm{m}$ & m & $\mathrm{m}$ & $\mathrm{m}$ & m & $\mathrm{m}$ & $\mathrm{m}$ & $\mathrm{m}$ & $\mathrm{m}$ \\
\hline Saudi Arabia & $m$ & m & m & m & m & $\mathrm{m}$ & m & m & m & m & m & $\mathrm{m}$ & $\mathrm{m}$ & $\mathrm{m}$ \\
\hline South Africa & m & m & m & m & m & $\mathrm{m}$ & $m$ & $\mathrm{~m}$ & $\mathrm{~m}$ & m & m & $\mathrm{m}$ & m & $\mathrm{m}$ \\
\hline
\end{tabular}

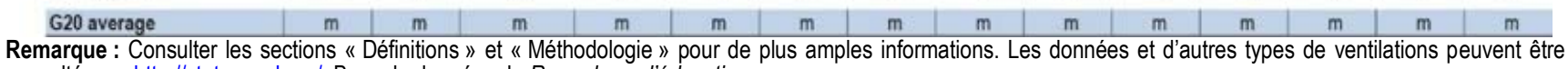
consultés sur http://stats.oecd.org/, Base de données de Regards sur l'éducation.

1. Année de référence : 2016.

2. Les revenus se rapportent aux programmes universitaires uniquement

3. Revenus nets d'impôts sur le revenu.

4. Lettres et arts, sciences sociales, journalisme et information ne comprennent pas le sous-domaines des langues étrangères

5. Les données se rapportent aux domaines d'études au niveau de la licence.

Source : OCDE (2019). Consulter la section « Source » pour tout complément d'information et l'annexe 3 pour les notes (https://doi.org/10.1787/f8d7880d-en).

Les symboles représentant les données manquantes et les abréviations figurent dans le Guide du lecteur. 


\section{Indicateur A5. Quels sont les facteurs financiers qui incitent à investir dans l'éducation?}

\section{Faits marquants}

- Le rendement privé de l'investissement dans l'enseignement tertiaire est considérable : les diplômés de l'enseignement tertiaire sont plus susceptibles que ceux qui ne sont pas diplômés de ce niveau d'enseignement de travailler et d'être mieux rémunérés.

- L'éducation est rentable non seulement pour les individus, mais aussi pour les comptes publics qui profitent des niveaux plus élevés de recettes fiscales et de cotisations sociales versés par les diplômés de l'enseignement tertiaire.

- Dans les pays de l'OCDE, les hommes investissent de l'ordre de 45100 USD (coûts directs et manque à gagner) en moyenne dans l'obtention d'un diplôme tertiaire, et les femmes, de l'ordre de 34800 USD. Car les hommes tendent à afficher des rémunérations et des taux d'emploi supérieurs, leur bénéfice total est également plus élevé pendant leur carrière : ils touchent 341000 USD, contre 262400 USD pour les femmes.

\section{Graphique A5.1. Rendement financier privé net de l'obtention d'un diplôme de l'enseignement tertiaire} chez les individus de sexe masculin ou féminin (2016)

Par comparaison avec un niveau de formation du deuxième cycle du secondaire, en équivalents USD convertis sur la base des PPA pour le PIB ; les coûts et bénéfices à venir sont actualisés à un taux de $2 \%$

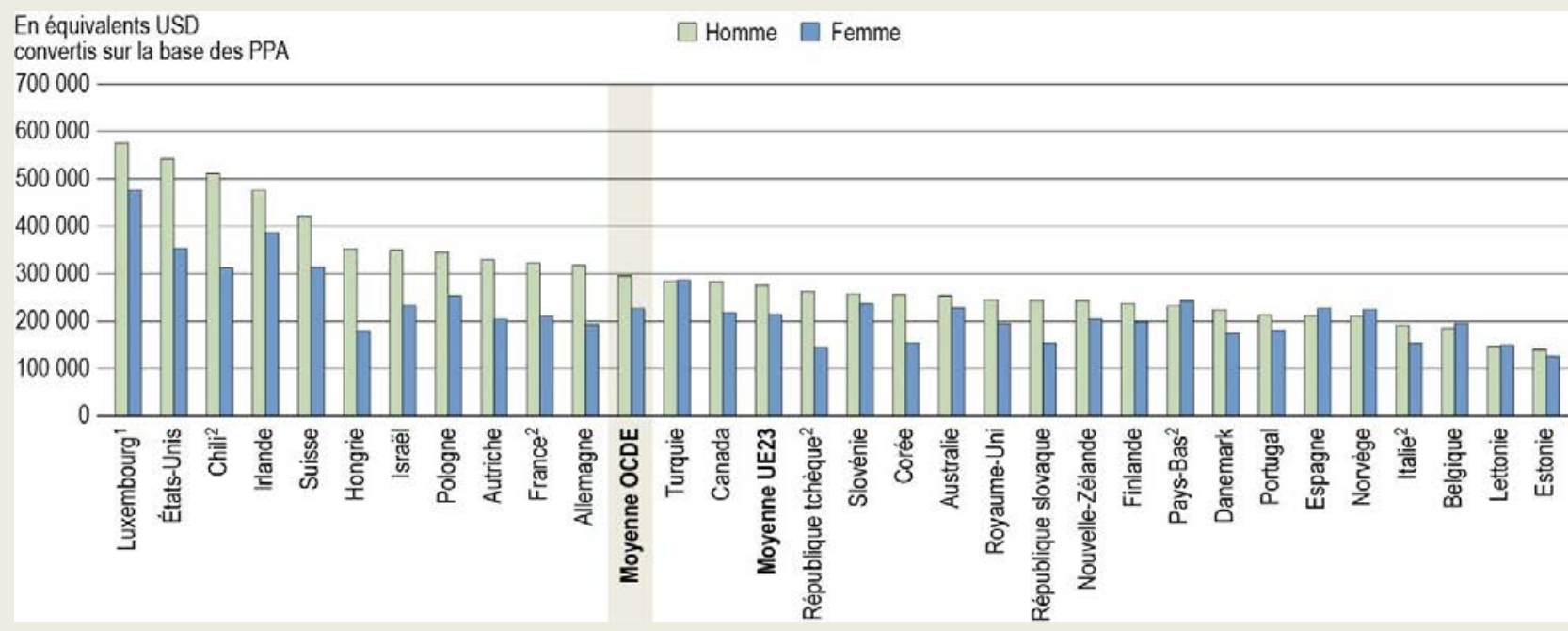

1. L'année de référence n'est pas 2016. Consulter le tableau source pour de plus amples informations.

2. Les résultats se basent sur les revenus nets des adultes diplômés de l'enseignement tertiaire (par comparaison avec les revenus nets des adultes diplômés du deuxième cycle de l'enseignement secondaire).

Les pays sont classés par ordre décroissant du rendement financier privé net pour un homme.

Source : OCDE (2019), tableaux A5.1a et A5.1b. Consulter la section « Source » pour tout complément d'information et l'annexe 3 pour les notes (https://doi.org/10.1787/f8d7880d-en). 


\section{Contexte}

Consacrer du temps et de l'argent aux études, c'est investir dans le capital humain. L'amélioration des débouchés sur le marché du travail (voir l'indicateur A3) et la perspective de revenus plus élevés (voir l'indicateur A4) sont des facteurs qui incitent fortement les individus à investir dans l'éducation et à retarder leur entrée dans la vie active. Le niveau de formation est plus élevé chez les femmes que chez les hommes (voir l'indicateur A1), mais ces derniers tirent un plus grand profit de leur investissement dans la poursuite de leurs études, sous la forme de meilleurs débouchés et de salaires plus élevés dans l'ensemble.

Les pays bénéficient également de l'élévation du niveau de formation de leur population au travers de l'augmentation des recettes fiscales et des cotisations sociales dès l'entrée des individus dans la vie active. Comme l'élévation du niveau de formation profite aux individus et aux pouvoirs publics, il est important d'analyser le rendement financier de l'éducation à la lumière d'autres indicateurs tels que les taux d'accès et de réussite des niveaux supérieurs d'enseignement (voir l'indicateur B5).

Cet indicateur n'aborde pas d'autres facteurs qui influent sur le rendement de l'éducation. Le rendement financier de l'éducation peut par exemple être affecté par le domaine d'études, la situation économique particulière des pays, le marché du travail et le cadre institutionnel ainsi que par des facteurs culturels et sociaux. En outre, les retombées de l'éducation ne sont pas uniquement financières, elles sont aussi économiques, comme l'accroissement de la productivité de la population, et sociales, comme la participation accrue des individus à des activités culturelles ou sportives (voir l'indicateur A6).

\section{Autres faits marquants}

- Dans la plupart des pays de l'OCDE, le principal coût lié aux études tertiaires est le manque à gagner des étudiants et non les coûts directs tels que les frais de scolarité et de subsistance, et ce, même en prenant en considération les revenus des étudiants qui travaillent pendant leurs études supérieures.

- Le rendement privé de l'investissement dans l'éducation dépend du régime fiscal et du système de cotisations sociales des pays. À titre d'exemple, les impôts sur le revenu et les cotisations sociales représentent moins d'un quart du salaire brut d'un homme diplômé de l'enseignement tertiaire au Chili, en Corée et en Estonie, mais en représentent plus de la moitié en Belgique et aux Pays-Bas.

- Dans la quasi-totalité des pays dont les données sont disponibles, le rendement financier net, tant public que privé, d'une licence, d'un master ou d'un doctorat est supérieur au rendement d'une formation tertiaire de cycle court.

\section{Remarque}

Cet indicateur fournit des informations sur les incitations à investir dans la poursuite des études compte tenu des coûts et des bénéfices, y compris le rendement financier net et le taux de rendement interne. II analyse le choix entre deux options, à savoir poursuivre des études ou entrer dans la vie active. Cet indicateur porte sur deux scénarios : 1) investir dans l'obtention d'un diplôme de l'enseignement tertiaire au lieu d'entrer dans la vie active dès l'obtention d'un diplôme du deuxième cycle de l'enseignement secondaire; et 2) investir dans l'obtention d'un diplôme du deuxième cycle de l'enseignement secondaire au lieu d'entrer dans la vie active sans ce diplôme (disponible en ligne).

II prend en considération deux types d'investisseurs : 1) les individus qui décident de poursuivre leurs études compte tenu des coûts et de l'avantage salarial net que cela implique (le rendement " privé ») ; et 2) les pouvoirs publics qui décident d'investir dans l'éducation compte tenu des coûts et de l'augmentation de leurs recettes (fiscales) que cela implique (le rendement " public »).

Comme cet indicateur n'estime le rendement financier de l'investissement dans l'éducation que jusqu'à 64 ans, l'âge théorique du départ à la retraite, il ne tient pas compte des pensions de retraite. Les coûts directs de l'éducation présentés dans cet indicateur ne prennent pas en considération les prêts d'études.

Précisons que les valeurs indiquées dans cette édition de Regards sur l'éducation ne sont pas nécessairement comparables à celles publiées dans des éditions antérieures, car la méthodologie de cet indicateur est constamment affinée. 


\section{Analyse}

\section{Facteurs financiers incitant les individus à investir dans l'enseignement tertiaire}

Dans les pays de l'OCDE, investir dans l'éducation est dans l'ensemble payant à long terme, tant pour les hommes que pour les femmes. Le gain sur lequel les individus peuvent tabler pendant toute leur carrière s'ils élèvent leur niveau de formation est supérieur au coût de leurs études à leur charge. Ce constat vaut pour l'enseignement tertiaire ainsi que pour le deuxième cycle de l'enseignement secondaire (voir le graphique A5.1, les tableaux A5.1 $a$ et $b$ et les tableaux A5.4a et b, disponibles en ligne).

Dans les pays de l'OCDE, le rendement privé de l'obtention, par un homme, d'un diplôme tertiaire s'élève en moyenne à 295900 USD. Chez les jeunes, les femmes tendent à être plus nombreuses que les hommes à suivre des études supérieures (voir l'indicateur A1), mais elles tendent aussi à ne pas bénéficier d'un rendement net aussi élevé à l'obtention d'un diplôme tertiaire. En moyenne, l'obtention d'un diplôme tertiaire procure aux femmes un rendement net de 227600 USD, soit environ trois quarts du rendement que ce diplôme procure aux hommes (voir le graphique A5 1).

Le rendement financier privé de l'enseignement tertiaire est plus élevé chez les hommes que chez les femmes dans la plupart des pays de l'OCDE dont les données sont disponibles. La Belgique, l'Espagne, la Lettonie, la Norvège, les Pays-Bas et la Turquie sont les seuls pays où le rendement financier privé est plus élevé chez femmes que chez les hommes (voir les tableaux A5.1a et b). Dans ces pays, les femmes accusent toujours une rémunération et un taux d'emploi moins élevés que les hommes selon les chiffres de 2016 (voir la base de données de Regards sur l'éducation), mais elles retirent un plus grand avantage qu'eux de l'obtention d'un diplôme tertiaire, par comparaison avec un diplôme du deuxième cycle de l'enseignement secondaire. En d'autres termes, l'écart entre la rémunération et le taux d'emploi par niveau de formation est plus important chez les femmes que chez les hommes dans ces pays.

Le rendement généralement inférieur chez les femmes peut s'expliquer par plusieurs facteurs, notamment leur rémunération moins élevée, leur taux de chômage plus élevé, leur plus grande propension moyenne à travailler à temps partiel et leur domaine d'études différent de celui des hommes. L'offre de structures d'accueil et d'éducation de la petite enfance de qualité peut aussi influer sur le taux d'emploi des femmes.

Le taux de rendement interne permet d'analyser le rendement de l'éducation sous un autre angle, car il évalue le taux d'intérêt réel auquel les coûts et bénéfices sont équivalents, c'est-à-dire le taux auquel un seul de rentabilité est atteint. Il peut être interprété comme le taux d'intérêt que l'investissement dans l'élévation du niveau de formation devrait rapporter aux individus chaque année durant leur carrière. En moyenne, dans les pays de I'OCDE, le taux de rendement interne de l'obtention d'un diplôme tertiaire s'établit à $17 \%$ chez les hommes et à $21 \%$ chez les femmes. Le taux de rendement interne supérieur chez les femmes reflète le fait que leur investissement initial dans l'élévation de leur niveau de formation est moins élevé (en termes de manque à gagner) (voir les tableaux A5.1a et b).

\section{Coûts et bénéfices privés de l'enseignement tertiaire}

Le rendement financier privé net des individus correspond à la différence entre les coûts et les bénéfices associés à l'élévation de leur niveau de formation. Dans cette analyse, les coûts comprennent les coûts directs de l'investissement dans la poursuite des études et le manque à gagner durant les études; et les bénéfices correspondent aux revenus du travail. Pour montrer l'impact de la fiscalité sur le bénéfice total, l'effet de l'impôt sur le revenu et l'effet des cotisations sociales sont également analysés (voir la section "Définitions »).

Les coûts privés totaux, qui sont composés des coûts directs et du manque à gagner, augmentent généralement avec l'élévation du niveau de formation. En moyenne, dans les pays de l'OCDE, le coût direct de l'investissement dans une formation tertiaire s'élève au total à 8400 USD chez les hommes et chez les femmes. Toutefois, dans la plupart des pays, le manque à gagner, c'est-à-dire la rémunération que les individus auraient pu percevoir s'ils 
n'avaient pas décidé de faire des études supérieures, est le poste de dépense le plus important. Il varie fortement entre les pays selon la durée de la formation, le niveau de salaire et les différentiels salariaux entre les niveaux de formation. Le modèle d'analyse tient également compte du fait que dans de nombreux pays, il est courant que les étudiants travaillent pendant leurs études, ce qui réduit leur manque à gagner et le coût total de l'investissement dans l'élévation du niveau de formation. L'indicateur A6 publié dans l'édition de 2017 de Regards sur l'éducation (OCDE, 2017 $[1]$ ) indique le taux d'emploi des étudiants et leur niveau de rémunération dans les pays membres et partenaires de l'OCDE.

\section{Graphique A5.2. Coûts et bénéfices privés de l'obtention d'un diplôme de l'enseignement tertiaire chez les individus de sexe masculin ou féminin (2016)}

Par comparaison avec un niveau de formation du deuxième cycle du secondaire, en équivalents USD convertis sur la base des PPA pour le PIB ; les coûts et bénéfices à venir sont actualisés à un taux de $2 \%$

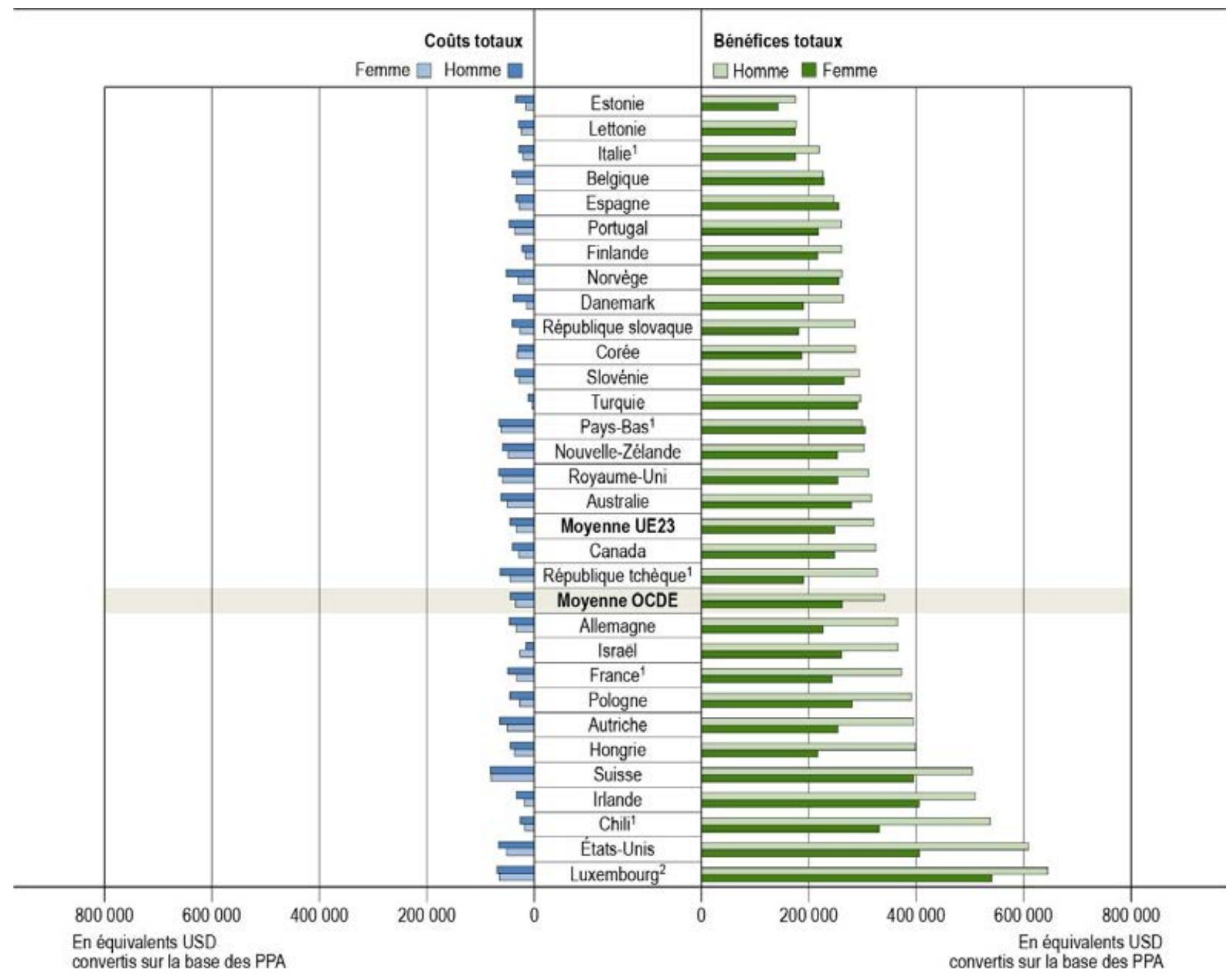

1. L'année de référence n'est pas 2016. Consulter le tableau source pour de plus amples informations.

2. Les résultats se basent sur les revenus nets des adultes diplômés de l'enseignement tertiaire (par comparaison avec les revenus nets des adultes diplômés du deuxième cycle de l'enseignement secondaire).

Les pays sont classés par ordre croissant des bénéfices privés totaux pour un homme.

Source : OCDE (2019), tableaux A5.1a et A5.1b. Consulter la section « Source » pour tout complément d'information et l'annexe 3 pour les notes (https://doi.org/10.1787/f8d7880d-en). 
Chez les hommes, le manque à gagner associé à l'obtention d'un diplôme tertiaire va de moins de 10000 USD en Israël et en Turquie, à près de 70000 USD en Suisse. Parmi tous les pays de l'OCDE dont les données sont disponibles, c'est en Suisse que les coûts privés totaux, c'est-à-dire la somme des coûts directs et du manque à gagner, sont les plus élevés, et en Turquie qu'ils sont les plus bas. Le coût privé total de l'obtention d'un diplôme tertiaire est plus de sept fois plus élevé en Suisse qu'en Turquie, tant chez les hommes que chez les femmes (voir les tableaux A5.1a et b).

Le graphique A5.2 montre que l'élévation du niveau de formation procure des bénéfices considérables aux individus, qui peuvent toutefois varier entre les hommes et les femmes selon la situation du marché du travail dans leur pays. En moyenne, l'obtention d'un diplôme de l'enseignement tertiaire procure un bénéfice total de 341000 USD aux hommes, mais de 262400 USD aux femmes. En d'autres termes, les hommes diplômés de l'enseignement tertiaire gagneront environ 2000 USD de plus par an (par comparaison avec les hommes diplômés au plus du deuxième cycle de l'enseignement secondaire) que leurs homologues féminines en 40 ans de carrière. Cette différence s'explique essentiellement par la variation des rémunérations entre les sexes (voir l'indicateur A4), mais elle est également imputable aux taux d'inactivité et de chômage plus élevés des femmes (voir l'indicateur A3) (voir les tableaux A5.1a et b).

L'élévation du niveau de formation accroît certes les revenus du travail des individus tout au long de leur carrière, mais les bénéfices privés qu'elle leur procure dépendent aussi de la fiscalité et du système de cotisations sociales des pays (Brys and Torres, 2013 ${ }_{[2]}$ ). À titre d'exemple, les impôts sur le revenu et les cotisations sociales représentent moins d'un quart du salaire brut d'un homme diplômé de l'enseignement tertiaire au Chili, en Corée et en Estonie, mais en représentent plus de la moitié en Belgique et aux Pays-Bas. Comme les femmes tendent à gagner moins, elles se situent souvent dans des tranches inférieures d'imposition. En Irlande et en Israël par exemple, les impôts sur le revenu et les cotisations sociales dus par les diplômés de l'enseignement tertiaire en fonction de leur salaire brut sont moins élevés de 10 points de pourcentage environ chez les femmes que chez les hommes (voir les tableaux A5.1a et b). Les impôts et les cotisations sociales sont également en rapport avec les régimes et les programmes de retraite, qui ne sont pas abordés dans cet indicateur.

\section{Facteurs financiers incitant les pouvoirs publics à investir dans l'enseignement tertiaire}

Les pouvoirs publics investissent massivement dans l'éducation (voir l'indicateur C3). D'un point de vue budgétaire, il est important de déterminer s'ils récupéreront les montants engagés, en particulier en temps d'austérité. Comme l'élévation du niveau de formation tend à se traduire par une augmentation des revenus (voir l'indicateur A4), les investissements dans l'éducation produisent un rendement public, puisque les diplômés de l'enseignement tertiaire paient plus de cotisations sociales et d'impôts sur le revenu. En moyenne, dans les pays de l'OCDE, le rendement public net de l'investissement pour chaque diplômé de l'enseignement tertiaire s'élève à 148200 USD environ pour un homme, et à 77300 USD pour une femme (voir le graphique A5.3).

Le rendement public net de l'investissement est étroitement lié au rendement privé. Les pays où le rendement de l'enseignement tertiaire est le plus élevé pour les individus sont aussi ceux où il est le plus élevé pour les pouvoirs publics (voir les graphiques A5.1 et A5.3). C'est le cas aux États-Unis, en Irlande et au Luxembourg, où le rendement financier net est très élevé, tant pour les individus que pour les pouvoirs publics.

Toutefois, les régimes fiscaux différents peuvent influer sensiblement sur la mesure dans laquelle le rendement public suit le rendement privé. Au Chili par exemple, le rendement masculin privé de l'obtention d'un diplôme tertiaire est l'un des plus élevés mais le rendement public y est le deuxième le moins élevé, car le régime fiscal est tel que les impôts et les cotisations sociales dus sur les tranches supérieures de rémunération sont proportionnellement moins élevés (voir les tableaux A5.1a et A5.2a).

\section{Coûts et bénéfices publics de l'enseignement tertiaire}

Le rendement financier net est évalué sur la base de la différence entre les coûts et bénéfices associés à l'élévation du niveau de formation des individus. Dans cette analyse, les coûts comprennent les dépenses 
publiques directes au titre de l'éducation et le manque à gagner fiscal. Les bénéfices sont calculés compte tenu des recettes fiscales et des cotisations sociales.

\section{Graphique A5.3. Rendement financier public net de l'obtention d'un diplôme de l'enseignement tertiaire chez les individus de sexe masculin ou féminin (2016)}

Par comparaison avec un niveau de formation du deuxième cycle du secondaire, en équivalents USD convertis sur la base des PPA pour le PIB ; les coûts et bénéfices à venir sont actualisés à un taux de $2 \%$

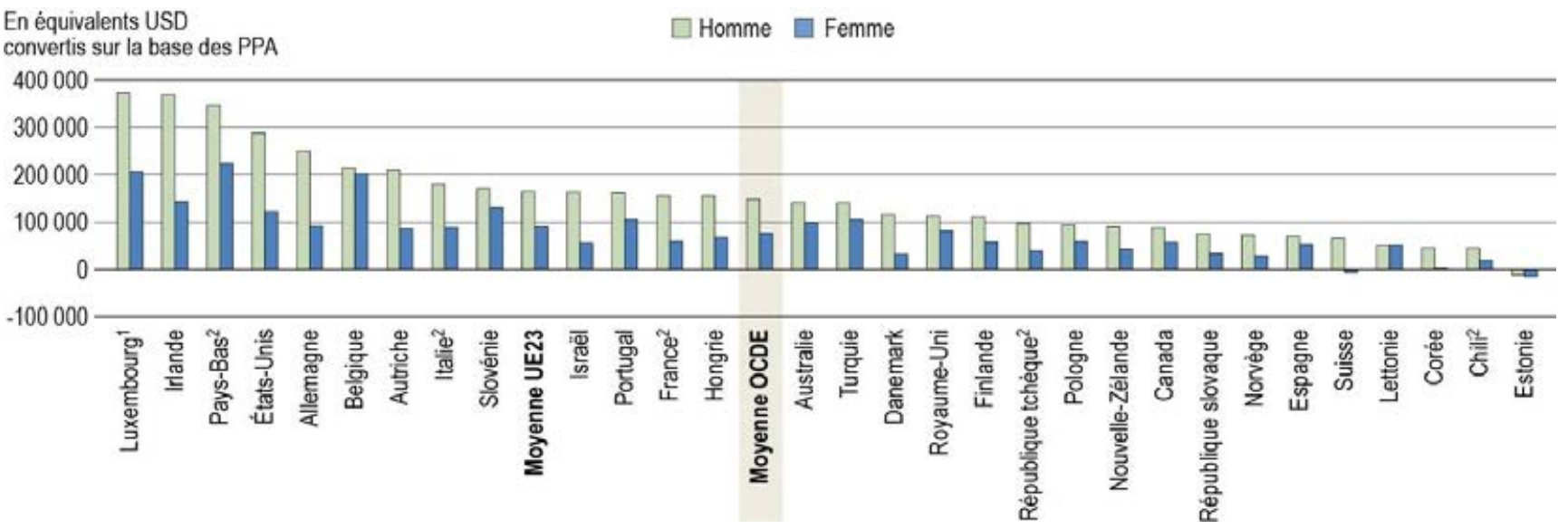

1. Les résultats se basent sur les revenus nets des adultes diplômés de l'enseignement tertiaire (par comparaison avec les revenus nets des adultes diplômés du deuxième cycle de l'enseignement secondaire).

2. L'année de référence n'est pas 2016. Consulter le tableau source pour de plus amples informations.

Les pays sont classés par ordre décroissant des rendements publics totaux pour un homme.

Source : OCDE (2019). Tableaux A5.2a. et A5.2b. Consulter la section « Source » pour tout complément d'information et l'annexe 3 pour les notes (https://doi.org/10.1787/f8d7880d-en).

StatLink : तils https://doi.org/10.1787/888933977239

Pour les pouvoirs publics, les coûts directs (y compris les bourses versées aux étudiants) représentent la plus grande partie du coût public total de l'enseignement tertiaire, même si les prêts d'études ne sont pas pris en considération dans cet indicateur. Ce constat vaut particulièrement pour des pays comme le Danemark, la Finlande et la Norvège, où les étudiants s'acquittent de frais de scolarité minimes, voire nuls, et où ils bénéficient d'aides publiques généreuses s'ils font des études supérieures (voir l'indicateur C5). Les pays où les coûts directs sont élevés sont aussi ceux où le coût public total est le plus élevé ; le coût public total est par exemple supérieur à 100000 USD pour les hommes au Danemark, au Luxembourg, en Norvège et en Suisse. Par contraste, c'est au Chili que le coût public total est le moins élevé de tous les pays de l'OCDE (environ 10000 USD pour les hommes et les femmes). En moyenne, dans les pays de l'OCDE, le coût public de l'obtention par un individu d'un diplôme tertiaire s'élève au total à 58100 USD pour un homme, et à 54100 USD pour une femme (voir les tableaux A5.2a et b).

Les pouvoirs publics compensent le coût direct de l'investissement et le manque à gagner fiscal associés à l'élévation du niveau de formation par les recettes fiscales et les cotisations sociales plus élevées des travailleurs qui sont souvent mieux rémunérés puisqu'ils sont plus instruits. En moyenne, le bénéfice public de l'obtention d'un diplôme tertiaire s'élève au total à 206300 USD pour un homme, et à 131400 USD pour une femme (voir les tableaux A5.2a et b).

Le bénéfice public total varie entre les sexes, essentiellement car hommes et femmes ne sont pas logés à la même enseigne sur le marché du travail. Ce constat donne à penser que les gouvernements pourraient prendre des mesures en vue de favoriser l'entrée des femmes sur le marché du travail et d'accroître leur taux d'emploi. 
En moyenne, le bénéfice public total de l'investissement dans l'obtention d'un diplôme de l'enseignement tertiaire est environ 57 \% plus élevé pour un homme que pour une femme. Parmi les pays de l'OCDE, c'est en Irlande, au Luxembourg et aux Pays-Bas que le rendement public total de l'investissement dans l'obtention d'un diplôme de l'enseignement tertiaire est le plus élevé pour les hommes (plus de 400000 USD), et en Belgique, au Luxembourg et aux Pays-Bas qu'il est le plus élevé pour les femmes (plus de 250000 USD) (voir les tableaux A5.2a et b).

Pour les pouvoirs publics, le taux de rendement interne de l'investissement dans l'obtention d'un diplôme tertiaire est plus élevé chez les hommes (9\%) que chez les femmes $(7 \%)$. Cette différence entre les sexes s'explique par le fait que le coût public (c'est-à-dire l'investissement public) est très similaire chez les hommes et chez les femmes, mais que le bénéfice public est plus élevé chez les hommes que chez les femmes (voir les tableaux A5.2a et b et les tableaux A5.5a et b, disponibles en ligne).

En moyenne, le bénéfice public total de l'obtention, par un homme, d'un diplôme tertiaire (206 300 USD) se décompose comme suit: l'effet des recettes fiscales (148 100 USD) et l'effet des cotisations sociales (58 200 USD). Quant au bénéfice public total de l'obtention, par une femme, d'un diplôme tertiaire, il est moins élevé (131 400 USD) et se décompose selon les effets suivants : 87300 USD de recettes fiscales et 44100 USD de cotisations sociales (voir les tableaux A5.2a et b).

Graphique A5.4. Rendement financier privé net de l'obtention, chez les individus de sexe féminin, d'un diplôme de l'enseignement tertiaire de cycle court, ou de licence, master, doctorat ou de niveaux équivalents (2016)

Par comparaison avec un niveau de formation du deuxième cycle du secondaire, en équivalents USD convertis sur la base des PPA pour le PIB ; les coûts et bénéfices à venir sont actualisés à un taux de $2 \%$

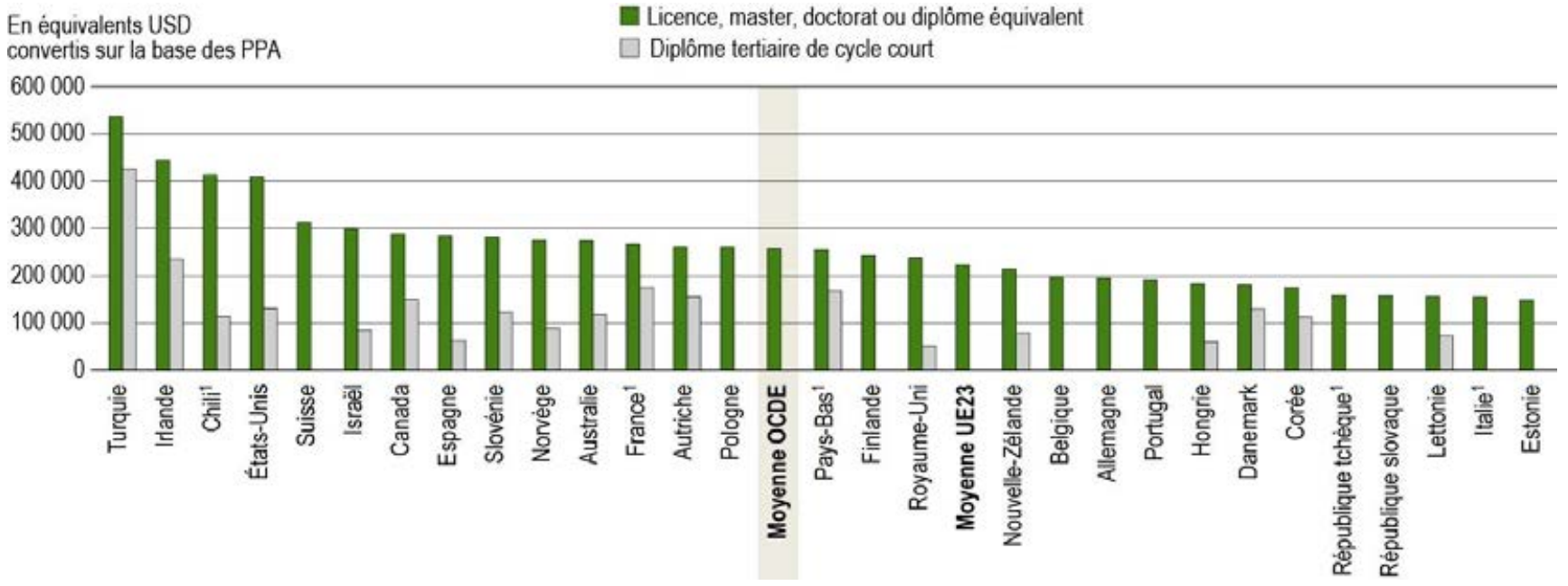

Remarque : Un diplôme de l'enseignement tertiaire de cycle court correspond au niveau 5 de la CITE, et un diplôme de licence, master, doctorat ou de niveaux équivalents, aux niveaux 6,7 et 8 de la CITE.

1. L'année de référence n'est pas 2016. Consulter le tableau source pour de plus amples informations.

Les pays sont classés par ordre décroissant des rendements privés totaux de l'obtention, chez les individus de sexe féminin, d'un diplôme de licence, master, doctorat ou de niveaux équivalents.

Source : OCDE (2019). Tableau A5.3b. Consulter la section «Source» pour tout complément d'information et l'annexe 3 pour les notes (https://doi.org/10.1787/f8d7880d-en). 


\section{Coûts et bénéfices publics et privés par niveau de l'enseignement tertiaire}

Le rendement de l'enseignement tertiaire peut être analysé par niveau d'enseignement, d'une part, dans les formations de cycle court (niveau 5 de la CITE) et, d'autre part, en licence, en master et en doctorat ou formations équivalentes (niveaux 6, 7 et 8 de la CITE). La composition de l'effectif diplômé de chaque niveau de l'enseignement tertiaire varie entre les pays (voir l'indicateur A1), et la répartition des diplômés entre les niveaux peut grandement influencer le rendement financier global de l'enseignement tertiaire (voir le graphique A5.4).

Dans la quasi-totalité des pays dont les données sont disponibles, une licence, un master ou un doctorat procure un rendement privé et public net plus élevé qu'une formation tertiaire de cycle court. Le coût total d'une licence, d'un master ou d'un doctorat tend à être supérieur à celui d'une formation tertiaire de cycle court, mais le bénéfice total que les individus retirent de leurs études pendant leur carrière compense le coût initial plus élevé de leurs études (voir les tableaux A5.3a et b).

La Turquie est le seul pays où le rendement public et privé de l'obtention, par un homme, d'un diplôme tertiaire de cycle court est supérieur à celui de l'obtention d'une licence, d'un master ou d'un doctorat. C'est également le pays de l'OCDE qui affiche le pourcentage le plus élevé (48\%) de l'effectif de nouveaux inscrits en formation tertiaire de cycle court (voir l'indicateur B4). En Corée et au Danemark, le rendement public de l'obtention, par une femme, d'un diplôme tertiaire de cycle court est supérieur à celui de l'obtention d'une licence, d'un master ou d'un doctorat.

\section{Encadré A5.1. L'effet du taux d'actualisation sur le rendement net de l'éducation}

Calculer le rendement financier, ou la valeur actuelle nette, de l'élévation du niveau de formation revient à analyser les coûts et bénéfices de l'investissement et, à cet effet, de convertir les flux futurs en flux actuels à l'aide d'un taux d'actualisation. Le taux d'actualisation permet de tenir compte de l'inflation et de convertir les montants futurs en montants actuels. Le taux d'actualisation est difficile à choisir, car il influe fortement sur l'évaluation des investissements qui ont des effets à long terme, comme ceux dans l'éducation.

Les montants indiqués dans les tableaux et graphiques de cet indicateur sont calculés sur la base d'un taux d'actualisation de $2 \%$, choisi en fonction de la moyenne des taux d'intérêt réel des obligations d'État dans les pays de l'OCDE. On aurait toutefois pu choisir un taux d'actualisation plus élevé au motif qu'investir dans l'éducation n'est pas sans risque. Les pays de l'OCDE qui se livrent à des analyses similaires de coûts et de bénéfices ont choisi un taux d'actualisation supérieur à $2 \%$, mais le taux utilisé varie entre eux (OCDE, 2018[3]).

Afin d'évaluer l'importance de l'impact du taux d'actualisation, il est utile d'effectuer une analyse de sensibilité. Le tableau A5.a indique la variation du rendement financier net de l'obtention, par un homme, d'un diplôme tertiaire, en fonction de trois taux d'actualisation différents. Passer d'un taux d'actualisation de $2 \%$ à un taux de $3.75 \%$ réduit la valeur actuelle nette de plus de $30 \%$ dans tous les pays dont les données sont disponibles. Si un taux d'actualisation de $8 \%$ est utilisé, la valeur actuelle nette chute d'au moins $70 \%$ dans tous les pays. Ces comparaisons montrent à quel point la valeur actuelle nette est sensible à la variation du taux d'actualisation. 
Tableau A5.a. Rendement financier net de l'obtention d'un diplôme tertiaire chez les hommes, selon le taux d'actualisation (2016)

Par comparaison avec un niveau de formation du deuxième cycle du secondaire chez les individus de sexe masculin, en équivalents USD convertis sur la base des PPA pour le PIB

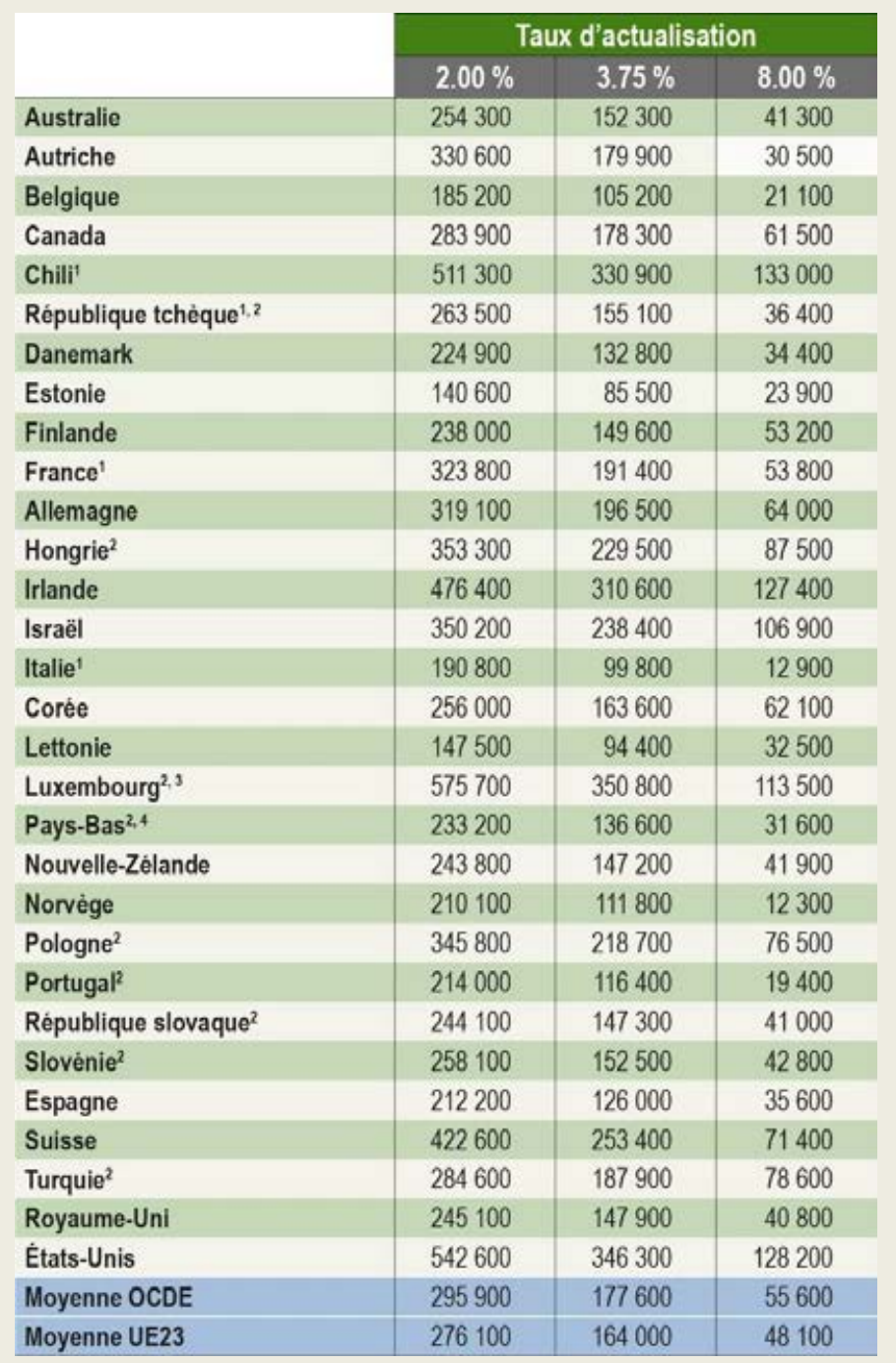

Remarque : Les données se basent sur la différence entre les hommes diplômés de l'enseignement tertiaire et ceux diplômés du deuxième cycle du secondaire. Les valeurs ont été arrondies à la centaine la plus proche.

1. Année de référence : 2015 .

2. La probabilité que les étudiants disposent de revenus correspond au taux d'emploi issu du questionnaire LSO TRANS et non au pourcentage d'actifs rémunérés selon le questionnaire LSO relatif aux revenus.

3. Les résultats se basent sur les revenus nets des adultes diplômés de l'enseignement tertiaire (par comparaison avec les revenus nets des adultes diplômés du deuxième cycle de l'enseignement secondaire).

4. Année de référence : 2014.

Source: OCDE (2019). Consulter la section "Source» pour tout complément d'information et l'annexe 3 pour les notes (https://doi.org/10.1787/f8d7880d-en). 


\section{Définitions}

Le terme « adultes » désigne la population âgée de 15 à 64 ans.

Les coûts directs correspondent aux dépenses directes d'éducation par élève/étudiant durant la durée des études. Les coûts directs de l'éducation n'incluent pas les prêts d'études.

- Les coûts privés directs correspondent aux dépenses totales des ménages au titre de l'éducation. Ils comprennent les montants nets que les ménages versent aux établissements d'enseignement, ainsi que les sommes qu'ils consacrent à l'achat de biens et services d'éducation en dehors des établissements (fournitures scolaires, tutorat, etc.).

- Les coûts publics directs correspondent aux dépenses publiques d'éducation par élève/étudiant. Ils comprennent les dépenses publiques directes au titre des établissements d'enseignement, les bourses et autres prestations versées aux élèves/étudiants et aux ménages ainsi que les transferts publics à d'autres entités privées au titre de l'éducation. Ils ne comprennent pas les prêts d'études.

Le manque à gagner privé correspond aux revenus nets qu'un individu non scolarisé (qui n'est pas en formation) pourrait percevoir s'il avait trouvé du travail au lieu de décider de poursuivre ses études.

Le manque à gagner fiscal correspond aux recettes fiscales supplémentaires que les pouvoirs publics auraient perçues si un individu était entré dans la vie active et avait trouvé du travail au lieu de décider de poursuivre ses études.

Les avantages salariaux bruts correspondent à la somme actualisée des avantages salariaux que perçoit un individu pendant sa vie active grâce à l'élévation de son niveau de formation.

L'effet de l'impôt sur le revenu correspond à la somme actualisée du supplément d'impôt sur le revenu versé aux pouvoirs publics par un individu au cours de sa carrière en raison de l'élévation de son niveau de formation.

Le taux de rendement interne est le taux d'intérêt (hypothétique) calculé sur la base des coûts et bénéfices de l'investissement dans l'éducation. II indique en quelque sorte les intérêts qu'un individu peut retirer chaque année durant sa carrière de l'investissement dans l'élévation de son niveau de formation.

Niveaux de formation : les niveaux de la CITE 2011 sont tous décrits dans le Guide du lecteur, au début du présent rapport.

Le rendement financier net est la valeur actuelle nette de l'investissement financier dans l'éducation. Le rendement financier net correspond à la différence entre les coûts et bénéfices financiers actualisés de l'investissement dans l'éducation, soit la plus-value de l'éducation en plus du taux d'intérêt réel de $2 \%$ ajouté à ces flux de trésorerie.

\section{Méthodologie}

Cet indicateur estime le rendement financier de l'investissement dans l'éducation entre l'âge de 15 ans et un âge théorique de départ à la retraite (64 ans). Le rendement de l'éducation est étudié sous l'angle d'un investissement financier.

Deux périodes sont examinées (voir le diagramme 1):

1) Le temps passé en formation, c'est-à-dire la période durant laquelle les individus et les pouvoirs publics paient le coût de l'éducation ;

2) Le temps passé après avoir quitté l'enseignement formel (soit lorsque les individus « ne sont plus scolarisés »), c'est-à-dire la période pendant laquelle l'individu et les pouvoirs publics bénéficient des retombées financières de l'élévation du niveau de formation. 
La méthode retenue ici pour calculer le rendement de l'éducation est celle dite de la valeur actuelle nette de l'investissement. Elle consiste à exprimer les flux financiers qui interviennent à différents moments sous la forme d'une valeur actuelle nette pour que les coûts et bénéfices soient directement comparables. Dans ce cadre, les coûts et avantages enregistrés durant toute la carrière sont rapportés au début de l'investissement. Cela consiste à actualiser tous les flux financiers depuis le début de l'investissement au moyen d'un taux d'intérêt fixe (le taux d'actualisation).

\section{Diagramme 1. Rendement financier de l'investissement dans l'éducation tout au long de la vie pour un} individu type

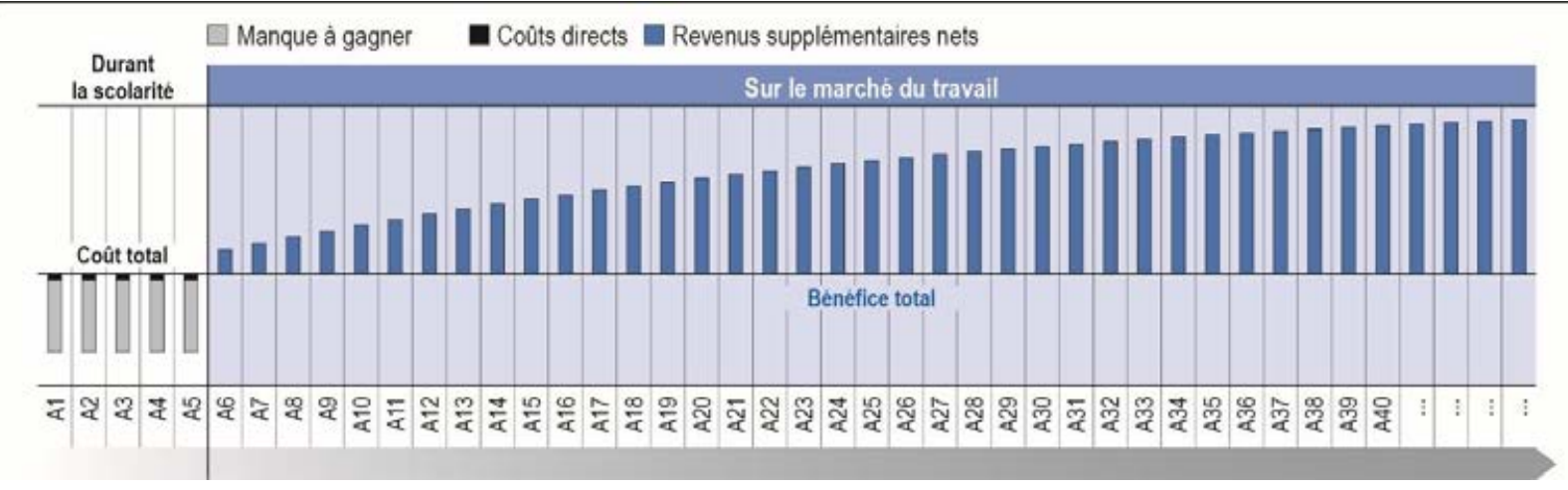

Ce sont les obligations d'État à long terme qui ont été utilisées comme référence pour choisir le taux d'actualisation. Le taux d'actualisation est difficile à choisir, car il doit refléter non seulement le terme de l'investissement, mais également le coût de l'emprunt ou le risque perçu de l'investissement (voir l'encadré A5.1). Pour permettre les comparaisons et faciliter l'interprétation des résultats, le même taux d'actualisation (2\%) a été appliqué dans tous les pays de l'OCDE. Tous les montants présentés dans les tableaux de cet indicateur sont des valeurs actuelles nettes, converties en équivalents USD sur la base des parités de pouvoir d'achat (PPA).

\section{Changements de méthodologie entre les éditions de 2018 et de 2019 de Regards sur l'éducation}

Le présent modèle porte essentiellement sur les revenus du travail. Les allocations de chômage et les transferts sociaux, mentionnés dans l'édition 2018 de Regards sur l'éducation, ne sont pas inclus dans l'édition 2019. Les principaux changements effectués par rapport aux éditions précédentes ont été l'utilisation du taux d'emploi (au lieu d'un ratio basé sur la population active) comme probabilité pour un individu de percevoir des revenus et la prise en compte des revenus effectifs des étudiants pour calculer le manque à gagner. Voir le Guide de l'OCDE pour l'établissement de statistiques internationalement comparables dans le domaine de l'éducation 2018 (OCDE, 2019[4] $)$ pour de plus amples informations. Voir les notes spécifiques aux pays à l'annexe 3 (https://doi.org/10.1787/f8d7880d-en).

\section{Source}

Les coûts directs de l'éducation proviennent de l'exercice UOE de collecte de données financières et se rapportent à l'année 2016 (sauf mention contraire dans les tableaux).

Les données sur les revenus proviennent d'une collecte de données réalisée par le réseau LSO de l'OCDE (Network on Labour Market and Social Outcomes, réseau chargé d'élaborer les données relatives aux retombées de l'éducation sur l'économie, le marché du travail et la société), qui compile les données des enquêtes nationales sur la population active, des Statistiques communautaires sur le revenu et les conditions de vie (SILC) de l'Union européenne ainsi que d'autres banques de données et enquêtes nationales. Les revenus sont ventilés 
par âge, sexe et niveau de formation. Les rémunérations sont agrégées pendant trois années différentes (2014 à 2016).

Les calculs relatifs à l'impôt sur le revenu ont été effectués sur la base du modèle de l'OCDE présenté dans Les impôts sur les salaires, qui détermine l'impôt dû par niveau de revenu. Ce modèle permet de calculer le niveau de la fiscalité sur le travail dans plusieurs scénarios, selon la composition des ménages. Le scénario retenu dans cet indicateur est celui d'un travailleur célibataire et sans enfants. Voir les détails spécifiques à chaque pays concernant le modèle relatif à l'impôt sur le revenu dans Les impôts sur les salaires 2018 (OCDE, 2018[5]).

Les cotisations sociales des salariés sont calculées à l'aide du modèle de l'OCDE présenté dans Les impôts sur les salaires, le scénario retenu étant celui d'un travailleur âgé de 40 ans, célibataire et sans enfants. Voir les détails spécifiques à chaque pays concernant le modèle relatif aux cotisations sociales dans Les impôts sur les salaires 2018 (OCDE, 2018[5]).

\section{Note concernant les données d'Israël}

Les données statistiques concernant Israël sont fournies par et sous la responsabilité des autorités israéliennes compétentes. L'utilisation de ces données par l'OCDE est sans préjudice du statut des hauteurs du Golan, de Jérusalem-Est et des colonies de peuplement israéliennes en Cisjordanie aux termes du droit international.

\section{Références}

Brys, B. and C. Torres (2013), "Effective personal tax rates on marginal skills investments in OECD countries: A new methodology", Documents de travail de l'OCDE sur la fiscalité, No. 16, Éditions OCDE, Paris, http://dx.doi.org/10.1787/5k425747xbr6-en.

OCDE (2019), Guide de l'OCDE pour l'établissement de statistiques internationalement comparables dans le domaine de l'éducation 2018: Concepts, normes, définitions et classifications, Éditions OCDE, Paris, https://dx.doi.org/10.1787/9789264305380-fr.

OCDE (2018), Les impôts sur les salaires 2018, Éditions OCDE, Paris, https://dx.doi.org/10.1787/tax wages-2018-fr.

OCDE (2018), Regards sur l'éducation 2018 : Les indicateurs de l'OCDE, Éditions OCDE, Paris, https://dx.doi.org/10.1787/eag-2018-fr.

OCDE (2017), Regards sur l'éducation 2017 : Les indicateurs de l'OCDE, Éditions OCDE, Paris, 


\section{Tableaux de l'indicateur A5}

Tableau A5.1a

Tableau A5.1b

Tableau A5.2a

Tableau A5.2b

Tableau A5.3a

Tableau A5.3b
Coûts et bénéfices privés de l'obtention d'un diplôme de l'enseignement tertiaire chez les individus de sexe masculin (2016)

Coûts et bénéfices privés de l'obtention d'un diplôme de l'enseignement tertiaire chez les individus de sexe féminin (2016)

Coûts et bénéfices publics de l'obtention d'un diplôme de l'enseignement tertiaire chez les individus de sexe masculin (2016)

Coûts et bénéfices publics de l'obtention d'un diplôme de l'enseignement tertiaire chez les individus de sexe féminin (2016)

Coûts et bénéfices privés/publics de l'obtention d'un diplôme de l'enseignement tertiaire chez les individus de sexe masculin, selon le niveau de l'enseignement tertiaire (2016)

Coûts et bénéfices privés/publics de l'obtention d'un diplôme de l'enseignement tertiaire chez les individus de sexe féminin, selon le niveau de l'enseignement tertiaire (2016)

WEB Tableau A5.4a. Coûts et bénéfices privés de l'obtention d'un diplôme du deuxième cycle de l'enseignement secondaire chez les hommes (2016)

WEB Tableau A5.4b. Coûts et bénéfices privés de l'obtention d'un diplôme du deuxième cycle de l'enseignement secondaire chez les femmes (2016)

WEB Tableau A5.5a. Coûts et bénéfices publics de l'obtention d'un diplôme du deuxième cycle de l'enseignement secondaire chez les hommes (2016)

WEB Tableau A5.5b. Coûts et bénéfices publics de l'obtention d'un diplôme du deuxième cycle de l'enseignement secondaire chez les hommes (2016)

Date butoir pour les données : 19 juillet 2019. Les mises à jour peuvent être consultées en ligne à l'adresse : http://dx.doi.org/10.1787/eag-data-fr. D'autres données désagrégées sont également disponibles dans la Base de données de Regards sur l'éducation (http://stats.oecd.org/).

StatLink: https://doi.org/10.1787/888933980868 
Tableau A5.1a. Coûts et bénéfices privés de l'obtention d'un diplôme de l'enseignement tertiaire chez les individus de sexe masculin (2016)

Par comparaison avec un niveau de formation du deuxième cycle du secondaire chez les individus de sexe masculin, en équivalents USD convertis sur la base des PPA pour le PIB ; les coûts et bénéfices à venir sont actualisés à un taux de $2 \%$

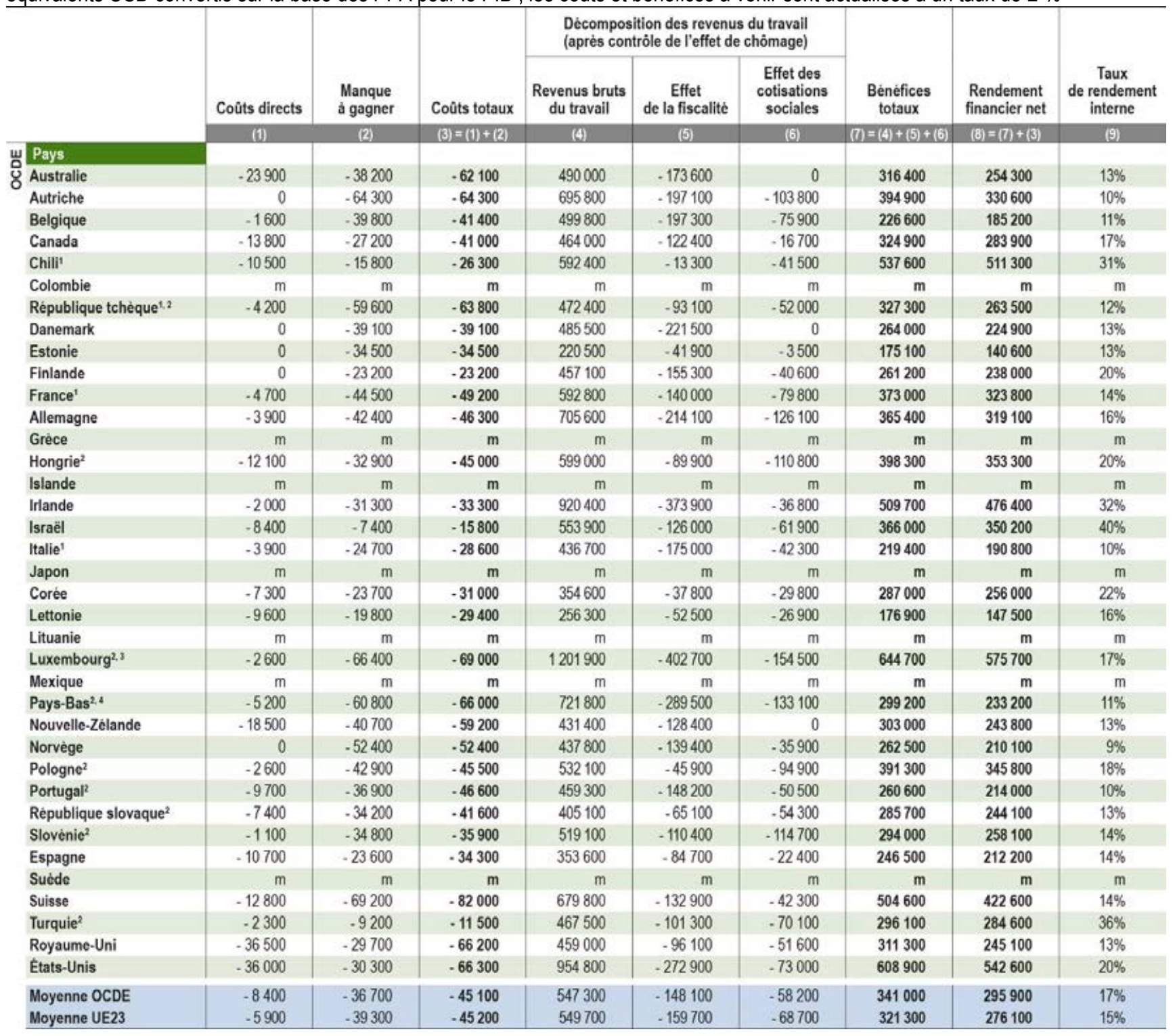

Remarque : Les données se basent sur la différence entre les hommes diplômés de l'enseignement tertiaire et ceux diplômés du deuxième cycle du secondaire. Les valeurs ont été arrondies à la centaine la plus proche. Les coûts directs de l'éducation n'incluent pas les prêts d'études.

En raison de changements de méthodologie, les valeurs de cette édition de Regards sur l'éducation ne peuvent pas être comparées à celles des éditions antérieures.

Consulter les sections « Définitions » et « Méthodologie » pour de plus amples informations.

1. Année de référence : 2015.

2. La probabilité que les étudiants disposent de revenus correspond au taux d'emploi issu du questionnaire LSO TRANS et non au pourcentage d'actifs rémunérés selon le questionnaire LSO relatif aux revenus.

3. Les résultats se basent sur les revenus nets des adultes diplômés de l'enseignement tertiaire (par comparaison avec les revenus nets des adultes diplômés du deuxième cycle de l'enseignement secondaire).

4. Année de référence : 2014.

Source : OCDE (2019). Consulter la section « Source » pour tout complément d'information et l'annexe 3 pour les notes (https://doi.org/10.1787/f8d7880d-en). Les symboles représentant les données manquantes et les abréviations figurent dans le Guide du lecteur. 
Tableau A5.1b. Coûts et bénéfices privés de l'obtention d'un diplôme de l'enseignement tertiaire chez les individus de sexe féminin (2016)

Par comparaison avec un niveau de formation du deuxième cycle du secondaire chez les individus de sexe féminin, en équivalents USD convertis sur la base des PPA pour le PIB ; les coûts et bénéfices à venir sont actualisés à un taux de $2 \%$

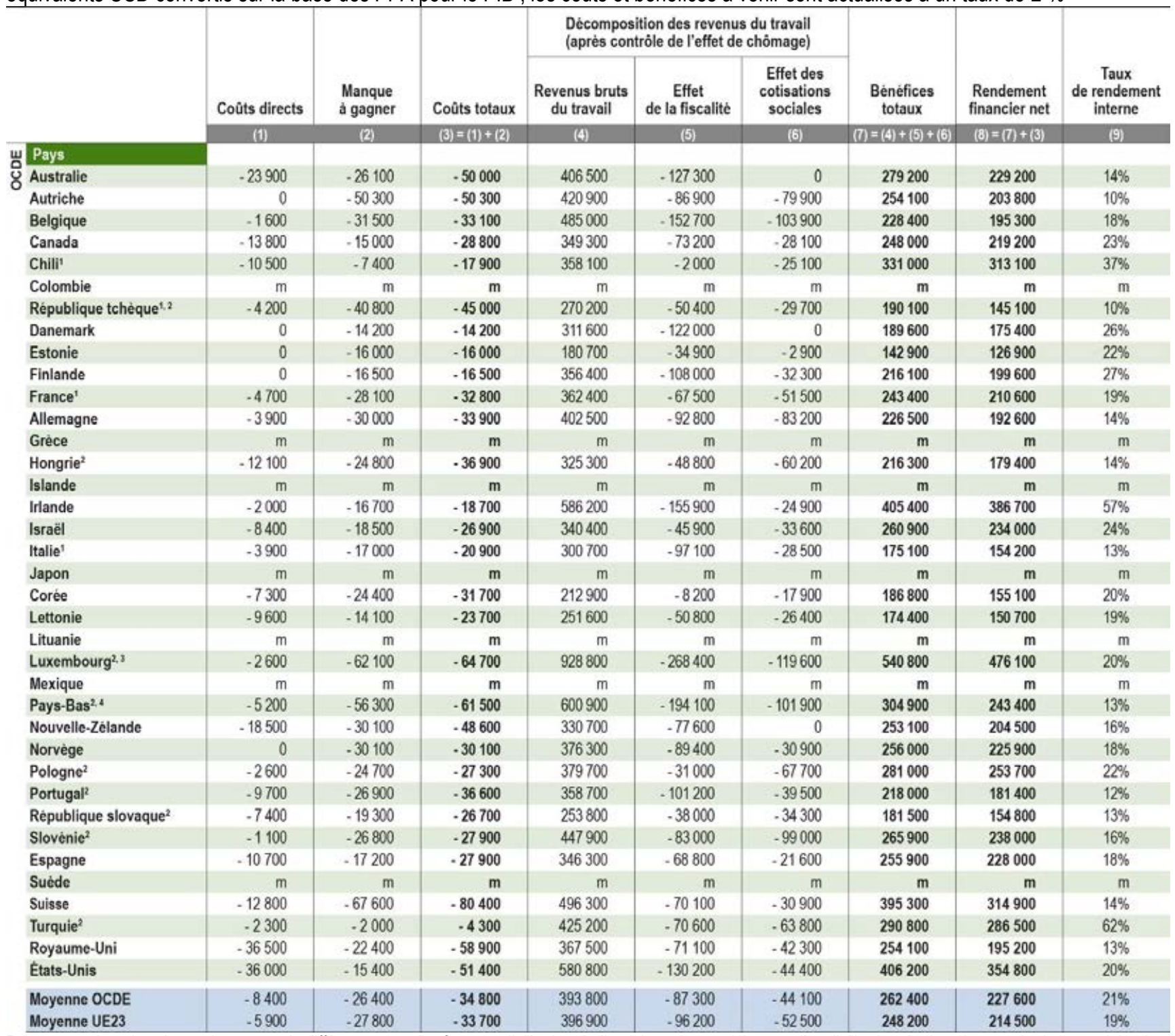

Remarque : Les données se basent sur la différence entre les femmes diplômées de l'enseignement tertiaire et celles diplômées du deuxième cycle du secondaire. Les valeurs ont été arrondies à la centaine la plus proche. Les coûts directs de l'éducation n'incluent pas les prêts d'études.

En raison de changements de méthodologie, les valeurs de cette édition de Regards sur l'éducation ne peuvent pas être comparées à celles des éditions antérieures.

Consulter les sections « Définitions » et « Méthodologie » pour de plus amples informations.

1. Année de référence : 2015.

2. La probabilité que les étudiants disposent de revenus correspond au taux d'emploi issu du questionnaire LSO TRANS et non au pourcentage d'actifs rémunérés selon le questionnaire LSO relatif aux revenus.

3. Les résultats se basent sur les revenus nets des adultes diplômés de l'enseignement tertiaire (par comparaison avec les revenus nets des adultes diplômés du deuxième cycle de l'enseignement secondaire).

4. Année de référence : 2014.

Source : OCDE (2019) Consulter la section « Source » pour tout complément d'information et l'annexe 3 pour les notes (https://doi.org/10.1787/f8d7880d-en).

Les symboles représentant les données manquantes et les abréviations figurent dans le Guide du lecteur. 
Tableau A5.2a. Coûts et bénéfices publics de l'obtention d'un diplôme de l'enseignement tertiaire chez les individus de sexe masculin (2016)

Par comparaison avec un niveau de formation du deuxième cycle du secondaire chez les individus de sexe masculin, en équivalents USD convertis sur la base des PPA pour le PIB ; les coûts et bénéfices à venir sont actualisés à un taux de $2 \%$

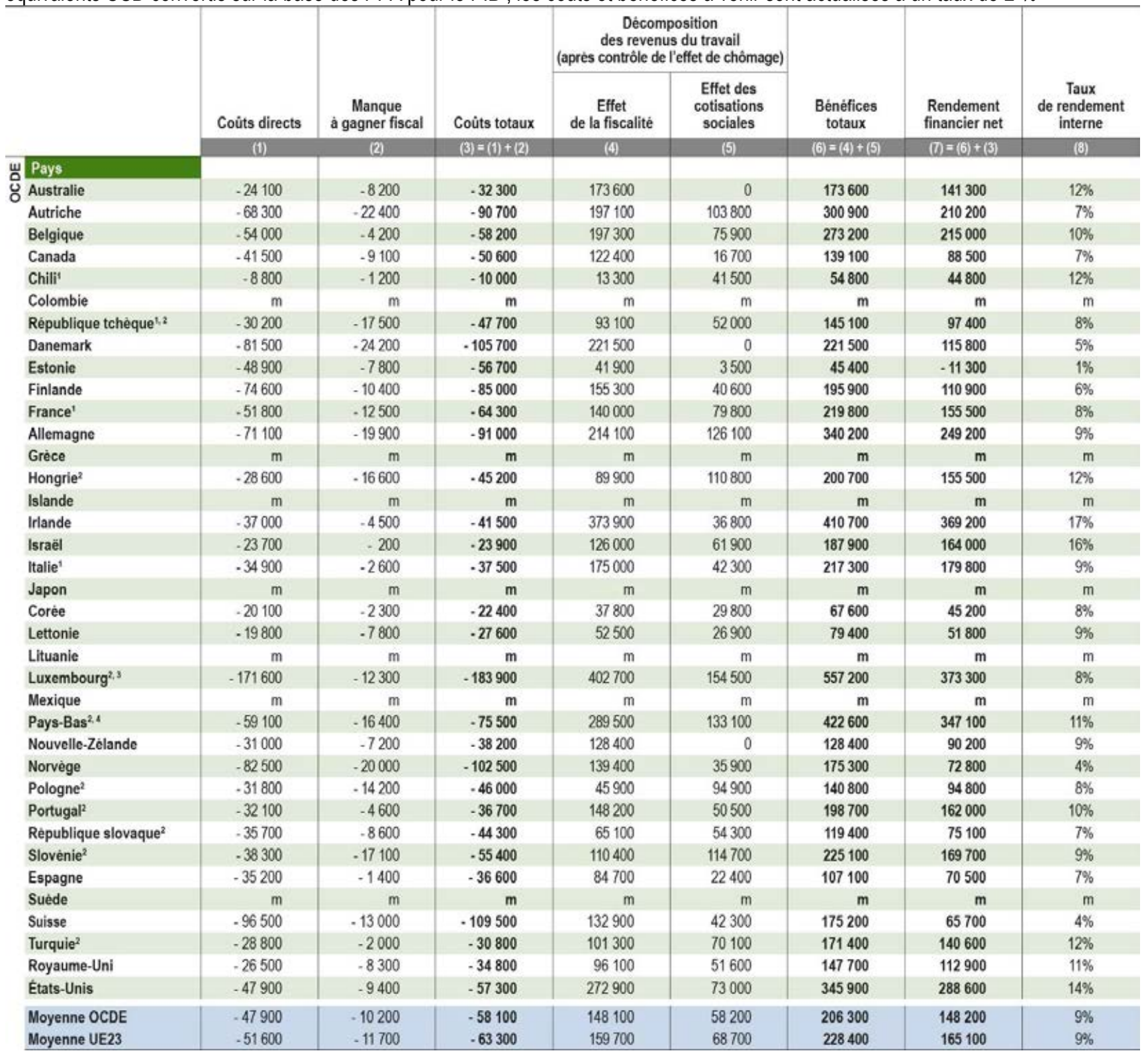

Remarque : Les données se basent sur la différence entre les femmes diplômées de l'enseignement tertiaire et celles diplômées du deuxième cycle du secondaire. Les valeurs ont été arrondies à la centaine la plus proche. Les coûts directs de l'éducation n'incluent pas les prêts d'études.

En raison de changements de méthodologie, les valeurs de cette édition de Regards sur l'éducation ne peuvent pas être comparées à celles des éditions antérieures. Consulter les sections « Définitions » et « Méthodologie » pour de plus amples informations.

1. Année de référence : 2015.

2. La probabilité que les étudiants disposent de revenus correspond au taux d'emploi issu du questionnaire LSO TRANS et non au pourcentage d'actifs rémunérés selon le questionnaire LSO relatif aux revenus.

3. Les résultats se basent sur les revenus nets des adultes diplômés de l'enseignement tertiaire (par comparaison avec les revenus nets des adultes diplômés du deuxième cycle de l'enseignement secondaire).

4. Année de référence : 2014.

Source : OCDE (2019). Consulter la section « Source » pour tout complément d'information et l'annexe 3 pour les notes (https://doi.org/10.1787/f8d7880d-en).

Les symboles représentant les données manquantes et les abréviations figurent dans le Guide du lecteur. 
Tableau A5.2b. Coûts et bénéfices publics de l'obtention d'un diplôme de l'enseignement tertiaire chez les individus de sexe féminin (2016)

Par comparaison avec un niveau de formation du deuxième cycle du secondaire chez les individus de sexe féminin, en équivalents USD convertis sur la base des PPA pour le PIB ; les coûts et bénéfices à venir sont actualisés à un taux de $2 \%$

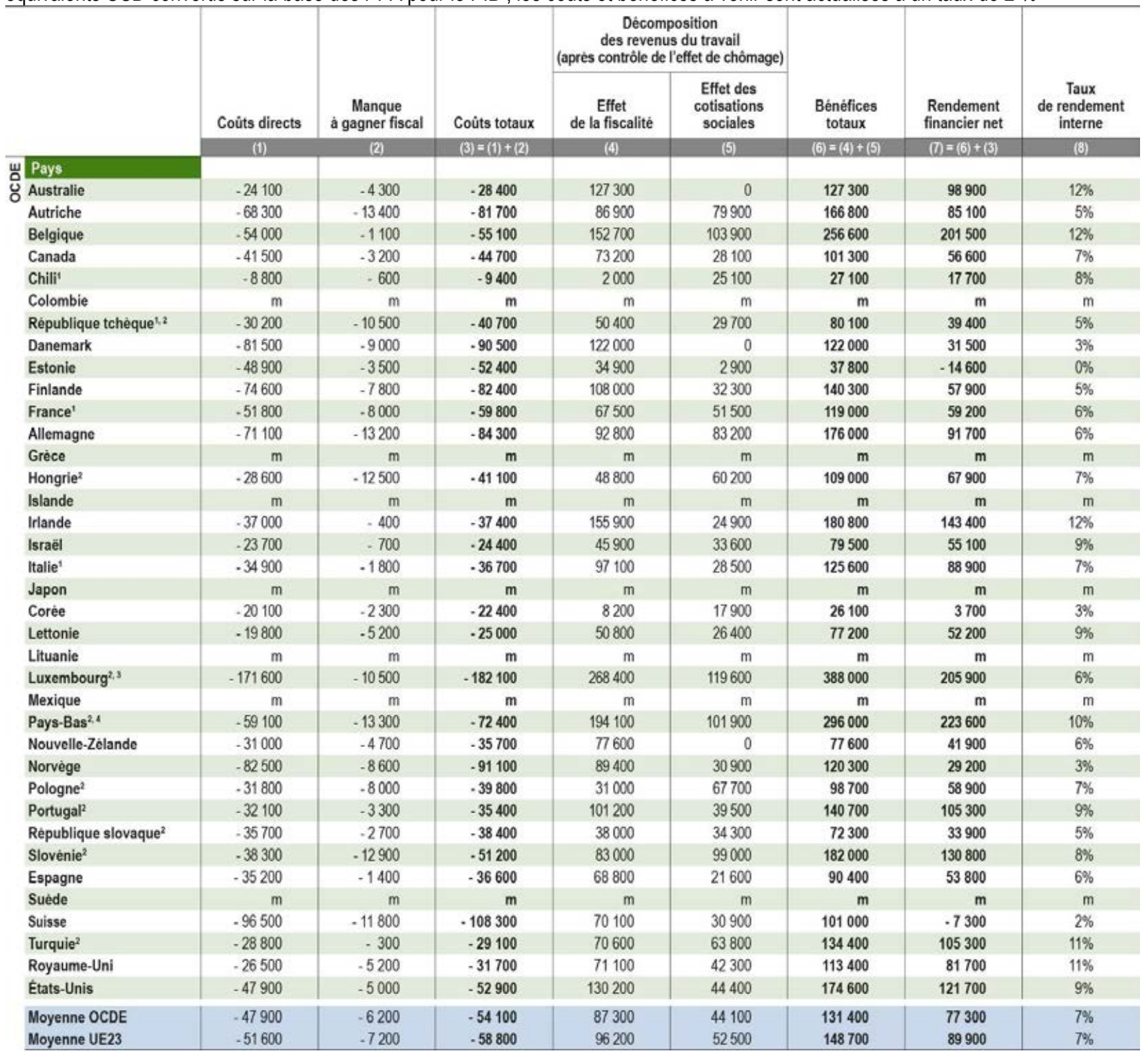

Remarque : Les données se basent sur la différence entre les femmes diplômées de l'enseignement tertiaire et celles diplômées du deuxième cycle du secondaire. Les valeurs ont été arrondies à la centaine la plus proche. Les coûts directs de l'éducation n'incluent pas les prêts d'études.

En raison de changements de méthodologie, les valeurs de cette édition de Regards sur l'éducation ne peuvent pas être comparées à celles des éditions antérieures. Consulter les sections « Définitions » et « Méthodologie » pour de plus amples informations.

1. Année de référence : 2015

2. La probabilité que les étudiants disposent de revenus correspond au taux d'emploi issu du questionnaire LSO TRANS et non au pourcentage d'actifs rémunérés selon le questionnaire LSO relatif aux revenus.

3. Les résultats se basent sur les revenus nets des adultes diplômés de l'enseignement tertiaire (par comparaison avec les revenus nets des adultes diplômés du deuxième cycle de l'enseignement secondaire).

4. Année de référence : 2014.

Source : OCDE (2019) Consulter la section « Source » pour tout complément d'information et l'annexe 3 pour les notes (https://doi.org/10.1787/f8d7880d-en).

Les symboles représentant les données manquantes et les abréviations figurent dans le Guide du lecteur. 
Tableau A5.3a. Coûts et bénéfices privés/publics de l'obtention d'un diplôme de l'enseignement tertiaire chez les individus de sexe masculin, selon le niveau de l'enseignement tertiaire (2016)

Par comparaison avec un niveau de formation du deuxième cycle du secondaire chez les individus de sexe masculin, en équivalents USD convertis sur la base des PPA pour le PIB ; les coûts et bénéfices à venir sont actualisés à un taux de $2 \%$

\begin{tabular}{|c|c|c|c|c|c|c|c|c|c|c|c|c|}
\hline & \multicolumn{6}{|c|}{ Tertiaire de cycle court (CITE 5) } & \multicolumn{6}{|c|}{ Licence, master et doctorat, ou niveaux équivalents (CITE 6 a 8) } \\
\hline & \multicolumn{3}{|c|}{ Privés } & \multicolumn{3}{|c|}{ Publics } & \multicolumn{3}{|c|}{ Privés } & \multicolumn{3}{|c|}{ Publics } \\
\hline & $\begin{array}{l}\text { Coûts } \\
\text { totaux }\end{array}$ & $\begin{array}{l}\text { Bénéfices } \\
\text { totaux }\end{array}$ & $\begin{array}{c}\text { Rendement } \\
\text { financier } \\
\text { net }\end{array}$ & $\begin{array}{l}\text { Coûts } \\
\text { totaux }\end{array}$ & $\begin{array}{l}\text { Bènéfices } \\
\text { totaux }\end{array}$ & $\begin{array}{c}\text { Rendement } \\
\text { financier } \\
\text { net }\end{array}$ & $\begin{array}{l}\text { Counts } \\
\text { totaux }\end{array}$ & $\begin{array}{l}\text { Bénéfices } \\
\text { totaux }\end{array}$ & $\begin{array}{c}\text { Rendement } \\
\text { financier } \\
\text { net }\end{array}$ & $\begin{array}{l}\text { Coûts } \\
\text { totaux }\end{array}$ & $\begin{array}{l}\text { Bénéfices } \\
\text { totaux }\end{array}$ & $\begin{array}{c}\text { Rendement } \\
\text { financier } \\
\text { net }\end{array}$ \\
\hline & (1) & (2) & (3) & (4) & (5) & (6) & (7) & (8) & (9) & (10) & (11) & (12) \\
\hline \multicolumn{13}{|l|}{ Ш Pays } \\
\hline 8 Australie & -22300 & 135400 & 113100 & -9900 & 60400 & 50500 & -77300 & 375300 & 298000 & -42500 & 210600 & 168100 \\
\hline Autriche & -54300 & 264200 & 209900 & .77200 & 204600 & 127400 & -69400 & 562600 & 493200 & -97900 & 420200 & 322300 \\
\hline Belgique & $\mathrm{m}$ & $\mathrm{m}$ & $\mathrm{m}$ & m & m & m & .41900 & 228500 & 186600 & .59300 & 275900 & 216600 \\
\hline Canada & .27100 & 193800 & 166700 & .31500 & 79900 & 48400 & -46300 & 428400 & 382100 & -58700 & 191900 & 133200 \\
\hline Chili' & -17500 & 189500 & 172000 & -4500 & 15400 & 10900 & -44500 & 684600 & 640100 & -18800 & 73300 & 54500 \\
\hline Colombie & $\mathrm{m}$ & $\mathrm{m}$ & $\mathrm{m}$ & $\mathrm{m}$ & m & m & $\mathrm{m}$ & m & $\mathrm{m}$ & $\mathrm{m}$ & $\mathrm{m}$ & $\mathrm{m}$ \\
\hline République tchèque ${ }^{1,2}$ & m & $\mathrm{m}$ & $\mathrm{m}$ & m & $\mathrm{m}$ & m & .63600 & 340400 & 276800 & .47500 & 151000 & 103500 \\
\hline Danemark & -18000 & 128700 & 110700 & -48600 & 86700 & 38100 & -41600 & 295400 & 253800 & -112400 & 258100 & 145700 \\
\hline Estonie & a & a & a & a & a & a & -34500 & 200600 & 166100 & .56700 & 52000 & .4700 \\
\hline Finlande & a & a & a & a & a & a & .23200 & 298900 & 275700 & -85000 & 228200 & 143200 \\
\hline France' & -24200 & 208100 & 183900 & -32700 & 102700 & 70000 & -56000 & 489600 & 433600 & -72500 & 302700 & 230200 \\
\hline Allemagne & $\mathrm{m}$ & $\mathrm{m}$ & $\mathrm{m}$ & $\mathrm{m}$ & m & m & -46500 & 392800 & 346300 & .91400 & 362700 & 271300 \\
\hline Grèce & a & a & a & a & a & a & $\mathrm{m}$ & m & $\mathrm{m}$ & $\mathrm{m}$ & m & m \\
\hline Hongrie $^{2}$ & -30100 & 163600 & 133500 & -20900 & 82400 & 61500 & -45500 & 404600 & 359100 & -46400 & 203900 & 157500 \\
\hline Islande & $\mathrm{m}$ & $\mathrm{m}$ & $\mathrm{m}$ & m & m & m & $\mathrm{m}$ & $\mathrm{m}$ & $\mathrm{m}$ & $\mathrm{m}$ & m & $\mathrm{m}$ \\
\hline Irlande & -20800 & 223600 & 202800 & -25800 & 154600 & 128800 & -36600 & 597500 & 560900 & -45500 & 498800 & 453300 \\
\hline Israël & -4200 & 147600 & 143400 & -6700 & 41800 & 35100 & -21900 & 465900 & 444000 & -32900 & 264400 & 231500 \\
\hline Italie' & $\mathrm{m}$ & m & $\mathrm{m}$ & $\mathrm{m}$ & m & m & .28600 & 219500 & 190900 & -37600 & 217300 & 179700 \\
\hline Japon & $\mathrm{m}$ & $\mathrm{m}$ & $\mathrm{m}$ & m & m & m & $\mathrm{m}$ & m & $\mathrm{m}$ & m & m & m \\
\hline Corée & -18700 & 191300 & 172600 & -8400 & 37100 & 28700 & -34800 & 309800 & 275000 & -27700 & 76000 & 48300 \\
\hline Lettonie & -21000 & 95500 & 74500 & -21700 & 41700 & 20000 & .32100 & 185100 & 153000 & -29500 & 82900 & 53400 \\
\hline Lituanie & a & a & a & a & a & a & m & m & m & m & m & m \\
\hline Luxembourg & $\mathrm{m}$ & $\mathrm{m}$ & $\mathrm{m}$ & m & m & m & m & m & $\mathrm{m}$ & $\mathrm{m}$ & $\mathrm{m}$ & m \\
\hline Mexique & $\mathrm{m}$ & $\mathrm{m}$ & m & $\mathrm{m}$ & m & m & $\mathrm{m}$ & $\mathrm{m}$ & m & $\mathrm{m}$ & m & m \\
\hline Pays-Bas ${ }^{2,3}$ & .31800 & 200000 & 168200 & .29600 & 215600 & 186000 & .66400 & 309800 & 243400 & .75900 & 444000 & 368100 \\
\hline Nouvelle-Zélande & -39500 & 161300 & 121800 & -18100 & 57000 & 38900 & -64900 & 325500 & 260600 & -44600 & 140200 & 95600 \\
\hline Norvege & -29400 & 107000 & 77600 & -43000 & 80300 & 37300 & -53400 & 351500 & 298100 & -105100 & 230200 & 125100 \\
\hline Pologne $^{2}$ & $\mathrm{~m}$ & $\mathrm{~m}$ & $\mathrm{~m}$ & m & m & $\mathrm{m}$ & -45500 & 405700 & 360200 & .46000 & 145900 & 99900 \\
\hline Portugal & m & m & $\mathrm{m}$ & $\mathrm{m}$ & $\mathrm{m}$ & m & -46600 & 273500 & 226900 & -36900 & 210300 & 173400 \\
\hline République slovaque $e^{2}$ & m & m & $\mathrm{m}$ & m & m & m & -42400 & 289700 & 247300 & -45200 & 121000 & 75800 \\
\hline Slovénie ${ }^{2}$ & -21500 & 167600 & 146100 & -14900 & 117500 & 102600 & .38200 & 341800 & 303600 & -63800 & 270500 & 206700 \\
\hline Espagne & -13900 & 128100 & 114200 & -17400 & 46500 & 29100 & -41200 & 286400 & 245200 & -42400 & 131400 & 89000 \\
\hline Suede & $\mathrm{m}$ & $\mathrm{m}$ & $\mathrm{m}$ & m & $\mathrm{m}$ & m & $\mathrm{m}$ & m & m & $\mathrm{m}$ & m & m \\
\hline Suisse & $\mathrm{m}$ & $\mathrm{m}$ & $\mathrm{m}$ & $\mathrm{m}$ & m & $\mathrm{m}$ & .83100 & 504100 & 421000 & -111000 & 175100 & 64100 \\
\hline Turquie ${ }^{2}$ & -6500 & 505100 & 498600 & -17300 & 301300 & 284000 & -13700 & 468000 & 454300 & -36600 & 280600 & 244000 \\
\hline Royaume-Uni & .53500 & 143600 & 90100 & -17400 & 66100 & 48700 & .68200 & 359100 & 290900 & -36400 & 176400 & 140000 \\
\hline Etats-Unis & .37400 & 151700 & 114300 & -32300 & 70300 & 38000 & -83000 & 732800 & 649800 & -71800 & 426800 & 355000 \\
\hline Moyenne OCDE & m & $\mathrm{m}$ & m & m & $\mathrm{m}$ & m & -48000 & 383700 & 335700 & -57900 & 228400 & 170500 \\
\hline Moyenne UE23 & $\mathrm{m}$ & $\mathrm{m}$ & $\mathrm{m}$ & $\mathrm{m}$ & $\mathrm{m}$ & m & .45700 & 341100 & 295400 & .59400 & 239600 & 180200 \\
\hline
\end{tabular}

Remarque : Les données se basent sur la différence entre les hommes diplômés de l'enseignement tertiaire et ceux diplômés du deuxième cycle du secondaire. Les valeurs ont été arrondies à la centaine la plus proche. Les coûts directs de l'éducation n'incluent pas les prêts d'études.

En raison de changements de méthodologie, les valeurs de cette édition de Regards sur l'éducation ne peuvent pas être comparées à celles des éditions antérieures.

Consulter les sections « Définitions » et « Méthodologie » pour de plus amples informations.

1. Année de référence : 2015.

2. La probabilité que les étudiants disposent de revenus correspond au taux d'emploi issu du questionnaire LSO TRANS et non au pourcentage d'actifs rémunérés selon le questionnaire LSO relatif aux revenus.

3. Année de référence : 2014.

Source : OCDE (2019) Consulter la section « Source » pour tout complément d'information et l'annexe 3 pour les notes (https://doi.org/10.1787/f8d7880d-en).

Les symboles représentant les données manquantes et les abréviations figurent dans le Guide du lecteur. 
Tableau A5.3b. Coûts et bénéfices privés/publics de l'obtention d'un diplôme de l'enseignement tertiaire chez les individus de sexe féminin, selon le niveau de l'enseignement tertiaire (2016)

Par comparaison avec un niveau de formation du deuxième cycle du secondaire chez les individus de sexe féminin, en équivalents USD convertis sur la base des PPA pour le PIB ; les coûts et bénéfices à venir sont actualisés à un taux de $2 \%$

\begin{tabular}{|c|c|c|c|c|c|c|c|c|c|c|c|c|}
\hline & \multicolumn{6}{|c|}{ Tertiaire de cycle court (CITE 5) } & \multicolumn{6}{|c|}{ Licence, master et doctorat, ou niveaux équivalents (CITE 6 a 8) } \\
\hline & \multicolumn{3}{|c|}{ Privès } & \multicolumn{3}{|c|}{ Publics } & \multicolumn{3}{|c|}{ Privès } & \multicolumn{3}{|c|}{ Publics } \\
\hline & $\begin{array}{l}\text { Coùts } \\
\text { totaux }\end{array}$ & $\begin{array}{l}\text { Bénéfices } \\
\text { totaux }\end{array}$ & $\begin{array}{c}\text { Rendement } \\
\text { financier } \\
\text { net }\end{array}$ & $\begin{array}{l}\text { Coûts } \\
\text { totaux }\end{array}$ & $\begin{array}{c}\text { Bènéfices } \\
\text { totaux }\end{array}$ & $\begin{array}{c}\text { Rendement } \\
\text { financier } \\
\text { net }\end{array}$ & $\begin{array}{l}\text { Coûts } \\
\text { totaux }\end{array}$ & $\begin{array}{l}\text { Bénéfices } \\
\text { totaux }\end{array}$ & $\begin{array}{c}\text { Rendement } \\
\text { financier } \\
\text { net }\end{array}$ & $\begin{array}{l}\text { Coûts } \\
\text { totaux }\end{array}$ & $\begin{array}{l}\text { Bènéfices } \\
\text { totaux }\end{array}$ & $\begin{array}{l}\text { Rendement } \\
\text { financier } \\
\text { net }\end{array}$ \\
\hline & (1) & (2) & (3) & (4) & (5) & (6) & (a) & (8) & (9) & (10) & (11) & (12) \\
\hline \multicolumn{13}{|l|}{ ш Pays } \\
\hline Uustralie & -16700 & 134600 & 117900 & -8000 & 52200 & 44200 & -63800 & 337500 & 273700 & -38100 & 155800 & 117700 \\
\hline Autriche & -42600 & 197500 & 154900 & -69600 & 116300 & 46700 & -54400 & 315000 & 260600 & -88200 & 220300 & 132100 \\
\hline Belgique & m & $\mathrm{m}$ & m & m & $\mathrm{m}$ & m & .33500 & 229900 & 196400 & .56300 & 257400 & 201100 \\
\hline Canada & -19000 & 168500 & 149500 & .27600 & 57000 & 29400 & .32500 & 321100 & 288600 & .52100 & 138200 & 86100 \\
\hline Chili' & -11100 & 124000 & 112900 & -4000 & 9300 & 5300 & -31000 & 444000 & 413000 & -17800 & 39700 & 21900 \\
\hline Colombie & m & $\mathrm{m}$ & m & $\mathrm{m}$ & $\mathrm{m}$ & m & $\mathrm{m}$ & m & $\mathrm{m}$ & $\mathrm{m}$ & $\mathrm{m}$ & m \\
\hline République tchèque $e^{1,2}$ & $\mathrm{~m}$ & m & m & m & $\mathrm{m}$ & m & .44900 & 203100 & 158200 & -40500 & 85900 & 45400 \\
\hline Danemark & .6500 & 135900 & 129400 & -41700 & 83000 & 41300 & -15100 & 195500 & 180400 & .96300 & 126500 & 30200 \\
\hline Estonic & a & a & a & a & a & a & -16000 & 164600 & 148600 & -52400 & 43400 & .9000 \\
\hline Finlande & a & a & a & a & a & a & -16500 & 259600 & 243100 & .82400 & 175800 & 93400 \\
\hline France $^{\prime}$ & -15300 & 191100 & 175800 & -30300 & 89400 & 59100 & -37800 & 305000 & 267200 & -67600 & 154100 & 86500 \\
\hline Allemagne & $\mathrm{m}$ & $\mathrm{m}$ & m & $\mathrm{m}$ & $\mathrm{m}$ & m & -34200 & 229700 & 195500 & -84600 & 179000 & 94400 \\
\hline Gréce & a & a & a & a & a & a & $\mathrm{m}$ & m & m & $\mathrm{m}$ & $\mathrm{m}$ & m \\
\hline Hongrie $^{2}$ & -24700 & 84300 & 59600 & -18200 & 42500 & 24300 & -37300 & 220100 & 182800 & -42200 & 110800 & 68600 \\
\hline Islande & $\mathrm{m}$ & m & m & m & m & m & $\mathrm{m}$ & m & $\mathrm{m}$ & $\mathrm{m}$ & m & m \\
\hline Irlande & -11700 & 246600 & 234900 & -23300 & 75200 & 51900 & .20600 & 464500 & 443900 & -41100 & 229400 & 188300 \\
\hline Israël & .9400 & 93900 & 84500 & .6900 & 12900 & 6000 & .34700 & 332800 & 298100 & .33400 & 110900 & 77500 \\
\hline Italie' & m & m & m & m & m & $\mathrm{m}$ & -20900 & 175200 & 154300 & -36800 & 125700 & 88900 \\
\hline Japon & $\mathrm{m}$ & $\mathrm{m}$ & m & $\mathrm{m}$ & $\mathrm{m}$ & m & $\mathrm{m}$ & $\mathrm{m}$ & m & $\mathrm{m}$ & $\mathrm{m}$ & m \\
\hline Corée & -19100 & 131100 & 112000 & -8400 & 14800 & 6400 & .35500 & 210700 & 175200 & -27700 & 32800 & 5100 \\
\hline Lettonie & -17300 & 90400 & 73100 & -20000 & 38100 & 18100 & -25800 & 181100 & 155300 & -26700 & 80400 & 53700 \\
\hline Lituanie & a & a & a & a & a & a & m & $m$ & m & m & m & m \\
\hline Luxembourg & $\mathrm{m}$ & $\mathrm{m}$ & m & m & $\mathrm{m}$ & m & $\mathrm{m}$ & $\mathrm{m}$ & m & $\mathrm{m}$ & $\mathrm{m}$ & m \\
\hline Mexique & $\mathrm{m}$ & $\mathrm{m}$ & m & m & $\mathrm{m}$ & m & $\mathrm{m}$ & $\mathrm{m}$ & $\mathrm{m}$ & $\mathrm{m}$ & $\mathrm{m}$ & m \\
\hline Pays-Bas ${ }^{2,3}$ & -29500 & 197200 & 167700 & -28000 & 126400 & 98400 & -61900 & 316800 & 254900 & .72800 & 317700 & 244900 \\
\hline Nouvelle-Zélande & -32300 & 111300 & 79000 & -16400 & 26900 & 10500 & -53300 & 267100 & 213800 & -41900 & 83800 & 41900 \\
\hline Norvège & -17500 & 105500 & 88000 & -36900 & 52400 & 15500 & -30600 & 304900 & 274300 & .93500 & 142500 & 49000 \\
\hline Pologne ${ }^{2}$ & m & $\mathrm{m}$ & m & m & m & $\mathrm{m}$ & -27300 & 287600 & 260300 & -39800 & 101100 & 61300 \\
\hline Portugal ${ }^{2}$ & $\mathrm{~m}$ & m & m & $\mathrm{m}$ & $\mathrm{m}$ & m & -36600 & 227800 & 191200 & -35600 & 148700 & 113100 \\
\hline Rèpublique slovaque $^{2}$ & m & m & m & m & $\mathrm{m}$ & m & -27300 & 185100 & 157800 & -39300 & 73800 & 34500 \\
\hline Slovénie ${ }^{2}$ & -16800 & 139800 & 123000 & -12500 & 87000 & 74500 & .29700 & 310600 & 280900 & .59300 & 218300 & 159000 \\
\hline Espagne & -10600 & 72900 & 62300 & -17400 & 15200 & -2200 & -33900 & 318300 & 284400 & -42400 & 120500 & 78100 \\
\hline Suède & m & $\mathrm{m}$ & m & $\mathrm{m}$ & $\mathrm{m}$ & m & $\mathrm{m}$ & $\mathrm{m}$ & m & $\mathrm{m}$ & m & m \\
\hline Suisse & $\mathrm{m}$ & $\mathrm{m}$ & $\mathrm{m}$ & $\mathrm{m}$ & $\mathrm{m}$ & $\mathrm{m}$ & .81500 & 394800 & 313300 & -109700 & 100900 & .8800 \\
\hline Turquie $^{2}$ & -2400 & 427900 & 425500 & -16400 & 231900 & 215500 & -5200 & 540800 & 535600 & -34600 & 286000 & 251400 \\
\hline Royaume-Uni & .48500 & 99800 & 51300 & -15200 & 48200 & 33000 & .60800 & 297900 & 237100 & -33300 & 132900 & 99600 \\
\hline États-Unis & .29000 & 159400 & 130400 & .29800 & 55900 & 26100 & .64400 & 474200 & 409800 & -66300 & 215300 & 149000 \\
\hline Moyenne OCDE & m & $\mathrm{m}$ & m & m & $\mathrm{m}$ & m & .36800 & 293600 & 256800 & -53500 & 145100 & 91600 \\
\hline Moyenne UE23 & $\mathrm{m}$ & $\mathrm{m}$ & $\mathrm{m}$ & $\mathrm{m}$ & $\mathrm{m}$ & m & .33400 & 257200 & 223800 & .54600 & 152700 & 98100 \\
\hline
\end{tabular}

Remarque : Les données se basent sur la différence entre les femmes diplômées de l'enseignement tertiaire et celles diplômées du deuxième cycle du secondaire. Les valeurs ont été arrondies à la centaine la plus proche. Les coûts directs de l'éducation n'incluent pas les prêts d'études.

En raison de changements de méthodologie, les valeurs de cette édition de Regards sur l'éducation ne peuvent pas être comparées à celles des éditions antérieures.

Consulter les sections « Définitions » et « Méthodologie » pour de plus amples informations.

1. Année de référence : 2015.

2. La probabilité que les étudiants disposent de revenus correspond au taux d'emploi issu du questionnaire LSO TRANS et non au pourcentage d'actifs rémunérés selon le questionnaire LSO relatif aux revenus.

3. Année de référence : 2014

Source : OCDE (2019) Consulter la section « Source » pour tout complément d'information et l'annexe 3 pour les notes (https://doi.org/10.1787/f8d7880d-en).

Les symboles représentant les données manquantes et les abréviations figurent dans le Guide du lecteur. 



\section{Indicateur A6. En quoi les retombées sociales sont-elles liées à l'éducation?}

\section{Faits marquants}

- L'élévation du niveau de formation est associée à de meilleures relations sociales. La corrélation est particulièrement frappante au sujet des activités culturelles et sportives dont le taux de participation s'établit en moyenne à plus de $90 \%$ chez les diplômés de l'enseignement tertiaire, mais à moins de $60 \%$ chez les adultes dont le niveau de formation est inférieur au deuxième cycle de l'enseignement secondaire, dans les pays de l'OCDE participant aux Statistiques de l'Union européenne sur le revenu et les conditions de vie (UE-SILC).

- L'équilibre entre vie professionnelle et vie privée est une dimension importante du bien-être. Toutefois, l'élévation du niveau de formation ne semble pas associée à un meilleur équilibre, contrairement aux relations sociales. Dans la moitié environ des pays dont les données sont disponibles, la variation de l'équilibre entre vie professionnelle et vie privée selon les niveaux de formation n'est pas statistiquement significative.

- L'instruction peut améliorer la motivation à l'idée de lire davantage et, inversement, lire souvent peut améliorer les ambitions scolaires. En moyenne, dans les pays et économies de l'OCDE participant à l'Évaluation des compétences des adultes (PIAAC), le pourcentage de lecteurs assidus augmente de niveau en niveau.

\section{Graphique A6.1. Participation à plusieurs activités sociales, selon le niveau de formation (2015 et 2017)}

Statistiques de l'Union européenne sur le revenu et les conditions de vie (UE-SILC-2015), individus âgés de 25 à 64 ans, moyenne

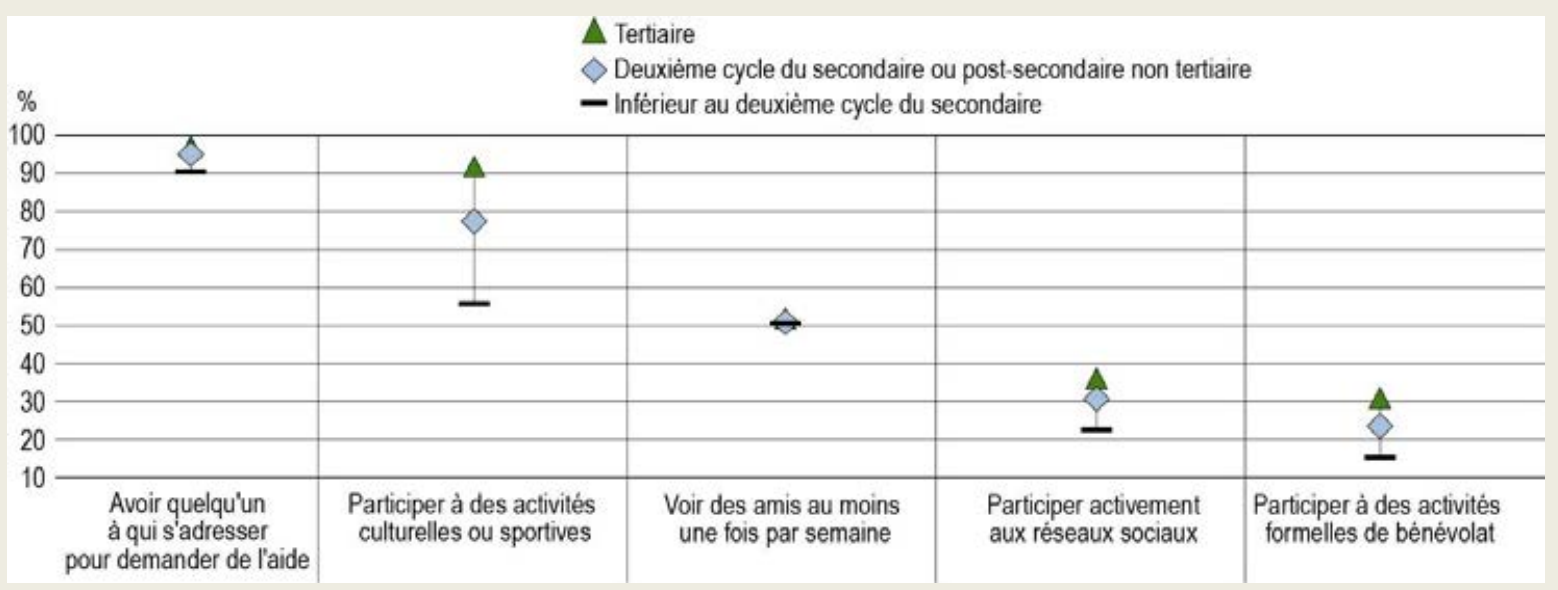

Remarque : Consulter le tableau source et l'annexe 3 pour de plus amples informations sur les questions posées.

Les indicateurs des liens sociaux sont classés par ordre décroissant du pourcentage de diplômés de l'enseignement tertiaire âgés de 25 à 64 ans ayant répondu par l'affirmative à la question.

Source: OCDE (2019), tableau A6.1. Consulter la section «Source» pour tout complément d'information et l'annexe 3 pour les notes (https://doi.org/10.1787/f8d7880d-en). 


\section{Contexte}

Promouvoir la cohésion sociale, qui se reflète souvent dans le degré d'engagement civique et social, est une priorité dans les pays de l'OCDE. II apparaît qu'en général, le degré d'engagement civique est insuffisant, ce qui compromet la survie et l'amélioration de nos sociétés. L'éducation joue un grand rôle dans la cohésion sociale, car elle renforce les compétences sociales et émotionnelles qui peuvent contribuer à améliorer les relations sociales et à protéger les individus contre l'isolement. Les réseaux sociaux des adultes sont constitués de plusieurs cercles, la famille, les amis, les collègues et, plus généralement, la communauté dans laquelle ils vivent. Les interactions sociales sont façonnées par le contexte social et le statut socio-économique des ménages, mais l'élévation du niveau de formation permet aux individus d'étendre leurs réseaux sociaux, d'accroître leur taux d'emploi (voir l'indicateur A3) et, en fin de compte, de bénéficier des vertus d'une bonne intégration sociale, d'une meilleure santé par exemple (VicHealth, 2010[1]).

Les réseaux sociaux en ligne ont pris beaucoup d'importance dans nos sociétés et sont le théâtre d'une part croissante de nos interactions personnelles. Selon les chiffres de 2019, Facebook compte 2,38 milliards d'utilisateurs actifs, soit plus de $30 \%$ de la population mondiale (Statista, 2019[2] ; Worldometers, 2019[3]). L'acception du terme « ami » est différente dans le monde virtuel où les interactions en personne ne sont plus préalables à l'établissement de liens d'amitié ; la fracture numérique peut empêcher une certaine partie de la population, dont les aînés et les moins instruits, à se constituer ce capital social.

L'équilibre entre vie professionnelle et vie privée est un aspect majeur du bien-être social et de la qualité de la vie. Le cumul excessif d'heures de travail ajoute au stress professionnel et familial, et l'on s'accorde de plus en plus à reconnaître que c'est l'un des problèmes majeurs dans de nombreuses sociétés aujourd'hui. L'équilibre entre vie professionnelle et vie privée est l'une des grandes dimensions du cadre d'évaluation de la qualité de la vie de l'Indice du vivre mieux de l'OCDE (OCDE, 2014 ${ }_{[4]}$ ) et fait partie des indicateurs des retombées sociales de l'éducation dans Regards sur l'éducation (OCDE, 2017[5]). Dans ce contexte, il est important d'évaluer dans quelle mesure le niveau de formation influe sur cette retombée sociale tout à fait déterminante pour le bien-être et la satisfaction à l'égard de la vie.

\section{Autres faits marquants}

- Les liens personnels, par exemple le fait d'avoir quelqu'un sur qui compter en cas de besoin ou de se retrouver entre amis, varient moins selon le niveau de formation que la participation à des activités culturelles et sportives, la présence sur les réseaux sociaux et le bénévolat formel.

- Dans la plupart des pays participant à l'Évaluation des compétences des adultes (PIAAC), il existe une relation positive entre le niveau de formation et la capacité de travailler selon un horaire plus flexible.

- Le fait de ne pas lire souvent de livres n'est pas toujours en lien avec un niveau peu élevé de littératie. Au Japon par exemple, il y a peu de lecteurs assidus, mais le niveau de littératie est l'un des plus élevés des pays et économies participant à l'Évaluation des compétences des adultes (PIAAC).

- Les résultats de l'Évaluation des compétences des adultes (PIAAC) montrent que le niveau de formation peut avoir des effets indirects sur la satisfaction professionnelle. Le niveau de formation n'a pas nécessairement d'effet direct sur la satisfaction professionnelle, mais il peut avoir des effets indirects sur cet aspect par l'intermédiaire de variables telles que la complexité du travail, la rémunération et l'autonomie des travailleurs.

\section{Remarque}

Les différences par niveau de formation présentées dans cet indicateur sont calculées abstraction faite du statut socio-économique et d'autres facteurs susceptibles d'intervenir. Dans ce contexte, il y a lieu de ne pas interpréter le gradient du niveau de formation comme l'effet de l'éducation sur la retombée sociale à l'étude. 


\section{Analyse}

\section{Liens sociaux, selon le niveau de formation}

En moyenne, dans les pays de l'OCDE, les 25-64 ans participent davantage à diverses activités sociales s'ils sont diplômés de l'enseignement tertiaire que si leur niveau de formation est inférieur. Toutefois, cet avantage sur les liens sociaux que procure l'élévation du niveau de formation varie en fonction du type d'activité à l'étude. En moyenne, dans les pays de l'OCDE participant aux Statistiques de l'Union européenne sur le revenu et les conditions de vie (UE-SILC), la participation à des activités culturelles et sportives, la présence sur les réseaux sociaux et le bénévolat formel sont étroitement liés au niveau de formation. Plus de $90 \%$ des diplômés de l'enseignement tertiaire ont participé à des activités culturelles et sportives au cours des 12 mois précédant l'enquête, contre moins de $60 \%$ des adultes dont le niveau de formation est inférieur au deuxième cycle de l'enseignement secondaire. C'est l'écart le plus important en fonction du niveau de formation de toutes les variables relatives aux liens sociaux analysées dans cet indicateur (voir le graphique A6.1).

En moyenne, dans les pays de l'OCDE participant à l'UE-SILC, près de $80 \%$ disent avoir participé à des activités sportives ou culturelles au cours des 12 mois précédents ; ce pourcentage augmente avec le niveau de formation dans tous les pays. Par contraste, moins d'un tiers des adultes font état d'une présence active au quotidien sur les réseaux sociaux et un quart environ d'entre eux, d'activités formelles de bénévolat au cours des 12 mois précédant l'enquête. Une tendance accrue aux activités formelles de bénévolat et à la présence sur les réseaux sociaux s'observe nettement chez ceux dont le niveau de formation est plus élevé, mais les différences (en points de pourcentage) aux niveaux de formation inférieurs sont moindres, ce qui s'explique en partie par le fait que ces activités sont moins courantes. Par contraste, les indicateurs relatifs aux liens personnels varient très peu selon le niveau de formation; le pourcentage d'adultes qui disent rencontrer des amis chaque semaine est pratiquement équivalent à tous les niveaux de formation. De même, le pourcentage d'adultes qui disent pouvoir compter sur l'aide (morale, matérielle ou financière) de quelqu'un varie de moins de 10 points de pourcentage entre les niveaux de formation (voir le graphique A6.1 et le tableau A6.1).

\section{Participation à des activités culturelles ou sportives au cours des 12 derniers mois, selon le niveau de formation}

Selon la tendance qui se dégage de l'analyse de la situation dans les pays de l'OCDE participant à l'EU-SILC, les 25-64 ans sont plus susceptibles de participer à des activités sportives ou culturelles s'ils sont diplômés de l'enseignement tertiaire que si leur niveau de formation est inférieur. En moyenne, 90 \% environ des diplômés de l'enseignement tertiaire font état d'au moins une activité sportive ou culturelle au cours des 12 mois précédant l'enquête ; les pourcentages les plus élevés (égaux ou supérieurs à $98 \%$ ) s'observent en Finlande, en Islande, en Norvège et en Suisse. Par contraste, moins de $80 \%$ d'entre eux en disent autant en Grèce et en Italie. Le taux de participation à ces activités est identique, voire moins élevé au niveau de formation égal à l'enseignement tertiaire en Grèce et en Italie qu'au niveau de formation inférieur au deuxième cycle de l'enseignement secondaire au Danemark, en Islande, en Norvège, aux Pays-Bas et en Suède. L'écart de taux de participation à des activités sportives ou culturelles entre les diplômés de l'enseignement tertiaire et les diplômés du deuxième cycle de l'enseignement secondaire ou de l'enseignement post-secondaire non tertiaire tend à augmenter lorsque le taux de participation des diplômés de l'enseignement tertiaire est moins élevé. Cet écart atteint 36 points de pourcentage en Pologne, 33 points de pourcentage en Hongrie et 29 points de pourcentage en Lituanie. Ceux qui ne sont pas diplômés du deuxième cycle de l'enseignement secondaire sont encore moins susceptibles de participer à ces activités : leur pourcentage est compris entre $89 \%$ en Islande et $21 \%$ en Hongrie. C'est en Islande que le taux de participation varie le moins entre les niveaux de formation : la différence de taux entre le niveau de formation inférieur au deuxième cycle de l'enseignement secondaire et le niveau de formation égal à l'enseignement tertiaire représente 9 points de pourcentage seulement, contre 36 points de pourcentage en moyenne (voir le graphique A6.2). 
Graphique A6.2. Participation à des activités culturelles ou sportives au cours des 12 derniers mois, selon le niveau de formation (2015 ou 2017)

Statistiques de l'Union européenne sur le revenu et les conditions de vie (UE-SILC-2015) et Programme international d'enquêtes sociales (ISSP-2017), individus âgés de 25 à 64 ans

$\Delta$ Tertiaire

$\diamond$ Deuxième cycle du secondaire ou post-secondaire non tertiaire

— Inférieur au deuxième cycle du secondaire

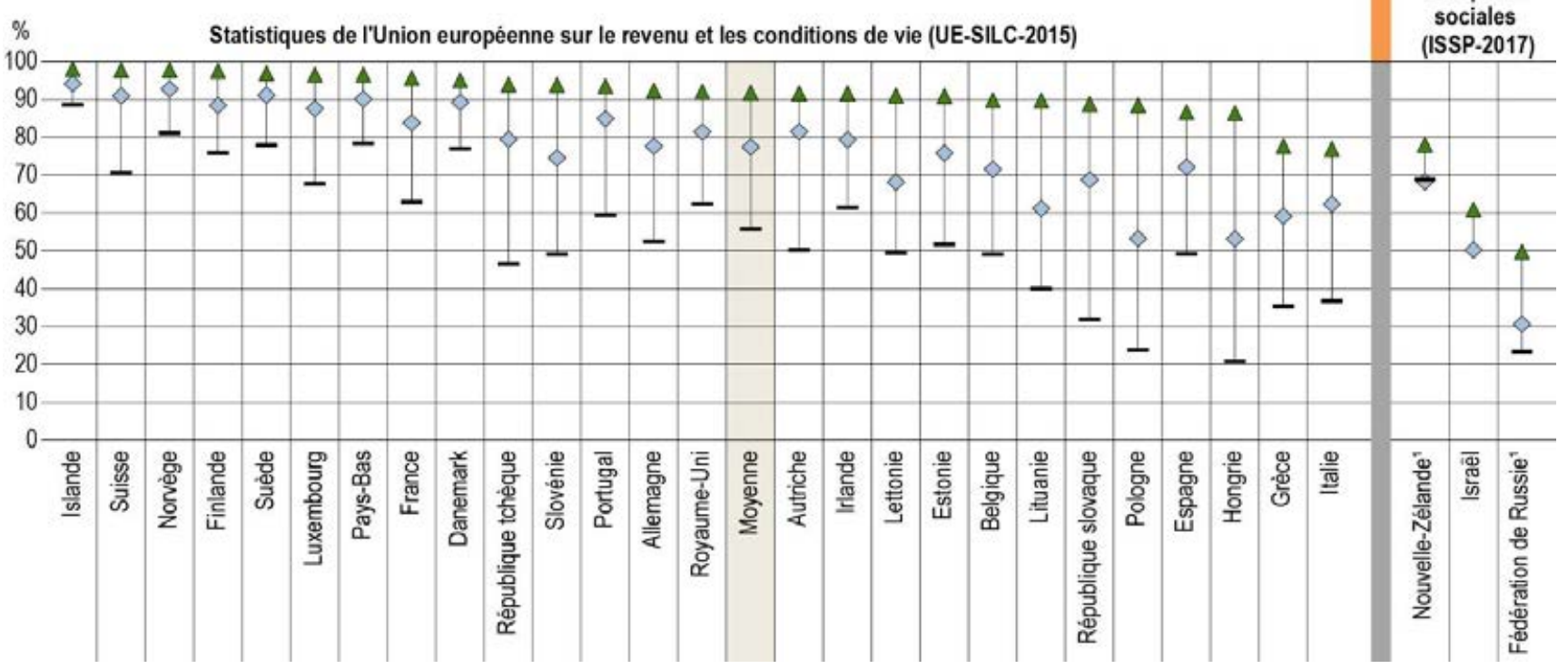

Remarque : Consulter le tableau source et l'annexe 3 pour de plus amples informations sur les questions posées dans les deux enquêtes.

1. La répartition du niveau de formation varie de 10-15 points de pourcentage par rapport aux données présentées dans l'indicateur $A 1$.

Les pays sont classés par ordre décroissant du pourcentage de diplômés de l'enseignement tertiaire âgés de 25 à 64 ans ayant participé à toute activité culturelle ou sportive au moins une fois au cours des 12 derniers mois.

Source: OCDE (2019), tableau A6.1. Consulter la section «Source» pour tout complément d'information et l'annexe 3 pour les notes (https://doi.org/10.1787/f8d7880d-en).

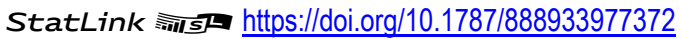

\section{Propension à se retrouver entre amis au moins une fois par semaine}

En moyenne, dans les pays de l'OCDE participant à l'UE-SILC, les 25-64 ans diplômés de l'enseignement tertiaire sont plus susceptibles de se retrouver entre amis chaque semaine que ceux dont le niveau de formation est inférieur, mais la différence entre eux et les diplômés du deuxième cycle de l'enseignement secondaire ou de l'enseignement post-secondaire non tertiaire représente 1 point de pourcentage seulement en moyenne. L'écart de taux entre le niveau de formation égal à l'enseignement tertiaire et le niveau de formation inférieur au deuxième cycle de l'enseignement secondaire est du même ordre. Les Pays-Bas et la République slovaque sont les deux seuls pays où les diplômés de l'enseignement tertiaire sont plus susceptibles de rencontrer des amis au moins une fois par semaine que les diplômés du deuxième cycle de l'enseignement secondaire ou de l'enseignement post-secondaire non tertiaire ; la différence de taux représente environ 7 points de pourcentage dans ces deux pays. L'écart de taux est inférieur à 5 points de pourcentage ailleurs, sauf en Finlande où la situation inverse s'observe : $65 \%$ des diplômés du deuxième cycle de l'enseignement secondaire ou de l'enseignement post-secondaire non tertiaire disent voir des amis au moins une fois par semaine, contre $55 \%$ seulement des diplômés de l'enseignement tertiaire (voir le tableau A6.1). 


\section{Participation à des activités formelles de bénévolat}

La participation à des activités formelles de bénévolat est généralement associée à un niveau de formation plus élevé. Dans les pays de l'OCDE participant à l'UE-SILC, le taux de participation à ces activités varie fortement, même à niveau de formation égal. Le pourcentage de diplômés de l'enseignement tertiaire qui font du bénévolat est compris entre $13 \%$ en Hongrie et en Lettonie et $59 \%$ en Norvège. Le pourcentage de bénévoles est légèrement moins élevé chez les diplômés du deuxième cycle de l'enseignement secondaire ou de l'enseignement post-secondaire non tertiaire : il est compris entre $5 \%$ en Hongrie et $53 \%$ en Norvège. Au niveau de formation inférieur au deuxième cycle de l'enseignement secondaire, il est compris entre $3 \%$ en Hongrie et $33 \%$ au Danemark et aux Pays-Bas. Le bénévolat est donc plus courant dans certains pays que dans d'autres, mais la différence entre les diplômés de l'enseignement tertiaire et les diplômés du deuxième cycle de l'enseignement secondaire représente en moyenne 7 points de pourcentage dans les pays de l'OCDE et est du même ordre que celle qui s'observe entre les 25-64 ans diplômés du deuxième cycle de l'enseignement secondaire et ceux qui ne le sont pas (9 points de pourcentage) (voir le tableau A6.1).

Les pays où la différence est la plus importante entre les diplômés de l'enseignement tertiaire et les diplômés du deuxième cycle de l'enseignement secondaire ou de l'enseignement post-secondaire non tertiaire sont la Lituanie et le Royaume-Uni (15 points de pourcentage). Par comparaison, la différence entre le niveau de formation égal au deuxième cycle de l'enseignement secondaire ou à l'enseignement post-secondaire non tertiaire et le niveau de formation inférieur au deuxième cycle de l'enseignement secondaire est supérieure à 15 points de pourcentage en Autriche, au Luxembourg, en Norvège et en Suisse (voir le tableau A6.1).

\section{L'assurance d'avoir quelqu'un à qui demander de l'aide, selon le niveau de formation}

Cet indicateur est celui qui varie le moins entre les niveaux de formation. Quel que soit leur niveau de formation, la grande majorité des individus ont un certain réseau social puisqu'ils disent avoir quelqu'un sur qui compter en cas de besoin dans les pays participants. En moyenne, dans les pays de l'OCDE participant à l'EU-SILC, le pourcentage d'adultes convaincus d'avoir quelqu'un à qui demander de l'aide en cas de besoin s'établit à $97 \%$ chez les diplômés de l'enseignement tertiaire ; il est moins élevé au niveau de formation égal au deuxième cycle de l'enseignement secondaire ou à l'enseignement post-secondaire non tertiaire (95\%) et inférieur au deuxième cycle de l'enseignement secondaire (90\%). Dans l'ensemble, les pays où un pourcentage élevé de diplômés de l'enseignement tertiaire ont quelqu'un à qui demander de l'aide en cas de besoin comptent aussi parmi ceux où l'effectif de moins instruits est relativement élevé. En Finlande, en Norvège, en République slovaque et en République tchèque, la quasi-totalité des diplômés de l'enseignement tertiaire ont quelqu'un sur qui compter en cas de besoin et leur pourcentage s'écarte de 1 point de pourcentage à peine à celui s'observe au niveau de formation égal au deuxième cycle de l'enseignement secondaire ou à l'enseignement post-secondaire non tertiaire (voir le tableau A6.1).

L'assurance de pouvoir compter sur quelqu'un en cas de besoin varie le plus entre les diplômés du deuxième cycle de l'enseignement secondaire ou de l'enseignement post-secondaire non tertiaire et ceux dont le niveau de formation est inférieur. La différence atteint au moins 8 points de pourcentage en Belgique, au Luxembourg, aux Pays-Bas et en Suisse (voir le tableau A6.1).

\section{Présence sur les médias sociaux, selon le niveau de formation}

En moyenne, dans les pays de l'OCDE participant à l'EU-SILC, 23 \% des adultes non diplômés du deuxième cycle de l'enseignement secondaire disent être activement présents au quotidien sur les réseaux sociaux. Ce pourcentage augmente pour atteindre $31 \%$ chez les diplômés du deuxième cycle de l'enseignement secondaire ou de l'enseignement post-secondaire non tertiaire et $36 \%$ chez les diplômés de l'enseignement tertiaire. La différence la plus marquée entre le niveau de formation inférieur au deuxième cycle de l'enseignement secondaire et le niveau de formation égal à l'enseignement tertiaire s'observe en République slovaque, où le pourcentage d'adultes actifs sur les réseaux sociaux s'établit à $8 \%$ dans le premier groupe, mais à $47 \%$ dans 
le second. Une tendance similaire s'observe en Grèce, où la différence représente plus de 30 points de pourcentage. Par contraste, la présence active sur les réseaux sociaux ne varie guère entre les niveaux de formation en Norvège, où $48 \%$ des adultes dont le niveau de formation est inférieur au deuxième cycle de l'enseignement secondaire se disent actifs sur les réseaux sociaux au quotidien. C'est le pourcentage le plus élevé à ce niveau de formation dans les pays de l'OCDE participant à I'EU-SILC ; il est proche aussi du pourcentage observé en Norvège (49 \%) chez les diplômés de l'enseignement tertiaire (voir le tableau A6.1).

\section{Équilibre entre vie professionnelle et vie privée, selon le niveau de formation}

Les données recueillies et les études menées à ce jour suggèrent l'existence possible d'une relation négative entre le niveau de formation et l'équilibre entre vie professionnelle et vie privée, une variable à relativiser dans une grande mesure en fonction de facteurs liés à la vie professionnelle, à la vie familiale et à des caractéristiques personnelles (Statistics Canada, 2016 $6_{[6]}$; Konishi et Dufour, 2016[7] ; Tausig et Fenwick, 2001 [8]). L'équilibre entre vie professionnelle et vie privée n'est pas une thématique traditionnelle des programmes de cours, ce qui pourrait expliquer pourquoi un niveau de formation plus élevé n'est pas en corrélation positive avec cette retombée sociale importante. Un niveau de formation plus élevé entraîne l'augmentation des taux d'emploi et du niveau de rémunération et est souvent associé à un meilleur état de santé. II est également synonyme de meilleures relations sociales, mais aucun élément ne vient conforter la thèse d'un lien étroit entre le niveau de formation et la capacité d'améliorer l'équilibre entre vie professionnelle et vie privée.

Cette section se base sur les données de l'Enquête européenne sur la qualité de vie (European Quality of Life Survey, EQLS) et du Programme international d'enquêtes sociales (International Social Survey Programme, ISSP) pour déterminer en quoi le niveau de formation influe sur la mesure dans laquelle les individus disent que leur travail nuit à leur vie familiale, et inversement. Cette section se base sur l'Évaluation des compétences des adultes (PIAAC) pour évaluer la flexibilité professionnelle et le nombre moyen d'heures de travail par semaine en fonction du niveau de formation. Ces deux éléments ne sont pas des indicateurs directs de la mesure dans laquelle les individus sont satisfaits de l'équilibre entre leur vie professionnelle et leur vie privée, mais ils sont révélateurs de l'intensité de la vie professionnelle et du temps libre en dehors du travail.

\section{Impact du travail sur la vie familiale, selon le niveau de formation}

Les résultats de I'EQLS et de I'ISSP montrent que la relation entre le niveau de formation et l'impact du travail sur la vie de famille n'est pas uniforme dans les pays membres et partenaires de l'OCDE. Le pourcentage d'adultes qui avouent que leur travail nuit à leur vie de famille augmente de niveau de formation en niveau de formation au Chili, en Islande et aux Pays-Bas. Par contraste, il diminue avec l'élévation du niveau de formation en Turquie. De plus, dans la moitié environ des pays dont les données sont disponibles, les différences ne sont pas statistiquement significatives entre les niveaux de formation. En moyenne, dans les pays de l'OCDE qui ont participé à l'EQLS, $50 \%$ des adultes diplômés du deuxième cycle de l'enseignement secondaire ou de l'enseignement post-secondaire non tertiaire ont déclaré avoir éprouvé des difficultés à remplir leurs responsabilités familiales parce qu'ils passaient trop de temps à leur travail au cours des 12 mois précédant l'enquête, contre 51 \% chez les diplômés de l'enseignement tertiaire (voir le graphique A6.3).

Comme le montre le graphique A6.3, ce pourcentage varie dans l'ensemble davantage entre les pays au même niveau de formation qu'entre les niveaux de formation au sein même des pays. II ressort de ce constat qu'indépendamment du niveau de formation, le pourcentage d'adultes déplorant l'impact négatif de leur travail sur leur vie familiale varie fortement entre les pays membres et partenaires de l'OCDE. En Turquie, par exemple, $88 \%$ des adultes dont le niveau est inférieur au deuxième cycle de l'enseignement secondaire ont déclaré avoir éprouvé des difficultés à remplir leurs responsabilités familiales parce qu'ils passaient trop de temps à leur travail au cours des 12 mois précédant l'enquête, contre $27 \%$ aux Pays-Bas. À titre de comparaison, la différence la plus importante dans le même pays s'observe en Belgique, où elle atteint 23 points de pourcentage entre le niveau de formation inférieur au deuxième cycle de l'enseignement secondaire et le niveau de formation égal au 
deuxième cycle de l'enseignement secondaire ou à l'enseignement post-secondaire non tertiaire (voir le graphique A6.3).

\section{Graphique A6.3. Impact négatif du travail sur la vie de famille, selon le niveau de formation (2015 ou 2016)}

Pourcentage d'actifs occupés âgés de 25 à 64 ans indiquant que leur travail a eu un impact négatif sur leur vie de famille au cours des 12 derniers mois

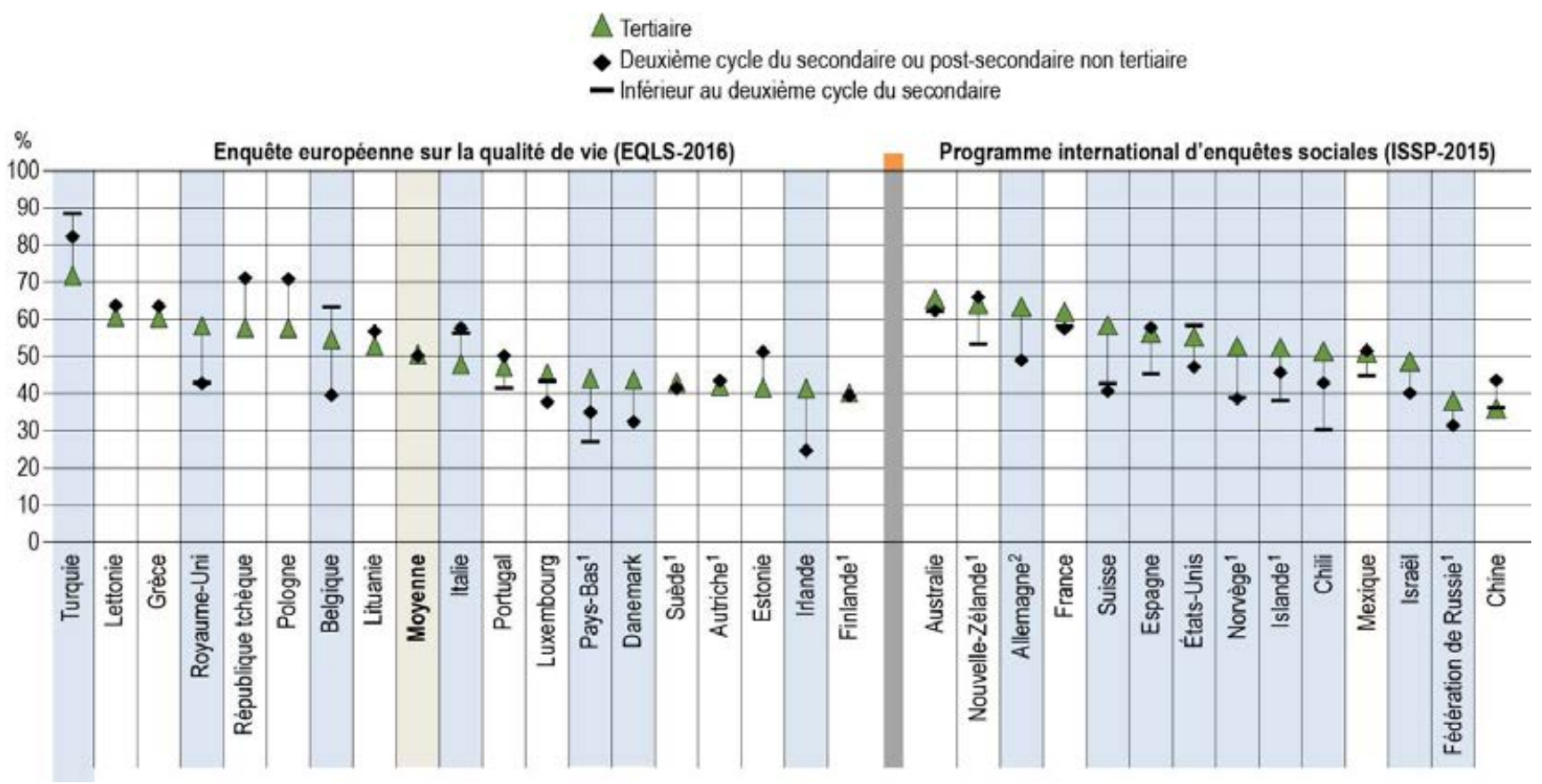

Remarque : Consulter le tableau source et l'annexe 3 pour de plus amples informations sur les questions posées dans les deux enquêtes. La zone bleue indique les différences statistiquement significatives entre tout ou partie des niveaux de formation.

Les pays sont classés par ordre décroissant du pourcentage de diplômés de l'enseignement tertiaire âgés de 25 à 64 ans indiquant que leur travail a eu un impact négatif sur leur vie de famille au cours des 12 derniers mois.

Source: OCDE (2019), tableau A6.2a. Consulter la section «Source» pour tout complément d'information et l'annexe 3 pour les notes (https://doi.org/10.1787/f8d7880d-en).

\section{Impact de la vie familiale sur le travail, selon le niveau de formation}

Les adultes disent moins souvent que leur vie familiale nuit à leur travail que l'inverse. Moins de la moitié d'entre eux reconnaissent que leur vie familiale empiète sur leur travail dans tous les pays de l'OCDE, mais certains pays font vraiment figure d'exception. En Turquie par exemple, $82 \%$ des adultes dont le niveau de formation est inférieur au deuxième cycle de l'enseignement secondaire ont dit avoir eu du mal à se concentrer sur leur travail à cause de leurs responsabilités familiales à plusieurs reprises au cours des 12 mois précédant l'enquête. Ce pourcentage est moins élevé chez les diplômés de l'enseignement tertiaire (63 \%), mais est supérieur à celui qui s'observe dans tous les autres pays membres ou partenaires de l'OCDE participant à l'EQLS ou à l'ISSP (voir le tableau A6.2a).

La relation entre le niveau de formation et le pourcentage d'adultes déplorant l'impact négatif de leur vie familiale sur leur travail varie aussi entre les pays membres et partenaires de l'OCDE. La différence entre les niveaux de formation est ténue dans l'ensemble; elle représente au plus 8 points de pourcentage dans plus de la moitié des pays membres et partenaires de l'OCDE dont les données sont disponibles (voir le tableau A6.2a). 


\section{Graphique A6.4. Flexibilité du travail, selon le niveau de formation (2012 ou 2015)}

Évaluation des compétences des adultes (PIAAC), pourcentage d'actifs occupés âgés de 25 à 64 ans indiquant avoir des horaires de travail très/extrêmement flexibles dans leur emploi principal

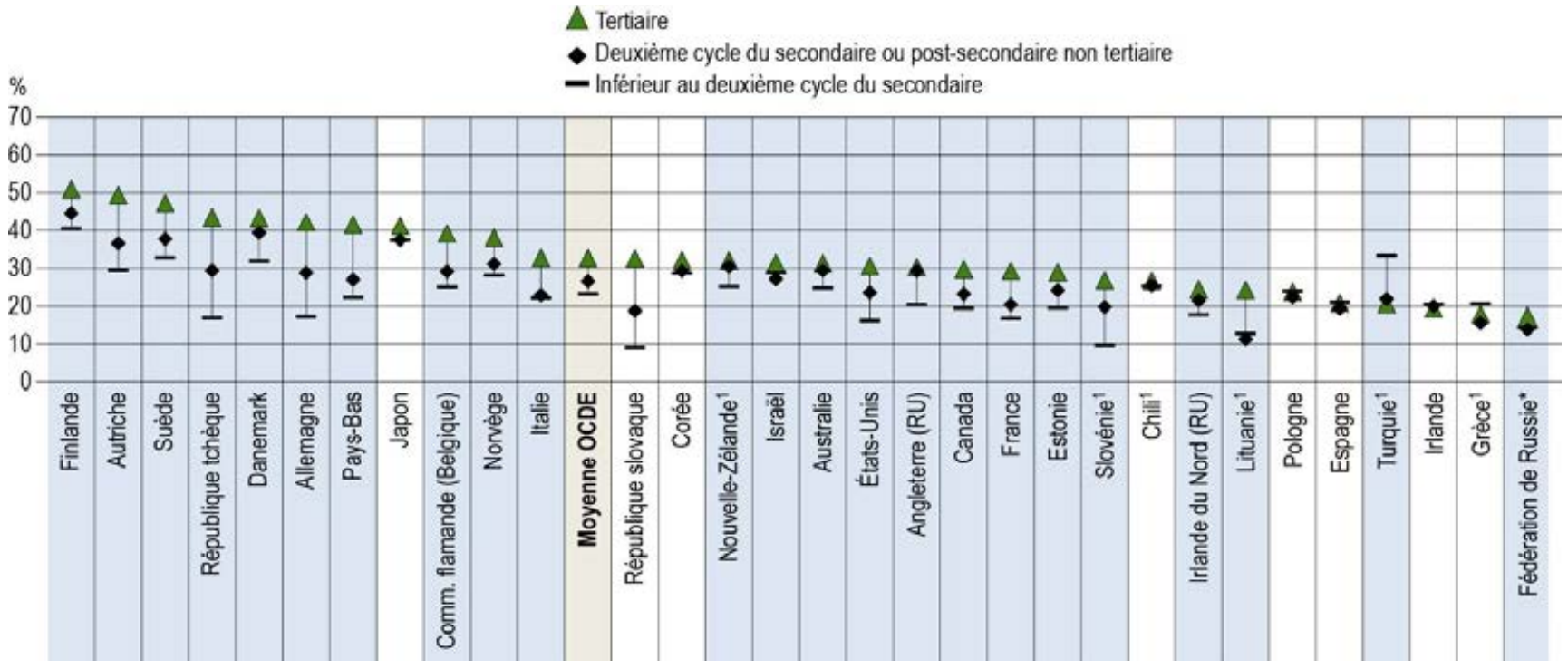

Remarque : La zone bleue indique les différences statistiquement significatives entre tout ou partie des niveaux de formation.

1. Année de référence : 2015 ; pour tous les autres pays et économies, année de référence : 2012.

* Voir la note concernant les données de la Fédération de Russie dans la section « Source ».

Les pays et économies sont classés par ordre décroissant du pourcentage d'actifs occupés diplômés de l'enseignement tertiaire âgés de 25 à 64 ans indiquant avoir des horaires de travail très/extrêmement flexibles dans leur emploi principal.

Source: OCDE (2019), tableau A6.2b. Consulter la section «Source» pour tout complément d'information et l'annexe 3 pour les notes (https://doi.org/10.1787/f8d7880d-en).

StatLink 제요 https://doi.org/10.1787/888933977410

\section{Flexibilité et intensité de l'activité professionnelle, selon le niveau de formation}

La flexibilité de l'activité professionnelle est l'un des aspects de l'équilibre entre vie professionnelle et vie privée dans lequel le niveau de formation semble avoir un impact plus important et plus uniforme. Selon l'Évaluation des compétences des adultes (PIAAC), $23 \%$ des adultes non diplômés du deuxième cycle de l'enseignement secondaire disent avoir des horaires très ou extrêmement flexibles dans leur emploi principal, en moyenne, dans les pays et économies de l'OCDE. Ce pourcentage augmente pour atteindre $27 \%$ chez les diplômés du deuxième cycle de l'enseignement secondaire ou de l'enseignement post-secondaire non tertiaire et $33 \%$ chez les diplômés de l'enseignement tertiaire. La différence est particulièrement importante entre les niveaux de formation, plus de 15 points de pourcentage, en Allemagne, en Autriche, aux Pays-Bas, en République slovaque, en République tchèque et en Slovénie (voir le graphique A6.4).

L'intensité de l'activité professionnelle est un autre aspect lié à l'équilibre entre vie professionnelle et vie privée. L'Évaluation des compétences des adultes (PIAAC) couvre également cet aspect : les personnes interrogées sont invitées à indiquer leur nombre moyen d'heures de travail par semaine dans leur emploi principal. En moyenne, dans les pays et économies de l'OCDE, le temps de travail hebdomadaire s'établit à 38 heures au niveau de formation inférieur au deuxième cycle de l'enseignement secondaire et à 39 heures au niveau de formation égal au deuxième cycle de l'enseignement secondaire et à l'enseignement post-secondaire non tertiaire et à l'enseignement tertiaire. Dans ce cas aussi, la moyenne occulte des résultats très différents. En Grèce par exemple, le temps de travail déclaré s'établit à 40 heures par semaine au niveau de formation égal à l'enseignement tertiaire, mais à 44 heures par semaine au niveau de formation inférieur au deuxième cycle de 
l'enseignement secondaire. Par contraste, en Allemagne et en Autriche, il s'établit à 40 heures par semaine au niveau de formation égal à l'enseignement tertiaire, mais au plus à 35 heures par semaine au niveau de formation inférieur au deuxième cycle de l'enseignement secondaire (voir le tableau A6.2b).

\section{Encadré A6.1. Lecture assidue hors cadre professionnel et niveau de formation (2012 ou 2015)}

La littérature foisonne d'éléments probants qui montrent que des activités qui requièrent de l'attention, comme la lecture, sont en déclin, alors que des activités invitant à la polyvalence, comme la messagerie instantanée, sont en hausse (Levine, Waite et Bowman, 2007[9]). Parmi les variables prédictives de mauvais résultats scolaires, citons l'utilisation accrue du smartphone (Beland et Murphy, 2016[10]), les activités multiples de communication (Junco, 2012[11] ; Levine, Waite et Bowman, 2007[9]), la présence sur les réseaux sociaux (Junco, 2011 [12]) et l'utilisation des médias électroniques en général (Jacobsen et Forste, 2011 [13]; Junco et Cotten, 2012[14]). Selon d'autres éléments, il existe une forte relation entre la lecture assidue de livres et un niveau plus élevé de littératie (OCDE, 2011 $1_{[15]}$ ).

Lire est important pour favoriser l'épanouissement personnel et enrichir la vie sociale, économique et civique (Holden, 2004[16]). Les principales vertus de la lecture en dehors du cadre professionnel que les adultes citent sont le plaisir, l'épanouissement, la relaxation, l'empathie, le savoir, l'interrelation, la cohésion sociale et l'augmentation du capital social (The Reading Agency, 2015[17]).

L'association entre le niveau de formation et la lecture de livres au quotidien n'est pas aussi établie, en particulier dans les comparaisons internationales, mais les données recueillies dans le cadre de l'Évaluation des compétences des adultes (PIAAC) démontrent son existence et permettent d'évaluer son intensité.

En moyenne, dans les pays et économies participants de l'OCDE, le pourcentage de lecteurs assidus augmente de niveau en niveau. Le Chili, la Fédération de Russie, les Pays-Bas, la République tchèque et la Suède sont les seuls pays où le pourcentage de lecteurs assidus ne varie pas dans une mesure statistiquement significative entre le niveau de formation inférieur au deuxième cycle de l'enseignement secondaire et le niveau de formation égal au deuxième cycle de l'enseignement secondaire ou à l'enseignement post-secondaire non tertiaire. La différence entre diplômés du deuxième cycle de l'enseignement secondaire ou de l'enseignement post-secondaire non tertiaire et diplômés de l'enseignement tertiaire est généralement plus importante; elle est statistiquement significative dans tous les pays et économies participants (voir le graphique A6.a).

Dans la plupart des pays et économies, la relation entre la fréquence de la lecture et le niveau de formation est forte également chez les actifs occupés. Le sexe, l'âge et le niveau de littératie comptent parmi les facteurs importants qui sont associés à la fréquence de la lecture. Les femmes lisent plus que les hommes dans tous les pays et économies et à tous les niveaux de formation. La relation entre l'âge et la fréquence de la lecture varie entre les pays et économies, mais il apparaît dans l'ensemble que les lecteurs assidus sont plus nombreux parmi les 45-64 ans que parmi les 25-44 ans (voir le tableau A6.a, disponible en ligne).

Le graphique A6.b montre que le niveau de littératie varie le plus entre les lecteurs assidus au quotidien et les autres (quelle que soit la fréquence à laquelle ils lisent). En moyenne, dans les pays et économies de l'OCDE, le score en littératie s'établit à 243 points chez les adultes qui disent ne jamais lire au quotidien en dehors du cadre professionnel, à 269 points chez ceux qui disent lire moins d'une fois par mois, à 273 points chez ceux qui disent lire moins d'une fois par semaine, mais au moins une fois par mois et à 277 points chez ceux qui disent lire au moins une fois par semaine (voir le graphique A6.b). 


\section{Graphique A6.a. Adultes lisant des livres au moins une fois par semaine, selon le niveau de formation (2012 ou 2015)}

Évaluation des compétences des adultes (PIAAC), adultes non scolarisés âgés de 25 à 64 ans

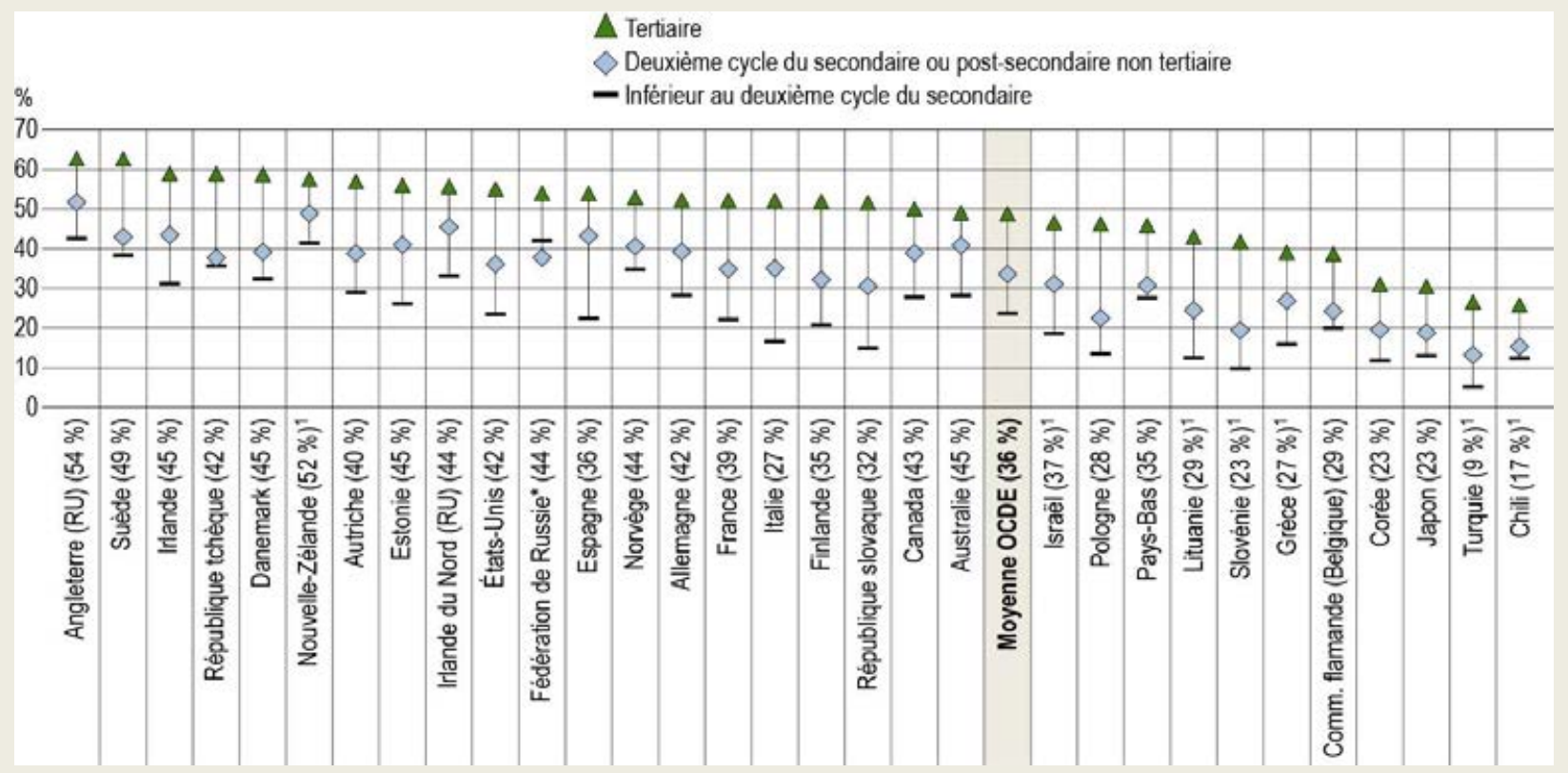

Remarque : La valeur entre parenthèses indique le pourcentage total d'adultes lisant des livres au moins une fois par semaine, indépendamment du niveau de formation. Tous les pays et économies présentent des différences statistiquement significatives entre tout ou partie des niveaux de formation.

1. Année de référence : 2015 ; pour tous les autres pays et économies, année de référence : 2012.

* Voir la note concernant les données de la Fédération de Russie dans la section « Source ».

Les pays sont classés par ordre décroissant du pourcentage de diplômés de l'enseignement tertiaire lisant des livres hors du cadre professionnel au moins une fois par semaine.

Source : OCDE (2019). Tableau A6.a, disponible en ligne. Consulter la section « Source » pour tout complément d'information et l'annexe 3 pour les notes ( https://doi.org/10.1787/f8d7880d-en).

II ressort de l'analyse des données que l'association entre la fréquence de la lecture et le score en littératie varie selon les pays et les économies. Les deux variables sont par exemple peu élevées au Chili et en Turquie. Au Japon, il y a peu de lecteurs assidus, mais le niveau de littératie est le plus élevé des pays et économies participants. Par contraste, la fréquence de la lecture est la plus élevée en Angleterre (Royaume-Uni) et en Nouvelle-Zélande, mais les scores de littératie y sont inférieurs à celui du Japon (voir le graphique A6.a and graphique A6.b). Certains pays ont mis en œuvre des politiques visant à promouvoir la lecture : ainsi, des organisations s'emploient activement à promouvoir la lecture en Angleterre (Royaume-Uni) et en NouvelleZélande, tandis qu'un programme national visant à promouvoir la lecture dès le début de l'enseignement primaire (Read First Programme) a été récemment adopté au Chili en raison tant de la fréquence peu élevée de la lecture que du faible niveau en littératie parmi la population. 


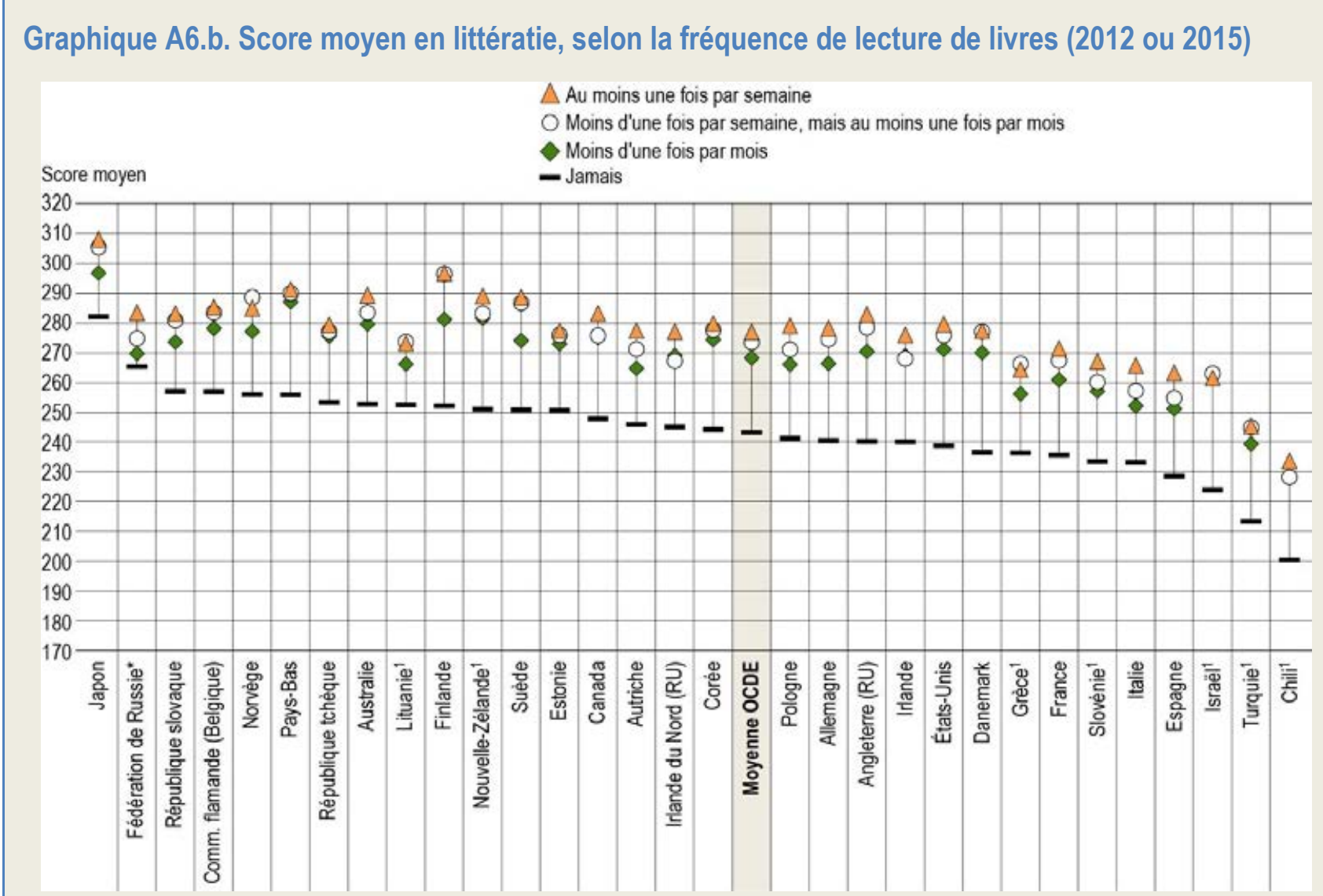

Remarque : La différence de score moyen en littératie entre les adultes indiquant ne jamais lire de livres et ceux indiquant en lire moins d'une fois par mois est statistiquement significative dans tous les pays et économies, à l'exception de la Fédération de Russie.

1. Année de référence : 2015 ; pour tous les autres pays et économies, année de référence : 2012.

* Voir la note concernant les données de la Fédération de Russie dans la section « Source ».

Les pays sont classés par ordre décroissant du score moyen en littératie de ceux indiquant ne jamais lire de livres dans la vie de tous les jours.

Source : OCDE (2019). Tableau A6.b, disponible en ligne. Consulter la section « Source » pour tout complément d'information et l'annexe 3 pour les notes ( https://doi.org/10.1787/f8d7880d-en).

En conclusion, les individus les plus instruits tendent à être des lecteurs assidus en dehors du cadre professionnel, mais cela n'implique pas de relation causale entre le niveau de formation et la fréquence de la lecture au quotidien. Toutefois, il est plausible que la performance en compréhension de l'écrit et la fréquence de la lecture se renforcent mutuellement (OCDE, 2011 $\left.{ }_{[15]}\right)$ et, donc, que la fréquence de la lecture et l'instruction se renforcent mutuellement. Lire au quotidien par plaisir ou en quête d'une forme d'épanouissement est une question de choix, et l'instruction peut accroître la motivation à l'idée de lire, tandis que la fréquence de la lecture peut amener les individus à nourrir de plus grandes ambitions scolaires. 


\section{Encadré A6.2. Satisfaction professionnelle et modélisation par équation structurelle, selon le niveau de formation (2012 ou 2015)}

\section{Analyse de l'effet indirect de l'éducation}

L'effet causal du niveau de formation sur les retombées sociales est souvent examiné dans des analyses de régression, où le niveau de formation est une variable prédictive et le coefficient représente son impact sur une retombée. Cette approche peut ne pas tenir compte du fait que le niveau de formation peut également avoir des effets indirects sur les retombées par l'intermédiaire d'autres facteurs. Concernant la satisfaction professionnelle par exemple, les résultats des études sur les effets directs du niveau de formation ne sont pas probants, mais estimer les effets indirects pourrait permettre de mieux cerner la relation entre les deux variables (Fabra et Camisón, 2009 $[18])$.

\section{Graphique A6.c. Modélisation des effets indirects de l'éducation sur la satisfaction professionnelle (Nouvelle-Zélande, 2015)}

Évaluation des compétences des adultes (PIAAC)

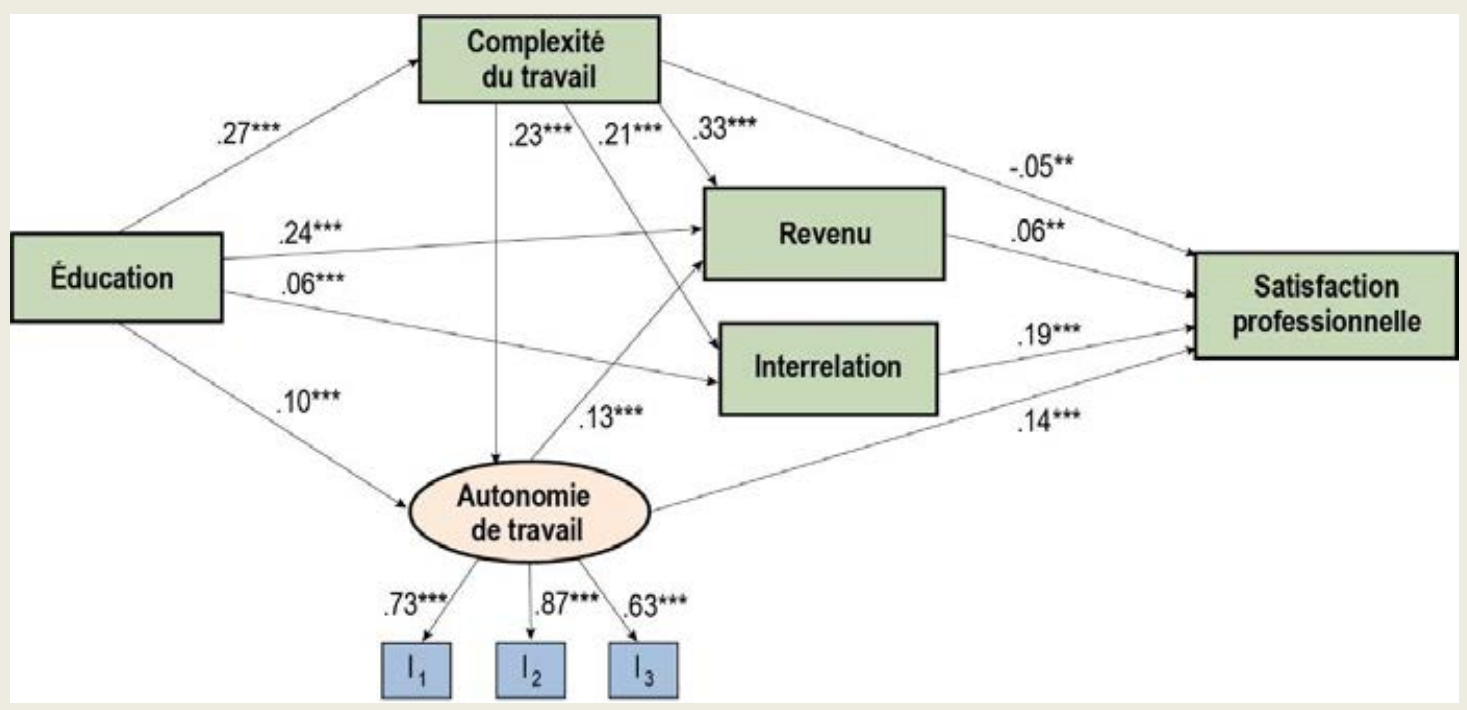

Remarque : Pour l'autonomie de travail, on disposait de trois indicateurs ; elle a donc été mesurée comme variable latente indiquée par la liberté de déterminer l'ordre des tâches à accomplir (I1), ainsi que les modalités (I2) et la vitesse (I3) de leur exécution. L'éducation est mesurée par les niveaux de la CITE, la complexité par la fréquence des problème complexes au travail, l'interrelation par la fréquence des échanges de connaissances entre salariés, et le revenu par les rangs centiles. Les effets sont standardisés. ${ }^{* *}$ indique que $p=0.001,{ }^{* *}$ indique que $p=0.05$.

Source : Calculs de l'OCDE à partir de données de l'Évaluation des compétences des adultes (PIAAC). Consulter la section « Source » pour tout complément d'information et l'annexe 3 pour les notes (https://doi.org/10.1787/f8d7880d-en).

StatLink 젶ㄴ https://doi.org/10.1787/888933977467

L'existence possible de relations indirectes entre le niveau de formation et la satisfaction professionnelle peut être illustrée grâce à l'élaboration d'un modèle par équation structurelle sur la base des données de l'Évaluation des compétences des adultes (PIAAC). Ce modèle part de l'hypothèse que le niveau de formation n'a pas d'effet direct sur la satisfaction professionnelle, mais qu'il peut avoir un effet indirect sur les conditions de travail et d'emploi, lesquelles interviennent dans la satisfaction professionnelle. Les variables retenues pour décrire ces conditions sont la complexité du travail, la rémunération, la fréquence des échanges entre collègues (interrelation) et l'autonomie des travailleurs. Le modèle part également de l'hypothèse que les variables prédictives de la satisfaction professionnelle sont interdépendantes. Le graphique A6.c présente 
sous forme schématique les effets indirects du niveau de formation sur la satisfaction professionnelle, sur la base des données de la Nouvelle-Zélande. Les flèches représentent les effets de chaque variable, et les chiffres, les coefficients normalisés de ces effets (voir le graphique A6.c).

II n'y a pas de flèche entre le niveau de formation et la satisfaction professionnelle (pas d'effet direct), certes, mais de nombreuses flèches relient indirectement, par différentes variables, le niveau de formation et la satisfaction professionnelle. Ces variables relient le niveau de formation et la satisfaction professionnelle par diverses voies et ont des effets d'une ampleur différente (voir le graphique A6.c).

L'analyse des effets indirects permet de mieux comprendre les voies par lesquelles diverses variables relatives aux conditions de travail et d'emploi peuvent influer sur la satisfaction professionnelle. En NouvelleZélande, le pays pris pour exemple dans ce modèle, le niveau de formation influe davantage sur la complexité du travail que l'autonomie des travailleurs laquelle a, contrairement à la complexité du travail, un effet positif direct sur la satisfaction professionnelle. L'analyse des effets indirects montre toutefois que la complexité du travail a bel et bien un effet indirect sur la satisfaction professionnelle par ses effets sur la rémunération, l'autonomie des travailleurs et l'interrelation (voir le graphique A6.c).

Ce modèle par équation structurelle permet de calculer la totalité des effets, en tenant compte des effets directs et indirects. La prise en compte des effets indirects permet donc d'identifier la relation entre le niveau de formation et la satisfaction professionnelle. Le tableau A6.c indique la totalité des effets des variables retenues dans le modèle en Corée, en Nouvelle-Zélande et en République slovaque. Dans ces pays, le niveau de formation affecte indirectement la satisfaction professionnelle. Toutefois, les relations entre les variables diffèrent selon les pays, ce qui montre qu'il est important de tenir compte du contexte national lors de la production ou de l'utilisation d'éléments pertinents pour l'action publique (voir le tableau A6.c).

\section{Tableau A6.c Effets cumulés des variables sur la satisfaction professionnelle (2012 ou 2015)}

Évaluation des compétences des adultes (PIAAC)

\begin{tabular}{lccc}
\hline \multicolumn{1}{c}{ Variables } & $\begin{array}{c}\text { République } \\
\text { slovaque }\end{array}$ & Corée & $\begin{array}{c}\text { Nouvelle- } \\
\text { Zélande }\end{array}$ \\
\hline Rémunération & 0.07 & 0.11 & $0.06^{*}$ \\
$\begin{array}{l}\text { Complexité du } \\
\text { travail }\end{array}$ & 0.09 & 0.07 & $0.04^{*}$ \\
$\begin{array}{l}\text { Interrelation } \\
\begin{array}{l}\text { Autonomie des } \\
\text { travailleurs }\end{array}\end{array}$ & 0.15 & 0.11 & 0.19 \\
$\begin{array}{l}\text { Niveau de } \\
\text { formation }\end{array}$ & 0.11 & 0.15 & 0.15 \\
\hline
\end{tabular}

Remarque : Pour l'autonomie de travail, on disposait de trois indicateurs ; elle a donc été mesurée comme variable latente indiquée par la liberté de déterminer l'ordre des tâches à accomplir (I1), ainsi que les modalités (I2) et la vitesse (I3) de leur exécution. L'éducation est mesurée par les niveaux de la CITE, la complexité par la fréquence des problème complexes au travail, l'interrelation par la fréquence des échanges de connaissances entre salariés, et le revenu par les rangs centiles. Les effets sont standardisés. ${ }^{* *}$ indique que $p=0.001,{ }^{* *}$ indique que $p=0.05$.

Source : Calculs de l'OCDE à partir de données de l'Évaluation des compétences des adultes (PIAAC). Consulter la section « Source » pour tout complément d'information et l'annexe 3 pour les notes (https://doi.org/10.1787/f8d7880d-en).

Les résultats du tableau A6.c montrent que le niveau de formation a un effet positif indirect sur la satisfaction professionnelle dans les pays à l'étude. Les effets indirects permettent de multiplier les options de modélisation des relations entre les variables ; cette méthode peut aboutir à des résultats différents de ceux dérivés de l'analyse des seuls effets directs. Les résultats montrent qu'il est important de déterminer avec précision l'impact des variables et de tenir compte des effets indirects lors de la conception d'interventions afin d'éviter de tirer des conclusions erronées à propos des relations causales. 


\section{Définitions}

Groupes d'âge : Le terme « adultes » désigne la population âgée de 25 à 64 ans.

Le niveau de formation correspond au plus haut niveau d'enseignement dont les individus sont diplômés.

Niveaux de formation : les niveaux de la CITE 2011 sont tous décrits dans le Guide du lecteur, au début du présent rapport.

La version précédente de la CITE (CITE 97) est utilisée dans les analyses des données de l'Évaluation des compétences des adultes (PIAAC): les niveaux de formation inférieurs au deuxième cycle de l'enseignement secondaire correspondent aux niveaux 0, 1, 2 et 3C (formations courtes) de la CITE 97 ; les niveaux de formation égaux au deuxième cycle de l'enseignement secondaire ou à l'enseignement postsecondaire non tertiaire correspondent aux niveaux 3A, 3B, 3C (formations longues) et 4 de la CITE 97 ; et les niveaux de formation égaux à l'enseignement tertiaire correspondent aux niveaux 5A, 5B et 6 de la CITE 97.

\section{Méthodologie}

Les pourcentages d'adultes à chaque niveau de formation indiqués dans l'Enquête européenne de 2016 sur la qualité de vie (European Quality of Life Survey, EQLS) et le Programme international d'enquêtes sociales (International Social Survey Programme, ISSP) de 2015 et de 2017 ont été comparés, par pays, aux pourcentages correspondants dans l'indicateur A1. Après consultation des pays concernés, les données des enquêtes ci-dessous sur les niveaux de formation ont été recodées pour améliorer leur compatibilité avec les niveaux de l'indicateur $\mathrm{A} 1$ :

- ISSP de 2017 : Fédération de Russie et Israël.

- ISSP de 2015 : Chili, États-Unis, Fédération de Russie, France et Israël.

L'annexe 3 fournit davantage d'informations sur les différences dans la répartition des échantillons des enquêtes (https://doi.org/10.1787/f8d7880d-en).

\section{Source}

Les liens sociaux sont dérivés des données du module de I'UE-SILC de 2015 sur la participation sociale et culturelle et la privation matérielle dans les pays européens membres de l'OCDE.

Les liens sociaux sont dérivés de l'ISSP de 2017 dans des pays non européens membres et partenaires de I'OCDE (ISSP Research Group, 2019 [19]).

L'équilibre entre vie professionnelle et vie privée est dérivé de l'EQLS dans les pays européens membres de l'OCDE (Eurofound, 2018[20]).

L'équilibre entre vie professionnelle et vie privée est dérivé de l'ISSP de 2015 dans les pays européens et non européens membres et partenaires de l'OCDE (ISSP Research Group, 2017[21]).

L'intensité et la flexibilité de l'activité professionnelle, la fréquence de la lecture hors du cadre professionnel par niveau de formation et la satisfaction professionnelle par niveau de formation sont dérivées du Programme de l'OCDE pour l'évaluation internationale des compétences des adultes (Évaluation des compétences des adultes [PIAAC]).

Note concernant les données de la Fédération de Russie dans l'Évaluation des compétences des adultes (PIAAC)

Il convient de signaler aux lecteurs que l'échantillon de la Fédération de Russie n'inclut pas la population de la municipalité de Moscou. Les données publiées dans le présent rapport ne sont donc pas représentatives de l'ensemble de la population 
âgée de 16 à 65 ans résidant en Fédération de Russie, mais de la population de la Fédération de Russie, à l'exclusion de la population de la municipalité de Moscou. Des informations plus détaillées concernant les données de la Fédération de Russie ainsi que celles d'autres pays sont disponibles dans le rapport technique de l'Évaluation des compétences des adultes, Technical Report of the Survey of Adult Skills, Second Edition (OCDE, 2016[22]).

\section{Remarque concernant les données fournies par Israël}

Les données statistiques concernant Israël sont fournies par et sous la responsabilité des autorités israéliennes compétentes. L'utilisation de ces données par l'OCDE est sans préjudice du statut des hauteurs du Golan, de Jérusalem-Est et des colonies de peuplement israéliennes en Cisjordanie aux termes du droit international.

\section{Références}

Beland, L. et R. Murphy (2016), « III Communication: Technology, distraction \& student performance », Labour Economics, vol. 41, pp. 61-76, http://dx.doi.org/10.1016/j.labeco.2016.04.004.

Eurofound (2018), European Quality of Life Survey Integrated Data File, 2003-2016, [data collection], UK Data Service. SN: 7348, https://discover.ukdataservice.ac.uk/catalogue/?sn=7348\&type=Data\%20catalogue.

Fabra, E. et C. Camisón (2009), « Direct and indirect effects of education on job satisfaction: A structural equation model for the Spanish case », Economics of education review, vol. 28/5, pp. 600-610.

Holden, J. (2004), Creative Reading: Young People, Reading and Public Libraries, Demos, https://www.demos.co.uk/files/creativereading.pdf (consulté le 10 mai 2019).

ISSP Research Group (2019), International Social Survey Programme: Social Relations and Social Networks III - ISSP 2017. GESIS Data Archive, Cologne. ZA6980 Data file Version 1.0.0, http://dx.doi.org/10.4232/1.13251.

ISSP Research Group (2017), International Social Survey Programme: Work Orientations IV - ISSP 2015. GESIS Data Archive, Cologne. ZA6770 Data file Version 2.1.0, http://dx.doi.org/10.4232/1.12848.

Jacobsen, W. et R. Forste (2011), «The Wired Generation: Academic and Social Outcomes of Electronic Media Use Among University Students », Cyberpsychology, Behavior, and Social Networking, vol. 14/5, pp. 275-280, http://dx.doi.org/10.1089/cyber.2010.0135.

Junco, R. (2012), "In-class multitasking and academic performance », Computers in Human Behavior, vol. 28/6, pp. 2236-2243, http://dx.doi.org/10.1016/J.CHB.2012.06.031.

Junco, R. (2011), « Too much face and not enough books: The relationship between multiple indices of Facebook use and academic performance ", Computers in Human Behavior, http://dx.doi.org/10.1016/j.chb.2011.08.026.

Junco, R. et S. Cotten (2012), « No A 4 U: The relationship between multitasking and academic performance », Computers \& Education, vol. 59/2, pp. 505-514, http://dx.doi.org/10.1016/j.compedu.2011.12.023. 
Konishi, M. et F. Dufour (2016), « Work-life balance: a typology of workers », https://www.europeansocialsurvey.org/docs/about/conference/KONISHI-DUFOUR Work-lifebalance-a-Typology.pdf (consulté le 8 février 2019).

Levine, L., B. Waite et L. Bowman (2007), Electronic Media Use, Reading, and Academic Distractibility in College Youth, http://dx.doi.org/10.1089/cpb.2007.9990.

OCDE (2017), Regards sur l'éducation 2017 : Les indicateurs de l'OCDE, Éditions OCDE, Paris, http://dx.doi.org/10.1787/eag-2017-fr.

OCDE (2016), Technical Report of the Survey of Adult Skills (PIAAC), 2nd Edition, OCDE, Paris, http://www.oecd.org/skills/piaac/PIAAC Technical Report 2nd Edition Full Report.pdf.

OCDE (2014), Comment va la vie ? 2013: Mesurer le bien-être, Éditions OCDE, Paris, https://dx.doi.org/10.1787/how life-2013-fr.

OCDE (2011), Résultats du PISA 2009 : Apprendre à apprendre: Les pratiques, les stratégies et l'engagement des élèves (Volume III), PISA, Éditions OCDE, Paris, https://dx.doi.org/10.1787/9789264091542-fr.

Statista (2019), Number of monthly active Facebook users worldwide as of 1st quarter 2019, https://www.statista.com/statistics/264810/number-of-monthly-active-facebook-users-worldwide/ (consulté le 10 mai 2019).

Statistics Canada (2016), Satisfaction with work-life balance: Fact sheet, Statistics Canada, https://www150.statcan.gc.ca/n1/en/pub/89-652-x/89-652-x2016003-eng.pdf?st=Ukrvj8pE (consulté le 8 February 2019).

Tausig, M. et R. Fenwick (2001), Unbinding Time: Alternate Work Schedules and Work-Life Balance, http://www3.uakron.edu/publications/tausig\%20Unbinding\%20Time.pdf (consulté le 8 février 2019).

The Reading Agency (2015), Literature Review: The impact of reading for pleasure and empowerment, BOP Consulting, https://readingagency.org.uk/news/The $\% 20$ Impact $\% 20$ of $\% 20$ Reading $\% 20$ for $\% 20$ Pleasure $\% 20$ and \%20Empowerment.pdf (consulté le 10 mai 2019).

VicHealth (2010), Opportunities for social connection, http://www.vichealth.vic.gov.au/ /media/ResourceCentre/PublicationsandResources/Social\%20con nection/opportunities for Social Connection Summary Nov10.ashx (consulté le 7 mai 2019).

Worldometers (2019), World Population Clock: 7.7 Billion People (2019), https://www.worldometers.info/world-population/ (consulté le 7 mai 2019). 


\section{Tableaux de l'indicateur A6}

Tableau A6.1

Tableau A6.2a

Tableau A6.2b

WEB Tableau A6.a

WEB Tableau A6.b
Liens sociaux, selon le niveau de formation (2015 ou 2017)

Équilibre entre vie professionnelle et vie privée, selon le niveau de formation (2015 ou 2016)

Intensité et flexibilité du travail, selon le niveau de formation (2012 ou 2015)

Adultes lisant des livres au moins une fois par semaine, selon la situation au regard de l'emploi, le sexe, l'âge et le niveau de formation (2012 ou 2015)

Score moyen en littératie, selon la fréquence de lecture de livres et le niveau de formation (2012 ou 2015)

Date butoir pour les données : 19 juillet 2019. Les mises à jour peuvent être consultées en ligne sur: http://dx.doi.org/10.1787/eag-data-en. D'autres données désagrégées sont également disponibles dans la Base de données de Regards sur l'éducation (http://stats.oecd.org/). 
Tableau A6.1. Liens sociaux, selon le niveau de formation (2015 ou 2017)

Statistiques de l'Union européenne sur le revenu et les conditions de vie (UE-SILC-2015) et Programme international d'enquêtes sociales (ISSP-2017), individus âgés de 25 à 64 ans

Statistiques de IUnion curopéenne sur le revenu et les conditions de vie (UE-SILC-2015)

\begin{tabular}{|c|c|c|c|c|c|c|c|c|c|c|c|c|c|c|c|}
\hline & \multicolumn{3}{|c|}{$\begin{array}{l}\text { Adultes ayant participé } \\
\text { à toute activité culturelle } \\
\text { ou sportive au cours } \\
\text { des } 12 \text { derniers mois }\end{array}$} & \multicolumn{3}{|c|}{$\begin{array}{l}\text { Adultes voyant des amis } \\
\text { extérieurs à leur foyer } \\
\text { au moins une fois par semaine }\end{array}$} & \multicolumn{3}{|c|}{$\begin{array}{l}\text { Adultes ayant participé } \\
\text { ad des activités formelles } \\
\text { de bénévolat au cours } \\
\text { des } 12 \text { derniers mois } \\
\text { (tout travail non obligatoire } \\
\text { non rémunére effectue pour } \\
\text { ou via une organisation, } \\
\text { un groupe formel ou un club) }\end{array}$} & \multicolumn{3}{|c|}{$\begin{array}{l}\text { Adultes ayant quelqu'un } \\
\text { a qui s'adresser pour } \\
\text { demander de l'aide (morale, } \\
\text { matérielle ou financière) }\end{array}$} & \multicolumn{3}{|c|}{$\begin{array}{l}\text { Adultes participant } \\
\text { chaque jour activement } \\
\text { aux réseaux sociaux }\end{array}$} \\
\hline & 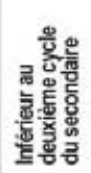 & 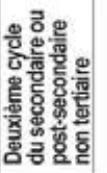 & 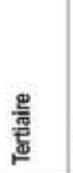 & 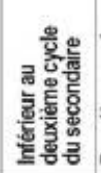 & 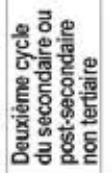 & 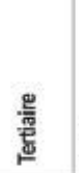 & 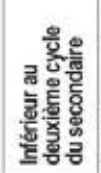 & 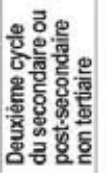 & 墨 & 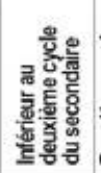 & 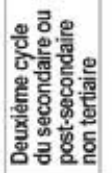 & 墨 & 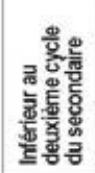 & 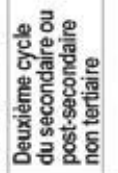 & 墨 \\
\hline & $\%$ & $\%$ & $\%$ & $\%$ & $\%$ & $\%$ & $\%$ & $\%$ & $\%$ & $\%$ & $\%$ & $\%$ & $\%$ & $\%$ & $\%$ \\
\hline & (1) & (3) & (5) & (9) & (11) & (13) & (17) & (19) & (21) & (25) & (27) & (29) & (33) & (35) & (37) \\
\hline \multicolumn{16}{|l|}{ u Pays } \\
\hline $\begin{array}{l}\text { Autriche } \\
\text { Belqique }\end{array}$ & $\begin{array}{l}50 \\
49\end{array}$ & 82 & 92 & $\begin{array}{l}45 \\
59\end{array}$ & $\begin{array}{l}48 \\
61\end{array}$ & 51 & 15 & $\begin{array}{l}31 \\
18\end{array}$ & 36 & 91 & 96 & 97 & 24 & 32 & 36 \\
\hline Republique tchèque & 47 & $\begin{array}{l}72 \\
79\end{array}$ & 94 & $\begin{array}{l}59 \\
37\end{array}$ & $\begin{array}{l}61 \\
41\end{array}$ & $\begin{array}{l}62 \\
45\end{array}$ & $\begin{array}{r}12 \\
5\end{array}$ & $\begin{array}{l}18 \\
12\end{array}$ & $\begin{array}{l}28 \\
19\end{array}$ & $\begin{array}{l}85 \\
94\end{array}$ & $\begin{array}{l}93 \\
98\end{array}$ & $\begin{array}{l}95 \\
99\end{array}$ & $\begin{array}{l}27 \\
15\end{array}$ & $\begin{array}{l}38 \\
19\end{array}$ & $\begin{array}{l}38 \\
33\end{array}$ \\
\hline Danemark & 77 & 89 & 95 & 38 & 33 & 37 & 33 & 39 & 43 & 91 & 95 & 98 & 36 & 41 & 45 \\
\hline Estonie & 52 & 76 & 91 & 46 & 41 & 40 & 10 & 15 & 23 & 89 & 92 & 96 & 22 & 25 & 31 \\
\hline Finlande & 76 & 88 & 98 & 65 & 65 & 55 & 26 & 35 & 43 & 98 & 98 & 99 & 28 & 39 & 44 \\
\hline France & 63 & 84 & 96 & 45 & 47 & 44 & 16 & 23 & 29 & 89 & 92 & 97 & 13 & 18 & 19 \\
\hline Allemagne & 52 & 78 & 92 & 44 & 44 & 48 & 15 & 28 & 35 & 91 & 97 & 98 & 25 & 23 & 25 \\
\hline Gréce & 35 & 59 & 78 & 78 & 81 & 83 & 9 & 12 & 17 & 95 & 96 & 97 & 11 & 33 & 47 \\
\hline Hongrie & 21 & 53 & 86 & 53 & 50 & 51 & 3 & 5 & 13 & 95 & 97 & 98 & 9 & 21 & 34 \\
\hline Islande & 89 & 94 & 98 & 30 & 30 & 30 & 25 & 36 & 42 & 93 & 96 & 99 & 37 & 31 & 37 \\
\hline Irlande & 61 & 79 & 92 & $53^{\prime}$ & $51^{\prime}$ & $50^{\prime}$ & $20^{\circ}$ & $27^{\prime}$ & $38^{\prime}$ & $95^{\circ}$ & $95^{\prime}$ & 97. & 28 & $46^{\prime}$ & $50^{\prime}$ \\
\hline Italie & 37 & 62 & 77 & 56 & 62 & 64 & 9 & 14 & 17 & 82 & 89 & 92 & 16 & 28 & 37 \\
\hline Lettonie & 49 & 68 & 91 & 39 & 32 & 32 & 5 & 6 & 13 & 86 & 92 & 95 & 14 & 16 & 28 \\
\hline Lituanie & 40 & 61 & 90 & 40 & 28 & 27 & 8 & 14 & 29 & 91 & 97 & 99 & 8 & 11 & 23 \\
\hline Luxembourg & 68 & 88 & 97 & 57 & 54 & 56 & 23 & 41 & 46 & 79 & 89 & 93 & 33 & 39 & 37 \\
\hline Pays-Bas & 78 & 90 & 97 & 47 & 49 & 57 & 33 & 39 & 50 & 85 & 93 & 96 & 36 & 44 & 43 \\
\hline Norvège & 81 & 93 & 98 & 64 & 64 & 64 & 31 & 53 & 59 & 93 & $\$ 8$ & 99 & 48 & 48 & 49 \\
\hline Pologne & 24 & 53 & 89 & 21. & 19. & $22 \%$ & 6. & 12 & $26{ }^{\circ}$ & $92:$ & 95 & 99: & 5 & $12^{\circ}$ & $26^{\prime}$ \\
\hline Portugal & 60 & 85 & 94 & 69 & 72 & 70 & 6 & 12 & 17 & 87 & 92 & 96 & 14 & 39 & 39 \\
\hline République slovaque & 32 & 69 & 89 & 49 & 55 & 62 & 5 & 7 & 14 & 92 & 98 & 99 & 8 & 27 & 47 \\
\hline Slovenie & 49 & 75 & 94 & 50 & 55 & 54 & 19 & 30 & 39 & 93 & 96 & 98 & 11 & 19 & 22 \\
\hline Espagne & 49 & 72 & 87 & 66 & 69 & 72 & 7 & 11 & 16 & 95 & 97 & 98 & 23 & 38 & 40 \\
\hline Suéde & 78 & 91 & 97 & 62 & 62 & 63 & 27 & 38 & 40 & 94 & 98 & 98 & 38 & 45 & 45 \\
\hline Suisse & 71 & 91 & 96 & 54 & 58 & 59 & 19 & 38 & 43 & 87 & 96 & 97 & 27 & 24 & 24 \\
\hline Royaume-Uni & 62 & 81 & 92 & $48^{\prime}$ & $51^{\prime}$ & $50^{\prime}$ & $12^{\prime}$ & $18^{\prime}$ & $33^{\prime}$ & $88^{\prime}$ & $94^{\prime}$ & $94^{\prime}$ & 34 & $45^{\prime}$ & $44^{\prime}$ \\
\hline \multirow[t]{6}{*}{ Moyenne } & 56 & 77 & 92 & 51 & 51 & 52 & 15 & 24 & 31 & 90 & 95 & 97 & 23 & 31 & 36 \\
\hline & \multicolumn{15}{|c|}{ Programme international d'enquëtes sociales (ISSP-2017) } \\
\hline & \multicolumn{3}{|c|}{$\begin{array}{l}\text { Adultes ayant participe à } \\
\text { des groupes ou associations } \\
\text { a des fins récréatives, } \\
\text { sportives ou culturelles au } \\
\text { cours des } 12 \text { derniers mois }\end{array}$} & \multicolumn{3}{|c|}{$\begin{array}{l}\text { Adultes ayant des contacts } \\
\text { avec un ami proche } \\
\text { au moins une fois par } \\
\text { semaine, en personne ou } \\
\text { par têléphone, Internet } \\
\text { ou tout autre moyen de } \\
\text { communication }\end{array}$} & \multicolumn{3}{|c|}{$\begin{array}{l}\text { Adultes ayant pris part a aux } \\
\text { activités d'organisations } \\
\text { caritatives ou religieuses } \\
\text { faisant du benévolat au } \\
\text { cours des } 12 \text { derniers mois }\end{array}$} & \multicolumn{3}{|c|}{$\begin{array}{l}\text { Adultes pouvant faire } \\
\text { appel à quelqu'un pour les } \\
\text { aider à faire les travaux } \\
\text { mènagers ou de jardinage } \\
\text { qu'ils ne sont pas en mesure } \\
\text { d'effectuer eux-mémes }\end{array}$} & \multicolumn{3}{|c|}{$\begin{array}{l}\text { Adultes principalement } \\
\text { en contact avec les } \\
\text { membres de leur famille } \\
\text { et leurs amis proches via } \\
\text { textos, téléphone portable } \\
\text { ou tout autre moyen de } \\
\text { communication par Internet }\end{array}$} \\
\hline & 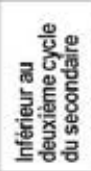 & 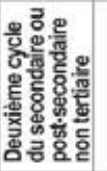 & 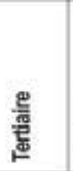 & 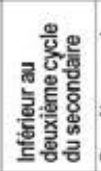 & 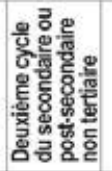 & 惫 & 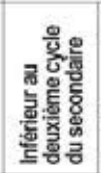 & 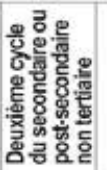 & 胥 & 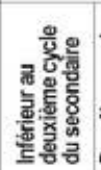 & 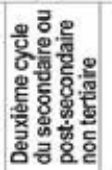 & 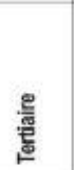 & 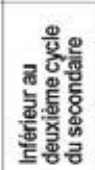 & 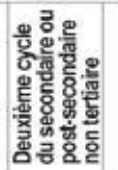 & 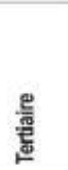 \\
\hline & $\%$ & $\%$ & $\%$ & $\%$ & $\%$ & $\%$ & $\%$ & $\%$ & $\%$ & $\%$ & $\%$ & $\%$ & $\%$ & $\%$ & $\%$ \\
\hline & (1) & (3) & (5) & (9) & (11) & (13) & (17) & (19) & (21) & (25) & (27) & (29) & (33) & (35) & (37) \\
\hline \multicolumn{16}{|l|}{ w Pays. } \\
\hline Israèl & c & 50 & 61 & 75 & 79 & 79 & c & 27 & 38 & 88 & 92 & 93 & 51 & 45 & 53 \\
\hline Nouvelle-Zélande' & 69 & 68 & 78 & 62 & 69 & 66 & 44 & 45 & 56 & 95 & 97 & 98 & 44 & 48 & 49 \\
\hline Fédération de Russie' & 23 & 31 & 50 & 77 & 73 & 78 & 6 & 10 & 15 & 97 & 96 & 96 & 35 & 29 & 36 \\
\hline
\end{tabular}

Remarque : Des colonnes supplémentaires présentant les données non ventilées par niveau de formation peuvent être consultées en ligne, ainsi que les erreurs-types des données tirées du Programme international d'enquêtes sociales (ISSP-2017) (voir le StatLink ci-dessous).

1. La répartition du niveau de formation varie de 10-15 points de pourcentage par rapport aux données présentées dans l'indicateur $A 1$.

Source : OCDE (2019). Consulter la section « Source » pour tout complément d'information et l'annexe 3 pour les notes (https://doi.org/10.1787/f8d7880d-en) .

Les symboles représentant les données manquantes et les abréviations figurent dans le Guide du lecteur. 
Tableau A6.2a. Équilibre entre vie professionnelle et vie privée, selon le niveau de formation (2015 ou 2016) Enquête européenne sur la qualité de vie (EQLS-2016) et Programme international d'enquêtes sociales (ISSP-2015), actifs occupés âgés de 25 à 64 ans

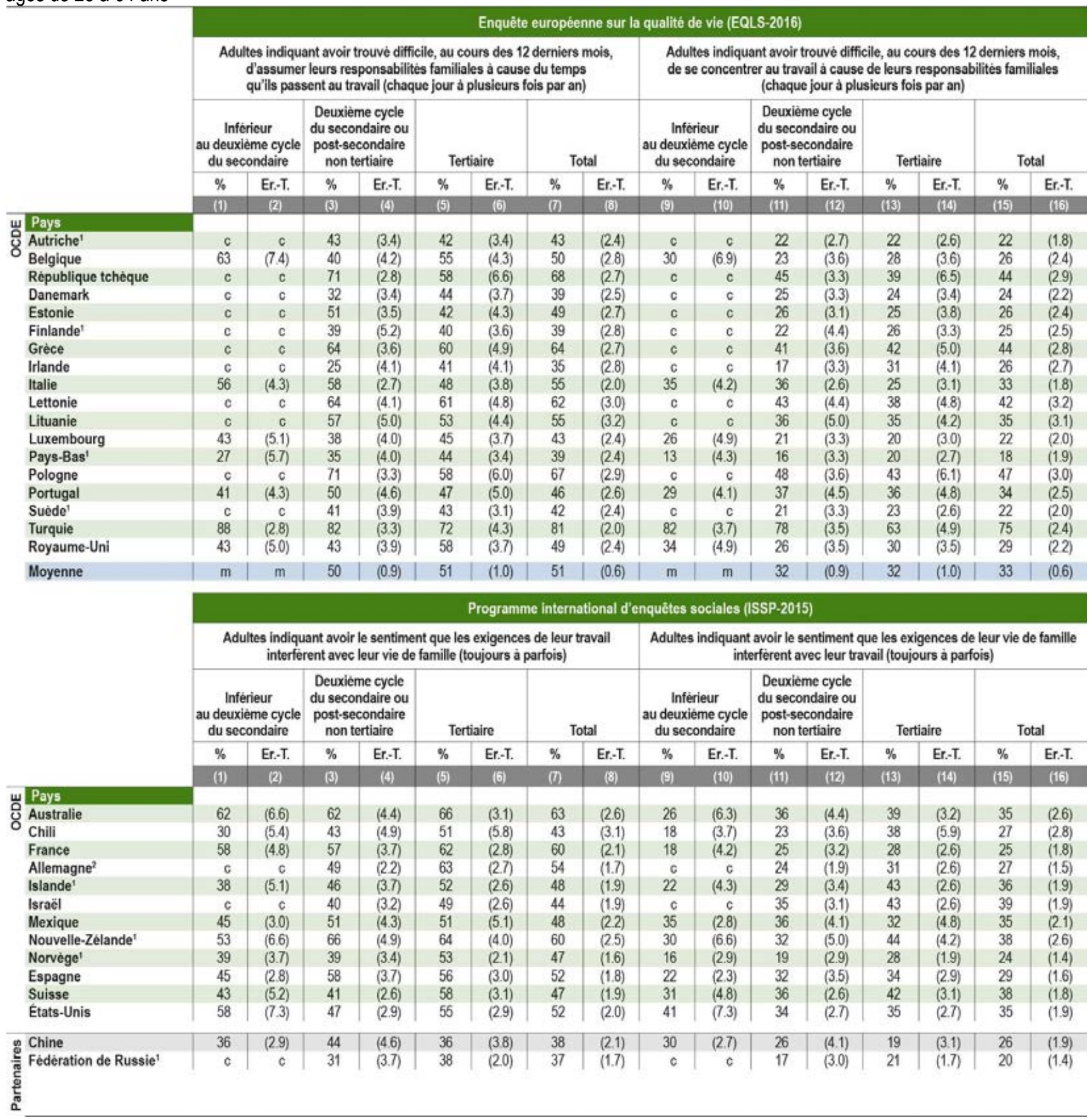

1. La répartition du niveau de formation varie de 10-15 points de pourcentage par rapport aux données présentées dans l'indicateur A1.

2. Année de référence : 2016.

Source : OCDE (2019). Consulter la section « Source » pour tout complément d'information et l'annexe 3 pour les notes (https://doi.org/10.1787/f8d7880d-en) . Les symboles représentant les données manquantes et les abréviations figurent dans le Guide du lecteur. 
Tableau A6.2b. Intensité et flexibilité du travail, selon le niveau de formation (2012 ou 2015)

Évaluation des compétences des adultes (PIAAC), actifs occupés âgés de 25 à 64 ans

\begin{tabular}{|c|c|c|c|c|c|c|c|c|c|c|c|c|c|c|c|c|}
\hline & \multicolumn{8}{|c|}{$\begin{array}{l}\text { Nombre hebdomadaire moyen d'heures de travail dans l'emploi principal } \\
\text { parmi les actifs occupés àgés de } 25 \text { à } 64 \text { ans }\end{array}$} & \multicolumn{8}{|c|}{$\begin{array}{l}\text { Pourcentage d'actifs occupés âgés de } 25 \text { à } 64 \text { ans indiquant avoir } \\
\text { des horaires de travail tresslextrèmement flexibles dans leur emploi princip }\end{array}$} \\
\hline & \multicolumn{2}{|c|}{$\begin{array}{c}\text { Inférieur } \\
\text { au deuxième cycle } \\
\text { du secondaire }\end{array}$} & \multicolumn{2}{|c|}{$\begin{array}{c}\text { Deuxième cycle } \\
\text { du secondaire ou } \\
\text { post-secondaire } \\
\text { non tertiaire }\end{array}$} & \multicolumn{2}{|c|}{ Tertiaire } & \multicolumn{2}{|c|}{ Total } & \multicolumn{2}{|c|}{$\begin{array}{c}\text { Inférieur } \\
\text { au deuxiéme cycle } \\
\text { du secondaire }\end{array}$} & \multicolumn{2}{|c|}{$\begin{array}{c}\text { Deuxième cycle } \\
\text { du secondaire ou } \\
\text { post-secondaire } \\
\text { non tertiaire }\end{array}$} & \multicolumn{2}{|c|}{ Tertiaire } & \multicolumn{2}{|c|}{ Total } \\
\hline & Moyenne & Er.T. & Moyenne & Er.-T. & Moyenne & Er.-T. & Moyenne & Er.-T. & $\%$ & Er.-T. & $\%$ & Er.-T. & $\%$ & Er.-T. & $\%$ & Er.-T. \\
\hline & (1) & (2) & (3) & (4) & (5) & (6) & (i) & (8) & (9) & (10) & (i1) & (12) & (13) & (14) & (15) & (16) \\
\hline \multicolumn{17}{|l|}{ w Pays } \\
\hline Australie & 36 & $(0.5)$ & 39 & $(0.4)$ & 38 & (0.3) & 38 & (0.2) & 25 & (1.7) & 29 & (1.6) & 31 & (1.2) & 29 & (0.7) \\
\hline Autriche & 35 & $(0.6)$ & 38 & (0.3) & 40 & (0.4) & 38 & (0.2) & 30 & (2.7) & 37 & (1.3) & 49 & (1.7) & $3 B$ & (1.0) \\
\hline Canada & 40 & $(0.6)$ & 38 & (0.2) & 39 & (0.2) & 39 & (0.1) & 19 & (1.7) & 23 & (1.1) & 30 & $(0.9)$ & 27 & (07) \\
\hline Chill' & 39 & $(0.8)$ & 39 & (0.7) & 39 & $(0.6)$ & 39 & (0.4) & 25 & (2.5) & 26 & (2.4) & 27 & (2.1) & 26 & (1.4) \\
\hline Rèpublique tchèque & 40 & $(0.9)$ & 43 & $(0.3)$ & 43 & (0.4) & 43 & (0.2) & 17 & (4.5) & 29 & (1.6) & 43 & (3.6) & 32 & (1.4) \\
\hline Danemark & 35 & $(0.5)$ & 38 & (0.3) & 38 & (0.2) & 37 & (0.2) & 32 & (2.5) & 39 & (1.3) & 43 & (1.2) & 40 & (0.7) \\
\hline Estonie & 40 & $(0.5)$ & 40 & (02) & 39 & (0.2) & 40 & $(0.1)$ & 20 & (1.9) & 24 & $(0.9)$ & 29 & (1.1) & 26 & (0.6) \\
\hline Finlande & 39 & (0.5) & 38 & $(0.3)$ & 38 & (0.2) & 38 & (0.2) & 41 & (2.9) & 45 & (1.6) & 51 & (1.2) & 47 & $(0.8)$ \\
\hline France & 35 & $(0.3)$ & 37 & $(0.2)$ & 38 & (0.2) & 37 & $(0.2)$ & 17 & (1.2) & 20 & $(0.7)$ & 29 & (1.1) & 23 & (0.5) \\
\hline Allemagne & 33 & (1.3) & 36 & $(0.3)$ & 40 & $(0.4)$ & 37 & (0.2) & 17 & $(3.0)$ & 29 & (12) & 42 & $(1.3)$ & 33 & (0.9) \\
\hline Gréce' $^{\prime}$ & 44 & (0.9) & 43 & (0.5) & 40 & (0.5) & 42 & (0.3) & 21 & (2.6) & 16 & (1.3) & 18 & (1.8) & 18 & (1.1) \\
\hline Irlande & 34 & (0.7) & 36 & (0.4) & 37 & $(0.3)$ & 36 & (0.3) & 21 & (1.9) & 20 & (1.4) & 19 & (1.1) & 20 & (0.8) \\
\hline Israël|' & 40 & $(0.9)$ & 41 & $(0.5)$ & 41 & $(0.4)$ & 41 & (0.2) & 29 & (2.9) & 27 & (1.5) & 31 & $(1,3)$ & 30 & $(1.0)$ \\
\hline Italie & 39 & (0.5) & 39 & (0.4) & 37 & (0.6) & 39 & (0.3) & 22 & (1.8) & 23 & (1.3) & 33 & $(2.0)$ & 24 & (1.1) \\
\hline Japon & 40 & $(0.8)$ & 40 & (0.4) & 42 & $(0.3)$ & 41 & $(0.2)$ & 37 & $(3.3)$ & 38 & (1.4) & 41 & (1.2) & 39 & $(0.8)$ \\
\hline Corée & 44 & $(0.7)$ & 44 & $(0.5)$ & 43 & $(0.3)$ & 43 & (0.3) & 29 & (2.1) & 29 & $(1.3)$ & 32 & (1.1) & 30 & (08) \\
\hline Lituanie' & 40 & $(0.9)$ & 40 & (02) & 38 & (0.3) & 40 & (0.2) & 13 & (4.1) & 11 & (0.9) & 24 & (1.5) & 16 & (0.8) \\
\hline Pays-Bas & 32 & $(0.4)$ & 34 & $(0.3)$ & 35 & $(0.3)$ & 34 & $(0.2)$ & 22 & (1.6) & 27 & (1.2) & 42 & (1.4) & 32 & (0.9) \\
\hline Nouvelle-Zélande' & 38 & $(0.6)$ & 38 & (0.5) & 38 & (0.3) & 38 & (0.2) & 25 & (1.7) & 30 & (1.7) & 32 & (1.1) & 30 & $(0.8)$ \\
\hline Norvège & 35 & $(0.5)$ & 36 & (0.3) & 38 & (0.2) & 37 & (0.2) & 28 & (2.1) & 31 & (1.3) & 38 & (1.1) & 34 & (0.6) \\
\hline Pologne & 41 & $(0.9)$ & 42 & $(0.3)$ & 39 & $(0.3)$ & 41 & (0.2) & 24 & (3.8) & 22 & (1.2) & 24 & (1.5) & 23 & (1.0) \\
\hline République slovaque & 39 & $(0.7)$ & 42 & (02) & 42 & $(0.4)$ & 42 & (0.2) & 9 & (1.8) & 19 & (1.2) & 33 & (1.8) & 22 & (0.9) \\
\hline Slovénie' & 41 & $(0.6)$ & 42 & (02) & 42 & (0.2) & 42 & (0.2) & 10 & (1.7) & 20 & (1.1) & 27 & (1.5) & 21 & (0.9) \\
\hline Espagne & 40 & $(0.4)$ & 38 & $(0.6)$ & 38 & $(0.3)$ & 38 & (0.2) & 21 & $(1.4)$ & 19 & $(1.8)$ & 21 & (1.2) & 21 & $(0.8)$ \\
\hline Suéde & 37 & (06) & 39 & (0.3) & 40 & $(03)$ & 39 & (0.2) & 33 & (25) & 38 & (1.3) & 47 & (1.3) & 41 & (09) \\
\hline Turquie' & 45 & $(0.6)$ & 45 & (0.7) & 43 & (0.4) & 45 & $(0.4)$ & 33 & (2.3) & 22 & (2.4) & 21 & (1.8) & 28 & (1.6) \\
\hline Etats-Unis & 39 & (0.9) & 39 & (0.3) & 42 & (0.4) & 40 & (0.2) & 16 & (28) & 24 & (1.2) & 31 & (1.1) & 26 & (0.8) \\
\hline \multicolumn{17}{|l|}{ Economies } \\
\hline Comm. flamande (Belgique) & 37 & $(0.8)$ & 38 & $(0.3)$ & 39 & $(0.3)$ & 39 & (0.2) & 25 & (2.5) & 29 & (1.1) & 39 & (1.4) & 33 & $(0.9)$ \\
\hline Angleterre (RU) & 35 & $(0.7)$ & 37 & $(0.4)$ & 37 & $(0.3)$ & 37 & (0.2) & 20 & $(2.0)$ & 29 & (1.6) & 30 & $(1.5)$ & 28 & (0.9) \\
\hline Irlande du Nord (RU) & 35 & $(0.6)$ & 36 & (0.5) & 37 & (0.4) & 36 & $(0.3)$ & 18 & (2.2) & 22 & (1.8) & 24 & $(1.7)$ & 22 & (12) \\
\hline Moyenne OCDE & 38 & $(0.1)$ & 39 & $(0.1)$ & 39 & (0.1) & 39 & $(0.0)$ & 23 & $(0.5)$ & 27 & $(0.3)$ & 33 & $(0.3)$ & 29 & (0.2) \\
\hline Q Fédération de Russie* & 40 & (22) & 42 & (0.6) & 41 & $(0.3)$ & 41 & (0.2) & 14 & $(5.4)$ & 14 & (1.2) & 17 & (1.4) & 16 & $(1.0)$ \\
\hline
\end{tabular}

1. Année de référence : 2015 ; pour tous les autres pays et économies, année de référence : 2012.

* Voir la note concernant les données de la Fédération de Russie dans la section « Source ».

Source : OCDE (2019). Consulter la section « Source » pour tout complément d'information et l'annexe 3 pour les notes (https://doi.org/10.1787/f8d7880d-en). Les symboles représentant les données manquantes et les abréviations figurent dans le Guide du lecteur. 


\section{Indicateur A7. Dans quelle mesure les adultes participent-ils équitablement à des activités de formation?}

\section{Faits marquants}

- L'apprentissage appelle l'apprentissage. En moyenne, dans les pays de l'OCDE, le taux de participation des diplômés de l'enseignement tertiaire à des activités formelles ou non formelles de formation est supérieur de 20 points de pourcentage environ à celui des diplômés du deuxième cycle de l'enseignement secondaire ou de l'enseignement post-secondaire non tertiaire.

- Le taux de participation à des activités de formation est nettement plus élevé si les activités sont non formelles plutôt que si elles sont formelles. Ce constat vaut même pour les 25-34 ans : en moyenne, 50 \% d'entre eux se sont dits en formation non formelle dans les pays de l'OCDE qui ont pris part à l'Enquête sur l'éducation des adultes (EEA), contre $16 \%$ seulement en formation formelle.

- La participation des adultes à des activités de formation est fortement liée à l'emploi. En moyenne, dans les pays de l'OCDE qui ont pris part à l'EEA, $70 \%$ des activités de formation suivies par les 25-64 ans diplômés de l'enseignement tertiaire en formation non formelle sont liées à leur vie professionnelle et financées par leur employeur.

Graphique A7.1. Participation à des activités formelles et/ou non formelles de formation, selon le niveau de formation (2016)

Enquête sur l'éducation des adultes (EEA), Évaluation des compétences des adultes (PIAAC) ou enquêtes nationales, adultes âgés de 25 à 64 ans

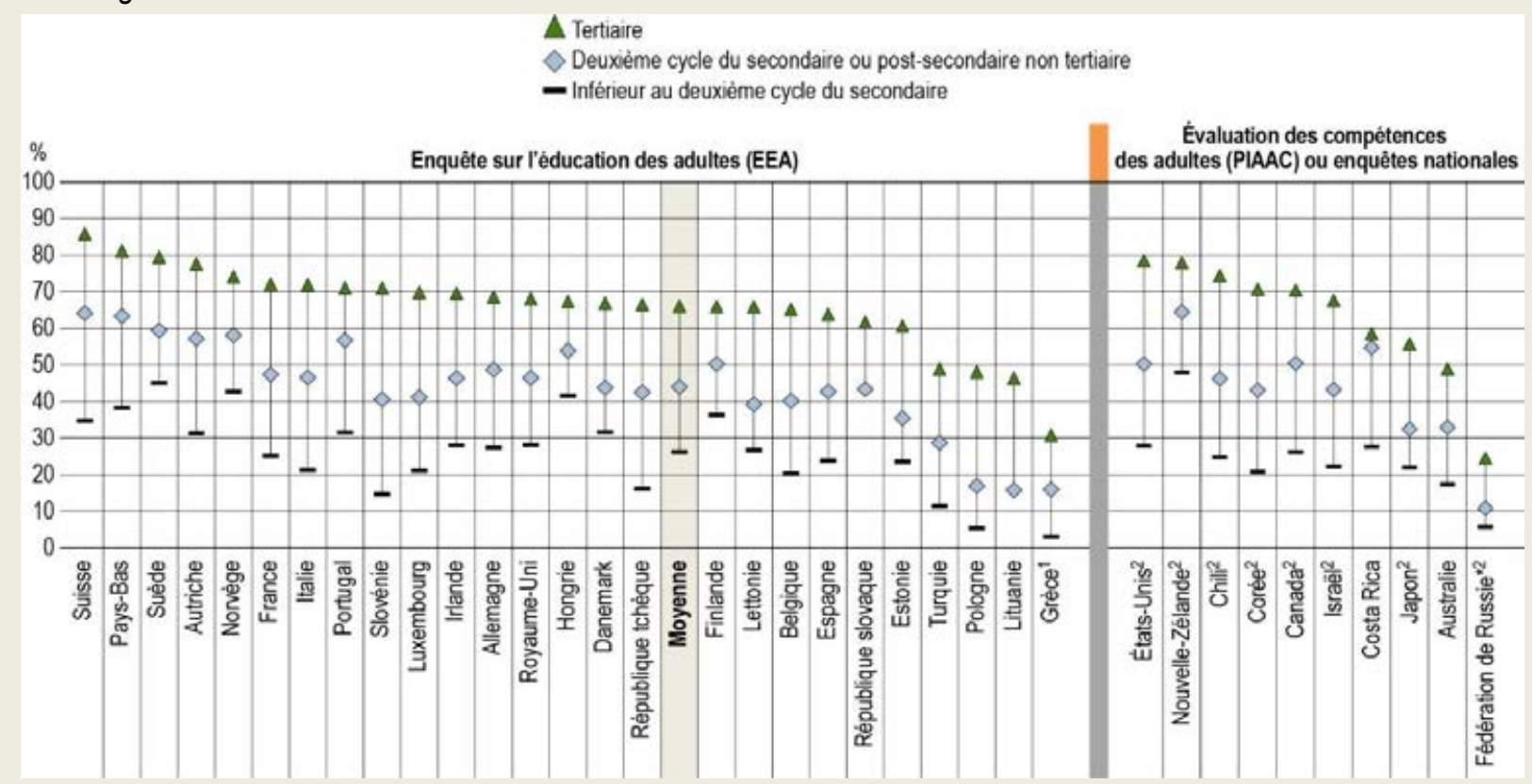

1. La prudence est de mise lors de l'interprétation de certaines catégories. Consulter le tableau source pour de plus amples informations.

2. L'année de référence n'est pas 2016. Consulter le tableau source pour de plus amples informations.

* Voir la note concernant les données de la Fédération de Russie dans la section « Source ».

Les pays sont classés par ordre décroissant du pourcentage de diplômés de l'enseignement tertiaire âgés de 25 à 64 ans qui ont participé à des activités formelles ou non formelles de formation.

Source: OCDE (2019), tableau A7.1. Consulter la section "Source» pour tout complément d'information et l'annexe 3 pour les notes (https://doi.org/10.1787/f8d7880d-en). 


\section{Contexte}

L'apprentissage à l'âge adulte peut jouer un rôle important pour aider les adultes à entretenir et à enrichir des compétences clés en matière de traitement de l'information et à acquérir de nouveaux savoirs et savoirfaire tout au long de leur vie. Il est crucial d'offrir aux adultes des possibilités d'apprentissage dans un cadre organisé au-delà de la formation initiale et de leur permettre d'y accéder ; c'est particulièrement vrai pour les travailleurs qui doivent s'adapter au changement tout au long de leur carrière (OCDE, 2013 $\left.{ }_{[1]}\right)$.

L'apprentissage à l'âge adulte peut aussi contribuer à atteindre des objectifs non économiques, par exemple aider les individus à s'épanouir sur le plan personnel, à se sentir en bonne santé, à s'intégrer dans la société et à participer à la vie publique. Toutefois, la forte variation des activités de formation pour adultes et de la participation de ceux-ci à ces activités entre des pays de l'OCDE dont le niveau de développement économique est similaire suggère l'existence de grandes différences dans les cultures d'apprentissage, les possibilités d'apprentissage dans le cadre professionnel et les systèmes de formation pour adultes (Borkowsky, 2013[2]).

\section{Autres faits marquants}

- Dans tous les pays de l'OCDE qui ont pris part à l'EEA, la participation à des activités formelles ou non formelles de formation augmente de niveau de formation en niveau de formation.

- Les cours à distance sont une forme de plus en plus courante d'apprentissage à l'âge adulte. Dans les pays et économies de l'OCDE qui ont pris part à l'Évaluation des compétences des adultes (PIAAC), $20 \%$ des adultes en formation non formelle ont déclaré suivre des cours à distance.

- Dans la plupart des pays de l'OCDE, la plupart des adultes en formation formelle suivent un cursus tertiaire. Toutefois, moins de la moitié des adultes en formation formelle suivent un cursus tertiaire en Australie, en Belgique, au Mexique et en Suède. 


\section{Analyse}

\section{Participation à des activités formelles et/ou non formelles de formation, selon le sexe, le groupe d'âge et le niveau d'enseignement}

En moyenne, dans les pays de l'OCDE qui ont pris part à l'Enquête sur l'éducation des adultes (EEA), 47 \% des 25-64 ans avaient participé à des activités formelles et/ou non formelles de formation au cours des 12 mois précédant l'enquête. Le taux de participation à des activités de formation est inférieur à $25 \%$ en Grèce et en Turquie, mais égal ou supérieur à $60 \%$ en Autriche, en Norvège, aux Pays-Bas, en Suède et en Suisse (voir le tableau A7.1).

Le graphique A7.1 montre que les adultes plus instruits sont plus susceptibles de participer à des activités formelles ou non formelles de formation. En moyenne, dans les pays de l'OCDE qui ont pris part à l'EEA, $26 \%$ des 25-64 ans non diplômés du deuxième cycle de l'enseignement secondaire ont participé à des activités formelles ou non formelles de formation au cours des 12 mois précédant l'enquête. Ce pourcentage augmente pour atteindre $44 \%$ chez les diplômés du deuxième cycle de l'enseignement secondaire ou de l'enseignement post-secondaire non tertiaire et 66 \% chez les diplômés de l'enseignement tertiaire. Le taux de participation varie fortement entre les pays même chez les diplômés de l'enseignement tertiaire : il est compris entre $31 \%$ en Grèce et $86 \%$ en Suisse. La différence de taux de participation entre le niveau de formation égal à l'enseignement tertiaire et le niveau de formation inférieur au deuxième cycle de l'enseignement secondaire est supérieure à 25 points de pourcentage dans tous les pays de l'OCDE ayant pris part à l'EEA ; il est égal ou supérieur à 50 points de pourcentage en Italie, en République tchèque, en Slovénie et en Suisse (voir le graphique A7.1)

Le diplôme du deuxième cycle de l'enseignement secondaire ou de l'enseignement post-secondaire non tertiaire est associé à de grandes différences de taux de participation : à ce niveau de formation, le taux de participation est supérieur de 25 points de pourcentage au moins au niveau de formation inférieur au deuxième cycle de l'enseignement secondaire en Autriche, en Italie, aux Pays-Bas, au Portugal, en République tchèque, en Slovénie et en Suisse. Par contraste, les différences sont les plus ténues (15 points de pourcentage ou moins) au Danemark, en Estonie, en Finlande, en Grèce, en Hongrie, en Lettonie, en Norvège, en Pologne et en Suède (voir le graphique A7.1).

Dans la plupart des pays, les taux de participation varient de moins de 5 points de pourcentage entre les hommes et les femmes. La différence entre les sexes n'est supérieure à 10 points de pourcentage qu'en Estonie et en Finlande, deux pays où le taux de participation est plus élevé chez les femmes que chez les hommes. En Turquie, la différence est favorable aux hommes et est particulièrement importante vu le taux de participation peu élevé en général : le taux de participation à des activités formelles ou non formelles de formation s'établit à $17 \%$ chez les femmes et à $25 \%$ chez les hommes (voir le tableau A7.1).

Dans tous les pays qui ont pris part à l'EEA, les 25-34 ans sont plus susceptibles de participer à des activités formelles ou non formelles de formation que leurs aînés (les 35-44 ans, les 45-54 ans et les 55-64 ans). En moyenne, dans les pays de l'OCDE qui ont pris part à l'EEA, $57 \%$ des $25-34$ ans ont participé à des activités formelles ou non formelles de formation, contre $52 \%$ des $35-44$ ans, $46 \%$ des $45-54$ ans et $33 \%$ des $55-64$ ans. C'est en Finlande que le taux de participation varie le plus entre les groupes d'âge : il s'établit à $68 \%$ chez les 25-34 ans, mais à $34 \%$ chez les 55-64 ans. Par contraste, c'est en Allemagne qu'il varie le moins : $57 \%$ des jeunes participent à des activités formelles ou non formelles de formation, contre $44 \%$ de leurs aînés (voir le tableau A7.1).

\section{Comparaison de la participation à des activités formelles vs non formelles de formation}

Les activités non formelles de formation l'emportent sur les activités formelles de formation dans tous les groupes d'âge. Ce constat vaut pour tous les pays, même chez les 25-34 ans, le groupe d'âge où le taux de participation à des activités formelles de formation est le plus élevé. En moyenne, dans les pays de l'OCDE qui ont pris part à l'EEA, $16 \%$ des 25-34 ans ont participé à des activités formelles de formation et $50 \%$ d'entre eux, à des 
activités non formelles de formation. Le taux de participation à des activités de formation, tant formelles que non formelles, est inférieur à $30 \%$ en Grèce, en Pologne et en Turquie. Par contraste, les taux sont supérieurs à $30 \%$ dans les deux types d'activités au Danemark et en Finlande. Au Danemark, il apparaît qu'un pourcentage non négligeable de jeunes qui participent à des activités non formelles de formation participent aussi à des activités formelles (voir le graphique A7.2).

Graphique A7.2. Participation des adultes âgés de 25 à 34 ans à des activités d'éducation ou de formation, selon la nature formelle/non formelle desdites activités (2016)

Enquête sur l'éducation des adultes (EEA), Évaluation des compétences des adultes (PIAAC) ou enquêtes nationales

\section{$\Delta$ Participation à des activités formelles et/ou non formelles de formation $\diamond$ Participation à des activités non formelles de formation \\ - Participation à des activités formelles de formation}

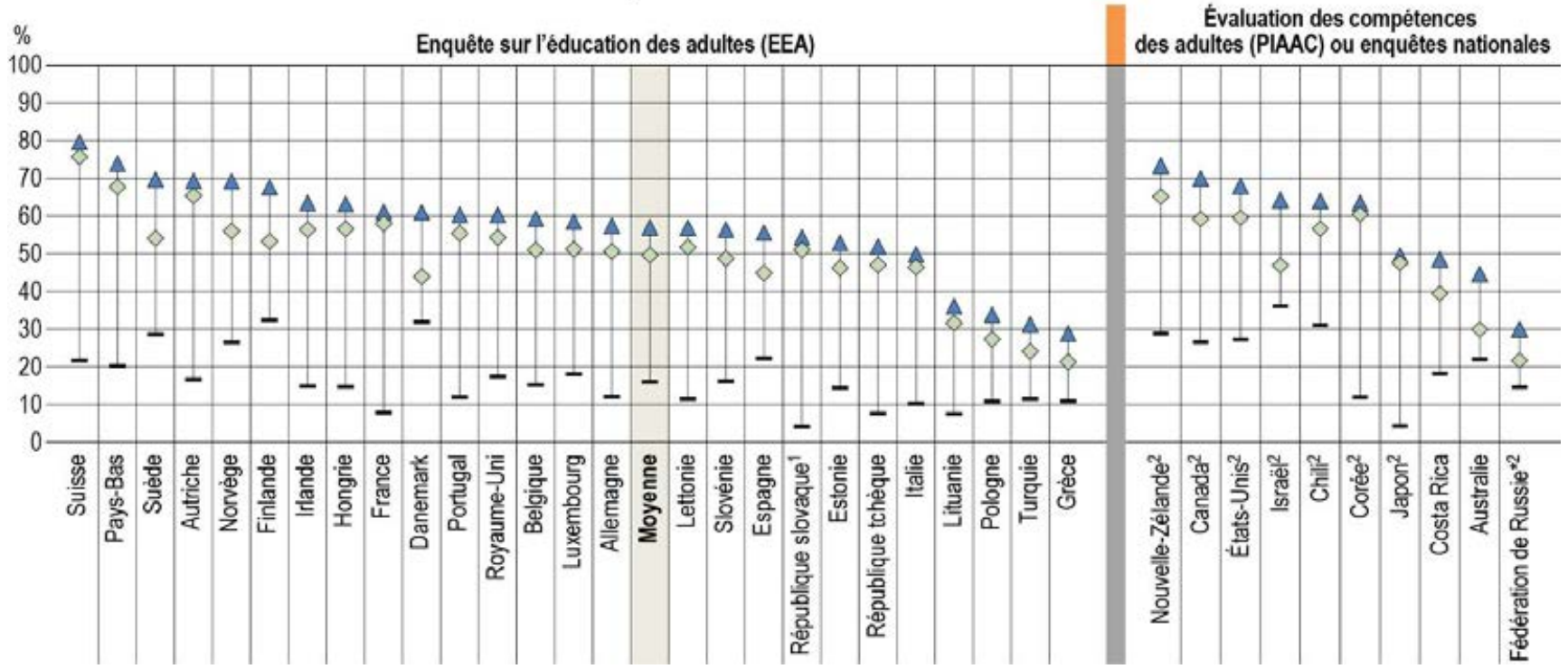

1. La prudence est de mise lors de l'interprétation de certaines catégories. Consulter le tableau source pour de plus amples informations.

2. L'année de référence n'est pas 2016. Consulter le tableau source pour de plus amples informations.

* Voir la note concernant les données de la Fédération de Russie dans la section « Source ॥.

Les pays sont classés par ordre décroissant du pourcentage d'individus âgés de 25 à 34 ans qui ont participé à des activités formelles ou non formelles de formation.

Source: OCDE (2019), tableau A7.1. Consulter la section "Source » pour tout complément d'information et l'annexe 3 pour les notes (https://doi.org/10.1787/f8d7880d-en).

StatLink त्ञाज https://doi.org/10.1787/888933977562

\section{Participation à des activités non formelles de formation (liées ou non à l'emploi)}

Le graphique A7.3 montre que les activités de formation financées par les employeurs constituent l'essentiel des activités non formelles de formation auxquelles les diplômés de l'enseignement tertiaire participent. C'est vrai dans tous les pays, sauf en Grèce, où les activités non formelles de formation les plus courantes sont liées à l'emploi, mais ne sont pas financées par les employeurs.

Les formations sans rapport avec l'emploi sont moins courantes que celles liées à l'emploi dans tous les pays, mais elles représentent au moins $20 \%$ des formations suivies par les adultes en Autriche, en France, en Italie, au Luxembourg, en Slovénie et en Suisse. II en ressort que la participation à des activités non formelles de formation est le plus souvent liée à la vie professionnelle ou à l'amélioration des compétences en prévision d'un nouveau poste et rarement motivée par le seul plaisir d'apprendre (voir le tableau A7.2a). 
Le pourcentage d'activités non formelles de formation non liées à l'emploi augmente avec le niveau de formation pour les participants dont le niveau de formation est inférieur au deuxième cycle de l'enseignement secondaire. Cela s'explique en partie par les taux d'emploi moins élevés des adultes moins diplômés (voir l'indicateur A3) et à leur exposition moindre à des possibilités de formation liées à l'emploi. C'est un constat important sachant que l'apprentissage est essentiel pour permettre aux sans-emploi d'améliorer leur capital humain et de retrouver du travail (voir le tableau A7.2a).

Graphique A7.3. Répartition des activités de formation liées à l'emploi et financées par l'employeur parmi les adultes diplômés de l'enseignement tertiaire ayant participé à des activités non formelles de formation (2016)

Enquête sur l'éducation des adultes (EEA), Évaluation des compétences des adultes (PIAAC), adultes âgés de 25 à 64 ans

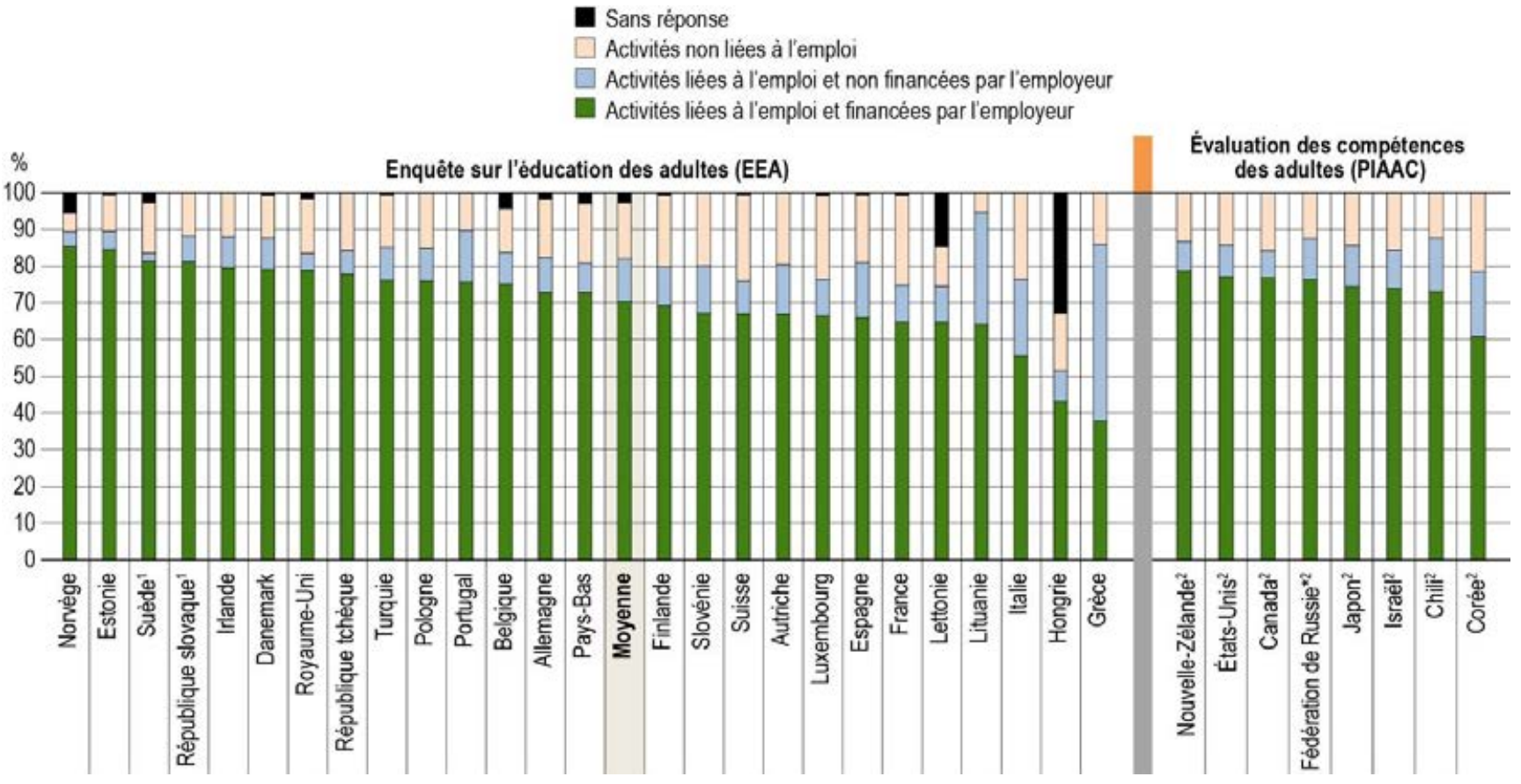

1. La prudence est de mise lors de l'interprétation de certaines catégories. Consulter le tableau source pour de plus amples informations.

2. L'année de référence n'est pas 2016. Consulter le tableau source pour de plus amples informations.

*Voir la note concernant les données de la Fédération de Russie dans la section « Source».

Les pays sont classés par ordre décroissant du pourcentage d'adultes âgés de 25 à 64 ans diplômés de l'enseignement tertiaire qui ont participé à des activités non formelles de formation liées à leur emploi et financées par leur employeur.

Source: OCDE (2019), tableau A7.2a. Consulter la section "Source» pour tout complément d'information et l'annexe 3 pour les notes (https://doi.org/10.1787/f8d7880d-en).

StatLink 제대 https://doi.org/10.1787/888933977581

\section{Cours à distance et activités non formelles de formation}

Les activités non formelles de formation peuvent se dérouler dans de nombreux contextes différents, par exemple pendant des séminaires, sur le lieu de travail ou encore lors de cours particuliers ou à distance (OCDE, 2014 $\left.{ }_{[3]}\right)$. L'augmentation de la participation à l'éducation a entraîné une hausse de la demande d'options plus flexibles d'apprentissage, et les cours à distance (en particulier en ligne) sont désormais courants (Kentnor, 2015[4]). Les cours à distance sont aussi caractéristiques des activités non formelles de formation ; en moyenne dans les pays de l'OCDE, $20 \%$ des adultes en formation non formelle selon l'Évaluation des compétences des adultes ont opté pour des cours à distance. Les pourcentages d'adultes suivant des formations non formelles à distance sont les 
plus élevés en Lituanie et en Pologne, où plus de $45 \%$ des adultes en ont suivi. À l'autre extrême, $9 \%$ seulement des adultes en formation non formelle ont suivi des cours à distance en Norvège et en Slovénie (voir le graphique A7.4 et le tableau A7.2c, disponible en ligne).

Des différences s'observent aussi dans les tendances d'apprentissage à distance en fonction du niveau de formation dans les pays de l'OCDE. Dans la majorité des pays, les diplômés de l'enseignement tertiaire sont plus susceptibles de suivre des cours non formels à distance que les adultes dont le niveau de formation est inférieur au deuxième cycle de l'enseignement secondaire. Ce constat reflète la plus grande propension des diplômés de l'enseignement tertiaire à participer à des activités non formelles de formation (voir le graphique A7.1). La différence est particulièrement importante en Corée, où le pourcentage de diplômés de l'enseignement tertiaire suivant des cours non formels à distance est supérieur de 40 points de pourcentage à celui qui s'observe chez les adultes dont le niveau de formation est inférieur au deuxième cycle de l'enseignement secondaire. À l'inverse, la différence entre les niveaux de formation est inférieure à 5 points de pourcentage en Allemagne, en Autriche, au Japon, en Norvège, en Nouvelle-Zélande, aux Pays-Bas et en Turquie (voir le graphique A7.4 et le tableau A7.2c, disponible en ligne).

\section{Graphique A7.4. Taux de participation à des cours à distance parmi les adultes ayant participé à des activités non formelles de formation (2012 ou 2015)}

Évaluation des compétences des adultes (PIAAC), adultes âgés de 25 à 64 ans

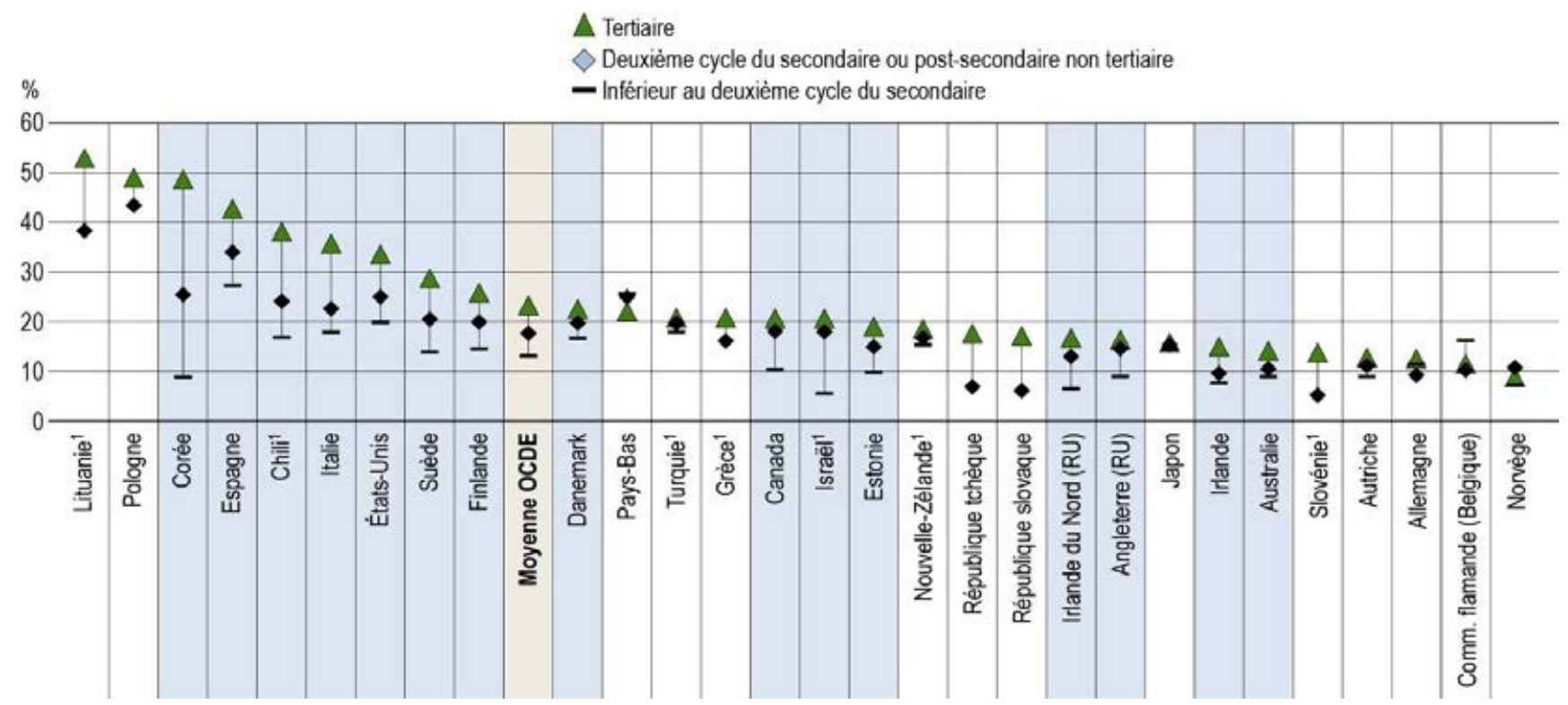

Remarque : Les différences statistiquement significatives entre les niveaux de formation inférieurs au deuxième cycle de l'enseignement secondaire et l'enseignement tertiaire sont indiquées dans une couleur plus foncée.

1. Année de référence : 2015 ; pour tous les autres pays et économies, année de référence : 2012.

Les pays et économies sont classés par ordre décroissant du taux de participation à des cours à distance parmi les adultes diplômés de l'enseignement tertiaire ayant participé à des activités non formelles de formation.

Source : OCDE (2019). Tableau A7.2c, disponible en ligne uniquement. Consulter la section "Source » pour tout complément d'information et l'annexe 3 pour les notes (https://doi.org/10.1787/f8d7880d-en).

StatLink 제대 https://doi.org/10.1787/888933977600

En moyenne, dans les pays de l'OCDE, la propension à suivre des cours non formels à distance varie peu selon le sexe (19\% chez les hommes, $21 \%$ chez les femmes). Les différences entre les sexes sont plus importantes dans quelques pays ; en Pologne par exemple, $57 \%$ des hommes en formation non formelle ont opté pour des cours à distance, un pourcentage supérieur de 21 points de pourcentage à celui des femmes. Ce pourcentage 
d'hommes en formation non formelle qui ont opté pour des cours à distance est également supérieur de 10 points de pourcentage à celui des femmes en Lituanie et en Turquie (voir le tableau A7.2c, disponible en ligne).

\section{Effectifs scolarisés à différents niveaux d'enseignement formel, selon le groupe d'âge}

Le pourcentage d'adultes en formation formelle, c'est-à-dire scolarisés dans le cadre institutionnel, diminue avec l'âge, mais leur répartition entre les niveaux d'enseignement ne varie guère selon les groupes d'âge. En moyenne, dans les pays de l'OCDE, l'effectif en formation formelle s'établit à $16 \%$ chez les $25-29$ ans, à $7 \%$ chez les 30-39 ans et à $2 \%$ seulement chez les 40-64 ans. Dans les trois groupes d'âge, l'enseignement tertiaire est le niveau le plus courant, mais son effectif diminue légèrement l'âge venant: il atteint $79 \%$ chez les 25-29 ans, mais passe à $72 \%$ chez les 30-39 ans et à $65 \%$ chez les 40-64 ans (voir le tableau A7.3).

Dans les pays de l'OCDE, le taux de scolarisation des 30-39 ans dans le cadre institutionnel s'établit à $2 \%$ en Corée, en France, au Luxembourg et en République slovaque, mais à plus de $15 \%$ en Australie, en Finlande et en Suède. Le niveau d'enseignement varie sensiblement aussi dans ce groupe d'âge entre les pays. Dans la plupart des pays, l'enseignement tertiaire est le plus important, signe que les profils tertiaires sont très demandés sur le marché du travail. Toutefois, moins de la moitié des individus en formation formelle suivent un cursus tertiaire en Australie, en Belgique, au Mexique et en Suède. En Australie, en Belgique et en Finlande, $40 \%$ au moins des 30-39 ans en formation formelle suivent un cursus relevant du deuxième cycle de l'enseignement secondaire ou de l'enseignement post-secondaire non tertiaire, alors qu'au Mexique, la moitié environ d'entre eux suivent un cursus relevant d'un niveau inférieur au deuxième cycle de l'enseignement secondaire (voir le graphique A7.5 et le tableau A7.3).

\section{Graphique A7.5. Effectifs scolarisés à différents niveaux d'enseignement formel (2017)}

\section{OCDE / ISU / Eurostat, 30-39 ans}

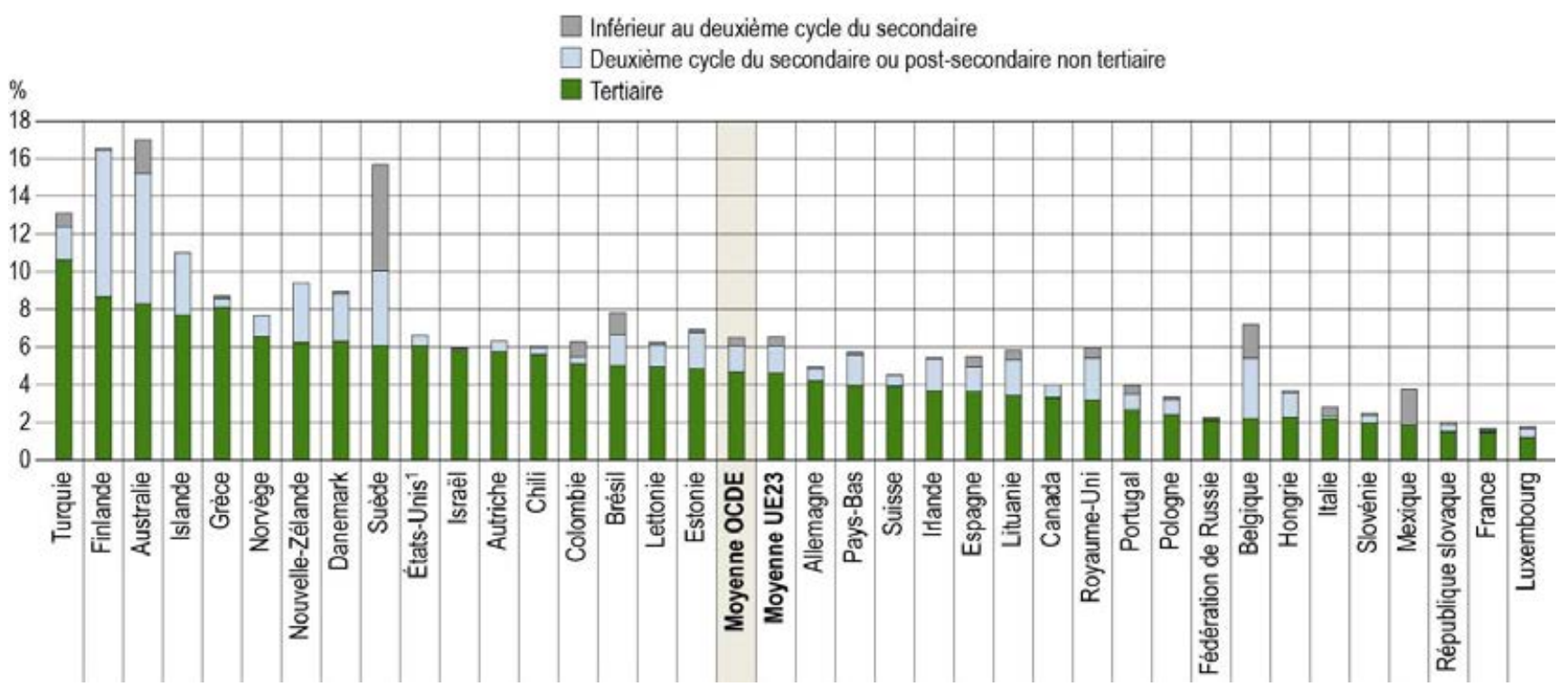

Remarque : Le taux de scolarisation pour chaque niveau d'enseignement est calculé sur la base de la répartition présentée dans le tableau A7.3.

1. Les données concernant la scolarisation dans le deuxième cycle de l'enseignement secondaire et l'enseignement post-secondaire non tertiaire excluent le deuxième cycle de l'enseignement secondaire.

Les pays sont classés par ordre décroissant du pourcentage de 30-39 ans scolarisés dans l'enseignement tertiaire formel.

Source : OCDE/ISU/Eurostat (2019), Table A7.3. Consulter la section « Source » pour tout complément d'information et l'annexe 3 pour les notes (https://doi.org/10.1787/f8d7880d-en). 
En Suède, le taux de participation élevé des 30-39 ans à des activités formelles de formation reflète les efforts du gouvernement visant à améliorer l'accessibilité de la formation pour adultes. Les activités formelles de formation pour adultes, organisées à l'échelle des municipalités, sont bien établies en Suède. Elles visent à offrir une éducation de base à tous les résidents suédois âgés d'au moins 20 ans dont le niveau de formation est inférieur au premier cycle de l'enseignement secondaire (Eurydice, 2018[5]). Dans le système d'enseignement public, l'éducation et la formation des adultes sont gratuites pour les citoyens suédois (OCDE, 2015[6]). De même, en Finlande, les adultes peuvent obtenir les mêmes diplômes ou qualifications professionnelles que les jeunes et, dans certains cas, les jeunes étudiants et les plus âgés apprennent ensemble. Ce constat s'explique en partie par le pourcentage moyen plus élevé de 30-39 ans inscrits en formation formelle dans le deuxième cycle de l'enseignement secondaire ou suivant un programme post-secondaire non tertiaire en Finlande. Enfin, informer et orienter les publics cibles est indispensable pour accroître les taux de participation et améliorer l'inclusivité. Au Danemark par exemple, les taux de scolarisation assez élevés pourraient s'expliquer par la façon proactive dont les pouvoirs publics diffusent des informations sur l'enseignement en général ainsi que sur l'enseignement supérieur et les formations pour adultes sur le site UddannelsesGuiden (OCDE, 2019[7])..

\section{Définitions}

Le terme « adultes » désigne la population âgée de 25 à 64 ans.

Formation des adultes : par activités formelles de formation, on entend les activités organisées dans le système d'éducation, c'est-à-dire dans les établissements d'enseignement (écoles, collèges, universités et autres établissements à vocation pédagogique), qui constituent le parcours normal de la scolarisation à temps plein des enfants et des jeunes. Les formations peuvent être dispensées par des établissements publics ou privés. Par activités non formelles de formation, on entend les activités organisées et régulières qui ne correspondent pas exactement aux activités formelles définies ci-dessus. Ces activités peuvent être organisées dans des établissements d'enseignement ou ailleurs et être suivies par des individus de tout âge. Selon les pays, il peut s'agir de programmes d'alphabétisation pour adultes ou de programmes visant à dispenser une formation de base aux jeunes en décrochage scolaire, à enseigner des savoir-faire professionnels et des compétences utiles dans la vie ou encore à enrichir la culture générale.

Niveaux de formation : les niveaux de la CITE 2011 sont tous décrits dans le Guide du lecteur, au début du présent rapport.

La version précédente de la CITE (CITE 97) est utilisée dans les analyses des données de l'Évaluation des compétences des adultes (PIAAC): les niveaux de formation inférieurs au deuxième cycle de l'enseignement secondaire correspondent aux niveaux 0, 1, 2 et 3C (formations courtes) de la CITE 97 ; les niveaux de formation égaux au deuxième cycle de l'enseignement secondaire ou à l'enseignement postsecondaire non tertiaire correspondent aux niveaux 3A, 3B, 3C (formations longues) et 4 de la CITE 97 ; et les niveaux de formation égaux à l'enseignement tertiaire correspondent aux niveaux 5A, 5B et 6 de la CITE 97.

\section{Méthodologie}

Les calculs des données issues de l'Enquête sur l'éducation des adultes (EEA) peuvent être consultés à l'adresse : https://circabc.europa.eu/ui/group/d14c857a-601d-438a-b878-4b4cebd0e10f/library/c28a2e5b-ecdf4b07-ac2f-f3811d032295/details.

Concernant les données issues de l'Évaluation des compétences des adultes (PIAAC), les chiffres dont le numérateur est inférieur à 5 observations ou dont le dénominateur est inférieur à 30 observations multipliées par le nombre de catégories sont remplacés par la lettre « $c$ » dans les tableaux. 


\section{Source}

Les données des tableaux A7.1, A7.2a et A7.2b sur l'éducation et la formation des adultes proviennent des sources mentionnées ci-dessous :

- Enquête sur l'éducation des adultes (EEA) dans les pays européens de l'OCDE.

- Le programme de l'OCDE pour l'évaluation internationale des compétences des adultes (Évaluation des compétences des adultes [PIAAC]) pour le Canada, le Chili, la Corée, les États-Unis, la Fédération de Russie, Israël, le Japon et la Nouvelle-Zélande.

- L'Enquête sur l'apprentissage et la formation des adultes liés à l'emploi, Bureau australien de statistique, pour l'Australie.

- L'Encuesta Continua de Empleo (ECE), Instituto Nacional de Estadística y Censos (INEC), pour le Costa Rica.

Les données du tableau A7.2c sur la participation à des cours à distance proviennent du Programme de l'OCDE pour l'évaluation internationale des compétences des adultes (Évaluation des compétences des adultes [PIAAC]) pour tous les pays et économies.

Les données du tableau A7.3 sur la participation à des activités formelles de formation proviennent de l'exercice UNESCO-ISU/OCDE/Eurostat de collecte de données statistiques sur l'éducation réalisé par l'OCDE en 2018 pour tous les pays ; toutes les données se rapportent à l'année académique 2016/17 (pour plus de précisions, voir l'annexe 3, https://doi.org/10.1787/f8d7880d-en).

\section{Note concernant les données de la Fédération de Russie dans l'Évaluation des compétences des adultes (PIAAC)}

Il convient de signaler aux lecteurs que l'échantillon de la Fédération de Russie n'inclut pas la population de la municipalité de Moscou. Les données publiées dans le présent rapport ne sont donc pas représentatives de l'ensemble de la population âgée de 16 à 65 ans résidant en Fédération de Russie, mais de la population de la Fédération de Russie, à l'exclusion de la population de la municipalité de Moscou. Des informations plus détaillées concernant les données de la Fédération de Russie ainsi que celles d'autres pays sont disponibles dans le rapport technique de l'Évaluation des compétences des adultes, Technical Report of the Survey of Adult Skills, Second Edition (OCDE, 2016[8]).

\section{Remarque concernant les données fournies par Israël}

Les données statistiques concernant Israël sont fournies par et sous la responsabilité des autorités israéliennes compétentes. L'utilisation de ces données par l'OCDE est sans préjudice du statut des hauteurs du Golan, de Jérusalem-Est et des colonies de peuplement israéliennes en Cisjordanie aux termes du droit international.

\section{Références}

Borkowsky, A. (2013), « Monitoring adult learning policies: A theoretical framework and indicators », Documents de travail de l'OCDE sur l'éducation, $\mathrm{n}^{\circ} 88$, Éditions OCDE, Paris, http://dx.doi.org/10.1787/5k4c0vxjlkzt-en.

Eurydice (2018), Adult Education and Training - Sweden, https://eacea.ec.europa.eu/nationalpolicies/eurydice/content/adult-education-and-training-80 en (consulté le 19 juillet 2019).

Kentnor, H. (2015), " Distance education and the evolution of online learning in the United States », Curriculum and Teaching Dialogue, vol. 17/1-2, pp. S21-S21. 
OCDE (2019), Getting Skills Right: Future-Ready Adult Learning Systems, Getting Skills Right, Éditions

OCDE, Paris, https://dx.doi.org/10.1787/9789264311756-en.

OCDE (2016), Technical Report of the Survey of Adult Skills (PIAAC), 2nd Edition, OCDE, Paris, http://www.oecd.org/skills/piaac/PIAAC Technical Report 2nd Edition Full Report.pdf.

OCDE (2015), Perspectives des politiques de l'éducation 2015: Les réformes en marche, Éditions OCDE, Paris, https://dx.doi.org/10.1787/9789264227330-fr.

OCDE (2014), Regards sur l'éducation 2014 : Les indicateurs de l'OCDE, Éditions OCDE, Paris, http://dx.doi.org/10.1787/eag-2014-fr.

OCDE (2013), Perspectives de l'OCDE sur les compétences 2013: Premiers résultats de l'Evaluation des compétences des adultes, Éditions OCDE, Paris, https://dx.doi.org/10.1787/9789264204096-fr.

\section{Tableaux de l'indicateur A7}

Tableau A7.1

Tableau A7.2a
Participation à des activités formelles et/ou non formelles de formation, selon le sexe, le groupe d'âge et le niveau d'enseignement (2016)

Répartition des activités non formelles de formation, selon le sexe, le groupe d'âge et le niveau d'enseignement (2016)

WEB Tableau A7.2b Participation à des activités non formelles de formation liées à l'emploi et non liées à l'emploi, selon le sexe, le groupe d'âge et le niveau d'enseignement (2016)

WEB Tableau A7.2c Participation à des cours à distance parmi les adultes ayant participé à des activités non formelles de formation, selon le sexe, le groupe d'âge et le niveau d'enseignement (2012 ou 2015)

Tableau A7.3

Scolarisation dans l'enseignement formel, selon le groupe d'âge, et répartition par niveau d'enseignement (2017)

Date butoir pour les données: 19 juillet 2019. Les mises à jour peuvent être consultées en ligne sur : http://dx.doi.org/10.1787/eag-data-en. D'autres données désagrégées sont également disponibles dans la Base de données de Regards sur l'éducation (http://stats.oecd.org/).

StatLink : https://doi.org/10.1787/888933980906 
Tableau A7.1. Participation à des activités formelles et/ou non formelles de formation, selon le sexe, le groupe d'âge et le niveau d'enseignement (2016)

Enquête sur l'éducation des adultes (EEA), Évaluation des compétences des adultes (PIAAC) ou enquêtes nationales, adultes âgés de 25 à 64 ans

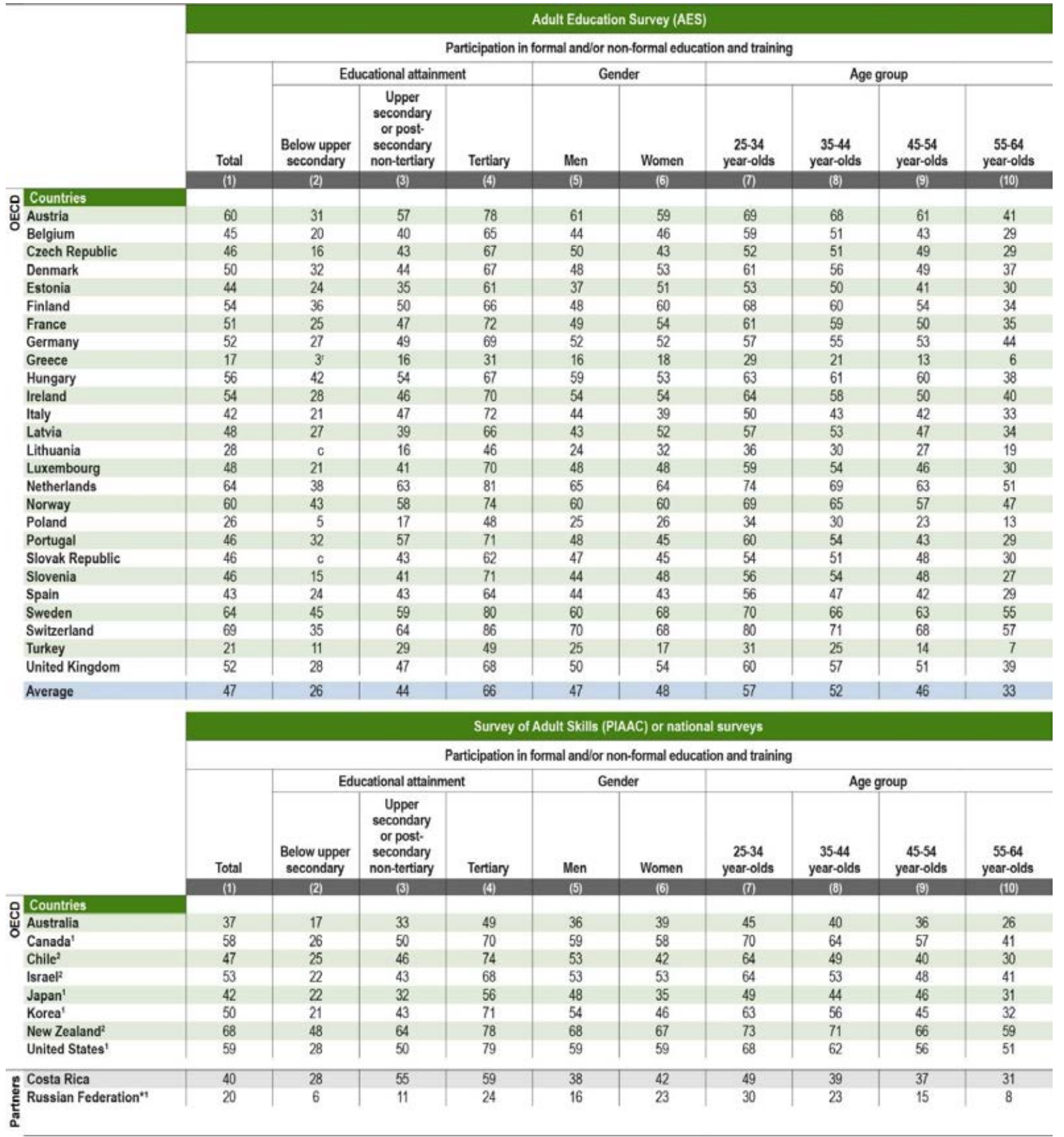

Remarque : Participation à des activités formelles et/ou non formelles de formation au cours des 12 derniers mois. Des colonnes supplémentaires présentant de manière distincte les données sur la participation à des activités formelles de formation et les données sur la participation à des activités non formelles de formation peuvent être consultées en ligne (voir le StatLink ci-dessous). II convient de noter que la moyenne diffère de celle publiée par Eurostat puisqu'il s'agit d'une moyenne non pondérée et que la représentativité est différente.

1. Année de référence : 2012

2. Année de référence : 2015.

* Voir la note concernant les données de la Fédération de Russie dans la section « Source ».

Source : OCDE (2019). Consulter la section « Source » pour tout complément d'information et l'annexe 3 pour les notes (https://doi.org/10.1787/f8d7880d-en). Les symboles représentant les données manquantes et les abréviations figurent dans le Guide du lecteur. 
Tableau A7.2a. Répartition des activités non formelles de formation, selon le sexe, le groupe d'âge et le niveau d'enseignement $(2016$

Enquête sur l'éducation des adultes (EEA), Évaluation des compétences des adultes (PIAAC) ou enquêtes nationales, adultes âgés de 25 à 64 ans ayant participé à des activités non formelles de formation

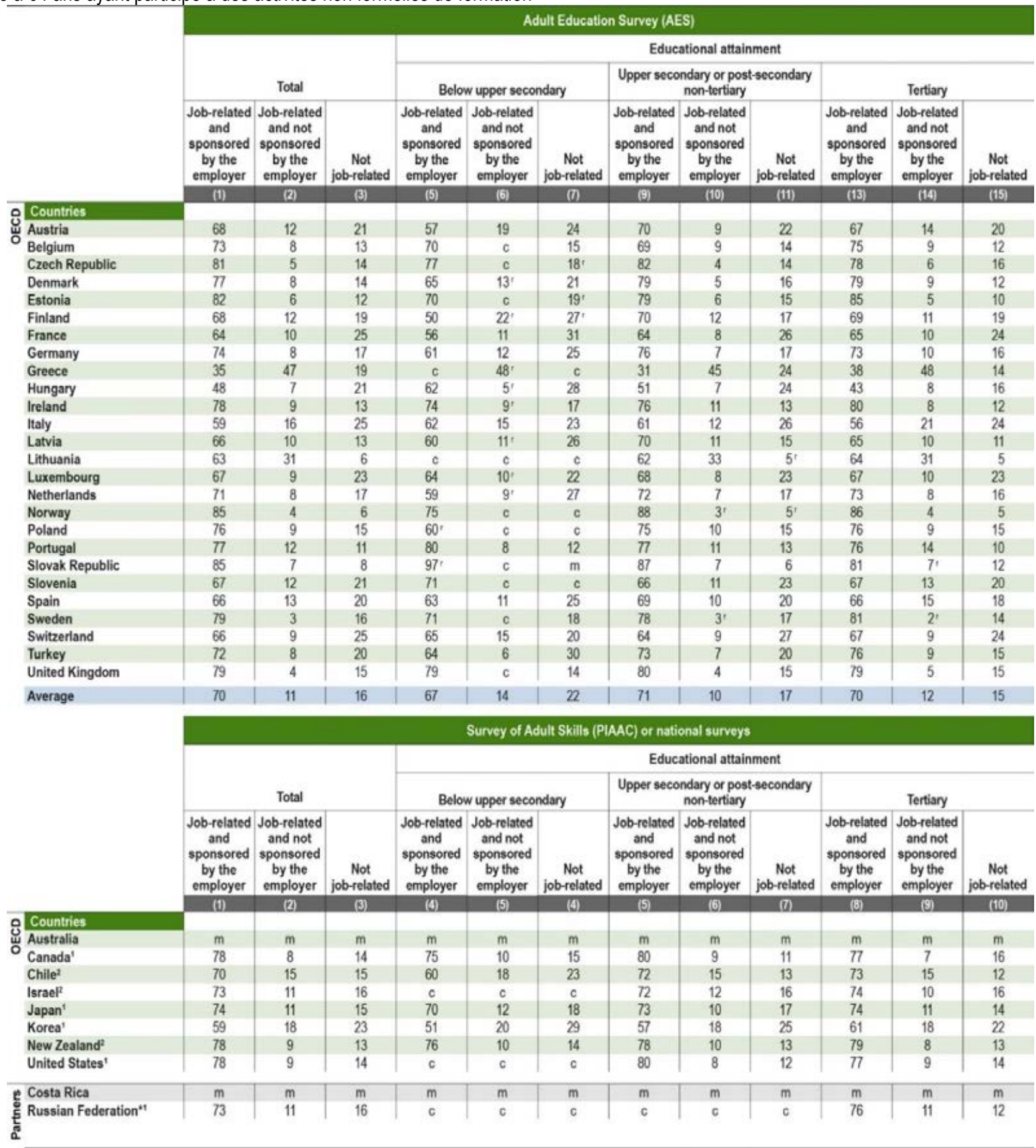

Remarque : La répartition des activités non formelles de formation se rapporte aux 12 derniers mois. Des colonnes supplémentaires présentant la catégorie « sans réponse » ainsi que les données ventilées selon le sexe et le groupe d'âge peuvent être consultées en ligne (voir le StatLink ci-dessous). II convient de noter que la moyenne diffère de celle publiée par Eurostat puisqu'il s'agit d'une moyenne non pondérée et que la représentativité est différente.

1. Année de référence : 2012.

2. Année de référence : 2015.

*Voir la note concernant les données de la Fédération de Russie dans la section « Source ».

Source : OCDE (2019). Consulter la section « Source » pour tout complément d'information et l'annexe 3 pour les notes (https://doi.org/10.1787/f8d7880d-en). Les symboles représentant les données manquantes et les abréviations figurent dans le Guide du lecteur. 
Tableau A7.3. Scolarisation dans l'enseignement formel, selon le groupe d'âge, et répartition par niveau d'enseignement (2017) OCDE/ISU/Eurostat

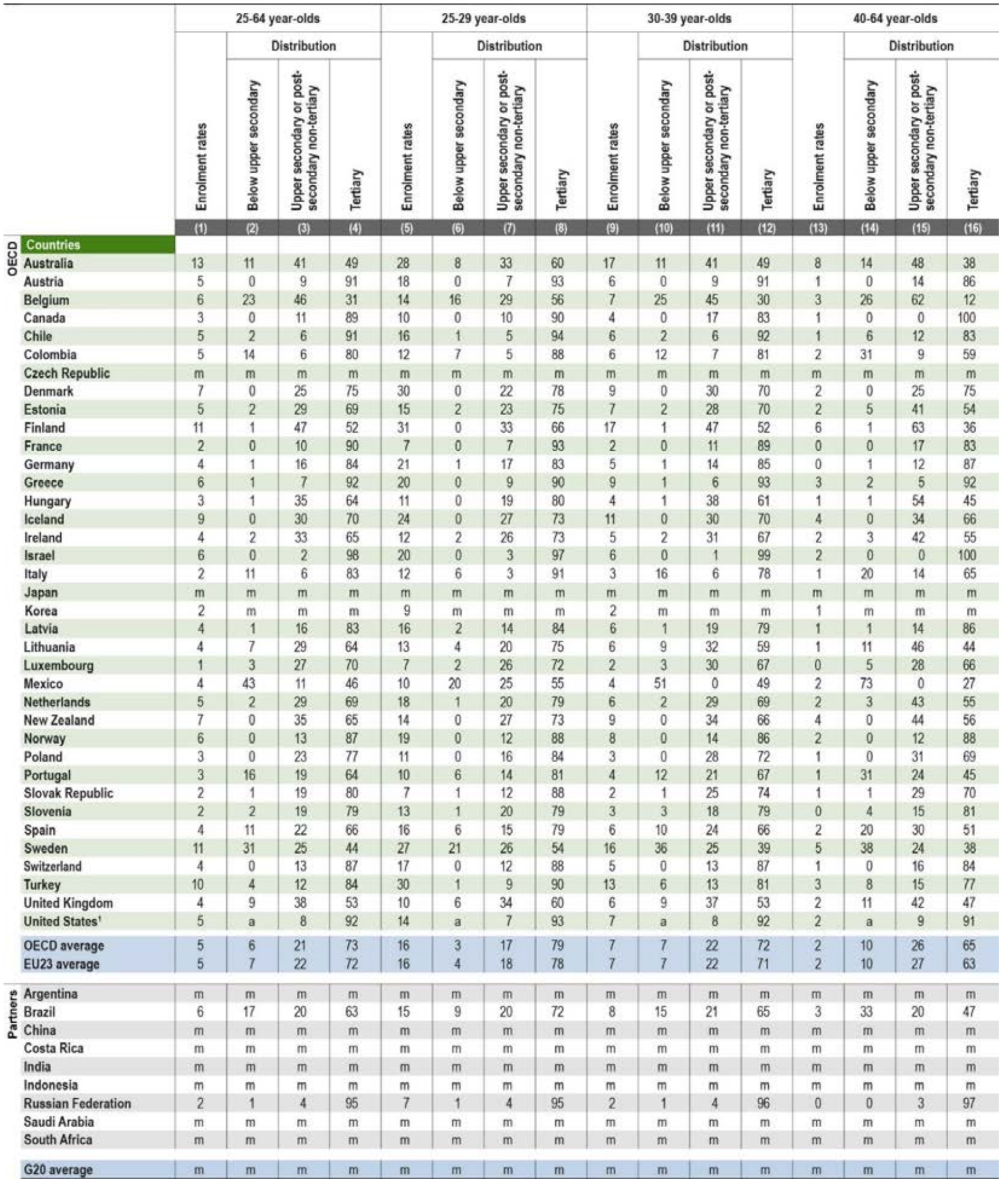

1. Les données concernant la scolarisation dans le deuxième cycle de l'enseignement secondaire et l'enseignement post-secondaire non tertiaire excluent le deuxième cycle de l'enseignement secondaire.

Source : OCDE/ISU/Eurostat (2019). Consulter la section « Source » pour tout complément d'information et l'annexe 3 pour les notes (https://doi.org/10.1787/f8d7880d-en). Les symboles représentant les données manquantes et les abréviations figurent dans le Guide du lecteur. 


\section{Chapitre B. Accès à l'éducation, participation et progression}

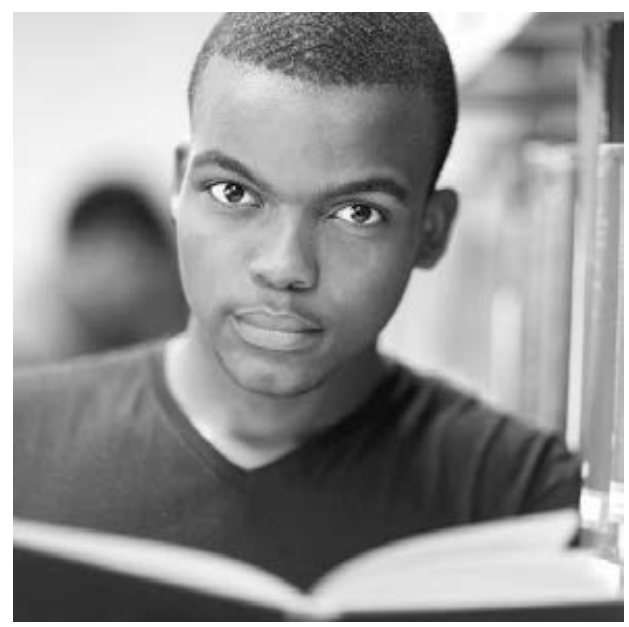

Indicateur B1 Quels sont les effectifs scolarisés ?

StatLink https://doi.org/10.1787/888933980925

Indicateur B2 En quoi les systèmes d'éducation de la petite enfance se différencientils dans le monde?

StatLink https://doi.org/10.1787/888933980944

Indicateur B3 Quel est le profil des diplômés du deuxième cycle de l'enseignement secondaire?

StatLink https://doi.org/10.1787/888933980963

Indicateur B4 Quel est le profil des nouveaux inscrits dans l'enseignement tertiaire ?

StatLink https://doi.org/10.1787/888933980982

Indicateur B5 Combien d'étudiants terminent-ils leurs études tertiaires ?

StatLink https://doi.org/10.1787/888933981001

Indicateur B6 Quel est le profil des étudiants en mobilité internationale?

StatLink https://doi.org/10.1787/888933981020

Indicateur B7 Quel sont le profil et les perspectives professionnelles des titulaires

d'un doctorat?

StatLink https://doi.org/10.1787/888933981039 


\section{Indicateur B1. Quels sont les effectifs scolarisés?}

\section{Faits marquants}

- En moyenne, près de $70 \%$ des $17-18$ ans sont scolarisés dans le deuxième cycle de l'enseignement secondaire (plus de $40 \%$ d'entre eux en filière générale et $30 \%$ environ d'entre eux en filière professionnelle) dans les pays de l'OCDE. Dans la plupart des pays, il est rare d'être scolarisé dans l'enseignement post-secondaire non tertiaire ou tertiaire dans ce groupe d'âge.

- Plus de $40 \%$ des $19-20$ ans sont scolarisés dans l'enseignement tertiaire dans près de la moitié des pays de l'OCDE. Le taux de scolarisation dans l'enseignement tertiaire est le plus élevé chez les 21 22 ans dans un tiers environ des pays ; le Danemark est le seul pays où c'est chez les 23-24 ans qu'il est le plus élevé.

- Les taux de scolarisation sont plus élevés en licence qu'à tout autre niveau de l'enseignement tertiaire. En licence, il atteint $32 \%$ en moyenne chez les $20-21$ ans dans les pays de l'OCDE.

\section{Graphique B1.1. Taux de scolarisation entre les âges de 19 et 28 ans (2017)}

Scolarisation à temps plein ou partiel, dans des établissements publics ou privés

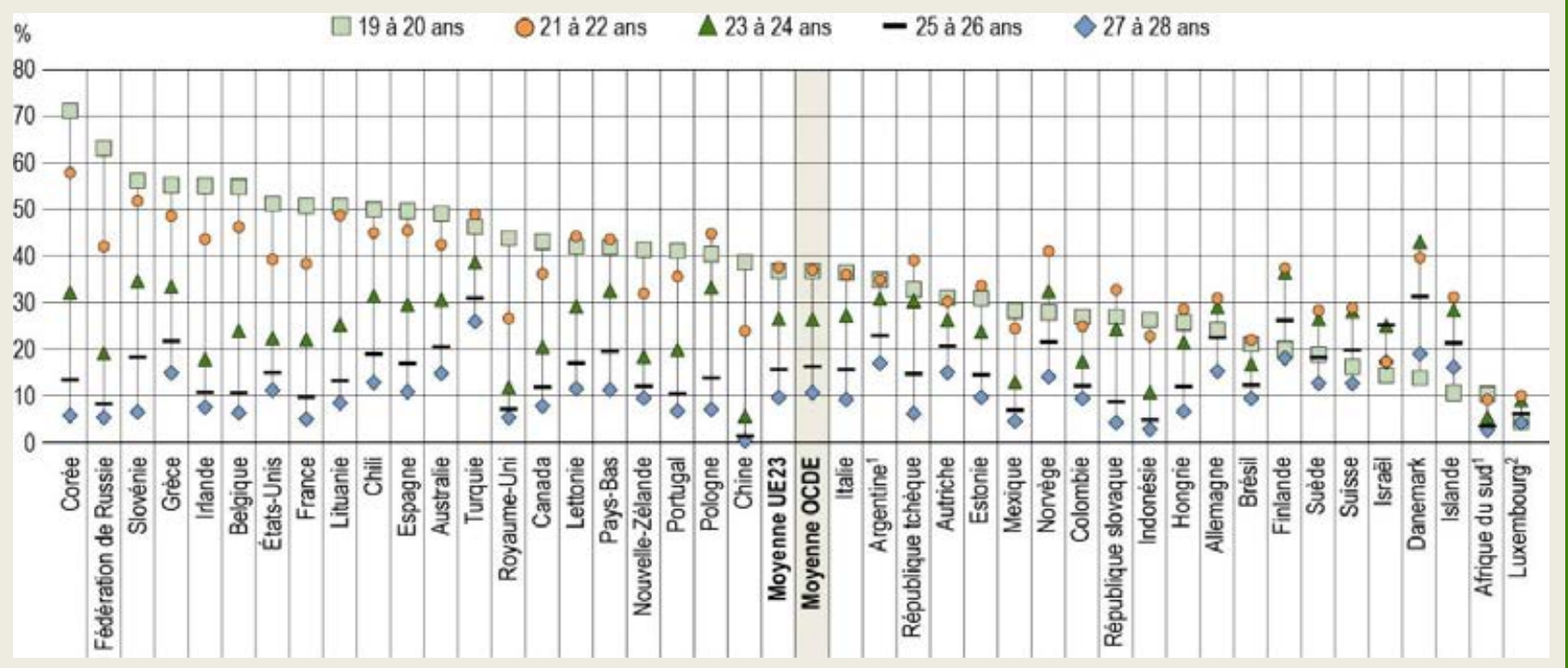

1. Année de référence : 2016.

2. Sous-estimé en raison du nombre important d'étudiants scolarisés dans les pays voisins.

Les pays sont classés par ordre décroissant du taux de scolarisation à 19-20 ans.

Source : OCDE/ISU/Eurostat (2019). Consulter la section «Source » pour tout complément d'information et l'annexe 3 pour les notes (https://doi.org/10.1787/f8d7880d-en). 


\section{Contexte}

Les parcours scolaires peuvent varier tant entre les pays qu'entre les individus au sein même des pays. Ils sont probablement les plus similaires dans l'enseignement primaire et le premier cycle de l'enseignement secondaire, des niveaux relevant de la scolarité obligatoire qui sont relativement homogènes dans l'ensemble. Toutefois, comme les préférences, les besoins et les aptitudes varient entre les individus, la plupart des systèmes d'éducation tentent de proposer des filières et des modes de scolarisation différents en particulier aux niveaux supérieurs d'enseignement, dans le deuxième cycle de l'enseignement secondaire et l'enseignement tertiaire.

Offrir à tous des possibilités adaptées d'atteindre un bon niveau de formation est un enjeu capital, qui dépend de la capacité des élèves de progresser de niveau en niveau dans le système d'éducation. Le développement et le renforcement des filières générale et professionnelle dans le deuxième cycle de l'enseignement secondaire sont un moyen de rendre l'éducation plus inclusive et plus attractive, puisque les individus n'ont ni les mêmes préférences ni les mêmes aptitudes. L'enseignement et la formation professionnels (EFP) séduisent les jeunes plus intéressés par des métiers concrets ou plus pressés d'entrer sur le marché du travail (OCDE, 2019 $\left.{ }_{[1]}\right)$. Dans de nombreux pays, l'EFP permet à des adultes de reprendre une formation et de développer des compétences pour accroître leur employabilité.

Dans une certaine mesure, la filière choisie dans le deuxième cycle de l'enseignement secondaire conditionne la suite du parcours scolaire. Les diplômés du deuxième cycle de l'enseignement secondaire ont accès à l'enseignement post-secondaire non tertiaire (si ce niveau existe) et à l'enseignement tertiaire. Les diplômés du deuxième cycle de l'enseignement secondaire ou de l'enseignement post-secondaire non tertiaire en filière professionnelle ont la possibilité d'entrer plus tôt dans la vie active, mais poursuivre des études offre souvent de meilleures perspectives financières et de meilleurs débouchés sur le marché du travail (voir les indicateurs A3 et A4). L'enseignement tertiaire est désormais un élément moteur majeur de la dynamique économique et sociétale. Les changements profonds intervenus sur le marché du travail au cours des dernières décennies donnent à penser les individus plus instruits continuent (et continueront) à tirer leur épingle du jeu sur un marché du travail de plus en plus fondé sur la connaissance. II s'ensuit qu'offrir à une grande partie de la population la possibilité de suivre une formation tertiaire de qualité et proposer des formations qui suivent l'évolution rapide des besoins sur le marché du travail compte parmi les grands défis à relever par les établissements d'enseignement tertiaire et, plus généralement, les systèmes d'éducation.

\section{Autres faits marquants}

- II existe divers types de formation en licence et en master. Dans les pays de l'OCDE, $72 \%$ des étudiants en licence ou en master suivent une formation de trois à quatre ans en licence.

- Dans l'enseignement tertiaire, les taux de scolarisation à temps partiel varient considérablement : en 2017, le pourcentage d'étudiants scolarisés à temps partiel s'établissait en moyenne à $16 \%$ en licence, à $21 \%$ en master et en doctorat et à $26 \%$ en formation tertiaire de cycle court dans les pays de l'OCDE.

- Dans les 23 pays membres de l'Union européenne qui sont également membres de l'OCDE, l'effectif des établissements publics (77 \%) est supérieur à la moyenne de l'OCDE $(71 \%)$ dans l'enseignement tertiaire. Parmi les pays de l'OCDE, moins de la moitié des étudiants n'étaient scolarisés dans un établissement public en 2017 qu'en Belgique, au Chili, en Corée, en Estonie, en Israël, au Japon, en Lettonie et au Royaume-Uni, contre au moins 95 \% en Arabie saoudite, au Canada, au Danemark, en Grèce, en Irlande et au Luxembourg. 


\section{Analyse}

\section{Scolarité obligatoire}

Dans les pays de l'OCDE, la scolarité obligatoire débute généralement avec l'enseignement primaire, à l'âge de 6 ans. Elle commence plus tôt dans un tiers environ des pays membres et partenaires de l'OCDE, mais plus tard, à l'âge de 7 ans, en Afrique du Sud, en Estonie, en Fédération de Russie, en Finlande, en Indonésie et en Lituanie. Elle se termine à la fin, totale ou partielle, du deuxième cycle de l'enseignement secondaire à 16 ans en moyenne dans les pays de l'OCDE, un âge qui varie entre 14 ans en Corée et en Slovénie et 18 ans en Allemagne, en Belgique, au Chili et au Portugal. Aux Pays-Bas, il existe une forme partielle de scolarité obligatoire (les élèves doivent être scolarisés au moins deux jours par semaine) entre l'âge de 16 et de 18 ans ou jusqu'à l'obtention d'un diplôme. Toutefois, les taux de scolarisation restent élevés au-delà de la scolarité obligatoire dans un certain nombre de pays. En moyenne, dans les pays de l'OCDE, la scolarisation est généralisée (les taux de scolarisation sont supérieurs à $90 \%$ dans un groupe d'âge) pendant 14 ans, entre l'âge de 4 et 17 ans. Elle est généralisée pendant 11 à 16 ans dans la plupart des pays et pendant 17 ans en Norvège. Elle ne l'est pas aussi longtemps au Costa Rica, en Indonésie et en Turquie et ne dure que quatre ans en Colombie.

Dans la quasi-totalité des pays de l'OCDE, le taux de scolarisation à l'âge de 4 et de 5 ans était supérieur à $90 \%$ en 2017. La scolarité débute relativement tôt dans les pays de l'OCDE : la scolarisation est généralisée à l'âge de 3 ans dans un tiers des pays environ. Elle est même généralisée à l'âge de 2 ans en Islande et en Norvège (voir l'indicateur B2). Dans d'autres pays, la scolarisation est généralisée à partir de l'âge de 5 ans, sauf en Finlande, en République slovaque et en Turquie, où elle l'est à l'âge de 6 ans, et en Colombie, où elle l'est à l'âge de 9 ans.

La scolarité obligatoire couvre l'enseignement primaire et le premier cycle de l'enseignement secondaire dans tous les pays de l'OCDE. Elle couvre aussi le deuxième cycle de l'enseignement secondaire dans la plupart d'entre eux, selon les groupes d'âge théoriques correspondant aux différents niveaux d'enseignement dans chaque pays. Dans les pays de l'OCDE, l'enseignement de base est généralisé : les taux de scolarisation atteignent ou dépassent $95 \%$ entre l'âge de 6 et 14 ans dans tous les pays membres et partenaires de l'OCDE, sauf en Colombie (88\%).

\section{Parcours dans le deuxième cycle de l'enseignement secondaire et l'enseignement post- secondaire non tertiaire}

Le deuxième cycle de l'enseignement secondaire est conçu pour préparer les élèves à entamer des études tertiaires ou leur permettre d'acquérir des compétences pertinentes sur le marché du travail, ces deux objectifs se combinant dans certains cas. À ce niveau, l'enseignement est plus varié, plus spécialisé et plus approfondi que dans le premier cycle de l'enseignement secondaire. Les élèves ont généralement entre 14 et 16 ans lorsqu'ils entament ce niveau d'enseignement, qui se termine d'ordinaire 12 ou 13 ans après le début de l'enseignement primaire. C'est donc à ce niveau d'enseignement que la plupart des 15-19 ans sont scolarisés. La longueur du deuxième cycle de l'enseignement secondaire varie : de deux ans en Australie, en Fédération de Russie, en Irlande et en Lituanie à cinq ans en Italie.

Les formations de la filière générale sont conçues pour développer les connaissances, compétences et facultés générales des individus, souvent dans le but de les préparer à poursuivre leurs études, tandis que les formations en filière professionnelle sont conçues pour inculquer des compétences directement valorisables sur le marché du travail. Dans le deuxième cycle de l'enseignement secondaire, la filière professionnelle prépare les élèves à entrer dans la vie active dès la fin de leurs études et séduisent un public diversifié, notamment des jeunes en quête de compétences techniques, des adultes désireux d'améliorer leur employabilité et des candidats à des études supérieures par la suite (OCDE, 2019[1] ). Les pays où la filière professionnelle et les formations sous contrat d'apprentissage sont bien établies ont mieux réussi à contenir le chômage des jeunes (OCDE, 2018[2]). Toutefois, certains pays considèrent que la filière professionnelle est moins attractive que la filière générale, et certaines études donnent à penser que suivre une formation professionnelle accroît le risque de chômage plus tard dans la vie (Hanushek, Woessmann et Zhang, 2011 $[3]$ ). 

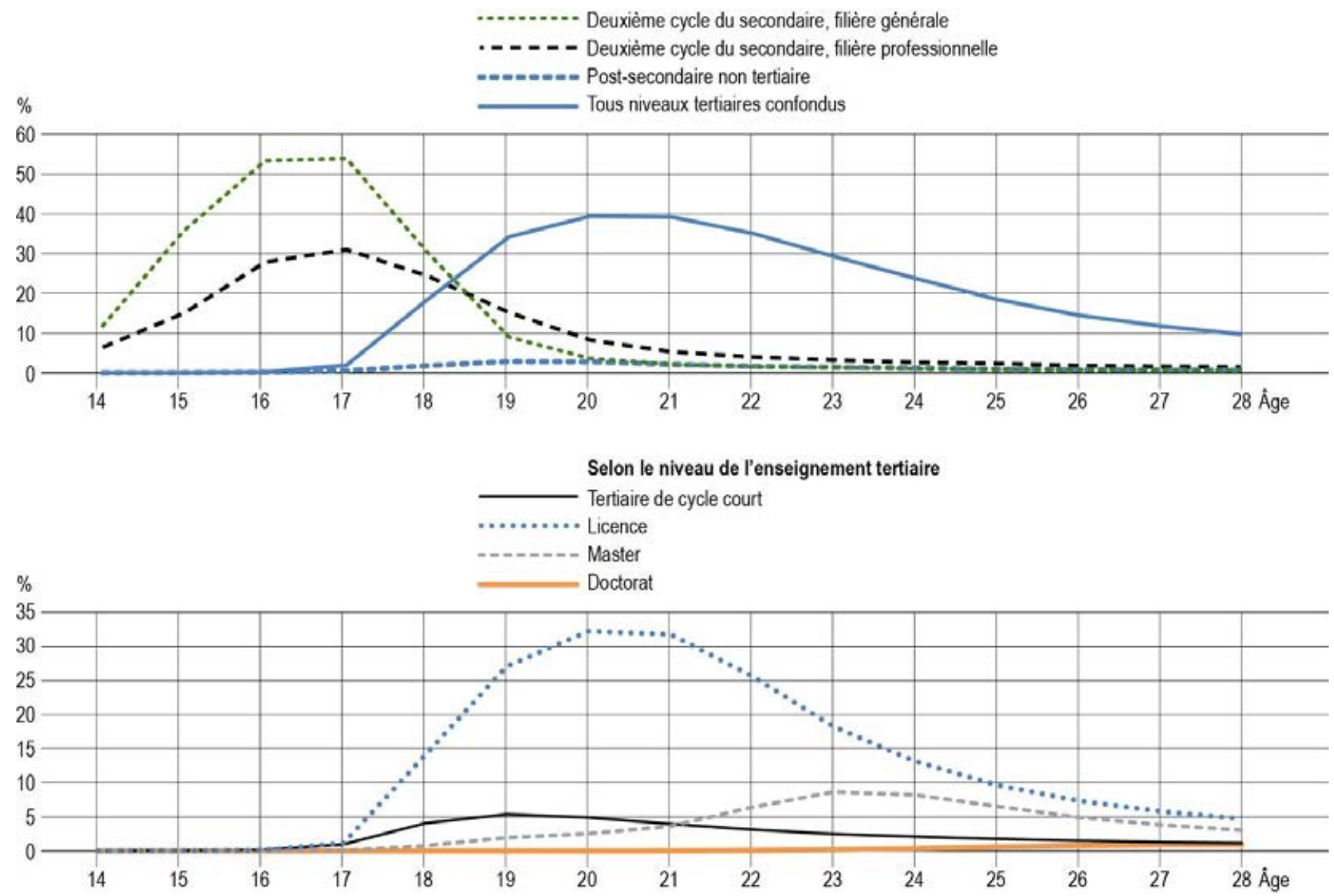

Source: OCDE/ISU/Eurostat (2019). Consulter la section "Source» pour tout complément d'information et l'annexe 3 pour les notes (https://doi.org/10.1787/f8d7880d-en).

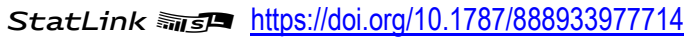

En moyenne dans les pays de l'OCDE, $42 \%$ des élèves sont scolarisés en filière professionnelle dans le deuxième cycle de l'enseignement secondaire. La répartition de l'effectif du deuxième cycle de l'enseignement secondaire entre la filière générale et la filière professionnelle dépend largement de l'offre de formations ainsi que de la variation des débouchés sur le marché du travail selon les filières. Dans un tiers environ des pays dont les données sont disponibles, les élèves scolarisés dans le deuxième cycle de l'enseignement secondaire sont plus nombreux en filière professionnelle qu'en filière générale : leur pourcentage en filière professionnelle atteint au moins $70 \%$ en Finlande, en République tchèque et en Slovénie.

C'est entre l'âge de 15 et 19 ans que le taux de scolarisation dans le deuxième cycle de l'enseignement secondaire en filière professionnelle est le plus élevé, plus précisément à l'âge de 17 ans (31\% en moyenne dans les pays de l'OCDE), mais la concentration est moindre qu'en filière générale. Le taux de scolarisation en filière générale est dans l'ensemble plus élevé et concerne un groupe d'âge plus réduit, entre 15 et 18 ans (voir le graphique B1.2).

La scolarisation dans l'enseignement post-secondaire non tertiaire concerne une tranche d'âge nettement plus large. L'enseignement post-secondaire non tertiaire est conçu pour inculquer des connaissances et des compétences d'une complexité moindre que celles caractéristiques de l'enseignement tertiaire et s'appuie sur les acquis de l'enseignement secondaire. Les formations de ce niveau préparent les jeunes à entrer dans la vie active ou à entamer des études tertiaires (UNESCO-IUS, 2012[4]). L'effectif de l'enseignement post-secondaire 
non tertiaire se situe en majorité dans le groupe d'âge des 18-22 ans, mais est généralement de faible importance (voir le graphique B1.2).

\section{Passage à l'enseignement tertiaire}

C'est dans l'enseignement tertiaire, en formation de cycle court, en licence, en master et en doctorat, que le taux de scolarisation est le plus élevé chez les 20-29 ans. Ce niveau d'enseignement propose des activités d'apprentissage dans des domaines spécialisés et s'appuie sur les acquis de l'enseignement secondaire. II vise à inculquer des connaissances très spécialisées d'une grande complexité. II propose des formations « académiques » ainsi que des formations techniques et professionnelles de haut niveau.

La filière choisie dans le deuxième cycle de l'enseignement secondaire tend à influer sur les taux de scolarisation dans l'enseignement tertiaire (voir l'indicateur B5). Les pays où le taux de scolarisation des 15-19 ans est plus élevé en filière générale qu'en filière professionnelle dans le deuxième cycle de l'enseignement secondaire affichent en général des taux de scolarisation plus élevés dans l'enseignement tertiaire. C'est par exemple le cas en Corée, aux États-Unis, en France, en Grèce et en Irlande, où le taux de scolarisation dans l'enseignement tertiaire est supérieur à $50 \%$ chez les 19-20 ans, et où le taux de scolarisation des 15-19 ans en filière générale dans le deuxième cycle de l'enseignement secondaire était égal ou supérieur à $40 \%$ (égal à $100 \%$ aux ÉtatsUnis) en 2017. Certains pays font toutefois figure d'exception : en Belgique, aux Pays-Bas et en Slovénie, plus de la moitié des 15-19 ans étaient scolarisés en filière professionnelle, mais le taux de scolarisation des 1922 ans dans l'enseignement tertiaire était supérieur à la moyenne de l'OCDE cette année-là.

Les pays se répartissent en trois groupes selon l'âge auquel les jeunes entament une formation tertiaire.

- Entrée dans l'enseignement tertiaire principalement entre l'âge de 19 et $\mathbf{2 0}$ ans : les pays membres et partenaires de l'OCDE où le taux de scolarisation est le plus élevé dans l'enseignement tertiaire comptent aussi parmi ceux où les étudiants entament plus tôt leurs études tertiaires. Dans la moitié environ des pays membres et partenaires de l'OCDE, le taux de scolarisation des 19-20 ans dans l'enseignement tertiaire est égal ou supérieur à $40 \%$; en Corée, aux États-Unis, en Fédération de Russie, en France, en Irlande et au Royaume-Uni, les taux de scolarisation dans ce groupe d'âge sont supérieurs de 10 points de pourcentage au moins à ceux qui s'observent chez les 21-22 ans. En Corée, le taux de scolarisation des $19-20$ ans dans l'enseignement tertiaire $(71 \%)$ est nettement supérieur à celui des autres pays (voir le graphique B1.1).

- Entrée dans l'enseignement tertiaire principalement entre l'âge de 19 et 22 ans : $37 \%$ des 1920 ans et des 21-22 ans étaient en moyenne scolarisés dans l'enseignement tertiaire en 2017 dans les pays de l'OCDE. Dans ces deux groupes d'âge, les taux de scolarisation sont très comparables et sont proches de la moyenne de l'OCDE dans un certain nombre de pays, dont l'Argentine, l'Autriche, l'Estonie, I'Italie et les Pays-Bas.

- Entrée dans l'enseignement tertiaire principalement entre l'âge de $\mathbf{2 1}$ et de 22 ans : les jeunes entrent un plus tard dans l'enseignement tertiaire et les taux de scolarisation sont les plus élevés chez les 21-22 ans en Hongrie, en Islande, en République slovaque et en République tchèque ainsi qu'en Norvège, en Pologne et en Turquie, où les taux de scolarisation passent la barre des $40 \%$. De plus, les taux de scolarisation dans l'enseignement tertiaire sont comparables entre les 21-22 ans et les 23-24 ans en Allemagne, en Finlande, en Suède et en Suisse. Le Danemark est le seul pays où le taux de scolarisation dans l'enseignement tertiaire est le plus élevé entre l'âge de 23 et 24 ans. Divers facteurs expliquent l'entrée plus tardive dans l'enseignement tertiaire (voir l'indicateur B4).

\section{Parcours dans l'enseignement tertiaire}

L'effectif scolarisé à chaque niveau de l'enseignement tertiaire et à chaque âge illustre la diversité des systèmes d'éducation et des parcours scolaires dans les pays. Au début, les étudiants entament une licence, puis peuvent s'orienter vers des niveaux supérieurs de l'enseignement tertiaire, le master, à partir de l'âge de 20 ans (ou plus 
jeune dans le cas d'un premier diplôme de type long ; voir l'encadré B1.1), et le doctorat, à partir de l'âge de 25 ans. Selon la structure des systèmes d'éducation, ils peuvent aussi opter pour une formation tertiaire de cycle court dès l'âge de 17 ans dans de nombreux pays de l'OCDE.

Les formations tertiaires de cycle court sont souvent destinées à inculquer aux étudiants des connaissances, aptitudes et compétences professionnelles; elles sont concrets et préparent les étudiants à entrer dans la vie active, mais peuvent aussi leur donner accès à un autre niveau de l'enseignement tertiaire. Dans les pays de l'OCDE, le taux de scolarisation en formation tertiaire de cycle court est le plus élevé dans le groupe d'âge des 18-21 ans et atteint entre $4 \%$ et $5 \%$. Ces formations ne sont pas proposées dans certains pays, par exemple en Estonie, en Finlande, en Grèce et en Lituanie. Toutefois, les taux de scolarisation en formation tertiaire de cycle court sont comparables à ceux enregistrés en licence dans des pays tels que le Canada, le Chili, la Corée, l'Espagne, les États-Unis, la Fédération de Russie, la France et la Turquie. Dans ces pays, le taux de scolarisation à ce niveau d'enseignement passe la barre des $10 \%$ chez les 19-20 ans. La durée typique de la scolarisation (de $50 \%$ au moins des étudiants) est comprise entre deux ans (en France) et sept ans (en Turquie).

\section{Encadré B1.1. Éventail de licences et de masters}

Il existe diverses formations en licence et en master. Les premières licences de cycle court (d'une durée théorique cumulée de trois à quatre ans) sont les plus prisées dans les pays membres et partenaires de l'OCDE : elles représentent en moyenne $72 \%$ de l'effectif de licence et de master dans les pays de l'OCDE et même $90 \%$ au moins de cet effectif au Brésil, en Corée et au Mexique (voir le graphique B1.a). Dans les pays de l'OCDE, $13 \%$ seulement des étudiants inscrits en licence ou en master optent pour un premier master court après leur licence. C'est particulièrement peu fréquent au Brésil, en Colombie, au Japon, au Mexique et en Nouvelle-Zélande, où ce type de cursus concerne moins de $10 \%$ de l'effectif de licence et de master (voir le graphique B1.a).

Les premiers cursus peuvent durer plus de quatre ans et être sanctionnés par un diplôme de licence ou, plus souvent, de master, selon le domaine d'études et la structure du système d'enseignement tertiaire dans chaque pays. Les formations sont plus longues en raison de la complexité du contenu des cours. Les premiers cursus, en particulier en master, concernent des disciplines professionnelles très spécialisées demandant davantage d'années d'études (comme la dentisterie, la médecine, l'architecture, le droit ou l'ingénierie). En Colombie, les premiers cursus sont tous de longue durée et concerne $91 \%$ de l'effectif de licence et de master selon les chiffres de 2017. Ces formations sont populaires non seulement en Colombie, mais aussi en France, en Italie, au Portugal et en Suède où leur effectif représentait plus de 19 \% la même année.

Après une première licence ou un premier master, les étudiants peuvent entamer un deuxième cursus qui représente en général une à deux années d'études à temps plein de plus en licence et entre une et quatre années d'études de plus en master (UNESCO-IUS, 2012[4]). Les seconds cursus sont plus rares dans les pays de l'OCDE, mais ils concernent $10 \%$ au moins de l'effectif de licence et de master en Nouvelle-Zélande, de l'effectif de licence en Pologne et de l'effectif de master au Luxembourg. En Nouvelle-Zélande, par exemple, il s'agit généralement de programmes professionnalisants d'un an dans un domaine d'études spécifique qui sont suivis par les diplômés de licence.

Les cursus dont la réussite est insuffisante pour être sanctionnés par un diplôme du niveau d'enseignement dont ils relèvent (avant l'obtention d'un premier diplôme) peuvent être classés à un niveau d'enseignement inférieur ou, simplement, dans la catégorie des cursus insuffisants pour être sanctionnés par un diplôme du niveau d'enseignement dont ils relèvent. À titre d'exemple, les classes préparatoires aux grandes écoles en France ne sont pas sanctionnées par un diplôme en tant que tel, mais préparent les étudiants à entamer une formation tertiaire (dans le domaine du commerce ou de l'ingénierie, par exemple). 


\section{Graphique B1.a. Répartition (en pourcentage) des étudiants de licence et de master, selon le programme éducatif (2017)}

Scolarisation à temps plein ou partiel, dans des établissements publics ou privés

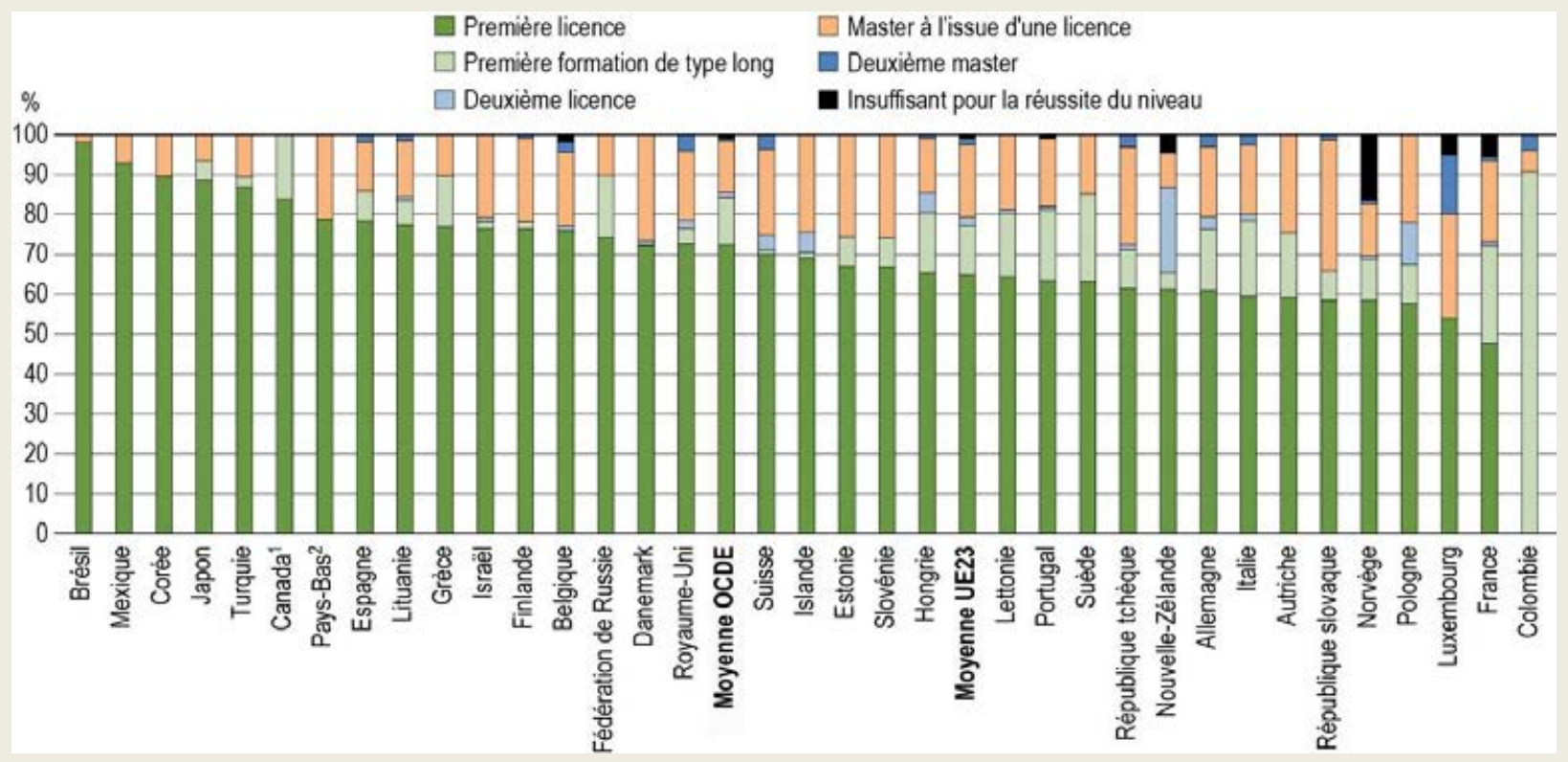

Remarque : Les programmes longs et les programmes insuffisant pour la réussite du niveau comportent des programmes qui peuvent être classés à la fois au niveau licence et au niveau master.

1. À l'exclusion des établissements privés dans le tertiaire de cycle court.

2. La catégorie master à l'issue d'une licence comprend les deuxièmes licences ou plus.

Les pays sont classés par ordre décroissant du pourcentage d'étudiants scolarisés dans un premier programme de licence ou de niveau équivalent. Source: OCDE/ISU/Eurostat (2019). Consulter la section «Source» pour tout complément d'information et l'annexe 3 pour les notes (https://doi.org/10.1787/f8d7880d-en).

StatLink त्ताज् https://doi.org/10.1787/888933977752

Le taux de scolarisation en licence est plus élevé qu'à tout autre niveau de l'enseignement tertiaire. Les cursus de ce niveau sont destinés à inculquer aux étudiants des connaissances, aptitudes et compétences académiques ou professionnelles intermédiaires et sont sanctionnés par un premier diplôme. Dans la plupart des pays de I'OCDE, les licences durent en moyenne 4 ou 5 ans et les étudiants les entament généralement à 18 ou 19 ans, mais plus tard (à 21 ou 22 ans) dans un certain nombre de pays, comme le Danemark, l'Islande et Israël. La durée typique des licences, trois ans en général, ne correspond exactement au groupe d'âge typique de scolarisation qu'en Belgique, en France, en Irlande, en Lituanie, en République slovaque, au Royaume-Uni et en Slovénie. Dans les pays de l'OCDE, le taux moyen de scolarisation en licence est le plus élevé entre l'âge de 19 et de 22 ans et atteint $32 \%$ chez les 20-21 ans. Les taux de scolarisation à ce niveau reflètent ceux de l'enseignement tertiaire en général (voir le graphique B1.2).

Les masters sont conçus pour inculquer aux étudiants des connaissances et compétences académiques ou professionnelles de haut niveau ; ils se caractérisent parfois par une composante importante de recherche. Le master est moins prisé que la licence dans les pays de l'OCDE où le taux moyen de scolarisation à ce niveau d'enseignement est inférieur à $10 \%$ : il est compris entre $5 \%$ et $9 \%$ entre l'âge de 22 et de 26 ans et est le plus élevé à l'âge de 23 ans. En 2017, 10 \% au moins de l'effectif des 21-22 ans étaient scolarisés en master en Belgique, en Fédération de Russie, en France, en Italie, en Pologne, au Portugal et en Suède. Le taux de scolarisation est en moyenne plus élevé chez les 23-24 ans que chez les 21-22 ans dans les pays de l'OCDE ; 
il s'établit à $15 \%$ en France et en Italie et est plus élevé en Pologne (20\%), en République slovaque (17\%), en République tchèque (17\%) et en Slovénie (20\%).

\section{Profil des étudiants dans l'enseignement tertiaire}

Les établissements publics tendent à dominer à tous les niveaux de l'enseignement tertiaire. Dans les pays de l'OCDE, l'effectif des établissements publics tend à diminuer aux niveaux supérieurs d'enseignement, de l'enseignement primaire jusqu'à l'enseignement tertiaire (OCDE, 2018[2]), mais l'inverse est vrai dans l'enseignement tertiaire où leur effectif augmente à chaque niveau d'enseignement.

Graphique B1.3. Répartition (en pourcentage) des effectifs scolarisés dans l'enseignement tertiaire, selon le type d'établissement (2017)

Scolarisation à temps plein ou partiel

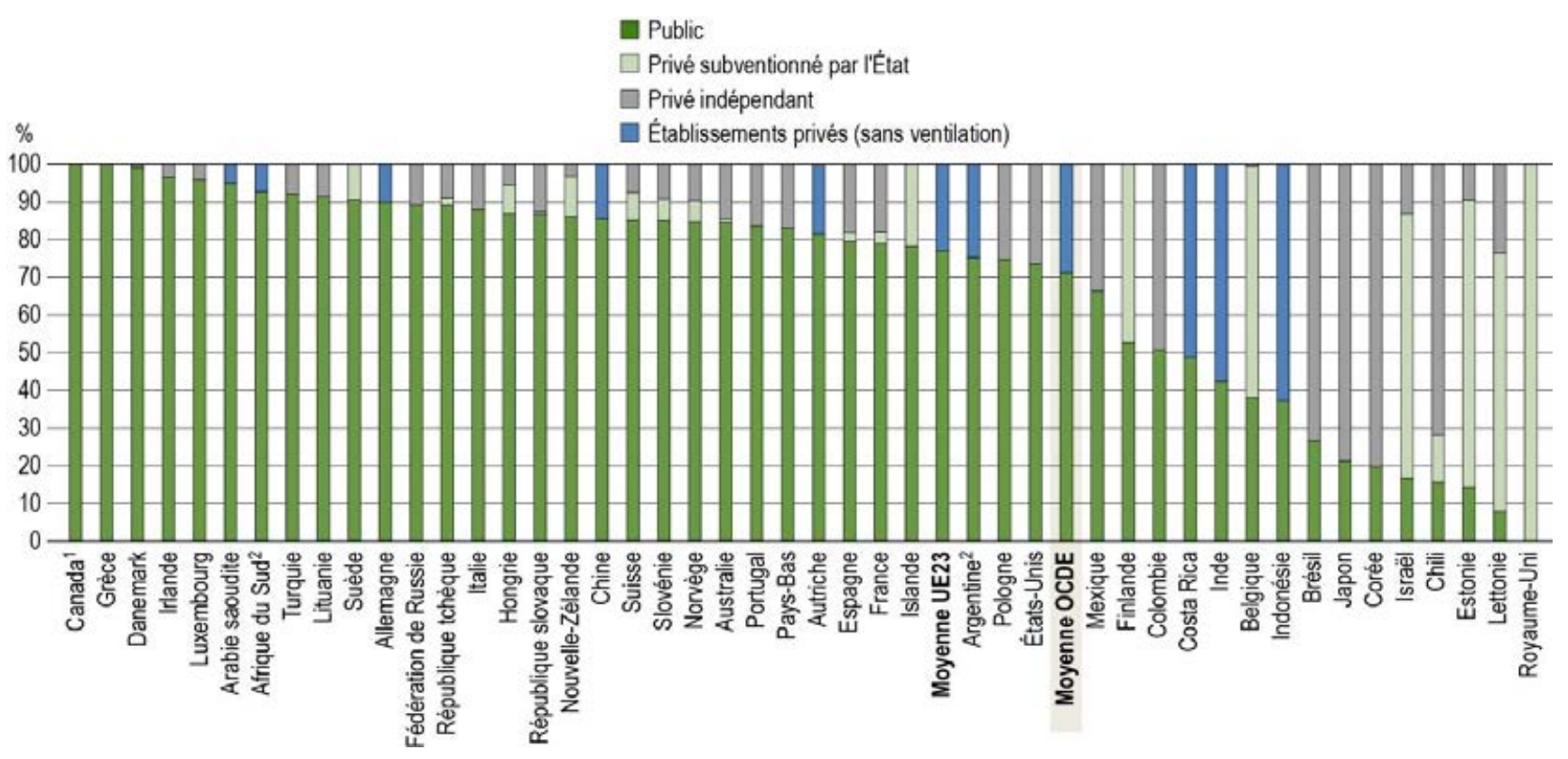

1. À l'exclusion des établissements privés dans le tertiaire de cycle court.

2. Année de référence : 2016.

Les pays sont classés par ordre décroissant du pourcentage d'étudiants scolarisés dans des établissements d'enseignement tertiaire publics.

Source: OCDE/ISU/Eurostat (2019). Consulter la section "Source» pour tout complément d'information et l'annexe 3 pour les notes (https://doi.org/10.1787/f8d7880d-en).

En moyenne, dans les pays de l'OCDE, $71 \%$ de l'effectif d'étudiants de l'enseignement tertiaire étaient scolarisés dans un établissement public en 2017, contre $77 \%$ en moyenne dans l'UE23. L'effectif d'étudiants ne passe la barre des $50 \%$ dans les établissements privés subventionnés par l'État qu'en Belgique, en Estonie, en Israël, en Lettonie et au Royaume-Uni et dans les établissements privés indépendants qu'au Brésil, au Chili, en Corée et au Japon parmi tous les pays membres et partenaires de l'OCDE. Par contraste, $95 \%$ au moins des étudiants étaient scolarisés dans un établissement public en 2017 en Arabie saoudite, au Canada, au Danemark, en Grèce, en Irlande et au Luxembourg (voir le graphique B1.3).

L'effectif des établissements publics varie selon le niveau d'enseignement. En moyenne, dans les pays de I'OCDE, $60 \%$ des étudiants en formation tertiaire de cycle court fréquentent un établissement public, contre $69 \%$ des étudiants en licence. Dans certains pays, l'effectif des établissements publics est nettement plus élevé 
en formation tertiaire de cycle court qu'en licence. C'est le cas au Brésil, en Colombie, au Costa Rica, en Israël, en Lettonie et au Mexique, où la différence entre les deux niveaux d'enseignement est égale ou supérieure à 30 points de pourcentage.

L'effectif des établissements publics est plus élevé de 1 point de pourcentage en master qu'en licence en moyenne, dans les pays de l'OCDE. Toutefois, cette différence est égale ou supérieure à 25 points de pourcentage au Brésil, en Finlande et au Japon. Par contraste, l'effectif des établissements publics est moins élevé en master qu'en licence dans certains pays : il est moins élevé de 15 points de pourcentage au moins en master qu'en licence en Arabie saoudite, en Estonie, aux États-Unis, au Mexique et aux Pays-Bas. En doctorat, l'effectif des établissements publics est supérieur de 8 points de points de pourcentage à celui enregistré en master ; il a atteint en moyenne $78 \%$ dans les pays de l'OCDE et était égal à $100 \%$ dans 15 pays membres et partenaires de l'OCDE en 2017. Les doctorants ne fréquentent en majorité un établissement privé qu'au Costa Rica, en Estonie, en Israël et en Lettonie (en Estonie, en Israël et en Lettonie, plus de neuf doctorants sur dix fréquentent un établissement privé subventionné par l'État).

L'effectif scolarisé à temps partiel augmente avec le niveau d'enseignement et l'âge moyen des étudiants (OCDE, 2018[2]). Toutefois, il varie entre les niveaux de l'enseignement tertiaire : en moyenne, le pourcentage d'étudiants scolarisés à temps partiel s'élevait en 2017 à $16 \%$ en licence, à $21 \%$ en master et en doctorat et à $26 \%$ en formation tertiaire de cycle court (voir le tableau B1.3). Toutefois, des écarts importants s'observent entre les pays. L'effectif d'étudiants scolarisés à temps partiel est inférieur ou égal à $2 \%$ en licence au Luxembourg et en République tchèque ainsi que dans des pays où la scolarisation à temps partiel n'est pas autorisée en licence (en Autriche, au Chili, en Colombie, au Costa Rica, en France, en Grèce, en Italie, au Mexique et en Turquie), mais égal à $49 \%$ en Fédération de Russie et à $53 \%$ en Suède. Le pourcentage d'étudiants scolarisés à temps partiel est le plus élevé en master en Nouvelle-Zélande (63\%) et en doctorat en Allemagne, en Finlande, en Norvège et en Slovénie, où $75 \%$ au moins des doctorants sont concernés.

\section{Variation infranationale des taux de scolarisation}

La variation infranationale des taux de scolarisation est révélatrice de l'égalité d'accès à l'enseignement, des débouchés sur le marché du travail et de l'intérêt pour l'apprentissage tout au long de la vie au-delà de la scolarité obligatoire dans chaque pays. Les différences infranationales sont relativement faibles entre l'âge de 6 et 14 ans (une tranche d'âge qui correspond à la scolarité obligatoire dans de nombreux pays) et de 15 et 19 ans (une tranche d'âge qui correspond au passage vers l'enseignement tertiaire ou à l'entrée dans la vie active) : les coefficients de variation entre les régions sont inférieurs à $20 \%$ dans tous les pays dont les données infranationales sont disponibles.

En moyenne, dans les pays dont les données infranationales et les données de tous les groupes d'âge à partir de l'âge de 6 ans sont disponibles, les taux de scolarisation varient le plus entre les régions chez les plus âgés. Les taux de scolarisation des 20-29 ans varient relativement peu entre les régions en Allemagne, en Estonie et en Suède, mais le coefficient de variation est plus élevé et passe la barre des $80 \%$ en Lettonie, en Lituanie, en République slovaque et en en République tchèque. La Lettonie accuse aussi le ratio le plus élevé entre les entités infranationales où le taux de scolarisation est respectivement le plus et le moins élevé dans ce groupe d'âge.

Les différences infranationales de taux de scolarisation sont plus marquées chez les 30-39 ans. La variation infranationale est particulièrement forte en Grèce, en Lettonie et en République slovaque où le coefficient de variation passe la barre des $70 \%$. Le taux de scolarisation des adultes plus âgés (de 40 à 64 ans) est relativement peu élevé : il atteint $2 \%$ en moyenne dans les pays de l'OCDE. Des différences régionales dans ce groupe d'âge s'observent tout de même dans les pays dont les données sont disponibles, en particulier en Grèce et en Lettonie, où les différences de taux de scolarisation entre les régions sont les plus élevées dans ce groupe d'âge par rapport à celui des 30-39 ans (OECD, 2019 $[5])$. 


\section{Définitions}

Les données de cet indicateur se rapportent aux formations institutionnelles d'une durée minimale de l'équivalent d'un semestre (ou d'une moitié d'année scolaire ou académique) qui sont dispensées exclusivement dans des établissements d'enseignement ou qui comportent en plus un stage en entreprise (les programmes " emploi-études »).

Par scolarisation généralisée, on entend un taux de scolarisation supérieur à $90 \%$ dans cet indicateur.

Les formations de la filière générale sont conçues pour développer les connaissances, compétences et facultés générales des individus, souvent dans le but de les préparer à suivre des études en filière générale ou professionnelle au même niveau d'enseignement ou à un niveau supérieur. Elles n'ont pas vocation à préparer les jeunes à exercer des professions spécifiques ou à travailler dans des secteurs spécifiques.

Les formations de la filière professionnelle (éducation et formation professionnelles, EFP) préparent les individus à exercer une profession spécifique dès l'obtention de leur diplôme, sans qu'ils aient à suivre une formation complémentaire. Elles sont conçues pour donner aux jeunes une qualification professionnelle ou technique valorisable sur le marché du travail.

Les établissements privés sont ceux dont la direction et la gestion relèvent d'acteurs non étatiques (tels qu'une église, un syndicat ou une entreprise) ou dont le conseil de direction est essentiellement constitué de membres qui n'ont pas été désignés par une instance publique. Les établissements privés subventionnés par l'État sont ceux dont le budget est financé à plus de $50 \%$ par les pouvoirs publics ou dont le personnel enseignant est rémunéré par une instance publique. Les établissements privés indépendants sont ceux dont moins de $50 \%$ du budget principal est financé par les pouvoirs publics et dont le personnel enseignant n'est pas rémunéré par une instance publique.

Par effectif scolarisé à temps plein, on entend les individus scolarisés dont la charge d'étude prévue est au moins égale à $75 \%$ de la charge d'étude annuelle à temps plein. Par effectif scolarisé à temps partiel, on entend les individus scolarisés dont la charge d'étude est inférieure à $75 \%$ de la charge d'étude annuelle à temps plein.

\section{Méthodologie}

Sauf mention contraire, les chiffres sont basés sur les nombres d'individus, à cause de la difficulté qu'éprouvent certains pays à chiffrer la scolarisation à temps partiel. Les taux nets de scolarisation sont calculés comme suit : les effectifs de tous les niveaux d'enseignement dans le groupe d'âge considéré sont divisés par la population totale de ce groupe d'âge. Les chiffres sur la démographie et la scolarisation se rapportent à la même période dans la plupart des cas, mais des décalages dus au manque de données expliquent pourquoi les taux de scolarisation sont supérieurs à $100 \%$ dans certains pays.

Pour de plus amples informations, veuillez consulter le Guide de l'OCDE pour l'établissement de statistiques internationalement comparables dans le domaine de l'éducation 2018 : Concepts, normes, définitions et classifications (OCDE, 2019[6]) et les notes spécifiques aux pays à l'annexe 3 (https://doi.org/10.1787/f8d7880d-en).

\section{Source}

Les données se rapportent à l'année académique 2016/17 et proviennent de l'exercice UNESCOISU/OCDE/Eurostat de collecte de données statistiques sur l'éducation réalisé par l'OCDE en 2018 (pour plus de précisions, voir l'annexe 3, https://doi.org/10.1787/f8d7880d-en). Les données de l'Afrique du Sud, de l'Arabie saoudite, de l'Argentine, de l'Inde, de l'Indonésie et de la République populaire de Chine proviennent de l'Institut de statistique de l'UNESCO (ISU).

Les données infranationales de certains indicateurs sont disponibles dans la Base de données régionales de I'OCDE (OECD, 2019 $[5])$. 


\section{Note concernant les données d'Israël}

Les données statistiques concernant Israël sont fournies par et sous la responsabilité des autorités israéliennes compétentes. L'utilisation de ces données par l'OCDE est sans préjudice du statut des hauteurs du Golan, de Jérusalem-Est et des colonies de peuplement israéliennes en Cisjordanie aux termes du droit international.

\section{Références}

Hanushek, E., L. Woessmann et L. Zhang (2011), « General education, vocational education, and labor-market outcomes over the life-cycle », IZA Discussion Paper No. 6083, http://ftp.iza.org/dp6083.pdf (consulté le 27 avril 2018).

OCDE (2019), Guide de l'OCDE pour l'établissement de statistiques internationalement comparables dans le domaine de l'éducation 2018 : Concepts, normes, définitions et classifications, Éditions OCDE, Paris, https://dx.doi.org/10.1787/9789264305380-fr.

OCDE (2019), "What characterises upper secondary vocational education and training? », Education Indicators in Focus, $n^{\circ}$ 68, OCDE, Paris, https://dx.doi.org/10.1787/a1a7e2f1-en.

OCDE (2018), Regards sur l'éducation 2018 : Les indicateurs de l'OCDE, Éditions OCDE, Paris, https://dx.doi.org/10.1787/eag-2018-fr.

OECD (2019), Base de données de statistiques régionales - Taux de scolarisation par âge, http://stats.oecd.org/Index.aspx?DataSetCode=REGION EDUCAT.

UNESCO-IUS (2012), Classification Internationale Type de l'Éducation CITE 2011, UNESCO / Institut de statistiques de l'UNESCO, http://uis.unesco.org/sites/default/files/documents/internationalstandard-classification-of-education-isced-2011-fr.pdf (consulté le 23 mai 2019).

\section{Tableaux de l'indicateur B1}

Tableau B1.1

Tableau B1.2

Tableau B1.3
Taux de scolarisation, par groupe d'âge (2005, 2010 et 2017)

Taux de scolarisation dans l'enseignement tertiaire, selon le groupe d'âge et le niveau d'enseignement (2017)

Profil des effectifs scolarisés dans l'enseignement tertiaire (2017)

Date butoir pour les données : 19 juillet 2019. Les mises à jour peuvent être consultées en ligne à l'adresse : http://dx.doi.org/10.1787/eag-data-en D'autres données désagrégées sont également disponibles dans la Base de données de Regards sur l'éducation (http://stats.oecd.org/).

StatLink : https://doi.org/10.1787/888933980925 
Tableau B1.1. Taux de scolarisation, par groupe d'âge (2005, 2010 et 2017)

Scolarisation à temps plein ou partiel, dans des établissements publics ou privés

\begin{tabular}{|c|c|c|c|c|c|c|c|c|c|c|c|c|c|c|}
\hline & \multirow{2}{*}{$\begin{array}{c}\text { Nombre d'années } \\
\text { pendant } \\
\text { lesquelles } \\
\text { au moins } 90 \% \\
\text { de la population } \\
\text { d'âge scolaire } \\
\text { est scolarisée }\end{array}$} & \multirow[b]{2}{*}{$\begin{array}{l}\text { Groupe d'âge } \\
\text { dans lequel } \\
\text { au moins } 90 \% \\
\text { de la population } \\
\text { d'ãge scolaire } \\
\text { est scolarisée }\end{array}$} & \multicolumn{12}{|c|}{ Effectifs scolarisés en pourcentage de la population d'un groupe d'äge donné } \\
\hline & & & $\begin{array}{c}6 \mathrm{a} \\
14 \text { ans }\end{array}$ & $\begin{array}{c}15 \mathrm{a} \\
19 \text { ans }\end{array}$ & $\begin{array}{c}20 \mathrm{a} \\
24 \text { ans }\end{array}$ & $\begin{array}{c}25 \mathrm{a} \\
29 \text { ans }\end{array}$ & $\begin{array}{c}30 \text { a } \\
39 \text { ans }\end{array}$ & $\begin{array}{c}40 \mathrm{a} \\
64 \text { ans }\end{array}$ & $\begin{array}{c}15 \text { à } \\
19 \text { ans }\end{array}$ & $\begin{array}{c}20 \mathrm{a} \\
24 \text { ans }\end{array}$ & $\begin{array}{c}25 \mathrm{a} \\
29 \text { ans }\end{array}$ & $\begin{array}{c}15 \mathrm{a} \\
19 \text { ans }\end{array}$ & $\begin{array}{c}20 \mathrm{a} \\
24 \text { ans }\end{array}$ & $\begin{array}{c}25 \mathrm{a} \\
29 \text { ans }\end{array}$ \\
\hline & \multicolumn{8}{|c|}{2017} & \multicolumn{3}{|c|}{2010} & \multicolumn{3}{|c|}{2005} \\
\hline & (1) & (2) & (3) & (4) & (5) & (6) & (7) & (8) & (9) & (10) & (11) & (12) & (13) & (14) \\
\hline \multicolumn{15}{|l|}{ w Pays } \\
\hline Ö Australie & 13 & $5-17$ & 100 & 90 & 56 & 28 & 17 & 8 & 83 & 45 & 19 & 82 & 44 & 21 \\
\hline Autriche & 12 & $4-15$ & 99 & 78 & 34 & 18 & 6 & 1 & 78 & 33 & 17 & $\mathrm{~m}$ & $\mathrm{~m}$ & m \\
\hline Belgique & 16 & 3-18 & 99 & 95 & 49 & 14 & 7 & 3 & 92 & 52 & 17 & 94 & 42 & 15 \\
\hline Canada' & 12 & 5-16 & 100 & 78 & 33 & 10 & 4 & 1 & 76 & 36 & 11 & $\mathrm{~m}$ & $\mathrm{~m}$ & $\mathrm{~m}$ \\
\hline Chili & 13 & $5-17$ & 97 & 81 & 43 & 16 & 6 & 1 & 76 & 37 & 13 & $\mathrm{~m}$ & $\mathrm{~m}$ & $\mathrm{~m}$ \\
\hline Colombic & 4 & $9-12$ & 88 & 59 & 25 & 12 & 6 & 2 & $\mathrm{~m}$ & $\mathrm{~m}$ & $\mathrm{~m}$ & $\mathrm{~m}$ & $\mathrm{~m}$ & m \\
\hline Rèpublique tchèque & 14 & $5-18$ & 98 & 91 & 41 & 10 & 2 & 1 & 91 & 39 & 11 & 91 & 34 & 10 \\
\hline Danemark & 15 & $3-17$ & 99 & 86 & 54 & 30 & 9 & 2 & 85 & 49 & 27 & $\mathrm{~m}$ & m & $\mathrm{m}$ \\
\hline Estonie & 15 & 4.18 & 97 & 89 & 39 & 15 & 7 & 2 & 91 & 44 & 14 & 91 & 40 & 14 \\
\hline Finlande & 13 & $6-18$ & 99 & 86 & 51 & 31 & 17 & 6 & 87 & 53 & 31 & 87 & 55 & 30 \\
\hline France & 15 & $3-17$ & 100 & 86 & 37 & 7 & 2 & 0 & 84 & 34 & 6 & 84 & 32 & 7 \\
\hline Allemagne & 15 & 3-17 & 99 & 87 & 48 & 21 & 5 & 0 & 89 & 45 & 17 & 88 & 41 & 18 \\
\hline Grèce & 13 & $5-17$ & 97 & 86 & 52 & 20 & 9 & 3 & $\mathrm{~m}$ & $\mathrm{~m}$ & $\mathrm{~m}$ & $\mathrm{~m}$ & $\mathrm{~m}$ & $\mathrm{~m}$ \\
\hline Hongrie & 13 & $4-16$ & 96 & 84 & 36 & 11 & 4 & 1 & 92 & 41 & 11 & 87 & 38 & 13 \\
\hline Islande & 16 & $2-17$ & 99 & 87 & 44 & 24 & 11 & 4 & $\mathrm{~m}$ & $\mathrm{~m}$ & $m$ & $\mathrm{~m}$ & $\mathrm{~m}$ & $\mathrm{~m}$ \\
\hline Irlande & 15 & 3.17 & 100 & 93 & 44 & 12 & 5 & 2 & 91 & 32 & 9 & 89 & 32 & 10 \\
\hline Israē| & 15 & 3-17 & 97 & 66 & 21 & 20 & 6 & 2 & 64 & 24 & 21 & $\mathrm{~m}$ & $\mathrm{~m}$ & $\mathrm{~m}$ \\
\hline Italie & 15 & 3-17 & 98 & 85 & 36 & 12 & 3 & 1 & 85 & 35 & 11 & 82 & 33 & 10 \\
\hline Japon ${ }^{2}$ & 14 & $4-17$ & 100 & $\mathrm{~m}$ & $\mathrm{~m}$ & $\mathrm{~m}$ & $\mathrm{~m}$ & $\mathrm{~m}$ & $\mathrm{~m}$ & $\mathrm{~m}$ & $\mathrm{~m}$ & $\mathrm{~m}$ & $\mathrm{~m}$ & $\mathrm{~m}$ \\
\hline Corèe & 14 & 3-17 & 97 & 87 & 50 & 9 & 2 & 1 & 85 & 54 & 10 & 87 & 46 & 9 \\
\hline Lettonie & 16 & 3-18 & 98 & 93 & 45 & 16 & 6 & 1 & 94 & 44 & 11 & $\mathrm{~m}$ & $\mathrm{~m}$ & $\mathrm{~m}$ \\
\hline Lituanic & 14 & $5-18$ & 100 & 94 & 47 & 13 & 6 & 1 & 98 & 56 & 16 & 98 & 49 & 17 \\
\hline Luxembourg & 12 & $4-15$ & 96 & 76 & 20 & 7 & 2 & 0 & $\mathrm{~m}$ & $\mathrm{~m}$ & $\mathrm{~m}$ & $\mathrm{~m}$ & $\mathrm{~m}$ & $\mathrm{~m}$ \\
\hline Mexique & 11 & $4-14$ & 100 & 61 & 26 & 10 & 4 & 2 & 51 & 19 & 5 & 48 & 17 & 5 \\
\hline Pays-Bas & 14 & $4-17$ & 100 & 93 & 54 & 18 & 6 & 2 & 90 & 47 & 12 & m & $\mathrm{m}$ & $\mathrm{m}$ \\
\hline Nouvelle-Zelande & 14 & $3-16$ & 99 & 80 & 35 & 14 & 9 & 4 & 80 & 42 & 19 & 74 & 41 & 20 \\
\hline Norvége & 17 & $2-18$ & 99 & 87 & 46 & 19 & 8 & 2 & 87 & 48 & 19 & 89 & 46 & 19 \\
\hline Pologne & 14 & $5-18$ & 96 & 93 & 50 & 11 & 3 & 1 & 84 & 11 & 2 & 85 & 12 & 3 \\
\hline Portugal & 14 & $4-17$ & 99 & 89 & 37 & 10 & 4 & 1 & 85 & 37 & 14 & 74 & 35 & 12 \\
\hline Republique slovaque & 11 & $6-16$ & 95 & 83 & 32 & 7 & 2 & 1 & $\mathrm{~m}$ & $\mathrm{~m}$ & $\mathrm{~m}$ & $\mathrm{~m}$ & $\mathrm{~m}$ & m \\
\hline Slovénie & 15 & $4-18$ & 98 & 93 & 60 & 13 & 3 & 0 & 94 & 54 & 16 & 93 & 50 & 17 \\
\hline Espagne & 15 & 3.17 & 97 & 87 & 49 & 16 & 6 & 2 & 82 & 37 & 12 & 78 & 34 & 11 \\
\hline Suède & 16 & 3-18 & 100 & 91 & 44 & 27 & 16 & 5 & $\mathrm{~m}$ & m & $\mathrm{m}$ & $\mathrm{m}$ & $\mathrm{m}$ & $\mathrm{m}$ \\
\hline Suisse & 13 & $5-17$ & 100 & 85 & 39 & 17 & 5 & 1 & 85 & 34 & 14 & 83 & 31 & 13 \\
\hline Turquie $^{3}$ & 10 & $6-15$ & $99^{4}$ & 73 & 51 & 30 & 13 & 3 & $\mathrm{~m}$ & $\mathrm{~m}$ & $\mathrm{~m}$ & $\mathrm{~m}$ & $m$ & $m$ \\
\hline Royaume-Uni & 15 & 3-17 & 98 & 85 & 31 & 10 & 6 & 2 & 76 & 27 & 10 & $\mathrm{~m}$ & $\mathrm{~m}$ & m \\
\hline Etats-Unis & 13 & $5-17$ & 100 & 83 & 36 & 14 & 7 & 2 & 80 & 38 & 15 & 77 & 32 & 13 \\
\hline Moyenne OCDE & 14 & $4-17$ & 98 & 84 & 42 & 16 & 6 & 2 & 84 & 40 & 14 & m & m & $\mathrm{m}$ \\
\hline $\begin{array}{l}\text { Moyenne des pays } \\
\text { disposant de donnees } \\
\text { pour toutes les annees } \\
\text { de référence }\end{array}$ & & & & 87 & 43 & 15 & & & 86 & 41 & 14 & $\mathrm{~m}$ & $\mathrm{~m}$ & m \\
\hline Moyenne UE23 & 14 & 417 & 98 & 88 & 43 & 15 & 6 & 2 & 88 & 41 & 14 & m & m & m \\
\hline \& Argentine ${ }^{4}$ & 13 & $5-17$ & 100 & 77 & 41 & 21 & $\mathrm{~m}$ & $\mathrm{~m}$ & $\mathrm{~m}$ & $\mathrm{~m}$ & $\mathrm{~m}$ & $\mathrm{~m}$ & $\mathrm{~m}$ & m \\
\hline Bresil & 11 & $4-14$ & 98 & 67 & 29 & 15 & 8 & 3 & $\mathrm{~m}$ & $\mathrm{~m}$ & $\mathrm{~m}$ & $\mathrm{~m}$ & $\mathrm{~m}$ & m \\
\hline Ф़ Chine & $\mathrm{m}$ & $\mathrm{m}$ & $\mathrm{m}$ & $\mathrm{m}$ & $\mathrm{m}$ & $\mathrm{m}$ & m & $\mathrm{m}$ & $\mathrm{m}$ & m & $\mathrm{m}$ & $\mathrm{m}$ & $\mathrm{m}$ & m \\
\hline Costa Rica & 7 & $6-12$ & 92 & $\mathrm{~m}$ & $\mathrm{~m}$ & $\mathrm{~m}$ & $\mathrm{~m}$ & $\mathrm{~m}$ & $\mathrm{~m}$ & $\mathrm{~m}$ & $\mathrm{~m}$ & $\mathrm{~m}$ & $\mathrm{~m}$ & $\mathrm{~m}$ \\
\hline Inde & $\mathrm{m}$ & $\mathrm{m}$ & $\mathrm{m}$ & $\mathrm{m}$ & m & $\mathrm{m}$ & $\mathrm{m}$ & m & $\mathrm{m}$ & m & $\mathrm{m}$ & $\mathrm{m}$ & $\mathrm{m}$ & $\mathrm{m}$ \\
\hline Indonésie & 7 & $5-11$ & m & $\mathrm{m}$ & m & 4 & 1 & 0 & $\mathrm{~m}$ & $\mathrm{~m}$ & $\mathrm{~m}$ & m & $\mathrm{m}$ & m \\
\hline Federation de Russie & 12 & $6-17$ & 98 & 87 & 35 & 7 & 2 & 0 & $\mathrm{~m}$ & $\mathrm{~m}$ & $\mathrm{~m}$ & 82 & 34 & 13 \\
\hline Arabie saoudite & $\mathrm{m}$ & $\mathrm{m}$ & $\mathrm{m}$ & $\mathrm{m}$ & $\mathrm{m}$ & m & m & m & m & m & $m$ & $\mathrm{~m}$ & m & $\mathrm{m}$ \\
\hline Afrique du Sud & $\mathrm{m}$ & m & $\mathrm{m}$ & m & m & m & m & $\mathrm{m}$ & $\mathrm{m}$ & $\mathrm{m}$ & $\mathrm{m}$ & $\mathrm{m}$ & $\mathrm{m}$ & $\mathrm{m}$ \\
\hline Moyenne G20 & m & $\mathrm{m}$ & $\mathrm{m}$ & $\mathrm{m}$ & m & $\mathrm{m}$ & m & $\mathrm{m}$ & m & $m$ & $\mathrm{~m}$ & m & $\mathrm{m}$ & m \\
\hline
\end{tabular}

1. A l'exclusion de l'enseignement post-secondaire non tertiaire.

2. La répartition par âge n'est pas disponible après l'âge de 15 ans.

3. Le groupe d'âge des 6-14 ans inclut un certain nombre d'élèves âgés de plus de 14 ans qui sont scolarisés dans l'enseignement primaire.

4. Année de référence : 2016

Source : OCDE/ISU/Eurostat (2019). Consulter la section « Source » pour tout complément d'information et l'annexe 3 pour les notes (https://doi.org/10.1787/f8d7880den).

Les symboles représentant les données manquantes et les abréviations figurent dans le Guide du lecteur. 
Tableau B1.2. Taux de scolarisation dans l'enseignement tertiaire, selon le groupe d'âge et le niveau d'enseignement (2017) Étudiants scolarisés à temps plein ou partiel, dans des établissements publics ou privés

\begin{tabular}{|c|c|c|c|c|c|c|c|c|c|c|c|c|c|c|c|c|}
\hline & \multicolumn{2}{|c|}{19 à 20 ans } & \multicolumn{3}{|c|}{21 d 22 ans } & \multicolumn{3}{|c|}{23 d 24 ans } & \multicolumn{4}{|c|}{25 d 26 ans } & \multicolumn{4}{|c|}{27 a 28 ans } \\
\hline & 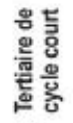 & 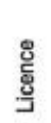 & 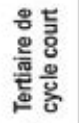 & 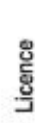 & $\begin{array}{l}\text { 总 } \\
\text { 要 }\end{array}$ & 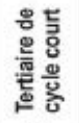 & 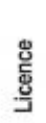 & 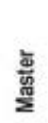 & 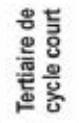 & $\begin{array}{l}\text { ઁ̆ } \\
\stackrel{\Xi}{\Xi}\end{array}$ & $\begin{array}{l}\text { 总 } \\
\text { 惫 }\end{array}$ & $\begin{array}{l}\text { 뜽 } \\
\text { 항 }\end{array}$ & 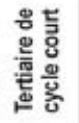 & 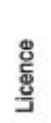 & $\begin{array}{l}\text { 总 } \\
\text { 贸 }\end{array}$ & $\begin{array}{l}\text { 똫 } \\
\text { 응 }\end{array}$ \\
\hline & (1) & (2) & (3) & (4) & (5) & (6) & (7) & (8) & (9) & (10) & (11) & (12) & (13) & (14) & (15) & (16) \\
\hline \multicolumn{17}{|l|}{ W Pays } \\
\hline Australie & 8 & 41 & 7 & 31 & 4 & 6 & 15 & 9 & 5 & 8 & 6 & 1 & 5 & 5 & 4 & 1 \\
\hline Autriche & 9 & 19 & 2 & 22 & 6 & 2 & 14 & 10 & 1 & 9 & 10 & 1 & 1 & 6 & 7 & 1 \\
\hline Belgique & 1 & 53 & 1 & 32 & 12 & 1 & 12 & 11 & 1 & 4 & 5 & 1 & 1 & 2 & 3 & 1 \\
\hline Canada' & 11 & 32 & 6 & 28 & 2 & 4 & 12 & 4 & 3 & 6 & 3 & 1 & 2 & 3 & 2 & 1 \\
\hline Chili & 16 & 33 & 12 & 32 & 1 & 7 & 22 & 2 & 5 & 12 & 2 & 0 & 4 & 7 & 2 & 0 \\
\hline Colombie & 9 & 18 & 6 & 19 & 0 & 4 & 12 & 1 & 3 & 8 & 1 & 0 & 3 & 5 & 1 & 0 \\
\hline Republique tchèque & 0 & 29 & 0 & 32 & 7 & 0 & 13 & 17 & 0 & 5 & 9 & 2 & 0 & 2 & 2 & 2 \\
\hline Danemark & 2 & 11 & 5 & 33 & 1 & 4 & 28 & 11 & 3 & 15 & 14 & 1 & 2 & 9 & 8 & 1 \\
\hline Estonic & a & 28 & a & 28 & 5 & a & 14 & 10 & a & 7 & 7 & 1 & a & 5 & 4 & 1 \\
\hline Finlande & a & 20 & a & 36 & 2 & a & 30 & 7 & a & 17 & 8 & 0 & a & 11 & 6 & 1 \\
\hline France & 16 & 27 & 5 & 15 & 19 & 2 & 5 & 15 & 1 & 2 & 6 & 1 & 0 & 1 & 3 & 1 \\
\hline Allemagne & 0 & 20 & 0 & 24 & 7 & 0 & 18 & 11 & 0 & 11 & 11 & 1 & 0 & 7 & 7 & 2 \\
\hline Grèce & a & 55 & a & 48 & 1 & a & 30 & 3 & a & 17 & 4 & 1 & a & 11 & 3 & 1 \\
\hline Hongrie & 2 & 20 & 1 & 21 & 6 & 1 & 12 & 9 & 0 & 6 & 5 & 1 & 0 & 3 & 2 & 1 \\
\hline Islande & 0 & 10 & 0 & 30 & 1 & 1 & 24 & 4 & 1 & 14 & 6 & 0 & 1 & 10 & 5 & 1 \\
\hline Irlande & 2 & 53 & 1 & 39 & 3 & 1 & 11 & 5 & 1 & 6 & 3 & 1 & 1 & 4 & 2 & 1 \\
\hline Israë| & 7 & 7 & 3 & 15 & 0 & 2 & 21 & 1 & 3 & 20 & 3 & 0 & 2 & 11 & 4 & 0 \\
\hline Italie & 0 & 31 & 0 & 26 & 10 & 0 & 12 & 15 & 0 & 6 & 9 & 1 & 0 & 4 & 5 & 1 \\
\hline Japon & m & $\mathrm{m}$ & $\mathrm{m}$ & $\mathrm{m}$ & $\mathrm{m}$ & $\mathrm{m}$ & m & $\mathrm{m}$ & $\mathrm{m}$ & $\mathrm{m}$ & m & $\mathrm{m}$ & $\mathrm{m}$ & m & $\mathrm{m}$ & $\mathrm{m}$ \\
\hline Corée & 22 & 50 & 12 & 46 & 1 & 4 & 26 & 2 & 1 & 9 & 3 & 1 & 1 & 2 & 2 & 1 \\
\hline Lettonie & 6 & 34 & 6 & 33 & 5 & 4 & 16 & 9 & 3 & 8 & 6 & 1 & 2 & 5 & 4 & 1 \\
\hline Lituanie & a & 47 & a & 44 & 4 & a & 14 & 11 & a & 7 & 6 & 1 & a & 4 & 3 & 1 \\
\hline Luxembourg ${ }^{2}$ & 1 & 4 & 2 & 8 & 0 & 2 & 5 & 2 & 1 & 2 & 3 & 0 & 0 & 1 & 3 & 1 \\
\hline Mexique & 2 & 27 & 1 & 24 & 0 & 0 & 12 & 1 & 0 & 6 & 1 & 0 & 0 & 3 & 1 & 0 \\
\hline Pays-Bas & 0 & 41 & 0 & 38 & 5 & 0 & 22 & 10 & 0 & 12 & 7 & 1 & 0 & 6 & 4 & 1 \\
\hline Nouvelle-Zèlande & 6 & 36 & 4 & 26 & 2 & 3 & 13 & 2 & 3 & 8 & 1 & 1 & 2 & 6 & 1 & 1 \\
\hline Norvège & 1 & 24 & 1 & 33 & 7 & 1 & 21 & 10 & 1 & 13 & 8 & 0 & 0 & 9 & 4 & 1 \\
\hline Pologne & 0 & 36 & 0 & 35 & 10 & 0 & 13 & 20 & 0 & 7 & 6 & 1 & 0 & 4 & 2 & 1 \\
\hline Portugal & 2 & 31 & 1 & 21 & 14 & 0 & 9 & 10 & 0 & 5 & 5 & 1 & 0 & 3 & 3 & 1 \\
\hline République slovaque & 1 & 24 & 1 & 23 & 9 & 0 & 7 & 17 & 0 & 2 & 5 & 1 & 0 & 1 & 2 & 1 \\
\hline Slovénie & 8 & 45 & 8 & 38 & 6 & 4 & 11 & 20 & 2 & 4 & 12 & 1 & 1 & 2 & 3 & 1 \\
\hline Espagne & 12 & 35 & 9 & 31 & 5 & 5 & 16 & 7 & 3 & 8 & 5 & 1 & 2 & 5 & 3 & 1 \\
\hline Suède & 1 & 12 & 1 & 18 & 10 & 1 & 14 & 11 & 1 & 10 & 7 & 1 & 1 & 7 & 4 & 1 \\
\hline Suisse & 0 & 16 & 0 & 26 & 2 & 0 & 20 & 8 & 0 & 11 & 7 & 2 & 0 & 6 & 4 & 2 \\
\hline Turquie & 19 & 26 & 16 & 31 & 2 & 13 & 23 & 3 & 10 & 16 & 4 & 0 & 8 & 13 & 4 & 0 \\
\hline Royaume-Uni & $2^{\circ}$ & 41 & $1^{4}$ & 20 & 5 & $1^{0}$ & 5 & 5 & $1^{0}$ & 3 & 3 & 1 & $1^{4}$ & 2 & 2 & 1 \\
\hline États-Unis & 19 & 32 & 12 & 26 & 2 & 7 & 10 & 5 & 5 & 5 & 5 & 0 & 4 & 3 & 3 & 0 \\
\hline Moyenne OCDE & 5 & 30 & 4 & 29 & 5 & 2 & 16 & 8 & 2 & 8 & 6 & 1 & 1 & 5 & 3 & 1 \\
\hline Moyenne UE23 & 3 & 31 & 2 & 29 & 7 & 1 & 14 & 11 & 1 & 7 & 7 & 1 & 1 & 4 & 4 & 1 \\
\hline is Argentine & $\mathrm{m}$ & $\mathrm{m}$ & $\mathrm{m}$ & $\mathrm{m}$ & $\mathrm{m}$ & $\mathrm{m}$ & $\mathrm{m}$ & $\mathrm{m}$ & $\mathrm{m}$ & $\mathrm{m}$ & $\mathrm{m}$ & $\mathrm{m}$ & $\mathrm{m}$ & $\mathrm{m}$ & $\mathrm{m}$ & $\mathrm{m}$ \\
\hline Brèsil & 0 & 21 & 0 & 22 & 0 & 0 & 17 & 0 & 0 & 12 & 0 & 0 & 0 & 9 & 0 & 0 \\
\hline Shine & $\mathrm{m}$ & $\mathrm{m}$ & $\mathrm{m}$ & $\mathrm{m}$ & $\mathrm{m}$ & $\mathrm{m}$ & $\mathrm{m}$ & $\mathrm{m}$ & $\mathrm{m}$ & $\mathrm{m}$ & $\mathrm{m}$ & $\mathrm{m}$ & $\mathrm{m}$ & $\mathrm{m}$ & $\mathrm{m}$ & $\mathrm{m}$ \\
\hline costa Rica & $\mathrm{m}$ & $\mathrm{m}$ & $\mathrm{m}$ & $\mathrm{m}$ & $\mathrm{m}$ & $\mathrm{m}$ & $\mathrm{m}$ & $\mathrm{m}$ & $\mathrm{m}$ & $\mathrm{m}$ & $\mathrm{m}$ & $\mathrm{m}$ & $\mathrm{m}$ & $\mathrm{m}$ & $\mathrm{m}$ & $\mathrm{m}$ \\
\hline Inde & a & $\mathrm{m}$ & a & $\mathrm{m}$ & $\mathrm{m}$ & a & $\mathrm{m}$ & $\mathrm{m}$ & a & $\mathrm{m}$ & $\mathrm{m}$ & $\mathrm{m}$ & a & $\mathrm{m}$ & $\mathrm{m}$ & $\mathrm{m}$ \\
\hline Indonésic & $\mathrm{m}$ & $\mathrm{m}$ & $\mathrm{m}$ & $\mathrm{m}$ & $\mathrm{m}$ & $\mathrm{m}$ & $\mathrm{m}$ & $\mathrm{m}$ & $\mathrm{m}$ & $\mathrm{m}$ & $\mathrm{m}$ & $\mathrm{m}$ & $\mathrm{m}$ & $\mathrm{m}$ & $\mathrm{m}$ & $\mathrm{m}$ \\
\hline Fédération de Russie ${ }^{4}$ & $21^{\circ}$ & 34 & $5^{4}$ & 26 & 11 & $2^{4}$ & 10 & 7 & $1^{\mathrm{d}}$ & 5 & 2 & 1 & $1^{\mathrm{d}}$ & 3 & 1 & 0 \\
\hline Arabie saoudite & $\mathrm{m}$ & $\mathrm{m}$ & $\mathrm{m}$ & $\mathrm{m}$ & $\mathrm{m}$ & $\mathrm{m}$ & $\mathrm{m}$ & $\mathrm{m}$ & $\mathrm{m}$ & $\mathrm{m}$ & $\mathrm{m}$ & $\mathrm{m}$ & $\mathrm{m}$ & $\mathrm{m}$ & $\mathrm{m}$ & $\mathrm{m}$ \\
\hline Afrique du Sud & $\mathrm{m}$ & $\mathrm{m}$ & $\mathrm{m}$ & m & m & $\mathrm{m}$ & $\mathrm{m}$ & $\mathrm{m}$ & $\mathrm{m}$ & m & $\mathrm{m}$ & $\mathrm{m}$ & $\mathrm{m}$ & $\mathrm{m}$ & $\mathrm{m}$ & $\mathrm{m}$ \\
\hline Moyenne G20 & m & $m$ & m & $\mathrm{m}$ & $m$ & m & $\mathrm{m}$ & m & m & $\mathrm{m}$ & $m$ & m & m & $\mathrm{m}$ & $m$ & $m$ \\
\hline
\end{tabular}

1. À l'exclusion des établissements privés dans le tertiaire de cycle court.

2. Sous-estimé en raison du nombre important d'étudiants scolarisés dans les pays voisins.

3. Les programmes tertiaires de cycle court incluent un petit nombre de licences professionnelles.

4. Les programmes tertiaires de cycle court incluent une partie des programmes professionnels du deuxième cycle du secondaire.

Source : OCDE/ISU/Eurostat (2019). Consulter la section « Source » pour tout complément d'information et l'annexe 3 pour les notes (https://doi.org/10.1787/f8d7880den).

Les symboles représentant les données manquantes et les abréviations figurent dans le Guide du lecteur.

StatLink त्गाड़ https://doi.org/10.1787/888933977657 
Tableau B1.3. Profil des effectifs scolarisés dans l'enseignement tertiaire (2017)

\begin{tabular}{|c|c|c|c|c|c|c|c|c|c|c|c|c|}
\hline & \multicolumn{4}{|c|}{ Áges typiques de scolarisation' } & \multicolumn{4}{|c|}{$\begin{array}{l}\text { Pourcentage des effectifs scolarisès } \\
\text { dans des établissements publics }\end{array}$} & \multicolumn{4}{|c|}{$\begin{array}{l}\text { Pourcentage des effectifs scolarisés } \\
\text { à temps partiel }\end{array}$} \\
\hline & 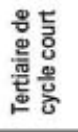 & 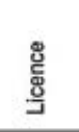 & $\begin{array}{l}\text { 殒 } \\
\text { 要 }\end{array}$ & $\begin{array}{l}\text { 뜽 } \\
\text { 영 }\end{array}$ & 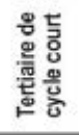 & $\begin{array}{l}\stackrel{\Xi}{\Xi ّ} \\
\stackrel{\Xi}{\Xi}\end{array}$ & $\begin{array}{l}\text { 离 } \\
\frac{\pi}{\Sigma}\end{array}$ & $\begin{array}{l}\text { 뜽 } \\
\text { ్ㅠㅇ }\end{array}$ & 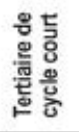 & 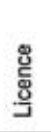 & 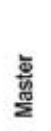 & $\begin{array}{l}\text { 뜬 } \\
\text { ㅎ̆ㅇ } \\
\text { व. }\end{array}$ \\
\hline \multicolumn{13}{|l|}{ w Pays } \\
\hline Ô. Australie & $18-28$ & $18-22$ & $22-27$ & 24,33 & 63 & 92 & 90 & 99 & 65 & 26 & 35 & 29 \\
\hline Autriche & $17-19$ & $19-23$ & 22.28 & 26.33 & 82 & 77 & 85 & 98 & a & a & a & a \\
\hline Belgique & $19-27$ & $19-21$ & $21-24$ & $25-30$ & 41 & 39 & 33 & 43 & 70 & 29 & 24 & 0 \\
\hline Canada $^{2}$ & $18-22$ & $19-22$ & $22-27$ & $26-32$ & m & 100 & 100 & 100 & 12 & 19 & 25 & 6 \\
\hline Chili & $18-23$ & $19-23$ & 22.31 & $27-33$ & 4 & 20 & 23 & 43 & a & a & a & a \\
\hline Colombic & $17-22$ & $18-23$ & 24.33 & $32-37$ & 80 & 39 & 30 & 63 & a & a & a & a \\
\hline République tchèque & $19-22$ & $20-23$ & $22-25$ & 25.30 & 80 & 86 & 93 & 100 & 0 & 2 & 8 & 0 \\
\hline Danemark & $20-25$ & $21-25$ & $23-26$ & $27-32$ & 98 & 99 & 100 & 100 & 25 & 12 & 7 & 0 \\
\hline Estonie & a & $19-23$ & $22-28$ & 26.32 & a & 22 & 1 & 0 & a & 10 & 9 & 13 \\
\hline Finlande & a & $20-25$ & 23.30 & 28.38 & a & 39 & 83 & 100 & a & 27 & 52 & 100 \\
\hline France & $18-19$ & $18-20$ & $21-24$ & $24-28$ & 67 & 86 & 76 & 99 & a & a & a & a \\
\hline Allemagne & 21.25 & $20-24$ & $23-27$ & $27 \cdot 31$ & 78 & 86 & 95 & 100 & 42 & 11 & 6 & 76 \\
\hline Grèce & a & $18-23$ & $23-32$ & $25-29$ & a & 100 & 100 & 100 & a & a & 5 & a \\
\hline Hongrie & 19.22 & $20-23$ & $21-25$ & $25-29$ & 86 & 86 & 88 & 93 & 29 & 29 & 27 & 22 \\
\hline Islande & $22-28$ & $21-25$ & $24-33$ & $26-36$ & 64 & 78 & 79 & 96 & 31 & 25 & 41 & 43 \\
\hline Irlande & $18-21$ & 19.21 & 22.30 & 24.31 & 100 & 96 & 93 & 100 & 60 & 7 & 46 & 19 \\
\hline |sraēl & $18-25$ & $22-26$ & 25.33 & 28.35 & 42 & 12 & 11 & 0 & 0 & 19 & 4 & 0 \\
\hline Italie & $19-21$ & $19-22$ & $22-26$ & $25-28$ & 0 & 87 & 90 & 96 & a & a & a & a \\
\hline Japon & $\mathrm{m}$ & $\mathrm{m}$ & $\mathrm{m}$ & $\mathrm{m}$ & 7 & 20 & 47 & 71 & 3 & 9 & 7 & 9 \\
\hline Corée & $18-20$ & $19-22$ & $23-30$ & $24 \cdot 34$ & 2 & 24 & 32 & 38 & m & $\mathrm{m}$ & $\mathrm{m}$ & $\mathrm{m}$ \\
\hline Lettonic & $19-26$ & $19-22$ & $22-27$ & $25-32$ & 45 & a & a & a & 49 & 30 & 6 & 1 \\
\hline Lituanie & a & $19-21$ & $23-26$ & $26-30$ & a & 90 & 97 & 99 & a & 24 & 14 & 11 \\
\hline Luxembourg & $21-23$ & $20-23$ & $23-28$ & $27-31$ & 100 & 93 & 98 & 100 & 0 & 2 & 48 & 8 \\
\hline Mexique & $18-20$ & $19-22$ & $24-29$ & $26-30$ & 97 & 67 & 39 & 61 & a & a & a & a \\
\hline Pays-Bas & $22-30$ & $19-22$ & $22-27$ & $26-30$ & 31 & 90 & 64 & 100 & 72 & 13 & 35 & a \\
\hline Nouvelle-Zèlande & $18-28$ & $18-22$ & $21-28$ & $25-34$ & 53 & 94 & 98 & 100 & 57 & 39 & 63 & 43 \\
\hline Norvège & $20-25$ & $19-24$ & 21.26 & $26-34$ & 71 & 82 & 93 & 98 & 42 & 35 & 28 & 100 \\
\hline Pologne & $21-29$ & $19-22$ & $22-24$ & $25-29$ & 100 & 73 & 78 & 92 & a & 26 & 40 & 13 \\
\hline Portugal & $18-20$ & $18-21$ & $20-24$ & 27.30 & 83 & 80 & 87 & 94 & 0 & 6 & 4 & 7 \\
\hline Rèpublique slovaque & $19-22$ & $20-22$ & $22-24$ & 2429 & 66 & 87 & 86 & 95 & 10 & 21 & 26 & 45 \\
\hline Slovènie & $19-22$ & $19-21$ & $23-25$ & 25.31 & 72 & 85 & 92 & 79 & 42 & 19 & 8 & 77 \\
\hline Espagne & $19-23$ & $18-22$ & $22-28$ & 24.33 & 75 & 83 & 71 & 95 & 11 & 29 & 30 & 0 \\
\hline Suède & $21-28$ & $20-26$ & $21-26$ & $26-33$ & 39 & 95 & 92 & 92 & 6 & 53 & 39 & 57 \\
\hline Suisse & $21 \cdot 31$ & $20-24$ & $23-27$ & $26-30$ & 13 & 81 & 96 & 100 & 93 & 31 & 15 & 0 \\
\hline Turquie & $19-25$ & $19-24$ & 23.29 & 27.33 & 94 & 92 & 83 & 91 & a & a & a & a \\
\hline Royaume-Uni & 18.29 & $18-20$ & $21-27$ & $22-29$ & a & a & a & a & 48 & 10 & 46 & 25 \\
\hline États-Unis & $18-23$ & $18-21$ & 22.28 & 23.33 & 91 & 68 & 48 & 52 & 58 & 22 & 44 & 35 \\
\hline $\begin{array}{l}\text { Moyenne OCDE } \\
\text { Moyenne UE23 }\end{array}$ & & & & & $\begin{array}{l}60 \\
65\end{array}$ & $\begin{array}{l}69 \\
73\end{array}$ & $\begin{array}{l}70 \\
74\end{array}$ & $\begin{array}{l}78 \\
81\end{array}$ & $\begin{array}{l}26 \\
25\end{array}$ & $\begin{array}{l}16 \\
16\end{array}$ & $\begin{array}{l}21 \\
21\end{array}$ & $\begin{array}{l}21 \\
21\end{array}$ \\
\hline \& Argentine' & $\mathrm{m}$ & m & $\mathrm{m}$ & $\mathrm{m}$ & $x(6)$ & $75^{\circ}$ & 74 & 88 & $\mathrm{~m}$ & $\mathrm{~m}$ & m & $\mathrm{m}$ \\
\hline Brésil & $30-32$ & $18-24$ & 24.31 & 26.33 & 64 & 25 & 83 & 88 & m & m & m & $\mathrm{m}$ \\
\hline Shine & $m$ & m & $\mathrm{m}$ & $\mathrm{m}$ & 87 & 83 & 100 & 100 & m & m & m & $\mathrm{m}$ \\
\hline Costa Rica & $m$ & m & m & $\mathrm{m}$ & 81 & 45 & 44 & 41 & a & a & a & a \\
\hline Inde & a & $\mathrm{m}$ & $\mathrm{m}$ & $\mathrm{m}$ & a & 40 & 56 & 74 & a & $\mathrm{m}$ & m & $\mathrm{m}$ \\
\hline Indonésie & m & m & $\mathrm{m}$ & m & 43 & 35 & 53 & 77 & $\mathrm{~m}$ & $\mathrm{~m}$ & $\mathrm{~m}$ & $\mathrm{~m}$ \\
\hline Fédération de Russie & $16-18$ & $18-21$ & $20-23$ & $23-26$ & 93 & 85 & 96 & 100 & 27 & 49 & 25 & 28 \\
\hline Arabie saoudite & m & m & $\mathrm{m}$ & $\mathrm{m}$ & 100 & 95 & 81 & 100 & $\mathrm{~m}$ & m & $\mathrm{m}$ & $\mathrm{m}$ \\
\hline Afrique du Sud ${ }^{3}$ & m & m & m & m & 87 & 94 & 97 & 100 & m & m & m & $\mathrm{m}$ \\
\hline Moyenne G20 & & & & & 62 & 67 & 71 & 81 & $\mathrm{~m}$ & $\mathrm{~m}$ & $\mathrm{~m}$ & m \\
\hline
\end{tabular}

1. Les âges typiques de scolarisation correspondent à la tranche d'âge la plus courte couvrant au moins $50 \%$ des effectifs scolarisés à ce niveau. 2. Dans le tertiaire de cycle court, les établissements privés sont exclus.

3. Année de référence : 2016.

Source : OCDE/ISU/Eurostat (2019). Consulter la section « Source » pour tout complément d'information et l'annexe 3 pour les notes (https://doi.org/10.1787/f8d7880den).

Les symboles représentant les données manquantes et les abréviations figurent dans le Guide du lecteur.

StatLink त्ता मी https://doi.org/10.1787/888933977676 


\section{Indicateur B2. En quoi les systèmes d'éducation de la petite enfance se différencient-ils dans le monde?}

\section{Faits marquants}

- Dans plus de $70 \%$ des pays de l'OCDE dont les données sont disponibles, les services d'éducation et d'accueil des jeunes enfants (EAJE) sont intégrés et une ou plusieurs instances publiques sont chargées de gérer le système d'EAJE dans son ensemble et de définir la composante éducative applicable aux enfants entre l'âge de 0 ou 1 an et le début de l'enseignement primaire.

- Depuis quelques décennies, les responsables politiques s'intéressent de près à l'EAJE, en particulier avant l'âge de 3 ans, dans les pays de l'OCDE. En 2017, plus d'un tiers des enfants de moins de 3 ans fréquentaient une structure d'éducation de la petite enfance (niveau 0 de la CITE) ou autre service agréé en dehors du niveau 0 de la CITE en moyenne dans les pays de l'OCDE, soit une augmentation de 8 points de pourcentage par rapport à 2010. En moyenne, les services d'EAJE accueillent $40 \%$ des enfants de 1 an et $62 \%$ des enfants de 2 ans.

- Tous les enfants ou presque en passent au moins par une année d'EAJE ; c'est désormais la norme dans les pays de l'OCDE, ce qui représente une grande avancée sur la voie de l'une des cibles relatives à l'éducation dans les objectifs de développement durable des Nations Unies (cible 4.2.2). Les taux de scolarisation des enfants de 5 ans dans l'enseignement préprimaire ou primaire sont supérieurs à $90 \%$ dans 36 des 43 pays dont les données de 2017 sont disponibles.

Graphique B2.1. Taux de scolarisation des enfants de moins de 3 ans dans les structures d'éducation et d'accueil de la petite enfance, selon l'âge (2017)

Tous services d'EAJE confondus (éducation de la petite enfance [CITE 0] et autres services agréés d'EAJE en dehors du cadre de la CITE 0)

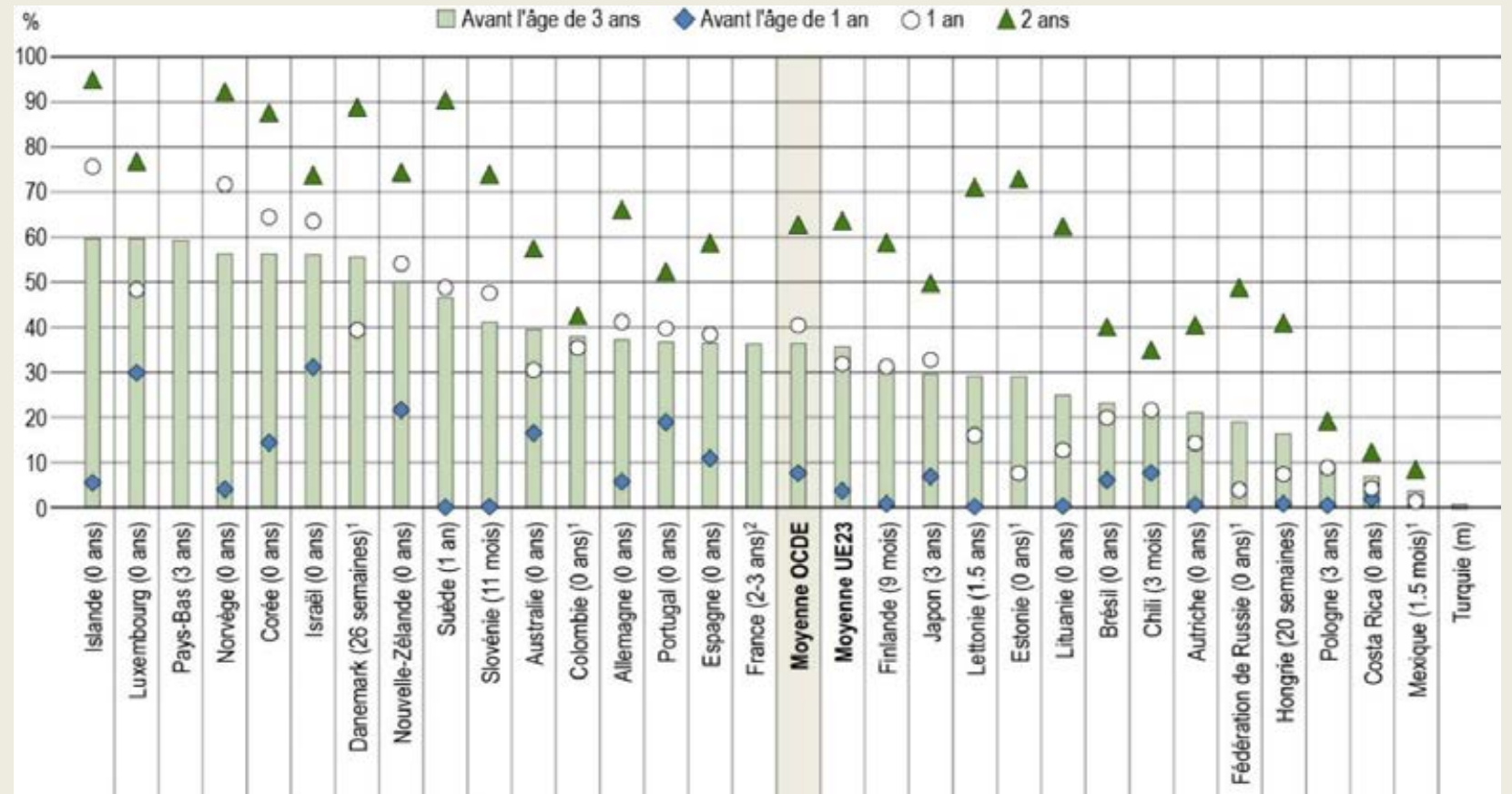

Remarque : Les chiffres entre parenthèses indiquent l'âge auquel les services d'EAJE commencent à comporter une composante éducative intentionnelle. 1. La catégorie 1 an inclut aussi des enfants de moins de 1 an.

2. Les données de la catégorie « Autres services agréés d'EAJE » sont tirées de l'enquête « Modes de garde et d'accueil des jeunes enfants 2013 » menée par la Direction des statistiques du ministère français des Solidarités et de la Santé (DREES). Les chiffres se rapportent au mode de garde principal.

Les pays sont classés par ordre décroissant du taux de scolarisation des enfants de moins de 3 ans au niveau 0 de la CITE.

Source : OCDE (2019). Table B2.1. Consulter la section « Source » pour tout complément d'information et l'annexe 3 pour les notes (https://doi.org/10.1787/f8d7880d-en).

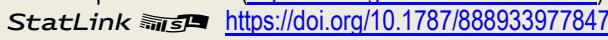




\section{Contexte}

Les vertus de l'EAJE ne se limitent pas à l'amélioration de la situation des parents dans le monde du travail ou à la hausse des taux de fécondité. L'on s'accorde de plus en plus à reconnaître le rôle majeur que l'EAJE joue dans le développement, l'apprentissage et le bien-être des enfants. Les enfants qui prennent un bon départ dans la vie sont plus susceptibles de bien s'en sortir l'âge venant. C'est particulièrement vrai pour les enfants issus de milieux socio-économiques défavorisés, qui ont souvent moins de possibilités de développer des capacités dans leur cadre familial (OCDE, 2018[1]).

II faut en outre que le ratio emploi-population reste élevé pour garantir la prospérité économique, et le nombre croissant de femmes sur le marché du travail a incité les gouvernements à s'intéresser de plus près au développement des services d'EAJE. Des services d'EAJE et autres dispositifs de grande qualité visant à améliorer l'équilibre entre vie professionnelle et vie privée offrent aux parents davantage de possibilités de travailler et de combiner leurs responsabilités professionnelles et familiales (OCDE, 2016[2] ; OCDE, 2018[3] ; OCDE, 2011 [4]).

Ces éléments ont incité les responsables politiques à concevoir des interventions précoces, à prendre des initiatives visant à améliorer la qualité des services d'EAJE et l'équité de leur accessibilité, à abaisser l'âge de la scolarité obligatoire et à revoir leurs postes de dépenses pour optimiser l'efficience du budget de l'éducation (Duncan et Magnuson, 2013[5]). En dépit de ces tendances générales, la qualité des structures d’EAJE, les types de services qui y sont proposés et le nombre d'heures que chaque enfant y passe d'ordinaire par semaine varient sensiblement entre les pays de l'OCDE.

\section{Autres faits marquants}

- Les pouvoirs publics financent $69 \%$ des dépenses totales au titre du développement éducatif de la petite enfance (niveau 01 de la CITE), contre $83 \%$ au titre de l'enseignement préprimaire (niveau 02 de la CITE). Au total, les dépenses au titre de l'EAJE (niveau 0 de la CITE) représentent en moyenne $0.8 \%$ du PIB, dont trois quarts au titre de l'enseignement préprimaire.

- La variation de la durée de l'EAJE entre les pays influe fortement sur le niveau de dépenses des structures concernées. Les enfants entament par exemple leurs études primaires à l'âge de 5 ans en Irlande, mais à l'âge de 7 ans en Finlande. Pour éviter ce biais, les dépenses sont désormais calculées par âge, et plus par niveau de la CITE, dans cet indicateur. Les dépenses au titre de l'effectif total d'enfants âgés de 3 à 5 ans fréquentant une structure d'EAJE ou scolarisés dans l'enseignement primaire représentent en moyenne $0.6 \%$ du PIB. Elles n'en représentent plus de $0.9 \%$ qu'en Islande, en Norvège et en Suède.

- Les enseignants en poste dans des structures d'EAJE doivent désormais être au moins licenciés (niveau 6 de la CITE) dans trois quarts environ des pays de l'OCDE dont les données sont disponibles.

- Abstraction faite des auxiliaires d'éducation, le taux d'encadrement dans l'enseignement préprimaire est supérieur à 25 élèves par enseignant en Colombie et au Mexique, mais inférieur à 10 élèves par enseignant en Allemagne et en Finlande, dans les pays de l'OCDE. Toutefois, certains pays recourent beaucoup aux auxiliaires d'éducation dans l'enseignement préprimaire, ce qui se traduit par de meilleurs taux d'encadrement par membre du personnel de contact que par enseignant dans ces pays. Dans la majorité d'entre eux, les auxiliaires d'éducation doivent être diplômés du deuxième cycle de l'enseignement secondaire. 


\section{Analyse}

\section{Types de services d'éducation et d'accueil des jeunes enfants}

Les pays de l'OCDE s'accordent de plus en plus à reconnaître l'importance de la qualité des structures d'éducation et d'accueil des jeunes enfants (EAJE). Toutefois, les types de services d'EAJE à la disposition des enfants et des parents varient fortement entre les pays de l'OCDE. En termes de groupes d'âge cibles, de gouvernance, de financement, de fréquentation (à temps plein ou à temps partiel) et de situation (dans des centres ou établissements d'enseignement ou à domicile) (OCDE, 2018[1]).

Dans l'ensemble, il existe deux catégories de services institutionnels d'EAJE :

- Les services d'EAJE décrits dans la CITE 2011 (OCDE/Eurostat/Institut de statistique de I'UNESCO, $\left.2016_{[6]}\right)$. Pour relever du niveau 0 de la CITE, les services d'EAJE doivent en principe :

1. Avoir des propriétés éducatives intentionnelles adéquates.

2. Être institutionnalisés (organisés dans le cadre scolaire, ou autre cadre institutionnel, à l'intention d'un groupe d'enfants).

3. Afficher une intensité et une durée représentant au moins l'équivalent de 2 heures par jour d'activités éducatives pendant 100 jours par an.

4. S'inscrire dans un cadre règlementaire reconnu par les autorités nationales compétentes (par exemple, un programme).

5. Employer un personnel formé ou agréé (par exemple, obligation pour les éducateurs d'attester de leurs qualifications pédagogiques).

- D'autres services agréés d'EAJE sont considérés comme faisant partie intégrante de l'offre nationale de services d'EAJE, mais ne respectent pas tous les critères du niveau 0 de la CITE pour y figurer (les crèches en France ou les amas au Portugal). La distinction entre ces deux sous-niveaux est explicite dans les tableaux B2.1 et B2.5.

Les services de garde informels (organisés par les parents pour faire garder leurs enfants à domicile ou ailleurs par des membres de leur famille, des amis, des voisins, des baby-sitters ou des nourrices) ne sont pas couverts dans cet indicateur (pour plus de détails, voir la section « Définitions »).

\section{Taux de fréquentation des structures d'éducation et d'accueil des jeunes enfants}

\section{Taux de fréquentation avant l'âge de 3 ans}

La fréquentation de services d'EAJE de grande qualité peut avoir des effets positifs sur le bien-être, l'apprentissage et le développement des enfants durant les premières années de leur vie (OCDE, 2018[3]).

En moyenne, un tiers environ des enfants de moins de 3 ans fréquentaient une structure d'EAJE à temps plein ou à temps partiel en 2017. Cette moyenne occulte de fortes différences entre les pays. Le pourcentage d'enfants de moins de 3 ans qui fréquentent une structure d'EAJE est inférieur à $5 \%$ au Mexique et en Turquie, mais égal ou supérieur à $50 \%$ en Corée, au Danemark, en Islande, en Israël, au Luxembourg, en Norvège, en NouvelleZélande et aux Pays-Bas (voir le tableau B2.1).

La longueur du congé parental et l'âge à partir duquel les enfants peuvent fréquenter un service d'EAJE influent aussi sur l'âge auquel les enfants commencent à fréquenter une structure d'EAJE. Le taux de fréquentation des enfants de moins de 1 an n'est par exemple supérieur à $10 \%$ que dans 7 des 22 pays dont les données sont disponibles, à savoir en Australie, en Corée, en Espagne, en Israël, au Luxembourg, en Nouvelle-Zélande et au Portugal. Par contraste, à l'âge de 1 an, le taux de fréquentation des services d'EAJE atteint $40 \%$ environ et dépasse les $50 \%$ en Corée, en Islande, en Israël, au Luxembourg, en Norvège et en Nouvelle-Zélande. À l'âge de 2 ans, il est devenu d'usage de fréquenter un service d'EAJE dans de nombreux pays : $62 \%$ des enfants de 
2 ans en fréquentent un. Toutefois, cette moyenne occulte une fois encore une forte variation entre les pays. À l'âge de 2 ans, le taux de fréquentation est inférieur à $20 \%$ au Costa Rica, au Mexique et en Pologne, mais égal ou supérieur à $89 \%$ au Luxembourg et dans tous les pays nordiques, sauf en Finlande (voir le graphique B2.1).

Une tendance commune se dessine malgré ces différences sensibles entre les pays. Le pourcentage d'inscrits avant l'âge de 3 ans est en hausse dans la plupart des pays dont les données de 2010 et 2017 sont disponibles et a augmenté en moyenne de 8 points de pourcentage entre ces deux années (passant de $26 \%$ à $34 \%$ ). Cette augmentation a été particulièrement marquée dans de nombreux pays européens à la suite de l'élan supplémentaire insufflé par la réalisation des objectifs fixés par l'Union européenne (UE) en 2002 lors de la réunion de Barcelone, pour proposer des places à temps plein en structures totalement subventionnées à un tiers des enfants de moins de 3 ans d'ici 2010 (OCDE, 2018[1] $)$. Globalement, l'augmentation de l'offre de services d'EAJE au cours des dernières décennies a grandement contribué à la hausse du taux d'emploi des femmes, en particulier celles dont les enfants ont moins de 3 ans. Les pays où les taux de fréquentation étaient plus élevés avant l'âge de 3 ans en 2017 tendent à compter parmi ceux où les taux d'emploi des mères sont les plus élevés ( (OCDE, 2018[7] ; OCDE, 2018[3]) et le tableau B2.1).

Toutefois, la fréquentation accrue des services d'EAJE ne permet pas de garantir la qualité de l'enseignement dispensé aux enfants. Dans des pays comme la Norvège par exemple, plus de la moitié des enfants de moins de 3 ans fréquentent une structure d'EAJE, où ils suivent des programmes intégrés dans le système d'éducation qui commencent avant l'âge de 1 an et prennent fin au début de l'enseignement primaire. Dans ces programmes, les enfants fréquentent souvent une structure d'EAJE où du personnel formé ou certifié est en poste, et ce, avant même l'âge de 3 ans. Dans d'autres pays où les taux de fréquentation sont élevés, comme en France et aux Pays-Bas, des normes différentes s'appliquent souvent aux structures d'EAJE différentes ou aux groupes d'âge différents (voir le tableau B2.1 et l'encadré B2.1).

\section{Taux de scolarisation entre l'âge de 3 ans et le début de l'enseignement primaire}

Dans de nombreux pays de l'OCDE, la plupart des enfants fréquentent une structure d'EAJE bien avant d'avoir 5 ans et le droit légal à une place dans ces structures est universel pendant un à deux ans avant le début de la scolarité obligatoire. En moyenne, $87 \%$ des enfants âgés de 3 à 5 ans fréquentent une structure d'EAJE (niveau 0 de la CITE) ou un établissement d'enseignement primaire, tout en étant généralement scolarisés dans l'enseignement préprimaire (niveau 02 de la CITE). Dans la moitié des 42 pays dont les données sont disponibles, la fréquentation d'une structure d'EAJE est pratiquement généralisée (supérieure à $90 \%$ ) entre l'âge de 3 et 5 ans (voir le tableau B2.2).

C'est en Belgique, au Danemark, en Espagne, en France, en Hongrie, en Islande, en Israël, en Norvège et au Royaume-Uni que les taux de fréquentation des structures d'EAJE sont les plus élevés à l'âge de 3 ans : ils passent la barre des $95 \%$. Dans les pays de l'OCDE, près de neuf enfants sur dix (88\%) sont scolarisés dans l'enseignement préprimaire ou primaire à l'âge de 4 ans. Dans les pays de l'UE23 (c'est-à-dire les pays membres de l'Union européenne et de l'OCDE), $92 \%$ des enfants sont scolarisés à l'âge de 4 ans. À cet âge, les taux de scolarisation sont égaux ou supérieurs à $98 \%$ en Belgique, au Danemark, en Espagne, en France, en Irlande, en Islande, en Israël et au Royaume-Uni, mais inférieurs à $50 \%$ en Arabie saoudite, en Suisse et en Turquie (voir le tableau B2.2).

Cette situation s'explique par l'expansion des services d'EAJE durant les dernières décennies dans de nombreux pays. Entre 2005 et 2017, le taux moyen de scolarisation des 3-5 ans dans l'enseignement préprimaire ou primaire a augmenté dans les pays de l'OCDE, passant de $76 \%$ à $86 \%$. L'augmentation a été spectaculaire durant cette période dans quelques pays, comme au Chili, en Fédération de Russie, en Israël, en Lituanie, en Pologne et en Turquie. Par contraste, il n'y a pas eu de telle évolution dans d'autres pays. En Suisse par exemple, le taux de fréquentation comptait parmi les moins élevés en, ce qui reste le cas en 2017 (voir le graphique B2.2).

Durant cette période, la plus grande priorité accordée à la politique de l'EAJE a entraîné l'abaissement de l'âge du début de la scolarité obligatoire, un élargissement de l'offre de services gratuits d'EAJE à certains âges et dans certains groupes cibles, la scolarisation généralisée des enfants plus âgés et, dans plusieurs pays, la 
création de programmes intégrés entre l'âge de 1 an et le début de l'enseignement primaire. La scolarité obligatoire débutait par exemple avec l'enseignement primaire il y a une dizaine d'années dans la plupart des pays. Par contraste, elle débute avec l'enseignement préprimaire dans un tiers des pays dont les données de 2017 sont disponibles (voir le tableau B2.2).

\section{Taux de scolarisation dans les structures d'EAJE, selon les entités infranationales}

Le taux de scolarisation des 3-5 ans dans l'enseignement préprimaire ou primaire dépasse désormais les $80 \%$ dans de nombreux pays, mais des différences sensibles d'accès à l'enseignement persistent entre les régions dans ce groupe d'âge. Dans 7 des 23 pays dont les données sont disponibles, le taux de scolarisation varie de plus de 20 points de pourcentage entre les régions où il est respectivement le plus et le moins élevé. Les différences sont par exemple frappantes aux États-Unis, où le taux de fréquentation des structures d'EAJE et de scolarisation dans l'enseignement primaire atteint $80 \%$ entre l'âge de 3 et 5 ans dans le District de Columbia, mais s'établit à $46 \%$ seulement dans le Dakota du Nord (OCDE, 2019 ${ }_{[8]}$ ). Des différences régionales d'une ampleur comparable s'observent en France (de $79 \%$ à Mayotte à $100 \%$ dans plusieurs régions), en Grèce (de $57 \%$ dans l'Attique à $78 \%$ en Macédoine occidentale), en Lituanie (de $65 \%$ à Tauragé à $94 \%$ à Vilnius), en République slovaque (de $63 \%$ dans l'est à $83 \%$ dans l'ouest) et en Suisse (de $39 \%$ en Suisse centrale à $86 \%$ dans le Tessin). Dans certains de ces pays, l'organisation et la gouvernance de l'EAJE varient fortement entre les régions. Les régions sont libres de décider de la priorité et du financement à accorder aux services d'EAJE, ce qui peut entraîner une forte variation des taux de fréquentation (voir l'encadré B2.1 pour plus de détails). Par contraste, la différence entre les régions est inférieure à 8 points de pourcentage en Allemagne, en Estonie, en Hongrie, en Lettonie, aux Pays-Bas, en Slovénie et en Suède. Ce constat souligne l'importance d'une égalité d'accès à l'EAJE entre les territoires et entre le milieu rural et urbain.

\section{Graphique B2.2. Évolution du taux de scolarisation des enfants âgés de 3 à 5 ans $(2005,2010$ et 2017)}

Éducation de la petite enfance (CITE 0) et enseignement primaire

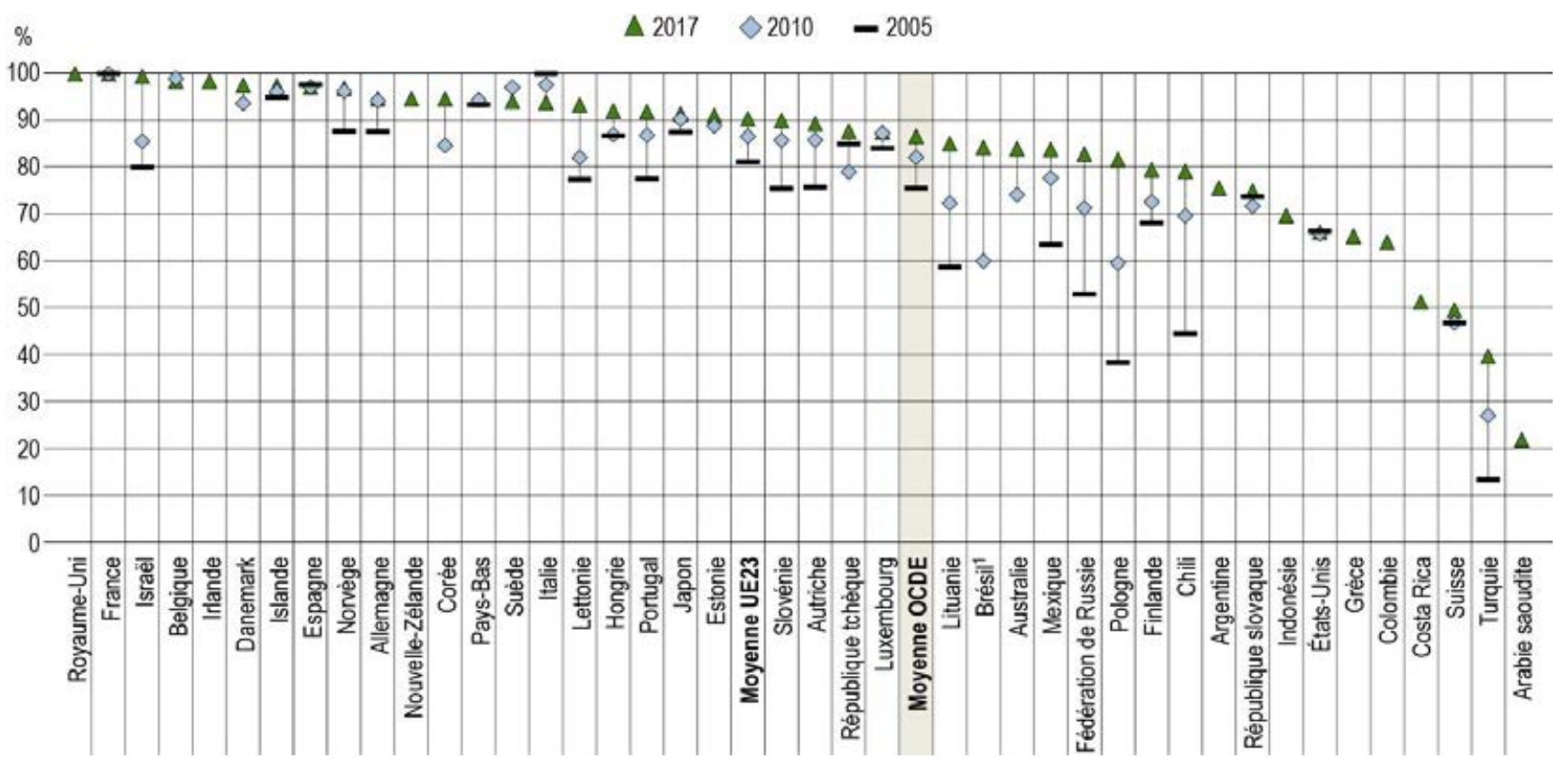

1. Année de référence : 2012, et non 2010.

Les pays sont classés par ordre décroissant du taux de scolarisation des 3-5 ans en 2017.

Source: OCDE (2019). Table B2.2. Consulter la section «Source» pour tout complément d'information et l'annexe 3 pour les notes (https://doi.org/10.1787/f8d7880d-en). 


\section{Taux de scolarisation dans les structures d'EAJE, selon le type de structures}

Les besoins et les attentes des parents concernant l'accessibilité des structures, leur coût, leur programme, la qualité de leur personnel et leur responsabilisation sont autant de facteurs importants à prendre en compte pour évaluer l'essor de l'EAJE et identifier les types de prestataires. Si les établissements publics ne sont pas en mesure de répondre aux besoins et attentes des parents en matière de qualité, d'accessibilité et de responsabilisation, certains parents risquent d'inscrire leur enfant dans des établissements privés (Shin, Jung et Park, 2009[9]).

Dans la plupart des pays, l'effectif des établissements privés est nettement plus élevé dans l'éducation de la petite enfance que dans l'enseignement primaire et secondaire. Il existe deux types d'établissements privés : les établissements privés indépendants et les établissements privés subventionnés par l'État. Les établissements sont considérés comme des établissements privés indépendants si leur gestion relève d'une instance non gouvernementale ou d'un conseil de direction dont les membres ne sont pas désignés par une instance publique et que les pouvoirs publics financent moins de $50 \%$ de leur budget principal. Les établissements privés subventionnés par l'État sont dirigés par des structures similaires, mais les pouvoirs publics financent plus de $50 \%$ de leur budget principal.

En moyenne, dans les pays de l'OCDE, les établissements privés accueillent environ la moitié de l'effectif du développement éducatif de la petite enfance (niveau 01 de la CITE). Cette moyenne occulte toutefois de grandes différences entre les pays. Les établissements privés d'EAJE accueillent au plus $20 \%$ de l'effectif du développement éducatif de la petite enfance au Chili, au Danemark, en Fédération de Russie, en Finlande, en Hongrie, en Islande, en Lettonie, en Lituanie, en Slovénie et en Suède, mais plus de $75 \%$ de cet effectif en Corée, au Costa Rica, en Indonésie, en Israël, en Nouvelle-Zélande et au Royaume-Uni (voir le tableau B2.3).

Les établissements privés accueillent généralement plus d'enfants âgés de moins de 3 ans que d'enfants plus âgés. Deux tiers environ de l'effectif de l'enseignement préprimaire (niveau 02 de la CITE) fréquentent un établissement privé dans les pays de l'OCDE et jusqu'à trois quarts de l'effectif en font de même dans les 23 pays membres de l'UE à l'étude, fruit de la politique visant à promouvoir l'essor de l'offre d'EAJE adoptée dans la plupart des pays européens au cours des deux dernières décennies. Dans quelques pays toutefois, les services d'EAJE restent essentiellement fournis et financés par le secteur privé : au moins $70 \%$ de l'effectif de l'enseignement préprimaire fréquente un établissement privé en Australie, en Corée, en Inde, en Indonésie, en Irlande, au Japon et en Nouvelle-Zélande (voir le tableau B2.3). En Irlande, le gouvernement offre une prime sur le capital investi aux garderies et structures d'accueil de jour fournissant des services d'EAJE.

\section{Financement de l'éducation et de l'accueil des jeunes enfants}

La pérennité des soutiens financiers publics est cruciale pour le développement et la qualité des services d'EAJE. Prévoir un budget adéquat permet de recruter du personnel expérimenté qui dispose des qualifications requises pour stimuler le développement cognitif, social et affectif des enfants. L'investissement dans des structures et leur équipement contribue également au développement d'environnements d'apprentissage centrés sur l'enfant et son bien-être. Dans les pays où le budget public n'est pas à la hauteur des objectifs qui sont de faire en sorte que les services d'EAJE soient à la fois largement accessibles et de grande qualité, les parents peuvent avoir plus tendance à se tourner vers des structures privées d'EAJE. De plus, si le coût de l'EAJE n'est pas suffisamment subventionné, la capacité des parents de le financer influera fortement sur le taux de fréquentation des enfants issus de milieux socio-économiques défavorisés (OCDE, 2018[1] $)$.

\section{Dépenses par enfant}

Dans l'enseignement préprimaire, les dépenses annuelles par enfant au titre des établissements publics et privés s'élèvent en moyenne à 8349 USD dans les pays de l'OCDE ; elles représentent moins de 5000 USD en Colombie, en Fédération de Russie, en Irlande et au Mexique, mais passent la barre des 10000 USD en Allemagne, en Autriche, en Finlande, en Islande, au Luxembourg, en Norvège, en Suède et en Suisse. Les 
dépenses annuelles par enfant au titre du développement éducatif de la petite enfance (niveau 01 de la CITE) s'élèvent en moyenne à 12080 USD ; elles sont nettement plus élevées que celles au titre de l'enseignement préprimaire (niveau 02 de la CITE) dans 10 des 15 pays de l'OCDE dont les données des deux sous-niveaux sont disponibles. Le taux d'encadrement supérieur dans le développement éducatif de la petite enfance (niveau 01 de la CITE) compte parmi les principaux facteurs qui expliquent cette différence (voir les tableaux B2.3 et B2.4). Le nombre moyen d'heures par an pendant lequel les enfants fréquentent leur structure d'EAJE explique aussi la différence de budget entre les pays (voir l'encadré B2.2 dans (OCDE, 2018[10])).

\section{Dépenses en pourcentage du PIB}

Les dépenses au titre de l'EAJE peuvent aussi s'analyser à l'aune de la richesse des pays. Les dépenses au titre de toutes les structures d'EAJE représentent en moyenne $0.8 \%$ du PIB dans les pays de l'OCDE, dont trois quarts au titre des établissements d'enseignement préprimaire. L'Australie, la Colombie, la Grèce, le Japon et la Norvège consacrent au plus $0.3 \%$ de leur PIB à l'enseignement préprimaire, alors que des pays tels que l'Islande et la Suède y consacrent au moins $1 \%$ de leur PIB (voir le tableau B2.4).

Ces différences s'expliquent dans une grande mesure par les taux de fréquentation, l'intensité de la fréquentation, les coûts et les droits légaux et l'âge du début de l'enseignement primaire, qui varient entre les pays. Sur ce dernier point, le fait que l'enseignement préprimaire dure moins longtemps puisque l'enseignement primaire commence plus tôt en Australie, en Irlande, en Nouvelle-Zélande et au Royaume-Uni explique en partie pourquoi les dépenses au titre de l'EAJE sont inférieures à la moyenne de l'OCDE en pourcentage du PIB dans ces quatre pays. De même, le début plus tardif de l'enseignement primaire, qui s'observe par exemple en Estonie, en Finlande, en Lettonie, en Pologne et en Suède, implique que la fréquentation des structures d'EAJE est plus longue et peut expliquer pourquoi les dépenses sont plus élevées en pourcentage du PIB dans certains pays que dans d'autres (voir l'âge du début de l'enseignement primaire dans les tableaux B2.1 et B2.4).

Graphique B2.3. Dépenses au titre de l'enseignement des enfants âgés de 3 à 5 ans scolarisés dans une structure d'éducation et d'accueil des jeunes enfants (CITE 0) ou dans l'enseignement primaire, en pourcentage du PIB (2016)

Établissements publics et privés

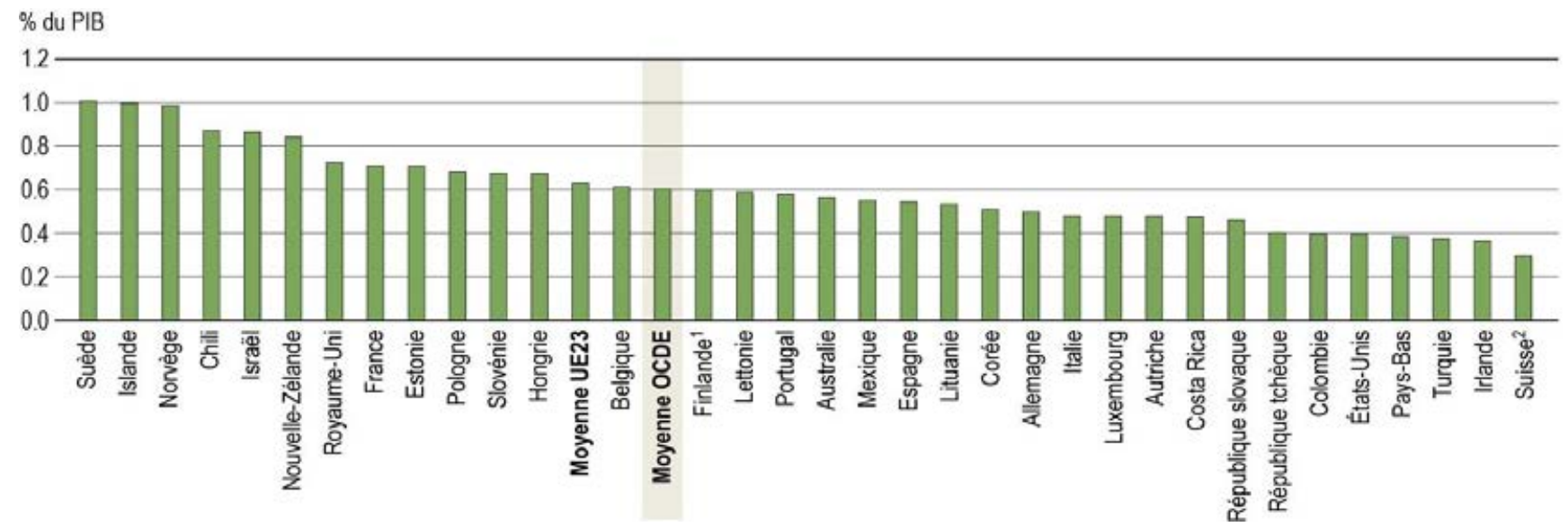

1. Les dépenses au titre de tous les enfants âgés de 3 à 5 ans sont sous-estimées en raison de la méthode d'estimation utilisée.

2. Sources publiques uniquement.

Les pays sont classés par ordre décroissant des dépenses en pourcentage du PIB.

Source: OCDE (2019). Tableau B2.4. Consulter la section "Source» pour tout complément d'information et l'annexe 3 pour les notes (https://doi.org/10.1787/f8d7880d-en). 
Pour éviter ce biais, les dépenses au titre de l'EAJE sont désormais présentées par âge ainsi que par niveau de la CITE dans cet indicateur. Comme c'est la première fois que les dépenses sont estimées sur la base de l'effectif total de l'EAJE et de l'enseignement primaire entre l'âge 3 et 5 ans, ces chiffres doivent être interprétés avec prudence. Cette nouvelle méthodologie a le mérite d'éviter les biais résultant des différences entre les groupes d'âge dans l'effectif de l'EAJE et de l'enseignement primaire et permet de comparer les dépenses par âge, ce qui donne un aperçu plus précis de l'investissement des pays dans la petite enfance. Dans les pays de l'OCDE, la part de la richesse nationale affectée aux services d'EAJE et à l'enseignement primaire entre l'âge de 3 et 5 ans s'élève à $0.6 \%$ du PIB. Cette part est inférieure à $0.4 \%$ du PIB en Colombie, aux États-Unis, en Irlande, aux Pays-Bas, en République tchèque, en Suisse et en Turquie, mais est supérieure à $0.8 \%$ du PIB au Chili, en Islande, en Israël, en Norvège, en Nouvelle-Zélande et en Suède (voir le graphique B2.3).

\section{Financement public et privé de l'EAJE}

La source du financement des structures d'EAJE varie entre les pays. Dans de nombreux pays, les enfants ont tous accès à une structure publique d'EAJE à partir d'un âge donné. De nombreux gouvernements délèguent aux autorités locales la responsabilité du financement public des services d'EAJE. En règle générale, le financement public est plus décentralisé dans l'EAJE qu'à tout autre niveau d'enseignement (OCDE, 2018 [11]).

Dans l'ensemble, le budget public de l'EAJE est considérable et en hausse, bien que des différences s'observent entre l'enseignement préprimaire (niveau 02 de la CITE) et le développement éducatif de la petite enfance (niveau 01 de la CITE). En moyenne, les pouvoirs publics financent $69 \%$ des dépenses totales au titre du développement éducatif de la petite enfance, mais $83 \%$ au titre de l'enseignement préprimaire. Le Japon et le Royaume-Uni sont les seuls pays où la part privée du budget total de l'enseignement préprimaire représente plus de $40 \%$. Au Royaume-Uni, la plupart des dépenses privées sont supportées par les ménages. Au Japon, le coût élevé est réparti entre les ménages, les fondations et les entreprises (voir le tableau B2.4).

\section{Encadré B2.1. Qui a la responsabilité de l'éducation et de l'accueil des jeunes enfants?}

La gouvernance de l'EAJE varie entre les pays (voir le graphique B2.a).

Actuellement, le système est intégré dans près de la moitié des pays de l'OCDE : la gestion de tous les services d'EAJE est du ressort d'une seule instance à l'échelle nationale ou régionale. Dans tous les pays où le système est intégré, sauf en Hongrie et en Islande, le ministère de l'Éducation est l'instance responsable au niveau central de l'effectif total de l'EAJE. La mission de cette instance responsable varie selon les pays, de la conception des programmes de cours à la définition des normes d'accueil, en passant par le contrôle et le financement. Ces pays ont également conçu un programme intégré d'EAJE adapté à l'âge des enfants entre l'âge de moins de 1 an et le début de l'enseignement primaire. Un nombre croissant de pays se sont orientés vers ce type de système intégré.

Le système est hybride dans 10 des 36 pays dont les données sont disponibles. Dans bon nombre des pays concernés, l'accueil et l'éducation de la petite enfance sont deux compétences différentes qui relèvent d'autorités différentes. Dans ces pays, les services d'EAJE sont sous la tutelle des ministères en charge des affaires sociales, de la famille, de la santé ou de la protection sociale s'ils accueillent des enfants de moins de 3 ans, mais sous la tutelle du ministère en charge de l'éducation s'ils accueillent des enfants de plus de 3 ans. Dans les pays où le système est hybride, il est fréquent que les normes de qualité varient entre les services d'EAJE et entre les groupes d'âge. II est fréquent aussi que les services d'EAJE pour enfants de moins de 3 ans ne s'inscrivent pas dans le niveau 0 de la CITE dans ces pays. Par contraste, dans tous les pays où le système est intégré, les mêmes normes de qualité s'appliquent à tous les services d'EAJE. 


\section{Graphique B2.a. Qui a la responsabilité de l'éducation et de l'accueil des jeunes enfants (EAJE) ?}

L'ensemble du système d'EAJE

(CITE 01 et CITE 02) est sous la

responsabilité du ministère de l'Éducation.

\begin{abstract}
L'enseignement préprimaire (CITE 02)
est administré sous la responsabilité du ministère de l'Éducation.

Les services d'EAJE à destination des enfants plus jeunes (CITE 01 et autres services ne relevant pas de la CITE) sont sous la responsabilité d'une autre autorité (par exemple, ministère de la Santé et de la Protection sociale : ministère du Travail, des Affaires sociales et de la Famille) ou soumis à des dispositions régionales.
\end{abstract}

L'ensemble du système d'EAJE (CITE 01 et 02) est administré par différentes autorités (qui peuvent varier en fonction des dispositions régionales).

\begin{tabular}{l}
\multicolumn{1}{c}{17 pays } \\
Australie, Brésil, Chili, Costa Rica, \\
Estonie, Espagne, Finlande, Hongrie', \\
Islande $^{2}$, Lettonie, Lituanie, Luxembourg, \\
Nouvelle-Zélande, Norvège, Royaume-Uni $^{3}$, \\
Slovénie et Suède
\end{tabular}

\section{0 pays}

Belgique, France, Italie, Corée ${ }^{4}$, Pays-Bas 5 , Pologne, Portugal ${ }^{4}$, République slovaque, République tchèque et Suisse

\section{9 pays}

Allemagne, Autriche ${ }^{6}$, Canada, Colombie? Danemark, États-Unis, Irlande ${ }^{8}$, Japon et Mexique

1. Le Secrétariat d'État à l'éducation est responsable de la CITE 0 , tandis que le Secrétariat d'État à la Famille et à la Jeunesse est responsable des services d'EAJE ne relevant pas de la CITE 0 . Tous deux opèrent sous l'égide du ministère des Ressources humaines.

2. L'ensemble du système d'EAJE (CITE 01 et CITE 02) est administré sous la responsabilité du ministère de la Santé et de la Protection sociale. 3. En Angleterre, en Écosse et en Irlande du Nord, l'ensemble du système d'EAJE est sous la responsabilité du ministère de l'Éducation, tandis qu'au Pays de Galles, les services d'EAJE à destination des enfants plus jeunes sont sous la responsabilité du ministère de la Santé et de la Protection sociale.

4. Au niveau CITE 02, les autorités en charge de la santé et de la protection sociale jouent également un rôle important.

5. Pour les enfants de 3 ans, les autorités en charge de la protection sociale sont responsables de l'EAJE, à l'exception des programmes ciblés, qui sont sous la responsabilité des autorités en charge de l'éducation. Pour les enfants de 4 et 5 ans, les autorités en charge de l'éducation sont responsables de l'EAJE.

6. Le Tageseltern, le Kinderkrippe et le Kindergarten relèvent de la législation régionale ; ce sont en revanche les autorités en charge de l'éducation qui ont la responsabilité du Vorschulstufe (CITE 02).

7. L'ensemble du système EAJE est placé sous l'autorité de la Commission intersectorielle pour la petite enfance, composée de plusieurs secteurs. 8. Le Département de l'enfance et de la jeunesse, en collaboration avec le Département de l'éducation et des compétences, a la responsabilité globale des politiques relatives à l'EAJE.

Source : Enquête ad hoc du réseau INES. Consulter la section "Source » pour tout complément d'information et l'annexe 3 pour les notes (https://doi.org/10.1787/f8d7880d-en).

Enfin, dans un troisième groupe de pays, l'ensemble du système d'EAJE (niveaux 01 et 02 de la CITE) est administré par différentes autorités (qui peuvent varier en fonction des dispositions régionales) et la plupart des services d'EAJE respectent les critères du niveau 0 de la CITE. Les pays de ce groupe sont souvent des États fédéraux. En Autriche par exemple, les services de développement de la petite enfance (niveau 01 de la CITE) sont réglementés à l'échelle régionale, tandis que l'enseignement préprimaire (niveau 02 de la CITE) est sous la tutelle du ministère de l'Éducation. En Irlande, le Département de l'enfance et de la jeunesse, en collaboration avec le Département de l'éducation et des compétences, a la responsabilité globale des politiques relatives à l'EAJE. Enfin, en Allemagne, l'ensemble des services d'EAJE, tous groupes d'âge confondus, relève de l'aide sociale et est sous la tutelle du ministère fédéral en charge des affaires familiales, des personnes âgées, des femmes et des jeunes ainsi que des Länder et des municipalités. Dans la plupart des pays de ce groupe, le programme de cours est intégré et les objectifs d'apprentissage sont définis entre l'âge de 0 ou 1 an jusqu'au début de l'enseignement primaire (OCDE, 2018[1]).

En principe, les enfants n'éprouvent aucune difficulté à passer des structures d'accueil de la petite enfance à l'enseignement préprimaire dans les pays où le système d'EAJE est intégré, car le programme de cours est 
généralement commun entre l'âge de 1 et 5 ans, ce qui vaut pour la majorité des pays dont les données sont disponibles. Par contraste, il peut y avoir des différences fondamentales d'objectifs, de moyens et de qualité entre les services d'accueil et les structures préprimaires dans les pays où le système est hybride ou à deux niveaux. Dans ces pays, les enfants et les familles risquent de manquer de cohérence en raison de différences prêtant à confusion dans les objectifs, les financements, les procédures, les cadres et la formation et la qualification du personnel.

\section{Personnel des services d'éducation et d'accueil des jeunes enfants}

\section{Qualifications minimales requises du personnel enseignant des services d'EAJE}

Les futurs enseignants doivent pouvoir suivre une formation initiale de grande qualité. La durée et le contenu des cursus proposés et les types de qualifications les sanctionnant sont autant de facteurs qui influent sur la mesure dans laquelle la formation initiale prépare les enseignants à exercer leur profession. II ressort de la littérature que le niveau et la durée de la formation initiale du personnel enseignant sont en corrélation positive avec la qualité globale de l'EAJE (Manning, 2017 $[12]$ ). Si le personnel est hautement qualifié, l'environnement peut être plus stimulant et les pratiques pédagogiques, de grande qualité, ce qui améliore le bien-être des enfants et les résultats de leur apprentissage (Litjens, 2010[13]).

Les formations d'enseignant d'EAJE relèvent de l'enseignement tertiaire dans la quasi-totalité des pays. Dans 19 des 25 pays dont les données sont disponibles, les individus au moins titulaires d'une licence (ou d'un diplôme équivalent), c'est-à-dire les diplômés du niveau 6 de la CITE, peuvent enseigner dans un service d'EAJE (niveau 0 de la CITE) dès la fin de leur formation initiale. Ce constat souffre toutefois quelques exceptions. En République slovaque, un diplôme du deuxième cycle de l'enseignement secondaire suffit pour donner cours dans l'enseignement préprimaire, mais un nombre croissant d'enseignants sont désormais titulaires d'un diplôme de licence ou de master. En Allemagne, un diplôme sanctionnant une formation professionnelle tertiaire suffit (Erzieherausbildung, niveau 6 de la CITE), tandis qu'en Autriche et en Israël, le diplôme le plus courant est celui sanctionnant une formation tertiaire de cycle court (niveau 5 de la CITE) de deux ans. À l'autre extrémité du spectre, les enseignants en poste dans l'enseignement préprimaire doivent être diplômés du niveau 7 de la CITE (master ou cursus équivalent) en France, en Pologne et au Portugal (voir le tableau B2.3). En France, depuis l'année scolaire 2010/2011, tout étudiant aspirant à devenir enseignant dans un service d'EAJE ou dans l'enseignement primaire doit obtenir un master ou un diplôme équivalent (voir le tableau B2.3).

On ne peut toutefois attendre de la formation initiale, quelle que soit sa qualité, qu'elle prépare les futurs enseignants à tous les défis qu'ils auront à relever durant leur carrière. Au vu de l'évolution du profil démographique des élèves, de la longueur de la carrière de beaucoup d'enseignants et de la nécessité d'actualiser les connaissances et les compétences, la formation initiale des enseignants doit être considérée seulement comme la première étape d'un développement permanent des enseignants. II ressort d'études récentes que dans l'enseignement préprimaire, la formation continue spécialisée a plus d'effets que la formation initiale, en particulier concernant le travail collaboratif, l'encadrement des activités ludiques et l'initiation à la lecture et à l'écriture, aux mathématiques et aux sciences (Assel, 2006[14] ; de Haan, 2013[15]).

\section{Taux d'encadrement}

Des recherches montrent que des environnements riches et stimulants et une pédagogie de qualité reposent sur du personnel plus qualifié et que la qualité des interactions entre le personnel et les enfants sont à la clé d'un meilleur rendement de l'apprentissage. Des taux d'encadrement plus élevés sont systématiquement associés à des relations de qualité entre le personnel et les enfants dans l'EAJE. Il est courant de considérer que des taux plus élevés sont bénéfiques, car ils permettent au personnel de se concentrer davantage sur les besoins de chacun des enfants et de passer moins de temps à gérer les perturbations pendant l'apprentissage (OCDE, 2018[16]). 
Le taux d'encadrement est un indicateur important des moyens mobilisés en faveur de l'éducation. La taille des classes et les taux d'encadrement sont les leviers les plus couramment utilisés pour améliorer la qualité de I'EAJE. Dans les pays de l'OCDE, on compte en moyenne 16 enfants par enseignant dans l'enseignement préprimaire, mais ce ratio varie fortement entre les pays. Abstraction faite des auxiliaires d'éducation, on compte plus de 20 enfants par enseignant en Afrique du Sud, au Brésil, au Chili, en Colombie, en France, en Israël, au Mexique et au Royaume-Uni, mais moins de 10 enfants par enseignant en Allemagne et en Finlande (voir le tableau B2.3).

\section{Graphique B2.4. Taux d'encadrement dans l'enseignement préprimaire (CITE 02) (2017)}

Établissements publics et privés, calculs fondés sur des équivalents temps plein

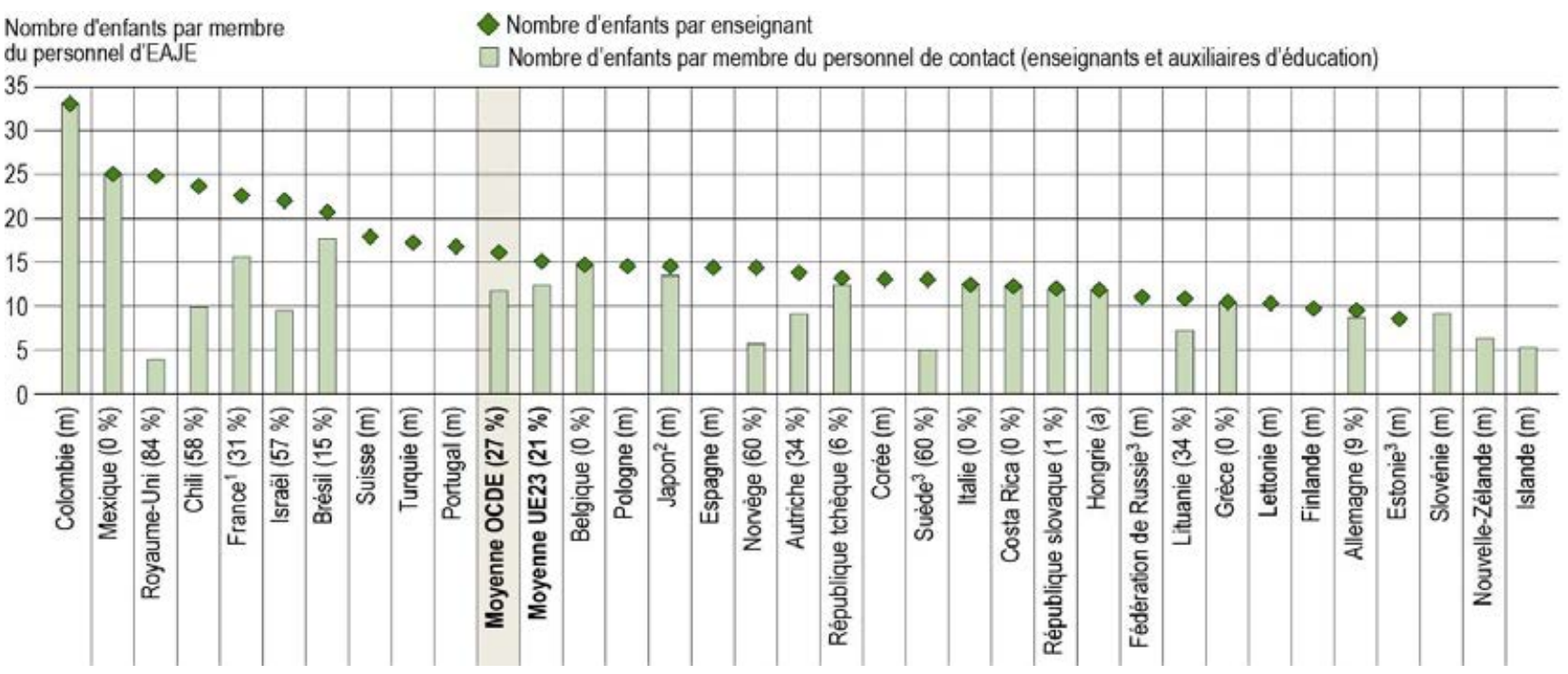

Remarque : Les chiffres entre parenthèses indiquent le pourcentage d'auxiliaires d'éducation dans le personnel de contact d'EAJE (enseignants et auxiliaires d'éducation).

1. À l'exclusion des établissements privés indépendants. Les données sur les enseignants ne sont pas comparables avec les années précédentes en raison de l'introduction d'une nouvelle méthodologie.

2. Les données sur le personnel n'incluent pas l'ensemble des services d'EAJE.

3. CITE 0, et non enseignement préprimaire (CITE 02).

Les pays sont classés par ordre décroissant du nombre d'enfants par enseignant dans l'enseignement préprimaire.

Source : OCDE (2019). Tableau B2.3. Consulter la section "Source» pour tout complément d'information et l'annexe 3 pour les notes (https://doi.org/10.1787/f8d7880d-en).

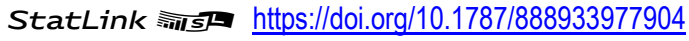

Certains pays, comme l'Autriche, le Chili, la France, Israël, la Lituanie, la Norvège, le Royaume-Uni et la Suède, recourent également beaucoup aux auxiliaires d'éducation dans l'enseignement préprimaire, ce qui peut se traduire par de meilleurs taux d'encadrement par membre du personnel de contact que par enseignant. Les auxiliaires d'éducation aident les enseignants dans leurs tâches quotidiennes et s'occupent des enfants ayant des besoins spécifiques. Dans la plupart des pays, ils sont diplômés du deuxième cycle de l'enseignement secondaire, souvent en filière professionnelle (voir le tableau B2.3 et le graphique B2.4).

Le nombre d'enfants par membre du personnel a plus d'importance pour les interactions avec les enfants de moins de 3 ans que pour celles avec les enfants de 3 à 5 ans (OCDE, 2018[16]). Dans la plupart des pays, les taux d'encadrement sont plus élevés dans le développement éducatif de la petite enfance que dans l'enseignement préprimaire. En moyenne, dans les 13 pays de l'OCDE dont les données des deux sous-niveaux de l'éducation de la petite enfance sont disponibles, on compte 12 enfants par personnel de contact (enseignant 
ou auxiliaire d'éducation) dans l'enseignement préprimaire, contre 5 enfants seulement par enseignant dans le développement éducatif de la petite enfance (voir le tableau B2.3). Toutefois, le nombre d'heures par semaine qui correspond à une scolarisation à temps plein au niveau 0 de la CITE varie fortement entre les pays ; c'est pourquoi la prudence est de mise lors de l'interprétation de ces données (voir la section « Méthodologie »).

\section{Définitions}

Le terme « adultes » désigne la population âgée de 25 à 64 ans.

Services d'EAJE : les types de services et de structures d'EAJE à la disposition des enfants et des parents sont très diversifiés. En dépit de cette grande diversité, la plupart des structures d'EAJE relèvent de l'une des catégories suivantes (voir (OCDE, 2018[1] $)$ et le tableau B2.5) :

- Centres d'EAJE ordinaires : les centres d'EAJE institutionnalisés appartiennent généralement à l'une des trois sous-catégories suivantes :

- Centres d'EAJE pour enfants de moins de 3 ans : ces structures, souvent appelées " crèches », peuvent avoir une vocation pédagogique, mais elles sont généralement rattachées au secteur de la protection sociale et axées sur les soins aux jeunes enfants. Elles proposent souvent un accueil à temps partiel et sont souvent implantées dans les établissements d'enseignement, mais il s'agit parfois de structures autonomes.

- Centres d'EAJE pour enfants à partir de 3 ans: ces structures, souvent appelées « écoles maternelles » ou " jardins d'enfants », sont en général plus institutionnalisées et sont souvent liées au système d'éducation.

- Centres d'EAJE pour enfants entre l'âge de 1 an et le début de l'enseignement primaire: ces structures, souvent appelées "écoles maternelles» ou établissements d'enseignement " préscolaire » ou " préprimaire », proposent une démarche holistique d'éducation et d'accueil (souvent à temps plein).

- Garde familiale d'enfants : il s'agit de services d'EAJE à domicile, très courants pour les enfants de moins de 3 ans. Ces services n'ont pas nécessairement de vocation pédagogique et ne font pas nécessairement partie du système d'EAJE ordinaire.

- Centres d'EAJE institutionnels ou haltes-garderies : ces structures accueillent souvent des enfants dont l'âge correspond à toute la tranche d'âge de l'EAJE, voire au-delà. Elles viennent en complément de la garde familiale d'enfants à domicile, car ce sont des services institutionnalisés à la carte (sans place attitrée).

Certains de ces services d'EAJE respectent les critères définis dans la CITE 2011 (voir la définition du niveau 0 de la CITE), mais d'autres ne les respectent pas tous, même s'ils font partie intégrante de l'offre nationale de services d'EAJE. Le tableau B2.5 fait explicitement la distinction entre ces deux catégories.

Services de garde informels : les services informels organisés par les parents pour faire garder leur enfant à domicile ou ailleurs par des membres de leur famille, des amis, des voisins, des baby-sitters ou des nourrices ne sont pas couverts dans cet indicateur.

Le niveau 01 de la CITE correspond au développement éducatif de la petite enfance, qui concerne principalement les enfants de moins de 3 ans. Les programmes de cette catégorie se caractérisent par un environnement d'apprentissage stimulant sur le plan visuel et riche sur le plan linguistique ; ils encouragent l'expression personnelle, tout en mettant l'accent sur l'acquisition du langage et son utilisation au service d'une communication sensée. Ils proposent des jeux actifs pour que les enfants puissent améliorer leur coordination et leur motricité, sous la supervision d'éducateurs et en interaction avec ceux-ci.

Le niveau 02 de la CITE correspond à l'enseignement préprimaire, qui concerne les enfants âgés de 3 à 5 ans, c'est-à-dire juste avant le début de la scolarité obligatoire. L'enseignement préprimaire vise à amener les enfants, 
au travers des interactions avec leurs pairs et les éducateurs, à améliorer leur utilisation du langage et leurs aptitudes sociales, à développer leurs compétences de raisonnement logique et à s'exprimer au fil de leurs processus de réflexion. Les enfants améliorent leur compréhension et leur utilisation du langage ; ils sont initiés à des concepts alphabétiques et mathématiques et encouragés à explorer le monde qui les entoure. Des activités supervisées de motricité (c'est-à-dire de l'exercice physique au travers de jeux et autres activités) et de jeu peuvent être utilisées comme opportunités d'apprentissage pour favoriser les interactions sociales entre pairs et développer aptitudes, autonomie et préparation à l'école.

Dans les collectes de données, les programmes intégrés sont répartis entre les deux sous-niveaux selon qu'ils ciblent principalement les enfants de moins de 3 ans (sous-niveau 01) ou de plus de 3 ans (sous-niveau 02). Cette méthode peut impliquer une estimation des dépenses et des taux d'encadrement dans les sous-niveaux 01 et 02 .

Enseignants et professionnels assimilés: les enseignants sont les professionnels principalement responsables des enfants en classe ou dans la salle de jeu. La dénomination de leur profession varie (pédagogue, éducateur, etc.), tandis que celle d'enseignant est dans l'ensemble utilisée à partir de l'enseignement primaire.

Auxiliaires d'éducation : ils aident les enseignants à prendre en charge un groupe ou une classe d'enfants. Les qualifications minimales requises sont généralement inférieures à celles des enseignants. Aucune qualification n'est exigée dans certains cas, mais une qualification, professionnelle par exemple, est exigée dans d'autres cas. Cette catégorie de personnel est uniquement incluse dans l'indicateur sur le taux d'encadrement dans Regards sur l'éducation.

Voir la définition des dépenses unitaires au titre des établissements d'enseignement, des dépenses au titre des établissements d'enseignement en pourcentage du PIB et des taux d'encadrement dans les indicateurs C1, C2 et D2.

\section{Méthodologie}

\section{Taux de scolarisation}

Les taux nets de scolarisation sont calculés comme suit : les effectifs de l'EAJE dans le groupe d'âge considéré sont divisés par la population totale de ce groupe d'âge. Les chiffres sur la démographie et la scolarisation se rapportent à la même période dans la plupart des cas, mais des décalages dus au manque de données et aux différentes sources utilisées expliquent pourquoi les taux de scolarisation sont supérieurs à $100 \%$ dans certains pays.

\section{Scolarisation à temps plein ou partiel}

Les concepts utilisés pour définir la scolarisation à temps plein et à temps partiel dans d'autres niveaux de la CITE, tels que la charge d'étude, la fréquentation et la valeur académique ou la progression dans le parcours scolaire, ne sont pas aisément applicables au niveau 0 de la CITE. De plus, le nombre d'heures par jour ou par semaine qui correspond à une scolarisation à temps plein au niveau 0 de la CITE varie fortement entre les pays. C'est pourquoi les effectifs ne peuvent être calculés en équivalents temps plein de la même façon au niveau 0 de la CITE qu'aux autres niveaux de la CITE.

Dans les collectes de données, les pays font la distinction entre les sous-niveaux 01 et 02 du niveau 0 de la CITE sur la base de l'âge uniquement : les programmes intégrés sont répartis entre les deux sous-niveaux selon qu'ils ciblent principalement les enfants de moins de 3 ans (sous-niveau 01) ou de plus de 3 ans (sous-niveau 02). Cette méthode peut impliquer une estimation des dépenses et des taux d'encadrement dans les sous-niveaux 01 et 02 . 
Pour de plus amples informations, veuillez consulter Guide de l'OCDE pour l'établissement de statistiques internationalement comparables dans le domaine de l'éducation (OCDE, 2019[17]) et l'annexe 3 pour les notes spécifiques aux pays (https://doi.org/10.1787/f8d7880d-en).

\section{Estimation des dépenses au titre de l'EAJE et de l'enseignement primaire entre l'âge de 3 et 5 ans}

Ce nouvel indicateur est basé sur la répartition des enfants âgés de 3 à 5 ans entre les niveaux 01 et 02 de la CITE et l'enseignement primaire (niveau 1 de la CITE). Il est dérivé dans chaque pays du pourcentage d'enfants de 3 à 5 ans à chacun de ces trois niveaux de la CITE. En Australie par exemple, l'effectif d'enfants de 3 à 5 ans se répartit comme suit entre les niveaux de la CITE : $5 \%$ au niveau $01,99 \%$ au niveau 02 et $12 \%$ au niveau 1. Ces pourcentages ont été utilisés pour estimer les dépenses totales de l'EAJE et de l'enseignement primaire entre l'âge de 3 et 5 ans. Les dépenses totales au titre de l'effectif total d'enfants de 3 à 5 ans correspondent à $5 \%$ des dépenses au titre du niveau 01 de la CITE, à $99 \%$ des dépenses au titre du niveau 02 de la CITE et à $12 \%$ des dépenses au titre du niveau 1 de la CITE. La même estimation a été calculée dans chaque pays.

\section{Source}

Les données se rapportent à l'année de référence 2017 (année académique 2016/17) et à l'année budgétaire 2016 .

Les données de l'Afrique du Sud, de l'Arabie saoudite, de l'Argentine, de l'Inde, de l'Indonésie et de la République populaire de Chine proviennent de l'Institut de statistique de l'UNESCO (ISU).

Les données proviennent de l'exercice UNESCO-ISU/OCDE/Eurostat de collecte de données statistiques sur l'éducation réalisé par l'OCDE en 2018 (pour plus de précisions, voir l'annexe 3, https://doi.org/10.1787/f8d7880d-en) ainsi que d'une enquête spéciale menée par l'OCDE en 2018.

Les données infranationales de certains indicateurs sont disponibles dans la Base de données régionales de l'OCDE (OCDE, 2019[8]).

\section{Remarque concernant les données fournies par Israël}

Les données statistiques concernant Israël sont fournies par et sous la responsabilité des autorités israéliennes compétentes. L'utilisation de ces données par l'OCDE est sans préjudice du statut des hauteurs du Golan, de Jérusalem-Est et des colonies de peuplement israéliennes en Cisjordanie aux termes du droit international.

\section{Références}

Assel, M. (2006), « An evaluation of curriculum, setting, and mentoring on the performance of children enrolled in prekindergarten" ", Reading and Writing, vol. 20/5, pp. 463-494, http://dx.doi.org/10.1007/s11145-006-9039-5.

de Haan, A. (2013), « Targeted versus mixed preschools and kindergartens: Effects of class composition and teacher-managed activities on disadvantaged children's emergent academic skills », School Effectiveness and School Improvement, vol. 24/2, https://doi.org/10.1080/09243453.2012.749792.

Duncan, G. et K. Magnuson (2013), « Investing in preschool programs », Journal of Economic Perspectives, vol. 27/2, pp. 109-132, http://dx.doi.org/10.1257/jep.27.2.109. 
Litjens, I. (2010), Literature overview for the 7th meeting of the OECD network on early childhood education, OCDE, Paris.

Manning, M. (2017), « The relationship between teacher qualification and the quality of the early childhood education and care environment" », Campbell Systematic Review, vol. 13/1, http://dx.doi.org/10.4073/csr.2017.1.

OCDE (2019), Base de données de statistiques régionales - Taux de scolarisation par âge, http://stats.oecd.org/Index.aspx?DataSetCode=REGION EDUCAT.

OCDE (2019), Guide de l'OCDE pour l'établissement de statistiques internationalement comparables dans le domaine de l'éducation 2018: Concepts, normes, définitions et classifications, Éditions OCDE, Paris, https://dx.doi.org/10.1787/9789264305380-fr.

OCDE (2018), « Accès aux services d'éducation et d'accueil des jeunes enfants: Quel impact sur la participation des femmes au marché du travail ? », Les indicateurs de l'éducation à la loupe, $n^{\circ} 59$, Éditions OCDE, Paris, https://dx.doi.org/10.1787/197fe9c5-fr.

OCDE (2018), Base de données de l'OCDE sur la famille, http://www.oecd.org/els/family/database.htm.

OCDE (2018), Base de données de l'OECD sur l'éducation, http://www.oecd.org/education/database.htm.

OCDE (2018), Engaging Young Children: Lessons from Research about Quality in Early Childhood Education and Care, Starting Strong, Éditions OCDE, Paris, http://dx.doi.org/10.1787/9789264085145-en.

OCDE (2018), Petite enfance, grands défis 2017: Les indicateurs clés de l'OCDE sur l'éducation et l'accueil des jeunes enfants, Petite enfance, grands défis, Éditions OCDE, Paris, https://dx.doi.org/10.1787/9789264300491-fr.

OCDE (2018), Regards sur l'éducation 2018 : Les indicateurs de l'OCDE, Éditions OCDE, Paris, https://dx.doi.org/10.1787/eag-2018-fr.

OCDE (2016), Walking the Tightrope: Background Brief on Parents' Work-Life Balance across the Stages of Childhood, OCDE, Paris, http://www.oecd.org/social/family/Background-brief-parentswork-life-balance-stages-childhood.pdf.

OCDE (2011), Comment va la vie ?: Mesurer le bien-être, Éditions OCDE, Paris, https://dx.doi.org/10.1787/9789264121195-fr.

OCDE/Eurostat/Institut de statistique de I'UNESCO (2016), Guide opérationnel CITE 2011: Directives pour la classification des programmes éducatifs nationaux et des certifications correspondantes, Institut de statistique de l'UNESCO, Paris, https://dx.doi.org/10.1787/9789264248823-fr.

Shin, E., M. Jung et E. Park (2009), A Survey on the Development of the Pre-school Free Service Model, Korean Educational Development Institute. 


\section{Tableaux de l'indicateur B2}

Tableau B2.1

Tableau B2.2

Tableau B2.3

Tableau B2.4
Taux de scolarisation des enfants de moins de 3 ans dans les structures d'éducation et d'accueil de la petite enfance, selon le type de service et l'âge (2005, 2010 et 2017)

Taux de scolarisation dans les structures d'éducation et d'accueil des jeunes enfants (EAJE) et l'enseignement primaire, selon l'âge (2005, 2010 et 2017)

Taux de scolarisation des enfants dans les structures privées d'éducation et d'accueil des jeunes enfants (CITE 0), taux d'encadrement et qualifications minimales requises (2017)

Financement des structures d'éducation et d'accueil des jeunes enfants (CITE 0 ) et évolution des dépenses en pourcentage du PIB (2012 et 2016)

WEB Tableau B2.5 Services d'éducation et d'accueil des jeunes enfants en place dans les pays de l'OCDE et les pays partenaires

Date butoir pour les données : 19 juillet 2019. Les mises à jour peuvent être consultées en ligne à l'adresse : http://dx.doi.org/10.1787/eag-data-en. D'autres données désagrégées sont également disponibles dans la Base de données de Regards sur l'éducation (http://stats.oecd.org/).

StatLink : https://doi.org/10.1787/888933980944 
Tableau B2.1. Taux de scolarisation des enfants de moins de 3 ans dans les structures d'éducation et d'accueil de la petite enfance, selon le type de service et l'âge $(2005,2010$ et 2017)

Structures publiques et privées

\begin{tabular}{|c|c|c|c|c|c|c|c|c|c|c|c|c|c|c|c|c|c|c|}
\hline & \multirow[b]{3}{*}{$\begin{array}{l}\text { Age auquel les services } \\
\text { d'EAJE (CITE 0) } \\
\text { commencent } \\
\text { a comporter } \\
\text { une composante } \\
\text { educative intentionnelle }\end{array}$} & \multirow{2}{*}{\multicolumn{3}{|c|}{\begin{tabular}{|c|} 
Avant l'âge de 1 an \\
2017
\end{tabular}}} & \multirow{2}{*}{\multicolumn{3}{|c|}{$\begin{array}{l}1 \text { an } \\
2017\end{array}$}} & \multirow{2}{*}{\multicolumn{3}{|c|}{\begin{tabular}{|c|} 
Avant l'âge de 2 ans \\
2017
\end{tabular}}} & \multirow{2}{*}{\multicolumn{3}{|c|}{$\begin{array}{l}2 \text { ans } \\
2017\end{array}$}} & \multicolumn{5}{|c|}{ Avant I'ãge de 3 ans } \\
\hline & & & & & & & & & & & & & & & 2017 & & 2010 & 2005 \\
\hline & & 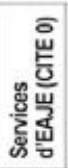 & 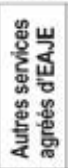 & 종 & 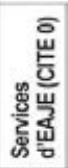 & 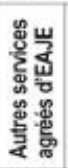 & 종 & 畩 & 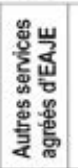 & 젱 & 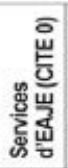 & 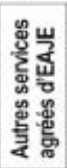 & 푱 & 总 & 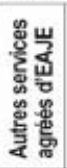 & 종 & 쫑 & 푱 \\
\hline & (1) & (2) & (3) & (4) & (5) & (6) & (7) & (8) & (9). & (10) & (11) & (12) & (13) & (14) & (15) & (16) & (17) & (18) \\
\hline 巴 Pays & & & & & & & & & & & & & & & & & & \\
\hline Oustralie & 0 an & 16 & 0 & 16 & 43 & 0 & 44 & 30 & 0 & 31 & 57 & 0 & 57 & 39 & 0 & 40 & 38 & $\mathrm{~m}$ \\
\hline Autriche & 0 an & 1 & $x(15)$ & 1 & 14 & $x(15)$ & 14 & 7 & $x(15)$ & 7 & 40 & $x(15)$ & 40 & 18 & 3 & 21 & 12 & m \\
\hline Belgique & $\mathrm{Fl}:$ : $3-6$ mois : Fr. : 2 ans & $\mathrm{m}$ & $\mathrm{m}$ & $\mathrm{m}$ & $\mathrm{m}$ & $\mathrm{m}$ & $\mathrm{m}$ & $\mathrm{m}$ & $\mathrm{m}$ & $\mathrm{m}$ & 53 & $\mathrm{~m}$ & $\mathrm{~m}$ & $\mathrm{~m}$ & $\mathrm{~m}$ & $\mathrm{~m}$ & $\mathrm{~m}$ & $\mathrm{~m}$ \\
\hline Canada & 3.4 ans & $\mathrm{m}$ & a & $\mathrm{m}$ & $\mathrm{m}$ & a & $\mathrm{m}$ & $\mathrm{m}$ & a & m & $\mathrm{m}$ & a & $\mathrm{m}$ & m & a & $\mathrm{m}$ & m & m \\
\hline Colombie & 0 an & $x(8)$ & $\times(9)$ & $x(10)$ & $x(8)$ & $\times(9)$ & $x(10)$ & 35 & 0 & 35 & 43 & 0 & 43 & 38 & 0 & 38 & $\mathrm{~m}$ & $\mathrm{~m}$ \\
\hline Chili & 3 mois & 7 & 0 & 8 & 21 & 0 & 22 & 14 & 0 & 15 & 34 & 1 & 35 & 21 & 0 & 22 & $\mathrm{~m}$ & m \\
\hline Rèpublique tchèque & 2.3 ans & a & $\times(9)$ & $x(10)$ & a & $x(9)$ & $x(10)$ & a & $\mathrm{m}$ & $\mathrm{m}$ & 17 & $\mathrm{~m}$ & $\mathrm{~m}$ & 6 & m & $\mathrm{m}$ & $\mathrm{m}$ & $\mathrm{m}$ \\
\hline Danemark & 26 semaines & $x(8)$ & $x(9)$ & $x(10)$ & $x(8)$ & $x(9)$ & $x(10)$ & 39 & $\mathrm{~m}$ & 39 & 89 & $\mathrm{~m}$ & 89 & 55 & $\mathrm{~m}$ & 55 & $\mathrm{~m}$ & $\mathrm{~m}$ \\
\hline Estonie & 0 an & $x(8)$ & $\times(9)$ & $x(10)$ & $x(8)$ & $\times(9)$ & $x(10)$ & 6 & 1 & 8 & 66 & 7 & 73 & 26 & 3 & 29 & 23 & $\mathrm{~m}$ \\
\hline Finlande & 9 mois & 1 & $\mathrm{~m}$ & 1 & 31 & $\mathrm{~m}$ & 31 & 16 & $\mathrm{~m}$ & 16 & 59 & $\mathrm{~m}$ & 59 & 31 & $\mathrm{~m}$ & 31 & 27 & 25 \\
\hline France' & $2-3$ ans & a & $\mathrm{m}$ & $\mathrm{m}$ & a & $\mathrm{m}$ & $\mathrm{m}$ & a & $\mathrm{m}$ & $\mathrm{m}$ & 12 & $\mathrm{~m}$ & $\mathrm{~m}$ & 4 & 32 & 36 & $\mathrm{~m}$ & $\mathrm{~m}$ \\
\hline Allemagne & 0 an & 6 & a & 6 & 41 & a & 41 & 23 & a & 23 & 66 & a & 66 & 37 & a & 37 & 27 & 17 \\
\hline Grèce' ${ }^{\circ}$ & 2 mois & $x(8)$ & $x(9)$ & $x(10)$ & $x(8)$ & $x(9)$ & $x(10)$ & 2 & m & $\mathrm{m}$ & 14 & $\mathrm{~m}$ & $\mathrm{~m}$ & 6 & $\mathrm{~m}$ & $\mathrm{~m}$ & $\mathrm{~m}$ & $\mathrm{~m}$ \\
\hline Hongrie & 20 semaines & 1 & 0 & 1 & 1 & 6 & 7 & 1 & 3 & 4 & 14 & 27 & 41 & 5 & 11 & 16 & 10 & 7 \\
\hline Islande & 0 an & 2 & 4 & 5 & 45 & 31 & 76 & 24 & 17 & 41 & 95 & 0 & 95 & 48 & 12 & 60 & 55 & 53 \\
\hline Irlande & 3 ans & $x(8)$ & $\times(9)$ & $x(10)$ & $x(8)$ & $\times(9)$ & $x(10)$ & 4 & m & m & 15 & m & $\mathrm{m}$ & 8 & $\mathrm{~m}$ & $\mathrm{~m}$ & $\mathrm{~m}$ & $\mathrm{~m}$ \\
\hline |sraë| & 0 an & 31 & a & 31 & 64 & a & 64 & 47 & a & 47 & 74 & a & 74 & 56 & a & 56 & $\mathrm{~m}$ & m \\
\hline Italie & 2.3 ans & $x(8)$ & $\times(9)$ & $x(10)$ & $x(8)$ & $x(9)$ & $x(10)$ & a & $\mathrm{m}$ & $\mathrm{m}$ & 15 & $\mathrm{~m}$ & $\mathrm{~m}$ & 5 & $\mathrm{~m}$ & $\mathrm{~m}$ & $\mathrm{~m}$ & $\mathrm{~m}$ \\
\hline Japon & 3 ans & a & 7 & 7 & a & 33 & 33 & a & 20 & 20 & 6 & 43 & 50 & 2 & 27 & 30 & 19 & 16 \\
\hline Corce & 0 an & 14 & a & 14 & 64 & a & $a$ & 40 & a & 40 & 88 & a & 88 & 56 & a & 6 & 38 & $\mathrm{~m}$ \\
\hline Lettonic & 1.5 an & 0 & a & 0 & 16 & a & 16 & 8 & a & 8 & 71 & a & 71 & 29 & a & 29 & 18 & 17 \\
\hline Lituanic & 0 an & 0 & a & 0 & 13 & a & 13 & 7 & a & 7 & 62 & a & 62 & 25 & a & 5 & 16 & 13 \\
\hline Luxembourg & 0 an & 27 & 2 & 30 & 64 & 4 & 68 & 46 & 3 & 49 & 73 & 5 & 78 & 55 & 4 & 59 & $\mathrm{~m}$ & m \\
\hline Mexique & 1.5 mois & $x(8)$ & a & $x(10)$ & $x(8)$ & a & $x(10)$ & 1 & a & 1 & 8 & a & 8 & 4 & a & 4 & 2 & 2 \\
\hline Pays-Bas & 3 ans & $x(14)$ & $x(15)$ & $x(16)$ & $x(14)$ & $x(15)$ & $x(16)$ & $x(14)$ & $x(15)$ & $x(16)$ & $x(14)$ & $x(15)$ & $x(16)$ & 0 & 59 & 59 & $\mathrm{~m}$ & $\mathrm{~m}$ \\
\hline Nouvelle-Zélande & 0 an & 18 & 4 & 22 & 48 & 6 & 54 & 33 & 5 & 38 & 67 & 7 & 74 & 44 & 6 & 50 & $\mathrm{~m}$ & $\mathrm{~m}$ \\
\hline Norvège & 0 an & 4 & 0 & 4 & 72 & 0 & 72 & 38 & 0 & 38 & 92 & 0 & 92 & 56 & 0 & 56 & 53 & 33 \\
\hline Pologne & 3 ans & 0 & 0 & 0 & 0 & 9 & 9 & 0 & 5 & 5 & 7 & 12 & 19 & 2 & 7 & 9 & 4 & 3 \\
\hline Portugal & 0 an & 18 & 1 & 19 & 38 & 1 & 40 & 28 & 1 & 29 & 51 & 1 & 52 & 36 & 1 & 37 & 27 & 21 \\
\hline Republique slovaque & 2.3 ans & a & $\mathrm{m}$ & $\mathrm{m}$ & a & $\mathrm{m}$ & $\mathrm{m}$ & a & $\mathrm{m}$ & $\mathrm{m}$ & 15 & m & $\mathrm{m}$ & 5 & $\mathrm{~m}$ & $\mathrm{~m}$ & 3 & 7 \\
\hline Slovenie & 11 mois & 0 & 0 & 0 & 48 & 0 & 48 & 24 & 0 & 2 & 74 & 0 & 74 & 41 & 0 & 41 & 34 & 25 \\
\hline Espagne & 0 an & 11 & $\mathrm{~m}$ & 11 & 38 & $\mathrm{~m}$ & 38 & 25 & $\mathrm{~m}$ & 25 & 59 & $\mathrm{~m}$ & 59 & 36 & $\mathrm{~m}$ & 36 & 26 & 15 \\
\hline Suede & 1 an & 0 & 0 & 0 & 48 & 1 & 49 & 24 & 1 & 24 & 88 & 2 & 90 & 45 & 1 & 47 & 46 & $\mathrm{~m}$ \\
\hline Suisse & $\mathrm{m}$ & a & $\mathrm{m}$ & $\mathrm{m}$ & a & $\mathrm{m}$ & $\mathrm{m}$ & a & $\mathrm{m}$ & $\mathrm{m}$ & a & $\mathrm{m}$ & $\mathrm{m}$ & a & $\mathrm{m}$ & $\mathrm{m}$ & $\mathrm{m}$ & $\mathrm{m}$ \\
\hline Turqu & m & $x(8)$ & $\times(9)$ & $x(10)$ & $x(8)$ & $\times(9)$ & $x(10)$ & m & m & $\mathrm{m}$ & $m$ & $\mathrm{~m}$ & m & 0 & a & 0 & $\mathrm{~m}$ & m \\
\hline Royaume-Uni & 0 an & $m$ & $\mathrm{~m}$ & $\mathrm{~m}$ & $\mathrm{~m}$ & $\mathrm{~m}$ & $\mathrm{~m}$ & $\mathrm{~m}$ & $\mathrm{~m}$ & $\mathrm{~m}$ & $\mathrm{~m}$ & $\mathrm{~m}$ & $\mathrm{~m}$ & $\mathrm{~m}$ & $\mathrm{~m}$ & $\mathrm{~m}$ & $\mathrm{~m}$ & $\mathrm{~m}$ \\
\hline Etats-Unis & $\mathrm{m}$ & $\mathrm{m}$ & $\mathrm{m}$ & $\mathrm{m}$ & $\mathrm{m}$ & $\mathrm{m}$ & $\mathrm{m}$ & $\mathrm{m}$ & $\mathrm{m}$ & m & $\mathrm{m}$ & $\mathrm{m}$ & $\mathrm{m}$ & m & $\mathrm{m}$ & $\mathrm{m}$ & $\mathrm{m}$ & $\mathrm{m}$ \\
\hline Moyenne OCDE & & m & $\mathrm{m}$ & 9 & $\mathrm{~m}$ & m & 40 & 21 & 3 & 24 & 49 & 13 & 62 & 26 & 10 & 36 & 25 & 18 \\
\hline Moyenne UE23 & & m & $\mathrm{m}$ & 6 & m & m & 31 & 16 & 3 & 19 & 46 & 17 & 62 & 23 & 12 & 36 & 21 & 15 \\
\hline $\begin{array}{l}\text { Moyenne OCDE (tous les } \\
\text { pays disposant de données }\end{array}$ & & m & $\mathrm{m}$ & $\mathrm{m}$ & $\mathrm{m}$ & $\mathrm{m}$ & $\mathrm{m}$ & m & $\mathrm{m}$ & $\mathrm{m}$ & $\mathrm{m}$ & $\mathrm{m}$ & $\mathrm{m}$ & m & $\mathrm{m}$ & 34 & 26 & $\mathrm{~m}$ \\
\hline
\end{tabular}

\begin{tabular}{|c|c|c|c|c|c|c|c|c|c|c|c|c|c|c|c|c|c|c|}
\hline 8. Argentine ${ }^{2}$ & $\mathrm{~m}$ & $x(8)$ & $x(9)$ & $x(10)$ & $x(8)$ & $x(9)$ & $x(10)$ & 2 & $\mathrm{~m}$ & $\mathrm{~m}$ & 11 & $\mathrm{~m}$ & $\mathrm{~m}$ & 5 & $\mathrm{~m}$ & $\mathrm{~m}$ & $\mathrm{~m}$ & $\mathrm{~m}$ \\
\hline Bresil & 0 an & 6 & a & 6 & 20 & a & 20 & 14 & a & 14 & 40 & a & 40 & 23 & a & 23 & 10 & $\mathrm{~m}$ \\
\hline Chine & $\mathrm{m}$ & m & m & $\mathrm{m}$ & $\mathrm{m}$ & $\mathrm{m}$ & m & $\mathrm{m}$ & $\mathrm{m}$ & $\mathrm{m}$ & $\mathrm{m}$ & $\mathrm{m}$ & $\mathrm{m}$ & $\mathrm{m}$ & $\mathrm{m}$ & $\mathrm{m}$ & $\mathrm{m}$ & $\mathrm{m}$ \\
\hline Costa Rica & 0 an & 1 & 1 & 2 & 1 & 5 & 7 & 1 & 3 & 4 & 3 & 10 & 12 & 2 & 5 & 7 & $\mathrm{~m}$ & $\mathrm{~m}$ \\
\hline ä Inde & $\mathrm{m}$ & $\mathrm{m}$ & $\mathrm{m}$ & $\mathrm{m}$ & $\mathrm{m}$ & $\mathrm{m}$ & $\mathrm{m}$ & m & $\mathrm{m}$ & $\mathrm{m}$ & $\mathrm{m}$ & $\mathrm{m}$ & $\mathrm{m}$ & $\mathrm{m}$ & $\mathrm{m}$ & $\mathrm{m}$ & $\mathrm{m}$ & $\mathrm{m}$ \\
\hline Indonésie & $\mathrm{m}$ & $x(8)$ & $x(9)$ & $x(10)$ & $x(8)$ & $x(9)$ & $x(10)$ & 3 & $\mathrm{~m}$ & $\mathrm{~m}$ & 12 & $\mathrm{~m}$ & $\mathrm{~m}$ & 6 & $\mathrm{~m}$ & $\mathrm{~m}$ & $\mathrm{~m}$ & $\mathrm{~m}$ \\
\hline Fédération de Russie & 0 an & $x(8)$ & $\times(9)$ & $x(10)$ & $x(8)$ & $x(9)$ & $x(10)$ & 4 & $\mathrm{~m}$ & 4 & 49 & $\mathrm{~m}$ & 49 & 19 & $\mathrm{~m}$ & 19 & 17 & 21 \\
\hline Arabie saoudite & $\mathrm{m}$ & a & $\mathrm{m}$ & $\mathrm{m}$ & $\mathrm{a}$ & m & m & a & $\mathrm{m}$ & $\mathrm{m}$ & $\mathrm{m}$ & $\mathrm{m}$ & $\mathrm{m}$ & $\mathrm{m}$ & $\mathrm{m}$ & $\mathrm{m}$ & $\mathrm{m}$ & $\mathrm{m}$ \\
\hline Afrigue du Sud & $\mathrm{m}$ & $\mathrm{m}$ & $\mathrm{m}$ & $\mathrm{m}$ & & & & $\mathrm{m}$ & $\mathrm{m}$ & $\mathrm{m}$ & $\mathrm{m}$ & $\mathrm{m}$ & $\mathrm{m}$ & $\mathrm{m}$ & $\mathrm{m}$ & $\mathrm{m}$ & $\mathrm{m}$ & $\mathrm{m}$ \\
\hline
\end{tabular}

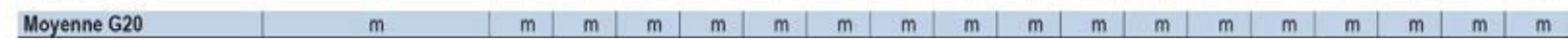

Remarque : Éducation de la petite enfance $=$ CITE 0 , autres services agréés d'éducation et d'accueil des jeunes enfants $(E A J E)=$ services d'EAJE ne relevant pas de la CITE 0 car ils ne satisfont pas l'ensemble de ses critères. Pour relever de la catégorie CITE 0 , les services d'EAJE doivent : 1) comporter une composante educative intentionnelle adéquate ; 2) s'inscrire dans un cadre institutionnel (en général scolaire ou à tout le moins, cadre s'adressant à un groupe d'enfants) ; 3) proposer au moins deux heures d'activités éducatives par jour sur une durée minimum de 100 jours par an ; 4) avoir un cadre réglementaire reconnu par les autorités nationales compétentes (par exemple, un programme); et 5) employer un personnel formé ou agréé (par exemple, obligation pour les éducateurs d'attester de leurs qualifications pédagogiques). 1. Pour la France, les données de la catégorie « Autres services agréés d'EAJE » sont tirées de l'enquête « Modes de garde et d'accueil des jeunes enfants 2013 » menée par la Direction des statistiques du ministère français des Solidarités et de la Santé (DREES). Les chiffres se rapportent au mode de garde principal. Pour la Grèce, les données relatives à l'EAJE incluent uniquement une partie des enfants scolarisés dans les programmes d'éducation de la petite enfance (CITE 01).

2. Année de référence : 2016 , et non 2017.

3. Année de référence : 2012 , et non 2010

Source : Enquête ad hoc du réseau INES et OCDE/ISU/Eurostat (2019). Consulter la section « Source » pour tout complément d'information et l'annexe 3 pour les notes (https://doi.org/10.1787/f8d7880d-en).

Les symboles représentant les données manquantes et les abréviations figurent dans le Guide du lecteur. 
Tableau B2.2 Taux de scolarisation dans les structures d'éducation et d'accueil des jeunes enfants (EAJE) et l'enseignement primaire, selon l'âge $(2005,2010$ et 2017)

Établissements publics et privés, enfants âgés de 3 à 6 ans

\begin{tabular}{|c|c|c|c|c|c|c|c|c|c|c|c|c|c|c|c|c|c|}
\hline & \multirow{2}{*}{ 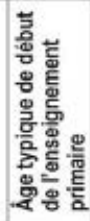 } & \multirow{2}{*}{ 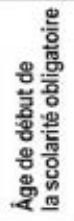 } & \multicolumn{3}{|c|}{3 ans } & \multicolumn{3}{|c|}{4 ans } & \multicolumn{3}{|c|}{5 ans } & \multicolumn{3}{|c|}{6 ans } & \multirow{2}{*}{\multicolumn{3}{|c|}{ 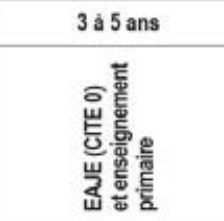 }} \\
\hline & & & 总 & 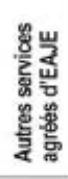 & 焉 & ్ㅡㅂ & 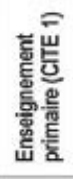 & 愛 & 总 & 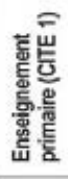 & 푱 & 릅 & 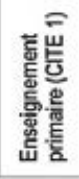 & 푱 & & & \\
\hline & \multicolumn{2}{|c|}{2017} & \multicolumn{3}{|c|}{2017} & \multicolumn{3}{|c|}{2017} & \multicolumn{3}{|c|}{2017} & \multicolumn{3}{|c|}{2017} & 2017 & 2010 & 2005 \\
\hline & (1) & (2) & (3) & (4) & (5) & (6) & (7) & (8) & (9) & (10) & (ii) & (12) & (13) & (14) & (15) & (16) & (17) \\
\hline س Pays & & & & & & & & & & & & & & & & & \\
\hline Oustralie & 5 & 6 & 66 & 1 & 67 & 85 & 1 & 86 & 20 & 79 & 99 & 2 & 99 & 100 & 84 & 74 & $\mathrm{~m}$ \\
\hline Autriche & 6 & 6 & 76 & $x(3)$ & 76 & 93 & 0 & 93 & 98 & 0 & 98 & 42 & 57 & 99 & 89 & 86 & 76 \\
\hline Belgique & 6 & 6 & 98 & 0 & 98 & 99 & 0 & 99 & 98 & 1 & 99 & 3 & 95 & 98 & 98 & 99 & 100 \\
\hline Canada & 6 & 6 & $\mathrm{~m}$ & a & $\mathrm{m}$ & $\mathrm{m}$ & m & $\mathrm{m}$ & 98 & 0 & 98 & 0 & 100 & 100 & $\mathrm{~m}$ & $\mathrm{~m}$ & m \\
\hline Chili & 6 & 6 & 58 & 1 & 58 & 85 & 0 & 85 & 94 & 0 & 94 & 16 & 81 & 98 & 79 & 70 & 45 \\
\hline Colombie & 6 & 5 & 53 & 0 & 53 & 62 & 0 & 63 & 58 & 19 & 77 & 6 & 73 & 79 & 64 & $\mathrm{~m}$ & $\mathrm{~m}$ \\
\hline République tchèque & 6 & 6 & 79 & 0 & 79 & 88 & 0 & 88 & 96 & 0 & 96 & 48 & 49 & 96 & 88 & 79 & 85 \\
\hline Danemark & 6 & 6 & 96 & 0 & 96 & 98 & 0 & 98 & 97 & 1 & 98 & 7 & 93 & 99 & 98 & 94 & $\mathrm{~m}$ \\
\hline Estonie & 7 & 7 & 88 & 3 & 91 & 92 & 0 & 92 & 93 & 0 & 93 & 92 & 1 & 93 & 91 & 89 & $\mathrm{~m}$ \\
\hline Finlande & 7 & 7 & 73 & $\mathrm{~m}$ & 73 & 80 & 0 & 80 & 85 & 0 & 85 & 98 & 0 & 99 & 79 & 73 & 68 \\
\hline France & 6 & 6 & 100 & a & 100 & 100 & 0 & 100 & 100 & 1 & 100 & 1 & 100 & 100 & 100 & 100 & 100 \\
\hline Allemagne & 6 & 6 & 91 & a & 91 & 95 & 0 & 95 & 97 & 0 & 98 & 36 & 63 & 99 & 95 & 94 & 88 \\
\hline Gréce' & 6 & 5 & 30 & $\mathrm{~m}$ & $\mathrm{~m}$ & 70 & 0 & 70 & 92 & 0 & 92 & 3 & 93 & 97 & 65 & m & $\mathrm{m}$ \\
\hline Hongrie & 7 & 3 & 85 & 14 & 99 & 96 & 0 & 96 & 96 & 0 & 96 & 61 & 31 & 92 & 92 & 87 & 87 \\
\hline Islande & 6 & 6 & 97 & 0 & 97 & 98 & 0 & 98 & 98 & 0 & 98 & 0 & 99 & 99 & 97 & 96 & 95 \\
\hline Irlande & 5 & 6 & 92 & 0 & 92 & 73 & 28 & 100 & 1 & 100 & 100 & 0 & 100 & 100 & 98 & $\mathrm{~m}$ & $\mathrm{~m}$ \\
\hline Israël & 6 & 3 & 100 & a & 100 & 98 & 0 & 98 & 97 & 0 & 97 & 13 & 83 & 96 & 99 & 86 & 80 \\
\hline Italie & 6 & 6 & 91 & 0 & 91 & 95 & 0 & 95 & 88 & 8 & 96 & 1 & 96 & 97 & 94 & 98 & 100 \\
\hline Japon & 6 & 6 & 83 & 0 & 83 & 95 & 0 & 95 & 96 & 0 & 96 & 0 & 100 & 100 & 91 & 90 & 87 \\
\hline Corée & 6 & 6 & 94 & a & 94 & 97 & 0 & 97 & 92 & 1 & 93 & 0 & 92 & 92 & 95 & 85 & $\mathrm{~m}$ \\
\hline Lettonie & 7 & 5 & 90 & a & 90 & 94 & 0 & 94 & 97 & 0 & 97 & 94 & 4 & 98 & 93 & 82 & $\pi$ \\
\hline Lituanie & 7 & 7 & 80 & a & 80 & 86 & 0 & 86 & 90 & 0 & 90 & 97 & 4 & 101 & 85 & 72 & 59 \\
\hline Luxembourg & 6 & 4 & 70 & $\mathrm{~m}$ & $\mathrm{~m}$ & 95 & 0 & 95 & 93 & 5 & 98 & 6 & 91 & 97 & 88 & 87 & 84 \\
\hline Mexique & 6 & 3 & 47 & a & 47 & 92 & 0 & 92 & 75 & 25 & 100 & 1 & 100 & 100 & 84 & 78 & 64 \\
\hline Pays-Bas & 6 & 5 & 88 & 5 & 93 & 96 & 0 & 96 & 99 & 0 & 99 & 0 & 100 & 100 & 94 & 94 & 93 \\
\hline Nouvelle-Zélande & 5 & 5 & 90 & 5 & 95 & 96 & 0 & 96 & 3 & 94 & 98 & 0 & 99 & 99 & 95 & $\mathrm{~m}$ & $\mathrm{~m}$ \\
\hline Norvège & 6 & 6 & 96 & 0 & 96 & 97 & 0 & 97 & 98 & 0 & 98 & 1 & 99 & 100 & 97 & 96 & 88 \\
\hline Pologne & 7 & 6 & 67 & 2 & 69 & 85 & 0 & 85 & 92 & 0 & 92 & 80 & 18 & 98 & 82 & 60 & 38 \\
\hline Portugal & 6 & 6 & 86 & 0 & 86 & 93 & 0 & 93 & 95 & 0 & 96 & 10 & 86 & 96 & 92 & 87 & 78 \\
\hline République slovaque & 6 & 6 & 68 & $\mathrm{~m}$ & 68 & 79 & 0 & 79 & 78 & 0 & 78 & 41 & 51 & 91 & 75 & 72 & 74 \\
\hline Slovénie & 6 & 6 & 86 & $\mathrm{~m}$ & 86 & 90 & 0 & 90 & 94 & 0 & 94 & 8 & 89 & 98 & 90 & 86 & 75 \\
\hline Espagne & 6 & 6 & 96 & 0 & 96 & 98 & 0 & 98 & 97 & 0 & 97 & 1 & 97 & 98 & 97 & 97 & 98 \\
\hline Suéde & 7 & 7 & 93 & 2 & 95 & 94 & 0 & 94 & 95 & 0 & 95 & 98 & 1 & 99 & 94 & 97 & $\mathrm{~m}$ \\
\hline Suisse & 6 & 4.5 & 2 & m & 2 & 48 & 0 & 48 & 98 & 1 & 98 & 54 & 46 & 100 & 50 & 47 & 47 \\
\hline Turquie & 6 & $5-6$ & 10 & a & 10 & 37 & 0 & 37 & 59 & 15 & 73 & 0 & 95 & 95 & 40 & 27 & 13 \\
\hline Royaume-Uni & 5 & 4.5 & 100 & 0 & 100 & 100 & 3 & 100 & 0 & 97 & 97 & 0 & 98 & 98 & 100 & $\mathrm{~m}$ & $\mathrm{~m}$ \\
\hline Etats-Unis & 6 & 46 & 42 & $m$ & 42 & 66 & 0 & 66 & 86 & 5 & 90 & 23 & 77 & 100 & 66 & 66 & 66 \\
\hline Moyenne OCDE & $\mathrm{m}$ & $\mathrm{m}$ & 77 & 3 & 79 & 87 & 1 & 88 & 82 & 12 & 94 & 25 & 72 & 97 & 87 & 82 & 76 \\
\hline $\begin{array}{l}\text { Moyenne UE23 } \\
\text { Moyenne OCDE }\end{array}$ & m & $\mathrm{m}$ & 84 & 4 & 88 & 91 & 1 & 92 & 86 & 9 & 95 & 36 & 62 & 98 & 90 & 87 & 81 \\
\hline $\begin{array}{l}\text { (tous les pays disposant } \\
\text { de donnees pour 2005, } \\
2010 \text { et } 2017 \text { ) }\end{array}$ & $\mathrm{m}$ & $\mathrm{m}$ & $\mathrm{m}$ & $\mathrm{m}$ & $\mathrm{m}$ & $\mathrm{m}$ & $\mathrm{m}$ & $\mathrm{m}$ & $\mathrm{m}$ & $\mathrm{m}$ & $\mathrm{m}$ & $\mathrm{m}$ & $\mathrm{m}$ & $\mathrm{m}$ & 86 & 81 & 76 \\
\hline Argentine ${ }^{2}$ & $\mathrm{~m}$ & 5 & 41 & 0 & 41 & 86 & 0 & 86 & 99 & 1 & 100 & 0 & 100 & 100 & 76 & $\mathrm{~m}$ & $\mathrm{~m}$ \\
\hline$\frac{2}{n}$ Brésilp & 6 & 4 & 64 & 0 & 64 & 90 & 0 & 90 & 91 & 7 & 98 & 11 & 93 & 100 & 84 & 60 & $\mathrm{~m}$ \\
\hline Chine & 6 & m & $\mathrm{m}$ & $\mathrm{m}$ & $\mathrm{m}$ & $\mathrm{m}$ & $\mathrm{m}$ & $\mathrm{m}$ & $\mathrm{m}$ & $\mathrm{m}$ & $\mathrm{m}$ & $\mathrm{m}$ & $\mathrm{m}$ & $\mathrm{m}$ & $\mathrm{m}$ & $\mathrm{m}$ & $\mathrm{m}$ \\
\hline Costa Rica & 6 & 4 & 5 & 14 & 19 & 63 & 0 & 63 & 85 & 1 & 85 & 1 & 93 & 95 & 51 & $\mathrm{~m}$ & $\mathrm{~m}$ \\
\hline Inde & 6 & $\mathrm{~m}$ & $\mathrm{~m}$ & $\mathrm{~m}$ & $\mathrm{~m}$ & $\mathrm{~m}$ & $\mathrm{~m}$ & $\mathrm{~m}$ & $\mathrm{~m}$ & $\mathrm{~m}$ & $\mathrm{~m}$ & $\mathrm{~m}$ & $\mathrm{~m}$ & $\mathrm{~m}$ & $\mathrm{~m}$ & $\mathrm{~m}$ & $\mathrm{~m}$ \\
\hline Indonésie & $\mathrm{m}$ & 7 & 36 & 0 & 36 & 73 & 0 & 73 & 99 & 3 & 100 & $X(14)$ & $\mathrm{X}(14)$ & 100 & 70 & $\mathrm{~m}$ & $\mathrm{~m}$ \\
\hline Fédération de Russie & 7 & 7 & 79 & 0 & 79 & 84 & 0 & 84 & 85 & 0 & 85 & 85 & 10 & 95 & 83 & 71 & 53 \\
\hline Arabie saoudite & $\mathrm{m}$ & 6 & 3 & 0 & 3 & 12 & 0 & 12 & 45 & 5 & 51 & 4 & 96 & 100 & 22 & $\mathrm{~m}$ & $\mathrm{~m}$ \\
\hline Afrique du Sud & $\mathrm{m}$ & 7 & $\mathrm{~m}$ & $\mathrm{~m}$ & $\mathrm{~m}$ & $\mathrm{~m}$ & $\mathrm{~m}$ & $\mathrm{~m}$ & $\mathrm{~m}$ & $\mathrm{~m}$ & $\mathrm{~m}$ & $\mathrm{~m}$ & $\mathrm{~m}$ & $\mathrm{~m}$ & $\mathrm{~m}$ & m & $\mathrm{m}$ \\
\hline
\end{tabular}

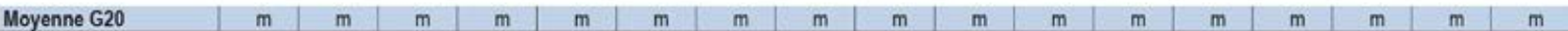

Remarque : Education de la petite enfance $=$ CITE 0 , autres services agréés d'éducation et d'accueil des jeunes enfants $(E A J E)=$ services d'EAJE ne relevant pas de la CITE 0 car ils ne satisfont pas l'ensemble de ses critères. Pour relever de la catégorie CITE 0 , les services d'EAJE doivent : 1) comporter une composante éducative intentionnelle adéquate ; 2) s'inscrire dans un cadre institutionnel (en général scolaire ou à tout le moins, cadre s'adressant à un groupe d'enfants) ; 3) proposer au moins deux heures d'activités éducatives par jour sur une durée minimum de 100 jours par an ; 4) avoir un cadre réglementaire reconnu par les autorités nationales compétentes (par exemple, un programme); et 5) employer un personnel formé ou agréé (par exemple, obligation pour les éducateurs d'attester de leurs qualifications pédagogiques).

1. Les données relatives à l'EAJE incluent uniquement une partie des enfants scolarisés dans les programmes d'éducation de la petite enfance (CITE 01).

2. Année de référence : 2016, et non 2017.

3. Année de référence : 2012 , et non 2010.

Source : Enquête ad hoc du réseau INES et OCDE/ISU/Eurostat (2019). Consulter la section « Source » pour tout complément d'information et l'annexe 3 pour les notes (https://doi.org/10.1787/f8d7880d-en).

Les symboles représentant les données manquantes et les abréviations figurent dans le Guide du lecteur. 
Tableau B2.3. Taux de scolarisation des enfants dans les structures privées d'éducation et d'accueil des jeunes enfants (CITE 0), taux d'encadrement et qualifications minimales (2017)

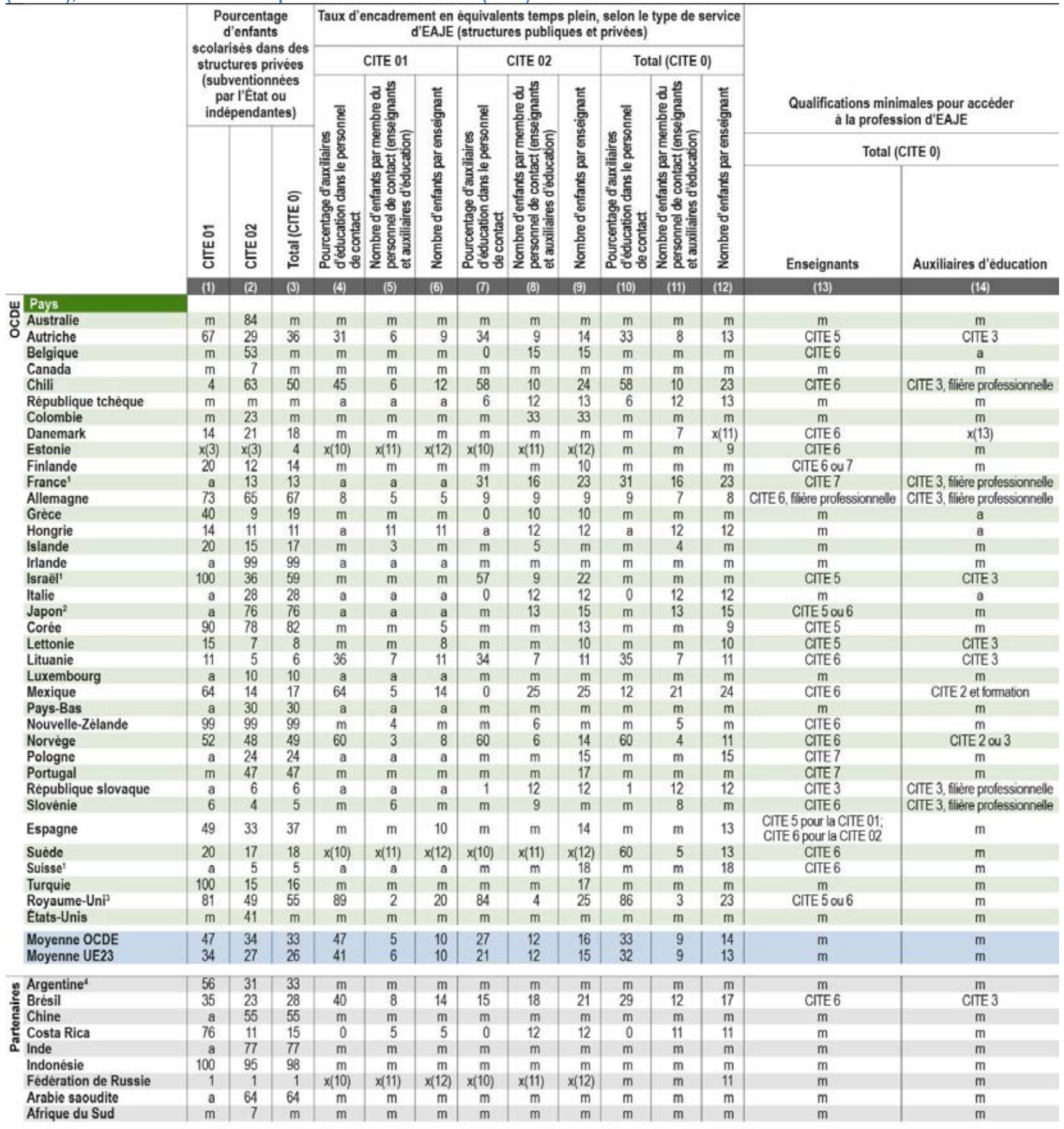

\begin{tabular}{l|l|l|l|l|l|l|l|l|l|l|l|l|l} 
Moyenne $\mathrm{G} 20$ & $\mathrm{~m}$ & 42 & 47 & $\mathrm{~m}$ & $\mathrm{~m}$ & $\mathrm{~m}$ & $\mathrm{~m}$ & $\mathrm{~m}$ & $\mathrm{~m}$ & $\mathrm{~m}$ & $\mathrm{~m}$ & $\mathrm{~m}$ & $\mathrm{~m}$
\end{tabular}

Remarque : Programmes de développement éducatif de la petite enfance $=$ CITE 01, enseignement préprimaire $=$ CITE $02 ;$ CITE $5=$ enseignement tertiaire de cycle court ; CITE 6 = licence ou niveau équivalent ; CITE 7 = master ou niveau équivalent.

1. France : Les données des colonnes 7 à 12 représentent uniquement les structures publiques et privées subventionnées par l'État. Les données sur les enseignants ne sont pas comparables avec les années précédentes en raison de l'introduction d'une nouvelle méthodologie. Israël et Suisse : Structures publiques uniquement.

2. Les données sur le personnel n'incluent pas l'ensemble des services d'EAJE.

3. Les qualifications minimales du personnel d'EAJE sont le niveau 6 de la CITE en Angleterre et le niveau 5 de la CITE en Écosse.

4. Année de référence : 2016 , et non 2017

Source : Enquête ad hoc du réseau INES et OCDE/ISU/Eurostat (2019). Consulter la section « Source » pour tout complément d'information et l'annexe 3 pour les notes (https://doi.org/10.1787/f8d7880d-en).

Les symboles représentant les données manquantes et les abréviations figurent dans le Guide du lecteur. 
Tableau B2.4. Financement des structures d'éducation et d'accueil des jeunes enfants (CITE 0) et évolution des dépenses en pourcentage du PIB (2012 et 2016)

Structures publiques et privées

\begin{tabular}{|c|c|c|c|c|c|c|c|c|c|c|c|c|c|c|}
\hline & \multirow{2}{*}{\multicolumn{3}{|c|}{\begin{tabular}{|c|} 
\\
Dépenses annuelles \\
par enfant en USD, convertis \\
sur la base des PPA \\
(calculs fondés \\
sur le nombre d'individus) \\
2016
\end{tabular}}} & \multicolumn{6}{|c|}{$\begin{array}{l}\text { Dépenses au titre des services d'EAJE, } \\
\text { en pourcentage du PIB }\end{array}$} & \multirow{2}{*}{\multicolumn{2}{|c|}{$\begin{array}{c}\text { Dépenses au titre } \\
\text { de tous les enfants } \\
\text { aggés de } 3 \text { a } 5 \text { ans } \\
\text { scolarisés dans une } \\
\text { structure d'EAJE ou } \\
\text { dans l'enseignement } \\
\text { primaire } \\
\text { (calculs fondès sur } \\
\text { le nombre d'individus) } \\
2016 \\
\end{array}$}} & \multirow{2}{*}{\multicolumn{3}{|c|}{$\begin{array}{c}\text { Part relative des dèpenses } \\
\text { privees au titre } \\
\text { des structures d'éducation } \\
\text { et d'accueil des jeunes } \\
\text { enfants (aprés transferts } \\
\text { provenant de sources } \\
\text { publiques) } \\
2016\end{array}$}} \\
\hline & & & & \multicolumn{3}{|c|}{2016} & \multicolumn{3}{|c|}{2012} & & & & & \\
\hline & 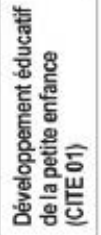 & 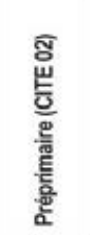 & 푱 & 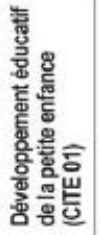 & 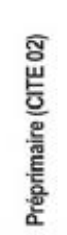 & 沓 & 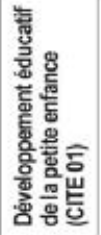 & 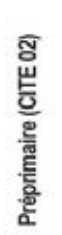 & ब्ञ⿰彳 & 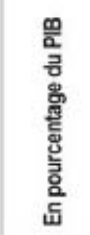 & 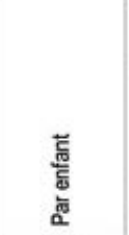 & 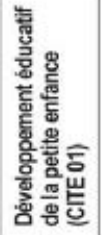 & 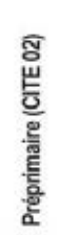 & 営 \\
\hline & (1) & (2) & (3) & (4) & (5) & (6) & (7) & (8) & (9) & (10) & (ii) & (12) & (13) & (14) \\
\hline س Pays & & & & & & & & & & & & & & \\
\hline oustralie & 7648 & 7536 & 7582 & 0.2 & 0.3 & 0.6 & 0.3 & 0.2 & 0.4 & 0.6 & 8325 & 40 & 34 & 36 \\
\hline Autriche & 11995 & 10028 & 10364 & 0.1 & 0.5 & 0.7 & 0.1 & 0.5 & 0.6 & 0.5 & 10112 & 25 & 13 & 15 \\
\hline Belgique & $\mathrm{m}$ & 8427 & m & $\mathrm{m}$ & 0.7 & $\mathrm{~m}$ & $\mathrm{~m}$ & m & $\mathrm{m}$ & 0.6 & 8433 & $\mathrm{~m}$ & 3 & $\mathrm{~m}$ \\
\hline Canada & $\mathrm{m}$ & $\mathrm{m}$ & $\mathrm{m}$ & $\mathrm{m}$ & $\mathrm{m}$ & $\mathrm{m}$ & $\mathrm{m}$ & $\mathrm{m}$ & $\mathrm{m}$ & $\mathrm{m}$ & $\mathrm{m}$ & $\mathrm{m}$ & $\mathrm{m}$ & $\mathrm{m}$ \\
\hline Chili' & 8018 & 6599 & 6908 & 0.3 & 0.9 & 1.2 & $\mathrm{~m}$ & 0.8 & $\mathrm{~m}$ & 0.9 & 6641 & 18 & 18 & 18 \\
\hline Colombie' & $\mathrm{m}$ & 1579 & $\mathrm{~m}$ & 0.1 & 0.3 & 0.5 & $\mathrm{~m}$ & $\mathrm{~m}$ & $\mathrm{~m}$ & 0.4 & 1771 & 89 & 28 & 45 \\
\hline Republique tcheque & a & 5125 & 5125 & a & 0.5 & 0.5 & a & 0.5 & 0.5 & 0.4 & 5125 & a & 11 & 11 \\
\hline Danemark & $\mathrm{m}$ & $\mathrm{m}$ & $\mathrm{m}$ & $\mathrm{m}$ & $\mathrm{m}$ & $\mathrm{m}$ & $x(9)$ & $x(9)$ & 1.3 & $\mathrm{~m}$ & $\mathrm{~m}$ & $\mathrm{~m}$ & $\mathrm{~m}$ & $\mathrm{~m}$ \\
\hline Estonic & $x(3)$ & $x(3)$ & 7146 & $x(6)$ & $x(6)$ & 12 & $\times(9)$ & $\times(9)$ & 0.4 & 0.7 & 7146 & $x(3)$ & $x(3)$ & 13 \\
\hline Finlande ${ }^{2}$ & 20815 & 10961 & 12819 & 0.4 & 0.9 & 1.2 & 0.4 & 0.8 & 1.2 & 0.6 & 10961 & 9 & 11 & 10 \\
\hline France & & 8165 & 8165 & a & 0.7 & 0.7 & a & 0.7 & 0.7 & 0.7 & 8164 & a & 7 & 7 \\
\hline Allemagne & 16169 & 10101 & 11724 & 0.3 & 0.6 & 0.9 & 0.3 & 0.5 & 0.8 & 0.5 & 10100 & 19 & 19 & 19 \\
\hline Gréce & $\mathrm{m}$ & 5697 & m & $\mathrm{m}$ & 0.3 & $\mathrm{~m}$ & 0.3 & 0.2 & 0.5 & $\mathrm{~m}$ & $\mathrm{~m}$ & $\mathrm{~m}$ & 9 & $\mathrm{~m}$ \\
\hline Hongrie & 6834 & 7171 & 7155 & 0.0 & 0.8 & 0.9 & 0.0 & 0.7 & 0.7 & 0.7 & 7169 & 8 & 8 & 8 \\
\hline Islande & 18934 & 13230 & 15012 & 0.7 & 1.0 & 1.7 & 0.6 & 1.0 & 1.6 & 1.0 & 13228 & 11 & 15 & 13 \\
\hline Irlande & $\times(3)$ & $x(3)$ & 3705 & $X(6)$ & $x(6)$ & 0.1 & $\times(9)$ & $\times(9)$ & 0.1 & 0.4 & 6269 & $X(3)$ & $x(3)$ & 3 \\
\hline |sraë| & 2971 & $5466^{\prime}$ & 4568 & 0.3 & 0.9 & 1.2 & $\mathrm{~m}$ & 0.7 & $m$ & 0.9 & 5469 & 84 & 9 & 27 \\
\hline Italie & a & 7395 & 7395 & a & 0.5 & 0.5 & a & 0.5 & 0.5 & 0.5 & 7411 & a & 12 & 12 \\
\hline Japon ${ }^{3}$ & a & 7473 & 7473 & a & 0.2 & 0.2 & a & 0.2 & 0.2 & $\mathrm{~m}$ & $\mathrm{~m}$ & a & 51 & 51 \\
\hline Corée & $\mathrm{m}$ & 7359 & $\mathrm{~m}$ & $\mathrm{~m}$ & 0.5 & $\mathrm{~m}$ & $\mathrm{~m}$ & $\mathrm{~m}$ & $\mathrm{~m}$ & 0.5 & 7366 & $\mathrm{~m}$ & 18 & $\mathrm{~m}$ \\
\hline Lettonie & a & 5574 & 5574 & a & 0.8 & 0.8 & a & 0.8 & 0.8 & 0.6 & 5574 & a & 3 & 3 \\
\hline Lituanie & 6189 & 6178 & 6180 & 0.2 & 0.7 & 0.9 & 0.1 & 0.6 & 0.7 & 0.5 & 6178 & 19 & 15 & 16 \\
\hline Luxembourg & a & 17533 & 17533 & a & 0.5 & 0.5 & a & 0.7 & 0.7 & 0.5 & 17539 & a & 2 & 2 \\
\hline Mexique & $x(3)$ & $x(3)$ & 2296 & $X(6)$ & $x(6)$ & 0.5 & $\times(9)$ & $\times(9)$ & 0.6 & 0.6 & 2317 & m & m & 16 \\
\hline Pays-Bas & & 6538 & 6538 & a & 0.4 & 0.4 & a & 0.4 & 0.4 & 0.4 & 6538 & a & 12 & 12 \\
\hline Nouvelle-Zélande & 9762 & 8141 & 8783 & 0.4 & 0.6 & 1.0 & 0.4 & 0.6 & 0.9 & 0.8 & 8191 & 29 & 14 & 21 \\
\hline Norvège & 25365 & 14344 & 18244 & 10 & 1.0 & 20 & 1.0 & 1.1 & 2.1 & 1.0 & 14344 & 14 & 14 & 14 \\
\hline Pologne & a & 6832 & 6832 & a & 0.8 & 0.8 & a & 0.7 & 0.7 & 0.7 & 6832 & a & 18 & 18 \\
\hline Portugal & $\mathrm{m}$ & 7451 & $\mathrm{~m}$ & $\mathrm{~m}$ & 0.6 & $\mathrm{~m}$ & $\mathrm{~m}$ & 0.6 & $\mathrm{~m}$ & 0.6 & 7451 & $\mathrm{~m}$ & 36 & $\mathrm{~m}$ \\
\hline Republique slovaque & & 6169 & 6169 & a & 0.6 & 0.6 & a & 0.5 & 0.5 & 0.5 & 6169 & a & 15 & 15 \\
\hline Slovénie & 10701 & 7819 & 8653 & 0.4 & 0.7 & 1.1 & 0.4 & 0.8 & 1.3 & 0.7 & 7819 & 25 & 25 & 25 \\
\hline Espagne & 8202 & 6916 & 7238 & 0.2 & 0.5 & 0.8 & 0.2 & 0.7 & 0.9 & 0.5 & 6918 & 41 & 18 & 24 \\
\hline Suéde & 17508 & 14528 & 15303 & 0.6 & 1.4 & 1.9 & 0.5 & 12 & 1.8 & 1.0 & 14528 & 6 & 5 & 6 \\
\hline Suisse $^{4}$ & a & 12592 & 12592 & a & 0.4 & 0.4 & a & $\mathrm{m}$ & $\mathrm{m}$ & 03 & 12607 & a & $\mathrm{m}$ & $\mathrm{m}$ \\
\hline Turquie & $x(3)$ & $x(3)$ & 5568 & $X(6)$ & $x(6)$ & 0.3 & $x(9)$ & $x(9)$ & 0.2 & 0.4 & 5381 & $X(3)$ & $x(3)$ & 28 \\
\hline Royaume-Uni & 5658 & 5932 & 5880 & 0.1 & 0.4 & 0.5 & 0.1 & 0.5 & 0.6 & 0.7 & 7561 & 62 & 50 & 52 \\
\hline Etats-Unis & m & 9151 & $\mathrm{~m}$ & $\mathrm{~m}$ & 0.4 & $\mathrm{~m}$ & $\mathrm{~m}$ & 0.4 & m & 0.4 & 9213 & $\mathrm{~m}$ & 26 & $\mathrm{~m}$ \\
\hline $\begin{array}{l}\text { Moyenne OCDE } \\
\text { Moyenne UE23 }\end{array}$ & $\begin{array}{l}12080 \\
11809\end{array}$ & $\begin{array}{l}8349 \\
9114\end{array}$ & $\begin{array}{l}8605 \\
9342\end{array}$ & $\begin{array}{l}0.3 \\
0.3\end{array}$ & $\begin{array}{l}0.6 \\
0.7\end{array}$ & $\begin{array}{l}0.8 \\
0.9\end{array}$ & $\begin{array}{l}0.3 \\
0.3\end{array}$ & $\begin{array}{l}0.6 \\
0.7\end{array}$ & $\begin{array}{l}0.8 \\
0.9\end{array}$ & $\begin{array}{l}0.6 \\
0.6\end{array}$ & $\begin{array}{l}8141 \\
8926\end{array}$ & $\begin{array}{l}31 \\
25\end{array}$ & $\begin{array}{l}17 \\
16\end{array}$ & $\begin{array}{l}18 \\
17\end{array}$ \\
\hline If Argentine ${ }^{4}$ & m & $m$ & $m$ & m & 0.5 & m & m & $m$ & m & $\mathrm{m}$ & m & $\mathrm{m}$ & $\mathrm{m}$ & m \\
\hline Brésil & $\mathrm{m}$ & $\mathrm{m}$ & $\mathrm{m}$ & m & $\mathrm{m}$ & $\mathrm{m}$ & $\mathrm{m}$ & $\mathrm{m}$ & $\mathrm{m}$ & $\mathrm{m}$ & $\mathrm{m}$ & $\mathrm{m}$ & $\mathrm{m}$ & m \\
\hline Chine & $\mathrm{m}$ & m & $\mathrm{m}$ & m & $\mathrm{m}$ & $\mathrm{m}$ & $\mathrm{m}$ & $\mathrm{m}$ & $\mathrm{m}$ & $\mathrm{m}$ & m & $\mathrm{m}$ & $\mathrm{m}$ & $\mathrm{m}$ \\
\hline Costa Rica'.4 & $\mathrm{m}$ & $\mathrm{m}$ & $\mathrm{m}$ & 0.1 & 0.4 & 0.5 & m & $\mathrm{m}$ & m & 0.5 & $\mathrm{~m}$ & $\mathrm{~m}$ & $\mathrm{~m}$ & $\mathrm{~m}$ \\
\hline Inde & $\mathrm{m}$ & $\mathrm{m}$ & $\mathrm{m}$ & $\mathrm{m}$ & $\mathrm{m}$ & $\mathrm{m}$ & $\mathrm{m}$ & m & $\mathrm{m}$ & $\mathrm{m}$ & $\mathrm{m}$ & $\mathrm{m}$ & $\mathrm{m}$ & $\mathrm{m}$ \\
\hline Indonésie & $\mathrm{m}$ & $\mathrm{m}$ & $\mathrm{m}$ & $\mathrm{m}$ & $\mathrm{m}$ & $\mathrm{m}$ & $\mathrm{m}$ & m & $\mathrm{m}$ & $\mathrm{m}$ & $\mathrm{m}$ & $\mathrm{m}$ & $\mathrm{m}$ & $\mathrm{m}$ \\
\hline Fédération de Russie & $x(3)$ & $x(3)$ & 4394 & $X(6)$ & $x(6)$ & 0.9 & $\times(9)$ & $\times(9)$ & 0.8 & m & m & $X(3)$ & $x(3)$ & 13 \\
\hline Arabie saoudite & $\mathrm{m}$ & $\mathrm{m}$ & m & m & $\mathrm{m}$ & $\mathrm{m}$ & $\mathrm{m}$ & $\mathrm{m}$ & $\mathrm{m}$ & m & m & m & m & m \\
\hline Afrique du Sud & $\mathrm{m}$ & m & m & $\mathrm{m}$ & m & $\mathrm{m}$ & $\mathrm{m}$ & m & $\mathrm{m}$ & m & $\mathrm{m}$ & $\mathrm{m}$ & 27 & m \\
\hline Moyenne G20 & $\mathrm{m}$ & m & $\mathrm{m}$ & $\mathrm{m}$ & m & $\mathrm{m}$ & $\mathrm{m}$ & $\mathrm{m}$ & $\mathrm{m}$ & $\mathrm{m}$ & $\mathrm{m}$ & $\mathrm{m}$ & $\mathrm{m}$ & $\mathrm{m}$ \\
\hline
\end{tabular}

1. Année de référence : 2017 , et non 2016.

2. Les dépenses au titre de tous les enfants âgés de 3 à 5 ans sont sous-estimées en raison de la méthode d'estimation utilisée.

3. Les données sur le financement ne couvrent pas tous les services d'EAJE.

4. Sources publiques uniquement.

Source : Enquête ad hoc du réseau INES et OCDE/ISU/Eurostat (2019). Consulter la section « Source » pour tout complément d'information et l'annexe 3 pour les notes (https://doi.org/10.1787/f8d7880d-en).

Les symboles représentant les données manquantes et les abréviations figurent dans le Guide du lecteur. 


\section{Indicateur B3. Quel est le profil des diplômés du deuxième cycle de l'enseignement secondaire?}

\section{Faits marquants}

- Dans la quasi-totalité des pays dont les données sont disponibles, les femmes représentent au moins la moitié des diplômés du deuxième cycle de l'enseignement secondaire en filière générale. Par contraste, les femmes sont sous-représentées en filière professionnelle dans plus de trois quarts des pays dont les données sont disponibles.

- Dans les pays de l'OCDE, l'âge moyen d'obtention d'un premier diplôme du deuxième cycle de l'enseignement secondaire est plus élevé en filière professionnelle (21 ans) qu'en filière générale (18 ans), et bien plus élevé en filière professionnelle dans l'enseignement post-secondaire non tertiaire (31 ans).

- Selon les estimations actuelles, en moyenne $86 \%$ des jeunes obtiendront un diplôme du deuxième cycle de l'enseignement secondaire au cours de leur vie dans les pays de l'OCDE, parmi lesquels $81 \%$ auront moins de 25 ans.

Graphique B3.1. Âge moyen des titulaires d'un premier diplôme du deuxième cycle du secondaire ou de l'enseignement post-secondaire non tertiaire, selon la filière d'enseignement (2017)

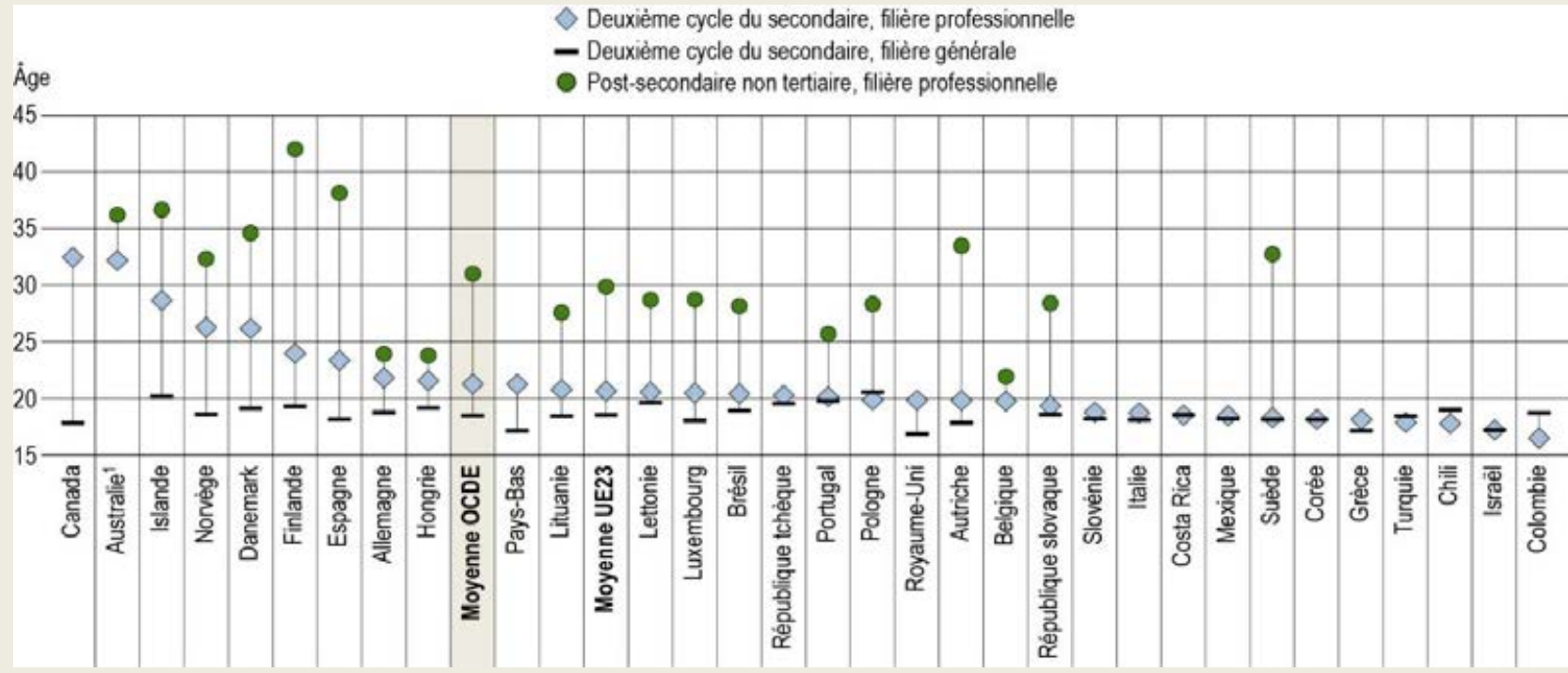

1. Année de référence : 2016.

Les pays sont classés par ordre décroissant de l'âge moyen des titulaires d'un premier diplôme de la filière professionnelle du deuxième cycle du secondaire.

Source : OCDE/ISU/Eurostat (2019), tableaux B3.1 et B3.2, Base de données de Regards sur l'éducation, http://stats.oecd.orgl. Consulter la section « Source » pour tout complément d'information et l'annexe 3 pour les notes (https://doi.org/10.1787/f8d7880d-en).

StatLink त्गाड़ https://doi.org/10.1787/888933977999

\section{Contexte}

Le deuxième cycle de l'enseignement secondaire, qui constitue le deuxième degré de l'apprentissage après le premier cycle de l'enseignement secondaire, est essentiel pour poursuivre des études supérieures et réussir 
son entrée sur le marché du travail. À ce niveau d'enseignement, les élèves peuvent opter pour une formation en filière générale ou en filière professionnelle, en s'inscrivant dans un établissement public ou privé, ou dans un institut technique ou professionnel. Dans de nombreux pays, ce niveau d'enseignement n'est pas obligatoire et dure entre deux et cinq ans. Les formations post-secondaires non tertiaires se situent à la frontière entre le deuxième cycle de l'enseignement secondaire et l'enseignement post-secondaire : elles relèvent du deuxième cycle de l'enseignement secondaire dans certains pays, mais de l'enseignement postsecondaire dans d'autres.

Dans les pays les plus avancés, la quasi-totalité des élèves du premier cycle de l'enseignement secondaire poursuivent leurs études dans un établissement du deuxième cycle de l'enseignement secondaire, et la plupart d'entre eux suivent une formation leur permettant ensuite d'accéder à l'enseignement tertiaire. Dans l'ensemble, la demande de formation dans le deuxième cycle de l'enseignement secondaire augmente à travers le monde, et les filières d'études se multiplient. En fait, il est devenu de plus en plus important d'obtenir un diplôme du deuxième cycle de l'enseignement secondaire dans tous les pays : les compétences requises sur le marché du travail sont de plus en plus spécifiques à l'économie de la connaissance et les travailleurs doivent progressivement s'adapter à une économie mondiale en constante évolution et aux incertitudes qui en résultent.

Les taux d'obtention d'un diplôme montrent certes dans quelle mesure les systèmes d'éducation réussissent à préparer les élèves à satisfaire aux exigences minimales requises sur le marché du travail, mais les taux en question ne permettent pas de mesurer la qualité des résultats de l'éducation.

\section{Autres faits marquants}

- L'âge moyen d'obtention d'un premier diplôme varie considérablement entre les pays, en particulier en filière professionnelle. Au Canada, l'âge moyen d'obtention d'un premier diplôme en filière professionnelle est de 32 ans, contre 16 ans en Colombie.

- Entre 2010 et 2017, le taux d'obtention d'un premier diplôme du deuxième cycle de l'enseignement secondaire a augmenté de 2 points de pourcentage, et celui d'un premier diplôme de l'enseignement post-secondaire non tertiaire d'un point de pourcentage, en moyenne, dans les pays de l'OCDE.

- En moyenne, dans les pays de l'OCDE, 54 \% des diplômés de l'enseignement post secondaire non tertiaire sont des femmes ; ce pourcentage varie toutefois sensiblement entre les pays, allant de $19 \%$ au Luxembourg à $75 \%$ en Autriche et en Pologne.

\section{Remarque}

Le taux d'obtention d'un diplôme, lorsqu'il est calculé tous âges confondus, est une estimation du pourcentage d'individus d'un âge donné qui obtiendront un diplôme dans un pays à un certain moment de leur vie. Cette estimation est basée sur le nombre d'individus qui ont obtenu leur diplôme en 2017 et sur la pyramide des âges dans ce groupe. Comme les taux d'obtention d'un diplôme sont calculés sur la base des taux actuels, ils sont sensibles à tout changement instauré dans le système d'éducation, par exemple la création de nouvelles formations ou l'allongement ou le raccourcissement de la durée des formations. Les taux d'obtention d'un diplôme peuvent être très élevés durant une période où, contre toute attente, un certain nombre d'individus reprennent des études.

Cette édition de Regards sur l'éducation se concentre en priorité sur les titulaires d'un premier diplôme. Le terme « diplômés » (tous les diplômés, pas uniquement les titulaires d'un premier diplôme) est exclusivement réservé à la répartition des diplômés par domaine d'études (voir la section « Définitions »). 


\title{
Analyse
}

\section{Profil des diplômés du deuxième cycle de l'enseignement secondaire}

\author{
Profil des diplômés du deuxième cycle de l'enseignement secondaire, selon la filière \\ d'enseignement
}

Bien que de nombreux pays proposent désormais un vaste éventail de formations en filière professionnelle dans l'enseignement secondaire, dans la plupart des pays, la majeure partie des élèves optent pour des formations en filière générale. En moyenne, dans les pays de l'OCDE, $40 \%$ des titulaires d'un premier diplôme du deuxième cycle de l'enseignement secondaire ont opté pour la filière professionnelle. Le pourcentage de titulaires d'un premier diplôme à l'issue d'une formation professionnelle à ce niveau d'enseignement est particulièrement peu élevé au Brésil, au Canada, en Colombie, en Corée, au Costa Rica, en Hongrie, en Islande, au Japon et en Lituanie (moins de $25 \%$ ). Par contraste, il est supérieur à $65 \%$ en Autriche, en République slovaque, en République tchèque et en Slovénie.

L'éducation et la formation professionnelles (EFP) représentent une part importante du deuxième cycle de l'enseignement secondaire dans de nombreux pays de l'OCDE et peuvent jouer un rôle central quand il s'agit de préparer les jeunes à travailler, de développer les compétences des adultes et de répondre aux besoins du marché du travail (voir l'indicateur A1). Dans certains pays, l'EFP a été négligé et marginalisé dans les débats sur l'action publique, souvent relégué au second rang à cause de l'intérêt croissant porté à la filière générale. Suivre un programme initial d'EFP a pourtant des avantages tant au niveau microéconomique que macroéconomique : la possibilité d'acquérir des qualifications, une entrée sur le marché du travail avec un salaire convenable, des perspectives professionnelles prometteuses, un statut professionnel et une compétitivité économique accrue (CEDEFOP, 2011[1]).

Il a également été démontré que l'EFP a un effet positif sur l'employabilité des diplômés, en raison de leur entrée précoce sur le marché du travail. La transition vers le monde du travail est plus rapide pour les diplômés du deuxième cycle de l'enseignement secondaire issus de la filière professionnelle que pour ceux qui ont suivi une formation en filière générale ; ils sont en effet plus susceptibles d'obtenir un premier emploi permanent et courent moins le risque d'occuper un poste en inadéquation avec leurs qualifications. À une époque où l'expérience professionnelle constitue souvent un prérequis à l'entrée sur le marché du travail, les diplômés de la filière professionnelle du deuxième cycle de l'enseignement secondaire bénéficient d'un avantage certain par rapport aux diplômés ne disposant que de peu, voire d'aucune, expérience professionnelle. En revanche, le constat inverse s'observe dans l'enseignement tertiaire : dans l'Union européenne, les diplômés à l'issue d'une formation technique mettent beaucoup plus de temps à trouver un emploi que les diplômés à l'issue d'un cursus universitaire, principalement en raison du fait que les formations techniques tertiaires permettent aux étudiants de développer des compétences plus spécifiques qui nécessitent davantage de recherches pour trouver un emploi en adéquation avec ces compétences (CEDEFOP, 2013[2]).

Les formations en filière professionnelle intègrent des programmes « emploi-études ", où entre 10 et $75 \%$ de la formation est dispensée en milieu scolaire ou par enseignement à distance. II s'agit notamment des formations dans lesquelles les périodes d'études en milieu scolaire et les périodes de formation pratique en entreprise sont soit concomitantes, soit en alternance (formation sous contrat d'apprentissage ou en alternance). Dans des pays tels que l'Allemagne, l'Australie, le Danemark, la Lettonie, la Norvège et la Suisse, ces systèmes de formation en alternance attirent au moins $30 \%$ des élèves du deuxième cycle de l'enseignement supérieur qui suivent un programme « emploi-études » en filière professionnelle (voir la base de données de Regards sur l'éducation). La composante de formation en entreprise permet aux élèves d'acquérir des compétences prisées dans le monde du travail. L'apprentissage en entreprise est aussi un moyen de développer des partenariats public-privé et d'impliquer les partenaires sociaux et les employeurs dans la conception des formations en filière professionnelle, souvent en définissant les cadres des cursus. 
De plus, les formations de qualité en filière professionnelle peuvent être efficaces pour développer des compétences chez des individus qui pourraient autrement manquer de qualifications leur permettant de réussir leur entrée sur le marché du travail. Toutefois, il est important de veiller à ce que les diplômés de la filière professionnelle du deuxième cycle de l'enseignement secondaire aient de bonnes perspectives sur le marché du travail, car les formations peuvent être plus coûteuses dans cette filière que dans d'autres (voir l'indicateur C1).

\section{Profil des diplômés du deuxième cycle de l'enseignement secondaire, selon le sexe}

Dans le deuxième cycle de l'enseignement secondaire, le pourcentage de femmes tend à être sensiblement plus élevé en filière générale qu'en filière professionnelle. En moyenne, dans les pays de l'OCDE, les femmes représentent $55 \%$ des diplômés du deuxième cycle de l'enseignement secondaire en filière générale, contre $48 \%$ en filière professionnelle.

Dans la quasi-totalité des pays dont les données sont disponibles, les femmes représentent au moins la moitié des diplômés du deuxième cycle de l'enseignement secondaire en filière générale ; leur pourcentage va de $49 \%$ en Corée à $61 \%$ en République slovaque et en République tchèque, et jusqu'à $62 \%$ en Italie. Par contraste, les femmes sont sous-représentées en filière professionnelle dans plus de trois quarts des pays dont les données sont disponibles (voir le graphique B3.2).

Graphique B3.2. Pourcentage de femmes parmi les diplômés du deuxième cycle du secondaire, selon la filière d'enseignement (2017)

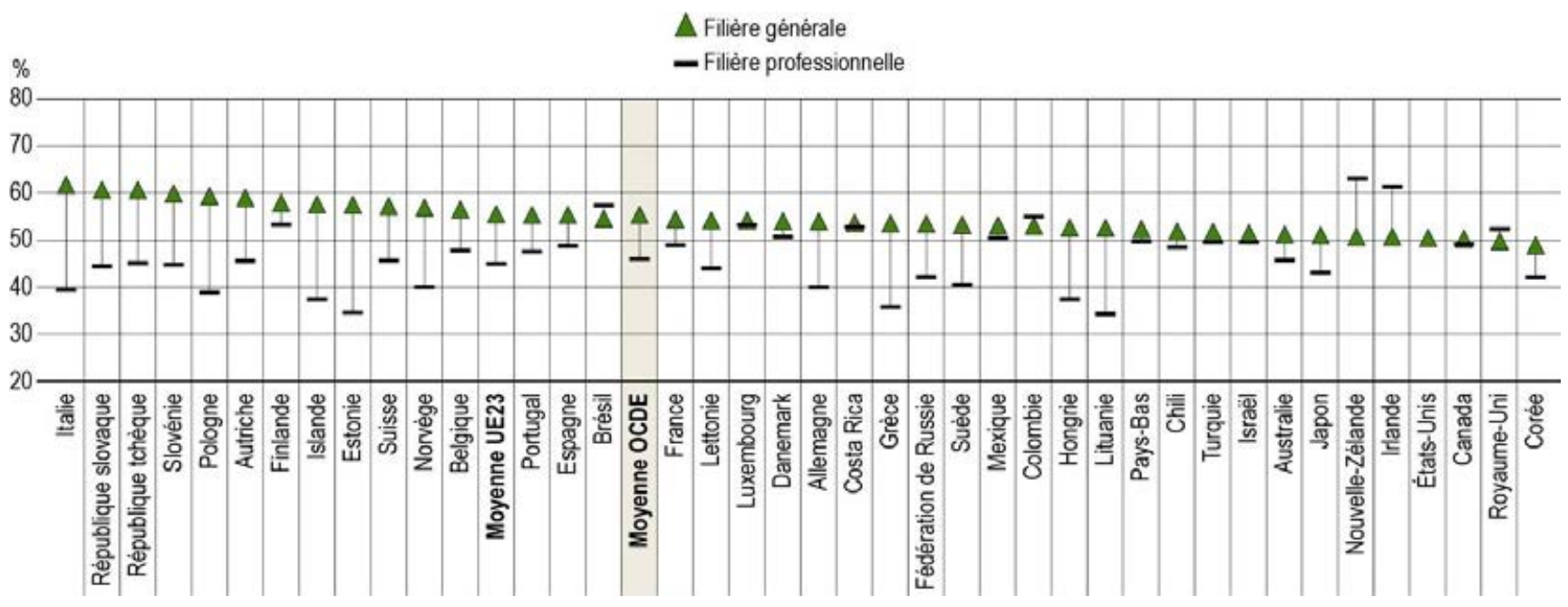

Les pays sont classés par ordre décroissant du pourcentage de femmes parmi les diplômés de la filière générale du deuxième cycle du secondaire. Source : OCDE/ISU/Eurostat (2019), Base de données de Regards sur l'éducation, http://stats.oecd.org/. Consulter la section «Source » pour tout complément d'information et l'annexe 3 pour les notes (https://doi.org/10.1787/f8d7880d-en).

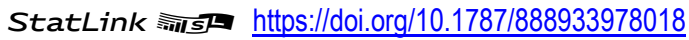

Le pourcentage de femmes en filière professionnelle varie toutefois sensiblement entre les pays. II est inférieur à $36 \%$ en Estonie et en Lituanie, mais passe la barre des $60 \%$ en Irlande. En fait, l'Irlande fait partie des quatre seuls pays - avec le Brésil, la Colombie et le Royaume-Uni - où les femmes sont plus nombreuses en filière professionnelle qu'en filière générale. Dans ces pays, la différence entre le pourcentage de femmes en filière générale et celui en filière professionnelle va de moins de 4 points de pourcentage au Brésil, en Colombie, et au Royaume-Uni à 11 points de pourcentage en Irlande (voir le graphique B3.2). 
Profil des diplômés du deuxième cycle de l'enseignement secondaire en filière professionnelle, selon le domaine d'études

En moyenne, dans les pays de l'OCDE, 32 \% des diplômés du deuxième cycle de l'enseignement secondaire en filière professionnelle ont suivi une formation en rapport avec l'ingénierie, les industries de transformation ou la construction. Ce pourcentage chute à $18 \%$ pour une spécialisation en commerce, en administration et en droit, et à $12 \%$ pour une formation dans le domaine de la santé et de la protection sociale. Cette tendance ne s'observe toutefois pas dans tous les pays. Au Chili, en Estonie, en Hongrie, en Islande et en Lituanie, près de la moitié des diplômés de la filière professionnelle du deuxième cycle de l'enseignement secondaire ont suivi une formation en rapport avec l'ingénierie, les industries de transformation ou la construction. Par contraste, au Brésil, en Italie, au Luxembourg et en Suisse, les domaines d'études les plus prisés par les élèves à ce niveau d'enseignement sont le commerce, l'administration et le droit. Au Danemark, en Espagne, aux Pays-Bas et au Royaume-Uni, les élèves optent plutôt pour des formations dans le domaine de la santé et de la protection sociale (voir le graphique B3.3).

Graphique B3.3 Répartition des titulaires d'un diplôme de la filière professionnelle du deuxième cycle de l'enseignement secondaire, selon le domaine d'études (2017)

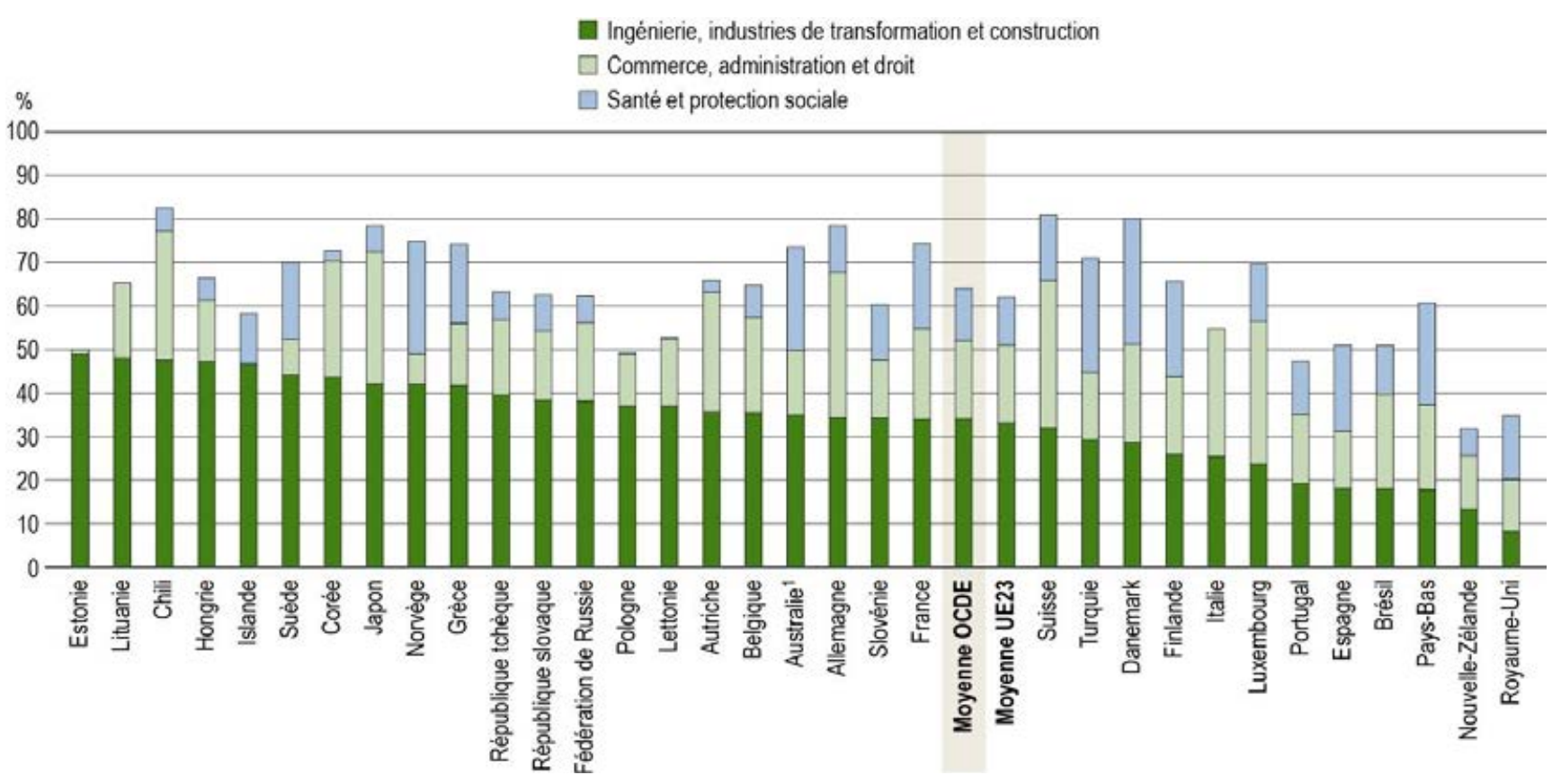

1. Année de référence : 2016.

Les pays sont classés par ordre décroissant du pourcentage de titulaires d'un diplôme en ingénierie, en industries de transformation et en construction. Source : OCDE/ISU/Eurostat (2019), tableau B3.1. Consulter la section « Source » pour tout complément d'information et l'annexe 3 pour les notes (https://doi.org/10.1787/f8d7880d-en).

Le pourcentage de femmes ayant opté pour une formation professionnelle en rapport avec l'ingénierie, les industries de transformation ou la construction dans le deuxième cycle de l'enseignement secondaire est peu élevé : les femmes ne représentent que $12 \%$ des diplômés de ces domaines d'études. Par contraste, les femmes sont surreprésentées dans les formations dans le domaine de la santé et de la protection sociale, où elles représentent $82 \%$ des diplômés. En fait, le pourcentage de femmes dans l'effectif de diplômés dans le domaine de la santé et de la protection sociale est partout supérieur à $75 \%$, sauf en Lettonie (71\%), en Pologne (56 \%), en Slovénie (73\%) et en Suède (72\%). Entre ces deux extrêmes, les pourcentages sont plus proches de la 
parité dans le secteur des services, où les femmes représentent $61 \%$ des diplômés en moyenne, et en commerce, en administration et en droit, où les femmes représentent $65 \%$ des diplômés (voir le tableau B3.1).

Le défaut de parité qui s'observe dans certains domaines d'études peut en partie s'expliquer par les stéréotypes sociaux au sujet des domaines dans lesquels hommes et femmes excellent et des professions qui leur conviennent le mieux. Ainsi, le pourcentage peu élevé de femmes en ingénierie, en industries de transformation et en construction pourrait s'expliquer par le fait que, socialement, ces domaines scientifiques sont perçus comme masculins, ce qui pourrait décourager les femmes de s'y aventurer (OCDE, 2015[3]).

\section{Profil des diplômés du deuxième cycle de l'enseignement secondaire en filière professionnelle,} selon l'âge

Les diplômés du deuxième cycle de l'enseignement secondaire tendent à être plus âgés en filière professionnelle qu'en filière générale. En moyenne, dans les pays de l'OCDE, les étudiants obtiennent leur diplôme du deuxième cycle de l'enseignement secondaire à l'âge de 21 ans en filière professionnelle, mais à 18 ans en filière générale (voir le graphique B3.1).

Toutefois, des écarts s'observent entre les pays. Hommes et femmes sont en moyenne diplômés à un âge nettement plus avancé (au moins sept ans de plus) en filière professionnelle qu'en filière générale au Canada, au Danemark, en Islande et en Norvège. Par contraste, ils sont diplômés au moins un an plus tard en filière générale qu'en filière professionnelle au Chili, en Colombie, au Costa Rica et en Pologne. En Corée, en Israël, au Mexique, au Portugal, en République slovaque, en République tchèque, en Suède et en Turquie, l'âge moyen d'obtention d'un diplôme est identique, quelle que soit la filière choisie (voir le graphique B3.1).

La variation de l'âge d'obtention d'un diplôme entre les filières peut s'expliquer par les différences relatives à la durée des formations en filière générale et en filière professionnelle. En Norvège, par exemple, les formations en filière professionnelle durent un an de plus qu'en filière générale, ce qui peut expliquer que les élèves inscrits en filière professionnelle soient plus âgés lorsqu'ils obtiennent leur diplôme (GPS de l'éducation de l'OCDE, 2018[4]).

\section{Profil des diplômés de l'enseignement post-secondaire non tertiaire}

Proposées sous différentes formes dans des pays de l'OCDE, les formations post-secondaires non tertiaires (niveau 4 de la CITE) se situent à la frontière entre le deuxième cycle de l'enseignement secondaire et l'enseignement post-secondaire : elles relèvent du deuxième cycle de l'enseignement secondaire dans certains pays, mais de l'enseignement post-secondaire dans d'autres. Les formations post-secondaires non tertiaires ne sont pas nécessairement d'un niveau beaucoup plus élevé que celles du deuxième cycle de l'enseignement secondaire, mais elles servent à enrichir les connaissances de ceux et celles qui sont déjà titulaires d'un diplôme de fin d'études secondaires. Ce type de formations n'est toutefois pas proposé dans 13 pays environ.

\section{Profil des diplômés de l'enseignement post-secondaire non tertiaire, selon la filière d'enseignement}

En moyenne, dans les pays de l'OCDE, on estime qu'environ $94 \%$ des titulaires d'un premier diplôme de l'enseignement post-secondaire non tertiaire ont suivi une formation en filière professionnelle. Les formations post-secondaires non tertiaires sont fortement professionnalisantes puisqu'elles visent à ce que leurs diplômés intègrent directement le marché du travail. Certains pays ont mis en place des initiatives visant à proposer des formations générales post-secondaires non tertiaires aux diplômés de la filière professionnelle du deuxième cycle de l'enseignement secondaire qui souhaitent multiplier leurs chances d'accéder à l'enseignement tertiaire. En Suisse, par exemple, une formation générale d'un an - le Programme Passerelle DUBS - prépare les diplômés de la filière professionnelle du deuxième cycle de l'enseignement secondaire à réussir une formation tertiaire en filière générale (OCDE/Eurostat/Institut de statistique de l'UNESCO, 2016[5]) 


\section{Profil des diplômés de l'enseignement post-secondaire non tertiaire, selon l'âge}

L'âge moyen d'obtention d'un premier diplôme en filière professionnelle tend à être plus élevé dans l'enseignement post-secondaire non tertiaire que dans le deuxième cycle de l'enseignement secondaire. En moyenne, dans les pays de l'OCDE, les étudiants de la filière professionnelle obtiennent leur premier diplôme à l'âge de 21 ans dans le deuxième cycle de l'enseignement secondaire, mais à 31 ans dans l'enseignement postsecondaire non tertiaire. Toutefois, ces chiffres varient fortement entre les pays : tandis que dans certains pays comme l'Allemagne, la Belgique et la Hongrie, les premiers diplômés du deuxième cycle de l'enseignement secondaire et de l'enseignement post-secondaire non tertiaire n'ont, en moyenne, que deux ans de différence, dans d'autres pays comme l'Espagne, la Finlande et la Suède, ils peuvent avoir plus de 14 ans d'écart (voir le graphique B3.1).

Cette tendance s'explique en partie par le fait que certains pays ont mis en œuvre des stratégies d'apprentissage tout au long de la vie. En fait, certains pays développent progressivement des filières spécifiques pour les adultes dans le cadre de leur stratégie d'EFP. Au Danemark, la formation professionnelle pour adultes (AMU) vise à doter les adultes de compétences et aptitudes pertinentes sur le marché du travail. Le programme aide les apprenants à approfondir leurs connaissances dans un domaine donné ou à développer de nouvelles connaissances dans des domaines connexes (CEDEFOP, 2019[6]).

\section{Profil des diplômés de l'enseignement post-secondaire non tertiaire, selon le domaine d'études}

En moyenne, dans les pays de l'OCDE, 21 \% des diplômés de la filière professionnelle de l'enseignement postsecondaire non tertiaire se sont spécialisés dans le domaine de la santé et de la protection sociale, $20 \%$ ont opté pour une spécialisation en commerce, en administration et en droit, $21 \%$ ont suivi une formation dans le domaine des services et $19 \%$ se sont tournés vers l'ingénierie, les industries de transformation et la construction. Cette tendance ne s'observe toutefois pas dans tous les pays. Au Luxembourg, par exemple, $80 \%$ des diplômés de l'enseignement post-secondaire non tertiaire ont obtenu une qualification en ingénierie, en industries de transformation et en construction, alors qu'ils ne sont qu'1 \% à avoir opté pour ce domaine en Autriche (voir le tableau B3.2).

\section{Profil des diplômés de l'enseignement post-secondaire non tertiaire, selon le sexe}

En moyenne, dans les pays de l'OCDE, 54 \% des diplômés de l'enseignement post secondaire non tertiaire sont des femmes ; ce pourcentage varie toutefois sensiblement entre les pays, allant de $19 \%$ au Luxembourg à $75 \%$ en Autriche et en Pologne.

Dans la quasi-totalité des pays dont les données sont disponibles, les femmes représentent plus de la moitié des diplômés de la filière professionnelle de l'enseignement post-secondaire non tertiaire, sauf en Australie, en Belgique, au Danemark, en Fédération de Russie, en Islande, au Luxembourg, au Portugal et en République tchèque. Le pourcentage de femmes ayant opté pour une formation en rapport avec l'ingénierie, les industries de transformation ou la construction dans l'enseignement post-secondaire non tertiaire est peu élevé : les femmes ne représentent en effet que $18 \%$ des diplômés de ces domaines d'études. Par contraste, les femmes sont surreprésentées dans les formations liées au domaine de la santé et de la protection sociale, où elles représentent au moins $75 \%$ des diplômés dans tous les pays, à l'exception de l'Australie (70 \%). Les pourcentages sont plus proches de la parité dans le secteur des services, où les femmes représentent $57 \%$ des diplômés en moyenne, et en commerce, en administration et en droit, où les femmes représentent $66 \%$ des diplômés (voir le tableau B3.2). 


\section{Taux d'obtention d'un premier diplôme}

\section{Taux d'obtention d'un diplôme du deuxième cycle de l'enseignement secondaire}

Les connaissances et compétences qui s'acquièrent dans le deuxième cycle de l'enseignement secondaire sont souvent considérées comme le bagage minimal requis pour réussir à entrer sur le marché du travail ; elles sont indispensables aussi pour poursuivre des études. Les coûts découlant du fait de ne pas terminer ce niveau d'enseignement dans le délai imparti peuvent être considérables, tant pour les individus que pour la société (voir l'indicateur A5).

Les taux d'obtention d'un diplôme montrent si les mesures prises par les pouvoirs publics pour accroître le pourcentage de diplômés du deuxième cycle de l'enseignement secondaire sont efficaces. Les différences marquées de taux d'obtention d'un diplôme entre les pays reflètent la diversité des systèmes d'éducation et des formations proposées, ainsi que d'autres facteurs spécifiques à chaque pays, tels que les normes sociales et la performance économique.

Selon les estimations actuelles, en moyenne $86 \%$ des jeunes obtiendront un diplôme du deuxième cycle de l'enseignement secondaire au cours de leur vie dans les pays de l'OCDE, parmi lesquels $81 \%$ auront moins de 25 ans. Le taux d'obtention d'un premier diplôme avant l'âge de 25 ans passe la barre des 80 \% dans plus de la moitié des pays de l'OCDE dont les données sont disponibles, mais il va de $60 \%$ au Mexique à $90 \%$ en Corée, en Grèce et en Slovénie (voir le tableau B3.3).

Le taux d'obtention d'un diplôme plus élevé en filière générale peut s'expliquer par le pourcentage moins important d'élèves inscrits en filière professionnelle qu'en filière générale dans le deuxième cycle de l'enseignement secondaire (voir l'indicateur B1), ainsi que par un taux de réussite moins élevé en filière professionnelle (voir l'encadré B3.1 dans (OCDE, 2017[7])).

Dans les pays dont les données sont disponibles, le taux d'obtention d'un premier diplôme du deuxième cycle de l'enseignement secondaire avant l'âge de 25 ans a augmenté de 4 points de pourcentage entre 2010 et 2017 , alors que le taux d'obtention d'un premier diplôme tous âges confondus a augmenté de 2 points de pourcentage durant la même période. Cette augmentation a été spectaculaire dans trois pays, à savoir en Espagne, en Turquie (de 18 points de pourcentage dans les deux pays) et au Mexique (de 15 points de pourcentage). Par contraste, le taux d'obtention d'un premier diplôme avant l'âge de 25 ans a diminué de 5 points de pourcentage en Autriche, en Lituanie et en Suède, et de 13 points de pourcentage en République slovaque durant la même période (voir le tableau B3.3).

II ne faut toutefois pas déduire de l'augmentation des taux d'obtention d'un diplôme du deuxième cycle de l'enseignement secondaire que tous les diplômés entameront des études tertiaires ou entreront immédiatement dans la vie active, ni qu'ils possèderont le bon éventail de compétences pour réussir une fois embauchés. En fait, le pourcentage de diplômés du deuxième cycle de l'enseignement secondaire qui ne travaillent pas et qui ne sont ni scolarisés, ni en formation (neither employed nor in education or training, NEET) a augmenté dans près de la moitié des pays de l'OCDE (voir l'indicateur A2). Dans ce contexte, il est important de proposer des formations de qualité dans le deuxième cycle de l'enseignement secondaire et d'offrir la bonne combinaison de possibilités d'apprentissage et d'orientations pour que des individus ne se retrouvent pas dans une impasse une fois leur diplôme en poche.

\section{Taux d'obtention d'un diplôme post-secondaire non tertiaire}

Les taux d'obtention d'un premier diplôme de l'enseignement post-secondaire non tertiaire sont peu élevés par comparaison avec ceux qui s'observent dans le deuxième cycle de l'enseignement secondaire. Dans les pays de l'OCDE, on estime qu'en moyenne, $12 \%$ des jeunes d'aujourd'hui décrocheront un diplôme de l'enseignement post-secondaire non tertiaire durant leur vie. Les seuls pays où le taux d'obtention d'un premier diplôme de l'enseignement post-secondaire non tertiaire (tous âges confondus) passe la barre des $20 \%$ sont l'Allemagne, les États-Unis, la Hongrie, la Lituanie, la Nouvelle-Zélande et la République tchèque. Dans les pays 
de l'OCDE dont les données de 2005, 2010 et 2017 sont disponibles, le taux d'obtention d'un premier diplôme de l'enseignement post-secondaire non tertiaire (parmi les individus âgés de moins de 30 ans) est resté constant durant les dix dernières années (3\% en moyenne). Ce niveau d'enseignement n'existe pas dans neuf pays, à savoir au Chili, en Corée, au Costa Rica, en Indonésie, au Mexique, aux Pays-Bas, au Royaume-Uni, en Slovénie et en Turquie (voir le tableau B3.3).

\section{Définitions}

Les individus diplômés durant la période de référence peuvent être soit titulaires d'un premier diplôme, soit titulaires de plusieurs diplômes. Par titulaires d'un premier diplôme, on entend les individus diplômés pour la première fois durant la période de référence du niveau d'enseignement considéré. Si un individu a obtenu plusieurs diplômes au fil du temps, il sera donc comptabilisé comme diplômé chaque année, mais comme titulaire d'un premier diplôme une seule fois durant la période de référence.

Le taux net d'obtention d'un diplôme, en l'occurrence du deuxième cycle de l'enseignement secondaire, correspond au pourcentage d'individus d'un âge donné dont on estime qu'ils réussiront ce niveau d'enseignement sur la base des taux actuels d'obtention d'un diplôme.

Par âge typique, on entend l'âge qu'ont les individus au début de la dernière année scolaire du niveau d'enseignement considéré, à l'issue de laquelle ils seront diplômés.

\section{Méthodologie}

Sauf mention contraire, les taux d'obtention d'un diplôme sont nets (ils correspondent à la somme des taux d'obtention d'un diplôme par âge). Dans les pays qui ne peuvent fournir des données aussi détaillées, ce sont les taux bruts qui sont indiqués. Les taux bruts sont calculés sur la base de l'âge typique d'obtention d'un diplôme communiqué par les pays (voir l'annexe 1). Le nombre de diplômés du niveau d'enseignement considéré, quel que soit leur âge, est divisé par l'effectif de la population ayant l'âge typique d'obtenir ce diplôme. Toutefois, dans de nombreux pays, il est difficile de définir un âge typique d'obtention d'un diplôme, car celui-ci est très variable.

Les diplômés par filière d'enseignement dans le deuxième cycle de l'enseignement secondaire et l'enseignement post-secondaire non tertiaire ne sont pas comptabilisés comme titulaires d'un premier diplôme, car ils sont nombreux à obtenir plus d'un diplôme à ces niveaux d'enseignement. II est impossible d'additionner les taux bruts d'obtention d'un diplôme, car certains titulaires de plusieurs diplômes seraient comptabilisés plus d'une fois. De plus, l'âge typique d'obtention d'un diplôme n'est pas nécessairement identique dans toutes les formations (voir l'annexe 1). Les formations professionnelles comprennent les formations organisées en milieu scolaire et en alternance (en milieu scolaire et en entreprise) qui sont reconnues par le système d'éducation. Les formations dispensées entièrement en entreprise sans la supervision des autorités de l'éducation sont exclues.

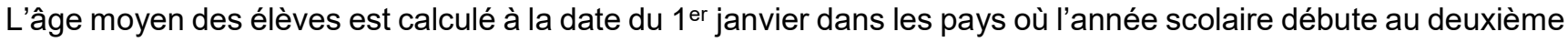
semestre de l'année civile et à la date du $1^{\mathrm{er}}$ juillet dans ceux où elle débute au premier semestre. Par voie de conséquence, l'âge moyen des titulaires d'un premier diplôme peut être sous-estimé de six mois.

Si la répartition par âge n'est pas disponible, c'est le taux brut d'obtention d'un diplôme qui est calculé. Le taux brut correspond au nombre total de diplômés divisé par l'effectif de la population ayant l'âge typique d'être diplômé du niveau d'enseignement considéré, qui est communiqué par les pays concernés.

Dans cet indicateur, l'âge des étudiants correspond en règle générale à l'âge qu'ils avaient au début de l'année civile ; des étudiants peuvent donc avoir un an de plus que l'âge indiqué lorsqu'ils obtiennent leur diplôme à la fin de l'année scolaire. L'âge de 25 ans est considéré comme l'âge maximal de fin du deuxième cycle de l'enseignement secondaire, car plus de $95 \%$ des diplômés en 2017 du deuxième cycle de l'enseignement secondaire en filière générale avaient moins de 25 ans dans les pays de l'OCDE (voir la Base de données de 
Regards sur l'éducation). Les individus diplômés de ce niveau d'enseignement après l'âge de 25 ans ont généralement suivi une formation spécifique, dans le cadre d'un programme dit de " seconde chance ». Dans l'enseignement post-secondaire non tertiaire, l'âge de 30 ans est considéré comme l'âge maximal d'obtention d'un diplôme.

Voir les remarques spécifiques aux pays à l'annexe 3 (https://doi.org/10.1787/f8d7880d-en).

\section{Source}

Les données se rapportent à l'année académique 2016/17 et proviennent de l'exercice UNESCOISU/OCDE/Eurostat de collecte de données statistiques sur l'éducation réalisé par l'OCDE en 2018 (pour plus de précisions, voir l'annexe 3, https://doi.org/10.1787/f8d7880d-en).

\section{Note concernant les données d'Israël}

Les données statistiques concernant Israël sont fournies par et sous la responsabilité des autorités israéliennes compétentes. L'utilisation de ces données par l'OCDE est sans préjudice du statut des hauteurs du Golan, de Jérusalem-Est et des colonies de peuplement israéliennes en Cisjordanie aux termes du droit international.

\section{Références}

CEDEFOP (2019), Spotlight on VET - 2018 compilation: vocational education and training systems in Europe, Office des publications de l'Union européenne, Luxembourg.

CEDEFOP (2013), Labour market outcomes of vocational education in Europe, Office des publications de l'Union européenne, Luxembourg.

CEDEFOP (2011), The benefits of vocational education and training, Office des publications de l'Union européenne, Luxembourg.

GPS de l'éducation de l'OCDE (2018), Diagram of the education system: Norway.

OCDE (2017), Regards sur l'éducation 2017: Les indicateurs de l'OCDE, Éditions OCDE, Paris, https://dx.doi.org/10.1787/eag-2017-fr.

OCDE (2015), L'égalité des sexes dans l'éducation: Aptitudes, comportement et confiance, PISA, Éditions OCDE, Paris, https://dx.doi.org/10.1787/9789264230644-fr.

OCDE/Eurostat/Institut de statistique de I'UNESCO (2016), Guide opérationnel CITE 2011: Directives pour la classification des programmes éducatifs nationaux et des certifications correspondantes, Institut de statistique de l'UNESCO, Paris, https://dx.doi.org/10.1787/9789264248823-fr. 
206 | B3. QUEL EST LE PROFIL DES DIPLÔMÉS DU DEUXIĖME CYCLE DE L'ENSEIGNEMENT SECONDAIRE ?

\section{Tableaux de l'indicateur B3}

Tableau B3.1

Tableau B3.2

Tableau B3.3

Date butoir pour les données : 19 juillet 2019. Les mises à jour peuvent être consultées en ligne sur : http://dx.doi.org/10.1787/eag-data-en. D'autres données désagrégées sont également disponibles dans la Base de données de Regards sur l'éducation (http://stats.oecd.org/).

Statlink : https://doi.org/10.1787/888933980963 
Tableau B3.1. Profil des diplômés de la filière professionnelle du deuxième cycle du secondaire (2017)

\begin{tabular}{|c|c|c|c|c|c|c|c|c|c|c|c|}
\hline & \multirow{2}{*}{ 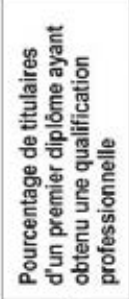 } & \multirow{2}{*}{ 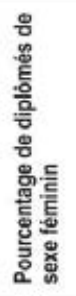 } & \multirow[b]{2}{*}{ 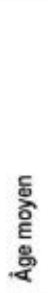 } & \multicolumn{4}{|c|}{$\begin{array}{l}\text { Répartition des diplòmés } \\
\text { par domaine d'études }\end{array}$} & \multicolumn{4}{|c|}{$\begin{array}{l}\text { Pourcentage de diplòmés de sexe féminin, } \\
\text { selon le domaine d'études }\end{array}$} \\
\hline & & & & 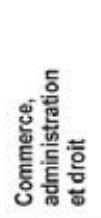 & 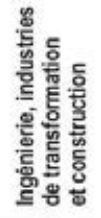 & 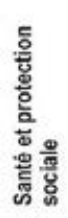 & 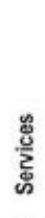 & 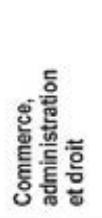 & 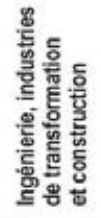 & 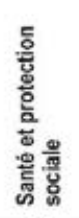 & 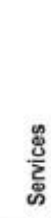 \\
\hline & (1) & (2) & (3) & (4) & (5) & (6) & (7) & (8) & (9) & (10) & (11) \\
\hline \multicolumn{12}{|l|}{ w Pays } \\
\hline Oustralie' & $\mathrm{m}$ & 46 & 33 & 15 & 35 & 24 & 14 & 64 & 10 & 85 & 60 \\
\hline Autriche & 77 & 46 & 20 & 28 & 36 & 3 & 19 & 65 & 13 & 79 & 74 \\
\hline Belgique & $\mathrm{m}$ & 48 & 19 & 22 & 35 & 7 & 23 & 54 & 20 & 88 & 74 \\
\hline Canada & 6 & 49 & 32 & $\mathrm{~m}$ & $\mathrm{~m}$ & $\mathrm{~m}$ & $\mathrm{~m}$ & $\mathrm{~m}$ & $\mathrm{~m}$ & $\mathrm{~m}$ & $\mathrm{~m}$ \\
\hline Chili & 31 & 49 & 18 & 30 & 48 & 5 & 4 & 64 & 28 & 85 & 62 \\
\hline Colombie & 24 & 55 & 16 & $\mathrm{~m}$ & $\mathrm{~m}$ & m & $\mathrm{m}$ & $\mathrm{m}$ & $\mathrm{m}$ & $\mathrm{m}$ & $\mathrm{m}$ \\
\hline République tcheque & 69 & 45 & 21 & 17 & 40 & 7 & 18 & 67 & 13 & 90 & 66 \\
\hline Danemark & 28 & 51 & 28 & 23 & 28 & 29 & 12 & 66 & 10 & 87 & 45 \\
\hline Estonie & $\mathrm{m}$ & 35 & 19 & 1 & 49 & 0 & 27 & 94 & 19 & a & 69 \\
\hline Finlande & 55 & 53 & 29 & 18 & 26 & 22 & 19 & 67 & 17 & 83 & 58 \\
\hline France & $\mathrm{m}$ & 49 & 20 & 21 & 34 & 20 & 19 & 63 & 11 & 91 & 63 \\
\hline Allemagne & 44 & 40 & 22 & 33 & 34 & 11 & 12 & 57 & 9 & 86 & 47 \\
\hline Grèce & 25 & 36 & 18 & 14 & 42 & 18 & 5 & 60 & 11 & 81 & 54 \\
\hline Hongrie & 20 & 37 & 22 & 14 & 47 & 5 & 29 & 72 & 8 & 91 & 57 \\
\hline Islande & 22 & 37 & 28 & 0 & 47 & 12 & 22 & 100 & 8 & 96 & 53 \\
\hline Irlande & $\mathrm{m}$ & 61 & 31 & $\mathrm{~m}$ & $\mathrm{~m}$ & $\mathrm{~m}$ & $\mathrm{~m}$ & $\mathrm{~m}$ & $\mathrm{~m}$ & $\mathrm{~m}$ & $\mathrm{~m}$ \\
\hline Israęl & 42 & 50 & 17 & $\mathrm{~m}$ & $\mathrm{~m}$ & $\mathrm{~m}$ & $\mathrm{~m}$ & $\mathrm{~m}$ & $\mathrm{~m}$ & $\mathrm{~m}$ & $\mathrm{~m}$ \\
\hline Italie ${ }^{2}$ & 58 & 39 & $\mathrm{~m}$ & 29 & 25 & 0 & 30 & 50 & 13 & a & 54 \\
\hline Japon & 23 & 43 & $\mathrm{~m}$ & 30 & 42 & 6 & 8 & 62 & 11 & 83 & 82 \\
\hline Corée & 18 & 42 & 18 & 27 & 44 & 2 & 5 & 74 & 14 & 78 & 65 \\
\hline Lituanie & 16 & 34 & 21 & 17 & 48 & 0 & 27 & 48 & 3 & a & 78 \\
\hline Lettonie & 25 & 44 & 21 & 15 & 37 & 0 & 24 & 75 & 10 & 71 & 70 \\
\hline Luxembourg & 60 & 53 & 21 & 33 & 24 & 13 & 6 & 65 & 17 & 81 & 65 \\
\hline Mexique & 33 & 50 & 18 & $\mathrm{~m}$ & $\mathrm{~m}$ & m & $\mathrm{m}$ & $\mathrm{m}$ & $\mathrm{m}$ & $\mathrm{m}$ & $\mathrm{m}$ \\
\hline Pays-Bas & 54 & 50 & 22 & 20 & 18 & 23 & 22 & 54 & 10 & 88 & 46 \\
\hline Nouvelle-Zèlande & $\mathrm{m}$ & 63 & 33 & 12 & 13 & 6 & 18 & 76 & 15 & 78 & 69 \\
\hline Norvège & 35 & 40 & 28 & 7 & 42 & 26 & 18 & 77 & 8 & 84 & 39 \\
\hline Pologne & 45 & 39 & 20 & 12 & 37 & 0 & 27 & 63 & 12 & 56 & 69 \\
\hline Portugal & 36 & 48 & 20 & 16 & 19 & 12 & 24 & 66 & 17 & 86 & 58 \\
\hline République slovaque & 71 & 44 & 19 & 16 & 38 & 8 & 24 & 71 & 10 & 84 & 62 \\
\hline Slovénie & 67 & 45 & 19 & 13 & 34 & 13 & 16 & 63 & 11 & 73 & 63 \\
\hline Espagne & 33 & 49 & 25 & 13 & 18 & 20 & 14 & 62 & 8 & 77 & 47 \\
\hline Suède & 33 & 41 & 18 & 8 & 44 & 18 & 20 & 58 & 9 & 72 & 62 \\
\hline Suisse & $\mathrm{m}$ & 46 & 22 & 34 & 32 & 15 & 9 & 59 & 12 & 89 & 55 \\
\hline Turquie & 50 & 50 & 18 & 16 & 29 & 26 & 8 & 51 & 13 & 81 & 63 \\
\hline Royaume-Uni & 63 & 52 & 21 & 12 & 8 & 15 & 14 & 53 & 6 & 80 & 51 \\
\hline Etats-Unis & a & a & a & a & a & a & a & a & a & a & a \\
\hline Moyenne OCDE & 40 & 46 & 22 & 18 & 34 & 12 & 17 & 65 & 12 & 82 & 61 \\
\hline Moyenne UE23 & 46 & 45 & 22 & 18 & 33 & 11 & 20 & 63 & 12 & 81 & 60 \\
\hline of Argentine & $\mathrm{m}$ & $\mathrm{m}$ & $\mathrm{m}$ & $\mathrm{m}$ & $\mathrm{m}$ & $\mathrm{m}$ & $\mathrm{m}$ & $\mathrm{m}$ & $\mathrm{m}$ & $\mathrm{m}$ & $\mathrm{m}$ \\
\hline$\frac{2}{m}$ Brésil & 8 & 57 & 21 & 22 & 18 & 11 & 4 & 62 & 32 & $\pi$ & 66 \\
\hline shine & $\mathrm{m}$ & $\mathrm{m}$ & $\mathrm{m}$ & $\mathrm{m}$ & $\mathrm{m}$ & m & $\mathrm{m}$ & $\mathrm{m}$ & $\mathrm{m}$ & $\mathrm{m}$ & $\mathrm{m}$ \\
\hline costa Rica & 24 & 53 & 18 & $\mathrm{~m}$ & $\mathrm{~m}$ & m & $\mathrm{m}$ & m & $\mathrm{m}$ & $\mathrm{m}$ & m \\
\hline Inde & m & $\mathrm{m}$ & $\mathrm{m}$ & $\mathrm{m}$ & $\mathrm{m}$ & m & $\mathrm{m}$ & $\mathrm{m}$ & $\mathrm{m}$ & $\mathrm{m}$ & $\mathrm{m}$ \\
\hline Indonésie & $\mathrm{m}$ & $\mathrm{m}$ & m & $\mathrm{m}$ & $\mathrm{m}$ & $\mathrm{m}$ & $\mathrm{m}$ & $\mathrm{m}$ & $\mathrm{m}$ & $\mathrm{m}$ & $\mathrm{m}$ \\
\hline Fédération de Russie & 46 & 42 & $\mathrm{~m}$ & 18 & 38 & 6 & 18 & $\mathrm{~m}$ & $\mathrm{~m}$ & $\mathrm{~m}$ & $\mathrm{~m}$ \\
\hline Arabie saoudite & $\mathrm{m}$ & $\mathrm{m}$ & $\mathrm{m}$ & $\mathrm{m}$ & $\mathrm{m}$ & $\mathrm{m}$ & $\mathrm{m}$ & $\mathrm{m}$ & $\mathrm{m}$ & $\mathrm{m}$ & $\mathrm{m}$ \\
\hline Afrique du Sud & $\mathrm{m}$ & $\mathrm{m}$ & $\mathrm{m}$ & $\mathrm{m}$ & $\mathrm{m}$ & m & $\mathrm{m}$ & $\mathrm{m}$ & $\mathrm{m}$ & $\mathrm{m}$ & $\mathrm{m}$ \\
\hline Moyenne G20 & m & $\mathrm{m}$ & $m$ & $\mathrm{~m}$ & $\mathrm{~m}$ & $m$ & m & m & $\mathrm{m}$ & $\mathrm{m}$ & m \\
\hline
\end{tabular}

Remarque : Ce tableau ne présente pas des données pour tous les domaines d'études. Les données relatives aux autres domaines peuvent être consultées sur http://stats.oecd.org/, Base de données de Regards sur l'éducation.

1. Année de référence : 2016.

2. Inclut le niveau post-secondaire non tertiaire.

Source : OCDE/ISU/Eurostat (2019). Consulter la section « Source » pour tout complément d'information et l'annexe 3 pour les notes (https://doi.org/10.1787/f8d7880den).

Les symboles représentant les données manquantes et les abréviations figurent dans le Guide du lecteur. 
Tableau B3.2. Profil des diplômés de la filière professionnelle de l'enseignement post-secondaire non tertiaire (2017)

\begin{tabular}{|c|c|c|c|c|c|c|c|c|c|c|c|}
\hline & \multirow{2}{*}{ 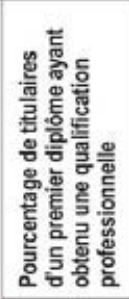 } & \multirow[b]{2}{*}{ 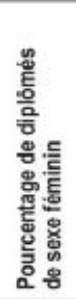 } & \multirow[b]{2}{*}{ 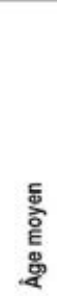 } & \multicolumn{4}{|c|}{$\begin{array}{l}\text { Répartition des diplômés } \\
\text { par domaine d'études }\end{array}$} & \multicolumn{4}{|c|}{$\begin{array}{l}\text { Pourcentage de diplômés de sexe fèminin, } \\
\text { selon le domaine d'études }\end{array}$} \\
\hline & & & & 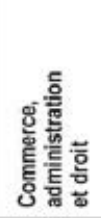 & 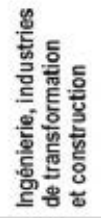 & 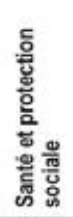 & 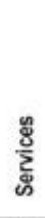 & 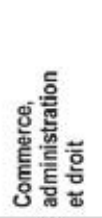 & 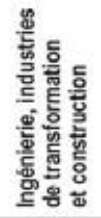 & 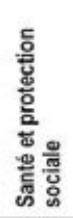 & 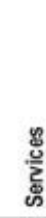 \\
\hline & (1) & (2) & (3) & (4) & (5) & (6) & (7) & (8) & (9) & (10) & (11) \\
\hline \multicolumn{12}{|l|}{ ए Pays } \\
\hline Australie' & 100 & 50 & 37 & 23 & 24 & 27 & 10 & 57 & 10 & 70 & 51 \\
\hline Autriche & 100 & 75 & 33 & 8 & 1 & 63 & 1 & 53 & 17 & 79 & 53 \\
\hline Belgique & 100 & 50 & 22 & 12 & 26 & 13 & 36 & 56 & 9 & 82 & 69 \\
\hline Canada & $\mathrm{m}$ & $\mathrm{m}$ & $\mathrm{m}$ & $\mathrm{m}$ & $\mathrm{m}$ & $\mathrm{m}$ & $\mathrm{m}$ & $\mathrm{m}$ & $\mathrm{m}$ & $\mathrm{m}$ & $\mathrm{m}$ \\
\hline Chili & a & a & a & a & a & a & a & a & a & a & a \\
\hline Colombie & a & a & a & a & a & a & a & a & a & a & a \\
\hline République tchèque & 19 & 44 & $\mathrm{~m}$ & $\mathrm{~m}$ & $\mathrm{~m}$ & $\mathrm{~m}$ & $\mathrm{~m}$ & $\mathrm{~m}$ & $\mathrm{~m}$ & $\mathrm{~m}$ & $\mathrm{~m}$ \\
\hline Danemark & 100 & 40 & 35 & 96 & 0 & 0 & 1 & 40 & a & a & 100 \\
\hline Estonic & $\mathrm{m}$ & 62 & 31 & 36 & 24 & 1 & 25 & 91 & 35 & 78 & 41 \\
\hline Finlande & 100 & 59 & 42 & 58 & 19 & 6 & 13 & 57 & 56 & 86 & 61 \\
\hline France & $\mathrm{m}$ & $\mathrm{m}$ & $\mathrm{m}$ & 7 & 3 & 16 & 1 & 57 & 29 & 90 & 7 \\
\hline Allemagne & 90 & 60 & 24 & 24 & 19 & 43 & 7 & 65 & 14 & 81 & 65 \\
\hline Grèce & $\mathrm{m}$ & 62 & 25 & 7 & 6 & 31 & 41 & 66 & 25 & 83 & 60 \\
\hline Hongrie & 100 & 53 & 24 & 19 & 20 & 23 & 17 & 76 & 11 & 78 & 58 \\
\hline Islande & 79 & 32 & 37 & 11 & 45 & 1 & 33 & 49 & 9 & 100 & 49 \\
\hline Irlande & $\mathrm{m}$ & 53 & 30 & 0 & 25 & 34 & 9 & 64 & 1 & 96 & 43 \\
\hline Israël & a & a & a & a & a & a & a & a & a & a & a \\
\hline Italie & $\mathrm{m}$ & $\mathrm{m}$ & $\mathrm{m}$ & $\mathrm{m}$ & $\mathrm{m}$ & $\mathrm{m}$ & $\mathrm{m}$ & $\mathrm{m}$ & $\mathrm{m}$ & $\mathrm{m}$ & $\mathrm{m}$ \\
\hline Japon & $\mathrm{m}$ & $\mathrm{m}$ & m & $\mathrm{m}$ & $\mathrm{m}$ & $\mathrm{m}$ & $\mathrm{m}$ & $\mathrm{m}$ & $\mathrm{m}$ & $\mathrm{m}$ & m \\
\hline Corée & a & a & a & a & a & a & a & a & a & a & a \\
\hline Lituanie & 100 & 63 & 29 & 15 & 19 & 22 & 28 & 83 & 20 & 91 & 70 \\
\hline Lettonie & 100 & 52 & 29 & 24 & 27 & 12 & 23 & 61 & 18 & 85 & 65 \\
\hline Luxembourg & 100 & 19 & 29 & 0 & 80 & 0 & 15 & a & 4 & a & 100 \\
\hline Mexique & a & a & a & a & a & a & a & a & a & a & a \\
\hline Pays-Bas & a & a & a & a & a & a & a & a & a & a & a \\
\hline Nouvelle-Zélande & 100 & 61 & 30 & 16 & 10 & 13 & 19 & 72 & 17 & 82 & 65 \\
\hline Norvège & 100 & 66 & 33 & 25 & 5 & 29 & 25 & 88 & 15 & 91 & 31 \\
\hline Pologne & 100 & 75 & 28 & 13 & 0 & 44 & 27 & 80 & 20 & 83 & 69 \\
\hline Portugal & 100 & 39 & 26 & 5 & 14 & 0 & 68 & 60 & 10 & a & 46 \\
\hline République slovaque & 100 & 50 & 28 & 13 & 15 & 18 & 39 & 60 & 9 & 83 & 31 \\
\hline Slovénie & a & a & a & a & a & a & a & a & a & a & a \\
\hline Espagne & 100 & 60 & 38 & 34 & 13 & 25 & 12 & 67 & 31 & 75 & 73 \\
\hline Suède & 87 & 56 & 33 & 10 & 24 & 22 & 12 & 75 & 22 & 95 & 49 \\
\hline Suisse & a & a & a & a & a & a & a & a & a & a & a \\
\hline Turquie & a & a & a & a & a & a & a & a & a & a & a \\
\hline Royaume-Uni & a & a & a & a & a & a & a & a & a & a & a \\
\hline Etats-Unis & 100 & 57 & m & 10 & 20 & 34 & 19 & 65 & 7 & 84 & 62 \\
\hline Moyenne OCDE & 94 & 54 & 31 & 20 & 19 & 21 & 21 & 66 & 18 & 85 & 57 \\
\hline Moyenne UE23 & 93 & 54 & 30 & 21 & 19 & 21 & 21 & 65 & 19 & 84 & 59 \\
\hline \& Argentine & $\mathrm{m}$ & $\mathrm{m}$ & $\mathrm{m}$ & $\mathrm{m}$ & $\mathrm{m}$ & $\mathrm{m}$ & $\mathrm{m}$ & m & $\mathrm{m}$ & $\mathrm{m}$ & $m$ \\
\hline Brèsil & 100 & 57 & 28 & 26 & 22 & 29 & 10 & 64 & 18 & 84 & 60 \\
\hline s్ Chine & $\mathrm{m}$ & $\mathrm{m}$ & $\mathrm{m}$ & $\mathrm{m}$ & $\mathrm{m}$ & $\mathrm{m}$ & $\mathrm{m}$ & $\mathrm{m}$ & $\mathrm{m}$ & m & $\mathrm{m}$ \\
\hline Costa Rica & a & a & a & a & a & a & a & a & a & a & a \\
\hline Inde & $\mathrm{m}$ & $\mathrm{m}$ & $\mathrm{m}$ & $\mathrm{m}$ & $\mathrm{m}$ & $\mathrm{m}$ & $\mathrm{m}$ & $\mathrm{m}$ & $\mathrm{m}$ & $\mathrm{m}$ & $\mathrm{m}$ \\
\hline Indonésie & $\mathrm{m}$ & $\mathrm{m}$ & $\mathrm{m}$ & $\mathrm{m}$ & $\mathrm{m}$ & $\mathrm{m}$ & $\mathrm{m}$ & $\mathrm{m}$ & $\mathrm{m}$ & $\mathrm{m}$ & $\mathrm{m}$ \\
\hline Fédération de Russie & 100 & 35 & 25 & 5 & 58 & 4 & 20 & 82 & 26 & 92 & 37 \\
\hline Arabie saoudite & $\mathrm{m}$ & $\mathrm{m}$ & $\mathrm{m}$ & $\mathrm{m}$ & $\mathrm{m}$ & $\mathrm{m}$ & $\mathrm{m}$ & $\mathrm{m}$ & $\mathrm{m}$ & $\mathrm{m}$ & $\mathrm{m}$ \\
\hline Afrique du Sud & m & m & m & $m$ & $\mathrm{~m}$ & m & m & $\mathrm{m}$ & m & m & m \\
\hline Moyenne G20 & $\mathrm{m}$ & $\mathrm{m}$ & $\mathrm{m}$ & $\mathrm{m}$ & $\mathrm{m}$ & $\mathrm{m}$ & $\mathrm{m}$ & $\mathrm{m}$ & $\mathrm{m}$ & $\mathrm{m}$ & $\mathrm{m}$ \\
\hline
\end{tabular}

Remarque : Ce tableau ne présente pas des données pour tous les domaines d'études. Les données relatives aux autres domaines peuvent être consultées sur http://stats.oecd.org/, Base de données de Regards sur l'éducation.

1. Année de référence : 2016.

Source : OCDE/ISU/Eurostat (2019). Consulter la section « Source » pour tout complément d'information et l'annexe 3 pour les notes (https://doi.org/10.1787/f8d7880den).

Les symboles représentant les données manquantes et les abréviations figurent dans le Guide du lecteur. 
Tableau B3.3. Évolution des taux d'obtention d'un premier diplôme du deuxième cycle du secondaire ou de l'enseignement post-secondaire non tertiaire $(2005,2010$ et 2017)

\begin{tabular}{|c|c|c|c|c|c|c|c|c|c|c|c|c|}
\hline & \multicolumn{6}{|c|}{ Deuxième cycle du secondaire } & \multicolumn{6}{|c|}{ Post-secondaire non tertiaire } \\
\hline & \multicolumn{3}{|c|}{ Tous âges confondus } & \multicolumn{3}{|c|}{ Moins de 25 ans } & \multicolumn{3}{|c|}{ Tous âges confondus } & \multicolumn{3}{|c|}{ Moins de 30 ans } \\
\hline & 2005 & 2010 & 2017 & 2005 & 2010 & 2017 & 2005 & 2010 & 2017 & 2005 & 2010 & 2017 \\
\hline & (1) & (2) & (3) & (4) & (5) & (6) & (7) & (8) & (9) & (10) & (11) & (12) \\
\hline \multicolumn{13}{|l|}{ W Pays } \\
\hline Australie & $\mathrm{m}$ & m & m & m & m & m & $\mathrm{m}$ & 16 & 9 & m & 7 & 3 \\
\hline Autriche & $\mathrm{m}$ & 87 & 85 & $\mathrm{~m}$ & 84 & 79 & $\mathrm{~m}$ & 7 & 7 & m & 4 & 3 \\
\hline Belgique & $\mathrm{m}$ & m & $\mathrm{m}$ & m & m & m & $\mathrm{m}$ & $\mathrm{m}$ & 5 & m & m & 5 \\
\hline Canada & 80 & 85 & 91 & 75 & 81 & 85 & $\mathrm{~m}$ & $\mathrm{~m}$ & $\mathrm{~m}$ & m & m & $\mathrm{m}$ \\
\hline Chili & 83 & 86 & 92 & 77 & 82 & 87 & a & a & a & a & a & a \\
\hline Colombie & $\mathrm{m}$ & $\mathrm{m}$ & $\mathrm{m}$ & $\mathrm{m}$ & $\mathrm{m}$ & $\mathrm{m}$ & $\mathrm{m}$ & $\mathrm{m}$ & $\mathrm{m}$ & $\mathrm{m}$ & $\mathrm{m}$ & $\mathrm{m}$ \\
\hline République tchêque & $116^{\circ}$ & $110^{\circ}$ & 80 & $\mathrm{~m}$ & $\mathrm{~m}$ & 78 & $x(1)$ & $x(2)$ & 30 & $\mathrm{~m}$ & $\mathrm{~m}$ & $\mathrm{~m}$ \\
\hline Danemark & 83 & 85 & 91 & 74 & 76 & 80 & 1 & 1 & 0 & 1 & 0 & 0 \\
\hline Estonie & $\mathrm{m}$ & m & $\mathrm{m}$ & $\mathrm{m}$ & $\mathrm{m}$ & $m$ & $\mathrm{~m}$ & $\mathrm{~m}$ & m & m & $\mathrm{m}$ & $\mathrm{m}$ \\
\hline Finlande & 94 & 95 & 100 & 85 & 85 & 89 & 6 & 7 & 9 & 1 & 1 & 1 \\
\hline France & $\mathrm{m}$ & $\mathrm{m}$ & m & m & m & $\mathrm{m}$ & $\mathrm{m}$ & m & m & m & m & $\mathrm{m}$ \\
\hline Allemagne & 78 & 83 & 81 & $\mathrm{~m}$ & m & 76 & 23 & 25 & 24 & $\mathrm{~m}$ & $\mathrm{~m}$ & 22 \\
\hline Gréce & 96 & 89 & 95 & 96 & 89 & 93 & $\mathrm{~m}$ & $\mathrm{~m}$ & m & m & m & $\mathrm{m}$ \\
\hline Hongrie & 84 & 86 & 84 & 80 & 82 & 79 & 20 & 18 & 21 & 18 & 16 & 18 \\
\hline Islande & $\mathrm{m}$ & $\mathrm{m}$ & 82 & $\mathrm{~m}$ & m & 68 & $\mathrm{~m}$ & $\mathrm{~m}$ & 14 & m & $\mathrm{m}$ & 6 \\
\hline Irlande & 92 & 86 & $\mathrm{~m}$ & 90 & 85 & m & 14 & 10 & $\mathrm{~m}$ & 14 & 7 & $\mathrm{~m}$ \\
\hline Israēl & 89 & 91 & 90 & 89 & 91 & 90 & $\mathrm{~m}$ & m & $\mathrm{m}$ & m & m & $\mathrm{m}$ \\
\hline Italie & 85 & 85 & $96^{\circ}$ & 67 & 67 & m & 6 & 4 & $x(3)$ & 4 & 2 & $\mathrm{~m}$ \\
\hline Japon & $\mathrm{m}$ & $\mathrm{m}$ & 98 & m & $\mathrm{m}$ & $\mathrm{m}$ & $\mathrm{m}$ & m & m & m & $\mathrm{m}$ & $\mathrm{m}$ \\
\hline Corée & 94 & 92 & 95 & m & $\mathrm{m}$ & 95 & a & a & a & a & a & a \\
\hline Lettonie & $\mathrm{m}$ & 89 & 89 & $\mathrm{~m}$ & 88 & 84 & $\mathrm{~m}$ & 3 & 10 & m & 2 & 8 \\
\hline Lituanie & 82 & 94 & 87 & 78 & 89 & 84 & 8 & 9 & 21 & 8 & 7 & 15 \\
\hline Luxembourg & 74 & 70 & 81 & 72 & 68 & 78 & $\mathrm{~m}$ & 2 & 1 & m & 1 & 1 \\
\hline Mexique & 40 & 45 & 61 & 39 & 44 & 60 & a & a & a & a & a & a \\
\hline Pays-Bas & $\mathrm{m}$ & $\mathrm{m}$ & 89 & $\mathrm{~m}$ & m & 84 & $\mathrm{~m}$ & $\mathrm{~m}$ & a & m & m & a \\
\hline Nouvelle-Zèlande & 95 & 91 & 95 & 86 & 80 & 90 & 26 & 29 & 22 & 12 & 18 & 14 \\
\hline Norvège & 90 & 87 & 93 & 74 & 75 & 82 & 5 & 10 & 4 & 3 & 7 & 2 \\
\hline Pologne & $\mathrm{m}$ & 84 & 88 & $\mathrm{~m}$ & 83 & 85 & 15 & 13 & 14 & 11 & 10 & 10 \\
\hline Portugal & 52 & 106 & 85 & 49 & 66 & 78 & 0 & 3 & 1 & 0 & 3 & 1 \\
\hline République slovaque & 86 & 86 & 72 & 84 & 84 & 71 & 12 & 10 & 7 & 11 & 8 & 5 \\
\hline Slovénic & 85 & 94 & 95 & 72 & 83 & 93 & a & a & a & a & a & a \\
\hline Espagne & 56 & 61 & 81 & 53 & 57 & 75 & a & a & 3 & a & a & 1 \\
\hline Suéde & 76 & 75 & 69 & 76 & 75 & 69 & 1 & 3 & 6 & 0 & 2 & 3 \\
\hline Suisse & $\mathrm{m}$ & $\mathrm{m}$ & $\mathrm{m}$ & $\mathrm{m}$ & $\mathrm{m}$ & $\mathrm{m}$ & $\mathrm{m}$ & $\mathrm{m}$ & m & $\mathrm{m}$ & $\mathrm{m}$ & $\mathrm{m}$ \\
\hline Turquie & 48 & 54 & 75 & 48 & 54 & 72 & a & a & a & a & a & a \\
\hline Royaume-Uni & 87 & 88 & 87 & m & m & 81 & a & a & a & a & a & a \\
\hline Etats-Unis & 74 & 77 & 85 & 74 & $\pi$ & 85 & 17 & 22 & 22 & m & m & m \\
\hline Moyenne OCDE & 81 & 84 & 86 & m & 77 & 81 & m & 11 & 12 & m & 6 & 7 \\
\hline $\begin{array}{l}\text { Moyenne des pays } \\
\text { dont les donnees de } \\
\text { chaque année de réference } \\
\text { sont disponibles }\end{array}$ & 80 & 84 & 86 & $\mathrm{~m}$ & 76 & 78 & $\mathrm{~m}$ & 6 & 7 & m & 3 & 3 \\
\hline Moyenne UE23 & 83 & 87 & 86 & m & 79 & 81 & 10 & 8 & 11 & m & 5 & 7 \\
\hline \& Argentine' & m & m & 65 & $\mathrm{~m}$ & $\mathrm{~m}$ & m & m & m & m & m & m & $\mathrm{m}$ \\
\hline Brésil & $\mathrm{m}$ & m & 67 & $\mathrm{~m}$ & m & 61 & $\mathrm{~m}$ & $\mathrm{~m}$ & 6 & $\mathrm{~m}$ & m & 3 \\
\hline En Chine & $\mathrm{m}$ & $\mathrm{m}$ & 83 & m & $\mathrm{m}$ & m & $\mathrm{m}$ & $\mathrm{m}$ & m & m & m & $\mathrm{m}$ \\
\hline 元 Costa Rica & $\mathrm{m}$ & $\mathrm{m}$ & 35 & $\mathrm{~m}$ & $\mathrm{~m}$ & 33 & $\mathrm{~m}$ & $\mathrm{~m}$ & a & m & m & a \\
\hline Inde & $\mathrm{m}$ & $\mathrm{m}$ & 30 & $\mathrm{~m}$ & $\mathrm{~m}$ & $\mathrm{~m}$ & $\mathrm{~m}$ & $\mathrm{~m}$ & $\mathrm{~m}$ & $\mathrm{~m}$ & m & $\mathrm{m}$ \\
\hline Indonésie & $\mathrm{m}$ & $\mathrm{m}$ & 66 & $\mathrm{~m}$ & $\mathrm{~m}$ & $\mathrm{~m}$ & a & a & a & a & a & a \\
\hline Fédération de Russie & 89 & 97 & 90 & m & m & $\mathrm{m}$ & 7 & 12 & 3 & m & m & $\mathrm{m}$ \\
\hline Arabie saoudite & $\mathrm{m}$ & $\mathrm{m}$ & $\mathrm{m}$ & $\mathrm{m}$ & $\mathrm{m}$ & $\mathrm{m}$ & $\mathrm{m}$ & $\mathrm{m}$ & $\mathrm{m}$ & $\mathrm{m}$ & $\mathrm{m}$ & $\mathrm{m}$ \\
\hline Afrique du Sud' & m & m & 43 & m & m & m & m & m & m & m & m & m \\
\hline Moyenne G20 & $\mathrm{m}$ & $\mathrm{m}$ & 86 & $\mathrm{~m}$ & $\mathrm{~m}$ & $\mathrm{~m}$ & $\mathrm{~m}$ & $\mathrm{~m}$ & $\mathrm{~m}$ & $\mathrm{~m}$ & m & $\mathrm{m}$ \\
\hline
\end{tabular}

1. Année de référence : 2016.

Source : OCDE/ISU/Eurostat (2019). Consulter la section « Source » pour tout complément d'information et l'annexe 3 pour les notes (https://doi.org/10.1787/f8d7880den).

Les symboles représentant les données manquantes et les abréviations figurent dans le Guide du lecteur. 


\section{Indicateur B4. Quel est le profil des nouveaux inscrits dans l'enseignement tertiaire?}

\section{Faits marquants}

- La licence est la principale porte d'entrée de l'enseignement tertiaire. En 2017, plus de sept nouveaux inscrits (première inscription) dans l'enseignement tertiaire sur dix ont opté pour une licence, deux, pour une formation tertiaire de cycle court et moins d'un, pour un master, en moyenne dans les pays de l'OCDE.

- Les nouveaux inscrits en licence et en premier master de type long avaient en moyenne 22 ans dans les pays de l'OCDE et étaient plus jeunes que les nouveaux inscrits en formation tertiaire de cycle court ( 25 ans).

- Les femmes sont plus nombreuses que les hommes parmi les nouveaux inscrits en formation tertiaire de cycle court, en licence et en premier master de type long. Toutefois, les différences sont très marquées entre les domaines d'études: les femmes sont sous-représentées en sciences, en ingénierie, en technologie et en mathématiques (STIM), mais surreprésentées dans le domaine de la santé et de la protection sociale.

\section{Graphique B4.1. Répartition des nouveaux inscrits (première inscription) dans l'enseignement tertiaire} (2017)

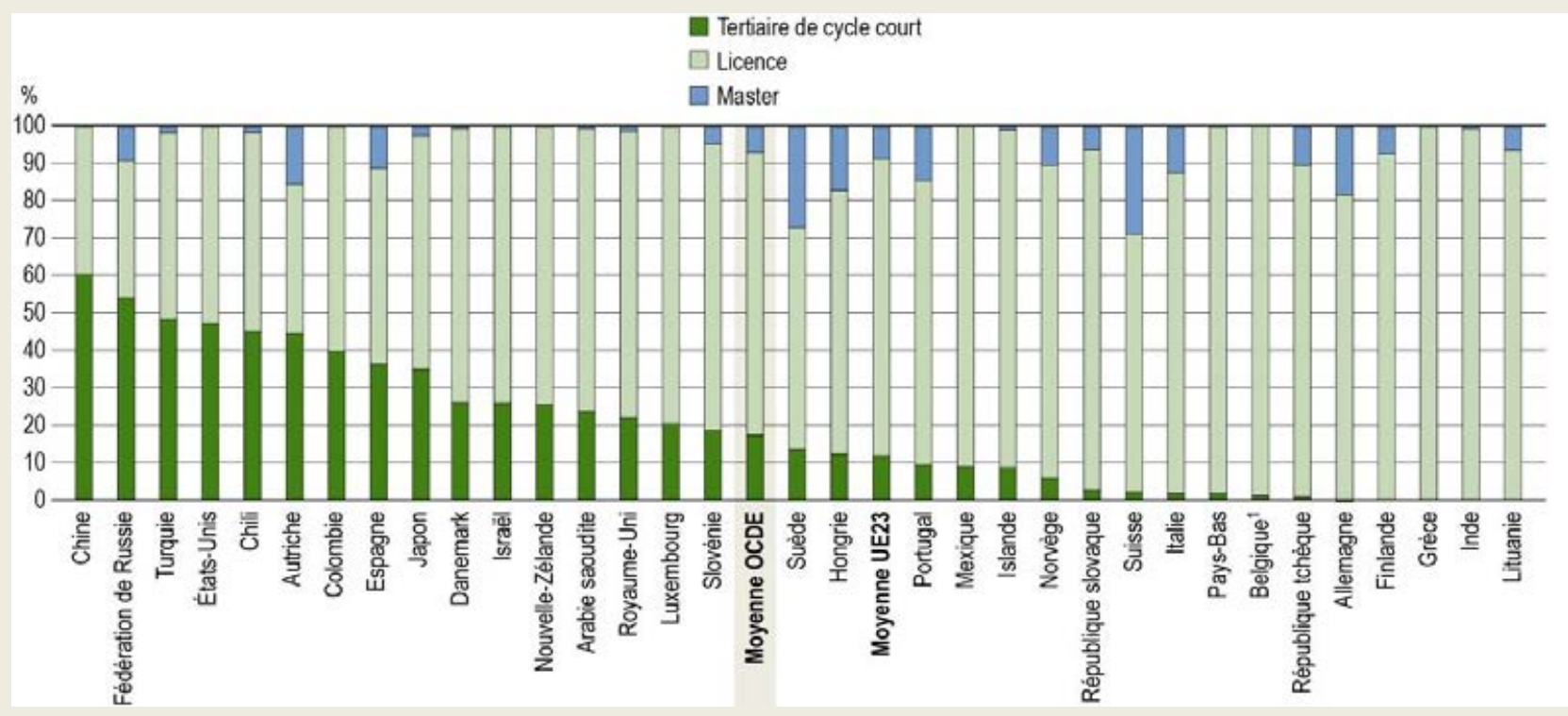

1. Tertiaire de cycle court : les données se rapportent uniquement à la Communauté flamande de Belgique.

Les pays sont classés par ordre décroissant du pourcentage de nouveaux inscrits (première inscription) dans des programmes tertiaires de cycle court en 2017.

Source : OCDE / ISU / Eurostat (2019), tableau B4.1. Consulter la section « Source » pour tout complément d'information et l'annexe 3 pour les notes (https://doi.org/10.1787/f8d7880d-en).

StatLink त्गार् https://doi.org/10.1787/888933978113

\section{Contexte}

L'accès à l'enseignement tertiaire est essentiel pour développer les compétences des jeunes adultes et leur permettre de contribuer pleinement à la vie de la société. Les profils et les aptitudes des étudiants peuvent toutefois être très variables. Les étudiants ne se progressent pas tous au même rythme, et la voie royale d'accès à l'enseignement tertiaire, un diplôme 
du deuxième cycle de l'enseignement secondaire, perd de son importance. Parallèlement, l'ordonnancement de l'enseignement tertiaire par cycle a aussi évolué. Les étudiants sont plus enclins à retarder leur entrée dans l'enseignement supérieur, à prendre une année sabbatique ou alterner études et incursions sur le marché du travail. Dans certains pays, le dynamisme du marché du travail et la prospérité économique ont incité des étudiants, en particulier ceux de condition modeste, à reporter leurs études et à se former dans le monde du travail. L'apprentissage tout au long de la vie prend doucement l'allure d'un nouveau modèle d'éducation, qui permet aux individus d'actualiser leurs compétences pour répondre à la demande en constante évolution sur le marché du travail.

Conscients des besoins croissants d'une population placée sous le signe de la diversité, certains pays ont progressivement adapté leurs cursus tertiaires pour qu'ils se prêtent à des modalités plus flexibles d'apprentissage afin de convenir à un effectif d'étudiants aux compétences et aux aptitudes cognitives variables. Ce processus consiste notamment à multiplier les passerelles entre le deuxième cycle de l'enseignement secondaire et l'enseignement tertiaire, y compris en filière professionnelle, et à multiplier les cursus tertiaires accessibles aux nouveaux inscrits (première inscription) : les formations tertiaires de cycle court, les licences et les premiers masters de type long. Chaque niveau d'enseignement, chaque cursus requiert des compétences préalables et répond à une demande spécifique sur le marché du travail. L'assouplissement des conditions d'accès à l'enseignement tertiaire et les programmes dits de « seconde chance » peuvent offrir de nouvelles possibilités aux individus plus âgés qui ont arrêté leurs études prématurément ou aux travailleurs qui veulent acquérir de nouvelles compétences. Proposer un éventail d'options d'apprentissage correspondant aux besoins et aux ambitions des jeunes est aussi un moyen d'adoucir la transition entre l'école et le monde du travail.

Le profil des nouveaux inscrits (première inscription) dans l'enseignement tertiaire donne un aperçu des caractéristiques des étudiants et de leur parcours entre les différents niveaux et cursus de l'enseignement tertiaire. II est également révélateur de l'égalité d'accès à l'enseignement tertiaire. Le taux d'accès de l'enseignement tertiaire est une estimation de la probabilité de voir les individus entamer une formation de ce niveau au cours de leur vie. Ces taux donnent une idée de l'accessibilité de l'enseignement tertiaire et de la mesure dans laquelle la population acquiert des connaissances et compétences de haut niveau dans les pays. Dans l'enseignement tertiaire, des taux élevés d'accès et de scolarisation sont le signe qu'une main-d'œuvre hautement qualifiée se développe et s'entretient.

\section{Autres faits marquants}

- En moyenne, dans les pays de l'OCDE, le pourcentage de nouveaux inscrits en mobilité internationale en premier master de type long s'établit à $15 \%$ et est plus élevé qu'en licence $(8 \%)$ et nettement plus élevé qu'en formation tertiaire de cycle court (5\%).

- En moyenne, dans les pays de l'OCDE, l'effectif féminin de nouveaux inscrits est nettement moins élevé en licence et en formation tertiaire de cycle court (53-54 \%) qu'en premier master de type long (62 \%).

- Sur la base des taux actuels, on estime qu'en moyenne, $58 \%$ des jeunes entameront au cours de leur vie une licence (ou formation équivalente) et $17 \%$ d'entre eux, une formation tertiaire de cycle court dans les pays de l'OCDE.

\section{Remarque}

Les formations tertiaires de cycle court et les premiers masters de type long n'existent pas ou ne sont pas courants dans un certain nombre de systèmes d'éducation. Dans le souci de préserver la pertinence des comparaisons entre les pays, la répartition des nouveaux inscrits (première inscription) par sexe, domaine d'études et mobilité entre ces niveaux d'enseignement est uniquement analysée dans les pays dont l'effectif de nouveaux inscrits atteint au moins $10 \%$ dans ces cursus.

Les taux d'accès sont sensibles aux changements intervenus dans le système d'éducation, par exemple l'introduction de nouvelles formations. Les taux d'accès peuvent être très élevés, même supérieurs à $100 \%$, en cas d'afflux imprévus d'inscrits. Dans certains pays, des taux élevés d'accès peuvent refléter des phénomènes temporaires, tels que les effets des cycles et crises économiques, la réforme de l'enseignement tertiaire dans le cadre de la mise en œuvre du processus de Bologne ou un accroissement important du nombre d'étudiants en mobilité internationale. Les programmes dits de « seconde chance », que les gouvernements mettent en œuvre pour inciter les individus plus âgés à reprendre des études, peuvent également doper les taux d'accès. 


\section{Analyse}

\section{Parcours des nouveaux inscrits (première inscription) dans l'enseignement tertiaire}

Les étudiants peuvent entamer leurs études tertiaires à trois niveaux : en formation tertiaire de cycle court (niveau 5 de la CITE), en licence (niveau 6 de la CITE) et en master (niveau 7 de la CITE). Chaque cursus se caractérise par ses propres conditions d'accès et par son propre ensemble de compétences valorisables sur le marché du travail. La licence est la voie d'accès la plus courante à l'enseignement tertiaire et existe dans tous les pays de l'OCDE. Les formations tertiaires de cycle court sont souvent destinées à enseigner aux étudiants des connaissances, aptitudes et compétences professionnelles. En général, les cours sont pratiques et axés sur une profession et préparent les étudiants à entrer directement dans la vie active. Les formations tertiaires de cycle court ont le mérite de permettre à la fois aux étudiants de suivre des études supérieures à un prix raisonnable (les coûts directs et indirects sont moins élevés dans un cursus de deux ans que de quatre ans - voir l'indicateur A5) et d'obtenir une qualification immédiatement valorisable sur le marché du travail, mais elles n'existent pas dans tous les pays.

En master, l'effectif de nouveaux inscrits (première inscription) est constitué des étudiants qui optent pour un premier master de type long et de ceux qui optent pour un master sans en être passés au préalable par une licence dans le pays d'accueil. Les premiers masters de type long, sanctionnés par un premier diplôme, durent au moins cinq ans et leur contenu est d'une complexité équivalente aux autres masters. II s'agit notamment de cursus hautement spécialisés dans des domaines tels que la médecine et la dentisterie et, dans certains cas, le droit et l'ingénierie (OCDE/Eurostat/Institut de statistique de I'UNESCO, 2016[1]). Dans des pays comme la Belgique et le Royaume-Uni où les premiers masters de type long n'existent pas, la grande majorité des nouveaux inscrits (première inscription) en master sont des étudiants étrangers ou en mobilité internationale (en Belgique, au Luxembourg et aux Pays-Bas, par exemple) ou des étudiants admis compte tenu de leur expérience professionnelle plutôt que de leur diplôme (au Royaume-Uni).

\section{Répartition des nouveaux inscrits (première inscription) dans l'enseignement tertiaire}

Le niveau de l'enseignement tertiaire que les nouveaux inscrits (première inscription) choisissent détermine la durée de leurs études, les possibilités de poursuivre leur formation par la suite et les débouchés qu'ils auront sur le marché du travail une fois diplômés. La répartition de ces nouveaux inscrits entre les niveaux de l'enseignement tertiaire dépend de l'existence des cursus, de leur capacité d'accueil et de leurs conditions d'accès dans le système national d'éducation.

En moyenne, dans les pays de l'OCDE, plus de trois quarts des nouveaux inscrits (première inscription) dans l'enseignement tertiaire optent pour une licence. Toutefois, l'importance de la licence dans le paysage de l'enseignement tertiaire varie fortement entre les pays. Plus de $90 \%$ des nouveaux inscrits (première inscription) dans l'enseignement tertiaire optent pour une licence en Belgique, en Finlande, en Grèce, en Islande, en Inde, en Lituanie, au Mexique, aux Pays-Bas et en République slovaque. Dans d'autres pays, les nouveaux inscrits (première inscription) se répartissent de façon plus uniforme entre différents niveaux de l'enseignement tertiaire. Ainsi, $45 \%$ au moins des nouveaux inscrits (première inscription) choisissent une formation tertiaire de cycle court en Autriche, au Chili, aux États-Unis, en Fédération de Russie, en République populaire de Chine et en Turquie, soit plus du double de la moyenne de l'OCDE (17\%). Ces formations présentent des avantages, mais elles n'existent pas dans tous les pays et lorsqu'elles existent, elles ne sont pas toujours très attractives aux yeux des étudiants. Dans 11 des pays membres et partenaires de l'OCDE qui proposent des formations tertiaires de cycle court, moins de $10 \%$ des nouveaux inscrits (première inscription) dans l'enseignement tertiaire optent pour ce type de formation (voir le graphique B4.1).

Le master est la voie d'accès la moins courante à l'enseignement tertiaire. En moyenne, dans les pays membres et partenaires de l'OCDE dont les données sont disponibles, $7 \%$ des nouveaux inscrits (première inscription) dans l'enseignement tertiaire optent pour un master; ce pourcentage est toutefois supérieur à $20 \%$ en Suède et en Suisse. Dans la plupart des pays, la majorité des nouveaux inscrits (première inscription) en master 
choisissent un premier master de type long. Le pourcentage de nouveaux inscrits (première inscription) en master est relativement peu élevé dans les pays où les premiers masters de type long n'existent pas : il est inférieur à $2 \%$ en Belgique et au Royaume-Uni (voir le graphique B4.1).

\section{Âge des nouveaux inscrits à chaque niveau de l'enseignement tertiaire}

Divers facteurs peuvent influer sur la pyramide des âges des nouveaux inscrits à chaque niveau de l'enseignement tertiaire. Ils peuvent résider dans l'existence de programmes dits de " seconde chance » et de programmes d'apprentissage tout au long de la vie qui sont caractéristiques de systèmes plus souples qui autorisent les individus à reprendre des études après une incursion sur le marché du travail. L'entrée tardive dans l'enseignement tertiaire peut s'expliquer par des obstacles à l'accès de ce niveau d'enseignement, par exemple des conditions strictes d'accès (voir l'indicateur D6), le numerus clausus (un quota défini de candidats admissibles par établissement d'enseignement) ou par la difficulté de financer les coûts privés associés à l'enseignement supérieur (voir l'indicateur C5). Sous l'angle économique, cette entrée tardive dans l'enseignement tertiaire peut être coûteuse pour les pouvoirs publics, car des jeunes reportent leur entrée dans la vie active et, donc, le moment où ils sont en mesure de commencer à contribuer financièrement à la vie de la société (voir l'indicateur A5).

\section{Graphique B4.2. Âge moyen des nouveaux inscrits dans l'enseignement tertiaire, selon le niveau} d'enseignement (2017)

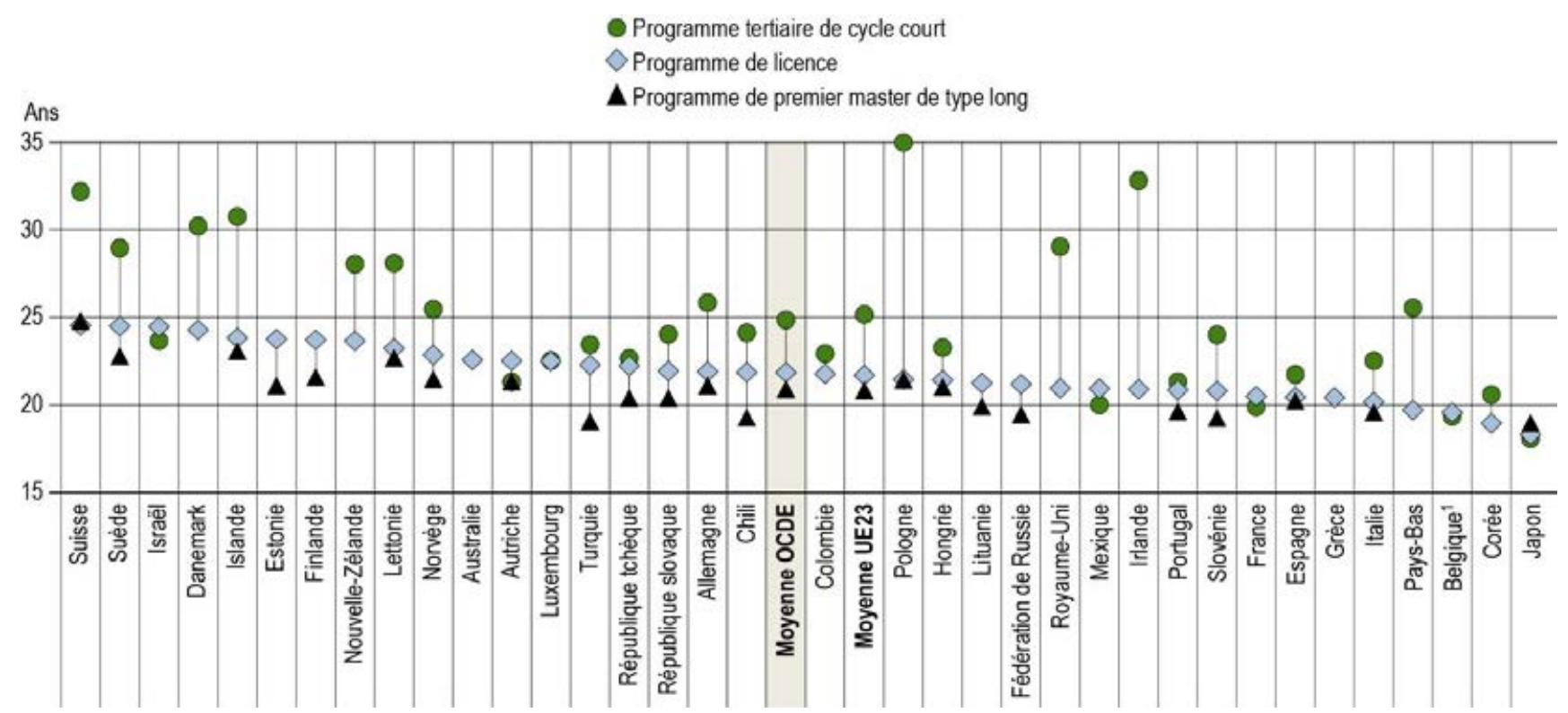

Remarque : Les données sur les premiers masters de type long peuvent reposer sur des échantillons de faible taille.

1. Tertiaire de cycle court : les données se rapportent uniquement à la Communauté flamande de Belgique..

Les pays sont classés par ordre décroissant de l'âge moyen des nouveaux inscrits en licence en 2017.

Source : OCDE/ISU/Eurostat (2019), tableau B4.1. Consulter la section « Source » pour tout complément d'information et l'annexe 3 pour les notes (https://doi.org/10.1787/f8d7880d-en).

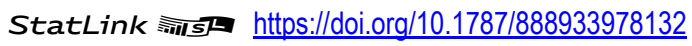

L'âge moyen au début des formations tertiaires varie aussi selon le niveau d'enseignement et le profil des étudiants que les différents niveaux d'enseignement tendent à attirer. Les jeunes ont tendance à entamer une licence ou un premier master de type long dès la fin du deuxième cycle de l'enseignement secondaire, tandis que les adultes plus âgés tendent à s'orienter vers une formation tertiaire de cycle court, parfois après une incursion sur le marché du travail. En moyenne, dans les pays de l'OCDE, les nouveaux inscrits ont 25 ans en 
formation tertiaire de cycle court et 22 ans en licence et premier master de type long. Toutefois, cet âge moyen varie sensiblement entre les pays. L'âge moyen des nouveaux inscrits en licence est de l'ordre de 18-19 ans au Japon et en Corée, mais atteint ou dépasse 24 ans en Suède et en Suisse. L'âge moyen des nouveaux inscrits en formation tertiaire de cycle court est égal à 18 ans au Japon, mais égal ou supérieur à 30 ans au Danemark, en Irlande, en Pologne et en Suisse (voir le graphique B4.2).

Des facteurs structurels, tels que les procédures d'admission, l'âge typique d'obtention du diplôme du deuxième cycle de l'enseignement secondaire et la perception culturelle de la valeur de l'expérience professionnelle ou des expériences personnelles en dehors des études, peuvent expliquer les différences d'âge moyen au début des formations tertiaires entre les pays. II est de tradition d'entamer des études tertiaires dès la fin du deuxième cycle de l'enseignement secondaire. Cet usage reste courant dans de nombreux cas. Dans quelques pays toutefois, moins de $25 \%$ des étudiants en licence se sont inscrits dès la fin du deuxième cycle de l'enseignement secondaire (voir l'encadré B4.1). C'est par exemple le cas en Israël, où le service militaire est obligatoire. En Finlande et en Suède, l'admission dans de nombreux cursus et domaines d'études est réglementée et plus de $60 \%$ des candidats ne sont pas admis (voir l'indicateur D6). Les pays où les étudiants sont en moyenne plus jeunes au début de leurs études tertiaires sont aussi ceux où ils ont tendance à s'inscrire dès qu'ils sont diplômés du deuxième cycle de l'enseignement secondaire. Dans certains pays, comme aux Pays-Bas, le processus d'inscription est moins ardu, car le régime d'admission est ouvert. Dans d'autres pays, davantage de jeunes ont tendance à entamer leurs études tertiaires dès la fin du deuxième cycle de l'enseignement secondaire grâce aux politiques de développement de l'enseignement tertiaire et à une culture valorisant fortement les résultats académiques. Au Japon par exemple, l'augmentation de la capacité d'accueil de l'enseignement tertiaire depuis les années 1970 et les politiques visant spécifiquement à promouvoir ce niveau d'enseignement adoptées dans le cadre de la stratégie de revitalisation du Japon ont entraîné une augmentation des taux de scolarisation en dépit d'un régime sélectif d'admission (OCDE, 2009[2]).

\section{Encadré B4.1. Transition entre le deuxième cycle de l'enseignement secondaire et l'enseignement tertiaire}

La flexibilité croissante des systèmes d'enseignement tertiaire se reflète dans la multiplication des parcours et modes d'apprentissage. La scolarisation à temps partiel, les cours en ligne et la possibilité de cumuler les crédits sans intention de réussir une formation sont autant d'exemples de l'adaptation des systèmes d'enseignement tertiaire au principe de l'apprentissage tout au long de la vie. Dans ce contexte, les étudiants ne peuvent pas être appelés, ni même encouragés à passer directement du deuxième cycle de l'enseignement secondaire à l'enseignement tertiaire dans de nombreux pays.

Le graphique B4.a indique le pourcentage d'inscrits en licence dès la fin du deuxième cycle de l'enseignement secondaire. En d'autres termes, il indique le pourcentage d'inscrits qui sont passés directement du deuxième cycle de l'enseignement secondaire à l'enseignement tertiaire sans s'accorder un certain répit. Leur pourcentage varie sensiblement entre les pays, signe de la diversité de l'effectif de nouveaux inscrits dans l'enseignement tertiaire. Plus de $90 \%$ des nouveaux inscrits en licence entament leurs études tertiaires dès la fin du deuxième cycle de l'enseignement secondaire aux États-Unis, un pourcentage qui s'établit à $20 \%$ en Finlande et à $3 \%$ en Israël.

Cette variation reflète d'importantes différences dans les facteurs institutionnels et sociaux spécifiques à chaque pays. Dans de nombreux pays, il est courant que les diplômés du deuxième cycle de l'enseignement secondaire fassent leur service militaire ou civil. II arrive aussi qu'ils prennent une année sabbatique à cause de systèmes très sélectifs d'admission dans l'enseignement tertiaire. En Finlande par exemple, il est courant que les candidats soumettent plusieurs candidatures avant d'être admis dans certains cursus tertiaires (voir l'indicateur D6) et le gouvernement s'emploie activement à réduire le nombre d'années entre la fin du deuxième cycle de l'enseignement secondaire et le début de l'enseignement tertiaire. Dans d'autres pays en revanche, des politiques encouragent les diplômés du deuxième cycle de l'enseignement tertiaire à vivre d'autres expériences (sur le marché du travail ou pendant le service militaire ou civil) avant d'entamer des 
études supérieures. En Lituanie et en Norvège, les étudiants qui ont pris une année sabbatique sont favorisés dans le système d'admission à l'enseignement tertiaire (cette expérience leur vaut un certain nombre de points supplémentaires lors de l'évaluation de leur dossier d'admission).

\section{Graphique B4.a. Pourcentage d'inscrits en licence ayant entamé ce cursus directement à l'issue du deuxième cycle du secondaire, selon la filière suivie dans ce dernier niveau d'enseignement}

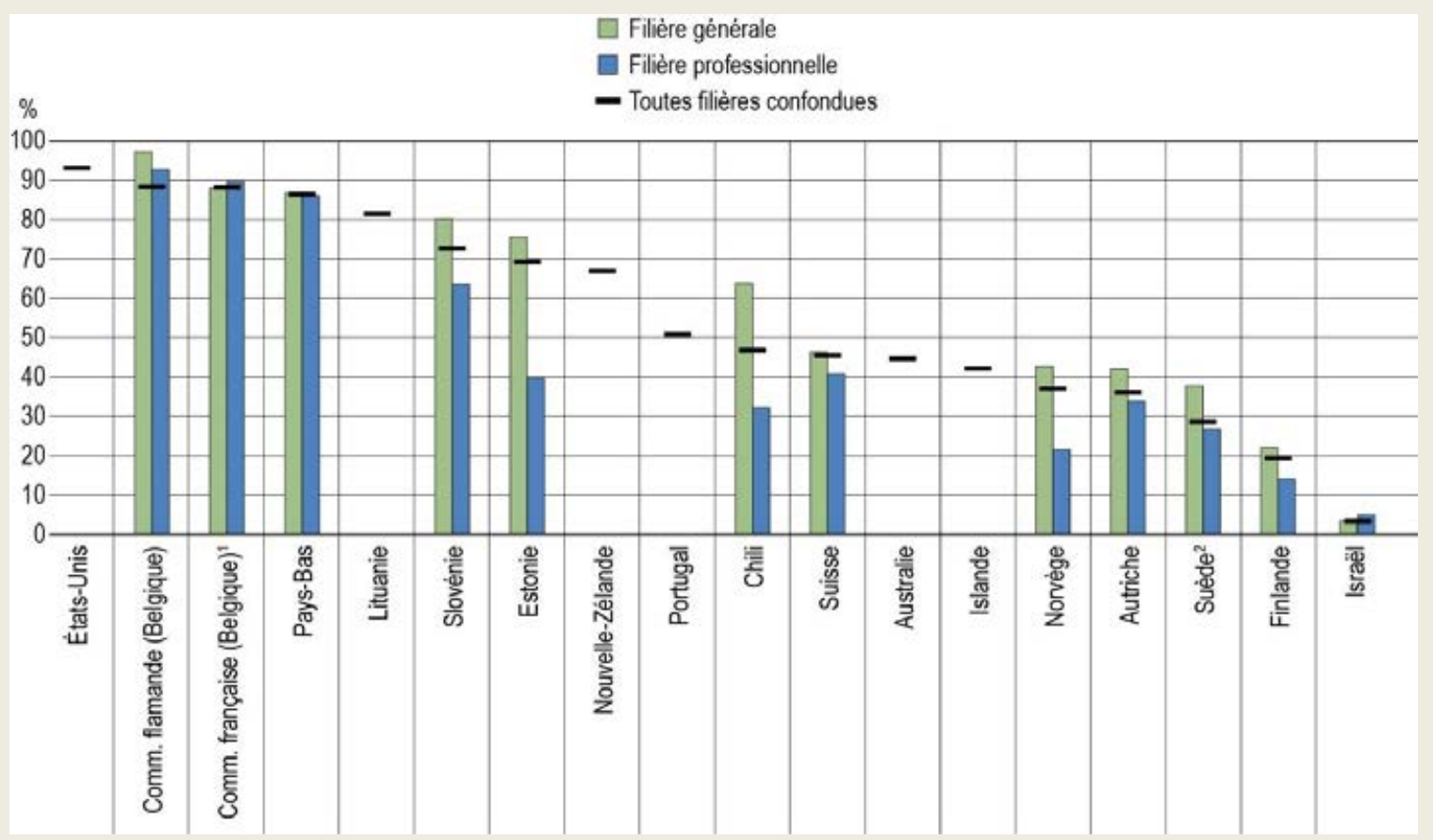

Lecture du graphique : En Estonie, environ $76 \%$ des inscrits dans un programme de licence, ou de niveau équivalent, diplômés de la filière générale du deuxième cycle du secondaire ont entamé ce cursus directement à l'issue du deuxième cycle du secondaire. Ce constat vaut également pour environ $40 \%$ des inscrits diplômés de la filière professionnelle du deuxième cycle du secondaire, et pour $70 \%$ de l'ensemble des inscrits diplômés de la filière générale ou professionnelle du deuxième cycle du secondaire.

Remarque : Les données de ce graphique sont tirées d'une enquête ad hoc sur les taux de réussite dans l'enseignement tertiaire, qui a suivi une cohorte d'étudiants depuis leur inscription en programme de licence jusqu'à trois ans après la fin de la durée théorique de ce programme. L'année de référence de l'enquête sur les taux de réussite est 2017, mais l'année d'accès au niveau licence dépend de la durée théorique des programmes proposés dans chaque pays. Pour la quasi-totalité des pays présentés dans ce graphique, les données se rapportent aux étudiants ayant entamé un programme de licence au cours de la période 2010-12. Pour les États-Unis, les données se rapportent aux étudiants ayant entamé un programme de licence en 2003.

1. Les données se rapportent uniquement aux hautes écoles (HE) et aux écoles des arts (ESA), soit environ $60 \%$ des inscrits dans des programmes de licence ou de niveau équivalent.

2. Les données désagrégés par filière sont fondées sur une cohorte d'entrée qui exclue les étudiants dont on ignore la qualification au niveau du deuxième cycle du secondaire. Ces données sont donc inférieures au total toutes filières confondues.

Les pays sont classés par ordre décroissant du pourcentage d'étudiants ayant entamé un cursus tertiaire directement à l'issue de l'une quelconque filière du deuxième cycle du secondaire.

Source : Enquête ad hoc sur les taux de réussite dans l'enseignement tertiaire, OCDE (2019). Consulter la section « Source » pour tout complément d'information et l'annexe 3 pour les notes (https://doi.org/10.1787/f8d7880d-en).

StatLink त्गारा https://doi.org/10.1787/888933978170

L'entrée dans l'enseignement tertiaire peut également être influencée par la filière choisie dans le deuxième cycle de l'enseignement secondaire. Dans certains pays, en Estonie, en Norvège et en Slovénie par exemple, les diplômés du deuxième cycle de l'enseignement secondaire sont nettement plus susceptibles de retarder leur entrée dans l'enseignement tertiaire s'ils sont diplômés de la filière professionnelle que de la filière générale. Cela peut s'expliquer par le fait que les diplômés de la filière professionnelle dans le deuxième cycle de l'enseignement secondaire peuvent choisir de faire une incursion sur le marché du travail avant d'entamer une licence ou encore par le fait qu'ils doivent parfois passer des examens spécifiques ou suivre des cours 
supplémentaires avant de pouvoir accéder à l'enseignement tertiaire. Dans d'autres pays toutefois, les diplômés du deuxième cycle de l'enseignement secondaire sont aussi susceptibles de retarder leur entrée dans l'enseignement tertiaire qu'ils aient suivi la filière générale ou la filière professionnelle. C'est par exemple le cas en Communauté flamande et en Communauté française de Belgique et aux Pays-Bas.

II est important d'approfondir l'analyse au-delà des moyennes pour décrire la transition entre le deuxième cycle de l'enseignement secondaire et l'enseignement tertiaire. La flexibilité et la perméabilité peuvent être des caractéristiques importantes des systèmes d'éducation, mais les moyennes nationales peuvent occulter des problèmes rencontrés dans des groupes défavorisés ou à risque durant cette transition. II est important aussi d'examiner le parcours des étudiants dans l'enseignement tertiaire et la mesure dans laquelle leurs acquis et leur milieu social peuvent influer sur leur capacité de réussir à ce niveau (voir l'indicateur B5).

La filière choisie dans le deuxième cycle de l'enseignement secondaire et le cursus choisi dans l'enseignement tertiaire influent fortement aussi sur l'âge moyen au début des études tertiaires. Dans certains pays, des cursus s'adressent spécifiquement aux adultes ayant déjà une expérience professionnelle et peuvent être assortis de conditions particulières d'admission. Au Danemark par exemple, il faut avoir deux ans d'expérience professionnelle pertinente pour entamer l'Akademiuddannelser. Ce type de cursus tend à séduire davantage les diplômés du deuxième cycle de l'enseignement secondaire en filière professionnelle, car ils sont plus susceptibles de reporter leur entrée dans l'enseignement tertiaire si leur diplôme de fin d'études secondaire leur promet de beaux débouchés sur le marché du travail.

\section{Pourcentage d'étudiants en mobilité internationale dans l'effectif de nouveaux inscrits dans l'enseignement tertiaire}

Les étudiants en mobilité internationale sont une autre source de recettes pour les établissements d'enseignement et contribuent à l'économie de leur pays d'accueil (García, De et Villarreal, 2014 ${ }_{[3]}$ ). Au-delà des avantages économiques, les interactions entre les étudiants nationaux et les étudiants en mobilité internationale promeuvent la compréhension mutuelle (dans le domaine de la culture, de la politique, de la religion, de l'appartenance ethnique et de la vision du monde) et le dialogue, deux atouts essentiels pour évoluer dans une économie de plus en plus mondialisée. En moyenne, dans les pays de l'OCDE, les étudiants en mobilité internationale représentent $5 \%$ de l'effectif de nouveaux inscrits en formation tertiaire de cycle court, mais $8 \%$ en licence et $15 \%$ en premier master de type long. Le pourcentage moins élevé d'étudiants en mobilité internationale dans l'effectif de nouveaux inscrits en formation tertiaire de cycle court peut s'expliquer par le fait que ce type de formation est proposé dans un nombre plus restreint de pays. Par contraste, la licence et le master sont deux niveaux d'enseignement dont les qualifications sont reconnues et qui offrent des débouchés prometteurs sur le marché du travail dans tous les pays de l'OCDE.

Certains pays réussissent mieux que d'autres à attirer les étudiants en mobilité internationale. Le pourcentage d'étudiants en mobilité internationale dans l'effectif de nouveaux inscrits en formation tertiaire de cycle court est pratiquement nul au Chili, en Colombie, en Suède et en Turquie, mais atteint $24 \%$ en Nouvelle-Zélande et $35 \%$ en Islande. Le pourcentage d'étudiants en mobilité internationale dans l'effectif de nouveaux inscrits en licence est inférieur ou égal à $2 \%$ au Chili, en Colombie, en Corée, en Espagne et au Mexique, mais supérieur à $30 \%$ en Nouvelle-Zélande. Le pourcentage d'étudiants en mobilité internationale dans l'effectif de nouveaux inscrits en premier master de type long est inférieur ou égal à $3 \%$ en Norvège et en Suède, mais égal ou supérieur à $27 \%$ en Allemagne, en Hongrie et en République tchèque.

\section{Répartition des nouveaux inscrits selon le domaine d'études et le sexe}

L'égalité des chances entre les sexes à l'admission dans l'enseignement tertiaire peut contribuer à une croissance plus forte et plus inclusive, car elle améliore le niveau global du capital humain et de la productivité des travailleurs (OCDE, 2011 ${ }_{[4]}$ ). Toutefois, l'expansion de l'enseignement tertiaire au cours des dernières décennies a davantage profité aux femmes qu'aux hommes dans les pays de l'OCDE, où $51 \%$ de femmes âgées 
de 25 à 34 ans sont diplômées de l'enseignement tertiaire en moyenne, contre $40 \%$ en 2008. Par contraste, 39 \% d'hommes âgés de 25 à 34 ans sont diplômées de l'enseignement tertiaire selon les chiffres de 2018, soit une augmentation de 8 points de pourcentage depuis 2008 (voir l'indicateur A1).

L'écart entre les sexes promet de continuer à se creuser, puisque les femmes sont plus nombreuses que les hommes dans l'effectif de nouveaux inscrits à chaque niveau de l'enseignement tertiaire. En moyenne, dans les pays de l'OCDE, les femmes représentent $53 \%$ de l'effectif de nouveaux inscrits en formation tertiaire de cycle court et en représentent $54 \%$ en licence et $61 \%$ en master. Le pourcentage de femmes est de l'ordre de $50 \%$, voire davantage, en licence et en master dans tous les pays. Dans certains pays, les hommes sont particulièrement sous-représentés, même en licence, pourtant la voie d'accès la plus courante à l'enseignement tertiaire. Ils représentent moins de $40 \%$ des nouveaux inscrits en licence en Islande et en Suède. Les différences sont plus marquées entre les sexes en formation tertiaire de cycle court et en master, car ces cursus concernent des domaines d'études qui tendent à être associés à des professions masculines ou féminines. Les premiers masters de type long, souvent en rapport avec la santé ou la science, tendent à moins attirer les hommes, qui représentent au plus $45 \%$ des nouveaux inscrits à ce niveau en Espagne, en Italie et en Suisse. Par contraste, les hommes représentent au moins $60 \%$ de l'effectif de nouveaux inscrits en formation tertiaire de cycle court en Slovénie. Les hommes sont également surreprésentés en formation tertiaire de cycle court en Italie, au Mexique, en Norvège et au Portugal, même si ces cursus attirent moins de $10 \%$ de l'effectif de nouveaux inscrits (première inscription) tous niveaux confondus (voir le tableau B4.1).

De nombreux pays se sont employés à promouvoir l'enseignement tertiaire auprès des hommes et ont incité ceux-ci à faire des études supérieures, mais sans grand succès. La sous-représentation des hommes peut en partie s'expliquer par les années critiques avant le début de l'enseignement tertiaire, pendant lesquelles les garçons sont plus susceptibles d'être en difficulté scolaire, de redoubler ou d'abandonner l'école (OCDE, 2017[5] ; OCDE, 2018[6]). Elle peut également s'expliquer par des différences de parcours scolaires aux niveaux d'enseignement inférieurs ; la filière professionnelle tend par exemple à séduire davantage les hommes que les femmes dans certains pays (voir l'indicateur B3). Les diplômés du deuxième cycle de l'enseignement secondaire en filière professionnelle sont en effet moins susceptibles d'entamer une formation tertiaire, en particulier une licence : en moyenne, 28 \% seulement des nouveaux inscrits en licence sont diplômés du deuxième cycle de l'enseignement secondaire en filière professionnelle dans les pays dont les données sont disponibles (voir l'indicateur B5). Les formations tertiaires de cycle court leur offrent plus de possibilités d'apprentissage dans l'enseignement tertiaire, mais elles ne sont proposées que dans un certain nombre de pays.

\section{Domaines d'études des nouveaux inscrits dans chaque niveau de l'enseignement tertiaire}

Les étudiants choisissent leur domaine d'études en fonction des débouchés sur le marché du travail et de leurs aspirations après leur formation. Le domaine d'études dont l'effectif de nouveaux inscrits, un sur quatre en moyenne dans les pays de l'OCDE, est le plus important à tous les niveaux de l'enseignement tertiaire est celui du commerce, de l'administration et du droit selon les chiffres de 2017 (OCDE, 2019 $\left.9_{[7]}\right)$. Un domaine d'études différent n'est plus prisé par les nouveaux inscrits que dans six pays de l'OCDE : la Belgique et la Finlande (la santé et la protection sociale), Israël (l'éducation), l'Italie (les lettres et arts) et la Corée et la Suède (l'ingénierie, les industries de transformation et la construction).

Promouvoir le domaine des sciences, de la technologie, de l'ingénierie et des mathématiques (STIM) est désormais une priorité dans de nombreux pays (OCDE, 2018 $\left.{ }_{[8]}\right)$. Les compétences scientifiques stimulent l'innovation technologique et la recherche et celles en rapport avec la résolution de problèmes et l'analyse quantitative sont de l'avis général essentielles dans l'économie imprévisible d'aujourd'hui qui est de plus en plus axée sur les mégadonnées, de sorte qu'elles sont très demandées sur le marché du travail. En moyenne, dans les pays membres et partenaires de l'OCDE, $27 \%$ des nouveaux inscrits en licence ont opté pour une discipline relevant des STIM ; leur pourcentage est le plus élevé en Allemagne (40\%), en Fédération de Russie (35\%) et en Autriche et en Grèce (34 \%) (voir le tableau B4.2). Parmi ces étudiants, ce sont ceux qui ont choisi les technologies de l'information et de la communication (TIC) ou l'ingénierie, les industries de transformation et la 
construction qui s'en sortiront le mieux sur le marché du travail (voir l'indicateur A3) et qui seront les mieux lotis sur le plan salarial (voir l'indicateur A4). Malgré ces débouchés prometteurs sur le marché du travail, ces domaines d'études séduisent moins d'étudiants. En moyenne, dans les pays de l'OCDE, $16 \%$ des nouveaux inscrits optent pour l'ingénierie, les industries de transformation et la construction et $5 \%$, pour les TIC, tous niveaux de l'enseignement tertiaire confondus (OCDE, 2019[7]).

\section{Graphique B4.3. Pourcentage de femmes parmi les nouveaux inscrits (première inscription), selon le niveau d'enseignement et le domaine d'études (2017)}

Moyenne OCDE

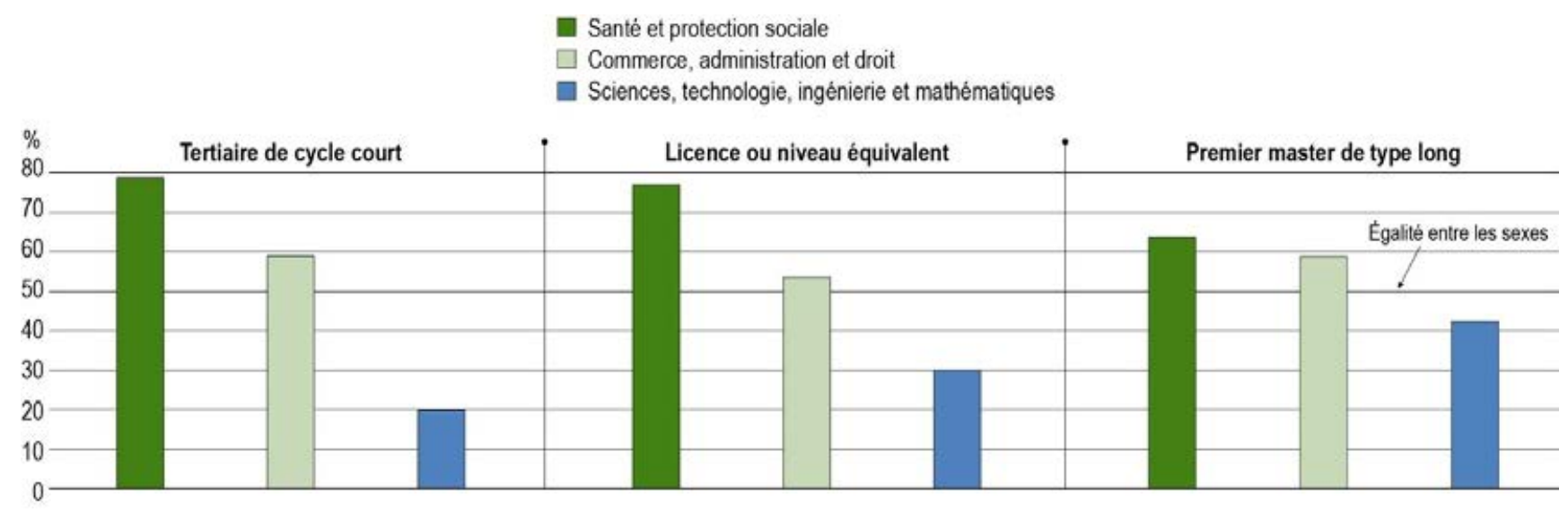

Source : OCDE / ISU / Eurostat (2019), tableau B4.2. Consulter la section « Source » pour tout complément d'information et l'annexe 3 pour les notes (https://doi.org/10.1787/f8d7880d-en).

StatLink त्ताज्य https://doi.org/10.1787//888933978151

L'analyse des domaines d'études des nouveaux inscrits révèle des différences marquées entre les sexes. Les femmes sont désormais plus nombreuses que les hommes parmi les nouveaux inscrits, mais elles restent sousreprésentées dans les domaines d'études en rapport avec les STIM et surreprésentées dans ceux en rapport avec la santé et la protection sociale à tous les niveaux de l'enseignement tertiaire. Toutefois, les différences entre les sexes varient entre les parcours et sont moins marquées dans l'effectif de nouveaux inscrits en master de type long dans ces deux domaines d'études (voir le graphique B4.3).

En moyenne, dans les pays de l'OCDE, le pourcentage de femmes ayant opté pour une discipline en rapport avec les STIM s'établissait en 2017 à $20 \%$ dans l'effectif de nouveaux inscrits en formation tertiaire de cycle court et à $30 \%$ dans l'effectif de nouveaux inscrits en licence. Dans le domaine des STIM, l'effectif de nouveaux inscrits n'est proche de la parité qu'en premier master de type long : le pourcentage de femmes y est de $42 \%$ en moyenne dans les pays de l'OCDE, mais il varie entre $33 \%$ en Suède et $58 \%$ en Hongrie et en Italie (voir le tableau B4.2).

À l'autre extrémité du spectre, les femmes sont surreprésentées dans des domaines d'études tels que celui de la santé et de la protection sociale, même si leur pourcentage tend à diminuer de niveau en niveau: elles représentent $79 \%$ des nouveaux inscrits en formation tertiaire de cycle court, contre $77 \%$ des nouveaux inscrits en licence et $64 \%$ des nouveaux inscrits en master de type long. Dans le domaine de la santé et de la protection sociale, les soins infirmiers et l'action sociale dominent en formation tertiaire de cycle court et en licence, mais la médecine domine en premier master de type long (voir l'encadré B4.2). 


\section{Encadré B4.2. Diplômés dans le domaine de la santé et de la protection sociale}

Un large éventail de disciplines sont regroupées dans le domaine d'études de la santé et de la protection sociale : la dentisterie, la médecine, les soins infirmiers et obstétriques, les technologies de diagnostic et de traitement médical, la rééducation, la pharmacie, etc. Les études sont très longues dans certaines de ces disciplines, par exemple en dentisterie et en médecine, mais sont d'une durée plus variable dans d'autres disciplines, par exemple les soins infirmiers et l'action sociale. C'est pourquoi le niveau d'enseignement de ces disciplines varie : une formation tertiaire de cycle court ou une licence suffit dans certaines d'entre elles, mais un premier master de type long s'impose dans d'autres. Toutefois, les cursus proposés aux différents niveaux varient fortement entre les pays.

\section{Graphique B4.b Pourcentage de diplômés dans les domaines de la santé et de la protection sociale parmi l'ensemble des diplômés de l'enseignement tertiaire, selon le domaine d'études et le niveau de l'enseignement tertiaire (2017)}

En moyenne dans les pays de l'OCDE

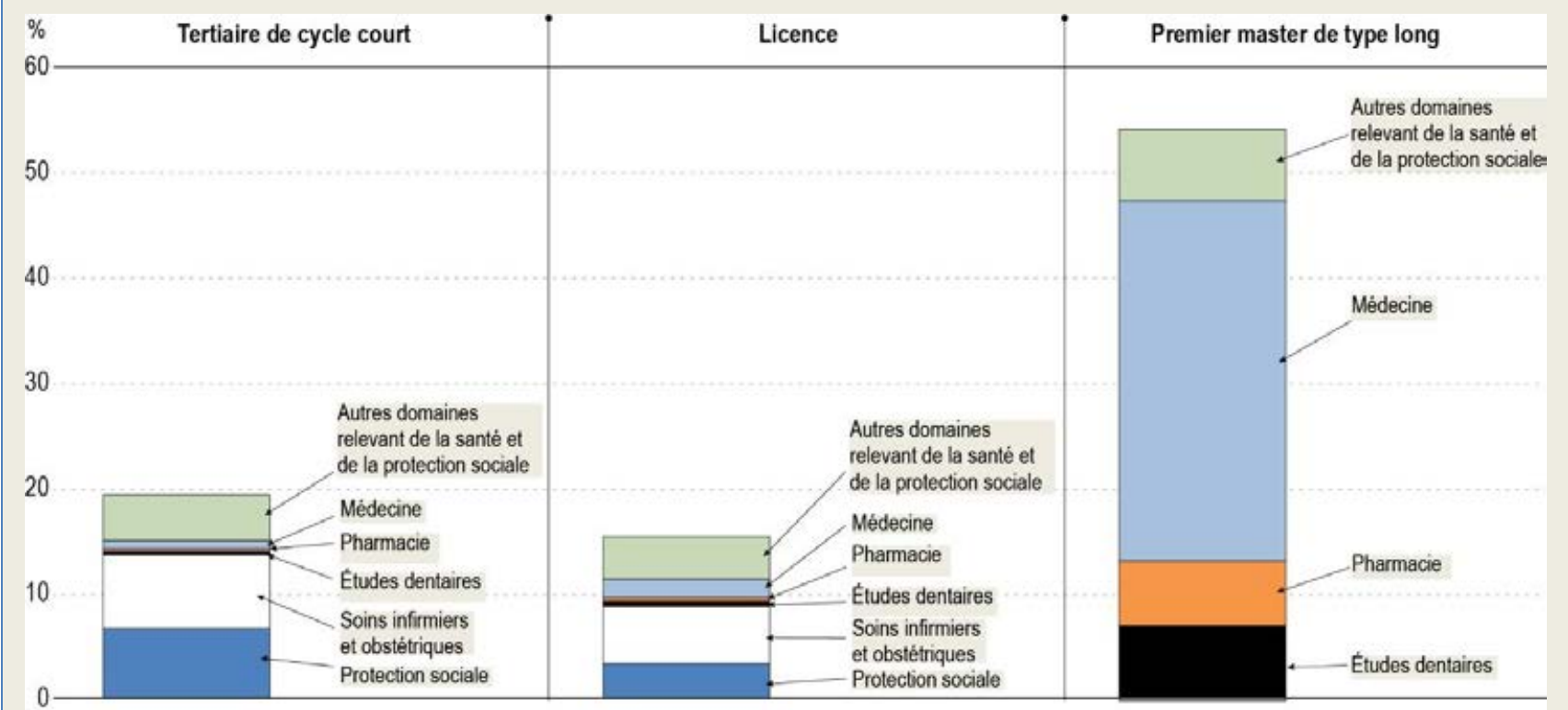

Remarque : Les autres domaines relevant de la santé et de la protection sociale incluent : les technologies de diagnostic et de traitement médicaux, la thérapie et la réhabilitation, la médecine et la thérapie traditionnelles ou complémentaires, et les domaines relevant de la santé et de la protection sociale sans autres spécifications ou non classés dans une autre catégorie.

Source : OCDE/ISU/Eurostat (2019) et OCDE/OIT/ISU (2019). Consulter la section « Source » pour tout complément d'information et l'annexe 3 pour les notes (https://doi.org/10.1787/f8d7880d-en).

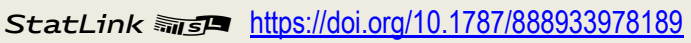

En moyenne, dans les pays de l'OCDE, les diplômés à l'issue d'une formation tertiaire de cycle court représentent $19 \%$ de l'effectif diplômé en santé ou en protection sociale, dont la moitié en soins infirmiers ou obstétriques (voir le graphique B4.b). Certains pays ne proposent des cursus de ce niveau que dans quelques disciplines. C'est le cas en Belgique et en Pologne, où une formation de cycle court est proposée exclusivement en soins infirmiers (Belgique) et en protection sociale (en Pologne). La médecine et la dentisterie, deux domaines dans lesquelles les études sont généralement plus longues, font l'objet de formations tertiaires de cycle court dans certains pays : le pourcentage de diplômés de ce niveau de 
l'enseignement tertiaire s'établit en médecine à $10 \%$ en Lettonie et à $3 \%$ en Espagne et en dentisterie à $2 \%$ en Corée et en Suède.

C'est en médecine et en dentisterie que le pourcentage de diplômés est le plus élevé en premier master de type long : $34 \%$ en médecine et $7 \%$ en dentisterie. Vient ensuite la pharmacie dont l'effectif diplômé s'établit à $6 \%$ (voir le graphique B4.b). L'effectif diplômé varie sensiblement aussi entre les pays. Les premiers masters de type long concernent tous la santé au Chili, en Finlande et en Islande, mais ils n'attirent que peu d'étudiants. Plus de $80 \%$ des diplômés à l'issue d'un premier master de type long ont opté pour la santé au Japon, en Lettonie, en République slovaque et en Turquie.

Les disciplines en rapport avec la santé et la protection sociale sont moins prisées en licence dans l'ensemble, mais des différences s'observent entre les pays. Le pourcentage de licenciés dans le domaine de la santé ou de la protection sociale s'élève à $15 \%$ en moyenne dans les pays de l'OCDE, mais il est égal ou supérieur à $30 \%$ en Belgique et au Danemark.

\section{Taux d'accès à l'enseignement tertiaire}

Dans les pays de l'OCDE, on estime qu'en moyenne, $65 \%$ des jeunes entameront une première formation tertiaire à un moment de leur vie si les taux actuels d'accès restent constants. Les taux de premier accès à l'enseignement tertiaire sont les plus élevés en Arabie saoudite (87\%), au Chili (85\%), en Fédération de Russie (95\%), en Nouvelle-Zélande (89\%) et en Suisse (82\%) parmi les pays de l'OCDE dont les données sont disponibles. Dans ces pays, ces taux sont gonflés par l'effectif plus important d'étudiants plus âgés ou en mobilité internationale ou par un taux élevé d'accès en formation tertiaire de cycle court (voir le tableau B4.3).

La comparaison des taux de premier accès entre les adultes de moins de 25 ans et l'effectif total de nouveaux premiers inscrits (hors étudiants en mobilité internationale) montre si l'enseignement tertiaire est accessible ou si les étudiants commencent leurs études plus tard. Les taux de premier accès avant l'âge de 25 ans sont du même ordre en Autriche et en Suisse (47\%, contre $49 \%$ en moyenne dans les pays de l'OCDE), mais le taux total de premier accès est plus élevé de 14 points de pourcentage en Suisse qu'en Autriche, ce qui donne à penser que le taux moins élevé avant l'âge de 25 ans s'explique davantage par l'entrée tardive dans l'enseignement tertiaire en Suisse et par l'accessibilité en Autriche. L'âge moyen des nouveaux inscrits à chaque niveau de l'enseignement tertiaire indiqué dans le graphique B4.2 conforte cette thèse.

Les étudiants en mobilité internationale peuvent affecter sensiblement les taux d'accès à l'enseignement tertiaire. En Australie par exemple, où les étudiants en mobilité internationale sont très nombreux, le taux d'accès en licence chute après déduction des étudiants en mobilité internationale, passant de $94 \%$ à $77 \%$, mais reste toutefois le plus élevé en licence dans les pays de l'OCDE. Au Luxembourg par contre, le taux d'accès est le moins élevé des pays de l'OCDE ( $12 \%$, après déduction des étudiants en mobilité internationale), car de nombreux Luxembourgeois partent étudier à l'étranger.

\section{Définitions}

Le taux d'accès est la somme des taux d'accès par âge qui sont calculés comme suit : le nombre de nouveaux inscrits d'un âge donné au niveau d'enseignement considéré est divisé par l'effectif total de la population de cet âge.

Le taux d'accès corrigé des étudiants en mobilité internationale est le taux d'accès par âge qui est calculé après déduction des étudiants en mobilité internationale du numérateur.

Le taux de premier accès à l'enseignement tertiaire est une estimation de la probabilité qu'ont les jeunes adultes d'entamer une première formation tertiaire à un moment de leur vie si les taux actuels d'accès se maintiennent à l'avenir. 
Par nouveaux inscrits (première inscription) dans l'enseignement tertiaire, on entend les étudiants qui s'inscrivent pour la première fois dans l'enseignement tertiaire, sans avoir suivi de formation à tout autre niveau de l'enseignement tertiaire auparavant. Ces nouveaux inscrits peuvent entamer leurs études à différents niveaux de l'enseignement tertiaire : en formation de cycle court (niveau 5 de la CITE), en licence (niveau 6 de la CITE) ou en master. Les nouveaux inscrits en master (première inscription) sont ceux qui s'inscrivent en premier master de type long ; ceux qui s'inscrivent dans un cursus du niveau 7 de la CITE insuffisant pour être sanctionné par un diplôme certifiant la réussite totale ou partielle de ce niveau ; les étudiants étrangers qui s'inscrivent en master (généralement après une licence), mais qui n'ont pas fait de licence dans leur pays d'accueil ; et les candidats admis en master après validation de leur expérience.

Les étudiants en mobilité internationale sont ceux qui ont quitté leur pays d'origine pour se rendre dans un autre pays dans l'intention d'y suivre des études. Les étudiants en mobilité internationale qui s'inscrivent pour la première fois dans une formation sont souvent considérés comme de nouveaux inscrits dans ce pays.

Les premiers masters de type long sont les cursus du niveau 7 de la CITE d'une durée de cinq à sept ans sanctionnés par un premier diplôme ou titre, dont le contenu des cours est d'une complexité équivalente aux autres masters. Ils concernent des domaines hautement spécialisés, tels que la médecine et la dentisterie et, dans certains cas, le droit et l'ingénierie.

Par nouveaux inscrits dans un niveau de l'enseignement tertiaire, on entend les étudiants qui s'inscrivent pour la première fois dans un niveau de l'enseignement tertiaire, mais qui peuvent avoir réussi une formation d'un autre niveau de l'enseignement tertiaire auparavant.

Le taux d'accès à l'enseignement tertiaire est une estimation de la probabilité, dans l'hypothèse du maintien des tendances actuelles d'accès, qu'ont les jeunes d'entamer une formation tertiaire au cours de leur vie.

\section{Méthodologie}

Les taux d'accès diffèrent des taux de scolarisation, car ils évaluent l'afflux de nouveaux inscrits durant une période donnée, c'est-à-dire le pourcentage d'une cohorte d'âge susceptible d'entamer une formation tertiaire à l'avenir. Le taux net d'accès à un âge donné est calculé comme suit : le nombre de nouveaux inscrits de cet âge dans chaque type de formation tertiaire est divisé par l'effectif total de la population du même âge. La somme des taux nets d'accès correspond à la somme des taux d'accès à chaque âge. Ce taux est une estimation de la probabilité que des jeunes entament des études tertiaires au cours de leur vie, dans l'hypothèse du maintien des taux d'accès par âge à leur niveau actuel.

Les étudiants en mobilité internationale représentent une part importante de l'effectif total d'étudiants dans certains pays ; ils peuvent gonfler artificiellement le pourcentage de jeunes adultes d'aujourd'hui qui entameront vraisemblablement une formation tertiaire. Après déduction des étudiants en mobilité internationale, les estimations des pourcentages de nouveaux inscrits dans l'enseignement tertiaire varient fortement.

Pour de plus amples informations, veuillez consulter le Guide de l'OCDE pour l'établissement de statistiques internationalement comparables dans le domaine de l'éducation 2018: Concepts, normes, définitions et classifications (OCDE, 2019[9]). Voir les notes spécifiques aux pays à l'annexe 3 (https://doi.org/10.1787/f8d7880d-en).

\section{Source}

Les données se rapportent à l'année académique 2016/17 et proviennent de l'exercice UNESCOISU/OCDE/Eurostat de collecte de données statistiques sur l'éducation réalisé par l'OCDE en 2018. Les données sur le pourcentage d'étudiants inscrits en licence dès la fin du deuxième cycle du secondaire selon la filière dans le deuxième cycle de l'enseignement secondaire se rapportent à l'année académique 2016/17 et proviennent d'une enquête spéciale menée en 2018. Les données de certains pays portent sur une autre année académique. Consulter l'annexe A3 (https://doi.org/10.1787/f8d7880d-en) pour de plus amples informations. 


\section{Note concernant les données d'Israël}

Les données statistiques concernant Israël sont fournies par et sous la responsabilité des autorités israéliennes compétentes. L'utilisation de ces données par l'OCDE est sans préjudice du statut des hauteurs du Golan, de Jérusalem-Est et des colonies de peuplement israéliennes en Cisjordanie aux termes du droit international.

\section{Références}

García, H., M. De et L. Villarreal (2014), « The Redirecting of International Students: American Higher Education Policy Hindrances and Implications », vol. 4/2, pp. 126-136, https://files.eric.ed.gov/fulltext/EJ1054820.pdf (consulté le 16 mai 2019).

OCDE (2019), Base de données de Regards sur l'éducation, https://stats.oecd.org/ (consulté le 10 juin 2019).

OCDE (2019), Guide de l'OCDE pour l'établissement de statistiques internationalement comparables dans le domaine de l'éducation 2018: Concepts, normes, définitions et classifications, Éditions OCDE, Paris, https://dx.doi.org/10.1787/9789264305380-fr.

OCDE (2018), Atteindre l'égalité femmes-hommes: Un combat difficile, Éditions OCDE, Paris, https://dx.doi.org/10.1787/9789264203426-fr.

OCDE (2018), Regards sur l'éducation 2018 : Les indicateurs de l'OCDE, Éditions OCDE, Paris, https://dx.doi.org/10.1787/eag-2018-fr.

OCDE (2017), Regards sur l'éducation 2017 : Les indicateurs de l'OCDE, Éditions OCDE, Paris, http://dx.doi.org/10.1787/eag-2017-fr.

OCDE (2011), Report on the Gender Initiative: Gender Equality in Education, Employment and Entrepreneurship, OCDE, Paris, https://www.oecd.org/education/48111145.pdf (consulté le 16 mai 2019).

OCDE (2009), OECD Reviews of Tertiary Education: Japan 2009, OECD Reviews of Tertiary Education, Éditions OCDE, Paris, https://dx.doi.org/10.1787/9789264039322-en.

OCDE/Eurostat/Institut de statistique de I'UNESCO (2016), Guide opérationnel CITE 2011: Directives pour la classification des programmes éducatifs nationaux et des certifications correspondantes, Institut de statistique de I'UNESCO, Paris, https://dx.doi.org/10.1787/9789264248823-fr. 
B4. QUEL EST LE PROFIL DES NOUVEAUX INSCRITS DANS L'ENSEIGNEMENT TERTIAIRE ? | 223

\section{Tableaux de l'indicateur B4}

Tableau B4.1

Tableau B4.2

Tableau B4.3
Profil des nouveaux inscrits (première inscription) dans l'enseignement tertiaire (2017)

Répartition des nouveaux inscrits selon le domaine d'études, le sexe et le niveau de l'enseignement tertiaire (2017)

Taux de premier accès, selon le niveau de l'enseignement tertiaire (2017)

Date butoir pour les données: 19 juillet 2019. Les mises à jour peuvent être consultées en ligne sur : http://dx.doi.org/10.1787/eag-data-en. D'autres données désagrégées sont également disponibles dans la Base de données de Regards sur l'éducation (http://stats.oecd.org/).

Statlink : https://doi.org/10.1787/888933980982 
Tableau B4.1. Profil des nouveaux inscrits (première inscription) dans l'enseignement tertiaire (2017)

\begin{tabular}{|c|c|c|c|c|c|c|c|c|c|c|c|c|}
\hline & \multirow{2}{*}{\multicolumn{3}{|c|}{$\begin{array}{c}\text { Distribution des nouveaux inscrits } \\
\text { (première inscription) } \\
\text { dans l'enseignement tertiaire, } \\
\text { selon le niveau : }\end{array}$}} & \multicolumn{9}{|c|}{ Profil des nouveaux inscrits dans des : } \\
\hline & & & & \multicolumn{3}{|c|}{$\begin{array}{l}\text { Programmes } \\
\text { tertiaires de cycle court }\end{array}$} & \multicolumn{3}{|c|}{$\begin{array}{l}\text { Programmes } \\
\text { de licence }\end{array}$} & \multicolumn{3}{|c|}{$\begin{array}{l}\text { Programmes } \\
\text { de premier master de type long }\end{array}$} \\
\hline & 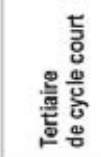 & $\begin{array}{l}\text { 巳 } \\
\stackrel{\Xi}{J}\end{array}$ & 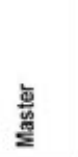 & 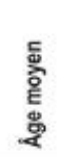 & 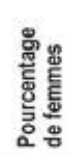 & 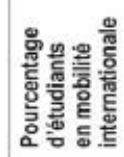 & 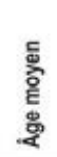 & 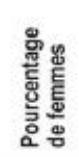 & 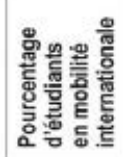 & 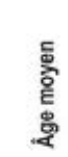 & 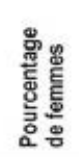 & 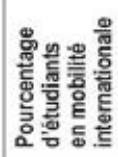 \\
\hline & (1) & (2) & (3) & (4) & (5) & (6) & (7) & (8) & (9) & (10) & (11) & (12) \\
\hline \multicolumn{13}{|l|}{ uf Pays } \\
\hline Australie & $\mathrm{m}$ & $\mathrm{m}$ & m & m & m & m & 23 & 57 & 19 & a & a & a \\
\hline Autriche & 45 & 40 & 15 & 21 & 53 & 2 & 23 & 55 & 22 & 21 & 59 & 20 \\
\hline Belgique' & 1 & 99 & a & 19 & 87 & 5 & 20 & 55 & 8 & a & a & a \\
\hline Canada & $\mathrm{m}$ & $\mathrm{m}$ & $\mathrm{m}$ & $\mathrm{m}$ & $\mathrm{m}$ & $\mathrm{m}$ & $\mathrm{m}$ & $\mathrm{m}$ & $\mathrm{m}$ & $\mathrm{m}$ & m & $\mathrm{m}$ \\
\hline Chili & 45 & 53 & 2 & 24 & 54 & 1 & 22 & 52 & 1 & 19 & 61 & 1 \\
\hline Colombie & 40 & 60 & a & 23 & 48 & 0 & 22 & 54 & 0 & a & a & a \\
\hline République tchèque & 1 & 89 & 10 & 23 & 62 & 5 & 22 & 58 & 12 & 20 & 63 & 28 \\
\hline Danemark & 26 & 74 & 0 & 30 & 47 & 11 & 24 & 57 & 8 & $\mathrm{~m}$ & $\mathrm{~m}$ & $\mathrm{~m}$ \\
\hline Estonie & $\mathrm{m}$ & $\mathrm{m}$ & $\mathrm{m}$ & a & a & a & 24 & 57 & 6 & 21 & 60 & 9 \\
\hline Finlande & a & 93 & 7 & a & a & a & 24 & 54 & 7 & 22 & 55 & 0 \\
\hline France & $\mathrm{m}$ & $\mathrm{m}$ & $\mathrm{m}$ & 20 & 50 & $\mathrm{~m}$ & 20 & 57 & $\mathrm{~m}$ & $\mathrm{~m}$ & $\mathrm{~m}$ & $\mathrm{~m}$ \\
\hline Allemagne & 0 & 82 & 18 & 26 & 67 & 0 & 22 & 49 & 6 & 21 & 62 & 39 \\
\hline Gréce & a & 100 & a & a & a & a & 20 & 52 & 3 & a & a & a \\
\hline Hongrie & 12 & 71 & 17 & 23 & 65 & 1 & 21 & 54 & 8 & 21 & 57 & 28 \\
\hline Islande & 9 & 91 & 1 & 31 & 54 & 35 & 24 & 61 & 11 & 23 & 62 & 0 \\
\hline Irlande & $\mathrm{m}$ & $\mathrm{m}$ & $\mathrm{m}$ & 33 & 56 & 4 & 21 & 51 & 5 & $\mathrm{~m}$ & $\mathrm{~m}$ & $\mathrm{~m}$ \\
\hline Israël & 26 & 74 & a & 24 & 50 & $\mathrm{~m}$ & 24 & 59 & 4 & a & a & a \\
\hline Italie & 2 & 86 & 12 & 23 & 28 & 7 & 20 & 53 & 6 & 20 & 65 & 5 \\
\hline Japon & 35 & 63 & 2 & 18 & 61 & $\mathrm{~m}$ & 18 & 45 & $\mathrm{~m}$ & 19 & 49 & $\mathrm{~m}$ \\
\hline Coree & $\mathrm{m}$ & $\mathrm{m}$ & $\mathrm{m}$ & 21 & 51 & 0 & 19 & 50 & 2 & a & a & a \\
\hline Lettonie & $\mathrm{m}$ & $\mathrm{m}$ & $\mathrm{m}$ & 28 & 59 & 2 & 23 & 51 & 9 & 23 & 65 & 44 \\
\hline Lituanie & a & 94 & 6 & a & a & a & 21 & 52 & 4 & 20 & 67 & 18 \\
\hline Luxembourg & 20 & 80 & a & 23 & 52 & 12 & 22 & 49 & 29 & a & a & a \\
\hline Mexique & 9 & 92 & a & 20 & 40 & 0 & 21 & 51 & 0 & a & a & a \\
\hline Pays-Bas & 2 & 98 & a & 26 & 50 & 0 & 20 & 53 & 14 & a & a & a \\
\hline Nouvelle-Zélande & 25 & 75 & a & 28 & 55 & 24 & 24 & 58 & 30 & a & a & a \\
\hline Norvège & 6 & 84 & 10 & 25 & 21 & 1 & 23 & 57 & 4 & 21 & 56 & 2 \\
\hline Pologne & a & $\mathrm{m}$ & $\mathrm{m}$ & 35 & 76 & a & 21 & 53 & m & 21 & 65 & $\mathrm{~m}$ \\
\hline Portugal & 9 & 76 & 14 & 21 & 36 & 3 & 21 & 57 & 5 & 20 & 51 & 6 \\
\hline République slovaque & 3 & 91 & 6 & 24 & 67 & 1 & 22 & 56 & 6 & 20 & 65 & 34 \\
\hline Slovenie & 18 & 77 & 5 & 24 & 39 & 3 & 21 & 56 & 5 & 19 & 70 & 8 \\
\hline Espagne & 36 & 53 & 11 & 22 & 45 & 1 & 20 & 56 & 2 & 20 & 67 & 12 \\
\hline Suéde & 14 & 59 & 27 & 29 & 49 & 0 & 24 & 61 & 5 & 23 & 52 & 3 \\
\hline Suisse & 2 & 69 & 29 & 32 & 65 & a & 25 & 49 & 10 & 25 & 80 & 17 \\
\hline Turquie & 48 & 50 & 2 & 23 & 50 & 0 & 22 & 50 & 3 & 19 & 53 & 7 \\
\hline Royaume-Uni & 22 & 77 & 1 & 29 & 58 & 3 & 21 & 56 & 16 & a & a & a \\
\hline États-Unis & 47 & 53 & a & 23 & 54 & 3 & m & $\mathrm{m}$ & $\mathrm{m}$ & a & a & a \\
\hline Moyenne OCDE & 17 & 76 & 7 & 25 & 53 & 5 & 22 & 54 & 8 & 21 & 61 & 15 \\
\hline Moyenne UE23 & 12 & 80 & 9 & 25 & 55 & 4 & 22 & 54 & 9 & 21 & 62 & 18 \\
\hline Argentine & $\mathrm{m}$ & $\mathrm{m}$ & $\mathrm{m}$ & $m$ & $\mathrm{~m}$ & $\mathrm{~m}$ & $\mathrm{~m}$ & $\mathrm{~m}$ & $\mathrm{~m}$ & a & a & a \\
\hline Brésil & $\mathrm{m}$ & $\mathrm{m}$ & $\mathrm{m}$ & $\mathrm{m}$ & $\mathrm{m}$ & $\mathrm{m}$ & $\mathrm{m}$ & m & $\mathrm{m}$ & $\mathrm{m}$ & m & $\mathrm{m}$ \\
\hline Бे Chine & 60 & 40 & a & m & 50 & m & m & 55 & m & m & m & $m$ \\
\hline Costa Rica & $\mathrm{m}$ & $m$ & $m$ & m & 60 & $\mathrm{~m}$ & m & 53 & m & a & a & a \\
\hline Inde & a & 100 & 0 & a & a & a & $\mathrm{m}$ & 47 & $\mathrm{~m}$ & $\mathrm{~m}$ & 36 & $\mathrm{~m}$ \\
\hline Indonésic & $\mathrm{m}$ & $\mathrm{m}$ & $\mathrm{m}$ & $\mathrm{m}$ & 63 & $\mathrm{~m}$ & $\mathrm{~m}$ & $\mathrm{~m}$ & $\mathrm{~m}$ & a & a & a \\
\hline Fédération de Russie & 54 & 37 & 9 & $\mathrm{~m}$ & 52 & 2 & 21 & 53 & 7 & 19 & 50 & 10 \\
\hline Arabie saoudite & 24 & 76 & 1 & $\mathrm{~m}$ & 23 & $\mathrm{~m}$ & $\mathrm{~m}$ & 50 & $\mathrm{~m}$ & $\mathrm{~m}$ & 45 & $\mathrm{~m}$ \\
\hline Afrique du Sud & $\mathrm{m}$ & $\mathrm{m}$ & $\mathrm{m}$ & $\mathrm{m}$ & $\mathrm{m}$ & $\mathrm{m}$ & $\mathrm{m}$ & m & $\mathrm{m}$ & a & a & a \\
\hline Moyenne G20 & 28 & 67 & 5 & m & 49 & $\mathrm{~m}$ & m & 52 & m & $\mathrm{m}$ & 53 & m \\
\hline
\end{tabular}

Remarque : Les colonnes 1 à 3 se rapportent aux nouveaux inscrits (première inscription) dans l'enseignement tertiaire, selon le niveau suivi. Les colonnes 4 à 12 se rapportent aux nouveaux inscrits dans chaque niveau de la CITE. Pour de plus amples informations, consulter les sections « Définitions » et « Méthodologie ». Les données et d'autres types de ventilations peuvent être consultés sur http://stats.oecd.org/, Base de données de Regards sur l'éducation.

1. Tertiaire de cycle court : les données se rapportent uniquement à la Communauté flamande de Belgique.

Source : OCDE/ISU/Eurostat (2019). Consulter la section "Source" pour tout complément d'information et l'annexe 3 pour les notes (https://doi.org/10.1787/f8d7880d-en).

Les symboles représentant les données manquantes et les abréviations figurent dans le Guide du lecteur

StatLink 제내 https://doi.org/10.1787/888933978056 
Tableau B4.2. Répartition des nouveaux inscrits selon le domaine d'études, le sexe et le niveau de l'enseignement tertiaire (2017)

\begin{tabular}{|c|c|c|c|c|c|c|c|c|c|c|c|c|c|c|c|c|c|}
\hline \multicolumn{6}{|c|}{ Tertiaire de cycle court } & \multicolumn{6}{|c|}{ Licence ou niveau équivalent } & \multicolumn{6}{|c|}{ Premier master de type long } \\
\hline \multicolumn{2}{|c|}{$\begin{array}{c}\text { Santé et } \\
\text { protection } \\
\text { sociale }\end{array}$} & \multicolumn{2}{|c|}{$\begin{array}{l}\text { Commerce, } \\
\text { administration } \\
\text { et droit }\end{array}$} & \multicolumn{2}{|c|}{$\begin{array}{c}\text { Sciences, } \\
\text { technologie, } \\
\text { ingénierie et } \\
\text { mathématiques }\end{array}$} & \multicolumn{2}{|c|}{$\begin{array}{c}\text { Santé et } \\
\text { protection } \\
\text { sociale }\end{array}$} & \multicolumn{2}{|c|}{$\begin{array}{c}\text { Commerce, } \\
\text { administration } \\
\text { et droit }\end{array}$} & \multicolumn{2}{|c|}{$\begin{array}{c}\text { Sciences, } \\
\text { technologie, } \\
\text { ingenierie et } \\
\text { mathematiques }\end{array}$} & \multicolumn{2}{|c|}{$\begin{array}{c}\text { Sante et } \\
\text { protection } \\
\text { sociale }\end{array}$} & \multicolumn{2}{|c|}{$\begin{array}{l}\text { Commerce, } \\
\text { administration } \\
\text { et droit }\end{array}$} & \multicolumn{2}{|c|}{\begin{tabular}{|c|} 
Sciences, \\
technologie, \\
ingenierie et \\
mathematiques
\end{tabular}} \\
\hline 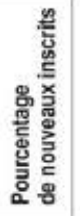 & 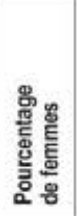 & 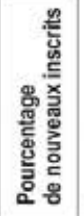 & 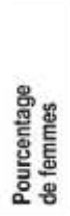 & 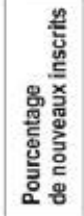 & 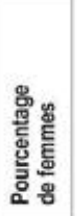 & 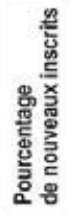 & 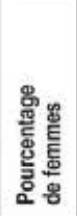 & 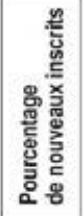 & 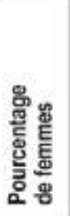 & 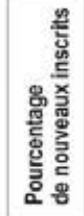 & 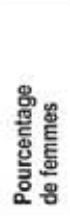 & 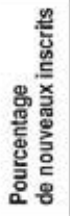 & 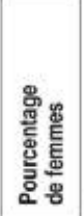 & 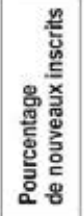 & 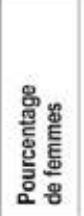 & 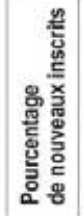 & 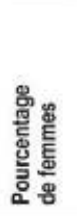 \\
\hline & & (3) & (4) & (5) & (6) & & 101 & (3) & (ai) & (1) & (12) & (1)) & (14) & 16) & $(106)$ & $\omega_{i}$ & \\
\hline
\end{tabular}

\begin{tabular}{|c|c|c|c|c|c|c|c|c|c|c|c|c|c|c|c|c|c|c|}
\hline \\
\hline \multicolumn{19}{|l|}{ Oustralie } \\
\hline Autriche & 4 & 68 & 25 & 61 & 34 & 17 & 6 & 78 & 15 & 56 & 34 & 35 & 23 & 53 & 64 & 60 & 0 & a \\
\hline Belgique' & 100 & 87 & 0 & a & 0 & a & 26 & 74 & 23 & 49 & 19 & 20 & a & a & a & a & a & a \\
\hline Canada & $\mathrm{m}$ & m & m & $\mathrm{m}$ & $\mathrm{m}$ & $\mathrm{m}$ & $\mathrm{m}$ & $\mathrm{m}$ & $\mathrm{m}$ & $\mathrm{m}$ & $\mathrm{m}$ & $\mathrm{m}$ & $\mathrm{m}$ & $\mathrm{m}$ & $\mathrm{m}$ & $\mathrm{m}$ & $\mathrm{m}$ & $\mathrm{m}$ \\
\hline Chili & 22 & 83 & 22 & 62 & 28 & 12 & 18 & 77 & 23 & 56 & 30 & 22 & 100 & 61 & 0 & a & 0 & a \\
\hline Colombie & 4 & 66 & 48 & 62 & 33 & 27 & 8 & 75 & 34 & 59 & 26 & 32 & a & a & a & a & a & a \\
\hline Rèpublique tchèque & 0 & a & 0 & a & 0 & a & 14 & 86 & 19 & 62 & 30 & 33 & 53 & 64 & 22 & 50 & 0.2 & 0 \\
\hline Danemark & 3 & 86 & 55 & 47 & 14 & 23 & 28 & 79 & 22 & 49 & 20 & 31 & $\mathrm{~m}$ & $\mathrm{~m}$ & $\mathrm{~m}$ & $\mathrm{~m}$ & $\mathrm{~m}$ & m \\
\hline Estonie & a & a & a & a & a & a & 11 & 90 & 21 & 64 & 32 & 34 & 41 & 67 & 0 & a & 36 & 32 \\
\hline Finlande & a & a & a & a & a & a & 22 & 83 & 21 & 52 & 31 & 22 & 100 & 55 & 0 & a & 0 & a \\
\hline France & 13 & 85 & 39 & 56 & 28 & 20 & 9 & 80 & 25 & 59 & 25 & 36 & $\mathrm{~m}$ & $\mathrm{~m}$ & $\mathrm{~m}$ & $\mathrm{~m}$ & $\mathrm{~m}$ & $\mathrm{~m}$ \\
\hline Allemagne & 0 & a & 0 & a & 28 & 33 & 5 & 80 & 23 & 54 & 40 & 26 & 16 & 65 & 25 & 59 & 19 & 47 \\
\hline Grece & a & a & a & a & a & a & 8 & 71 & 20 & 50 & 34 & 33 & a & a & a & a & a & a \\
\hline Hongric & 6 & 84 & 49 & 70 & 10 & 14 & 7 & 82 & 19 & 59 & 31 & 26 & 41 & 56 & 20 & 58 & 3 & 58 \\
\hline Islande & 0 & a & 6 & 42 & 16 & 43 & 12 & 86 & 17 & 58 & 28 & 37 & 100 & 62 & 0 & a & 0 & a \\
\hline Irlande & 11 & 68 & 25 & 52 & 32 & 29 & 14 & 80 & 19 & 48 & 31 & 29 & $\mathrm{~m}$ & $\mathrm{~m}$ & $\mathrm{~m}$ & $m$ & $\mathrm{~m}$ & $m$ \\
\hline Israë| & 3 & 82 & 2 & 82 & 59 & 26 & 7 & 81 & 15 & 58 & 28 & 36 & a & a & a & a & a & a \\
\hline Italie & 0 & a & 17 & 36 & 52 & 14 & 9 & 57 & 16 & 45 & 30 & 36 & 37 & 64 & 46 & 62 & 7 & 58 \\
\hline Japon ${ }^{2}$ & $25^{\circ}$ & $69^{\circ}$ & $12^{\circ}$ & $61^{\circ}$ & $15^{d}$ & $16^{\circ}$ & $9^{\circ}$ & $71^{\circ}$ & 284 & $31^{4}$ & $19^{d}$ & $17^{d}$ & $96^{\circ}$ & $48^{\circ}$ & 0 & a & 0 & a \\
\hline Corée & 22 & 72 & 11 & 62 & 28 & 14 & 12 & 69 & 14 & 50 & 34 & 31 & a & a & a & a & a & a \\
\hline Lettonie & 24 & 89 & 34 & 63 & 19 & 14 & 6 & 84 & 25 & 54 & 32 & 25 & 94 & 65 & 0 & a & 0 & a \\
\hline Lituanie & a & a & a & a & a & a & 14 & 87 & 25 & 57 & 33 & 23 & 59 & 70 & 22 & 62 & 7 & 55 \\
\hline Luxembourg & 28 & 74 & 36 & 55 & 22 & 12 & 12 & 47 & 20 & 63 & 20 & 24 & a & a & $a$ & a & a & a \\
\hline Mexique & 7 & 60 & 34 & 60 & 53 & 24 & 11 & 69 & 36 & 54 & 29 & 30 & a & a & a & a & a & a \\
\hline Pays-Bas & 10 & 80 & 51 & 47 & 12 & 5 & 17 & 78 & 28 & 44 & 20 & 26 & a & a & a & a & a & a \\
\hline Nouvelle-Zèlande & 8 & 85 & 25 & 56 & 21 & 26 & 12 & 79 & 22 & 54 & 28 & 42 & a & a & a & a & a & a \\
\hline Norvege & 0 & 100 & 0 & 56 & 66 & 5 & 16 & 84 & 19 & 51 & 16 & 31 & 13 & 75 & 17 & 67 & 34 & 40 \\
\hline Pologne & 100 & 76 & 0 & a & 0 & $a$ & 8 & 74 & 19 & 57 & 32 & 33 & 33 & 64 & 34 & 58 & 0 & 42 \\
\hline Portugal & 9 & 86 & 19 & 55 & 44 & 13 & 14 & 81 & 27 & 58 & 21 & 33 & 30 & 72 & 0 & a & 55 & 36 \\
\hline République slovaque & 32 & 83 & 14 & 69 & 12 & 39 & 13 & 77 & 18 & 59 & 27 & 29 & 86 & 66 & 0 & a & 0 & a \\
\hline Slovénie & 2 & 79 & 18 & 70 & 45 & 16 & 11 & 77 & 17 & 60 & 29 & 29 & 63 & 75 & 0 & a & 20 & 56 \\
\hline Espagne & 15 & 74 & 20 & 56 & 31 & 11 & 11 & 74 & 22 & 54 & 24 & 31 & 74 & 70 & 0 & a & 16 & 51 \\
\hline Suède & 4 & 82 & 30 & 78 & 46 & 23 & 17 & 82 & 14 & 59 & 21 & 35 & 12 & 67 & 15 & 53 & 37 & 33 \\
\hline Suisse & 26 & 86 & 48 & 69 & 11 & 12 & 16 & 77 & 30 & 44 & 27 & 22 & 0 & a & 0 & a & 0 & a \\
\hline Turquie & 11 & 67 & 32 & 46 & 18 & 29 & 11 & 67 & 32 & 46 & 18 & 29 & 89 & 55 & 0 & a & 0 & a \\
\hline Royaume-Uni & 31 & 76 & 32 & 56 & 14 & 18 & 11 & 78 & 20 & 51 & 32 & 39 & a & a & a & a & a & a \\
\hline Etats-Unis & $\mathrm{m}$ & m & $\mathrm{m}$ & $\mathrm{m}$ & $\mathrm{m}$ & $\mathrm{m}$ & m & $m$ & $\mathrm{~m}$ & $\mathrm{~m}$ & $\mathrm{~m}$ & $\mathrm{~m}$ & a & a & a & a & a & a \\
\hline Moyenne OCDE & 17 & 79 & 24 & 59 & 26 & 20 & 13 & 77 & 22 & 54 & 27 & 30 & 55 & 64 & 13 & 59 & 11 & 42 \\
\hline Moyenne UE23 & 21 & 80 & 24 & 58 & 23 & 19 & 13 & 77 & 21 & 55 & 28 & 30 & 51 & 65 & 17 & 58 & 13 & 43 \\
\hline
\end{tabular}

\begin{tabular}{|c|c|c|c|c|c|c|c|c|c|c|c|c|c|c|c|c|c|c|}
\hline Argentine & $\mathrm{m}$ & $\mathrm{m}$ & $\mathrm{m}$ & $\mathrm{m}$ & $\mathrm{m}$ & m & m & $\mathrm{m}$ & $\mathrm{m}$ & $\mathrm{m}$ & $\mathrm{m}$ & $\mathrm{m}$ & a & a & a & a & a & a \\
\hline Erèsil & $m$ & $\mathrm{~m}$ & $\mathrm{~m}$ & $\mathrm{~m}$ & $\mathrm{~m}$ & m & $m$ & $\mathrm{~m}$ & $\mathrm{~m}$ & $m$ & $m$ & $\mathrm{~m}$ & $\mathrm{~m}$ & $\mathrm{~m}$ & m & m & $\mathrm{m}$ & $\mathrm{m}$ \\
\hline Chine & $\mathrm{m}$ & $\mathrm{m}$ & $\mathrm{m}$ & $m$ & $\mathrm{~m}$ & $\mathrm{~m}$ & $\mathrm{~m}$ & $\mathrm{~m}$ & $\mathrm{~m}$ & $\mathrm{~m}$ & m & $\mathrm{m}$ & $\mathrm{m}$ & $\mathrm{m}$ & $\mathrm{m}$ & $\mathrm{m}$ & $\mathrm{m}$ & m \\
\hline ä Costa Rica & 1 & 75 & 31 & 70 & 31 & 39 & 11 & 67 & 30 & 58 & 28 & 31 & a & a & a & a & a & a \\
\hline Inde & a & a & a & a & a & a & $\mathrm{m}$ & $\mathrm{m}$ & $\mathrm{m}$ & $m$ & $\mathrm{~m}$ & $\mathrm{~m}$ & $\mathrm{~m}$ & $\mathrm{~m}$ & $\mathrm{~m}$ & $\mathrm{~m}$ & $\mathrm{~m}$ & $\mathrm{~m}$ \\
\hline Indonésie & $\mathrm{m}$ & $\mathrm{m}$ & m & $\mathrm{m}$ & m & $\mathrm{m}$ & $\mathrm{m}$ & $\mathrm{m}$ & $\mathrm{m}$ & $\mathrm{m}$ & m & $\mathrm{m}$ & a & a & a & a & a & a \\
\hline Fédération de Russie & 14 & 84 & 24 & 68 & 35 & 25 & 1 & 80 & 25 & 55 & 35 & 29 & 36 & 65 & 11 & 56 & 25 & 21 \\
\hline Arabie saoudite & $\mathrm{m}$ & $\mathrm{m}$ & $\mathrm{m}$ & $\mathrm{m}$ & $\mathrm{m}$ & $\mathrm{m}$ & $\mathrm{m}$ & $\mathrm{m}$ & $\mathrm{m}$ & $\mathrm{m}$ & $\mathrm{m}$ & $\mathrm{m}$ & $\mathrm{m}$ & $\mathrm{m}$ & $\mathrm{m}$ & $\mathrm{m}$ & $\mathrm{m}$ & $\mathrm{m}$ \\
\hline Afrique du Sud & $\mathrm{m}$ & $\mathrm{m}$ & $\mathrm{m}$ & $\mathrm{m}$ & m & $\mathrm{m}$ & $\mathrm{m}$ & $\mathrm{m}$ & $\mathrm{m}$ & $\mathrm{m}$ & m & $\mathrm{m}$ & a & a & a & a & a & a \\
\hline
\end{tabular}

\begin{tabular}{|l|l|l|l|l|l|l|l|l|l|l|l|l|l|l|l|l|l|l|} 
Moyenne $\mathrm{G} 20$ & $\mathrm{~m}$ & $\mathrm{~m}$ & $\mathrm{~m}$ & $\mathrm{~m}$ & $\mathrm{~m}$ & $\mathrm{~m}$ & $\mathrm{~m}$ & $\mathrm{~m}$ & $\mathrm{~m}$ & $\mathrm{~m}$ & $\mathrm{~m}$ & $\mathrm{~m}$ & $\mathrm{~m}$ & $\mathrm{~m}$ & $\mathrm{~m}$ & $\mathrm{~m}$ & $\mathrm{~m}$ & $\mathrm{~m}$ \\
\hline
\end{tabular} Remarque : Pour de plus amples informations, consulter les sections " Définitions » et " Méthodologie ». Les données et d'autres types de ventilations peuvent être consultés sur http://stats.oecd.org/, Base de données de Regards sur l'éducation.

1. Tertiaire de cycle court : les données se rapportent uniquement à la Communauté flamande de Belgique.

2. Tous les domaines d'enseignement incluent le domaine « Technologies de l'information et de la communication (TIC) ».

Source : OCDE/ISU/Eurostat (2019). Consulter la section « Source » pour tout complément d'information et l'annexe 3 pour les notes (https://doi.org/10.1787/f8d7880d-en). Les symboles représentant les données manquantes et les abréviations figurent dans le Guide du lecteur. 
Tableau B4.3. Taux de premier accels, selon le niveau de l'enseignement tertiaire (2017)

\begin{tabular}{|c|c|c|c|c|c|c|c|c|c|c|c|c|c|c|c|}
\hline & \multicolumn{3}{|c|}{ Tertiaire de cycle court } & \multicolumn{3}{|c|}{ Licence } & \multicolumn{3}{|c|}{ Master } & \multicolumn{3}{|c|}{ Doctorat } & \multicolumn{3}{|c|}{$\begin{array}{l}\text { Premier accès da } \\
\text { l'enseignement tertiaire }\end{array}$} \\
\hline & \multirow[b]{2}{*}{ Total } & \multicolumn{2}{|c|}{$\begin{array}{l}\text { A l'exclusion } \\
\text { des étudiants } \\
\text { en mobilité } \\
\text { internationale }\end{array}$} & \multirow[b]{2}{*}{ Total } & \multicolumn{2}{|c|}{$\begin{array}{l}\text { A l'exclusion } \\
\text { des étudiants } \\
\text { en mobilitè } \\
\text { internationale }\end{array}$} & \multirow[b]{2}{*}{ Total } & \multicolumn{2}{|c|}{$\begin{array}{l}\text { À Pexclusion } \\
\text { des étudiants } \\
\text { en mobilitè } \\
\text { internationale }\end{array}$} & \multirow[b]{2}{*}{ Total } & \multicolumn{2}{|c|}{$\begin{array}{l}\text { À l'exclusion } \\
\text { des étudiants } \\
\text { en mobilité } \\
\text { internationale }\end{array}$} & \multirow[b]{2}{*}{ Total } & $\begin{array}{l}\text { A l'e) } \\
\text { des é } \\
\text { en n } \\
\text { interr }\end{array}$ & $\begin{array}{l}\text { llusion } \\
\text { Idiants } \\
\text { obilite } \\
\text { tionale }\end{array}$ \\
\hline & & 覀 & 产 & & 퐁 & 竞 旅 & & 픙 & 总这 & & 楼 & 产 & & 哣 & 产 \\
\hline & (1) & (2) & (3) & (4) & (5) & (6) & (7) & (8) & (9) & (10) & (11) & (12) & (13) & (14) & (15) \\
\hline ш Pays & & & & & & & & & & & & & & & \\
\hline Australie & $\mathrm{m}$ & $\mathrm{m}$ & $\mathrm{m}$ & 94 & 77 & 61 & 33 & 15 & 8 & 3.3 & 2.0 & 0.8 & $\mathrm{~m}$ & m & $\mathrm{m}$ \\
\hline Autriche & 34 & 34 & 29 & 43 & 34 & 29 & 24 & 16 & 14 & 3.1 & 1.9 & 1.3 & 68 & 54 & 47 \\
\hline Belgique' & 1 & 1 & 1 & 81 & 74 & 72 & 30 & 26 & 25 & 0.9 & 0.5 & 0.4 & 76 & 69 & 67 \\
\hline Canada & $\mathrm{m}$ & $\mathrm{m}$ & $\mathrm{m}$ & $\mathrm{m}$ & $\mathrm{m}$ & $\mathrm{m}$ & $\mathrm{m}$ & $\mathrm{m}$ & $\mathrm{m}$ & $\mathrm{m}$ & $\mathrm{m}$ & $\mathrm{m}$ & $\mathrm{m}$ & $\mathrm{m}$ & $\mathrm{m}$ \\
\hline Chili & 46 & 45 & 31 & 58 & 58 & 48 & 11 & 11 & 5 & 0.4 & 0.4 & 0.2 & 85 & 85 & 70 \\
\hline Colombie & 21 & 21 & 14 & 31 & 31 & 23 & 8 & 8 & 3 & 0.1 & 0.1 & 0.0 & 51 & 51 & 37 \\
\hline Rêpublique tchèque & 1 & 0 & 0 & 58 & 51 & 45 & 29 & 23 & 22 & 3.3 & 0.3 & $\mathrm{~m}$ & 64 & 54 & 48 \\
\hline Danemark & 29 & 26 & 10 & 68 & 63 & 47 & 36 & 28 & 24 & 3.1 & 1.9 & 1.1 & 79 & 72 & 53 \\
\hline Estonie & a & a & a & 64 & 60 & 47 & 30 & 25 & 18 & 20 & 1.5 & 0.9 & $\mathrm{~m}$ & m & $\mathrm{m}$ \\
\hline Finlande & a & a & a & 57 & 53 & 42 & 14 & 10 & 5 & 2.2 & 1.6 & 0.6 & 59 & 52 & 43 \\
\hline France & 29 & m & $\mathrm{m}$ & 55 & $\mathrm{~m}$ & $\mathrm{~m}$ & 42 & $\mathrm{~m}$ & $\mathrm{~m}$ & 2.5 & $\mathrm{~m}$ & $\mathrm{~m}$ & $\mathrm{~m}$ & $\mathrm{~m}$ & $\mathrm{~m}$ \\
\hline Allemagne & 0 & 0 & 0 & 49 & 46 & 39 & 30 & 22 & 20 & 38 & 32 & 27 & 60 & 53 & 45 \\
\hline Grece & a & a & a & 72 & 70 & 64 & 22 & 22 & 12 & 28 & 28 & 1.3 & 47 & 45 & 40 \\
\hline Hongrie & 5 & 5 & 4 & 31 & 28 & 26 & 16 & 13 & 11 & 17 & 1.4 & 1.0 & 43 & 39 & 35 \\
\hline Islande & 9 & 6 & 2 & 61 & 54 & 42 & 32 & 28 & 14 & 26 & 16 & 0.4 & 65 & 56 & 43 \\
\hline Irlande & 14 & 13 & 5 & 73 & 69 & 61 & 33 & 25 & 14 & 3.2 & 2.1 & 1.2 & $\mathrm{~m}$ & m & $\mathrm{m}$ \\
\hline Israél & 20 & $\mathrm{~m}$ & $\mathrm{~m}$ & 54 & 52 & 35 & 24 & 22 & 9 & 19 & 1.8 & 0.6 & 67 & $\mathrm{~m}$ & $\mathrm{~m}$ \\
\hline Italie & 1 & 1 & 1 & 43 & 41 & 37 & 26 & 24 & 22 & 1.4 & 1.2 & 0.9 & 50 & 48 & 43 \\
\hline Japon & 28 & m & $\mathrm{m}$ & 49 & $\mathrm{~m}$ & $\mathrm{~m}$ & 8 & $\mathrm{~m}$ & $\mathrm{~m}$ & 1.2 & 1.0 & $\mathrm{~m}$ & 79 & m & $\mathrm{m}$ \\
\hline Corée & 32 & 32 & 29 & 58 & 57 & 56 & 13 & 12 & 6 & 3.4 & 3.0 & 1.2 & $\mathrm{~m}$ & m & $\mathrm{m}$ \\
\hline Lettonie & 28 & 27 & 15 & $\pi$ & 70 & 56 & 29 & 23 & 18 & 21 & 1.9 & 1.0 & m & m & $\mathrm{m}$ \\
\hline Lituanie & a & a & a & 72 & 70 & 62 & 23 & 20 & 17 & 1.5 & 1.4 & 0.8 & 77 & 74 & 66 \\
\hline Luxembourg & 4 & 4 & 3 & 17 & 12 & 11 & 15 & 3 & 3 & 1.8 & 0.3 & 0.2 & 21 & 17 & 15 \\
\hline Mexique & 4 & 4 & 4 & 47 & 46 & 39 & 6 & 6 & 3 & 0.6 & 0.6 & 0.2 & 51 & 51 & 43 \\
\hline Pays-Bas & 2 & 2 & 1 & 61 & 53 & 51 & 23 & 16 & 15 & 1.4 & 0.7 & 0.6 & 62 & 54 & 52 \\
\hline Nouvelle-Zèlande & 31 & 24 & 11 & 76 & 54 & 41 & 12 & 8 & 4 & 3.1 & 1.4 & 0.6 & 89 & 61 & 48 \\
\hline Norvège & 5 & 5 & 3 & 65 & 62 & 52 & 29 & 28 & 22 & 28 & 20 & 0.8 & 70 & 68 & 58 \\
\hline Pologne & 0 & 0 & 0 & 71 & m & $\mathrm{m}$ & 34 & $\mathrm{~m}$ & $\mathrm{~m}$ & 1.9 & $\mathrm{~m}$ & $\mathrm{~m}$ & 77 & 73 & 66 \\
\hline Portugal & 6 & 6 & 5 & 49 & 46 & 42 & 36 & 32 & 27 & 3.8 & 26 & 12 & 62 & 59 & 55 \\
\hline Republique slovaque & 1 & 1 & 1 & 48 & 46 & 41 & 33 & 31 & 28 & 2.2 & 20 & 1.4 & 53 & 49 & 44 \\
\hline Slovénie & 25 & 24 & 19 & 73 & 69 & 65 & 29 & 28 & 25 & 3.0 & 28 & 1.6 & 74 & 70 & 67 \\
\hline Espagne & 31 & 31 & 27 & 49 & 48 & 44 & 19 & 15 & 13 & 3.8 & 3.1 & 1.8 & 79 & 74 & 68 \\
\hline Suède & 9 & 9 & 3 & 44 & 41 & 30 & 31 & 25 & 20 & 22 & 1.3 & 0.6 & 63 & 56 & 41 \\
\hline Suisse & 2 & 2 & 1 & 62 & 55 & 40 & 23 & 15 & 13 & 4.7 & 2.0 & 1.5 & 82 & 68 & 47 \\
\hline Turquie & 50 & 49 & 35 & 51 & 49 & 39 & 11 & 10 & 9 & 1.0 & 0.9 & 0.5 & $\mathrm{~m}$ & $\mathrm{~m}$ & $\mathrm{~m}$ \\
\hline Royaume-Uni & 16 & 15 & 8 & 66 & 56 & 49 & 29 & 17 & 11 & 4.0 & 2.3 & 1.5 & 74 & 66 & 53 \\
\hline Etats-Unis & 39 & 38 & 29 & $\mathrm{~m}$ & $\mathrm{~m}$ & $\mathrm{~m}$ & 14 & 12 & 7 & 1.3 & 0.9 & 0.5 & 49 & 47 & 44 \\
\hline Moyenne OCDE & 17 & 15 & 10 & 58 & 53 & 45 & 24 & 19 & 14 & 2.3 & 1.6 & 0.9 & 65 & 58 & 50 \\
\hline Moyenne UE23 & 12 & 11 & 7 & 57 & 52 & 46 & 27 & 21 & 17 & 2.5 & 1.7 & 1.1 & 63 & 57 & 50 \\
\hline If Argentine & $m$ & $\mathrm{~m}$ & $\mathrm{~m}$ & $m$ & $\mathrm{~m}$ & $\mathrm{~m}$ & 5 & $m$ & $m$ & 0.6 & $\mathrm{~m}$ & $\mathrm{~m}$ & $m$ & $\mathrm{~m}$ & $\mathrm{~m}$ \\
\hline Brèsil & $\mathrm{m}$ & m & $\mathrm{m}$ & $\mathrm{m}$ & m & m & m & m & $\mathrm{m}$ & m & m & m & $\mathrm{m}$ & m & $\mathrm{m}$ \\
\hline Chine & 40 & m & $\mathrm{m}$ & 38 & $\mathrm{~m}$ & m & 4 & m & $\mathrm{m}$ & 0.4 & m & $\mathrm{m}$ & 67 & m & $\mathrm{m}$ \\
\hline Costa Rica & 6 & $\mathrm{~m}$ & $\mathrm{~m}$ & 44 & m & $\mathrm{m}$ & $\mathrm{m}$ & m & m & $\mathrm{m}$ & $\mathrm{m}$ & m & $\mathrm{m}$ & m & m \\
\hline Inde & a & a & a & 46 & $\mathrm{~m}$ & $\mathrm{~m}$ & 10 & $\mathrm{~m}$ & $\mathrm{~m}$ & $\mathrm{~m}$ & m & $\mathrm{m}$ & 42 & m & m \\
\hline Indonésic & 5 & $\mathrm{~m}$ & m & $\mathrm{m}$ & m & $\mathrm{m}$ & $m$ & m & m & $\mathrm{m}$ & $\mathrm{m}$ & m & $m$ & $\mathrm{~m}$ & m \\
\hline Fédération de Russie & 48 & 47 & $\mathrm{~m}$ & 52 & 48 & 47 & 25 & 23 & 23 & 20 & 1.8 & $\mathrm{~m}$ & 88 & m & $\mathrm{m}$ \\
\hline Arabie saoudite & 20 & $\mathrm{~m}$ & $\mathrm{~m}$ & 66 & $\mathrm{~m}$ & $\mathrm{~m}$ & 2 & m & $\mathrm{m}$ & 0.3 & m & m & 87 & m & $\mathrm{m}$ \\
\hline Afrique du Sud & $\mathrm{m}$ & $\mathrm{m}$ & $\mathrm{m}$ & $\mathrm{m}$ & $\mathrm{m}$ & $\mathrm{m}$ & $\mathrm{m}$ & $\mathrm{m}$ & m & $\mathrm{m}$ & $\mathrm{m}$ & $\mathrm{m}$ & $\mathrm{m}$ & m & $\mathrm{m}$ \\
\hline Moyenne G20 & 24 & $\mathrm{~m}$ & m & 55 & m & m & 17 & m & $\mathrm{m}$ & 2 & $\mathrm{~m}$ & $\mathrm{~m}$ & 66 & $\mathrm{~m}$ & m \\
\hline
\end{tabular}

1. Tertiaire de cycle court : les données se rapportent uniquement à la Communauté flamande de Belgique.

Source : OCDE (2019). Consulter la section « Source » pour tout complément d'information et l'annexe 3 pour les notes (https://doi.org/10.1787/f8d7880d-en). Les symboles représentant les données manquantes et les abréviations figurent dans le Guide du lecteur. 



\section{Indicateur B5. Combien d'étudiants terminent-ils leurs études tertiaires?}

\section{Faits marquants}

- Selon la moyenne calculée sur la base des pays dont les données portent sur des cohortes effectives (d'étudiants), $39 \%$ des étudiants scolarisés à temps plein qui entament une licence réussissent celle-ci sans en dépasser la durée théorique. Le taux de réussite trois ans plus tard augmente pour atteindre $67 \%$.

- En moyenne, le taux de réussite (trois ans après la durée théorique de la formation) des étudiants est plus élevé s'ils étaient inscrits en filière générale $(70 \%)$ plutôt qu'en filière professionnelle $(58 \%)$ dans le deuxième cycle de l'enseignement secondaire.

- En moyenne, $12 \%$ des étudiants abandonnent la licence qu'ils ont entamée avant le début de leur deuxième année d'études. Ce pourcentage augmente pour atteindre $20 \%$ à la fin de la durée théorique de la formation et $24 \%$ trois ans plus tard.

Graphique B5.1. Taux de réussite des étudiants scolarisés à plein temps ayant entamé un programme de licence ou de niveau équivalent (2017)

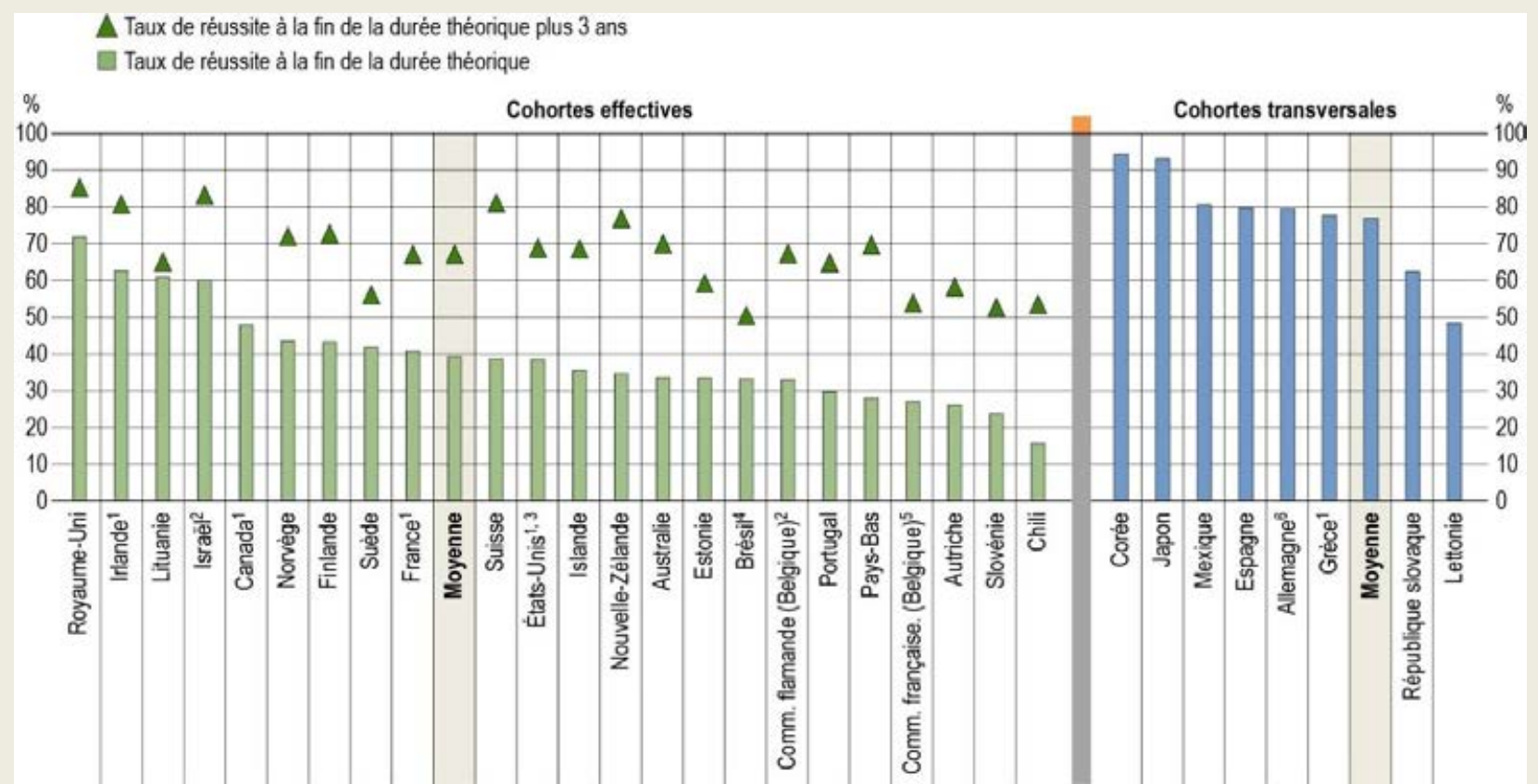

Remarque : Pour les pays disposant de données sur les cohortes effectives, le taux de réussite inclut les étudiants ayant effectué un transfert et obtenu un diplôme d'un autre niveau de l'enseignement tertiaire.

1. L'année de référence n'est pas 2017. Consulter le tableau source pour de plus amples informations.

2. Le taux de réussite des étudiants ayant entamé un programme de licence n'inclut pas ceux ayant effectué un transfert et obtenu un diplôme d'un programme tertiaire de cycle court.

3. La durée théorique plus 3 ans correspond à la durée théorique plus 2 ans.

4. Les données ne comprennent pas les étudiants ayant entamé une licence d'une durée de 6 ans, ce qui correspond à environ $2 \%$ de l'ensemble des étudiants ayant entamé un programme de ce niveau.

5. Les données se rapportent uniquement aux hautes écoles (HE) et aux écoles des arts (ESA), soit environ $60 \%$ des inscrits dans des programmes de licence ou de niveau équivalent.

6. Les données correspondent à des taux de réussite estimés sur la base d'une relation modélisée entre les futurs diplômés et les étudiants encore inscrits.

Les pays et économies sont classés par ordre décroissant du taux de réussite à la fin de la durée théorique (cohortes effectives) ou sur la base de cohortes transversales.

Source: OCDE (2019), tableau B5.1. Consulter la section "Source» pour tout complément d'information et l'annexe 3 pour les notes (https://doi.org/10.1787/f8d7880d-en). 


\section{Contexte}

Les taux de réussite dans l'enseignement tertiaire sont révélateurs de l'efficience des systèmes d'enseignement tertiaire puisqu'ils indiquent le pourcentage d'étudiants qui mènent à bien la formation tertiaire qu'ils ont entamée. Des taux peu élevés de réussite n'impliquent toutefois pas nécessairement que les systèmes concernés ne sont pas adéquats, dans la mesure où les étudiants peuvent interrompre leurs études pour diverses raisons. Des étudiants peuvent par exemple se rendre compte qu'ils ont choisi une matière ou une formation qui ne leur convenait pas ou trouver un emploi intéressant avant d'arriver au terme de leurs études. Dans certains systèmes d'éducation, il est également courant que des étudiants entament une formation non dans l'intention d'en être diplômé, mais dans l'intention de suivre une partie seulement des cours dans le cadre de leur apprentissage tout au long de la vie ou du développement de leurs compétences.

Plusieurs facteurs différents influent sur les taux de réussite, notamment le parcours scolaire antérieur des étudiants et leurs caractéristiques sociales et économiques. Cet indicateur analyse le taux de réussite dans l'enseignement tertiaire selon le sexe des étudiants et leur filière (générale ou professionnelle) dans le deuxième cycle de l'enseignement secondaire. Il analyse également la mesure dans laquelle le fait d'être issu de l'immigration et le niveau de formation des parents peuvent influer sur la probabilité des étudiants de réussir leurs études tertiaires (voir l'encadré B5.2).

La réussite d'une formation peut se définir de façons différentes selon les pays. Cet indicateur se concentre sur les étudiants scolarisés à temps plein et sur leur réussite à deux échéances différentes : 1) le pourcentage d'étudiants qui réussissent leurs études tertiaires à la fin de la durée théorique de leurs études ; et 2) le pourcentage d'étudiants qui réussissent leurs études dans les trois ans suivant la fin de la durée théorique de leurs études. La différence entre ces deux échéances peut indiquer dans quelle mesure les étudiants parviennent ou non à réussir leurs études " dans les temps » (dans le délai imparti en fonction de la durée théorique de leur formation). Cet indicateur analyse également le pourcentage d'étudiants qui changent de niveau d'enseignement tertiaire et le pourcentage d'étudiants qui arrêtent leurs études avant d'être diplômés.

\section{Autres faits marquants}

- Dans tous les pays dont les données sont disponibles, le taux de réussite est plus élevé chez les femmes que chez les hommes en licence. Le taux de réussite à la fin de la durée théorique des études varie de plus de 27 points de pourcentage entre les sexes en Finlande.

- Selon la moyenne calculée sur la base des pays et économies dont les données sont disponibles, $45 \%$ des étudiants en formation tertiaire de cycle court ont été diplômés de l'enseignement tertiaire à la fin de la durée théorique de leur formation.

- Dans certains pays, il est fréquent que les étudiants changent de niveau d'enseignement tertiaire pendant leur formation. En France, $13 \%$ des étudiants ayant entamé une licence sont passés à une formation de cycle court ou à un master (première formation de type long) avant le début de leur deuxième année d'études.

\section{Remarque}

Le taux de réussite, le taux d'obtention d'un diplôme et le niveau de formation sont trois indicateurs différents. Les taux de réussite indiquent le pourcentage d'étudiants qui sont diplômés de la formation qu'ils ont entamée après un nombre donné d'années. Les taux d'obtention d'un diplôme sont des estimations du pourcentage d'individus d'une cohorte d'âge donnée susceptibles d'obtenir un diplôme à un certain moment de leur vie. Ils indiquent le nombre de diplômés d'un niveau d'enseignement par rapport à la population des pays (Base de données de Regards sur l'éducation). Quant au troisième indicateur, le niveau de formation, il indique le pourcentage de diplômés d'un niveau d'enseignement donné dans la population (voir l'indicateur A1). Il est le rapport entre l'effectif total de diplômés (durant l'année de référence et les années précédentes) et l'ensemble de la population.

Cet indicateur porte uniquement sur les étudiants scolarisés à temps plein. En moyenne, dans les pays de l'OCDE, le pourcentage d'étudiants scolarisés à temps partiel est de l'ordre de $26 \%$ en formation tertiaire de cycle court environ et de $16 \%$ en licence. L'indicateur B1 fournit davantage d'informations sur le pourcentage d'étudiants scolarisés à temps partiel à chaque niveau de l'enseignement tertiaire.

La durée théorique des formations tertiaires varie parfois entre les pays. II s'ensuit que l'année de référence d'obtention d'un diplôme (2017, sauf mention contraire) est la même, mais que l'année de référence du début des études varie selon la durée des formations. 


\section{Analyse}

\section{Taux de réussite par niveau d'enseignement}

Dans cet indicateur, les taux de réussite sont calculés selon deux méthodes différentes en fonction des données dont disposent les pays : la première méthode est celle dite de la cohorte effective, et la seconde, celle dite de la cohorte transversale. Les résultats obtenus par ces deux méthodes sont analysés séparément, car ils ne sont pas comparables (voir l'encadré B5.1).

\section{Taux de réussite basés sur les cohortes effectives}

En moyenne, dans les pays et économies dont les données portent sur les cohortes effectives, $39 \%$ des étudiants qui entament une licence en sont diplômés à la fin de sa durée théorique. Ce pourcentage inclut tous les étudiants diplômés de l'enseignement tertiaire, même à un niveau différent. Le taux moyen de réussite augmente trois ans après la fin de la durée théorique des études et atteint $67 \%$ (voir le tableau B5.1).

Les taux de réussite à la fin de la durée théorique des études varient fortement entre les pays et économies : ils sont inférieurs à $30 \%$ en Autriche, au Chili, en Communauté française de Belgique, aux Pays-Bas et en Slovénie, mais égaux ou supérieurs à $60 \%$ en Irlande, en Israël, en Lituanie et au Royaume-Uni (voir le graphique B5.1). Les taux de réussite trois ans plus tard augmentent dans tous les pays et économies, mais ils tendent à augmenter davantage si les taux de réussite à la fin de la durée théorique des études sont inférieurs. C'est pourquoi les taux de réussite trois ans plus tard varient moins entre les pays et économies : ils sont compris entre $50 \%$ au Brésil et $85 \%$ au Royaume-Uni. Les taux de réussite trois ans plus tard augmentent en particulier de plus de 40 points de pourcentage en Nouvelle-Zélande, aux Pays-Bas et en Suisse.

Divers facteurs institutionnels et des caractéristiques nationales peuvent expliquer la variation des taux de réussite trois ans plus tard entre les pays. Dans certains pays, il est par exemple courant que les étudiants suivent des cours de soutien ou des cours préparatoires qui ne font nécessairement pas partie du programme officiel (Scrivener et al., 2018[1]). Dans certains pays, comme aux États-Unis, les cours de soutien sont comptabilisés comme des années d'études dans l'enseignement tertiaire. Dans d'autres pays, comme en Norvège, on considère que les étudiants commencent leurs études tertiaires après en avoir terminé avec les cours de soutien, ce qui n'affecte donc pas le taux de réussite.

Le fait que les taux de réussite varient sensiblement entre les périodes de référence plus courte et plus longue n'est toutefois pas nécessairement négatif. En Communauté flamande de Belgique par exemple, les formations supérieures sont très flexibles et ne sont pas scindées en années d'études. Les étudiants doivent obtenir un certain nombre de crédits pour être diplômés, mais leurs années d'études, même s'ils les suivent à temps plein, ne sont pas nécessairement consécutives. Ce type de système flexible tend à réduire le taux de réussite à la fin de la durée théorique des formations, mais il peut présenter de nombreux avantages pour les étudiants. Dans les pays où l'enseignement tertiaire est largement accessible, comme en Communauté flamande de Belgique, la flexibilité peut être particulièrement importante, car les étudiants disposent de plus de temps pour atteindre les normes fixées par leur établissement d'enseignement.

Dix pays seulement disposent de données sur les formations tertiaires de cycle court. Les taux de réussite de ces formations varient fortement, comme ceux de licence. Aux États-Unis, quelque $9 \%$ seulement des étudiants qui entament une formation de type court sont diplômés d'un niveau de l'enseignement tertiaire dans les deux ans, la durée théorique de ces formations. En Autriche, près de $70 \%$ des étudiants sont diplômés dans les deux ans. Trois ans après la durée théorique des études, les taux de réussite augmentent dans tous les pays, en particulier dans ceux où les taux sont moins élevés à la fin de la durée théorique. Le taux de réussite passe du simple au double au Chili (de $23 \%$ à $46 \%$ ) et à plus du triple aux États-Unis (de $9 \%$ à $31 \%$ ).

Les taux de réussite sont plus élevés en formation tertiaire de cycle court qu'en licence dans la moitié environ des pays dont les données sont disponibles. C'est en Autriche que la différence entre les deux niveaux 
d'enseignement est la plus importante : le taux de réussite (à la fin de la durée théorique des études) en formation tertiaire de cycle court est supérieur de 43 points de pourcentage à celui observé en licence. Pour replacer ces différences dans leur contexte, il est important d'examiner le pourcentage d'étudiants à chaque niveau de l'enseignement tertiaire. L'Autriche est par exemple le seul pays de l'OCDE où le nombre de nouveaux inscrits dans l'enseignement tertiaire est plus élevé en formation de type court qu'en licence (voir l'indicateur B4).

Sept pays seulement disposent de données sur les masters (première formation de type long) et dans chacun d'entre eux, les taux de réussite sont plus élevés en master qu'en licence. Le taux de réussite à la fin de la durée théorique des études varie entre $32 \%$ au Chili et $53 \%$ en Norvège et en Suisse. Le taux de réussite trois ans après la fin de la durée théorique des études augmente sensiblement dans tous les pays ; il est compris entre $65 \%$ en Autriche et en Slovénie et $89 \%$ en Norvège.

Ces dernières années, de nombreux pays ont adopté diverses politiques visant à accroître les taux de réussite dans l'enseignement tertiaire. L'une des approches souvent retenue consiste à subordonner dans une certaine mesure le financement des établissements aux taux de réussite des étudiants. C'est le cas en Autriche, au Brésil, en Estonie, en Finlande et en Israël. Dans d'autres pays, les taux de réussite sont pris en considération dans les aides financières directement versées aux étudiants. Au Chili, les frais de scolarité sont nuls uniquement pendant la durée théorique des études. En Norvège, les prêts d'études peuvent en partie être convertis en bourse si les étudiants ne prennent pas de retard dans leurs études. Dans certains pays, au Brésil par exemple, les établissements reçoivent un budget spécifiquement destiné à aider les étudiants issus de milieux défavorisés à obtenir leur diplôme sans retard excessif. D'autres politiques consistent à faire en sorte que les étudiants choisissent mieux leurs études et que les enseignants disposent des outils requis pour aider les étudiants à réussir.

\section{Taux de réussite basés sur les cohortes transversales}

Les taux de réussite basés sur les cohortes transversales sont calculés compte tenu de tous les étudiants diplômés durant l'année académique de référence, quel que soit le nombre d'années d'études. Les taux de réussite tendent donc à être sensiblement plus élevés s'ils sont calculés sur la base des cohortes transversales plutôt que sur la base des cohortes effectives (voir l'encadré B5.1 pour de plus amples informations sur la comparaison des deux méthodes de calcul).

Selon la moyenne calculée sur la base des sept pays qui ont fourni des données sur les cohortes transversales, $77 \%$ des étudiants qui entament une licence en sont diplômés. Ce pourcentage s'établit à 48 \% en Lettonie, mais est supérieur à $90 \%$ en Corée et au Japon. En formation tertiaire de cycle court, les taux de réussite sont compris entre $55 \%$ en République slovaque et $89 \%$ au Japon. La différence de taux de réussite en formation tertiaire de cycle court et en licence varie entre les pays. Au Mexique, le taux de réussite en formation tertiaire de cycle court est inférieur de plus de 20 points de pourcentage à celui enregistré en licence. L'inverse s'observe en Lettonie, où taux de réussite en formation tertiaire de cycle court est supérieur de 13 points de pourcentage à celui enregistré en licence.

\section{Taux de réussite selon le sexe}

Dans tous les pays dont les données sont disponibles (sur les cohortes effectives et transversales), les taux de réussite sont plus élevés chez les femmes que chez les hommes en licence (voir le tableau B5.1). En moyenne, dans les pays et économies dont les données sur les cohortes effectives sont disponibles, le pourcentage de nouveaux inscrits diplômés à la fin de la durée théorique de leurs études s'établit à $44 \%$ chez les femmes et à $33 \%$ chez les hommes en licence. L'écart moyen est similaire trois ans après la fin de la durée théorique des études : le pourcentage de nouveaux inscrits diplômés pendant cette période augmente et atteint $72 \%$ chez les femmes et $61 \%$ chez les hommes. 


\section{Encadré B5.1. Différence entre les taux de réussite basés sur les cohortes effectives et les taux de réussite basés sur les cohortes transversales}

Dans cet indicateur, les taux de réussite sont calculés selon deux méthodes différentes : l'une basée sur les cohortes effectives et l'autre, sur les cohortes transversales. La méthode basée sur les cohortes effectives consiste à suivre une cohorte de nouveaux inscrits à deux moments spécifiques, en l'espèce à la fin de la durée théorique des études, puis trois ans après. Cette méthode est préférable pour analyser les taux de réussite, mais seuls les pays administrant des enquêtes longitudinales ou tenant des registres longitudinaux peuvent fournir ces données. Les données de panel peuvent être extraites d'un registre d'étudiants (où les étudiants sont répertoriés individuellement) ou des résultats d'une enquête longitudinale auprès d'une cohorte d'étudiants. Le taux de réussite calculé sur la base d'une cohorte effective correspond au pourcentage d'étudiants de cette cohorte diplômés à l'issue de l'une des deux périodes de référence.

\section{Tableau B5.a. Différence de taux de réussite des étudiants ayant entamé un programme de licence ou de niveau équivalent, selon que le calcul se base sur les cohortes effectives ou transversales (2017)}

\begin{tabular}{l|c|c|c|}
\hline & \multicolumn{3}{|c|}{ Cohortes effectives } \\
\cline { 2 - 4 } & Á la fin de la durée théorique & $\begin{array}{c}\text { Á la fin de la durée théorique } \\
\text { plus 3 ans }\end{array}$ & $\begin{array}{c}\text { Cohortes transversales } \\
\text { (en fonction de la durée théorique) }\end{array}$ \\
\hline Comm. flamande (Belgique) & 33 & 67 & 82 \\
\hline Comm. française (Belgique) & 27 & 54 & 64 \\
\hline Finlande & 43 & 73 & 93 \\
\hline Israël & 60 & 83 & 92 \\
\hline
\end{tabular}

1. Les données se rapportent uniquement aux hautes écoles (HE) et aux écoles des arts (ESA), soit environ $60 \%$ des inscrits dans des programmes de licence ou de niveau équivalent.

Source: OCDE (2019). Consulter la section "Source» pour tout complément d'information et l'annexe 3 pour les notes (https://doi.org/10.1787/f8d7880d-en).

Les taux de réussite sont calculés selon la méthode basée sur les cohortes transversales dans les pays dont les données sur les cohortes effectives ne sont pas disponibles. Avec cette méthode, il suffit de disposer du nombre de nouveaux inscrits dans un niveau donné de la CITE et du nombre de diplômés de ce niveau $n$ années plus tard (où $n$ correspond à la durée théorique de la formation visée). Dans l'hypothèse de flux constants (une augmentation ou une diminution constante de l'effectif de nouveaux inscrits dans un niveau d'enseignement donné pendant la durée théorique de la formation), les taux de réussite dérivés des cohortes transversales sont plus proches des taux de réussite dérivés des cohortes effectives analysées pendant des périodes plus longues. Cela s'explique par le fait que les taux de réussite basés sur les cohortes transversales sont calculés compte tenu de tous les étudiants diplômés durant l'année académique de référence, quel que soit leur nombre d'années d'études.

Il convient de ne pas comparer les taux entre les deux méthodes. Le tableau B5.a montre la différence de taux de réussite entre les deux méthodes dans les quelques pays qui ont fourni des données sur les cohortes effectives et transversales. En toute logique, le taux de réussite dérivé des cohortes transversales est nettement supérieur à celui dérivé des cohortes effectives, même compte tenu des taux trois ans après la durée théorique des études. 
La différence entre les sexes est plus ténue dans certains pays que dans d'autres. En licence, les taux de réussite à la fin de la durée théorique des études varient de moins de 7 points de pourcentage au Royaume-Uni et en Suisse, mais de 27 points de pourcentage en Finlande entre les femmes et les hommes. Dans la plupart des pays, la différence entre les sexes ne change pas sensiblement trois ans après la fin de la durée théorique des études. Elle ne varie de plus de 10 points de pourcentage qu'en Finlande, où elle diminue pour atteindre 16 points de pourcentage.

\section{Taux de réussite selon la filière dans le deuxième cycle de l'enseignement secondaire}

La filière dans le deuxième cycle de l'enseignement secondaire est un autre facteur qui peut influer sur les taux de réussite des étudiants dans l'enseignement tertiaire. En moyenne, dans les pays et économies dont les données sont disponibles, $38 \%$ des étudiants en licence qui étaient en filière générale dans le deuxième cycle de l'enseignement secondaire sont diplômés à la fin de la durée théorique de leur formation. II en va de même pour $35 \%$ des étudiants qui étaient en filière professionnelle dans le deuxième cycle de l'enseignement secondaire. Cette différence de 3 points de pourcentage augmente pour atteindre 12 points de pourcentage trois ans après la fin de la durée théorique des études.

Les taux de réussite à la fin de la durée théorique des études varient fortement entre les pays : ils sont plus élevés chez les diplômés de la filière générale que chez les diplômés de la filière professionnelle dans exactement la moitié des pays dont les données sont disponibles. Toutefois, les tendances sont plus claires si l'analyse porte sur les taux de réussite trois ans après. Trois ans après en effet, le taux de réussite des diplômés du deuxième cycle de l'enseignement secondaire en filière générale est soit supérieur, soit très proche de celui des diplômés en filière professionnelle dans la quasi-totalité des pays. En fait, les diplômés en filière professionnelle dans le deuxième cycle de l'enseignement secondaire ne sont plus susceptibles que ceux en filière générale de réussir leur licence que dans un seul pays, l'Autriche (voir le graphique B5.2).

Pour comprendre le contexte dans lequel ces résultats s'inscrivent, il est important d'évaluer la représentativité de ces étudiants parmi les nouveaux inscrits en licence (voir le tableau B5.2). En Lituanie par exemple, $53 \%$ des diplômés en filière professionnelle dans le deuxième cycle de l'enseignement secondaire réussissent leur licence à la fin de la durée théorique de celle-ci, mais ils représentent moins de $1 \%$ des inscrits à ce niveau d'enseignement. Dans la quasi-totalité des pays dont les données sont disponibles, le pourcentage d'inscrits en licence est plus élevé chez les diplômés de la filière générale que chez les diplômés en filière professionnelle dans le deuxième cycle de l'enseignement secondaire. En moyenne, dans les pays et économies dont les données sont disponibles, $28 \%$ des inscrits en licence étaient en filière professionnelle. Ce pourcentage est inférieur à $15 \%$ en Estonie, en Lituanie et en Norvège, mais atteint 51 \% en Autriche, le seul pays où les diplômés de la filière professionnelle sont majoritaires parmi les inscrits en licence.

Il est important de préciser que dans de nombreux pays, en Belgique et en Estonie par exemple, certaines formations en filière professionnelle dans le deuxième cycle de l'enseignement secondaire ne donnent pas accès à la licence. Selon l'effectif de ces formations, cela pourrait expliquer le pourcentage inférieur de diplômés de la filière professionnelle inscrits en licence.

Par comparaison avec la licence, les diplômés de la filière professionnelle dans le deuxième cycle de l'enseignement secondaire représentent un pourcentage plus élevé des inscrits en formation tertiaire de cycle court, mais un pourcentage nettement moins élevé des inscrits en master (première formation de type long) dans les quelques pays dont les données sont disponibles au sujet de ces niveaux d'enseignement (voir le tableau B5.2, panneaux B et C). Au Chili et en Norvège, les diplômés de la filière professionnelle dans le deuxième cycle de l'enseignement secondaire affichent en formation tertiaire de cycle court des taux de réussite supérieurs à ceux des diplômés de la filière générale. II est vrai que dans certains pays, il est courant que les formations tertiaires de cycle court s'adressent spécifiquement aux diplômés de la filière professionnelle dans le deuxième cycle de l'enseignement secondaire. 
Graphique B5.2. Taux de réussite des étudiants scolarisés à plein temps ayant entamé un programme de licence ou de niveau équivalent, selon la filière suivie dans le deuxième cycle du secondaire (2017)

Cohorte effective uniquement

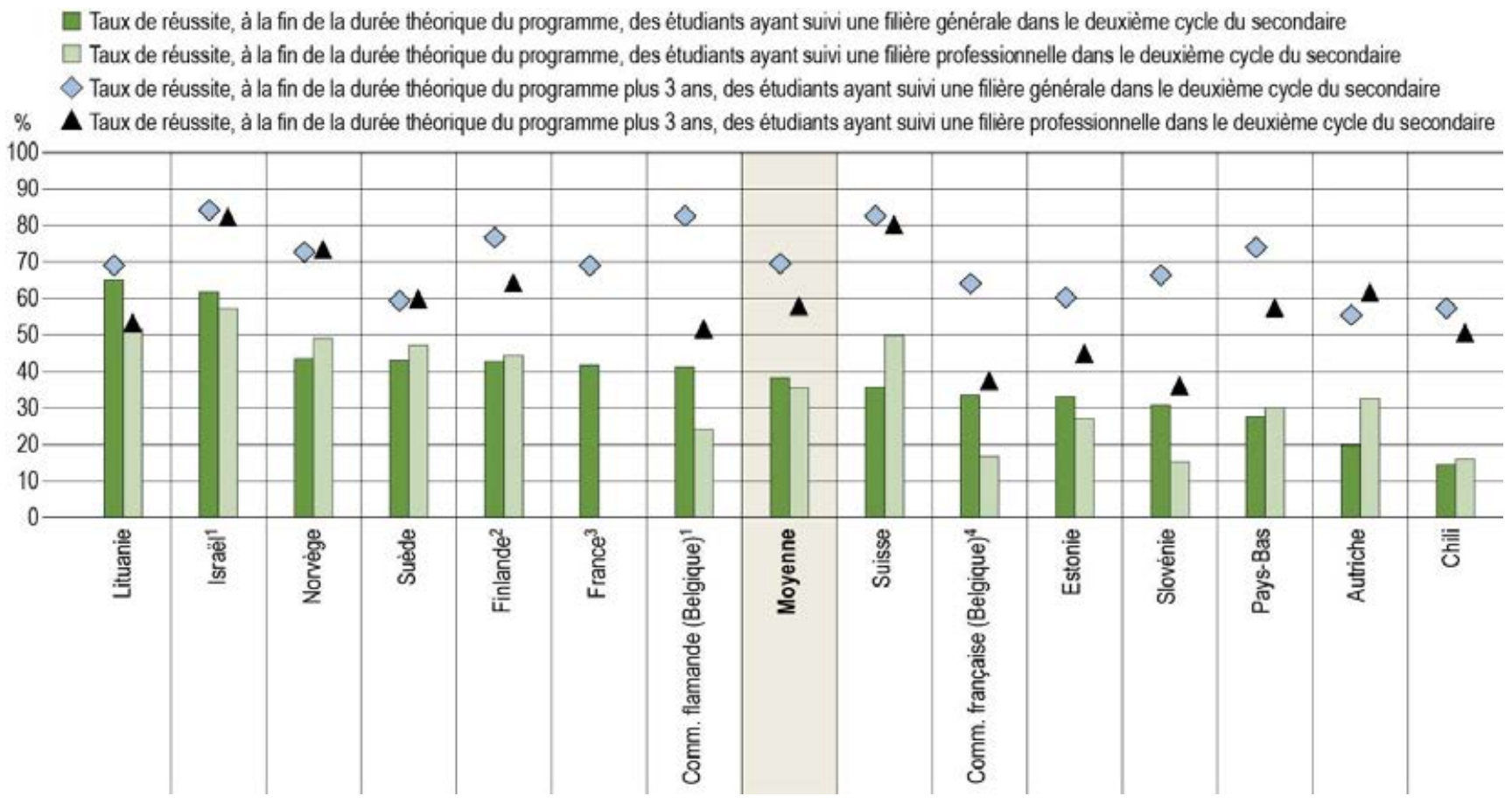

1. Le taux de réussite des étudiants ayant entamé un programme de licence n'inclut pas ceux ayant effectué un transfert et obtenu un diplôme d'un programme tertiaire de cycle court.

2. Si l'étudiant a réussi à la fois un programme de la filière générale et de la filière professionnelle du deuxième cycle du secondaire, ou si les données sur son parcours antérieur d'éducation sont manquantes, il est comptabilisé dans la catégorie « Filière professionnelle du deuxième cycle du secondaire ".

3. L'année de référence n'est pas 2017. Consulter le tableau source pour de plus amples informations. Les données sur les étudiants ayant suivi une filière professionnelle dans le deuxième cycle du secondaire ont été retirées en raison de la taille trop faible de l'échantillon.

4. Les données se rapportent uniquement aux hautes écoles (HE) et aux écoles des arts (ESA), soit environ $60 \%$ des inscrits dans des programmes de licence ou de niveau équivalent.

Les pays et économies sont classés par ordre décroissant du taux de réussite, à la fin de la durée théorique du programme, des étudiants ayant suivi une filière générale dans le deuxième cycle du secondaire.

Source: OCDE (2019), tableau B5.2. Consulter la section «Source» pour tout complément d'information et l'annexe 3 pour les notes (https://doi.org/10.1787/f8d7880d-en).

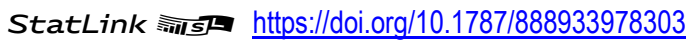

\section{Diversité des parcours dans l'enseignement tertiaire}

Outre les taux de réussite, il est important d'analyser la diversité des parcours des étudiants dans l'enseignement tertiaire. Cette analyse aide en effet à comprendre la flexibilité et l'efficacité des systèmes d'éducation. Elle permet aussi de comprendre ce qu'il advient des autres étudiants, ceux qui n'ont pas décroché de diplôme. Sontils toujours scolarisés ? Ont-ils changé de niveau dans l'enseignement tertiaire ? Ou ont-ils arrêté leurs études avant terme? 


\section{Où en sont les étudiants un an après leur inscription ?}

La situation des étudiants un an après leur inscription peut être très utile pour comprendre ce qui se passe durant leur découverte de l'enseignement tertiaire. Elle peut par exemple être révélatrice de l'efficacité de l'orientation des étudiants ou de la qualité de leur préparation à l'enseignement tertiaire. En moyenne, dans les pays et économies dont les données sont disponibles, $12 \%$ environ des étudiants inscrits en licence ne suivent plus d'études tertiaires la deuxième année, plus de $2 \%$ ont changé de niveau dans l'enseignement tertiaire et $85 \%$ poursuivent leur licence ou en choisissent une autre (voir le tableau B5.3).

Dans certains pays, des étudiants entament des études à un niveau de l'enseignement tertiaire, mais optent pour une formation d'un autre niveau qu'ils réussissent. En fait, un pourcentage élevé des étudiants qui changent de niveau dans l'enseignement tertiaire le font très rapidement après leur inscription. En France, $11 \%$ des étudiants qui ont entamé une licence optent pour une formation de cycle court dès la deuxième année. Ce pourcentage passe la barre des $3 \%$ au Chili et en Slovénie (voir le tableau B5.3).

Graphique B5 3. Pourcentage d'étudiants ayant entamé un programme de licence à plein temps qui ne sont plus scolarisés dans l'enseignement tertiaire (et n'ont pas obtenu leur diplôme) à différents délais après leur inscription (2017)

Cohorte effective uniquement

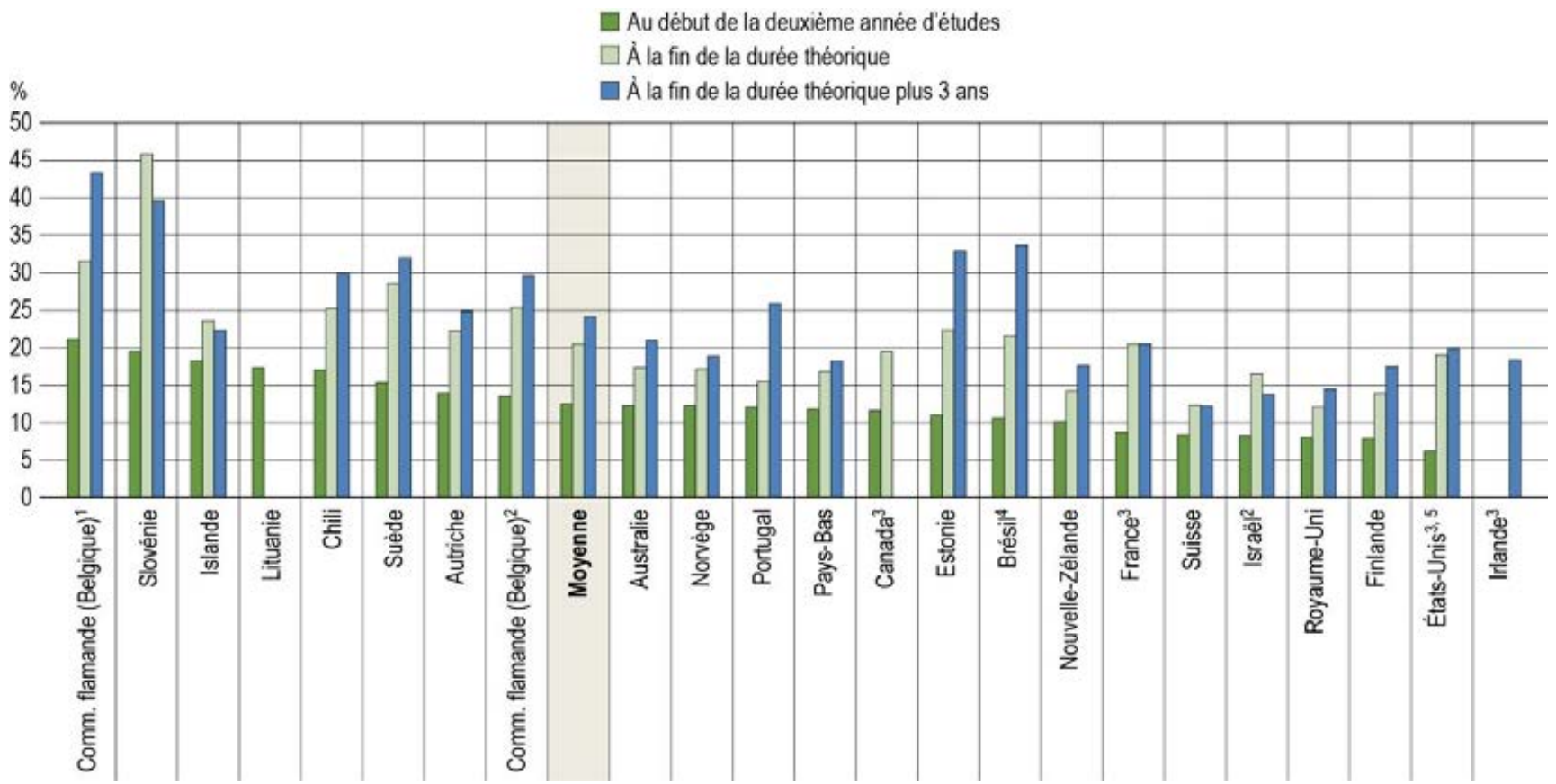

Remarque : Le pourcentage d'étudiants « non diplômés et plus scolarisés dans l'enseignement tertiaire » peut inclure des étudiants ayant quitté le pays avant l'obtention de leur diplôme.

1. Les données se rapportent uniquement aux hautes écoles (HE) et aux écoles des arts (ESA), soit environ $60 \%$ des inscrits dans des programmes de licence ou de niveau équivalent.

2. Inclut les étudiants ayant effectué un transfert vers un programme tertiaire de cycle court.

3. L'année de référence n'est pas 2017. Consulter le tableau source pour de plus amples informations.

4. Les données ne comprennent pas les étudiants ayant entamé une licence d'une durée de 6 ans, ce qui correspond à environ $2 \%$ de l'ensemble des étudiants ayant entamé un programme de ce niveau.

5. La durée théorique plus 3 ans correspond à la durée théorique plus 2 ans.

Les pays et économies sont classés par ordre décroissant du pourcentage d'étudiants qui ne sont plus scolarisés au début de la deuxième année d'études. Source: OCDE (2019), tableau B5.3. Consulter la section «Source » pour tout complément d'information et l'annexe 3 pour les notes (https://doi.org/10.1787/f8d7880d-en). 
Le pourcentage d'étudiants qui ne sont plus scolarisés un an après leur inscription est égal à $6 \%$ aux États-Unis, mais atteint au moins $20 \%$ en Communauté française de Belgique et en Slovénie. Le fait que de nombreux étudiants arrêtent leur formation un an seulement après leur inscription est très préoccupant sachant que ce nombre tend à augmenter avec le temps. En fait, leur pourcentage passe presque du simple au double - voire au triple dans certains cas - trois ans après la fin théorique de leur formation dans la plupart des pays et économies dont les données sont disponibles (voir le graphique B5.3).

\section{Où en sont les étudiants à la fin de la durée théorique de leurs études ? Et trois ans plus tard?}

Les deux échéances retenues dans cet indicateur pour évaluer la situation des étudiants sont : 1) à la fin de la durée théorique de la formation qu'ils ont entamée ; et 2) trois ans après la fin de la durée théorique de cette formation.

En moyenne, dans les pays et économies dont les données sont disponibles, $39 \%$ des étudiants inscrits en licence sont diplômés de cette formation ou d'une autre formation à la fin de la durée théorique de leurs études. Environ $1 \%$ d'entre eux ont changé de voie et sont diplômés d'une formation tertiaire de cycle court, $41 \%$ sont toujours scolarisés dans l'enseignement tertiaire (parfois à un niveau différent) et $20 \%$ ne sont plus scolarisés dans l'enseignement tertiaire. La situation change sensiblement trois ans après la fin de la durée théorique des études : bon nombre des étudiants toujours scolarisés décrochent leur diplôme ou arrêtent leurs études. À ce moment-là, on constate qu'en moyenne, 64 \% des étudiants sont diplômés à l'issue d'une licence, $2 \%$, à l'issue d'une formation tertiaire de cycle court et $1 \%$, à l'issue d'un master (première formation de type long). Quelque $9 \%$ des étudiants sont toujours scolarisés et $24 \%$ ont arrêté leurs études (voir le graphique B5.4).

Le pourcentage élevé d'étudiants qui optent pour un autre niveau d'enseignement explique en partie le fait que certains d'entre eux décrochent leur diplôme plus tard. Ces retards sont susceptibles de se produire lorsqu'il est difficile de transférer des crédits ou que les étudiants optent pour une formation dont la durée théorique est plus longue (la situation des étudiants est systématiquement évaluée compte tenu de la durée théorique de la formation qu'ils ont choisie initialement). Le pourcentage d'étudiants de licence qui changent de formation est le plus élevé en France, où $8 \%$ environ d'entre eux sont diplômés d'une formation tertiaire de cycle court, et en Slovénie, où $2 \%$ environ d'entre eux sont diplômés d'une formation tertiaire de cycle court et $6 \%$, d'un master (première formation de type long) (trois ans après la fin de la durée théorique de leur formation initiale).

Dans l'ensemble, le parcours des étudiants entre la fin de la durée théorique de leur formation et trois ans après varie entre les pays. Le taux de réussite augmente de plus de 40 points de pourcentage en Nouvelle-Zélande, aux Pays-Bas et en Suisse, mais de 4 points de pourcentage seulement en Lituanie. La situation des étudiants encore scolarisés à la fin de la durée théorique de leur formation varie également fortement. Dans certains pays, comme en Israël et en Slovénie, plus de 90 \% d'entre eux décrochent leur diplôme dans les trois ans qui suivent. Dans d'autres pays et économies, comme au Brésil, en Communauté française de Belgique et en Estonie, $20 \%$ au moins des étudiants encore scolarisés à la fin de la durée théorique de leur formation arrêtent leurs études dans les trois ans qui suivent sans être diplômés.

Le fait d'être diplômé tardivement, voire de ne pas l'être, peut être coûteux pour les gouvernements et les individus. Le coût de l'enseignement tertiaire est élevé, et les étudiants et les pouvoirs publics ne rentabilisent pas pleinement leur investissement tant que les études ne sont pas terminées avec succès. II ressort des données que les diplômés de l'enseignement tertiaire tendent à afficher une rémunération et un taux d'emploi supérieurs, ce qui se traduit par des recettes fiscales et des cotisations sociales plus élevées pour les pouvoirs publics (voir l'indicateur A5). Toutefois, le fait d'être diplômé plus tard que prévu ou d'abandonner ses études n'est pas nécessairement un échec pour les individus ou les systèmes d'éducation. Dans certains pays, la réussite partielle de formations tertiaires est reconnue, officiellement ou non, ce qui peut encourager des étudiants à travailler à temps partiel (au risque de reporter l'obtention de leur diplôme) ou à abandonner leurs études pour travailler à temps plein. En Suède par exemple, la forte demande de profils spécialisés, notamment en ingénierie, incite de nombreux étudiants à commencer à travailler avant d'être diplômés. 
Graphique B5.4. Situation des étudiants de licence scolarisés à plein temps, à la fin de la durée théorique du programme et à la fin de cette durée théorique plus 3 ans (2017)

Cohorte effective uniquement
Diplômés d'un programme de lenseignement tertiaire
$\square$ Encore scolarisés dans l'enseignement tertiaire
Non diplômés et plus scolarisés dans l'enseignement tertiaire
- Non diplômés (aucune ventilation)
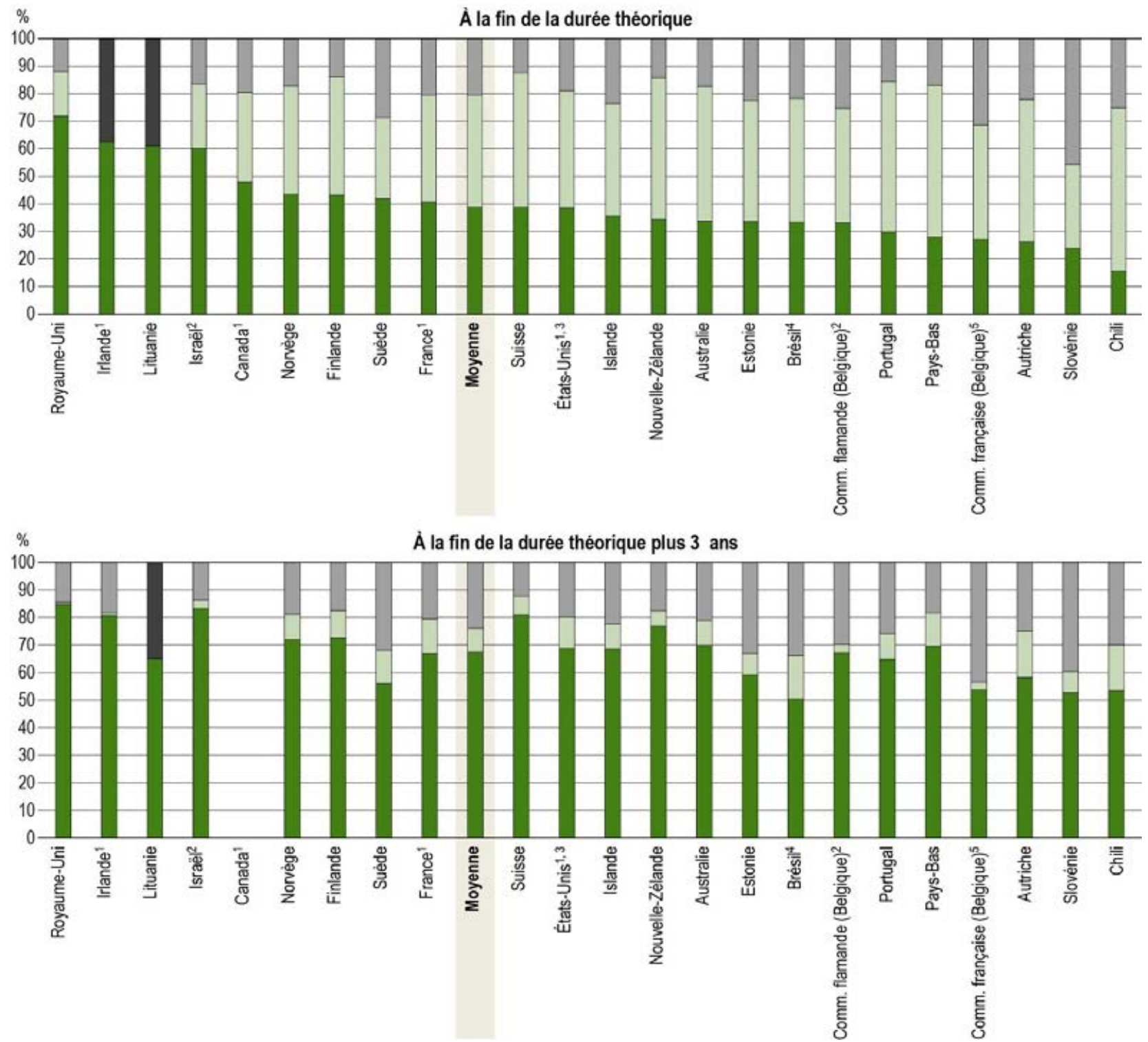

Remarque : Le pourcentage d'étudiants « non diplômés et plus scolarisés dans l'enseignement tertiaire » peut inclure des étudiants ayant quitté le pays avant l'obtention de leur diplôme.

1. L'année de référence n'est pas 2017. Consulter le tableau source pour de plus amples informations.

2. Le pourcentage d'étudiants ayant obtenu un diplôme n'inclut pas ceux ayant effectué un transfert et obtenu un diplôme d'un programme tertiaire de cycle court.

3. La durée théorique plus 3 ans correspond à la durée théorique plus 2 ans.

4. Les données ne comprennent pas les étudiants ayant entamé une licence d'une durée de 6 ans, ce qui correspond à environ $2 \%$ de l'ensemble des étudiants ayant entamé un programme de ce niveau.

5. Les données se rapportent uniquement aux hautes écoles (HE) et aux écoles des arts (ESA), soit environ $60 \%$ des inscrits dans des programmes de licence ou de niveau équivalent.

Les pays et économies sont classés par ordre décroissant du pourcentage d'étudiants ayant obtenu un diplôme à la fin de la théorique du programme. Source : OCDE (2019), tableau B5.3. Consulter la section «Source» pour tout complément d'information et l'annexe 3 pour les notes (https://doi.org/10.1787/f8d7880d-en). 


\section{Encadré B5.2. Taux de réussite des étudiants selon le niveau de formation de leurs parents et leur statut au regard de l'immigration}

Selon certaines études, le fait d'être issu d'un milieu socio-économique défavorisé a une forte incidence sur les taux de réussite dans l'enseignement tertiaire (Vossensteyn et al., 2015[2] ; Thomas et Quinn, 2006[3]). Les étudiants issus de milieux défavorisés, même très performants, courent un plus grand risque d'abandonner leurs études à cause de problèmes financiers ou familiaux ou de la pression de leurs pairs (Quinn, 2013[4]). Cet encadré montre dans quelle mesure les taux de réussite varient entre les étudiants issus de milieux défavorisés, qui sont identifiés par deux indicateurs, d'une part le niveau de formation le plus élevé de leurs deux parents et leur statut au regard de l'immigration.

\section{Graphique B5.a. Taux de réussite des étudiants scolarisés à plein temps ayant entamé un programme} de licence ou de niveau équivalent, selon le niveau de formation des parents (2017)

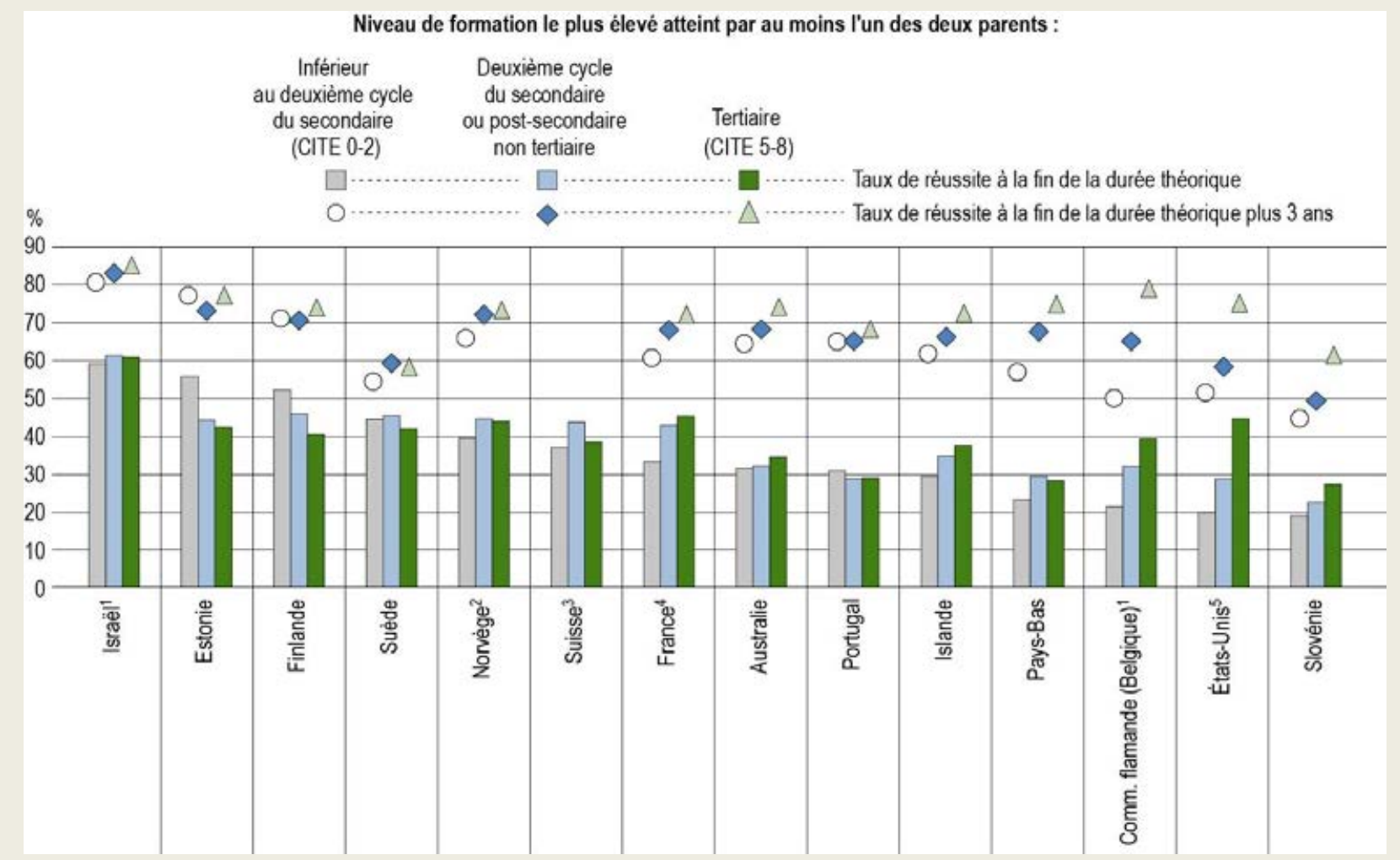

1. Le taux de réussite des étudiants ayant entamé un programme de licence n'inclut pas ceux ayant effectué un transfert et obtenu un diplôme d'un programme tertiaire de cycle court.

2. Le niveau de formation du deuxième cycle du secondaire et du post-secondaire non tertiaire inclut le tertiaire de cycle court; quant au niveau de formation tertiaire, il inclut uniquement les licences, masters et doctorats, ou niveaux équivalents.

3. Année de référence : 2018.

4. Année de référence de la cohorte d'entrée : 2008. Les années d'obtention du diplôme varient en fonction de la durée théorique des programmes.

5. Année de référence de la cohorte d'entrée : 2003. Les années d'obtention du diplôme varient en fonction de la durée théorique des programmes. La durée théorique plus 3 ans pour les programmes de licence ou de niveau équivalent correspond à la durée théorique plus 2 ans.

Les pays et économies sont classés par ordre décroissant du taux de réussite, à la fin de la durée théorique du programme, des étudiants dont les parents ne sont pas diplômés du deuxième cycle du secondaire.

Source: OCDE (2019). Consulter la section "Source» pour tout complément d'information et l'annexe 3 pour les notes (https://doi.org/10.1787/f8d7880d-en).

StatLink त्ता sम https://doi.org/10.1787/888933978360 


\section{Taux de réussite selon le niveau de formation des parents}

Les études qu'ont faites les parents sont liées aux revenus et à la richesse et sont, selon certains éléments, en forte corrélation avec une série d'aspects relatifs au parcours scolaire de leurs enfants, tels que le niveau de formation (voir l'indicateur A1), le choix de l'orientation (voir l'indicateur B3) et l'acquisition de compétences (OCDE, 2013 $[5]$ ). Le graphique B5.a indique le taux de réussite des étudiants de licence ventilé en fonction du niveau de formation le plus élevé d'un de leurs parents. Aucune tendance nette de corrélation ne se dégage du niveau de formation des parents et du taux de réussite à la fin de la durée théorique des études. II apparaît toutefois que dans la quasi-totalité des pays dont les données sont disponibles, le taux de réussite des étudiants trois ans après la fin de la durée théorique de leurs études est plus élevé si l'un de leurs deux parents au moins est diplômé de l'enseignement tertiaire que si leurs parents ne sont pas diplômés du deuxième cycle de l'enseignement secondaire.

La différence de taux entre étudiants est plus importante dans certains pays que dans d'autres. La différence de taux de réussite trois ans après la fin de la durée théorique des études entre les étudiants dont l'un des parents est diplômé de l'enseignement tertiaire et ceux dont les parents ne sont pas diplômés du deuxième cycle de l'enseignement secondaire est inférieure à 5 points de pourcentage en Estonie, en Finlande, au Portugal et en Suède, mais supérieure à 20 points de pourcentage en Communauté flamande de Belgique et aux États-Unis (voir le graphique B5.a). Pour lutter contre certains problèmes d'équité à ce niveau d'enseignement, le gouvernement flamand vient de se fixer pour objectif de parvenir à ce que $60 \%$ au moins de diplômés du deuxième cycle de l'enseignement secondaire dont le niveau de formation de la mère est inférieur à l'enseignement tertiaire suivent des études tertiaires d'ici à 2020 (Cabinet du ministre-président du gouvernement flamand, en charge de l'économie, des affaires étrangères, de l'agriculture et de la politique rurale, $\left.2009_{[6]}\right)$.

La différence de taux de réussite entre ces étudiants montre que les nouveaux inscrits issus de milieux défavorisés peuvent se heurter à des obstacles particuliers lorsqu'ils cherchent à faire des études tertiaires. Cet indicateur ne suffit toutefois pas à lui seul à évaluer l'équité des systèmes d'éducation. Deux autres facteurs au moins doivent être pris en considération : 1) le pourcentage d'étudiants de chaque groupe dans la cohorte d'inscrits; et 2) la représentativité de la population totale dans la cohorte. Le tableau B5.b (disponible en ligne) montre la répartition des inscrits en licence selon le niveau de formation de leurs parents. En Estonie par exemple, les étudiants dont les parents ne sont pas diplômés du deuxième cycle de l'enseignement secondaire sont plus susceptibles de réussir leurs études que leurs pairs, mais ils ne représentent que $2 \%$ des inscrits en licence. Au Portugal, ils représentent $44 \%$ des inscrits.

II est important également d'évaluer la représentativité de la population dans la cohorte d'inscrits. Les systèmes ne sont pas équitables si les jeunes dont les parents ne sont pas diplômés de l'enseignement tertiaire sont minoritaires dans l'effectif de licence alors qu'ils sont majoritaires dans la population. Voir l'indicateur B7 dans (OCDE, 2018[7]) pour de plus amples informations sur la représentativité de groupes potentiellement défavorisés dans l'effectif de l'enseignement tertiaire.

Enfin, il y a lieu de souligner que les étudiants issus de milieux défavorisés sont parfois plus susceptibles de suivre des études à temps partiel dans certains pays, mais que cet indicateur ne tient pas compte de cet aspect des choses.

\section{Taux de réussite des étudiants selon leur statut au regard de l'immigration}

Le fait d'être issu de l'immigration n'est pas forcément synonyme de handicap, mais est associé à de moins bons résultats scolaires (OCDE, 2018 $[7])$. Les individus issus de l'immigration doivent souvent surmonter des problèmes liés au déracinement, à une mauvaise situation socio-économique et à la barrière de la langue. 


\section{Graphique B5.b. Taux de réussite des étudiants scolarisés à plein temps ayant entamé un programme de licence ou de niveau équivalent, selon leur statut au regard de l'immigration (2017)}

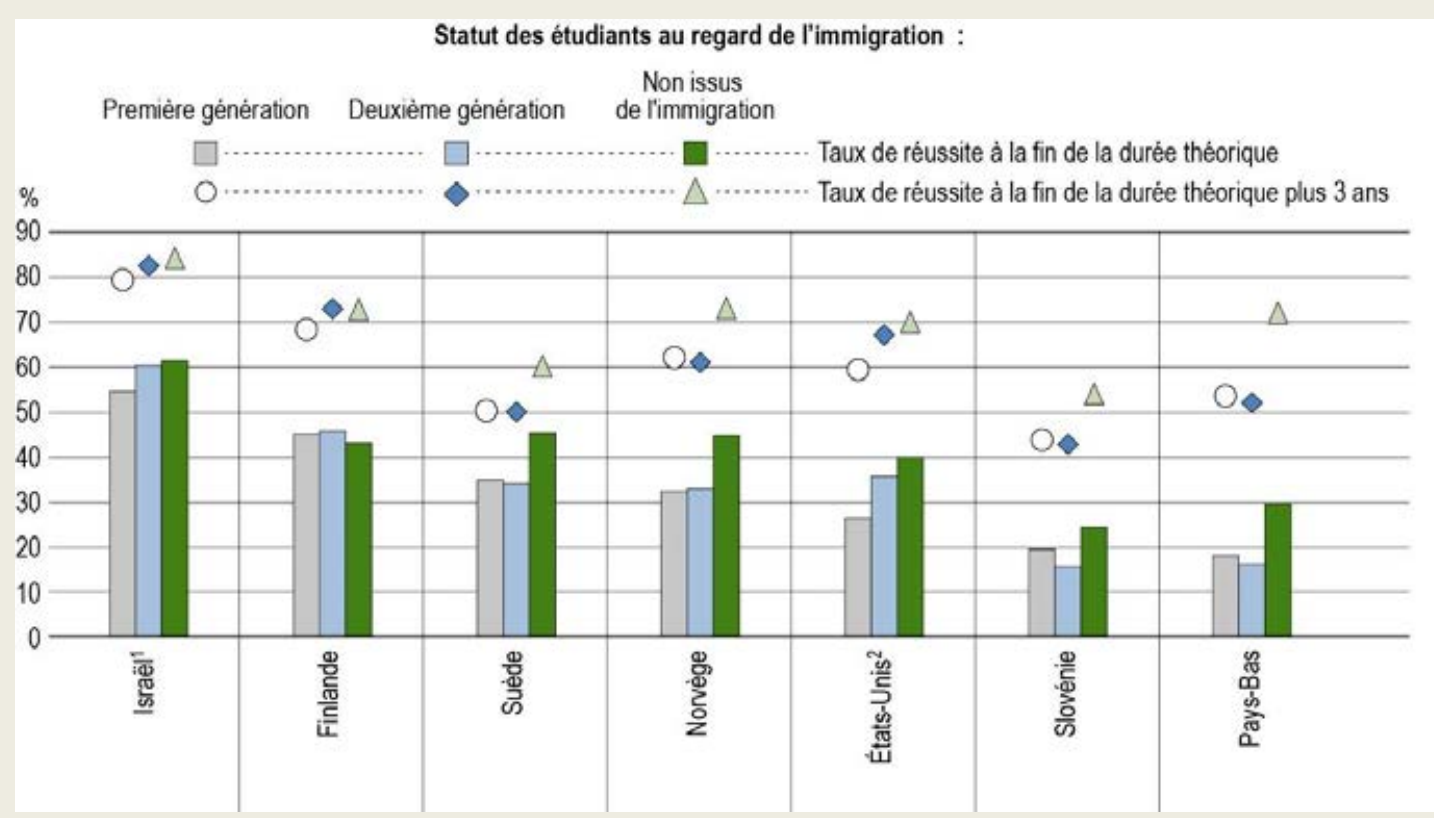

1. Le taux de réussite des étudiants ayant entamé un programme de licence n'inclut pas ceux ayant effectué un transfert et obtenu un diplôme d'un programme tertiaire de cycle court.

2. Année de référence de la cohorte d'entrée : 2003. Les années d'obtention du diplôme varient en fonction de la durée théorique des programmes. La durée théorique plus 3 ans pour les programmes de licence ou de niveau équivalent correspond à la durée théorique plus 2 ans.

Les pays sont classés par ordre décroissant du taux de réussite, à la fin de la durée théorique du programme, des étudiants immigrés de la première génération.

Source : OCDE (2019). Consulter la section «Source» pour tout complément d'information et l'annexe 3 pour les notes (https://doi.org/10.1787/f8d7880d-en).

StatLink त्ञाजम https://doi.org/10.1787/888933978379

Le graphique B5.b indique le taux de réussite des étudiants en licence à temps plein en fonction de leur statut au regard de l'immigration. Dans la quasi-totalité des pays dont les données sont disponibles, les étudiants autochtones (ceux nés dans le pays dont au moins un des deux parents y est également né) affichent un taux de réussite supérieur à celui des étudiants issus de l'immigration, tant à la fin de la durée théorique de leurs études que trois ans plus tard. La différence entre les étudiants de la première et de la deuxième génération varie entre les pays, mais la différence tend à être plus ténue (en valeur absolue) entre eux qu'entre eux et les étudiants autochtones.

Comme avec le niveau de formation des parents, il est important de tenir compte du pourcentage de chaque groupe dans la cohorte d'inscrits (voir le tableau B5.c, en ligne) et dans la population (OCDE, 2018[7]). La Finlande est par exemple le seul pays où le taux de réussite des étudiants autochtones est inférieur à celui des étudiants issus de l'immigration, tant de la première que de la deuxième génération. La Finlande est toutefois le pays où le pourcentage d'étudiants issus de l'immigration est le moins élevé dans l'effectif d'inscrits en licence : $4 \%$ d'étudiants de la première génération et $0.1 \%$ d'étudiants de la deuxième génération. Les étudiants issus de l'immigration représentent un pourcentage nettement plus élevé de l'effectif d'inscrits en licence dans d'autres pays, par exemple en Israël (25\%) et en Suède (18\%). 


\section{Encadré B5.3. Évaluer la qualité dans l'enseignement supérieur grâce aux enquêtes auprès des étudiants}

Cet encadré montre que les enquêtes sur les expériences des étudiants peuvent fournir des informations très utiles pour orienter les politiques sur l'amélioration de la qualité dans l'enseignement post-secondaire et comparer les résultats de ce niveau d'enseignement entre les pays.

Il est difficile d'évaluer la qualité de l'enseignement et de l'apprentissage dans l'enseignement tertiaire, tant à l'échelle des établissements qu'à l'échelle des systèmes, faute de données appropriées. Mesurer directement les résultats académiques des étudiants est coûteux, laborieux et difficile à mettre en œuvre à l'échelle nationale.

Les enquêtes auprès des étudiants ou des diplômés offrent une alternative pour évaluer la qualité de l'enseignement. Ces enquêtes évaluent des aspects de l'expérience que les étudiants ont vécue pendant leurs études et permettent de recueillir des informations précieuses sur un large éventail de facteurs contextuels et personnels qui influent sur l'apprentissage. Parmi ces enquêtes auprès des étudiants, citons la National Survey of Student Engagement (NSSE) aux États-Unis et au Canada, la National Student Survey (NSS) au Royaume-Uni, la Student Experience Survey (SES) en Australie et le programme Eurostudent mené dans 25 à 30 pays européens.

\section{Graphique B5.c. Évaluation générale des programmes d'études (en pourcentage d'avis positifs), tous les étudiants (2016)}

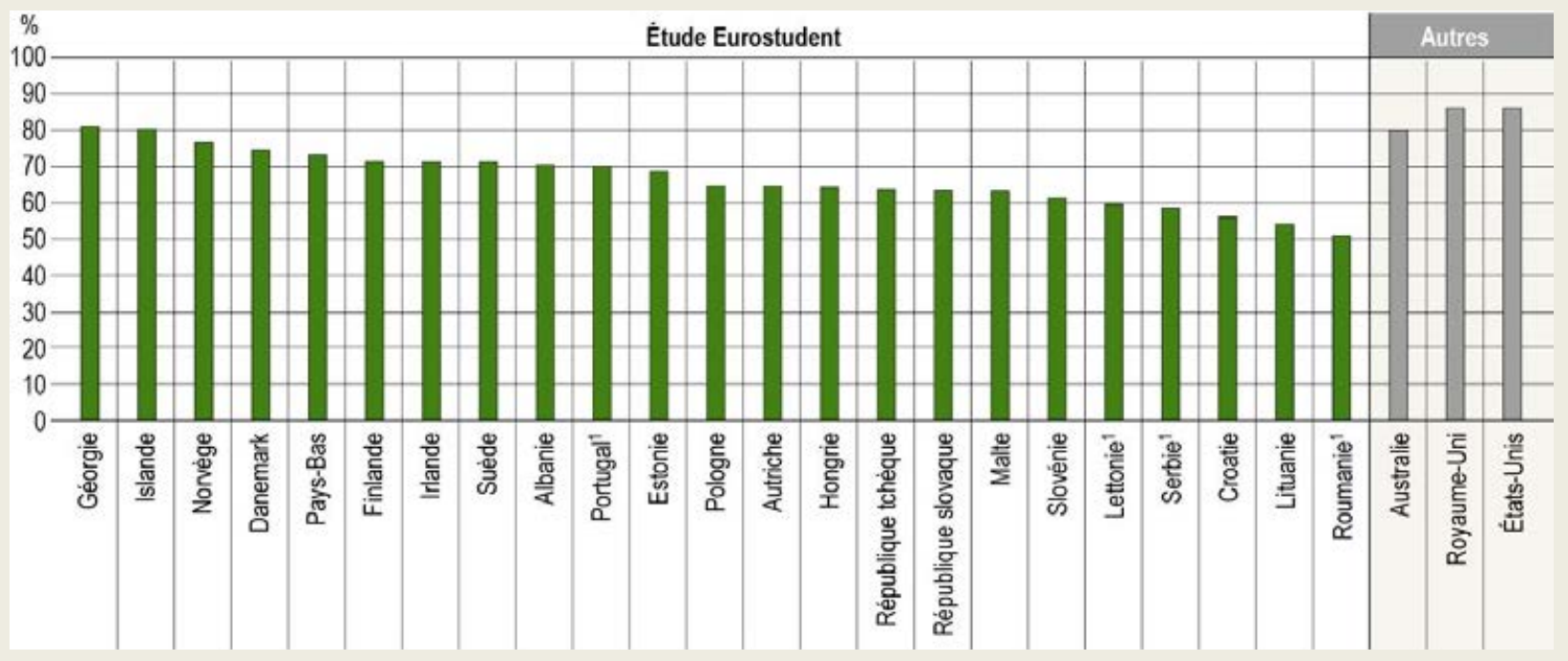

1. Année de référence : 2017.

Source : National Survey of Student Engagement (NSSE) pour les États-Unis, Student Experience Survey (SES) pour l'Australie, National Student Survey (NSS) pour le Royaume-Uni et le programme Eurostudent pour les 22 autres pays européens.

L'analyse de la qualité des expériences vécues par les étudiants peut aider les établissements à accroître leurs taux de rétention grâce à l'identification de facteurs tels que les méthodes pédagogiques, les services d'appui et les ressources académiques qui motivent les étudiants et favorisent leur réussite. Des faiblesses relatives peuvent être isolées à l'échelle des établissements ou des matières ou, à l'inverse, des modèles de pratiques optimales peuvent être identifiés. L'expérience des étudiants peut aussi être améliorée grâce à des mesures portant sur des items spécifiques des enquêtes, par exemple ceux liés à la rétention. Dans la SES menée en Australie, les répondants sont invités à indiquer s'ils ont envisagé d'arrêter leurs études au cours des 12 derniers mois et, dans l'affirmative, à indiquer pour quelles raisons. 
Les résultats des enquêtes auprès des étudiants peuvent également servir à comparer les systèmes d'enseignement supérieur. Le graphique B5.c propose un exemple de comparaisons internationales sur la base des résultats publics du programme Eurostudent dans les pays participants et d'enquêtes menées en Australie, aux États-Unis et au Royaume-Uni.

Les enquêtes auprès des étudiants présentent des limites s'agissant de mesurer la qualité de l'enseignement et les résultats de l'apprentissage. Elles permettent non pas de produire directement un indicateur objectif sur les résultats de l'apprentissage, mais d'agréger les évaluations subjectives des étudiants à propos des résultats de leur apprentissage ou d'identifier des facteurs supposés importants pour la réussite de l'apprentissage. Les résultats des enquêtes auprès des étudiants doivent donc être analysés dans le contexte du parcours scolaire et des caractéristiques démographiques des étudiants.

Les niveaux absolus de performance dérivés d'enquêtes sont moins importants que les relations établies entre des sous-groupes de la population (en fonction des caractéristiques démographiques des étudiants ou des établissements, par exemple) et l'évolution de la performance au fil du temps. Ces analyses bénéficient de la modularité et de la reproductibilité des instruments d'enquête.

Les résultats des enquêtes auprès des étudiants ne doivent pas être interprétés de manière simpliste. Les enquêtes mesurent des concepts similaires certes, mais il est important de savoir que des différences de méthodologie et de formulation précise des items peuvent avoir des effets considérables sur les résultats. Le graphique B5.c est basé, d'une part, sur un item du Programme Eurostudent qui invite les étudiants à indiquer s'ils recommanderaient leur formation à d'autres personnes et, d'autre part, sur des items relatifs à l'expérience et la satisfaction des étudiants dans l'ensemble en Australie, aux États-Unis et au Royaume-Uni. De plus, les résultats d'enquête peuvent être affectés par des différences dans la constitution démographique des cohortes d'étudiants ou par des différences de culture nationale et d'attentes en matière de formation.

Étant donné ces limites, l'évolution dans le temps des relations entre les indicateurs à l'échelle nationale est vraisemblablement plus édifiante que les scores absolus à tel ou tel moment. Le graphique B5.d. présente un exemple de comparaison d'une série chronologique.

\section{Graphique B5.d. Évaluation générale des étudiants/diplômés de leur expérience d'étudiant (en pourcentage d'avis positifs), sélection de pays, 2008 à 2018}

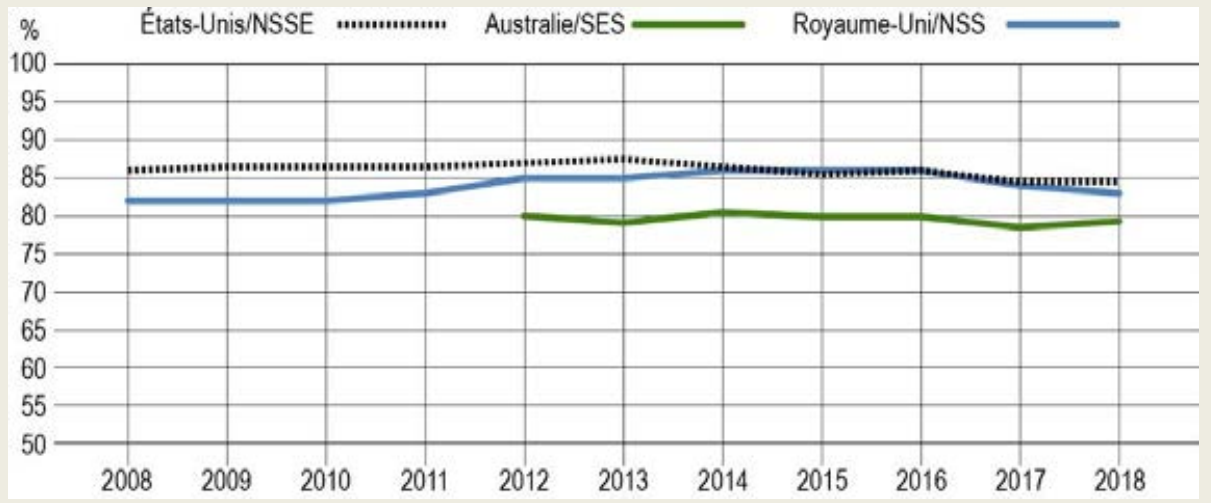

Source : National Survey of Student Engagement (NSSE) pour les États-Unis National Student Survey (NSS) pour le Royaume-Uni et Student Experience Survey (SES) pour l'Australie.

Des progrès dans la conception d'items comparables et la compréhension des différences culturelles dans la façon de répondre aux items contribueraient à mieux interpréter les résultats d'enquêtes et enrichiraient les comparaisons internationales. 


\section{Définitions}

Dans la méthode de la cohorte effective, il faut suivre une cohorte de nouveaux inscrits pendant une période spécifique, correspondant ici à la durée théorique des formations et à cette durée plus trois ans. Seuls les pays administrant des enquêtes longitudinales ou tenant des registres longitudinaux des étudiants peuvent fournir ces données.

Dans la méthode de la cohorte transversale, le nombre de nouveaux inscrits à un niveau donné de la CITE et le nombre de diplômés $n$ années plus tard (où $n$ correspond à la durée théorique de la formation visée) suffisent.

Dans cet indicateur, les étudiants scolarisés à temps plein sont ceux qui ont commencé leur formation tertiaire sous le régime du temps plein. Ils peuvent avoir changé de régime durant leur formation.

La durée théorique des études correspond au nombre réglementaire ou courant d'années d'études à suivre à temps plein pour obtenir le diplôme de la formation visée.

Statut au regard de l'immigration

- Par immigrés de la première génération, on entend les individus nés à l'étranger de parents tous deux nés à l'étranger. Les étudiants en mobilité internationale sont exclus de cette catégorie.

- Par immigrés de la seconde génération, on entend les individus nés dans le pays de parents tous deux nés à l'étranger.

- Par individus autochtones, on entend les individus dont au moins un parent est né dans le pays.

Niveau de formation des parents

- Par parents dont le niveau est inférieur au deuxième cycle de l'enseignement secondaire, on entend le fait que les deux parents sont au plus diplômés du niveau 0, 1 ou 2 de la CITE 2011. Se classent également dans cette catégorie au sens de la CITE 2011 les formations reconnues de niveau 3 (voir le "Guide du lecteur ») qui ne sont pas suffisantes pour que les individus qui les ont réussies soient considérés comme diplômés du niveau 3 et qui ne donnent pas directement accès à l'enseignement postsecondaire non tertiaire ou à l'enseignement tertiaire ;

- Par parents dont le niveau de formation est égal au deuxième cycle de l'enseignement secondaire ou à l'enseignement post-secondaire non tertiaire, on entend le fait que l'un des deux parents au moins est au plus diplômé du niveau 3 ou 4 de la CITE 2011 ;

- Par parents dont le niveau de formation est égal à l'enseignement tertiaire, on entend le fait que l'un des deux parents au moins est diplômé du niveau 5, 6, 7 ou 8 de la CITE 2011.

\section{Méthodologie}

Dans les pays qui ont fourni leurs données selon la méthode de la cohorte effective, il est possible de calculer deux taux de réussite différents (décrits ci-après), à deux termes différents (correspondant à la durée théorique $n$ et à $n+3)$ :

- Le taux de réussite des étudiants diplômés du même niveau de la CITE que la formation qu'ils ont entamée, à savoir le nombre d'individus diplômés une année civile donnée d'un niveau donné de la CITE divisé par le nombre de nouveaux inscrits au même niveau de la CITE $n$ et $n+3$ années civiles plus tôt ;

- Le taux de réussite des étudiants diplômés de tout niveau tertiaire de la CITE, à savoir la somme des diplômés de tous les niveaux tertiaires de la CITE une année civile donnée parmi ceux qui ont entamé une formation tertiaire à un niveau donné de la CITE $n$ et $n+3$ années civiles plus tôt.

Les pays qui ont fourni des données sur les cohortes effectives ont utilisé soit les nouveaux inscrits (première inscription) dans l'enseignement tertiaire (c'est-à-dire uniquement les étudiants qui s'inscrivent pour la première 
fois dans l'enseignement tertiaire), soit les nouveaux inscrits (c'est-à-dire l'effectif total de nouveaux inscrits à chaque niveau de l'enseignement tertiaire, qu'ils se soient inscrits ou non à un autre niveau de l'enseignement tertiaire auparavant). L'annexe 3 indique la méthode utilisée dans les différents pays (https://doi.org/10.1787/f8d7880d-en).

Si les données portent sur des cohortes transversales, un seul taux de réussite est calculé : le nombre d'individus diplômés une année civile donnée d'un niveau donné de la CITE divisé par le nombre de nouveaux inscrits à ce niveau de la CITE $n$ années civiles plus tôt.

Si des pays proposent des formations d'une durée théorique différente au même niveau de la CITE, le taux de réussite de chaque formation est calculé séparément, puis il est pondéré par l'effectif de nouveaux inscrits de chaque formation.

Voir le Guide de l'OCDE pour l'établissement de statistiques internationalement comparables dans le domaine de l'éducation 2018 (OCDE, 2019[8] $)$ pour de plus amples informations. Voir les notes spécifiques aux pays à l'annexe 3 (https://doi.org/10.1787/f8d7880d-en).

\section{Source}

Les données sur les taux de réussite se rapportent à l'année scolaire 2016/17 et ont été recueillies lors d'une enquête spéciale administrée en 2018. Dans certains pays, les données portent sur d'autres années de référence. Voir les notes spécifiques aux pays à l'annexe 3 (https://doi.org/10.1787/f8d7880d-en). Les pays ont soumis leurs données selon la méthode basée soit sur les cohortes effectives, soit sur les cohortes transversales.

\section{Remarque concernant les données fournies par Israël}

Les données statistiques concernant Israël sont fournies par et sous la responsabilité des autorités israéliennes compétentes. L'utilisation de ces données par l'OCDE est sans préjudice du statut des hauteurs du Golan, de Jérusalem-Est et des colonies de peuplement israéliennes en Cisjordanie aux termes du droit international.

\section{Références}

Cabinet du ministre-président du gouvernement flamand, en charge de l'économie, des affaires étrangères, de l'agriculture et de la politique rurale (2009), Pact 2020. Een nieuw toekomstpact voor Vlaanderen - 20 doelstellingen | Vlaanderen.be, https://www.vlaanderen.be/publicaties/pact-2020een-nieuw-toekomstpact-voor-vlaanderen-20-doelstellingen (consulté le 19 juin 2019).

OCDE (2019), Guide de l'OCDE pour l'établissement de statistiques internationalement comparables dans le domaine de l'éducation 2018: Concepts, normes, définitions et classifications, Éditions OCDE, Paris, https://dx.doi.org/10.1787/9789264305380-fr.

OCDE (2018), Regards sur l'éducation 2018 : Les indicateurs de l'OCDE, Éditions OCDE, Paris, https://dx.doi.org/10.1787/eag-2018-fr.

OCDE (2013), Perspectives de l'OCDE sur les compétences 2013: Premiers résultats de l'Evaluation des compétences des adultes, Éditions OCDE, Paris, https://dx.doi.org/10.1787/9789264204096-fr.

Quinn, J. (2013), Drop-out and Completion in Higher Education in Europe among Students from Underrepresented Groups, Union européenne, http://nesetweb.eu/wp-content/uploads/2015/09/2013Drop-out-and-Completion-in-Higher-Education-in-Europe-among-students-from-under-representedgroups.pdf (consulté le 17 mai 2019). 
Scrivener, S. et al. (2018), Becoming College-Ready: Early Findings from a CUNY Start Evaluation,

MDRC, http://www.mdrc.org. (consulté le 14 mai 2019).

Thomas, L. et J. Quinn (2006), First Generation Entry into Higher Education: An International Study, Open University Press.

Vossensteyn, H. et al. (2015), Dropout and Completion in Higher education in Europe, Publications

Office of the European Union, Luxembourg, http://dx.doi.org/10.2766/826962.

\section{Tableaux de l'indicateur B5}

Tableau B5.1

Tableau B5.2

Tableau B5.3

Tableau B5.a

WEB Tableau B5.b

WEB Tableau B5.c
Taux de réussite des étudiants de l'enseignement tertiaire scolarisés à plein temps, selon le niveau d'enseignement et le sexe (2017)

Taux de réussite des étudiants de l'enseignement tertiaire scolarisés à plein temps, selon le niveau d'enseignement et la filière suivie dans le deuxième cycle du secondaire (2017)

Situation des étudiants de licence scolarisés à plein temps à différents délais après leur inscription (2017)

Différence de taux de réussite des étudiants ayant entamé un programme de licence ou de niveau équivalent, selon que le calcul se base sur les cohortes effectives ou transversales (2017)

Répartition des étudiants entamant un programme de licence ou de niveau équivalent, selon le niveau de formation des parents (2017)

Répartition des étudiants entamant un programme de licence ou de niveau équivalent, selon leur statut au regard de l'immigration (2017)

Date butoir pour les données : 19 juillet 2019. Les mises à jour peuvent être consultées en ligne sur : http://dx.doi.org/10.1787/eag-data-en. D'autres données désagrégées sont également disponibles dans la Base de données de Regards sur l'éducation (http://stats.oecd.org/).

StatLink : https://doi.org/10.1787/888933981001 
Tableau B5.1. Taux de réussite des étudiants de l'enseignement tertiaire scolarisés à plein temps, selon le niveau d'enseignement et le sexe (2017)

\section{Panneau A. Taux de réussite - cohortes effectives}

Etudiants ayant entamé un programme tertiaire de cycle court et reussi tout Etudiants ayant entamé un programme de licence et reussi tout programme programme de l'enseignement tertiaire. de Penseignement tertiaire..

\begin{tabular}{|c|c|c|c|c|c|c|c|c|c|c|c|c|c|c|}
\hline & \multirow{3}{*}{ 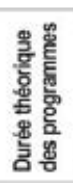 } & \multicolumn{3}{|c|}{$\begin{array}{l}\text { A la fin de la durée théorique } \\
\text { du programme qu'ils ont entamé }\end{array}$} & \multicolumn{3}{|c|}{$\begin{array}{l}\text { A la fin de la durée théorique } \\
\text { du programme qu'ils ont entame } \\
\text { plus } 3 \text { ans }\end{array}$} & \multirow{3}{*}{ 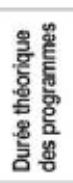 } & \multicolumn{3}{|c|}{$\begin{array}{l}\text { A la fin de la durée theorique } \\
\text { du programme qu'ils ont entamé }\end{array}$} & \multicolumn{3}{|c|}{$\begin{array}{l}\text { A la fin de la durée théorique } \\
\text { du programme qu'ils ont entame } \\
\text { plus } 3 \text { ans }\end{array}$} \\
\hline & & Hommes & Femmes & Total & Hommes & Femmes & Total & & Hommes & Femmes & Total & Hommes & Femmes & Total \\
\hline & & (1) & (2) & (3) & (4) & (5) & (6) & & (n) & (8) & (9) & $(10)$ & (11) & (12) \\
\hline \multicolumn{15}{|l|}{ Pays } \\
\hline Australie & $m$ & $\mathrm{~m}$ & m & m & $\mathrm{m}$ & m & $m$ & 3.5 & 29 & 37 & 34 & 66 & 73 & 70 \\
\hline Autriche & 2 & 64 & 73 & 69 & 81 & 87 & 84 & 3 & 22 & 30 & 26 & 53 & 63 & 58 \\
\hline Comm, française (Belgique) $)^{2}$ & $m$ & m & $m$ & m & m & $m$ & $m$ & $3-4$ & 19 & 33 & 27 & 46 & 60 & 54 \\
\hline BrèsilP & $m$ & m & m & m & $\mathrm{m}$ & m & m & 4.5 & 28 & 37 & 33 & 45 & 55 & 50 \\
\hline Canada & $m$ & $\mathrm{~m}$ & $\mathrm{~m}$ & $\mathrm{~m}$ & $\mathrm{~m}$ & $\mathrm{~m}$ & $\mathrm{~m}$ & 4 & 41 & 53 & 48 & $\mathrm{~m}$ & $\mathrm{~m}$ & $\mathrm{~m}$ \\
\hline Chili & 2.3 & 15 & 31 & 23 & 38 & 54 & 46 & 4.5 & 11 & 19 & 16 & 45 & 60 & 54 \\
\hline Estonie & $a$ & a & a & a & a & a & a & $3-4$ & 23 & 42 & 34 & 47 & 68 & 59 \\
\hline Finlande & a & a & a & a & a & a & a & 4 & 28 & 55 & 43 & 64 & 79 & 73 \\
\hline Frances & 2 & 62 & 60 & 61 & 78 & 75 & 77 & 3 & 34 & 44 & 41 & 61 & 70 & 67 \\
\hline Islande & $m$ & $\mathrm{~m}$ & $\mathrm{~m}$ & $\mathrm{~m}$ & $\mathrm{~m}$ & $\mathrm{~m}$ & $\mathrm{~m}$ & $3-4$ & 33 & 37 & 36 & 64 & 72 & 69 \\
\hline |sraël' & $m$ & $\mathrm{~m}$ & m & $\mathrm{m}$ & $\mathrm{m}$ & m & $\mathrm{m}$ & $3-4$ & 55 & 64 & 60 & 79 & 87 & 83 \\
\hline Lituanie & $m$ & $\mathrm{~m}$ & $\mathrm{~m}$ & m & $\mathrm{m}$ & $\mathrm{m}$ & $\mathrm{m}$ & $3-4$ & 52 & 68 & 61 & 57 & 72 & 65 \\
\hline Pays-Bas & $m$ & $\mathrm{~m}$ & $\mathrm{~m}$ & $\mathrm{~m}$ & $m$ & $\mathrm{~m}$ & $\mathrm{~m}$ & $3-4$ & 20 & 35 & 28 & 62 & 77 & 70 \\
\hline Nouvelle-Zélande & 2 & 59 & 69 & 65 & 68 & 76 & 73 & 3 & 27 & 40 & 35 & 73 & 79 & 77 \\
\hline Norvège & 2 & 61 & 41 & 55 & 68 & 57 & 65 & $3-4$ & 38 & 47 & 44 & 65 & 77 & 72 \\
\hline Portugal & $m$ & $m$ & m & m & $m$ & $\mathrm{~m}$ & m & 3 & 23 & 35 & 30 & 55 & 73 & 65 \\
\hline Slovènie & 3 & 17 & 27 & 22 & 33 & 45 & 39 & 4 & 18 & 28 & 24 & 42 & 60 & 53 \\
\hline Suède & 2 & 30 & 45 & 37 & 39 & 57 & 48 & 3 & 32 & 48 & 42 & 45 & 63 & 56 \\
\hline Suisse & $m$ & $\mathrm{~m}$ & $\mathrm{~m}$ & $\mathrm{~m}$ & m & $\mathrm{m}$ & $\mathrm{m}$ & 3 & 35 & 42 & 39 & 78 & 84 & 81 \\
\hline Royaume-Unn & 2 & 57 & 62 & 59 & 71 & 79 & 75 & $3-4$ & 70 & 74 & 72 & 83 & 87 & 85 \\
\hline Etats-Unis? & 2 & 9 & 8 & 9 & 30 & 32 & 31 & 4 & 33 & 43 & 38 & 65 & 72 & 69 \\
\hline Moyenne & & 41 & 47 & 45 & 56 & 63 & 60 & & 33 & 44 & 39 & 61 & 72 & 67 \\
\hline
\end{tabular}

\begin{tabular}{|c|c|c|c|c|c|c|c|c|}
\hline & \multicolumn{8}{|c|}{ Panneau B. Taux de réussite - cohortes transversales } \\
\hline & \multicolumn{4}{|c|}{ Etudiants ayant entamé un programme tertiaire de cycle court } & \multicolumn{4}{|c|}{ Etudiants ayant entamé un programme de licence ou de niveau équivalent } \\
\hline & \multirow{2}{*}{ 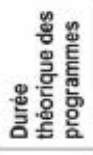 } & Hommes & Femmes & Total & \multirow{2}{*}{ 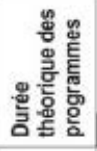 } & Hommes & Femmes & \multirow{2}{*}{$\begin{array}{c}\text { Total } \\
\text { (6) }\end{array}$} \\
\hline & & (1) & (2) & (3) & & (4) & (5) & \\
\hline \multicolumn{9}{|l|}{ Pays } \\
\hline Grèce $^{4}$ & $m$ & $\mathrm{~m}$ & $\mathrm{~m}$ & $\mathrm{~m}$ & 4.5 & 74 & 81 & 78 \\
\hline Japon & 2 & 86 & 90 & 89 & 4 & 91 & 96 & 93 \\
\hline Corée & $2 \cdot 3$ & 71 & 84 & 78 & 4 & 89 & 101 & 94 \\
\hline Lettonic & 2 & 51 & 69 & 61 & $3-4$ & 33 & 53 & 48 \\
\hline Mexique & 2 & 55 & 62 & 58 & 5 & 74 & 87 & 81 \\
\hline République slovaque & 23 & 51 & 57 & 55 & $3-4$ & 53 & 70 & 62 \\
\hline Espagne & 2 & 77 & 87 & 82 & 4 & 71 & 87 & 80 \\
\hline
\end{tabular}

Remarque : Les taux de réussite des cohortes effectives (données de niveau individuel) et transversales (données agrégées) ne sont pas comparables entre eux. Consulter la section « Méthodologie » pour une explication des méthodologies des cohortes effectives et transversales. L'année de référence des données (2017) correspond à l'année d'obtention du diplôme 3 ans après la fin de la durée théorique du programme. L'année de référence de la cohorte d'entrée change en fonction de la durée des programmes.

1. Le taux de réussite des étudiants ayant entamé un programme de licence n'inclut pas ceux ayant effectué un transfert et obtenu un diplôme d'un programme tertiaire de cycle court. 2. Les données se rapportent uniquement aux hautes écoles (HE) et aux écoles des arts (ESA), soit environ $60 \%$ des inscrits dans des programmes de licence ou de niveau équivalent.

3. Les données ne comprennent pas les étudiants ayant entamé une licence d'une durée de 6 ans, ce qui correspond à environ $2 \%$ de l'ensemble des étudiants ayant entamé un programme de ce niveau.

4. Année de référence : 2015 .

5. Année de référence de la cohorte d'entrée : 2008. Les années d'obtention du diplôme varient en fonction de la durée théorique des programmes.

6. Les données sur le tertiaire de cycle court se rapportent uniquement aux programmes d'enseignement supérieur dispensés dans les universités.

7. Année de référence de la cohorte d'entrée : 2003. Les années d'obtention du diplôme varient en fonction de la durée théorique des programmes. La durée théorique plus 3 ans pour les programmes de licence ou de niveau équivalent correspond à la durée théorique plus 2 ans.

8. Les données correspondent à des taux de réussite estimés sur la base d'une relation modélisée entre les futurs diplômés et les étudiants encore inscrits.

Source : OCDE (2019). Consulter la section « Source » pour tout complément d'information et l'annexe 3 pour les notes (https://doi.org/10.1787/f8d7880d-en).

Les symboles représentant les données manquantes et les abréviations figurent dans le Guide du lecteur.

StatLink 가매 https://doi.org/10.1787/888933978208 
Tableau B5.2. Taux de réussite des étudiants de l'enseignement tertiaire scolarisés à plein temps, selon le niveau d'enseignement et la filière suivie dans le deuxième cycle du secondaire (2017)

Cohorte effective uniquement

Panneau A. Taux de réussite des étudiants ayant entamé un programme de licence ou de niveau équivalent et réussi tout programme de l'enseignement tertiaire

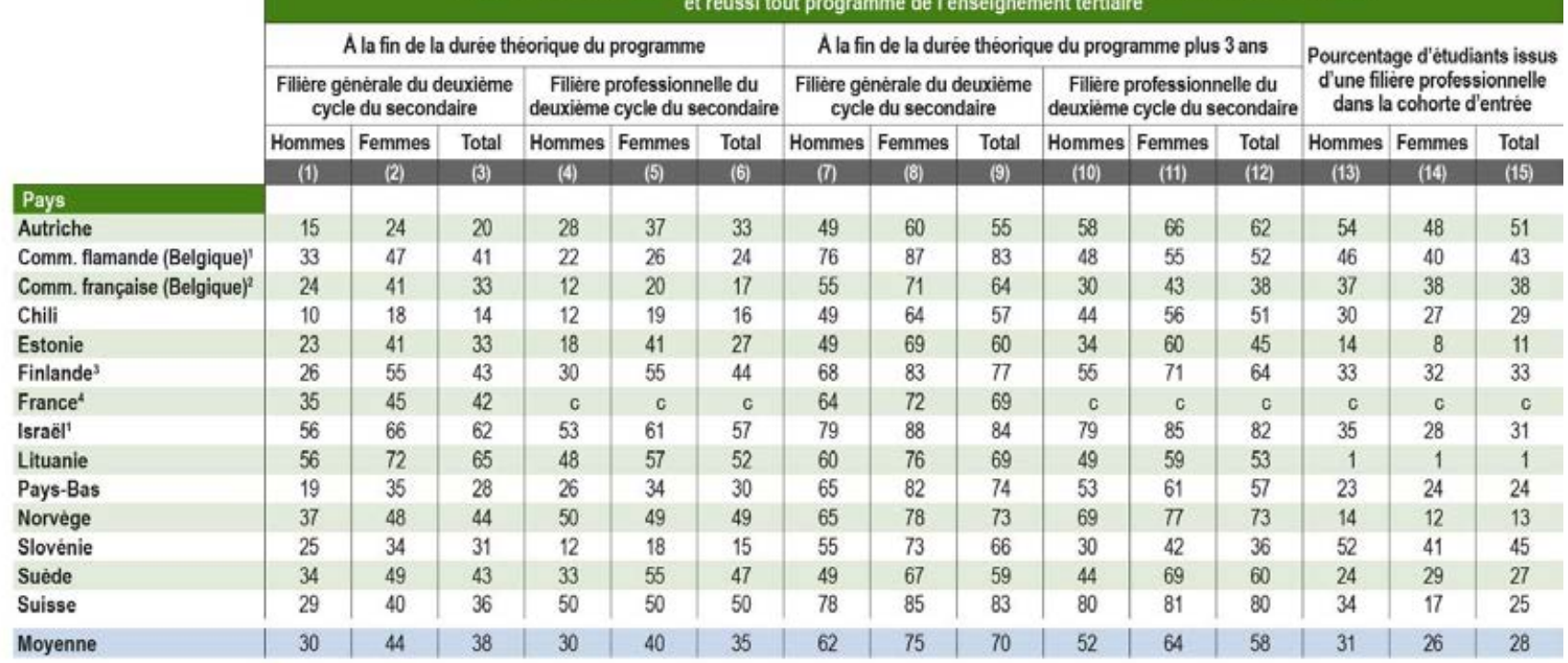

\begin{tabular}{|c|c|c|c|c|c|c|c|c|c|c|c|c|c|c|c|}
\hline \multicolumn{16}{|l|}{ Pays } \\
\hline Chili & 13 & 29 & 21 & 14 & 30 & 22 & 34 & 53 & 44 & 40 & 54 & 47 & 50 & 48 & 49 \\
\hline France $^{4}$ & 65 & 67 & 66 & 48 & 32 & 40 & 83 & 84 & 84 & 59 & 42 & 51 & 21 & 21 & 21 \\
\hline Norvège & 44 & 43 & 43 & 71 & 39 & 67 & 57 & 64 & 61 & 77 & 55 & 74 & 84 & 31 & 69 \\
\hline Slovènie & 26 & 36 & 32 & 14 & 19 & 16 & 44 & 54 & 50 & 28 & 38 & 32 & 69 & 51 & 60 \\
\hline Suède & 31 & 44 & 38 & 30 & 47 & 38 & 40 & 56 & 48 & 39 & 60 & 48 & 47 & 38 & 43 \\
\hline
\end{tabular}

\begin{tabular}{|c|c|c|c|c|c|c|c|c|c|c|c|c|c|c|c|}
\hline \multirow[b]{2}{*}{ Pays } & \multicolumn{15}{|c|}{$\begin{array}{l}\text { Panneau C. Taux de réussite des étudiants ayant entamé un premier programme de master de type long } \\
\qquad \text { et réussi tout programme de Penseignement tertiaire }\end{array}$} \\
\hline & & & & & & & & & & & & & & & \\
\hline Autriche & 33 & 44 & 40 & 42 & 44 & 43 & 61 & 72 & 68 & 59 & 64 & 62 & 35 & 37 & 36 \\
\hline Chili & 32 & 33 & 33 & 12 & 9 & 10 & 76 & 81 & 78 & 41 & 50 & 46 & 1 & 1 & 1 \\
\hline Estonie & 22 & 54 & 39 & 30 & 0 & 21 & 62 & 78 & 70 & 40 & 25 & 36 & 4 & 1 & 2 \\
\hline France $^{4}$ & 52 & 50 & 51 & $\mathrm{~m}$ & $\mathrm{~m}$ & $\mathrm{~m}$ & $\mathrm{~m}$ & $\mathrm{~m}$ & $\mathrm{~m}$ & m & $\mathrm{m}$ & $\mathrm{m}$ & $\mathrm{m}$ & $\mathrm{m}$ & m \\
\hline Norvège & 54 & 52 & 53 & 61 & 50 & 56 & 88 & 91 & 90 & 90 & 91 & 90 & 4 & 3 & 4 \\
\hline Slovènie & 31 & 39 & 36 & 31 & 26 & 29 & 57 & 70 & 65 & 47 & 57 & 51 & 7 & 3 & 5 \\
\hline Suède & 45 & 60 & 52 & 41 & 66 & 57 & 65 & 80 & 73 & 57 & 75 & 69 & 14 & 22 & 18 \\
\hline
\end{tabular}

Remarque : L'année de référence des données (2017) correspond à l'année d'obtention du diplôme 3 ans après la fin de la durée théorique du programme. L'année de référence de la cohorte d'entrée change en fonction de la durée des programmes.

1. Le taux de réussite des étudiants ayant entamé un programme de licence n'inclut pas ceux ayant effectué un transfert et obtenu un diplôme d'un programme tertiaire de cycle court.

2. Les données se rapportent uniquement aux hautes écoles (HE) et aux écoles des arts (ESA), soit environ $60 \%$ des inscrits dans des programmes de licence ou de niveau équivalent.

3. Si l'étudiant a réussi à la fois un programme de la filière générale et de la filière professionnelle du deuxième cycle du secondaire, ou si les données sur son parcours antérieur d'éducation sont manquantes, il est comptabilisé dans la catégorie « Filière professionnelle du deuxième cycle du secondaire ».

4. Année de référence de la cohorte d'entrée : 2008 . Les années d'obtention du diplôme varient en fonction de la durée théorique des programmes.

Source : OCDE (2019). Consulter la section « Source » pour tout complément d'information et l'annexe 3 pour les notes (https://doi.org/10.1787/f8d7880d-en).

Les symboles représentant les données manquantes et les abréviations figurent dans le Guide du lecteur.

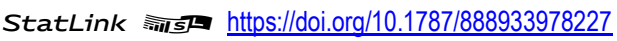


Tableau B5.3. Situation des étudiants de licence scolarisés à plein temps à différents délais après leur inscription (2017) Cohorte effective uniquement

\begin{tabular}{|c|c|c|c|c|c|c|c|c|c|c|c|c|c|c|}
\hline & \multicolumn{4}{|c|}{ Au début de la deuxième année d'études } & \multicolumn{5}{|c|}{ A la fin de la duree thêorique du programme } & \multicolumn{5}{|c|}{$\begin{array}{l}\text { A la fin de la duree théorique } \\
\text { du programme plus } 3 \text { ans }\end{array}$} \\
\hline & \multirow[b]{2}{*}{ 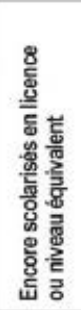 } & \multicolumn{2}{|c|}{$\begin{array}{l}\text { Ayant effectué } \\
\text { un transfert }\end{array}$} & \multirow[b]{2}{*}{ 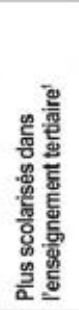 } & \multicolumn{3}{|c|}{ Diplômés } & \multirow[b]{2}{*}{ 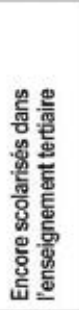 } & \multirow[b]{2}{*}{ 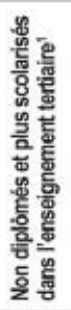 } & \multicolumn{3}{|c|}{ Diplômés } & \multirow[b]{2}{*}{ 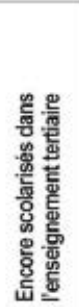 } & \multirow[b]{2}{*}{ 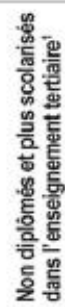 } \\
\hline & & 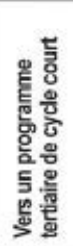 & 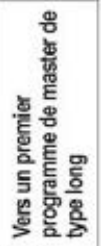 & & 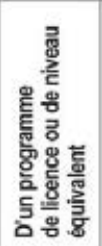 & 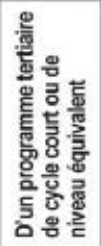 & 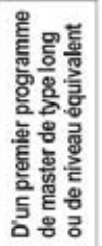 & & & 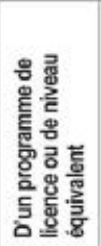 & 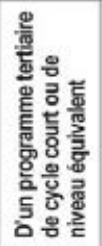 & 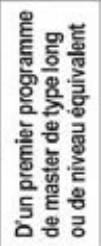 & & \\
\hline & (1) & (2) & (3) & (4) & (5) & (6) & (7) & (8) & (9) & (10) & (11) & (12) & (13) & (14) \\
\hline \multicolumn{15}{|l|}{ Pays } \\
\hline Australie $^{2}$ & 87 & $0.5^{\mathrm{c}}$ & a & 12 & 33 & $0.2^{\circ}$ & a & 49 & 17 & 69 & $0.6^{d}$ & a & 9 & 21 \\
\hline Autriche & 82 & 0.8 & 3.3 & 14 & 25 & 0.5 & 0.6 & 52 & 22 & 55 & 1.2 & 1.9 & 17 & 25 \\
\hline Comm. flamande (Belgique) & 86 & m & a & 14 & 33 & $\mathrm{~m}$ & a & 42 & 25 & 67 & $\mathrm{~m}$ & a & 3 & 30 \\
\hline Comm. française (Belgique) & 79 & 0.0 & a & 21 & 27 & 00 & a & 41 & 32 & 54 & 0.0 & a & 3 & 43 \\
\hline Brèsil' & 89 & 0.0 & a & 11 & 33 & 0.0 & a & 45 & 22 & 50 & 0.1 & a & 16 & 34 \\
\hline Canada 5 & 86 & 27 & 0.0 & 12 & 45 & 3.1 & 0.0 & 33 & 19 & $\mathrm{~m}$ & $\mathrm{~m}$ & $\mathrm{~m}$ & $\mathrm{~m}$ & m \\
\hline Chilli & 80 & 32 & 02. & 17 & 13 & 23 & 0.1 & 59 & 25 & 47 & 65 & 03 & 17 & 30 \\
\hline Estonie & 88 & 0.0 & 0.6 & 11 & 34 & 0.0 & 0.0 & 44 & 22 & 59 & 0.0 & 0.1 & 8 & 33 \\
\hline Finlande & 91 & a & 1.0 & 8 & 43 & a & 0.7 & 43 & 14 & 70 & a & 2.6 & 10 & 18 \\
\hline France $^{6}$ & 79 & 11.0 & 1.7 & 9 & 34 & 72 & 0.0 & 39 & 20 & 59 & 80 & 0.4 & 12 & 21 \\
\hline Islande & 81 & 0.2 & 0.2 & 18 & 35 & 0.6 & 0.0 & 41 & 24 & 68 & 0.6 & 0.0 & 9 & 22 \\
\hline Irlande ${ }^{6}$ & $\mathrm{~m}$ & m & $\mathrm{m}$ & $\mathrm{m}$ & $63^{\circ}$ & $\times(5)$ & $x(5)$ & $\mathrm{m}$ & $\mathrm{m}$ & $81^{4}$ & $x(10)$ & $x(10)$ & 1 & 18 \\
\hline Israë| & 91 & 0.3 & a & 8 & 60 & $\mathrm{~m}$ & a & 23 & 17 & 83 & $\mathrm{~m}$ & a & 3 & 14 \\
\hline Lituanie & $83^{d}$ & $x(1)$ & $x(1)$ & 17 & $61^{\circ}$ & $x(5)$ & $x(5)$ & $\mathrm{m}$ & m & $65^{d}$ & $x(10)$ & $x(10)$ & $\mathrm{m}$ & m \\
\hline Pays-Bas & 88 & 0.2 & a & 12 & 28 & 0.1 & a & 55 & 17 & 69 & 0.3 & a & 12 & 18 \\
\hline Nouvelle-Zelande & 89 & 1.3 & a & 10 & 32 & 26 & a & 51 & 14 & 74 & 29 & a & 6 & 18 \\
\hline Norvège & 86 & 0.3 & 1.3 & 12 & 43 & 0.2 & 0.2 & 39 & 17 & 70 & 0.4 & 1.7 & 9 & 19 \\
\hline Portugal & 87 & 0.0 & 1.2 & 12 & 30 & 0.0 & 0.1 & 55 & 16 & 64 & 0.1 & 0.7 & 9 & 26 \\
\hline Slovénie & 76 & 4.0 & 0.9 & 20 & 23 & 0.7 & 0.3 & 30 & 46 & 44 & 24 & 6.3 & 8 & 40 \\
\hline Suéde & 82 & 0.5 & 1.8 & 15 & 41 & 0.5 & 0.6 & 30 & 29 & 54 & 0.6 & 1.8 & 12 & 32 \\
\hline Suisse & 92 & 0.0 & 0.0 & 8 & 39 & 0.0 & 0.0 & 49 & 12 & 81 & 0.0 & 0.0 & 7 & 12 \\
\hline Royaume-Uni & 92 & 0.1 & 0.0 & 8 & 68 & 3.5 & 0.0 & 16 & 12 & 80 & 4.7 & 0.0 & 0 & 14 \\
\hline Etats-Unis ${ }^{7}$ & 91 & 2.5 & a & 6 & 36 & 25 & a & 42 & 19 & 66 & 29 & a & 11 & 20 \\
\hline Moyenne & 85 & 1.5 & 0.9 & 12 & 37 & 1.3 & 0.2 & 41 & 20 & 64 & 1.8 & 1.3 & 9 & 24 \\
\hline
\end{tabular}

Remarque : L'année de référence des données (2017) correspond à l'année d'obtention du diplôme 3 ans après la fin de la durée théorique du programme. L'année de référence de la cohorte d'entrée change en fonction de la durée des programmes.

1. Les colonnes « Plus scolarisés dans l'enseignement tertiaire » ou « Non diplômés et plus scolarisés dans l'enseignement tertiaire » peuvent inclure des étudiants ayant quitté le pays avant l'obtention de leur diplôme.

2. La catégorie « Tertiaire de cycle court » inclut des étudiants ayant effectué un transfert vers/diplômés d'un programme de master ou de doctorat dans le délai imparti.

3. Les données se rapportent uniquement aux hautes écoles (HE) et aux écoles des arts (ESA), soit environ $60 \%$ des inscrits dans des programmes de licence ou de niveau équivalent.

4. Les données ne comprennent pas les étudiants ayant entamé une licence d'une durée de 6 ans, ce qui correspond à environ $2 \%$ de l'ensemble des étudiants ayant entamé un programme de ce niveau.

5. Année de référence : 2015.

6. Année de référence de la cohorte d'entrée : 2008. Les années d'obtention du diplôme varient en fonction de la durée théorique des programmes.

7. Année de référence de la cohorte d'entrée : 2003. Les années d'obtention du diplôme varient en fonction de la durée théorique des programmes. La durée théorique plus 3 ans correspond à la durée théorique plus 2 ans.

Source : OCDE (2019). Consulter la section « Source » pour tout complément d'information et l'annexe 3 pour les notes (https://doi.org/10.1787/f8d7880d-en).

Les symboles représentant les données manquantes et les abréviations figurent dans le Guide du lecteur.

StatLink 제대 https://doi.org/10.1787/888933978246 



\section{Indicateur B6. Quel est le profil des étudiants en mobilité internationale?}

\section{Faits marquants}

- Dans l'ensemble, le pourcentage d'étudiants en mobilité internationale a augmenté de 2 points de pourcentage dans les pays de l'OCDE entre 2010 et 2017. Durant cette période, ledit pourcentage a augmenté dans la quasitotalité des pays dont les données sont disponibles, en particulier en Estonie, en Hongrie, en Lettonie, en Nouvelle-Zélande et aux Pays-Bas.

- Dans l'ensemble, les pays anglophones sont les plus attractifs pour les étudiants en mobilité internationale. L'Australie, le Canada, les États-Unis et le Royaume-Uni accueillent ensemble plus de $40 \%$ des étudiants en mobilité dans tous les pays membres et partenaires de I'OCDE. L'Allemagne, la Fédération de Russie et la France comptent parmi les autres principaux pays de destination.

- Les Asiatiques forment le plus gros contingent d'étudiants en mobilité internationale en formation tertiaire (tous niveaux d'enseignement confondus) et représentaient $56 \%$ de l'effectif total d'étudiants en mobilité dans les pays de l'OCDE en 2017. Deux tiers des étudiants asiatiques convergent vers cinq pays seulement : l'Australie, le Canada, les États-Unis, le Japon et le Royaume-Uni. Les étudiants européens préfèrent rester dans l'Union européenne (UE) ; ils représentent $24 \%$ des étudiants en mobilité dans l'ensemble des pays de destination de I'OCDE, mais $42 \%$ dans les pays de destination de l'OCDE membres de l'UE.

\section{Graphique B6.1. Mobilité entrante des étudiants dans l'enseignement tertiaire en 2010 et 2017}

Pourcentage d'étudiants étrangers/en mobilité internationale dans les effectifs totaux de l'enseignement tertiaire

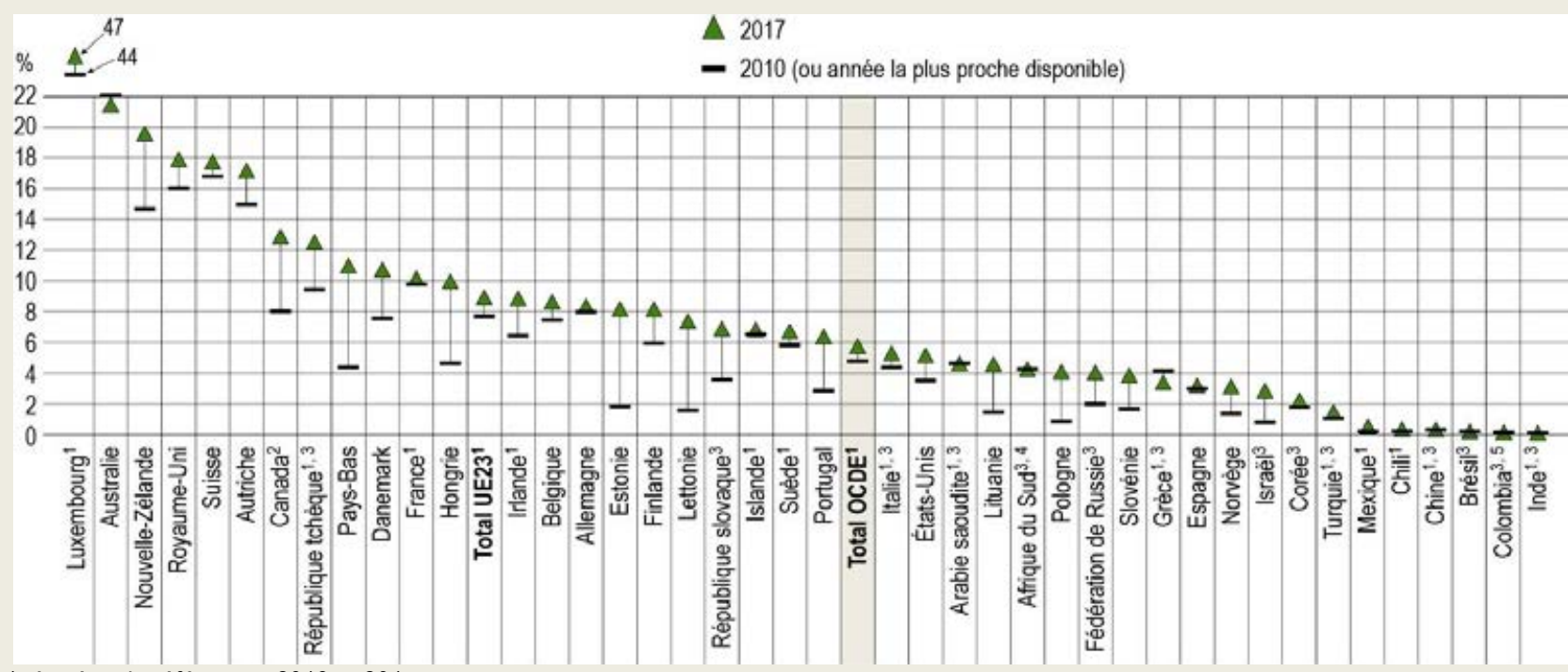

1. Années de référence : 2013 et 2017.

2. Années de référence : 2012 et 2017.

3. Pourcentage d'étudiants étrangers, et non en mobilité internationale.

4. Années de référence : 2013 et 2016.

5. Années de référence : 2014 et 2017.

Les pays sont classés par ordre décroissant du pourcentage d'étudiants étrangers/en mobilité internationale en 2017.

Source : OCDE/ISU/Eurostat (2019). Consulter la section «Source» pour tout complément d'information et l'annexe 3 pour les notes (https://doi.org/10.1787/f8d7880d-en). 


\section{Contexte}

Pour les jeunes adultes en formation dans l'enseignement tertiaire, étudier à l'étranger est une expérience distinctive majeure, et la mobilité internationale des étudiants suscite un intérêt croissant chez les responsables politiques depuis quelques années. Étudier à l'étranger offre la possibilité d'accéder à un enseignement de haute qualité, d'acquérir des compétences qui ne sont pas forcément enseignées dans le pays d'origine et de se rapprocher d'un marché du travail où le rendement de la formation est plus élevé. C'est aussi un moyen d'accroître l'employabilité sur des marchés d'emploi de plus en plus mondialisés. Découvrir d'autres sociétés et améliorer leurs compétences linguistiques, en particulier en anglais, font aussi partie de leurs motivations.

Pour les pays d'accueil, les étudiants en mobilité internationale peuvent être une source importante de revenus et avoir un énorme impact sur l'économie et l'innovation. Les étudiants en mobilité internationale paient souvent des frais de scolarité plus élevés que les ressortissants nationaux (voir l'indicateur C5) et s'acquittent de frais d'inscription plus élevés qu'eux dans certains pays. Ils contribuent aussi à l'économie locale par leur consommation durant leur séjour. À plus long terme, les individus très instruits sont susceptibles d'intégrer le marché du travail local et de contribuer à l'innovation et à la croissance économique.

Attirer les étudiants internationaux, en particulier s'ils restent après leurs études, est un moyen de puiser dans le réservoir mondial de talents, de compenser de plus faibles capacités aux niveaux inférieurs d'enseignement, de favoriser l'innovation et le développement des systèmes de production et, dans de nombreux pays, d'atténuer l'impact du vieillissement sur l'offre de main-d'œuvre qualifiée (OCDE, 2018[1]). Cette stratégie risque toutefois d'évincer les ressortissants nationaux des établissements où les frais de scolarité dépendent de la nationalité des étudiants et qui pourraient préférer accueillir des étudiants qui rapportent davantage grâce à des frais de scolarité plus élevés.

Dans les pays d'origine, la mobilité internationale des étudiants peut être considérée comme une perte de talents (ou une « fuite des cerveaux »). Pourtant, les étudiants mobiles contribuent à l'acquisition du savoir, à la modernisation des technologies et au renforcement des capacités dans leur pays d'origine, pour autant qu'ils y reviennent après leurs études ou qu'ils entretiennent à distance des liens forts avec leurs compatriotes sur place. Les étudiants internationaux acquièrent des connaissances tacites lors d'interactions informelles et peuvent permettre à leur pays d'origine d'intégrer les réseaux mondiaux du savoir. Selon certaines études, les étudiants qui partent à l'étranger sont une bonne variable prédictive de flux futurs de scientifiques en sens contraire, preuve d'un mouvement significatif de main-d'œuvre qualifiée entre les pays, ce que l'on appelle également « la circulation des cerveaux » (Appelt et al., 2015[2]). De plus, la mobilité des étudiants semble façonner plus profondément les réseaux internationaux de coopération scientifique que la proximité linguistique, géographique ou scientifique.

La course aux talents se mondialise et s'intensifie, ce qui pousse les établissements d'enseignement à puiser dans un vivier plus riche d'étudiants talentueux afin d'accroître leur réputation et leurs recettes (Hénard, Diamond et Roseveare, 2012[3]). La popularité des classements internationaux d'universités a accentué la perception d'un écart de qualité entre établissements (Perkins et Neumayer, 2014[4]). Dans le cadre de leur stratégie d'internationalisation, davantage d'établissements créent des campus satellites ou des formations à double diplôme, revoient leurs critères d'admission d'étudiants étrangers, modifient leurs programmes pour dispenser leurs cours en langue étrangère ou proposent des cours en ligne et des stages internationaux. Les activités internationales des établissements d'enseignement se sont donc non seulement intensifiées et diversifiées, mais elles sont aussi devenues plus complexes.

\section{Autres faits marquants}

- Le nombre d'étudiants en formation tertiaire à l'étranger a considérablement augmenté en quelques décennies, passant de 2 millions en 1998 à 5.3 millions en 2017. En 2017, 3.7 millions d'étudiants sont partis à l'étranger, dans un pays de l'OCDE, soit $6 \%$ de plus qu'en 2016.

- Les étudiants sont plus mobiles aux niveaux supérieurs d'enseignement. Dans l'enseignement tertiaire, les étudiants en mobilité internationale représentent seulement $3 \%$ de l'effectif total en formation de cycle court et $4 \%$ de l'effectif total en licence, mais $22 \%$ de l'effectif en doctorat. 


\section{Analyse}

\section{Évolution du nombre d'étudiants en mobilité internationale}

Dans l'OCDE, la migration des étudiants reste dynamique, mais la mobilité internationale des étudiants se consolide aussi dans les pays en développement (voir l'encadré B6.1). Cet indicateur porte à la fois sur les étudiants en mobilité internationale (ceux partis à l'étranger dans la seule intention d'y faire des études) et sur les étudiants étrangers (ceux qui n'ont pas la nationalité du pays où ils sont en formation), dont le nombre est utilisé dans certains pays comme indicateur du nombre d'étudiants en mobilité internationale (voir la section " Définitions »).

La concentration relative des étudiants étrangers et en mobilité internationale aux différents niveaux de l'enseignement tertiaire est révélatrice de la variation de l'attractivité des cursus entre les pays. Le pourcentage d'étudiants en mobilité internationale présents dans un pays s'évalue à l'aune de leur pourcentage dans l'effectif total d'étudiants de l'enseignement tertiaire. II s'établit à $6 \%$ en moyenne dans les pays de l'OCDE, mais est égal ou supérieur à $10 \%$ dans un tiers environ des pays de l'OCDE. Les étudiants en mobilité internationale représentent au moins $15 \%$ de l'effectif d'étudiants de l'enseignement tertiaire en Australie, en Autriche, au Luxembourg, en Nouvelle-Zélande, au Royaume-Uni et en Suisse, et leur pourcentage est le plus élevé au Luxembourg ( $47 \%$ ) et en Australie ( $21 \%$ ). Le pourcentage d'étudiants étrangers dans l'effectif d'étudiants de l'enseignement tertiaire est le plus élevé en République slovaque $(7 \%)$ et en République tchèque (13\%).

Dans les pays de l'OCDE, le pourcentage d'étudiants en mobilité internationale a augmenté de 0.4 point de pourcentage entre 2010 et 2013 et de 1.6 point de pourcentage entre 2013 et 2017 , mais la croissance de cet effectif varie sensiblement entre les pays. Entre 2010 et 2017, le pourcentage d'étudiants en mobilité internationale a augmenté dans la quasi-totalité des pays dont les données sont disponibles. II a légèrement diminué en Australie ( 1 point de pourcentage), mais reste élevé. Le pourcentage d'étudiants en mobilité internationale a augmenté de 3 points de pourcentage au moins durant la même période (voir le graphique B6.1) dans plus de la moitié de ces pays, en particulier aux Pays-Bas (de 7 points de pourcentage), en Estonie et en Lettonie (de 6 points de pourcentage), ainsi qu'en Hongrie et en Nouvelle-Zélande (de 5 points de pourcentage). II a le plus augmenté, de 2 points de pourcentage au moins, entre 2013 et 2017 en Irlande, au Luxembourg et en République tchèque parmi les pays dont les données portent sur une période plus courte.

L'analyse des tendances à plus long terme révèle que le nombre d'étudiants en mobilité inscrits en formation tertiaire a fortement augmenté dans le monde au cours des deux dernières décennies. II est passé de 2 millions en 1998 à 5.3 millions en 2017, soit un taux moyen de croissance de $5 \%$ par an dans les pays de l'OCDE et de $6 \%$ par an dans les pays tiers. Cette augmentation a été constante ; les pays ont enregistré les pourcentages les plus élevés en 2002-03 et en 2014-16, et une légère stabilisation des tendances à long terme en 1999, 2004 et 2012 (voir le graphique B6.2). Toutefois, le nombre d'étudiants en mobilité internationale a recommencé à augmenter fortement en 2014 (de $7 \%$, par rapport à 2013) et durant les années suivantes, avec une hausse annuelle de $8 \%$ en 2015 et en 2016. Cette croissance a été un peu plus modérée la dernière année dont les données sont disponibles ( $5 \%$ entre 2016 et 2017).

L'effectif d'étudiants étrangers a augmenté sous l'effet de divers facteurs internes ou externes d'incitation (les encourageant à quitter leur pays) ou d'attraction (les encourageant à se rendre à l'étranger) (UNESCO, 2013 ${ }_{[5]}$ ). La demande de compétences dans des économies de plus en plus basées sur le savoir et l'innovation a dopé la demande de diplômés de l'enseignement tertiaire dans le monde, alors que les systèmes d'éducation n'ont toujours pas évolué à un rythme suffisamment rapide pour y répondre à l'échelle nationale. L'enrichissement des économies émergentes a incité les jeunes issus d'une classe moyenne en plein essor à rechercher des possibilités de formation à l'étranger. Dans le même temps, des facteurs économiques (les tarifs des vols internationaux), technologiques (la possibilité de garder le contact grâce à Internet et aux médias sociaux) et culturels (l'emploi de l'anglais comme langue de travail et d'enseignement) ont largement contribué à démocratiser la mobilité internationale et à la rendre moins irréversible que par le passé. 
La plupart des pays ont engagé des réformes pour réduire les obstacles à la migration des individus plus qualifiés au-delà des objectifs de formation et participent à des programmes qui financent l'afflux, le départ ou le retour des étudiants. Les conditions de mobilité (à court ou long terme) varient, mais la plupart des programmes ciblent principalement les étudiants et les chercheurs avant et après le doctorat.

\section{Graphique B6.2. Croissance des effectifs d'étudiants étrangers/en mobilité internationale scolarisés dans l'enseignement tertiaire dans le monde entier (1998 à 2017)}

Nombre d'étudiants étrangers ou en mobilité internationale scolarisés dans des pays membres de l'OCDE ou non

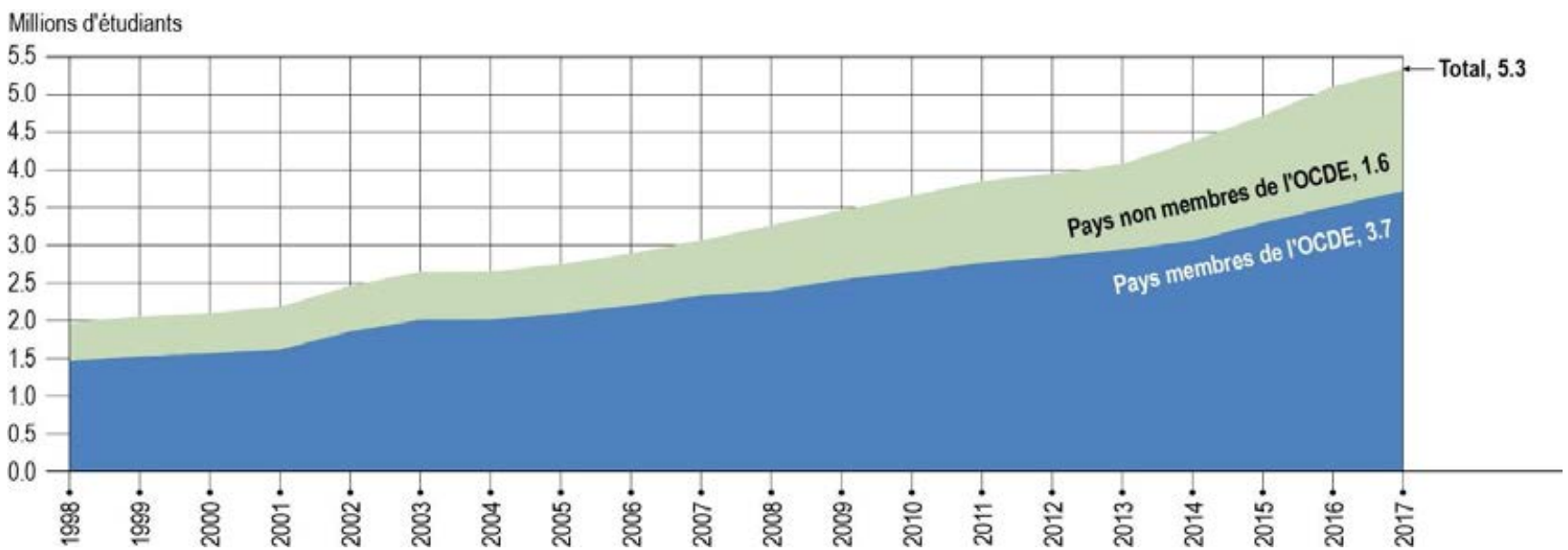

Remarque : Les sources des données utilisent des définitions similaires, permettant donc leur combinaison. Les données manquantes ont été imputées sur la base des données les plus proches pour éviter que des lacunes dans la couverture des données ne donnent lieu à des ruptures de séries chronologiques.

Source : OCDE/ISU/Eurostat (2019). Autres pays non membres de l'OCDE et années antérieures à 2013 : Institut de statistique de l'UNESCO. Consulter la section « Source » pour tout complément d'information et l'annexe 3 pour les notes (https://doi.org/10.1787/f8d7880d-en).

\section{Encadré B6.1. Évolution de l'effectif international de diplômés}

Le pourcentage de diplômés de l'enseignement tertiaire a augmenté chez les 25-34 ans dans les pays de l'OCDE et du G20 au cours de la dernière décennie et devrait continuer à augmenter dans les 15 prochaines années. Les pays à la traîne devraient enregistrer la plus forte hausse et rattraper leur retard, tandis que les pays où l'effectif de diplômés de l'enseignement tertiaire est déjà important devraient marquer le pas. Si les tendances actuelles se confirment, l'Inde et la République populaire de Chine pourraient se distinguer par un vivier particulièrement important de jeunes diplômés de l'enseignement tertiaire parmi les pays de l'OCDE et du G20, malgré la baisse prévue de l'effectif de jeunes en Chine.

Comme le montre le graphique B6.a, il est possible de prévoir la contribution régionale au vivier de jeunes diplômés de l'enseignement tertiaire des pays de l'OCDE et du G20 d'ici 2030 sur la base de l'évolution prévue du niveau de formation et des projections démographiques. La Chine et l'Inde, dont la part dans l'effectif de jeunes diplômés de l'enseignement tertiaire s'élevait à $40 \%$ en 2015, devraient conserver leur rang dans l'ensemble. La contribution de la Chine devrait diminuer de 4 points de pourcentage durant la prochaine décennie, essentiellement à cause de la décroissance démographique, mais celle de l'Inde devrait sensiblement augmenter. Les pays d'Amérique latine, où $20 \%$ des jeunes étaient diplômés de l'enseignement tertiaire en 2015 , devraient enregistrer une croissance particulièrement soutenue (de plus de $2.5 \%$ par an). 
Par contraste, c'est en Fédération de Russie et dans les pays d'Amérique du Nord que la croissance devrait être la moins forte.

Graphique B6.a. Projection des contributions des différentes régions à la population mondiale de diplômés de l'enseignement tertiaire âgés

de 25 à 34 ans (2015 à 2030)

Panneau A Contribution à la population de diplômés de l'enseignement tertiaire de l'OCDE-G20

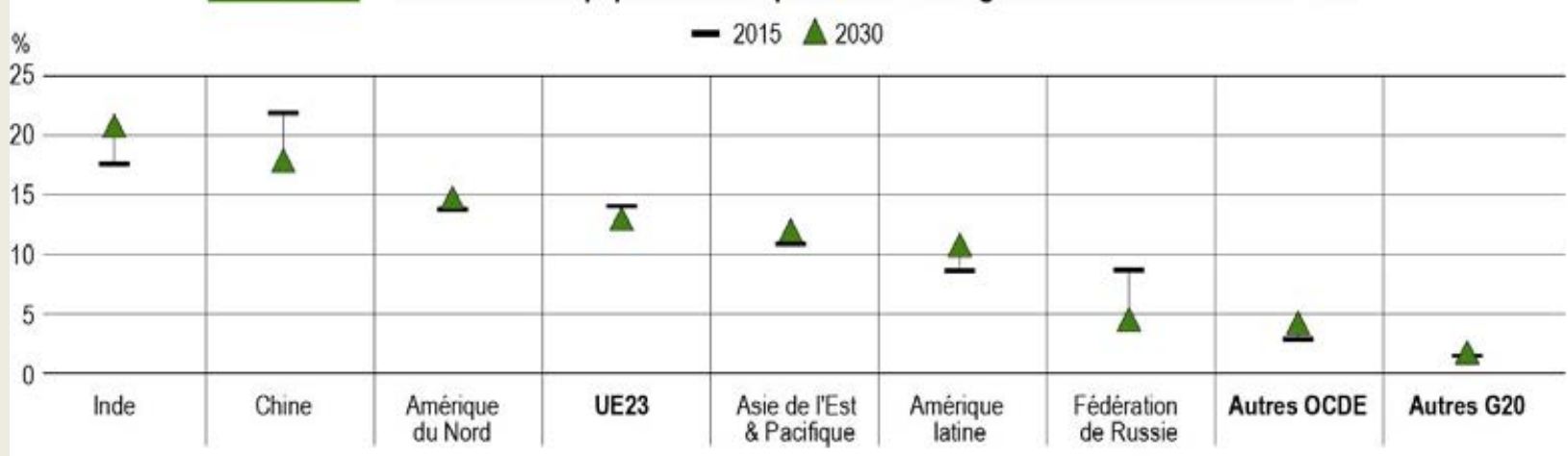

Panneau B Évolution annuelle moyenne du pourcentage d'adultes diplômés de l'enseignement tertiaire et de la population

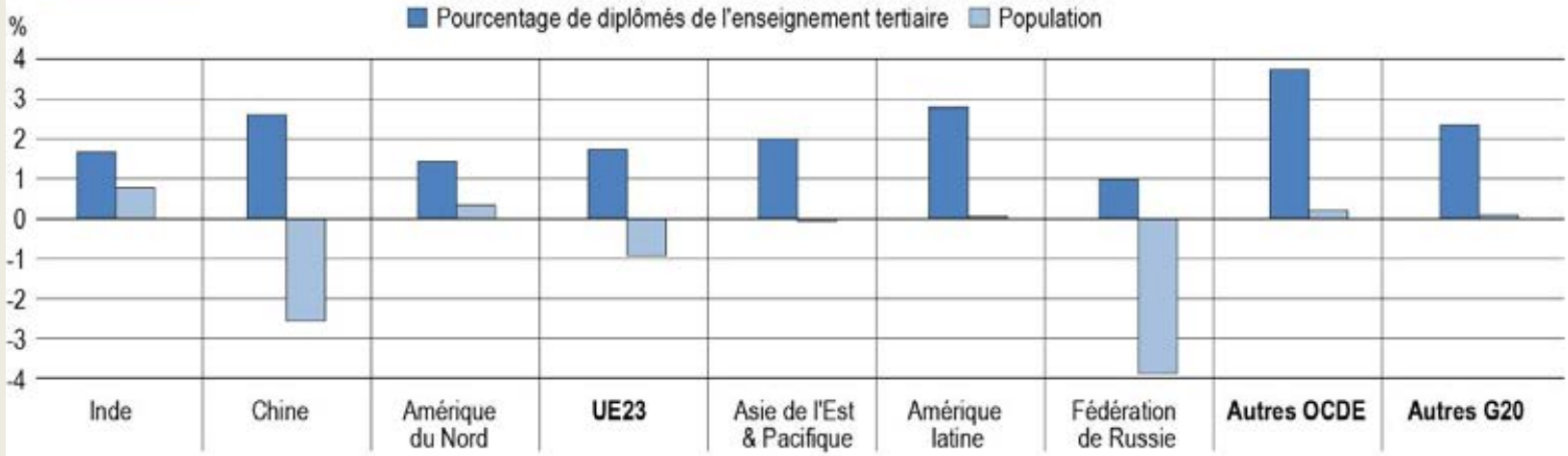

Lecture du graphique : La contribution de la Chine à la population de diplômés de l'enseignement tertiaire de l'OCDE-G20 devrait reculer, passant de $22 \%$ en 2015 à $18 \%$ en 2030 (panneau A), même si le pourcentage de diplômés de l'enseignement tertiaire âgés de 25 à 34 ans de ce pays devrait enregistrer une augmentation annuelle moyenne de $2.6 \%$ entre 2015 et 2030 . Le recul de la contribution de la Chine s'explique par la diminution annuelle de sa population de $2.6 \%$ (panneau B).

Les pays et régions sont classés par ordre décroissant de la projection de leur contribution à la population de diplômés de l'enseignement tertiaire âgés de 25 à 34 ans de l'OCDE-G20 en 2030.

Source : OCDE (2018[6]) «Diplômés de l'enseignement tertiaire : Quelles évolutions ? », Les indicateurs de l'éducation à la loupe, $n^{\circ} 61$, https://doi.org/10.1787/1a4e9f01-fr.

StatLink त्ता Sh https://doi.org/10.1787/888933978569

\section{Profil des étudiants en mobilité internationale}

Les étudiants sont plus susceptibles de voyager à l'étranger pour accéder à des niveaux supérieurs d'enseignement. Le pourcentage d'étudiants en mobilité internationale dans l'enseignement tertiaire augmente avec le niveau d'enseignement dans la quasi-totalité des pays. En moyenne, dans les pays de l'OCDE, les 
étudiants en mobilité internationale représentent $6 \%$ de l'effectif total de l'enseignement tertiaire, mais $22 \%$ de l'effectif total de doctorants.

En licence, le pourcentage d'étudiants en mobilité internationale reste relativement peu élevé (moins de $5 \%$ dans près de la moitié des pays dont les données sont disponibles). Toutefois, l'enseignement s'internationalise davantage en licence dans quelques pays. Plus de $15 \%$ des étudiants de licence sont en mobilité internationale en Autriche, au Luxembourg et en Nouvelle-Zélande (voir le graphique B6.3).

Le pourcentage d'étudiants en mobilité internationale augmente nettement en master. En moyenne, dans les pays de l'OCDE, $13 \%$ des étudiants sont en mobilité internationale ou étrangers à ce niveau d'enseignement. Le pourcentage d'étudiants en mobilité internationale passe au moins du simple au double entre la licence et le master dans près de deux tiers des pays de l'OCDE. Le pourcentage d'étudiants en mobilité internationale est au moins quatre fois plus élevé en master qu'en licence au Chili, en Espagne et en Suède. À l'autre extrême, la Grèce semble relativement moins attractive aux yeux des étudiants en master, car le pourcentage d'étudiants étrangers y est un peu moins élevé en master qu'en licence (voir le graphique B6.3).

\section{Graphique B6.3. Mobilité entrante des étudiants dans l'enseignement tertiaire, selon le niveau d'enseignement (2017)}

Pourcentage d'étudiants étrangers/en mobilité internationale dans les effectifs totaux de l'enseignement tertiaire

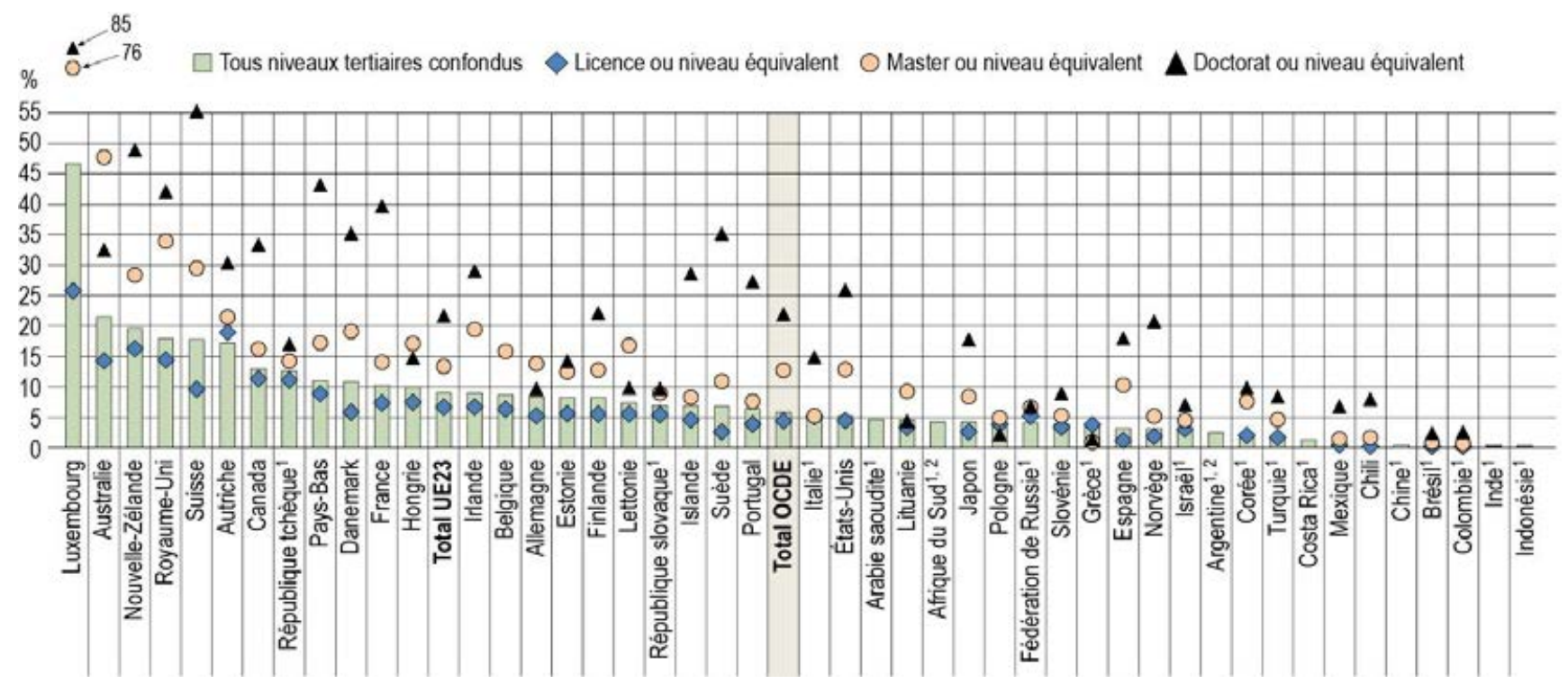

Remarque : La catégorie « Tous niveaux tertiaires confondus » inclut les programmes tertiaires de cycle court, qui ne font pas l'objet d'une catégorie distincte dans ce graphique.

1. Pourcentage d'étudiants étrangers, et non en mobilité internationale.

2. Année de référence : 2016.

Les pays sont classés par ordre décroissant du pourcentage d'étudiants étrangers/en mobilité internationale dans l'enseignement tertiaire.

Source: OCDE (2019), tableau B6.1. Consulter la section "Source» pour tout complément d'information et l'annexe 3 pour les notes (https://doi.org/10.1787/f8d7880d-en).

Les étudiants en mobilité internationale sont nettement plus nombreux en doctorat dans les pays de l'OCDE, en particulier en France, au Luxembourg, en Nouvelle-Zélande, aux Pays-Bas, au Royaume-Uni et en Suisse, où $40 \%$ au moins des doctorants viennent de l'étranger. Au Luxembourg et en Suisse, on compte plus d'étudiants en mobilité internationale que de ressortissants nationaux en doctorat (respectivement $85 \%$ et $55 \%$ des doctorants viennent de l'étranger). On compte davantage d'étudiants en mobilité internationale en doctorat qu'en 
master dans la plupart des pays, mais l'inverse s'observe dans un certain nombre de pays. C'est particulièrement frappant en Allemagne (14\% en master, contre $10 \%$ en doctorat), en Australie (48 \%, contre $32 \%$ ), en Hongrie $(17 \%$, contre $15 \%)$, en Lettonie (17\%, contre $10 \%)$, en Lituanie (9\%, contre $4 \%)$, et en Pologne (5\%, contre $2 \%$ ) (voir le graphique B6.3).

\section{Mobilité internationale des étudiants dans l'enseignement tertiaire}

En 2017, les pays de l'OCDE ont accueilli 3.7 millions d'étudiants en mobilité internationale dans l'enseignement tertiaire. Les effectifs et les flux de ces étudiants restent très concentrés dans le monde, et les choix de destination sont fortement influencés par des tendances historiques.

Identifier les facteurs déterminants de la mobilité internationale des étudiants est essentiel pour concevoir des politiques efficaces en vue d'encourager la circulation de la main-d'œuvre qualifiée. La mobilité des étudiants est stimulée par des différences de capacité entre les systèmes d'éducation (par exemple, le manque d'établissements d'enseignement dans les pays d'origine ou le prestige des établissements d'enseignement dans les pays de destination). Elle est également dopée par la variation du rendement de l'élévation du niveau de formation ou de l'amélioration des compétences entre les pays d'origine et les pays de destination. Parmi les facteurs économiques, citons les performances économiques plus élevées dans les pays de destination, les taux de change, le coût plus abordable de la mobilité (grâce à des frais de scolarité moins élevés ou à des aides au titre de l'éducation plus élevées, par exemple) et la meilleure qualité de l'instruction dans les pays de destination. De plus, la décision d'étudier à l'étranger peut être prise pour des raisons autres qu'économiques, par exemple la stabilité politique ou la proximité culturelle et religieuse entre les pays d'origine et de destination (Guha, 1977 [7] ; Weisser, 2016[8] ; UNESCO, 2013[5]).

Appliquer des frais de scolarité appropriés reste l'une des questions les plus débattues de la politique de l'éducation, d'autant que les responsables politiques cherchent à accroître les taux de scolarisation dans l'enseignement supérieur et à améliorer l'équité de l'éducation. Le coût des études à charge des individus varie sensiblement entre les pays, à cause des différences dans le modèle de financement des établissements d'enseignement tertiaire et dans les aides financières publiques accordées aux étudiants de l'enseignement tertiaire (voir l'indicateur C5).

Les étudiants en mobilité internationale tiennent compte de l'idée qu'ils se font de la qualité de l'enseignement et de la réputation des établissements lorsqu'ils choisissent leur pays de destination (Abbott et Silles, 2016 ${ }_{[9]}$ ). Les pays où les établissements d'enseignement en bonne position dans les classements internationaux sont nombreux figurent parmi les destinations les plus prisées par les étudiants en mobilité internationale. Dans le monde entier, les étudiants sont de plus en plus conscients des différences de qualité entre les systèmes d'enseignement tertiaire, car les classements internationaux des universités sont largement diffusés. Parallèlement, la capacité d'attirer des étudiants en mobilité internationale est devenue un critère d'évaluation de la performance et de la qualité des établissements. Comme les gouvernements cherchent à encourager l'internationalisation de l'enseignement supérieur, ils ont revu leurs accords de performance avec les établissements et tiennent désormais compte entre autres de l'afflux d'étudiants en mobilité internationale pour calculer les budgets alloués aux universités.

\section{Principaux pays d'origine et d'accueil des étudiants en mobilité internationale dans des pays de l'OCDE}

L'anglais est la langue véhiculaire par excellence à l'heure de la mondialisation : plus d'une personne sur quatre le parle dans le monde (Sharifian, 2013[10]). II n'est pas surprenant de constater que dans l'ensemble, les pays anglophones attirent le plus les étudiants : quatre d'entre eux accueillent plus de $40 \%$ des étudiants en mobilité internationale dans les pays membres et partenaires de l'OCDE. Les États-Unis sont en tête du classement des destinations des étudiants en mobilité internationale en formation tertiaire dans l'OCDE. Sur les 3.7 millions d'étudiants en mobilité internationale dans l'OCDE, 985000 ont choisi les États-Unis. Après les États-Unis, viennent le Royaume-Uni (qui accueille 436000 étudiants en mobilité internationale), l'Australie (381 000) et le Canada (210 000) parmi les pays anglophones (voir le graphique B6.4). Les États-Unis s'arrogent $22 \%$ du 
marché international de l'éducation dans les pays membres et partenaires de l'OCDE (et accueillent environ $18 \%$ de l'effectif mondial d'étudiants en mobilité internationale). La part de marché de l'Australie et du RoyaumeUni est comprise entre $9 \%$ et $10 \%$ et celle du Canada atteint $5 \%$, parmi les pays membres et partenaires de I'OCDE. La part de marché est encore plus importante en doctorat aux États-Unis, qui accueillent $26 \%$ de l'effectif total de doctorants en mobilité internationale dans des pays membres et partenaires de l'OCDE.

\section{Graphique B6.4. Parts du marché international de l'éducation (2017)}

Étudiants étrangers/en mobilité internationale scolarisés dans chaque pays de destination, en pourcentage de l'ensemble des effectifs d'étudiants en mobilité dans les pays membres ou partenaires de l'OCDE

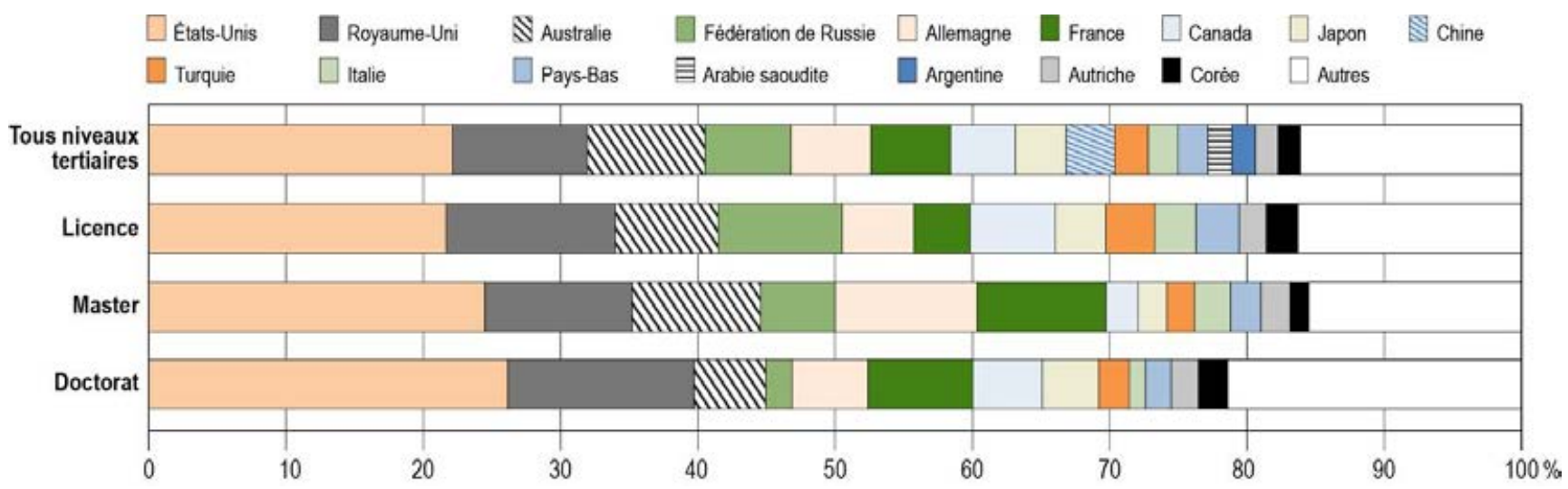

Remarque : La catégorie « Tous niveaux tertiaires confondus » inclut les programmes tertiaires de cycle court, qui ne font pas l'objet d'une catégorie distincte dans ce graphique. Année de référence : 2016 pour l'Afrique du Sud et l'Argentine.

Les pays sont classés par ordre décroissant des flux d'entrée d'étudiants étrangers/en mobilité internationale en pourcentage des effectifs totaux d'étudiants en mobilité dans les pays membres ou partenaires de l'OCDE.

Source: OCDE (2019), tableau B6.3. Consulter la section «Source» pour tout complément d'information et l'annexe 3 pour les notes (https://doi.org/10.1787/f8d7880d-en).

StatLink 제요 https://doi.org/10.1787/888933978531

L'Union européenne est une autre région majeure de destination : les 23 pays de l'OCDE également membres de I'UE (UE23) accueillent en effet 1.7 million d'étudiants en mobilité internationale. Après le Royaume-Uni, l'Allemagne et la France sont des pays majeurs de destination pour les étudiants en mobilité internationale (les deux pays en accueillent chacun 260000 ), loin devant l'Italie (98 000), les Pays-Bas (96 000) et l'Autriche (74 000). L'Allemagne et la France accueillent $6 \%$ de l'effectif d'étudiants en mobilité internationale dans des pays membres et partenaires de l'OCDE (soit environ $5 \%$ de l'effectif mondial). Ils en accueillent davantage en master : les deux pays accueillent entre $9 \%$ et $10 \%$ de l'effectif d'étudiants en mobilité en master dans des pays membres et partenaires de l'OCDE en 2017 (voir le tableau B6.3). La Fédération de Russie est également une destination majeure, avec 278000 étudiants venus de l'étranger, soit $6 \%$ de l'effectif d'étudiants en mobilité dans des pays membres et partenaires de l'OCDE tous niveaux de l'enseignement tertiaire confondus et $9 \%$ de cet effectif en licence.

Le Japon est la destination la plus prisée d'Asie parmi les pays membres et partenaires de l'OCDE : il accueille 164000 étudiants en mobilité internationale, un peu plus que la Chine (157 000 étudiants étrangers) ; les deux pays s'arrogent environ chacun $4 \%$ du marché de l'éducation internationale dans les pays membres et partenaires de l'OCDE et environ $3 \%$ du marché mondial. Enfin, l'Argentine est la destination la plus prisée en Amérique latine : elle accueille $2 \%$ de l'effectif d'étudiants en mobilité dans les pays membres et partenaires de l'OCDE (voir le graphique B6.4). 


\section{Encadré B6.2. Mobilité des crédits dans les pays européens membres de l’OCDE}

Les initiatives supranationales, nationales, régionales et locales ainsi que celles prises par des établissements ont aussi contribué à favoriser la mobilité internationale. En 2011, l'Union européenne (UE) s'est fixé l'objectif ambitieux d'accroître de 20 \% d'ici 2020 le pourcentage de diplômés de l'enseignement supérieur ayant suivi une partie de leurs études ou de leur formation à l'étranger (Conseil de l'Union européenne, 2011[11]).

\section{Tableau B6.a. Mobilité des crédits dans les pays européens membres de l'OCDE (2017)}

\begin{tabular}{|c|c|c|c|c|c|c|c|c|c|}
\hline & \multirow[b]{3}{*}{$\begin{array}{l}\text { Pourcentage } \\
\text { de diplômes } \\
\text { nationaux } \\
\text { bénéficiant } \\
\text { d'une mobilité } \\
\text { de crédits }\end{array}$} & \multirow{2}{*}{\multicolumn{2}{|c|}{$\begin{array}{l}\text { Pourcentage de diplômés } \\
\text { bénéficiant d'une mobilité } \\
\text { de crédits, selon la durée } \\
\text { de leur séjour }\end{array}$}} & \multicolumn{6}{|c|}{ Diplômés bénéficiant d'une mobilité de crédits (au moins 3 mois ou 15 crédits ECTS) } \\
\hline & & & & \multicolumn{2}{|c|}{$\begin{array}{l}\text { Répartition selon le type } \\
\text { de mobilité des crédits }\end{array}$} & \multicolumn{3}{|c|}{$\begin{array}{l}\text { Répartition selon le régime de mobilité } \\
\text { des crédits }\end{array}$} & \multirow{2}{*}{$\begin{array}{l}\text { Pourcentage de } \\
\text { titulaires d'un } \\
\text { master ou d'un } \\
\text { doctorat parmi } \\
\text { les diplômés } \\
\text { bénéficiant } \\
\text { d'une mobilite } \\
\text { de crédits }\end{array}$} \\
\hline & & $\begin{array}{c}\text { Moins de } 3 \text { mois } \\
\text { (ou } 15 \text { crédits } \\
\text { ECTS) }\end{array}$ & $\begin{array}{c}\text { Au moins } \\
3 \text { mois } \\
\text { (ou } 15 \text { crédits } \\
\text { ECTS) }\end{array}$ & $\begin{array}{c}\text { Etudes } \\
\text { ou êtudes } \\
\text { combinées avec } \\
\text { un stage }\end{array}$ & Stage & $\begin{array}{c}\text { Dans le cadre } \\
\text { de programmes } \\
\text { de rUE } \\
\text { (ERASMUS } \\
\text { ou autres) }\end{array}$ & $\begin{array}{l}\text { Dans le cadre } \\
\text { d'autres } \\
\text { programmes } \\
\text { internationaux/ } \\
\text { nationaux }\end{array}$ & $\begin{array}{c}\text { Autres } \\
\text { programmes }\end{array}$ & \\
\hline & (1) & & & (4) & (5) & (5) & (7) & (B) & (9) \\
\hline \multicolumn{10}{|l|}{ 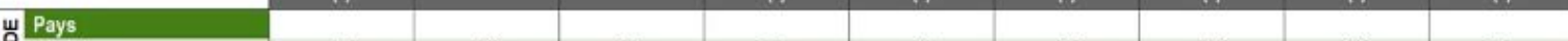 } \\
\hline Autriche & 17 & 19 & 81 & 77 & 23 & 58 & 19 & 23 & 55 \\
\hline Rèpublique tchéque & 10 & 16 & 84 & m & $\mathrm{m}$ & 85 & 1 & 14 & 67 \\
\hline Danemark & 12 & $\mathrm{~m}$ & $\mathrm{~m}$ & $\mathrm{~m}$ & m & 21 & 39 & 40 & 40 \\
\hline Finlande & 22 & 11 & 89 & 85 & 15 & 57 & 9 & 35 & 36 \\
\hline France & $\mathrm{m}$ & $\mathrm{m}$ & $\mathrm{m}$ & $\mathrm{m}$ & $\mathrm{m}$ & 29 & 16 & 55 & 65 \\
\hline Allemagne & 13 & $\mathrm{~m}$ & $\mathrm{~m}$ & 81 & 19 & 47 & 7 & 47 & 43 \\
\hline Grèce & 2 & $\mathrm{~m}$ & $\mathrm{~m}$ & $\mathrm{~m}$ & $\mathrm{~m}$ & 99 & 1 & 0 & 3 \\
\hline Hongrie & 4 & $\mathrm{~m}$ & $\mathrm{~m}$ & $\mathrm{~m}$ & $\mathrm{~m}$ & 95 & 4 & 1 & 52 \\
\hline Italio & 10 & $\mathrm{~m}$ & $\mathrm{~m}$ & $\mathrm{~m}$ & $\mathrm{~m}$ & 76 & 20 & 4 & 61 \\
\hline Lettonie & 9 & 4 & 96 & 100 & a & 96 & 3 & 1 & 20 \\
\hline Lituanie & 9 & 15 & 85 & 85 & 15 & 83 & 16 & 0 & 24 \\
\hline Luxembourg & 36 & a & 100 & 100 & a & 81 & 19 & 0 & 12 \\
\hline Pays-Bas & 28 & $\mathrm{~m}$ & $\mathrm{~m}$ & 70 & 30 & 37 & 12 & 50 & 27 \\
\hline Norvège & 10 & a & 100 & $\mathrm{~m}$ & $\mathrm{~m}$ & 3 & 83 & 14 & 44 \\
\hline Portugal & 8 & $\mathrm{~m}$ & $\mathrm{~m}$ & 87 & 13 & 90 & 9 & 1 & 33 \\
\hline République slovaque & 5 & 54 & 46 & 91 & 9 & 93 & 5 & 3 & 69 \\
\hline Slovénie & 3 & 16 & 84 & 66 & 34 & 95 & 4 & 1 & 40 \\
\hline Espagne & 9 & 7 & 93 & $\mathrm{~m}$ & $\mathrm{~m}$ & 86 & 14 & 0 & 23 \\
\hline Suede & 14 & 6 & 94 & $\mathrm{~m}$ & $\mathrm{~m}$ & 28 & 35 & 37 & 50 \\
\hline Suisse & 14 & 23 & 77 & 80 & 20 & 40 & 31 & 29 & 48 \\
\hline Royaume-Uni & 7 & 38 & 62 & 76 & 24 & 50 & 0 & 50 & 8 \\
\hline \multicolumn{10}{|l|}{ Economies } \\
\hline Comm. flamande (Belgique) & 9 & 18 & 82 & $\mathrm{~m}$ & m & 65 & 5 & 30 & 31 \\
\hline Moyenne & 12 & 16 & 84 & $\mathrm{~m}$ & $\mathrm{~m}$ & 64 & 16 & 20 & 39 \\
\hline
\end{tabular}

Remarque : Les crédits ECTS (European Credit Transfer and Accumulation System [Système européen de transfert et d'accumulation de crédits]) se basent sur la charge de travail nécessaire aux étudiants pour atteindre les résultats d'apprentissage escomptés. Soixante crédits correspondent à une année complète d'études ou de travail. Dans une année académique standard, ces 60 crédits se subdiviseraient en général en plusieurs sous-unités.

Source : OCDE/ISU/Eurostat (2019). Consulter la section «Source » pour tout complément d'information et l'annexe 3 pour les notes (https://doi.org/10.1787/f8d7880d-en).

StatLink त्नाज् https://doi.org/10.1787/888933978455

L'UE a déjà commencé à harmoniser l'enseignement supérieur et à le rendre plus comparable entre les pays et plus attractif aux yeux des étudiants en mobilité internationale avec l'adoption, en 1999, du processus de Bologne qui a entraîné une série de réformes. Le principal objectif du processus de Bologne était d'instaurer et de normaliser des études tertiaires en trois cycles (licence, master et doctorat) et de reconnaître les qualifications obtenues et les études faites à l'étranger. II visait aussi à doper la mobilité des étudiants, des enseignants et des chercheurs en Europe. 
Le programme Erasmus+ (et son prédécesseur le programme Erasmus) offre aux étudiants et aux enseignants la possibilité d'améliorer leurs compétences et leurs perspectives professionnelles. Les étudiants peuvent passer jusqu'à 12 mois en formation à l'étranger (durant chaque cycle de l'enseignement tertiaire). Entre 2014 et 2020, près de 2 millions d'étudiants devraient bénéficier du programme Erasmus+ (EUROSTAT, 2018[12]).

La mobilité des crédits concerne les étudiants en formation temporaire dans l'enseignement tertiaire à l'étranger dans l'intention d'y obtenir des crédits valables pour la formation suivie dans leur établissement d'attache (Institut de Statistique de I'Unesco, OCDE et Eurostat, 2016[13]). La mobilité des crédits est différente de la mobilité des diplômes, car les étudiants en quête d'un diplôme à l'étranger - l'objet du présent indicateur - partent dans l'intention d'obtenir un diplôme à l'étranger. En moyenne, dans les pays européens membres de l'OCDE, $12 \%$ des diplômés en 2017 ont obtenu des crédits à l'étranger; ce pourcentage est inférieur à $5 \%$ en Grèce et en Slovénie, mais atteint $36 \%$ au Luxembourg. Dans tous les pays, sauf en République slovaque, la plupart d'entre eux (84\% de ceux en quête de crédits) ont passé au moins trois mois (ou période équivalente en termes de charge de travail) en formation à l'étranger (voir le tableau B6.a). Parmi eux, 38 \% étaient en master ou en doctorat.

C'est grâce au Programme Erasmus+ et à d'autres programmes européens que la grande majorité des diplômés (64 \%) ont obtenu des crédits à l'étranger après une période de trois mois au moins. Ce pourcentage s'élève à $3 \%$ en Norvège (pays tiers de l'UE), à $21 \%$ au Danemark et à $95 \%$ ou plus en Grèce, en Hongrie, en Lettonie et en Slovénie. De plus, les étudiants peuvent obtenir des crédits à l'étranger grâce à d'autres programmes internationaux ou nationaux, dont des programmes bilatéraux ou multilatéraux, par exemple des partenariats entre universités ou autres programmes dans lesquels les étudiants organisent leur mobilité et dont les crédits sont transférés à leur établissement initial. Les pays nordiques et baltiques se sont par exemple associés dans le cadre du Nordplus Higher Education Programme pour créer un vaste dispositif de mobilité qui vise à renforcer la collaboration entre eux, à concevoir les formations en concertation, à favoriser la mobilité des enseignants et des étudiants et à faciliter l'échange de bonnes pratiques entre établissements.

La mobilité des crédits implique de faire des études, mais peut aussi intervenir dans d'autres cadres, des stages par exemple. Dans tous les pays dont les données sont disponibles, la plupart des diplômés qui se sont rendus à l'étranger pendant trois mois au moins l'ont fait dans l'intention d'y suivre des études (avec ou sans stage), mais dans 10 pays, ils peuvent aussi bénéficier de la mobilité des crédits dans le cadre d'un stage uniquement.

\section{Régions d'origine}

Les données sur les flux d'étudiants en mobilité internationale montrent que des facteurs de proximité, dont la langue, les liens historiques, la distance géographique, les relations bilatérales et les accords politiques (comme l'Espace européen de l'enseignement supérieur), ont une influence tout à fait déterminante sur le choix des pays de destination.

Les Asiatiques forment le plus gros contingent d'étudiants en mobilité internationale en formation tertiaire (tous niveaux d'enseignement confondus) et représentaient 2.1 millions de l'effectif total d'étudiants en mobilité dans les pays de l'OCDE, soit 56 \%, en 2017 (voir le graphique B6.5). Parmi eux, 860000 sont originaires de Chine. Deux tiers des étudiants asiatiques convergent vers cinq pays seulement : l'Australie, le Canada, les États-Unis, le Japon et le Royaume-Uni.

La deuxième région d'origine la plus importante est l'Europe : les Européens représentent $24 \%$ de l'effectif total d'étudiants en mobilité internationale en formation dans les pays de l'OCDE. Les étudiants européens préfèrent rester en Europe : ils représentent $42 \%$ des étudiants en mobilité dans l'EU23 (voir l'encadré B6.2). Au moins huit étudiants en mobilité sur dix en formation en Autriche, au Danemark, au Luxembourg, en Pologne, au Portugal, en République slovaque et en Slovénie sont originaires d'un pays d'Europe. Les étudiants 
luxembourgeois sont les plus mobiles dans l'enseignement tertiaire : trois sur quatre sont en formation à l'étranger dans l'enseignement tertiaire (ce qui explique la sous-estimation de l'effectif de l'enseignement tertiaire au Luxembourg, voir l'indicateur B1). Les étudiants originaires d'Islande et de République slovaque sont plus susceptibles de partir étudier à l'étranger que ceux originaires d'autres pays membres et partenaires de l'OCDE : entre $14 \%$ et $18 \%$ d'entre eux sont en formation tertiaire à l'étranger (voir le tableau B6.3). L'Autriche, le Luxembourg, la République slovaque, la République tchèque et la Suisse démontrent l'importance de la proximité géographique : plus de $50 \%$ des étudiants en mobilité internationale en formation dans ces pays en 2017 étaient originaires de pays limitrophes.

\section{Graphique B6.5. Répartition des étudiants étrangers/en mobilité internationale selon la région d’origine (2017)}

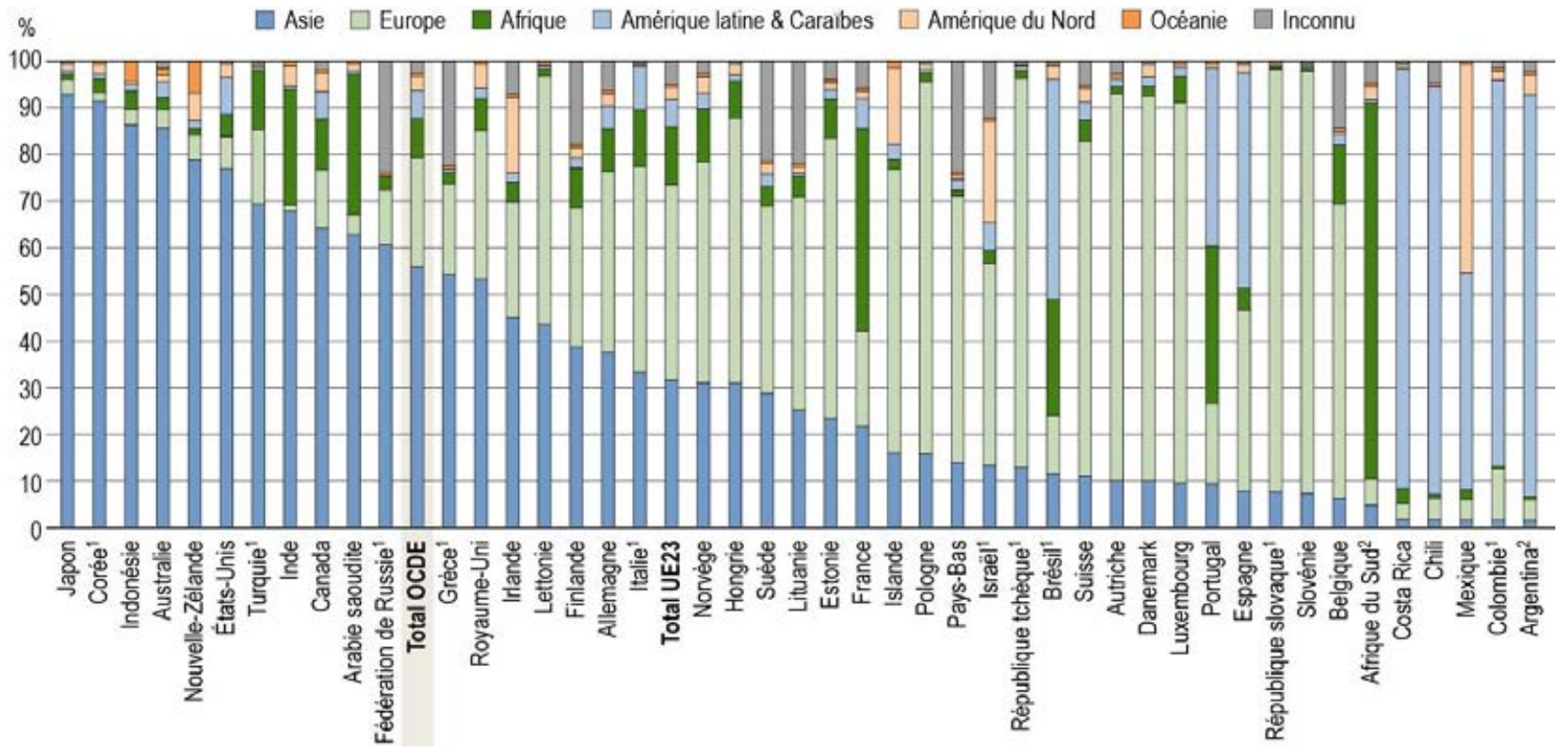

1. Pourcentage d'étudiants étrangers, et non en mobilité internationale.

2. Année de référence : 2016.

Les pays sont classés par ordre décroissant du pourcentage d'étudiants étrangers/en mobilité internationale originaires d'Asie.

Source: OCDE (2019), tableau B6.2. Consulter la section «Source» pour tout complément d'information et l'annexe 3 pour les notes (https://doi.org/10.1787/f8d7880d-en).

Les étudiants originaires d'Afrique ne sont majoritaires dans l'effectif d'étudiants en mobilité qu'en Afrique du Sud (81\%) parmi les pays membres et partenaires de l'OCDE ; ils sont au moins trois sur dix en Arabie saoudite, en France et au Portugal. Ceux originaires d'Amérique latine et des Caraïbes démontrent eux aussi l'importance de la proximité géographique, puisqu'ils sont majoritaires dans l'effectif d'étudiants en mobilité en Argentine, au Brésil, au Chili, en Colombie, au Costa Rica et au Mexique, ainsi que l'importance de la langue d'enseignement, puisqu'ils représentent entre quatre et cinq étudiants en mobilité sur dix en Espagne et au Portugal. Enfin, les étudiants originaires d'Amérique du Nord ne représentent plus de $10 \%$ de l'effectif d'étudiants en mobilité internationale qu'en Irlande, en Islande, en Israël et au Mexique, tandis que ceux originaires d'Océanie sont minoritaires dans l'effectif d'étudiants en mobilité internationale dans tous les pays membres et partenaires de l'OCDE et représentent $1 \%$ seulement de l'effectif d'étudiants en mobilité internationale dans les pays de l'OCDE (voir le graphique B6.5). 


\section{Définitions}

Il existe deux types de mobilité : la mobilité en quête d'un diplôme et la mobilité en quête de crédits. Les étudiants en quête d'un diplôme suivent à l'étranger pendant un semestre ou un trimestre une formation dans leur pays de destination dans l'intention d'en être diplômés (les étudiants à distance ne relèvent pas de la catégorie des étudiants en mobilité). Les étudiants en quête de crédits suivent une formation tertiaire ou font un stage à l'étranger dans le cadre de leur formation tertiaire dans leur pays d'origine, souvent dans l'intention d'engranger des crédits. Ils ne sont pas diplômés de la formation qu'ils ont suivie à l'étranger.

Par étudiants étrangers, on entend les étudiants en formation dans un pays dont ils ne sont pas ressortissants, parmi les pays dont les données sont disponibles. Ces étudiants sont comptabilisés comme étant en mobilité internationale, alors qu'ils peuvent résider depuis longtemps, voire être nés dans le pays où ils sont en formation. Cette définition est pragmatique et opérationnelle, mais n'est pas nécessairement appropriée pour prendre la mesure de la mobilité internationale des étudiants, en raison de différences dans les politiques nationales de naturalisation des immigrants. L'Australie a par exemple plus tendance que la Suisse à accorder le statut de résident permanent aux migrants. Pour cette raison, le pourcentage d'étudiants étrangers en formation tertiaire est similaire dans ces deux pays, mais le pourcentage d'étudiants en mobilité internationale à ce niveau d'enseignement est moins élevé en Suisse qu'en Australie. En conséquence, la prudence est de rigueur lors de l'interprétation des données qui se fondent sur le concept d'étudiants étrangers dans les comparaisons relatives à la mobilité des étudiants ainsi que dans les comparaisons bilatérales. En règle générale, les étudiants en mobilité internationale sont un sous-groupe des étudiants étrangers.

Par étudiants en mobilité internationale, on entend les étudiants qui ont quitté leur pays d'origine pour se rendre dans un autre pays avec l'intention d'y suivre des études. Le pays d'origine des étudiants est soit leur "pays d'obtention du diplôme de fin d'études secondaires ", soit leur " pays de scolarisation antérieure ", soit celui où ils avaient le statut de "résident permanent ou habituel » (voir ci-dessous). Selon la législation des pays en matière d'immigration (la libre circulation des personnes dans les pays membres de l'Union européenne et de l'Espace économique européen, par exemple) et les données disponibles, les étudiants en mobilité internationale peuvent être définis comme des individus qui suivent des études dans un pays autre que celui dont ils sont des résidents habituels ou permanents ou que celui dans lequel ils étaient scolarisés auparavant.

Par pays de scolarisation antérieure, on entend le pays où les étudiants ont obtenu le titre requis (un diplôme du deuxième cycle de l'enseignement secondaire ou de l'enseignement post-secondaire non tertiaire donnant accès à l'enseignement tertiaire) pour s'inscrire dans leur niveau d'enseignement actuel. Les pays qui ne sont pas en mesure d'appliquer concrètement cette définition sont invités à déterminer le pays d'origine sur la base de la résidence permanente ou habituelle ou, si cette approche ne convient pas non plus et qu'il n'existe pas d'autre indicateur probant, à le déterminer sur la base de la nationalité.

Le statut de résident permanent ou habituel est défini en fonction de la législation des pays ayant fourni des données. Dans les faits, ce statut peut être subordonné à l'obtention d'une autorisation ou d'un permis de séjour étudiant ou à la domiciliation dans un pays étranger l'année précédant l'inscription dans le système d'éducation du pays qui fournit les données.

Les définitions nationales spécifiques des étudiants en mobilité internationale sont indiquées dans les tableaux ainsi qu'à l'annexe 3 (https://doi.org/10.1787/f8d7880d-en).

\section{Méthodologie}

Définir et identifier les étudiants en mobilité internationale ainsi que leur forme de mobilité est un défi majeur dans l'élaboration de statistiques internationales d'éducation puisque les systèmes nationaux et internationaux de statistiques rendent uniquement compte de l'apprentissage à l'échelle nationale (OECD, 2018[14]). 
Les données sur les étudiants étrangers et en mobilité internationale ont été recueillies par leur pays de destination. Comme les effectifs totaux, les effectifs d'étudiants étrangers ou en mobilité internationale proviennent des registres d'inscription des établissements. Les étudiants inscrits dans des pays qui n'ont pas déclaré leur effectif d'étudiants en mobilité internationale ou d'étudiants étrangers à l'OCDE ou à l'Institut de statistique de I'UNESCO sont exclus et leur effectif total peut être sous-estimé dans leur pays d'origine.

L'effectif total d'étudiants en formation à l'étranger correspond au nombre d'étudiants en mobilité internationale, sauf si les données ne sont pas disponibles, auquel cas il correspond au nombre d'étudiants étrangers. Les effectifs sont estimés sur la base d'un recensement effectué à une date ou à une période déterminée de l'année.

Cette méthode a toutefois quelques inconvénients. Les statistiques internationales de l'OCDE sur l'éducation tendent à sous-estimer l'impact de l'enseignement à distance ou en ligne, en particulier les formations en ligne ouvertes à tous $(\mathrm{MOOC})$ en forte croissance ; et les étudiants qui se rendent chaque jour à l'étranger pour suivre leur formation ou qui participent à un programme d'échange de courte durée ne sont pas recensés. D'autres inconvénients résident dans la classification des étudiants en formation sur des campus à l'étranger (ou dans des écoles européennes) dans l'effectif d'étudiants des pays de destination.

Les données actuelles sur les étudiants en mobilité internationale portent uniquement sur les flux d'étudiants dans des pays de destination parmi les pays membres et partenaires de l'OCDE. II n'est pas possible d'évaluer leurs flux en dehors de l'OCDE, ni la contribution des échanges Sud-Sud à la circulation mondiale des cerveaux.

Pour de plus amples informations, veuillez consulter le Guide de l'OCDE pour l'établissement de statistiques internationalement comparables dans le domaine de l'éducation 2018: Concepts, normes, définitions et classifications (OCDE, 2019 ${ }_{[15]}$ ) et les notes spécifiques aux pays à l'annexe 3 (https://doi.org/10.1787/f8d7880den).

\section{Source}

Les données se rapportent à l'année académique 2016/17 et proviennent de l'exercice UNESCOISU/OCDE/Eurostat de collecte de données statistiques sur l'éducation réalisé par l'OCDE en 2018 (pour plus de précisions, voir l'annexe 3, https://doi.org/10.1787/f8d7880d-en). Les données sur les étudiants en quête de crédits proviennent de l'exercice UNESCO-ISU/OCDE/Eurostat de collecte de données statistiques sur l'éducation réalisé par Eurostat en 2018.

L'Institut de statistique (ISU) de l'UNESCO a fourni les données 1) de l'Afrique du Sud, de l'Arabie saoudite, de l'Argentine, de la Chine, de l'Inde et de l'Indonésie ; 2) de tous les pays autres que les pays membres et partenaires de l'OCDE; et 3) des pays de l'OCDE durant la période que ne couvrent pas les statistiques de l'OCDE (en 2005 et entre 2010 et 2017).

\section{Remarque concernant les données fournies par Israël}

Les données statistiques concernant Israël sont fournies par et sous la responsabilité des autorités israéliennes compétentes. L'utilisation de ces données par l'OCDE est sans préjudice du statut des hauteurs du Golan, de Jérusalem-Est et des colonies de peuplement israéliennes en Cisjordanie aux termes du droit international.

\section{Références}

Abbott, A. et M. Silles (2016), « Determinants of international student migration », The World Economy, vol. 39/5, pp. 621-635, http://dx.doi.org/10.1111/twec.12319. 
Appelt, S. et al. (2015), "Which factors influence the international mobility of research scientists? ", Documents de travail de l'OCDE sur la science, la technologie et l'industrie, $n^{\circ}$ 2015/2, Éditions OCDE, Paris, https://dx.doi.org/10.1787/5js1tmrr2233-en.

Conseil de l'Union européenne (2011), « Conclusions du Conseil sur la modernisation de l'enseignement supérieur », 3128e Conseil Éducation, Jeunesse, Culture et Sport, Bruxelles, 28-29 novembre 2011, Conseil de l'Union européenne, Bruxelles.

EUROSTAT (2018), Learning mobility statistics - Statistics Explained, https://ec.europa.eu/eurostat/statisticsexplained/index.php/Learning mobility statistics\#Credit mobile students (consulté le 4 juin 2019).

Guha, A. (1977), « Brain-drain issue and indicators on brain-drain », International Migration, vol. 15/1, pp. 3-20, http://dx.doi.org/10.1111/j.1468-2435.1977.tb00953.x.

Hénard, F., L. Diamond et D. Roseveare (2012), Approaches to Internationalisation and Their Implications for Strategic Management and Institutional Practice: A Guide for Higher Education Institutions, OECD, http://www.oecd.org/education/imhe/Approaches\%20to\%20internationalisation $\% 20-\% 20$ final\%20\%20web.pdf (consulté le 29 avril 2018).

Institut de Statistique de I'Unesco, OCDE et Eurostat (2016), UOE data collection on formal education: Manual on concepts, definitions and classifications, Institut de Statistique de I'Unesco, OCDE et Eurostat, Montreal, Paris, Luxembourg, http://uis.unesco.org/sites/default/files/documents/uoe2016manual 11072016 0.pdf (consulté le 26 juillet 2018).

OCDE (2019), Guide de l'OCDE pour l'établissement de statistiques internationalement comparables dans le domaine de l'éducation 2018: Concepts, normes, définitions et classifications, Éditions OCDE, Paris, https://dx.doi.org/10.1787/9789264305380-fr.

OCDE (2018), « Diplômés de l'enseignement tertiaire: Quelles évolutions ? », Les indicateurs de l'éducation à la loupe, $\mathrm{n}^{\circ}$ 61, Éditions OCDE, Paris, https://dx.doi.org/10.1787/1a4e9f01-fr.

OCDE (2018), Science, technologie et innovation : Perspectives de l'OCDE 2016, Éditions OCDE, Paris, https://dx.doi.org/10.1787/sti in outlook-2016-fr.

OECD (2018), OECD Handbook for Internationally Comparative Education Statistics 2018: Concepts, Standards, Definitions and Classifications, OECD Publishing, Paris, https://doi.org/10.1787/9789264304444-en.

Perkins, R. et E. Neumayer (2014), « Geographies of educational mobilities: Exploring the uneven flows of international students », The Geographical Journal, vol. 180/3, pp. 246-259, http://dx.doi.org/10.1111/geoj.12045.

Sharifian, F. (2013), « Globalisation and developing metacultural competence in learning English as an International Language », Multilingual Education, vol. 3/1, p. 7, http://dx.doi.org/10.1186/2191-5059$\underline{3-7}$.

UNESCO (2013), The International Mobility of Students in Asia and the Pacific, UNESCO, Paris, http://unesdoc.unesco.org/images/0022/002262/226219E.pdf (consulté le 7 mai 2018). 
Weisser, R. (2016), « Internationally mobile students and their post-graduation migratory behaviour: An analysis of determinants of student mobility and retention rates in the EU », Documents de travail de l'OCDE sur les questions sociales, l'emploi et les migrations, $n^{\circ} 186$, Éditions OCDE, Paris, http://dx.doi.org/10.1787/5jlwxbvmb5zt-en.

\section{Tableaux de l'indicateur B6}

Tableau B6.1

Tableau B6.2

Tableau B6.3
Étudiants étrangers/en mobilité internationale scolarisés dans l'enseignement tertiaire (2010, 2013 et 2017)

Répartition des étudiants étrangers/en mobilité internationale, selon le domaine d'études et la région d'origine (2017)

Profil des effectifs d'étudiants étrangers/en mobilité internationale (2017)

Date butoir pour les données : 19 juillet 2019. Les mises à jour peuvent être consultées en ligne à l'adresse : http://dx.doi.org/10.1787/eag-data-fr. D'autres données désagrégées sont également disponibles dans la Base de données de Regards sur l'éducation (http://stats.oecd.org/).

StatLink : https://doi.org/10.1787/888933981020 
Tableau B6.1. Étudiants étrangers/en mobilité internationale scolarisés dans l'enseignement tertiaire (2010, 2013 et 2017) Pourcentage d'étudiants étrangers/en mobilité internationale dans les effectifs totaux de l'enseignement tertiaire

Lecture de la $1^{10}$ colonne de la partie supérieure du tableau (étudiants en mobilité internationale) : Le pourcentage d'étudiants en mobilitẻ internationale dans les effectifs totaux de l'enseignement tertiaire représente $21 \%$ en Australie et $18 \%$ en Suisse.

Lecture de la $1^{\text {" }}$ colonne de la partie inférieure du tableau (étudiants étrangers) : Les ressortissants étrangers représentent $3 \%$ des effectifs totaux de l'enseignement tertiaire en Grèce, et $2 \%$ en Corée.

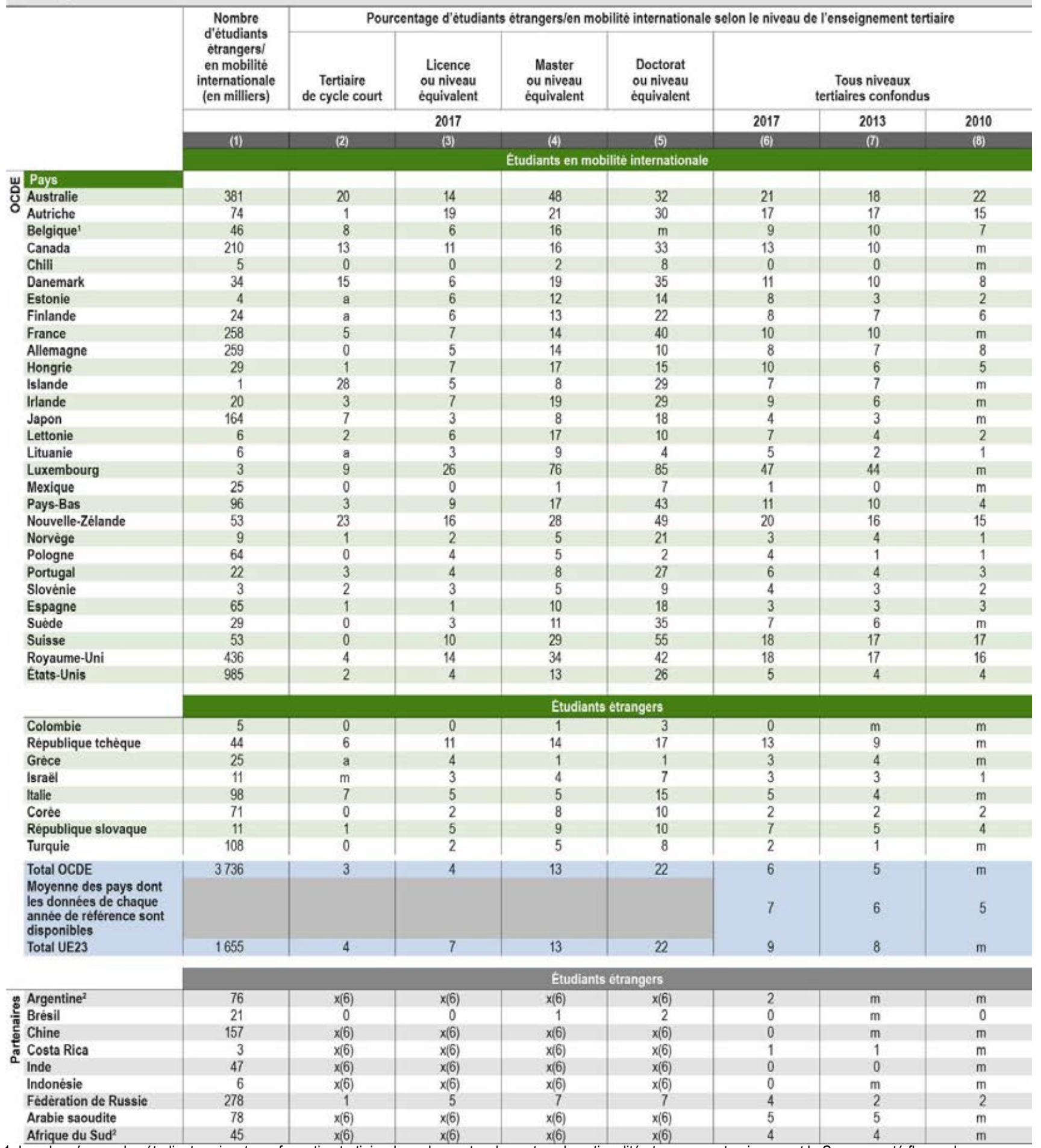

1. Les données sur les étudiants suivant une formation tertiaire de cycle court se basent sur la nationalité et concernent uniquement la Communauté flamande.

2. Année de référence : 2016.

Source : OCDE/ISU/Eurostat (2019). Consulter la section « Source » pour tout complément d'information et l'annexe 3 pour les notes (http://dx.doi.org/10.1787/eag-201936-en).

Les symboles représentant les données manquantes et les abréviations figurent dans le Guide du lecteur.

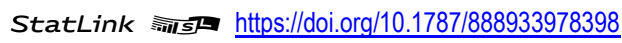


Tableau B6.2 Répartition des étudiants étrangers/en mobilité internationale, selon le domaine d'études et la région d'origine (2017) Tous programmes tertiaires confondus

\begin{tabular}{|c|c|c|c|c|c|c|c|c|c|c|c|c|c|c|c|c|}
\hline & \multicolumn{10}{|c|}{ Rèpartition des ètudiants ètrangers/en mobilitè internationale selon le domaine d'ètudes } & \multicolumn{6}{|c|}{$\begin{array}{l}\text { Répartition des étudiants étrangers/en mobilité } \\
\text { internationale selon la région d'origine }\end{array}$} \\
\hline & 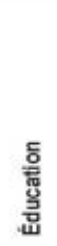 & 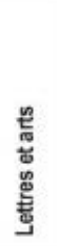 & 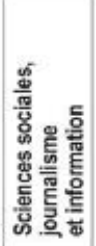 & 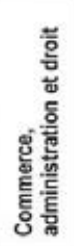 & 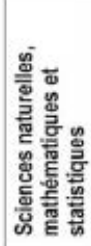 & 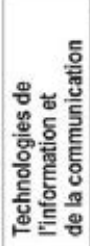 & 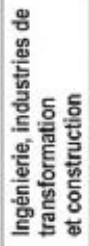 & 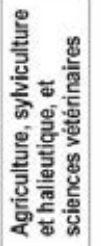 & 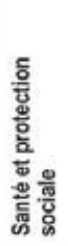 & 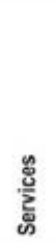 & $\frac{\text { בั }}{\frac{9}{2}}$ & 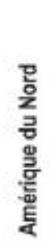 & 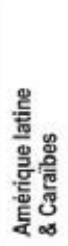 & $\frac{9}{8}$ & $\begin{array}{l}\text { 을 } \\
\text { 플 }\end{array}$ & 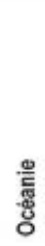 \\
\hline & (1) & (2) & (3) & (4) & (5) & (6) & (7) & (8) & (9) & (10) & (11) & (12) & (13) & (14) & (15) & (16) \\
\hline & \multicolumn{16}{|c|}{ Etudiants en mobilité internationale } \\
\hline w Pays & & & & & & & & & & & & & & & & \\
\hline Ô. Australie & 2 & 7 & 3 & 51 & 5 & 10 & 12 & 1 & 9 & 1 & 3 & 1 & 3 & 86 & 4 & 1 \\
\hline Autriche & 6 & 15 & 20 & 16 & 10 & 5 & 16 & 2 & 9 & 1 & 1 & 1 & 2 & 10 & 83 & 0 \\
\hline Belgique & 3 & 14 & 11 & 12 & 4 & 2 & 11 & 5 & 36 & 2 & 13 & 1 & 2 & 6 & 63 & 0 \\
\hline Canada & 1 & 10 & 12 & 29 & 12 & 7 & 19 & 2 & 5 & 1 & 11 & 4 & 6 & 64 & 12 & 0 \\
\hline Chili & 10 & 5 & 7 & 33 & 6 & 3 & 15 & 2 & 13 & 6 & 1 & 1 & 88 & 2 & 5 & 0 \\
\hline Danemark & 2 & 12 & 8 & 28 & 6 & 7 & 20 & 2 & 8 & 5 & 2 & 3 & 2 & 10 & 83 & 1 \\
\hline Estonie & 1 & 13 & 11 & 39 & 5 & 10 & 13 & 5 & 4 & 0 & 8 & 2 & 2 & 23 & 60 & 0 \\
\hline Finlande & 3 & 10 & 5 & 23 & 6 & 17 & 20 & 2 & 10 & 5 & 8 & 3 & 2 & 39 & 30 & 0 \\
\hline France' 1 & 2 & 16 & 11 & 30 & 12 & 5 & 16 & 0 & 6 & 1 & 43 & 2 & 6 & 22 & 20 & 0 \\
\hline Allemagne & 2 & 17 & 8 & 18 & 9 & 9 & 30 & 2 & 6 & 1 & 9 & 3 & 5 & 38 & 39 & 0 \\
\hline Hongrie & 3 & 10 & 12 & 9 & 3 & 4 & 10 & 8 & 41 & 2 & 8 & 3 & 1 & 31 & 57 & 0 \\
\hline Islande & 6 & 46 & 7 & 10 & 17 & 1 & 6 & 2 & 3 & 1 & 2 & 16 & 3 & 16 & 61 & 1 \\
\hline Irlande & 3 & 10 & 6 & 21 & 8 & 9 & 11 & 1 & 28 & 2 & 4 & 16 & 2 & 45 & 25 & 1 \\
\hline Japon $^{2}$ & $2^{\mathrm{d}}$ & $26^{4}$ & $43^{\circ}$ & $x(3)$ & $2^{\mathrm{d}}$ & $\mathrm{x}$ & $19^{d}$ & $2^{\mathrm{a}}$ & $3^{4}$ & $3^{\circ}$ & 1 & 2 & 1 & 93 & 3 & 0 \\
\hline Lettonie & $i$ & 4 & 7 & 31 & 1 & 8 & 9 & 0 & 32 & 8 & 2 & 1 & 0 & 44 & 53 & 0 \\
\hline Lituanie & 2 & 12 & 18 & 26 & 1 & 3 & 15 & 1 & 19 & 1 & 4 & 2 & 1 & 25 & 46 & 0 \\
\hline Luxembourg & 5 & 7 & 12 & 45 & 8 & 7 & 7 & 2 & 5 & 3 & 5 & 1 & 2 & 9 & 82 & 0 \\
\hline Mexique & $\mathrm{m}$ & $\mathrm{m}$ & $\mathrm{m}$ & $\mathrm{m}$ & $\mathrm{m}$ & $\mathrm{m}$ & $\mathrm{m}$ & $\mathrm{m}$ & $\mathrm{m}$ & $\mathrm{m}$ & 2 & 45 & 47 & 2 & 4 & 0 \\
\hline Pays-Bas & 2 & 12 & 18 & 30 & 7 & 3 & 12 & 2 & 8 & 6 & 1 & 1 & 2 & 14 & 57 & 0 \\
\hline Nouvelle-Zelande & 4 & 7 & 8 & 37 & 8 & 10 & 12 & 2 & 5 & 7 & 1 & 6 & 2 & 79 & 5 & 7 \\
\hline Norvège & 5 & 19 & 11 & 13 & 16 & 6 & 13 & 2 & 12 & 3 & 11 & 3 & 3 & 31 & 47 & 1 \\
\hline Pologne & 3 & 9 & 20 & 28 & 2 & 7 & 7 & 1 & 14 & 9 & 2 & 2 & 0 & 16 & 80 & 0 \\
\hline Portugal & 7 & 12 & 12 & 23 & 6 & 2 & 21 & 1 & 11 & 5 & 34 & 1 & 38 & 9 & 17 & 0 \\
\hline Slovenie & 5 & 11 & 16 & 16 & 7 & 6 & 22 & 3 & 8 & 5 & 1 & 0 & 1 & 7 & 91 & 0 \\
\hline Espagne & 6 & 8 & 10 & 24 & 5 & 2 & 12 & 2 & 25 & 4 & 5 & 2 & 46 & 8 & 39 & 0 \\
\hline Suéde & 3 & 12 & 13 & 12 & 14 & 7 & 25 & 1 & 12 & 1 & 4 & 2 & 3 & 29 & 40 & 0 \\
\hline Suisse & 5 & 14 & 12 & 21 & 17 & 3 & 18 & 1 & 8 & 2 & 5 & 3 & 4 & 11 & 72 & 0 \\
\hline Royaume-Uni & 2 & 13 & 12 & 33 & 12 & 5 & 15 & 1 & 7 & 0 & 7 & 5 & 2 & 53 & 32 & 1 \\
\hline \multirow[t]{2}{*}{ États-Unis ${ }^{3}$} & 3 & $14^{4}$ & 10 & 24 & 9 & 11 & 20 & 1 & $7^{4}$ & 2 & 5 & 3 & 8 & 77 & 7 & 1 \\
\hline & \multicolumn{16}{|c|}{ Étudiants êtrangers } \\
\hline Colombie & 8 & 10 & 13 & 28 & 2 & 4 & 15 & 2 & 17 & 3 & 1 & 2 & 83 & 2 & 11 & 0 \\
\hline Rèpublique tchèque & 2 & 9 & 10 & 20 & 7 & 10 & 14 & 3 & 19 & 4 & 2 & 1 & 1 & 13 & 83 & 0 \\
\hline Grèce & 5 & 19 & 14 & 14 & 10 & 3 & 16 & 2 & 11 & 4 & 3 & 1 & 0 & 54 & 19 & 0 \\
\hline Israë| & 7 & 19 & 18 & 16 & 12 & 5 & 9 & 1 & 12 & 0 & 3 & 22 & 6 & 13 & 43 & 1 \\
\hline Italic & 2 & 26 & 11 & 19 & 5 & 2 & 21 & 2 & 11 & 0 & 12 & 1 & 9 & 33 & 44 & 0 \\
\hline Corée & 2 & 20 & 14 & 30 & 3 & 3 & 14 & 1 & 4 & 7 & 3 & 2 & 1 & 91 & 2 & 0 \\
\hline République slovaque & 8 & 7 & 4 & 10 & 2 & 2 & 6 & 3 & 56 & 2 & 1 & 0 & 0 & 8 & 91 & 0 \\
\hline Turquie & 6 & 13 & 14 & 19 & 6 & 1 & 25 & 2 & 12 & 3 & 13 & 1 & 0 & 69 & 16 & 0 \\
\hline Total OCDE & 3 & 14 & 11 & 27 & 8 & 7 & 18 & 1 & 9 & 2 & 8 & 3 & 6 & 56 & 24 & 1 \\
\hline \multirow[t]{2}{*}{ Total UE23 } & 3 & 14 & 12 & 25 & 9 & 6 & 17 & 1 & 11 & 2 & 13 & 3 & 6 & 32 & 42 & 0 \\
\hline & \multicolumn{16}{|c|}{ Etudiants etrangers } \\
\hline Argentine & $\mathrm{m}$ & $\mathrm{m}$ & $\mathrm{m}$ & $\mathrm{m}$ & $\mathrm{m}$ & $\mathrm{m}$ & $\mathrm{m}$ & $\mathrm{m}$ & $\mathrm{m}$ & $\mathrm{m}$ & 1 & 5 & 86 & 2 & 4 & 0 \\
\hline Brésil & 10 & 8 & 8 & 18 & 8 & 4 & 22 & 5 & 13 & 4 & 25 & 3 & 47 & 12 & 12 & 0 \\
\hline Ê Chine & $\mathrm{m}$ & $\mathrm{m}$ & $\mathrm{m}$ & m & $\mathrm{m}$ & m & m & $\mathrm{m}$ & $\mathrm{m}$ & m & $\mathrm{m}$ & $\mathrm{m}$ & $\mathrm{m}$ & m & $\mathrm{m}$ & m \\
\hline Costa Rica & m & $\mathrm{m}$ & m & $\mathrm{m}$ & $\mathrm{m}$ & $\mathrm{m}$ & $\mathrm{m}$ & $\mathrm{m}$ & $\mathrm{m}$ & $\mathrm{m}$ & 3 & 1 & 90 & 2 & 3 & 0 \\
\hline Inde & $\mathrm{m}$ & $\mathrm{m}$ & $\mathrm{m}$ & $\mathrm{m}$ & $\mathrm{m}$ & $\mathrm{m}$ & $\mathrm{m}$ & $\mathrm{m}$ & $\mathrm{m}$ & $\mathrm{m}$ & 25 & 4 & 0 & 68 & 1 & 1 \\
\hline Indonésie & $\mathrm{m}$ & $\mathrm{m}$ & m & m & $\mathrm{m}$ & m & $\mathrm{m}$ & $\mathrm{m}$ & $\mathrm{m}$ & $\mathrm{m}$ & 4 & 0 & 2 & 86 & 3 & 4 \\
\hline Federation de Russie & $\mathrm{m}$ & $\mathrm{m}$ & m & $\mathrm{m}$ & $\mathrm{m}$ & m & $\mathrm{m}$ & $\mathrm{m}$ & $\mathrm{m}$ & m & 3 & 0 & 0 & 61 & 12 & 0 \\
\hline Arabie saoudite & $\mathrm{m}$ & $\mathrm{m}$ & $\mathrm{m}$ & $\mathrm{m}$ & $\mathrm{m}$ & $\mathrm{m}$ & $\mathrm{m}$ & $\mathrm{m}$ & $\mathrm{m}$ & $\mathrm{m}$ & 30 & 2 & 0 & 63 & 4 & 0 \\
\hline Afrique du Sud" & $\mathrm{m}$ & $\mathrm{m}$ & $\mathrm{m}$ & $\mathrm{m}$ & $\mathrm{m}$ & $\mathrm{m}$ & $\mathrm{m}$ & $\mathrm{m}$ & $\mathrm{m}$ & $\mathrm{m}$ & 81 & 3 & 1 & 5 & 6 & 0 \\
\hline
\end{tabular}

Remarque : Ce tableau ne présente pas les pourcentages d'étudiants scolarisés dans des programmes généraux et de ceux dont la région d'origine n'est pas connue. 1. Le pourcentage d'étudiants selon le pays d'origine se base sur des critères de nationalité.

2. Les données sur les technologies de l'information et de la communication sont incluses dans d'autres domaines.

3. La colonne 2 inclut l'ensemble des programmes interdisciplinaires, et la colonne 9 , l'administration publique.

4. Année de référence : 2016

Source : OCDE/ISU/Eurostat (2019). Consulter la section « Source » pour tout complément d'information et l'annexe 3 pour les notes (http://dx.doi.org/10.1787/eag-201936-en).

Les symboles représentant les données manquantes et les abréviations figurent dans le Guide du lecteur.

StatLink त्ञाजी https://doi.org/10.1787/888933978417 
Tableau B6.3. Profil de mobilite] des eltudiants eltrangers/en mobilite] internationale (2017)

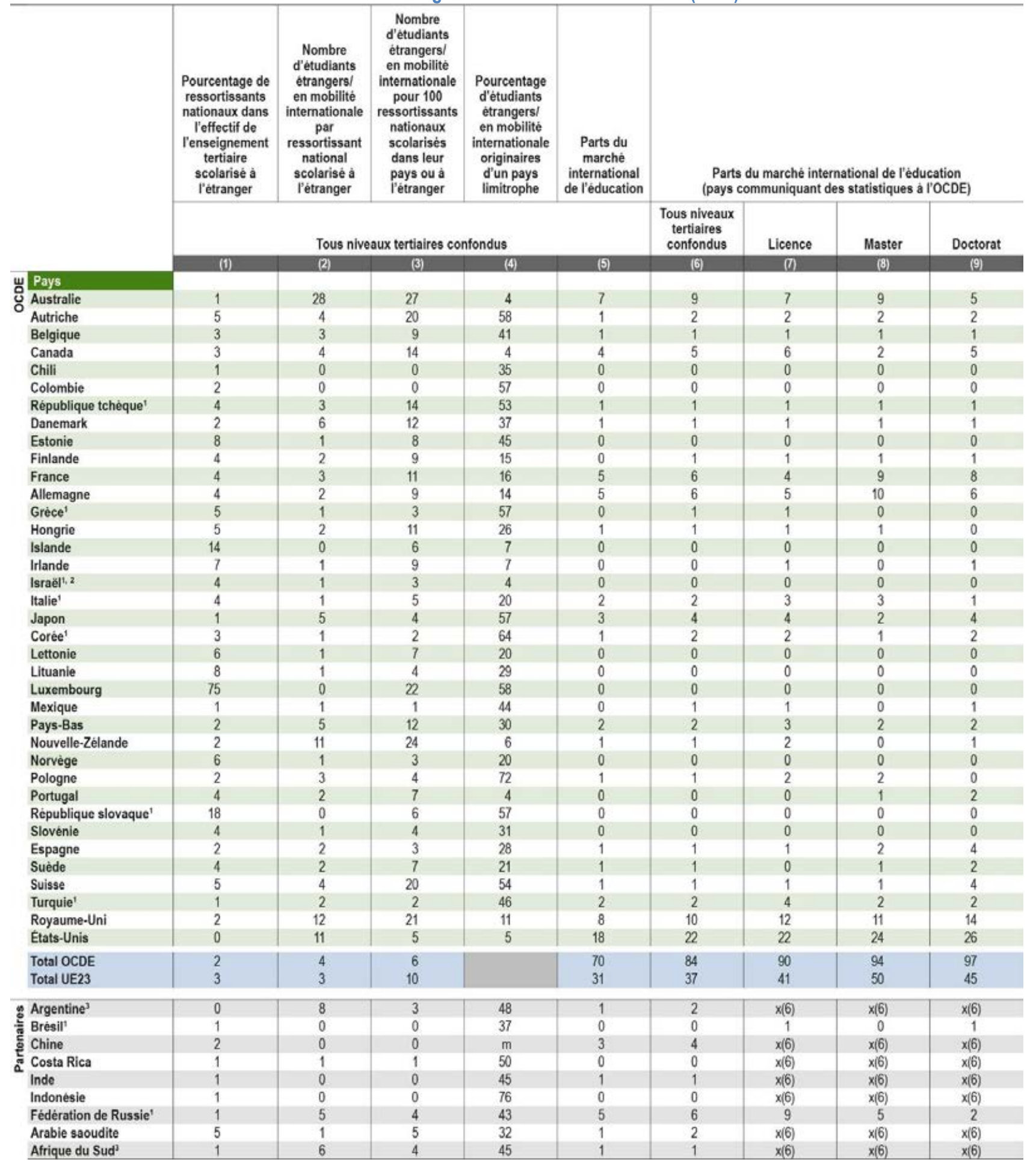

Remarque : Par pays limitrophe, on entend un pays ayant une frontière terrestre ou maritime commune avec le pays d'accueil. Les parts du marché international de l'éducation correspondent au nombre d'étudiants en mobilité internationale scolarisés dans chaque pays d'accueil en pourcentage du total des étudiants en mobilité internationale (colonne 5) ou des étudiants en mobilité internationale dans les pays membres ou partenaire de l'OCDE (colonnes 6 à 10).

1. Le calcul du nombre d'étudiants ressortissants nationaux dans l'enseignement tertiaire se fait en soustrayant le nombre d'étudiants étrangers, et non celui des étudiants en mobilité internationale, des effectifs totaux.

2. À l'exclusion des étudiants en mobilité internationale suivant une formation tertiaire de cycle court.

3. Année de référence : 2016.

Source : OCDE/ISU/Eurostat (2019). Consulter la section « Source » pour tout complément d'information et l'annexe 3 pour les notes (http://dx.doi.org/10.1787/eag-2019-36-en). Les symboles représentant les données manquantes et les abréviations figurent dans le Guide du lecteur. 


\section{Indicateur B7. Quels sont le profil et les perspectives professionnelles des titulaires d'un doctorat?}

\section{Faits marquants}

- Les titulaires d'un doctorat représentent en moyenne $1.1 \%$ des adultes âgés de 25 à 64 ans dans les pays de l'OCDE, mais ce pourcentage varie entre $0.1 \%$ ou moins en Indonésie et au Mexique et plus de $3 \%$ en Slovénie et en Suisse.

- Les femmes tendent à être sous-représentées dans certains domaines d'études en doctorat, alors même qu'elles y sont surreprésentées en master. En 2017 dans les pays de l'OCDE, les femmes représentaient en moyenne 54 \% des diplômés de master à l'issue de formations en rapport avec les sciences naturelles, les mathématiques et les statistiques, mais seulement $46 \%$ des titulaires d'un doctorat dans ces domaines d'études.

- Dans les pays de l'OCDE, les titulaires d'un doctorat jouissent sur le marché du travail d'un avantage relatif par rapport aux diplômés de master, qui varie entre 10 \% en Finlande, en Hongrie et en Italie et $1 \%$ en Islande et en Suède.

\section{Graphique B7.1. Pourcentage d'adultes âgés de 25 à 64 ans titulaires d'un doctorat (2018)}

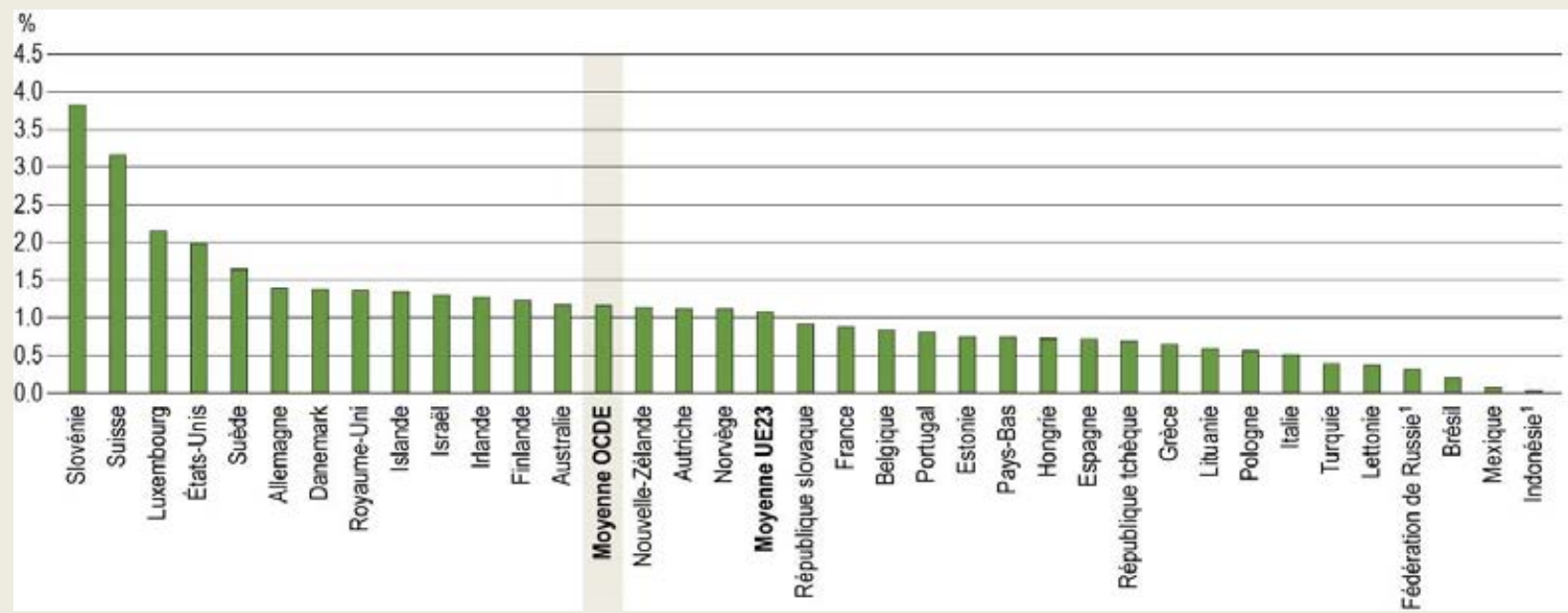

1. L'année de référence n'est pas 2018.

Les pays sont classés par ordre décroissant du pourcentage de 25-64 ans titulaires d'un doctorat.

Source: OCDE (2019), tableau B7.3. Consulter la section «Source » pour tout complément d'information et l'annexe 3 pour les notes (https://doi.org/10.1787/f8d7880d-en). 


\section{Contexte}

Le doctorat est le diplôme le plus élevé délivré par les universités. Les études qui y mènent jouent un rôle important dans le développement des innovations du futur, en formant les chercheurs nécessaires à l'avancement des connaissances et à l'exploration de nouveaux domaines de recherche pertinents pour l'économie et la société de demain. Les titulaires d'un doctorat sont à même de développer un ensemble unique de savoir-faire quantitatifs et qualitatifs en termes de méthodologie de recherche et d'analyse statistique, autant de connaissances utiles tant en milieu universitaire qu'en milieu industriel. Les docteurs sont très demandés sur le marché du travail et leur taux d'emploi demeure élevé, en moyenne, même en cas de dégradation de la conjoncture économique. Les docteurs bénéficient aussi de revenus relatifs élevés, en particulier ceux qui travaillent pour le secteur privé (Commission européenne, 2016[1]).

Ce constat a conduit de nombreux pays à engager des réformes visant à développer et soutenir les programmes de doctorat et les travaux de recherche post-doctorale, ce qui souligne le rôle crucial joué par les doctorants et les titulaires d'un doctorat en termes de croissance économique, d'innovation et de recherche scientifique. En raison de l'important investissement tant personnel que financier qui est requis, et du rôle central que jouent les titulaires d'un doctorat pour faire reculer les frontières du savoir, on a vu croître la volonté politique d'attirer de jeunes talents vers des carrières de recherche scientifique, d'assurer l'égalité d'accès entre hommes et femmes aux programmes de doctorat, et d'offrir des perspectives d'emploi prometteuses aux diplômés de ces programmes (OCDE, 2019[2]).

\section{Autres faits marquants}

- En moyenne dans les pays de l'OCDE, l'âge médian des étudiants qui entament un doctorat est de 29 ans, et $60 \%$ des nouveaux inscrits ont entre 26 et 37 ans.

- En moyenne, dans les pays de l'OCDE, $25 \%$ des étudiants inscrits en doctorat sont en mobilité internationale. Dans certains pays, ces étudiants représentent la majorité des diplômés de ce niveau d'enseignement : au Luxembourg et en Suisse plus de la moitié des doctorants sont des étudiants en mobilité internationale.

- Dans les pays de l'OCDE, les femmes titulaires d'un doctorat affichent un taux d'emploi supérieur de $5 \%$ en moyenne par rapport à celui des diplômées de master, et l'écart atteint au moins $15 \%$ en Grèce et en Hongrie. Par contraste, le taux d'emploi des hommes titulaires d'un doctorat est supérieur de $3 \%$ en moyenne par rapport à celui des hommes titulaires d'un diplôme de master dans les pays de l'OCDE, et cet écart n'excède $8 \%$ dans aucun pays membre ou partenaire de l'OCDE. 


\section{Analyse}

\section{Taux d'obtention d'un diplôme et taux d'accès en doctorat}

Si les tendances actuelles se poursuivent, $2.3 \%$ des jeunes adultes vivant aujourd'hui dans les pays de l'OCDE s'inscriront dans un programme de doctorat au cours de leur existence. Ce chiffre varie entre $4 \%$ ou plus au Royaume-Uni et en Suisse - essentiellement en raison de la forte proportion d'étudiants en mobilité internationale accueillis par ces pays - et moins de $0.5 \%$ en Arabie saoudite, au Chili, en Chine et en Colombie. Si les étudiants en mobilité internationale sont exclus, les pays qui enregistrent les taux d'accès les plus élevés en doctorat sont l'Allemagne (3.2\%), l'Espagne (3.1\%) et la Corée (3.0\%).

Les titulaires d'un doctorat ne représentent qu'un faible pourcentage de la population adulte. En 2018, $1.1 \%$ seulement des adultes âgés 25 à 64 ans détenait un doctorat, en moyenne dans les pays de l'OCDE, bien que ce pourcentage varie entre moins de $0.1 \%$ en Indonésie et au Mexique et plus de $3 \%$ en Slovénie et en Suisse (voir le graphique B7.1). Malgré ces taux d'accès peu élevés, le nombre de docteurs a progressé. Entre 2013 et 2017 , le nombre de titulaires d'un doctorat a augmenté d'environ $8 \%$ dans les pays de l'OCDE, atteignant un total de 276800 docteurs en 2017. Cette augmentation a été portée essentiellement par l'essor, durant cette période, du nombre des diplômés à l'issue d'un doctorat en Espagne, aux États-Unis et au Mexique. Les ÉtatsUnis demeurent le principal pourvoyeur de docteurs parmi les pays de l'OCDE, avec environ 71000 diplômés en 2017, suivis par l'Allemagne et le Royaume-Uni (environ 28000 diplômés dans chacun des deux pays).

Les doctorants tendent plus souvent à partir étudier à l'étranger que les autres étudiants suivant des formations tertiaires. En moyenne, dans les pays de l'OCDE, $22 \%$ des étudiants inscrits en doctorat sont des étudiants étrangers ou en mobilité internationale, contre $13 \%$ en master et $4 \%$ en licence. Dans certains pays, les étudiants en mobilité internationale constituent la majorité des diplômés à l'issue d'un doctorat : ils représentent ainsi plus de la moitié des diplômés de ce niveau d'enseignement au Luxembourg et en Suisse (voir le graphique B7.2).

\section{Graphique B7.2. Pourcentage de docteurs en mobilité internationale (2017)}

En pourcentage du nombre total de titulaires d'un doctorat

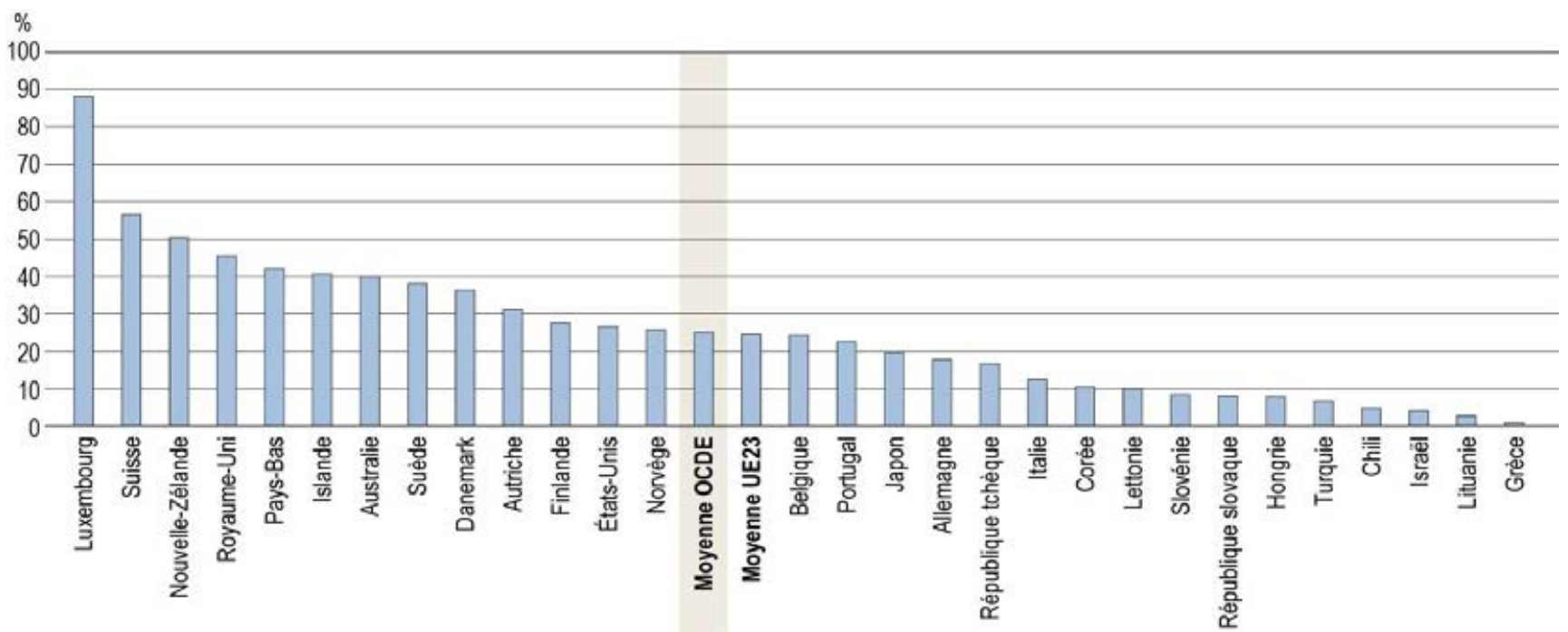

Les pays sont classés par ordre décroissant du pourcentage de docteurs en mobilité internationale dans l'effectif total de titulaires d'un doctorat. Source : OCDE (2019), tableau B7.1. Consulter la section «Source» pour tout complément d'information et l'annexe 3 pour les notes (https://doi.org/10.1787/f8d7880d-en). 
Attirer les doctorants les plus talentueux à travers le monde permet aux pays de se forger un rôle de premier plan dans la recherche et l'innovation ; certains pays ont donc adopté des politiques favorisant un environnement propice à la recherche et attractif pour de potentiels étudiants. Dans certains pays, comme l'Australie, l'Italie et la Suisse, les frais de scolarité sont moins élevés en doctorat qu'aux niveaux inférieurs d'enseignement (voir l'indicateur C5). D'autres pays attribuent aux doctorants un statut d'employé plutôt que d'étudiant, comme la Norvège ou la Suisse (Eurydice Report, 2017[3]). La langue d'enseignement joue également un rôle important auprès des étudiants lorsqu'ils sélectionnent l'établissement et le pays où ils souhaitent suivre un programme de doctorat. Les pays anglophones attirent un pourcentage plus important d'étudiants en mobilité internationale parmi les doctorants : ils représentent ainsi $40 \%$ ou plus de l'effectif des titulaires d'un doctorat en Australie, en Nouvelle-Zélande et au Royaume-Uni. Quelques pays non anglophones, comme le Danemark, les Pays-Bas et la Suède proposent également de nombreux programmes dispensés en anglais afin d'attirer davantage de jeunes talents venant de l'étranger (Wächter et Maiworm, 2014[4]]). Dans ces trois pays, le pourcentage de titulaires d'un doctorat en mobilité internationale en 2017 était supérieur à la moyenne de l'OCDE (voir le graphique B7.2).

Les perspectives de carrière et la disponibilité de sources de financement durables pour la recherche et le développement (R-D) jouent un rôle majeur dans le parcours des doctorants, tant durant leurs années d'études qu'après l'obtention de leur diplôme. Le budget consacré aux établissements d'enseignement supérieur est un bon indicateur de l'importance accordée par les pays à la R-D, et peut également donner une idée des possibilités de recherche futures. En 2015, les dépenses au titre de la recherche et du développement dans les établissements d'enseignement tertiaire représentaient en moyenne $0.5 \%$ du PIB dans les pays de l'OCDE, mais dépassaient $0.8 \%$ au Danemark, en Suède et en Suisse (OCDE, 2018[5]). Si dans la plupart des pays de I'OCDE, la R-D menée au sein des établissements d'enseignement tertiaire est principalement financée par le secteur public, certains systèmes sont également en mesure de mobiliser des fonds auprès du secteur des entreprises : c'est le cas de l'Allemagne ( $14 \%$ du financement total) ou de la Corée (13\% du budget total). Dans ces pays, le financement des entreprises commerciales et industrielles représente au total plus de $60 \%$ des dépenses intérieures brutes consacrées à la R-D (OCDE, 2019 $\left.{ }_{[2]}\right)$. L'importante contribution financière des entreprises à la R-D met en évidence la volonté du secteur privé de soutenir la recherche de pointe et montre que les titulaires d'un doctorat pourront bénéficier d'un plus large éventail de possibilités de carrière dans la recherche, au-delà du milieu universitaire. Ces deux facteurs contribuent à l'attractivité des programmes de doctorat : les taux d'inscription en doctorat sont ainsi plus élevés en Allemagne et en Corée que dans les autres pays de l'OCDE.

\section{Pyramide des âges des nouveaux inscrits en doctorat}

Dans la plupart des pays, l'admission à un programme de doctorat se fait généralement sur la base d'un master ou d'un diplôme équivalent. Toutefois, dans quelques pays, comme en Australie et aux États-Unis, les étudiants peuvent s'inscrire en doctorat après une licence, à ceci près qu'en Australie une bonne mention (Classe I ou IIA) est également requise (OCDE, 2019[2]). L'âge médian d'entrée en doctorat est de 29 ans en moyenne dans les pays de l'OCDE, et $60 \%$ des nouveaux inscrits ont entre 26 à 37 ans. L'âge médian varie toutefois sensiblement entre les pays, allant de 26 ans en France et aux Pays-Bas à 35 ans en Colombie (voir le graphique B7.3).

L'âge d'entrée en doctorat dépend largement de l'âge auquel les étudiants entament leurs études tertiaires et de l'âge auquel ils obtiennent leur diplôme, mais aussi de la mesure dans laquelle ils sont susceptibles d'avoir commencé à travailler entre deux diplômes tertiaires. Dans les pays où les étudiants entament leurs études tertiaires à un âge relativement jeune, les étudiants tendent également à entamer plus tôt leur doctorat. C'est le cas en Belgique, en France, en Hongrie, en Italie, en Lituanie, aux Pays-Bas, en Pologne et au Royaume-Uni, où l'âge moyen d'entrée en licence et l'âge médian d'entrée en doctorat sont inférieurs à la moyenne de l'OCDE. De même, dans les pays où les étudiants sont plus âgés lorsqu'ils entament leur licence, comme en Australie, en Finlande, en Islande, en Israël, en Lettonie, en Norvège et en Nouvelle-Zélande, ces derniers tendent aussi à être plus âgés lorsqu'ils s'inscrivent en doctorat. Certains pays font toutefois figure d'exception : c'est le cas de la Corée, de l'Espagne de la Grèce, du Mexique et du Portugal où les étudiants s'inscrivent pour la première fois 
en licence à l'âge de 21 ans, voire plus jeunes, mais où ceux qui poursuivent leurs études en doctorat tendent à s'y inscrire à 30 ans ou plus. II est possible que les étudiants de ces pays estiment utile de se donner d'abord la possibilité d'exercer un emploi, afin d'acquérir de l'expérience dans l'industrie ou dans un secteur d'activité particulier, qu'ils pourront ensuite valoriser dans leur travail de recherche lors du doctorat. Par contraste, les jeunes qui entament pour la première fois des études tertiaires en licence au Danemark, en Estonie ou en Suisse sont parmi les plus âgés des pays de l'OCDE, mais l'âge médian d'entrée en doctorat y est inférieur à la moyenne de 29 ans de l'OCDE. Ce constat peut s'expliquer par la prévalence plus élevée des premières formations de type long dans certains de ces pays (en Estonie et en Suède), ou par la forte proportion d'étudiants en mobilité internationale parmi l'effectif de doctorants, qui sont souvent plus jeunes que les ressortissants nationaux.

La pyramide d'âge des nouveaux inscrits en doctorat donne une idée de la diversité des âges à l'inscription par rapport à la valeur médiane. Dans certains pays, la pyramide d'âge est très proche de l'âge médian, ce qui signifie que les différences d'âge entre doctorants sont relativement faibles. C'est le cas de l'Allemagne et des Pays-Bas, où la différence entre les groupes d'âge du $80^{\circ}$ et du $20^{e}$ percentile est de moins de 6 ans. Dans d'autres pays, l'âge est beaucoup moins uniforme chez les nouveaux inscrits en doctorat. En Corée, en Islande et au Portugal, par exemple, les nouveaux inscrits du $80^{\mathrm{e}}$ percentile ont au moins 17 ans de plus que ceux du $20^{e}$ percentile. L'âge médian est toutefois plus proche du $20^{e}$ percentile dans les pays de l'OCDE, signe de l'asymétrie de la pyramide d'âge qui penche davantage du côté des plus jeunes (voir le graphique B7.3).

\section{Graphique B7.3. Pyramide des âges des nouveaux inscrits en doctorat (2017)}

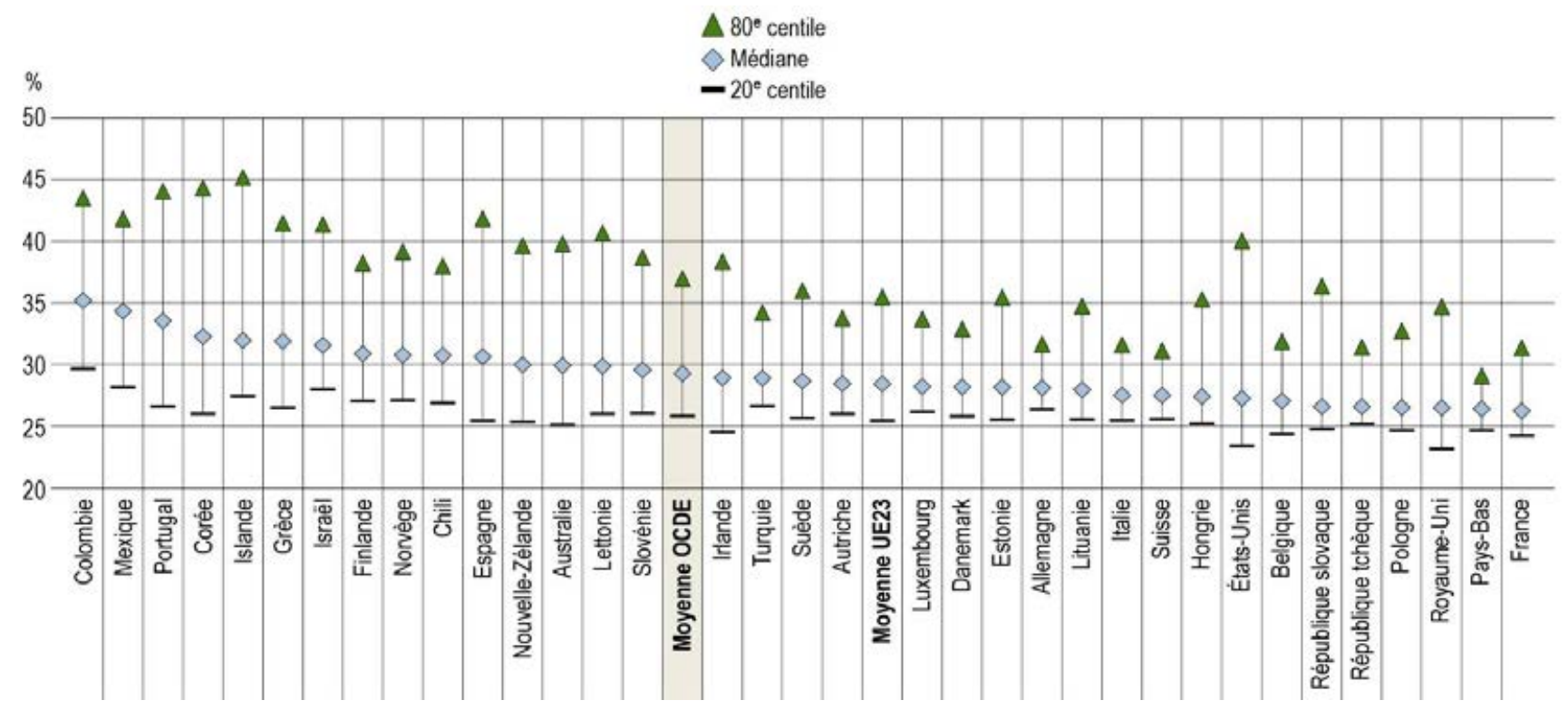

Les pays sont classés par ordre décroissant de l'âge médian des nouveaux inscrits en doctorat.

Source : OCDE (2019), tableau B7.1. Consulter la section "Source» pour tout complément d'information et l'annexe 3 pour les notes (https://doi.org/10.1787/f8d7880d-en).

StatLink 제에 https://doi.org/10.1787/888933978683

\section{Domaines d'études des doctorants}

On attend des étudiants inscrits en doctorat qu'ils contribuent à l'avancée et à l'élargissement du socle de connaissances dans le domaine d'études qu'ils ont choisi. Par comparaison avec les niveaux inférieurs d'enseignement, les doctorants tendent à se spécialiser de manière bien plus pointue dans les domaines d'études liés à la science et à la technologie. Les grands domaines d'études qui regroupent les sciences naturelles, les mathématiques et les statistiques attirent le pourcentage de doctorants le plus élevé, soit $23 \%$ en 
moyenne dans les pays de l'OCDE. Viennent ensuite les domaines de l'ingénierie, des industries de transformation et de la construction, et les domaines de la santé et la protection sociale, choisis dans l'un et l'autre cas par $17 \%$ des doctorants (voir le tableau B7.2). Par contraste, seulement $10 \%$ des doctorants optent pour le commerce, l'administration et le droit, qui sont pourtant les domaines les plus prisés par les diplômés de licence.

Des écarts importants s'observent entre les pays dans la répartition des domaines d'études des doctorants. En moyenne dans les pays de l'OCDE, la plupart des docteurs sont titulaires d'un diplôme en sciences naturelles, en mathématiques et en statistiques, mais le pourcentage de ces diplômés est quasi nul en Colombie alors qu'il atteint $43 \%$ en France. Les domaines de la santé et de la protection sociale sont courants au Danemark, au Japon, en Norvège et aux Pays-Bas, où ils attirent plus de $30 \%$ des doctorants. Au Canada, $18 \%$ des doctorants obtiennent leur diplôme en sciences sociales, en journalisme et en information, mais le pourcentage de doctorants dans ces domaines d'études ne dépasse pas les $13 \%$ dans trois quarts des pays dont les données sont disponibles. Enfin, au Luxembourg, plus de $22 \%$ des doctorants obtiennent leur diplôme en technologies de l'information et de la communication (TIC), contre seulement $4 \%$ en moyenne dans les pays de l'OCDE (voir le tableau B7.2).

Le choix du domaine d'études constitue un facteur déterminant pour les étudiants qui décident d'aller entamer un doctorat à l'étranger. Certains pays consacrent davantage de ressources à la recherche dans des domaines spécifiques, ce qui leur permet de jouir d'une importante reconnaissance internationale. En moyenne, dans les pays de l'OCDE, la répartition des domaines choisis par les doctorants en mobilité internationale reflète les choix de l'ensemble des doctorants, mais certains domaines d'études font figure d'exception. L'ingénierie, les industries de transformation et la construction attirent $22 \%$ des doctorants en mobilité internationale, contre $17 \%$ en moyenne pour l'ensemble des doctorants dans ce domaine. Des différences frappantes s'observent également au sein des pays, mettant en évidence des spécialisations potentielles et soulignant le caractère attractif de certains pays pour la recherche dans un domaine d'études donné. Au Chili et aux États-Unis par exemple, le pourcentage de doctorants dans les domaines de l'ingénierie, des industries de transformation et de la construction est deux fois plus élevé chez les étudiants en mobilité internationale que chez les ressortissants nationaux. En Islande, $65 \%$ des doctorants en mobilité internationale étudient les sciences naturelles, les mathématiques et les statistiques, contre $34 \%$ de l'ensemble des doctorants (voir le tableau B7.2).

\section{Répartition des titulaires d'un doctorat selon le sexe}

Les femmes sont plus nombreuses que les hommes en licence et en master, mais elles demeurent légèrement sous-représentées en doctorat. En 2017, on comptait $47 \%$ de femmes parmi l'effectif des titulaires d'un doctorat, soit une augmentation de $4 \%$ par rapport à 2005. La parité entre les sexes (lorsque les femmes représentent entre 48 et $52 \%$ de l'ensemble des diplômés) ne s'observe que dans moins d'un tiers des pays membres et partenaires de l'OCDE dont les données sont disponibles. En outre, des différences de parité marquées s'observent entre les pays : en 2017 , les femmes représentaient plus de $60 \%$ des titulaires d'un doctorat en Islande et en Lettonie, mais moins de $40 \%$ de l'effectif des docteurs en Arabie saoudite, en Corée, en Indonésie, au Japon et République populaire de Chine.

Compte tenu du pourcentage élevé d'étudiants en mobilité internationale dans les programmes de doctorat, le degré de parité des titulaires d'un doctorat peut également être affecté par les caractéristiques de ce groupe d'arrivants qui, à ce niveau d'enseignement, est majoritairement composé d'hommes. En 2017, les femmes représentaient seulement $40 \%$ de l'effectif des doctorants en mobilité internationale, contre $53 \%$ en moyenne des ressortissants nationaux à ce niveau d'enseignement dans les pays de l'OCDE. Les différences entre le pourcentage de doctorantes en mobilité internationale et le pourcentage de ressortissantes nationales inscrites en doctorat dépassent les 30 points de pourcentage en Islande, en Lettonie et en Lituanie - résultat d'un pourcentage élevé de femmes parmi les ressortissants nationaux inscrits en doctorat et d'un faible pourcentage de femmes parmi les doctorants en mobilité internationale. En Nouvelle-Zélande, au Royaume-Uni et en Suisse, où $45 \%$ des doctorants sont des étudiants en mobilité internationale, la différence de pourcentage entre les 
ressortissantes nationales et les doctorantes en mobilité internationale est bien moins marquée et ne dépasse pas les 10 points de pourcentage.

Les différences de parité sont plus marquées lorsque l'on analyse les tendances en matière d'obtention d'un diplôme selon les domaines d'études. Les femmes tendent à être sous-représentées en doctorat, même dans les domaines d'études où elles sont surreprésentées en master. En 2017, les femmes représentaient $54 \%$ des diplômés de master en sciences naturelles, en mathématiques et en statistiques, mais seulement $46 \%$ des titulaires d'un doctorat dans ce domaine, en moyenne, dans les pays de l'OCDE (voir le graphique B7.4). Une tendance similaire s'observe chez les étudiantes en commerce, en administration et en droit. Dans d'autres domaines, comme l'éducation, la santé et la protection sociale, ou les sciences sociales, les lettres et les arts, le pourcentage de femmes parmi l'effectif d'étudiants diminue entre le master et le doctorat, mais les femmes continuent de représenter la majorité des récents titulaires d'un doctorat. Par contraste, les femmes sont sousreprésentées en master dans les domaines de l'ingénierie, des industries de transformation et de la construction, mais leur pourcentage dans ces domaines reste à un niveau très similaire parmi les titulaires d'un doctorat (voir le tableau B7.1).

Au-delà de ces tendances générales, de fortes variations s'observent entre les pays. La diminution la plus marquée du pourcentage d'étudiantes en sciences naturelles, en mathématiques et en statistiques, s'observe en Arabie saoudite, en Corée, au Danemark, en Inde, en Pologne, en République tchèque et en Slovénie, où le pourcentage de diplômées chute de 15 points de pourcentage entre le master et le doctorat. Si la parité entre les sexes des doctorants s'en trouve améliorée en Pologne et en Slovénie (car les femmes sont largement surreprésentées parmi l'effectif d'étudiants en master), cela génère également un défaut de parité accru, au désavantage des femmes, en Corée et au Danemark (voir le graphique B7.4).

\section{Graphique B7.4. Pourcentage de femmes titulaires d'un master ou d'un doctorat en sciences naturelles, mathématiques et statistiques (2017)}

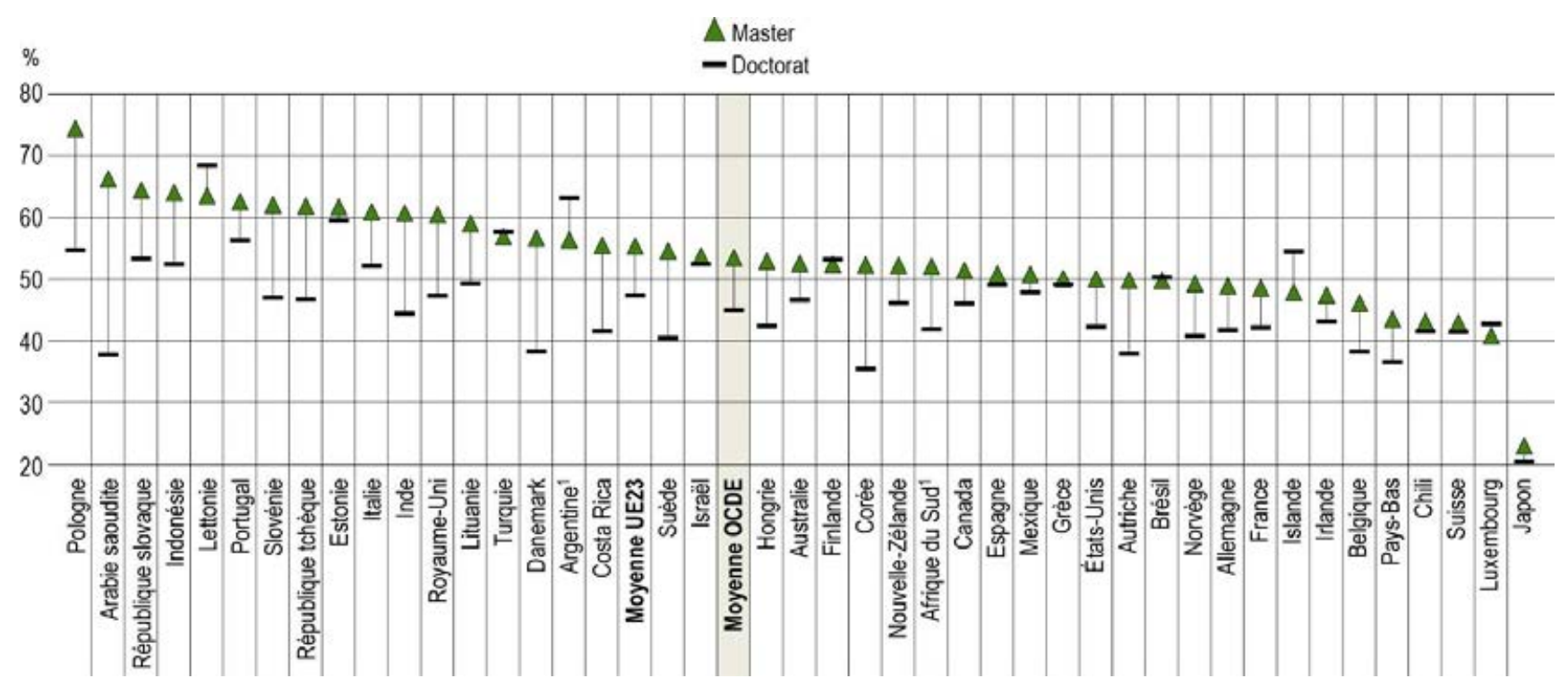

1. Année de référence : 2016.

Les pays sont classés par ordre décroissant du pourcentage de femmes titulaires d'un master en sciences naturelles, mathématiques et statistiques.

Source: OCDE (2019), tableau B7.1. Consulter la section «Source» pour tout complément d'information et l'annexe 3 pour les notes (https://doi.org/10.1787/f8d7880d-en). 
Des tendances légèrement différentes s'observent dans les domaines de l'ingénierie, des industries de transformation et de la construction, même si en moyenne, dans les pays de l'OCDE, le pourcentage de femmes parmi les diplômés n'évolue pas entre le master et le doctorat. Dans ces domaines d'études, près de la moitié des pays membres et partenaires de l'OCDE ont fait progresser la parité entre les sexes en doctorat par rapport au master. Ces progrès sont particulièrement frappants en Israël et en Lettonie, où le pourcentage de femmes diplômées a augmenté respectivement de 12 et de 20 points de pourcentage entre le master et le doctorat. Par contraste, dans les domaines de l'ingénierie, des industries de transformation et de la construction, le pourcentage de femmes a diminué d'au moins 10 points de pourcentage entre ces deux niveaux d'enseignement en Afrique du Sud, en Colombie, en Islande, en Inde, en Nouvelle-Zélande et en République tchèque (voir le tableau B7.1).

Le pourcentage moins élevé de femmes dans les domaines scientifiques se reflète dans leur contribution aux résultats de la recherche et de l'innovation. Les femmes ne représentent que $22 \%$ des auteurs de publications scientifiques, et le pourcentage de brevets déposés par des femmes varie entre $4 \%$ en Autriche et plus de $15 \%$ au Portugal (OCDE, 2018[6]). Ce constat a incité certains pays à prendre des mesures politiques pour promouvoir le rôle des femmes dans le domaine des STIM (sciences, technologies, ingénierie et mathématiques) et, plus généralement, dans la recherche scientifique. L'Union européenne (UE) a adopté la Charte européenne et le code de conduite du chercheur qui mettent l'accent sur la parité entre les sexes pour toutes les catégories de personnel (Commission européenne, 2016 $6_{[7]}$ ). En outre, le programme de recherche « Horizon 2020 » inclut la parité entre les sexes dans la recherche et l'innovation et, entre autres objectifs, vise à renforcer, dans les pays membres de l'UE, la présence et la progression des femmes dans le domaine des STIM. Certains pays ont mis en œuvre des incitations financières et des dispositifs de soutien pour favoriser l'accès d'un plus grand nombre de femmes à des domaines d'études scientifiques. Aux États-Unis, par exemple, la National Science Foundation octroie des bourses afin de soutenir le programme ADVANCE, qui vise à accroître l'accès des femmes à des carrières universitaires en sciences et en ingénierie ainsi qu'à améliorer leurs perspectives professionnelles dans ces carrières. En Corée, un fonds spécifique sert à financer les recherches menées par des équipes d'étudiantes sur des thèmes liés à l'architecture, à l'étude des matériaux et des machines, ou à l'informatique (Borgonovi et al., 2018[8])

\section{Situation sur le marché du travail des titulaires d'un doctorat}

Pour les étudiants, la perspective d'opportunités professionnelles prometteuses peut constituer une incitation à s'inscrire dans un programme de doctorat et à y poursuivre leurs études jusqu'à obtenir leur diplôme ; c'est aussi un facteur essentiel d'évaluation de l'attractivité des différents programmes de doctorats pour les candidats potentiels. Les titulaires d'un doctorat disposent d'une large gamme de possibilités d'emploi, le plus souvent en dehors des établissements d'enseignement supérieur (voir l'indicateur A3).

En moyenne, dans les pays de l'OCDE, ce sont les titulaires d'un doctorat âgés de 25 à 64 ans qui affichent le taux d'emploi le plus élevé, tous niveaux d'enseignement confondus : $92 \%$ des docteurs ont un emploi, contre $88 \%$ pour les titulaires d'un master. L'avantage sur le marché du travail dont bénéficient les docteurs par rapport aux titulaires d'un master varie toutefois d'un pays à l'autre, entre $10 \%$ en Finlande, en Hongrie et en Italie et $1 \%$ en Islande et en Suède (voir le tableau B7.3).

Les docteurs les plus jeunes, soit ceux qui ont entre 25 et 34 ans, ont également de bonnes perspectives professionnelles, bien que leur taux d'emploi tende à être inférieur à celui des docteurs âgés de 25 à 64 ans, et que leur avantage relatif sur le marché du travail par rapport à leurs homologues titulaires d'un master tende à être plus variable (voir l'indicateur A3).

Les titulaires d'un doctorat, hommes ou femmes, bénéficient d'un taux d'emploi supérieur à celui des titulaires d'un master, et les différences entre les sexes s'atténuent avec l'élévation du niveau de formation. En moyenne dans les pays de l'OCDE, le taux d'emploi des hommes âgés de 25 à 64 ans et titulaires d'un doctorat est supérieur de 5 points de pourcentage à celui des femmes du même âge diplômées du même niveau d'enseignement. Parmi les titulaires d'un master, l'avantage des hommes sur le marché du travail s'élève à 
6 points de pourcentage (voir le tableau B7.3). Toutefois, certains pays affichent des différences de taux d'emploi faibles ou non significatives entre titulaires d'un master et titulaires d'un doctorat, et la prudence est de mise lors de l'interprétation de ces résultats.

L'atténuation des différences entre les sexes en matière d'emploi parmi les titulaires d'un doctorat s'explique par le fait que le taux d'emploi des femmes augmente davantage que celui des hommes à ce niveau d'enseignement. Alors que parmi les titulaires d'un master le taux d'emploi des femmes est inférieur à celui des hommes dans tous les pays de l'OCDE, la situation tend à évoluer en doctorat. Les femmes titulaires d'un doctorat ont un taux d'emploi supérieur à celui de leurs homologues masculins en Australie, en Belgique, en Grèce, au Portugal et en Suède. Dans de nombreux autres pays, le fait d'avoir un doctorat plutôt qu'un master se traduit par une augmentation du taux d'emploi plus importante chez les femmes que chez les hommes. Dans les pays de l'OCDE, les femmes titulaires d'un doctorat affichent un taux d'emploi supérieur de $5 \%$ en moyenne par rapport à celui des diplômées de master, et l'écart atteint au moins $15 \%$ en Grèce et en Hongrie. Par contraste, les hommes titulaires d'un doctorat affichent un taux d'emploi supérieur de $3 \%$, en moyenne, à celui des diplômés de master dans les pays de l'OCDE, et cet avantage ne dépasse les $8 \%$ dans aucun des pays membres ou partenaires de l'OCDE (voir le graphique B7.5).

\section{Graphique B7.5. Taux d'emploi relatif des titulaires d'un doctorat âgés de 25 à 64 ans par comparaison} aux titulaires d'un master (2018)

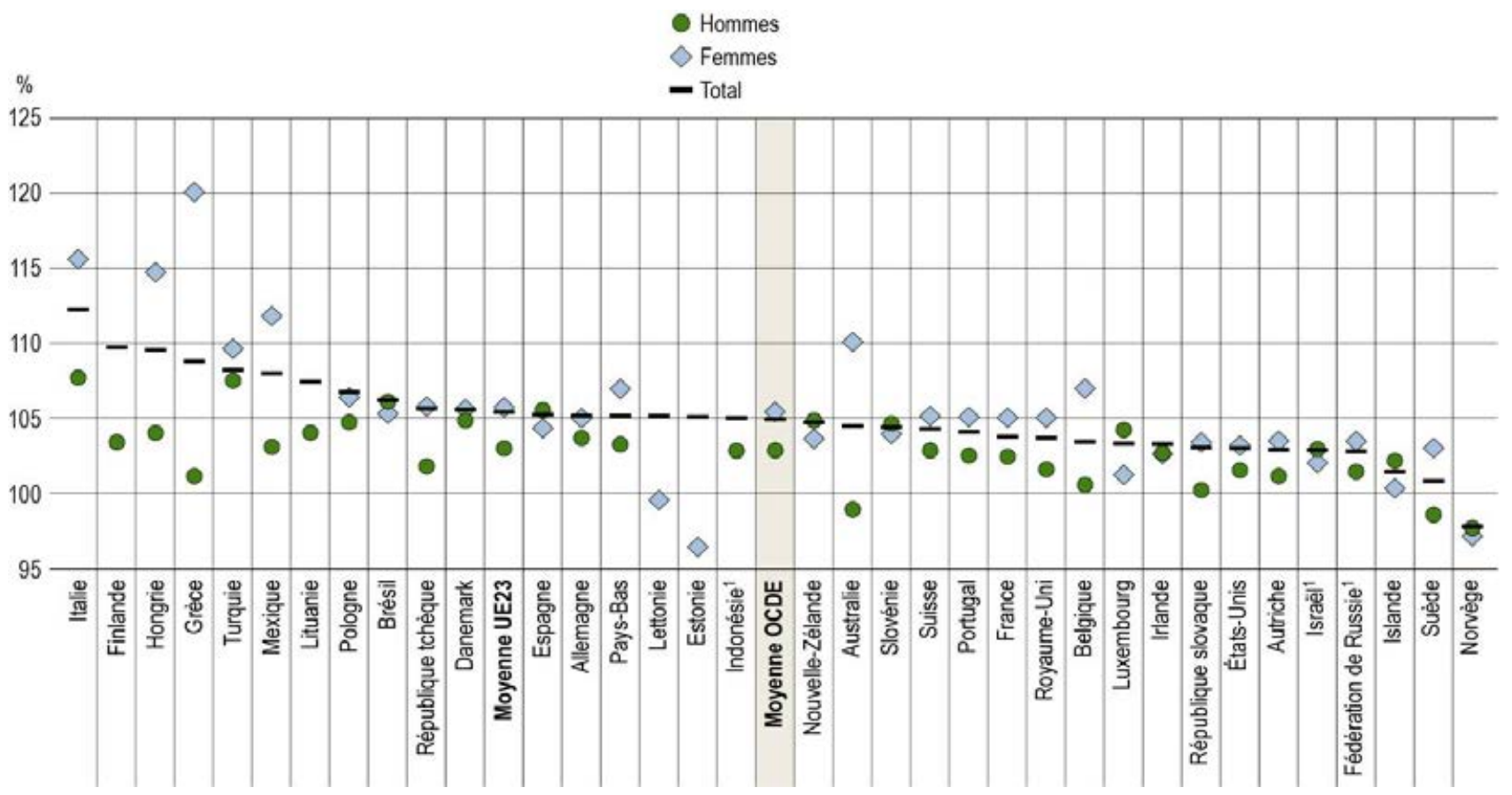

Comment lire ce graphique: Un taux d'emploi relatif supérieur à $100 \%$ indique que les titulaires d'un doctorat ont un taux d'emploi plus élevé que les adultes titulaires d'un master. Un taux d'emploi relatif inférieur à $100 \%$ indique le contraire.

1. L'année de référence n'est pas 2018.

Les pays sont classés par ordre décroissant du taux d'emploi relatif des titulaires d'un doctorat par comparaison aux titulaires d'un master.

Source: OCDE (2019), tableau B7.3. Consulter la section «Source» pour tout complément d'information et l'annexe 3 pour les notes (https://doi.org/10.1787/f8d7880d-en).

StatLink त्ञात https://doi.org/10.1787/888933978721

Dans certains pays, les adultes titulaires d'un doctorat continuent d'afficher un taux d'emploi inférieur à celui des titulaires d'un master : c'est le cas pour les femmes en Estonie et en Norvège, et pour les hommes en Australie, en Norvège et en Suède. 
Tout comme la probabilité de trouver un emploi, les perspectives de carrière et le niveau de salaire attendu sont autant d'éléments que les étudiants prennent en compte lorsqu'ils décident d'entamer un programme de doctorat et de faire carrière dans la recherche. Les débouchés sur le marché du travail des titulaires d'un doctorat peuvent être multiples, allant de l'enseignement supérieur, au commerce et à l'industrie, en passant par l'administration publique et les professions libérales (voir l'encadré A3.1 dans l'indicateur A3).

Si l'enseignement supérieur a longtemps constitué le principal débouché des titulaires d'un doctorat, nombre d'entre eux se tournent aujourd'hui vers le commerce et l'industrie, qui leur offrent des emplois généralement mieux rémunérés. En Corée, aux États-Unis, en Israël et au Japon, le secteur du commerce emploie le pourcentage le plus important de chercheurs (plus de $70 \%$ ) (OCDE, 2018[6]). Les opportunités offertes dans les différents domaines d'études peuvent toutefois être inégales, reflétant les variations de la demande en compétences et en savoirs spécialisés sur le marché du travail. Par exemple, dans de nombreux pays, la rémunération des docteurs dans les domaines de l'agriculture et des sciences humaines est inférieure au revenu médian de l'ensemble des titulaires d'un doctorat, tandis que les docteurs en médecine et en sciences de la santé tendent à bénéficier d'une rémunération supérieure au revenu médian (Auriol, Misu et Freeman, 2013[9])

\section{Définitions}

Le doctorat correspond au niveau 8 de la CITE 2011, qui désigne les programmes de recherche de haut niveau donnant directement lieu à la délivrance d'un titre équivalent à un doctorat. Ces formations correspondent en théorie à trois années d'études à temps plein dans la plupart des pays (soit un total cumulé d'au moins sept années d'études à temps plein dans l'enseignement tertiaire), mais elles durent généralement plus longtemps. Les programmes de ce niveau de la CITE sont consacrés à des études approfondies et à des travaux de recherche originaux, et sont généralement proposés par des établissements d'enseignement tertiaire axés sur la recherche, comme les universités. Les programmes de doctorat existent aussi bien dans des domaines académiques que professionnels (OCDE/Eurostat/Institut de statistique de I'UNESCO, 2016[10]).

Le terme doctorant désigne tout individu poursuivant des études donnant lieu à la délivrance d'un doctorat, quel que soit son statut légal dans le pays d'études (étudiant ou employé).

Les titulaires d'un doctorat sont des adultes âgés de 25 à 64 ans ayant obtenu un diplôme de docteur.

Les individus diplômés sont ceux qui ont obtenu leur diplôme durant l'année de référence. Ils peuvent être soit titulaires d'un premier diplôme, soit titulaires de plusieurs diplômes. Par titulaires d'un premier diplôme, on entend les individus diplômés pour la première fois du niveau d'enseignement considéré, tandis que les titulaires de plusieurs diplômes peuvent avoir déjà obtenu précédemment un diplôme du même niveau d'enseignement.

Les étudiants en mobilité internationale sont ceux qui ont quitté leur pays d'origine pour se rendre dans un autre pays dans l'intention d'y suivre des études. Les étudiants en mobilité internationale qui s'inscrivent pour la première fois dans une formation sont souvent considérés comme de nouveaux inscrits dans ce pays.

L'âge moyen des étudiants est calculé à la date du $1^{\mathrm{er}}$ janvier dans les pays où l'année académique débute au deuxième semestre de l'année civile et à la date du $1^{\text {er }}$ juillet dans ceux où elle débute au premier semestre. Par voie de conséquence, l'âge moyen des titulaires d'un premier diplôme peut être sous-estimé de six mois.

\section{Méthodologie}

Voir la section « Méthodologie » des indicateurs A1, A3 et B4.

Voir le Guide de l'OCDE pour l'établissement de statistiques internationalement comparables dans le domaine de l'éducation 2018 (OCDE, 2019[11]) pour de plus amples informations. Voir les notes spécifiques aux pays à l'annexe 3 (https://doi.org/10.1787/f8d7880d-en). 


\section{Source}

Voir les indicateurs A1 et A3 pour des informations sur les sources des données sur le niveau de formation et l'emploi.

Les données sur les nouveaux inscrits et les diplômés se rapportent à l'année académique 2016/17 et proviennent de l'exercice UNESCO-ISU/OCDE/Eurostat de collecte de données statistiques sur l'éducation réalisé par l'OCDE en 2018 (pour plus de précisions, voir l'annexe 3, https://doi.org/10.1787/f8d7880d-en).

\section{Remarque concernant les données fournies par Israël}

Les données statistiques concernant Israël sont fournies par et sous la responsabilité des autorités israéliennes compétentes. L'utilisation de ces données par l'OCDE est sans préjudice du statut des hauteurs du Golan, de Jérusalem-Est et des colonies de peuplement israéliennes en Cisjordanie aux termes du droit international.

\section{Références}

Auriol, L., M. Misu et R. Freeman (2013), « Careers of doctorate holders: Analysis of labour market and mobility indicators ", Documents de travail de l'OCDE sur la science, la technologie et l'industrie, $n^{\circ}$ 2013/04, Éditions OCDE, Paris, http://dx.doi.org/10.1787/5kmh8phxvvf5-en.

Borgonovi, F. et al. (2018), Empowering Women in the Digital Age; Where Do We Stand?, OCDE, Paris, https://www.oecd.org/social/empowering-women-in-the-digital-age-brochure.pdf (consulté le 30 août 2018).

Commission européenne (2016), PEGASUS - Giving Wings to the Career of Experienced Researchers, Commission européenne, Bruxelles, https://cordis.europa.eu/result/rcn/191992 en.html (consulté le 23 mai 2018).

Commission européenne (2016), She Figures 2015, Office des publications de l'Union européenne, Luxembourg, http://dx.doi.org/10.2777/064694.

Eurydice Report (dir. pub.) (2017), Modernisation of Higher Education in Europe: Academic Staff 2017, Office des publications de l'Union européenne, Luxembourg, https://publications.europa.eu/en/publication-detail/-/publication/40f84414-683f-11e7-b2f201aa75ed71a1/language-en (consulté le 18 octobre 2018).

OCDE (2019), Benchmarking Higher Education System Performance, Éditions OCDE, Paris, https://doi.org/10.1787/be5514d7-en.

OCDE (2019), Guide de l'OCDE pour l'établissement de statistiques internationalement comparables dans le domaine de l'éducation 2018: Concepts, normes, définitions et classifications, Éditions OCDE, Paris, https://dx.doi.org/10.1787/9789264305380-fr.

OCDE (2018), Science, technologie et industrie : Tableau de bord de l'OCDE 2017: La transformation numérique, Éditions OCDE, Paris, https://dx.doi.org/10.1787/sti scoreboard-2017-fr.

OCDE (2018), Statistiques de l'OCDE de la science et technologie et de la R-D, https://doi.org/10.1787/strd-data-fr. 
OCDE/Eurostat/Institut de statistique de I'UNESCO (2016), Guide opérationnel CITE 2011: Directives pour la classification des programmes éducatifs nationaux et des certifications correspondantes, Institut de statistique de I'UNESCO, Paris, https://dx.doi.org/10.1787/9789264248823-fr.

Wächter, B. et F. Maiworm (2014), « English-taught programmes in European higher education », ACA [4] Papers on International Cooperation in Education, http://www.acasecretariat.be/fileadmin/aca docs/images/members/ACA-2015 English Taught 01.pdf (consulté le 28 mai 2019).

\section{Tableaux de l'indicateur B7}

Tableau B7.1

Tableau B7.2

Tableau B7.3
Profil des diplômés à l'issue d'un doctorat (2017)

Répartition des diplômés à l'issue d'un doctorat, selon le domaine d'études (2017)

Niveau de formation et taux d'emploi des adultes âgés de 25 à 64 ans titulaires d'un master ou d'un doctorat (2018)

Date butoir pour les données : 19 juillet 2019. Les mises à jour peuvent être consultées en ligne à l'adresse : http://dx.doi.org/10.1787/eag-data-fr. D'autres données désagrégées sont également disponibles dans la Base de données de Regards sur l'éducation (http://stats.oecd.org/).

StatLink : https://doi.org/10.1787/888933981039 
Tableau B7.1. Profil des diplômés à l'issue d'un doctorat (2017)

Répartition selon l'âge, pourcentage de docteurs en mobilité internationale, pourcentage de femmes titulaires d'un master ou d'un doctorat selon le domaine d'études, et nombre de diplômés à l'issue d'un doctorat

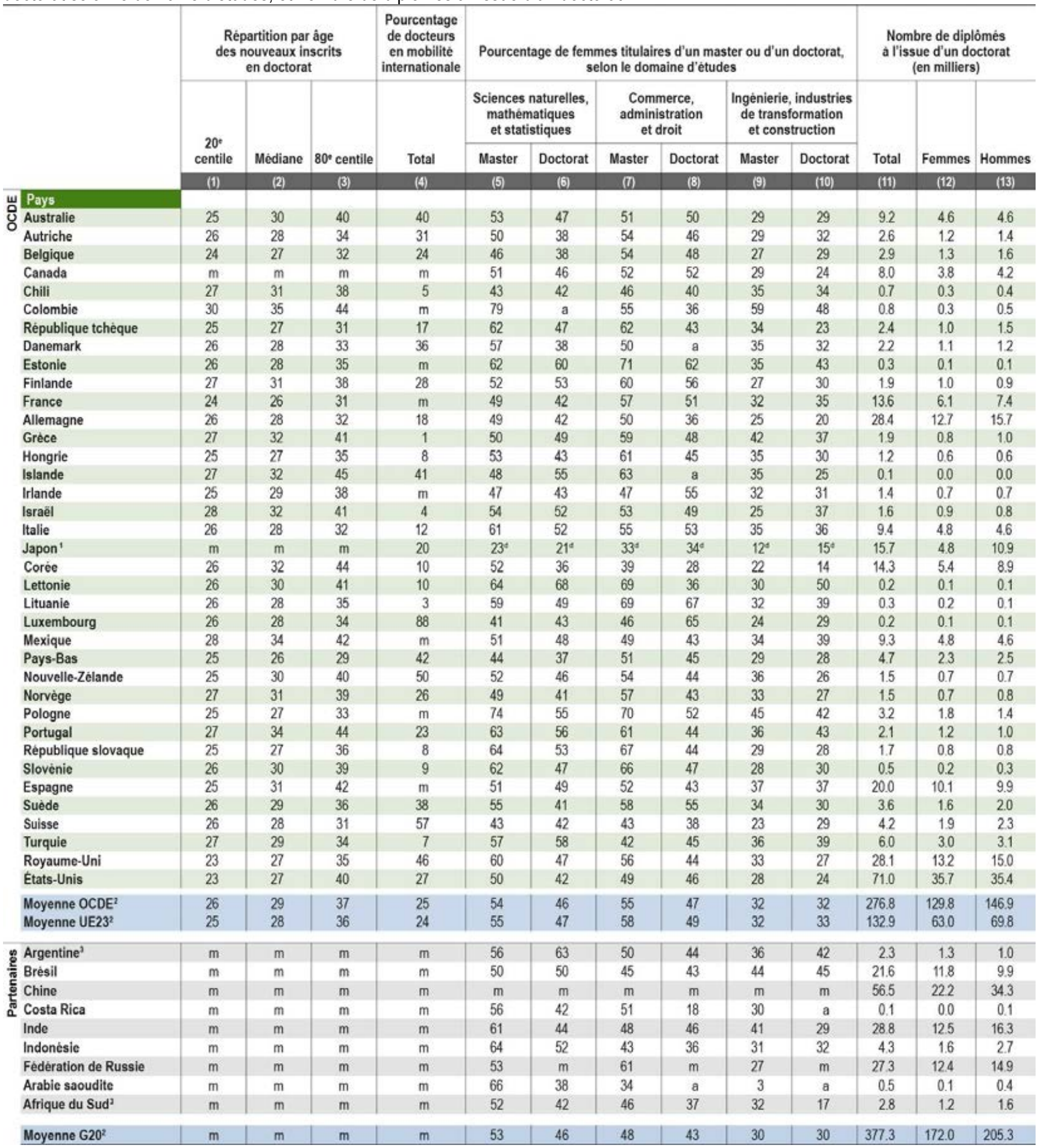

Remarque : Les données présentées dans ce tableau se rapportent au nombre total de diplômés, à l'exception du pourcentage de docteurs en mobilité internationale qui se rapporte aux titulaires d'un premier diplôme.

1.Tous les domaines d'études incluent le domaine des technologies de l'information et de la communication (TIC)

2. Les colonnes $11,12,13$ présentent la somme de l'ensemble des pays de l'OCDE et non une moyenne.

3. Année de référence : 2016.

Source : OCDE/ISU/Eurostat (2019). Consulter la section « Source » pour tout complément d'information et l'annexe 3 pour les notes (https://doi.org/10.1787/f8d7880d-en). Les symboles représentant les données manquantes et les abréviations figurent dans le Guide du lecteur. 
Tableau B7.2. Répartition des diplômés à l'issue d'un doctorat, selon le domaine d'études (2017)

\begin{tabular}{|c|c|c|c|c|c|c|c|c|c|c|c|c|c|c|}
\hline & \multicolumn{7}{|c|}{ Pourcentage de diplômés par domaine d'études } & \multicolumn{7}{|c|}{ Pourcentage de docteurs en mobilité internationale par domaine d'études } \\
\hline & 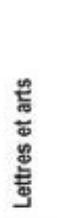 & 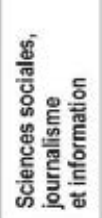 & 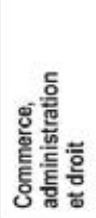 & 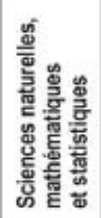 & 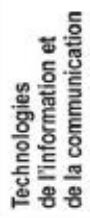 & 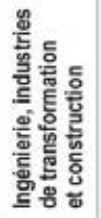 & 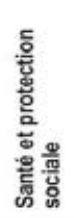 & 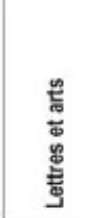 & 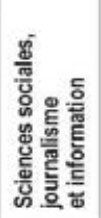 & 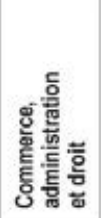 & 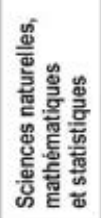 & 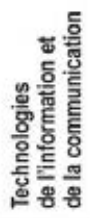 & 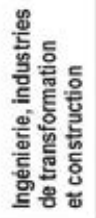 & 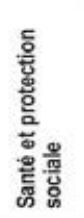 \\
\hline & (1) & (2) & (3) & (4) & (5) & (6) & (7) & (8) & (9) & (10) & (11) & (12) & (13) & (14) \\
\hline \multicolumn{15}{|l|}{ س Pays } \\
\hline Australie & 11 & 12 & 8 & 23 & 4 & 17 & 16 & 6 & 7 & 10 & 27 & 6 & 23 & 11 \\
\hline Autriche & 15 & 10 & 14 & 18 & 4 & 21 & 11 & 15 & 8 & 9 & 23 & 4 & 20 & 13 \\
\hline Belgique & 11 & 12 & 8 & 23 & 1 & 16 & 25 & 13 & 12 & 8 & 24 & 0 & 19 & 21 \\
\hline Canada & 9 & 18 & 4 & 26 & 3 & 21 & 9 & 7 & 10 & 4 & 30 & 4 & 32 & 6 \\
\hline Chili & 15 & 10 & 3 & 37 & 2 & 12 & 7 & 12 & 0 & 0 & 39 & 6 & 24 & 0 \\
\hline Colombie & 0 & 2 & 42 & 0 & 2 & 29 & 19 & 25 & 31 & 6 & 6 & 6 & 13 & 6 \\
\hline République tchèque & 11 & 7 & 9 & 24 & 3 & 24 & 10 & 10 & 7 & 7 & 29 & 2 & 18 & 11 \\
\hline Danemark & 9 & 12 & 0 & 17 & 0 & 24 & 31 & 7 & 10 & 0 & 21 & 0 & 37 & 15 \\
\hline Estonic & 14 & 13 & 5 & 33 & 8 & 14 & 6 & 10 & 18 & 5 & 18 & 13 & 21 & 3 \\
\hline Finlande & 12 & 12 & 7 & 17 & 7 & 18 & 19 & 7 & 8 & 7 & 23 & 11 & 24 & 13 \\
\hline France & 14 & 9 & 9 & 43 & 5 & 14 & 3 & m & $\mathrm{m}$ & $\mathrm{m}$ & $\mathrm{m}$ & $\mathrm{m}$ & $\mathrm{m}$ & $\mathrm{m}$ \\
\hline Allemagne & 7 & 6 & 9 & 29 & 3 & 13 & 26 & 8 & 6 & 5 & 42 & 5 & 16 & 12 \\
\hline Grece & 13 & 6 & 4 & 14 & 4 & 23 & 25 & 35 & 6 & 0 & 35 & 0 & 18 & 0 \\
\hline Hongrie & 16 & 14 & 4 & 24 & 4 & 9 & 23 & 23 & 5 & 7 & 15 & 8 & 8 & 23 \\
\hline Islande & 8 & 9 & 5 & 34 & 0 & 6 & 28 & 0 & 4 & 8 & 65 & 0 & 12 & 4 \\
\hline Irlande & 12 & 14 & 7 & $n$ & 4 & 15 & 19 & 13 & 9 & 6 & 23 & 8 & 23 & 13 \\
\hline Israël & 13 & 12 & 4 & 40 & 6 & 11 & 5 & 16 & 12 & 0 & 40 & 6 & 21 & 0 \\
\hline Italie & 12 & 7 & 11 & 24 & 2 & 22 & 16 & 7 & 9 & 10 & 24 & 6 & 30 & 10 \\
\hline Japon' & $8^{4}$ & $3^{4}$ & $4^{4}$ & $14^{4}$ & $x$ & $23^{\circ}$ & 394 & $10^{\circ}$ & $11^{\mathrm{d}}$ & $x(9)$ & $8^{4}$ & $x$ & $44^{4}$ & $15^{4}$ \\
\hline Corée & 10 & 5 & 12 & 13 & 3 & 24 & 19 & 12 & 6 & 10 & 17 & 5 & 30 & 10 \\
\hline Lettonie & 8 & 11 & 22 & 13 & 5 & 20 & 15 & 7 & 13 & 60 & 0 & 0 & 13 & 7 \\
\hline Lituanie & 12 & 10 & 7 & 25 & 2 & 23 & 12 & 33 & 11 & 11 & 11 & 0 & 11 & 0 \\
\hline Luxembourg & 9 & 15 & 13 & 23 & 22 & 11 & 0 & 4 & 13 & 14 & 24 & 25 & 13 & 0 \\
\hline Mexique & 3 & 9 & 25 & 10 & 1 & 8 & 2 & m & $\mathrm{m}$ & $\mathrm{m}$ & $\mathrm{m}$ & $\mathrm{m}$ & $\mathrm{m}$ & $\mathrm{m}$ \\
\hline Pays-Bas & 8 & 10 & 8 & 16 & 2 & 11 & 36 & $\mathrm{~m}$ & m & m & $\mathrm{m}$ & $\mathrm{m}$ & $\mathrm{m}$ & m \\
\hline Nouvelle-Zèlande & 9 & 14 & 8 & 24 & 4 & 15 & 15 & 9 & 12 & 8 & 27 & 4 & 17 & 11 \\
\hline Norvège & 9 & 11 & 4 & 27 & 2 & 10 & 31 & 4 & 4 & 6 & 44 & 4 & 16 & 20 \\
\hline Pologne & 19 & 9 & 9 & 22 & 2 & 16 & 14 & $\mathrm{~m}$ & $\mathrm{~m}$ & $\mathrm{~m}$ & $\mathrm{~m}$ & $\mathrm{~m}$ & $\mathrm{~m}$ & $\mathrm{~m}$ \\
\hline Portugal & 13 & 12 & 5 & 18 & 3 & 20 & 13 & 14 & 13 & 8 & 16 & 5 & 19 & 3 \\
\hline République slovaque & 14 & 10 & 13 & 17 & 2 & 18 & 15 & 20 & 8 & 26 & 6 & 0 & 13 & 19 \\
\hline Slovénie & 21 & 4 & 10 & 13 & 3 & 24 & 19 & 20 & 11 & 5 & 25 & 7 & 25 & 5 \\
\hline Espagne & 16 & 12 & 7 & 29 & 5 & 8 & 16 & $\mathrm{~m}$ & $\mathrm{~m}$ & $\mathrm{~m}$ & $\mathrm{~m}$ & $\mathrm{~m}$ & $\mathrm{~m}$ & $\mathrm{~m}$ \\
\hline Suède & 5 & 8 & 3 & 20 & 5 & 25 & 28 & 2 & 6 & 2 & 27 & 8 & 32 & 20 \\
\hline Suisse & 8 & 8 & 9 & 32 & 3 & 15 & 20 & 6 & 7 & 8 & 38 & 5 & 20 & 12 \\
\hline Turquie & 15 & 9 & 14 & 19 & 0 & 19 & 9 & 14 & 7 & 9 & 19 & 0 & 34 & 7 \\
\hline Royaume-Uni & 16 & 9 & 6 & 29 & 4 & 15 & 16 & 14 & 11 & 9 & 25 & 5 & 20 & 12 \\
\hline Etats-Unis & 11 & 14 & 6 & 24 & 3 & 15 & 9 & 7 & 9 & 5 & 29 & 6 & 32 & 4 \\
\hline Moyenne OCDE & 11 & 10 & 9 & 23 & 4 & 17 & 17 & 12 & 10 & 9 & 25 & 5 & 22 & 10 \\
\hline Moyenne UE23 & 12 & 10 & 8 & 22 & 4 & 18 & 17 & 14 & 10 & 10 & 22 & 6 & 20 & 10 \\
\hline \&. Argentine ${ }^{2}$ & 10 & 17 & 9 & 40 & 1 & 7 & 7 & $\mathrm{~m}$ & $\mathrm{~m}$ & $\mathrm{~m}$ & $\mathrm{~m}$ & $\mathrm{~m}$ & $\mathrm{~m}$ & $\mathrm{~m}$ \\
\hline Erèsil & 11 & 7 & 5 & 15 & 2 & 14 & 19 & 7 & 4 & 2 & 31 & 2 & 23 & 9 \\
\hline Chine & $\mathrm{m}$ & $\mathrm{m}$ & $\mathrm{m}$ & $\mathrm{m}$ & $\mathrm{m}$ & $\mathrm{m}$ & $\mathrm{m}$ & m & $\mathrm{m}$ & $\mathrm{m}$ & $\mathrm{m}$ & $\mathrm{m}$ & $\mathrm{m}$ & $\mathrm{m}$ \\
\hline ¿ Costa Rica & 1 & 7 & 10 & 11 & 0 & 0 & 0 & $\mathrm{~m}$ & $\mathrm{~m}$ & $\mathrm{~m}$ & $\mathrm{~m}$ & $\mathrm{~m}$ & $\mathrm{~m}$ & $\mathrm{~m}$ \\
\hline Inde & 14 & 14 & 9 & 29 & 1 & 12 & 6 & $\mathrm{~m}$ & m & $\mathrm{m}$ & $\mathrm{m}$ & $\mathrm{m}$ & $\mathrm{m}$ & $\mathrm{m}$ \\
\hline Indonésic & 8 & 28 & 14 & 5 & 1 & 5 & 9 & m & $\mathrm{m}$ & $\mathrm{m}$ & $\mathrm{m}$ & $\mathrm{m}$ & $\mathrm{m}$ & $\mathrm{m}$ \\
\hline Féderation de Russie & 11 & 8 & 16 & 17 & 7 & 21 & 10 & $\mathrm{~m}$ & $\mathrm{~m}$ & $\mathrm{~m}$ & m & $\mathrm{m}$ & m & $\mathrm{m}$ \\
\hline Arabie saoudite & 39 & 3 & 4 & 16 & 1 & 3 & 20 & $\mathrm{~m}$ & $\mathrm{~m}$ & $\mathrm{~m}$ & $\mathrm{~m}$ & $\mathrm{~m}$ & $\mathrm{~m}$ & $\mathrm{~m}$ \\
\hline Afrique du Sud ${ }^{2}$ & 10 & 13 & 17 & 23 & 2 & 9 & 11 & m & $m$ & m & m & m & $\mathrm{m}$ & $\mathrm{m}$ \\
\hline Moyenne G20 & 12 & 11 & 10 & 22 & 3 & 14 & 14 & $\mathrm{~m}$ & $\mathrm{~m}$ & $\mathrm{~m}$ & $\mathrm{~m}$ & $\mathrm{~m}$ & $\mathrm{~m}$ & $\mathrm{~m}$ \\
\hline
\end{tabular}

Remarque : Le domaine « Agriculture, sylviculture et halieutique, et sciences vétérinaires », ainsi que les domaines de l'éducation et des services, qui tendent à représenter un pourcentage plus faible de diplômés à l'issue d'un doctorat, ne sont pas inclus dans cette répartition.

1.Tous les domaines d'études incluent le domaine des technologies de l'information et de la communication (TIC).

2. Année de référence : 2016.

Source : OCDE/ISU/Eurostat (2019). Consulter la section « Source » pour tout complément d'information et l'annexe 3 pour les notes (https://doi.org/10.1787/f8d7880d-en). Les symboles représentant les données manquantes et les abréviations figurent dans le Guide du lecteur. 
Tableau B7.3. Niveau de formation et taux d'emploi des adultes âgés de 25 à 64 ans titulaires d'un master ou d'un doctorat (2018)

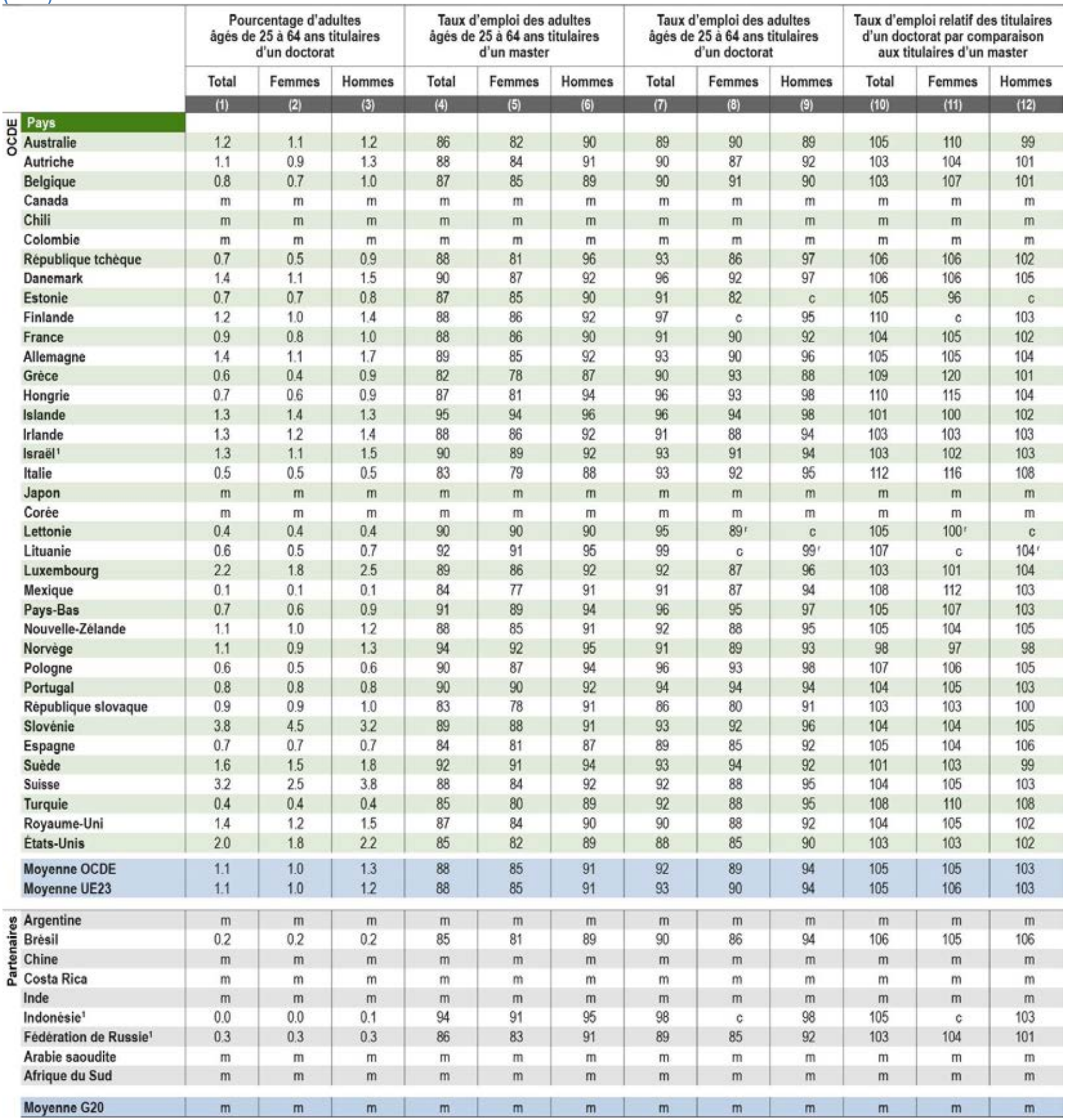

1. L'année de référence n'est pas 2018. Pour de plus amples informations, consulter le tableau A1.1. pour les colonnes 1 à 3 , et le tableau A3.1. pour les colonnes 4 à 9. Source : OCDE/OIT/ISU (2019). Consulter la section « Source » pour tout complément d'information et l'annexe 3 pour les notes (https://doi.org/10.1787/f8d7880d-en). Les symboles représentant les données manquantes et les abréviations figurent dans le Guide du lecteur. 


\section{Chapitre C. Ressources financières et humaines investies dans l'éducation}

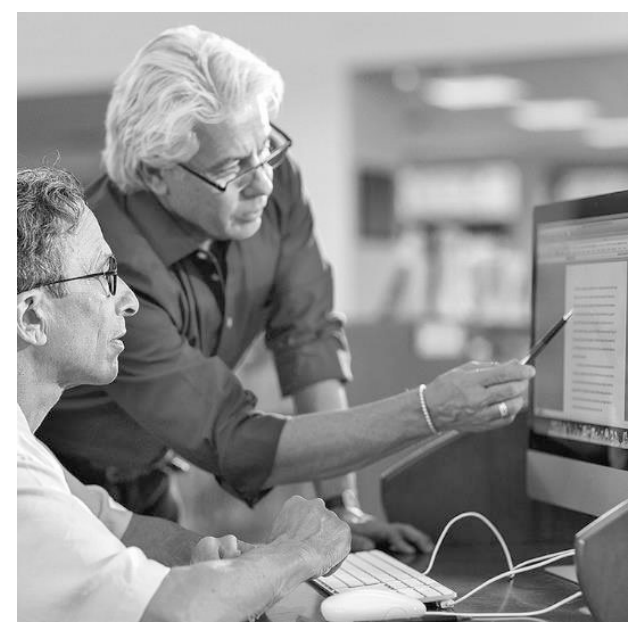

Indicator C1 Quel est le montant des dépenses par élève / étudiant ?

StatLink https://doi.org/10.1787/888933981058

Indicator C2 Quelle part de leur richesse nationale les pays consacrent-ils à l'éducation ?

StatLink https://doi.org/10.1787/888933981077

Indicator C3 Quelle est la répartition entre les investissements publics et privés au titre des établissements d'enseignement?

StatLink https://doi.org/10.1787/888933981096

Indicator C4 Quel est le montant total des dépenses publiques d'éducation?

StatLink https://doi.org/10.1787/888933981115

Indicator C5 Combien les étudiants paient-ils et quelles aides publiques reçoivent-ils

dans l'enseignement tertiaire?

StatLink https://doi.org/10.1787/888933981134

Indicator C6 À quelles catégories de services et de ressources les dépenses d'éducation sont-elles affectées?

StatLink https://doi.org/10.1787/888933981153

Indicator C7 Quels facteurs influent sur le coût salarial des enseignants ?

StatLink https://doi.org/10.1787/888933981172 


\section{Cadre des indicateurs sur le financement de l'éducation}

Les indicateurs internationaux sur le financement de l'éducation sont définis en termes de biens et de services d'éducation acquis dans le cadre des programmes éducatifs. Dans les faits ce sont les établissements d'enseignement, et non les biens et services d'éducation, qui servent le plus souvent d'unités de référence, signe de l'intérêt traditionnellement porté au coût des écoles, des établissements d'enseignement secondaire et des universités. Toutefois, si la dimension institutionnelle demeure importante, les dépenses en dehors des établissements, en particulier celles qui proviennent de sources publiques, contribuent à améliorer l'apprentissage et l'accès à l'éducation au sein des établissements d'enseignement. En outre, différencier les dépenses consacrées aux biens et aux services d'éducation d'une part, et aux biens et aux services non éducatifs d'autre part (biens et services offerts par les établissements) permet d'analyser les dépenses totales au titre de l'éducation. Enfin, les sources du financement des dépenses d'éducation déterminent qui sont les principaux contributeurs ainsi que l'impact que ce modèle peut avoir sur l'accès à l'éducation et l'offre de services d'éducation.

Dans ce contexte, il est important d'envisager un cadre sur les dépenses d'éducation élaboré autour des trois dimensions suivantes :

- la localisation des prestataires de services (au sein ou en dehors des établissements)

- le type de biens et de services fournis ou acquis (biens principaux ou marginaux)

- la source du financement de l'offre ou de l'acquisition de ces biens et services (source publique, privée ou internationale).

\section{Classification des dépenses d'éducation}

Les fonds consacrés à l'éducation sont classés dans cet indicateur selon les trois dimensions suivantes :

La première dimension - représentée par l'axe horizontal dans le tableau ci-dessous - définit la destination des fonds. Les dépenses au titre des établissements d'enseignement comprennent les dépenses consacrées aux établissements tels que les écoles et les universités, mais aussi à d'autres institutions telles que les ministères de l'Éducation et d'autres agences qui ont pour vocation de dispenser ou de soutenir l'enseignement. Les dépenses d'éducation en dehors des établissements d'enseignement incluent les dépenses au titre des biens et des services acquis en dehors des établissements, telles que les dépenses consacrées aux manuels scolaires, aux ordinateurs et aux cours particuliers. Ces dépenses comprennent également les frais de subsistance ou de transport des élèves/étudiants qui ne sont pas assumés par les établissements d'enseignement.

La deuxième dimension - représentée par l'axe vertical dans le tableau ci-dessous - a trait aux biens et services acquis. Les biens et les services d'éducation incluent toutes les dépenses qui sont en rapport direct avec l'enseignement et l'éducation, soit la rémunération des enseignants, l'entretien des locaux scolaires, le matériel pédagogique, les manuels, les frais engagés en dehors des établissements d'enseignement et la gestion des établissements. Toutefois, les fonds affectés aux établissements d'enseignement ne peuvent pas tous être classés comme des dépenses directes en matière d'enseignement ou d'éducation. Dans de nombreux pays de l'OCDE, les établissements d'enseignement proposent non seulement des services en matière d'enseignement, mais également divers types de services auxiliaires dans le but d'aider les élèves/étudiants et leur famille. À titre d'exemple, citons les repas, le transport, le logement, etc. Par ailleurs, il convient de souligner que la part des ressources consacrée aux activités de recherche et développement peut être relativement importante dans l'enseignement tertiaire. En outre, les dépenses en matière de biens et de services d'éducation ne sont pas toutes effectuées au sein des établissements d'enseignement. Les parents peuvent, par exemple, acheter du matériel scolaire ou des manuels à leur enfant, ou lui faire suivre des cours particuliers. En ce sens, les dépenses " autres que celles d'éducation " incluent toutes les dépenses globalement liées aux frais de subsistance des élèves/étudiants ou aux services offerts par les établissements au grand public.

La troisième dimension - représentée par les couleurs dans le tableau ci-dessous - sert à classer les fonds par provenance. Ce tableau comprend les ressources du secteur public et d'agences internationales (indiquées en bleu clair) et celles des ménages et autres entités privées (indiquées en bleu moyen). Dans les cas pour lesquels les dépenses à caractère privé sont subventionnées par des fonds publics, les cellules du tableau sont colorées en gris. Les cellules non colorées indiquent les éléments du cadre qui ne sont pas couverts par les indicateurs sur le financement dans la publication Regards sur l'éducation. 


\begin{tabular}{|c|c|c|c|}
\hline \multirow{3}{*}{\multicolumn{2}{|c|}{ Types de biens et de services }} & \multicolumn{2}{|l|}{$\begin{array}{l}\square \text { Fonds publics et internationaux } \\
\text { Fonds privés } \\
\text { Fonds privés subventionnés par les pouvoirs publics }\end{array}$} \\
\hline & & \multicolumn{2}{|c|}{ Localisation des prestataires de services } \\
\hline & & $\begin{array}{c}\text { Dépenses au titre des établissements d'enseignement } \\
\text { (Exemple : écoles, universités, } \\
\text { administrations et services d'aide aux élèves/ } \\
\text { étudiants) }\end{array}$ & $\begin{array}{c}\text { Dépenses d'éducation en dehors des établissements } \\
\text { d'enseignement } \\
\text { (Exemple : acquisition de biens } \\
\text { et de services d'éducation, y compris cours } \\
\text { particuliers) }\end{array}$ \\
\hline \multirow{3}{*}{\multicolumn{2}{|c|}{$\begin{array}{r}\text { Dépenses } \\
\text { au titre des biens } \\
\text { et des services d'éducation }\end{array}$}} & $\begin{array}{l}\text { Fonds publics et internationaux } \\
\text { Exemple : dépenses publiques en matière de } \\
\text { services d'éducation dans les établissements } \\
\text { d'enseignement }\end{array}$ & $\begin{array}{l}\text { Fonds privés subventionnés par les pouvoirs } \\
\text { publics } \\
\text { Exemple: dépenses privées subventionnées } \\
\text { liées à l'achat de livres et de matériel } \\
\text { pédagogique, ou aux cours particuliers }\end{array}$ \\
\hline & & $\begin{array}{l}\text { Fonds privés subventionnés par } \\
\text { les pouvoirs publics } \\
\text { Exemple: dépenses privées subventionnées } \\
\text { en matière de services d'éducation dans } \\
\text { les établissements d'enseignement }\end{array}$ & \multirow[t]{2}{*}{$\begin{array}{l}\text { Fonds privés } \\
\text { Exemple: dépenses privées liées à l'achat de } \\
\text { matériel et de manuels scolaires, et aux cours } \\
\text { particuliers }\end{array}$} \\
\hline & & $\begin{array}{l}\text { Fonds privés } \\
\text { Exemple : dépenses privées en matière } \\
\text { de droits de scolarité }\end{array}$ & \\
\hline \multirow{5}{*}{$\begin{array}{r}\text { Biens et } \\
\text { services } \\
\text { d'éducation } \\
\text { marginaux }\end{array}$} & \multirow{2}{*}{$\begin{array}{r}\text { Dépenses en } \\
\text { matière de } \\
\text { recherche et } \\
\text { développement }\end{array}$} & $\begin{array}{l}\text { Fonds publics et internationaux } \\
\text { Exemple: dépenses publiques au titre } \\
\text { de la recherche dans les établissements } \\
\text { d'enseignement tertiaire }\end{array}$ & \\
\hline & & $\begin{array}{l}\text { Fonds privés } \\
\text { Exemple : fonds privés consacrés } \\
\text { à la recherche et au développement dans } \\
\text { les établissements d'enseignement }\end{array}$ & \\
\hline & \multirow{3}{*}{$\begin{array}{r}\text { Dépenses } \\
\text { en matière de } \\
\text { services } \\
\text { d'éducation } \\
\text { autres que } \\
\text { l'enseignement }\end{array}$} & $\begin{array}{l}\text { Fonds publics et internationaux } \\
\text { Exemple: dépenses publiques en matière de } \\
\text { services auxiliaires (repas, transport scolaire ou } \\
\text { logement en internat) }\end{array}$ & $\begin{array}{l}\text { Fonds privés subventionnés par les pouvoirs } \\
\text { publics } \\
\text { Exemple: dépenses privées subventionnées au } \\
\text { titre des frais de subsistance ou des réductions } \\
\text { des frais de transport }\end{array}$ \\
\hline & & $\begin{array}{l}\text { Fonds privés subventionnés par les pouvoirs } \\
\text { publics } \\
\text { Exemple: aides publiques pour le logement, la } \\
\text { cantine, les services de santé ou autres services } \\
\text { d'aide offerts aux élèves/étudiants par les } \\
\text { établissements d'enseignement }\end{array}$ & \\
\hline & & $\begin{array}{l}\text { Fonds privés } \\
\text { Exemple: dépenses publiques au titre des droits } \\
\text { liés aux services auxiliaires }\end{array}$ & $\begin{array}{l}\text { Fonds privés } \\
\text { Exemple: dépenses privées au titre des frais de } \\
\text { subsistance ou de transport }\end{array}$ \\
\hline
\end{tabular}

\section{Indicateurs sur le financement de l'éducation}

Le présent chapitre analyse de manière détaillée et exhaustive les dépenses consacrées à l'éducation dans les pays de l'OCDE, en portant une attention particulière aux sept aspects suivants du financement de l'éducation :

- Les ressources financières investies dans les établissements d'enseignement, en fonction du nombre d'élèves/étudiants (voir l'indicateur C1) et de la richesse nationale des pays (voir l'indicateur C2).

- Les sources des investissements au titre des établissements d'enseignement (voir l'indicateur C3).

- Le montant total des dépenses publiques d'éducation, au sein et en dehors des établissements d'enseignement, en fonction des dépenses publiques totales (voir l'indicateur C4).

- Les frais à la charge des étudiants et les aides financières dans l'enseignement tertiaire (voir l'indicateur C5).

- La répartition des dépenses au titre de l'éducation selon les catégories de ressources (voir l'indicateur C6).

- La contribution de divers facteurs au coût salarial des enseignants par élève dans les établissements d'enseignement publics (voir l'indicateur C7). 


\section{Indicateur C1. Quel est le montant des dépenses par élève/étudiant?}

\section{Faits marquants}

- En moyenne, les pays de l'OCDE dépensent environ 1.7 fois plus par étudiant dans l'enseignement tertiaire que par élève dans l'enseignement non tertiaire (enseignement primaire, secondaire et postsecondaire non tertiaire). Les dépenses unitaires (c'est-à-dire par élève/étudiant) au titre des établissements d'enseignement, de l'enseignement primaire à l'enseignement tertiaire, s'élèvent à 10500 USD en moyenne dans les pays de l'OCDE. Elles sont de l'ordre de 9400 USD dans l'enseignement primaire, secondaire et post-secondaire non tertiaire, et de 15600 USD dans l'enseignement tertiaire.

- Dans l'enseignement non tertiaire, les dépenses au titre des services d'éducation représentent $93 \%$ des dépenses unitaires au titre des établissements. Dans l'enseignement tertiaire, la part des dépenses unitaires d'éducation dévolue aux services d'éducation est nettement moins élevée (67\%), mais celle allouée aux activités de recherche et développement (R-D) est plus élevée, de l'ordre de $30 \%$.

- Les dépenses unitaires cumulées entre l'âge de 6 et 15 ans s'élèvent à environ 93000 USD, en moyenne, dans les pays de l'OCDE.

Graphique C1.1. Dépenses totales au titre des établissements d'enseignement par élève/étudiant en équivalents temps plein, selon le niveau d'enseignement (2016)

En équivalents USD convertis sur la base des PPA

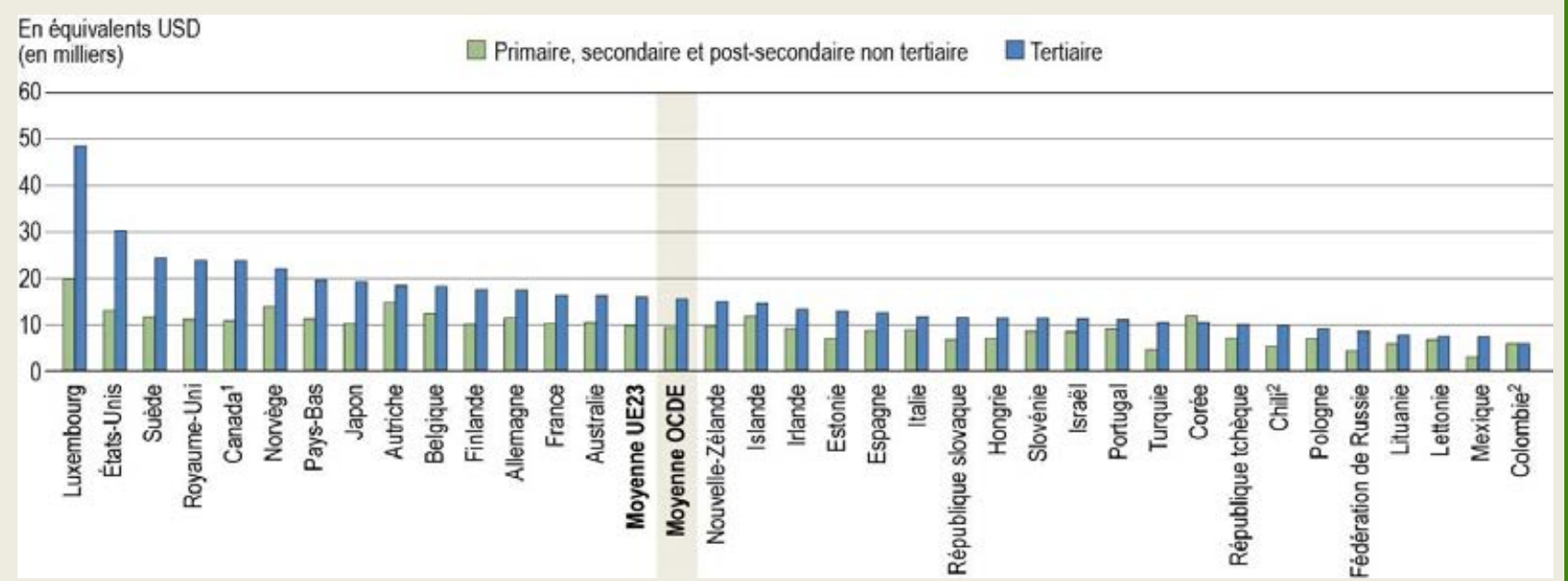

1. L'enseignement primaire inclut des programmes de l'enseignement préprimaire. Les chiffres de l'enseignement post-secondaire non tertiaire sont considérés comme négligeables.

2. Année de référence : 2017.

Les pays sont classés par ordre décroissant des dépenses totales au titre des établissements d'enseignement tertiaires par élève/étudiant. Source : OCDE/ISU/Eurostat (2019), tableau C1.1. Consulter la section « Source » pour tout complément d'information et l'annexe 3 pour les notes (https://doi.org/10.1787/f8d7880d-en). 


\section{Contexte}

Les responsables politiques veulent multiplier les possibilités d'apprentissage et dispenser un enseignement de qualité, mais ces objectifs peuvent donner lieu à une augmentation des coûts unitaires qui doit être équilibrée par rapport à d'autres postes de dépenses et à l'ensemble des charges fiscales. C'est pourquoi la question de savoir si l'investissement dans l'éducation est suffisamment rentable est une thématique majeure du débat public. Certes, il est difficile de déterminer le volume optimal de ressources requises pour préparer chaque individu à vivre et à travailler dans les sociétés modernes, mais les comparaisons internationales des dépenses unitaires au titre des établissements d'enseignement (voir les sections "Définitions " et "Méthodologie ») peuvent fournir des valeurs de référence utiles.

Cet indicateur évalue l'investissement dans la scolarité de chaque individu. Les dépenses unitaires au titre des établissements d'enseignement dépendent du salaire des enseignants (voir les indicateurs C7 et D3), des régimes de retraite, des temps d'instruction et d'enseignement (voir les indicateurs C7, D1 et D4), du coût des infrastructures scolaires et du matériel pédagogique (voir l'indicateur C6), des filières d'enseignement (générale ou professionnelle) et des effectifs scolarisés (voir l'indicateur B1). Les politiques mises en œuvre pour susciter des vocations d'enseignant, réduire la taille moyenne des classes ou modifier la dotation en personnel (voir l'indicateur D2) ont aussi contribué à la variation des dépenses unitaires. Les services auxiliaires et les activités de recherche et développement (R-D) peuvent en outre influer sur le niveau des dépenses unitaires.

Dans l'enseignement primaire et secondaire, les services d'éducation constituent le principal poste de dépenses. Dans l'enseignement tertiaire, d'autres services, en particulier les services auxiliaires et les activités de R-D, peuvent constituer un poste de dépenses considérable.

\section{Autres faits marquants}

- En moyenne, les dépenses unitaires totales sont plus élevées dans les établissements privés que dans les établissements publics. Les dépenses totales au titre des établissements publics de l'enseignement primaire à l'enseignement tertiaire s'élèvent à plus de 10300 USD par étudiant/élève, contre 10800 USD dans les établissements privés (voir le tableau C1.5, disponible en ligne).

- Entre 2010 et 2016, les dépenses au titre des établissements d'enseignement non tertiaire ont augmenté de $5 \%$ en moyenne dans les pays de l'OCDE, mais le nombre d'élèves est resté stable au cours de cette période. Les dépenses unitaires ont donc progressé de $5 \%$ durant cette période.

- Dans les pays de l'OCDE, les dépenses unitaires annuelles au titre des établissements d'enseignement représentent en moyenne $23 \%$ du produit intérieur brut (PIB) par habitant dans l'enseignement primaire, secondaire et post-secondaire non tertiaire. Elles sont beaucoup plus élevées dans l'enseignement tertiaire : les pays investissent en moyenne l'équivalent de $38 \%$ de leur PIB par habitant pour financer les formations de cycle court, les licences, les masters et les doctorats. 


\section{Analyse}

\section{Dépenses unitaires annuelles au titre des établissements d'enseignement par niveau d'enseignement}

Les dépenses unitaires annuelles au titre des établissements d'enseignement de l'enseignement primaire à l'enseignement tertiaire chiffrent l'investissement consenti dans la scolarité de chaque individu. Selon les chiffres de 2016, les dépenses unitaires annuelles de l'enseignement primaire à l'enseignement tertiaire sont égales ou légèrement supérieures à 3600 USD en Colombie et au Mexique, et sont supérieures à 15000 USD en Autriche, aux États-Unis et en Norvège ; elles frôlent même la barre des 22000 USD au Luxembourg (voir le tableau C1.1 et le graphique C1.1). Les dépenses unitaires au titre des établissements d'enseignement, de l'enseignement primaire à l'enseignement tertiaire, s'élèvent à 10500 USD en moyenne dans les pays de l'OCDE.

La méthode de répartition des ressources varie fortement entre les différents niveaux d'enseignement et reflète largement le mode d'organisation de l'enseignement. L'enseignement reste essentiellement dispensé dans des cadres où l'organisation, les programmes, les méthodes pédagogiques et la gestion sont similaires dans l'ensemble. Ces caractéristiques communes tendent à se traduire par des tendances similaires de dépenses unitaires de l'enseignement primaire à l'enseignement post-secondaire non tertiaire. Ces dernières décennies, l'augmentation des dépenses privées au titre de l'enseignement tertiaire a modifié la répartition des ressources à ce niveau d'enseignement, par comparaison avec les niveaux inférieurs (voir l'indicateur C3 et le tableau C1.5, disponible en ligne). Selon les chiffres de 2016, les dépenses unitaires des pays de l'OCDE s'élèvent en moyenne à 9400 USD dans l'enseignement primaire, secondaire et post-secondaire non tertiaire, et à 15600 USD dans l'enseignement tertiaire, mais cette moyenne est biaisée dans l'enseignement tertiaire à cause des dépenses élevées de quelques pays, en particulier le Canada, les États-Unis, le Luxembourg, la Norvège, le Royaume-Uni et la Suède (voir le tableau C1.1 et le graphique C1.1). Ces différences peuvent également entraîner une forte variation des dépenses unitaires cumulées sur toute la durée théorique de la scolarité (voir le tableau C1.6, disponible en ligne). En outre, des différences importantes s'observent entre les entités infranationales (voir l'encadré C1.1).

\section{Encadré C1.1. Variation infranationale des dépenses unitaires annuelles au titre des établissements d'enseignement}

Les dépenses unitaires annuelles peuvent être très hétérogènes d'un pays à l'autre, avec de grandes différences entre les régions. Parmi les trois pays dont les données des entités infranationales sont disponibles, c'est au Canada que les dépenses unitaires annuelles au titre des établissements d'enseignement primaire et secondaire varient le plus entre les entités infranationales : la région où ces dépenses sont les plus élevées (23000 USD) dépense près de trois fois plus par élève et par an que la région où ces dépenses sont les moins élevées (8 000 USD). Les différences régionales sont les plus ténues en Allemagne et en Belgique (OCDE, 2019 $[1]$ ).

L'analyse des différences régionales des dépenses au titre des établissements d'enseignement primaire et secondaire révèle des tendances contrastées. En Allemagne, huit des douze Länder où les dépenses unitaires sont inférieures à la moyenne nationale se situent dans la partie occidentale du pays. Cela pourrait s'expliquer par le grave déclin démographique enregistré dans les Länder situés à l'est qui a entrainé une réduction des effectifs scolarisés (OCDE, 2019[1]).

Afin de garantir la comparabilité internationale des données, les dépenses ont été converties dans la même devise (USD) à l'aide des parités de pouvoir d'achat (PPA). II convient toutefois de noter que la variation du coût de la vie au sein même des pays n'a pas été prise en considération. 
Graphique C1.2. Dépenses totales au titre des établissements d'enseignement par élève/étudiant en équivalents temps plein, selon le type de service (2016)

En équivalents USD convertis sur la base des PPA

$\square$ Total $\square$ R-D $\square$ Services auxiliaires $\square$ Services d'éducation

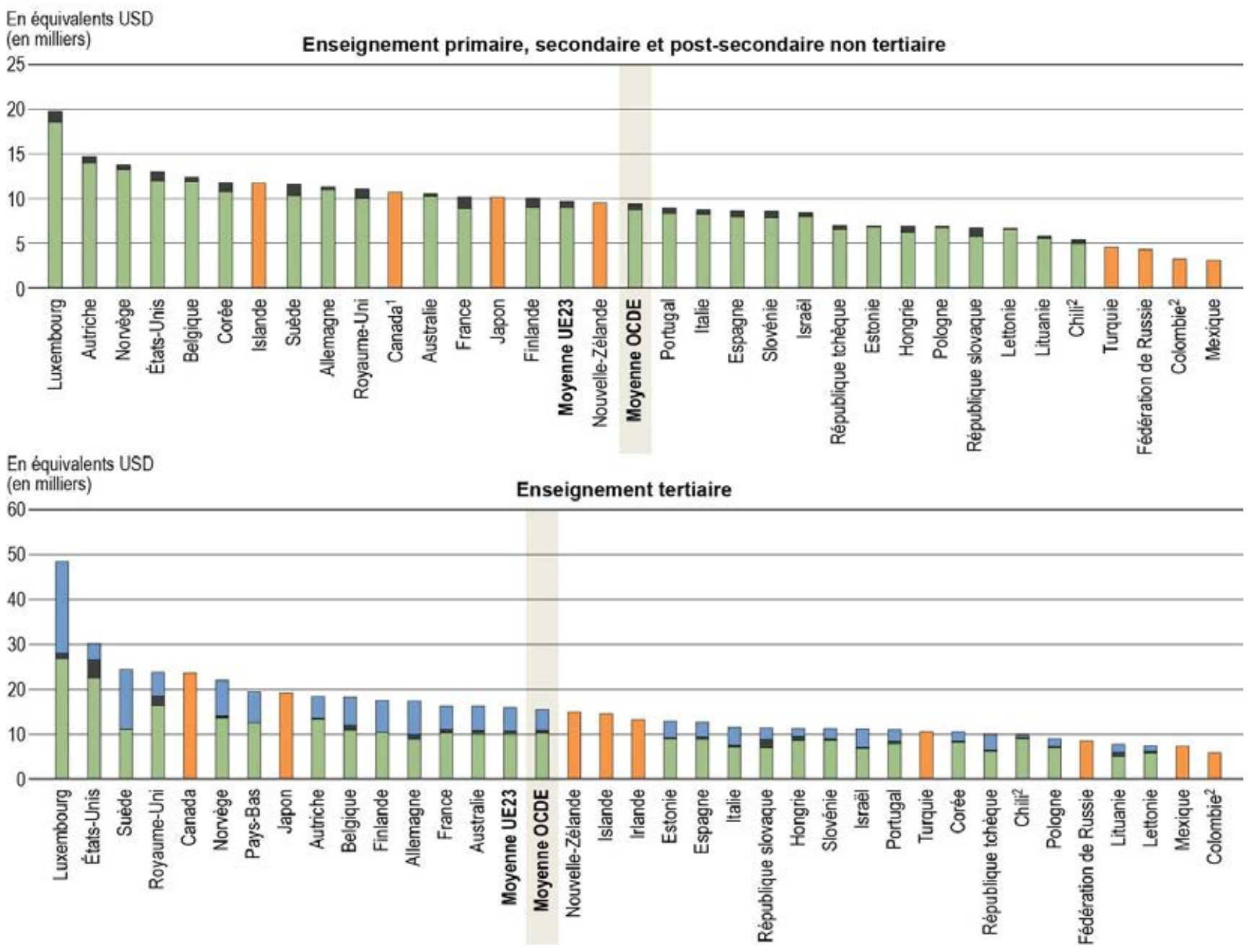

1. L'enseignement primaire inclut des programmes de l'enseignement préprimaire. Les chiffres de l'enseignement post-secondaire non tertiaire sont considérés comme négligeables.

2. Année de référence : 2017.

Les pays sont classés par ordre décroissant des dépenses totales au titre des établissements d'enseignement par élève/étudiant en équivalents temps plein.

Source : OCDE/ISU/Eurostat (2019), tableau C1.2. Consulter la section « Source » pour tout complément d'information et l'annexe 3 pour les notes (https://doi.org/10.1787/f8d7880d-en).

StatLink 젠 https://doi.org/10.1787/888933978816

La répartition des dépenses entre les différents niveaux d'enseignement permet de montrer la priorité que les gouvernements accordent à ces niveaux ainsi que le coût relatif de l'enseignement. Les dépenses unitaires d'éducation augmentent avec le niveau d'enseignement dans la quasi-totalité des pays de l'OCDE, mais l'ampleur des différentiels varie sensiblement d'un pays à l'autre (voir le tableau C1.1). Les pays de l'OCDE dépensent en moyenne $18 \%$ de plus par élève dans l'enseignement secondaire que dans l'enseignement primaire. Ce pourcentage est égal ou supérieur à $50 \%$ au Canada, en France, aux Pays-Bas et en République tchèque, tandis que d'autres pays comme le Chili, la Colombie, I'Islande, Israël, la Lituanie, la République slovaque, le RoyaumeUni et la Slovénie investissent davantage par élève dans l'enseignement primaire que dans l'enseignement 
secondaire - et ce en dépit du fait que les salaires des enseignants tendent à augmenter avec le niveau d'enseignement. Dans les pays de l'OCDE, les établissements d'enseignement dépensent en moyenne $31 \%$ de plus par étudiant dans l'enseignement tertiaire (activités de R-D non comprises) que par élève dans l'enseignement primaire. Les États-Unis et la Turquie dépensent deux fois plus par étudiant dans l'enseignement tertiaire (activités de R-D non comprises) que par élève dans l'enseignement primaire (voir le tableau C1.1).

\section{Dépenses unitaires au titre des services d'éducation, des services auxiliaires et de la $R-D$}

Dans les pays de l'OCDE, les dépenses au titre des services d'éducation proprement dits (dont le coût de l'enseignement et d'autres dépenses au titre de l'éducation) représentent en moyenne $87 \%$ des dépenses unitaires totales au titre des établissements d'enseignement, de l'enseignement primaire à l'enseignement tertiaire ; ce pourcentage passe la barre des $90 \%$ au Chili, en Lettonie et en Pologne. Dans environ un tiers des pays membres et partenaires de l'OCDE dont les données sont disponibles, les dépenses unitaires annuelles au titre de la recherche et du développement (R-D) et des services auxiliaires représentent environ au moins $15 \%$ des dépenses unitaires annuelles totales de l'enseignement primaire à l'enseignement tertiaire. En République slovaque et en Suède, ce pourcentage atteint $20 \%$.

Cette tendance globale occulte pourtant une variation importante entre les niveaux d'enseignement (voir le tableau C1.2 et le graphique C1.2). Dans l'enseignement non tertiaire (enseignement primaire, secondaire et post-secondaire non tertiaire), ce sont les services d'éducation qui représentent le poste de dépenses le plus important. En moyenne, dans les pays de l'OCDE, les dépenses au titre des services d'éducation représentent $93 \%$ (soit environ 8700 USD) des dépenses unitaires totales des établissements à ces niveaux d'enseignement. Les dépenses au titre des services auxiliaires représentent toutefois $10 \%$, voire un peu plus, des dépenses unitaires en Finlande, en France, en République slovaque et en Suède (voir le tableau C1.2).

Des différences plus marquées s'observent dans le pourcentage des dépenses unitaires totales au titre des établissements d'enseignement tertiaire consacré aux services d'éducation, car les dépenses au titre de la R-D peuvent représenter une part importante des dépenses d'éducation (voir le tableau C1.2). En moyenne, dans les pays de l'OCDE, les services d'éducation absorbent $67 \%$ des dépenses totales au titre des établissements d'enseignement tertiaire, mais la recherche et le développement représentent environ $30 \%$ de ces dépenses. Les pays de l'OCDE où les activités de R-D sont en grande partie menées par les établissements d'enseignement tertiaire ont tendance à afficher des niveaux plus élevés de dépenses unitaires que les pays où ces activités sont essentiellement du ressort de l'industrie ou d'autres institutions publiques. Abstraction faite des activités de R-D, les dépenses unitaires moyennes s'élèvent à plus de 11000 USD en moyenne dans les pays de l'OCDE, allant de moins de 6000 USD en Lituanie et au Mexique à plus de 25000 USD aux États-Unis et au Luxembourg.

En moyenne, dans les pays de l'OCDE, les dépenses unitaires au titre de la R-D et des services auxiliaires représentent $33 \%$ des dépenses unitaires totales au titre des établissements d'enseignement tertiaire. Dans cinq des pays membres et partenaires de l'OCDE dont les données sont disponibles, les dépenses unitaires au titre de la R-D et des services auxiliaires représentent au moins $40 \%$ des dépenses unitaires totales au titre des établissements d'enseignement tertiaire; ce pourcentage est le plus élevé en Suède (54\%). Toutefois, le pourcentage des dépenses unitaires au titre des services auxiliaires tend à être moins élevé dans l'enseignement tertiaire qu'aux niveaux inférieurs d'enseignement. En moyenne, ils représentent $5 \%$ seulement des dépenses au titre des établissements d'enseignement tertiaire ; leur pourcentage est même négligeable (avec moins de 100 USD par étudiant) en Autriche, au Chili, en Corée, en Estonie, en Finlande, en Israël, en Pologne, en République tchèque et en Suède. Parmi tous les pays de l'OCDE, ce sont les États-Unis et le Royaume-Uni qui consacrent le budget le plus important aux dépenses unitaires au titre des services auxiliaires dans l'enseignement tertiaire, avec plus de 2000 USD par étudiant. 


\section{Graphique C1.3. Dépenses cumulées au titre des établissements d'enseignement par élève entre les} âges de 6 et 15 ans en équivalents temps plein (2016)

En équivalents USD convertis sur la base des PPA

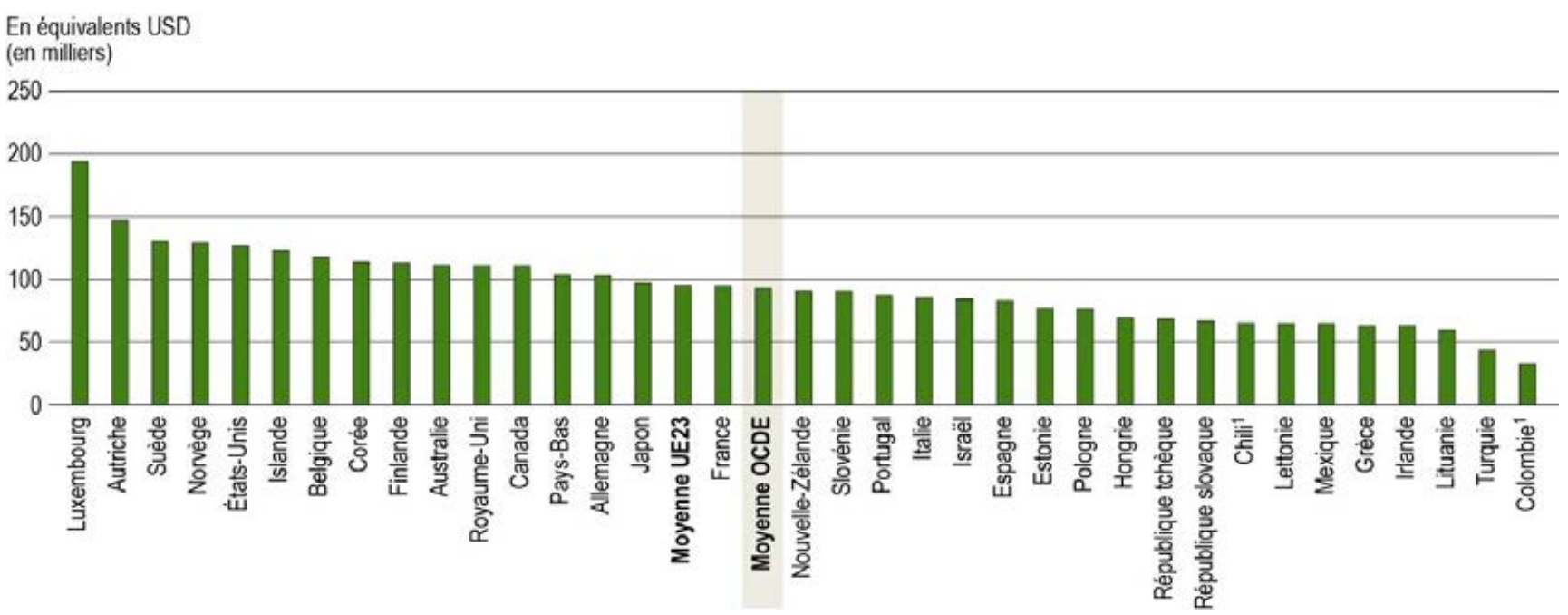

1. Année de référence : 2017.

Les pays sont classés par ordre décroissant des dépenses totales au titre des établissements d'enseignement par élève, cumulées sur la durée théorique de la scolarité primaire et secondaire entre les âges de 6 et 15 ans.

Source : OCDE/ISU/Eurostat (2019), tableau C1.6 (disponible en ligne). Consulter la section "Source » pour tout complément d'information et l'annexe 3 pour les notes (https://doi.org/10.1787/f8d7880d-en).

StatLink 제대 https://doi.org/10.1787/888933978835

Les responsables politiques s'intéressent à la relation entre le budget de l'éducation et le rendement des systèmes d'éducation (voir l'encadré B1.1 dans l'édition de 2017 de Regards sur l'éducation (OCDE, 2017[2])). Le coût de l'enseignement dans les pays dépend non seulement des dépenses unitaires annuelles, mais également de la durée totale des études à chaque niveau d'enseignement et des effectifs scolarisés. Des dépenses unitaires élevées peuvent par exemple être compensées par l'existence de formations courtes ou par l'accessibilité limitée de certains niveaux d'enseignement. À l'inverse, un système d'éducation à première vue économe en termes de dépenses unitaires peut se révéler dispendieux si l'effectif scolarisé est important et que les études sont longues.

Comme l'enseignement primaire et secondaire relève généralement de la scolarité obligatoire dans les pays de I'OCDE, les dépenses unitaires cumulées sur ces deux niveaux entre l'âge de 6 et 15 ans permettent d'évaluer le budget à consacrer à chaque individu durant la scolarité obligatoire dans les conditions actuelles (voir le graphique $\mathrm{C} 1.3$ et le tableau $\mathrm{C} 1.6$, disponible en ligne). Les dépenses unitaires cumulées entre l'âge de 6 et 15 ans s'élèvent à environ 92700 USD, en moyenne, dans les pays de l'OCDE. Les dépenses théoriques cumulées au titre des établissements d'enseignement varient considérablement entre les pays : elles sont supérieures à 120000 USD en Autriche, aux États-Unis, en Islande, au Luxembourg, en Norvège et en Suède, mais inférieures à 50000 USD en Colombie et en Turquie durant la période de référence.

\section{Dépenses unitaires au titre des établissements d'enseignement en pourcentage du PIB par habitant}

Les dépenses unitaires au titre des établissements d'enseignement en pourcentage du produit intérieur brut (PIB) par habitant sont un indicateur qui tient compte de la richesse relative des pays de l'OCDE. Comme la scolarisation est généralisée (et le plus souvent obligatoire) aux premiers niveaux d'enseignement dans la plupart des pays de l'OCDE, rapporter les dépenses unitaires au PIB par habitant permet de déterminer si le budget consacré à chaque individu est proportionnel à la capacité financière des pays. Aux niveaux supérieurs d'enseignement, cet indicateur n'est plus aussi probant, car les taux de scolarisation varient fortement entre les 
pays. Dans l'enseignement tertiaire, la valeur de cet indicateur peut par exemple être assez élevée dans les pays de l'OCDE qui consacrent une part relativement importante de leur richesse aux études d'un nombre relativement restreint d'individus.

Dans les pays de l'OCDE, les dépenses unitaires d'éducation tous niveaux d'enseignement confondus (de l'enseignement primaire à l'enseignement tertiaire) représentent en moyenne $26 \%$ du PIB par habitant ; plus précisément $23 \%$ dans l'enseignement primaire, secondaire et post-secondaire non tertiaire et $38 \%$ dans l'enseignement tertiaire (voir le tableau C1.4, disponible en ligne). Certains des pays où les dépenses unitaires sont peu élevées peuvent toutefois investir davantage dans l'éducation en pourcentage de leur PIB par habitant. Au Portugal par exemple, les dépenses unitaires au titre de tous les niveaux d'enseignement et le PIB par habitant sont tous deux inférieurs à la moyenne de l'OCDE, mais le budget unitaire est supérieur à la moyenne en pourcentage du PIB par habitant à chaque niveau d'enseignement.

La relation entre le PIB par habitant et les dépenses unitaires au titre des établissements d'enseignement est complexe. II existe toutefois une relation positive manifeste entre les dépenses unitaires au titre des établissements d'enseignement non tertiaire, et le PIB par habitant. En d'autres termes, les dépenses unitaires tendent à être moins élevées dans les pays moins riches que dans les pays plus riches. Cette relation est généralement positive à ces niveaux d'enseignement, mais des différences s'observent même entre des pays dont le PIB par habitant est comparable, en particulier parmi ceux où il est supérieur à 30000 USD. Par exemple, l'Autriche et les Pays-Bas affichent un PIB par habitant du même ordre (de 50000 USD environ, voir le tableau X2.1 à l'annexe 2), mais en affectent un pourcentage très différent à l'enseignement primaire, secondaire et post-secondaire non tertiaire. L'Autriche consacre l'équivalent de $28 \%$ de son PIB par habitant aux établissements d'enseignement non tertiaire (soit un pourcentage supérieur à la moyenne de l'OCDE de $23 \%$ ), alors que les Pays-Bas y consacrent $22 \%$ de leur PIB par habitant (voir le tableau C1.4, disponible en ligne).

Les dépenses unitaires au titre des établissements d'enseignement varient davantage dans l'enseignement tertiaire selon les pays, et la relation entre la richesse relative des pays et leur niveau de dépenses est plus variable à ce niveau d'enseignement. Dans l'enseignement tertiaire, le Canada, les États-Unis et le RoyaumeUni consacrent par étudiant l'équivalent de plus de 50 \% de leur PIB par habitant (voir le tableau C1.4, disponible en ligne). Le pourcentage élevé des dépenses unitaires du Royaume-Uni par exemple s'explique principalement par le montant extrêmement élevé de ses dépenses au titre de la R-D, qui représentent environ un quart des dépenses unitaires totales (voir le tableau C1.2).

\section{Évolution des dépenses unitaires au titre des établissements d'enseignement entre 2010 et 2016}

Les dépenses au titre des établissements d'enseignement sont largement soumises à l'évolution de la population d'âge scolaire et du niveau de rémunération des enseignants. La rémunération des enseignants (qui est le principal poste de dépenses d'éducation) a progressé au cours des dix dernières années dans la majorité des pays (voir l'indicateur D3). La taille de la population d'âge scolaire a un impact sur l'effectif scolarisé et sur les ressources et les efforts d'organisation que les pays doivent consacrer à leur système d'éducation. Plus la population à scolariser est importante, plus la demande potentielle de services d'éducation est forte. Les dépenses unitaires peuvent également varier entre les différents niveaux d'enseignement au sein même des pays, car les effectifs et les dépenses peuvent suivre des tendances différentes à chaque niveau d'enseignement.

Dans l'enseignement non tertiaire, les effectifs sont restés en moyenne plutôt stables, dans les pays de l'OCDE, entre 2010 et 2016. Durant cette même période, les dépenses au titre des établissements d'enseignement non tertiaire ont progressé de $5 \%$ en moyenne (voir le tableau C1.3). Par conséquent, les dépenses unitaires dans l'enseignement non tertiaire ont augmenté de $5 \%$ en 2016, par rapport à leur niveau de 2010. Les dépenses unitaires sont plus élevées en 2016 qu'elles ne l'étaient en 2010 dans la plupart des pays de l'OCDE, sauf dans certains pays durement touchés par la crise économique de 2008, tels que l'Australie, l'Estonie, l'Espagne, la France, l'Irlande, l'Italie et la Slovénie. Les dépenses unitaires ont augmenté de plus de $20 \%$ au Chili, en Israël, et en Lettonie. Au Chili, en Lettonie, en Pologne et en République slovaque, la diminution de plus de $5 \%$ de l'effectif scolarisé a coïncidé avec une forte augmentation des dépenses unitaires au titre des établissements d'enseignement entre 2010 et 2016. Par 
contraste, en Espagne, en Irlande et en Slovénie, l'augmentation de l'effectif scolarisé est allée de pair avec une diminution des dépenses unitaires au titre des établissements d'enseignement.

Dans l'enseignement tertiaire, les dépenses ont augmenté à un rythme nettement plus soutenu qu'aux niveaux inférieurs d'enseignement : elles ont progressé de $9 \%$ en moyenne entre 2010 et 2016. Elles ont également augmenté plus rapidement que l'effectif d'élèves durant cette période $(3 \%)$. Les pays de l'OCDE ont donc enregistré une augmentation moyenne de $8 \%$ des dépenses unitaires entre 2010 et 2016. Des écarts importants s'observent toutefois entre les pays. Parmi les pays membres et partenaires de l'OCDE dont les données sont disponibles, l'Allemagne, l'Australie, l'Espagne, la Finlande, la France, l'Italie, la Lituanie, le Mexique et le Portugal ont enregistré une baisse des dépenses unitaires au titre de l'enseignement tertiaire. Dans la quasitotalité de ces pays, cette diminution s'explique en grande partie par l'augmentation rapide des effectifs d'étudiants dans l'enseignement tertiaire. Par contraste, dans des pays tels que l'Estonie, I'Islande et la République slovaque par exemple, l'augmentation des dépenses unitaires à ce niveau d'enseignement est imputable à l'augmentation des dépenses totales et à la diminution de l'effectif de l'enseignement tertiaire (voir le tableau C1.3). L'évolution des dépenses au titre des établissements d'enseignement tertiaire peut influer sur l'affectation des ressources parmi les différents types de service et, en particulier, sur l'investissement dans les biens et services d'éducation (voir l'encadré C1.2).

\section{Encadré C1.2. Évolution des dépenses au titre des biens et des services d'éducation dans les établissements d'enseignement tertiaire}

Les dépenses au titre des biens et des services d'éducation fournissent aux établissements d'enseignement les ressources nécessaires pour accomplir leur mission principale : développer les compétences de leurs étudiants. Comparer l'évolution des dépenses au titre des services d'éducation à celle des dépenses publiques totales permet de mieux comprendre comment les changements intervenus dans les dépenses totales au titre des établissements d'enseignement influent sur le financement des biens et des services d'éducation. Ces comparaisons sont particulièrement pertinentes au regard des différents niveaux de l'enseignement tertiaire, où un pourcentage plus élevé des dépenses totales est alloué aux services autres que les biens et services d'éducation, tels que les services auxiliaires ou la recherche et le développement (R-D). Accorder la priorité aux dépenses dans ces domaines peut, certes, être justifié, mais réduire les investissements dans les services d'éducation peut avoir un impact sur la qualité de l'apprentissage et les conditions dans lesquelles l'enseignement est dispensé, en particulier dans les pays marqués par l'augmentation massive des taux de scolarisation dans l'enseignement tertiaire.

Entre 2012 et 2016, les dépenses au titre des services d'éducation et les dépenses totales au titre des établissements d'enseignement tertiaire ont évolué à un rythme sensiblement différent selon les pays (voir le graphique C1.a). Les dépenses totales au titre des établissements d'enseignement tertiaire ont augmenté dans deux tiers des pays membres et partenaires de l'OCDE durant cette période. Dans la plupart d'entre eux, les dépenses au titre des biens et services d'éducation ont également augmenté, mais de manière contrastée. Les dépenses au titre des biens et services d'éducation ont augmenté d'au moins 24 points de pourcentage de plus que les dépenses totales au titre des établissements d'enseignement tertiaire en Estonie et en République slovaque. Par contraste, les dépenses au titre des biens et services d'éducation ont évolué à un rythme moins soutenu que les dépenses totales au titre des établissements d'enseignement tertiaire en Belgique, au Chili, aux États-Unis, en Fédération de Russie, en Finlande, en Irlande, en Israël, en Lituanie, au Royaume-Uni et en Suède. Le Luxembourg est le seul pays à enregistrer à la fois une hausse des dépenses totales au titre de l'enseignement tertiaire (+34 \%) et une diminution des dépenses au titre des services d'éducation (-24\%). Cet écart suggère des investissements accrus dans les services auxiliaires ou la R-D au cours de la période de référence au détriment des services d'éducation, ce qui caractérise un système d'enseignement supérieur axé sur la recherche.

L'autre tiers des pays ont vu leurs investissements totaux au titre des établissements d'enseignement tertiaire décliner entre 2012 et 2016. En Hongrie et au Portugal, les gouvernements sont néanmoins parvenus à 
accroître leurs dépenses totales au titre des biens et services d'éducation malgré les coupes budgétaires, en réallouant une partie du budget affecté aux services auxiliaires ou à la R-D. Par contraste, les dépenses au titre des biens et des services d'éducation ont diminué en Italie, en Lettonie, en République tchèque et en Slovénie, quoique dans une moindre mesure, par rapport aux dépenses totales au titre des établissements d'enseignement tertiaires.

\section{Graphique C1.a. Taux de croissance des dépenses consacrées aux services d'éducation et des dépenses totales au titre des établissements d'enseignement tertiaire entre 2012 et 2016}

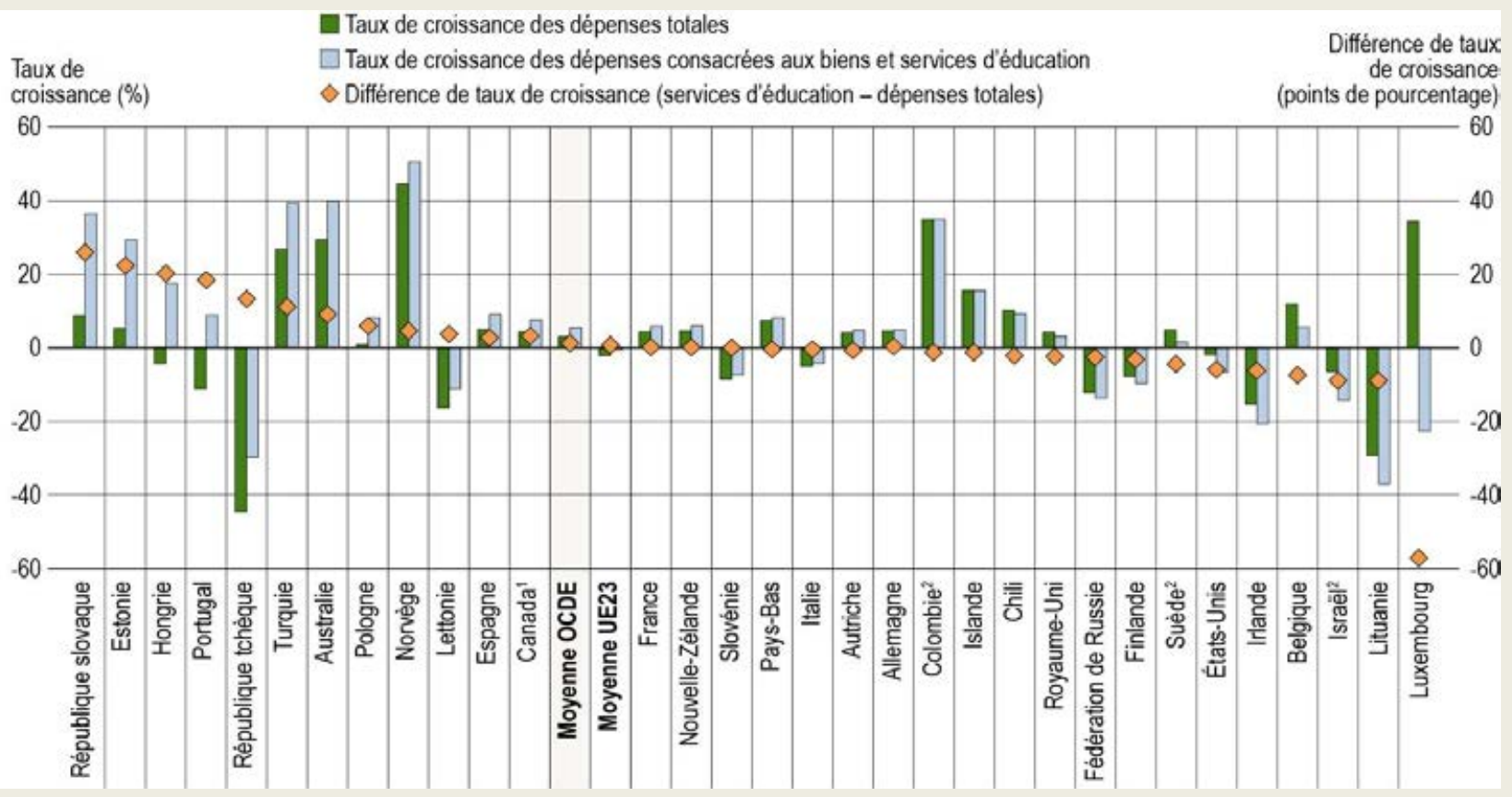

Remarque : Les dépenses consacrées aux services d'éducation sont obtenues en soustrayant les dépenses consacrées aux services auxiliaires et aux activités de R-D des dépenses totales au titre des établissements d'enseignement. Un chiffre positif correspond à un taux de croissance plus élevé des dépenses au titre des services d'éducation par comparaison avec le taux de croissance des dépenses totales, tous services confondus. Consulter les sections « Définitions » et « Méthodologie » pour de plus amples informations.

1. Période de référence : 2013-2016.

2. Période de référence : 2012-2015.

Les pays sont classés par ordre décroissant de la différence de taux en points de pourcentage.

Source : OCDE/ISU/Eurostat (2019), Base de données de Regards sur l'éducation. Consulter la section « Source " pour tout complément d'information et l'annexe 3 pour les notes (https://doi.org/10.1787/f8d7880d-en).

StatLink 셈ㄴ https://doi.org/10.1787/888933978854

\section{Définitions}

Par services auxiliaires, on entend les services fournis par les établissements d'enseignement en marge de leur mission principale d'éducation. II s'agit principalement des services à caractère social à l'intention des élèves/étudiants. Dans l'enseignement primaire, secondaire et post-secondaire non tertiaire, ces services à caractère social englobent la cantine, les soins de santé ainsi que le transport scolaire. Dans l'enseignement tertiaire, ils comprennent le logement (résidences d'étudiants), la cantine et les soins de santé.

Les dépenses au titre des services d'éducation comprennent toutes les dépenses en rapport direct avec l'enseignement que dispensent les établissements, soit la rémunération des enseignants, la construction et l'entretien des bâtiments scolaires, le matériel pédagogique et les manuels et, enfin, la gestion des établissements. 
Les activités de recherche et développement sont les activités de recherche menées par les universités et autres établissements d'enseignement tertiaire, qu'elles soient financées par des fonds institutionnels ou par des bourses ou des contrats proposés par des entités publiques ou privées.

\section{Méthodologie}

Les dépenses unitaires au titre des établissements d'enseignement d'un niveau d'enseignement donné sont calculées comme suit: les dépenses totales au titre des établissements d'enseignement de ce niveau sont divisées par l'effectif de ce niveau converti en équivalents temps plein. Ne sont pris en compte que les établissements d'enseignement et les programmes de cours dont les données sur les effectifs et les dépenses sont disponibles. Les dépenses exprimées en devise nationale sont divisées par l'indice de parité de pouvoir d'achat (PPA) pour le PIB pour obtenir leur équivalent en dollars des États-Unis (USD). La conversion basée sur l'indice PPA est préférée à celle basée sur le taux de change du marché, car celui-ci subit l'influence de nombreux facteurs (taux d'intérêt, politiques commerciales, prévisions de croissance économique, etc.) sans grand rapport avec le pouvoir d'achat relatif du moment dans les différents pays de l'OCDE (voir l'annexe 2 pour davantage de précisions).

Les dépenses unitaires d'éducation des entités infranationales sont ajustées sur la base des parités de pouvoir d'achat (PPA) à l'échelle nationale. Des travaux plus approfondis s'imposent au sujet de la variation infranationale du coût de la vie pour ajuster les dépenses unitaires utilisées dans cette section.

Les dépenses unitaires au titre des établissements d'enseignement en pourcentage du PIB par habitant correspondent aux dépenses unitaires rapportées au PIB par habitant. Dans les pays de l'OCDE où les données sur les dépenses d'éducation et les données sur le PIB portent sur des périodes de référence différentes, les données sur les dépenses sont corrigées à l'aide des taux d'inflation nationaux de manière à correspondre à la période de référence des données du PIB (voir l'annexe 2).

Effectif d'élèves/étudiants en équivalents temps plein : le classement des pays de l'OCDE en fonction des dépenses unitaires annuelles d'éducation est influencé par les différences de définition des notions de scolarisation à « temps plein » et à " temps partiel », et d'« équivalent temps plein » entre les pays. Certains pays de l'OCDE comptabilisent tous les inscrits dans l'enseignement tertiaire comme des étudiants à temps plein, alors que d'autres mesurent l'intensité de leur scolarisation d'après les unités de valeur qu'ils ont obtenues à l'issue de modules spécifiques de cours pendant une période de référence donnée. Les pays de l'OCDE qui peuvent évaluer avec précision le taux de scolarisation à temps partiel affichent des dépenses apparemment plus élevées par étudiant en équivalent temps plein que les pays qui ne peuvent établir de distinction entre les diverses modalités de scolarisation.

Voir le Guide de l'OCDE pour l'établissement de statistiques internationalement comparables dans le domaine de l'éducation 2018 (OCDE, 2019 $9_{[3]}$ ) pour de plus amples informations. Voir les notes spécifiques aux pays à l'annexe 3 (https://doi.org/10.1787/f8d7880d-en).

\section{Source}

Les données se rapportent à l'année budgétaire 2016 (sauf mention contraire) et proviennent de la collecte de données statistiques sur l'éducation de I'UNESCO, de l'OCDE et d'Eurostat (UOE) réalisée en 2017 par l'OCDE (pour plus de précisions, voir l'annexe 3, https://doi.org/10.1787/f8d7880d-en). Les données de l'Afrique du Sud, de l'Arabie saoudite, de l'Argentine, de l'Inde, de l'Indonésie et de la République populaire de Chine proviennent de l'Institut de statistique de l'UNESCO (ISU).

Les données relatives aux dépenses de 2005, de 2011 et de 2016 proviennent d'une enquête menée en 201819. Les dépenses de 2005 à 2015 ont été ajustées en fonction des méthodes et des définitions appliquées lors du dernier exercice UOE de collecte de données en date. 
Les données infranationales sont actuellement disponibles pour trois pays: l'Allemagne, la Belgique et le Canada. Les estimations infranationales ont été fournies par les pays sur la base de sources nationales. Les données infranationales sont issues d'une enquête spéciale menée par l'OCDE en 2019.

\section{Note concernant les données d'Israël}

Les données statistiques concernant Israël sont fournies par et sous la responsabilité des autorités israéliennes compétentes. L'utilisation de ces données par l'OCDE est sans préjudice du statut des hauteurs du Golan, de Jérusalem-Est et des colonies de peuplement israéliennes en Cisjordanie aux termes du droit international.

\section{Références}

OCDE (2019), Base de données de statistiques régionales, http://stats.oecd.org/Index.aspx?DataSetCode=REGION DEMOGR.

OCDE (2019), Guide de l'OCDE pour l'établissement de statistiques internationalement comparables dans le domaine de l'éducation 2018: Concepts, normes, définitions et classifications, Éditions OCDE, Paris, https://dx.doi.org/10.1787/9789264305380-fr.

OCDE (2017), Regards sur l'éducation 2017 : Les indicateurs de l'OCDE, Éditions OCDE, Paris,

\section{Tableaux de l'indicateur C1}

Tableau C1.1

Tableau C1.2

Tableau C1.3

WEB Tableau C1.4

WEB Tableau C1.5
Dépenses totales au titre des établissements d'enseignement par élève/étudiant en équivalents temps plein, sources finales de financement (2016)

Dépenses totales au titre des établissements d'enseignement par élève/étudiant en équivalents temps plein pour les services d'éducation, les services auxiliaires et la R-D (2016)

Indice de variation des dépenses totales au titre des établissements d'enseignement par élève/étudiant en équivalents temps plein (2005, 2011 et 2016)

Dépenses totales au titre des établissements d'enseignement par élève/étudiant en équivalents temps plein, en pourcentage du PIB par habitant (2016)

Dépenses totales au titre des établissements d'enseignement par élève/étudiant en équivalents temps plein, selon le type d'établissement (2016)

WEB Tableau C1.6 Dépenses cumulées au titre des établissements d'enseignement par élève entre les âges de 6 et 15 ans en équivalents temps plein (2016)

Date butoir pour les données : 19 juillet 2019. Les mises à jour peuvent être consultées en ligne sur : http://dx.doi.org/10.1787/eag-data-en. D'autres données désagrégées sont également disponibles dans la Base de données de Regards sur l'éducation (http://stats.oecd.org/).

StatLink: https://doi.org/10.1787/888933981058 
Tableau C1.1. Dépenses totales au titre des établissements d'enseignement par élève/étudiant en équivalents temps plein, sources finales de financement (2016)

En équivalents USD convertis sur la base des PPA pour le PIB, dépenses directes au sein des établissements, selon le niveau d'enseignement, calculs fondés sur des équivalents temps plein

\begin{tabular}{|c|c|c|c|c|c|c|c|c|c|c|c|c|c|c|}
\hline & \multirow[b]{3}{*}{ 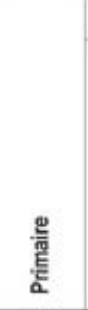 } & \multicolumn{5}{|c|}{ Secondaire } & \multirow{3}{*}{ 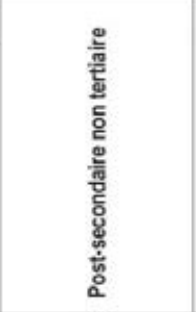 } & \multirow{3}{*}{ 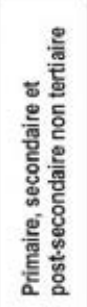 } & \multicolumn{4}{|c|}{ Tertiaire } & \multirow{3}{*}{ 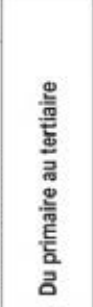 } & \multirow{3}{*}{ 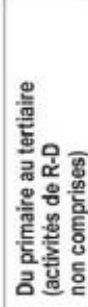 } \\
\hline & & \multirow[b]{2}{*}{ 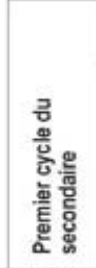 } & \multicolumn{3}{|c|}{$\begin{array}{l}\text { Deuxième cycle } \\
\text { du secondaire }\end{array}$} & \multirow{2}{*}{ 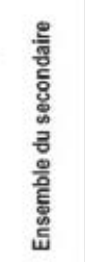 } & & & \multirow{2}{*}{ 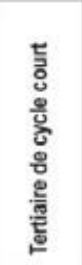 } & \multirow{2}{*}{ 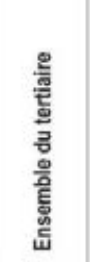 } & \multirow{2}{*}{ 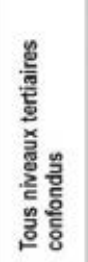 } & \multirow{2}{*}{ 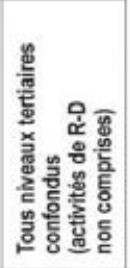 } & & \\
\hline & & & 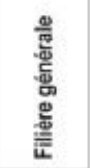 & 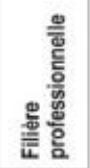 & 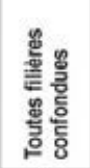 & & & & & & & & & \\
\hline & (1) & (2) & (3) & (4) & (5) & (6) & (7) & (8) & (9) & (10) & (11) & (12) & (13) & (14) \\
\hline \multicolumn{15}{|l|}{ سu Pays } \\
\hline Australie & 10013 & 12684 & 13543 & 4529 & 10199 & 11651 & 4778 & 10506 & 7200 & 20650 & 16170 & 10791 & 11867 & 10574 \\
\hline Autriche & 12299 & 16282 & 14190 & 17827 & 16351 & 16313 & 5436 & 14679 & 17837 & 18424 & 18332 & 13596 & 15806 & 14345 \\
\hline Belgique & 10646 & 13409 & $13451^{\circ}$ & $13881^{\circ}$ & $13704^{\circ}$ & $13603^{\circ}$ & $x(3,4,5,6)$ & 12324 & 12833 & 18366 & 18169 & 11848 & 13446 & 12233 \\
\hline Canada' & $9207^{\circ}$ & $x(1)$ & $x(5)$ & $x(5)$ & 13856 & 13856 & $\mathrm{~m}$ & $10681^{\circ}$ & 18228 & 26606 & 23700 & 16907 & $13682^{\circ}$ & $12116^{\circ}$ \\
\hline Chili $^{2}$ & 5371 & 5556 & 5031 & 5432 & 5142 & 5278 & a & 5324 & 4928 & 11683 & 9769 & 9271 & 6613 & 6468 \\
\hline Colombie $^{2}$ & 3323 & 3091 & $x(5)$ & $\mathbf{x}(5)$ & $3001^{\circ}$ & $3066^{d}$ & $\times(5,6)$ & 3184 & $x(11)$ & $x(11)$ & 5787 & $\mathrm{~m}$ & 3661 & $\mathrm{~m}$ \\
\hline République tchèque & 5104 & 8598 & 7236 & 8629 & 8257 & 8425 & 2759 & 6960 & 16908 & 9990 & 10009 & 6389 & 7612 & 6857 \\
\hline Danemark & $\mathrm{m}$ & m & $\mathrm{m}$ & m & $\mathrm{m}$ & $\mathrm{m}$ & $\mathrm{m}$ & $\mathrm{m}$ & $\mathrm{m}$ & $\mathrm{m}$ & $\mathrm{m}$ & $\mathrm{m}$ & m & m \\
\hline Estonie & 6872 & 7047 & 6548 & 7031 & 6742 & 6887 & 7719 & 6914 & a & 12909 & 12909 & 9237 & 8243 & 7429 \\
\hline Finlande & 9447 & 15041 & 8441 & $8270^{\circ}$ & $8315^{\circ}$ & $10427^{\circ}$ & $x(4,5,6)$ & 10045 & a & 17541 & 17541 & 10314 & 11531 & 10099 \\
\hline France & 7603 & 10599 & 13431 & 15392 & 14132 & 12100 & 9389 & 10186 & 14502 & 16697 & 16173 & 11031 & 11364 & 10352 \\
\hline Allemagne & 8960 & 11159 & 11893 & 16323 & 14094 & 12268 & 11211 & 11294 & 10783 & 17429 & 17429 & 9863 & 12583 & 10994 \\
\hline Grece & 5973 & 6859 & $5836^{\circ}$ & $8930^{\circ}$ & $6704^{\circ}$ & $6779^{\circ}$ & $\mathrm{m}$ & $\mathrm{m}$ & a & $\mathrm{m}$ & $\mathrm{m}$ & $\mathrm{m}$ & $\mathrm{m}$ & $\mathrm{m}$ \\
\hline Hongrie & 5454 & 5788 & 7312 & 12783 & 8508 & 7174 & 12605 & 6899 & 7206 & 11470 & 11288 & 9541 & 7639 & 7345 \\
\hline Islande & 11757 & 13501 & 8878 & 14043 & 10360 & 11578 & 15653 & 11707 & 10015 & 14688 & 14551 & $\mathrm{~m}$ & 12250 & m \\
\hline Irlande & 8468 & 9814 & $x(5)$ & $x(5)$ & 10094 & 9948 & 7771 & 9020 & $x(11)$ & $x(11)$ & 13237 & 9102 & 9736 & 9034 \\
\hline Israël & 8498 & $x(3,4,5)$ & $6286^{\circ}$ & $16115^{\circ}$ & $8330^{\circ}$ & 8330 & 1186 & 8365 & 5231 & 14132 & 11153 & 7050 & 8891 & 8117 \\
\hline Italie & 7991 & 8893 & $x(5)$ & $x(5)$ & $9377^{\circ}$ & $9193^{d}$ & $\times(5,6)$ & 8736 & 6318 & 11616 & 11589 & 7577 & 9298 & 8507 \\
\hline Japon & 8978 & 10546 & $\times(5)$ & $\times(5)$ & $11863^{4}$ & $11219^{d}$ & $\times(5,6,9,10,11)$ & 10143 & $14124^{\circ}$ & $20537^{\circ}$ & $19191^{d}$ & $\mathrm{~m}$ & 12096 & $\mathrm{~m}$ \\
\hline Coree & 11029 & 11477 & $x(5)$ & $x(5)$ & 13113 & 12370 & a & 11762 & 5770 & 11781 & 10486 & 8385 & 11318 & 10586 \\
\hline Lettonie & 6453 & 6504 & 6816 & 7295 & 7006 & 6761 & 7816 & 6625 & 9322 & 7143 & 7449 & 6110 & 6814 & 6508 \\
\hline Lituanie & 6053 & 5651 & 5660 & 5651 & 5657 & 5653 & 5593 & 5767 & a & 7701 & 7701 & 5860 & 6245 & 5790 \\
\hline Luxembourg & 17913 & 21739 & 20673 & 21587 & 21231 & 21464 & 1760 & 19770 & 23098 & 51918 & 48407 & 27955 & 21705 & 20323 \\
\hline Mexique & 2961 & 2561 & 3935 & 4617 & 4187 & 3167 & a & 3062 & $x(11)$ & $x(11)$ & 7347 & 5865 & 3632 & 3435 \\
\hline Pays-Bas & 8609 & 12831 & 10593 & 14530 & 13196 & 13006 & a & 11121 & 10815 & 19552 & 19513 & 12517 & 12926 & 11422 \\
\hline Nouvelle-Zèlande & 8287 & 9362 & 11157 & 13935 & 11765 & 10467 & 9885 & 9487 & 10557 & 15956 & 14933 & 11910 & 10530 & 9951 \\
\hline Norvège & 12619 & 13532 & 16242 & 15565 & 15901 & 14860 & 17381 & 13758 & 17361 & 22135 & 21993 & 14050 & 15459 & 13819 \\
\hline Pologne & 6808 & 7136 & 6158 & 7863 & 7114 & 7124 & 3964 & 6892 & 24012 & 8974 & 8977 & 7270 & 7356 & 6976 \\
\hline Portugal & 7689 & 10382 & $x(5)$ & $x(5)$ & $9628^{\circ}$ & $9999^{\circ}$ & $\times(5,6,9,10,11,12)$ & 8945 & $8954^{4}$ & $11064^{4}$ & $11014^{4}$ & $8380^{\circ}$ & 9346 & 8835 \\
\hline République slovaque & 6922 & 6426 & 5890 & 7148 & 6698 & 6551 & 7377 & 6686 & 6827 & 11493 & 11413 & 8816 & 7530 & 7067 \\
\hline Slovénie & 8621 & 10481 & 7586 & 7069 & 7236 & 8487 & a & 8550 & 2707 & 12507 & 11257 & 8974 & 9080 & 8633 \\
\hline Espagne & 7653 & 9056 & 9108 & $11772^{\circ}$ & $9946^{\circ}$ & $9502^{\circ}$ & $\times(4,5,6)$ & 8594 & 9339 & 13422 & 12614 & 9416 & 9464 & 8772 \\
\hline Suède & 11338 & 12020 & 10664 & 13670 & 11790 & 11892 & 5717 & 11549 & 6723 & 25766 & 24341 & 11137 & 13693 & 11480 \\
\hline Suisse & $\mathrm{m}$ & $\mathrm{m}$ & $x(5)$ & $x(5)$ & $18990^{4}$ & $\mathrm{~m}$ & $x(5)$ & $\mathrm{m}$ & $\mathrm{m}$ & $\mathrm{m}$ & $\mathrm{m}$ & $\mathrm{m}$ & $\mathrm{m}$ & $\mathrm{m}$ \\
\hline Turquie & 4168 & 4063 & 4896 & 5573 & 5213 & 4659 & a & 4505 & $x(11)$ & $x(11)$ & 10519 & 8626 & 5633 & 5278 \\
\hline Royaume-Uni & 11188 & 10921 & 12263 & 9437 & 10992 & 10963 & a & 11061 & $23769^{\circ}$ & 23772 & 23771 & 18405 & 13038 & 12203 \\
\hline Etats-Unis & 12184 & 13153 & $x(5)$ & $x(5)$ & 14566 & 13845 & 14496 & 13019 & $x(11)$ & $\mathrm{x}(11)$ & 30165 & 26550 & 16987 & 16151 \\
\hline Moyenne OCDE & 8470 & 9884 & 9397 & 10922 & 10368 & 9968 & $\mathrm{~m}$ & 9357 & 11745 & 16756 & 15556 & 11056 & 10502 & 9732 \\
\hline Moyenne UE23 & 8548 & 10302 & 9671 & 11320 & 10308 & 10205 & m & 9649 & 12468 & 16388 & 15863 & 10635 & 10688 & 9772 \\
\hline
\end{tabular}

\begin{tabular}{|c|c|c|c|c|c|c|c|c|c|c|c|c|c|c|}
\hline Argentine & m & $\mathrm{m}$ & $\mathrm{m}$ & a & m & $\mathrm{m}$ & a & $\mathrm{m}$ & $\mathrm{m}$ & m & m & m & m & $\mathrm{m}$ \\
\hline Brésil & m & $\mathrm{m}$ & m & m & m & $\mathrm{m}$ & $\mathrm{m}$ & $\mathrm{m}$ & $\mathrm{m}$ & $\mathrm{m}$ & m & $\mathrm{m}$ & $\mathrm{m}$ & $\mathrm{m}$ \\
\hline 密 Chine & m & $\mathrm{m}$ & m & m & m & m & m & m & $\mathrm{m}$ & m & m & m & m & m \\
\hline ¿ై Costa Rica ${ }^{2}$ & m & $\mathrm{m}$ & m & m & m & $\mathrm{m}$ & a & $\mathrm{m}$ & $\mathrm{m}$ & $\mathrm{m}$ & $\mathrm{m}$ & $\mathrm{m}$ & $\mathrm{m}$ & $\mathrm{m}$ \\
\hline Inde & $\mathrm{m}$ & $\mathrm{m}$ & $\mathrm{m}$ & m & m & m & $\mathrm{m}$ & m & $\mathrm{m}$ & $\mathrm{m}$ & m & m & $\mathrm{m}$ & m \\
\hline Indonésie ${ }^{2}$ & $\mathrm{~m}$ & $\mathrm{~m}$ & $\mathrm{~m}$ & m & $\mathrm{m}$ & $\mathrm{m}$ & a & $\mathrm{m}$ & $\mathrm{m}$ & $\mathrm{m}$ & $\mathrm{m}$ & $\mathrm{m}$ & $\mathrm{m}$ & $\mathrm{m}$ \\
\hline Fédération de Russie & $x(8)$ & $x(8)$ & $x(8)$ & $x(8)$ & $x(8)$ & $x(8)$ & $x(8)$ & 4247 & 5289 & 9516 & 8479 & 7693 & 5210 & 5031 \\
\hline Arabie saoudite & $\mathrm{m}$ & $\mathrm{m}$ & $\mathrm{m}$ & m & $\mathrm{m}$ & m & $\mathrm{m}$ & $\mathrm{m}$ & $\mathrm{m}$ & $\mathrm{m}$ & m & $\mathrm{m}$ & $\mathrm{m}$ & $\mathrm{m}$ \\
\hline Afrique du Sud ${ }^{2}$ & m & $\mathrm{m}$ & $\mathrm{m}$ & m & $\mathrm{m}$ & $\mathrm{m}$ & m & m & $\mathrm{m}$ & m & m & $\mathrm{m}$ & m & m \\
\hline
\end{tabular}

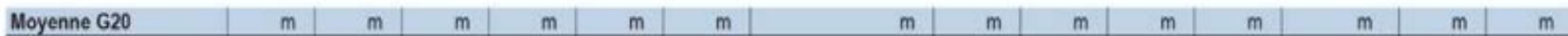

Remarque : Pour de plus amples informations, consulter les sections « Définitions» et « Méthodologie ». Les données et d'autres types de ventilations peuvent être consultés sur http://stats.oecd.org/, Base de données de Regards sur l'éducation.

1. L'enseignement primaire inclut des programmes de l'enseignement préprimaire. Les chiffres de l'enseignement post-secondaire non tertiaire sont considérés comme négligeables.

2. Année de référence : 2017.

Source : OCDE/ISU/Eurostat (2019). Consulter la section « Source » pour tout complément d'information et l'annexe 3 pour les notes (https://doi.org/10.1787/f8d7880d-en) Les symboles représentant les données manquantes et les abréviations figurent dans le Guide du lecteur. 
Tableau C1.2. Dépenses totales au titre des établissements d'enseignement par élève/étudiant en équivalents temps plein pour les services d'éducation, les services auxiliaires et la R-D (2016)

En équivalents USD convertis sur la base des PPA pour le PIB, dépenses directes au sein des établissements, selon le niveau d'enseignement, calculs fondés sur des équivalents temps plein

\begin{tabular}{|c|c|c|c|c|c|c|c|c|c|c|c|c|c|}
\hline & \multicolumn{3}{|c|}{$\begin{array}{l}\text { Primaire, secondaire } \\
\text { et post-secondaire non tertiaire }\end{array}$} & \multicolumn{5}{|c|}{ Tertiaire } & \multicolumn{5}{|c|}{ Du primaire au tertiaire } \\
\hline & $\begin{array}{c}\text { Services } \\
\text { d'éducation }\end{array}$ & $\begin{array}{c}\text { Services } \\
\text { auxiliaires }\end{array}$ & $\begin{array}{c}\text { Tous } \\
\text { services } \\
\text { confondus }\end{array}$ & $\begin{array}{c}\text { Services } \\
\text { d'éducation }\end{array}$ & $\begin{array}{c}\text { Services } \\
\text { auxiliaires }\end{array}$ & R.D & $\begin{array}{c}\text { Tous } \\
\text { services } \\
\text { confondus }\end{array}$ & $\begin{array}{c}\text { Tous } \\
\text { services } \\
\text { confondus } \\
\text { (activités } \\
\text { de R-D non } \\
\text { comprises) }\end{array}$ & $\begin{array}{c}\text { Services } \\
\text { d'éducation }\end{array}$ & $\begin{array}{c}\text { Services } \\
\text { auxiliaires }\end{array}$ & R.D & $\begin{array}{c}\text { Tous } \\
\text { services } \\
\text { confondus }\end{array}$ & $\begin{array}{c}\text { Tous } \\
\text { services } \\
\text { confondus } \\
\text { (activités } \\
\text { de R-D non } \\
\text { comprises) }\end{array}$ \\
\hline & (1) & (2) & (3) & (4) & (5) & (6) & (7) & (8) & (9) & (10) & (ii) & (12) & (13) \\
\hline \multicolumn{14}{|l|}{ ш Pays } \\
\hline Australie & 10298 & 208 & 10506 & 10031 & 760 & 5379 & 16170 & 10791 & 10234 & 340 & 1293 & 11867 & 10574 \\
\hline Autriche & 14000 & 679 & 14679 & 13424 & 171 & 4736 & 18332 & 13596 & 13823 & 523 & 1460 & 15806 & 14345 \\
\hline Belgique & 11891 & 433 & 12324 & 10839 & 1009 & 6321 & 18169 & 11848 & 11689 & 544 & 1213 & 13446 & 12233 \\
\hline Canada' & $x(3)$ & $x(3)$ & 10681 & 15720 & 1187 & 6793 & 23700 & 16907 & $x(12)$ & $x(12)$ & 1566 & $13682^{4}$ & $12116^{d}$ \\
\hline Chili ${ }^{2}$ & 4931 & 393 & 5324 & 9205 & 66 & 498 & 9769 & 9271 & 6170 & 298 & 144 & 6613 & 6468 \\
\hline Colombie $^{2}$ & $x(3)$ & $x(3)$ & 3184 & $x(7)$ & $x(7)$ & $x(7)$ & 5787 & $\mathrm{~m}$ & $x(12)$ & $x(12)$ & $x(12)$ & 3661 & $\mathrm{~m}$ \\
\hline République tchèque & 6508 & 472 & 6980 & 6307 & 81 & 3621 & 10009 & 6389 & 6466 & 391 & 756 & 7612 & 6857 \\
\hline Danemark & $\mathrm{m}$ & $\mathrm{m}$ & $\mathrm{m}$ & $\mathrm{m}$ & $m$ & $\mathrm{~m}$ & $\mathrm{~m}$ & $\mathrm{~m}$ & $\mathrm{~m}$ & $\mathrm{~m}$ & $\mathrm{~m}$ & $\mathrm{~m}$ & $\mathrm{~m}$ \\
\hline Estonie & 6810 & 104 & 6914 & 9236 & 1 & 3672 & 12909 & 9237 & 7347 & 81 & 814 & 8243 & 7429 \\
\hline Finlande & 9030 & 1015 & 10045 & 10314 & 0 & 7226 & 17541 & 10314 & 9285 & 814 & 1433 & 11531 & 10099 \\
\hline France & 8901 & 1285 & 10186 & 10255 & 776 & 5143 & 16173 & 11031 & 9167 & 1185 & 1011 & 11364 & 10352 \\
\hline Allemagne & 10992 & 302 & 11294 & 8866 & 998 & 7565 & 17429 & 9863 & 10546 & 448 & 1589 & 12583 & 10994 \\
\hline Grèce & m & $\mathrm{m}$ & $\mathrm{m}$ & m & $\mathrm{m}$ & $\mathrm{m}$ & $\mathrm{m}$ & $\mathrm{m}$ & $\mathrm{m}$ & $\mathrm{m}$ & $\mathrm{m}$ & $\mathrm{m}$ & $\mathrm{m}$ \\
\hline Hongrie & 6229 & 670 & 6899 & 8577 & 964 & 1747 & 11288 & 9541 & 6625 & 720 & 295 & 7639 & 7345 \\
\hline Islande & $x(3)$ & $x(3)$ & 11707 & $x(7)$ & $x(7)$ & $x(7)$ & 14551 & m & $x(12)$ & $x(12)$ & $x(12)$ & 12250 & m \\
\hline Irlande & 9020 & a & 9020 & $x(7)$ & $x(7)$ & 4135 & 13237 & 9102 & $x(12)$ & $x(12)$ & 702 & 9736 & 9034 \\
\hline Israél & 7968 & 397 & 8365 & 7008 & 41 & 4104 & 11153 & 7050 & 7787 & 330 & 774 & 8891 & 8117 \\
\hline Italie & 8267 & 468 & 8736 & 7160 & 417 & 4012 & 11589 & 7577 & 8049 & 458 & 791 & 9298 & 8507 \\
\hline Japon & $x(3,7)$ & $\times(3,7)$ & 10143 & $x(7)$ & $x(7)$ & $x(7)$ & $19191^{\circ}$ & $\mathrm{m}$ & $x(12)$ & $x(12)$ & $x(12)$ & 12096 & $\mathrm{~m}$ \\
\hline Corée & 10746 & 1015 & 11762 & 8286 & 99 & 2101 & 10486 & 8385 & 9890 & 696 & 731 & 11318 & 10586 \\
\hline Lettonie & 6509 & 117 & 6625 & 5974 & 136 & 1338 & 7449 & 6110 & 6386 & 121 & 306 & 6814 & 6508 \\
\hline Lituanie & 5507 & 260 & 5767 & 5079 & 781 & 1841 & 7701 & 5860 & 5401 & 389 & 455 & 6245 & 5790 \\
\hline Luxembourg & 18542 & 1228 & 19770 & 26841 & 1114 & 20452 & 48407 & 27955 & 19102 & 1220 & 1382 & 21705 & 20323 \\
\hline Mexique & $\times(3)$ & $x(3)$ & 3062 & $x(7)$ & $x(7)$ & 1483 & 7347 & 5865 & $x(12)$ & $x(12)$ & 197 & 3632 & 3435 \\
\hline Pays-Bas & 11121 & a & 11121 & 12517 & a & 6996 & 19513 & 12517 & 11422 & a & 1504 & 12926 & 11422 \\
\hline Nouvelle-Zélande & $x(3)$ & $x(3)$ & 9487 & $x(7)$ & $x(7)$ & 3024 & 14933 & 11910 & $x(12)$ & $x(12)$ & 579 & 10530 & 9951 \\
\hline Norvège & 13279 & 479 & 13758 & 13681 & 369 & 7943 & 21993 & 14050 & 13362 & 457 & 1640 & 15459 & 13819 \\
\hline Pologne & 6729 & 163 & 6892 & 7222 & 48 & 1707 & 8977 & 7270 & 6839 & 137 & 380 & 7356 & 6976 \\
\hline Portugal & 8356 & 589 & 8945 & $7956^{\circ}$ & $424^{\circ}$ & $2633^{\circ}$ & $11014^{\circ}$ & $8380^{\circ}$ & 8278 & 557 & 511 & 9346 & 8835 \\
\hline République slovaque & 5733 & 953 & 6686 & 7004 & 1812 & 2597 & 11413 & 8816 & 5960 & 1107 & 464 & 7530 & 7067 \\
\hline Slovénie & 7843 & 707 & 8550 & 8607 & 367 & 2284 & 11257 & 8974 & 7992 & 641 & 447 & 9080 & 8633 \\
\hline Espagne & 7950 & 645 & 8594 & 8891 & 525 & 3198 & 12614 & 9416 & 8153 & 619 & 692 & 9464 & 8772 \\
\hline Suède & 10356 & 1192 & 11549 & 11137 & 0 & 13204 & 24341 & 11137 & 10487 & 992 & 2213 & 13693 & 11480 \\
\hline Suisse & $\mathrm{m}$ & $\mathrm{m}$ & $\mathrm{m}$ & $\mathrm{m}$ & $\mathrm{m}$ & $\mathrm{m}$ & $\mathrm{m}$ & $\mathrm{m}$ & $\mathrm{m}$ & m & $\mathrm{m}$ & $\mathrm{m}$ & $\mathrm{m}$ \\
\hline Turquie & $x(3)$ & $x(3)$ & 4505 & $x(7)$ & $x(7)$ & 1893 & 10519 & 8626 & $x(12)$ & $x(12)$ & 355 & 5633 & 5278 \\
\hline Royaume-Uni & 10014 & 1047 & 11061 & 16297 & 2107 & 5367 & 23771 & 18405 & 10991 & 1212 & 835 & 13038 & 12203 \\
\hline Etats-Unis & 11975 & 1044 & 13019 & 22474 & 4076 & 3616 & 30165 & 26550 & 14405 & 1746 & 837 & 16987 & 16151 \\
\hline Moyenne OCDE & 8722 & 635 & 9357 & 10351 & 705 & 4500 & 15556 & 11056 & 9091 & 641 & 770 & 10502 & 9732 \\
\hline Moyenne UE23 & 9000 & 649 & 9649 & 10018 & 617 & 5228 & 15863 & 10635 & 9132 & 640 & 917 & 10688 & 9772 \\
\hline
\end{tabular}

\begin{tabular}{|c|c|c|c|c|c|c|c|c|c|c|c|c|c|}
\hline \& Argentine & m & m & $\mathrm{m}$ & $\mathrm{m}$ & $m$ & $\mathrm{~m}$ & $\mathrm{~m}$ & $\mathrm{~m}$ & $\mathrm{~m}$ & m & $\mathrm{m}$ & $\mathrm{m}$ & $\mathrm{m}$ \\
\hline Brésil & $\mathrm{m}$ & $\mathrm{m}$ & $\mathrm{m}$ & $\mathrm{m}$ & $\mathrm{m}$ & $\mathrm{m}$ & $\mathrm{m}$ & $\mathrm{m}$ & $\mathrm{m}$ & m & $\mathrm{m}$ & $\mathrm{m}$ & $\mathrm{m}$ \\
\hline og Chine & $\mathrm{m}$ & m & $\mathrm{m}$ & $\mathrm{m}$ & m & $\mathrm{m}$ & $\mathrm{m}$ & $\mathrm{m}$ & m & m & $\mathrm{m}$ & $\mathrm{m}$ & $\mathrm{m}$ \\
\hline ¿ Costa Rica ${ }^{2}$ & $\mathrm{~m}$ & $\mathrm{~m}$ & $\mathrm{~m}$ & $\mathrm{~m}$ & $\mathrm{~m}$ & $\mathrm{~m}$ & $\mathrm{~m}$ & $\mathrm{~m}$ & $\mathrm{~m}$ & $\mathrm{~m}$ & $\mathrm{~m}$ & $\mathrm{~m}$ & $\mathrm{~m}$ \\
\hline Inde & m & m & $\mathrm{m}$ & $\mathrm{m}$ & m & $\mathrm{m}$ & m & $\mathrm{m}$ & m & m & $\mathrm{m}$ & $\mathrm{m}$ & m \\
\hline Indonésie ${ }^{2}$ & $\mathrm{~m}$ & $\mathrm{~m}$ & $\mathrm{~m}$ & $\mathrm{~m}$ & $\mathrm{~m}$ & $\mathrm{~m}$ & $\mathrm{~m}$ & $\mathrm{~m}$ & $\mathrm{~m}$ & m & $\mathrm{m}$ & $\mathrm{m}$ & $\mathrm{m}$ \\
\hline Féderation de Russie & $x(3)$ & $x(3)$ & 4247 & $x(7)$ & $x(7)$ & 786 & 8479 & 7693 & $x(12)$ & $x(12)$ & 179 & 5210 & 5031 \\
\hline Arabie saoudite & $\mathrm{m}$ & $\mathrm{m}$ & $\mathrm{m}$ & m & $\mathrm{m}$ & $\mathrm{m}$ & $\mathrm{m}$ & $\mathrm{m}$ & $\mathrm{m}$ & m & $\mathrm{m}$ & $\mathrm{m}$ & m \\
\hline Afrique du Sud ${ }^{2}$ & $\mathrm{~m}$ & $\mathrm{~m}$ & $\mathrm{~m}$ & $\mathrm{~m}$ & $m$ & $\mathrm{~m}$ & $\mathrm{~m}$ & $\mathrm{~m}$ & $\mathrm{~m}$ & $m$ & $\mathrm{~m}$ & $\mathrm{~m}$ & $\mathrm{~m}$ \\
\hline
\end{tabular}

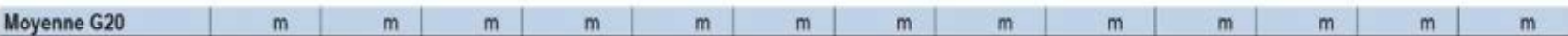

Remarque : Pour de plus amples informations, consulter les sections « Définitions » et « Méthodologie ». Les données et d'autres types de ventilations peuvent être consultés sur http://stats.oecd.org/, Base de données de Regards sur l'éducation.

1. L'enseignement primaire inclut des programmes de l'enseignement préprimaire. Les chiffres de l'enseignement post-secondaire non tertiaire sont considérés comme négligeables.

2. Année de référence : 2017

Source : OCDE/ISU/Eurostat (2019). Consulter la section « Source » pour tout complément d'information et l'annexe 3 pour les notes (https://doi.org/10.1787/f8d7880d-en) Les symboles représentant les données manquantes et les abréviations figurent dans le Guide du lecteur. 
Tableau C1.3. Indice de variation des dépenses totales au titre des établissements d'enseignement par élèvelétudiant en équivalents temps plein $(2005,2011$ et 2016)

Déflateur du PIB $2010=100$, prix constants

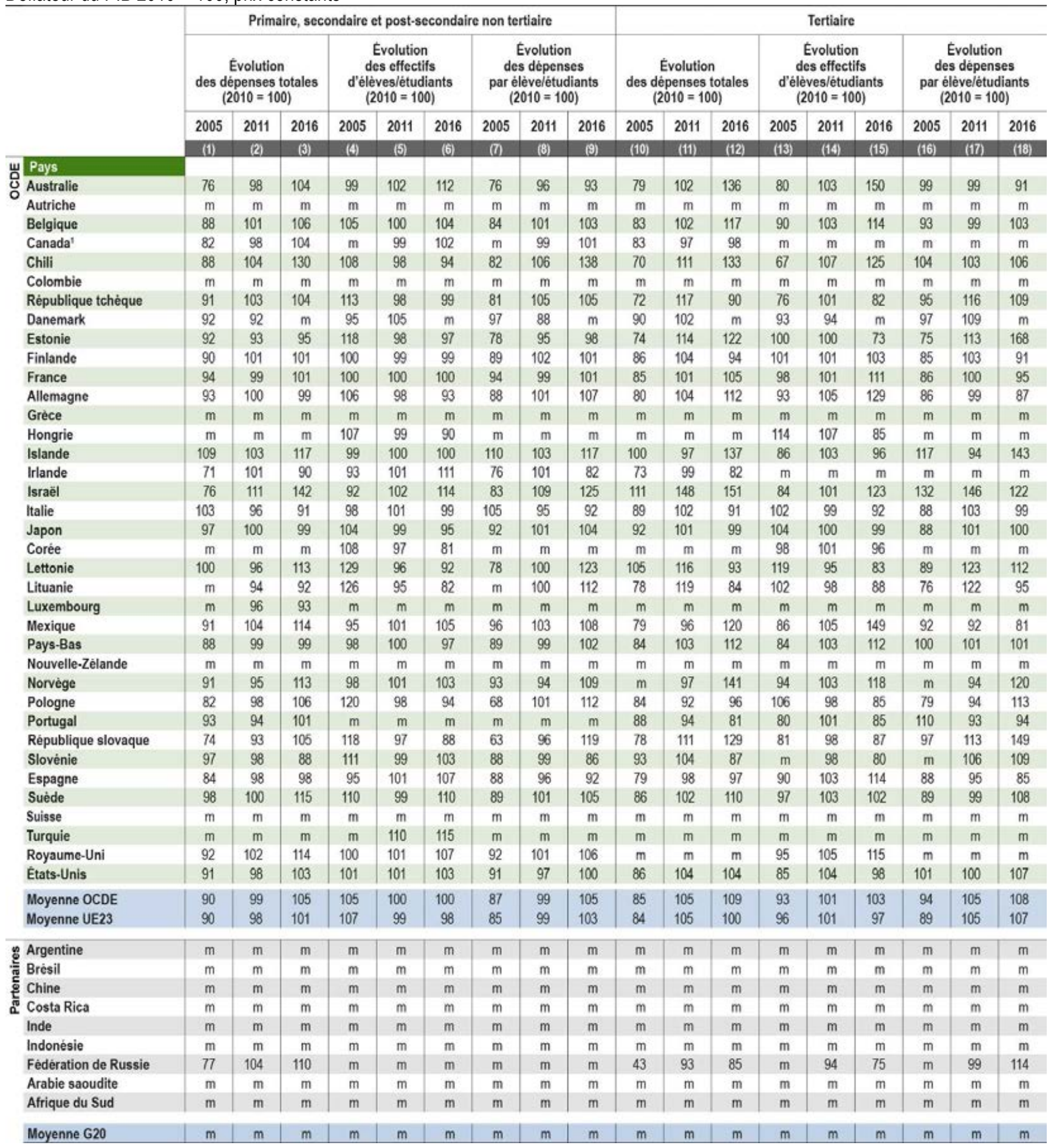

Remarque : Pour de plus amples informations, consulter les sections " Définitions » et « Méthodologie ». Les données et d'autres types de ventilations peuvent être consultés sur http://stats.oecd.org/, Base de données de Regards sur l'éducation.

1. Le primaire inclut des données du préprimaire et du premier cycle du secondaire.

Source : OCDE/ISU/Eurostat (2019). Consulter la section « Source » pour tout complément d'information et l'annexe 3 pour les notes (https://doi.org/10.1787/f8d7880den).

Les symboles représentant les données manquantes et les abréviations figurent dans le Guide du lecteur. 


\section{Indicateur C2. Quelle part de leur richesse nationale les pays consacrent-ils à l'éducation?}

\section{Faits marquants}

- En 2016, les pays de l'OCDE ont consacré en moyenne $5 \%$ de leur produit intérieur brut (PIB) au financement de leurs établissements d'enseignement (de l'enseignement primaire à l'enseignement tertiaire), mais ce pourcentage varie fortement entre les pays membres et partenaires de l'OCDE. En moyenne, dans les pays de l'OCDE, la part de la richesse affectée aux établissements d'enseignement s'élève à $3.5 \%$ du PIB dans l'enseignement non tertiaire (enseignement primaire, secondaire et postsecondaire non tertiaire) ; elle est nettement plus élevée que celle affectée à l'enseignement tertiaire (1.5\% du PIB).

- Le secteur privé joue un rôle crucial dans le financement de l'enseignement tertiaire : sa part représente un tiers en moyenne des dépenses au titre des établissements d'enseignement (soit l'équivalent de $0.5 \%$ du PIB). Dans l'enseignement non tertiaire, les dépenses privées au titre de l'éducation représentent un dixième seulement des dépenses totales au titre des établissements d'enseignement, soit $0.4 \%$ du PIB.

- Entre 2010 et 2016, les dépenses totales au titre des établissements d'enseignement, de l'enseignement primaire à l'enseignement tertiaire, ont diminué en pourcentage du PIB dans plus de deux tiers des pays membres et partenaires de l'OCDE, essentiellement en raison du rythme moins soutenu auquel les dépenses publiques au titre des établissements de ces niveaux d'enseignement ont progressé par comparaison avec le PIB.

\section{Graphique C2.1. Dépenses totales au titre des établissements d'enseignement en pourcentage du PIB (2016)}

Dépenses provenant de sources publiques, privées ou internationales, selon le niveau d'enseignement

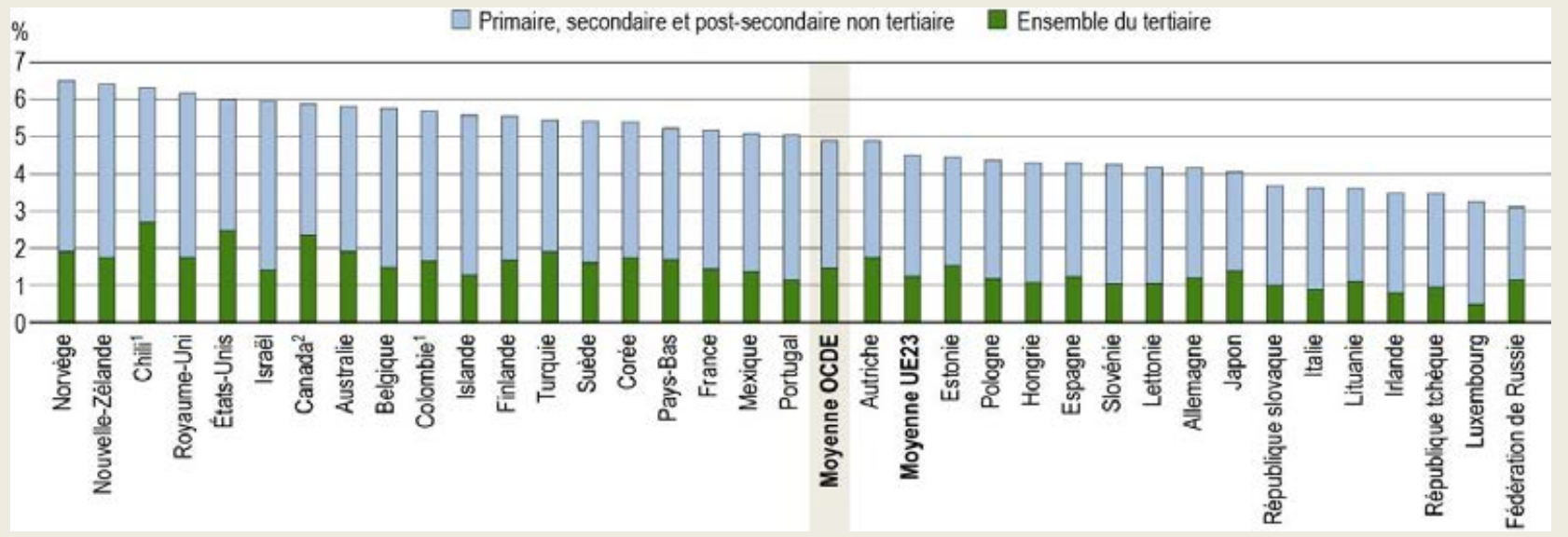

1. Année de référence : 2017.

2. L'enseignement primaire inclut des programmes de l'enseignement préprimaire.

Les pays sont classés par ordre décroissant des dépenses totales au titre des établissements d'enseignement en pourcentage du PIB.

Source : OCDE/ISU/Eurostat (2019), tableau C2.1. Consulter la section « Source » pour tout complément d'information et l'annexe 3 pour les notes (https://doi.org/10.1787/f8d7880d-en). 


\section{Contexte}

Les pays investissent dans l'éducation entre autres raisons pour contribuer à promouvoir la croissance économique, à accroître la productivité, à favoriser l'épanouissement personnel et le développement social et à réduire les inégalités sociales. Le niveau de dépenses au titre des établissements d'enseignement dépend de la taille de la population d'âge scolaire, des taux de scolarisation, des niveaux de salaire des enseignants et de la façon dont l'enseignement est organisé et dispensé. Dans l'enseignement primaire et le premier cycle de l'enseignement secondaire (qui correspondent approximativement au groupe d'âge des 6-14 ans), les taux de scolarisation sont proches de $100 \%$ dans la plupart des pays de l'OCDE. L'effectif d'élèves varie donc fortement en fonction de l'évolution démographique. II n'en va pas de même dans le deuxième cycle de l'enseignement secondaire et dans l'enseignement tertiaire, car une partie de la population concernée ne sera plus scolarisée (voir l'indicateur B1).

Pour tenir compte de ces facteurs, le présent indicateur évalue les dépenses au titre des établissements d'enseignement à l'aune de la richesse nationale pour montrer la priorité accordée à l'éducation en fonction des ressources globales des pays. La richesse nationale est estimée sur la base du PIB, et les dépenses d'éducation englobent les dépenses du secteur public, des entreprises ainsi que des effectifs scolarisés et de leur famille. Cet indicateur couvre les dépenses au titre des établissements d'enseignement, des universités et des autres établissements publics et privés fournissant des services d'éducation ou d'appui à l'éducation.

Les gouvernements surveillent leur budget de très près et peuvent décider de restrictions budgétaires même dans des secteurs majeurs tels que l'éducation en cas de ralentissement économique. Cet indicateur montre à titre de référence comment les dépenses d'éducation ont évolué au fil du temps en pourcentage du PIB national dans les pays de l'OCDE. Dans leurs décisions d'affectation budgétaire, les gouvernements doivent faire des arbitrages entre les postes où investir davantage, notamment le salaire des enseignants et le budget des infrastructures scolaires.

\section{Autres faits marquants}

- Dans le budget de l'éducation, l'enseignement primaire et l'enseignement secondaire sont le poste de dépenses le plus important ( $69 \%$ du budget total, soit $3.4 \%$ du PIB) ; leur part varie selon la taille de l'effectif scolarisé.

- Les dépenses privées au titre des établissements d'enseignement, de l'enseignement primaire à l'enseignement tertiaire, représentaient $0.9 \%$ du PIB, en moyenne, dans les pays de l'OCDE, après transferts entre le gouvernement et le secteur privé.

- Entre 2010 et 2016, les dépenses publiques au titre des établissements d'enseignement ont diminué légèrement en pourcentage du PIB dans les niveaux d'enseignement tertiaire (4\% en moyenne dans les pays de l'OCDE). En revanche, la réduction des dépenses au titre des établissements d'enseignement non tertiaire a été plus marquée, avec un recul d'un peu plus de $8 \%$ en moyenne dans les pays de l'OCDE. 


\section{Analyse}

\section{Investissement global en pourcentage du PIB}

Tous les pays membres et partenaires de l'OCDE investissent une part importante de leurs ressources nationales dans l'éducation. En 2016, les pays de l'OCDE ont consacré en moyenne $5 \%$ de leur PIB au financement de leurs établissements d'enseignement, de l'enseignement primaire à l'enseignement tertiaire (voir le tableau C2.1).

En pourcentage du PIB, les dépenses au titre des établissements d'enseignement tertiaire représentent $6 \%$ au Chili, aux États-Unis, en Israël, en Norvège, en Nouvelle-Zélande et au Royaume-Uni, mais sont de l'ordre de 3$4 \%$ en Fédération de Russie, en Irlande, en Italie, au Japon, en Lituanie, au Luxembourg, en République slovaque et en République tchèque (voir le graphique C2.1et le tableau C2.1). De nombreux facteurs influent sur la place relative des pays dans le classement selon cet indicateur, notamment la taille relative de l'effectif scolarisé, la durée des études et l'affectation des fonds. Dans l'enseignement tertiaire, les dépenses peuvent être influencées par les critères d'admission à des niveaux supérieurs d'enseignement, la taille de l'effectif scolarisé dans chaque secteur et domaine d'études, ainsi que l'ampleur de l'investissement dans des activités de recherche.

\section{Dépenses au titre des établissements d'enseignement, selon le niveau d'enseignement}

Dans tous les pays membres et partenaires de l'OCDE dont les données sont disponibles, la part de la richesse nationale consacrée à l'enseignement non tertiaire (enseignement primaire, secondaire et post-secondaire non tertiaire) est nettement supérieure à celle consacrée à l'enseignement tertiaire (voir le tableau C2.1 et le graphique C2.1). En moyenne, dans les pays de l'OCDE, $70 \%$ des dépenses au titre des établissements d'enseignement, soit $3.5 \%$ du PIB, concernent les niveaux d'enseignement non tertiaire, en raison des taux élevés de scolarisation à ces niveaux. La part du budget allouée aux établissements d'enseignement non tertiaire représente environ $4.5 \%$ du PIB en Israël, en Norvège et en Nouvelle-Zélande, mais un peu moins de $2 \%$ du PIB en Fédération de Russie.

En moyenne, dans les pays de l'OCDE, les dépenses au titre des établissements d'enseignement représentent $1.5 \%$ du PIB dans l'enseignement primaire et $1 \%$ du PIB dans le premier cycle de l'enseignement secondaire. La part des dépenses au titre des établissements d'enseignement est toutefois fortement influencée par la composition démographique des pays. La durée de chaque niveau d'enseignement est un autre facteur qui influe sur les dépenses. Les pays où les taux de fécondité sont relativement peu élevés sont moins susceptibles de consacrer une plus grande part de leur richesse à l'enseignement primaire et au premier cycle de l'enseignement secondaire. II apparaît d'ailleurs que les pays qui investissent moins de $1 \%$ de leur PIB dans l'enseignement primaire tendent à afficher des taux de natalité peu élevés (c'est le cas de l'Allemagne, l'Autriche, la Hongrie, la Lituanie, la République slovaque et la République tchèque, voir le tableau C2.1). Dans le deuxième cycle de l'enseignement secondaire, les dépenses au titre des filières générale et professionnelle représentent entre $0.5 \%$ du PIB en filière professionnelle et $0.6 \%$ en filière générale, en moyenne dans les pays de l'OCDE. Ces chiffres varient toutefois fortement entre les pays. Moins de la moitié des pays dont les données sont disponibles consacrent une part plus élevée de leur PIB à la filière professionnelle qu'à la filière générale ; les différences les plus importantes s'observent en Finlande, aux Pays-Bas et en République tchèque (0.5-0.6 points de pourcentage).

L'enseignement tertiaire représente en moyenne $1.5 \%$ du PIB des pays. À ce niveau d'enseignement, les différents parcours des étudiants, les filières d'enseignement, la durée des études, l'organisation de l'enseignement et le budget alloué à la recherche et au développement (R-D) sont autant de facteurs qui influent sur le niveau des dépenses. En 2016, ce sont le Canada, le Chili et les États-Unis qui ont consacré la part la plus élevée de leur PIB à l'enseignement tertiaire (entre 2 et $3 \%$ ). Sans surprise, ces pays comptent aussi parmi ceux 
où la part privée du financement de ce niveau d'enseignement est la plus élevée après contrôle des transferts public-privé (entre 1.1 et $1.7 \%$ du PIB ; voir le tableau C2.2 et le graphique C2.2).

Graphique C2.2. Dépenses totales au titre des établissements d'enseignement en pourcentage du PIB, selon la provenance des financements (2016)

Après transferts ; dépenses provenant de sources publiques, privées ou internationales

Dépenses privées $\square$ Dépenses publiques
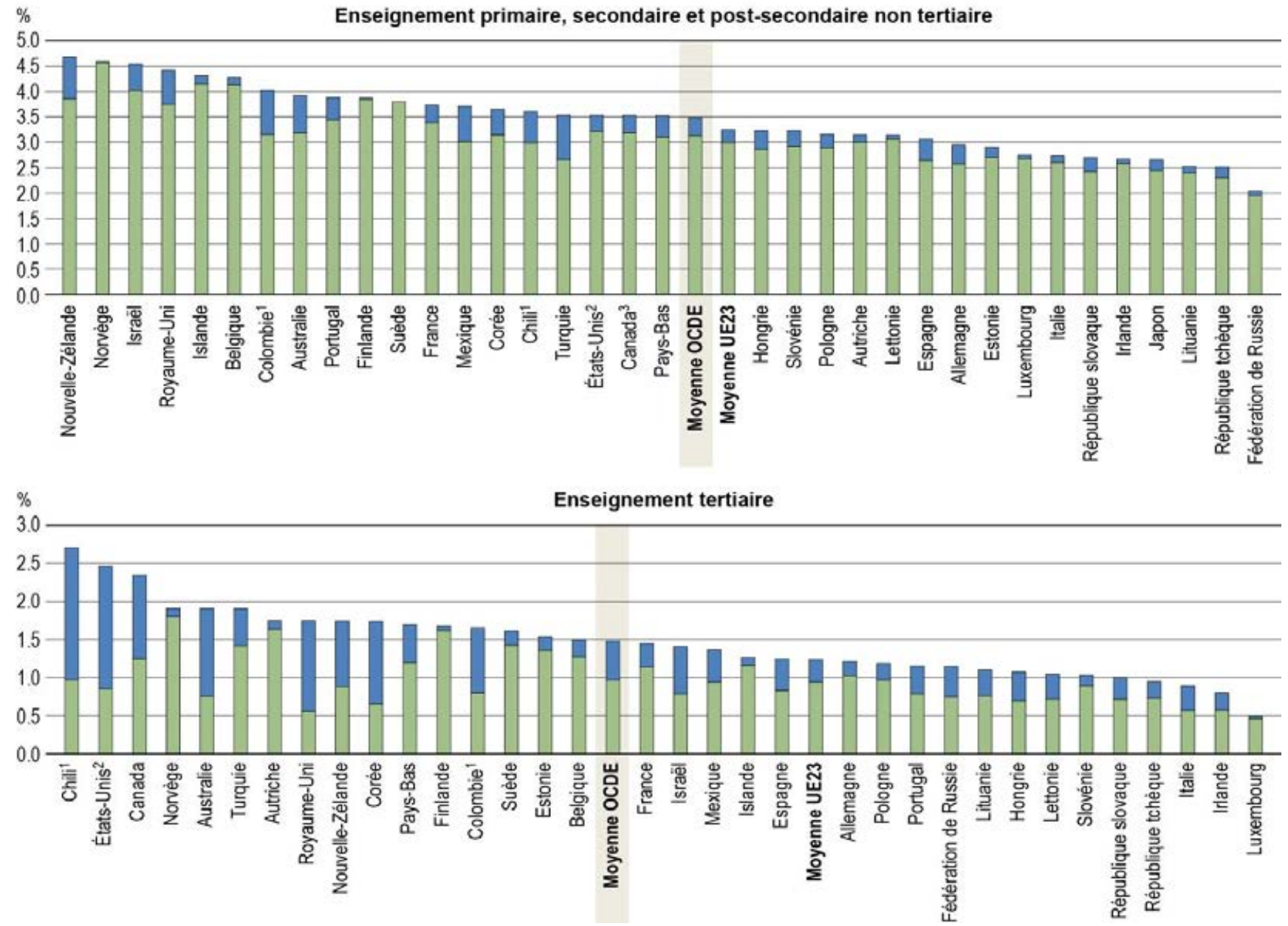

Remarque : Les dépenses internationales sont regroupées avec les dépenses publiques pour des raisons de présentation.

1. Année de référence : 2017.

2. Les valeurs présentées pour les États-Unis correspondent aux prêts d'études nets, et non bruts, ce qui induit donc une sous-estimation des transferts publics.

3. L'enseignement primaire inclut des programmes de l'enseignement préprimaire.

Les pays sont classés par ordre décroissant des dépenses totales au titre des établissements d'enseignement en pourcentage du PIB.

Source : OCDE/ISU/Eurostat (2019), Tableau C2.2. Consulter la section « Source » pour tout complément d'information et l'annexe 3 pour les notes (https://doi.org/10.1787/f8d7880d-en).

StatLink त्ता

Les dépenses de R-D dans les établissements d'enseignement tertiaire peuvent représenter une part importante du budget total de ce niveau d'enseignement ; leur ampleur dépend de la structure des activités de recherche subventionnées par les fonds publics ainsi que des infrastructures et des équipements disponibles. L'Australie, 
la Norvège, la Suède ainsi que les autres pays de l'OCDE où la majeure partie des activités de recherche subventionnées par l'État s'effectuent dans les établissements d'enseignement tertiaire tendent à consacrer une part plus élevée de leur PIB à l'éducation que les pays où la majeure partie de ces activités s'effectuent dans d'autres structures. Si les activités de R-D sont exclues, les dépenses au titre des établissements d'enseignement diminuent en pourcentage du PIB de 0.4 point de pourcentage en moyenne dans les pays de l'OCDE ; cette diminution représente au moins 0.7 point de pourcentage en Finlande, en Norvège et en Suède (voir le tableau C2.1).

\section{Dépenses au titre des établissements d'enseignement, selon la provenance des fonds}

Le budget de l'éducation reste essentiellement constitué de fonds publics dans les pays de l'OCDE. En moyenne, les dépenses publiques au titre des établissements d'enseignement, de l'enseignement primaire à l'enseignement tertiaire, représentent (après transferts au secteur privé) $4 \%$ du PIB. Toutefois, ce pourcentage varie fortement entre les pays dont les données sont disponibles. L'investissement public direct représente environ $3 \%$ du PIB en Fédération de Russie, en Grèce, en Hongrie, en Irlande, en Italie, au Japon, en Lituanie, au Luxembourg, en République slovaque et en République tchèque, mais entre 5 et $7 \%$ du PIB en Belgique, au Brésil, en Finlande, en Islande, en Norvège et en Suède (voir le graphique C2.2).

L'austérité budgétaire conduit de nombreux systèmes d'éducation à mettre davantage le secteur privé à contribution, en particulier pour financer l'enseignement tertiaire. Après transferts, les financements privés au titre des établissements d'enseignement, de l'enseignement primaire à l'enseignement tertiaire, représentent en moyenne $0.9 \%$ du PIB. Les transferts directs du secteur privé aux établissements d'enseignement varient toutefois sensiblement entre les pays : ils ne représentent pas plus de $0.1 \%$ du PIB en Finlande, au Luxembourg et en Norvège, mais atteignent au moins 1.9 \% du PIB en Australie, au Chili, aux États-Unis et au Royaume-Uni (voir le graphique C2.2).

L'investissement privé est peu élevé dans l'enseignement non tertiaire : il représente en moyenne $0.4 \%$ du PIB dans les pays de I'OCDE, mais au moins $0.7 \%$ du PIB en Australie, en Colombie, au Mexique, en NouvelleZélande, au Royaume-Uni et en Turquie, les pays où la part relative des fonds privés est la plus élevée dans l'enseignement non tertiaire. Dans l'enseignement tertiaire, l'investissement privé prend plus d'importance et représente en moyenne $0.5 \%$ du PIB. Dans certains pays, les sources privées contribuent davantage que dans d'autres : au Chili et aux États-Unis, les dépenses privées au titre des établissements d'enseignement tertiaire représentent plus de $1.6 \%$ du PIB, soit le pourcentage le plus élevé parmi tous les pays de l'OCDE (voir le tableau $\mathrm{C} 2.2$ et le graphique $\mathrm{C} 2.2$ ).

\section{Évolution des dépenses d'éducation entre 2010 et 2016}

Les effets de la crise économique mondiale qui a éclaté en 2008 s'observent encore dans les ajustements des budgets publics et, donc, dans les dépenses au titre des établissements d'enseignement à tous les niveaux d'enseignement. Les dépenses publiques au titre des établissements d'enseignement ont recommencé à augmenter en 2010, mais à un rythme moins soutenu que le PIB, à cause du temps qu'il a fallu pour ajuster les budgets publics (voir le tableau C2.4, disponible en ligne, et le graphique C2.3). En pourcentage du PIB et toutes sources confondues, les dépenses moyennes totales au titre de l'enseignement primaire à l'enseignement tertiaire ont toutefois diminué de $7 \%$ entre 2010 et 2016 dans les pays de l'OCDE, essentiellement à cause du rythme moins soutenu auquel les dépenses rapportées au PIB ont progressé durant cette période (voir le tableau C2.3). Les dépenses totales au titre des établissements d'enseignement ont diminué en pourcentage du PIB dans la plupart des pays dont les données sont disponibles. Les ajustements négatifs les plus importants ont été enregistrés en Irlande et en Lituanie avec une augmentation du PIB de $20 \%$ durant la même période. Par contraste, le Chili et Israël ont fait vraiment figure d'exception, avec une augmentation d'au moins $7 \%$ des dépenses totales au titre des établissements d'enseignement malgré une augmentation sensible de leur PIB. 


\section{Graphique C2.3. Indice de variation des dépenses publiques au titre des établissements d'enseignement} en pourcentage du PIB (2010 et 2016)

Sources finales de financement, par niveau d'enseignement, année de référence : $2010=100$

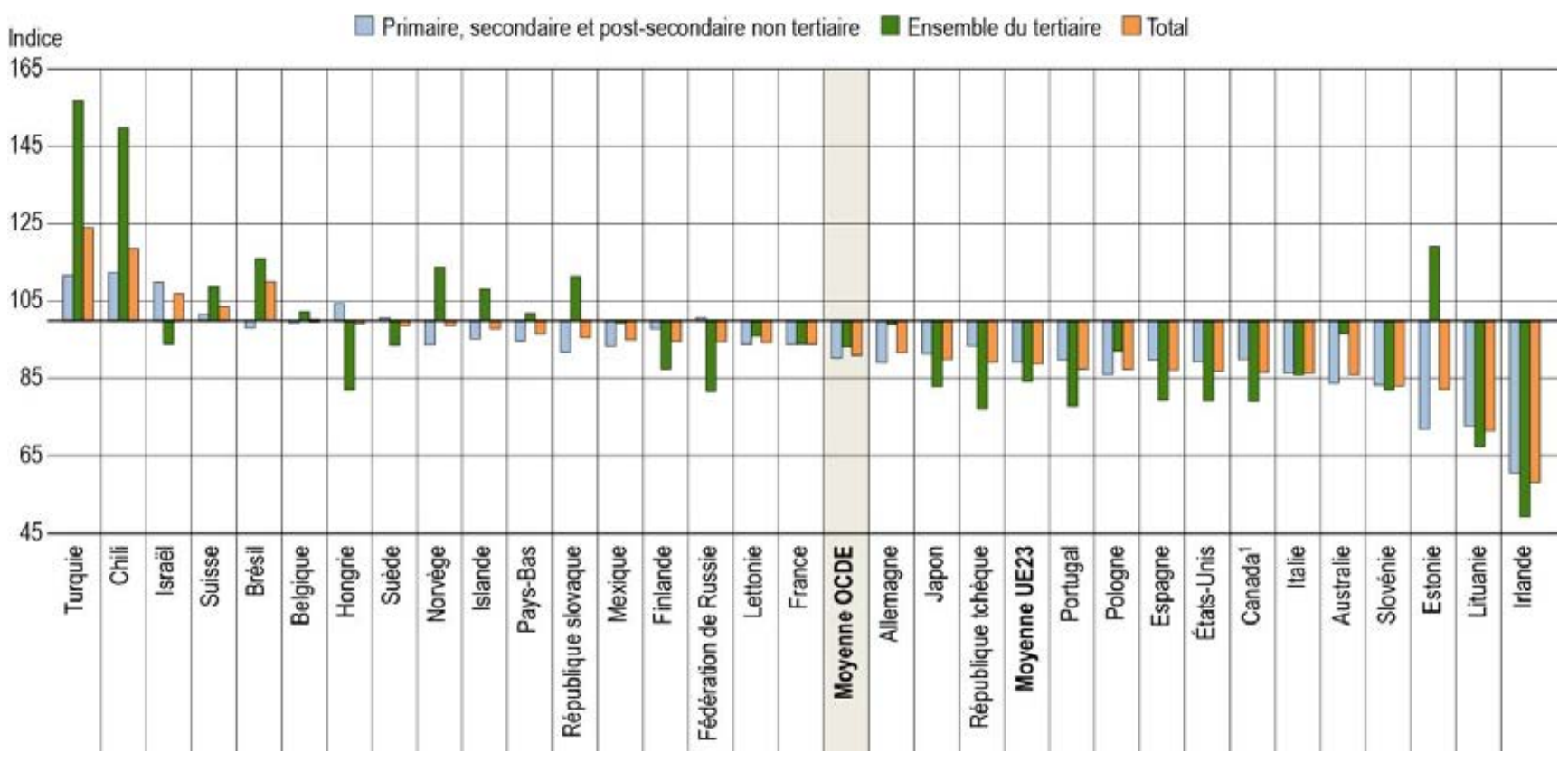

1. L'enseignement primaire inclut des programmes de l'enseignement préprimaire.

Les pays sont classés par ordre décroissant de l'indice de variation des dépenses publiques au titre des établissements d'enseignement en pourcentage du PIB.

Source : OCDE/ISU/Eurostat (2019), Table C2.4 (disponible en ligne). Consulter la section « Source » pour tout complément d'information et l'annexe 3 pour les notes (https://doi.org/10.1787/f8d7880d-en).

L'évolution des dépenses au titre des différents niveaux d'enseignement a suivi la même tendance entre 2010 et 2016. Les dépenses au titre des établissements d'enseignement, dans les niveaux de l'enseignement non tertiaire et de l'enseignement tertiaire, ont diminué de $8 \%$ en pourcentage du PIB. Ces moyennes occultent toutefois des variations importantes dans certains pays. Durant la période de six ans à l'étude, les dépenses au titre des établissements d'enseignement non tertiaire ont par exemple augmenté d'au moins $5 \%$ en pourcentage du PIB au Chili et en Israël. La réduction observée en Irlande (40\%) s'explique en grande partie par la révision des chiffres du PIB de 2015. Durant la même période, les plus fortes augmentations des dépenses au titre de ces niveaux d'enseignement ont été enregistrées en Estonie, en Lituanie et au Luxembourg (plus de 20 \%).

Dans un tiers environ des pays dont les données sont disponibles, les investissements dans l'enseignement tertiaire ont augmenté entre 2010 et 2016, alors qu'ils ont diminué ou sont restés presque stables dans l'enseignement non tertiaire. L'Australie, I'Islande, Israël, la Norvège et la République slovaque illustrent clairement cette tendance: en pourcentage du PIB, les dépenses ont augmenté de plus de $10 \%$ dans l'enseignement tertiaire, mais elles ont diminué d'au moins $5 \%$ dans l'enseignement non tertiaire durant cette période. De tous les pays membres et partenaires de l'OCDE, c'est en Israël que les dépenses totales au titre de l'enseignement tertiaire ont le plus augmenté en pourcentage du PIB, ce qui s'explique par une hausse substantielle de l'investissement dans l'éducation, tant dans le chef du secteur public que du secteur privé. 


\section{Définitions}

Les dépenses au titre des établissements d'enseignement correspondent aux dépenses publiques, privées et internationales au titre des entités qui fournissent des services d'éducation aux individus ou des services en rapport avec l'éducation aux individus et à d'autres établissements d'enseignement (écoles, universités et autres institutions publiques et privées).

Les parts finales des secteurs public, privé et international correspondent aux pourcentages des dépenses directes des acheteurs publics, privés et internationaux de services d'éducation après transferts. Les dépenses publiques finales comprennent les achats publics directs de ressources d'éducation et les versements publics aux établissements d'enseignement.

Les dépenses privées finales comprennent toutes les dépenses directes au titre des établissements d'enseignement (frais de scolarité et autres montants versés par les ménages aux établissements d'enseignement), qu'elles soient ou non partiellement financées par des subventions publiques, après transferts. Elles incluent également les dépenses des entreprises privées au titre de la composante de pratique professionnelle dans les programmes « emploi-études » et les programmes de formation en milieu professionnel.

Les dépenses internationales finales comprennent les montants directement versés par le secteur international aux établissements d'enseignement, par exemple des budgets de recherche et autres fonds internationaux versés directement aux établissements d'enseignement, après transferts.

Les dépenses publiques directes au titre des établissements d'enseignement couvrent les dépenses des pouvoirs publics au titre de ressources d'éducation fournies aux établissements d'enseignement ou les versements des pouvoirs publics aux établissements d'enseignement qui sont responsables de l'achat de ressources d'éducation.

Les dépenses privées (des ménages et autres entités privées) directes au titre des établissements d'enseignement comprennent les frais de scolarité et autres montants versés par le secteur privé aux établissements d'enseignement, qu'ils soient ou non partiellement financés par des subventions publiques.

\section{Méthodologie}

Les dépenses au titre des établissements d'enseignement en pourcentage du PIB d'un niveau d'enseignement sont calculées comme suit : les dépenses totales au titre des établissements d'enseignement de ce niveau sont divisées par le PIB. Les dépenses et le PIB exprimés en devise nationale sont divisés par l'indice de parité de pouvoir d'achat (PPA) pour le PIB afin d'obtenir leur équivalent en dollars des États-Unis (USD). La conversion basée sur l'indice PPA est préférée à celle basée sur le taux de change du marché, car celui-ci subit l'influence de nombreux facteurs (taux d'intérêt, politiques commerciales, prévisions de croissance économique, etc.) sans grand rapport avec le pouvoir d'achat relatif du moment dans les différents pays de I'OCDE (voir l'annexe 2 pour davantage de précisions).

Toutes les entités qui financent l'éducation sont publiques, privées ou internationales (organismes internationaux et autres entités étrangères). Les chiffres fournis ici regroupent les dépenses publiques et internationales pour des raisons de présentation. Comme la part des dépenses internationales est relativement minime par rapport à celle des autres dépenses, inclure les dépenses internationales dans les dépenses publiques n'affecte pas l'analyse de la part des dépenses publiques.

Les dépenses au titre des biens et services d'éducation ne sont pas toutes effectuées au sein des établissements d'enseignement. Les familles peuvent par exemple acheter des fournitures et des manuels scolaires dans le commerce ou recourir aux services d'un professeur particulier en dehors des établissements d'enseignement. Dans l'enseignement tertiaire, les frais de subsistance et le manque à gagner des étudiants pendant leur formation peuvent représenter une part importante du coût de l'éducation. Toutes ces dépenses effectuées en 
dehors des établissements d'enseignement sont exclues de cet indicateur, même si elles font l'objet de subventions publiques. Le financement public des coûts de l'éducation en dehors des établissements d'enseignement est étudié dans les indicateurs C4 et C5.

Une partie du budget des établissements d'enseignement est consacrée aux services auxiliaires généralement proposés aux effectifs scolarisés (cantine, logement et transport). La part du coût de ces services financée par les effectifs scolarisés est également incluse dans cet indicateur.

Les dépenses au titre des établissements d'enseignement sont calculées sur la base de la comptabilité de caisse et donnent dès lors un aperçu des dépenses effectuées lors de l'année de référence. De nombreux pays mettent en place un système de prêt et de remboursement dans l'enseignement tertiaire. Les prêts publics sont pris en considération, mais les remboursements des emprunteurs privés ne le sont pas ; la contribution privée aux coûts de l'éducation peut donc être sous-estimée.

Voir le Guide de l'OCDE pour l'établissement de statistiques internationalement comparables dans le domaine de l'éducation 2018 (OCDE, 2019 $\left.9_{[1]}\right)$ pour de plus amples informations. Voir les notes spécifiques aux pays à l'annexe 3 (https://doi.org/10.1787/f8d7880d-en).

\section{Source}

Les données se rapportent à l'année budgétaire 2016 (sauf mention contraire) et proviennent de l'exercice de I'UNESCO, I'OCDE et Eurostat (UOE) de collecte de données statistiques sur l'éducation réalisé par l'OCDE en 2018 (pour plus de précisions, voir l'annexe 3, https://doi.org/10.1787/f8d7880d-en). Les données de l'Afrique du Sud, de l'Arabie saoudite, de l'Argentine, de l'Inde, de l'Indonésie et de la République populaire de Chine proviennent de l'Institut de statistique de I'UNESCO (ISU).

Les données relatives aux dépenses de 2005, de 2011 et de 2016 proviennent d'une enquête menée en 201819. Les dépenses de 2005 à 2015 ont été ajustées en fonction des méthodes et des définitions appliquées lors du dernier exercice UOE de collecte de données en date.

\section{Note concernant les données d'Israël}

Les données statistiques concernant Israël sont fournies par et sous la responsabilité des autorités israéliennes compétentes. L'utilisation de ces données par l'OCDE est sans préjudice du statut des hauteurs du Golan, de Jérusalem-Est et des colonies de peuplement israéliennes en Cisjordanie aux termes du droit international.

\section{Références}

OCDE (2019), Guide de l'OCDE pour l'établissement de statistiques internationalement comparables dans le domaine de l'éducation 2018: Concepts, normes, définitions et classifications, Éditions OCDE, Paris, https://dx.doi.org/10.1787/9789264305380-fr. 


\section{Tableaux de l'indicateur C2}

Tableau C2.1

Tableau C2.2

Tableau C2.3
Dépenses totales au titre des établissements d'enseignement en pourcentage du PIB (2016)

Dépenses totales au titre des établissements d'enseignement en pourcentage du PIB, selon la source finale des financements (2016)

Évolution des dépenses totales au titre des établissements d'enseignement en pourcentage du PIB $(2005,2011$ et 2016)

WEB Tableau C2.4 Évolution des dépenses publiques au titre des établissements d'enseignement en pourcentage du PIB $(2005,2011$ et 2016)

Date butoir pour les données: 19 juillet 2019. Les mises à jour peuvent être consultées en ligne sur: http://dx.doi.org/10.1787/eag-data-en. D'autres données désagrégées sont également disponibles dans la Base de données de Regards sur l'éducation (http://stats.oecd.org/).

StatLink https://doi.org/10.1787/888933981077 
Tableau C2.1. Dépenses totales au titre des établissements d'enseignement en pourcentage du PIB (2016)

Dépenses au titre des établissements d'enseignement, selon le niveau d'enseignement

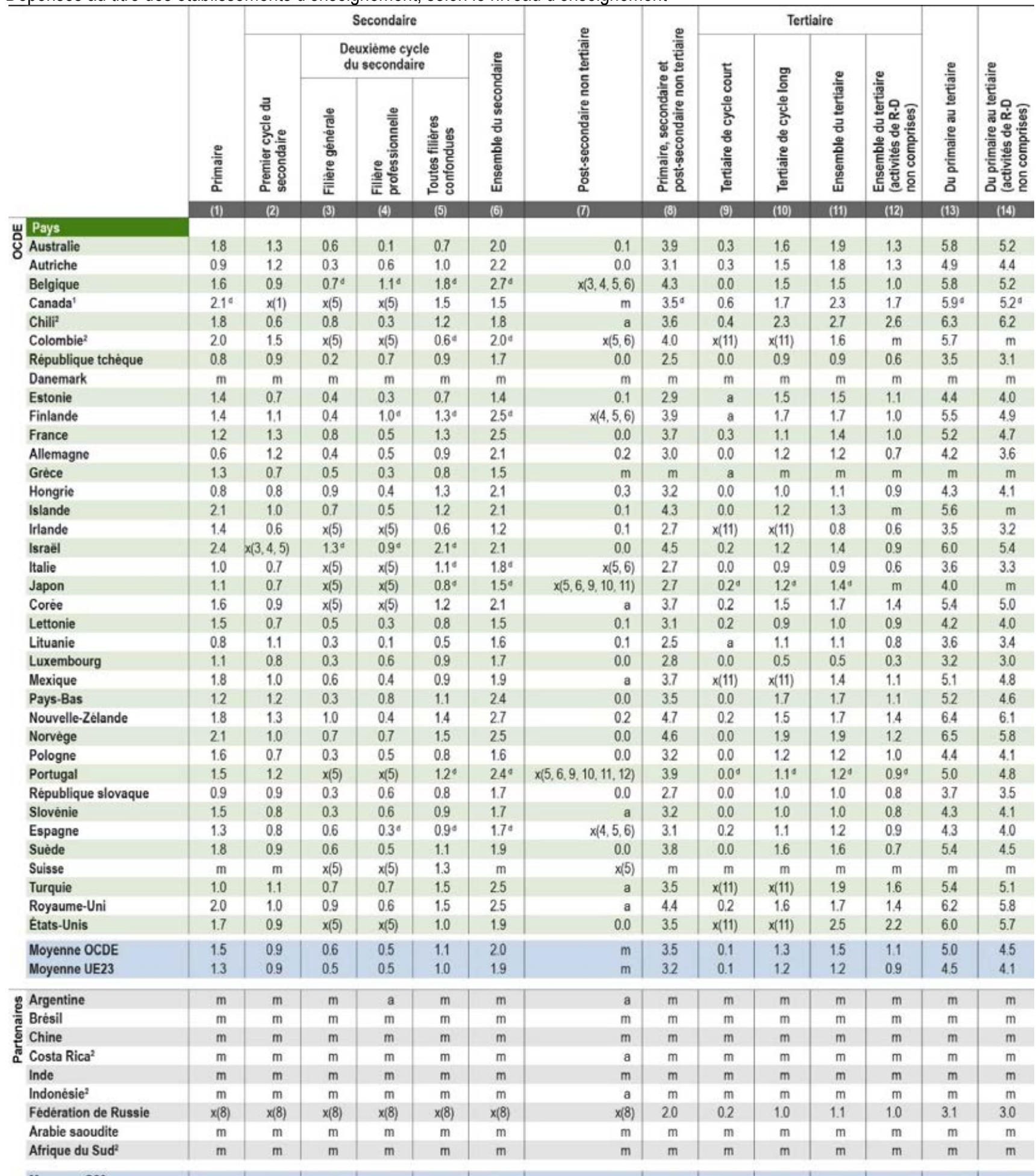

\begin{tabular}{l|l|l|l|l|l|l|l|l|l|l|l|c|c|c|c|} 
Moyenne G20 & $m$ & $m$ & $m$ & $m$ & $m$ & $m$ & $m$ & $m$ & $m$ & $m$ & $m$ & $m$ & $m$ & $m$ \\
\hline
\end{tabular}

Remarque : Pour de plus amples informations, consulter les sections « Définitions » et « Méthodologie ». Les données et d'autres types de ventilations peuvent être consultés sur http://stats.oecd.org/, Base de données de Regards sur l'éducation.

1. L'enseignement primaire inclut des programmes de l'enseignement préprimaire. Les chiffres de l'enseignement post-secondaire non tertiaire sont considérés comme négligeables.

2. Année de référence : 2017

Source : OCDE/ISU/Eurostat (2019). Consulter la section « Source » pour tout complément d'information et l'annexe 3 pour les notes (https://doi.org/10.1787/f8d7880d-en). Les symboles représentant les données manquantes et les abréviations figurent dans le Guide du lecteur. 
Tableau C2.2. Dépenses totales au titre des établissements d'enseignement en pourcentage du PIB, selon la source finale des financements (2016)

Dépenses au sein des établissements, selon le niveau d'enseignement

\begin{tabular}{|c|c|c|c|c|c|c|c|c|c|c|c|c|}
\hline & \multicolumn{4}{|c|}{$\begin{array}{l}\text { Primaire, secondaire et post-secondaire } \\
\text { non tertiaire }\end{array}$} & \multicolumn{4}{|c|}{ Tertiaire } & \multicolumn{4}{|c|}{ Du primaire au tertiaire } \\
\hline & $\frac{u}{3}$ & 总 & 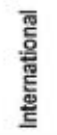 & 醌 & $\frac{\underline{0}}{\bar{z}}$ & 悹 & 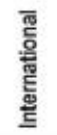 & 嵒 & $\frac{\text { 음 }}{3}$ & 总 & 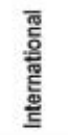 & 푱 \\
\hline & (1) & (2) & (3) & (4) & (5) & (6) & (7) & (8) & (9) & (10) & (11) & (12) \\
\hline \multicolumn{13}{|l|}{ سل Pays } \\
\hline Australie & 32 & 0.7 & 0.0 & 3.9 & 0.8 & $12^{\circ}$ & $x(6)$ & 1.9 & 39 & $19^{\circ}$ & $x(10)$ & 5.8 \\
\hline Autriche & 3.0 & 0.1 & a & 3.1 & 1.6 & 0.1 & a & 1.8 & 4.6 & 0.3 & a & 4.9 \\
\hline Belgique & 4.1 & 0.1 & 0.0 & 4.3 & 12 & 0.2 & 0.0 & 1.5 & 5.3 & 0.4 & 0.1 & 5.8 \\
\hline Canada' & $3.2^{\circ}$ & $03^{\circ}$ & $0.0^{\circ}$ & $3.5^{\circ}$ & 12 & 1.1 & 0.0 & 23 & $44^{d}$ & $14^{\circ}$ & $0.0^{4}$ & $5.9^{4}$ \\
\hline Chili $^{2}$ & 3.0 & 0.6 & a & 3.6 & 1.0 & 1.7 & a & 2.7 & 4.0 & 2.4 & a & 6.3 \\
\hline Colombie $^{2}$ & 32 & 0.9 & 0.0 & 4.0 & 0.8 & 0.8 & 0.0 & 1.6 & 4.0 & 1.7 & 0.0 & 5.7 \\
\hline République tchèque & 23 & 0.2 & 0.0 & 25 & 0.7 & 0.2 & 0.0 & 0.9 & 30 & 0.4 & 0.0 & 3.5 \\
\hline Danemark & $\mathrm{m}$ & m & $\mathrm{m}$ & $\mathrm{m}$ & $\mathrm{m}$ & $\mathrm{m}$ & $\mathrm{m}$ & m & m & $\mathrm{m}$ & $\mathrm{m}$ & $\mathrm{m}$ \\
\hline Estonie & 27 & 0.2 & 0.0 & 29 & 1.2 & 0.2 & 0.1 & 1.5 & 3.9 & 0.4 & 0.1 & 4.4 \\
\hline Finlande & 3.8 & 0.0 & 0.0 & 3.9 & 1.5 & 0.1 & 0.1 & 1.7 & 5.4 & 0.1 & 0.1 & 5.5 \\
\hline France & 3.4 & 0.3 & 0.0 & 3.7 & 1.1 & 0.3 & 0.0 & 1.4 & 4.5 & 0.7 & 0.0 & 5.2 \\
\hline Allemagne & 26 & 04 & 0.0 & 30 & 10 & 0.2 & 0.0 & 1.2 & 36 & 0.6 & 0.0 & 4.2 \\
\hline Grece & 2.6 & $\mathrm{~m}$ & 0.0 & $\mathrm{~m}$ & 0.6 & $\mathrm{~m}$ & 0.1 & $\mathrm{~m}$ & 3.2 & $\mathrm{~m}$ & 0.1 & $\mathrm{~m}$ \\
\hline Hongrie & 29 & 0.4 & 00 & 32 & 0.7 & 0.4 & 00 & 1.1 & 35 & 0.7 & 0.0 & 43 \\
\hline Islande & 4.1 & 0.2 & 0.0 & 4.3 & 1.1 & 0.1 & 0.0 & 1.3 & 53 & 0.3 & 0.0 & 5.6 \\
\hline Irlande & 2.6 & 0.1 & a & 2.7 & 0.6 & 0.2 & a & 0.8 & 3.2 & 0.3 & a & 3.5 \\
\hline Israèl & 4.0 & 0.5 & 0.0 & 4.5 & 0.8 & 0.6 & 0.0 & 1.4 & 4.8 & 1.1 & 0.0 & 60 \\
\hline Italie & 2.6 & 0.1 & 0.0 & 2.7 & 0.5 & 0.3 & 0.0 & 0.9 & 3.1 & 0.5 & 0.0 & 3.6 \\
\hline Japon & 2.4 & 02 & 0.0 & 2.7 & $0.4^{d}$ & $1.0^{\circ}$ & 0.0 & $1.4^{\mathrm{d}}$ & 29 & 1.2 & 0.0 & 4.0 \\
\hline Corée & 3.1 & 0.5 & 0.0 & 3.7 & 0.7 & 1.1 & 0.0 & 1.7 & 3.8 & 1.6 & 0.0 & 5.4 \\
\hline Lettonie & 3.0 & 0.1 & 0.0 & 3.1 & 0.7 & 0.3 & 0.0 & 1.0 & 3.7 & 0.4 & 0.1 & 42 \\
\hline Lituanie & 24 & 0.1 & 0.0 & 2.5 & 0.7 & 0.3 & 0.0 & 1.1 & 3.1 & 0.5 & 0.1 & 3.6 \\
\hline Luxembourg & 26 & 0.1 & 0.1 & 28 & 0.4 & 0.0 & 0.0 & 0.5 & 3.0 & 0.1 & 0.1 & 32 \\
\hline Mexique & 30 & 0.7 & 0.0 & 3.7 & 0.9 & 0.4 & 0.0 & 1.4 & 40 & 1.1 & 0.0 & 5.1 \\
\hline Pays-Bas & 3.1 & 0.4 & 0.0 & 3.5 & 1.1 & 0.5 & 0.1 & 1.7 & 4.2 & 0.9 & 0.1 & 5.2 \\
\hline Nouvelle-Zèlande & 3.9 & 0.8 & 0.0 & 47 & 0.9 & 0.9 & 0.0 & 1.7 & 4.7 & 17 & 0.0 & 6.4 \\
\hline Norvège & 4.6 & 0.0 & 0.0 & 4.6 & 1.8 & 0.1 & 0.0 & 1.9 & 6.3 & 0.1 & 0.0 & 6.5 \\
\hline Pologne & 29 & 0.3 & 0.0 & 3.2 & 0.9 & 0.2 & 0.0 & 12 & 3.8 & 0.5 & 0.1 & 4.4 \\
\hline Portugal & 34 & 0.4 & 0.1 & 3.9 & $0.7^{d}$ & $0.4^{4}$ & $0.1^{4}$ & $1.2^{\mathrm{d}}$ & 4.1 & 0.8 & 0.2 & 50 \\
\hline Republique slovaque & 2.4 & 0.3 & 0.0 & 27 & 0.7 & 0.3 & 0.0 & 1.0 & 3.1 & 0.6 & 0.0 & 3.7 \\
\hline Slovénie & 29 & 0.3 & 0.0 & 32 & 0.8 & 0.1 & 0.0 & 1.0 & 38 & 0.4 & 0.1 & 4.3 \\
\hline Espagne & 26 & 0.4 & 0.0 & 3.1 & 0.8 & 0.4 & 0.0 & 12 & 3.5 & 0.8 & 0.0 & 4.3 \\
\hline Suède & 38 & a & a & 38 & 14 & 02 & 0.1 & 16 & 52 & 02 & 0.1 & 54 \\
\hline Suisse & $\mathrm{m}$ & $\mathrm{m}$ & $\mathrm{m}$ & $\mathrm{m}$ & 1.3 & $\mathrm{~m}$ & 0.0 & $\mathrm{~m}$ & $\mathrm{~m}$ & $\mathrm{~m}$ & $\mathrm{~m}$ & $\mathrm{~m}$ \\
\hline Turquie & 27 & 0.9 & 0.0 & 3.5 & 1.4 & 0.5 & 0.0 & 1.9 & 4.1 & 1.4 & 0.0 & 5.4 \\
\hline Royaume-Uni & 3.7 & 0.7 & 0.0 & 4.4 & 0.5 & 1.2 & 0.1 & 1.7 & 4.2 & 1.9 & 0.1 & 62 \\
\hline Etats-Unis ${ }^{3}$ & 32 & 0.3 & a & 3.5 & 0.9 & 1.6 & a & 25 & 4.1 & 1.9 & a & 6.0 \\
\hline Moyenne OCDE & 3.1 & 0.4 & 0.0 & 3.5 & 0.9 & 0.5 & 0.0 & 1.5 & 40 & 0.9 & 0.1 & 5.0 \\
\hline Moyenne UE23 & 3.0 & 0.3 & 0.0 & 32 & 0.9 & 0.3 & 0.0 & 12 & 39 & 0.5 & 0.1 & 4.5 \\
\hline
\end{tabular}

\begin{tabular}{|c|c|c|c|c|c|c|c|c|c|c|c|c|}
\hline of Argentine & 39 & $\mathrm{~m}$ & a & $\mathrm{m}$ & 1.1 & $\mathrm{~m}$ & a & $m$ & 4.9 & $m$ & $a$ & $\mathrm{~m}$ \\
\hline Brèsil & 4.1 & $\mathrm{~m}$ & $\mathrm{~m}$ & m & 1.0 & $\mathrm{~m}$ & $\mathrm{~m}$ & $\mathrm{~m}$ & 5.1 & m & m & $\mathrm{m}$ \\
\hline gूँ Chine & $\mathrm{m}$ & $\mathrm{m}$ & $\mathrm{m}$ & $\mathrm{m}$ & $\mathrm{m}$ & m & $\mathrm{m}$ & $\mathrm{m}$ & $\mathrm{m}$ & $\mathrm{m}$ & $\mathrm{m}$ & $\mathrm{m}$ \\
\hline$\frac{5}{\pi}{ }_{0}^{2}$ Costa Rica & $\mathrm{m}$ & $\mathrm{m}$ & m & $\mathrm{m}$ & $\mathrm{m}$ & $\mathrm{m}$ & $\mathrm{m}$ & $\mathrm{m}$ & $\mathrm{m}$ & $\mathrm{m}$ & $\mathrm{m}$ & $\mathrm{m}$ \\
\hline Inde & $\mathrm{m}$ & $\mathrm{m}$ & $\mathrm{m}$ & $\mathrm{m}$ & $\mathrm{m}$ & m & $\mathrm{m}$ & $\mathrm{m}$ & $\mathrm{m}$ & $\mathrm{m}$ & $\mathrm{m}$ & $\mathrm{m}$ \\
\hline Indonésic ${ }^{2}$ & $\mathrm{~m}$ & $\mathrm{~m}$ & $\mathrm{~m}$ & $\mathrm{~m}$ & $\mathrm{~m}$ & $\mathrm{~m}$ & a & $\mathrm{m}$ & $\mathrm{m}$ & $\mathrm{m}$ & $\mathrm{m}$ & $\mathrm{m}$ \\
\hline Féderation de Russie & 19 & 0.1 & 0.0 & 20 & 0.7 & 0.4 & 0.0 & 1.1 & 26 & 0.5 & 0.0 & 3.1 \\
\hline Arabie saoudite & m & $\mathrm{m}$ & $\mathrm{m}$ & $\mathrm{m}$ & $\mathrm{m}$ & $\mathrm{m}$ & $\mathrm{m}$ & $\mathrm{m}$ & $\mathrm{m}$ & $\mathrm{m}$ & $\mathrm{m}$ & $\mathrm{m}$ \\
\hline Afrique du Sud ${ }^{2}$ & 4.1 & $\mathrm{~m}$ & $\mathrm{~m}$ & $\mathrm{~m}$ & 06 & $\mathrm{~m}$ & $\mathrm{~m}$ & $\mathrm{~m}$ & 47 & $\mathrm{~m}$ & $\mathrm{~m}$ & $\mathrm{~m}$ \\
\hline
\end{tabular}

\begin{tabular}{l|l|l|l|l|l|l|l|l|l|l|l|l|} 
Moyenne $\mathrm{G} 20$ & $\mathrm{~m}$ & $\mathrm{~m}$ & $\mathrm{~m}$ & $\mathrm{~m}$ & $\mathrm{~m}$ & $\mathrm{~m}$ & $\mathrm{~m}$ & $\mathrm{~m}$ & $\mathrm{~m}$ & $\mathrm{~m}$ & $\mathrm{~m}$ & $\mathrm{~m}$
\end{tabular}

Remarque : Pour de plus amples informations, consulter les sections « Définitions » et « Méthodologie ». Les données et d'autres types de ventilations peuvent être consultés sur http://stats.oecd.org/, Base de données de Regards sur l'éducation.

1. L'enseignement primaire inclut des programmes de l'enseignement préprimaire. Les chiffres de l'enseignement post-secondaire non tertiaire sont considérés comme négligeables.

2. Année de référence : 2017.

Source : OCDE/ISU/Eurostat (2019). Consulter la section « Source » pour tout complément d'information et l'annexe 3 pour les notes (https://doi.org/10.1787/f8d7880d$\underline{\text { en). }}$.

Les symboles représentant les données manquantes et les abréviations figurent dans le Guide du lecteur.

StatLink त्ञाIs https://doi.org/10.1787/888933978892 
Tableau C2.3. Évolution des dépenses totales au titre des établissements d'enseignement en pourcentage du PIB (2005, 2011 et 2016)

Déflateur du PIB $2010=100$, prix constants, selon le niveau d'enseignement

\begin{tabular}{|c|c|c|c|c|c|c|c|c|c|c|c|c|}
\hline & \multicolumn{3}{|c|}{$\begin{array}{l}\text { Primaire, secondaire } \\
\text { et post-secondaire non tertiaire }\end{array}$} & \multicolumn{3}{|c|}{ Tertiaire } & \multicolumn{3}{|c|}{ Du primaire au tertiaire } & \multicolumn{3}{|c|}{$\begin{array}{l}\text { Evolution du PIB } \\
\qquad(2010=100)\end{array}$} \\
\hline & 2005 & 2011 & 2016 & 2005 & 2011 & 2016 & 2005 & 2011 & 2016 & 2005 & 2011 & 2016 \\
\hline & (1) & (2) & (3) & (4) & (5) & (6) & (7) & (8) & (9) & (10) & (11) & (12) \\
\hline \multicolumn{13}{|l|}{ ш Pays } \\
\hline Australie & 86.4 & 93.2 & 87.4 & 907 & 97.2 & 113.7 & 876 & 943 & 94.6 & 87.5 & 105.3 & 1192 \\
\hline Autriche & $\mathrm{m}$ & $\mathrm{m}$ & m & $\mathrm{m}$ & $\mathrm{m}$ & $\mathrm{m}$ & $\mathrm{m}$ & $\mathrm{m}$ & $\mathrm{m}$ & 93.7 & 1029 & 107.7 \\
\hline Belgique & 94.9 & 99.2 & 996 & 89.2 & 100.5 & 109.2 & 935 & 99.5 & 101.9 & 93.2 & 101.8 & 106.9 \\
\hline Canada' & 87.5 & 95.0 & 89.4 & 88.3 & 94.5 & 84.9 & 87.9 & 94.8 & 87.6 & 94.2 & 102.8 & 115.9 \\
\hline Chili & 106.3 & 98.2 & 105.7 & 84.2 & 104.2 & 108.2 & 97.4 & 100.6 & 106.7 & 83.1 & 106.1 & 123.1 \\
\hline Colombie & $\mathrm{m}$ & $\mathrm{m}$ & $\mathrm{m}$ & $\mathrm{m}$ & $\mathrm{m}$ & $\mathrm{m}$ & $\mathrm{m}$ & $\mathrm{m}$ & $\mathrm{m}$ & 80.4 & 107.4 & 128.4 \\
\hline Rèpublique tchèque & 102.4 & 100.7 & 93.1 & 81.0 & 115.3 & 80.6 & 95.9 & 105.2 & 89.3 & 88.6 & 101.8 & 111.3 \\
\hline Danemark & 93.4 & 912 & m & 90.7 & 101.0 & $\mathrm{~m}$ & 92.6 & 93.9 & $\mathrm{~m}$ & 99.0 & 101.3 & 109.2 \\
\hline Estonie & 90.3 & 862 & 76.2 & 72.7 & 105.6 & 98.1 & 85.1 & 91.9 & 82.6 & 102.0 & 107.6 & 124.1 \\
\hline Finlande & 93.4 & 98.7 & 97.9 & 89.9 & 101.1 & 90.9 & 92.3 & 99.5 & 95.6 & 96.0 & 102.6 & 103.0 \\
\hline France & 98.4 & 96.6 & 94.5 & 88.1 & 98.8 & 98.5 & 95.6 & 97.2 & 95.6 & 96.0 & 102.2 & 106.5 \\
\hline Allemagne & 98.8 & 96.1 & 89.1 & 85.5 & 100.7 & 101.1 & 95.3 & 97.3 & 92.3 & 94.0 & 103.7 & 111.3 \\
\hline Grèce & $\mathrm{m}$ & $\mathrm{m}$ & $\mathrm{m}$ & m & $\mathrm{m}$ & $\mathrm{m}$ & $\mathrm{m}$ & $\mathrm{m}$ & $\mathrm{m}$ & 101.7 & 90.9 & 81.6 \\
\hline Hongrie & m & $\mathrm{m}$ & m & $\mathrm{m}$ & $\mathrm{m}$ & $\mathrm{m}$ & $\mathrm{m}$ & $\mathrm{m}$ & $\mathrm{m}$ & 101.1 & 101.7 & 112.7 \\
\hline Islande & 114.8 & 101.0 & 95.3 & 105.5 & 952 & 111.6 & 112.9 & 99.8 & 98.6 & 946 & 1019 & 122.5 \\
\hline Irlande & 72.9 & 97.6 & 60.0 & 74.8 & 95.7 & 54.6 & 73.4 & 97.1 & 58.7 & 97.7 & 103.7 & 150.5 \\
\hline Israël & 94.4 & 105.5 & 114.5 & 136.7 & 140.4 & 121.2 & 96.8 & 105.5 & 107.9 & 80.8 & 105.1 & 124.3 \\
\hline Italie & 101.8 & 95.5 & 92.7 & 88.1 & 100.9 & 93.2 & 98.4 & 96.8 & 92.8 & 101.6 & 100.6 & 98.1 \\
\hline Japon & 95.9 & 97.5 & 92.4 & $90.9^{d}$ & $98.2^{\circ}$ & $93.2^{\circ}$ & 94.2 & 97.7 & 92.6 & 100.7 & 102.9 & 106.7 \\
\hline Corée & $\mathrm{m}$ & $\mathrm{m}$ & $\mathrm{m}$ & $\mathrm{m}$ & $\mathrm{m}$ & $\mathrm{m}$ & $\mathrm{m}$ & $\mathrm{m}$ & m & 81.7 & 103.7 & 119.3 \\
\hline Lettonie & 97.6 & 90.1 & 929 & 102.8 & 109.2 & 76.5 & 99.1 & 95.6 & 88.2 & 102.5 & 106.4 & 121.4 \\
\hline Lituanie & $\mathrm{m}$ & 88.9 & 74.8 & 82.7 & 112.1 & 67.8 & $\mathrm{~m}$ & 96.4 & 72.5 & 94.3 & 106.0 & 123.2 \\
\hline Luxembourg & $\mathrm{m}$ & 932. & 79.3 & $\mathrm{~m}$ & $\mathrm{~m}$ & $\mathrm{~m}$ & m & $\mathrm{m}$ & $\mathrm{m}$ & 88.6 & 102.5 & 117.6 \\
\hline Mexique & 98.2 & 99.9 & 95.4 & 85.0 & 93.0 & 1012 & 94.8 & 98.1 & 96.9 & 929 & 103.7 & 119.0 \\
\hline Pays-Bas & 94.0 & 97.8 & 93.4 & 90.1 & 101.9 & 105.9 & 92.8 & 99.0 & 97.2 & 93.4 & 101.6 & 106.1 \\
\hline Nouvelle-Zélande & m & $\mathrm{m}$ & m & m & $\mathrm{m}$ & m & $\mathrm{m}$ & $\mathrm{m}$ & $\mathrm{m}$ & 92.3 & 102.6 & 118.9 \\
\hline Norvège & 100.6 & 97.3 & 94.3 & m & 99.1 & 117.6 & $\mathrm{~m}$ & 97.7 & 100.2 & 90.6 & 97.5 & 119.7 \\
\hline Pologne & 103.5 & 93.7 & 88.7 & 106.1 & 872 & 80.1 & 104.6 & 921 & 86.5 & 79.2 & 105.0 & 119.6 \\
\hline Portugal & 956 & 95.3 & 104.1 & 91.0 & 95.5 & 82.7 & 94.4 & 95.4 & 982 & 97.0 & 982 & 97.5 \\
\hline République slovaque & 93.7 & 90.6 & 89.9 & 98.8 & 107.6 & 110.4 & 94.9 & 94.5 & 94.7 & 79.3 & 1028 & 117.1 \\
\hline Slovénie & 105.6 & 97.3 & 84.1 & 101.1 & 103.5 & 82.9 & 104.5 & 98.8 & 83.8 & 91.8 & 100.6 & 105.1 \\
\hline Espagne & 88.4 & 986 & 95.5 & 83.2 & 98.6 & 949 & 86.9 & 98.6 & 95.3 & 94.9 & 99.0 & 102.4 \\
\hline Suéde & 105.8 & 97.6 & 100.7 & 92.7 & 99.3 & 96.9 & 101.8 & 98.1 & 99.5 & 924 & 102.7 & 114.1 \\
\hline Suisse & m & $\mathrm{m}$ & $\mathrm{m}$ & m & $\mathrm{m}$ & m & $\mathrm{m}$ & $\mathrm{m}$ & $\mathrm{m}$ & 89.8 & 101.7 & 110.3 \\
\hline Turquie & $\mathrm{m}$ & $\mathrm{m}$ & $\mathrm{m}$ & m & $\mathrm{m}$ & $\mathrm{m}$ & $\mathrm{m}$ & $\mathrm{m}$ & $\mathrm{m}$ & 85.3 & 111.1 & 145.4 \\
\hline Royaume-Uni & 95.5 & 100.9 & 101.4 & $\mathrm{~m}$ & $\mathrm{~m}$ & $\mathrm{~m}$ & $\mathrm{~m}$ & $\mathrm{~m}$ & $\mathrm{~m}$ & 96.2 & 101.4 & 112.4 \\
\hline Etats-Unis & 97.0 & 96.8 & 90.6 & 90.7 & 102.0 & 91.8 & 94.5 & 98.9 & 91.1 & 94.3 & 101.6 & 113.8 \\
\hline Moyenne OCDE & 96.6 & 962 & 91.9 & 91.6 & 102.2 & 94.9 & 947 & 97.6 & 92.3 & 92.5 & 102.7 & 114.8 \\
\hline Moyenne UE23 & 95.9 & 95.3 & 89.9 & 89.4 & 101.9 & 89.7 & 94.2 & 97.1 & 89.7 & 94.5 & 102.0 & 111.3 \\
\hline \& Argentine & $\mathrm{m}$ & $\mathrm{m}$ & $\mathrm{m}$ & $\mathrm{m}$ & $\mathrm{m}$ & $\mathrm{m}$ & $\mathrm{m}$ & $\mathrm{m}$ & m & 78.8 & 106.0 & 105.4 \\
\hline Brésil & m & m & m & $\mathrm{m}$ & m & m & $\mathrm{m}$ & $\mathrm{m}$ & m & 80.3 & 104.0 & 102.3 \\
\hline Chine & $\mathrm{m}$ & $\mathrm{m}$ & m & m & $\mathrm{m}$ & $\mathrm{m}$ & $\mathrm{m}$ & $\mathrm{m}$ & $\mathrm{m}$ & 58.5 & 109.5 & 155.8 \\
\hline a Costa Rica & $\mathrm{m}$ & $\mathrm{m}$ & m & $\mathrm{m}$ & $\mathrm{m}$ & m & $\mathrm{m}$ & $\mathrm{m}$ & $\mathrm{m}$ & 79.3 & 104.3 & 125.0 \\
\hline Inde & $\mathrm{m}$ & $\mathrm{m}$ & $\mathrm{m}$ & $\mathrm{m}$ & $\mathrm{m}$ & $\mathrm{m}$ & $\mathrm{m}$ & $\mathrm{m}$ & m & 67.1 & 106.6 & 148.9 \\
\hline Indonésie & m & $\mathrm{m}$ & m & m & $\mathrm{m}$ & $\mathrm{m}$ & $\mathrm{m}$ & $\mathrm{m}$ & $\mathrm{m}$ & 75.5 & 106.2 & 137.4 \\
\hline Federation de Russie & 91.5 & 99.6 & 102.4 & 51.0 & 89.3 & 79.5 & 74.1 & 95.2 & 92.5 & 840 & 104.3 & 107.4 \\
\hline Arabie saoudite & m & $\mathrm{m}$ & m & $\mathrm{m}$ & $\mathrm{m}$ & m & $\mathrm{m}$ & $\mathrm{m}$ & $\mathrm{m}$ & 75.3 & 110.0 & 130.6 \\
\hline Afrique du Sud & m & m & m & m & m & m & m & m & m & 85.8 & 103.3 & 112.0 \\
\hline Moyenne G20 & $\mathrm{m}$ & m & m & m & m & $\mathrm{m}$ & m & m & m & 85.8 & 104.7 & 119.3 \\
\hline
\end{tabular}

Remarque : Pour de plus amples informations, consulter les sections « Définitions » et « Méthodologie ». Les données et d'autres types de ventilations peuvent être consultés sur http://stats.oecd.org/, Base de données de Regards sur l'éducation.

1. L'enseignement primaire inclut des programmes de l'enseignement préprimaire. Les chiffres de l'enseignement post-secondaire non tertiaire sont considérés comme négligeables.

2. Année de référence : 2017.

Source : OCDE/ISU/Eurostat (2019). Consulter la section « Source » pour tout complément d'information et l'annexe 3 pour les notes (https://doi.org/10.1787/f8d7880den).

Les symboles représentant les données manquantes et les abréviations figurent dans le Guide du lecteur.

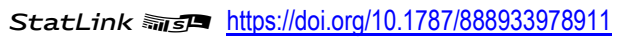




\section{Indicateur C3. Quelle est la répartition entre les investissements publics et privés au titre des établissements d'enseignement?}

\section{Faits marquants}

- En moyenne, dans les pays de l'OCDE, les fonds publics représentent une plus grande part des dépenses totales dans l'enseignement primaire, secondaire et post-secondaire non tertiaire $(90 \%)$ que dans l'enseignement tertiaire (66\%).

- La part de l'investissement privé dans l'enseignement tertiaire dépend essentiellement des frais de scolarité auxquels sont soumis les étudiants. Plus de $60 \%$ des dépenses totales sont financées par des sources privées en Australie, au Chili, en Corée, aux États-Unis, au Japon et au Royaume-Uni.

- Dans l'enseignement tertiaire, les transferts publics au secteur privé accordent un soutien financier au secteur privé et représentent en moyenne $9 \%$ des dépenses totales au titre des établissements d'enseignement tertiaire dans les pays de l'OCDE. Ces transferts représentent toutefois plus de $20 \%$ des dépenses en Australie et au Royaume-Uni.

Graphique C3.1. Répartition des transferts et des dépenses publiques et privées au titre des établissements d'enseignement (2016)

Niveaux d'enseignement tertiaire

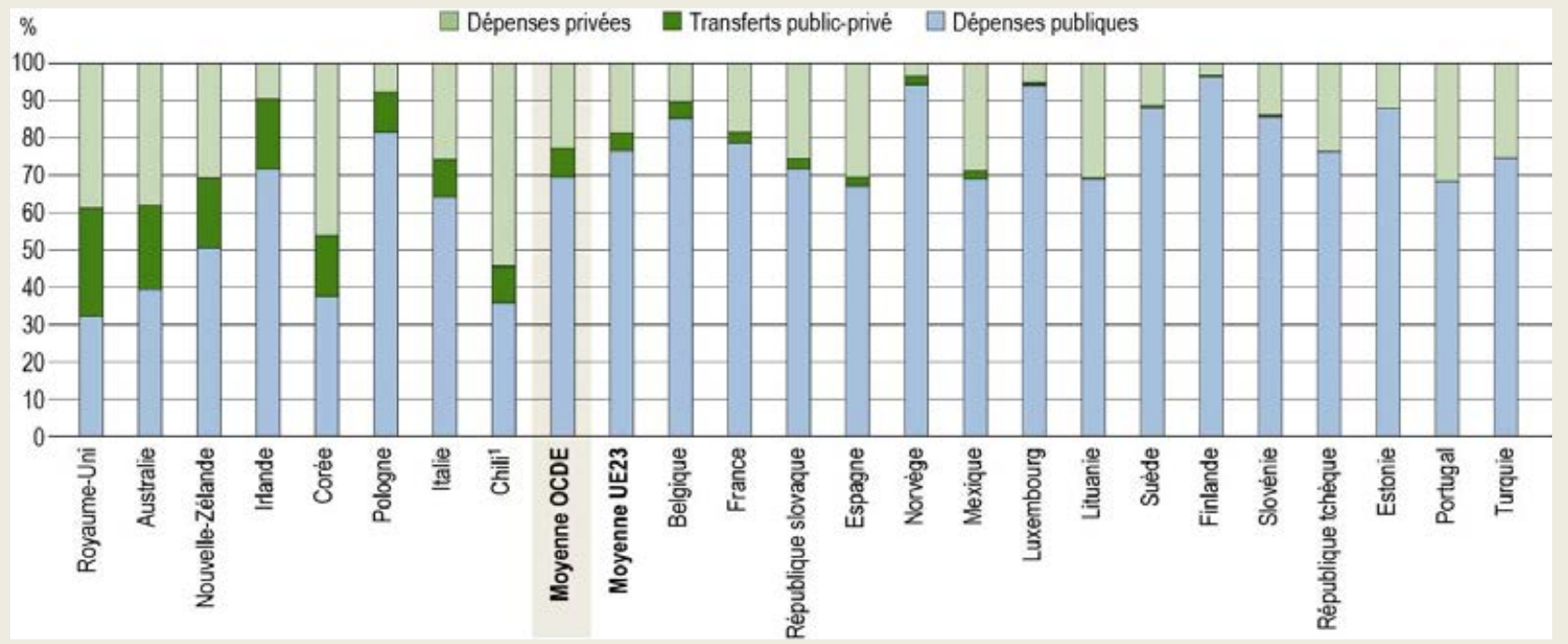

Remarque : Les dépenses internationales sont regroupées avec les dépenses publiques pour des raisons de présentation. 1. Année de référence : 2017.

Les pays et économies sont classés par ordre décroissant de la part de transferts public-privé.

Source : OCDE/ISU/Eurostat (2019), tableaux C3.1 et C3.2. Consulter la section « Source » pour tout complément d'information et l'annexe 3 pour les notes (https://doi.org/10.1787/f8d7880d-en). 


\section{Contexte}

Aujourd'hui, les individus sont plus nombreux que jamais à suivre l'une des nombreuses formations proposées par un nombre croissant de prestataires de services d'éducation. La question de la répartition du financement de l'éducation entre le secteur public et le secteur privé est donc de plus en plus au cœur des débats. Dans la conjoncture économique actuelle, de nombreux gouvernements peinent à réunir les fonds nécessaires pour financer la demande d'éducation en hausse en comptant uniquement sur les deniers publics. De plus, selon certains responsables politiques, ceux qui profitent le plus de l'éducation - ceux qui suivent des études devraient prendre en charge au moins une partie des coûts y afférents. Les pouvoirs publics financent toujours une partie élevée de l'investissement dans l'éducation, mais le secteur privé joue un rôle de plus en plus important à certains niveaux d'enseignement.

Le financement est essentiellement public dans les niveaux d'enseignement non tertiaire, qui relèvent de la scolarité obligatoire dans la plupart des pays. Dans les pays de l'OCDE, la répartition entre le financement public et le financement privé varie principalement dans l'enseignement préprimaire (voir l'indicateur C2) et l'enseignement tertiaire, que les pouvoirs publics ont moins tendance à financer totalement ou presque. À ces niveaux d'enseignement, ce sont essentiellement les ménages qui constituent le financement privé, ce qui soulève la question de l'égalité de l'accès à l'éducation. Le débat sur le financement de l'enseignement tertiaire est particulièrement intense. Certains craignent que la répartition entre financement public et financement privé ne décourage des individus d'entamer une formation tertiaire. Les uns estiment que les pouvoirs publics devraient revoir sensiblement à la hausse les aides aux effectifs scolarisés, comme les prêts d'études, alors que les autres soutiennent les efforts consentis pour amener les entreprises privées à accroître le financement de l'enseignement tertiaire. Les prêts d'études peuvent réduire les obstacles à l'éducation qui sont créés par les dépenses privées directes ainsi que le coût des dépenses publiques directes pour les contribuables. En particulier, les prêts d'études transfèrent le coût de l'éducation dans le temps, entre la période des études (quand les étudiants n'ont que peu, voire pas, de revenus) à la période qui suit l'obtention de leur diplôme et conduit, en règle générale, à l'augmentation de leurs revenus.

Cet indicateur examine la part des secteurs public, privé et international dans le financement des établissements d'enseignement à différents niveaux d'enseignement. Dans les dépenses privées, il fait également la distinction entre les dépenses des ménages et les dépenses d'autres entités privées. Il éclaire le grand débat sur la question de la répartition idéale du financement des établissements d'enseignement entre le secteur public et le secteur privé, en particulier dans l'enseignement tertiaire. Enfin, il analyse la part relative des transferts publics aux établissements privés et aux effectifs scolarisés et à leur famille, qui aident ceux-ci à financer le coût de l'enseignement tertiaire.

\section{Autres faits marquants}

- Les ménages financent la part la plus élevée des dépenses privées au titre des établissements d'enseignement (74 \% en moyenne dans les pays de l'OCDE).

- Entre 2010 et 2016 , la part des dépenses privées au titre des établissements d'enseignement, de l'enseignement primaire à l'enseignement tertiaire, a augmenté de 3 points de pourcentage, tandis que la part des dépenses publiques a diminué du même pourcentage en moyenne dans les pays de l'OCDE.

- La part des dépenses privées au titre des établissements d'enseignement varie entre les niveaux d'enseignement non tertiaire. Dans l'enseignement primaire et le premier cycle de l'enseignement secondaire, $8 \%$ des dépenses au titre des établissements d'enseignement primaire sont financées par le secteur privé. Ce pourcentage atteint $14 \%$ dans le deuxième cycle de l'enseignement secondaire. 


\section{Analyse}

\section{Parts publique et privée des dépenses au titre des établissements d'enseignement}

Dans les pays de l'OCDE, les établissements d'enseignement restent en grande partie financés par les pouvoirs publics, même si la part des fonds privés est substantielle dans l'enseignement tertiaire. Toutefois, dans cette moyenne globale, les parts publique, privée et internationale du financement varient fortement entre les pays.

En moyenne, dans les pays de l'OCDE, les pouvoirs publics financent directement $83 \%$ du budget des établissements d'enseignement, de l'enseignement primaire à l'enseignement tertiaire, tandis que $17 \%$ de ce budget provient de sources privées (voir le tableau C3.1). Toutefois, de nombreux écarts s'observent entre les pays. Le secteur privé finance au plus $3 \%$ du budget des établissements d'enseignement en Finlande, au Luxembourg, en Norvège et en Suède. Par contraste, il finance un tiers environ du budget de l'éducation en Australie, au Chili, en Colombie, en Corée, aux États-Unis, au Japon et au Royaume-Uni. Les sources internationales financent seulement une part minime des dépenses au titre des établissements d'enseignement. En moyenne, dans les pays de l'OCDE, elles représentent $1 \%$ des dépenses totales, et atteignent environ $3 \%$ en Estonie, au Luxembourg et au Portugal.

\section{Établissements d'enseignement non tertiaire}

Dans tous les pays, le financement est essentiellement public dans l'enseignement non tertiaire. En moyenne, dans les pays de l'OCDE, le financement privé représente $10 \%$ des dépenses à ces niveaux d'enseignement, même s'il passe la barre des 20 \% en Colombie et en Turquie (voir le tableau C3.1 et le graphique C3.2). Dans la plupart des pays, les ménages financent la part la plus importante des dépenses privées au titre de ces niveaux d'enseignement, principalement sous la forme de frais de scolarité.

La part privée des dépenses d'éducation varie entre les pays et entre les niveaux d'enseignement. Dans l'enseignement primaire, le secteur privé finance en moyenne $8 \%$ des dépenses au titre des établissements d'enseignement dans les pays de l'OCDE. Toutefois, en Norvège et en Suède, le secteur public finance l'ensemble des dépenses au titre de l'enseignement primaire, tandis qu'au Chili, en Colombie, en Espagne, au Mexique et en Turquie, plus de $15 \%$ du budget de l'éducation à ce niveau d'enseignement provient de sources privées (OCDE, 2018[1]).

La part du financement privé dans le premier cycle de l'enseignement secondaire est similaire à celle allouée dans l'enseignement primaire. Dans le premier cycle de l'enseignement secondaire, le secteur privé finance, en moyenne, environ $8 \%$ des dépenses au titre des établissements d'enseignement, dans les pays de l'OCDE. Dans les trois quarts des pays dont les données sont disponibles, les dépenses privées représentent moins de $10 \%$ des dépenses totales à ce niveau d'enseignement, mais elles en représentent plus de $20 \%$ en Australie, en Colombie et en Turquie (OCDE, 2018[1]).

Le secteur privé finance une part plus importante du budget dans le deuxième cycle de l'enseignement secondaire que dans l'enseignement primaire et le premier cycle de l'enseignement secondaire : $14 \%$ en moyenne dans les pays de l'OCDE. La part du financement privé est similaire en filière professionnelle et en filière générale ; elle s'établit en moyenne à $13 \%$ des dépenses au titre des établissements du deuxième cycle de l'enseignement secondaire dans les pays de l'OCDE. En Allemagne, en Nouvelle-Zélande et aux Pays-Bas, la part du financement privé est toutefois plus élevée de 35 points de pourcentage au moins en filière professionnelle qu'en filière générale dans le deuxième cycle de l'enseignement secondaire. À l'inverse, la part du financement privé est plus élevée d'au moins 10 points de pourcentage en filière générale qu'en filière professionnelle au Chili, en Espagne, au Royaume-Uni et en Turquie (OCDE, 2018[1]).

Dans les pays de l'OCDE, la part du financement public ne représente que $72 \%$ en moyenne dans l'enseignement post-secondaire non tertiaire. Contrairement aux trois niveaux d'enseignement présentés ci- 
dessus, l'enseignement post-secondaire non tertiaire est davantage financé par le secteur privé que par le secteur public en Allemagne, aux États-Unis, en Israël, en Nouvelle-Zélande et en Pologne (OCDE, 2018[1]).

Graphique C3.2. Répartition des dépenses publiques et privées au titre des établissements d'enseignement (2016)

Source finale de financement, par niveau d'éducation
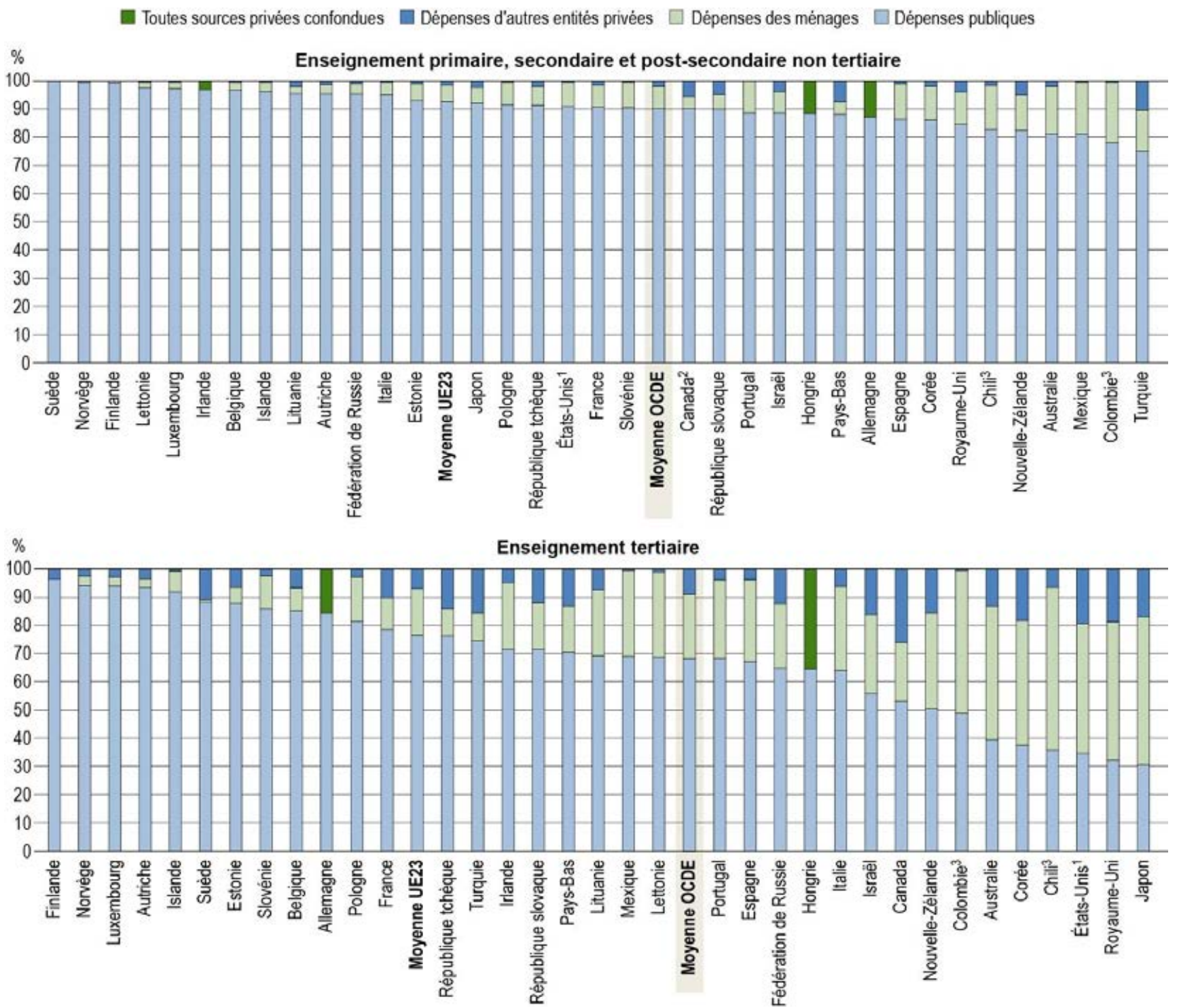

1. Les valeurs présentées pour les États-Unis correspondent aux prêts d'études nets, et non bruts, ce qui induit donc une sous-estimation des transferts publics.

2. L'enseignement primaire inclut des programmes de l'enseignement préprimaire.

3. Année de référence : 2017.

Remarque : Les dépenses internationales sont regroupées avec les dépenses publiques pour des raisons de présentation.

Les pays sont classés par ordre décroissant de la part des dépenses publiques et internationales au titre des établissements d'enseignement.

Source : OCDE/ISU/Eurostat (2019), tableau C3.1. Consulter la section « Source » pour tout complément d'information et l'annexe 3 pour les notes (https://doi.org/10.1787/f8d7880d-en). 


\section{Établissements d'enseignement tertiaire}

Le rendement élevé de l'enseignement tertiaire (voir l'indicateur A5) a conduit un certain nombre de pays à attendre que le secteur privé participe davantage au financement de ce niveau d'enseignement. Certains pays ont mis en œuvre des mécanismes de soutien financier pour venir en aide aux étudiants qui doivent mobiliser des ressources privées, mais ce n'est pas toujours le cas (voir l'indicateur C5). Dans tous les pays membres et partenaires de l'OCDE, la part privée des dépenses d'éducation après transferts est nettement plus élevée dans l'enseignement tertiaire qu'aux niveaux inférieurs d'enseignement. En moyenne, dans les pays de l'OCDE, près de $32 \%$ des dépenses totales au titre des établissements d'enseignement tertiaire sont financées par le secteur privé (voir le tableau C3.1 et le graphique C3.2).

La part privée des dépenses d'éducation est étroitement liée au niveau des frais de scolarité pratiqués par les établissements d'enseignement tertiaire (voir l'indicateur C5). Dans les pays où les frais de scolarité tendent à être peu élevés, voire négligeables, comme en Autriche, en Finlande, en Islande, au Luxembourg et en Norvège, la part des dépenses au titre des établissements d'enseignement tertiaire financée par le secteur privé (y compris les versements privés subventionnés, comme les prêts d'études au titre des frais de scolarité) est inférieure à $10 \%$. Par contraste, plus de $60 \%$ des dépenses au titre des établissements d'enseignement tertiaire sont financées par des sources privées en Australie, au Chili, en Corée, aux États-Unis, au Japon et au RoyaumeUni, où les établissements demandent des frais de scolarité plus élevés aux étudiants.

En moyenne, dans les pays de l'OCDE, les dépenses des ménages représentent $74 \%$ des dépenses privées au titre des établissements d'enseignement tertiaire. Les ménages sont les principaux contributeurs privés dans la majorité des pays de l'OCDE, mais la quasi-totalité des fonds privés proviennent d'autres entités privées (essentiellement pour financer la recherche et le développement) en Finlande et en Suède (voir le graphique C3.2).

\section{Évolution des parts publique et privée des dépenses au titre des établissements d'enseignement}

Si les établissements d'enseignement, de l'enseignement primaire à l'enseignement tertiaire, restent essentiellement financés par les pouvoirs publics, ils dépendent de plus en plus du financement privé (voir le tableau C3.3). Entre 2010 et 2016, la part des dépenses privées après transferts au titre des établissements d'enseignement primaire, secondaire et tertiaire a augmenté de 3 points de pourcentage en moyenne dans les pays de l'OCDE, la part des dépenses publiques diminuant du même pourcentage environ. La part privée du financement a augmenté dans environ la moitié des pays des pays membres et partenaires de l'OCDE, et les augmentations les plus fortes ont été enregistrées en Australie et en Espagne (7 points de pourcentage). Par contraste, c'est au Chili que la part privée du financement a le plus diminué, mais la part publique a augmenté du même pourcentage (voir le graphique C3.3).

Dans de nombreux pays de l'OCDE, l'accroissement des taux de scolarisation dans l'enseignement non tertiaire (voir l'indicateur B1) résulte de la forte demande de formation, tant de la part des individus que de la société. Cet accroissement est allé de pair avec une augmentation du niveau d'investissement, surtout privé, et une évolution des parts publique et privée du financement. Entre 2010 et 2016, la part privée du financement a augmenté légèrement plus (de 3 points de pourcentage) que la part publique (de 2.6 points de pourcentage). Ces chiffres sont toutefois fortement influencés par des valeurs hors normes, comme celles de l'Espagne, de l'Estonie, du Portugal et du Royaume-Uni, où la part des dépenses privées au titre des établissements d'enseignement non tertiaire a augmenté de plus de 5 points de pourcentage entre 2010 et 2016 . Durant cette période, la part publique du financement a aussi fortement augmenté dans certains pays, surtout au Chili et au Royaume-Uni (d'environ 5 points de pourcentage).

La part publique du financement au titre des établissements d'enseignement tertiaire a augmenté dans certains pays, mais est retombée en deçà des niveaux de 2010 dans d'autres. Dans de nombreux pays, ces diminutions ont toutefois été compensées par une augmentation du même ordre du financement privé. C'est le cas par exemple en Australie, en Belgique, en Espagne, aux États-Unis et en Irlande où la part publique du financement 
a diminué de 5 points de pourcentage entre 2010 et 2016, mais où la part privée a augmenté du même pourcentage durant cette période (OCDE, 2018[1]).

Graphique C3.3. Évolution de la part relative des dépenses publiques, privées et internationales au titre des établissements d'enseignement (2010 et 2016)

Source finale de financement, du primaire au tertiaire

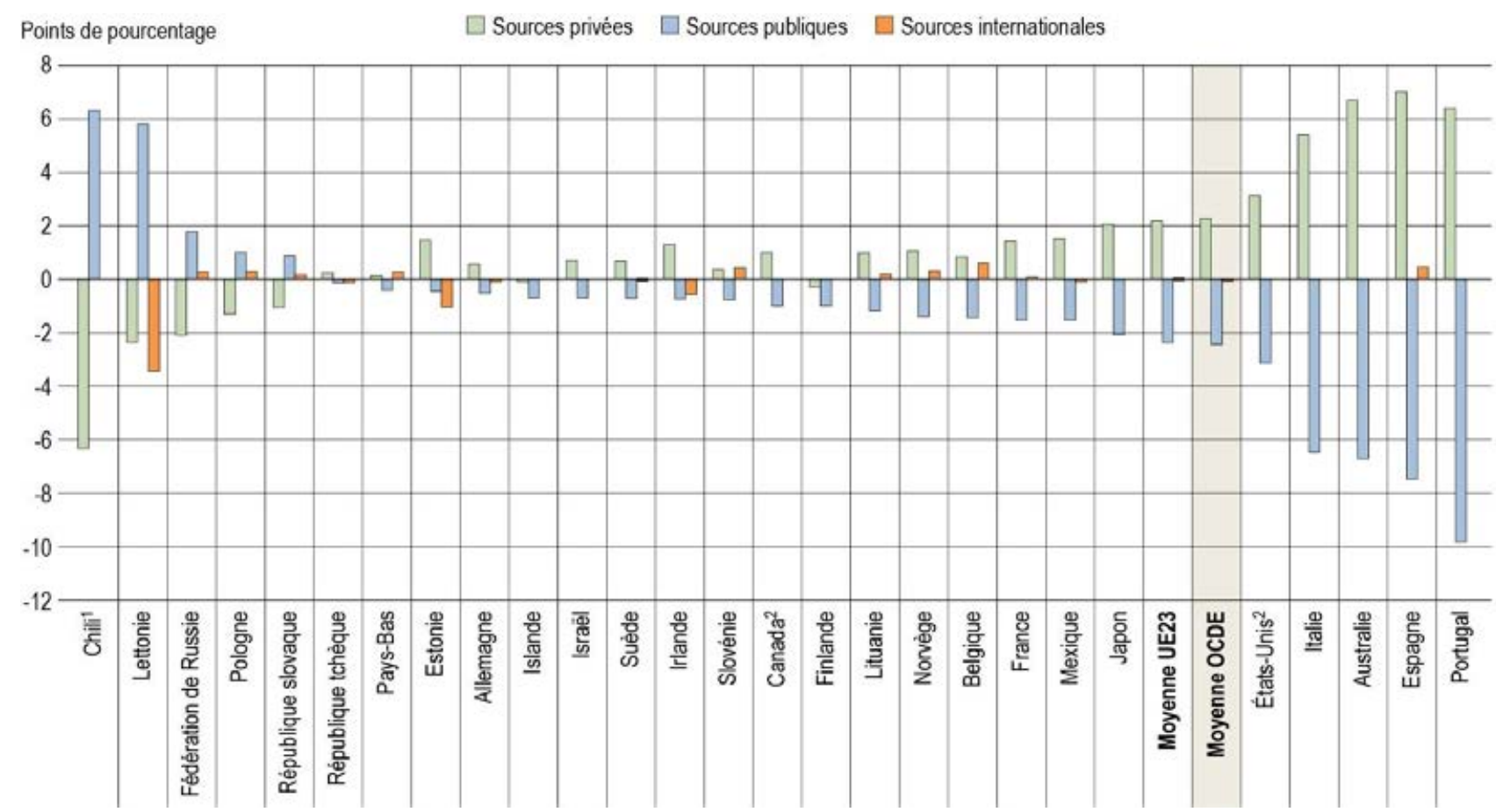

1. Année de référence : 2017.

2. Les valeurs présentées pour les États-Unis correspondent aux prêts d'études nets, et non bruts, ce qui induit donc une sous-estimation des transferts publics.

3. L'enseignement primaire inclut des programmes de l'enseignement préprimaire.

Les pays sont classés par ordre décroissant de l'évolution (en points de pourcentage) de la part des dépenses privées au titre des établissements d'enseignement.

Source : OCDE/ISU/Eurostat (2019), tableau C3.3. Consulter la section « Source » pour tout complément d'information et l'annexe 3 pour les notes (https://doi.org/10.1787/f8d7880d-en).

StatLink त्ञात https://doi.org/10.1787/888933979082

\section{Transferts publics au secteur privé}

Une grande partie de la part publique du financement va directement aux établissements d'enseignement, mais les pouvoirs publics leur transfèrent également des fonds via divers mécanismes d'affectation (au travers des frais de scolarité ou de dotations directes basées sur les effectifs scolarisés ou les crédits d'heures) ou par les subventions aux effectifs scolarisés, aux ménages ou à d'autres entités privées (au travers des bourses, allocations ou prêts d'études pour couvrir les frais de scolarité à verser aux établissements d'enseignement).

Les gouvernements utilisent les transferts pour inciter les établissements d'enseignement à organiser leurs cours et leur enseignement afin de mieux répondre aux besoins des effectifs scolarisés ainsi que pour améliorer l'accès à l'éducation et réduire les inégalités sociales. Financer les établissements d'enseignement par l'intermédiaire des effectifs scolarisés contribue à accroître la concurrence entre établissements et à améliorer l'efficience du financement de l'éducation. 
Les transferts publics au secteur privé jouent un rôle important dans le financement de l'enseignement tertiaire dans certains pays (voir le graphique C3.1). Dans les pays où l'enseignement tertiaire est en expansion et, en particulier, dans ceux où les étudiants versent des frais de scolarité, on considère souvent que les transferts publics au secteur privé servent à accroître l'accès aux études des étudiants à moins hauts revenus. Toutefois, le modèle d'affectation varie entre les pays de l'OCDE (OCDE, 2018[2]). En dépit de l'impact important des transferts publics sur la réduction du fardeau financier que représente le fait d'accéder à l'enseignement tertiaire, les aides publiques et internationales semblent couvrir une partie relativement limitée des coûts privés de l'enseignement tertiaire dans certains pays, alors que les dépenses privées sont largement compensées par les transferts publics dans d'autres pays. Cette situation complique l'accès et l'apprentissage, car des dépenses privées plus élevées pourraient dissuader des individus de faire des études tertiaires, en particulier dans les pays où les frais de scolarité sont élevés mais où les mécanismes de soutien financier sont limités.

En moyenne, dans les pays de l'OCDE, les transferts du secteur public au secteur privé représentent $9 \%$ du budget total au titre des établissements d'enseignement tertiaire. Les pays où les transferts sont les plus élevés sont aussi ceux où les frais de scolarité tendent à être les plus élevés. Les transferts passent ainsi la barre des $20 \%$ en Australie et au Royaume-Uni, où les frais de scolarité sont particulièrement élevés. Par contraste, les transferts publics sont inférieurs à $1 \%$ dans les pays où les frais de scolarité sont inexistants ou peu élevés, comme en Estonie, en Finlande, en Lituanie, au Portugal, en Slovénie, en Suède, en République tchèque et en Turquie. Dans certains pays toutefois, la part privée du financement est élevée, sans grand soutien des pouvoirs publics ; c'est le cas par exemple au Chili et en Corée (OCDE, 2018[2]).

\section{Définitions}

Les parts initiales des secteurs public, privé et international correspondent aux pourcentages des dépenses totales d'éducation des secteurs public, privé et international avant transferts. Les dépenses publiques initiales comprennent les dépenses publiques directes au titre des établissements d'enseignement ainsi que les transferts publics au secteur privé et excluent les transferts du secteur international. Les dépenses privées initiales correspondent aux frais de scolarité et autres montants versés par les ménages aux établissements d'enseignement, déduction faite de la partie de ces sommes qui est financée par des subventions publiques. Les dépenses internationales initiales comprennent les dépenses internationales directes au titre des établissements d'enseignement (par exemple un budget de recherche accordé par une société étrangère à une université publique) et les transferts internationaux aux gouvernements.

Les parts finales des secteurs public, privé et international correspondent aux pourcentages des dépenses directes des acheteurs publics, privés et internationaux de services d'éducation après transferts. Les dépenses publiques finales comprennent les achats publics directs de ressources d'éducation et les versements publics aux établissements d'enseignement. Les dépenses privées finales comprennent toutes les dépenses directes au titre des établissements d'enseignement (frais de scolarité et autres montants versés par les ménages aux établissements d'enseignement), qu'elles soient ou non partiellement financées par des subventions publiques. Elles incluent également les dépenses des entreprises privées au titre de la composante de pratique professionnelle dans les programmes « emploi-études » et les programmes de formation en milieu professionnel. Les dépenses internationales finales comprennent les montants directement versés par le secteur international aux établissements d'enseignement, par exemple des budgets de recherche et autres fonds internationaux versés directement aux établissements d'enseignement.

Par ménages, on entend les effectifs scolarisés et leur famille.

Par autres entités privées, on entend les entreprises privées et les organisations à but non lucratif, notamment les organisations confessionnelles, caritatives, patronales, syndicales, et autres organisations à but non lucratif.

Les subventions publiques incluent les transferts publics et internationaux, tels que les bourses et les aides financières aux effectifs scolarisés, ainsi que certaines subventions à d'autres entités privées. 


\section{Méthodologie}

Toutes les entités qui financent l'éducation, que ce soit en tant qu'acquéreur initial ou final, sont publiques, privées ou internationales (organismes internationaux et autres entités étrangères). Les chiffres fournis ici regroupent les dépenses publiques et internationales pour des raisons de présentation. Comme la part des dépenses internationales est relativement minime par rapport à celle des autres dépenses, inclure les dépenses internationales dans les dépenses publiques n'affecte pas l'analyse de la part des dépenses publiques.

Les dépenses au titre des biens et services d'éducation ne sont pas toutes effectuées au sein des établissements d'enseignement. Les familles peuvent par exemple acheter des fournitures et des manuels scolaires dans le commerce ou recourir aux services d'un professeur particulier en dehors des établissements d'enseignement. Dans l'enseignement tertiaire, les frais de subsistance et le manque à gagner des étudiants pendant leur formation peuvent représenter une part importante du coût de l'éducation. Toutes ces dépenses effectuées en dehors des établissements d'enseignement sont exclues de cet indicateur, même si elles font l'objet de subventions publiques. Le financement public des coûts de l'éducation en dehors des établissements d'enseignement est étudié dans les indicateurs C4 et C5.

Une partie du budget des établissements d'enseignement est consacrée aux services auxiliaires généralement proposés aux effectifs scolarisés (cantine, logement et transport). La part du coût de ces services financée par les effectifs scolarisés est également incluse dans cet indicateur.

Les dépenses au titre des établissements d'enseignement sont calculées sur la base de la comptabilité de caisse et donnent dès lors un aperçu des dépenses effectuées lors de l'année de référence. De nombreux pays mettent en place un système de prêt et de remboursement dans l'enseignement tertiaire. Les prêts publics sont pris en considération, mais les remboursements des emprunteurs privés ne le sont pas ; la contribution privée aux coûts de l'éducation peut donc être sous-estimée.

Les prêts accordés par des institutions financières privées (et non par les pouvoirs publics) sont comptabilisés dans les dépenses privées, tandis que les subventions publiques au titre des intérêts et des défauts de remboursement sont comptabilisées dans les dépenses publiques.

Dans le présent indicateur, tout transfert du secteur public au secteur privé est pris en compte à partir de la source finale de financement.

Voir le Guide de l'OCDE pour l'établissement de statistiques internationalement comparables dans le domaine de l'éducation 2018 (OCDE, 2019[3]) pour de plus amples informations. Voir les notes spécifiques aux pays à l'annexe 3 (https://doi.org/10.1787/f8d7880d-en).

\section{Source}

Les données se rapportent à l'année budgétaire 2016 (sauf mention contraire) et proviennent de la collecte de données statistiques sur l'éducation de I'UNESCO, de l'OCDE et d'Eurostat (UOE) réalisée en 2018 par l'OCDE (pour plus de précisions, voir l'annexe 3, https://doi.org/10.1787/f8d7880d-en). Les données de l'Afrique du Sud, de l'Arabie saoudite, de l'Argentine, de l'Inde, de l'Indonésie et de la République populaire de Chine proviennent de l'Institut de statistique de l'UNESCO (ISU).

Les données relatives aux dépenses de 2005, de 2010 et de 2016 proviennent d'une enquête menée en 201819. Les dépenses de 2005 à 2015 ont été ajustées en fonction des méthodes et des définitions appliquées lors du dernier exercice UOE de collecte de données en date. 


\section{Note concernant les données d'Israël}

Les données statistiques concernant Israël sont fournies par et sous la responsabilité des autorités israéliennes compétentes. L'utilisation de ces données par l'OCDE est sans préjudice du statut des hauteurs du Golan, de Jérusalem-Est et des colonies de peuplement israéliennes en Cisjordanie aux termes du droit international.

\section{Références}

OCDE (2019), Guide de l'OCDE pour l'établissement de statistiques internationalement comparables dans le domaine de l'éducation 2018: Concepts, normes, définitions et classifications, Éditions OCDE, Paris, https://dx.doi.org/10.1787/9789264305380-fr.

OCDE (2018), Base de données de Regards sur l'éducation, https://stats.oecd.org/ (consulté le 6 juillet 2018).

OCDE (2018), « Qui assume réellement les coûts de l'éducation ?: Ou comment la prise en charge des dépenses d'éducation passe du secteur public privé », Les indicateurs de l'éducation à la loupe, $\mathrm{n}^{\circ}$ 56, Éditions OCDE, Paris, https://dx.doi.org/10.1787/67d4d9e0-fr.

\section{Tableaux de l'indicateur C3}

Tableau C3.1

Tableau C3.2

Tableau C3.3
Part relative des dépenses publiques, privées et internationales au titre des établissements d'enseignement, source finale de financement (2016)

Part relative des dépenses publiques, privées et internationales au titre des établissements d'enseignement, source initiale de financement (2016)

Évolution de la part des dépenses publiques, privées et internationales au titre des établissements d'enseignement (2005, 2010 et 2016)

Date butoir pour les données: 19 juillet 2019. Les mises à jour peuvent être consultées en ligne sur: http://dx.doi.org/10.1787/eag-data-en. D'autres données désagrégées sont également disponibles dans la Base de données de Regards sur l'éducation (http://stats.oecd.org/).

StatLink: https://doi.org/10.1787/888933981096 
Tableau C3.1. Part relative des dépenses publiques, privées et internationales au titre des établissements d'enseignement, source finale de financement (2016)

Après transferts entre les secteurs public et privé, selon le niveau d'enseignement

\begin{tabular}{|c|c|c|c|c|c|c|c|c|c|c|c|c|c|c|c|}
\hline & \multicolumn{5}{|c|}{$\begin{array}{l}\text { Primaire, secondaire et post-secondaire } \\
\text { non tertiaire }\end{array}$} & \multicolumn{5}{|c|}{ Tertiaire } & \multicolumn{5}{|c|}{ Du primaire au tertiaire } \\
\hline & \multirow[b]{2}{*}{ 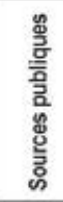 } & \multicolumn{3}{|c|}{ Sources privees } & \multirow[b]{2}{*}{ 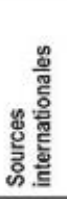 } & \multirow[b]{2}{*}{ 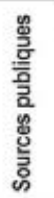 } & \multicolumn{3}{|c|}{ Sources privées } & \multirow[b]{2}{*}{ 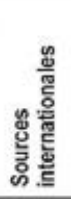 } & \multirow[b]{2}{*}{ 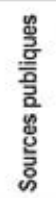 } & \multicolumn{3}{|c|}{ Sources privées } & \multirow[b]{2}{*}{ 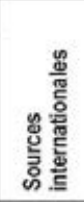 } \\
\hline & & 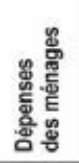 & 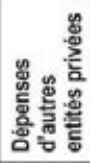 & 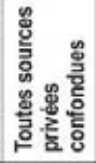 & & & 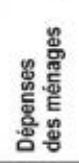 & 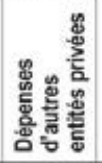 & 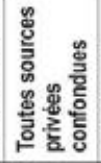 & & & 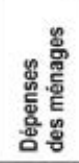 & 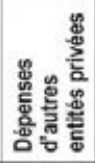 & 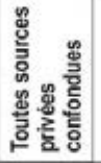 & \\
\hline & (1) & (2) & (3) & (4) & (5) & (6) & (7) & (8) & (9) & (10) & (11) & (12) & (13) & (14) & (15) \\
\hline \multicolumn{16}{|l|}{ س Pays } \\
\hline Oustralie & 81 & 17 & 2 & 19 & 0 & 40 & 47 & $13^{\mathrm{d}}$ & $60^{4}$ & $x(8,9)$ & 68 & 27 & $6^{4}$ & $32^{\mathrm{d}}$ & $x(13,14)$ \\
\hline Autriche & 95 & 3 & 1 & 5 & a & 94 & 3 & 3 & 6 & a & 95 & 3 & 2 & 5 & a \\
\hline Belgique & 96 & 3 & 0 & 3 & 1 & 82 & 8 & 7 & 15 & 3 & 93 & 5 & 2 & 6 & 1 \\
\hline Canada' & $90^{4}$ & $4^{4}$ & $6^{\circ}$ & $10^{\circ}$ & $0^{d}$ & 53 & 21 & 26 & 47 & 0 & $75^{\circ}$ & $11^{\circ}$ & $14^{4}$ & $25^{4}$ & $0^{4}$ \\
\hline Chili² $^{2}$ & 83 & 16 & 2 & 17 & a & 36 & 58 & 6 & 64 & a & 63 & 34 & 4 & 37 & a \\
\hline Colombie $^{2}$ & 78 & 22 & 0 & 22 & 0 & 49 & 51 & 0 & 51 & 0 & 70 & 30 & 0 & 30 & 0 \\
\hline République tchèque & 91 & 7 & 2 & 9 & 0 & 73 & 10 & 14 & 24 & 4 & 86 & 7 & 5 & 13 & 1 \\
\hline Danemark & $\mathrm{m}$ & $\mathrm{m}$ & $\mathrm{m}$ & $\mathrm{m}$ & $\mathrm{m}$ & m & $\mathrm{m}$ & $\mathrm{m}$ & $\mathrm{m}$ & $\mathrm{m}$ & $\mathrm{m}$ & $\mathrm{m}$ & $\mathrm{m}$ & $\mathrm{m}$ & $\mathrm{m}$ \\
\hline Estonic & 93 & 6 & 1 & 7 & 0 & 81 & 6 & 6 & 12 & 7 & 89 & 6 & 3 & 9 & 3 \\
\hline Finlande & 99 & 1 & 0 & 1 & 0 & 92 & 0 & 3 & 3 & 4 & 97 & 1 & 1 & 2 & 1 \\
\hline France & 91 & 8 & 1 & 9 & 0 & 77 & 11 & 10 & 21 & 2 & 87 & 9 & 4 & 13 & 0 \\
\hline Allemagne & 87 & $x(4)$ & $x(4)$ & 13 & 0 & 83 & $x(9)$ & $x(9)$ & 15 & 2 & 86 & $x(14)$ & $x(14)$ & 14 & 0 \\
\hline Grèce & m & $\mathrm{m}$ & $\mathrm{m}$ & $\mathrm{m}$ & $\mathrm{m}$ & m & $\mathrm{m}$ & $\mathrm{m}$ & $\mathrm{m}$ & $\mathrm{m}$ & m & m & $\mathrm{m}$ & $\mathrm{m}$ & m \\
\hline Hongrie & 89 & $x(4)$ & $x(4)$ & 11 & 0 & 63 & $x(9)$ & $x(9)$ & 35 & 2 & 82 & $x(14)$ & $x(14)$ & 17 & 0 \\
\hline Islande & 96 & 3 & 0 & 4 & 0 & 89 & 7 & 1 & 8 & 3 & 95 & 4 & 0 & 5 & 1 \\
\hline Irlande & 97 & 3 & a & 3 & a & 72 & 24 & 5 & 28 & a & 91 & 8 & 1 & 9 & a \\
\hline |sraē| & 89 & 8 & 4 & 11 & 0 & 56 & 28 & 16 & 44 & 0 & 81 & 12 & 7 & 19 & 0 \\
\hline Italie & 95 & 5 & 0 & 5 & 0 & 61 & 30 & 6 & 36 & 3 & 86 & 11 & 2 & 13 & 1 \\
\hline Japon & 92 & 6 & 2 & 8 & 0 & $31^{\circ}$ & $53^{d}$ & $17^{\circ}$ & $69^{4}$ & $0^{\circ}$ & 71 & 22 & 7 & 29 & 0 \\
\hline Corèe & 86 & 12 & 2 & 14 & 0 & 38 & 44 & 18 & 62 & 0 & 70 & 22 & 7 & 30 & 0 \\
\hline Lettonie & 97 & 2 & 0 & 2 & 1 & 65 & 30 & 1 & 31 & 4 & 89 & 9 & 0 & 10 & 1 \\
\hline Lituanie & 95 & 2 & 2 & 5 & 1 & 66 & 24 & 7 & 31 & 3 & 86 & 9 & 4 & 12 & 1 \\
\hline Luxembourg & 94 & 2 & 0 & 3 & 3 & 92 & 3 & 3 & 6 & 2 & 94 & 3 & 1 & 3 & 3 \\
\hline Mexique & 81 & 19 & 0 & 19 & 0 & 69 & 31 & 0 & 31 & 0 & 78 & 22 & 0 & 22 & 0 \\
\hline Pays-Bas & 88 & 4 & 7 & 12 & 0 & 67 & 16 & 13 & 29 & 3 & 81 & 8 & 9 & 18 & 1 \\
\hline Nouvelle-Zélande & 83 & 12 & 5 & 17 & 0 & 51 & 34 & 15 & 49 & 0 & 74 & 18 & 8 & 26 & 0 \\
\hline Norvège & 100 & 0 & 0 & 0 & 0 & 93 & 3 & 2 & 6 & 1 & 98 & 1 & 1 & 2 & 0 \\
\hline Pologne & 91 & 8 & 0 & 8 & 1 & 79 & 16 & 3 & 18 & 3 & 88 & 10 & 1 & 11 & 1 \\
\hline Portugal & 86 & 11 & 0 & 11 & 2 & $61^{d}$ & $28^{d}$ & $4^{d}$ & $32^{\mathrm{d}}$ & $7^{\circ}$ & 81 & 15 & 1 & 16 & 3 \\
\hline Rèpublique slovaque & 90 & 5 & 5 & 10 & 0 & 70 & 16 & 12 & 28 & 2 & 84 & 8 & 7 & 15 & 1 \\
\hline Slovénie & 90 & 9 & 0 & 9 & 0 & 82 & 12 & 2 & 14 & 4 & 88 & 10 & 1 & 11 & 1 \\
\hline Espagne & 86 & 13 & 1 & 14 & 0 & 66 & 29 & 4 & 33 & 2 & 80 & 17 & 2 & 19 & 0 \\
\hline Suède & 100 & a & a & a & a & 84 & 1 & 11 & 12 & 4 & 95 & 0 & 3 & 3 & 1 \\
\hline Suisse & $\mathrm{m}$ & $\mathrm{m}$ & $\mathrm{m}$ & $\mathrm{m}$ & a & $\mathrm{m}$ & $\mathrm{m}$ & $\mathrm{m}$ & $\mathrm{m}$ & $\mathrm{m}$ & $\mathrm{m}$ & $\mathrm{m}$ & $\mathrm{m}$ & $\mathrm{m}$ & $\mathrm{m}$ \\
\hline Turquie & 75 & 15 & 10 & 25 & 0 & 74 & 10 & 15 & 25 & 1 & 75 & 13 & 12 & 25 & 0 \\
\hline Royaume-Uni & 85 & 11 & 4 & 15 & 0 & 28 & 49 & 19 & 68 & 4 & 69 & 22 & 8 & 30 & 1 \\
\hline Etats-Unis² & 91 & 9 & 0 & 9 & a & 35 & 46 & 19 & 65 & a & 68 & 24 & 8 & 32 & a \\
\hline Moyenne OCDE & 90 & 8 & 2 & 10 & 0 & 66 & 23 & 9 & 32 & 2 & 83 & 13 & 4 & 17 & 1 \\
\hline Moyenne UE23 & 92 & 6 & 2 & 8 & 0 & 73 & 17 & 7 & 24 & 3 & 87 & 8 & 3 & 12 & 1 \\
\hline \& Argentine & $\mathrm{m}$ & $\mathrm{m}$ & $\mathrm{m}$ & $\mathrm{m}$ & a & $\mathrm{m}$ & $\mathrm{m}$ & $\mathrm{m}$ & $\mathrm{m}$ & a & $\mathrm{m}$ & $\mathrm{m}$ & $\mathrm{m}$ & $\mathrm{m}$ & a \\
\hline Brèsil & m & $\mathrm{m}$ & m & m & $\mathrm{m}$ & $\mathrm{m}$ & $\mathrm{m}$ & $\mathrm{m}$ & $\mathrm{m}$ & $\mathrm{m}$ & m & $\mathrm{m}$ & $\mathrm{m}$ & $\mathrm{m}$ & $\mathrm{m}$ \\
\hline छ్ Chine & $\mathrm{m}$ & $\mathrm{m}$ & $\mathrm{m}$ & $\mathrm{m}$ & m & $\mathrm{m}$ & $\mathrm{m}$ & $\mathrm{m}$ & $\mathrm{m}$ & $\mathrm{m}$ & m & m & $\mathrm{m}$ & $\mathrm{m}$ & $\mathrm{m}$ \\
\hline Costa Rica ${ }^{2}$ & $\mathrm{~m}$ & $\mathrm{~m}$ & $\mathrm{~m}$ & $\mathrm{~m}$ & $\mathrm{~m}$ & m & $\mathrm{m}$ & $\mathrm{m}$ & $\mathrm{m}$ & $\mathrm{m}$ & $\mathrm{m}$ & $\mathrm{m}$ & $\mathrm{m}$ & $\mathrm{m}$ & $\mathrm{m}$ \\
\hline Inde & $\mathrm{m}$ & m & m & $\mathrm{m}$ & m & $\mathrm{m}$ & $\mathrm{m}$ & $\mathrm{m}$ & $\mathrm{m}$ & m & m & m & $\mathrm{m}$ & $\mathrm{m}$ & $\mathrm{m}$ \\
\hline Indonésie $^{2}$ & $\mathrm{~m}$ & $\mathrm{~m}$ & $\mathrm{~m}$ & $\mathrm{~m}$ & $\mathrm{~m}$ & $\mathrm{~m}$ & $\mathrm{~m}$ & $\mathrm{~m}$ & $\mathrm{~m}$ & $\mathrm{~m}$ & $\mathrm{~m}$ & $\mathrm{~m}$ & $\mathrm{~m}$ & $\mathrm{~m}$ & $\mathrm{~m}$ \\
\hline Féderation de Russie & 95 & 4 & 1 & 5 & 0 & 64 & 23 & 12 & 35 & 1 & 84 & 11 & 5 & 16 & 0 \\
\hline Arabie saoudite & $\mathrm{m}$ & $\mathrm{m}$ & $\mathrm{m}$ & $\mathrm{m}$ & $\mathrm{m}$ & $\mathrm{m}$ & $\mathrm{m}$ & $\mathrm{m}$ & $\mathrm{m}$ & $\mathrm{m}$ & m & m & $\mathrm{m}$ & $\mathrm{m}$ & $\mathrm{m}$ \\
\hline Afrique du Sud ${ }^{2}$ & $\mathrm{~m}$ & $\mathrm{~m}$ & $\mathrm{~m}$ & $\mathrm{~m}$ & $\mathrm{~m}$ & $\mathrm{~m}$ & $\mathrm{~m}$ & $\mathrm{~m}$ & $\mathrm{~m}$ & $\mathrm{~m}$ & $\mathrm{~m}$ & $\mathrm{~m}$ & $\mathrm{~m}$ & $\mathrm{~m}$ & $\mathrm{~m}$ \\
\hline
\end{tabular}

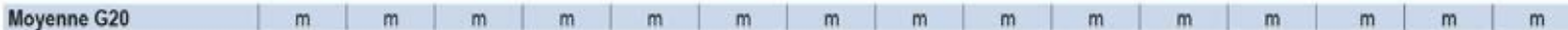

Remarque : Certains niveaux d'enseignement se confondent. Pour plus de détails, voir le code " $\mathrm{X}$ 》 dans le tableau C1.1 Les données sur les dépenses privées incluent les prêts au titre du financement des frais de scolarité et les bourses (subventions au titre des paiements aux établissements d'enseignement provenant de sources publiques). Les remboursements des prêts par les particuliers ne sont pas pris en considération, la contribution privée aux coûts de l'éducation peut donc être sousreprésentée. Les données sur les dépenses publiques présentées ici excluent les programmes non classifiés. Pour de plus amples informations, consulter les sections " Définitions » et « Méthodologie ». Les données et d'autres types de ventilations peuvent être consultés sur http://stats.oecd.org/, Base de données de Regards sur l'éducation.

1. L'enseignement primaire inclut des programmes de l'enseignement préprimaire.

2. Année de référence : 2017.

Source : OCDE//SU/Eurostat (2019). Consulter la section « Source » pour tout complément d'information et l'annexe 3 pour les notes (https://doi.org/10.1787/f8d7880d-en) Les symboles représentant les données manquantes et les abréviations figurent dans le Guide du lecteur. 
Tableau C3.2. Part relative des dépenses publiques, privées et internationales au titre des établissements d'enseignement, source initiale de financement (2016)

Avant transferts entre les secteurs public et privé, selon le niveau d'enseignement

\begin{tabular}{|c|c|c|c|c|c|c|c|c|c|}
\hline & \multicolumn{3}{|c|}{$\begin{array}{l}\text { Primaire, secondaire } \\
\text { et post-secondaire non tertiaire }\end{array}$} & \multicolumn{3}{|c|}{ Tertiaire } & \multicolumn{3}{|c|}{ Du primaire au tertiaire } \\
\hline & $\begin{array}{c}\text { Sources } \\
\text { publiques }\end{array}$ & $\begin{array}{l}\text { Sources } \\
\text { privées }\end{array}$ & $\begin{array}{c}\text { Sources } \\
\text { internationales }\end{array}$ & $\begin{array}{c}\text { Sources } \\
\text { publiques }\end{array}$ & $\begin{array}{l}\text { Sources } \\
\text { privées }\end{array}$ & $\begin{array}{c}\text { Sources } \\
\text { internationales }\end{array}$ & $\begin{array}{c}\text { Sources } \\
\text { publiques }\end{array}$ & $\begin{array}{l}\text { Sources } \\
\text { privées }\end{array}$ & $\begin{array}{c}\text { Sources } \\
\text { internationales }\end{array}$ \\
\hline & (1) & (2) & (3) & (4) & (5) & (6) & (t) & (8) & (9) \\
\hline \multicolumn{10}{|l|}{ س Pays } \\
\hline Australie & 82 & 18 & 0 & 62 & $38^{\circ}$ & $x(5)$ & 75 & $25^{4}$ & $x(8)$ \\
\hline Autriche & $\mathrm{m}$ & $\mathrm{m}$ & a & $\mathrm{m}$ & $\mathrm{m}$ & $\mathrm{m}$ & m & $\mathrm{m}$ & $\mathrm{m}$ \\
\hline Belgique & 98 & 2 & 1 & 87 & 10 & 3 & 95 & 4 & 1 \\
\hline Canada' & $\mathrm{m}$ & $\mathrm{m}$ & $\mathrm{m}$ & $\mathrm{m}$ & $\mathrm{m}$ & $\mathrm{m}$ & $\mathrm{m}$ & $\mathrm{m}$ & $\mathrm{m}$ \\
\hline Chili $^{2}$ & 83 & 17 & 0 & 46 & 54 & 0 & 67 & 33 & 0 \\
\hline Colombie $^{2}$ & $\mathrm{~m}$ & $\mathrm{~m}$ & m & $\mathrm{m}$ & $\mathrm{m}$ & m & $\mathrm{m}$ & $\mathrm{m}$ & m \\
\hline République tchèque & 91 & 9 & 0 & 73 & 24 & 4 & 86 & 13 & 1 \\
\hline Danemark & $\mathrm{m}$ & $\mathrm{m}$ & $\mathrm{m}$ & $\mathrm{m}$ & $\mathrm{m}$ & $\mathrm{m}$ & $\mathrm{m}$ & $\mathrm{m}$ & $\mathrm{m}$ \\
\hline Estonic & 86 & 7 & 7 & 78 & 12 & 10 & 83 & 9 & 8 \\
\hline Finlande & 99 & 1 & 0 & 93 & 3 & 4 & 97 & 1 & 1 \\
\hline France & 93 & 7 & 0 & 80 & 18 & 2 & 89 & 10 & 0 \\
\hline Allemagne & $\mathrm{m}$ & $\mathrm{m}$ & $\mathrm{m}$ & $\mathrm{m}$ & $\mathrm{m}$ & $\mathrm{m}$ & $\mathrm{m}$ & $\mathrm{m}$ & $\mathrm{m}$ \\
\hline Grèce & $\mathrm{m}$ & $\mathrm{m}$ & $\mathrm{m}$ & $\mathrm{m}$ & $\mathrm{m}$ & $\mathrm{m}$ & $\mathrm{m}$ & $\mathrm{m}$ & $\mathrm{m}$ \\
\hline Hongrie & $\mathrm{m}$ & $\mathrm{m}$ & $\mathrm{m}$ & $\mathrm{m}$ & $\mathrm{m}$ & $\mathrm{m}$ & $\mathrm{m}$ & $\mathrm{m}$ & $\mathrm{m}$ \\
\hline Islande & $\mathrm{m}$ & $\mathrm{m}$ & $\mathrm{m}$ & $\mathrm{m}$ & $\mathrm{m}$ & $\mathrm{m}$ & $\mathrm{m}$ & m & $\mathrm{m}$ \\
\hline Irlande & 96 & 3 & 0 & 90 & 10 & 0 & 95 & 5 & 0 \\
\hline Israél & 90 & 10 & 0 & $\mathrm{~m}$ & $\mathrm{~m}$ & $\mathrm{~m}$ & $\mathrm{~m}$ & $\mathrm{~m}$ & $\mathrm{~m}$ \\
\hline Italie & 95 & 5 & 0 & 71 & 26 & 3 & 89 & 10 & 1 \\
\hline Japon & $\mathrm{m}$ & $\mathrm{m}$ & $\mathrm{m}$ & $\mathrm{m}$ & $\mathrm{m}$ & $\mathrm{m}$ & $\mathrm{m}$ & $\mathrm{m}$ & $\mathrm{m}$ \\
\hline Corée & 87 & 13 & 0 & 54 & 46 & 0 & 76 & 24 & 0 \\
\hline Lettonie & $\mathrm{m}$ & $\mathrm{m}$ & $\mathrm{m}$ & $\mathrm{m}$ & $\mathrm{m}$ & $\mathrm{m}$ & $\mathrm{m}$ & $\mathrm{m}$ & $\mathrm{m}$ \\
\hline Lituanie & 94 & 4 & 2 & 61 & 31 & 8 & 84 & 12 & 4 \\
\hline Luxembourg & 94 & 3 & 3 & 93 & 5 & 2 & 94 & 3 & 3 \\
\hline Mexique & 83 & 17 & 0 & 71 & 29 & 0 & 80 & 20 & 0 \\
\hline Pays-Bas & $\mathrm{m}$ & $\mathrm{m}$ & $\mathrm{m}$ & $\mathrm{m}$ & $\mathrm{m}$ & $\mathrm{m}$ & $\mathrm{m}$ & $\mathrm{m}$ & $\mathrm{m}$ \\
\hline Nouvelle-Zélande & 85 & 15 & 0 & 69 & 31 & 0 & 81 & 19 & 0 \\
\hline Norvège & 100 & 0 & 0 & 96 & 3 & 1 & 99 & 1 & 0 \\
\hline Pologne & 91 & 8 & 1 & 88 & 8 & 4 & 90 & 8 & 2 \\
\hline Portugal & 86 & 11 & 2 & 60 & 32 & 8 & 80 & 16 & 4 \\
\hline Rèpublique slovaque & 92 & 7 & 1 & 67 & 26 & 7 & 85 & 12 & 2 \\
\hline Slovènie & 90 & 9 & 1 & 81 & 14 & 5 & 88 & 10 & 2 \\
\hline Espagne & 86 & 14 & 0 & 68 & 30 & 2 & 81 & 18 & 0 \\
\hline Suède & 100 & 0 & 0 & 84 & 11 & 4 & 95 & 3 & 1 \\
\hline Suisse & $\mathrm{m}$ & $\mathrm{m}$ & $\mathrm{m}$ & $\mathrm{m}$ & $\mathrm{m}$ & $\mathrm{m}$ & $\mathrm{m}$ & $\mathrm{m}$ & $\mathrm{m}$ \\
\hline Turquie & 75 & 25 & 0 & 74 & 25 & 1 & 75 & 25 & 0 \\
\hline Royaume-Uni & 86 & 14 & 0 & 57 & 39 & 4 & 78 & 21 & 1 \\
\hline Etats-Unis & $\mathrm{m}$ & $\mathrm{m}$ & m & $\mathrm{m}$ & $\mathrm{m}$ & $\mathrm{m}$ & $\mathrm{m}$ & $\mathrm{m}$ & m \\
\hline Moyenne OCDE & 90 & 9 & 1 & 74 & 23 & 3 & 85 & 13 & 2 \\
\hline Moyenne UE23 & 92 & 6 & 1 & 77 & 19 & 4 & 88 & 10 & 2 \\
\hline \& Argentine & $\mathrm{m}$ & $\mathrm{m}$ & $\mathrm{m}$ & $\mathrm{m}$ & $\mathrm{m}$ & $\mathrm{m}$ & $\mathrm{m}$ & $\mathrm{m}$ & $\mathrm{m}$ \\
\hline Brèsil & m & $\mathrm{m}$ & $\mathrm{m}$ & $\mathrm{m}$ & $\mathrm{m}$ & $\mathrm{m}$ & $\mathrm{m}$ & $\mathrm{m}$ & $\mathrm{m}$ \\
\hline ghine & $\mathrm{m}$ & $\mathrm{m}$ & $\mathrm{m}$ & $\mathrm{m}$ & $\mathrm{m}$ & $\mathrm{m}$ & $\mathrm{m}$ & $\mathrm{m}$ & $\mathrm{m}$ \\
\hline 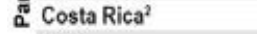 & $\mathrm{m}$ & $\mathrm{m}$ & $\mathrm{m}$ & $\mathrm{m}$ & $\mathrm{m}$ & $\mathrm{m}$ & $\mathrm{m}$ & $\mathrm{m}$ & $\mathrm{m}$ \\
\hline Inde & $\mathrm{m}$ & $\mathrm{m}$ & $\mathrm{m}$ & $\mathrm{m}$ & $\mathrm{m}$ & $\mathrm{m}$ & $\mathrm{m}$ & $\mathrm{m}$ & m \\
\hline Indonesie ${ }^{2}$ & $\mathrm{~m}$ & $\mathrm{~m}$ & $\mathrm{~m}$ & $\mathrm{~m}$ & $\mathrm{~m}$ & $\mathrm{~m}$ & $\mathrm{~m}$ & $\mathrm{~m}$ & m \\
\hline Fédération de Russie & $\mathrm{m}$ & $\mathrm{m}$ & $\mathrm{m}$ & $\mathrm{m}$ & $\mathrm{m}$ & $\mathrm{m}$ & $\mathrm{m}$ & $\mathrm{m}$ & m \\
\hline Arabie saoudite & $\mathrm{m}$ & $\mathrm{m}$ & $\mathrm{m}$ & $\mathrm{m}$ & $\mathrm{m}$ & $\mathrm{m}$ & $\mathrm{m}$ & $\mathrm{m}$ & $\mathrm{m}$ \\
\hline Afrique du Sud ${ }^{2}$ & $\mathrm{~m}$ & $\mathrm{~m}$ & m & $\mathrm{m}$ & $\mathrm{m}$ & $\mathrm{m}$ & $\mathrm{m}$ & m & m \\
\hline Moyenne G20 & $\mathrm{m}$ & $\mathrm{m}$ & $\mathrm{m}$ & $\mathrm{m}$ & $\mathrm{m}$ & $\mathrm{m}$ & $\mathrm{m}$ & $\mathrm{m}$ & $\mathrm{m}$ \\
\hline
\end{tabular}

Remarque : Pour de plus amples informations, consulter les sections « Définitions » et " Méthodologie ». Les données et d'autres types de ventilations peuvent être consultés sur http://stats.oecd.org/, Base de données de Regards sur l'éducation.

1. L'enseignement primaire inclut des programmes de l'enseignement préprimaire.

2. Année de référence : 2017.

Source : OCDE/ISU/Eurostat (2019). Consulter la section « Source » pour tout complément d'information et l'annexe 3 pour les notes (https://doi.org/10.1787/f8d7880den).

Les symboles représentant les données manquantes et les abréviations figurent dans le Guide du lecteur. 
Tableau C3.3. Évolution de la part des dépenses publiques, privées et internationales au titre des établissements d'enseignement $(2005,2010$ et 2016)

Source finale de financement

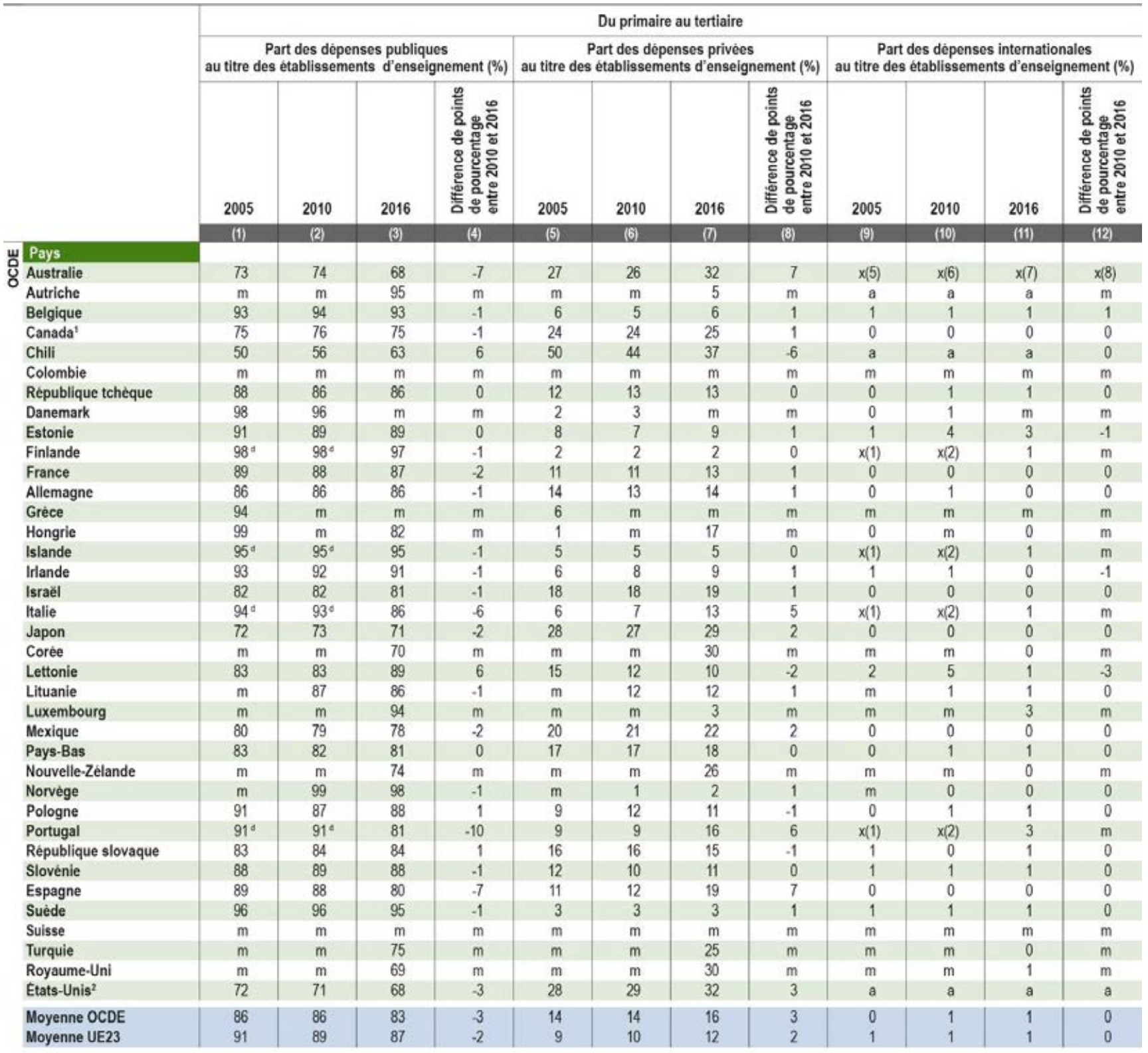

\begin{tabular}{|c|c|c|c|c|c|c|c|c|c|c|c|c|}
\hline \& Argentine & $\mathrm{m}$ & $\mathrm{m}$ & $\mathrm{m}$ & $\mathrm{m}$ & $\mathrm{m}$ & $\mathrm{m}$ & $\mathrm{m}$ & $\mathrm{m}$ & $\mathrm{m}$ & $\mathrm{m}$ & $\mathrm{m}$ & $\mathrm{m}$ \\
\hline Brèsil & $\mathrm{m}$ & $\mathrm{m}$ & $\mathrm{m}$ & $\mathrm{m}$ & $\mathrm{m}$ & $\mathrm{m}$ & $\mathrm{m}$ & $\mathrm{m}$ & $\mathrm{m}$ & $\mathrm{m}$ & $\mathrm{m}$ & m \\
\hline छू Chine & m & $\mathrm{m}$ & $\mathrm{m}$ & m & $\mathrm{m}$ & $\mathrm{m}$ & $\mathrm{m}$ & $\mathrm{m}$ & $\mathrm{m}$ & $\mathrm{m}$ & $\mathrm{m}$ & m \\
\hline Costa Rica & $\mathrm{m}$ & $\mathrm{m}$ & $\mathrm{m}$ & $\mathrm{m}$ & $\mathrm{m}$ & $\mathrm{m}$ & $\mathrm{m}$ & $\mathrm{m}$ & m & $\mathrm{m}$ & $\mathrm{m}$ & $\mathrm{m}$ \\
\hline Inde & $\mathrm{m}$ & $\mathrm{m}$ & $\mathrm{m}$ & $\mathrm{m}$ & $\mathrm{m}$ & $\mathrm{m}$ & $\mathrm{m}$ & $\mathrm{m}$ & $\mathrm{m}$ & $\mathrm{m}$ & $\mathrm{m}$ & $\mathrm{m}$ \\
\hline Indonésie & $\mathrm{m}$ & $\mathrm{m}$ & $\mathrm{m}$ & $\mathrm{m}$ & $\mathrm{m}$ & $\mathrm{m}$ & $\mathrm{m}$ & $\mathrm{m}$ & $\mathrm{m}$ & $\mathrm{m}$ & $\mathrm{m}$ & $\mathrm{m}$ \\
\hline Fèdération de Russie & 100 & 82 & 84 & 2 & 0 & 18 & 16 & -2 & 0 & 0 & 0 & 0 \\
\hline Arabie saoudite & $\mathrm{m}$ & $\mathrm{m}$ & $\mathrm{m}$ & $\mathrm{m}$ & $\mathrm{m}$ & $\mathrm{m}$ & $\mathrm{m}$ & $\mathrm{m}$ & $\mathrm{m}$ & $\mathrm{m}$ & $\mathrm{m}$ & $\mathrm{m}$ \\
\hline Afrique du Sud & $\mathrm{m}$ & $\mathrm{m}$ & m & m & $\mathrm{m}$ & $\mathrm{m}$ & $\mathrm{m}$ & $\mathrm{m}$ & $\mathrm{m}$ & m & m & m \\
\hline
\end{tabular}

Moyenne G20

m

\begin{tabular}{l|l|l}
$m$ & $m$ & $m$
\end{tabular}

\begin{tabular}{l|l}
$m$ & $m$
\end{tabular}

\begin{tabular}{l|l}
$m$ & $m$
\end{tabular}

Remarque : Les données sur les dépenses privées incluent les prêts au titre du financement des frais de scolarité et les bourses (subventions au titre des paiements aux établissements d'enseignement provenant de sources publiques). Les remboursements des prêts par les particuliers ne sont pas pris en considération, la contribution privée aux coûts de l'éducation peut donc être sous-représentée. Les données sur les dépenses publiques présentées ici excluent les programmes non classifiés. Pour de plus amples informations, consulter les sections "Définitions » et "Méthodologie ». Les données et d'autres types de ventilations peuvent être consultés sur http://stats.oecd.org/, Base de données de Regards sur l'éducation.

1. L'enseignement primaire inclut des programmes de l'enseignement préprimaire.

Source : OCDE/ISU/Eurostat (2019). Consulter la section « Source » pour tout complément d'information et l'annexe 3 pour les notes (https://doi.org/10.1787/f8d7880d-en). Les symboles représentant les données manquantes et les abréviations figurent dans le Guide du lecteur. 


\section{Indicateur C4. Quel est le montant total des dépenses publiques d'éducation?}

\section{Faits marquants}

- Le budget public total de l'éducation, de l'enseignement primaire à l'enseignement tertiaire, représente en moyenne $11 \%$ des dépenses publiques totales dans les pays de l'OCDE ; ce pourcentage varie entre $7 \%$ et $17 \%$ environ.

- Selon les chiffres de 2016, les transferts aux acteurs privés sans vocation pédagogique, de l'enseignement primaire à l'enseignement tertiaire, représentent en moyenne moins de $1 \%$ du budget public total. Ils représentent $8 \%$ du budget public total de l'éducation, les $92 \%$ restants allant aux dépenses directes au titre des établissements d'enseignement.

- Dans l'enseignement non tertiaire (enseignement primaire, secondaire et post-secondaire non tertiaire), les dépenses sont en grande partie décentralisées : les exécutifs régionaux et locaux gèrent $57 \%$ du budget final (après transferts de fonds entre les niveaux de l'exécutif). Par contraste, les dépenses au titre de l'enseignement tertiaire sont davantage centralisées : seulement $17 \%$ du budget public final provient des exécutifs régionaux et locaux.

\section{Graphique C4.1. Composition des dépenses publiques totales d'éducation en pourcentage} des dépenses publiques totales (2016)

Du primaire au tertiaire

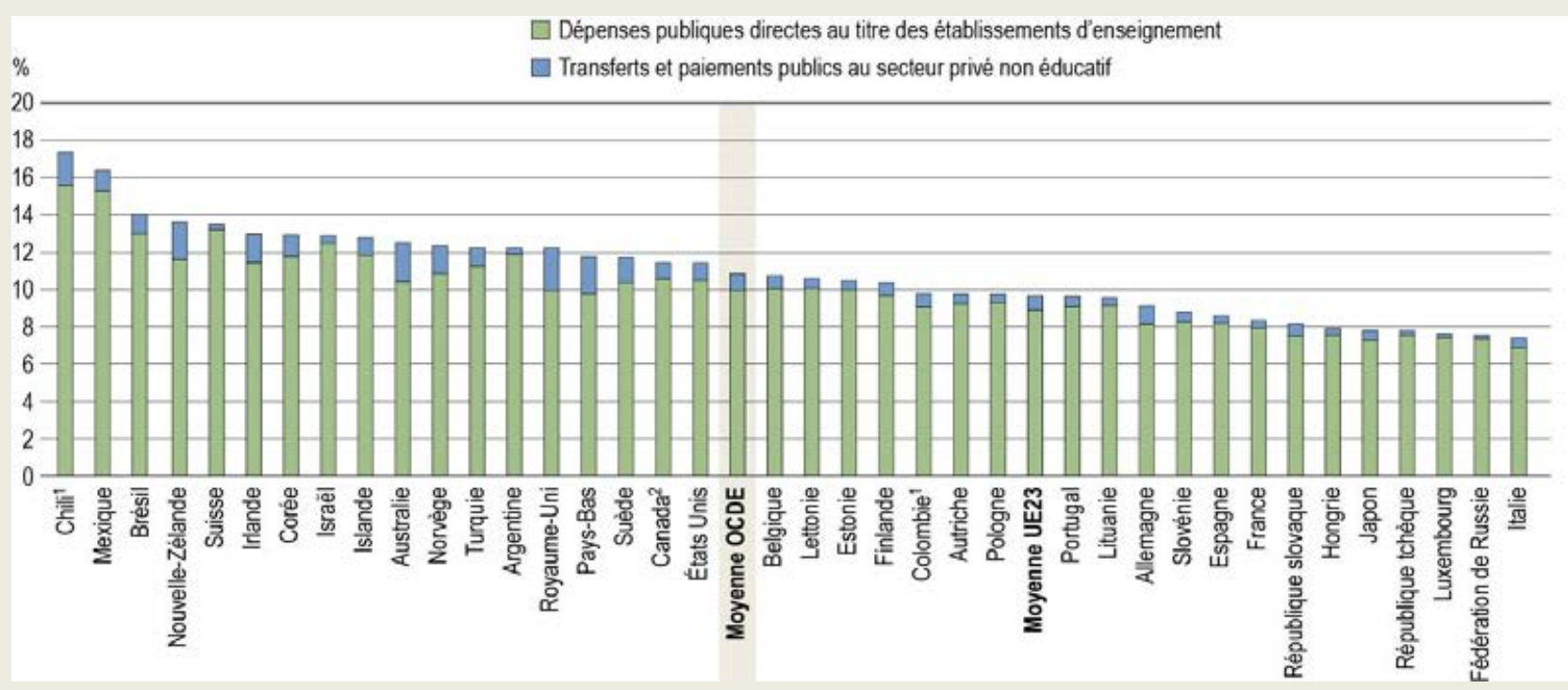

1. Année de référence : 2017.

2. L'enseignement primaire inclut des programmes de l'enseignement préprimaire.

Les pays sont classés par ordre décroissant des dépenses publiques totales d'éducation en pourcentage des dépenses publiques totales.

Source : OCDE/ISU/Eurostat (2019), tableau C4.1. Consulter la section « Source » pour tout complément d'information et l'annexe 3 pour les notes (https://doi.org/10.1787/f8d7880d-en). 


\section{Contexte}

Les décisions des pays concernant la répartition des fonds publics entre les différents domaines de l'action publique (dont l'éducation, les soins de santé, la sécurité sociale et la défense) dépendent non seulement de leurs priorités, mais également de la possibilité que ces services soient fournis par le secteur privé. Les fonds publics sont nécessaires dans les situations où le bénéfice public est élevé, mais où les coûts privés sont supérieurs aux bénéfices privés. L'éducation est un domaine dans lequel tous les gouvernements interviennent dans le financement ou l'organisation des services. Comme rien ne garantit que les marchés offriraient l'égalité d'accès aux possibilités d'apprentissage, le financement public des services d'éducation est indispensable pour faire en sorte que l'éducation ne soit pas hors de portée de certains membres de la société.

Dans certains pays, le financement public de l'éducation a diminué sous l'effet de l'austérité budgétaire due à la crise économique. Les coupes budgétaires peuvent donner lieu à une meilleure répartition des fonds publics et à des gains d'efficience et relancer ainsi l'économie, mais elles peuvent aussi altérer la qualité de l'enseignement public, en particulier quand l'investissement dans l'éducation est important pour favoriser la croissance économique.

Le présent indicateur rapporte les dépenses publiques totales d'éducation au budget public total dans les pays membres et partenaires de l'OCDE. De plus, il fournit des données sur les différentes sources (locales, régionales et centrales) des fonds publics investis dans l'éducation ainsi que sur les transferts de fonds entre ces niveaux de l'exécutif.

\section{Autres faits marquants}

- Entre 2010 et 2016, la part moyenne des dépenses publiques totales allouée à l'éducation, de l'enseignement primaire à l'enseignement tertiaire, est restée relativement stable ( $11 \%$ environ) dans les pays de l'OCDE. Durant cette période, elle a diminué dans la moitié des pays de l'OCDE.

- Les pays membres et partenaires de l'OCDE dépensent deux fois plus dans l'enseignement non tertiaire (enseignement primaire, secondaire et post-secondaire non tertiaire) que dans l'enseignement tertiaire, essentiellement à cause de la scolarisation quasi généralisée aux niveaux inférieurs d'enseignement.

- La part des dépenses publiques d'éducation, de l'enseignement primaire à l'enseignement tertiaire, a diminué entre 2005 et 2016 dans plus de $70 \%$ des pays dont les données des deux années de référence sont disponibles. Elle est restée stable dans la plupart des autres pays et a augmenté dans un certain nombre de pays, en particulier au Chili et en Israël, où elle a augmenté d'un peu plus de 2.7 points de pourcentage. 


\section{Analyse}

\section{Investissement public global dans l'éducation}

La part du budget public total allouée à l'éducation varie entre les pays. Selon les chiffres de 2016, les dépenses publiques totales d'éducation représentent, de l'enseignement primaire à l'enseignement tertiaire, $11 \%$ en moyenne du budget public total tous services confondus dans les pays de l'OCDE. Ce pourcentage varie toutefois entre les pays membres et partenaires de l'OCDE : il s'établit à $7 \%$ environ en Italie et atteint $17 \%$ environ au Chili (voir le tableau C4.1 et le graphique C4.1).

Dans l'ensemble, une part considérable du budget public est allouée aux niveaux d'enseignement inférieurs à l'enseignement tertiaire. Dans la plupart des pays, ainsi qu'en moyenne dans les pays de l'OCDE, l'enseignement non tertiaire absorbe environ trois quarts du budget public total de l'enseignement primaire à l'enseignement tertiaire (soit $8 \%$ environ du budget public total) (voir le tableau C4.1). Ce constat s'explique en grande partie par la scolarisation quasi généralisée dans l'enseignement non tertiaire (voir l'indicateur B1), la composition démographique de la population et le fait que le secteur privé joue un rôle prédominant dans la structure du financement de l'enseignement tertiaire par rapport aux niveaux inférieurs d'enseignement, en moyenne dans les pays de l'OCDE.

Le budget public total de l'enseignement tertiaire varie fortement entre les pays. Dans les pays de l'OCDE, le budget public total de l'enseignement tertiaire représente en moyenne $27 \%$ du budget public total de l'enseignement primaire à l'enseignement tertiaire. Le pourcentage varie entre $15 \%$ et $20 \%$ en Irlande, en Israël, au Japon, en Lettonie, au Luxembourg et au Portugal, et atteint $35 \%$ ou plus en Autriche, au Canada, en Estonie, aux Pays-Bas, en Norvège et en Turquie (voir le tableau C4.1).

Les dépenses publiques totales d'éducation incluent les dépenses directes au titre des établissements d'enseignement (dont celles au titre du fonctionnement des établissements publics), les transferts aux acteurs privés sans vocation pédagogique à affecter aux établissements d'enseignement ainsi que les aides publiques aux ménages au titre de frais de subsistance qui ne financent pas les établissements d'enseignement. Les transferts et versements publics aux acteurs privés sans vocation pédagogique (tels que les bourses et les prêts d'études publics, et les subventions publiques au titre de prêts d'études privés) représentent une petite partie du budget public total dans les pays membres et partenaires de l'OCDE, mais leur pourcentage varie sensiblement entre les pays (voir le graphique C4.1). Selon les chiffres de 2016, ils représentent moins de $1 \%$ du budget public total et $8 \%$ des dépenses au titre de l'éducation, les $92 \%$ restants allant aux dépenses publiques directes au titre de l'éducation. Leur pourcentage varie toutefois entre les pays : les transferts et versements publics aux acteurs privés sans vocation pédagogique représentent entre $2 \%$ et $3 \%$ du budget public total dans des pays tels que l'Australie, les Pays-Bas, la Nouvelle-Zélande et le Royaume-Uni, mais moins de $0.3 \%$ en Fédération de Russie, au Luxembourg et en République tchèque.

La taille relative des budgets publics doit être prise en considération lors de l'analyse des dépenses publiques d'éducation en pourcentage des dépenses publiques totales. Le pourcentage du PIB que représente le budget public total varie fortement entre les pays (voir le tableau C4.1 - colonnes disponibles dans la version en ligne). Selon les chiffres de 2016, les dépenses publiques totales, tous services confondus, représentent plus de $50 \%$ du PIB dans environ $13 \%$ des pays dont les données sont disponibles. Que les dépenses publiques d'éducation soient élevées en pourcentage du budget public total ne signifie pas nécessairement qu'elles sont élevées aussi en pourcentage du PIB national. En Irlande par exemple, les dépenses publiques d'éducation représentent $13 \%$ du budget public total (un pourcentage supérieur à la moyenne de l'OCDE, qui s'établit à $11 \%$ ), mais $3.6 \%$ seulement du PIB (un pourcentage relativement inférieur à la moyenne de l'OCDE, qui s'établit à $4.4 \%$ ). Ce constat s'explique par le fait que le budget public total est relativement peu élevé en pourcentage du PIB en Irlande (28\%). 


\section{Évolution des dépenses publiques d'éducation en pourcentage des dépenses publiques totales entre 2005 et 2016}

La part des dépenses publiques totales allouée à l'éducation, de l'enseignement primaire à l'enseignement tertiaire, a légèrement diminué dans les pays de l'OCDE entre 2005 et 2016 (voir le tableau C4.3), tombant sous la barre des $11 \%$ du budget public total. Durant cette période, le pourcentage du budget public total affecté aux dépenses publiques totales d'éducation, de l'enseignement primaire à l'enseignement tertiaire, a diminué en moyenne de 0.7 point de pourcentage dans les pays de l'OCDE et dans plus de $70 \%$ des pays dont les données de 2005 et de 2016 sont disponibles. Cette diminution a été particulièrement forte (égale à environ 3 points de pourcentage) en Estonie, en Islande, en Lituanie, au Mexique, en Norvège et en Slovénie. À l'inverse, le Chili a enregistré la plus forte augmentation des dépenses publiques d'éducation (de presque 3 points de pourcentage).

Les dépenses totales ont légèrement diminué entre 2005 et 2010, essentiellement sous l'effet de la crise financière de 2008. Durant cette période, les dépenses publiques totales d'éducation, de l'enseignement primaire à l'enseignement tertiaire, ont diminué en pourcentage du PIB dans deux tiers des pays de l'OCDE et de 0.6 point de pourcentage en moyenne. Des pays comme l'Irlande, l'Islande, la Lettonie et le Mexique ont été durement touchés par la crise durant cette période : la part de leur budget public total allouée aux dépenses publiques totales d'éducation, de l'enseignement primaire à l'enseignement tertiaire, a diminué d'un peu plus de 2 points de pourcentage (voir le tableau C4.3).

Graphique C4.2. Indice de variation des dépenses publiques totales d'éducation en pourcentage des dépenses publiques totales (2010 et 2016)

Du primaire au tertiaire $(2010=100$, prix constants $)$

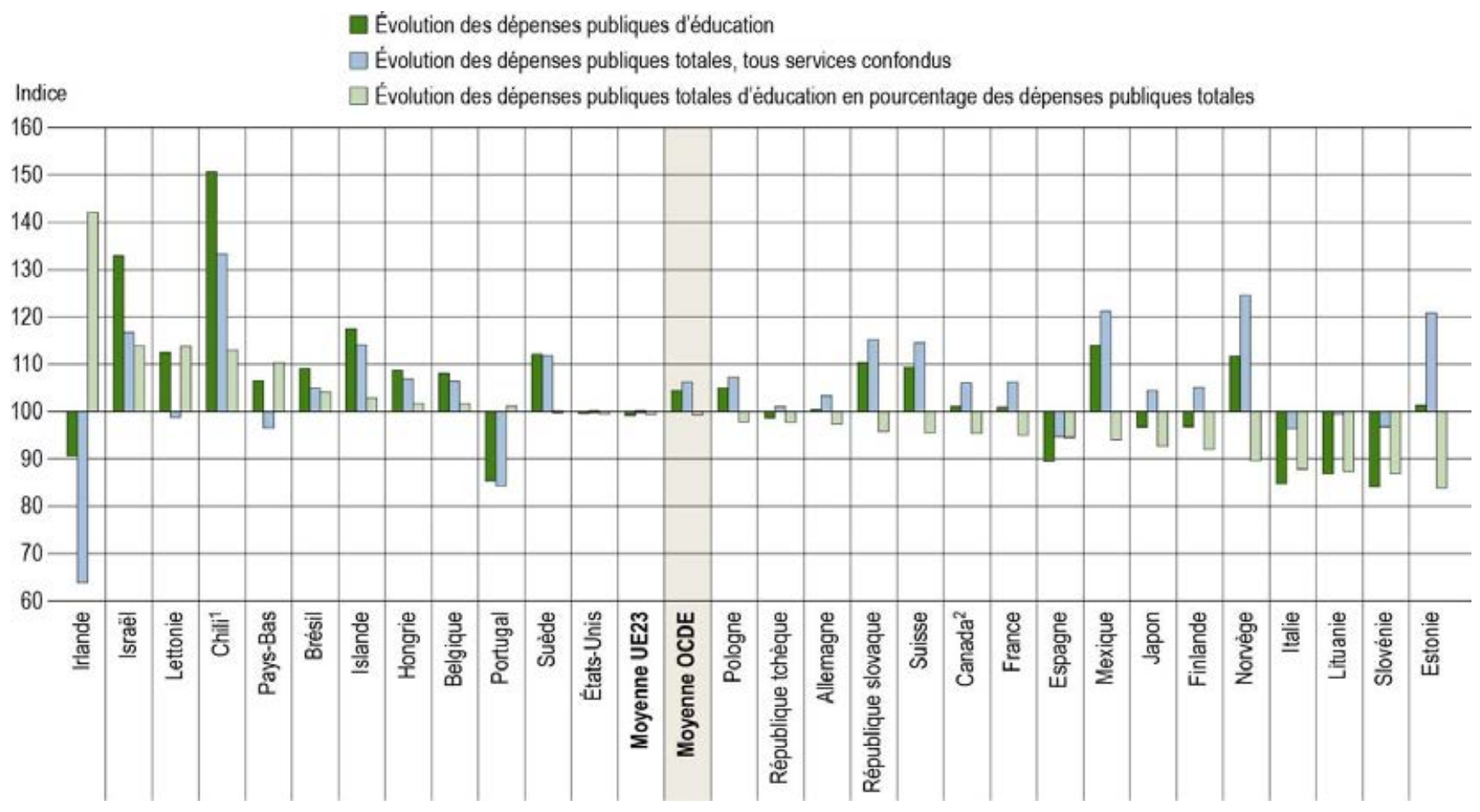

1. Année de référence : 2017.

2. L'enseignement primaire inclut des programmes de l'enseignement préprimaire.

Les pays sont classés par ordre décroissant de l'évolution des dépenses publiques totales d'éducation en pourcentage des dépenses publiques totales.

Source : OCDE/ISU/Eurostat (2019), tableau C4.3. Consulter la section « Source » pour tout complément d'information et l'annexe 3 pour les notes (https://doi.org/10.1787/f8d7880d-en). 
Une tendance différente a été enregistrée durant les années qui ont suivi la crise, entre 2010 et 2016 , probablement en partie car les pays ont été moins incités à poursuivre dans la voie de la consolidation fiscale (voir le tableau C4.3 et le graphique C4.2). Les dépenses publiques d'éducation, de l'enseignement primaire à l'enseignement tertiaire, ont augmenté dans un grand nombre de pays durant cette période et le budget public total a fortement augmenté. Durant cette période de six ans, la part des dépenses publiques d'éducation dans le budget public total a augmenté dans environ $30 \%$ des pays dont les données sont disponibles ; c'est en Irlande que la hausse la plus forte a été enregistrée (4 points de pourcentage environ). Le budget public total, tous biens et services confondus, a augmenté dans $75 \%$ des pays dont les données sont disponibles. Toutefois, dans environ la moitié des pays membres et partenaires de l'OCDE les dépenses publiques d'éducation n'ont pas augmenté autant que le budget public total. L'Estonie et la Norvège se démarquent des autres pays : le budget public total y a augmenté de 10 à 20 points de pourcentage de plus que les dépenses publiques d'éducation (voir le tableau C4.3 et le graphique C4.2).

\section{Sources du financement public de l'éducation}

La répartition des responsabilités du financement de l'éducation entre les niveaux de l'exécutif (gouvernement central et exécutifs régionaux et locaux) est un facteur important de la politique de l'éducation. En fait, des décisions importantes concernant le financement de l'éducation sont prises à deux niveaux de l'exécutif, celui qui libère les fonds et celui qui les dépense. Le niveau de l'exécutif qui libère les fonds décide du volume de ressources à affecter à l'éducation et des restrictions concernant l'affectation du budget (voir l'encadré C4.1). Le niveau de l'exécutif qui dépense le budget public de l'éducation peut décider de restrictions supplémentaires concernant l'affectation des fonds et peut même payer directement des ressources d'éducation (le salaire des enseignants, par exemple).

\section{Encadré C4.1. Comment le financement est-il alloué aux établissements d'enseignement ?}

Il existe généralement quatre approches principales pour allouer les fonds aux établissements :

1. La décision sur une base discrétionnaire est fondée sur une évaluation individuelle du montant des ressources dont chaque établissement a besoin.

2. Les coûts différentiels tiennent compte des dépenses historiques pour calculer le montant des fonds à allouer l'année suivante. Ces coûts peuvent intégrer des modifications mineures pour tenir compte de changements spécifiques (p. ex. effectifs, infrastructures scolaires ou prix des intrants).

3. Les procédures de soumission et les négociations impliquent que les établissements entrent en compétition pour obtenir un financement supplémentaire en participant à un programme particulier ou en introduisant une demande de ressources supplémentaires.

4. Le financement préétabli correspond à l'utilisation de critères objectifs et de règles universellement applicables pour établir le montant des ressources auxquelles chaque établissement a droit.

L'allocation du financement sur une base discrétionnaire ou différentielle est rarement efficace ou équitable et tend à être associée à de faibles niveaux de transparence budgétaire. Les établissements ne sont aucunement incités à accroitre leur efficience ou à réduire leurs dépenses. Les deux approches, qui sont souvent combinées, sont principalement utilisées dans des systèmes centralisés. Par contraste, l'utilisation d'un financement préétabli assure un degré élevé de transparence au système d'allocation des fonds. Traditionnellement, une formule de financement est calculée par une formule mathématique qui tient compte de quatre grands groupes de variables : 1) l'effectif d'élèves et les niveaux d'enseignement ; 2) les besoins des établissements ; 3 ) les programmes de cours ou éducatifs ; et 4) les caractéristiques propres à chaque établissement (OCDE, 2017 $[1])$. 
Graphique C4.3. Répartition des sources initiales du financement public de l'éducation et évolution de la part publique des financements après transferts entre les différents niveaux de l'exécutif (2016)

Primaire, secondaire et post-secondaire non tertiaire

Répartition des sources initiales du financement public de l'éducation, selon le niveau de gouvernement

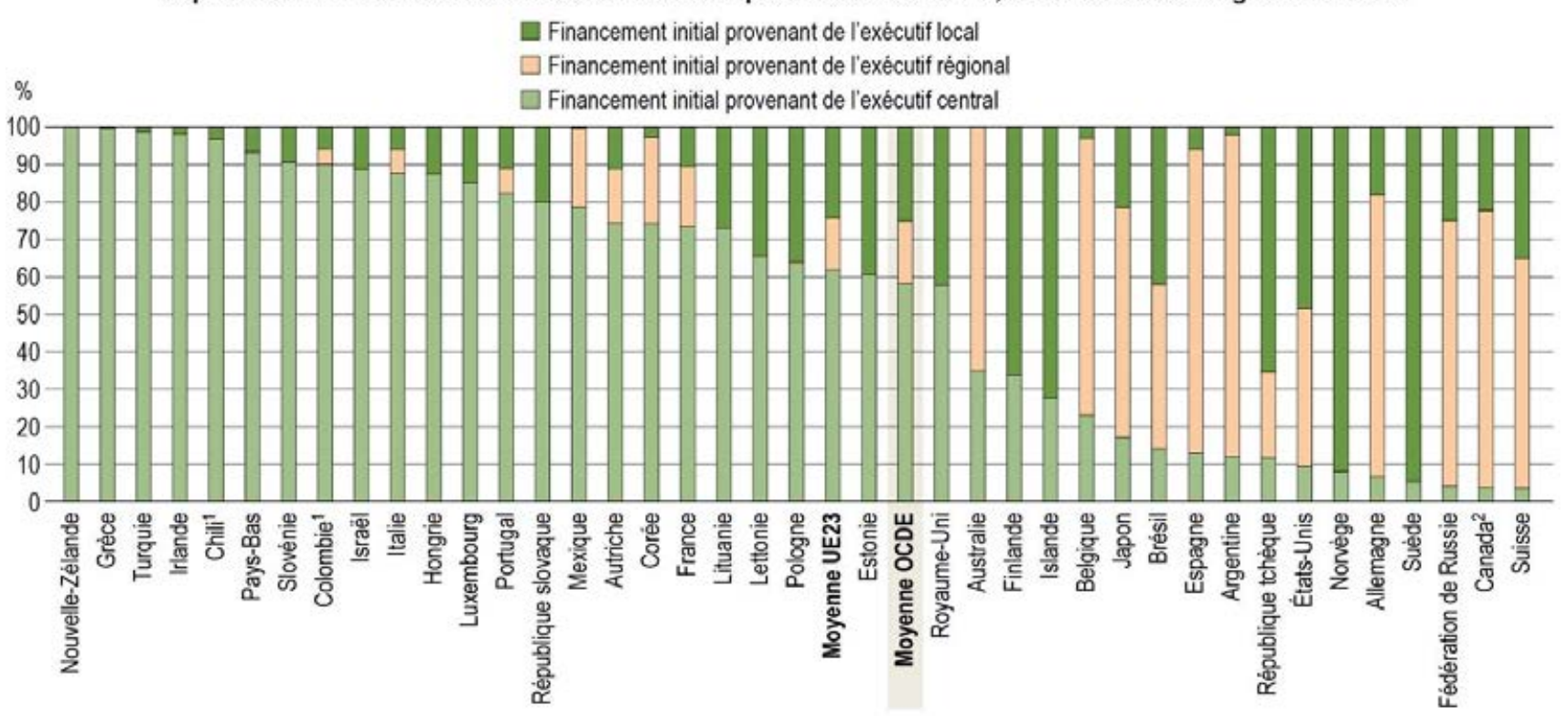

Évolution de la part publique des financements après transferts entre les différents niveaux de l'exécutif

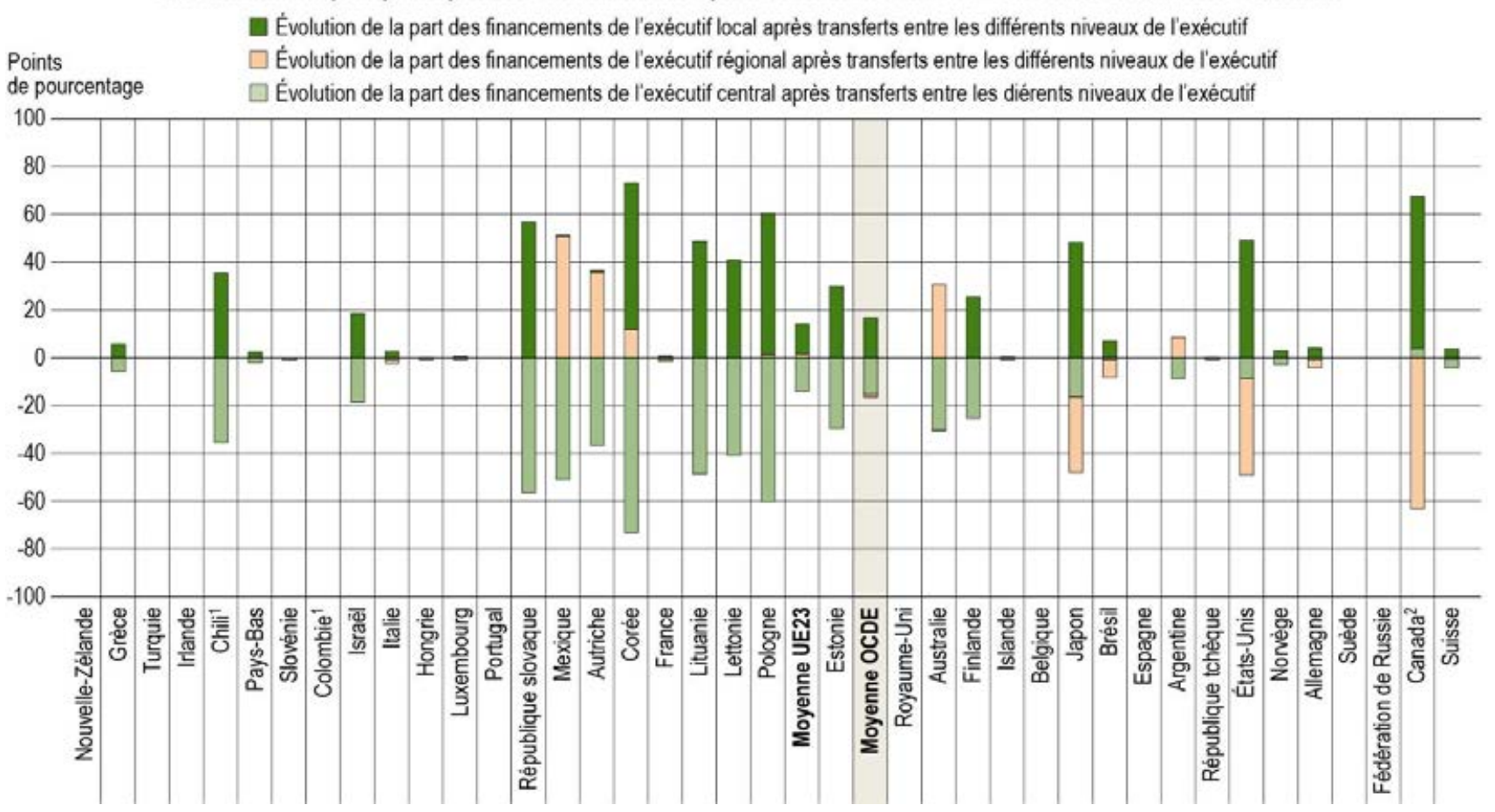

1. Année de référence : 2017.

2. L'enseignement primaire inclut des programmes de l'enseignement préprimaire.

Les pays sont classés par ordre décroissant de la part du financement initial provenant de l'exécutif central.

Source : OCDE/ISU/Eurostat (2019), tableau C4.2. Consulter la section «Source » pour tout complément d'information et l'annexe 3 pour les notes (https://doi.org/10.1787/f8d7880d-en). 
Le financement de l'éducation est centralisé dans certains pays, mais est décentralisé dans d'autres pays, avec des transferts de fonds entre les niveaux de l'exécutif. La prise de décisions peut être ralentie si le financement est totalement centralisé. Les décisions prises loin de ceux qu'elles affecteront peuvent également négliger des changements dans les besoins et les pratiques souhaitées à l'échelle locale. Si le financement de l'éducation est totalement décentralisé, des niveaux de l'exécutif peuvent allouer un volume différent de ressources à l'éducation, à cause de différences dans leurs priorités en matière d'éducation ou dans leur capacité de lever des fonds. La variabilité des normes et des ressources d'éducation peut se traduire par une inégalité dans les possibilités d'apprentissage et un manque d'attention aux exigences nationales à long terme.

Ces dernières années, de nombreux établissements d'enseignement sont devenus des organisations plus autonomes et plus décentralisées, plus responsables aussi de leurs résultats à l'égard de leurs élèves/étudiants, des parents et de l'opinion publique. Les résultats du Programme international de l'OCDE pour le suivi des acquis des élèves (PISA) suggèrent l'existence d'une corrélation entre, d'une part, l'adoption d'une combinaison intelligente d'autonomie et de responsabilisation et, d'autre part, l'amélioration des résultats des élèves (OCDE, 2017[2]).

Les niveaux de l'exécutif qui financent l'éducation varient entre les niveaux d'enseignement. Le financement public est dans l'ensemble plus centralisé dans l'enseignement tertiaire qu'aux niveaux inférieurs d'enseignement. Les chiffres de 2016 montrent qu'en moyenne, le gouvernement central finance 58 \% du budget public de l'enseignement non tertiaire avant transferts à d'autres niveaux de l'exécutif ; à titre de comparaison, il en finance $87 \%$ dans l'enseignement tertiaire (voir le tableau C4.2).

La répartition des responsabilités concernant le financement public de l'enseignement non tertiaire varie fortement entre les pays (voir le tableau C4.2 et le graphique C4.3) :

- Dans l'ensemble, le gouvernement central et les exécutifs régionaux sont les principales sources initiales et finales des fonds dans l'enseignement non tertiaire. Toutefois, le gouvernement central est la seule source initiale des fonds et le seul acquéreur final des services d'éducation en Nouvelle-Zélande. Dans des pays tels que le Chili, la Colombie, la France, la Grèce, la Hongrie, l'Irlande, Israël, l'Italie, le Luxembourg, les Pays-Bas, le Portugal, le Royaume-Uni, la Slovénie et la Turquie, le gouvernement central constitue la source de la majorité des fonds initiaux et le principal acquéreur final de biens et services d'éducation.

- En Autriche, en Corée, en Estonie, en Lettonie, en Lituanie, au Mexique, en Pologne et en République slovaque, le gouvernement central est la principale source initiale des fonds, mais les exécutifs régionaux et locaux sont les principaux acquéreurs finaux des services d'éducation dans l'enseignement non tertiaire.

- Les exécutifs régionaux financent et dépensent l'essentiel du budget de l'éducation en Allemagne, en Australie, en Belgique, en Espagne et en Suisse. Au Canada et au Japon, les exécutifs régionaux sont les principales sources des fonds initiaux, mais les exécutifs locaux sont les principaux acquéreurs des services d'éducation.

- En Finlande et en Norvège, les exécutifs locaux sont à la fois la principale source initiale des fonds et les principaux acquéreurs finaux des services d'éducation. Aux États-Unis, les exécutifs locaux et régionaux sont tous deux la principale source initiale de fonds, mais les exécutifs locaux sont les principaux acquéreurs finaux des services d'éducation.

Dans les pays de l'OCDE, le montant des transferts du gouvernement central aux exécutifs régionaux et locaux est dans l'ensemble plus élevé dans l'enseignement non tertiaire que dans l'enseignement tertiaire, signe que la décentralisation est plus importante aux niveaux inférieurs d'enseignement. En moyenne, dans les pays de l'OCDE, la part des fonds publics alloués à l'enseignement non tertiaire par le gouvernement central diminue de $58 \%$ à $43 \%$ après transferts aux autres niveaux de l'exécutif, de sorte que la part des fonds des exécutifs locaux augmente et passe de $25 \%$ à $42 \%$. La source des fonds après transferts du gouvernement central aux exécutifs régionaux et locaux varie fortement entre les pays. La différence représente plus de 50 points de pourcentage après transferts aux exécutifs régionaux et locaux en Corée, au Mexique, en Pologne et en République slovaque, tandis qu'elle représente entre 25 et 40 points de pourcentage en Australie, en Autriche, au Chili, en Estonie et en Finlande. Au Canada et aux États-Unis, où les exécutifs régionaux sont les principaux responsables des 
transferts de fonds aux établissements d'enseignement, la part des dépenses financée par les exécutifs régionaux diminue de 40 points de pourcentage ou plus après transferts aux exécutifs locaux (voir le tableau C4.2 et le graphique C4.3).

Le financement de l'éducation est toutefois bien plus centralisé dans l'enseignement tertiaire que dans l'enseignement non tertiaire. En effet, la part des fonds publics qui provient du gouvernement central est relativement élevée dans l'enseignement tertiaire, tant avant qu'après transferts aux exécutifs locaux et régionaux (voir le tableau C4.2). En moyenne, dans les pays de l'OCDE, $87 \%$ des fonds avant transferts sont gérés par le gouvernement central ; ce pourcentage change à peine si les transferts entre niveaux de l'exécutif sont pris en compte. Dans la plupart des pays membres et partenaires de l'OCDE dont les données sont disponibles, le gouvernement central finance directement plus de $60 \%$ du budget public de l'enseignement tertiaire ; dans 15 pays, le gouvernement central est la seule source des fonds initiaux et ne transfère rien aux exécutifs régionaux ou locaux. Par contraste, dans des pays tels que l'Allemagne, la Belgique, l'Espagne et la Suisse, les exécutifs régionaux financent plus de $60 \%$ du budget de l'enseignement tertiaire et leurs transferts aux exécutifs locaux sont minimes, voire nuls. Les exécutifs locaux n'interviennent guère dans le financement de l'enseignement tertiaire dans l'ensemble, sauf aux États-Unis où ils financent et dépensent plus de $10 \%$ du budget.

\section{Définitions}

Par transferts entre niveaux de l'exécutif, on entend les transferts de fonds au titre de l'éducation entre les différents niveaux de l'exécutif. II s'agit des transferts nets d'un niveau supérieur à un niveau inférieur de l'exécutif. Le financement initial renvoie au budget avant transferts entre les niveaux de l'exécutif, et le financement final, au budget après transferts.

Les dépenses publiques d'éducation incluent les dépenses au titre des établissements d'enseignement et les aides au titre des frais de subsistance des élèves/étudiants et autres dépenses privées en dehors des établissements d'enseignement, contrairement aux indicateurs C1, C2 et C3 qui portent uniquement sur les dépenses au titre des établissements d'enseignement. Elles incluent aussi les dépenses de toutes les entités publiques, dont celles du ministère de l'Éducation et d'autres ministères, des exécutifs locaux et régionaux et autres instances publiques. Le mode d'affectation du budget public de l'éducation varie selon les pays de l'OCDE. Les ressources publiques peuvent être allouées aux établissements d'enseignement soit directement, soit indirectement par l'intermédiaire des ménages ou au travers de programmes gouvernementaux. Elles peuvent aussi être limitées à l'acquisition de services d'éducation ou être destinées au financement des frais de subsistance des élèves/étudiants.

Les sources publiques de financement de l'éducation, exception faite des sources internationales, se répartissent en trois catégories : 1) le gouvernement central (national) ; 2) les exécutifs régionaux (États, provinces, Länder, etc.) ; et 3) les exécutifs locaux (municipalités, districts, communes, etc.). Les adjectifs " régional » et « local » désignent les exécutifs dont les compétences sont limitées à un territoire administratif dans un pays. Ils ne s'appliquent pas à des instances gouvernementales dont les compétences ne sont pas limitées de manière géographique, mais sont définies en termes de services, de fonctions ou de catégories d'élèves/étudiants.

Les dépenses publiques totales correspondent à la somme des dépenses en capital et des dépenses de fonctionnement non remboursables dans tous les domaines (y compris l'éducation) de tous les niveaux de l'exécutif (gouvernement central et exécutifs régionaux et locaux) et des producteurs non marchands (c'est-àdire qui fournissent des biens et services gratuitement, ou à un coût négligeable). Elles n'incluent pas les dépenses de sociétés publiques, telles que les banques, les ports et les aéroports publics. Elles incluent les dépenses publiques directes au titre des établissements d'enseignement (définies ci-dessus) ainsi que les aides publiques aux ménages (par exemple, les bourses, les prêts d'études et les aides au titre des frais de subsistance et des frais de scolarité des élèves/étudiants) et à d'autres entités privées au titre de l'éducation (par exemple, les subventions aux entreprises privées ou aux organisations syndicales au titre de la formation sous contrat d'apprentissage). 


\section{Méthodologie}

Les chiffres relatifs aux dépenses publiques totales et au PIB proviennent de la Base de données de l'OCDE sur les comptes nationaux (voir l'annexe 2).

Les dépenses publiques d'éducation des pays sont rapportées en pourcentage de leurs dépenses publiques totales. Le concept statistique de budget public total est défini selon la Classification des fonctions des administrations publiques (CFAP). La CFAP et la collecte de données de l'UNESCO, l'OCDE et Eurostat (UOE) sont assez proches, mais certains de leurs concepts statistiques diffèrent à quelques égards (Eurostat (European Commission), 2011[3]).

Les dépenses au titre du service de la dette (remboursements afférents à la dette publique) sont incluses dans les dépenses publiques totales, mais sont exclues des dépenses publiques d'éducation, car certains pays sont dans l'impossibilité de faire la distinction entre les intérêts dus pour l'éducation et les intérêts dus pour les autres services. Par voie de conséquence, les dépenses publiques d'éducation en pourcentage des dépenses publiques totales peuvent être sous-estimées dans les pays où le service de la dette représente une partie importante des dépenses publiques totales tous services confondus.

Voir le Guide de l'OCDE pour l'établissement de statistiques internationalement comparables dans le domaine de l'éducation 2018 (OCDE, 2019[4]) pour de plus amples informations. Voir les notes spécifiques aux pays à l'annexe 3 (https://doi.org/10.1787/f8d7880d-en).

\section{Source}

Les données se rapportent à l'année budgétaire 2016 (sauf mention contraire) et proviennent de la collecte de données statistiques sur l'éducation de l'UOE réalisée en 2018 par l'OCDE (pour plus de précisions, voir l'annexe 3, https://doi.org/10.1787/f8d7880d-en). Les données de l'Afrique du Sud, de l'Arabie saoudite, de l'Argentine, de l'Inde, de l'Indonésie et de la République populaire de Chine proviennent de l'Institut de statistique de I'UNESCO (ISU).

\section{Note concernant les données d'Israël}

Les données statistiques concernant Israël sont fournies par et sous la responsabilité des autorités israéliennes compétentes. L'utilisation de ces données par l'OCDE est sans préjudice du statut des hauteurs du Golan, de Jérusalem-Est et des colonies de peuplement israéliennes en Cisjordanie aux termes du droit international.

\section{Références}

Eurostat (European Commission) (2011), « Manual on sources and methods for the compilation of COFOG Statistics - EU Law and Publications », Methodologies and Working papers, Office des publications de l'Union européenne, Luxembourg, http://dx.doi.org/10.2785/16355.

OCDE (2019), Guide de l'OCDE pour l'établissement de statistiques internationalement comparables dans le domaine de l'éducation 2018: Concepts, normes, définitions et classifications, Éditions OCDE, Paris, https://dx.doi.org/10.1787/9789264305380-fr.

OCDE (2017), Résultats du PISA 2015 (Volume II): Politiques et pratiques pour des établissements performants, PISA, Éditions OCDE, Paris, https://dx.doi.org/10.1787/9789264267558-fr.

OCDE (2017), The Funding of School Education: Connecting Resources and Learning, OECD Reviews

of School Resources, Éditions OCDE, Paris, https://dx.doi.org/10.1787/9789264276147-en. 


\section{Tableaux de l'indicateur C4}

Tableau C4.1

Tableau C4.2

Tableau C4.3
Dépenses publiques totales d'éducation en pourcentage des dépenses publiques totales (2016)

Dépenses publiques totales d'éducation en pourcentage des dépenses publiques totales, selon la provenance des financements (2016)

Évolution des dépenses publiques totales d'éducation en pourcentage des dépenses publiques totales $(2005,2010$ et 2016)

Date butoir pour les données : 19 juillet 2019. Les mises à jour peuvent être consultées en ligne sur : http://dx.doi.org/10.1787/eag-data-en. D'autres données désagrégées sont également disponibles dans la Base de données de Regards sur l'éducation (http://stats.oecd.org/).

StatLink: https://doi.org/10.1787/888933981115 
Tableau C4.1. Dépenses publiques totales d'éducation en pourcentage des dépenses publiques totales (2016)

Selon le niveau d'enseignement

\begin{tabular}{|c|c|c|c|c|c|c|c|c|c|c|c|c|c|c|c|}
\hline & & \multicolumn{5}{|c|}{ Secondaire } & \multirow{3}{*}{ 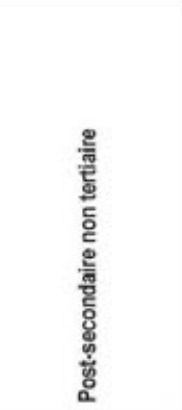 } & \multirow{3}{*}{ 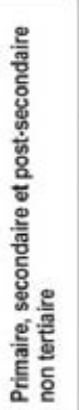 } & \multicolumn{4}{|c|}{ Tertiaire } & \multicolumn{2}{|c|}{$\begin{array}{l}\text { Du primaire } \\
\text { au tertiaire } \\
\text { (activites de } \\
\text { R.D comprises) }\end{array}$} & \multirow{3}{*}{ 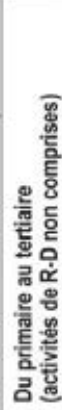 } \\
\hline & & \multirow{2}{*}{ 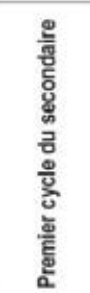 } & \multicolumn{3}{|c|}{$\begin{array}{l}\text { Deuxieme cycle } \\
\text { du secondaire }\end{array}$} & \multirow{2}{*}{ 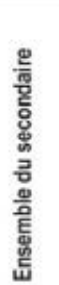 } & & & & & & & & & \\
\hline & 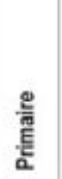 & & 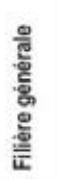 & 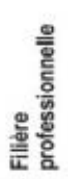 & 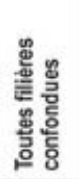 & & & & 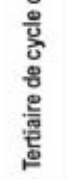 & 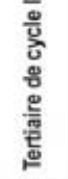 & 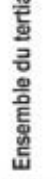 & 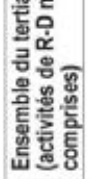 & 픙 & 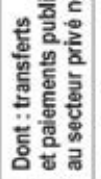 & \\
\hline & (1) & (2) & (3) & (4) & (5) & (6) & (7) & (8) & (9) & (10) & (11) & (12) & (13) & (14) & (15) \\
\hline ü Pays & & & & & & & & & & & & & & & \\
\hline Oustralie & 4.5 & 27 & 12 & 0.3 & 16 & 42 & 02 & 8.9 & 0.7 & 2.9 & 36 & 2.1 & 12.5 & 2.1 & 11.0 \\
\hline Autriche & 1.8 & 24 & 0.7 & 1.3 & 1.9 & 4.3 & 0.0 & 62 & 0.6 & 3.0 & 3.6 & 2.7 & 9.7 & 0.5 & 8.8 \\
\hline Belgique & 2.9 & 1.7 & $1.3^{6}$ & $2.1^{\circ}$ & $3.4^{\mathrm{d}}$ & $5.1^{\circ}$ & $\times(3,4,5,6)$ & 8.0 & 0.1 & 27 & 27 & 2.0 & 10.8 & 0.7 & 10.0 \\
\hline 'Canada' & $4.5^{d}$ & $\times(5)$ & $x(5)$ & $x(5)$ & 3.1 & 3.1 & $\mathrm{~m}$ & $7.6^{d}$ & 1.2 & 26 & 3.8 & 28 & $11.4^{d}$ & $0.9^{4}$ & 10.4 \\
\hline Chilf ${ }^{2}$ & 5.9 & 22 & 2.6 & 13 & 39 & 6.1 & a & 120 & 0.7 & 4.7 & 5.4 & 5.0 & 17.4 & 1.8 & 17.0 \\
\hline Colombie $^{2}$ & 3.6 & 28 & $x(5)$ & $\times(5)$ & $10^{\mathrm{d}}$ & $38^{\circ}$ & $\times(5,6)$ & 74 & $\mathrm{x}(11)$ & $\mathrm{x}(11)$ & 23 & $\mathrm{~m}$ & 9.8 & 0.7 & $\mathrm{~m}$ \\
\hline République tchèque & 1.9 & 2.1 & 0.5 & 1.5 & 20 & 4.1 & 0.0 & 60 & 0.0 & 1.8 & 1.8 & 1.0 & 7.8 & 02 & 7.0 \\
\hline Danemark & $\mathrm{m}$ & $\mathrm{m}$ & $\mathrm{m}$ & $\mathrm{m}$ & $\mathrm{m}$ & $\mathrm{m}$ & $\mathrm{m}$ & $\mathrm{m}$ & $\mathrm{m}$ & $\mathrm{m}$ & $\mathrm{m}$ & $\mathrm{m}$ & $\mathrm{m}$ & $\mathrm{m}$ & $\mathrm{m}$ \\
\hline Estonie & 3.3 & 1.6 & 1.0 & 0.8 & 1.7 & 3.3 & 0.4 & 6.9 & a & 3.6 & 3.6 & 28 & 10.5 & 0.5 & 9.7 \\
\hline Finlande & 2.5 & 2.0 & 0.7 & $1.9^{d}$ & $26^{\mathrm{d}}$ & $46^{\circ}$ & $\times(4,5,6)$ & 7.1 & a & 3.3 & 3.3 & 2.3 & 10.4 & 0.7 & 9.3 \\
\hline France & 20 & 2.1 & 13 & 0.8 & 20 & 4.2 & 0.0 & 62 & 0.5 & 1.7 & 22 & 1.5 & 84 & 0.4 & 7.7 \\
\hline Allemagne & 1.4 & 2.6 & 0.9 & 0.9 & 1.9 & 4.5 & 0.3 & 6.3 & 0.0 & 2.8 & 28 & 1.9 & 9.1 & 1.0 & 8.1 \\
\hline Gréce & 25 & 1.4 & 0.9 & 0.6 & 1.5 & 29 & 0.0 & 5.4 & a & $\mathrm{m}$ & $\mathrm{m}$ & $\mathrm{m}$ & $\mathrm{m}$ & $\mathrm{m}$ & $\mathrm{m}$ \\
\hline Hongrie & 1.6 & 1.7 & 1.5 & 0.8 & 23 & 4.0 & 0.6 & 6.3 & 0.0 & 1.6 & 1.6 & 1.3 & 7.9 & 0.3 & 7.6 \\
\hline Islande & 4.7 & 2.1 & 1.5 & 10 & 24 & 46 & 0.1 & 9.4 & 0.1 & 3.3 & 3.4 & $\mathrm{~m}$ & 12.8 & 0.9 & $\mathrm{~m}$ \\
\hline Irlande & 50 & 23 & $x(5)$ & $x(5)$ & 25 & 4.8 & 0.6 & 10.4 & $x(11)$ & $x(11)$ & 26 & 19 & 130 & 1.5 & 122 \\
\hline Israë| & 5.9 & $\times(3,4,5)$ & $2.9^{\circ}$ & $1.7^{\circ}$ & $47^{\circ}$ & 4.7 & 0.0 & 10.6 & 0.5 & 1.8 & 23 & $\mathrm{~m}$ & 12.9 & 0.4 & $\mathrm{~m}$ \\
\hline Italie & 1.9 & 1.3 & $x(5)$ & $x(5)$ & $22^{\mathrm{d}}$ & $3.5^{\circ}$ & $x(5,6)$ & 5.4 & 0.0 & 1.5 & 1.5 & 0.9 & 6.9 & 0.5 & 6.3 \\
\hline Japon & 28 & 1.7 & $\times(5)$ & $\times(5)$ & $17^{\mathrm{d}}$ & $34^{d}$ & $\times(5,6,9,10,11)$ & 62 & $02^{\circ}$ & $1.4^{4}$ & $16^{d}$ & $\mathrm{~m}$ & 7.8 & 0.5 & $\mathrm{~m}$ \\
\hline Corce & 4.5 & 26 & $x(5)$ & $\times(5)$ & 29 & 5.5 & a & 10.0 & 0.3 & 2.6 & 29 & 2.1 & 12.9 & 12 & 12.1 \\
\hline Lettonie & 4.1 & 1.9 & 1.4 & 1.0 & 24 & 4.3 & 0.2 & 8.5 & 0.4 & 1.7 & 20 & 1.6 & 10.6 & 0.5 & 10.1 \\
\hline Lituanie & 22 & 32 & 10 & 0.4 & 13 & 4.5 & 04 & 7.1 & a & 24 & 24 & 1.8 & 9.5 & 0.4 & 89 \\
\hline Luxembourg & 24 & 1.8 & 0.7 & 1.4 & 21 & 3.9 & 0.0 & 6.3 & 0.1 & 1.1 & 1.1 & 0.7 & 7.4 & 02 & 7.0 \\
\hline Mexique & 6.2 & 3.3 & 1.8 & 1.1 & 30 & 6.2 & a & 12.4 & $x(11)$ & $x(11)$ & 40 & 2.9 & 16.4 & 1.1 & 153 \\
\hline Pays-Bas & 2.7 & 27 & 0.7 & 1.7 & 24 & 5.1 & 00 & 78 & 0.0 & 4.0 & 4.0 & 2.9 & 11.8 & 20 & 10.7 \\
\hline Nouvelle-Zélande & 4.1 & 2.7 & 2.1 & 0.8 & 28 & 5.5 & 0.3 & 9.9 & 0.5 & 3.2 & 3.7 & 3.2 & 13.6 & 2.0 & 13.1 \\
\hline Norvege & 3.6 & 1.7 & 1.4 & 1.4 & 28 & 4.5 & 0.1 & 8.1 & 0.1 & 4.1 & 42 & 3.1 & 12.3 & 1.5 & 11.3 \\
\hline Pologne & 3.6 & 1.7 & 0.7 & 1.2 & 1.8 & 3.5 & 0.0 & 72 & 0.0 & 2.6 & 26 & 2.1 & 9.7 & 0.4 & 9.3 \\
\hline Portugal & 3.1 & 2.5 & $\times(5)$ & $\times(5)$ & $22^{\mathrm{a}}$ & $47^{\circ}$ & $\times(5,6,9,10,11,12)$ & 7.8 & $0.0^{6}$ & $18^{\circ}$ & $18^{\circ}$ & $14^{\circ}$ & 96 & 0.5 & 92 \\
\hline Reppublique slovaque & 21 & 21 & 06 & 1.3 & 19 & 4.0 & 0.1 & 62 & 0.0 & 20 & 20 & 1.5 & 82 & 0.6 & 76 \\
\hline Slovénie & 3.0 & 1.6 & 0.6 & 12 & 20 & 3.7 & a & 6.7 & 0.1 & 20 & 2.1 & 1.8 & 8.8 & 0.5 & 8.5 \\
\hline Espagne & 2.7 & 1.7 & 1.2 & $0.8^{\mathrm{c}}$ & $20^{\mathrm{d}}$ & $3.7^{\circ}$ & $x(4,5,6)$ & 6.4 & 0.4 & 1.8 & 22 & 1.5 & 8.6 & 0.4 & 7.9 \\
\hline Suede & 3.7 & 1.8 & 1.4 & 1.0 & 2.5 & 4.2 & 0.1 & 8.0 & 0.1 & 36 & 3.7 & 2.4 & 11.7 & 1.4 & 10.4 \\
\hline Suisse & 4.3 & 2.7 & $1.0^{\circ}$ & $1.6^{4}$ & $26^{\circ}$ & $5.3^{\circ}$ & $\times(3,4,5,6)$ & 9.6 & $x(11)$ & $x(11)$ & 3.9 & 2.2 & 13.5 & 0.3 & 11.9 \\
\hline Turquie & 23 & 23 & 1.1 & 1.8 & 29 & 5.3 & a & 7.6 & $x(11)$ & $x(11)$ & 4.6 & 3.8 & 122 & 1.0 & 11.4 \\
\hline Royaume-Uni & 4.1 & 20 & 1.6 & 13 & 29 & 4.8 & a & 9.0 & 0.3 & 30 & 33 & 2.7 & 12.2 & 23 & 117 \\
\hline Etats-Unis & 39 & 21 & $x(5)$ & $x(5)$ & 22 & 4.3 & 0.0 & 83 & $\mathrm{x}(11)$ & $x(11)$ & 3.1 & 26 & 11.4 & 0.9 & 11.0 \\
\hline $\begin{array}{l}\text { Moyenne OCDE } \\
\text { Moyenne UE23 }\end{array}$ & $\begin{array}{l}3.4 \\
2.8\end{array}$ & $\begin{array}{l}21 \\
2.0\end{array}$ & $\begin{array}{l}1.2 \\
1.0\end{array}$ & $\begin{array}{l}12 \\
1.1\end{array}$ & $\begin{array}{l}24 \\
22\end{array}$ & $\begin{array}{l}4.4 \\
4.2\end{array}$ & $\begin{array}{l}\mathrm{m} \\
\mathrm{m}\end{array}$ & $\begin{array}{l}7.9 \\
7.0\end{array}$ & $\begin{array}{l}0.3 \\
0.2\end{array}$ & $\begin{array}{l}2.6 \\
2.4\end{array}$ & $\begin{array}{l}2.9 \\
25\end{array}$ & $\begin{array}{l}2.2 \\
1.8\end{array}$ & $\begin{array}{r}10.8 \\
9.6\end{array}$ & $\begin{array}{l}0.9 \\
0.7\end{array}$ & $\begin{array}{r}10.1 \\
9.0\end{array}$ \\
\hline Argentine & 40 & 32 & $x(5)$ & a & 22 & 55 & a & 9.5 & $x(11)$ & $x(11)$ & 27 & $\mathrm{~m}$ & 122 & 03 & $\mathrm{~m}$ \\
\hline Brésil & 4.1 & 3.5 & $\begin{array}{l}x(5) \\
x(5)\end{array}$ & $\times(5)$ & $30^{\mathrm{d}}$ & $6.5^{\circ}$ & $\times(5.6)$ & 10.5 & $x(11)$ & $x(11)$ & 3.5 & $\mathrm{~m}$ & 14.0 & 12 & $\mathrm{~m}$ \\
\hline Chine & $\mathrm{m}$ & $\mathrm{m}$ & $\mathrm{m}$ & $\mathrm{m}$ & $\mathrm{m}$ & $\mathrm{m}$ & $\mathrm{m}$ & $\mathrm{m}$ & $\mathrm{m}$ & $\mathrm{m}$ & $\mathrm{m}$ & $\mathrm{m}$ & $\mathrm{m}$ & $\mathrm{m}$ & $\mathrm{m}$ \\
\hline Costa Rica ${ }^{2}$ & $\mathrm{~m}$ & $\mathrm{~m}$ & $\mathrm{~m}$ & $\mathrm{~m}$ & $\mathrm{~m}$ & m & a & $\mathrm{m}$ & $\mathrm{m}$ & $\mathrm{m}$ & $\mathrm{m}$ & $\mathrm{m}$ & $\mathrm{m}$ & $\mathrm{m}$ & $\mathrm{m}$ \\
\hline Inde & $\mathrm{m}$ & m & m & m & m & m & m & m & m & $\mathrm{m}$ & m & m & m & m & $\mathrm{m}$ \\
\hline Indonésie ${ }^{2}$ & $\mathrm{~m}$ & $\mathrm{~m}$ & $\mathrm{~m}$ & m & $\mathrm{m}$ & $\mathrm{m}$ & $a$ & m & $\mathrm{m}$ & $\mathrm{m}$ & $\mathrm{m}$ & $\mathrm{m}$ & $\mathrm{m}$ & $\mathrm{m}$ & $\mathrm{m}$ \\
\hline Federation de Russie & $x(8)$ & $x(8)$ & $x(8)$ & $x(8)$ & $x(8)$ & $x(8)$ & $x(8)$ & 5.1 & 0.4 & 1.8 & 22 & 2.1 & 7.3 & 02 & 72 \\
\hline Arabie saoudite & $\mathrm{m}$ & $\mathrm{m}$ & $\mathrm{m}$ & $\mathrm{m}$ & m & $\mathrm{m}$ & $\mathrm{m}$ & $\mathrm{m}$ & $\mathrm{m}$ & $\mathrm{m}$ & $\mathrm{m}$ & $\mathrm{m}$ & $\mathrm{m}$ & $\mathrm{m}$ & $\mathrm{m}$ \\
\hline Afrique du Sud & $\mathrm{m}$ & $\mathrm{m}$ & $\mathrm{m}$ & $\mathrm{m}$ & m & m & 0.6 & $\mathrm{~m}$ & $\mathrm{~m}$ & $\mathrm{~m}$ & 25 & $\mathrm{~m}$ & $\mathrm{~m}$ & $\mathrm{~m}$ & m \\
\hline
\end{tabular}

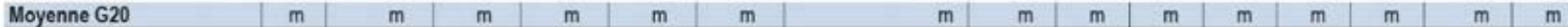

Remarque : Dans ce tableau, les dépenses publiques comprennent à la fois les transferts/paiements publics au secteur privé non éducatif qui sont affectés aux établissements d'enseignement, et ceux accordés aux ménages au titre de leurs frais de subsistance, qui ne sont donc pas affectés aux établissements d'enseignement. C'est la raison pour laquelle les chiffres présentés ici (avant transferts) sont plus élevés que ceux relatifs aux dépenses publiques au titre des établissements d'enseignement présentés dans les indicateurs C1, C2 et C3. Les données sur les dépenses publiques en pourcentage du PIB (soit les colonnes 16 à 19) peuvent être consultées en ligne (voir le StatLink ci-dessous). Consulter les sections « Définitions » et « Méthodologie » pour de plus amples informations. Les données et d'autres types de ventilations peuvent être consultés sur http://stats.oecd.org/, Base de données de Regards sur l'éducation.

1. L'enseignement primaire inclut des programmes de l'enseignement préprimaire.

2. Année de référence : 2017.

Source : OCDE/ISU/Eurostat (2019). Consulter la section « Source » pour tout complément d'information et l'annexe 3 pour les notes (https://doi.org/10.1787/f8d7880d-en). Les symboles représentant les données manquantes et les abréviations figurent dans le Guide du lecteur. 
Tableau C4.2. Dépenses publiques totales d'éducation en pourcentage des dépenses publiques totales, selon la provenance des financements (2016)

Avant et après transferts, selon le niveau d'enseignement

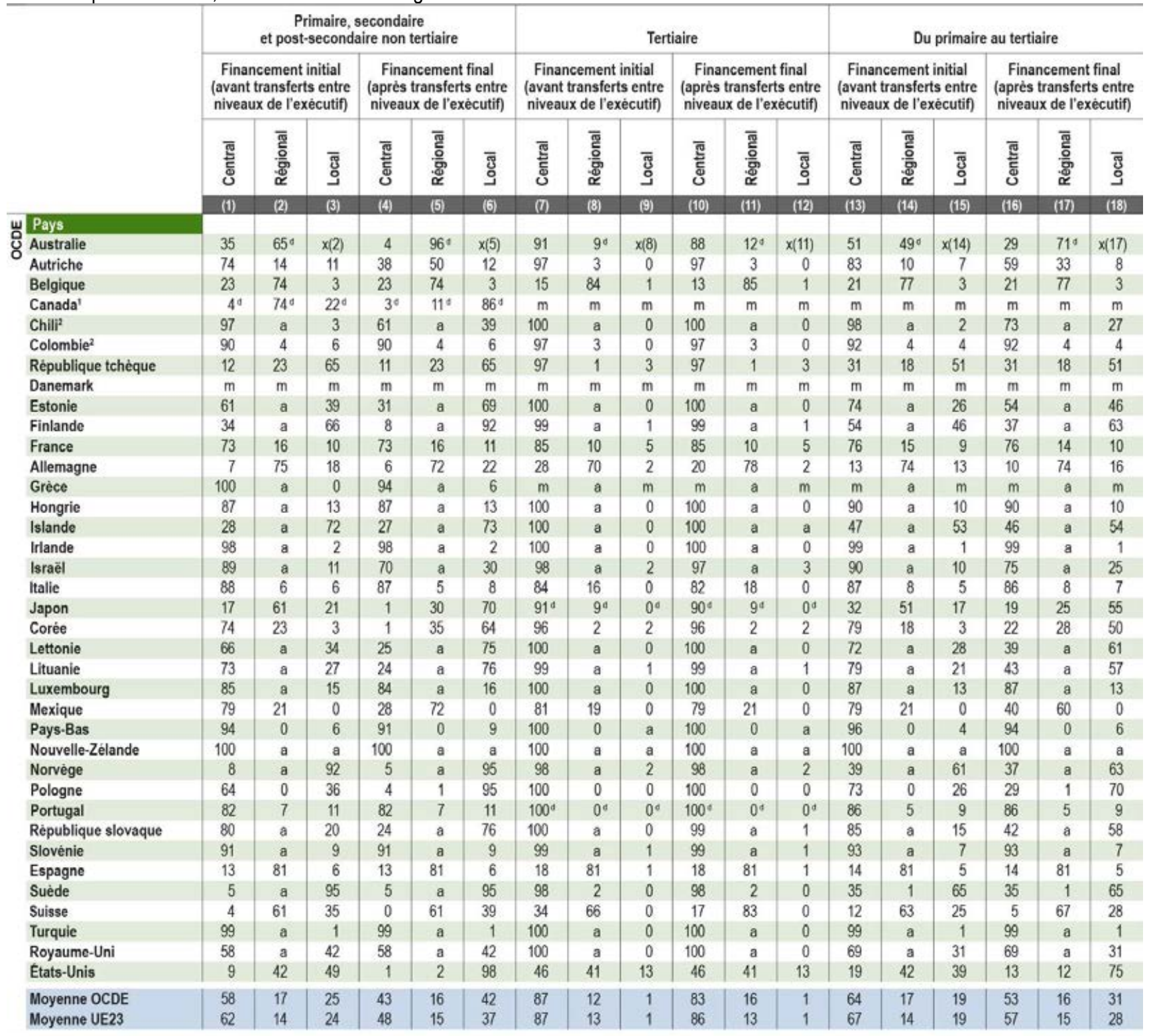

\begin{tabular}{|c|c|c|c|c|c|c|c|c|c|c|c|c|c|c|c|c|c|c|}
\hline of Argentine & 12 & 86 & 2 & 3 & 94 & 2 & 76 & 24 & 0 & 74 & $\mathrm{~m}$ & $\mathrm{~m}$ & 26 & 72 & 2 & 19 & $\mathrm{~m}$ & $\mathrm{~m}$ \\
\hline Brésil & 14 & 44 & 42 & 7 & 44 & 49 & 80 & 19 & 1 & 80 & 19 & 1 & 30 & 38 & 32 & 25 & 38 & 37 \\
\hline Chine & $\mathrm{m}$ & $\mathrm{m}$ & $\mathrm{m}$ & $\mathrm{m}$ & $\mathrm{m}$ & $\mathrm{m}$ & $\mathrm{m}$ & $\mathrm{m}$ & m & m & $\mathrm{m}$ & $\mathrm{m}$ & $\mathrm{m}$ & $\mathrm{m}$ & m & m & m & $\mathrm{m}$ \\
\hline Costa Rica $a^{2}$ & $\mathrm{~m}$ & $\mathrm{~m}$ & $\mathrm{~m}$ & $\mathrm{~m}$ & $\mathrm{~m}$ & $\mathrm{~m}$ & $\mathrm{~m}$ & $\mathrm{~m}$ & $\mathrm{~m}$ & m & $\mathrm{m}$ & $\mathrm{m}$ & $\mathrm{m}$ & $\mathrm{m}$ & $\mathrm{m}$ & $\mathrm{m}$ & $\mathrm{m}$ & $\mathrm{m}$ \\
\hline Inde & m & m & $\mathrm{m}$ & $\mathrm{m}$ & $\mathrm{m}$ & $m$ & $\mathrm{~m}$ & $\mathrm{~m}$ & m & m & m & $\mathrm{m}$ & $\mathrm{m}$ & $\mathrm{m}$ & $\mathrm{m}$ & $\mathrm{m}$ & m & $\mathrm{m}$ \\
\hline Indonésie ${ }^{2}$ & $\mathrm{~m}$ & $\mathrm{~m}$ & $\mathrm{~m}$ & $\mathrm{~m}$ & $\mathrm{~m}$ & $\mathrm{~m}$ & $\mathrm{~m}$ & $\mathrm{~m}$ & $\mathrm{~m}$ & $\mathrm{~m}$ & $\mathrm{~m}$ & $\mathrm{~m}$ & $\mathrm{~m}$ & $\mathrm{~m}$ & $\mathrm{~m}$ & $\mathrm{~m}$ & $\mathrm{~m}$ & $\mathrm{~m}$ \\
\hline Federation de Russie & 4 & 71 & 25 & 4 & 71 & 25 & 80 & 19 & 0 & 80 & 19 & 0 & 27 & 55 & 17 & 27 & 55 & 17 \\
\hline Arabie saoudite & $\mathrm{m}$ & $\mathrm{m}$ & $\mathrm{m}$ & $\mathrm{m}$ & $\mathrm{m}$ & $\mathrm{m}$ & $\mathrm{m}$ & $\mathrm{m}$ & $\mathrm{m}$ & m & $\mathrm{m}$ & $\mathrm{m}$ & $\mathrm{m}$ & $\mathrm{m}$ & $\mathrm{m}$ & $\mathrm{m}$ & m & $\mathrm{m}$ \\
\hline Afrique du Sud? & $\mathrm{m}$ & $\mathrm{m}$ & $\mathrm{m}$ & $\mathrm{m}$ & 94 & $\mathrm{~m}$ & 100 & 0 & 0 & 100 & 0 & 0 & $\mathrm{~m}$ & $\mathrm{~m}$ & $\mathrm{~m}$ & $\mathrm{~m}$ & 78 & $\mathrm{~m}$ \\
\hline
\end{tabular}

Moyenne G20

Remarque : Certains niveaux d'enseignement se confondent. Pour plus de détails, voir le code " $x$ » dans le tableau $C 4.1$ Consulter les sections « Définitions $n$ et « Méthodologie » pour de plus amples informations. Les données et d'autres types de ventilations peuvent être consultés sur http://stats.oecd.org/, Base de données de Regards sur l'éducation.

1. L'enseignement primaire inclut des programmes de l'enseignement préprimaire.

2. Année de référence : 2017.

Source : OCDE/ISU/Eurostat (2019). Consulter la section « Source » pour tout complément d'information et l'annexe 3 pour les notes (https://doi.org/10.1787/f8d7880den).

Les symboles représentant les données manquantes et les abréviations figurent dans le Guide du lecteur. 
Tableau C4.3. Évolution des dépenses publiques totales d'éducation en pourcentage des dépenses publiques totales (2005, 2010 et 2016 ) Sources initiales de financement, selon le niveau d'éducation, par année

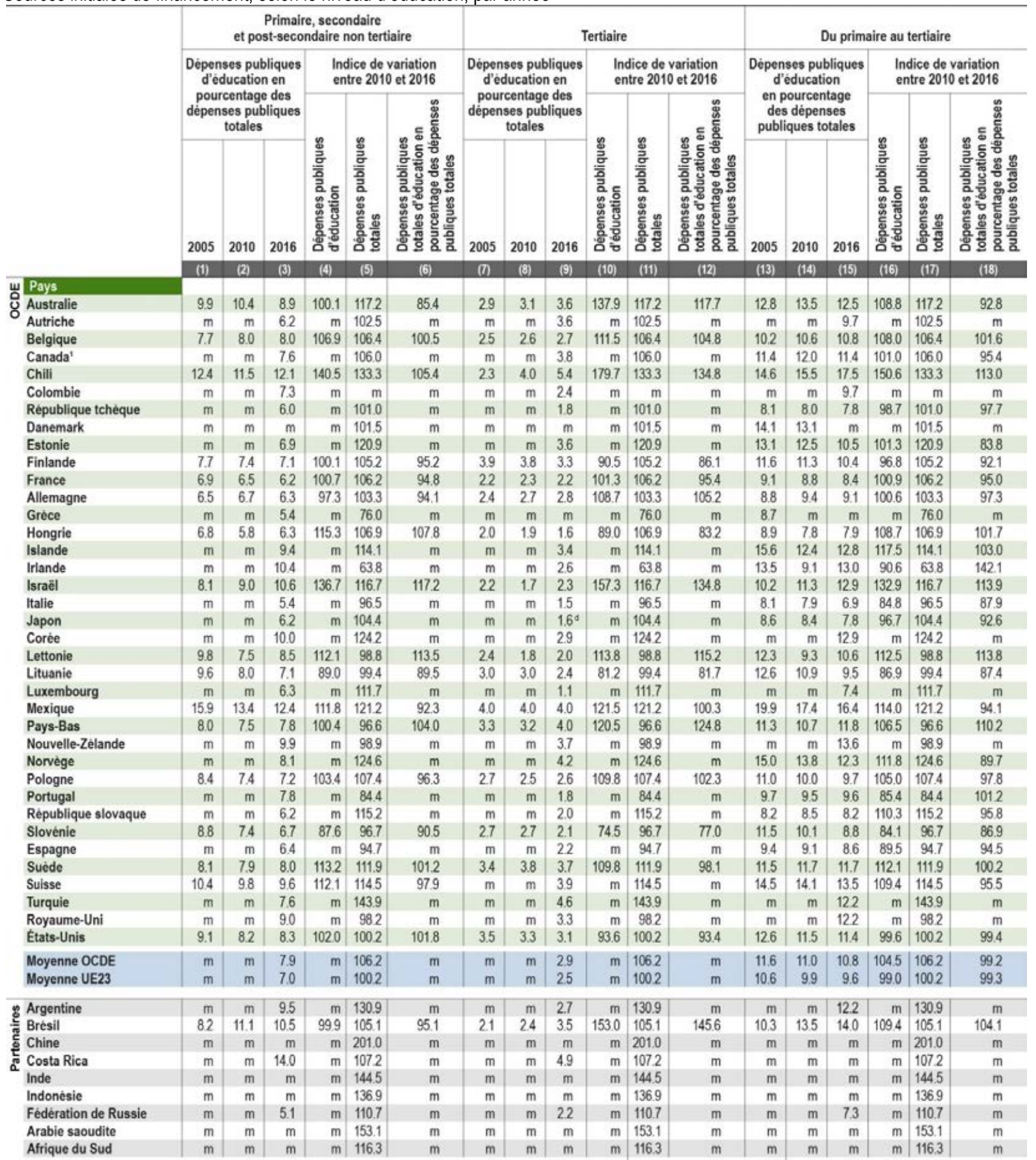

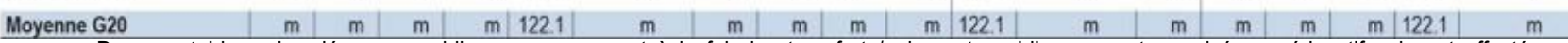

Remarque : Dans ce tableau, les dépenses publiques comprennent à la fois les transferts/paiements publics au secteur privé non éducatif qui sont affectés aux établissements d'enseignement, et ceux accordés aux ménages au titre de leurs frais de subsistance, qui ne sont donc pas affectés aux établissements d'enseignement. C'est la raison pour laquelle les chiffres présentés ici (avant transferts) sont plus élevés que ceux relatifs aux dépenses publiques au titre des établissements d'enseignement présentés dans les indicateurs C1, C2 et C3. Consulter les sections « Définitions » et « Méthodologie » pour de plus amples informations. Les données et d'autres types de ventilations peuvent être consultés sur http://stats.oecd.org/, Base de données de Regards sur l'éducation.

1. L'enseignement primaire inclut des programmes de l'enseignement préprimaire.

Source : OCDE//SU/Eurostat (2019). Consulter la section « Source » pour tout complément d'information et l'annexe 3 pour les notes (https://doi.org/10.1787//88d7880d-en) Les symboles représentant les données manquantes et les abréviations figurent dans le Guide du lecteur. 



\section{Indicateur C5. Combien les étudiants paient-ils et quelles aides publiques reçoivent-ils dans l'enseignement tertiaire?}

\section{Faits marquants}

- Les frais de scolarité demandés par les établissements d'enseignement varient fortement entre les pays. Dans un tiers environ des pays, les frais de scolarité à charge des ressortissants nationaux en licence (ou cursus équivalent) sont nuls dans les établissements publics. Dans un autre tiers environ des pays, ils sont peu élevés ou modérés (inférieurs à 2600 USD par an). Dans les pays restants, les frais annuels de scolarité sont élevés, de 3000 USD à plus de 9000 USD.

- Les frais de scolarité annuels à acquitter varient non seulement entre les pays, mais également entre les niveaux d'enseignement au sein même des pays. En licence (ou cursus équivalent), les pays où les frais de scolarité sont les plus élevés tendent aussi à compter parmi ceux où les frais de scolarité varient largement. Par contraste, dans les pays où les frais de scolarité sont les moins élevés, ceux-ci varient peu - et la différence entre les frais de scolarité maximum et minimum atteint au plus 200 USD par an.

- Les mécanismes financiers d'aide aux étudiants en formation tertiaire, tels que les allocations, les bourses et les prêts d'études, sont en général plus développés dans les pays où les frais de scolarité sont soit très élevés, soit nuls.

\section{Contexte}

Les pays membres et partenaires de l'OCDE ont choisi des approches différentes pour apporter un soutien financier aux étudiants en formation dans l'enseignement tertiaire et répartir le coût de l'enseignement tertiaire entre les pouvoirs publics, les étudiants et leur famille et d'autres entités privées.

Les frais de scolarité comblent l'écart entre les dépenses des établissements d'enseignement tertiaire et les dotations qu'ils reçoivent de sources autres que les étudiants et leur famille. De nombreux facteurs influent sur leurs coûts : le salaire des enseignants et des chercheurs ; l'essor de l'enseignement en ligne et l'augmentation de l'offre de services autres que les services d'enseignement; l'évolution de la demande de formations tertiaires; les investissements en faveur de l'internationalisation; et le volume et la nature des recherches menées par le corps enseignant. Les établissements d'enseignement tertiaire financent en partie leurs coûts par leurs ressources internes (fondations) et par des fonds de sources privées autres que les étudiants et leur famille (voir l'indicateur C3). Le reste des coûts est couvert par les frais de scolarité versés par les étudiants et par les fonds reçus des pouvoirs publics.

Les aides publiques aux étudiants et à leur famille peuvent être utilisées pour encourager les jeunes à faire des études tout en finançant indirectement les établissements d'enseignement tertiaire. Le financement des établissements d'enseignement par l'intermédiaire des étudiants peut aussi avoir pour effet d'intensifier la concurrence entre ces établissements et de les amener à être plus attentifs aux besoins des étudiants. Le soutien aux étudiants revêt de multiples formes : aides octroyées selon des critères de ressources, allocations familiales versées à tous les étudiants, allégements fiscaux accordés aux étudiants ou à leurs parents ou autres transferts aux ménages. Les gouvernements s'emploient à trouver le juste équilibre entre ces différentes subventions, en particulier en temps de crise financière. Compte tenu du budget disponible, les aides publiques accordées sans conditions particulières, comme les allègements fiscaux, sont moins susceptibles d'aider les jeunes de condition modeste à poursuivre des études que les aides octroyées selon des critères de ressources financières, car elles ne ciblent pas spécifiquement les individus à bas revenus. Elles peuvent toutefois contribuer à atténuer les disparités financières entre les ménages avec ou sans enfants scolarisés.

\section{Autres faits marquants}

- Les frais de scolarité sont rarement à la hauteur des débouchés sur le marché du travail. Dans la plupart des pays, les frais de scolarité sont du même ordre quel que soit le niveau d'enseignement, et ce, même si l'avantage salarial d'un master ou d'un doctorat est supérieur à celui d'une licence. Dans plus de la moitié des pays de l'OCDE, les frais de scolarité sont similaires quel que soit le niveau d'enseignement dans les établissements publics. 
- Dans un tiers environ des pays de l'OCDE dont les données sont disponibles, les frais de scolarité des ressortissants étrangers sont plus élevés que ceux des ressortissants nationaux dans les établissements publics. C'est en Australie, au Canada et en Suède que la différence est la plus importante. Dans ces trois pays, les ressortissants étrangers versent en moyenne plus de 13900 USD de plus par an que les ressortissants nationaux dans les établissements publics.

- Les pouvoirs publics subventionnent les frais de scolarité ou de subsistance des étudiants selon différentes combinaisons d'allocations, de bourses et de prêts d'études. Dans la plupart des pays où les frais de scolarité sont nuls en licence, les étudiants tendent à bénéficier à la fois de prêts d'études, de bourses et d'allocations. Dans les pays où les frais de scolarité sont peu élevés ou modérés (inférieurs à 2600 USD par an), moins de la moitié des étudiants reçoivent un soutien financier, octroyé le plus souvent sous la forme de bourses ou d'allocations uniquement. La situation est moins uniforme dans les pays où les frais de scolarité sont élevés, mais il apparaît que dans l'ensemble, les étudiants tendent à compter dans une certaine mesure sur les prêts d'études remboursables en fonction des ressources financières.

Graphique C5.1. Frais de scolarité applicables aux ressortissants nationaux dans I'enseignement tertiaire dans les établissements publics, selon le niveau d'enseignement (2017/18) Frais de scolarité annuels moyens (ou les plus courants) applicables aux ressortissants nationaux scolarisés à temps plein, en équivalents USD convertis sur la base des PPA pour le PIB

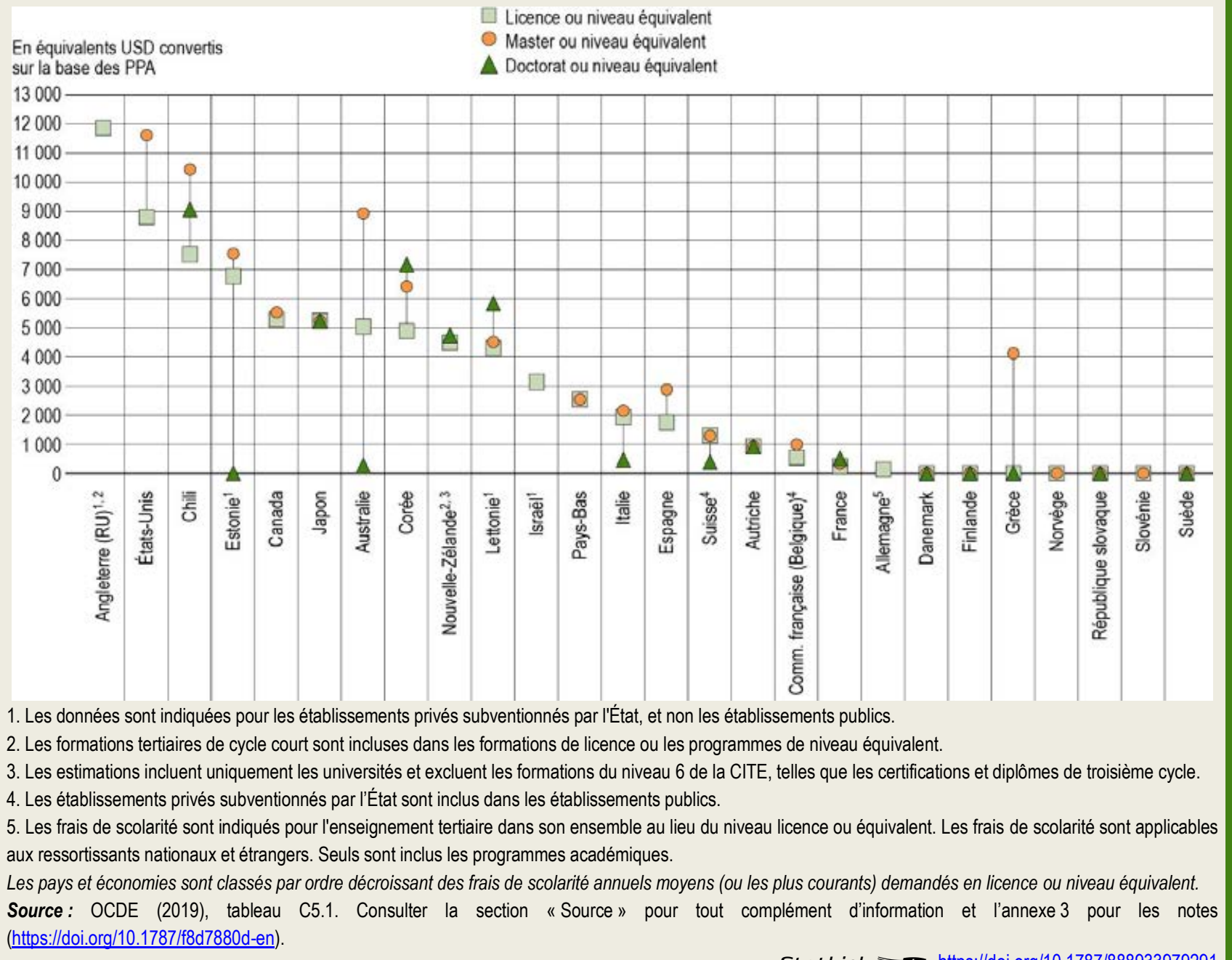




\section{Analyse}

\section{Différenciation des frais de scolarité entre les niveaux de l'enseignement tertiaire}

Les études tertiaires impliquent des frais de scolarité et de subsistance pour les étudiants et leur famille, qui peuvent toutefois recevoir des aides financières qui leur permettent de se lancer dans l'aventure. Les frais de scolarité varient sensiblement entre les pays. C'est vrai en licence par exemple, le niveau de l'enseignement tertiaire le plus courant des nouveaux inscrits dans les pays de l'OCDE (voir l'indicateur B4). Les frais de scolarité dans les établissements publics sont nuls dans un tiers environ des pays - notamment dans les pays nordiques (le Danemark, la Finlande, la Norvège et la Suède) ainsi que dans d'autres pays tels que la Grèce, la République slovaque et la Slovénie. Dans un autre tiers environ des pays (en grande partie européens), les frais de scolarité annuels sont peu élevés ou modérés, inférieurs à 2600 USD en moyenne par étudiant. Dans les autres pays dont les données sont disponibles (I'Angleterre [Royaume-Uni], l'Australie, le Canada, le Chili, la Corée, les ÉtatsUnis, Israël, le Japon, la Lettonie et la Nouvelle-Zélande), les frais annuels de scolarité vont de 3000 USD à plus de 9000 USD. Ils sont supérieurs à 10000 USD en Angleterre (Royaume-Uni), où la majorité des étudiants fréquentent un établissement privé subventionné par l'État. Enfin, l'Estonie fait figure d'exception : les frais de scolarité en licence sont nuls dans les établissements publics, mais atteignent 6700 USD dans les établissements privés subventionnés par l'État (qui accueillent $65 \%$ de l'effectif d'étudiants en formation à ce niveau d'enseignement) (voir le graphique C5.1).

Les niveaux d'enseignement supérieurs à la licence sont associés à de meilleurs débouchés sur le marché du travail et à de meilleures perspectives financières (voir l'indicateur A4). Si les frais de scolarité étaient à la hauteur des débouchés sur le marché du travail, ils auraient tendance à augmenter avec le niveau d'enseignement. Toutefois, dans la majorité des pays de l'OCDE, les frais de scolarité à acquitter par les ressortissants nationaux scolarisés à temps plein sont du même ordre en master et en doctorat qu'en licence dans les établissements publics (voir le graphique C5.1). Les frais supplémentaires à charge des étudiants en master et en doctorat se limitent au manque à gagner durant les années supplémentaires de formation et à leur entrée plus tardive sur le marché du travail. Les frais de scolarité sont par exemple nuls en master et en doctorat dans tous les pays où ils sont nuls en licence (sauf en Grèce, dans un certain nombre de masters). De même, les frais de scolarité ne varient guère entre les niveaux de l'enseignement tertiaire dans plusieurs pays où les frais de scolarité sont peu élevés, modérés ou élevés (comme l'Autriche, le Canada, la France, le Japon, la Nouvelle-Zélande et les Pays-Bas).

Par contraste, dans certains pays, les frais de scolarité moyens sont davantage à la hauteur des débouchés sur le marché de travail, puisqu'ils sont plus élevés en master qu'en licence. C'est le cas par exemple au Chili, en Corée et aux États-Unis, où les frais de scolarité moyens sont environ $30 \%$ plus élevés en master qu'en licence dans les établissements publics. En Australie, en Communauté française de Belgique et en Espagne, ils sont plus de $50 \%$ plus élevés (voir le graphique C5.1).

Dans quelques pays, les frais de scolarité sont moins élevés en doctorat qu'en licence et en master. C'est le cas en Australie, en Estonie (dans les établissements privés subventionnés par l'État), en Italie et en Suisse (dans les établissements publics). En Australie, les frais de scolarité annuels moyens dans les établissements publics sont par exemple 20 fois moins élevés en doctorat (260 USD) qu'en licence (5 000 USD). Par contraste, les établissements publics facturent des frais de scolarité plus élevés en doctorat qu'en licence et en master au Chili et en Corée. C'est le cas également en Lettonie dans les établissements privés subventionnés par l'État (voir le graphique C5.1).

\section{Variation infranationale des frais de scolarité en licence}

Les frais de scolarité varient non seulement entre les pays et les niveaux d'enseignement, mais également au sein même des pays au même niveau d'enseignement. En licence (ou formation équivalente), les pays où les frais de scolarité sont les plus élevés tendent à compter parmi ceux où les frais de scolarité varient davantage. 
Au Canada par exemple, les frais de scolarité annuels varient entre 2250 USD et 7000 USD et sont de l'ordre de 5300 USD en moyenne dans les établissements publics. De même, au Chili, ils varient entre 5450 USD et 10400 USD et atteignent 7500 USD en moyenne. Aux États-Unis, ils varient entre 6700 USD et 10750 USD et atteignent 8800 USD en moyenne (voir le graphique C5.2).

Graphique C5.2. Frais de scolarité annuels minimum, maximum et moyens (ou les plus courants) applicables aux ressortissants nationaux par les établissements publics en licence ou niveau équivalent (2017/18)

Frais de scolarité annuels applicables aux ressortissants nationaux scolarisés à temps plein, en équivalents USD convertis sur la base des PPA pour le PIB

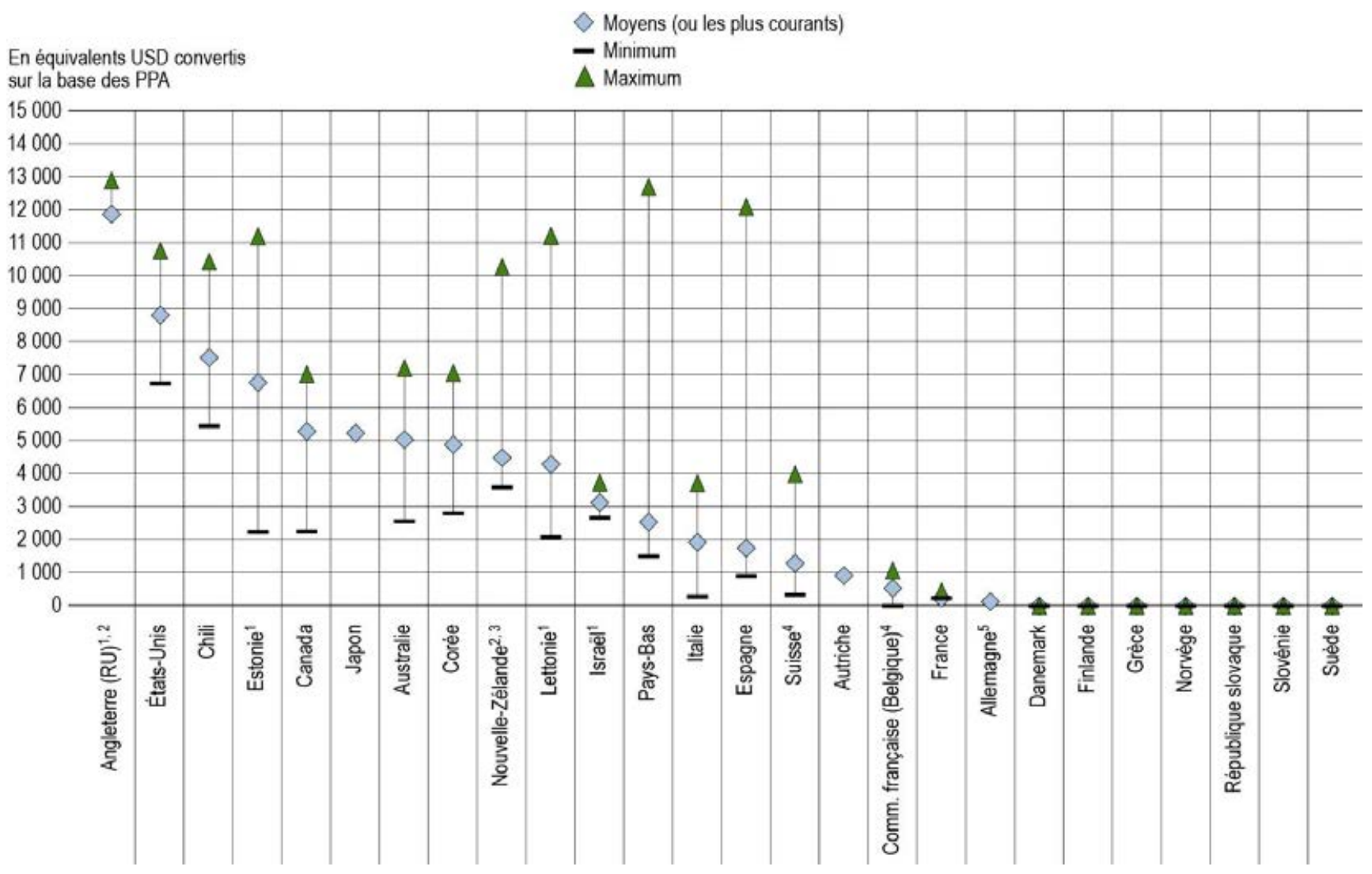

Remarque : L'année de référence peut différer entre les pays et économies. Consulter l'annexe 3 pour de plus amples informations.

1. Les données sont indiquées pour les établissements privés subventionnés par l'État, et non les établissements publics.

2. Les formations tertiaires de cycle court sont incluses dans les formations de licence ou les programmes de niveau équivalent.

3. Les estimations incluent uniquement les universités et excluent les formations du niveau 6 de la CITE, telles que les certifications et diplômes de troisième cycle.

4. Les établissements privés subventionnés par l'État sont inclus dans les établissements publics.

5. Les frais de scolarité sont indiqués pour l'enseignement tertiaire dans son ensemble au lieu du niveau licence ou équivalent. Les frais de scolarité sont applicables aux ressortissants nationaux et étrangers. Seuls sont inclus les programmes académiques.

Les pays et économies sont classés par ordre décroissant des frais de scolarité annuels moyens (ou les plus courants).

Source: OCDE (2019), tableau C5.2. Consulter la section «Source» pour tout complément d'information et l'annexe 3 pour les notes (https://doi.org/10.1787/f8d7880d-en).

StatLink त्ञात https://doi.org/10.1787/888933979310

Les frais de scolarité varient également dans une grande mesure dans quelques pays où ils sont plus modérés, comme en Espagne (où ils s'élèvent à 1750 USD par an en moyenne) et aux Pays-Bas (2 500 USD par an en 
moyenne). Ils sont compris entre 900 USD et 12100 USD en Espagne et entre 1500 USD et 12700 USD aux Pays-Bas. Dans ces deux pays, les frais de scolarité élevés concernent un petit nombre d'étudiants.

Par contraste, les frais de scolarité varient très peu - moins de 200 USD de différence par an entre les frais maximum et minimum - dans les pays où ils sont les moins élevés en moyenne (au Danemark, en Finlande, en France, en Grèce, en Norvège, en République slovaque, en Slovénie et en Suède).

\section{Différenciation des frais de scolarité en licence entre les types d'établissement}

La nécessité de disposer des moyens financiers requis et l'objectif de garantir à tous l'accès à un enseignement de qualité expliquent pourquoi les frais de scolarité varient entre les types d'établissements. Souvent, les établissements privés indépendants sont moins affectés par les règles édictées par les pouvoirs publics et dépendent moins de leur financement que les établissements publics. Dans certains cas, la concurrence d'autres établissements les pousse à proposer les meilleurs services possibles aux étudiants. C'est pourquoi ils peuvent facturer des frais de scolarité annuels moyens plus élevés que les établissements publics en licence (ou formation équivalente) dans tous les pays membres de l'OCDE dont les données sont disponibles.

Dans plus d'un tiers des pays dont les données sont disponibles, les frais de scolarité sont au moins deux fois plus élevés dans les établissements privés indépendants que dans les établissements publics (voir le tableau C5.1). Aux États-Unis, les frais de scolarité applicables aux ressortissants nationaux s'élèvent en moyenne à 29500 USD par an en licence (ou formation équivalente) dans les établissements privés indépendants, soit plus de trois fois plus que dans les établissements publics (8 800 USD environ). En Corée et au Japon, les frais de scolarité annuels à ce niveau d'enseignement se situent en moyenne entre 8700 USD et 8800 USD dans les établissements privés indépendants, mais plus proches de 5000 USD dans les établissements publics. Les frais de scolarité sont environ quatre fois plus élevés dans les établissements privés indépendants que dans les établissements publics en Espagne, trois fois plus élevés en Italie et deux fois plus élevés en Israël. En République slovaque, les frais de scolarité en licence (ou formation équivalente) sont de l'ordre de 2150 USD, mais sont nuls dans les établissements publics. De même, en Norvège, les frais de scolarité en licence et en master sont de l'ordre de 5700 USD dans les établissements privés indépendants, mais nuls dans les établissements publics.

Par contraste, la différence de frais de scolarité annuels moyens entre les établissements publics et les établissements privés subventionnés par l'État est minime en licence (ou formation équivalente) dans tous les pays dont les données sont disponibles. Les frais de scolarité sont nuls dans les deux types d'établissements en Finlande, en Slovénie et en Suède et sont très similaires dans les deux types d'établissements en Autriche et en Israël (voir le tableau C5.1).

\section{Différenciation des frais de scolarité entre les ressortissants nationaux et étrangers}

Les politiques nationales en matière de frais de scolarité visent généralement tous les étudiants scolarisés dans les établissements d'enseignement du pays, y compris les étudiants étrangers ou en mobilité internationale (voir la section « Définitions »). Toutefois, les frais de scolarité peuvent être plus élevés pour les étudiants étrangers. Les différences de frais de scolarité entre les ressortissants nationaux et étrangers peuvent avoir un impact sur les flux d'étudiants étrangers ou en mobilité internationale, comme d'autres facteurs, tels que le soutien public accordé à ces derniers par leur pays d'origine (OCDE, 2018 $\left.{ }_{[1]}\right)$. Ces différences peuvent encourager les étudiants à se rendre dans certains pays ou les en dissuader (voir l'indicateur B6), en particulier dans un contexte où un nombre croissant de pays de l'OCDE imposent à ces étudiants des frais de scolarité supérieurs à ceux applicables à leurs ressortissants. Toutefois, les établissements d'enseignement tertiaire où les frais de scolarité à charge des étudiants étrangers sont plus élevés peuvent rester attractifs s'il s'agit d'institutions prestigieuses ou réputées pour leur qualité ou qu'ils sont situés dans des pays offrant de belles perspectives professionnelles après les études.

Les frais de scolarité à charge des ressortissants nationaux et étrangers sont généralement similaires au Chili, en Corée, en Espagne, en France, en Grèce, en Israël, en Italie, au Japon, en Norvège et en 
République slovaque (voir le tableau C5.1). Dans les pays membres de l'Union européenne (UE) et de l'Espace économique européen (EEE), les frais de scolarité ne varient pas entre les ressortissants nationaux et les ressortissants d'un autre pays membre de l'UE et de l'EEE.

Dans certains pays, les frais de scolarité varient parfois sensiblement entre les ressortissants nationaux et étrangers. En Australie, au Canada et aux États-Unis par exemple, les frais de scolarité en licence applicables aux ressortissants étrangers sont en moyenne 13900 USD plus élevés que ceux applicables aux ressortissants nationaux dans les établissements publics (voir le tableau C5.1). Aux États-Unis, les ressortissants étrangers et les ressortissants nationaux en formation dans un autre État s'acquittent de frais de scolarité plus élevés que les ressortissants nationaux en formation dans leur État d'origine. En Autriche, les frais de scolarité moyens à charge des étudiants qui ne sont pas ressortissants d'un pays membre de l'UE ou de l'EEE représentent par exemple plus du double de ceux applicables aux ressortissants d'un de ces pays en licence, en master et en doctorat (ou formation équivalente). Ces frais de scolarité restent toutefois modérés (de l'ordre de 1850 USD par an à charge des étudiants étrangers). En Suède, les frais de scolarité sont nuls pour les ressortissants nationaux et ceux originaires de pays membres de I'UE, mais s'élèvent à plus de 14500 USD par an en licence pour les ressortissants de pays tiers de l'UE. En Finlande, les étudiants en licence ou en master qui ne sont pas ressortissants d'un pays membre de l'UE ou de l'EEE doivent verser des frais de scolarité depuis l'année académique 2017/18 si leur formation est dispensée en anglais.

Des frais de scolarité plus élevés ne dissuadent toutefois nécessairement les étudiants étrangers. En Australie, en Autriche et au Canada par exemple, les étudiants étrangers ou en mobilité internationale constituent plus de $11 \%$ de l'effectif d'étudiants en licence, un pourcentage qui s'établit à $4 \%$ seulement en moyenne dans les pays de l'OCDE (voir l'indicateur B6).

\section{Politiques nationales de financement de l'enseignement tertiaire}

Les pays de l'OCDE ont choisi des approches différentes pour apporter un soutien financier aux étudiants en formation dans l'enseignement tertiaire. Les systèmes nationaux de financement de l'enseignement supérieur peuvent être classés en fonction de plusieurs caractéristiques communes en dépit de la réorientation de l'action publique dans certains pays (voir l'encadré C5.1) et des différences de contexte. Les pays et les économies sont répartis entre quatre groupes selon deux facteurs : d'une part, le niveau des frais de scolarité et, d'autre part, le niveau des aides publiques prévu dans le système national d'aide financière aux étudiants dans l'enseignement tertiaire (OCDE, 2015[2]).

\section{- Groupe 1 : frais de scolarité nuls et aides généreuses aux étudiants}

Ce profil est celui de tous les pays nordiques dont les données sont disponibles : le Danemark, la Finlande, la Norvège et la Suède. Les frais de scolarité sont nuls en licence dans les établissements publics, et les étudiants bénéficient d'aides publiques généreuses au titre de l'enseignement tertiaire qui les aident à financer leurs frais de subsistance. Dans ces pays, plus de $55 \%$ des étudiants bénéficient d'allocations, de bourses ou de prêts d'études publics ou d'une combinaison des deux types d'aide (voir le graphique C5.3). Dans ces pays, l'impôt sur le revenu est élevé et le régime fiscal est plus progressif (voir l'indicateur A5 et (OCDE, 2015[2])).

\section{- Groupe 2 : frais de scolarité élevés et systèmes d'aide aux étudiants bien développés}

Ce groupe est celui de l'Angleterre (Royaume-Uni), de l'Australie, du Canada, des États-Unis et de la Nouvelle-Zélande. Dans ces pays et économies, l'enseignement tertiaire est relativement coûteux (les frais de scolarité sont supérieurs à 4400 USD par an en licence dans les établissements publics), mais les étudiants bénéficient d'aides généreuses. Le pourcentage d'étudiants en licence et en premier master de type long qui bénéficient d'une aide financière est supérieur à $70 \%$ au Canada et à $85 \%$ en Angleterre (Royaume-Uni), en Australie, aux États-Unis et en Nouvelle-Zélande (voir le graphique C5.3).

L'Angleterre (Royaume-Uni) a rejoint ce groupe depuis 1995, car les frais de scolarité et le soutien financier aux étudiants ont sensiblement augmenté. Les Pays-Bas sont en passe de rejoindre ce groupe, quittant le 
premier groupe, puisque les frais de scolarité y ont augmenté et que le système d'aide aux étudiants s'y est développé (voir le graphique B5.1 dans (OCDE, 2014[3])). Israël se situe à la limite entre le premier et le deuxième groupe, car le système d'aide aux étudiants est relativement bien développé (deux tiers des étudiants bénéficient d'allocations, de bourses ou de prêts d'études), alors que les frais de scolarité annuels sont de l'ordre de 3000 USD en licence dans les établissements publics (voir le tableau C5.1). En 2018, la Nouvelle-Zélande a commencé à se rapprocher du premier groupe en éliminant les frais de scolarité à charge des ressortissants nationaux qui s'inscrivent pour la première fois dans l'enseignement tertiaire. D'ici 2024, tous les ressortissants nationaux auront droit à trois années d'études tertiaires sans frais.

\section{- Groupe 3 : frais de scolarité élevés et systèmes d'aide aux étudiants moins développés}

Au Chili (voir le graphique C5.3), en Corée et au Japon (OCDE, 2015[2]), la plupart des étudiants versent des frais de scolarité élevés (plus de 4800 USD par an) en licence dans les établissements publics, mais le système d'aide aux étudiants est légèrement moins développé que dans les deux premiers groupes. Le Chili a toutefois engagé d'importantes réformes du système d'enseignement tertiaire. L'accès à l'enseignement tertiaire est ainsi devenu entièrement gratuit pour les étudiants de condition modeste. En outre, le montant maximum facturé aux étudiants ne bénéficiant pas d'une exemption de frais de scolarité est désormais soumis à la réglementation et le montant des ressources allouées aux bourses dans l'enseignement tertiaire a été augmenté. C'est également le cas du Japon qui vient d'engager une réforme pour améliorer le système d'aide aux étudiants et l'assortir d'un programme de bourses, et qui a augmenté les prêts d'études sans intérêts et a instauré un dispositif de remboursement à mensualités variables en fonction des revenus des diplômés. De même, le système d'aide aux étudiants s'est développé en Corée, notamment grâce à la mise en place de prêts d'études en 2010, ainsi que d'un programme national d'octroi de bourses/d'allocations en 2012.

\section{- Groupe 4 : frais de scolarité peu élevés ou modérés, et systèmes d'aide aux étudiants moins développés}

Ce groupe est celui de la plupart des autres pays et économies européens dont les données sont disponibles, à savoir l'Autriche, la Communauté française de Belgique, l'Espagne, la France, l'Italie et la Suisse (voir le graphique C5.3 et (OCDE, 2015[2])). Dans ces pays, les frais de scolarité annuels moyens sont peu élevés ou modérés (inférieurs à 2600 USD) en licence dans les établissements publics et les aides financières sont ciblées (moins de $45 \%$ des étudiants en bénéficient).

\section{Encadré C5.1. Évolution des frais de scolarité et de l'aide publique aux étudiants (entre 2007/08 et 2017/18)}

Les réformes portant sur le niveau des frais de scolarité et le système de prêts d'études et d'allocations et de bourses font l'objet de débats houleux. Ces thématiques sont souvent débattues ensemble, car les pays tentent d'améliorer ou d'ajuster la répartition des coûts de l'enseignement tertiaire entre le secteur public et le secteur privé, dont les étudiants et leur famille. Entre les périodes 2007/08 et 2017/18, 15 des 28 pays et économies dont les données sont disponibles ont entrepris de réformer les frais de scolarité. Dans 12 d'entre eux, la réforme des frais de scolarité est allée de pair avec une modification du niveau des aides publiques aux étudiants (voir le tableau C5.4).

Dans la moitié environ des pays dont les données sont disponibles, les frais de scolarité en licence ont augmenté de plus de $20 \%$ dans les établissements publics durant les dix dernières années. C'est le cas dans certains pays où les frais de scolarité annuels sont élevés en moyenne (supérieurs à 4400 USD en 2017/18), comme en Angleterre (Royaume-Uni), au Canada, aux États-Unis et en Nouvelle-Zélande, mais également où ils sont plus modérés (inférieurs à 2600 USD en 2017/18), comme en Espagne, aux Pays-Bas et en Suisse. 
Par contraste, les frais de scolarité n'ont pas évolué au cours des dix dernières années dans des pays où ils étaient nuls en 2007/08 (au Danemark, en Finlande, en Grèce, en Norvège, en République slovaque et en Slovénie). De même, en Autriche et en France, les frais de scolarité moyens sont restés assez stables (de l'ordre de 950 USD et de 200 USD, respectivement). Enfin, le Chili est le seul des pays dont les données sont disponibles où les frais de scolarité ont fortement diminué (passant de 8050 USD à 7500 USD par an).

Les données tendancielles sont rares, mais il est intéressant aussi d'examiner la variation du pourcentage d'étudiants bénéficiaires de prêts d'études ou d'allocations ou de bourses. En Nouvelle-Zélande, parmi les pays où les frais de scolarité ont sensiblement augmenté, le pourcentage d'étudiants bénéficiaires d'un soutien financier n'a guère évolué (85 \% environ) au cours des dix dernières années (voir le tableau C5.4), mais le capital emprunté par an a augmenté en moyenne (passant de 6400 USD à 7600 USD), tandis que le montant annuel des bourses et allocations a légèrement diminué en moyenne (passant de 5700 USD à 5100 USD) (voir l'annexe 3 pour plus de détails).

Au Danemark et en Finlande, les deux pays où les frais de scolarité étaient nuls en 2007/08 ou en 2017/18 parmi ceux dont les données sont disponibles, le pourcentage d'étudiants bénéficiant d'un soutien financier a augmenté, passant respectivement de $69 \%$ à $83 \%$ et de $55 \%$ à $58 \%$ (voir le tableau C5.4). Au Danemark, le montant annuel moyen des prêts d'études et des bourses et allocations a augmenté, tandis qu'en Finlande, celui des prêts d'études a augmenté, mais celui des bourses et allocations a diminué (voir l'annexe 3 pour plus de détails).

Enfin, au Chili, où les frais de scolarité ont considérablement diminué au cours des dix dernières années, le pourcentage d'étudiants bénéficiant de prêts d'études publics/garantis par l'État et/ou de bourses a également nettement augmenté, passant de $17 \%$ en $2007 / 08$ à $58 \%$ en $2017 / 18$ - soit la progression la plus forte parmi tous les pays dont les données sont disponibles.

Les frais de scolarité et l'aide financière aux étudiants peuvent avoir un impact sensible sur l'équité et sur l'accessibilité de l'enseignement tertiaire. Selon certains éléments, des frais de scolarité élevés couplés à des aides généreuses aux étudiants peuvent permettre aux pays d'élargir l'accès à l'enseignement tertiaire, d'utiliser au mieux les fonds publics en temps d'austérité budgétaire et de reconnaître le rendement important que procure l'enseignement tertiaire aux diplômés (OCDE, 2018[4] $)$. En Australie et en Nouvelle-Zélande par exemple, où le système d'aide aux étudiants est particulièrement bien développé (et prévoit notamment des prêts d'études), les taux d'accès à l'enseignement tertiaire sont supérieurs à la moyenne malgré des frais de scolarité élevés (voir I'indicateur B4).

Les taux élevés d'accès à l'enseignement tertiaire qui s'observent dans certains des pays où les frais de scolarité sont nuls s'expliquent sans doute autant par l'absence de frais de scolarité que par le système très développé d'aides financières aux étudiants (voir l'indicateur B4). Au Danemark et en Norvège par exemple, deux pays où les taux d'accès à l'enseignement tertiaire sont supérieurs à la moyenne, les frais de scolarité sont nuls et plus de $80 \%$ des étudiants bénéficient d'allocations ou de bourses ou de prêts d'études ou d'une combinaison des deux dispositifs.

\section{Aide financière aux étudiants : prêts d'études, bourses et allocations}

De nombreux pays de l'OCDE se posent la question cruciale de savoir si les aides financières aux étudiants doivent essentiellement revêtir la forme de bourses ou allocations ou de prêts dans l'enseignement tertiaire. Les partisans des prêts d'études font valoir que ce type de soutien permet de venir en aide à un nombre plus élevé d'étudiants (OCDE, 2014[3]). En effet, si le budget consacré aux bourses et allocations servait plutôt à garantir les prêts, les mêmes fonds pourraient aider plus d'étudiants et les études seraient globalement plus accessibles. Les prêts reviennent aussi à reporter une partie du coût de l'éducation sur ceux qui bénéficient le plus de l'investissement dans l'éducation, en l'espèce, les diplômés de l'enseignement tertiaire qui bénéficient d'un rendement privé élevé après leurs études (voir l'indicateur A5). 


\section{Graphique C5.3. Répartition des étudiants bénéficiant de prêts publics/subventionnés par l'État et de bourses/allocations en licence et en premier master de type long ou niveaux équivalents (2017/18)}

Pourcentage d'étudiants
Ne bénéficient ni de prêts publics/privés garantis par l'État, ni de bourses/d'allocations de l'État
$\square$ Bénéficient uniquement de prêts publics/privés garantis par l'État
$\square$ Bénéficient uniquement de bourses/d'allocations de l'État
Bénéficient ả la fois de prêts publics/privès garantis par l'État et de bourses/d'allocations de l'Élat

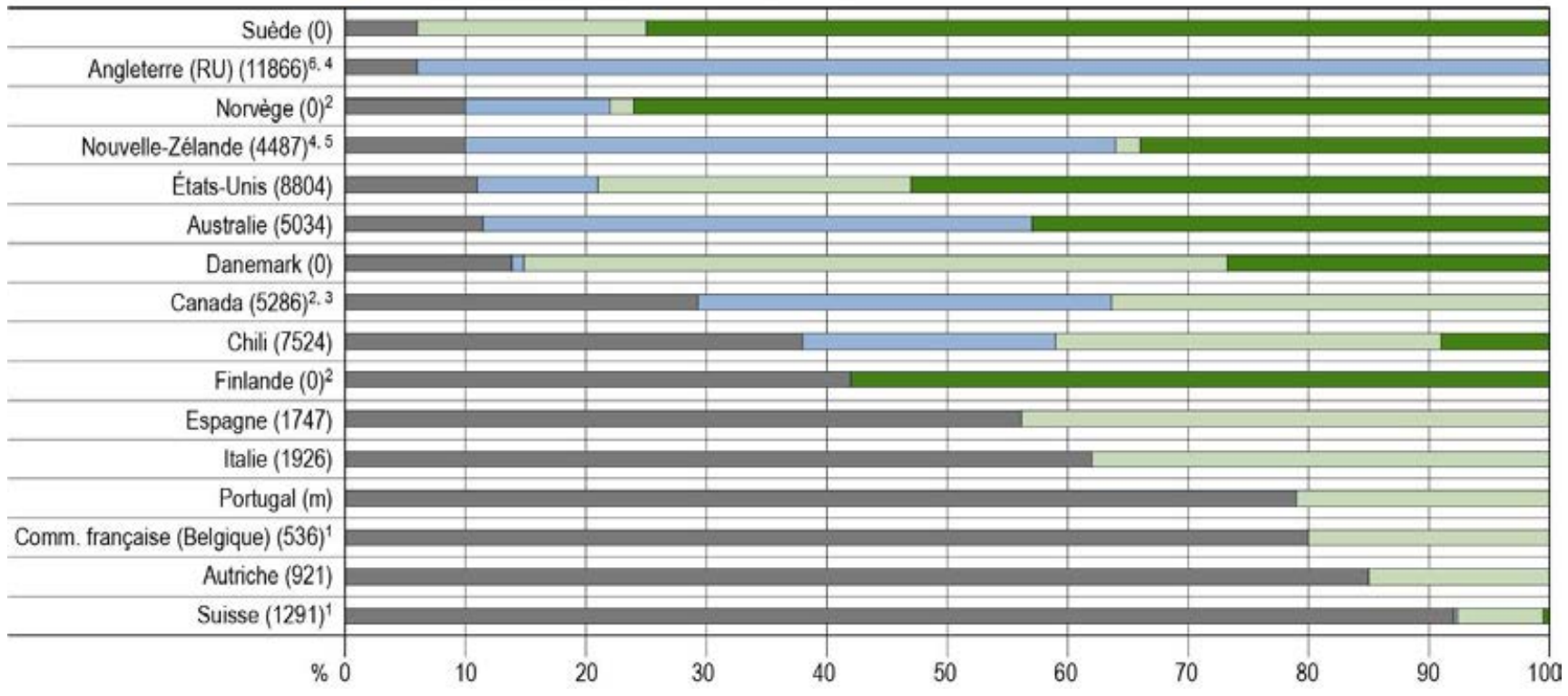

Remarque : Les frais de scolarité annuels moyens (ou les plus courants) demandés par les établissements publics aux étudiants nationaux en licence sont indiqués entre parenthèses (en équivalents USD convertis sur la base des PPA). L'année de référence peut différer entre les pays et économies. Consulter l'annexe 3 pour de plus amples informations.

1. Les frais de scolarité correspondent à la combinaison des établissements publics et des établissements privés subventionnés par l'État.

2. Les données sur l'aide financière se réfèrent à l'enseignement tertiaire dans son ensemble au lieu des licences et premiers masters de type long ou programmes de niveau équivalent.

3. Les données des catégories «Bénéficient uniquement de prêts publics/privés garantis par l'État uniquement » et « Bénéficient uniquement de bourses/d'allocations de l'État » incluent quiconque a bénéficié d'un prêt ou d'une bourse/allocation durant l'année de référence (même s'il est possible qu'ils aient également bénéficié d'autres types d'aide financière).

4. Les frais de scolarité incluent les formations tertiaires de cycle court et les formations de licence ou programmes de niveau équivalent.

5. Les estimations incluent uniquement les universités et excluent les formations du niveau 6 de la CITE, telles que les certifications et diplômes de troisième cycle.

6. Les frais de scolarité concernent les établissements privés subventionnés par l'État, et non les établissements publics.

Les pays et économies sont classés par ordre décroissant du pourcentage d'étudiants ne bénéficiant ni de prêts publics/subventionnés par l'État, ni de bourses/allocations.

Source: OCDE (2019), tableau C5.2. Consulter la section «Source» pour tout complément d'information et l'annexe 3 pour les notes (https://doi.org/10.1787/f8d7880d-en).

StatLink 제대 https://doi.org/10.1787/888933979329

En revanche, les adversaires des prêts d'études considèrent que ces derniers sont moins efficaces que les bourses pour encourager les jeunes de condition modeste à faire des études tertiaires. Ils estiment qu'un endettement excessif à la fin des études peut être lourd de conséquences à la fois pour les étudiants et les pouvoirs publics si un grand nombre de diplômés sont incapables de rembourser leur prêt (OCDE, 2014[3]). Un pourcentage élevé d'étudiants endettés pourrait poser un problème si les perspectives d'emploi ne suffisent pas à garantir le remboursement des prêts d'études.

Dans les pays de l'OCDE, les pouvoirs publics subventionnent les frais de scolarité ou de subsistance des étudiants selon différentes combinaisons de bourses ou allocations et de prêts d'études - des combinaisons qui 
varient même entre les pays dont les frais de scolarité sont similaires. La différence est par exemple importante entre les pays et économies où les frais de scolarité sont élevés en licence dans les établissements publics (égaux ou supérieurs à 4500 USD). En Angleterre (Royaume-Uni), plus de $90 \%$ des étudiants ont uniquement accès à un prêt d'études (et ne bénéficient pas de bourses ou d'allocations) pour financer le coût de leur formation (en licence et en premier master de type long). Aux États-Unis, 53 \% des étudiants contractent un prêt d'études et reçoivent une bourse ou des allocations, $26 \%$ d'entre eux reçoivent uniquement une bourse ou des allocations et $10 \%$ d'entre eux contractent un prêt d'études, mais ne reçoivent ni bourse, ni allocations. En Australie et en Nouvelle-Zélande, la plupart des étudiants contractent un prêt d'études et peuvent recevoir en plus une bourse ou des allocations, tandis qu'au Canada, les deux dispositifs s'appliquent soit séparément, soit en combinaison (voir le graphique C5.3).

Dans les pays où les frais de scolarité sont nuls en licence dans les établissements publics parmi ceux dont les données sont disponibles, la plupart des étudiants contractent un prêt d'études et bénéficient d'une bourse ou d'allocations qui les aident à financer leurs frais de subsistance. Les étudiants concernés sont $58 \%$ en Finlande et $75 \%$ environ en Norvège et en Suède. Au Danemark par contre, la plupart des étudiants bénéficient d'une bourse ou d'allocations (58 \%), mais $27 \%$ d'entre eux seulement contractent en plus un prêt d'études.

Enfin, dans des pays et économies tels que l'Autriche, la Communauté française de Belgique, l'Espagne, l'Italie, le Portugal et la Suisse où les frais de scolarité moyens sont inférieurs à 2000 USD en licence, moins de $45 \%$ des étudiants bénéficient d'une quelconque aide financière - sous la forme uniquement d'une bourse ou d'allocations le plus souvent.

\section{Systèmes de prêts d'études, capital emprunté et endettement en fin de cursus}

Il existe deux types principaux de prêts d'études: ceux comparables aux prêts hypothécaires et ceux à remboursement variable sous conditions de ressources. Dans les prêts de type hypothécaire, les ex-étudiants sont dans l'obligation de rembourser leur prêt dans un délai imparti, quelle que soit leur situation financière après leurs études. Cela peut représenter une lourde charge financière pour les diplômés (et pour ceux qui n'ont pas réussi leur formation) si leurs revenus sont peu élevés. Par contraste, dans les systèmes de prêts à remboursement variable, le remboursement dépend du revenu de l'emprunteur, qui doit atteindre un certain seuil, et une clause de remise de dette est incluse après une certaine période. Ces modalités tiennent compte de la capacité des individus à rembourser le prêt contracté pour financer leurs études et sont par conséquent considérés comme plus équitables.

Les deux systèmes de prêts impliquent des coûts à charge des pouvoirs publics si ceux-ci garantissent le remboursement des prêts. Toutefois, le fardeau financier à charge des pouvoirs publics est plus incertain dans le système de prêts à remboursement variable, puisque le remboursement de ces derniers dépend de la mesure dans laquelle les emprunteurs trouvent du travail et gagnent suffisamment pour passer au-dessus du seuil minimum de remboursement.

Plusieurs pays ont adopté récemment un système de prêts remboursables sous conditions de ressources. Le Royaume-Uni a par exemple remplacé son système de prêts de type hypothécaire par un système de prêts à remboursement variable sous conditions de ressources en 1999 - à ce jour, $45 \%$ des prêts d'études ne sont pas remboursés. Des systèmes de prêts à remboursement variable ont également été instaurés aux États-Unis à cause de l'accroissement de la dette des étudiants : le programme de prêts remboursables sous conditions de ressources, en 2009, et le plan Pay-As-You-Earn (PAYE), en 2012 (voir le tableau C5.3 et (OCDE, 2015[2])). Parmi les pays dont les données sont disponibles, l'Australie, le Chili et la Nouvelle-Zélande ont également adopté un système de prêts d'études remboursables sous conditions de ressources. En Corée, au Japon et aux Pays-Bas, le système est hybride et comporte des prêts d'études de type hypothécaire et des prêts d'études remboursables sous conditions de ressources (voir le tableau C5.3).

Non seulement le pourcentage d'étudiants qui contractent un prêt d'études varie entre les pays comme indiqué ci-dessus, mais le capital emprunté en moyenne par an varie aussi entre eux. Parmi les pays et économies où 
la plupart des étudiants contractent un prêt d'études (au moins $70 \%$ ), le capital emprunté est en moyenne de l'ordre de 5600 USD par an en Australie, de 7000 USD en Nouvelle-Zélande et en Suède, de 10400 USD en Norvège et de 17000 USD en Angleterre (Royaume-Uni). Dans les pays où entre $25 \%$ et $35 \%$ des étudiants contractent un prêt d'études (au Canada, au Chili, au Danemark et au Japon), ils empruntent en moyenne entre 3900 USD environ par an au Danemark et 7700 USD environ par an au Japon (voir le tableau C5.3).

\section{Encadré C5.2. Quel pourcentage des prêts d'études publics est remboursé ?}

Dans certains pays et économies, les prêts d'études sont devenus une composante importante de l'aide aux étudiants. Il est difficile d'évaluer le budget que les pouvoirs publics y consacrent vu la diversité des systèmes de prêts d'études et de types de remboursement qui existent dans le monde. Estimer les remboursements permet d'améliorer la comparabilité. Il existe deux méthodes d'analyse :

- La comptabilité de trésorerie : cette méthode consiste à analyser les remboursements effectués durant l'année de référence concernant des prêts contractés auparavant. Le montant des remboursements est indiqué en pourcentage du montant brut des prêts d'études durant l'année de référence dans le graphique C5.a.

- La valeur actuelle nette : cette méthode consiste à évaluer le remboursement futur des prêts d'études contractés durant l'année de référence, ce qui permet de déterminer les orientations politiques retenues par les gouvernements. Le graphique C5.a indique le montant actualisé des remboursements prévus des prêts contractés durant l'année de référence en pourcentage du montant brut des prêts contractés la même année.

Ces deux méthodes peuvent aboutir à des résultats très différents dans un pays donné, car elles se rapportent à des périodes et à des cohortes d'étudiants qui sont différentes. Dans la comptabilité de trésorerie, le montant remboursé des prêts contractés lors d'années précédentes est comparé au montant des prêts contractés la même année. En d'autres termes, cette méthode compare les prêts d'études de plusieurs cohortes : 1) les étudiants qui contractent un prêt durant l'année de référence ; et 2) les ex-étudiants qui remboursent leur prêt la même année. Dans les pays où les systèmes de prêts d'études sont bien ancrés, le nombre d'étudiants qui remboursent leur prêt durant l'année de référence peut être nettement plus élevé que le nombre d'étudiants qui en contractent un.

La méthode basée sur la valeur actuelle nette porte quant à elle sur les prêts en cours (le capital emprunté durant l'année de référence et son remboursement futur). En d'autres termes, elle concerne le capital emprunté par les étudiants durant l'année de référence et l'estimation du montant que les mêmes étudiants rembourseront à l'avenir.

Le graphique C5.a montre que le montant remboursé par les étudiants qui ont contracté un prêt d'études varie sensiblement entre les pays, en particulier si l'analyse est faite sur la base de la comptabilité de trésorerie. En Angleterre (Royaume-Uni), en Australie et en Finlande, le montant remboursé durant l'année de référence est inférieur de $40 \%$ au montant brut des prêts contractés la même année. Ce pourcentage est de l'ordre de $65 \%$ en Norvège et de $90 \%$ au Canada et aux États-Unis. Il est même supérieur à $100 \%$ en Corée (117 \%) et en République slovaque (110\%).

Les résultats qui s'observent reflètent le degré de maturité des systèmes de prêts d'études dans certains cas : les systèmes plus anciens se caractérisent par un nombre plus élevé d'ex-étudiants en cours de remboursement que d'étudiants contractant un prêt, et les systèmes plus récents, par un nombre relativement peu élevé d'ex-étudiants en cours de remboursement. Des valeurs élevées peuvent également s'expliquer par une réduction du soutien financier aux étudiants durant l'année de référence par comparaison avec les autres années (par exemple, la diminution du montant moyen du capital emprunté, du nombre d'étudiants contractant un prêt, etc.) ou par le montant élevé des remboursements concernant des prêts contractés les années précédentes. En Corée, par exemple, le montant élevé remboursé durant l'année de référence 
(117\%) reflète 1) le nombre élevé d'individus remboursant des prêts lors de l'année de référence par rapport au nombre d'étudiants contractant un prêt lors de la même année ; 2) la dépendance accrue au système de bourses d'études ; et 3) l'augmentation du montant des remboursements concernant les prêts contractés.

\section{Graphique C5.a. Quel pourcentage des prêts d'études publics est remboursé ?}

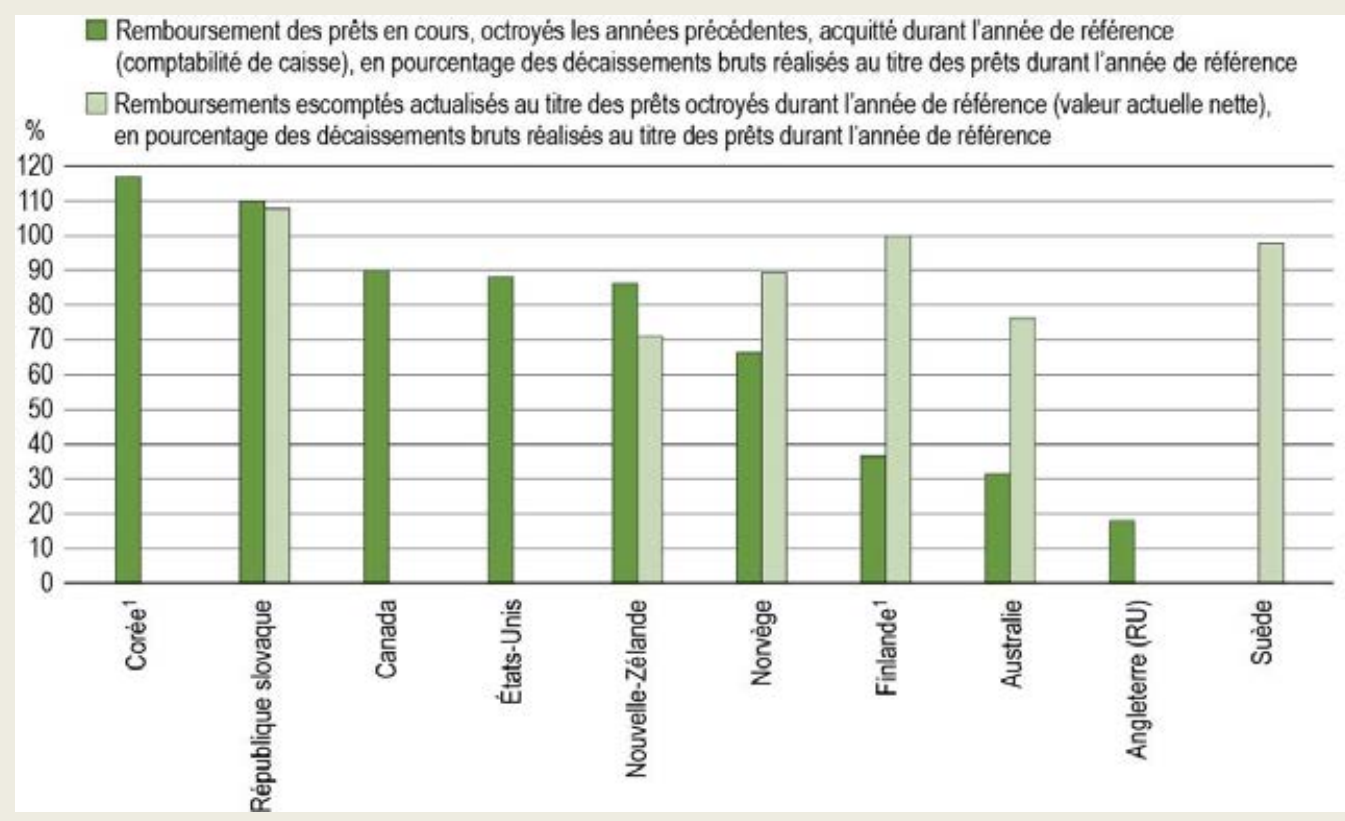

Remarque : Les données de ce graphique sont fondées sur des estimations et doivent être interprétées avec prudence. L'année de référence peut différer entre les pays. Consulter l'annexe 3 pour de plus amples informations.

1. Prêts privés subventionnés par l'État et non prêts publics.

Les pays et économies sont classés par ordre décroissant du pourcentage des prêts d'études qui est remboursé, sur la base de la méthodologie de la comptabilité de caisse.

Source: OCDE (2019). Consulter la section «Source» pour tout complément d'information et l'annexe 3 pour les notes (https://doi.org/10.1787/f8d7880d-en).

StatLink त्ना15 https://doi.org/10.1787/888933979348

II y a lieu de préciser que les remboursements ne sont pas nécessairement réinjectés dans l'éducation. En fait, la Corée est le seul des pays dont les données sont disponibles où $100 \%$ des remboursements de prêts d'études sont réinjectés dans d'autres prêts d'études.

Dans l'analyse selon la méthode de la valeur actuelle nette, entre $70 \%$ et $75 \%$ des prêts d'études contractés durant l'année de référence devraient être remboursés en Australie et en Nouvelle-Zélande. Par contraste, ce pourcentage est de l'ordre de $90 \%$ en Norvège et de $100 \%$ en Finlande et en Suède. Il est même supérieur à $100 \%$ à cause des taux d'intérêt en République slovaque.

L'endettement cumulé des étudiants est l'un des facteurs qui peut intervenir dans leur décision d'investir dans une formation tertiaire. La mesure dans laquelle le remboursement peut devenir problématique dépend essentiellement du montant emprunté et des conditions de prêt, par comparaison avec les perspectives professionnelles des diplômés, leurs revenus et l'incertitude régnant sur le marché du travail.

Parmi les pays et économies où les frais de scolarité sont élevés, en Angleterre (Royaume-Uni), en Australie et en Nouvelle-Zélande, $70 \%$ au moins des étudiants sont endettés à la fin de leur formation à cause du prêt d'études qu'ils ont contracté. Toutefois, l'endettement moyen à la fin des études varie sensiblement : il est de l'ordre de 10500 USD en Australie et de 24100 USD en Nouvelle-Zélande et est supérieur à 49800 USD en Angleterre (Royaume-Uni). L'endettement est généralement moins élevé dans les pays où les frais de scolarité 
sont nuls ou peu élevés dans l'enseignement tertiaire que dans les pays où les frais de scolarité sont élevés, puisque les prêts d'études servent essentiellement à financer les frais de subsistance des étudiants. Toutefois, dans les pays nordiques, où les frais de scolarité sont nuls ou minimes, l'endettement peut être important, car le coût de la vie est élevé. C'est par exemple le cas en Norvège, où l'endettement des étudiants est supérieur à 28700 USD (voir le tableau C5.3).

\section{Définitions}

Dans ce chapitre, les ressortissants nationaux sont les étudiants en formation dans le pays dont ils ont la nationalité. Par étudiants étrangers, on entend les étudiants en formation dans un pays dont ils ne sont pas ressortissants, parmi les pays dont les données sont disponibles. Cette définition est pragmatique et opérationnelle, mais n'est pas appropriée pour prendre la mesure de la mobilité internationale des étudiants, en raison de différences dans les politiques nationales de naturalisation des immigrants. Dans les pays membres de l'Union européenne, les frais de scolarité ne varient généralement pas entre les ressortissants nationaux et les ressortissants étrangers originaires d'autres pays membres de l'UE. Dans ces cas, les étudiants étrangers sont ceux originaires de pays tiers de l'Union européenne. L'indicateur B6 fournit des détails supplémentaires au sujet de ces définitions.

\section{Méthodologie}

Les montants des frais de scolarité et des prêts d'études exprimés en devise nationale ont été divisés par l'indice des parités de pouvoir d'achat (PPA) pour le PIB afin d'obtenir leur équivalent en dollars américains (USD). Les montants des frais de scolarité et les pourcentages d'étudiants bénéficiaires d'aides doivent être interprétés avec prudence dans la mesure où ils sont basés sur des moyennes pondérées des principales formations de l'enseignement tertiaire et où ils ne couvrent pas tous les établissements d'enseignement.

Les prêts d'études accordés ou garantis par les pouvoirs publics sont indiqués en valeur totale afin de fournir des informations sur le niveau d'aide dont bénéficient les étudiants. Le montant brut des prêts permet d'évaluer le volume d'aide dont les étudiants bénéficient pendant leur formation. Les remboursements des créances et des intérêts par les emprunteurs devraient être pris en compte pour évaluer le coût net des prêts d'études contractés auprès d'agences publiques ou privées. Dans la plupart des pays, ces prêts ne sont pas remboursés aux autorités en charge de l'éducation, qui ne peuvent donc pas utiliser ces montants pour financer d'autres dépenses d'éducation.

Les indicateurs de l'OCDE incluent le montant global (brut) des bourses et prêts lorsqu'il s'agit de rendre compte de l'aide financière apportée aux étudiants pendant leur formation. Certains pays de l'OCDE éprouvent des difficultés à chiffrer les prêts d'études accordés aux étudiants. Une certaine prudence s'impose donc lors de l'interprétation des données sur les prêts d'études.

Voir le Guide de l'OCDE pour l'établissement de statistiques internationalement comparables dans le domaine de l'éducation 2018 (OCDE, 2019 $\left.9_{[5]}\right)$ pour de plus amples informations. Voir les notes spécifiques aux pays à l'annexe 3, (https://doi.org/10.1787/f8d7880d-en).

\section{Source}

Les données se rapportent à l'année académique 2017/18 et proviennent d'une enquête spéciale réalisée par l'OCDE en 2019 (pour des détails, voir l'annexe 3, https://doi.org/10.1787/f8d7880d-en). 


\section{Remarque concernant les données fournies par Israël}

Les données statistiques concernant Israël sont fournies par et sous la responsabilité des autorités israéliennes compétentes. L'utilisation de ces données par l'OCDE est sans préjudice du statut des hauteurs du Golan, de Jérusalem-Est et des colonies de peuplement israéliennes en Cisjordanie aux termes du droit international.

\section{Références}

OCDE (2019), Guide de l'OCDE pour l'établissement de statistiques internationalement comparables dans le domaine de l'éducation 2018: Concepts, normes, définitions et classifications, Éditions OCDE, Paris, https://dx.doi.org/10.1787/9789264305380-fr.

OCDE (2018), « Réforme des frais de scolarité et mobilité internationale », Les indicateurs de l'éducation à la loupe, $\mathrm{n}^{\circ}$ 51, Éditions OCDE, Paris, https://dx.doi.org/10.1787/8351e555-fr.

OCDE (2018), Regards sur l'éducation 2018: Les indicateurs de l'OCDE, Éditions OCDE, Paris, https://dx.doi.org/10.1787/eag-2018-fr.

OCDE (2015), Regards sur l'éducation 2015: Les indicateurs de l'OCDE, Éditions OCDE, Paris, https://dx.doi.org/10.1787/eag-2015-fr.

OCDE (2014), Regards sur l'éducation 2014: Les indicateurs de l'OCDE, Éditions OCDE, Paris, https://dx.doi.org/10.1787/eag-2014-fr.

\section{Tableaux de l'indicateur C5}

Tableau C5.1

Tableau C5.2

Tableau C5.3

Tableau C5.4
Frais de scolarité annuels moyens (ou les plus courants) demandés par les établissements d'enseignement tertiaire aux étudiants nationaux et étrangers (2017/18)

Frais de scolarité demandés par les établissements d'enseignement aux étudiants scolarisés à temps plein, en équivalents USD convertis sur la base des PPA, et pourcentage d'étudiants nationaux bénéficiant d'une aide financière (2017/18)

Prêts publics aux étudiants, remboursement et allègement de la dette dans l'enseignement tertiaire (2017/18)

Évolution des politiques de frais de scolarité et de l'aide publique aux étudiants (2007/08 à 2017/18)

Date butoir pour les données : 19 juillet 2019. Les mises à jour peuvent être consultées en ligne à l'adresse : http://dx.doi.org/10.1787/eag-data-en D'autres données désagrégées sont également disponibles dans la Base de données de Regards sur l'éducation (http://stats.oecd.org/).

StatLink : https://doi.org/10.1787/888933981134 
Tableau C5.1. Frais de scolarité annuels moyens (ou les plus courants) demandés par les établissements d'enseignement tertiaire aux étudiants nationaux et étrangers (2017/18)

Montants convertis en équivalents USD sur la base des PPA, selon le type d'établissement et le niveau d'enseignement

\begin{tabular}{|c|c|c|c|c|c|c|c|c|c|}
\hline & \multirow{3}{*}{\multicolumn{2}{|c|}{\begin{tabular}{|c|} 
\\
Pourcentage \\
d'etudiants (niveaux licence, \\
master et doctorat confondus) \\
scolarisés dans :
\end{tabular}}} & \multirow{4}{*}{$\begin{array}{c}\text { Pourcentage } \\
\text { d'étudiants } \\
\text { en mobilité } \\
\text { internationale } \\
\text { (niveaux } \\
\text { licence, master } \\
\text { et doctorat } \\
\text { confondus) }\end{array}$} & \multirow{2}{*}{\multicolumn{6}{|c|}{$\begin{array}{l}\text { Frais de scolarité annuels moyens demandés par les établissements d'enseignement } \\
\text { aux étudiants scolarisés à temps plein } \\
\text { Établissements publics (ou privès subventionnés par l'État, si c'est le plus courant) }\end{array}$}} \\
\hline & & & & & & & & & \\
\hline & & & & \multicolumn{3}{|c|}{ Etudiants nationaux } & \multicolumn{3}{|c|}{ Etudiants ètrangers } \\
\hline & $\begin{array}{l}\text { Des ètablissements } \\
\text { publics (ou privés } \\
\text { subventionnés } \\
\text { par l'Etat, si c'est } \\
\text { le plus courant) }\end{array}$ & $\begin{array}{l}\text { Des } \\
\text { etablissements } \\
\text { prives } \\
\text { independants }\end{array}$ & & $\begin{array}{l}\text { Licence } \\
\text { ou niveau } \\
\text { équivalent }\end{array}$ & $\begin{array}{c}\text { Master } \\
\text { ou niveau } \\
\text { equivalent }\end{array}$ & $\begin{array}{l}\text { Doctorat } \\
\text { ou niveau } \\
\text { equivalent }\end{array}$ & $\begin{array}{l}\text { Licence } \\
\text { ou niveau } \\
\text { equivalent }\end{array}$ & $\begin{array}{l}\text { Master } \\
\text { ou niveau } \\
\text { equivalent }\end{array}$ & $\begin{array}{l}\text { Doctorat } \\
\text { ou niveau } \\
\text { equivalent }\end{array}$ \\
\hline & & & (3) & (4) & (5) & (6) & (7) & (8) & (9) \\
\hline \multicolumn{10}{|l|}{ w Pays } \\
\hline Australie' & 92 & $8^{\circ}$ & 22 & 5034 & 8929 & 260 & 19029 & 18318 & 16187 \\
\hline Autriche' & 82 & $18^{\circ}$ & 20 & 921 & 921 & 921 & 1841 & 1841 & 1841 \\
\hline Canada & 100 & a & 13 & 5286 & 5527 & $\mathrm{~m}$ & 20406 & 13040 & m \\
\hline Chili & 20 & 63 & 0 & 7524 & 10446 & 9067 & \multicolumn{3}{|c|}{ Aucune différenciation pour les étudiants étrangers } \\
\hline Danemark & 99 & a & 10 & 0 & 0 & 0 & m & m & m \\
\hline Estonie $^{23}$ & 76 & 10 & 8 & 6764 & 7536 & 0 & 6764 & 7536 & 0 \\
\hline Finlande & 53 & a & 8 & 0 & 0 & 0 & \multicolumn{2}{|c|}{$\begin{array}{l}\text { Differenciation des frais de scolarité en } \\
\text { fonction de la langue du programme. }\end{array}$} & 0 \\
\hline France & 82 & 17 & 11 & 237 & 330 & 504 & \multicolumn{2}{|c|}{$\begin{array}{l}\text { Aucune différenciation pour les } \\
\text { étudiants êtrangers }\end{array}$} & \\
\hline Allemagne ${ }^{1 / 4}$ & 91 & $9^{\circ}$ & 8 & $133^{4}$ & $x(4)$ & $x(4)$ & $x(4)$ & $x(4)$ & $x(4)$ \\
\hline Grèce & 100 & a & 3 & 0 & 4114 & 0 & \multicolumn{3}{|c|}{ Aucune diffèrenciation pour les étudiants étrangers } \\
\hline $\mid$ |sraë| $\left.\right|^{2}$ & 74 & 14 & 3 & 3130 & $\mathrm{~m}$ & $\mathrm{~m}$ & \multicolumn{3}{|c|}{ Aucune différenciation pour les ètudiants étrangers } \\
\hline Italie & 88 & 12 & 5 & 1926 & 2149 & 464 & \multicolumn{3}{|c|}{ Aucune différenciation pour les étudiants étrangers } \\
\hline Japon & 25 & 75 & 4 & 5234 & 5231 & 5231 & \multicolumn{3}{|c|}{ Aucune differenciation pour les étudiants étrangers } \\
\hline Corèe & 25 & 75 & 3 & 4886 & 6414 & 7167 & \multicolumn{3}{|c|}{ Aucune differenciation pour les étudiants étrangers } \\
\hline Lettonie $^{2}$ & 78 & 22 & 9 & 4291 & 4505 & 5836 & 7301 & 8096 & 10543 \\
\hline Pays-Bas & 85 & 15 & 11 & 2537 & 2537 & a & m & m & a \\
\hline Nouvelle-Zélandes, & 95 & 2 & 19 & $4487^{\circ}$ & $\mathrm{m}$ & 4739 & $\mathrm{~m}$ & $\mathrm{~m}$ & 4739 \\
\hline Norvège & 85 & 10 & 3 & 0 & 0 & a & \multicolumn{3}{|c|}{ Aucune différenciation pour les étudiants étrangers } \\
\hline République slovaque & 87 & 13 & 7 & 0 & 0 & 0 & \multicolumn{3}{|c|}{ Aucune differenciation pour les étudiants étrangers } \\
\hline Slovénie & 87 & 7 & 4 & 0 & 0 & m & \multicolumn{2}{|c|}{$\begin{array}{l}\text { Les ètablissements peuvent demander } \\
\text { des frais de scolarité plus élevés aux } \\
\text { étudiants originaires de pays tiers de } \\
\text { rEspace économique européen }\end{array}$} & m \\
\hline Espagne & 82 & 18 & 3 & 1747 & 2873 & m & \multicolumn{3}{|c|}{ Aucune différenciation pour les étudiants étrangers } \\
\hline Suède & 94 & a & 7 & 0 & 0 & 0 & 14679 & 14679 & 0 \\
\hline Suisse ${ }^{7}$ & $93^{4}$ & 7 & 18 & $1291^{d}$ & $1291^{\circ}$ & $386^{4}$ & m & m & m \\
\hline Etats-Unis' & 63 & 37 & 7 & 8804 & $11617^{\circ}$ & $x(5)$ & 24854 & m & m \\
\hline \multicolumn{10}{|l|}{ Economies } \\
\hline Comm. flamande (Belgique) & 62 & 0.2 & 9 & $\mathrm{~m}$ & $\mathrm{~m}$ & 580 & \multicolumn{3}{|c|}{$\begin{array}{l}\text { Les établissements peuvent fixer en toute autonomie } \\
\text { le montant de leurs frais de scolarité pour les étudiants } \\
\text { originaires de pays tiers de l'Espace économique européen, } \\
\text { à l'exception de certaines catégories (par ex., réfugiés. } \\
\text { demandeurs d'asile) }\end{array}$} \\
\hline Comm. française (Belgique) & $99.8^{4}$ & 0.2 & 9 & $536^{4}$ & $993^{4}$ & m & \multicolumn{3}{|c|}{$\begin{array}{l}\text { Les établissements peuvent demander des frais de scolarité } \\
\text { plus élevés aux étudiants originaires de pays tiers de } \\
\text { I'Espace économique européen }\end{array}$} \\
\hline Angleterre $(\mathrm{RU})^{2.5}$ & 100 & a & 20 & $11866^{d}$ & $\mathrm{~m}$ & $\mathrm{~m}$ & m & $\mathrm{m}$ & $\mathrm{m}$ \\
\hline
\end{tabular}




\begin{tabular}{|c|c|c|c|c|c|c|}
\hline & \multicolumn{6}{|c|}{ Frais de scolarité annuels moyens demandés par les établissements d'enseignement aux étudiants scolarisés à temps plein } \\
\hline & \multicolumn{6}{|c|}{ Établissements privés indépendants } \\
\hline & \multicolumn{3}{|c|}{ Etudiants nationaux } & \multicolumn{3}{|c|}{ Etudiants étrangers } \\
\hline & $\begin{array}{l}\text { Licence ou niveau } \\
\text { equivalent }\end{array}$ & $\begin{array}{l}\text { Master ou niveau } \\
\text { equivalent }\end{array}$ & $\begin{array}{l}\text { Doctorat ou niveau } \\
\text { equivalent }\end{array}$ & $\begin{array}{l}\text { Licence ou niveau } \\
\text { equivalent }\end{array}$ & $\begin{array}{l}\text { Master ou niveau } \\
\text { equivalent }\end{array}$ & $\begin{array}{c}\text { Doctorat ou niveau } \\
\text { equivalent }\end{array}$ \\
\hline & (10) & (11) & (12) & (13) & (14) & (15) \\
\hline \multicolumn{7}{|l|}{ w Pays } \\
\hline ¿ू Australie' & $9360^{\circ}$ & $12023^{\circ}$ & $2531^{\circ}$ & $10810^{\circ}$ & $11449^{\circ}$ & $20093^{d}$ \\
\hline Autriche' & $\mathrm{m}$ & m & $\mathrm{m}$ & $\mathrm{m}$ & $\mathrm{m}$ & $\mathrm{m}$ \\
\hline Canada & a & a & a & a & a & a \\
\hline Chili & 6723 & 10727 & 8898 & \multicolumn{3}{|c|}{ Aucune différenciation pour les étudiants étrangers } \\
\hline Danemark & a & a & a & a & a & a \\
\hline Estonic $^{23}$ & 8565 & 8747 & 0 & 8565 & 8747 & 0 \\
\hline Finlande & a & a & a & a & a & a \\
\hline France & $\mathrm{m}$ & m & $\mathrm{m}$ & $\mathrm{m}$ & $\mathrm{m}$ & $\mathrm{m}$ \\
\hline Allemagne $e^{1 / 4}$ & $4908^{\circ}$ & $x(10)$ & $x(10)$ & $x(10)$ & $x(10)$ & $x(10)$ \\
\hline Grèce & a & a & a & a & a & a \\
\hline |sraẹl ${ }^{2}$ & 6872 & m & m & \multicolumn{3}{|c|}{ Aucune differenciation pour les étudiants étrangers } \\
\hline Italie & 6707 & 8050 & 2512 & \multicolumn{3}{|c|}{ Aucune diftèrenciation pour les étudiants étrangers } \\
\hline Japon & 8784 & 7644 & 5988 & \multicolumn{3}{|c|}{ Aucune différenciation pour les étudiants ètrangers } \\
\hline Corèe & 8760 & 11755 & 12674 & \multicolumn{3}{|c|}{ Aucune differenciation pour les étudiants êtrangers } \\
\hline Lettonie $^{2}$ & 4652 & 5477 & 6276 & 5877 & 6771 & 6961 \\
\hline Pays-Bas & $\mathrm{m}$ & $\mathrm{m}$ & a & m & m & a \\
\hline Nouvelle-Zélande $e^{5,0}$ & $\mathrm{~m}$ & m & a & $\mathrm{m}$ & m & a \\
\hline Norvège & $5680^{\circ}$ & $x(10)$ & a & \multicolumn{3}{|c|}{ Aucune différenciation pour les étudiants êtrangers } \\
\hline République slovaque & 2148 & 2571 & 2590 & \multicolumn{3}{|c|}{ Aucune diftérenciation pour les étudiants étrangers } \\
\hline Slovènie & 0 & 0 & 0 & \multicolumn{2}{|c|}{$\begin{array}{l}\text { Les établissements peuvent demander des frais } \\
\text { de scolanté plus elevés aux étudiants oniginaires } \\
\text { de pays tiers de IEspace économique européen }\end{array}$} & m \\
\hline Espagne & 7771 & 12030 & m & \multicolumn{3}{|c|}{ Aucune différenciation pour les étudiants étrangers } \\
\hline Suède & a & a & a & a & a & a \\
\hline Suisse? & 3202 & 3202 & 5456 & m & m & m \\
\hline Etats-Unis ${ }^{*}$ & 29478 & $24712^{\circ}$ & $x(11)$ & \multirow{2}{*}{\multicolumn{3}{|c|}{ Aucune différenciation pour les étudiants en mobilité internationale }} \\
\hline Economies & & & & & & \\
\hline Comm. flamande (Belgique) ${ }^{2}$ & m & m & m & m & $\mathrm{m}$ & $\mathrm{m}$ \\
\hline Comm. française (Belgique) ${ }^{7}$ & a & a & a & a & a & a \\
\hline Angleterre $(\mathrm{RU})^{2,6}$ & a & a & a & a & a & a \\
\hline
\end{tabular}

Remarque : Les données sur les effectifs scolarisés sont présentées pour l'année 2016/17. L'année de référence peut différer entre les pays. Consulter l'annexe 3 pour de plus amples informations. Pour les pays européens, les frais de scolarités demandés aux étudiants étrangers se rapportent aux étudiants originaires de pays tiers de l'Espace économique européen. La valeur « 0 » est indiquée pour les établissements ne demandant pas de frais de scolarité.

La ventilation des données par type d'établissements est disponible en ligne (voir le StatLink ci-dessous).

1. Les établissements privés subventionnés par l'État sont inclus dans les établissements privés indépendants. Pour l'Allemagne et l'Autriche, les établissements privés subventionnés par l'État sont uniquement inclus dans les établissements privés indépendants pour les données sur les effectifs scolarisés.

2. Établissements privés subventionnés par l'État, et non établissements publics.

3. Les établissements publics et les établissements privés subventionnés par l'État peuvent fixer en toute autonomie le montant de leurs frais de scolarité pour les programmes dispensés dans d'autres langues que l'estonien.

4. Les frais de scolarité sont indiqués pour l'enseignement tertiaire dans son ensemble au lieu du niveau licence ou équivalent. Seuls sont inclus les programmes académiques.

5. Les formations tertiaires de cycle court sont incluses dans les formations de licence ou les programmes de niveau équivalent.

6. Les estimations incluent uniquement les universités et excluent les formations du niveau 6 de la CITE, telles que les certifications et diplômes de troisième cycle.

7. Les établissements privés subventionnés par l'État sont inclus dans les établissements publics.

8. Les frais de scolarité demandés aux étudiants étrangers se rapportent aux étudiants étrangers et aux ressortissants nationaux originaires d'un autre État. Cependant, dans un faible proportion d'établissements, les frais de scolarité peuvent être moins élevés pour les ressortissants nationaux issus d'un autre État.

Source : OCDE (2019). Consulter la section « Source » pour tout complément d'information et l'annexe 3 pour les notes (https://doi.org/10.1787/f8d7880d-en).

Les symboles représentant les données manquantes et les abréviations figurent dans le Guide du lecteur. 
Tableau C5.2. Frais de scolarité demandés par les établissements d'enseignement aux étudiants scolarisés à temps plein, en équivalents USD convertis sur la base des PPA, et pourcentage d'étudiants nationaux bénéficiant d'une aide financière (2017/18) Licence uniquement pour les frais de scolarité, et licence et premier master de type long ou programme de niveau équivalent pour l'aide financière

\begin{tabular}{|c|c|c|c|c|c|c|c|c|c|c|c|}
\hline & \multicolumn{7}{|c|}{ Licence ou niveau équivalent } & \multirow{2}{*}{\multicolumn{4}{|c|}{$\begin{array}{l}\text { Licence et premier master de type long } \\
\text { ou programme de niveau équivalent } \\
\text { Pourcentage d'ètudiants bènéficiant } \\
\text { une aide financière sous la forme de... }\end{array}$}} \\
\hline & \multirow{3}{*}{ 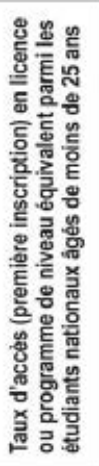 } & \multicolumn{2}{|c|}{$\begin{array}{l}\text { Pourcentage } \\
\text { d'étudiants } \\
\text { scolarisés dans : }\end{array}$} & \multicolumn{4}{|c|}{$\begin{array}{l}\text { Frais de scolarité annuels demandés par les établissements } \\
\text { aux étudiants ressortissants nationaux scolarisés à temps plein } \\
\text { (en équivalents USD convertis sur la base des PPA pour le PIB) }\end{array}$} & & & & \\
\hline & & \multirow{2}{*}{ 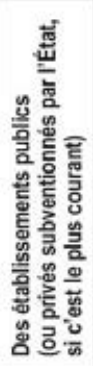 } & \multirow[b]{2}{*}{ 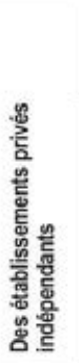 } & \multicolumn{2}{|c|}{$\begin{array}{l}\text { Établissements publics } \\
\text { (ou privés subventionnés par } \\
\text { l"État, si c'est le plus courant) }\end{array}$} & \multicolumn{2}{|c|}{$\begin{array}{l}\text { Etablissements privès } \\
\text { indépendants }\end{array}$} & \multirow[b]{2}{*}{ 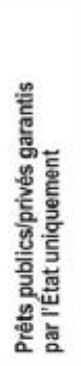 } & \multirow[b]{2}{*}{ 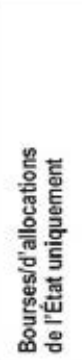 } & \multirow{2}{*}{ 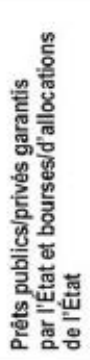 } & \multirow{2}{*}{ 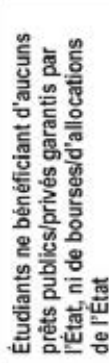 } \\
\hline & & & & 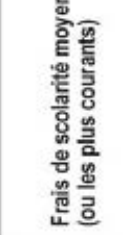 & 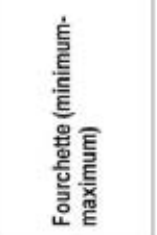 & 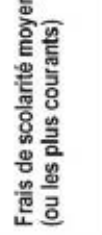 & 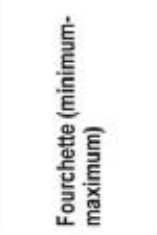 & & & & \\
\hline & (1) & (2) & (3) & (4) & (5) & (6) & (7) & (8) & (9) & (10) & (11) \\
\hline \multicolumn{12}{|l|}{ س Pays } \\
\hline Australie ${ }^{1}$ & 61 & 92 & $8^{4}$ & 5034 & $2564-7199$ & $9360^{\circ}$ & $4022-16823^{4}$ & 46 & 0 & 43 & 11 \\
\hline Autriche' & 30 & 78 & $22^{\mathrm{d}}$ & 921 & m & m & m & a & 15 & a & 85 \\
\hline Canada $^{2}$ & m & 100 & a & 5286 & $2253-7018$ & a & a & $34^{\circ}$ & $36^{4}$ & $x(8,9)$ & 29 \\
\hline Chili & 48 & 20 & 64 & 7524 & $5448-10416$ & 6723 & $3455-11385$ & 21 & 32 & 9 & 38 \\
\hline Danemark & 47 & 99 & 0 & 0 & 0.0 & a & a & 1 & 58 & 27 & 14 \\
\hline Estonie $^{3}$ & 47 & 65 & 13 & 6764 & $2239-11195$ & 8565 & m & a & a & a & a \\
\hline Finlande ${ }^{2}$ & 42 & 39 & a & 0 & 0.0 & a & a & $x(10)$ & $x(10)$ & $58^{\circ}$ & 42 \\
\hline France & m & 86 & 13 & 237 & $237-441$ & m & $\mathrm{m}$ & $\mathrm{m}$ & m & $\mathrm{m}$ & m \\
\hline Allemagne $e^{1.4}$ & 39 & 87 & $13^{d}$ & $133^{4}$ & m & $4908^{\circ}$ & $\mathrm{m}$ & $\mathrm{m}$ & $\mathrm{m}$ & $\mathrm{m}$ & $\mathrm{m}$ \\
\hline Grèce & 64 & 100 & a & 0 & 0.0 & a & a & $\mathrm{m}$ & $\mathrm{m}$ & $\mathrm{m}$ & $\mathrm{m}$ \\
\hline Israẹl & 35 & 74 & 14 & 3130 & $2663-3729$ & 6872 & $3196-10121$ & $\mathrm{~m}$ & $\mathrm{~m}$ & $\mathrm{~m}$ & $\mathrm{~m}$ \\
\hline Italie & 37 & 87 & 13 & 1926 & $287-3713$ & 6707 & $2298-12926$ & 0 & 38 & 0 & 62 \\
\hline Japon & $\mathrm{m}$ & 20 & 80 & 5234 & $\mathrm{~m}$ & 8784 & $\mathrm{~m}$ & $\mathrm{~m}$ & $\mathrm{~m}$ & $\mathrm{~m}$ & $m$ \\
\hline Corèe & 56 & 24 & 76 & 4886 & $2804-7050$ & 8760 & $2064-10560$ & $\mathrm{~m}$ & $\mathrm{~m}$ & $\mathrm{~m}$ & $m$ \\
\hline Lettonie' & 56 & 75 & 25 & 4291 & $2076-11208$ & 4652 & $1100-15833$ & $\mathrm{~m}$ & $\mathrm{~m}$ & $\mathrm{~m}$ & $\mathrm{~m}$ \\
\hline Pays-Bas & 51 & 90 & 10 & 2537 & $1499 \cdot 12687$ & $\mathrm{~m}$ & $m$ & m & $\mathrm{m}$ & $\mathrm{m}$ & $m$ \\
\hline Nouvelle-Zélande ${ }^{2,6}$ & 41 & 94 & 2 & $4487^{d}$ & $3590-10260$ & $\mathrm{~m}$ & $\mathrm{~m}$ & 54 & 2 & 34 & 10 \\
\hline Norvège $^{2}$ & 52 & 82 & 13 & 0 & 0.0 & $5680^{\circ}$ & $2820-7557$ & 12 & 2 & 76 & 10 \\
\hline Portugal & 42 & 80 & 20 & $\mathrm{~m}$ & $1187-1840$ & $\mathrm{~m}$ & $\mathrm{~m}$ & 0 & 21 & 0 & 79 \\
\hline Rèpublique slovaque & 41 & 87 & 13 & 0 & 0.0 & 2148 & $1266-7470$ & $\mathrm{~m}$ & m & $\mathrm{m}$ & $\mathrm{m}$ \\
\hline Slovenie & 65 & 85 & 9 & 0 & 0.0 & 0 & $0-0$ & $a$ & $\mathrm{~m}$ & a & m \\
\hline Espagne & 44 & 83 & 17 & 1747 & $902-12082$ & 7771 & $902-21052$ & 0 & 44 & 0 & 56 \\
\hline Suéde & 30 & 95 & a & 0 & $0-0$ & a & a & 0 & 19 & 75 & 6 \\
\hline Suisse' & 40 & $90^{\circ}$ & 10 & $1291^{d}$ & $335-3981^{\circ}$ & 3202 & $\mathrm{~m}$ & 0 & 7 & 1 & 92 \\
\hline Etats-Unis & m & 67 & 33 & 8804 & $6737-10753$ & 29478 & $16975-41304$ & 10 & 26 & 53 & 11 \\
\hline \multicolumn{12}{|l|}{ Economies } \\
\hline Comm. flamande (Belgique) & 72 & 39 & 0.1 & m & $137-1160$ & m & $\mathrm{m}$ & m & m & m & m \\
\hline Comm. française (Belgique) ${ }^{27}$ & 72 & $99.9^{\circ}$ & 0.1 & $536^{4}$ & $0-1069$ & a & a & 0 & 20 & 0 & 80 \\
\hline Angleterre $(\mathrm{RU})^{3,5}$ & 48 & 100 & a & $11866^{4}$ & $m-12882$ & a & a & $94^{\circ}$ & $x(8)$ & $x(8)$ & 6 \\
\hline
\end{tabular}

Remarque : Les données sur les effectifs scolarisés sont présentées pour l'année 2016/17. L'année de référence peut différer entre les pays. Consulter l'annexe 3 pour de plus amples informations. La valeur « 0 » est indiquée pour les établissements ne demandant pas de frais de scolarité.

La ventilation des données par type d'établissements est disponible en ligne (voir le StatLink ci-dessous).

1. Les établissements privés subventionnés par l'État sont inclus dans les établissements privés indépendants. Pour l'Allemagne et l'Autriche, les établissements privés subventionnés par l'Etat sont uniquement inclus dans les établissements privés indépendants pour les données sur les effectifs scolarisés.

2. Les données sur l'aide financière se réfèrent à l'enseignement tertiaire dans son ensemble au lieu des licences et premiers masters de type long ou programmes de niveau équivalent.

3. Les données sont indiquées pour les établissements privés subventionnés par l'État, et non les établissements publics.

4. Les frais de scolarité sont indiqués pour l'enseignement tertiaire dans son ensemble au lieu du niveau licence ou équivalent. Ils correspondent aux étudiants nationaux et aux étudiants étrangers. Seuls sont inclus les programmes académiques.

5. Les formations tertiaires de cycle court sont incluses dans les formations de licence ou les programmes de niveau équivalent.

6. Les estimations incluent uniquement les universités et excluent les formations du niveau 6 de la CITE, telles que les certifications et diplômes de troisième cycle.

7. Les établissements privés subventionnés par l'État sont inclus dans les établissements publics.

Source : OCDE (2019). Consulter la section « Source » pour tout complément d'information et l'annexe 3 pour les notes (https://doi.org/10.1787/f8d7880d-en). Les symboles représentant les données manquantes et les abréviations figurent dans le Guide du lecteur. 
Tableau C5.3. Prêts publics aux étudiants, remboursement et allègement de la dette dans l'enseignement tertiaire (2017/18)

\begin{tabular}{|c|c|c|c|c|c|c|c|c|c|c|c|c|}
\hline & \multicolumn{4}{|c|}{ Disponibilitè des prêts } & \multicolumn{2}{|c|}{$\begin{array}{l}\text { Dette au moment } \\
\text { de l'obtention du } \\
\text { diplöme tertiaire }\end{array}$} & \multicolumn{4}{|c|}{ Remboursement } & \multicolumn{2}{|c|}{$\begin{array}{l}\text { Allégement } \\
\text { de la dette }\end{array}$} \\
\hline & 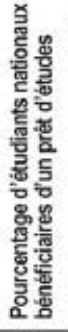 & 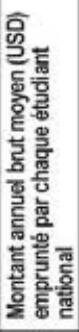 & 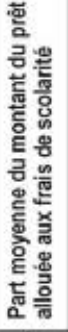 & 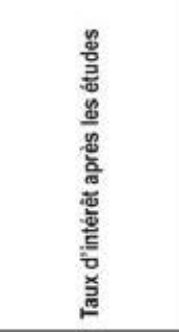 & 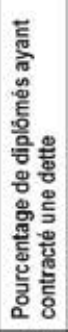 & 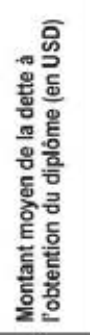 & 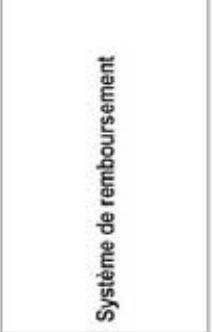 & 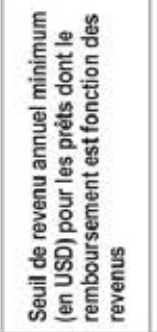 & 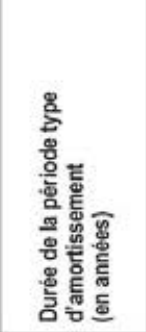 & 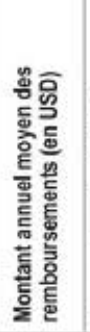 & 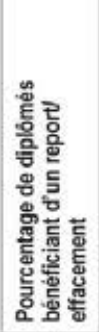 & 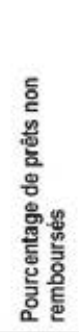 \\
\hline & (1) & (2) & (3) & (4) & (5) & (6) & (7) & (8) & (9) & (10) & (ii) & (12) \\
\hline س Pays & & & & & & & & & & & & \\
\hline O Australie & 81 & 5573 & $\mathrm{~m}$ & $1.9 \%$ & 78 & 10479 & En fonction des revenus & 38682 & 9 & 3002 & m & a \\
\hline Canada & 34 & 6286 & 85 & $\mathrm{~m}$ & 60 & 17622 & $\mathrm{~m}$ & $\mathrm{~m}$ & 10 & $\mathrm{~m}$ & m & 10 \\
\hline Chili & 23 & 4561 & 100 & $2.0 \%$ & $\mathrm{~m}$ & m & $\begin{array}{l}\text { En fonction des revenus } \\
\text { (Gusqu'a } 5 \% \text { des } \\
\text { revenus mensuels) }\end{array}$ & $\mathrm{m}$ & m & m & m & $\mathrm{m}$ \\
\hline Danemark & 26 & 3937 & 100 & $1.0 \%$ & $\mathrm{~m}$ & 13902 & $\begin{array}{l}\text { Sur le modèle des prets } \\
\text { hypothécaires }\end{array}$ & a & $\mathrm{m}$ & $\mathrm{m}$ & $\mathrm{m}$ & $\mathrm{m}$ \\
\hline Estonic' & 6 & $\mathrm{~m}$ & $\mathrm{~m}$ & $5.0 \%$ & a & a & $\begin{array}{c}\text { Sur le modète des prêts } \\
\text { hypothécares }\end{array}$ & a & 6 & a & a & 0 \\
\hline Finlande' & 55 & 6063 & 0 & $\begin{array}{c}\text { Taux d'intérêt } \\
\text { convenu avec les } \\
\text { banques privées }\end{array}$ & 57 & 11719 & $\begin{array}{c}\text { Sur le modèle des préts } \\
\text { hypothécaires }\end{array}$ & a & 5 à 15 & 1982 & $\begin{array}{l}\text { Moins } \\
\text { de } 2 \%\end{array}$ & $\begin{array}{l}\text { Moins } \\
\text { de } 2 \%\end{array}$ \\
\hline Allemagne & $\mathrm{m}$ & $\mathrm{m}$ & $\mathrm{m}$ & $0.0 \%$ & m & $\mathrm{m}$ & $\begin{array}{c}\text { Sur le modèle des prêtts } \\
\text { hypothécaires }\end{array}$ & 18219 & m & $\mathrm{m}$ & m & m \\
\hline Italie & 0 & $\mathrm{~m}$ & $\mathrm{~m}$ & $\mathrm{~m}$ & $\mathrm{~m}$ & $\mathrm{~m}$ & $\mathrm{~m}$ & $\mathrm{~m}$ & $\mathrm{~m}$ & $\mathrm{~m}$ & $\mathrm{~m}$ & $\mathrm{~m}$ \\
\hline Japon $^{2}$ & 37 & 7669 & m & $0 \%$ à $3 \%$ & m & 28269 & $\begin{array}{l}\text { Hybrid. Sur le modèle } \\
\text { des prets hypothécares } \\
\text { and En fonctoon des } \\
\text { revenus }\end{array}$ & a & 13 & 1674 & 0 & $\mathrm{~m}$ \\
\hline Corèe ${ }^{1}$ & $m$ & 4798 & 76 & $2.2 \%$ & $\mathrm{~m}$ & $\mathrm{~m}$ & $\begin{array}{l}\text { Hytride : sur le modèle } \\
\text { des prets hypothécaires } \\
\text { et en fonction des } \\
\text { revenus }\end{array}$ & \begin{tabular}{|c|} 
Pour les \\
prêts dont le \\
remboursement \\
est fonction des \\
revenus : 23608
\end{tabular} & 10 (maximum) & $\mathrm{m}$ & $\mathrm{m}$ & $\mathrm{m}$ \\
\hline Lettonie' & 5 & 2407 & m & $\begin{array}{l}\begin{array}{l}6 \text { mois EURIBOR } \\
+2.5 \%\end{array}\end{array}$ & 0 & a & $\begin{array}{l}\text { Sur le modèle des prêts } \\
\text { hypothécaires }\end{array}$ & a & $\begin{array}{l}10 \text { ans pour les } \\
\text { prêts supérieurs } \\
\text { d2 } 2900 \text { USD. } \\
5 \text { ans pour les } \\
\text { autres }\end{array}$ & a & a & 2 \\
\hline Mexique & & & & & & & $m$ & & & & & \\
\hline Pays-Bas & 48 & 8433 & $\mathrm{~m}$ & $0.3 \%$ & 67 & 18974 & $\begin{array}{l}\text { Hybride : sur le modèle } \\
\text { des préts hypothécaires } \\
\text { et en fonction des } \\
\text { revenus }\end{array}$ & 17372 & 15 & 1567 & $\mathrm{~m}$ & 10 \\
\hline Nouvelle-Zelande & 84 & 7596 & 64 & $\begin{array}{c}\text { Taux dintérét } \\
\text { de } 0 \% \text { pour les } \\
\text { induidus installés en } \\
\text { Nouvelle-Zélande, } \\
\text { et de } 4.4 \% \text { pourl les } \\
\text { autues }\end{array}$ & 72 & 24117 & En fonction des revenus & 13011 & 8 & 2010 & $\begin{array}{c}0.2 \% \\
\text { approx. }\end{array}$ & $\mathrm{m}$ \\
\hline Norvège & 88 & 10382 & $\mathrm{~m}$ & $2.2 \%$ & m & 28698 & $\begin{array}{l}\text { Surle modele des prêts } \\
\text { hypothécaires }\end{array}$ & 0 & 20 & 1820 & 1 & 3 \\
\hline République slovaque & 1 & 4669 & m & $3.0 \%$ & 1 & 3263 & $\begin{array}{c}\text { Sur le modèle des prêts } \\
\text { hypothécaires }\end{array}$ & a & 7 & 871 & m & m \\
\hline Slovénie & a & a & a & a & a & a & $\mathrm{m}$ & a & a & a & a & a \\
\hline Espagne & 0 & 0 & m & m & m & m & $\mathrm{m}$ & $\mathrm{m}$ & $\mathrm{m}$ & m & m & m \\
\hline Suéde & 71 & 7186 & 1 & $0.1 \%$ & 73 & 19116 & $\begin{array}{c}\text { Sur le modele des préts } \\
\text { hypothécaires }\end{array}$ & a & 25 & 903 & 0 & 0 \\
\hline Suisse & 1 & 6101 & a & $\mathrm{m}$ & $\mathrm{m}$ & $\mathrm{m}$ & $\mathrm{m}$ & $\mathrm{m}$ & $\mathrm{m}$ & $\mathrm{m}$ & $\mathrm{m}$ & $\mathrm{m}$ \\
\hline Etats-Unis & m & m & m & $5.1 \%$ à $72 \%$ & m & $\mathrm{m}$ & m & m & m & $\mathrm{m}$ & m & $m$ \\
\hline \multicolumn{13}{|l|}{ Economies } \\
\hline Comm. française (Belgi & 0 & 0 & $\mathrm{~m}$ & $\mathrm{~m}$ & $\mathrm{~m}$ & $\mathrm{~m}$ & $\mathrm{~m}$ & m & $\mathrm{m}$ & $\mathrm{m}$ & $\mathrm{m}$ & $\mathrm{m}$ \\
\hline Angleterre (RU) ${ }^{1,3}$ & 94 & 17033 & $\mathrm{~m}$ & $1.6 \%$ a $4.6 \%$ & 94 & 49812 & En fonction des revenus & 30059 & 30 & $\mathrm{~m}$ & 70 & 45 \\
\hline
\end{tabular}

Remarque : L'année de référence peut différer entre les pays. Consulter l'annexe 3 pour de plus amples informations.

1. Les informations sur la dette, le remboursement et le report se réfèrent aux prêts privés garantis par l'Etat, et non aux prêts publics.

2. Les deux types de remboursement sont : le remboursement fixe (qui est fonction du montant total emprunté et du nombre d'échéances de remboursement) ; et le remboursement en fonction des revenus (qui dépend des revenus de l'étudiant l'année précédente).

3. Le pourcentage d'étudiants bénéficiant d'un prêt et le montant annuel moyen emprunté sont présentés pour les programmes tertiaires de cycle court, les licences et les masters de type long.

Source : OCDE (2019). Consulter la section « Source » pour tout complément d'information et l'annexe 3 pour les notes (https://doi.org/10.1787/f8d7880d-en). Les symboles représentant les données manquantes et les abréviations figurent dans le Guide du lecteur. 
Tableau C5.4. Évolution des politiques de frais de scolarité et de l'aide publique aux étudiants (2007/08 à 2017/18) Frais de scolarité en équivalents USD convertis sur la base des PPA (prix constants de 2017), étudiants nationaux scolarisés à temps plein

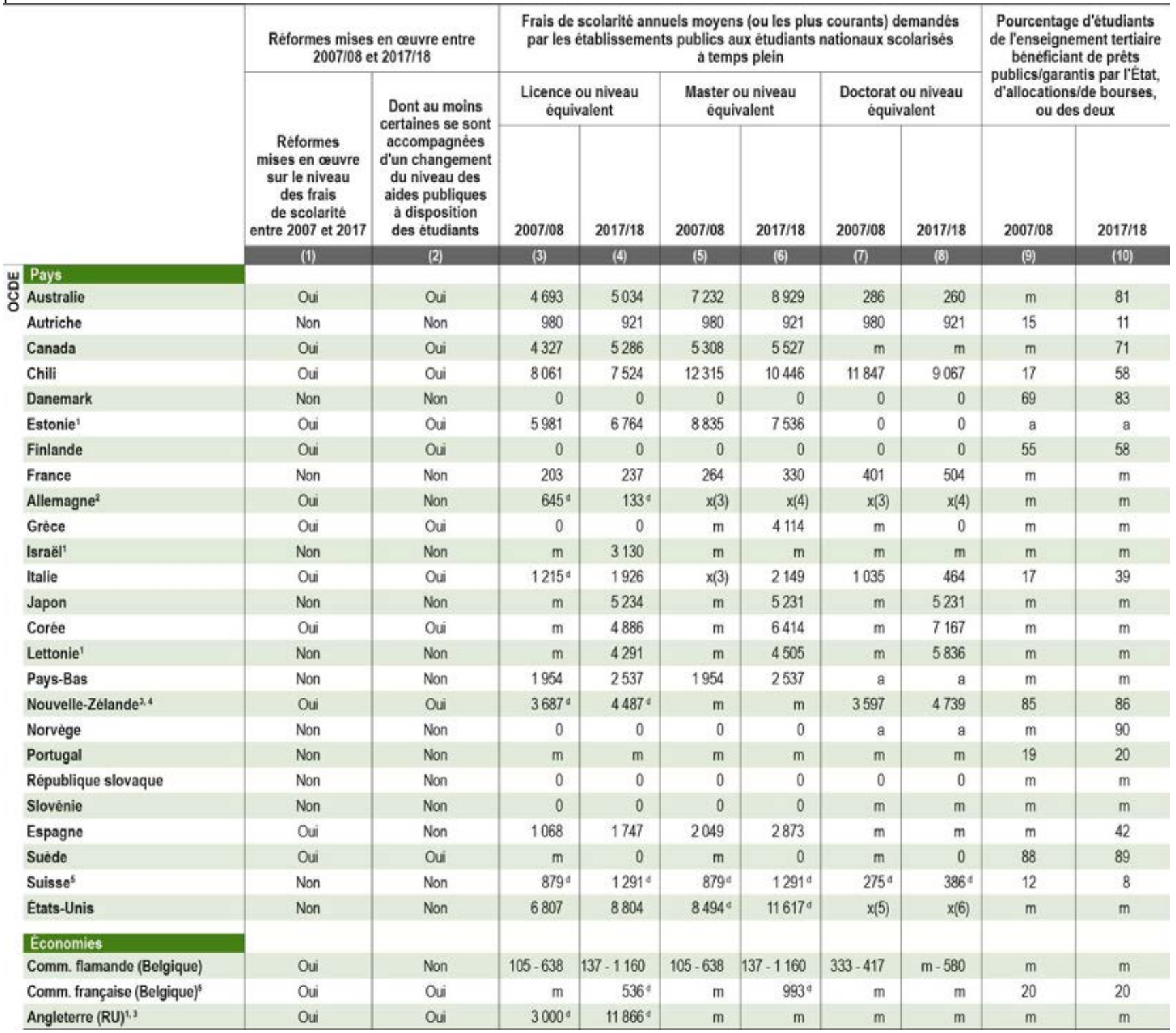

Remarque : L'année de référence peut différer entre les pays. Consulter l'annexe 3 pour de plus amples informations.

1. Établissements privés subventionnés par l'État, et non établissements publics.

2. Les frais de scolarité sont indiqués pour l'enseignement tertiaire dans son ensemble au lieu du niveau licence ou équivalent. Les frais de scolarité sont applicables aux ressortissants nationaux et étrangers. Seuls sont inclus les programmes académiques.

3. Les formations tertiaires de cycle court sont incluses dans les formations de licence ou les programmes de niveau équivalent.

4. Les estimations incluent uniquement les universités et excluent les formations du niveau 6 de la CITE, telles que les certifications et diplômes de troisième cycle.

5. Les établissements privés subventionnés par l'État sont inclus dans les établissements publics.

Source : OCDE (2019). Consulter la section « Source » pour tout complément d'information et l'annexe 3 pour les notes (https://doi.org/10.1787/f8d7880d-en). Les symboles représentant les données manquantes et les abréviations figurent dans le Guide du lecteur. 



\section{Indicateur C6. À quelles catégories de services et de ressources les dépenses d'éducation sont- elles affectées?}

\section{Faits marquants}

- En moyenne, dans les pays de l'OCDE, les dépenses de fonctionnement (biens et services consommés durant l'année) représentent $92 \%$ des dépenses des établissements, de l'enseignement primaire à l'enseignement tertiaire.

- La rémunération du personnel constitue la part la plus importante des dépenses de fonctionnement à tous les niveaux d'enseignement. Dans les pays de l'OCDE, elle représente en moyenne $78 \%$ des dépenses de fonctionnement dans l'enseignement non tertiaire à l'exclusion de l'enseignement préprimaire (enseignement primaire, secondaire et post-secondaire non tertiaire) et $69 \%$ dans l'enseignement tertiaire.

- Les pays de l'OCDE consacrent aux dépenses en capital $8 \%$ en moyenne de leurs dépenses totales d'éducation. Ce pourcentage est plus élevé dans l'enseignement tertiaire (10\%) que dans l'enseignement non tertiaire ( $7 \%)$, mais il varie selon les pays et le type d'établissement.

\section{Graphique C6.1. Part des dépenses en capital, selon le type d'établissement (2016)}

Niveau de formation égal à l'enseignement tertiaire

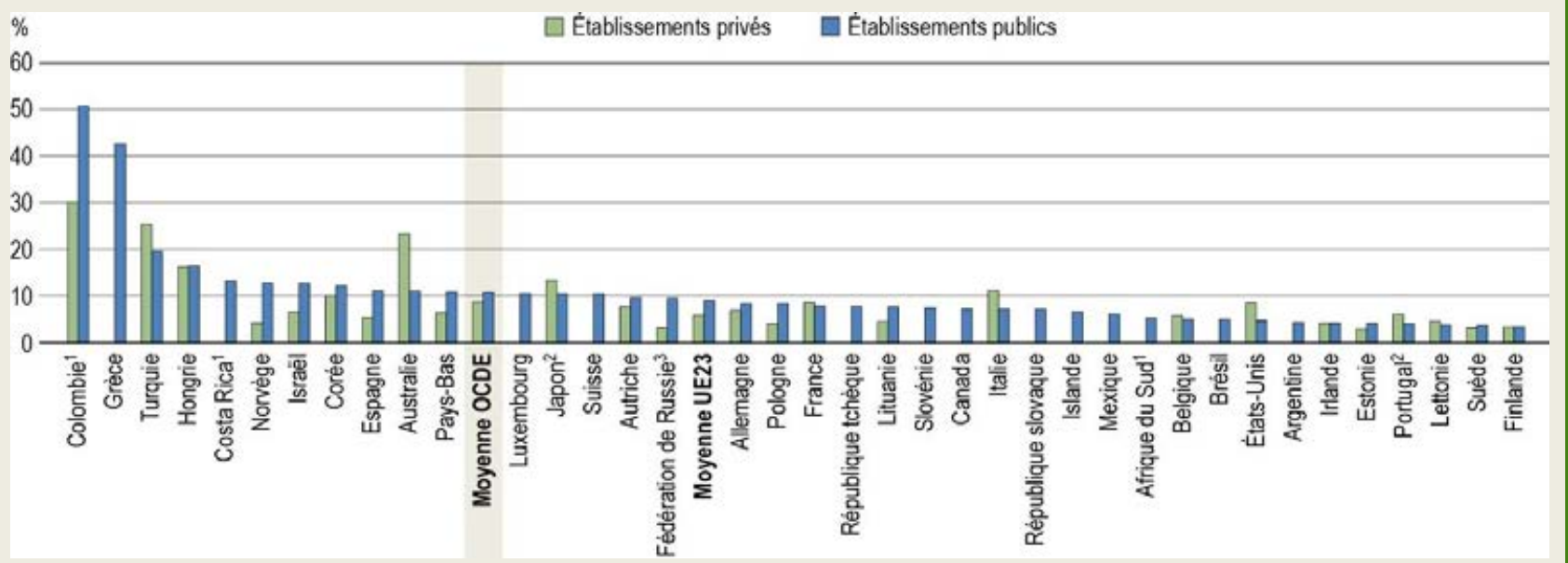

1. Année de référence : 2017.

2. L'enseignement tertiaire inclut les programmes d'enseignement post-secondaire non tertiaire.

3. L'enseignement tertiaire inclut le deuxième cycle du secondaire (filière professionnelle). Les pays sont classés par ordre décroissant de la part des dépenses en capital dans les établissements d'enseignement publics. Source : OCDE/ISU/Eurostat (2019), Base de données de Regards sur l'éducation, http://stats.oecd.org/. Consulter la section « Source » pour tout complément d'information et l'annexe 3 pour les notes (https://doi.org/10.1787/f8d7880d-en). 


\section{Contexte}

La répartition des ressources entre les dépenses de fonctionnement et les dépenses en capital peut avoir un impact sur la qualité de l'instruction (notamment au travers de la rémunération des enseignants), les conditions dans lesquelles l'enseignement est dispensé (telles que les dépenses au titre de l'entretien des locaux) ainsi que la capacité du système d'éducation à s'adapter aux tendances démographiques et à l'évolution des taux de scolarisation. Les décisions relatives à l'affectation des ressources peuvent donc influer sur la nature de l'enseignement et, en fin de compte, sur les résultats de l'apprentissage. Trouver le bon équilibre, en fonction des priorités des pays en matière d'éducation, est un défi que doivent relever tous les gouvernements et établissements. Comparer la répartition des dépenses au titre de l'éducation selon les catégories de ressources peut donner des indications sur les différentes structures d'organisation et de fonctionnement mises en œuvre par les pays.

Cet indicateur décrit les ressources et les services que finance le budget de l'éducation, toutes sources de financement confondues (sources publiques, internationales et privées). II montre la différence entre les dépenses de fonctionnement et les dépenses en capital. Les dépenses en capital peuvent augmenter avec l'accroissement des effectifs, qui nécessite souvent la construction de nouveaux bâtiments. Cet indicateur étudie également en détail la nature des dépenses de fonctionnement, de la rémunération du personnel aux services tels que la cantine, les transports scolaires, le logement et/ou les activités de recherche.

\section{Autres faits marquants}

- La rémunération du personnel constitue la part la plus importante des dépenses de fonctionnement à tous les niveaux d'enseignement. Dans l'enseignement non tertiaire (hormis l'enseignement préprimaire), la rémunération des enseignants absorbe quatre cinquièmes de la masse salariale, le cinquième restant allant au personnel non enseignant.

- Dans l'enseignement non tertiaire, la part des dépenses totales allouée aux dépenses de fonctionnement des établissements publics $(93 \%)$ est similaire à celle des établissements privés (94\%). À l'inverse, dans l'enseignement tertiaire, les établissements privés consacrent une part plus élevée aux dépenses de fonctionnement (92 \%) que les établissements publics (89\%).

- La part des dépenses de fonctionnement consacrée à la rémunération du personnel non enseignant varie selon les établissements non tertiaires. Elle varie entre environ $20 \%$ ou plus en Estonie, aux États-Unis, en France, en Islande et en Lituanie, et moins de $10 \%$ en Autriche, en Colombie et au Luxembourg. 


\section{Analyse}

\section{Répartition du budget de l'éducation entre dépenses de fonctionnement et dépenses en capital, selon le niveau d'enseignement}

Les dépenses des établissements d'enseignement sont réparties entre dépenses de fonctionnement et dépenses en capital. Les dépenses de fonctionnement comprennent les dépenses au titre des ressources consommées chaque année pour le fonctionnement des établissements, tandis que les dépenses en capital sont les dépenses afférentes à l'acquisition ou la maintenance d'actifs à amortir pendant plus d'un an (voir la section « Définitions "). L'importance des ressources humaines mobilisées par l'enseignement explique pourquoi les dépenses de fonctionnement, en particulier la rémunération du personnel, représentent la part la plus élevée du budget global de l'éducation dans les pays de l'OCDE. En 2016 dans les pays de l'OCDE, les dépenses de fonctionnement représentaient en moyenne $92 \%$ du budget total de l'éducation tous niveaux confondus, de l'enseignement primaire à l'enseignement tertiaire. Tous niveaux d'enseignement confondus, la part des dépenses de fonctionnement des pays varie entre $81 \%$ en Colombie et $96 \%$ en Belgique, en Islande, en Italie, au Portugal et au Royaume-Uni (voir le tableau C6.1).

La part moyenne des dépenses de fonctionnement des pays de l'OCDE est plus élevée dans l'enseignement non tertiaire (93\%) que dans l'enseignement tertiaire (90\%). Dans l'enseignement primaire, la part des dépenses de fonctionnement des pays varie entre $80 \%$ en Slovénie et $99 \%$ en Italie, tandis que dans l'enseignement secondaire, elle varie entre $87 \%$ en Slovénie et en Turquie et $98 \%$ en Autriche. Dans l'enseignement post-secondaire non tertiaire, elle varie entre $87 \%$ en Irlande et $100 \%$ en Israël et au Luxembourg, alors que dans l'enseignement tertiaire, elle varie entre $57 \%$ en Grèce et $97 \%$ en Estonie et en Finlande. La part globale des dépenses de fonctionnement ne varie pas de plus 3 points de pourcentage en moyenne, tous niveaux d'enseignement confondus. Dans la plupart des pays, cette part est plus élevée dans l'enseignement non tertiaire que dans l'enseignement tertiaire. La Corée, l'Estonie, les États-Unis, la Finlande, I'Irlande, Israël, la Lettonie, la Norvège, la Slovénie et la Suède sont les seuls pays où la part des dépenses de fonctionnement est plus élevée dans l'enseignement tertiaire que dans l'enseignement non tertiaire.

La variation de la répartition des dépenses selon les pays reflète la façon dont les différents niveaux d'enseignement sont organisés dans chaque pays ainsi que la mesure dans laquelle les pays ont investi dans la construction de nouveaux bâtiments, qui devient souvent nécessaire avec l'accroissement des effectifs. En moyenne, dans les pays de l'OCDE la part des dépenses en capital est généralement plus élevée dans l'enseignement tertiaire (10\%) que dans l'enseignement non tertiaire (7\%). Dans l'enseignement tertiaire, la part des dépenses en capital atteint même $21 \%$ en Turquie, $40 \%$ en Colombie et $43 \%$ en Grèce. Dans l'enseignement non tertiaire, c'est la Slovénie qui consacre la part la plus élevée (16\%) du budget de l'éducation aux dépenses en capital, parmi les pays dont les données sont disponibles.

Les différences de répartition du budget de l'éducation entre dépenses de fonctionnement et dépenses en capital dans l'enseignement tertiaire peuvent s'expliquer en partie par les contrats de propriété ou de location des bâtiments universitaires. Par exemple, dans de nombreux cas, les établissements d'enseignement tertiaire peuvent être propriétaires des bâtiments et des terrains utilisés pour leur mission d'enseignement, mais ils peuvent aussi les occuper gracieusement ou les louer. Par conséquent, le montant des dépenses de fonctionnement et des dépenses en capital dépend en partie du type de gestion de l'infrastructure immobilière en vigueur dans chaque pays (voir l'encadré B6.1 dans OCDE (2012[1])).

\section{Répartition des dépenses de fonctionnement}

Les dépenses de fonctionnement au titre de l'éducation se répartissent entre trois grandes catégories fonctionnelles : 1) la rémunération des enseignants ; 2 ) la rémunération du personnel non enseignant ; et 3 ) les autres dépenses de fonctionnement (par exemple, l'achat de matériel pédagogique et de fournitures scolaires, l'entretien des locaux, la cantine, la location d'infrastructures scolaires). La part relative de ces postes de 
dépenses ne varie généralement guère d'une année à l'autre. Toutefois, l'évolution des taux de scolarisation aujourd'hui et à l'avenir, de la rémunération du personnel de l'éducation et des coûts d'entretien des infrastructures scolaires peut influer sur le budget de chaque poste, tant en valeur absolue qu'en valeur relative.

Graphique C6.2. Répartition des dépenses de fonctionnement dans les établissements d'enseignement publics et privés (2016)
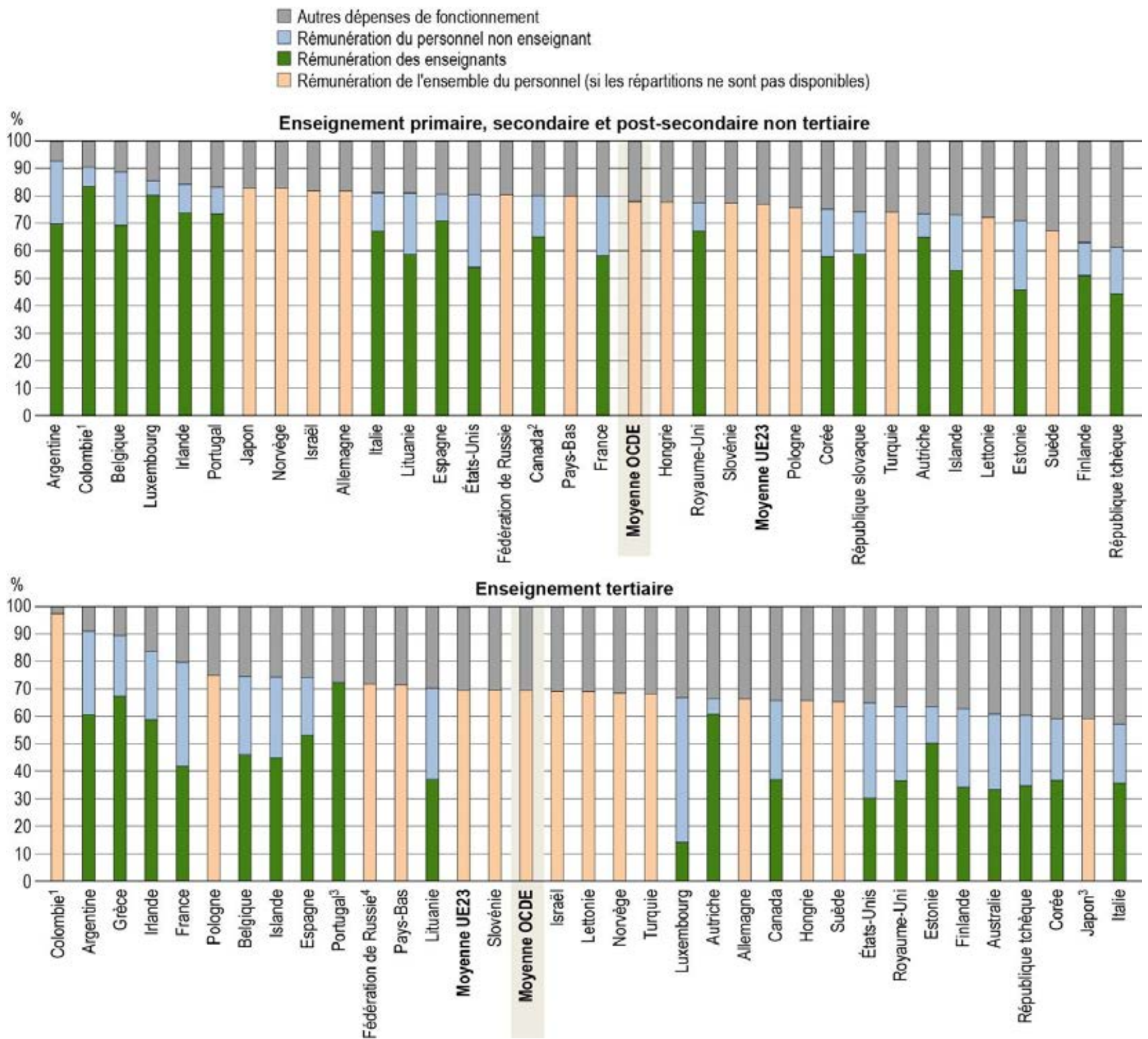

1. Année de référence : 2017.

2. L'enseignement primaire inclut des programmes de l'enseignement préprimaire.

3. L'enseignement tertiaire inclut les programmes d'enseignement post-secondaire non tertiaire.

4. L'enseignement tertiaire inclut le deuxième cycle du secondaire (filière professionnelle).

Les pays sont classés par ordre décroissant de la part de la rémunération de tous les personnels dans les établissements d'enseignement primaire, secondaire et post-secondaire non tertiaire.

Source : OCDE/ISU/Eurostat (2019), tableau C6.2. Consulter la section « Source » pour tout complément d'information et l'annexe 3 pour les notes (https://doi.org/10.1787/f8d7880d-en). 
La rémunération des enseignants et des autres personnels constitue la part la plus importante des dépenses de fonctionnement tant dans l'enseignement non tertiaire que dans l'enseignement tertiaire. En revanche, les salaires représentent une part des dépenses plus élevée dans l'enseignement non tertiaire (78\%) que dans l'enseignement tertiaire (69\%), soit une différence de 9 points de pourcentage. Dans l'enseignement non tertiaire, les pays de l'OCDE consacrent en moyenne $63 \%$ des dépenses totales de fonctionnement à la rémunération des enseignants et en consacrent $15 \%$ à la rémunération du personnel non enseignant, ce qui laisse 22 \% pour les autres postes de dépenses de fonctionnement (voir le tableau C6.2 et le graphique C6.2).

La répartition des dépenses de fonctionnement varie sensiblement entre les niveaux d'enseignement selon les pays. Tous niveaux d'enseignement confondus, la part de la rémunération du personnel dans les dépenses totales de fonctionnement est la moins élevée dans l'enseignement tertiaire dans la plupart des pays. La Colombie et l'Islande sont les seuls pays où la part de la rémunération du personnel dans les dépenses de fonctionnement est plus élevée dans l'enseignement tertiaire qu'à tout autre niveau d'enseignement (voir le tableau C6.2), avec une différence de respectivement 1 et 6 points de pourcentage entre l'enseignement tertiaire et l'enseignement non tertiaire. Tous niveaux d'enseignement confondus, la Colombie se distingue nettement des autres pays: elle tend à consacrer une part plus importante des dépenses de fonctionnement à la rémunération du personnel $(92 \%)$ et une part moins importante aux autres services acquis et contractuels, tels que les services de maintenance (l'entretien des bâtiments, par exemple), les services auxiliaires (la cantine, par exemple) et la location des bâtiments scolaires et autres.

La variation de la part des dépenses de fonctionnement allouée aux « autres dépenses » s'explique dans une certaine mesure par les différences de taille des systèmes administratifs (par exemple, les moyens humains et matériels des services administratifs peuvent varier entre les niveaux d'enseignement). Le coût des infrastructures et de l'équipement est généralement plus élevé dans l'enseignement tertiaire que dans les autres niveaux d'enseignement. En outre, dans certains pays, les établissements d'enseignement tertiaire sont plus susceptibles de prendre des bâtiments en location, ce qui peut absorber une part substantielle des dépenses de fonctionnement. La variation de la part de la rémunération du personnel non enseignant entre les pays s'explique en partie par la mesure dans laquelle ce personnel (les chefs d'établissement, les conseillers d'orientation, les chauffeurs de cars scolaires, les infirmières scolaires, les concierges et le personnel d'entretien) est inclus dans la catégorie du «personnel non enseignant ». Dans l'enseignement tertiaire, la rémunération du personnel responsable des activités de recherche et de développement peut également expliquer en partie la variation de la part des dépenses dans cette catégorie entre les pays et entre les niveaux d'enseignement (voir l'indicateur C1).

\section{Répartition de la part des dépenses de fonctionnement et de la part des dépenses en capital entre les établissements publics et privés}

La part réservée aux dépenses de fonctionnement et aux dépenses en capital varie généralement d'une façon similaire entre les établissements publics et privés, même si les différences sont plus marquées dans l'enseignement tertiaire que dans l'enseignement non tertiaire. Dans les pays de l'OCDE, la part moyenne des dépenses de fonctionnement dans les établissements privés (94\%) est inférieure d'un point de pourcentage à celle qui est allouée dans les établissements publics (93\%) dans l'enseignement non tertiaire. Dans l'enseignement tertiaire, la part des dépenses de fonctionnement dans les établissements privés (92\%) est supérieure de 3 points de pourcentage à celle qui est consacrée dans les établissements publics (89\%). C'est en Colombie que la différence est la plus marquée à ce niveau d'enseignement (21 points de pourcentage). La part des dépenses de fonctionnement est sensiblement plus élevée dans l'enseignement public en Australie, où la différence atteint 12 points de pourcentage (voir le tableau C6.3).

La part des dépenses de fonctionnement allouée aux différents postes varie aussi entre les établissements publics et privés (voir le tableau C6.3). En moyenne, dans les pays de l'OCDE, la part des dépenses de fonctionnement consacrée à la rémunération du personnel dans l'enseignement non tertiaire est plus élevée de 8 points de pourcentage dans les établissements publics ( $80 \%$ ) que dans les établissements privés ( $72 \%$ ). Les 
différences entre le secteur public et le secteur privé sont les plus marquées en Italie, au Portugal et en Turquie, où elles sont supérieures à 20 points de pourcentage. La tendance inverse s'observe en Norvège, où la rémunération du personnel absorbe une part plus élevée des dépenses de fonctionnement dans les établissements privés que dans les établissements publics. Dans l'enseignement tertiaire, les établissements publics consacrent également une part plus importante de leurs dépenses de fonctionnement à la rémunération du personnel (69\% en moyenne, dans les pays de l'OCDE) que les établissements privés (63\%). Toutefois, la part des dépenses de fonctionnement consacrée à la rémunération du personnel est moins élevée dans l'enseignement tertiaire qu'aux niveaux inférieurs d'enseignement, ce qui suggère l'existence de postes de dépenses autres que la rémunération du personnel dans l'enseignement tertiaire, tant dans les établissements publics que privés.

Que les établissements privés consacrent une part moins élevée de leurs dépenses de fonctionnement à la rémunération du personnel peut s'expliquer par des facteurs inhérents au système d'éducation de chaque pays. Les établissements privés sont par exemple plus susceptibles de sous-traiter des services, de louer des bâtiments scolaires et autres infrastructures (contrairement aux établissements publics, dont les sites sont des biens publics), et de payer leurs fournitures plus cher puisqu'ils ne peuvent pas faire autant d'économies d'échelle que le secteur public.

En moyenne, dans les pays de l'OCDE, la part des dépenses en capital dans le budget total est très similaire dans les établissements d'enseignement tertiaire publics (11\%) et privés $(9 \%)$. Elle varie toutefois fortement entre les établissements publics et privés dans certains pays (voir le graphique C6.1). La part des dépenses en capital est la plus élevée dans les établissements publics en Colombie, en Grèce et en Turquie, où elle représente plus de $20 \%$ des dépenses totales dans l'enseignement tertiaire. Ce constat peut s'expliquer par les plus faibles taux d'obtention d'un diplôme de l'enseignement tertiaire en Colombie et en Turquie (voir l'indicateur A1) et le fait que la plupart des étudiants colombiens sont inscrits dans des établissements privés (voir l'indicateur B1). La part des dépenses en capital est la moins élevée (moins de $5 \%$ ) dans les établissements publics en Argentine, en Estonie, en Finlande, en Irlande, en Lettonie, au Portugal et en Suède. Les différences sont plus marquées entre les pays dans les établissements privés : les dépenses en capital représentent plus de $25 \%$ du budget total des établissements privés en Colombie et en Turquie, mais moins de $4 \%$ en Estonie, en Fédération de Russie, en Finlande et en Suède. La part du budget total consacrée aux dépenses en capital varie de moins de 3 points de pourcentage entre les établissements publics et privés dans deux tiers des pays dont les données sont disponibles. La part des dépenses en capital varie le plus en Colombie, où elle est proportionnellement plus élevée de 20 points de pourcentage dans les établissements privés que dans les établissements publics.

\section{Définitions}

Les dépenses en capital sont les dépenses consacrées aux actifs dont la durée de vie est supérieure à un an et comprennent les dépenses relatives à la construction de locaux, à leur rénovation et aux grosses réparations, ainsi que les dépenses liées à l'acquisition de nouveaux équipements ou au remplacement des équipements existants. Les dépenses en capital rapportées ici représentent la valeur du capital acquis ou créé au cours de l'année considérée - soit la valeur du capital constitué -, que ces dépenses aient été financées par des recettes courantes ou au moyen d'emprunts. Ni les dépenses de fonctionnement, ni les dépenses en capital ne tiennent compte des dépenses afférentes au service de la dette.

Les dépenses de fonctionnement sont les dépenses afférentes aux biens et aux services utilisés pendant l'année en cours qui doivent être effectuées de manière récurrente pour fournir les services d'éducation. Les dépenses de fonctionnement des établissements d'enseignement (autres que celles afférentes à la rémunération des personnels) comprennent les dépenses liées aux services sous-traités, comme les services de maintenance (l'entretien des locaux scolaires, par exemple), les services auxiliaires (la cantine, par exemple) et la location des bâtiments scolaires et autres. Ces services sont fournis par des prestataires extérieurs, contrairement aux services fournis par les autorités responsables de l'éducation ou par les établissements et leur propre personnel. 
La rémunération du personnel (personnel enseignant et non enseignant, voir ci-dessous) comprend 1) les salaires (les salaires bruts du personnel de l'éducation, avant impôts, hors cotisations de retraite, d'assurance maladie, de sécurité sociale et autres et primes, etc.) ; 2) les dépenses au titre de la retraite (budget dépensé ou imputé par les employeurs ou tiers pour financer les pensions de retraite du personnel de l'éducation); et 3) les dépenses au titre d'avantages sociaux (assurance maladie ou invalidité, allocations de chômage, primes de naissance et frais de garde d'enfants et autres formes d'assurance sociale). Le "personnel enseignant » désigne uniquement le personnel qui participe directement à l'instruction. Le "personnel non enseignant " désigne le personnel ayant des fonctions pédagogiques, administratives, d'appui et de soutien (les chefs d'établissement, de département et autre, les conseillers, les psychologues et infirmiers scolaires, les bibliothécaires et le personnel technique).

\section{Méthodologie}

Les dépenses se rapportent aux établissements d'enseignement publics ou, si ces données sont disponibles, aux établissements d'enseignement publics et privés.

Pour de plus amples informations, veuillez consulter le Guide de l'OCDE pour l'établissement de statistiques internationalement comparables dans le domaine de l'éducation 2018: Concepts, normes, définitions et classifications (OCDE, 2019 ${ }_{[2]}$ ) et les notes spécifiques aux pays à l'annexe 3 (https://doi.org/10.1787/f8d7880den).

\section{Sources}

Les données se rapportent à l'année budgétaire 2016 (sauf mention contraire) et proviennent de l'exercice de I'UNESCO, I'OCDE et Eurostat (UOE) de collecte de données statistiques sur l'éducation réalisé par l'OCDE en 2018 (pour plus de précisions, voir l'annexe 3, https://doi.org/10.1787/f8d7880d-en). Les données de l'Afrique du Sud, de l'Arabie saoudite, de l'Argentine, de l'Inde, de l'Indonésie et de la République populaire de Chine proviennent de l'Institut de statistique de I'UNESCO (ISU).

\section{Note concernant les données d'Israël}

Les données statistiques concernant Israël sont fournies par et sous la responsabilité des autorités israéliennes compétentes. L'utilisation de ces données par l'OCDE est sans préjudice du statut des hauteurs du Golan, de Jérusalem-Est et des colonies de peuplement israéliennes en Cisjordanie aux termes du droit international.

\section{Références}

OCDE (2019), Guide de l'OCDE pour l'établissement de statistiques internationalement comparables dans le domaine de l'éducation 2018: Concepts, normes, définitions et classifications, Éditions OCDE, Paris, https://dx.doi.org/10.1787/9789264305380-fr.

OCDE (2012), Regards sur l'éducation 2012: Les indicateurs de l'OCDE, Éditions OCDE, Paris, 


\section{Tableaux de l'indicateur C6}

Tableau C6.1

Tableau C6.2

Tableau C6.3
Part des dépenses de fonctionnement et des dépenses en capital, selon le niveau d'enseignement (2016)

Répartition des dépenses de fonctionnement, selon la catégorie de ressources (2016)

Part des dépenses de fonctionnement, selon la catégorie de ressources et le type d'établissement (2016)

Date butoir pour les données: 19 juillet 2019. Les mises à jour peuvent être consultées en ligne sur : http://dx.doi.org/10.1787/eag-data-en. D'autres données désagrégées sont également disponibles dans la Base de données de Regards sur l'éducation (http://stats.oecd.org/).

StatLink: https://doi.org/10.1787/888933981153 
Tableau C6.1. Part des dépenses de fonctionnement et des dépenses en capital, selon le niveau d'enseignement (2016) Répartition des dépenses en capital et de fonctionnement (de sources publiques ou privées) des établissements d'enseignement

\begin{tabular}{|c|c|c|c|c|c|c|c|c|c|c|c|c|c|c|c|c|}
\hline & & & \multicolumn{6}{|c|}{ Secondaire } & \multirow{2}{*}{\multicolumn{2}{|c|}{$\begin{array}{l}\text { Post-secondaire } \\
\text { non tertiaire }\end{array}$}} & \multirow{2}{*}{\multicolumn{2}{|c|}{$\begin{array}{c}\text { Primaire, } \\
\text { secondaire et } \\
\text { post-secondaire } \\
\text { non tertiaire }\end{array}$}} & \multirow{2}{*}{\multicolumn{2}{|c|}{ Tertiaire }} & \multirow{2}{*}{\multicolumn{2}{|c|}{$\begin{array}{l}\text { Du primaire } \\
\text { au tertiaire }\end{array}$}} \\
\hline & \multicolumn{2}{|c|}{ Primaire } & \multicolumn{2}{|c|}{$\begin{array}{l}\text { Premier cycle } \\
\text { du secondaire }\end{array}$} & \multicolumn{2}{|c|}{$\begin{array}{l}\text { Deuxième cycle } \\
\text { du secondaire }\end{array}$} & \multicolumn{2}{|c|}{$\begin{array}{c}\text { Ensemble } \\
\text { du secondaire }\end{array}$} & & & & & & & & \\
\hline & 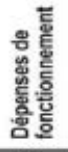 & 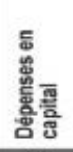 & 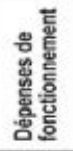 & 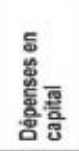 & 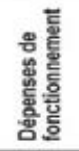 & 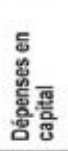 & 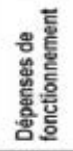 & 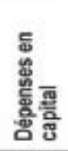 & 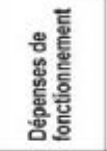 & 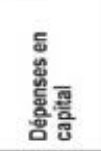 & 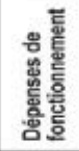 & 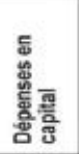 & 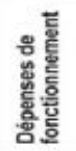 & 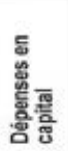 & 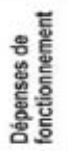 & 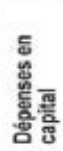 \\
\hline & (1) & (2) & (3) & (4) & (5) & (6) & (7) & (8) & (9) & (10) & (11) & (12) & (13) & (14) & (15) & (16) \\
\hline \multicolumn{17}{|l|}{ w Pays } \\
\hline Oustralie & 93 & 7 & $\mathrm{~m}$ & $m$ & $\mathrm{~m}$ & $\mathrm{~m}$ & m & $\mathrm{m}$ & $\mathrm{m}$ & $\mathrm{m}$ & m & m & 88 & 12 & $m$ & m \\
\hline Autriche & 93 & 7 & 97 & 3 & 98 & 2 & 98 & 2 & 99 & 1 & 96 & 4 & 91 & 9 & 94 & 6 \\
\hline Belgique & 95 & 5 & 97 & 3 & $97^{\circ}$ & $3^{4}$ & $97^{\circ}$ & $3^{\circ}$ & $\times(5,7)$ & $x(6,8)$ & 96 & 4 & 95 & 5 & 96 & 4 \\
\hline Canada $^{\top}$ & $93^{\circ}$ & $7^{4}$ & $x(1)$ & $x(2)$ & 93 & 7 & 93 & 7 & $\mathrm{~m}$ & $\mathrm{~m}$ & $93^{\circ}$ & $7^{d}$ & 93 & 7 & $93^{\circ}$ & $7^{4}$ \\
\hline Chill $^{2}$ & m & $\mathrm{m}$ & $\mathrm{m}$ & $\mathrm{m}$ & $\mathrm{m}$ & $\mathrm{m}$ & m & m & a & a & $\mathrm{m}$ & $\mathrm{m}$ & $\mathrm{m}$ & $\mathrm{m}$ & m & m \\
\hline Colombie $^{2}$ & 90 & 10 & 93 & 7 & $92^{\circ}$ & $8^{4}$ & $92^{\circ}$ & $8^{\circ}$ & $\times(5,7)$ & $x(6,8)$ & 92 & 8 & 60 & 40 & 81 & 19 \\
\hline République tchèque & 91 & 9 & 91 & 9 & 95 & 5 & 93 & 7 & 94 & 6 & 93 & 7 & 93 & 7 & 93 & 7 \\
\hline Danemark & $\mathrm{m}$ & $\mathrm{m}$ & $\mathrm{m}$ & $\mathrm{m}$ & $\mathrm{m}$ & $\mathrm{m}$ & m & $\mathrm{m}$ & $\mathrm{m}$ & $\mathrm{m}$ & m & $\mathrm{m}$ & $\mathrm{m}$ & $\mathrm{m}$ & m & $\mathrm{m}$ \\
\hline Estonie & 92 & 8 & 93 & 7 & 94 & 6 & 94 & 6 & 98 & 2 & 93 & 7 & 97 & 3 & 94 & 6 \\
\hline Finlande & 88 & 12 & 88 & 12 & $92^{\circ}$ & $8^{4}$ & $90^{4}$ & $10^{d}$ & $\times(5,7)$ & $x(6,8)$ & 89 & 11 & 97 & 3 & 91 & 9 \\
\hline France & 94 & 6 & 93 & 7 & 91 & 9 & 92 & 8 & 92 & 8 & 93 & 7 & 92 & 8 & 93 & 7 \\
\hline Allemagne & 94 & 6 & 95 & 5 & 90 & 10 & 92 & 8 & 93 & 7 & 93 & 7 & 92 & 8 & 92 & 8 \\
\hline Grece & 97 & 3 & 98 & 2 & 96 & 4 & 97 & 3 & $\mathrm{~m}$ & $\mathrm{~m}$ & $\mathrm{~m}$ & $\mathrm{~m}$ & 57 & 43 & $\mathrm{~m}$ & $\mathrm{~m}$ \\
\hline Hongrie & 98 & 2 & 97 & 3 & 97 & 3 & 97 & 3 & 97 & 3 & 97 & 3 & 84 & 16 & 94 & 6 \\
\hline Islande & 95 & 5 & 95 & 5 & 98 & 2 & 97 & 3 & 97 & 3 & 96 & 4 & 94 & 6 & 96 & 4 \\
\hline Irlande & 93 & 7 & 91 & 9 & 91 & 9 & 91 & 9 & 87 & 13 & 92 & 8 & 96 & 4 & 93 & 7 \\
\hline Israë| & 89 & 11 & $\times(5,7)$ & $\times(6,8)$ & $93^{\circ}$ & $7^{4}$ & 93 & 7 & 100 & 0 & 91 & 9 & 93 & 7 & 91 & 9 \\
\hline Italie & 99 & 1 & 99 & 1 & $93^{\circ}$ & $7^{\mathrm{d}}$ & $96^{\circ}$ & $4^{d}$ & $\times(5,7)$ & $x(6,8)$ & 97 & 3 & 92 & 8 & 96 & 4 \\
\hline Japon & 87 & 13 & 87 & 13 & $90^{\circ}$ & $10^{4}$ & $89^{\circ}$ & $11^{\circ}$ & $\times(5,7,13)$ & $x(6,8,14)$ & 88 & 12 & $88^{4}$ & $12^{\circ}$ & 88 & 12 \\
\hline Corée & 86 & 14 & 87 & 13 & 89 & 11 & 89 & 11 & a & a & 87 & 13 & 89 & 11 & 88 & 12 \\
\hline Lettonie & 89 & 11 & 89 & 11 & 92 & 8 & 91 & 9 & 96 & 4 & 90 & 10 & 96 & 4 & 91 & 9 \\
\hline Lituanie & 93 & 7 & 93 & 7 & 92 & 8 & 93 & 7 & 92 & 8 & 93 & 7 & 93 & 7 & 93 & 7 \\
\hline Luxembourg & 98 & 2 & 90 & 10 & 90 & 10 & 90 & 10 & 100 & 0 & 93 & 7 & 90 & 10 & 92 & 8 \\
\hline Mexique & $\mathrm{m}$ & $\mathrm{m}$ & $\mathrm{m}$ & m & $\mathrm{m}$ & $\mathrm{m}$ & $\mathrm{m}$ & $\mathrm{m}$ & a & a & m & $\mathrm{m}$ & $\mathrm{m}$ & $\mathrm{m}$ & $\mathrm{m}$ & $\mathrm{m}$ \\
\hline Pays-Bas & 89 & 11 & 89 & 11 & 91 & 9 & 90 & 10 & a & a & 90 & 10 & 90 & 10 & 90 & 10 \\
\hline Nouvelle-Zélande & $\mathrm{m}$ & $\mathrm{m}$ & $\mathrm{m}$ & $\mathrm{m}$ & $\mathrm{m}$ & $\mathrm{m}$ & $\mathrm{m}$ & $\mathrm{m}$ & $\mathrm{m}$ & m & $\mathrm{m}$ & $\mathrm{m}$ & $\mathrm{m}$ & $\mathrm{m}$ & $\mathrm{m}$ & $\mathrm{m}$ \\
\hline Norvege & 87 & 13 & 87 & 13 & 88 & 12 & 88 & 12 & 88 & 12 & 87 & 13 & 88 & 12 & 87 & 13 \\
\hline Pologne & 94 & 6 & 97 & 3 & 95 & 5 & 96 & 4 & 95 & 5 & 95 & 5 & 92 & 8 & 94 & 6 \\
\hline Portugal & 97 & 3 & 97 & 3 & $94^{\circ}$ & $6^{d}$ & $95^{\circ}$ & $5^{a}$ & $\times(5,7,13)$ & $\times(6,8,14)$ & 96 & 4 & $96^{d}$ & $4^{\circ}$ & 96 & 4 \\
\hline $\begin{array}{l}\text { Republique } \\
\text { slovaque }\end{array}$ & 96 & 4 & 98 & 2 & 95 & 5 & 96 & 4 & 95 & 5 & 96 & 4 & m & m & m & m \\
\hline Slovénie & 80 & 20 & 80 & 20 & 95 & 5 & 87 & 13 & a & a & 84 & 16 & 93 & 7 & 86 & 14 \\
\hline Espagne & 97 & 3 & 98 & 2 & $97^{d}$ & $3^{d}$ & $97^{\circ}$ & $3^{d}$ & $\times(5,7)$ & $x(6,8)$ & 97 & 3 & 90 & 10 & 95 & 5 \\
\hline Suède & 95 & 5 & 95 & 5 & 93 & 7 & 94 & 6 & 94 & 6 & 95 & 5 & 96 & 4 & 95 & 5 \\
\hline Suisse & m & $\mathrm{m}$ & $\mathrm{m}$ & $\mathrm{m}$ & $\mathrm{m}$ & $\mathrm{m}$ & m & m & $\mathrm{m}$ & $\mathrm{m}$ & $\mathrm{m}$ & $\mathrm{m}$ & $\mathrm{m}$ & $\mathrm{m}$ & $\mathrm{m}$ & $\mathrm{m}$ \\
\hline Turquie & 89 & 11 & 90 & 10 & 86 & 14 & 87 & 13 & a & a & 88 & 12 & 79 & 21 & 85 & 15 \\
\hline Royaume-Uni & 97 & 3 & 96 & 4 & 97 & 3 & 96 & 4 & a & a & 97 & 3 & 95 & 5 & 96 & 4 \\
\hline Etats-Unis & 91 & 9 & 91 & 9 & 91 & 9 & 91 & 9 & 92 & 8 & 91 & 9 & 94 & 6 & 92 & 8 \\
\hline Moyenne OCDE & 93 & 7 & 93 & 7 & 93 & 7 & 93 & 7 & $\mathrm{~m}$ & m & 93 & 7 & 90 & 10 & 92 & 8 \\
\hline Moyenne UE23 & 94 & 6 & 94 & 6 & 94 & 6 & 94 & 6 & $\mathrm{~m}$ & $\mathrm{~m}$ & 93 & 7 & 91 & 9 & 93 & 7 \\
\hline
\end{tabular}

\begin{tabular}{|c|c|c|c|c|c|c|c|c|c|c|c|c|c|c|c|c|}
\hline Argentine & $\mathrm{m}$ & $\mathrm{m}$ & m & $\mathrm{m}$ & $\mathrm{m}$ & $m$ & m & m & a & a & $\mathrm{m}$ & m & $\mathrm{m}$ & m & $\mathrm{m}$ & $\mathrm{m}$ \\
\hline "ू Brésil & $\mathrm{m}$ & $\mathrm{m}$ & $\mathrm{m}$ & $\mathrm{m}$ & $\mathrm{m}$ & $\mathrm{m}$ & $\mathrm{m}$ & $\mathrm{m}$ & $\mathrm{m}$ & $\mathrm{m}$ & $\mathrm{m}$ & $\mathrm{m}$ & $\mathrm{m}$ & $\mathrm{m}$ & $\mathrm{m}$ & $\mathrm{m}$ \\
\hline Chine & m & $\mathrm{m}$ & $\mathrm{m}$ & $\mathrm{m}$ & m & $\mathrm{m}$ & $\mathrm{m}$ & $\mathrm{m}$ & $\mathrm{m}$ & $\mathrm{m}$ & $\mathrm{m}$ & $\mathrm{m}$ & $\mathrm{m}$ & $\mathrm{m}$ & $\mathrm{m}$ & $\mathrm{m}$ \\
\hline Costa Rica ${ }^{2}$ & m & $\mathrm{m}$ & $\mathrm{m}$ & $\mathrm{m}$ & $\mathrm{m}$ & $\mathrm{m}$ & $\mathrm{m}$ & $\mathrm{m}$ & a & a & $\mathrm{m}$ & $\mathrm{m}$ & $\mathrm{m}$ & $\mathrm{m}$ & $\mathrm{m}$ & $\mathrm{m}$ \\
\hline Inde & $\mathrm{m}$ & $\mathrm{m}$ & $\mathrm{m}$ & $\mathrm{m}$ & m & $\mathrm{m}$ & $\mathrm{m}$ & m & $\mathrm{m}$ & $\mathrm{m}$ & $\mathrm{m}$ & $\mathrm{m}$ & $\mathrm{m}$ & $\mathrm{m}$ & $\mathrm{m}$ & $\mathrm{m}$ \\
\hline Indonésie ${ }^{2}$ & $\mathrm{~m}$ & $\mathrm{~m}$ & $\mathrm{~m}$ & $\mathrm{~m}$ & $\mathrm{~m}$ & $\mathrm{~m}$ & $\mathrm{~m}$ & $\mathrm{~m}$ & $\mathrm{~m}$ & $\mathrm{~m}$ & $\mathrm{~m}$ & $\mathrm{~m}$ & $\mathrm{~m}$ & $\mathrm{~m}$ & $\mathrm{~m}$ & $\mathrm{~m}$ \\
\hline Fédération de Russie & $x(11)$ & $x(12)$ & $x(11)$ & $x(12)$ & $x(13)$ & $x(14)$ & $x(11)$ & $x(12)$ & $x(11)$ & $x(12)$ & 93 & 7 & 91 & 9 & 92 & 8 \\
\hline Arabie saoudite & $\mathrm{m}$ & m & $\mathrm{m}$ & m & $\mathrm{m}$ & $\mathrm{m}$ & $\mathrm{m}$ & $\mathrm{m}$ & $\mathrm{m}$ & $\mathrm{m}$ & $\mathrm{m}$ & $\mathrm{m}$ & $\mathrm{m}$ & $\mathrm{m}$ & $\mathrm{m}$ & $\mathrm{m}$ \\
\hline Afrique du Sud ${ }^{2}$ & $\mathrm{~m}$ & $\mathrm{~m}$ & $\mathrm{~m}$ & $\mathrm{~m}$ & $\mathrm{~m}$ & $\mathrm{~m}$ & $\mathrm{~m}$ & $\mathrm{~m}$ & $\mathrm{~m}$ & $\mathrm{~m}$ & $\mathrm{~m}$ & $\mathrm{~m}$ & $\mathrm{~m}$ & $\mathrm{~m}$ & m & $\mathrm{m}$ \\
\hline
\end{tabular}

\begin{tabular}{l|l|l|l|l|l|l|l|l|l|l|l|l|l|l|l|l|} 
Moyenne $\mathrm{G} 20$ & $\mathrm{~m}$ & $\mathrm{~m}$ & $\mathrm{~m}$ & $\mathrm{~m}$ & $\mathrm{~m}$ & $\mathrm{~m}$ & $\mathrm{~m}$ & $\mathrm{~m}$ & $\mathrm{~m}$ & $\mathrm{~m}$ & $\mathrm{~m}$ & $\mathrm{~m}$ & $\mathrm{~m}$ & $\mathrm{~m}$ & $\mathrm{~m}$ & $\mathrm{~m}$ \\
\hline
\end{tabular} Remarque : Consulter les sections « Définitions » et « Méthodologie » pour de plus amples informations. Les données et d'autres types de ventilations peuvent être consultés sur http://stats.oecd.org/, Base de données de Regards sur l'éducation.

1. L'enseignement primaire inclut des programmes de l'enseignement préprimaire. Les chiffres de l'enseignement post-secondaire non tertiaire sont considérés comme négligeables.

2. Année de référence : 2017.

Source : OCDE/ISU/Eurostat (2019). Consulter la section « Source » pour tout complément d'information et l'annexe 3 pour les notes (https://doi.org/10.1787/f8d7880d-en). Les symboles représentant les données manquantes et les abréviations figurent dans le Guide du lecteur. 
Tableau C6.2. Dépenses de fonctionnement, selon la catégorie de ressources (2016)

Répartition des dépenses de fonctionnement (de sources publiques ou privées) des établissements d'enseignement en pourcentage des dépenses totales de fonctionnement

\begin{tabular}{|c|c|c|c|c|c|c|c|c|c|c|c|c|}
\hline & \multicolumn{4}{|c|}{$\begin{array}{l}\text { Primaire, secondaire } \\
\text { et post-secondaire non tertiaire }\end{array}$} & \multicolumn{4}{|c|}{ Tertiaire } & \multicolumn{4}{|c|}{ Du primaire au tertiaire } \\
\hline & \multicolumn{3}{|c|}{ Rémunération du personnel } & \multirow{2}{*}{ 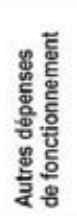 } & \multicolumn{3}{|c|}{ Rémunèration du personnel } & \multirow{2}{*}{ 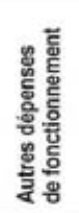 } & \multicolumn{3}{|c|}{ Rèmunération du personnel } & \multirow{2}{*}{ 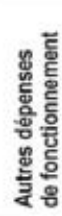 } \\
\hline & Enseignants & $\begin{array}{c}\text { Autres } \\
\text { personnels }\end{array}$ & Total & & Enseignants & $\begin{array}{c}\text { Autres } \\
\text { personnels }\end{array}$ & Total & & Enseignants & $\begin{array}{c}\text { Autres } \\
\text { personnels }\end{array}$ & Total & \\
\hline & (1) & (2) & (3) & (4) & (5) & (6) & (7) & (8) & (9) & (10) & (11) & (12) \\
\hline \multicolumn{13}{|l|}{ 㟒 Pays } \\
\hline Australie & $\mathrm{m}$ & $\mathrm{m}$ & $\mathrm{m}$ & $\mathrm{m}$ & 33 & 28 & 61 & 39 & m & $\mathrm{m}$ & m & $\mathrm{m}$ \\
\hline Autriche & 65 & 8 & 74 & 26 & 61 & 6 & 66 & 34 & 64 & 7 & 71 & 29 \\
\hline Belgique & 69 & 19 & 89 & 11 & 46 & 28 & 74 & 26 & 63 & 22 & 85 & 15 \\
\hline Canada' & $65^{\circ}$ & $15^{\circ}$ & $80^{\circ}$ & $20^{\circ}$ & 37 & 29 & 66 & 34 & $54=$ & $20^{\circ}$ & $75^{\circ}$ & $25^{\circ}$ \\
\hline Chili $^{2}$ & $\mathrm{~m}$ & $\mathrm{~m}$ & m & m & $\mathrm{m}$ & m & m & $\mathrm{m}$ & $\mathrm{m}$ & $\mathrm{m}$ & m & m \\
\hline Colombie $^{2}$ & 84 & 7 & 91 & 9 & $x(7)$ & $x(7)$ & 97 & 3 & $\mathrm{x}(11)$ & $x(11)$ & 92 & 8 \\
\hline République tchèque & 44 & 17 & 62 & 38 & 35 & 26 & 60 & 40 & 42 & 19 & 61 & 39 \\
\hline Danemark & $\mathrm{m}$ & $\mathrm{m}$ & $\mathrm{m}$ & $\mathrm{m}$ & $\mathrm{m}$ & $\mathrm{m}$ & $\mathrm{m}$ & $\mathrm{m}$ & $\mathrm{m}$ & $\mathrm{m}$ & $\mathrm{m}$ & $\mathrm{m}$ \\
\hline Estonie & 46 & 25 & 71 & 29 & 50 & 13 & 64 & 36 & 47 & 21 & 68 & 32 \\
\hline Finlande & 51 & 12 & 63 & 37 & 34 & 29 & 63 & 37 & 46 & 17 & 63 & 37 \\
\hline France & 58 & 22 & 80 & 20 & 42 & 38 & 80 & 20 & 54 & 26 & 80 & 20 \\
\hline Allemagne & $x(3)$ & $x(3)$ & 82 & 18 & $x(7)$ & $x(7)$ & 66 & 34 & $x(11)$ & $x(11)$ & 77 & 23 \\
\hline Grece & $\mathrm{m}$ & $\mathrm{m}$ & $\mathrm{m}$ & $\mathrm{m}$ & 67 & 22 & 89 & 11 & $\mathrm{~m}$ & $\mathrm{~m}$ & $\mathrm{~m}$ & $\mathrm{~m}$ \\
\hline Hongrie & $\mathrm{m}$ & $\mathrm{m}$ & 78 & 22 & $x(7)$ & $x(7)$ & 66 & 34 & $\mathrm{~m}$ & m & 75 & 25 \\
\hline Islande & 53 & 20 & 73 & 27 & 45 & 29 & 74 & 26 & 51 & 22 & 73 & 27 \\
\hline Irlande & 74 & 10 & 84 & 16 & 59 & 25 & 84 & 16 & 70 & 14 & 84 & 16 \\
\hline Israél & $x(3)$ & $x(3)$ & 82 & 18 & $x(7)$ & $x(7)$ & 69 & 31 & $x(11)$ & $\mathrm{x}(11)$ & 78 & 22 \\
\hline Italie & 67 & 14 & 81 & 19 & 36 & 21 & 57 & 43 & 60 & 16 & 76 & 24 \\
\hline Japon & $x(3)$ & $x(3)$ & 83 & 17 & $x(7)$ & $x(7)$ & $59^{\circ}$ & $41^{\circ}$ & $\mathrm{x}(11)$ & $x(11)$ & 75 & 25 \\
\hline Corée & 58 & 17 & 75 & 25 & 37 & 22 & 59 & 41 & 51 & 19 & 70 & 30 \\
\hline Lettonie & $x(3)$ & $x(3)$ & 72 & 28 & $x(7)$ & $x(7)$ & 69 & 31 & $\mathrm{x}(11)$ & $x(11)$ & 71 & 29 \\
\hline Lituanie & 59 & 22 & 81 & 19 & 37 & 33 & 70 & 30 & 52 & 26 & 78 & 22 \\
\hline Luxembourg & 80 & 5 & 86 & 14 & 14 & 53 & 67 & 33 & 70 & 12 & 83 & 17 \\
\hline Mexique & $\mathrm{m}$ & $\mathrm{m}$ & $\mathrm{m}$ & $\mathrm{m}$ & $\mathrm{m}$ & $\mathrm{m}$ & $\mathrm{m}$ & $\mathrm{m}$ & $\mathrm{m}$ & $\mathrm{m}$ & $\mathrm{m}$ & $\mathrm{m}$ \\
\hline Pays-Bas & $x(3)$ & $x(3)$ & 80 & 20 & $x(7)$ & $x(7)$ & 71 & 29 & $\mathrm{x}(11)$ & $x(11)$ & 77 & 23 \\
\hline Nouvelle-Zélande & $\mathrm{m}$ & $\mathrm{m}$ & $\mathrm{m}$ & $\mathrm{m}$ & $\mathrm{m}$ & $\mathrm{m}$ & $\mathrm{m}$ & $\mathrm{m}$ & $\mathrm{m}$ & $\mathrm{m}$ & $\mathrm{m}$ & $\mathrm{m}$ \\
\hline Norvège & $x(3)$ & $x(3)$ & 83 & 17 & $x(7)$ & $x(7)$ & 68 & 32 & $x(11)$ & $x(11)$ & 79 & 21 \\
\hline Pologne & $x(3)$ & $x(3)$ & 76 & 24 & $x(7)$ & $x(7)$ & 75 & 25 & $\mathrm{x}(11)$ & $x(11)$ & 76 & 24 \\
\hline Portugal & 74 & 10 & 83 & 17 & 72 & 0 & $72^{\circ}$ & $28^{\circ}$ & 73 & 7 & 81 & 19 \\
\hline République slovaque & 59 & 16 & 74 & 26 & $\mathrm{~m}$ & $\mathrm{~m}$ & $\mathrm{~m}$ & $\mathrm{~m}$ & $\mathrm{~m}$ & $\mathrm{~m}$ & $\mathrm{~m}$ & $\mathrm{~m}$ \\
\hline Slovènie & $x(3)$ & $x(3)$ & 78 & 22 & $x(7)$ & $x(7)$ & 70 & 30 & $x(11)$ & $x(11)$ & 76 & 24 \\
\hline Espagne & 71 & 10 & 81 & 19 & 53 & 21 & 74 & 26 & 66 & 13 & 79 & 21 \\
\hline Suéde & 54 & 13 & 67 & 33 & $x(7)$ & $x(7)$ & 65 & 35 & $x(11)$ & $x(11)$ & 67 & 33 \\
\hline Suisse & $\mathrm{m}$ & $\mathrm{m}$ & $\mathrm{m}$ & $\mathrm{m}$ & $\mathrm{m}$ & $\mathrm{m}$ & $\mathrm{m}$ & $\mathrm{m}$ & $\mathrm{m}$ & $\mathrm{m}$ & $\mathrm{m}$ & $\mathrm{m}$ \\
\hline Turquie & $x(3)$ & $x(3)$ & 74 & 26 & $x(7)$ & $x(7)$ & 68 & 32 & $\mathrm{x}(11)$ & $x(11)$ & 72 & 28 \\
\hline Royaume-Uni & 67 & 10 & 78 & 22 & 37 & 27 & 64 & 36 & 59 & 15 & 74 & 26 \\
\hline Etats-Unis & 54 & 27 & 81 & 19 & 30 & 34 & 65 & 35 & 44 & 30 & 74 & 26 \\
\hline Moyenne OCDE & 63 & 15 & 78 & 22 & $m$ & m & 69 & 31 & m & m & 76 & 24 \\
\hline Moyenne UE23 & 63 & 15 & $\pi$ & 23 & m & $\mathrm{m}$ & 70 & 30 & $\mathrm{~m}$ & $\mathrm{~m}$ & 75 & 25 \\
\hline
\end{tabular}

\begin{tabular}{|c|c|c|c|c|c|c|c|c|c|c|c|c|}
\hline Argentine & m & m & m & $\mathrm{m}$ & $m$ & $m$ & $\mathrm{~m}$ & $m$ & $m$ & $\mathrm{~m}$ & m & $\mathrm{m}$ \\
\hline Brésil & m & $\mathrm{m}$ & $\mathrm{m}$ & $\mathrm{m}$ & m & m & m & $\mathrm{m}$ & m & m & $\mathrm{m}$ & $\mathrm{m}$ \\
\hline Chine & m & $\mathrm{m}$ & $\mathrm{m}$ & $\mathrm{m}$ & $\mathrm{m}$ & $\mathrm{m}$ & $\mathrm{m}$ & $\mathrm{m}$ & $\mathrm{m}$ & m & $\mathrm{m}$ & $\mathrm{m}$ \\
\hline 吅 Costa Rica ${ }^{2}$ & m & $\mathrm{m}$ & $\mathrm{m}$ & m & m & $\mathrm{m}$ & m & $\mathrm{m}$ & m & m & $\mathrm{m}$ & m \\
\hline Inde & m & $\mathrm{m}$ & m & $\mathrm{m}$ & m & m & m & $\mathrm{m}$ & m & m & $\mathrm{m}$ & $\mathrm{m}$ \\
\hline Indonésie ${ }^{2}$ & $\mathrm{~m}$ & $\mathrm{~m}$ & $\mathrm{~m}$ & $\mathrm{~m}$ & $\mathrm{~m}$ & $\mathrm{~m}$ & $\mathrm{~m}$ & $\mathrm{~m}$ & $\mathrm{~m}$ & $\mathrm{~m}$ & $\mathrm{~m}$ & $\mathrm{~m}$ \\
\hline Fédération de Russie & $x(3)$ & $x(3)$ & 81 & 19 & $x(7)$ & $x(7)$ & 72 & 28 & $\mathrm{x}(11)$ & $x(11)$ & 77 & 23 \\
\hline Arabie saoudite & $\mathrm{m}$ & $\mathrm{m}$ & $\mathrm{m}$ & $\mathrm{m}$ & $\mathrm{m}$ & $\mathrm{m}$ & $\mathrm{m}$ & $\mathrm{m}$ & $\mathrm{m}$ & m & $\mathrm{m}$ & $\mathrm{m}$ \\
\hline Afrique du Sud² & $\mathrm{m}$ & $\mathrm{m}$ & $\mathrm{m}$ & $\mathrm{m}$ & $\mathrm{m}$ & $\mathrm{m}$ & $\mathrm{m}$ & $\mathrm{m}$ & $\mathrm{m}$ & m & $\mathrm{m}$ & $\mathrm{m}$ \\
\hline
\end{tabular}

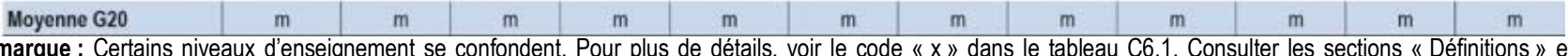

Remarque : Certains niveaux d'enseignement se confondent. Pour plus de détails, voir le code " $\mathrm{x}$ » dans le tableau C6.1. Consulter les sections « Définitions » et " Méthodologie » pour de plus amples informations. Les données et d'autres types de ventilations peuvent être consultés sur http://stats.oecd.org/, Base de données de Regards sur l'éducation.

1. L'enseignement primaire inclut des programmes de l'enseignement préprimaire.

2. Année de référence : 2017

Source : OCDE/ISU/Eurostat (2019). Consulter la section « Source » pour tout complément d'information et l'annexe 3 pour les notes (https://doi.org/10.1787/f8d7880d-en). Les symboles représentant les données manquantes et les abréviations figurent dans le Guide du lecteur. 
Tableau C6.3. Part des dépenses de fonctionnement, selon la catégorie de ressources et le type d'établissement (2016) Répartition des dépenses de fonctionnement des établissements d'enseignement

\begin{tabular}{|c|c|c|c|c|c|c|c|c|c|c|c|c|c|c|c|c|}
\hline & \multicolumn{8}{|c|}{ Primaire, secondaire et post-secondaire non tertiaire } & \multicolumn{8}{|c|}{ Tertiaire } \\
\hline & \multirow{2}{*}{\multicolumn{2}{|c|}{$\begin{array}{c}\text { Part des } \\
\text { dèpenses de } \\
\text { fonctionnement } \\
\text { dans les dépenses } \\
\text { totales }\end{array}$}} & \multicolumn{6}{|c|}{$\begin{array}{l}\text { Rèmunèration du personnel en pourcentage } \\
\text { des dépenses de fonctionnement }\end{array}$} & \multirow{2}{*}{\multicolumn{2}{|c|}{$\begin{array}{c}\text { Part des } \\
\text { dépenses de } \\
\text { fonctionnement } \\
\text { dans les deppenses } \\
\text { totales }\end{array}$}} & \multicolumn{6}{|c|}{$\begin{array}{l}\text { Rèmunèration du personnel en pourcentage } \\
\text { des dépenses de fonctionnement }\end{array}$} \\
\hline & & & \multicolumn{2}{|c|}{$\begin{array}{c}\text { Rémunération } \\
\text { des enseignants }\end{array}$} & \multicolumn{2}{|c|}{$\begin{array}{c}\text { Rémunération } \\
\text { des autres } \\
\text { personnels }\end{array}$} & \multicolumn{2}{|c|}{$\begin{array}{l}\text { Remunération } \\
\text { totale }\end{array}$} & & & \multicolumn{2}{|c|}{$\begin{array}{c}\text { Rèmunération } \\
\text { des enseignants }\end{array}$} & \multicolumn{2}{|c|}{$\begin{array}{l}\text { Rémunération } \\
\text { des autres } \\
\text { personnels }\end{array}$} & \multicolumn{2}{|c|}{$\begin{array}{l}\text { Rémunération } \\
\text { totale }\end{array}$} \\
\hline & 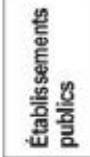 & 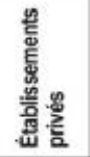 & 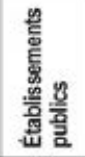 & 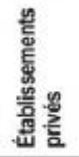 & 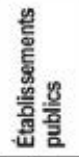 & 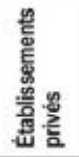 & 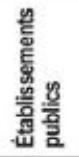 & 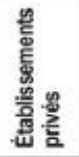 & 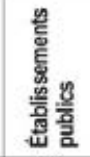 & 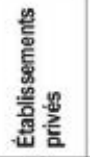 & 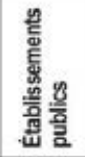 & 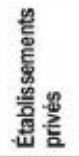 & 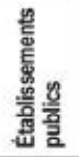 & 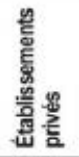 & 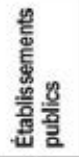 & 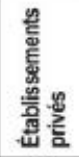 \\
\hline & (1) & (2) & (3) & (4) & (5) & (6) & (a) & (8) & (9) & (10) & (11) & (12) & (13) & (14) & (15) & (16) \\
\hline 宸 Pays & & & & & & & & & & & & & & & & \\
\hline Australie & 95 & m & 62 & m & 15 & $\mathrm{~m}$ & 78 & m & 89 & 77 & 33 & 34 & 28 & 21 & 61 & 56 \\
\hline Autriche & 96 & 99 & 65 & 66 & 9 & 4 & 74 & 70 & 90 & 92 & 61 & 59 & 6 & 3 & 67 & 62 \\
\hline Belgique & 95 & 97 & 68 & 71 & 22 & 18 & 90 & 88 & 95 & 94 & 46 & 46 & 28 & 29 & 74 & 75 \\
\hline Canada' & $93^{4}$ & $94^{\circ}$ & $66^{\circ}$ & $52^{d}$ & $15^{\circ}$ & $20^{\circ}$ & $81^{\circ}$ & $71^{\circ}$ & 93 & a & 37 & a & 29 & a & 66 & a \\
\hline Chilp $^{2}$ & $\mathrm{~m}$ & m & m & $\mathrm{m}$ & m & m & $\mathrm{m}$ & m & $\mathrm{m}$ & $\mathrm{m}$ & m & $\mathrm{m}$ & $\mathrm{m}$ & $\mathrm{m}$ & $\mathrm{m}$ & m \\
\hline Colombie $^{2}$ & 95 & 87 & 87 & 78 & 9 & 4 & 96 & 82 & 49 & 70 & m & 99 & $\mathrm{~m}$ & 1 & 93 & 100 \\
\hline République tchèque & 92 & 100 & 45 & 43 & 17 & 18 & 62 & 61 & 92 & 100 & 36 & 6 & 27 & 3 & 63 & 9 \\
\hline Danemark & m & m & $\mathrm{m}$ & m & $\mathrm{m}$ & $\mathrm{m}$ & $\mathrm{m}$ & $\mathrm{m}$ & $\mathrm{m}$ & $\mathrm{m}$ & m & $\mathrm{m}$ & m & $\mathrm{m}$ & $\mathrm{m}$ & $\mathrm{m}$ \\
\hline Estonie & 93 & 97 & 46 & 51 & 26 & 14 & 72 & 65 & 96 & 97 & 17 & 59 & 37 & 7 & 54 & 66 \\
\hline Finlande & 89 & 95 & 52 & 47 & 11 & 19 & 63 & 66 & 97 & 97 & 31 & 43 & 30 & 26 & 61 & 69 \\
\hline France & 93 & 93 & 59 & 52 & 22 & 20 & 81 & 73 & 92 & 91 & 40 & 53 & 41 & 22 & 81 & 74 \\
\hline Allemagne & 94 & 88 & $x(7)$ & $x(8)$ & $x(7)$ & $x(8)$ & 83 & 76 & 92 & 93 & $x(15)$ & $x(16)$ & $x(15)$ & $x(16)$ & 67 & 60 \\
\hline Grèce & 97 & m & 92 & $\mathrm{~m}$ & 2 & $m$ & 93 & $\mathrm{~m}$ & 57 & a & 67 & a & 22 & a & 89 & a \\
\hline Hongrie & 97 & 97 & $\mathrm{~m}$ & $\mathrm{~m}$ & $\mathrm{~m}$ & $\mathrm{~m}$ & 78 & 77 & 83 & 84 & $\mathrm{~m}$ & $\mathrm{~m}$ & $\mathrm{~m}$ & $\mathrm{~m}$ & 66 & 66 \\
\hline Islande & 96 & 100 & 53 & 55 & 20 & 18 & 73 & 73 & 93 & 100 & 45 & 45 & 29 & 29 & 74 & 74 \\
\hline Irlande & 92 & 100 & 74 & a & 11 & a & 85 & a & 96 & 96 & 59 & a & 25 & a & 84 & a \\
\hline |sraë| & 89 & 96 & $x(7)$ & $x(8)$ & $x(7)$ & $x(8)$ & $85^{\circ}$ & $72^{\circ}$ & 87 & 93 & $x(15)$ & $x(16)$ & $x(15)$ & $x(16)$ & 55 & 70 \\
\hline Italie & 97 & 97 & 68 & 50 & 15 & 0 & 83 & 50 & 93 & 89 & 36 & 34 & 22 & 20 & 58 & 54 \\
\hline Japon & 88 & 85 & $x(7)$ & $x(8)$ & $x(7)$ & $x(8)$ & 84 & 73 & $90^{4}$ & $87^{\circ}$ & $x(15)$ & $x(16)$ & $x(15)$ & $x(16)$ & $54^{\circ}$ & $62^{4}$ \\
\hline Corée & 86 & 93 & 58 & 59 & 18 & 14 & 76 & 73 & 88 & 90 & 28 & 41 & 25 & 21 & 53 & 62 \\
\hline Lettonie & 90 & 89 & $x(7)$ & $x(8)$ & $x(7)$ & $x(8)$ & 72 & 73 & 96 & 95 & $x(15)$ & $x(16)$ & $x(15)$ & $x(16)$ & 64 & 69 \\
\hline Lituanie & 93 & 94 & 59 & 58 & 23 & 18 & 81 & 76 & 92 & 96 & 38 & 24 & 33 & 31 & 71 & 55 \\
\hline Luxembourg & 93 & 93 & 82 & 70 & 4 & 14 & 86 & 84 & 90 & a & 14 & a & 53 & a & 67 & a \\
\hline Mexique & 97 & $\mathrm{~m}$ & 77 & $\mathrm{~m}$ & 14 & $\mathrm{~m}$ & 91 & $\mathrm{~m}$ & 94 & $\mathrm{~m}$ & 54 & $\mathrm{~m}$ & 15 & $\mathrm{~m}$ & 69 & $\mathrm{~m}$ \\
\hline Pays-Bas & 89 & 97 & $x(7)$ & $x(8)$ & $x(7)$ & $x(8)$ & 80 & 86 & 89 & 94 & $x(15)$ & $x(16)$ & $x(15)$ & $x(16)$ & 70 & 78 \\
\hline Nouvelle-Zèlande & $\mathrm{m}$ & $\mathrm{m}$ & $\mathrm{m}$ & $\mathrm{m}$ & $\mathrm{m}$ & $\mathrm{m}$ & $\mathrm{m}$ & $\mathrm{m}$ & $\mathrm{m}$ & $\mathrm{m}$ & $\mathrm{m}$ & $\mathrm{m}$ & $\mathrm{m}$ & $\mathrm{m}$ & $\mathrm{m}$ & $\mathrm{m}$ \\
\hline Norvège & 87 & 100 & $x(7)$ & $x(8)$ & $x(7)$ & $x(8)$ & 82 & 100 & 87 & 96 & $x(15)$ & $x(16)$ & $x(15)$ & $x(16)$ & 69 & 65 \\
\hline Pologne & 96 & 80 & $x(7)$ & $x(8)$ & $x(7)$ & $x(8)$ & 76 & $\pi 7$ & 92 & 96 & $x(15)$ & $x(16)$ & $x(15)$ & $x(16)$ & 76 & 70 \\
\hline Portugal & 98 & 89 & 79 & 48 & 9 & 12 & 89 & 60 & $96^{\circ}$ & $94^{\circ}$ & $75^{4}$ & $59^{\circ}$ & $0^{\circ}$ & $0^{\circ}$ & $75^{\circ}$ & $59^{d}$ \\
\hline République slovaque & 96 & 100 & 59 & 61 & 16 & 13 & 74 & 74 & 93 & $\mathrm{~m}$ & 32 & $\mathrm{~m}$ & 23 & m & 55 & $\mathrm{~m}$ \\
\hline Slovenie & 83 & 100 & $x(7)$ & $x(8)$ & $x(7)$ & $x(8)$ & 78 & 63 & 93 & 100 & $x(15)$ & $x(16)$ & $x(15)$ & $x(16)$ & 71 & 43 \\
\hline Espagne & 98 & 96 & 73 & 64 & 9 & 11 & 83 & 75 & 89 & 95 & 57 & $35^{\circ}$ & 21 & 21 & 78 & 56 \\
\hline Suède & 95 & 94 & 54 & 53 & 14 & 11 & 68 & 66 & 96 & 97 & $x(15)$ & $x(16)$ & $x(15)$ & $x(16)$ & 65 & 65 \\
\hline Suisse & 90 & $\mathrm{~m}$ & 72 & $\mathrm{~m}$ & 14 & $\mathrm{~m}$ & 86 & $\mathrm{~m}$ & 90 & $\mathrm{~m}$ & 50 & $\mathrm{~m}$ & 27 & $\mathrm{~m}$ & 77 & $\mathrm{~m}$ \\
\hline Turquie & 88 & 88 & $x(7)$ & $x(8)$ & $x(7)$ & $x(8)$ & 85 & 38 & 80 & 75 & $\mathrm{x}(15)$ & $x(16)$ & $x(15)$ & $x(16)$ & 68 & 67 \\
\hline Royaume-Uni & 98 & 96 & 67 & 67 & 12 & 9 & 79 & 76 & a & 95 & a & 37 & a & 27 & a & 64 \\
\hline Etats-Unis & 91 & 91 & 54 & 53 & 27 & 26 & 81 & 78 & 95 & 91 & 31 & 28 & 36 & 33 & 67 & 61 \\
\hline Moyenne OCDE & 93 & 94 & 65 & $\mathrm{~m}$ & 15 & m & 80 & 72 & 89 & 92 & m & $\mathrm{m}$ & $\mathrm{m}$ & $\mathrm{m}$ & 69 & 63 \\
\hline Moyenne UE23 & 94 & 95 & 65 & $\mathrm{~m}$ & 14 & $\mathrm{~m}$ & 79 & 72 & 91 & 94 & $\mathrm{~m}$ & $\mathrm{~m}$ & $\mathrm{~m}$ & $\mathrm{~m}$ & 69 & 61 \\
\hline
\end{tabular}

\begin{tabular}{|c|c|c|c|c|c|c|c|c|c|c|c|c|c|c|c|c|}
\hline Argentine & 87 & $\mathrm{~m}$ & 70 & $\mathrm{~m}$ & 23 & $\mathrm{~m}$ & 93 & $\mathrm{~m}$ & 96 & $\mathrm{~m}$ & 61 & $\mathrm{~m}$ & 30 & $\mathrm{~m}$ & 91 & $m$ \\
\hline Brésil & 97 & $\mathrm{~m}$ & $x(7)$ & $\mathrm{m}$ & $x(7)$ & m & 78 & $\mathrm{~m}$ & 95 & $\mathrm{~m}$ & $x(15)$ & m & $x(15)$ & $\mathrm{m}$ & 80 & $\mathrm{~m}$ \\
\hline Chine & $\mathrm{m}$ & $\mathrm{m}$ & $\mathrm{m}$ & $\mathrm{m}$ & $\mathrm{m}$ & $\mathrm{m}$ & $\mathrm{m}$ & $\mathrm{m}$ & $\mathrm{m}$ & $\mathrm{m}$ & $\mathrm{m}$ & $\mathrm{m}$ & $\mathrm{m}$ & m & $\mathrm{m}$ & m \\
\hline Costa Rica ${ }^{2}$ & 93 & m & 79 & $\mathrm{~m}$ & 4 & $\mathrm{~m}$ & 83 & $\mathrm{~m}$ & 87 & $\mathrm{~m}$ & $\mathrm{~m}$ & $\mathrm{~m}$ & $\mathrm{~m}$ & $\mathrm{~m}$ & 77 & $\mathrm{~m}$ \\
\hline${ }^{a}$ Inde & $\mathrm{m}$ & $\mathrm{m}$ & $\mathrm{m}$ & $\mathrm{m}$ & $\mathrm{m}$ & $\mathrm{m}$ & $\mathrm{m}$ & $\mathrm{m}$ & $\mathrm{m}$ & $\mathrm{m}$ & $\mathrm{m}$ & $\mathrm{m}$ & m & m & m & m \\
\hline Indonésie ${ }^{2}$ & $\mathrm{~m}$ & $\mathrm{~m}$ & $\mathrm{~m}$ & $\mathrm{~m}$ & $\mathrm{~m}$ & $\mathrm{~m}$ & $\mathrm{~m}$ & $\mathrm{~m}$ & $\mathrm{~m}$ & $\mathrm{~m}$ & $\mathrm{~m}$ & $\mathrm{~m}$ & $\mathrm{~m}$ & $\mathrm{~m}$ & $\mathrm{~m}$ & $\mathrm{~m}$ \\
\hline Fédération de Russie & 93 & 95 & $x(7)$ & $x(8)$ & $x(7)$ & $x(8)$ & 81 & 62 & $90^{4}$ & $97^{\circ}$ & $x(15)$ & $x(16)$ & $x(15)$ & $x(16)$ & $72^{\circ}$ & $61^{\circ}$ \\
\hline Arabie saoudite & $\mathrm{m}$ & $\mathrm{m}$ & $\mathrm{m}$ & $\mathrm{m}$ & $\mathrm{m}$ & $\mathrm{m}$ & $\mathrm{m}$ & $\mathrm{m}$ & $\mathrm{m}$ & $\mathrm{m}$ & $\mathrm{m}$ & $\mathrm{m}$ & $\mathrm{m}$ & $\mathrm{m}$ & m & m \\
\hline Afrique du Sud ${ }^{2}$ & 95 & $\mathrm{~m}$ & 77 & $\mathrm{~m}$ & 7 & $\mathrm{~m}$ & 83 & $\mathrm{~m}$ & 95 & $\mathrm{~m}$ & 56 & $\mathrm{~m}$ & 0 & $\mathrm{~m}$ & 56 & $\mathrm{~m}$ \\
\hline
\end{tabular}

\begin{tabular}{|l|l|l|l|l|l|l|l|l|l|l|l|l|l|l|l|l|} 
Moyenne $\mathrm{G} 20$ & $\mathrm{~m}$ & $\mathrm{~m}$ & $\mathrm{~m}$ & $\mathrm{~m}$ & $\mathrm{~m}$ & $\mathrm{~m}$ & $\mathrm{~m}$ & $\mathrm{~m}$ & $\mathrm{~m}$ & $\mathrm{~m}$ & $\mathrm{~m}$ & $\mathrm{~m}$ & $\mathrm{~m}$ & $\mathrm{~m}$ & $\mathrm{~m}$ & $\mathrm{~m}$
\end{tabular}

Remarque : Certains niveaux d'enseignement se confondent. Pour plus de détails, voir le code « $\mathrm{x}$ » dans le tableau C6.1. Les données sur le total des dépenses du primaire au tertiaire (soit les colonnes 17 à 24) peuvent être consultées en ligne (voir le StatLink ci-dessous). Consulter les sections « Définitions » et « Méthodologie » pour de plus amples informations. Les données et d'autres types de ventilations peuvent être consultés sur http://stats.oecd.org/, Base de données de Regards sur l'éducation.

1. L'enseignement primaire inclut des programmes de l'enseignement préprimaire.

2. Année de référence : 2017.

Source : OCDE/ISU/Eurostat (2019). Consulter la section « Source » pour tout complément d'information et l'annexe 3 pour les notes (https://doi.org/10.1787/f8d7880d-en). Les symboles représentant les données manquantes et les abréviations figurent dans le Guide du lecteur. 



\section{Indicateur C7. Quels facteurs influent sur le coût salarial des enseignants?}

\section{Faits marquants}

- Dans cet indicateur, le coût salarial des enseignants par élève est calculé sur la base de quatre facteurs : le salaire et le temps d'enseignement des enseignants, le temps d'instruction des élèves et la taille théorique des classes (voir la section "Définitions "). La variation du coût salarial des enseignants par élève peut donc résulter de différentes combinaisons de ces quatre facteurs.

- En moyenne, dans les pays de l'OCDE, le coût salarial des enseignants par élève passe de 2784 USD dans l'enseignement primaire à 3380 USD dans le premier cycle de l'enseignement secondaire.

- Les deux facteurs principaux qui influent sur le coût salarial des enseignants sont le salaire des enseignants et la taille théorique des classes. Entre 2005 et 2017, le salaire des enseignants a progressé dans la plupart des pays de l'OCDE, mais la hausse de ce coût a souvent été compensée par une augmentation de la taille moyenne des classes.

Graphique C7.1. Coût salarial annuel des enseignants par élève dans les établissements publics, selon le niveau d'enseignement (2017)

En équivalents USD convertis sur la base des PPA pour la consommation privée

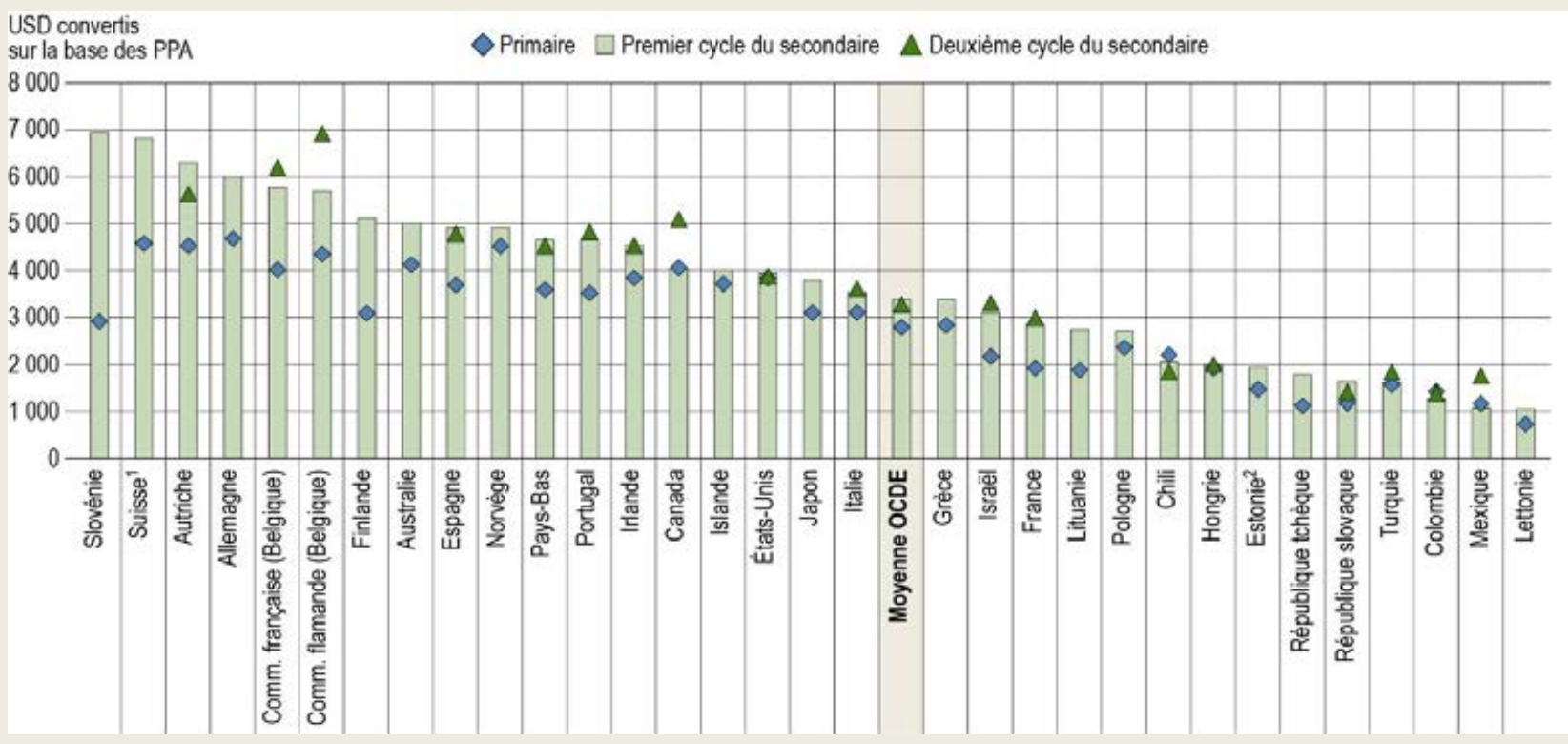

1. Salaire statutaire des enseignants après 10 , et non 15 ans d'exercice.

2. Salaire statutaire des enseignants en début de carrière, et non après 15 ans d'exercice.

Les pays et économies sont classés par ordre décroissant du coût salarial annuel des enseignants par élève dans le premier cycle du secondaire. Source : OCDE (2019), tableau C7.1. Consulter la section "Source » pour tout complément d'information et l'annexe 3 pour les notes (https://doi.org/10.1787/f8d7880d-en). 


\section{Contexte}

Les pouvoirs publics s'intéressent de plus en plus à la relation entre les moyens mobilisés en faveur de l'éducation et les résultats obtenus, car ils cherchent à accroître l'offre d'éducation et à en améliorer la qualité, tout en veillant à l'efficience de l'utilisation du financement public, en particulier en temps d'austérité budgétaire. La rémunération des enseignants est généralement le poste le plus important du budget de l'éducation et, par voie de conséquence, des dépenses par élève. Le coût salarial des enseignants par élève tel qu'il est calculé dans cet indicateur varie en fonction du temps d'instruction des élèves, du temps d'enseignement des enseignants, du salaire statutaire des enseignants et de la taille théorique des classes (voir la section « Méthodologie »).

La variation de ces facteurs entre les pays peut donc expliquer les différences dans le niveau de dépenses unitaires. De même, un niveau comparable de dépenses unitaires peut être le résultat de différentes combinaisons de ces facteurs. Cet indicateur analyse les choix d'affectation budgétaire des pays dans l'enseignement primaire et secondaire et montre dans quelle mesure les orientations politiques différentes au sujet de ces facteurs affectent le coût salarial des enseignants.

Le coût salarial des enseignants par élève peut varier en fonction d'autres facteurs qui ne sont pas directement évalués dans cet indicateur, notamment l'évolution démographique. Dans les pays où l'effectif d'élèves a par exemple commencé à diminuer au cours des dernières années, la taille des classes devrait également diminuer (dans l'hypothèse où les autres facteurs restent constants), sauf dans l'hypothèse d'une diminution concomitante du nombre d'enseignants. Dans cet indicateur, il n'y a pas de distinction entre les motifs, l'évolution démographique ou une décision politique, de la réduction de la taille des classes.

\section{Autres faits marquants}

- Un niveau de dépenses similaire entre les pays peut occulter la diversité de choix politiques contrastés. En France et en Hongrie par exemple, le coût salarial des enseignants par élève est similaire, mais le salaire statutaire des enseignants est $80 \%$ plus élevé en France qu'en Hongrie, ce qui est plus que compensé par le fait que l'on compte sept élèves de plus environ de plus par classe en France (selon la taille théorique des classes).

- En moyenne, dans les pays de l'OCDE, le coût salarial des enseignants par élève représente $6.7 \%$ du produit intérieur brut (PIB) par habitant dans l'enseignement primaire et $8.2 \%$ dans le premier cycle de l'enseignement secondaire.

- À un coût salarial donné, une diminution de la taille des classes peut être compensée par une diminution du salaire des enseignants ou du temps d'instruction ou une augmentation du temps d'enseignement. En Australie par exemple, pour réduire la taille théorique des classes d'un élève sans modifier le coût salarial par élève, le salaire annuel des enseignants devrait diminuer de 3600 USD, le temps annuel d'instruction devrait diminuer de 57 heures ou le temps annuel d'enseignement devrait augmenter de 53 heures.

\section{Remarque}

Le coût salarial des enseignants par élève est estimé sur la base du salaire statutaire brut des enseignants ayant les qualifications les plus courantes (voir l'indicateur D3) après 15 ans d'exercice, du temps d'instruction théorique des élèves (voir l'indicateur D1) et du temps d'enseignement statutaire des enseignants (voir l'indicateur D4). Par conséquent, cette estimation peut différer du coût salarial effectif des enseignants (voir l'encadré C7.1).

Le choix du salaire statutaire implique que le niveau de qualification et la pyramide des âges du corps enseignant ne sont pas pris en considération dans cet indicateur. Le salaire statutaire s'entend hors cotisations patronales au régime de sécurité sociale et de retraite de sorte qu'il ne correspond pas au coût total à charge de l'employeur (les pouvoirs publics, en l'espèce). II s'ensuit que cet indicateur n'est pas comparable à l'indicateur sur les dépenses au titre de la rémunération des enseignants (voir l'indicateur B6). 


\section{Analyse}

\section{Variation du coût salarial des enseignants par élève, selon le niveau d'enseignement}

En moyenne, dans les pays et économies de l'OCDE, le coût salarial des enseignants par élève s'établit à 2784 USD dans l'enseignement primaire, à 3380 USD dans le premier cycle de l'enseignement secondaire et à 3274 USD dans le deuxième cycle de l'enseignement secondaire (voir le graphique C7.1). Chacune de ces moyennes occulte la forte variation du coût salarial entre les pays. Dans l'enseignement primaire par exemple, le coût salarial des enseignants par élève est plus de six fois plus élevé en Allemagne (4 679 USD) qu'en Lettonie (720 USD). Le coût salarial est plus élevé lorsque le salaire des enseignants ou le taux d'encadrement est plus élevé, ce qui est le cas si les classes sont moins denses, que les élèves ont plus d'heures de cours à suivre ou que les enseignants ont moins d'heures de cours à donner.

L'accroissement généralisé du coût salarial des enseignants entre l'enseignement primaire et le premier cycle de l'enseignement secondaire s'explique par le fait que les enseignants gagnent plus et donnent moins d'heures de cours et que les élèves suivent plus d'heures de cours, autant d'éléments qui poussent le coût à la hausse. Selon les chiffres de 2017 des pays de l'OCDE, le salaire statutaire annuel des enseignants après 15 ans d'exercice s'établit en moyenne à 43007 USD dans le premier cycle de l'enseignement secondaire, soit 1950 USD de plus que dans l'enseignement primaire. De plus, le temps annuel d'instruction dans le premier cycle de l'enseignement secondaire est supérieur de 124 heures à celui prévu dans l'enseignement primaire et le temps moyen d'enseignement est inférieur de 83 heures, ce qui implique qu'il faut davantage d'enseignants pour prendre en charge un nombre donné d'élèves.

Contrairement aux autres facteurs, la taille théorique des classes tend à augmenter entre l'enseignement primaire et le premier cycle de l'enseignement secondaire, ce qui compense en partie l'augmentation du coût entre les deux niveaux d'enseignement (dans les pays de l'OCDE, la taille théorique des classes passe en moyenne de 15 élèves dans l'enseignement primaire à 17 élèves dans le premier cycle de l'enseignement secondaire). Toutefois, l'effet de la taille supérieure des classes n'est pas suffisant pour compenser l'augmentation du coût due aux trois autres facteurs. Le Chili, la Colombie et le Mexique sont les seuls pays de I'OCDE où le coût salarial des enseignants par élève est moins élevé dans le premier cycle de l'enseignement secondaire que dans l'enseignement primaire (voir les tableaux C7.5a et b, disponibles en ligne), ce qui s'explique essentiellement par une augmentation de la taille théorique des classes entre l'enseignement primaire et le premier cycle de l'enseignement secondaire.

Dans quelques pays, l'environnement d'apprentissage et l'organisation des établissements d'enseignement sont relativement similaires dans l'enseignement primaire et le premier cycle de l'enseignement secondaire. En 2017 par exemple, la différence de coût salarial des enseignants par élève entre l'enseignement primaire et le premier cycle de l'enseignement secondaire était inférieure à 100 USD au Canada, en Hongrie, au Mexique et en Turquie. La différence la plus importante s'observe en Slovénie, où elle atteint 4036 USD.

\section{Variation du coût salarial des enseignants par élève, après contrôle de la richesse nationale}

Comme le niveau du coût salarial des enseignants par élève est en corrélation positive avec le PIB par habitant des pays, il est important de tenir compte également de la richesse relative des pays dans les comparaisons internationales. En moyenne, dans les pays de l'OCDE, le coût salarial des enseignants par élève représente $6.7 \%$ du PIB par habitant dans l'enseignement primaire, $8.2 \%$ dans le premier cycle de l'enseignement secondaire et $8.0 \%$ dans la filière générale du deuxième cycle de l'enseignement secondaire (voir le tableau C7.1).

Le classement de quelques pays change une fois que le PIB par habitant est pris en considération. En Pologne par exemple, le coût salarial des enseignants par élève, 2355 USD, est inférieur à la moyenne de l'OCDE. Toutefois, ce montant représente $7.9 \%$ du PIB par habitant du pays, soit un pourcentage supérieur à la moyenne de l'OCDE (6.7 \%). II s'ensuit qu'en Pologne, le coût salarial des enseignants est supérieur à la moyenne en 
pourcentage du PIB par habitant, alors qu'il est relativement peu élevé en valeur absolue. L'inverse s'observe en Irlande, où le coût salarial des enseignants par élève dans l'enseignement primaire (3 844 USD) est nettement supérieur à la moyenne de l'OCDE, mais ne représente que $5 \%$ du PIB par habitant, un pourcentage nettement inférieur à la moyenne de l'OCDE.

\section{Encadré C7.1. Réserves méthodologiques et pistes potentielles d'analyse à l'avenir}

Le coût salarial des enseignants par élève présenté dans cet indicateur est une estimation du budget consacré à la rémunération du corps enseignant dans chaque pays. En plus des salaires des enseignants, cet indicateur prend en considération trois facteurs qui influent sur le nombre d'enseignants requis : le temps d'instruction obligatoire pour les élèves, le temps d'enseignement des enseignants et la taille théorique des classes. La section « Méthodologie » fournit de plus amples informations sur les relations entre ces facteurs et sur la façon dont ils sont combinés pour calculer le coût salarial.

Il est important de tenir compte des réserves méthodologiques de cet indicateur lors de l'interprétation des résultats. En premier lieu, le coût salarial est calculé compte tenu du salaire et du temps d'enseignement des enseignants et du temps d'instruction des élèves sous leur forme statutaire. II s'ensuit que les résultats présentés dans cet indicateur sont théoriques et ne reflètent ni le temps d'enseignement réel des enseignants, ni leur rémunération annuelle réelle. En fait, même le temps d'instruction et le temps d'enseignement sont devenus des concepts de nature plus théorique à mesure que les cadres d'apprentissage ont gagné en souplesse, de sorte que ces variables sont difficiles à mesurer avec précision.

En second lieu, comme cet indicateur se base sur des données nationales, il ne peut rendre compte des grandes différences susceptibles d'exister au sein même des pays. L'arbitrage entre le salaire des enseignants et la taille des classes peut par exemple avoir des effets très différents selon le statut socioéconomique des élèves et des établissements d'enseignement. De plus, les arbitrages dont traite cet indicateur ne sont que quelques-unes des nombreuses décisions que les pays doivent prendre concernant l'affectation de leurs ressources. Les pays doivent également faire des arbitrages concernant d'autres domaines d'investissement, tels que la formation des enseignants et les infrastructures scolaires, ainsi que des arbitrages entre les différents niveaux d'enseignement.

Il est difficile de lever certaines de ces réserves méthodologiques vu les données disponibles actuellement, mais il existe plusieurs pistes à envisager pour exploiter pleinement le potentiel d'analyse de cet indicateur dès que des données supplémentaires seront disponibles. La première serait d'améliorer la variable retenue pour estimer le coût des enseignants, par exemple, utiliser leur salaire effectif moyen, avec primes et autres compléments de salaire, au lieu de leur salaire statutaire. Une autre possibilité serait de baser l'estimation sur le coût total de la rémunération des enseignants à charge des pouvoirs publics, dont une partie concerne les cotisations patronales au régime de sécurité sociale et au régime de retraite, des sommes qui ne sont pas directement versées aux enseignants.

Parmi les autres pistes à envisager pour exploiter le potentiel d'analyse de cet indicateur, citons l'examen du lien entre le coût salarial des enseignants et le financement du système d'éducation et des différences d'arbitrage concernant le coût salarial des enseignants entre les niveaux infranationaux de décision, dont les établissements, les arrondissements scolaires et les municipalités.

\section{Contribution de chaque facteur au coût salarial des enseignants par élève}

Les quatre facteurs qui déterminent le coût salarial des enseignants par élève ont des effets différents. L'impact du premier facteur, le salaire des enseignants, est direct : des salaires plus élevés entraînent des coûts salariaux plus élevés. Les autres facteurs affectent le coût salarial, car ils font varier le nombre d'enseignants requis dans l'hypothèse d'un effectif d'élèves constant. Si le temps d'instruction augmente ou que le temps d'enseignement 
diminue, il faut engager plus d'enseignants pour que la taille des classes reste constante. II faudrait aussi engager davantage d'enseignants pour réduire la taille des classes sans modifier les autres facteurs.

\section{Graphique C7.2. Contribution de divers facteurs au coût salarial des enseignants par élève dans les établissements publics d'enseignement primaire (2017)}

En équivalents USD convertis sur la base des PPA pour la consommation privée

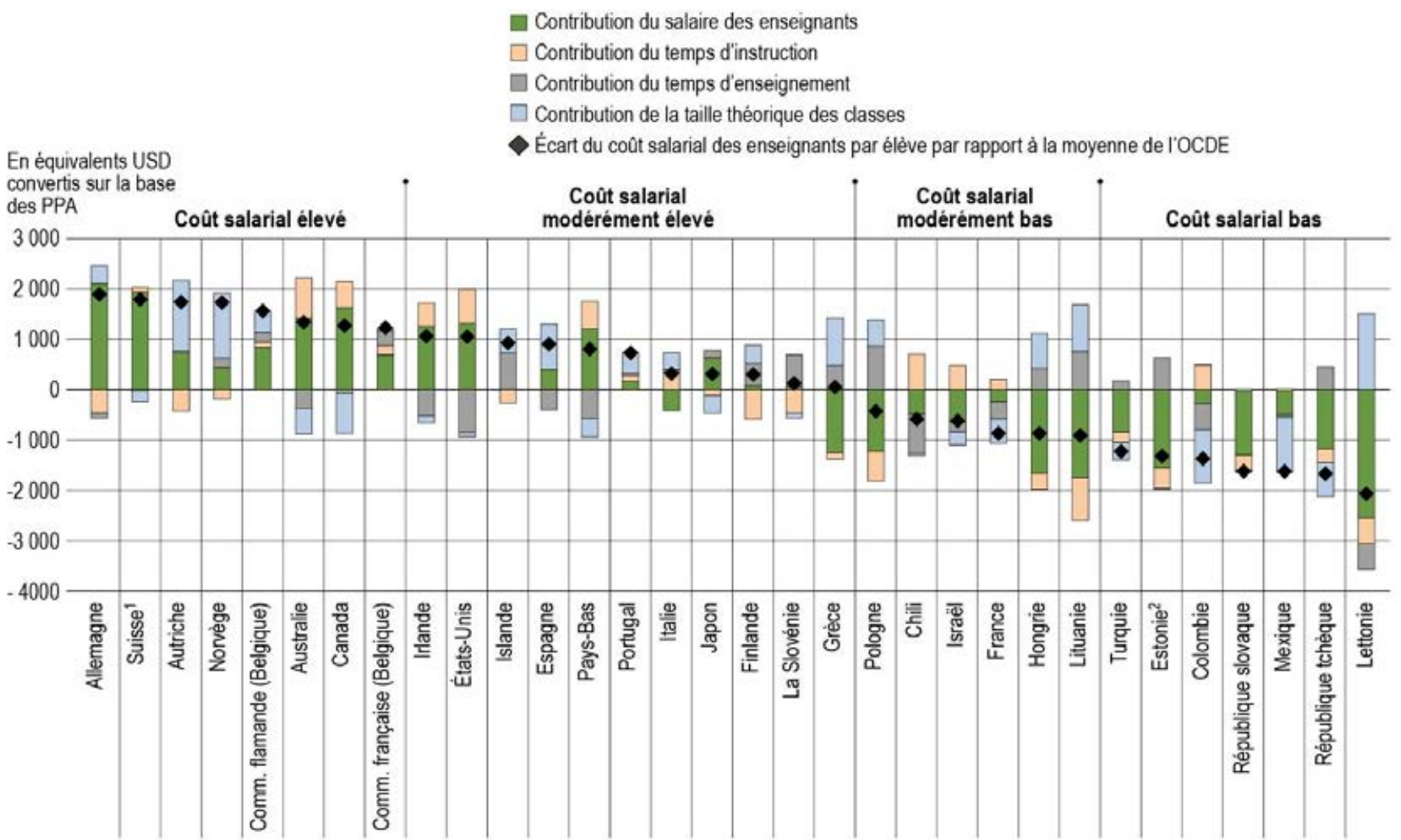

Lecture du graphique : Ce graphique illustre la contribution (en USD) des facteurs influant sur l'écart entre le coût salarial des enseignants par élève dans un pays donné et la moyenne de l'OCDE. Par exemple, en Pologne, le coût salarial des enseignants par élève est inférieur de 420 USD à la moyenne de l'OCDE. La Pologne a une taille théorique des classes inférieure à la moyenne de l'OCDE (+ 521 USD), tout comme le temps d'enseignement (+ 864 USD), facteurs qui contribuent tous deux à l'augmentation du coût salarial des enseignants. Toutefois, cet aspect est largement compensé par un salaire des enseignants inférieur à la moyenne (- 1226 USD) et à un temps d'instruction également inférieur à la moyenne (- 588 USD), qui font diminuer le coût salarial.

1. Salaire statutaire des enseignants après 10 , et non 15 ans d'exercice.

2. Salaire statutaire des enseignants en début de carrière, et non après 15 ans d'exercice.

Les pays et économies sont classés par ordre décroissant de l'écart du coût salarial des enseignants par élève par rapport à la moyenne de l'OCDE.

Source: OCDE (2019), tableau C7.2. Consulter la section «Source» pour tout complément d'information et l'annexe 3 pour les notes (https://doi.org/10.1787/f8d7880d-en).

La comparaison du coût salarial des pays à la moyenne de l'OCDE permet de chiffrer la contribution de chacun des quatre facteurs à l'écart de coût par rapport à la moyenne. En d'autres termes, il est possible de déterminer si un coût salarial donné est supérieur à la moyenne à cause d'un salaire plus élevé, d'un temps d'enseignement moins élevé, d'un temps d'instruction plus élevé, d'une taille des classes moins élevée ou de l'effet conjugué de ces quatre facteurs. La modification de l'un de ces facteurs peut nécessiter la modification des autres facteurs pour que le coût salarial total reste constant (voir l'encadré C7.2). 
Le graphique C7.2 montre le large éventail de combinaisons des quatre facteurs et indique l'effet de ces combinaisons sur le coût salarial des enseignants. L'ampleur de la contribution de chaque facteur à l'écart entre le coût salarial des pays et la moyenne de l'OCDE dépend de la différence entre l'effet de ce facteur dans les pays et son effet moyen dans l'OCDE. La somme des contributions des quatre facteurs dans chacun des pays égale la différence entre leur coût salarial et la moyenne de l'OCDE. En Pologne par exemple, le coût salarial des enseignants par élève, 2355 USD, est inférieur de 429 USD à la moyenne de l'OCDE. Cette différence est le résultat de l'effet conjugué des quatre facteurs: la taille théorique des classes inférieure à la moyenne augmente la différence de 521 USD ; le temps d'enseignement inférieur à la moyenne l'augmente de 864 USD ; le salaire inférieur à la moyenne la réduit de 1226 USD ; et le temps d'instruction inférieur à la moyenne la réduit de 588 USD (voir le tableau C7.2).

\section{Différences de politique entre des pays où le niveau de dépenses est similaire}

Des niveaux plus élevés de dépenses au titre de l'éducation ne vont pas nécessairement de pair avec une meilleure performance des systèmes d'éducation (OCDE, 2017 $\left.{ }_{[1]}\right)$. Des changements structurels ne garantissent pas l'amélioration du rendement de l'apprentissage, et les pays consacrant un budget similaire à l'éducation n'ont pas nécessairement opté pour les mêmes orientations politiques et les mêmes pratiques dans le système d'éducation. Les pays et économies de l'OCDE repris dans le graphique $\mathrm{C7.2}$ sont répartis entre quatre groupes où le coût salarial des enseignants par élève est du même ordre pour mieux illustrer l'éventail d'orientations politiques envisageables - que d'autres pays ont retenues - à un niveau comparable de dépenses.

\section{Groupe 1 : coût salarial des enseignants par élève élevé dans l'enseignement primaire}

Ce groupe, où le coût salarial des enseignants par élève est le plus élevé dans l'enseignement primaire, est constitué de l'Allemagne, de l'Australie, de l'Autriche, des Communautés flamande et française de Belgique, du Canada, de la Norvège et de la Suisse. Le coût salarial des enseignants par élève varie entre 4013 USD et 4679 USD dans ce groupe. Le PIB par habitant est supérieur à la moyenne dans tous ces pays, mais la relation entre le coût salarial et le PIB par habitant n'est pas bi-univoque. Certains pays affectent à ce type de dépenses une part plus importante de leur richesse que d'autres (voir le tableau C7.1).

Par comparaison avec des pays des autres groupes, il semble que ces pays qui dépensent beaucoup n'aient pas d'arbitrages à faire entre les quatre facteurs analysés dans cet indicateur. En fait, la plupart des pays de ce groupe peuvent se permettre de verser des salaires supérieurs à la moyenne aux enseignants et de constituer des classes dont la taille théorique est inférieure à la moyenne. Toutefois, l'ampleur de la différence entre ces facteurs et les moyennes respectives de l'OCDE varie sensiblement entre ces pays. Le coût salarial élevé des enseignants s'explique par exemple essentiellement par le salaire des enseignants élevé en Allemagne, mais par la taille théorique peu élevée des classes en Autriche.

\section{Groupe 2 : coût salarial des enseignants par élève modérément élevé dans l'enseignement primaire}

Ce groupe est constitué de 11 pays où le coût salarial est supérieur à la moyenne : l'Espagne, les États-Unis, la Finlande, la Grèce, l'Irlande, l'Islande, l'Italie, le Japon, les Pays-Bas, le Portugal et la Slovénie. Le coût salarial des enseignants par élève varie entre 2833 USD et 3844 USD dans ce groupe (voir le tableau C7.1). Ce groupe est extrêmement hétérogène en termes de PIB par habitant et de dépenses d'éducation, ce qui montre bien le nombre élevé d'orientations différentes parmi lesquelles les pays qui affichent un niveau similaire de dépenses peuvent choisir.

Un arbitrage qui s'observe dans certains pays concerne le temps d'instruction des élèves et le temps d'enseignement des enseignants. Aux Pays-Bas par exemple, le temps d'instruction est supérieur de 147 heures par an à la moyenne de l'OCDE, mais cette différence est presque totalement compensée par le fait que le temps d'enseignement est supérieur de 150 heures à la moyenne. Accroître le nombre d'heures de cours que donnent 
les enseignants permet non seulement de limiter le nombre d'enseignants à engager, mais aussi de compenser le niveau plus élevé de salaire. C'est le cas aux États-Unis, où les 224 heures de cours de plus que les enseignants donnent par rapport à la moyenne de l'OCDE contribuent à compenser les 19970 USD de plus qu'ils perçoivent (le salaire statutaire des enseignants s'établit à 61028 USD aux États-Unis, contre 41058 USD en moyenne dans les pays de l'OCDE).

\section{Groupe 3 : coût salarial des enseignants par élève modérément faible dans l'enseignement primaire}

Ce groupe est constitué de six pays où le coût salarial des enseignants par élève est inférieur à la moyenne : le Chili, la France, la Hongrie, Israël, la Lituanie et la Pologne. Le coût salarial des enseignants par élève varie entre 1875 USD et 2355 USD dans ce groupe (voir le tableau C7.1). Le PIB par habitant est inférieur à la moyenne dans tous ces pays, sauf en France.

Le coût salarial inférieur à la moyenne dans l'enseignement primaire s'explique essentiellement par le salaire des enseignants inférieur à la moyenne dans ces six pays. Toutefois, des écarts importants s'observent entre ces pays. En Hongrie, en Lituanie et en Pologne, les salaires inférieurs des enseignants sont en partie compensés par une taille théorique des classes et un temps d'enseignement moins élevés. Ce n'est pas le cas dans les trois autres pays, où la taille théorique des classes et le temps d'enseignement sont tous deux supérieurs à la moyenne. En France et en Hongrie, le coût salarial des enseignants par élève est similaire, mais le salaire est 80 \% plus élevé en France qu'en Hongrie, ce qui est plus que compensé par le fait que l'on compte environ sept élèves de plus par classe (sur la base de la taille théorique des classes).

\section{Groupe 4 : coût salarial des enseignants par élève peu élevé dans l'enseignement primaire}

Ce groupe est constitué des sept pays où le coût salarial des enseignants par élève est le moins élevé dans l'enseignement primaire : la Colombie, l'Estonie, la Lettonie, le Mexique, la République slovaque, la République tchèque et la Turquie. Le coût salarial des enseignants par élève varie entre 720 USD et 1560 USD dans ce groupe (voir le tableau C7.1). Ces pays accusent tous un PIB par habitant inférieur à la moyenne.

Dans la comparaison globale des pays, la Lettonie et la République slovaque sont similaires dans la mesure où leur coût salarial est peu élevé à cause d'un salaire et d'une taille théorique des classes inférieurs à la moyenne. Toutefois, des différences importantes s'observent dans les caractéristiques du système d'éducation de ces deux pays. La taille théorique des classes relativement plus élevée (par comparaison avec celle de la Lettonie) permet à la République slovaque de verser aux enseignants un salaire qui représente plus du double de celui qui leur est versé en Lettonie, où le taille théorique des classes et le salaire des enseignants sont les moins élevés de tous les pays de l'OCDE.

\section{Évolution de la taille moyenne des classes et du salaire des enseignants}

À chaque niveau d'enseignement, c'est généralement le salaire des enseignants qui influe le plus sur la mesure dans laquelle le coût salarial des enseignants s'écarte de la moyenne de l'OCDE. Le deuxième facteur le plus déterminant est la taille théorique des classes. Les arbitrages entre ces deux facteurs, qui sont souvent l'objet des réformes de la politique de l'éducation, reflètent les choix que les pays doivent faire entre l'augmentation du salaire des enseignants et le recrutement d'enseignants supplémentaires. En fait, après contrôle du coût salarial total des enseignants, les pays où le salaire des enseignants est plus élevé tendent à se caractériser par une taille des classes supérieure (OCDE, 2018[2]).

Le graphique $\mathrm{C} 7.3$ retrace l'évolution du salaire statutaire des enseignants et de la taille moyenne des classes entre 2005 et 2017. Contrairement à la taille théorique des classes utilisée ci-dessus, la taille moyenne des classes correspond à la taille effective des classes en moyenne, qui s'obtient par division de l'effectif d'élèves par le nombre de classes dans chaque pays (la section "Définitions " explique de manière plus détaillée la différence entre la taille moyenne et la taille théorique des classes). 
Dans le graphique, les pays sont répartis entre quatre groupes, occupant chacun un quadrant. Dans les pays des quadrants supérieur droit et inférieur gauche du graphique, la taille moyenne des classes et le salaire des enseignants se sont neutralisés durant la période à l'étude. Dans les pays du quadrant supérieur droit du graphique, la taille moyenne des classes a augmenté (ce qui a fait diminuer le coût salarial des enseignants), tout comme le salaire des enseignants (ce qui a fait augmenter le coût). Le Mexique donne l'exemple le plus marquant dans ce groupe de pays : la taille moyenne des classes a augmenté de plus de $20 \%$ durant cette période, ce qui a en partie compensé l'augmentation du salaire des enseignants de plus de $30 \%$. L'inverse s'observe dans deux pays seulement (la Grèce et le Japon) : la taille moyenne des classes a diminué, mais le coût supplémentaire a été en partie compensé par la diminution du salaire des enseignants. II faut noter cependant que si ces changements ont des effets opposés sur le coût salarial, ils ne sont pas nécessairement pris en réponse l'un de l'autre. Par exemple, au Japon, la diminution de la taille moyenne des classes est principalement due à un changement démographique, alors que la diminution du coût salarial des enseignants est, en partie au moins, due à un renouvellement de génération chez les enseignants.

\section{Graphique C7.3. Indice de variation du salaire des enseignants et de la taille moyenne des classes dans l'enseignement primaire entre 2005 et 2017}

Établissements publics uniquement.

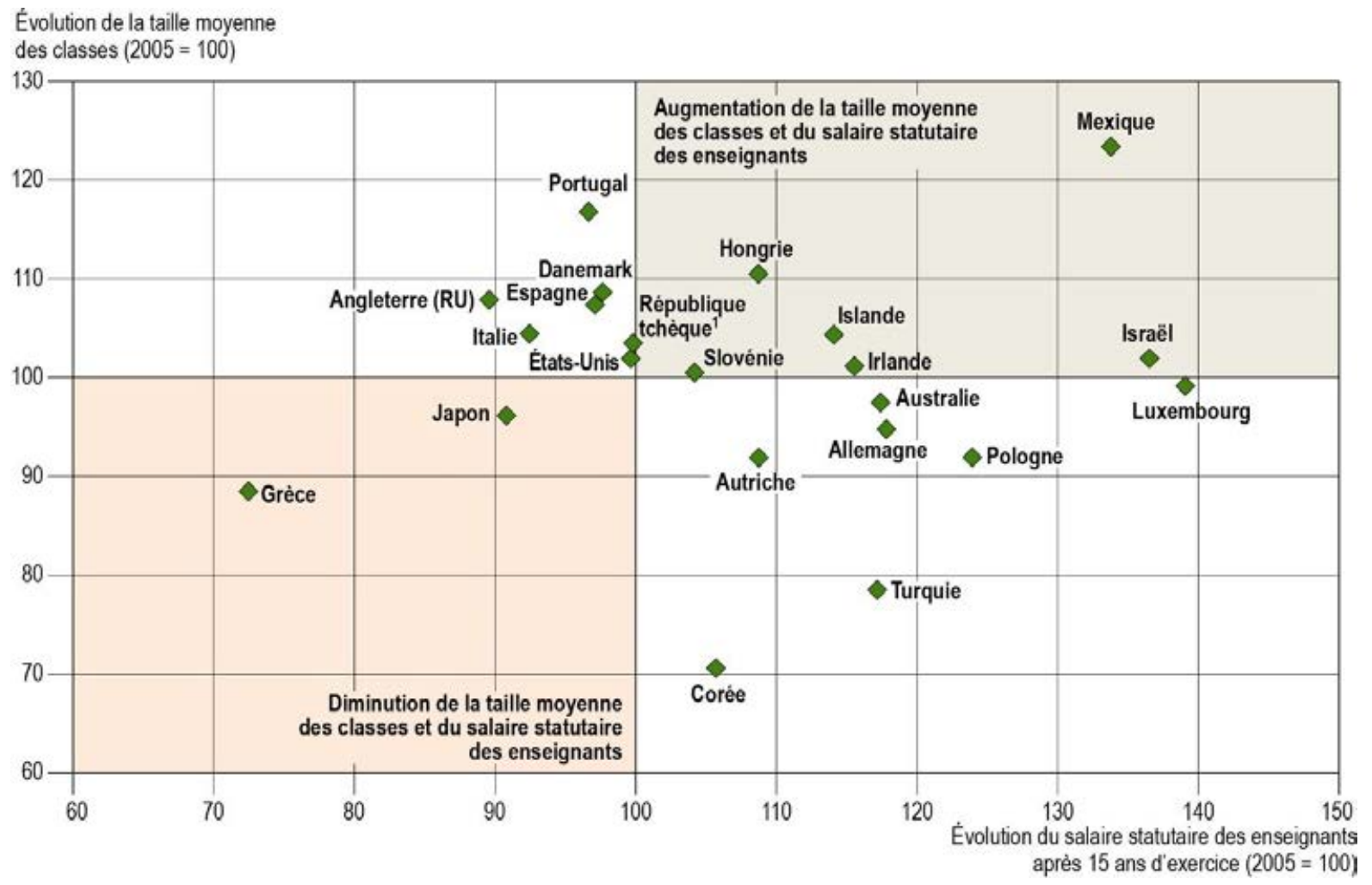

Remarque : Les données sur la taille moyenne des classes proviennent du questionnaire CLASS de l'UOE. La taille moyenne des classes ne correspond pas à la taille théorique des classes (voir la section « Définitions »).

1. Salaire statutaire des enseignants basé sur les qualifications minimales et non sur les qualifications typiques.

Source : OCDE (2019), base de données de Regards sur l'éducation, http://stats.oecd.org. Consulter la section " Source » pour tout complément d'information et l'annexe 3 pour les notes (https://doi.org/10.1787/f8d7880d-en). 
Aucun arbitrage n'a semble-t-il eu lieu entre ces deux variables durant cette période dans les pays et économies situés dans les quadrants supérieur gauche et inférieur droit. Durant cette période, la taille moyenne des classes a augmenté et le salaire des enseignants a diminué, ce qui a réduit le coût salarial des enseignants dans les pays situés dans le quadrant supérieur gauche. Le coût a diminué essentiellement à cause de l'augmentation de la taille moyenne des classes dans certains pays et économies - au Portugal, la taille moyenne des classes a par exemple augmenté de $17 \%$ durant cette période -, mais à cause de la diminution du salaire des enseignants dans d'autres - en Angleterre (Royaume-Uni), le salaire des enseignants a diminué de $10 \%$.

L'inverse s'observe dans les pays du quadrant inférieur droit : la taille moyenne des classes a diminué et le salaire des enseignants a augmenté, deux mesures qui ont fait augmenter le coût salarial des enseignants. Dans ce cas également, l'ampleur de l'évolution de chaque variable diffère selon les pays. Entre 2005 et 2017, le salaire des enseignants a augmenté de près de $40 \%$ au Luxembourg, tandis que la taille moyenne des classes a diminué de près de $30 \%$ en Corée.

Il est intéressant de constater que dans certains pays, l'un des facteurs a évolué de la même façon, alors que les autres ont évolué d'une façon très différente. En Autriche et en Hongrie par exemple, le salaire des enseignants a augmenté de $9 \%$ environ entre 2005 et 2017. Toutefois, durant la même période, la taille moyenne des classes a augmenté de $10 \%$ en Hongrie, ce qui a en partie compensé le coût supplémentaire occasionné par l'augmentation des salaires, tandis que la taille moyenne des classes a diminué de $8 \%$ environ en Autriche, ce qui a fait augmenter le coût salarial des enseignants.

Les classes moins peuplées sont souvent considérées comme bénéfiques, mais les éléments à l'appui de leur impact sur l'apprentissage des élèves sont mitigés. Les résultats de la dernière édition du Programme international de l'OCDE pour le suivi des acquis des élèves (PISA) montrent que dans les pays de l'OCDE, les élèves sont dans l'ensemble plus performants en sciences s'ils sont nombreux en classe (OCDE, 2016[3]). Selon une autre étude, les classes moins denses peuvent être bénéfiques dans certains cas, par exemple pour les élèves issus de milieux défavorisés qui peuvent avoir besoin qu'on leur accorde une attention plus individualisée (Dynarski, Hyman et Schanzenbach, 2013[4] ). Comme réduire la taille des classes est une mesure onéreuse (voir l'encadré C7.2), il est important de comparer ses vertus à celles d'autres mesures (OCDE, 2017[1]).

Comme le montre le graphique $\mathrm{C} 7.3$, l'une de ces autres mesures consiste à accroître le salaire des enseignants. Selon l'enquête PISA, la qualité de l'enseignement joue un grand rôle dans l'amélioration des résultats des élèves (OCDE, 2017 $\left.{ }_{[1]}\right)$ : proposer des salaires plus élevés est l'un des moyens qui aident les systèmes d'éducation à encourager les meilleurs éléments à embrasser la profession d'enseignant. Toutefois, attirer les meilleurs éléments et faire en sorte que les enseignants efficaces n'abandonnent pas la profession n'est pas qu'une question de salaire plus élevé. D'autres facteurs interviennent, par exemple la qualité de la formation avant et après l'entrée en fonction et la relation entre les enseignants et la société.

\section{Encadré C7.2. Quels arbitrages envisager pour réduire la taille des classes d'un élève ?}

Cet indicateur évalue l'impact de quatre facteurs (le salaire des enseignants, le temps d'instruction, le temps d'enseignement et la taille théorique des classes) sur le coût salarial des enseignants par élève et sur les arbitrages concernant ces facteurs. Cette analyse peut être utilisée pour répondre à la question de savoir quels arbitrages envisager concernant les autres facteurs pour compenser une réduction de la taille des classes dans l'hypothèse où l'effectif d'élèves et le coût salarial restent constants. Ou, plus précisément, de combien réduire le salaire ou le temps d'instruction ou de combien augmenter le temps d'enseignement pour que le coût salarial reste constant.

Le tableau C7.a montre les résultats du scénario dans lequel la taille théorique des classes diminue d'un élève. La valeur de chaque facteur est calculée toutes choses étant égales par ailleurs. En Australie par exemple, pour réduire la taille estimée des classes d'un élève dans l'enseignement primaire sans modifier le coût salarial par élève, le salaire des enseignants devrait diminuer de 3600 USD, le temps annuel 
d'instruction devrait diminuer de 57 heures ou le temps annuel d'enseignement devrait augmenter de 53 heures. L'une de ces mesures compenserait le coût supplémentaire qu'entraînerait la réduction de la taille des classes, sans que le coût salarial des enseignants par élève ne change.

Tableau C7.a. Maintien du coût salarial à un niveau constant : quels arbitrages envisager pour réduire la taille des classes d'un élève? (2017)

Arbitrages visant à réduire la taille théorique des classes dans l'enseignement primaire, établissements publics uniquement

\begin{tabular}{|c|c|c|c|}
\hline Pays et économies de l'OCDE & $\begin{array}{l}\text { Salaire statutaire des enseignants } \\
\text { (en équivalents USD par an) }\end{array}$ & $\begin{array}{l}\text { Temps d'instruction } \\
\text { (en nombre d'heures par an) }\end{array}$ & $\begin{array}{l}\text { Temps d'enseignement } \\
\text { (en nombre d'heures par an) }\end{array}$ \\
\hline Australie & -3600 & .57 & 53 \\
\hline Autriche & -5000 & -69 & 85 \\
\hline Comm. flamande (Belgique) & -3900 & -62 & 60 \\
\hline Comm. française (Belgique) & -3400 & .57 & 52 \\
\hline Canada & -3500 & -49 & 45 \\
\hline Chili & -2200 & -69 & 75 \\
\hline Colombie & -1400 & -40 & 41 \\
\hline République tchèque & -1000 & -32 & 30 \\
\hline Estonie $^{1}$ & -1300 & -44 & 42 \\
\hline Finlande & -3200 & -49 & 55 \\
\hline France & -2000 & -47 & 51 \\
\hline Allemagne & -5300 & 51 & 63 \\
\hline Grèce & -2500 & .70 & 67 \\
\hline Hongrie & -1800 & -61 & 63 \\
\hline Islande & -3200 & -56 & 52 \\
\hline Irlande & -3800 & -58 & 62 \\
\hline Israë| & -1900 & -58 & 54 \\
\hline Italie & -2700 & -67 & 62 \\
\hline Japon & -3000 & -45 & 47 \\
\hline Lettonie & -1200 & -83 & 165 \\
\hline Lituanie & -1900 & -54 & 62 \\
\hline Mexique & -1200 & -29 & 31 \\
\hline Pays-Bas & -3600 & -56 & 59 \\
\hline Norvège & -4400 & -72 & 78 \\
\hline Pologne & -2100 & -52 & 50 \\
\hline Portugal & -3300 & -63 & 64 \\
\hline République slovaque & -1400 & -45 & 57 \\
\hline Slovénie & -2700 & -43 & 43 \\
\hline Espagne & -4100 & .70 & 85 \\
\hline Suisse ${ }^{2}$ & -4400 & -51 & 53 \\
\hline Turquic & -1600 & -41 & 43 \\
\hline États-Unis & -4000 & .63 & 70 \\
\hline
\end{tabular}

Remarque : Les résultats des calculs du salaire statutaire des enseignants sont arrondis à la centaine la plus proche. Le salaire des enseignants utilisé dans le calcul de cet indicateur correspond au salaire statutaire annuel, dans les établissements publics, des enseignants ayant les qualifications les plus courantes, après 15 ans d'exercice (indicateur D3). Le temps d'instruction correspond au nombre annuel moyen d'heures d'instruction obligatoire (indicateur D1), et le temps d'enseignement, au nombre statutaire net d'heures d'enseignement durant l'année scolaire (indicateur D4). L'année de référence de ces facteurs peut différer d'une année dans certains pays. Consulter les notes relatives à chaque facteur dans le tableau C7.5a, disponible en ligne.

1. Salaire statutaire des enseignants en début de carrière, et non après 15 ans d'exercice.

2. Salaire statutaire des enseignants après 10 , et non 15 ans d'exercice.

Source : OCDE (2019), tableau C7.5a, disponible en ligne. Consulter la section « Source » pour tout complément d'information et l'annexe 3 pour les notes (https://doi.org/10.1787/f8d7880d-en). 
Ces résultats montrent bien que réduire la taille des classes, même d'un seul élève, est une mesure coûteuse. La taille des classes a diminué dans plusieurs pays de l'OCDE ces dernières années (voir l'indicateur D2), mais plus souvent sous l'effet de l'évolution démographique que par choix politique. La taille des classes tend à diminuer quand l'effectif scolarisé diminue à cause des défis politiques, économiques et organisationnels qu'il faudrait relever pour réduire le nombre d'enseignants en même temps. À long terme toutefois, décider de ne pas réduire le corps enseignant est en soi un choix politique qui implique de garder des classes moins denses. Le tableau C7.a montre que le coût de tailles de classes plus limitées peut être compensé soit par un coût salarial plus élevé, soit par des changements dans les trois autres facteurs.

Il est important de se baser sur les valeurs actuelles de chaque facteur dans chaque pays pour évaluer les résultats du tableau C7.a. Au Chili par exemple, le temps d'enseignement est plus élevé que dans tout autre pays de l'OCDE ; l'augmenter pour compenser la réduction de la taille des classes ne semble ni réalisable, ni souhaitable.

Cette simulation n'est pas conçue pour chiffrer le coût réel des réformes, puisque le modèle ne comporte que quatre facteurs et ne montre qu'un arbitrage concernant un seul facteur à la fois. En fait, les arbitrages consisteront souvent à modifier plusieurs facteurs en même temps. De plus, d'importantes variations régionales, dont cet indicateur ne rend pas compte, pourraient requérir des mesures spécifiques qui ne se refléteraient pas nécessairement dans les moyennes nationales. Cette analyse est uniquement proposée pour illustrer l'importance des arbitrages dans les décisions politiques et donner des orientations concernant les arbitrages qu'il est possible d'envisager parmi les quatre facteurs étudiés dans cet indicateur.

\section{Définitions}

La taille moyenne des classes s'obtient par division de l'effectif d'élèves d'un niveau d'enseignement donné par le nombre de classes à ce niveau. Cette variable correspond au nombre moyen d'élèves par classe (voir l'indicateur D2).

Par temps d'instruction, on entend le temps pendant lequel les établissements publics sont censés dispenser aux élèves des cours dans toutes les matières inscrites au programme obligatoire et non obligatoire, dans leurs locaux, pendant la journée de classe ou lors des activités organisées avant ou après la journée de classe, qui sont des composantes officielles du programme obligatoire (voir l'indicateur D1).

Par temps d'enseignement des enseignants, on entend le nombre d'heures de cours que les enseignants travaillant à temps plein donnent chaque année à un groupe ou à une classe d'élèves, heures supplémentaires comprises (voir l'indicateur D4).

Le salaire des enseignants correspond au salaire statutaire des enseignants après 15 ans d'exercice, converti en USD sur la base des parités de pouvoir d'achat (PPA) pour la consommation privée (voir l'indicateur D3).

La taille théorique des classes est dérivée du temps statutaire - ou théorique - d'instruction et d'enseignement et du taux d'encadrement (voir la section « Méthodologie "). Cette variable ne correspond pas à la taille moyenne effective des classes dans les pays.

\section{Méthodologie}

Le coût salarial des enseignants par élève (CCS) est calculé comme suit :

$$
\text { CCS }=\text { Salaire des enseignants } * \text { Temps d'instruction } * \frac{1}{\text { Temps d'enseignement }} * \frac{1}{\text { Taille théorique des classes }}
$$

Où la taille théorique des classes est calculée comme suit :

$$
\text { Taille théorique des classes }=\frac{\text { Temps d'instruction }}{\text { Temps d'enseignement }} * \frac{\text { Élèves }}{\text { Enseignants }}
$$


La contribution de chaque facteur au niveau du coût salarial des enseignants par élève est analysée comme suit : le coût salarial des enseignants par élève de chaque pays est comparé à la moyenne de l'OCDE, puis la contribution de chaque facteur à l'écart du coût par rapport à la moyenne de l'OCDE est calculée. Cette analyse repose sur une relation mathématique entre les différents facteurs retenus et s'effectue selon la méthode présentée dans la publication canadienne Bulletin statistique de l'éducation (Ministère de l'Éducation, du Loisir et du Sport du Québec, $\left.2003_{[5]}\right)$. Avec cette relation mathématique, il est possible de calculer les écarts entre la valeur des quatre facteurs dans un pays et la moyenne de l'OCDE, puis d'évaluer la contribution directe et indirecte de chacun de ces facteurs à l'écart entre le coût salarial des enseignants par élève de ce pays et la moyenne de l'OCDE.

Voir le Guide de l'OCDE pour l'établissement de statistiques internationalement comparables dans le domaine de l'éducation 2018 (OCDE, 2019[6]) pour de plus amples informations. Voir les notes spécifiques aux pays à l'annexe 3 (https://doi.org/10.1787/f8d7880d-en).

\section{Source}

Les données relatives à l'année scolaire 2017 proviennent de l'exercice UOE de collecte de données statistiques sur l'éducation et de l'enquête sur les enseignants et les programmes réalisés par l'OCDE en 2018.

\section{Remarque concernant les données fournies par Israël}

Les données statistiques concernant Israël sont fournies par et sous la responsabilité des autorités israéliennes compétentes. L'utilisation de ces données par l'OCDE est sans préjudice du statut des hauteurs du Golan, de Jérusalem-Est et des colonies de peuplement israéliennes en Cisjordanie aux termes du droit international.

\section{Références}

Dynarski, S., J. Hyman et D. Schanzenbach (2013), « Experimental evidence on the effect of childhood investments on postsecondary attainment and degree completion », Journal of Policy Analysis and Management, vol. 32/4, pp. 692-717, http://dx.doi.org/10.1002/pam.21715.

Ministère de l'Éducation, du Loisir et du Sport du Québec (2003), « Le coût salarial des enseignants par élève pour l'enseignement primaire et secondaire en 2000-2001 », Bulletin statistique de l'éducation, $\mathrm{n}^{\circ} 29$, http://www.education.gouv.qc.ca/fileadmin/site web/documents/PSG/statistiques info decisionnelle lbulletin 29.pdf.

OCDE (2019), Guide de l'OCDE pour l'établissement de statistiques internationalement comparables dans le domaine de l'éducation 2018: Concepts, normes, définitions et classifications, Éditions OCDE, Paris, https://dx.doi.org/10.1787/9789264305380-fr.

OCDE (2018), Regards sur l'éducation 2018: Les indicateurs de l'OCDE, Éditions OCDE, Paris, https://dx.doi.org/10.1787/eag-2018-fr.

OCDE (2017), Résultats du PISA 2015 (Volume II): Politiques et pratiques pour des établissements performants, PISA, Éditions OCDE, Paris, https://dx.doi.org/10.1787/9789264267558-fr.

OCDE (2016), Résultats du PISA 2015 (Volume l): L'excellence et l'équité dans l'éducation, PISA, Éditions OCDE, Paris, https://dx.doi.org/10.1787/9789264267534-fr. 


\section{Tableaux de l'indicateur C7}

Tableau C7.1

Tableau C7.2

Tableau C7.3

WEB Tableau C7.4

WEB Tableau C7.5a établissements publics d'enseignement primaire (2017)

WEB Tableau C7.5b Facteurs utilisés pour calculer le coût salarial des enseignants par élève, dans les établissements publics du premier cycle de l'enseignement secondaire (2017)

WEB Tableau C7.5c Facteurs utilisés pour calculer le coût salarial des enseignants par élève, en filière générale, dans les établissements publics du deuxième cycle de l'enseignement secondaire (2017)

Date butoir pour les données: 19 juillet 2019. Les mises à jour peuvent être consultées en ligne sur : http://dx.doi.org/10.1787/eag-data-en. D'autres données désagrégées sont également disponibles dans la Base de données de Regards sur l'éducation (http://stats.oecd.org/).

StatLink : https://doi.org/10.1787/888933981172 
Tableau C7.1. Coût salarial des enseignants par élève, selon le niveau d'enseignement (2017)

Coût salarial annuel des enseignants par élève dans les établissements d'enseignement publics, en équivalents USD convertis sur la base des PPA pour la consommation privée, et en pourcentage du PIB par habitant

\begin{tabular}{|c|c|c|c|c|c|c|}
\hline & \multicolumn{3}{|c|}{$\begin{array}{l}\text { Coût salarial des enseignants par ćlève } \\
\text { (en USD, prix constants de 2017) }\end{array}$} & \multicolumn{3}{|c|}{$\begin{array}{l}\text { Coût salarial des enseignants par élève } \\
\text { (en pourcentage du PIB par habitant) }\end{array}$} \\
\hline & Primaire & $\begin{array}{l}\text { Premier cycle } \\
\text { du secondaire }\end{array}$ & $\begin{array}{l}\text { Deuxic̀me cycle } \\
\text { du secondaire, } \\
\text { filière génerale }\end{array}$ & Primaire & $\begin{array}{l}\text { Premier cycle } \\
\text { du secondaire }\end{array}$ & $\begin{array}{l}\text { Deuxième cycle } \\
\text { du secondaire, } \\
\text { filière genenerale }\end{array}$ \\
\hline & (1) & (2) & (3) & (4) & (5) & (6) \\
\hline \multicolumn{7}{|l|}{ س Pays } \\
\hline ¿ू. Australic & 4127 & 5008 & $\mathrm{~m}$ & 7.9 & 96 & $\mathrm{~m}$ \\
\hline Autriche & 4525 & 6299 & 5635 & 8.4 & 11.7 & 10.4 \\
\hline Canada & 4057 & 4057 & 5092 & 8.6 & 8.6 & 10.9 \\
\hline Chili & 2198 & 2048 & 1841 & 9.0 & 84 & 76 \\
\hline Colombie & 1416 & 1274 & 1384 & 9.7 & 87 & 9.5 \\
\hline République tchèque & 1117 & 1779 & $\mathrm{~m}$ & 2.9 & 4.7 & $\mathrm{~m}$ \\
\hline Danemark & $\mathrm{m}$ & $\mathrm{m}$ & $\mathrm{m}$ & $\mathrm{m}$ & $\mathrm{m}$ & $\mathrm{m}$ \\
\hline Estonie' & 1463 & 1930 & $\mathrm{~m}$ & 4.4 & 5.8 & $\mathrm{~m}$ \\
\hline Finlande & 3087 & 5112 & $\mathrm{~m}$ & 6.7 & 11.0 & $\mathrm{~m}$ \\
\hline France & 1915 & 2843 & 2993 & 4.3 & 6.4 & 6.8 \\
\hline Allemagne & 4679 & 6008 & $\mathrm{~m}$ & 8.9 & 11.4 & $\mathrm{~m}$ \\
\hline Grèce & 2833 & 3376 & $\mathrm{~m}$ & 9.9 & 11.8 & $\mathrm{~m}$ \\
\hline Hongrie & 1915 & 2000 & 1990 & 6.7 & 7.0 & 6.9 \\
\hline Islande & 3714 & 4010 & $\mathrm{~m}$ & 6.6 & 7.1 & $\mathrm{~m}$ \\
\hline Irlande & 3844 & 4532 & 4532 & 5.0 & 5.9 & 5.9 \\
\hline Israël & 2165 & 3005 & 3307 & 5.5 & 7.9 & 8.4 \\
\hline Italie & 3103 & 3546 & 3616 & 7.6 & 8.7 & 8.8 \\
\hline Japon & 3096 & 3798 & $\mathrm{~m}$ & 7.4 & 9.1 & $\mathrm{~m}$ \\
\hline Corée & $q$ & 9 & $m$ & $q$ & $q$ & m \\
\hline Lettonie & 720 & 1044 & $\mathrm{~m}$ & 2.8 & 4.1 & m \\
\hline Lituanie & 1875 & 2738 & m & 5.7 & 8.3 & m \\
\hline Luxembourg & $\mathrm{m}$ & $\mathrm{m}$ & $\mathrm{m}$ & $\mathrm{m}$ & $\mathrm{m}$ & $\mathrm{m}$ \\
\hline Mexique & 1159 & 1061 & 1743 & 5.8 & 5.4 & 8.8 \\
\hline Pays-Bas & 3590 & 4650 & 4531 & 6.6 & 8.5 & 83 \\
\hline Nouvelle-Zèlande & $\mathrm{m}$ & $\mathrm{m}$ & $\mathrm{m}$ & $\mathrm{m}$ & $\mathrm{m}$ & m \\
\hline Norvège & 4518 & 4900 & $\mathrm{~m}$ & 8.6 & 9.3 & $\mathrm{~m}$ \\
\hline Pologne & 2355 & 2699 & $m$ & 7.9 & 9.0 & $m$ \\
\hline Portugal & 3518 & 4641 & 4831 & 10.8 & 14.3 & 14.9 \\
\hline République slovaque & 1164 & 1627 & 1406 & 3.6 & 5.0 & 4.3 \\
\hline Slovènie & 2911 & 6948 & $m$ & 8.1 & 19.2 & $m$ \\
\hline Espagne & 3691 & 4912 & 4787 & 9.4 & 12.6 & 12.2 \\
\hline Suède & $\mathrm{m}$ & m & $\mathrm{m}$ & m & $\mathrm{m}$ & m \\
\hline Suisse ${ }^{2}$ & 4579 & 6818 & $\mathrm{~m}$ & 6.9 & 10.2 & $\mathrm{~m}$ \\
\hline Turquie & 1560 & 1605 & 1830 & 5.5 & 5.7 & 6.5 \\
\hline Etats-Unis & 3834 & 3940 & 3880 & 6.4 & 66 & 6.5 \\
\hline \multicolumn{7}{|l|}{ Economies } \\
\hline Comm. flamande (Belgique) & 4349 & 5699 & 6920 & 8.8 & 11.5 & 14.0 \\
\hline Comm. française (Belgique) & 4013 & 5775 & 6200 & 8.1 & 11.7 & 12.5 \\
\hline Angleterre (RU) & $\mathrm{m}$ & $\mathrm{m}$ & $\mathrm{m}$ & $\mathrm{m}$ & $\mathrm{m}$ & $\mathrm{m}$ \\
\hline Ecosse (RU) & $\mathrm{m}$ & $\mathrm{m}$ & $m$ & $\mathrm{~m}$ & $\mathrm{~m}$ & $\mathrm{~m}$ \\
\hline Moyenne OCDE & 2784 & 3380 & 3274 & 6.7 & 8.2 & 8.0 \\
\hline
\end{tabular}

Remarque : Le salaire des enseignants utilisé dans le calcul de cet indicateur correspond au salaire statutaire annuel, dans les établissements publics, des enseignants ayant les qualifications les plus courantes, après 15 ans d'exercice (indicateur D3). Le temps d'instruction correspond au nombre annuel moyen d'heures d'instruction obligatoire (indicateur D1), et le temps d'enseignement, au nombre statutaire net d'heures d'enseignement durant l'année scolaire (indicateur D4). L'année de référence de ces facteurs peut différer d'une année dans certains pays. Consulter les notes relatives à chaque facteur dans le tableau C7.5a, disponibles en ligne.

1. Salaire statutaire des enseignants en début de carrière, et non après 15 ans d'exercice.

2. Salaire statutaire des enseignants après 10 , et non 15 ans d'exercice.

3. La moyenne OCDE inclut uniquement les pays et économies disposant de données sur l'ensemble des facteurs utilisés pour le calcul du coût salarial.

Source : OCDE (2019). Consulter la section « Source » pour tout complément d'information et l'annexe 3 pour les notes (https://doi.org/10.1787/f8d7880d-en).

Les symboles représentant les données manquantes et les abréviations figurent dans le Guide du lecteur. 
Tableau C7.2. Contribution de divers facteurs au coût salarial des enseignants par élève dans l'enseignement primaire (2017) En équivalents USD, convertis sur la base des PPA pour la consommation privée

\begin{tabular}{|c|c|c|c|c|c|c|}
\hline & \multirow[b]{2}{*}{$\begin{array}{c}\text { Coût salarial } \\
\text { des enseignants } \\
\text { par élève (2017) }\end{array}$} & \multirow[b]{2}{*}{$\begin{array}{c}\text { Ecart (en USD) } \\
\text { par rapport } \\
\text { a la moyenne de } 2017 \\
\text { de I'OCDE de } \\
2784 \text { USD }\end{array}$} & \multicolumn{4}{|c|}{ Contribution des facteurs sous-jacents à l'écart par rapport à la moyenne de l'OCDE } \\
\hline & & & $\begin{array}{c}\text { Effet (en USD) } \\
\text { d'un salaire } \\
\text { des enseignants } \\
\text { inférieur/supérieur } \\
\text { à la moyenne de } 2017 \\
\text { de l'OCDE de } \\
41058 \text { USD }\end{array}$ & $\begin{array}{c}\text { Effet (en USD) } \\
\text { d'un temps } \\
\text { d'instruction } \\
\text { (pour les elèves) } \\
\text { inférieur/superieur } \\
\text { à la moyenne de } 2017 \\
\text { de l'OCDE de } \\
793 \text { heures }\end{array}$ & $\begin{array}{c}\text { Effet (en USD) } \\
\text { d'un temps } \\
\text { d'enseignement } \\
\text { (pour les enscignants) } \\
\text { inférieur/superieur } \\
\text { à la moyenne de } 2017 \\
\text { de l'OCDE de } \\
780 \text { heures }\end{array}$ & $\begin{array}{c}\text { Effet (en USD) } \\
\text { d'une taille théorique } \\
\text { des classes } \\
\text { inférieure/supérieure } \\
\text { à la moyenne de } 2017 \\
\text { de I'OCDE de } \\
15 \text { élèves par classe }\end{array}$ \\
\hline & (i) & $(2)=(3)+(4)+(5)+(6)$ & (3) & (4) & (5) & (6) \\
\hline \multicolumn{7}{|l|}{ шays } \\
\hline Australie & 4127 & 1343 & 1423 & 804 & -363 & -521 \\
\hline Autriche & 4525 & 1741 & 767 & -429 & 2 & 1401 \\
\hline Canada & 4057 & 1273 & 1633 & 515 & .79 & .797 \\
\hline Chili & 2198 & .586 & -491 & 704 & -778 & -21 \\
\hline Colombie & 1416 & -1368 & -285 & 493 & -513 & -1063 \\
\hline Rèpublique tchèque & 1117 & -1668 & -1176 & .272 & 457 & -677 \\
\hline Danemark & $\mathrm{m}$ & m & m & $\mathrm{m}$ & $\mathrm{m}$ & m \\
\hline Estonie' & 1463 & -1321 & -1550 & -391 & 633 & -13 \\
\hline Finlande & 3087 & 303 & 79 & .583 & 434 & 374 \\
\hline France & 1915 & -869 & -250 & 202 & -334 & -488 \\
\hline Allemagne & 4679 & 1895 & 2110 & -464 & -98 & 346 \\
\hline Grèce & 2833 & 49 & -1253 & -128 & 482 & 948 \\
\hline Hongrie & 1915 & .869 & -1667 & -315 & 428 & 685 \\
\hline Islande & 3714 & 930 & 8 & -274 & 721 & 474 \\
\hline Irlande & 3844 & 1060 & 1262 & 460 & -517 & -145 \\
\hline Israël & 2165 & .619 & -646 & 479 & -194 & -258 \\
\hline Italie & 3103 & 319 & -415 & 345 & 55 & 334 \\
\hline Japon & 3096 & 312 & 634 & -114 & 147 & -355 \\
\hline Corée & q & q & q & q & q & 9 \\
\hline Lettonie & 720 & -2064 & -2541 & .526 & .505 & 1509 \\
\hline Lituanie & 1875 & -909 & -1743 & -853 & 756 & 931 \\
\hline Luxembourg & $\mathrm{m}$ & $\mathrm{m}$ & $\mathrm{m}$ & $\mathrm{m}$ & $\mathrm{m}$ & $\mathrm{m}$ \\
\hline Mexique & 1159 & -1625 & -499 & 18 & .49 & -1095 \\
\hline Pays-Bas & 3590 & 806 & 1202 & 549 & -570 & -375 \\
\hline Nouvelle-Zelande & $\mathrm{m}$ & m & $\mathrm{m}$ & $\mathrm{m}$ & m & $\mathrm{m}$ \\
\hline Norvège & 4518 & 1734 & 445 & .185 & 185 & 1289 \\
\hline Pologne & 2355 & -429 & -1226 & -588 & 864 & 521 \\
\hline Portugal & 3518 & 733 & 158 & 160 & 6 & 410 \\
\hline Republique slovaque & 1164 & -1620 & -1296 & -302 & -34 & 13 \\
\hline Slovénie & 2911 & 127 & 65 & .468 & 625 & .94 \\
\hline Espagne & 3691 & 907 & 396 & -3 & -393 & 907 \\
\hline Suede & $\mathrm{m}$ & $\mathrm{m}$ & $\mathrm{m}$ & $\mathrm{m}$ & $\mathrm{m}$ & $\mathrm{m}$ \\
\hline Suisse $^{2}$ & 4579 & 1795 & 1931 & 106 & -23 & -220 \\
\hline Turquie & 1560 & -1225 & -844 & -205 & 172 & -348 \\
\hline États-Unis & 3834 & 1050 & 1315 & 677 & -854 & -87 \\
\hline \multicolumn{7}{|l|}{ Economies } \\
\hline Comm. flamande (Belgique) & 4349 & 1565 & 838 & 106 & 190 & 431 \\
\hline Comm. française (Belgique) & 4013 & 1229 & 694 & 177 & 288 & 70 \\
\hline Angleterre (RU) & $\mathrm{m}$ & m & m & m & $\mathrm{m}$ & m \\
\hline Ecosse (RU) & $\mathrm{m}$ & m & $\mathrm{m}$ & $\mathrm{m}$ & m & $\mathrm{m}$ \\
\hline
\end{tabular}

Remarque : Le salaire des enseignants utilisé dans le calcul de cet indicateur correspond au salaire statutaire annuel, dans les établissements publics, des enseignants ayant les qualifications les plus courantes, après 15 ans d'exercice (indicateur D3). Le temps d'instruction correspond au nombre annuel moyen d'heures d'instruction obligatoire (indicateur D1), et le temps d'enseignement, au nombre statutaire net d'heures d'enseignement durant l'année scolaire (indicateur D4). L'année de référence de ces facteurs peut différer d'une année dans certains pays. Consulter les notes relatives à chaque facteur dans le tableau C7.5a, disponible en ligne.

1. Salaire statutaire des enseignants en début de carrière, et non après 15 ans d'exercice.

2. Salaire statutaire des enseignants après 10 , et non 15 ans d'exercice.

Source : OCDE (2019). Consulter la section « Source » pour tout complément d'information et l'annexe 3 pour les notes (https://doi.org/10.1787/f8d7880d-en) Les symboles représentant les données manquantes et les abréviations figurent dans le Guide du lecteur. 
Tableau C7.3. Contribution de divers facteurs au coût salarial des enseignants par élève dans le premier cycle de l'enseignement secondaire (2017)

En équivalents USD, convertis sur la base des PPA pour la consommation privée

\begin{tabular}{|c|c|c|c|c|c|c|}
\hline & \multirow[b]{2}{*}{$\begin{array}{c}\text { Coût salarial } \\
\text { des enseignants } \\
\text { par elève (2017) }\end{array}$} & \multirow[b]{2}{*}{$\begin{array}{c}\text { Ecart (en USD) } \\
\text { par rapport } \\
\text { a la moyenne de } 2017 \\
\text { de l'OCDE de } \\
3380 \text { USD }\end{array}$} & \multicolumn{4}{|c|}{ Contribution des facteurs sous-jacents à l'écart par rapport à la moyenne de l'OCDE } \\
\hline & & & $\begin{array}{c}\text { Effet (en USD) } \\
\text { d'un salaire } \\
\text { des enseignants } \\
\text { inférieur/supérieur } \\
\text { a la moyenne de } 2017 \\
\text { de I'OCDE de } \\
43007 \text { USD }\end{array}$ & $\begin{array}{l}\text { Effet (en USD) } \\
\text { d'un temps } \\
\text { d'instruction } \\
\text { (pour les élèves) } \\
\text { inférieur/supérieur } \\
\text { a la moyenne de 2017 } \\
\text { de l'OCDE de } \\
916 \text { heures }\end{array}$ & $\begin{array}{c}\text { Effet (en USD) } \\
\text { d'un temps } \\
\text { d'enseignement } \\
\text { (pour les enseignants) } \\
\text { inférieur/supérieur } \\
\text { a la moyenne de } 2017 \\
\text { de l'OCDE de } \\
696 \text { heures }\end{array}$ & $\begin{array}{c}\text { Effet (en USD) } \\
\text { d'une taille theorique } \\
\text { des classes } \\
\text { inferrieure/superieure } \\
\text { à la moyenne de } 2017 \\
\text { de l'OCDE de } \\
17 \text { elèves par classe }\end{array}$ \\
\hline & (1) & $(2)=(3)+(4)+(5)+(6)$ & (3) & (4) & (5) & (6) \\
\hline \multicolumn{7}{|l|}{ Ш Pays } \\
\hline Australie & 5008 & 1628 & 1524 & 367 & .570 & 308 \\
\hline Autriche & 6299 & 2919 & 1014 & -85 & 651 & 1339 \\
\hline Canada & 4057 & 677 & 1621 & 33 & .253 & -724 \\
\hline Chili & 2048 & -1331 & -650 & 422 & -1130 & 27 \\
\hline Colombie & 1274 & .2106 & .418 & 636 & .531 & -1793 \\
\hline République tchèque & 1779 & -1601 & -1720 & -82 & 316 & -114 \\
\hline Danemark & $\mathrm{m}$ & m & $\mathrm{m}$ & $\mathrm{m}$ & $\mathrm{m}$ & $\mathrm{m}$ \\
\hline Estonie' & 1930 & .1450 & -2085 & .294 & 401 & 528 \\
\hline Finlande & 5112 & 1732 & 242 & -537 & 706 & 1321 \\
\hline France & 2843 & -537 & .349 & 100 & 56 & -344 \\
\hline Allemagne & 6008 & 2628 & 2805 & 1 & .334 & 157 \\
\hline Grèce & 3376 & .4 & -1694 & .538 & 474 & 1754 \\
\hline Hongrie & 2000 & -1380 & -1999 & -356 & 170 & 805 \\
\hline Islande & 4010 & 630 & .162 & .328 & 407 & 713 \\
\hline Irlande & 4532 & 1152 & 1360 & 10 & .141 & .76 \\
\hline Israël & 3095 & -285 & -681 & 235 & -11 & 172 \\
\hline Italie & 3546 & 166 & .351 & 269 & 368 & .120 \\
\hline Japon & 3798 & 418 & 608 & -91 & 478 & -576 \\
\hline Corée & $q$ & $q$ & q & $q$ & q & $q$ \\
\hline Lettonic & 1044 & -2336 & -3418 & -351 & -76 & 1509 \\
\hline Lituanie & 2738 & -642 & -2529 & -775 & 432 & 2229 \\
\hline Luxembourg & $\mathrm{m}$ & $\mathrm{m}$ & $\mathrm{m}$ & $\mathrm{m}$ & $\mathrm{m}$ & $\mathrm{m}$ \\
\hline Mexique & 1061 & -2319 & -138 & 539 & -857 & -1863 \\
\hline Pays-Bas & 4650 & 1270 & 2250 & 359 & -305 & -1034 \\
\hline Nouvelle-Zélande & $\mathrm{m}$ & m & $\mathrm{m}$ & $\mathrm{m}$ & $\mathrm{m}$ & m \\
\hline Norvège & 4909 & 1529 & 317 & -195 & 202 & 1205 \\
\hline Pologne & 2699 & -681 & -1588 & -385 & 1188 & 103 \\
\hline Portugal & 4641 & 1261 & 16 & -108 & 489 & 865 \\
\hline République slovaque & 1627 & -1753 & -1801 & .266 & 166 & 149 \\
\hline Slovénie & 6948 & 3568 & -125 & -949 & 548 & 4094 \\
\hline Espagne & 4912 & 1533 & 758 & 573 & .96 & 297 \\
\hline Suède & $\mathrm{m}$ & $\mathrm{m}$ & $\mathrm{m}$ & $\mathrm{m}$ & $\mathrm{m}$ & $\mathrm{m}$ \\
\hline Suisse $^{2}$ & 6818 & 3438 & 3035 & 254 & .363 & 513 \\
\hline Turquic & 1605 & -1775 & -1089 & -208 & 825 & -1303 \\
\hline Etats-Unis & 3940 & 560 & 1421 & 400 & -1228 & -32 \\
\hline \multicolumn{7}{|l|}{ Economies } \\
\hline Comm. flamande (Belgique) & 5699 & 2319 & 858 & 121 & 251 & 1089 \\
\hline Comm. française (Belgique) & 5775 & 2395 & 719 & 185 & 263 & 1228 \\
\hline Angleterre (RU) & $\mathrm{m}$ & $\mathrm{m}$ & m & $\mathrm{m}$ & $\mathrm{m}$ & $\mathrm{m}$ \\
\hline Ecosse (RU) & $\mathrm{m}$ & $\mathrm{m}$ & $\mathrm{m}$ & $\mathrm{m}$ & $\mathrm{m}$ & $\mathrm{m}$ \\
\hline
\end{tabular}

Remarque : Le salaire des enseignants utilisé dans le calcul de cet indicateur correspond au salaire statutaire annuel, dans les établissements publics, des enseignants ayant les qualifications les plus courantes, après 15 ans d'exercice (indicateur D3). Le temps d'instruction correspond au nombre annuel moyen d'heures d'instruction obligatoire (indicateur D1), et le temps d'enseignement, au nombre statutaire net d'heures d'enseignement durant l'année scolaire (indicateur D4). L'année de référence de ces facteurs peut différer d'une année dans certains pays. Consulter les notes relatives à chaque facteur dans le tableau C7.5b, disponible en ligne.

1. Salaire statutaire des enseignants en début de carrière, et non après 15 ans d'exercice.

2. Salaire statutaire des enseignants après 10 , et non 15 ans d'exercice.

Source : OCDE (2019). Consulter la section « Source » pour tout complément d'information et l'annexe 3 pour les notes (https://doi.org/10.1787/f8d7880d-en).

Les symboles représentant les données manquantes et les abréviations figurent dans le Guide du lecteur. 



\section{Chapitre D. Enseignants, environnement d'apprentissage et organisation scolaire}

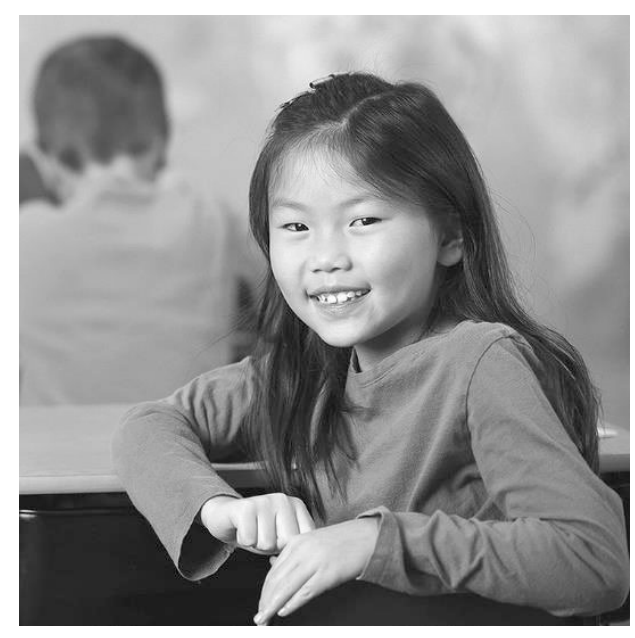

Indicateur D1 Combien de temps les élèves passent-ils en classe ?

StatLink https://doi.org/10.1787/888933981191

Indicateur D2 Quels sont les taux d'encadrement et la taille des classes ?

StatLink https://doi.org/10.1787/888933981210

Indicateur D3 Quel est le niveau de salaire des enseignants et des chefs

d'établissement?

StatLink https://doi.org/10.1787/888933981229

Indicateur D4 Quel est le temps de travail des enseignants ?

StatLink https://doi.org/10.1787/888933981248

Indicateur D5 Qui sont les enseignants ?

StatLink https://doi.org/10.1787/888933981267

Indicateur D6 Quels sont les systèmes d'admission dans l'enseignement tertiaire ?

StatLink https://doi.org/10.1787/888933981286 


\section{Indicateur D1. Combien de temps les élèves passent-ils en classe?}

\section{Faits marquants}

- Dans les pays et économies de l'OCDE, les élèves suivent en moyenne 7590 heures de cours obligatoires dans l'enseignement primaire et le premier cycle de l'enseignement secondaire. Ce nombre s'élève à 5973 heures seulement en Hongrie, mais atteint près du double en Australie (11 000 heures) et au Danemark (10 960 heures).

- En moyenne, dans les pays et économies de l'OCDE, le temps annuel d'instruction obligatoire est de 799 heures dans l'enseignement primaire et de 919 heures dans le premier cycle de l'enseignement secondaire, soit 120 heures de plus que dans l'enseignement primaire.

- En moyenne, dans les pays et économies de l'OCDE, les cours de lecture, d'expression écrite et de littérature, de mathématiques et de disciplines artistiques représentent $52 \%$ du temps d'instruction obligatoire dans l'enseignement primaire ; les cours de lecture, d'expression écrite et de littérature, de langues étrangères (première langue étrangère et autres langues étrangères) et de mathématiques représentent environ $42 \% \mathrm{du}$ temps d'instruction obligatoire dans le premier cycle de l'enseignement secondaire.

\section{Contexte}

Le temps d'instruction en classe représente une grande partie de l'investissement public consacré à l'apprentissage des élèves dans le cadre institutionnel. Les pays diffèrent dans leurs choix en ce qui concerne le temps total d'instruction et la sélection des matières obligatoires du programme. Ces choix reflètent les priorités et les préférences nationales ou régionales à propos de ce qui doit être enseigné aux élèves en fonction de leur âge. La quasi-totalité des pays fixent le nombre officiel ou réglementaire d'heures de cours, qui correspond le plus souvent au nombre minimal d'heures de cours que les établissements doivent dispenser aux élèves. Le principe à la base de ces normes minimales est souvent qu'un nombre suffisant d'heures de cours est impératif pour que l'apprentissage génère de bons résultats. L'adaptation des ressources aux besoins des élèves et l'optimisation de l'utilisation du temps constituent un défi majeur pour la politique d'éducation. Le salaire des enseignants, l'entretien des infrastructures scolaires et le coût des autres ressources éducatives requises sont les principaux postes de dépenses de l'éducation. Le temps pendant lequel ces ressources sont mises à la disposition des élèves (dont cet indicateur traite en partie) est donc un facteur important lors de l'affectation du budget de l'éducation (voir l'indicateur C7, qui décrit les facteurs influant sur le coût salarial des enseignants par élève). De surcroît, on s'accorde de plus en plus à reconnaître l'importance du temps consacré par les élèves à des activités autres que l'apprentissage en dehors de la salle de classe durant la journée de classe, notamment lors des pauses et des récréations. À côté du temps d'instruction prévu dans le cadre institutionnel, les élèves peuvent participer à des activités périscolaires avant ou après la journée de classe ou durant les vacances scolaires, mais ces activités ainsi que les périodes d'examen sortent du cadre du présent indicateur.

\section{Autres faits marquants}

- Dans l'enseignement primaire, le pourcentage du programme obligatoire qui est consacré à la lecture, à l'expression écrite et à la littérature va de $18 \%$ au Portugal à $38 \%$ en France; dans le premier cycle de l'enseignement secondaire, il va de $9 \%$ en Irlande (pourcentage du programme de cours en anglais, l'une des deux langues nationales) à $25 \%$ en Grèce (et $33 \%$ en Italie, si on inclut la part du programme obligatoire consacrée aux sciences sociales).

- Dans l'enseignement primaire, le pourcentage du programme obligatoire qui est consacré aux mathématiques va de $12 \%$ au Danemark à $27 \%$ au Mexique ; dans le premier cycle de l'enseignement secondaire, il va de $11 \%$ environ en Corée, en Hongrie et en Irlande, à $16 \%$ au Chili, en Fédération de Russie et en Lettonie (et jusqu'à $20 \%$ en Italie si on inclut la part du programme obligatoire consacrée aux sciences naturelles).

- À l'exception de quelques pays où le programme obligatoire est principalement consacré à des matières à option, la part du temps d'instruction obligatoire qui est consacrée à des matières obligatoires modulables représente, en moyenne dans les pays et économies de l'OCDE, 1 \% ou moins dans l'enseignement primaire 
et dans le premier cycle de l'enseignement secondaire. Dans l'enseignement primaire et dans le premier cycle de l'enseignement secondaire, en moyenne $5 \%$ du temps d'instruction obligatoire est consacré à des matières obligatoires modulables choisies par les établissements.

- Dans un quart des pays dont les données sont disponibles, la répartition du temps d'instruction entre les années d'études est flexible, c'est-à-dire que le temps d'instruction par matière est défini durant un certain nombre d'années d'études, voire durant toute la scolarité obligatoire, sans précision du temps à y consacrer durant chaque année d'études.

Graphique D1.1. Temps d'instruction obligatoire en filière générale (2019)

Primaire et premier cycle du secondaire, établissements publics

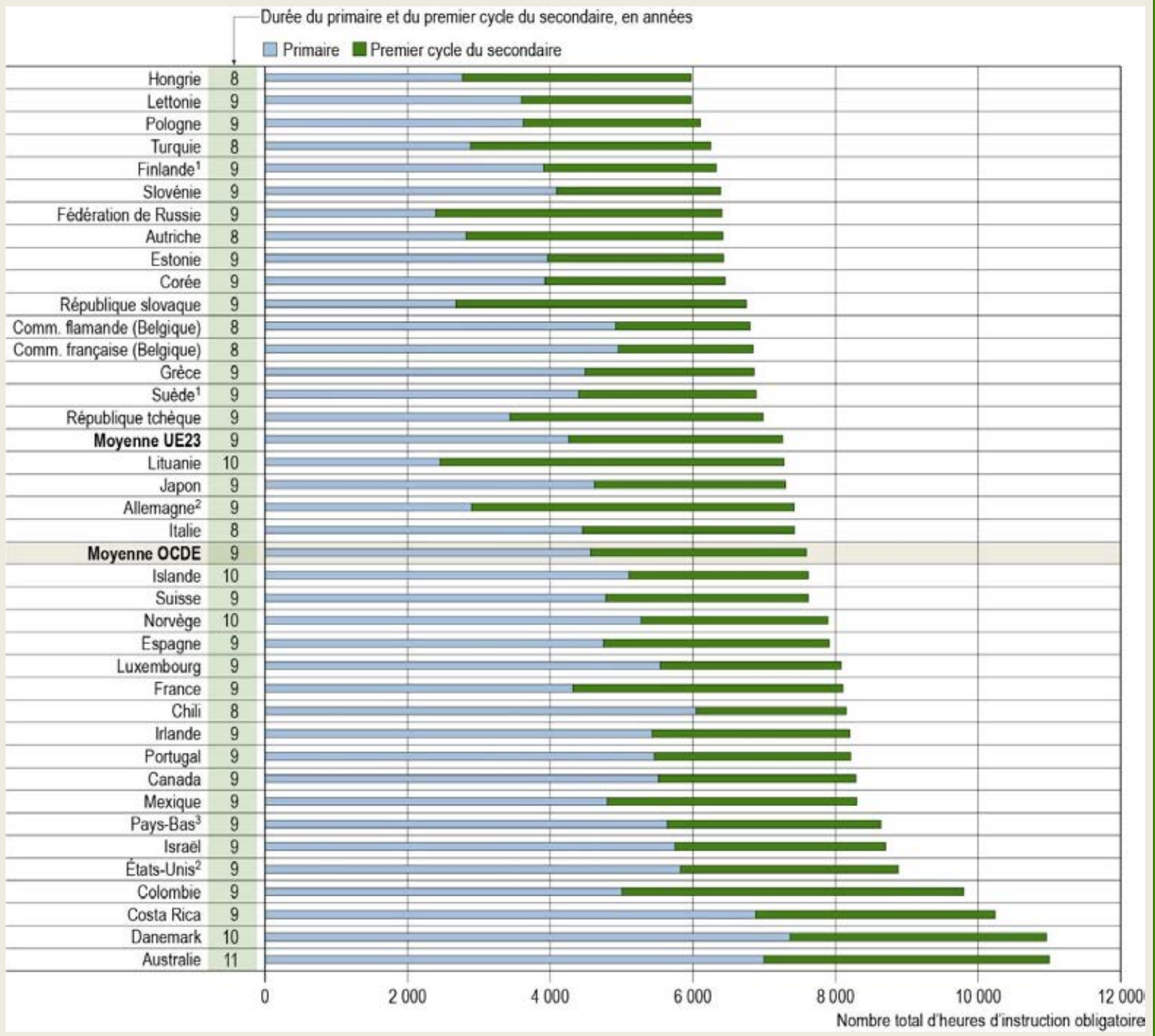

1. Estimation du nombre d'heures selon le niveau d'enseignement sur la base du nombre annuel moyen d'heures, l'affectation du temps d'instruction, pour certaines matières, étant flexible entre les différentes années d'études.

2. Année de référence : 2018 .

3. Le premier cycle du secondaire compte 3 ou 4 années d'études selon la filière d'enseignement. La $4 \mathrm{e}$ année d'enseignement secondaire en filière préprofessionnelle (VMBO) a été exclue des calculs.

Les pays et économies sont classés par ordre croissant du nombre total d'heures d'instruction obligatoire.

Source: OCDE (2019), tableau D1.1. Consulter la section "Source» pour tout complément d'information et l'annexe 3 pour les notes (https://doi.org/10.1787/f8d7880d-en). 


\section{Analyse}

\section{Scolarité obligatoire en filière générale}

Le temps annuel d'instruction et la durée de la scolarité obligatoire ont tous deux une incidence sur le temps total d'instruction durant la scolarité obligatoire. Dans certains pays, la scolarité obligatoire est moins longue et la charge de travail annuelle des élèves est plus importante selon les exigences statutaires. Dans d'autres pays, la charge de travail des élèves est répartie de manière uniforme sur une période plus longue. Le présent indicateur porte sur la scolarité obligatoire dans l'enseignement primaire et dans le premier cycle de l'enseignement secondaire. Toutefois, dans certains pays tels que les Pays-Bas, l'enseignement préprimaire est également obligatoire ; par conséquent, l'âge du début de la scolarisation obligatoire est inférieur à l'âge où débute l'enseignement primaire (voir l'annexe 3 pour plus de détails sur la durée de la scolarité obligatoire). En outre, dans environ trois pays et économies sur cinq parmi ceux dont les données sont disponibles, une année au moins du deuxième cycle de l'enseignement secondaire fait partie de la scolarité obligatoire à temps plein (voir le tableau D1.1).

\section{Encadré D1.1. Programmation des congés durant l'année scolaire dans le premier cycle de l'enseignement secondaire (2019)}

La longueur de l'année scolaire varie fortement entre les pays de l'OCDE, ce qui implique que le nombre de semaines pendant lequel les élèves n'ont pas classe varie fortement aussi entre les pays. La fréquence et la longueur des congés varient entre les pays, car la façon dont ils organisent l'année scolaire diffère.

Les congés scolaires sont généralement programmés à l'échelle nationale, mais ils varient parfois entre les entités infranationales, en particulier dans les pays fédéraux. Les congés sont d'ordinaire similaires dans l'enseignement primaire et le premier cycle de l'enseignement secondaire ; par rapport à l'enseignement primaire, à la fin de l'année scolaire, les élèves du premier cycle de l'enseignement secondaire ont deux semaines de congés de moins en Grèce, une semaine de moins en Fédération de Russie, une semaine de plus en Islande, en Israël et au Portugal, et trois semaines de plus en Irlande (voir l'encadré D1.1 dans OCDE (2018[1] $)$ pour tout complément d'information sur les congés durant l'année scolaire dans l'enseignement primaire).

La répartition des congés durant l'année scolaire peut varier aussi entre les régions. Des dates différentes de congé sont par exemple fixées dans les trois zones en France; une souplesse similaire s'observe dans la programmation de tout ou partie des congés dans des pays fédéraux ainsi qu'en Angleterre (Royaume-Uni), en Australie, en Autriche, en Italie, aux Pays-Bas, en Pologne, en République slovaque, en République tchèque et en Slovénie (voir l'organisation de l'année scolaire dans l'enseignement primaire et le premier cycle de l'enseignement secondaire à l'annexe 3 ).

Dans tous les pays, la période la plus longue de congé est celle programmée entre deux années scolaires successives. Dans le premier cycle de l'enseignement secondaire, à l'exception de la Colombie, la période de congés entre deux années scolaires successives ne dure que 5 semaines dans certaines entités infranationales de Suisse, mais peut aller jusqu'à 13 semaines au Chili (entre 11 et 13 semaines), en Fédération de Russie, en Italie (entre 12 et 13 semaines), en Lettonie, en Lituanie, au Portugal (entre 12 et 13 semaines) et en Turquie. Dans la quasi-totalité des pays dont les données sont disponibles, cette période de congé entre deux années scolaires représente au moins la moitié des congés scolaires (voir le graphique D1.a).

Outre cette longue période de congé, trois ou quatre périodes plus courtes sont généralement programmées durant l'année scolaire. Une cinquième période de congé est prévue durant le troisième trimestre de l'année 
scolaire en Angleterre (Royaume-Uni), en Écosse (Royaume-Uni) et au Luxembourg ainsi que dans certains Länder allemands.

La longueur et les dates des périodes de congé qui parsèment l'année scolaire varient selon les pays, l'interruption des cours la plus courante est celle programmée à la fin de l'année civile qui correspond soit à environ deux semaines de congé (dans l'hémisphère Nord), soit à la fin de l'année scolaire (dans l'hémisphère Sud). Ces différences dans la programmation des congés expliquent la souplesse de l'année scolaire (par exemple, les congés à Pâques).

Dans la plupart des pays, la longueur des différentes périodes de congé varie pendant l'année scolaire, de quelques jours à deux semaines. Le Danemark, la Fédération de Russie, la Lituanie et la Slovénie font figure d'exception, avec des congés d'une semaine (de trois à quatre périodes de congé par année scolaire), tout comme l'Australie, la France, la Grèce et la Nouvelle-Zélande, avec des congés de deux semaines (de deux périodes de congé en Grèce à quatre périodes de congé en France). Les congés d'une semaine alternent avec ceux de deux semaines durant l'année scolaire en Angleterre (Royaume-Uni), en Belgique, au Luxembourg et en Pologne.
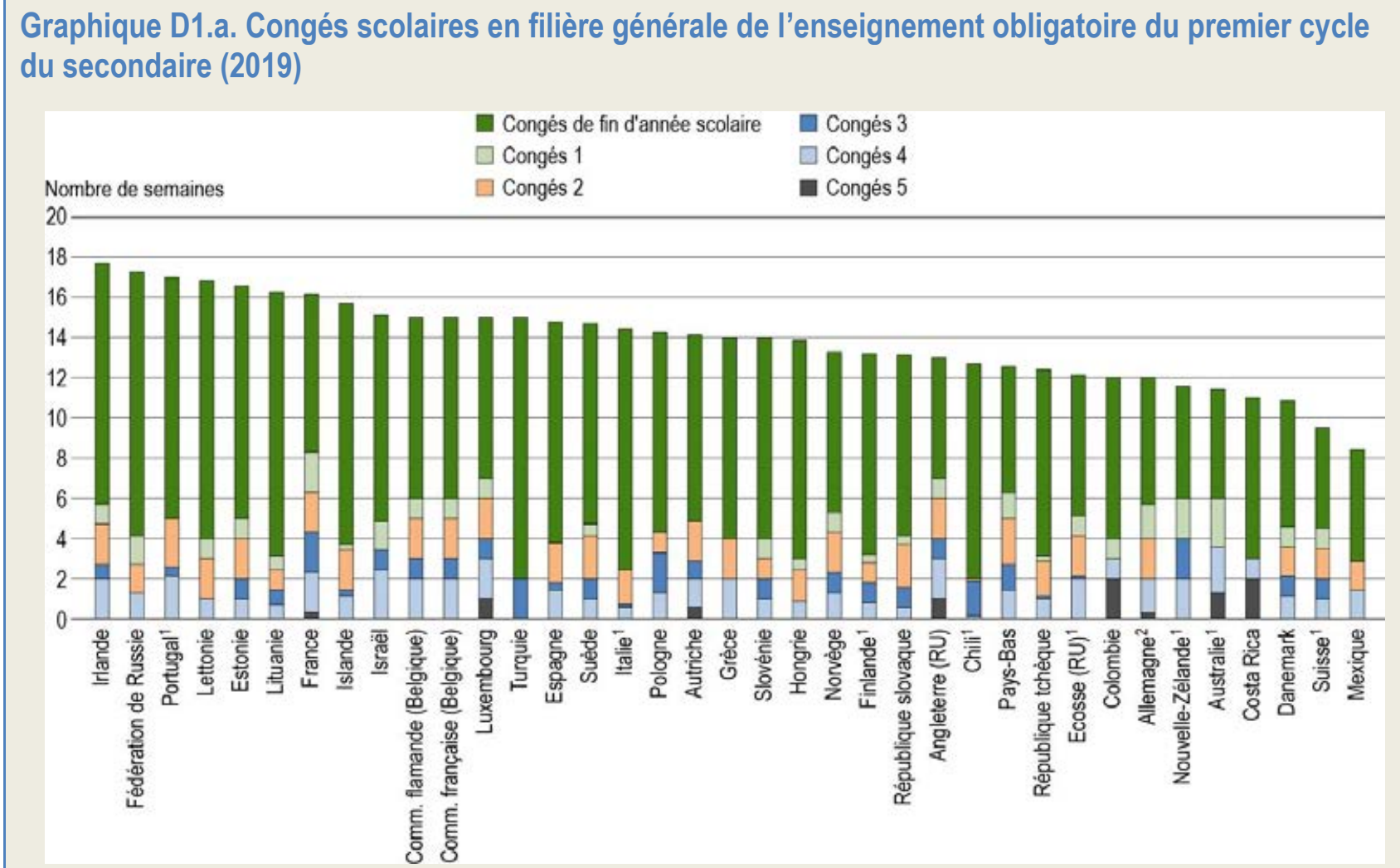

Remarque : Les congés n'incluent ni les jours fériés ni les jours de fête religieuse, sauf si ces jours sont inclus dans des périodes de congé plus longues.

1. Durée minimale des périodes de congé, certaines périodes pouvant être plus longues selon les régions au sein du pays.

2. Données concernant la Rhénanie du Nord-Westphalie. La durée des congés en Allemagne n'est communiquée qu'à titre indicatif, car des variations peuvent exister entre les entités infrarégionales et en leur sein.

Les pays et économies sont classés par ordre décroissant du nombre de semaines de congé durant l'année scolaire.

Source: OCDE (2019). Consulter la section "Source» pour tout complément d'information et l'annexe 3 pour les notes (https://doi.org/10.1787/f8d7880d-en). 
Dans environ trois pays et économies sur quatre parmi ceux dont les données sont disponibles, les élèves entrent dans l'enseignement primaire à l'âge de 6 ans. Dans la plupart des autres pays, ils ne commencent pas avant l'âge de 7 ans. C'est le cas en Estonie, en Fédération de Russie, en Finlande, en Lettonie, en Lituanie, en Pologne et en Suède. L'enseignement primaire ne débute à l'âge de 5 ans qu'en Angleterre (Royaume-Uni), en Australie, en Écosse (Royaume-Uni) et en Nouvelle-Zélande.

La durée de l'enseignement primaire varie aussi considérablement. En moyenne, dans les pays et économies de l'OCDE, l'enseignement primaire dure 6 ans, mais sa durée va de 4 ans en Allemagne, en Autriche, en Fédération de Russie, en Hongrie, en Lituanie, en République slovaque et en Turquie, à 7 ans, en Australie, au Danemark, en Écosse (Royaume-Uni), en Islande et en Norvège. En moyenne, le premier cycle de l'enseignement secondaire dure 3 ans, mais sa durée va de 2 ans au Chili et dans les Communautés flamande et française de la Belgique, à 5 ans en Allemagne, en Fédération de Russie et en République slovaque, et jusqu'à 6 ans en Lituanie (voir le tableau D1.2).

Les pays se distinguent aussi par la façon dont ils répartissent le temps d'instruction durant l'année. Le nombre de jours d'instruction, tout comme la façon dont ces jours sont répartis durant l'année scolaire, peut varier sensiblement entre les pays, car ces derniers n'organisent pas les vacances scolaires de la même manière (voir l'encadré D1.1). Ces jours d'instruction varient également, car les pays organisent les récréations et les pauses différemment (voir l'encadré D1.2 dans OCDE (2018[1])).

\section{Encadré D1.2. Comparabilité des données sur le temps d'instruction (2019)}

Les données sur le temps d'instruction (prévu) défini dans la réglementation sont recueillies lors d'une collecte de données basée sur des normes internationales convenues et selon des méthodes qui garantissent la comparabilité des données. Toutefois, des problèmes de comparabilité se posent non seulement à cause d'écarts par rapport aux normes et méthodes convenues, mais également à cause de différences dans la définition du temps d'instruction dans la réglementation.

\section{Type d'informations sur le temps d'instruction}

Le temps d'instruction prévu désigne souvent le temps d'instruction minimum, mais il peut aussi désigner le temps d'instruction recommandé. Les deux concepts impliquent que les établissements ou les exécutifs locaux jouissent d'une certaine autonomie pour décider du nombre d'heures de cours à dispenser. Dans certains pays, les données sont mixtes. Au Danemark par exemple, le temps d'instruction minimum est défini dans trois matières (la lecture, l'expression écrite et la littérature, les mathématiques et l'histoire) dans chaque année d'études, mais est recommandé dans les autres matières.

Le temps d'instruction prévu est généralement comparable entre les établissements des pays, mais il correspond à une moyenne pondérée des temps d'instruction définis dans différents règlements dans certains pays. C'est le cas lorsque le temps d'instruction prévu varie entre les groupes d'élèves (en Lettonie et en Lituanie, dans les établissements accueillant des minorités), entre les orientations en filière générale (au Chili, dans les filières avec ou sans Jornada Escolar Completa, et en Italie, dans divers cursus du deuxième cycle de l'enseignement secondaire [licel]) ou entre les différentes entités infranationales (comme dans des pays fédéraux tels que l'Allemagne, l'Australie, le Canada et les États-Unis).

\section{Nombre de journées de classe par an}

La plupart des pays réglementent la longueur de l'année scolaire en termes de journées de classe (nombre de journées de classe par année scolaire ou nombre de journées de classe par semaine et de semaines de classe par an). Ces nombres ne tiennent pas compte du fait que la longueur (statutaire) d'une journée de classe peut varier. En Autriche, en Corée et au Danemark par exemple, le nombre de cours par semaine et, donc, la longueur de la journée de classe varient entre les années d'études dans l'enseignement primaire. 
Quelques pays tiennent compte de la longueur variable de la journée de classe pour déterminer le nombre de journées de classe par an. En Communauté flamande de Belgique et en France, la réglementation se base sur 4.5 journées de classe par semaine, car il n'y a pas classe le mercredi après-midi. Le nombre de journées de classe peut donc y être inférieur par rapport à des pays où la longueur des journées de classe ne varie pas par semaine ou par an.

\section{Nombre d'heures de cours}

Le temps d'instruction est indiqué en heures (de 60 minutes) pour garantir la comparabilité des données entre les pays. Toutefois, il est parfois défini en d'autres unités dans la réglementation. Dans la moitié environ des pays, il correspond à un certain nombre de cours ou à une unité de référence différente de l'année scolaire. La conversion de ces données en un nombre annuel d'heures de cours peut poser des problèmes. Dans certains pays, la durée d'un cours n'est pas uniforme sur tout le territoire. Dans ce cas, c'est la durée moyenne (au Costa Rica et en Grèce, par exemple) ou la plus courante (comme en Lettonie) qui est retenue pour calculer le nombre d'heures de cours. Dans un tiers environ des pays et économies, le temps d'instruction est défini par semaine de classe et non par année scolaire, de sorte que les chiffres hebdomadaires sont multipliés par le nombre estimé de semaines de classe par année scolaire.

Pour garantir la comparabilité du temps d'instruction entre les pays, les pauses entre les cours sont exclues. Dans certains pays toutefois, les pauses entre les cours sont incluses dans le temps d'instruction prévu dans la réglementation, mais elles sont exclues dans le temps d'instruction déclaré comme le prévoit la définition internationale. Au Danemark par exemple, les pauses font partie du temps d'instruction obligatoire dans l'enseignement primaire et le premier cycle de l'enseignement secondaire. En Espagne, les pauses entre les cours (87.5 heures par an) sont également incluses dans le temps d'instruction obligatoire dans la législation sur l'enseignement primaire des communautés autonomes.

Pour plus de plus amples informations sur les problèmes de comparabilité, voir les notes spécifiques aux pays à l'annexe 3 .

\section{Temps d'instruction obligatoire}

Par temps d'instruction obligatoire, on entend le temps d'instruction et sa répartition entre les matières qui s'appliquent à la quasi-totalité des établissements publics et à la quasi-totalité des élèves qui y sont scolarisés, selon la réglementation.

En moyenne, dans les pays et économies de l'OCDE, les élèves suivent 4568 heures de cours obligatoires durant l'enseignement primaire et 3022 heures de cours obligatoires durant le premier cycle de l'enseignement secondaire. Dans les pays et économies de l'OCDE, le temps total d'instruction obligatoire est en moyenne de 7590 heures dans l'enseignement primaire et le premier cycle de l'enseignement secondaire (sur 9 ans, en moyenne), mais il varie selon les pays, de 5973 heures en Hongrie (sur 8 ans) à 11000 heures en Australie (sur 11 ans) (voir le graphique D1.1). Le temps d'instruction obligatoire en milieu scolaire n'est pas défini dans la réglementation en Angleterre (Royaume-Uni), en Écosse (Royaume-Uni) et en Nouvelle-Zélande. Les établissements y sont toutefois tenus de dispenser un nombre minimal d'heures de cours aux élèves (en Nouvelle-Zélande) et de prévoir un temps d'instruction suffisant pour enseigner un programme vaste et équilibré qui respecte toutes les exigences énoncées dans la réglementation (pour la variation du temps d'instruction au niveau infranational, voir l'encadré D1.3).L'instruction peut également avoir lieu en dehors des heures de cours obligatoires et en dehors de la classe ou du milieu scolaire. Dans certains pays, les élèves sont encouragés à suivre durant leurs études secondaires des cours extrascolaires dans des matières qui leur sont enseignées à l'école afin de les aider à améliorer leurs résultats. Ils peuvent suivre des cours supplémentaires de soutien (dits de « rattrapage ») ou de perfectionnement, qui leur sont donnés soit individuellement par un professeur particulier, soit en groupe par des enseignants. Ils peuvent également suivre d'autres cours indépendants (voir 
l'encadré D1.2 dans OCDE (2017[2] $)$. Ces cours sont financés soit par les pouvoirs publics, soit par les élèves et leur famille (voir l'encadré D1.1 dans OCDE (2011[3]).

Cet indicateur sur le temps d'instruction obligatoire ne porte que sur le temps que les élèves passent en classe (tel que fixé par la réglementation). II ne représente qu'une partie du temps total d'instruction des élèves. II ne permet pas de déterminer le nombre d'heures de cours que les élèves suivent effectivement, ni d'évaluer le temps qu'ils consacrent à l'apprentissage en dehors du cadre scolaire.

\section{Encadré D1.3. Variation infranationale du temps d'instruction obligatoire dans l'enseignement primaire et le premier cycle de l'enseignement secondaire}

Le temps d'instruction obligatoire varie entre les pays de l'OCDE à tous les niveaux d'enseignement. II varie parfois aussi sensiblement au sein même des pays, en particulier dans les pays fédéraux où les normes sont définies à l'échelle infranationale. Cette variation est décrite à titre d'exemple dans quatre pays (la Belgique, le Canada, les États-Unis et le Royaume-Uni) sur la base des données infranationales sur le temps d'instruction obligatoire dans l'enseignement primaire et le premier cycle de l'enseignement secondaire en 2019.

Dans l'enseignement primaire, c'est en Belgique que le temps total d'instruction obligatoire varie le moins entre les entités infranationales : la différence est inférieure à $1 \%$ (40 heures) entre les Communautés flamande et française (4916 heures, contre 4956 heures). La différence de temps total d'instruction obligatoire entre les entités infranationales est supérieure à $6 \%$ (342 heures) au Royaume-Uni (Pays de Galles et Irlande du Nord uniquement). Au Canada, le temps d'instruction prévu (obligatoire et non obligatoire) varie de $15 \%$ (745 heures) entre les entités infranationales. II varie encore plus aux États-Unis, où la différence entre le temps d'instruction obligatoire le plus et le moins élevé atteint 3240 heures.

La même tendance générale s'observe dans le premier cycle de l'enseignement secondaire, même si la variation infranationale est moindre que dans l'enseignement primaire dans les quatre pays à l'étude. Dans le premier cycle de l'enseignement secondaire, le temps d'instruction obligatoire total varie à peine entre les entités infranationales en Belgique (2 heures). II varie de plus de $3 \%$ ( 86 heures environ) au Royaume-Uni (Pays de Galles et Irlande du Nord uniquement). II varie de $13 \%$ (353 heures) entre les entités infranationales au Canada. La différence entre entités infranationales atteint 1620 heures aux États-Unis.

L'ampleur de ces écarts entre les entités infranationales peut s'expliquer par des différences de nombre annuel de journées de classe entre ces entités à la fois dans l'enseignement primaire et dans le premier cycle de l'enseignement secondaire. Selon les chiffres de 2019, le nombre de journées de classe par année scolaire varie de 10 jours entre les entités infranationales au Canada (entre 180 et 190 journées de classe), de 19 jours dans l'enseignement primaire (entre 158 et 177 journées de classe) et de 17 jours dans le premier cycle de l'enseignement secondaire (entre 160 et 177 journées de classe) en Belgique et de 26 jours aux États-Unis (entre 160 et 186 journées de classe). Par contraste, le nombre de journées de classe par année scolaire ne varie pas entre les entités infranationales au Royaume-Uni (190 journées de classe).

Source : Base de données de Regards sur l'éducation, http://stats.oecd.org.

\section{Temps d'instruction prévu}

Le temps total d'instruction prévu correspond au nombre d'heures de cours que les établissements doivent dispenser aux élèves dans les matières obligatoires et, le cas échéant, dans les matières non obligatoires.

Le temps d'instruction prévu et le temps d'instruction obligatoire sont identiques (le temps d'instruction prévu est totalement obligatoire) dans l'enseignement primaire et le premier cycle de l'enseignement secondaire dans 
environ trois pays sur quatre parmi ceux dont les données sont disponibles. Le temps d'instruction prévu est supérieur de $5 \%$ au moins au temps d'instruction obligatoire en Finlande, en France (dans le premier cycle de l'enseignement secondaire), en Grèce, en Lituanie, en Pologne, au Portugal (dans l'enseignement primaire) et en Slovénie. Le temps d'instruction prévu peut toutefois différer du temps d'instruction réel des élèves (voir l'encadré D1.2).

\section{Temps d'instruction par matière}

En moyenne, dans les pays de l'OCDE, $52 \%$ du temps d'instruction obligatoire dans l'enseignement primaire est consacré à trois matières : la lecture, l'expression écrite et la littérature $(25 \%)$, les mathématiques $(17 \%)$ et les disciplines artistiques (10\%). Ces matières sont, avec l'éducation physique et la santé $(9 \%)$, les sciences naturelles $(7 \%)$ et les sciences sociales $(6 \%)$, les six matières principales du programme de cours dans tous les pays de l'OCDE où le temps d'instruction par matière est spécifié. Le reste du programme obligatoire non flexible dans l'enseignement primaire est consacré aux cours de langues étrangères, de religion, d'éthique ou de morale, de technologies de l'information et de la communication (TIC), de technologie, de formation professionnelle et pratique et représente en moyenne environ $19 \%$ du temps d'instruction obligatoire dans les pays de l'OCDE (voir le tableau D1.3a et le graphique D1.2a).

\section{Graphique D1.2a. Temps d'instruction par matière dans l'enseignement primaire (2019)}

En pourcentage du temps total d'instruction obligatoire, établissements publics

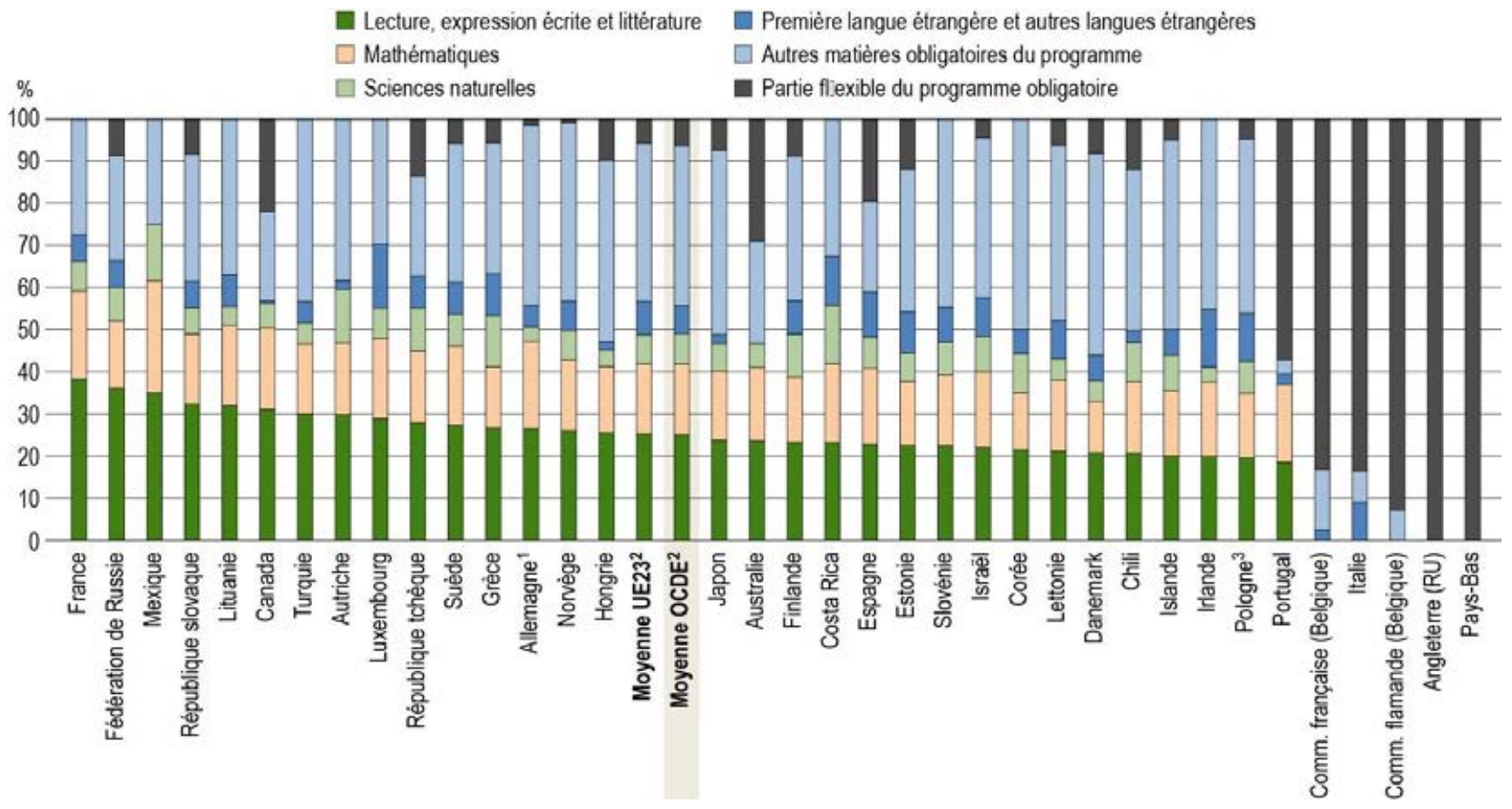

1. Année de référence : 2018.

2. À l'exclusion de l'Angleterre (Royaume-Uni), de la Communauté flamande (Belgique), de la Communauté française (Belgique), de l'Italie, des Pays-Bas et du Portugal.

3. À l'exclusion des trois premières années d'enseignement primaire durant lesquelles une part importante du temps d'instruction consacré aux matières obligatoires est flexible.

Les pays et économies sont classés par ordre décroissant de la part du temps d'instruction consacrée à la lecture, l'expression écrite et la littérature.

Source: OCDE (2019), tableau D1.3a. Consulter la section "Source» pour tout complément d'information et l'annexe 3 pour les notes (https://doi.org/10.1787/f8d7880d-en). 
Dans le premier cycle de l'enseignement secondaire, environ $42 \%$ du programme obligatoire est en moyenne consacré à trois matières dans les pays et économies de l'OCDE : la lecture, l'expression écrite et la littérature $(15 \%)$, les langues étrangères (première langue étrangère et autres langues étrangères) (15\%) et les mathématiques (13\%). Les sciences naturelles représentent en moyenne $12 \%$ du programme obligatoire, les sciences sociales, $11 \%$, l'éducation physique et la santé, $8 \%$, et les arts, $7 \%$. Ces matières sont les sept matières principales du programme de cours prévu dans ce niveau d'enseignement dans tous les pays de l'OCDE où le temps d'instruction est spécifié par matière. Le reste (environ $12 \%$ ) du programme obligatoire non flexible de ce niveau d'enseignement est consacré aux cours de religion, d'éthique ou de morale, de TIC, de technologie, de formation professionnelle et pratique, etc. (voir le tableau D1.3b et le graphique D1.2b).

\section{Graphique D1.2b. Temps d'instruction par matière en filière générale du premier cycle de l'enseignement secondaire (2019)}

En pourcentage du temps total d'instruction obligatoire, établissements publics

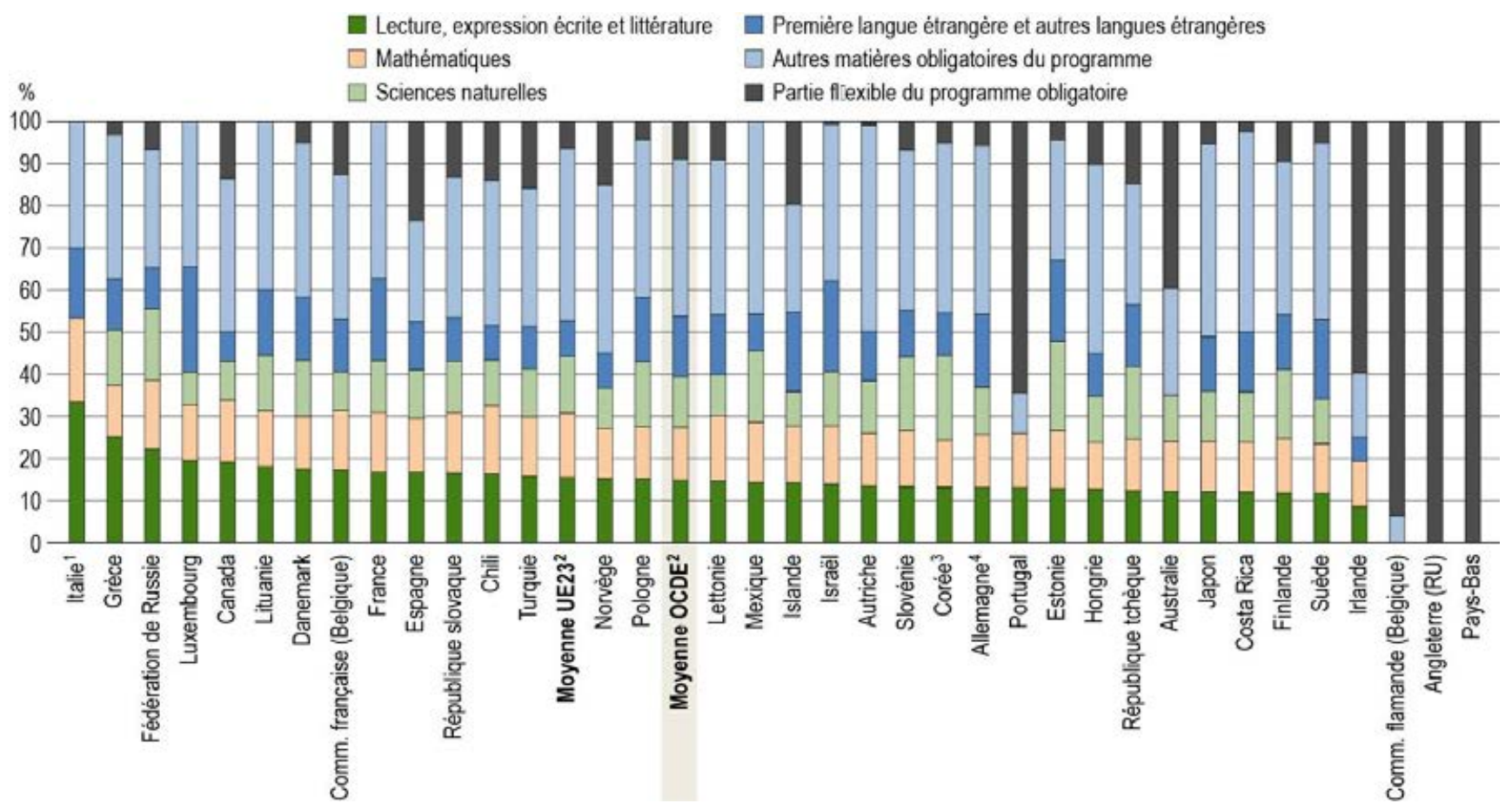

1. Les sciences sociales sont incluses dans la lecture, l'expression écrite et la littérature, et les sciences naturelles, dans les mathématiques.

2. À l'exclusion de l'Angleterre (Royaume-Uni), de la Communauté flamande (Belgique), de l'Irlande, des Pays-Bas et du Portugal.

3. Les technologies de l'information et de la communication et la formation professionnelle et pratique sont incluses dans les sciences naturelles.

4. Année de référence : 2018 .

Les pays et économies sont classés par ordre décroissant de la part du temps d'instruction consacrée à la lecture, l'expression écrite et la littérature.

Source: OCDE (2019), tableau D1.3b. Consulter la section "Source» pour tout complément d'information et l'annexe 3 pour les notes (https://doi.org/10.1787/f8d7880d-en).

C'est une répartition sensiblement différente du temps par rapport à l'enseignement primaire. En moyenne, dans les pays et économies de l'OCDE, la part de la lecture, de l'expression écrite et de la littérature diminue pour passer de $25 \%$ à $15 \%$ du temps d'instruction obligatoire. La part des mathématiques passe quant à elle de $17 \%$ à $13 \%$ du temps d'instruction obligatoire. À l'inverse, la part des sciences naturelles augmente, passant de $7 \%$ du programme obligatoire à $12 \%$, comme celle des sciences sociales, qui passe de $6 \%$ à $11 \%$, et celle des langues étrangères (première langue étrangère et autres langues étrangères), qui passe de $6 \%$ à $15 \%$. Les 
langues étrangères représentent la partie la plus importante du programme obligatoire de base dans le premier cycle de l'enseignement secondaire en Allemagne, au Costa Rica, en France, en Islande, en Israël, au Japon, au Luxembourg et en Suède (voir les tableaux D1.3a et b).

Dans le premier cycle de l'enseignement secondaire, la répartition du temps entre les matières du programme obligatoire varie sensiblement d'un pays à l'autre. La lecture, l'expression écrite et la littérature représentent par exemple $12 \%$ ou moins du temps d'instruction obligatoire en Australie, au Costa Rica, en Finlande, en Irlande, au Japon, en République tchèque et en Suède, mais plus de $25 \%$ du temps d'instruction obligatoire en Grèce et en Italie (en Italie, cette part comprend également le temps consacré aux sciences sociales). En Irlande, les cours de lecture, d'expression écrite et de littérature sont dispensés dans les deux langues nationales et leur temps d'instruction combiné peut atteindre quelque $15 \%$ du temps total d'instruction obligatoire. La part du temps d'instruction obligatoire consacrée aux langues étrangères (première langue étrangère et autres langues étrangères) varie également fortement entre les pays. La première langue étrangère représente moins de $7 \%$ du temps d'instruction obligatoire en Grèce et en Irlande, contre $13 \%$ au moins en Communauté française de Belgique, en Islande et au Japon. Par ailleurs, dans plus de quatre pays sur dix parmi ceux dont les données sont disponibles, l'apprentissage d'une autre langue étrangère en plus de la deuxième langue étrangère est obligatoire dans le premier cycle de l'enseignement secondaire.

Comme le montrent les différences entre l'enseignement primaire et le premier cycle de l'enseignement secondaire, la répartition du temps entre les matières varie sensiblement selon l'âge des élèves. En moyenne, dans les pays de l'OCDE, la part du temps d'instruction consacrée à la lecture, à l'expression écrite et à la littérature représente $28 \%$ à l'âge de 7 ans, $19 \%$ à l'âge de 11 ans et $12 \%$ à l'âge de 15 ans. Par contraste, les élèves consacrent à l'apprentissage d'une langue étrangère une part moyenne de leur temps d'instruction égale à $3 \%$ à l'âge de 7 ans, mais à $10 \%$ pour la première langue étrangère et à $1 \%$ pour les autres langues étrangères à l'âge de 11 ans et à $9 \%$ pour la première langue étrangère et à $5 \%$ pour les autres langues étrangères à l'âge de 15 ans. La part du temps d'instruction consacrée aux sciences naturelles augmente avec l'âge, passant de $6 \%$ à l'âge de 7 ans à $9 \%$ à l'âge de 11 ans et à $12 \%$ à l'âge de 15 ans, tout comme celle consacrée aux sciences sociales, qui passe de $5 \%$ à l'âge de 7 ans à $9 \%$ à l'âge de 11 ans et à $10 \%$ à l'âge de 15 ans. La part du temps d'instruction consacrée aux disciplines artistiques diminue avec l'âge, passant de respectivement $11 \%$ et $9 \%$ à l'âge de 7 ans et 11 ans à $4 \%$ à l'âge de 15 ans, tout comme la part de l'éducation physique, qui passe de $10 \%$ à l'âge de 7 ans à $8 \%$ à l'âge de 11 ans, pour atteindre $6 \%$ à l'âge de 15 ans (voir les tableaux D1.5b, $f$ et $\mathrm{j}$, disponibles en ligne).

\section{Flexibilité des programmes}

Dans la plupart des pays, les autorités nationales ou centrales règlementent le temps d'instruction et les programmes ou font des recommandations les concernant. Toutefois, les autorités locales, les établissements, les enseignants ou les élèves jouissent d'une certaine liberté quant à l'organisation du temps d'instruction ou au choix des matières.

Dans un quart des pays dont les données sont disponibles, la répartition du temps d'instruction entre les années d'études est flexible, c'est-à-dire que le temps d'instruction par matière est défini durant un certain nombre d'années d'études, voire durant toute la scolarité obligatoire, sans précision du temps à y consacrer durant chaque année d'études. Dans ce cas, les établissements ou les autorités locales sont libres de décider combien de temps consacrer aux matières durant chaque année d'études (voir le tableau D1.2).

Dans quelques pays, il est courant d'inscrire la plupart des matières obligatoires dans un horaire flexible. Au Portugal, les matières obligatoires dans l'emploi du temps modulable représentent plus de la moitié du temps d'instruction dans l'enseignement primaire, et cette proportion dépasse les $80 \%$ du temps d'instruction dans les Communautés flamande et française de Belgique et en Italie. En Angleterre (Royaume-Uni) et aux Pays-Bas, l'ensemble du programme de cours est constitué de matières modulables. Des tendances similaires s'observent dans le premier cycle de l'enseignement secondaire en Angleterre (Royaume-Uni), en Communauté flamande de Belgique, aux Pays-Bas et au Portugal. Dans ces pays et économies, les matières obligatoires ou le temps 
total d'instruction sont spécifiés, mais pas la répartition du temps à consacrer à chaque matière. Les autorités locales, les établissements ou les enseignants sont libres de décider du temps à consacrer à chaque matière obligatoire. En Écosse (Royaume-Uni), le temps total d'instruction n'est pas réglementé dans l'enseignement primaire et le premier cycle de l'enseignement secondaire (même si certaines matières obligatoires sont spécifiées) et est du ressort des autorités locales et des établissements eux-mêmes. À l'exception de ces pays et économies, les matières obligatoires modulables représentent moins de $1 \%$ du temps d'instruction obligatoire tant dans l'enseignement primaire que dans le premier cycle de l'enseignement secondaire, même si elles pourraient représenter une part importante du programme de cours dans certains pays. L'emploi du temps modulable représente plus de $10 \%$ des matières obligatoires uniquement au Canada dans l'enseignement primaire.

La flexibilité dans le choix des matières est moins courante dans les pays de l'OCDE. En moyenne, $5 \%$ du temps d'instruction obligatoire est consacré à des matières choisies par les établissements dans l'enseignement primaire. Dans le premier cycle de l'enseignement secondaire, $5 \%$ du temps d'instruction obligatoire est consacré à des matières choisies par les établissements et $4 \%$, à des matières choisies par les élèves. Toutefois, certains pays réservent une partie substantielle du temps d'instruction obligatoire à des matières à option. Au Canada (dans le premier cycle de l'enseignement secondaire), au Chili, en Communauté française de Belgique (dans le premier cycle de l'enseignement secondaire), en Espagne, en Estonie (dans l'enseignement primaire), en Hongrie, en République slovaque (dans le premier cycle de l'enseignement secondaire) et en République tchèque, par exemple, environ $10 \%$ ou plus du temps d'instruction est consacré à des matières choisies par les établissements. Au moins $20 \%$ du temps d'instruction obligatoire y est consacré en Australie (29\% dans l'enseignement primaire et $22 \%$ dans le premier cycle de l'enseignement secondaire), en Communauté flamande de Belgique (20\% dans le premier cycle de l'enseignement secondaire), en Espagne (23\% dans le premier cycle de l'enseignement secondaire) et en Irlande (60\% dans le premier cycle de l'enseignement secondaire). En Australie, en Islande, en Norvège et en Turquie, $15 \%$ à $20 \%$ du temps d'instruction obligatoire est consacré à des matières choisies par les élèves dans le premier cycle de l'enseignement secondaire (voir les tableaux D1.3a et b).

\section{Temps d'instruction non obligatoire}

II n'est pas courant de prévoir un temps d'instruction non obligatoire dans les pays de l'OCDE. Ce type de temps d'instruction n'est prévu que dans six pays dans l'enseignement primaire et dans huit pays dans le premier cycle de l'enseignement secondaire. Dans les pays de l'OCDE, le temps d'instruction non obligatoire représente en moyenne $4 \%$ du temps total d'instruction obligatoire dans l'enseignement primaire et dans le premier cycle de l'enseignement secondaire. Dans certains pays, le temps d'instruction non obligatoire supplémentaire peut toutefois être considérable. Dans l'enseignement primaire par exemple, le temps d'instruction non obligatoire supplémentaire représente $53 \%$ du temps d'instruction obligatoire total en Grèce, $14 \%$ au Portugal et $21 \%$ en Slovénie. Dans le premier cycle de l'enseignement secondaire, le temps d'instruction non obligatoire représente $11 \%$ du temps total d'instruction obligatoire en Finlande, $20 \%$ en France, $32 \%$ en Grèce, $15 \%$ en Lituanie et $23 \%$ en Slovénie (voir les tableaux D1.3a et b).

\section{Définitions}

Par temps d'instruction/programme obligatoire, on entend le temps d'instruction et sa répartition entre matières obligatoires qui s'appliquent à la quasi-totalité des établissements publics et à la quasi-totalité des élèves qui y sont scolarisés. Le programme obligatoire peut être flexible, puisque les autorités locales, les établissements, les enseignants et/ou les élèves peuvent jouir d'une certaine liberté pour choisir les matières et/ou la répartition du temps d'instruction obligatoire entre les matières.

Par matières flexibles du programme obligatoire choisies par les établissements, on entend la part totale du temps d'instruction obligatoire définie par les autorités centrales que les autorités régionales ou locales, les établissements ou les enseignants consacrent à des matières de leur choix (ou qu'ils choisissent dans une liste 
dressée par les autorités centrales en charge de l'éducation). II est obligatoire pour les établissements de proposer une de ces matières et pour les élèves de la suivre.

Par matières obligatoires à option choisies par les élèves, on entend le temps total d'instruction consacré à une ou plusieurs matières que les élèves sont tenus de choisir (dans une série de matières que les établissements sont tenus de proposer) pour se constituer un horaire correspondant au temps total d'instruction obligatoire.

Par matières obligatoires modulables, on entend le temps total d'instruction défini par les autorités centrales dans une série donnée de matières, que les autorités régionales ou locales, les établissements d'enseignement ou les enseignants affectent à des matières particulières. Une certaine flexibilité leur est laissée concernant le temps consacré aux matières, mais pas concernant le choix des matières.

La répartition flexible du temps d'instruction entre plusieurs années d'études correspond aux cas dans lesquels le programme indique uniquement le temps total d'instruction dans une matière durant un certain nombre d'années d'études, voire durant toute la scolarité obligatoire, sans préciser le temps qu'il convient d'y consacrer durant chaque année d'études. Dans ces cas, les établissements ou les autorités locales sont libres de décider combien de temps y consacrer durant chaque année d'études.

Par temps d'instruction, on entend le temps pendant lequel les établissements publics sont censés dispenser aux élèves des cours dans toutes les matières inscrites au programme obligatoire et non obligatoire, dans leurs locaux, pendant la journée de classe ou lors des activités organisées avant et après la journée de classe, qui sont des composantes officielles du programme obligatoire. Le temps d'instruction est calculé abstraction faite des pauses entre les cours et d'autres types d'interruptions, du temps non obligatoire en dehors de la journée de classe, du temps consacré aux devoirs et leçons à domicile, du tutorat individuel ou des cours particuliers et des périodes d'examen (journées d'examen en dehors du cadre scolaire, par exemple journées consacrées aux examens nationaux).

Par temps d'instruction prévu, on entend le nombre annuel d'heures de cours, parties obligatoire et non obligatoire du programme confondues, que les élèves sont censés suivre dans les établissements publics. Le programme prévu peut être basé sur des règlements ou des normes émanant des autorités centrales (à l'échelon le plus élevé de la hiérarchie) en charge de l'éducation ou peut être défini dans une série de recommandations à l'échelle régionale.

Par partie non obligatoire du programme, on entend le temps total d'instruction que les établissements publics sont tenus de proposer en plus du temps d'instruction obligatoire, mais qui ne s'imposent pas à tous les élèves. Les matières concernées, dites «à option », peuvent varier d'un établissement ou d'une région à l'autre. Les activités proposées avant et après la journée classe ne font pas partie du programme non obligatoire par exemple si elles ne font pas partie du programme officiel ou que les établissements publics ne sont pas tenus de les proposer. Le programme non obligatoire exclut l'accueil des enfants avant et après la journée de classe, même s'il est réglementé.

\section{Méthodologie}

Dans le cadre du temps d'instruction obligatoire, cet indicateur porte sur le temps d'instruction prévu, tel qu'il est fixé par la réglementation, soit le temps d'exposition des élèves à l'enseignement en classe dans le cadre institutionnel. II ne permet pas de déterminer le nombre d'heures de cours que les élèves suivent effectivement, ni d'évaluer le temps qu'ils consacrent à l'apprentissage en dehors du cadre scolaire. Des différences entre le nombre minimal d'heures de cours prévues par la réglementation et le nombre d'heures de cours effectivement suivies par les élèves ne sont pas à exclure dans certains pays. Le nombre minimal d'heures de cours n'est pas toujours atteint, que ce soit en raison du calendrier scolaire fixé par les établissements, de l'annulation de cours ou de l'absentéisme des enseignants (voir l'encadré D1.1 dans OCDE (2007[4]). 
Cet indicateur présente aussi la répartition du temps minimal (ou recommandé) d'instruction entre les diverses matières du programme. II indique le temps d'instruction prévu dans les années d'études qui font partie de l'enseignement obligatoire à temps plein en filière générale. Ces chiffres sont difficiles à comparer entre les pays en raison de différences dans leur politique de programmes, mais ils donnent un aperçu du nombre d'heures de cours jugé nécessaire pour permettre aux élèves d'atteindre les objectifs qui leur sont fixés en matière d'apprentissage.

Lorsque la répartition du temps d'instruction est flexible entre les années d'études, c'est-à-dire que le temps d'instruction par matière est défini durant un certain nombre d'années d'études, voire durant toute la scolarité obligatoire, sans précision du temps à y consacrer durant chaque année d'étude, le temps d'instruction par âge ou par niveau d'enseignement est calculé dans l'hypothèse que le nombre total d'heures d'instruction est réparti de manière équitable entre les années d'études.

Voir le Guide de l'OCDE pour l'établissement de statistiques internationalement comparables dans le domaine de l'éducation 2018 (OCDE, 2019 $\left.9_{[5]}\right)$ pour de plus amples informations. Voir les notes spécifiques aux pays à l'annexe 3 (https://doi.org/10.1787/f8d7880d-en).

\section{Source}

Les données sur le temps d'instruction proviennent d'une collecte de données conjointe d'Eurydice et de l'OCDE sur le temps d'instruction réalisée en 2018 et se rapportent au temps d'instruction obligatoire dans l'enseignement primaire et dans l'enseignement secondaire (premier et deuxième cycle) en filière générale à temps plein durant l'année scolaire 2018/19.

\section{Note concernant les données d'Israël}

Les données statistiques concernant Israël sont fournies par et sous la responsabilité des autorités israéliennes compétentes. L'utilisation de ces données par l'OCDE est sans préjudice du statut des hauteurs du Golan, de Jérusalem-Est et des colonies de peuplement israéliennes en Cisjordanie aux termes du droit international.

\section{Références}

OCDE (2019), Guide de l'OCDE pour l'établissement de statistiques internationalement comparables dans le domaine de l'éducation 2018: Concepts, normes, définitions et classifications, Éditions OCDE, Paris, https://dx.doi.org/10.1787/9789264305380-fr.

OCDE (2018), Regards sur l'éducation 2018: Les indicateurs de l'OCDE, Éditions OCDE, Paris, https://dx.doi.org/10.1787/eag-2018-fr.

OCDE (2017), Regards sur l'éducation 2017: Les indicateurs de l'OCDE, Éditions OCDE, Paris, https://dx.doi.org/10.1787/eag-2017-fr.

OCDE (2011), Regards sur l'éducation 2011: Les indicateurs de l'OCDE, Éditions OCDE, Paris, https://dx.doi.org/10.1787/eag-2011-fr.

OCDE (2007), Regards sur l'éducation 2007: Les indicateurs de l'OCDE, Éditions OCDE, Paris, 


\section{Tableaux de l'indicateur D1}

Tableau D1.1

Tableau D1.2

Tableau D1.3a

Tableau D1.3b
Temps d'instruction en filière générale de l'enseignement obligatoire (2019)

Organisation de la filière générale de l'enseignement obligatoire (2019)

Temps d'instruction par matière dans l'enseignement primaire (2019)

Temps d'instruction par matière en filière générale du premier cycle de l'enseignement secondaire (2019)

WEB Tableau D1.4 Temps d'instruction en filière générale de l'enseignement obligatoire, selon l'âge (2019)

WEB Tableau D1.5a Temps d'instruction par matière pour les élèves âgés de 6 ans (2019)

WEB Tableau D1.5 Temps d'instruction par matière pour les élèves âgés de 7 ans (2019)

WEB Tableau D1.5c Temps d'instruction par matière pour les élèves âgés de 8 ans (2019)

WEB Tableau D1.5d Temps d'instruction par matière pour les élèves âgés de 9 ans (2019)

WEB Tableau D1.5e Temps d'instruction par matière pour les élèves âgés de 10 ans (2019)

WEB Tableau D1.5f Temps d'instruction par matière pour les élèves âgés de 11 ans (2019)

WEB Tableau D1.5g Temps d'instruction par matière pour les élèves âgés de 12 ans (2019)

WEB Tableau D1.5h Temps d'instruction par matière pour les élèves âgés de 13 ans (2019)

WEB Tableau D1.5i Temps d'instruction par matière pour les élèves âgés de 14 ans (2019)

WEB Tableau D1.5j Temps d'instruction par matière pour les élèves âgés de 15 ans (2019)

WEB Tableau D1.5k Temps d'instruction par matière pour les élèves âgés de 16 ans (2019)

WEB Tableau D1.5I Temps d'instruction par matière pour les élèves âgés de 17 ans (2019)

Date butoir pour les données : 19 juillet 2019. Les mises à jour peuvent être consultées en ligne sur : http://dx.doi.org/10.1787/eag-data-en. D'autres données désagrégées sont également disponibles dans la Base de données de Regards sur l'éducation (http://stats.oecd.org/). 
Tableau D1.1. Temps d'instruction en filière générale de l'enseignement obligatoire1 (2019)

Selon le niveau d'enseignement, établissements publics

\begin{tabular}{|c|c|c|c|c|c|c|c|c|c|c|c|c|c|c|}
\hline & \multicolumn{7}{|c|}{ Primaire } & \multicolumn{7}{|c|}{ Premier cycle du secondaire } \\
\hline & \multirow[b]{2}{*}{ 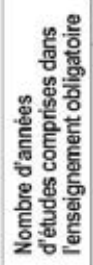 } & \multicolumn{3}{|c|}{ Nombre annuel moyen d'heures } & \multicolumn{3}{|c|}{ Nombre total d'heures } & \multirow[b]{2}{*}{ 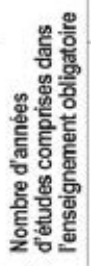 } & \multicolumn{3}{|c|}{ Nombre annuel moyen d'heures } & \multicolumn{3}{|c|}{ Nombre total d'heures } \\
\hline & & 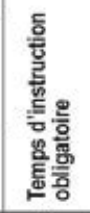 & 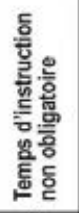 & 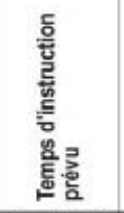 & 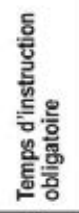 & 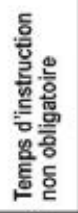 & 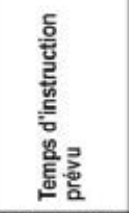 & & 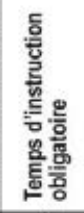 & 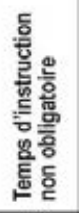 & 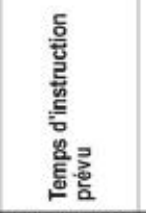 & 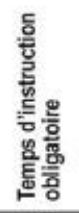 & 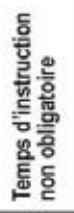 & 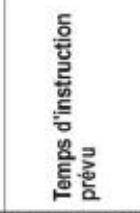 \\
\hline & (i) & (2) & (3) & $(4)=(2)+(3)$ & (5) & (6) & $(7)=(5)+(6)$ & (8) & (9) & (10) & $(11)=(9)+(10)$ & (12) & (13) & $(14)=(12)+(13)$ \\
\hline Pays & & & & & & & & & & & & & & \\
\hline Australie & 7 & 1000 & $\mathrm{~m}$ & $\mathrm{~m}$ & 7000 & $\mathrm{~m}$ & $\mathrm{~m}$ & 4 & 1000 & $\mathrm{~m}$ & m & 4000 & $\mathrm{~m}$ & $\mathrm{~m}$ \\
\hline${ }^{\circ}$ Autriche & 4 & 705 & $\mathrm{~m}$ & $\mathrm{~m}$ & 2820 & m & $\mathrm{m}$ & 4 & 900 & $\mathrm{~m}$ & $\mathrm{~m}$ & 3600 & $\mathrm{~m}$ & $\mathrm{~m}$ \\
\hline Canada & 6 & 920 & a & 920 & 5518 & a & 5518 & 3 & 924 & 3 & 927 & 2771 & 9 & 2780 \\
\hline Chili & 6 & 1008 & a & 1008 & 6047 & a & 6047 & 2 & 1052 & a & 1052 & 2103 & a & 2103 \\
\hline Colombie & 5 & 1000 & a & 1000 & 5000 & a & 5000 & 4 & 1200 & a & 1200 & 4800 & a & 4800 \\
\hline République tchèque & 5 & 687 & a & 687 & 3434 & a & 3434 & 4 & 888 & a & 828 & 3550 & a & 3550 \\
\hline Danemark & 7 & 1051 & a & 1051 & 7360 & a & 7360 & 3 & 1200 & a & 1200 & 3600 & a & 3600 \\
\hline Estonie & 6 & 661 & a & 661 & 3964 & a & 3964 & 3 & 823 & a & 823 & 2468 & a & 2468 \\
\hline Finlande $^{2}$ & 6 & 651 & 33 & 683 & 3905 & 195 & 4100 & 3 & 808 & 87 & 894 & 2423 & 261 & 2683 \\
\hline France & 5 & 864 & a & 864 & 4320 & a & 4320 & 4 & 946 & 189 & 1135 & 3784 & 756 & 4540 \\
\hline Allemagne ${ }^{24}$ & 4 & 724 & a & 724 & 2896 & a & 2896 & 5 & 905 & a & 905 & 4526 & a & 4526 \\
\hline Grèce & 6 & 748 & 396 & 1144 & 4488 & 2376 & 6864 & 3 & 791 & 253 & 1044 & 2374 & 758 & 3132 \\
\hline Hongrie & 4 & 692 & a & 692 & 2769 & a & 2769 & 4 & 801 & a & 801 & 3204 & a & 3204 \\
\hline Islande & 7 & 729 & a & 729 & 5100 & a & 5100 & 3 & 839 & a & 839 & 2516 & a & 2516 \\
\hline Irlande & 6 & 905 & a & 905 & 5430 & a & 5430 & 3 & 924 & a & 924 & 2772 & a & 2772 \\
\hline Israël & 6 & 968 & a & 958 & 5751 & a & 5751 & 3 & 984 & a & 984 & 2952 & a & 2952 \\
\hline Italie & 5 & 891 & a & 891 & 4455 & a & 4455 & 3 & 990 & a & 990 & 2970 & a & 2970 \\
\hline Japon & 6 & 770 & a & 770 & 4621 & a & 4621 & 3 & 893 & a & 893 & 2680 & a & 2680 \\
\hline Corèe & 6 & 655 & a & 655 & 3928 & a & 3928 & 3 & 842 & a & 842 & 2525 & a & 2525 \\
\hline Lettonie & 6 & 599 & $\mathrm{~m}$ & m & 3595 & $\mathrm{~m}$ & $\mathrm{~m}$ & 3 & 794 & $\mathrm{~m}$ & $\mathrm{~m}$ & 2381 & $\mathrm{~m}$ & $\mathrm{~m}$ \\
\hline Lituanie & 4 & 613 & 37 & 650 & 2452 & 149 & 2600 & 6 & 804 & 119 & 923 & 4826 & 713 & 5539 \\
\hline Luxembourg & 6 & 924 & a & 924 & 5544 & a & 5544 & 3 & 845 & a & 845 & 2535 & a & 2535 \\
\hline Mexique & 6 & 800 & a & 800 & 4800 & a & 4800 & 3 & 1167 & a & 1167 & 3500 & a & 3500 \\
\hline Pays-Bas ${ }^{5}$ & 6 & 940 & a & 940 & 5640 & a & 5640 & 3 & 1000 & a & 1000 & 3000 & a & 3000 \\
\hline Nouvelle-Zélande & 6 & $\mathrm{~m}$ & $\mathrm{~m}$ & m & $\mathrm{m}$ & $\mathrm{m}$ & $\mathrm{m}$ & 4 & $\mathrm{~m}$ & $\mathrm{~m}$ & $\mathrm{~m}$ & $\mathrm{~m}$ & $\mathrm{~m}$ & $\mathrm{~m}$ \\
\hline Norvege & 7 & 753 & a & 753 & 5272 & a & 5272 & 3 & 874 & a & 874 & 2622 & a & 2622 \\
\hline Pologne & 6 & 603 & 58 & 661 & 3619 & 348 & 3967 & 3 & 829 & 63 & 893 & 2488 & 190 & 2678 \\
\hline Portugal & 6 & 910 & 129 & 1039 & 5460 & 774 & 6234 & 3 & 918 & 27 & 945 & 2754 & 80 & 2834 \\
\hline République slovaque & 4 & 670 & a & 670 & 2678 & a & 2678 & 5 & 815 & a & 815 & 4073 & a & 4073 \\
\hline Slovènie & 6 & 682 & 140 & 822 & 4091 & 840 & 4931 & 3 & 766 & 179 & 944 & 2298 & 536 & 2833 \\
\hline Espagne & 6 & 792 & a & 792 & 4750 & a & 4750 & 3 & 1054 & a & 1054 & 3161 & a & 3161 \\
\hline Suède $^{2}$ & 6 & 733 & $\mathrm{~m}$ & $\mathrm{~m}$ & 4400 & m & $\mathrm{m}$ & 3 & 830 & $\mathrm{~m}$ & $\mathrm{~m}$ & 2490 & $\mathrm{~m}$ & m \\
\hline Suisse & 6 & 797 & $\mathrm{~m}$ & $\mathrm{~m}$ & 4782 & $\mathrm{~m}$ & $\mathrm{~m}$ & 3 & 945 & $\mathrm{~m}$ & $\mathrm{~m}$ & 2836 & $\mathrm{~m}$ & $\mathrm{~m}$ \\
\hline Turquie & 4 & 720 & a & 720 & 2880 & a & 2880 & 4 & 843 & a & 843 & 3371 & a & 3371 \\
\hline États-Unis ${ }^{3}$ & 6 & 971 & $\mathrm{~m}$ & $\mathrm{~m}$ & 5824 & m & $\mathrm{m}$ & 3 & 1020 & $\mathrm{~m}$ & m & 3059 & $\mathrm{~m}$ & m \\
\hline Economies & & & & & & & & & & & & & & \\
\hline Comm. flamande (Belgique) & 6 & 819 & a & 819 & 4916 & a & 4916 & 2 & 945 & a & 945 & 1890 & a & 1890 \\
\hline Comm. française (Belgique) & 6 & 826 & a & 826 & 4956 & a & 4956 & 2 & 944 & a & 944 & 1888 & a & 1888 \\
\hline Angleterre (RU) & 6 & $\mathrm{~m}$ & a & $\mathrm{m}$ & $\mathrm{m}$ & a & $\mathrm{m}$ & 3 & $\mathrm{~m}$ & a & $\mathrm{m}$ & $\mathrm{m}$ & a & $\mathrm{m}$ \\
\hline Écosse (RU) & 7 & $\mathrm{~m}$ & a & $\mathrm{m}$ & m & a & $\mathrm{m}$ & 3 & $\mathrm{~m}$ & a & $\mathrm{m}$ & $\mathrm{m}$ & a & $\mathrm{m}$ \\
\hline $\begin{array}{l}\text { Moyenne OCDE } \\
\text { Moyenne UE23 }\end{array}$ & $\begin{array}{l}6 \\
6\end{array}$ & $\begin{array}{l}799 \\
769\end{array}$ & $\begin{array}{l}\mathrm{m} \\
\mathrm{m}\end{array}$ & $\begin{array}{l}\mathrm{m} \\
\mathrm{m}\end{array}$ & $\begin{array}{l}4568 \\
4258\end{array}$ & $\begin{array}{l}m \\
m\end{array}$ & $\begin{array}{l}\mathrm{m} \\
\mathrm{m}\end{array}$ & $\begin{array}{l}3 \\
3\end{array}$ & $\begin{array}{l}919 \\
892\end{array}$ & $\begin{array}{l}\mathrm{m} \\
\mathrm{m}\end{array}$ & $\begin{array}{l}\mathrm{m} \\
\mathrm{m}\end{array}$ & $\begin{array}{l}3022 \\
3002\end{array}$ & $\begin{array}{l}\mathrm{m} \\
\mathrm{m}\end{array}$ & $\begin{array}{l}\mathrm{m} \\
\mathrm{m}\end{array}$ \\
\hline Argentine & m & $\mathrm{m}$ & $\mathrm{m}$ & $\mathrm{m}$ & $\mathrm{m}$ & $\mathrm{m}$ & $\mathrm{m}$ & $\mathrm{m}$ & $\mathrm{m}$ & $\mathrm{m}$ & $\mathrm{m}$ & $\mathrm{m}$ & $\mathrm{m}$ & $\mathrm{m}$ \\
\hline Brésil & 5 & $\mathrm{~m}$ & $\mathrm{~m}$ & $\mathrm{~m}$ & m & m & $\mathrm{m}$ & 4 & $\mathrm{~m}$ & $\mathrm{~m}$ & $\mathrm{~m}$ & $\mathrm{~m}$ & $\mathrm{~m}$ & $\mathrm{~m}$ \\
\hline Chine & $\mathrm{m}$ & $\mathrm{m}$ & $\mathrm{m}$ & $\mathrm{m}$ & & m & m & $\mathrm{m}$ & $\mathrm{m}$ & $\mathrm{m}$ & $\mathrm{m}$ & $\mathrm{m}$ & $\mathrm{m}$ & $\mathrm{m}$ \\
\hline Costa Rica & 6 & 1147 & a & 1147 & 6880 & a & 6880 & 3 & 1120 & a & 1120 & 3360 & a & 3360 \\
\hline a Inde & m & $\mathrm{m}$ & $\mathrm{m}$ & $\mathrm{m}$ & m & m & $\mathrm{m}$ & $\mathrm{m}$ & $\mathrm{m}$ & $\mathrm{m}$ & $\mathrm{m}$ & $\mathrm{m}$ & $\mathrm{m}$ & $\mathrm{m}$ \\
\hline Indonèsie & $\mathrm{m}$ & m & $\mathrm{m}$ & $\mathrm{m}$ & m & m & $\mathrm{m}$ & $\mathrm{m}$ & $\mathrm{m}$ & $\mathrm{m}$ & $\mathrm{m}$ & $\mathrm{m}$ & $\mathrm{m}$ & $\mathrm{m}$ \\
\hline Fédération de Russie & 4 & 598 & $\mathrm{~m}$ & $\mathrm{~m}$ & 2393 & m & $\mathrm{m}$ & 5 & 803 & $\mathrm{~m}$ & $\mathrm{~m}$ & 4016 & $\mathrm{~m}$ & m \\
\hline Arabie saoudite & m & m & m & $\mathrm{m}$ & $\mathrm{m}$ & m & $\mathrm{m}$ & m & $\mathrm{m}$ & $\mathrm{m}$ & m & $\mathrm{m}$ & $\mathrm{m}$ & m \\
\hline Afrique du Sud & m & $\mathrm{m}$ & $\mathrm{m}$ & $\mathrm{m}$ & $\mathrm{m}$ & m & $\mathrm{m}$ & $\mathrm{m}$ & $\mathrm{m}$ & $\mathrm{m}$ & m & $\mathrm{m}$ & $\mathrm{m}$ & m \\
\hline Moyenne G20 & $\mathrm{m}$ & $\mathrm{m}$ & $\mathrm{m}$ & $\mathrm{m}$ & $\mathrm{m}$ & $\mathrm{m}$ & $\mathrm{m}$ & $\mathrm{m}$ & $\mathrm{m}$ & $\mathrm{m}$ & $\mathrm{m}$ & $\mathrm{m}$ & $\mathrm{m}$ & $\mathrm{m}$ \\
\hline
\end{tabular}

Remarque : Les colonnes présentant le temps d'instruction dans l'enseignement obligatoire du primaire et du premier cycle du secondaire combinés (soit les colonnes 15 à 18), et du deuxième cycle du secondaire (soit les colonnes 19 à 25), peuvent être consultées en ligne. Consulter les sections « Définitions » et « Méthodologie » pour de plus amples informations. Les données peuvent être consultées sur http://stats.oecd.org/, Base de données de Regards sur l'éducation.

1. Concerne l'enseignement obligatoire à temps plein et exclut l'enseignement préprimaire, même lorsque ce dernier est obligatoire.

2. Estimation du nombre d'heures selon le niveau d'enseignement sur la base du nombre annuel moyen d'heures; pour certaines matières, l'affectation du temps d'instruction est flexible entre les différentes années d'études.

3. Année de référence : 2018.

4. À l'exclusion de la dernière année d'enseignement obligatoire, qui peut être comptabilisée soit dans le premier, soit dans le deuxième cycle du secondaire.

5. Le premier cycle du secondaire compte 3 ou 4 années d'études selon la filière d'enseignement. La 4e année d'enseignement secondaire en filière préprofessionnelle (VMBO) a été exclue des calculs.

Source : OCDE (2019). Consulter la section « Source » pour tout complément d'information et l'annexe 3 pour les notes (https://doi.org/10.1787/f8d7880d-en). Les symboles représentant les données manquantes et les abréviations figurent dans le Guide du lecteur. 
Tableau D1.2. Organisation de la filière générale de l'enseignement obligatoire (2019)

Selon le niveau d'enseignement, établissements publics

\begin{tabular}{|c|c|c|c|c|c|c|c|c|}
\hline & \multicolumn{4}{|c|}{ Primaire } & \multicolumn{4}{|c|}{ Premier cycle du secondaire } \\
\hline & $\begin{array}{c}\text { Nombre } \\
\text { d'annees } \\
\text { d'études } \\
\text { comprises dans } \\
\text { l'enseignement } \\
\text { obligatoire }\end{array}$ & $\begin{array}{l}\text { Age theorique } \\
\text { de début }\end{array}$ & $\begin{array}{l}\text { Nombre moyen } \\
\text { de jours } \\
\text { d'instruction } \\
\text { par an }\end{array}$ & $\begin{array}{c}\text { Répartition } \\
\text { flexible } \\
\text { du temps } \\
\text { d'instruction } \\
\text { entre differentes } \\
\text { années d'études }\end{array}$ & $\begin{array}{c}\text { Nombre } \\
\text { d'années } \\
\text { d'ćtudes } \\
\text { comprises dans } \\
\text { l'enseignement } \\
\text { obligatoire }\end{array}$ & $\begin{array}{l}\text { Age theorique } \\
\text { de début }\end{array}$ & $\begin{array}{l}\text { Nombre moyen } \\
\text { de jours } \\
\text { d'instruction } \\
\text { par an }\end{array}$ & $\begin{array}{c}\text { Rèpartition } \\
\text { flexible } \\
\text { du temps } \\
\text { d'instruction } \\
\text { entre différentes } \\
\text { années d'études }\end{array}$ \\
\hline & (1) & (2) & (3) & (4) & (5) & (6) & (7) & (8) \\
\hline \multicolumn{9}{|l|}{ w Pays } \\
\hline ôs Australie & 7 & 5 & 200 & Non & 4 & 12 & 200 & Non \\
\hline Autriche & 4 & 6 & 180 & Non & 4 & 10 & 180 & Non \\
\hline Canada & 6 & 6 & 183 & Non & 3 & 12 & 183 & Non \\
\hline Chili & 6 & 6 & 183 & Non & 2 & 12 & 182 & Non \\
\hline Colombie & 5 & 6 & 200 & Non & 4 & 11 & 200 & Non \\
\hline République tchèque & 5 & 6 & 194 & Oui & 4 & 11 & 194 & Oui \\
\hline Danemark & 7 & 6 & 200 & Non & 3 & 13 & 200 & Non \\
\hline Estonie & 6 & 7 & 175 & Oui & 3 & 13 & 175 & Oui \\
\hline Finlande $^{2}$ & 6 & 7 & 188 & Oui & 3 & 13 & 188 & Oui \\
\hline France & 5 & 6 & 162 & Non & 4 & 11 & 162 & Non \\
\hline Allemagne ${ }^{2 / 4}$ & 4 & 6 & 188 & Non & 5 & 10 & 188 & Non \\
\hline Grèce & 6 & 6 & 176 & Non & 3 & 12 & 166 & Non \\
\hline Hongrie & 4 & 6 & 181 & Non & 4 & 10 & 181 & Non \\
\hline Islande & 7 & 6 & 170 & Oui & 3 & 13 & 170 & Oui \\
\hline Irlande & 6 & 6 & 181 & Non & 3 & 12 & 165 & Non \\
\hline Israël & 6 & 6 & 219 & Non & 3 & 12 & 209 & Non \\
\hline Italie & 5 & 6 & 200 & Non & 3 & 11 & 200 & Non \\
\hline Japon & 6 & 6 & 201 & Non & 3 & 12 & 201 & Non \\
\hline Corée & 6 & 6 & 190 & Oui & 3 & 12 & 190 & Oui \\
\hline Lettonie & 6 & 7 & 169 & Non & 3 & 13 & 173 & Non \\
\hline Lituanie & 4 & 7 & 175 & Oui & 6 & 11 & 185 & Oui \\
\hline Luxembourg & 6 & 6 & 180 & Non & 3 & 12 & 169 & Non \\
\hline Mexique & 6 & 6 & 200 & Non & 3 & 12 & 200 & Non \\
\hline Pays-Bas ${ }^{6}$ & 6 & 6 & $\mathrm{~m}$ & Oui & 3 & 12 & $\mathrm{~m}$ & Oui \\
\hline Nouvelle-Zélande & 6 & 5 & 195 & $\mathrm{~m}$ & 4 & 11 & 193 & $\mathrm{~m}$ \\
\hline Norvège & 7 & 6 & 190 & Oui & 3 & 13 & 190 & Oui \\
\hline Pologne & 6 & 7 & 176 & Non & 3 & 13 & 176 & Non \\
\hline Portugal & 6 & 6 & 180 & Non & 3 & 12 & 178 & Non \\
\hline Republique slovaque & 4 & 6 & 186 & Non & 5 & 10 & 186 & Non \\
\hline Slovénie & 6 & 6 & 190 & Non & 3 & 12 & 185 & Non \\
\hline Espagne & 6 & 6 & 175 & Non & 3 & 12 & 175 & Non \\
\hline Suede ${ }^{2}$ & 6 & 7 & 178 & Oui & 3 & 13 & 178 & Oui \\
\hline Suisse & 6 & 6 & 188 & Non & 3 & 12 & 188 & Non \\
\hline Turquic & 4 & 6 & 180 & Non & 4 & 10 & 180 & Non \\
\hline Etats-Unis ${ }^{3}$ & 6 & 6 & 180 & m & 3 & 12 & 180 & $\mathrm{~m}$ \\
\hline \multicolumn{9}{|l|}{ Economies } \\
\hline Comm. flamande (Belgique) & 6 & 6 & 158 & Non & 2 & 12 & 160 & Non \\
\hline Comm. française (Belgique) & 6 & 6 & 177 & Non & 2 & 12 & 177 & Non \\
\hline Angleterre (RU) & 6 & 5 & 190 & $\mathrm{~m}$ & 3 & 11 & 190 & $\mathrm{~m}$ \\
\hline Ecosse (RU) & 7 & 5 & 190 & Oui & 3 & 12 & 190 & Oui \\
\hline Moyenne OCDE & 6 & 6 & 185 & m & 3 & 12 & 184 & m \\
\hline Moyenne UE23 & 6 & 6 & 181 & m & 3 & 12 & 180 & m \\
\hline Argentine & $\mathrm{m}$ & $\mathrm{m}$ & $\mathrm{m}$ & $\mathrm{m}$ & $\mathrm{m}$ & $\mathrm{m}$ & $\mathrm{m}$ & $\mathrm{m}$ \\
\hline Brésil & 5 & 6 & 200 & Non & 4 & 11 & 200 & Non \\
\hline Chine & m & $\mathrm{m}$ & m & $\mathrm{m}$ & $\mathrm{m}$ & $\mathrm{m}$ & $\mathrm{m}$ & $\mathrm{m}$ \\
\hline שू Costa Rica & 6 & 6 & 200 & Non & 3 & 12 & 200 & Non \\
\hline${ }^{a}$ Inde & $\mathrm{m}$ & $\mathrm{m}$ & $\mathrm{m}$ & $\mathrm{m}$ & $\mathrm{m}$ & $\mathrm{m}$ & $\mathrm{m}$ & $\mathrm{m}$ \\
\hline Indonésic & $\mathrm{m}$ & $\mathrm{m}$ & $\mathrm{m}$ & $\mathrm{m}$ & $\mathrm{m}$ & $\mathrm{m}$ & $\mathrm{m}$ & $\mathrm{m}$ \\
\hline Fédération de Russie & 4 & 7 & 169 & Non & 5 & 11 & 175 & Non \\
\hline Arabie saoudite & $\mathrm{m}$ & $\mathrm{m}$ & $\mathrm{m}$ & $\mathrm{m}$ & $\mathrm{m}$ & m & $\mathrm{m}$ & $\mathrm{m}$ \\
\hline Afrique du Sud & $\mathrm{m}$ & $\mathrm{m}$ & m & $\mathrm{m}$ & $\mathrm{m}$ & m & m & m \\
\hline
\end{tabular}

Moyenne G20

$\mathrm{m} \quad \mathrm{m}$

m $\quad m$

$\mathrm{m}$

m

m

Remarque : Les élèves vont à l'école cinq jours par semaine (six en Israël et dans l'enseignement secondaire en Italie). Dans certains pays, la durée statutaire de la journée de classe varie durant la semaine. Les colonnes présentant l'organisation de l'enseignement obligatoire du deuxième cycle du secondaire (soit les colonnes 9 à 12) peuvent être consultées en ligne. Consulter les sections " Définitions » et « Méthodologie " pour de plus amples informations. Les données peuvent être consultées sur http://stats.oecd.org/, Base de données de Regards sur l'éducation.

1. Concerne l'enseignement obligatoire à temps plein et exclut l'enseignement préprimaire, même lorsque ce dernier est obligatoire.

2. Dans certaines matières, l'affectation du temps d'instruction est flexible entre les différentes années d'études.

3. Année de référence : 2018.

4. À l'exclusion de la dernière année d'enseignement obligatoire, qui peut être comptabilisée soit dans le premier, soit dans le deuxième cycle du secondaire. 5. Le premier cycle du secondaire compte 3 ou 4 années d'études selon la filière d'enseignement. La $4^{\mathrm{e}}$ année d'enseignement secondaire en filière préprofessionnelle (VMBO) a été exclue des calculs.

Source : OCDE (2019). Consulter la section « Source » pour tout complément d'information et l'annexe 3 pour les notes (https://doi.org/10.1787/f8d7880d-en). Les symboles représentant les données manquantes et les abréviations figurent dans le Guide du lecteur. 
Tableau D1.3a. Temps d'instruction par matière dans l'enseignement primaire (2019)

En pourcentage du temps total d'instruction obligatoire, établissements publics

\begin{tabular}{|c|c|c|c|c|c|c|c|c|c|c|c|c|c|c|c|c|c|c|}
\hline & 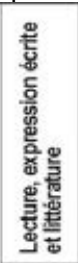 & 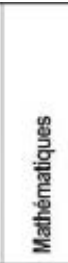 & 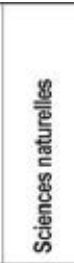 & 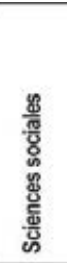 & 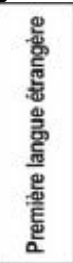 & 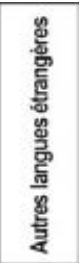 & 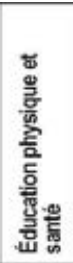 & 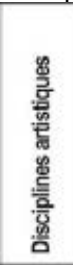 & 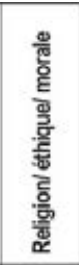 & 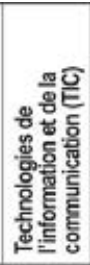 & $\begin{array}{l}\text { 을 } \\
\text { 을 } \\
\text { 듕 } \\
\end{array}$ & 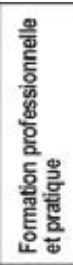 & 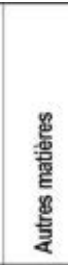 & 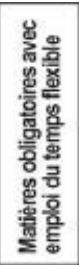 & 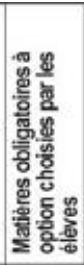 & 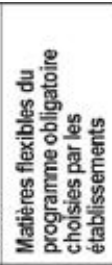 & 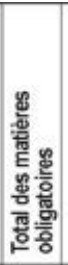 & 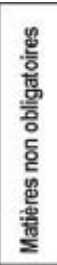 \\
\hline & (1) & (2) & (3) & (4) & (5) & (6) & (7) & (8) & (9) & (10) & (11) & (12) & (13) & (14) & (15) & (16) & (17) & (18) \\
\hline \multicolumn{19}{|l|}{ س Pays } \\
\hline Australie & 24 & 17 & 6 & $8^{\circ}$ & $x(16)$ & $x(16)$ & 8 & 5 & $x(4)$ & $x(11)$ & $4^{\mathrm{a}}$ & $x(11)$ & $x(16)$ & $x(16)$ & $\mathrm{m}$ & $29^{\mathrm{d}}$ & 100 & m \\
\hline Autriche & 30 & 17 & $13^{d}$ & $x(3)$ & 2 & a & 11 & 9 & 9 & $x(17)$ & $x(3)$ & 6 & 4 & a & a & a & 100 & $\mathrm{~m}$ \\
\hline Canada & 31 & 19 & 6 & 5 & 1 & a & 9 & 5 & 0 & a & 0 & 0 & 1 & 17 & a & 5 & 100 & \\
\hline Chili & 21 & 17 & 9 & 9 & 3 & $x(16)$ & 9 & 10 & 6 & $x(16)$ & 2 & $x(16)$ & 2 & a & a & $12^{\circ}$ & 100 & a \\
\hline Colombie & $\mathrm{m}$ & $\mathrm{m}$ & $\mathrm{m}$ & m & $\mathrm{m}$ & $\mathrm{m}$ & $\mathrm{m}$ & $\mathrm{m}$ & $\mathrm{m}$ & $\mathrm{m}$ & $\mathrm{m}$ & $\mathrm{m}$ & $\mathrm{m}$ & m & m & $\mathrm{m}$ & $\mathrm{m}$ & \\
\hline République tchèque & 28 & 17 & $10^{d}$ & $x(3)$ & 8 & a & 8 & 10 & $x(13)$ & 1 & $4^{4}$ & $x(11)$ & $x(16)$ & a & $x(16)$ & $14^{4}$ & 100 & a \\
\hline Danemark & 21 & 12 & 5 & 3 & 5 & 1 & 6 & 8 & 3 & $x(14)$ & a & 4 & 23 & $8^{d}$ & a & a & 100 & a \\
\hline Estonie & 23 & 15 & 7 & 5 & 8 & 2 & 11 & 15 & $x(16)$ & $x(16)$ & 3 & a & a & a & a & $12^{4}$ & 100 & a \\
\hline Finlande ${ }^{t}$ & 23 & 15 & 10 & 4 & 7 & 1 & 9 & 16 & 5 & $x(17)$ & a & a & a & 4 & a & 4 & 100 & 5 \\
\hline France & 38 & 21 & $7^{\circ}$ & 3 & 6 & a & 13 & 8 & 4 & $\times(3)$ & $x(3)$ & a & a & a & a & a & 100 & a \\
\hline Allemagne $^{2}$ & 26 & 21 & 4 & 6 & 5 & a & 11 & 13 & 6 & 0 & 2 & 0 & 4 & a & 1 & a & 100 & a \\
\hline Grèce & 27 & 14 & 12 & 6 & 8 & 2 & 9 & 10 & 3 & 3 & a & a & a & a & a & 6 & 100 & 53 \\
\hline Hongrie & 25 & 16 & 4 & a & 2 & a & 20 & 16 & 4 & a & 4 & a & a & a & a & 10 & 100 & a \\
\hline Islande & 20 & 16 & 8 & $13^{\circ}$ & $6^{4}$ & $\times(5,15)$ & 9 & $19^{d}$ & $x(4)$ & 3 & a & $x(8)$ & a & a & $5^{4}$ & $x(15)$ & 100 & a \\
\hline Irlande & 20 & 17 & $4^{d}$ & 8 & 14 & a & 4 & 12 & 10 & $x(17)$ & $x(3)$ & a & 11 & a & a & a & 100 & a \\
\hline Israël & 22 & 18 & 8 & 8 & 6 & 3 & 6 & 6 & 14 & a & a & 4 & a & a & a & 4 & 100 & a \\
\hline Italiet & $x(14)$ & $x(14)$ & $x(14)$ & $x(14)$ & 9 & a & $x(14)$ & $x(14)$ & 7 & a & $x(14)$ & a & a & $84^{\circ}$ & a & $x(17)$ & 100 & 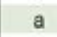 \\
\hline Japon & 24 & 16 & 7 & 6 & 2 & a & 10 & 12 & 3 & a & a & a & 13 & 7 & a & a & 100 & a \\
\hline Corée & 2 & 14 & $9^{d}$ & $9^{\circ}$ & 6 & a & 7 & 9 & $x(4,13)$ & $x(12,13)$ & $\mathrm{x}(12)$ & $x(3)$ & $25^{\mathrm{d}}$ & a & a & a & 100 & a \\
\hline Lettonic & 21 & 17 & 5 & 6 & 8 & 1 & 8 & 12 & 2 & 1 & a & 4 & 9 & a & a & 6 & 100 & m \\
\hline Lituanie & 32 & 19 & 4 & 4 & 8 & a & 12 & $17^{\circ}$ & 4 & a & $x(8)$ & a & a & a & a & a & 100 & 6 \\
\hline Luxembourg $^{2}$ & 29 & 19 & 7 & 2 & 15 & a & 10 & 11 & 7 & a & a & a & a & a & a & a & 100 & a \\
\hline Mexique & 35 & 27 & 13 & 10 & $\mathrm{~m}$ & a & 5 & 5 & 5 & a & a & a & a & a & a & a & 100 & a \\
\hline Pays-Bas ${ }^{4}$ & $x(14)$ & $x(14)$ & $x(14)$ & $x(14)$ & $x(14)$ & a & $x(14)$ & $\times(14)$ & $x(14)$ & $x(14)$ & $x(14)$ & $x(14)$ & a & $100^{\mathrm{d}}$ & a & a & 100 & a \\
\hline Nouvelle-Zèlande & $m$ & $\mathrm{~m}$ & $\mathrm{~m}$ & $\mathrm{~m}$ & $\mathrm{~m}$ & $\mathrm{~m}$ & $\mathrm{~m}$ & $\mathrm{~m}$ & $\mathrm{~m}$ & $\mathrm{~m}$ & $\mathrm{~m}$ & $\mathrm{~m}$ & $\mathrm{~m}$ & $\mathrm{~m}$ & m & $\mathrm{m}$ & $\mathrm{m}$ & $\mathrm{m}$ \\
\hline Norvège & 2 & 17 & 7 & 7 & 7 & a & 11 & 14 & 8 & a & a & 2 & a & a & a & 1 & 100 & a \\
\hline Pologne ${ }^{5}$ & 20 & 15 & 8 & 7 & 12 & a & 15 & 8 & a & 4 & 4 & a & 4 & a & a & 5 & 100 & 9 \\
\hline Portugal" & 18 & 18 & $x(14)$ & $x(14)$ & 3 & a & 3 & $x(14)$ & a & $x(17)$ & $x(14)$ & a & $x(16)$ & $53^{d}$ & a & $4^{d}$ & 100 & 14 \\
\hline République slovaque & 3. & 17 & 6 & 3 & 6 & $x(16)$ & 8 & $10^{\prime}$ & 4 & 2 & a & 2 & $x(16)$ & a & $\times(16)$ & $8^{4}$ & 100 & a \\
\hline Slovénie & 22 & 17 & 8 & $7^{d}$ & 8 & a & 14 & 15 & $x(4)$ & $x(17)$ & 5 & 2 & 1 & a & a & a & 100 & 21 \\
\hline Espagne & 23 & 18 & 7 & 7 & 11 & $x(16)$ & 9 & $x(16)$ & 5 & a & a & a & 0 & a & $x(16)$ & $20^{\circ}$ & 100 & a \\
\hline Suede' & 27 & 19 & 8 & 12 & 6 & 1 & 7 & 6 & a & a & 3 & 5 & a & a & 6 & a & 100 & $\mathrm{~m}$ \\
\hline Suisse & $\mathrm{m}$ & $\mathrm{m}$ & $\mathrm{m}$ & $\mathrm{m}$ & a & a & $\mathrm{m}$ & $\mathrm{m}$ & $\mathrm{m}$ & $\mathrm{m}$ & $\mathrm{m}$ & $\mathrm{m}$ & a & a & a & a & $\mathrm{m}$ & $\mathrm{m}$ \\
\hline Turquie & 30 & 17 & 5 & 13 & 5 & a & 14 & 7 & 2 & a & a & 1 & 7 & a & a & a & 100 & a \\
\hline Etats-Unis & m & m & m & m & $\mathrm{m}$ & m & m & m & m & m & m & m & m & m & m & m & m & m \\
\hline \multicolumn{19}{|l|}{ Economies } \\
\hline Comm. flamande () & $x(14)$ & $x(14)$ & $x(14)$ & $x(14)$ & $x(14)$ & a & $x(14)$ & $x(14)$ & 7 & $x(17)$ & $x(3)$ & a & $x(17)$ & $93^{\circ}$ & a & $x(14)$ & 100 & a \\
\hline se (Belgique) $)^{t}$ & $x(14)$ & $x(14)$ & (14) & $x(14)$ & 2 & a & 7 & $x(14)$ & 7 & a & $x(14)$ & a & a & $83^{\circ}$ & a & a & 100 & a \\
\hline England $(\mathrm{RU})^{4}$ & $x(14)$ & $x(14)$ & $x(14)$ & $x(14)$ & $x(14)$ & a & $x(14)$ & $x(14)$ & $x(14)$ & $x(14)$ & $x(14)$ & a & a & $100^{\circ}$ & a & a & 100 & a \\
\hline Ecosse (RU) & $\mathrm{m}$ & m & $\mathrm{m}$ & $\mathrm{m}$ & $\mathrm{m}$ & a & $\mathrm{m}$ & m & $\mathrm{m}$ & $\mathrm{m}$ & $\mathrm{m}$ & $\mathrm{m}$ & a & a & a & a & $\mathrm{m}$ & a \\
\hline Moyenne OCDE & 25 & 17 & 7 & 6 & 6 & 0 & 9 & 10 & 5 & 1 & 1 & 1 & 4 & 1 & 0 & 5 & 100 & 4 \\
\hline Moyenne UE23 ${ }^{4}$ & 25 & 17 & 7 & 5 & 7 & 1 & 10 & 11 & 4 & 1 & 2 & 1 & 3 & 1 & 0 & 4 & 100 & 6 \\
\hline of Argentine & $\mathrm{m}$ & $\mathrm{m}$ & $\mathrm{m}$ & $\mathrm{m}$ & $\mathrm{m}$ & $\mathrm{m}$ & $\mathrm{m}$ & $\mathrm{m}$ & $\mathrm{m}$ & m & $\mathrm{m}$ & $\mathrm{m}$ & $m$ & m & $\mathrm{m}$ & $\mathrm{m}$ & $m$ & $\mathrm{~m}$ \\
\hline Brésil & $\mathrm{m}$ & $\mathrm{m}$ & $\mathrm{m}$ & $\mathrm{m}$ & $\mathrm{m}$ & a & $\mathrm{m}$ & $\mathrm{m}$ & $\mathrm{m}$ & m & a & a & $\mathrm{m}$ & $\mathrm{m}$ & $\mathrm{m}$ & $\mathrm{m}$ & $\mathrm{m}$ & $\mathrm{m}$ \\
\hline Chine & $\mathrm{m}$ & $\mathrm{m}$ & $\mathrm{m}$ & m & $\mathrm{m}$ & $\mathrm{m}$ & $\mathrm{m}$ & $\mathrm{m}$ & $\mathrm{m}$ & m & $\mathrm{m}$ & $\mathrm{m}$ & $\mathrm{m}$ & $\mathrm{m}$ & m & $\mathrm{m}$ & m & $\mathrm{m}$ \\
\hline Costa Rica & 23 & 19 & 14 & 9 & 12 & a & 5 & 5 & 5 & a & a & a & 9 & a & a & a & 100 & a \\
\hline Inde & m & $\mathrm{m}$ & $\mathrm{m}$ & m & $\mathrm{m}$ & $\mathrm{m}$ & m & $\mathrm{m}$ & $\mathrm{m}$ & $\mathrm{m}$ & m & $\mathrm{m}$ & m & m & m & $\mathrm{m}$ & $\mathrm{m}$ & $\mathrm{m}$ \\
\hline Indonésie & m & m & $\mathrm{m}$ & $\mathrm{m}$ & $\mathrm{m}$ & $\mathrm{m}$ & m & m & $\mathrm{m}$ & $\mathrm{m}$ & m & m & $\mathrm{m}$ & $\mathrm{m}$ & $\mathrm{m}$ & m & $\mathrm{m}$ & $\mathrm{m}$ \\
\hline Fédératior & 36 & 16 & 8 & a & 6 & a & 12 & 8 & 1 & a & 4 & a & a & a & a & 9 & 100 & $\mathrm{~m}$ \\
\hline Arabie saoudite & $\mathrm{m}$ & $\mathrm{m}$ & $\mathrm{m}$ & $\mathrm{m}$ & $\mathrm{m}$ & $\mathrm{m}$ & $\mathrm{m}$ & m & $\mathrm{m}$ & $\mathrm{m}$ & m & $\mathrm{m}$ & $\mathrm{m}$ & $\mathrm{m}$ & $\mathrm{m}$ & $\mathrm{m}$ & m & $\mathrm{m}$ \\
\hline Afrique du Sud & m & m & m & m & m & $\mathrm{m}$ & m & m & m & $\mathrm{m}$ & $\mathrm{m}$ & m & $\mathrm{m}$ & $\mathrm{m}$ & $\mathrm{m}$ & m & $\mathbf{m}$ & $\mathrm{m}$ \\
\hline
\end{tabular}

Moyenne G20

Remarque : Les moyennes ont été ajustées pour que leur somme soit égale à $100 \%$ et ne correspondent pas exactement à la moyenne de chaque colonne. Consulter les tableaux D1.5a à D1.5I, disponibles en ligne, pour la répartition du temps d'instruction par matière pour chaque âge (voir le StatLink à la fin de cet indicateur). Consulter les sections "Définitions » et "Méthodologie » pour de plus amples informations. Les données peuvent être consultées sur http://stats.oecd.orgl, Base de données de Regards sur l'éducation.

1. Pour certaines matières, l'affectation du temps d'instruction est flexible entre les différentes années d'études.

2. Année de référence : 2018

3. La première langue étrangère inclut les autres langues nationales enseignées.

4. L'Angleterre (Royaume-Uni), la Communauté flamande (Belgique), la Communauté française (Belgique), I'ltalie, les Pays-Bas et le Portugal ne sont pas inclus dans les moyennes. 5. A l'exclusion des trois premières années d'enseignement primaire durant lesquelles une part importante du temps d'instruction consacré aux matières obligatoires est flexible. Source : OCDE (2019). Consulter la section « Source » pour tout complément d'information et l'annexe 3 pour les notes (https://doi.org/10.1787/f8d7880d-en). Les symboles représentant les données manquantes et les abréviations figurent dans le Guide du lecteur. 
Tableau D1.3b. Temps d'instruction par matière en filière générale du premier cycle de l'enseignement secondaire (2019) En pourcentage du temps total d'instruction obligatoire, établissements publics

\begin{tabular}{|c|c|c|c|c|c|c|c|c|c|c|c|c|c|c|c|c|c|c|}
\hline & 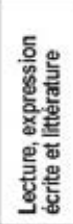 & 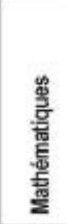 & 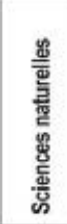 & 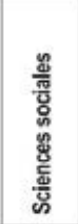 & 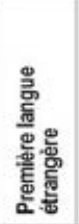 & 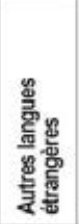 & 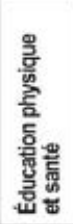 & 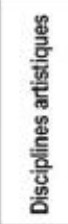 & 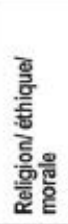 & 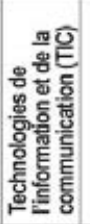 & $\begin{array}{l}\text { 옹 } \\
\text { 응 } \\
\frac{5}{5} \\
\text { 엩 }\end{array}$ & 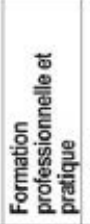 & 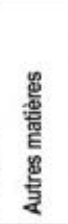 & 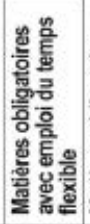 & 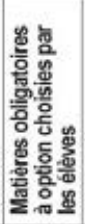 & 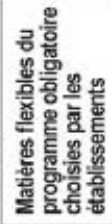 & 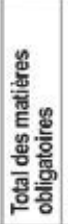 & 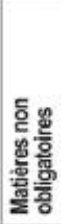 \\
\hline & (1) & (2) & (3) & (4) & (5) & (6) & (7) & (8) & (9) & (10) & (11) & (12) & (13) & (14) & (15) & (16) & (17) & (18) \\
\hline \multicolumn{19}{|l|}{ w Pays } \\
\hline Oustralie' & 12 & 12 & 11 & $10^{4}$ & $x(16)$ & $x(16)$ & 8 & 4 & $x(4)$ & $x(11)$ & $4^{4}$ & $x(11)$ & $x(16)$ & $x(16)$ & 18 & $22^{4}$ & 100 & m \\
\hline Autriche & 13 & 13 & 12 & 11 & 12 & $x(15)$ & 12 & 13 & 7 & $x(17)$ & a & 7 & $x(15)$ & a & $1^{\circ}$ & a & 100 & $\mathrm{~m}$ \\
\hline Canada & 19 & 15 & 9 & 13 & 7 & a & 10 & 7 & 2 & a & 3 & 1 & 1 & 0 & 4 & 10 & 100 & 0 \\
\hline Chili & 16 & 16 & 11 & 11 & 8 & $x(16)$ & 5 & 8 & 5 & $x(16)$ & 3 & $x(16)$ & 3 & a & a & $14^{4}$ & 100 & a \\
\hline Colombie & $\mathrm{m}$ & $\mathrm{m}$ & $\mathrm{m}$ & $\mathrm{m}$ & $\mathrm{m}$ & m & $\mathrm{m}$ & $\mathrm{m}$ & $\mathrm{m}$ & $\mathrm{m}$ & m & m & m & m & m & $\mathrm{m}$ & $\mathrm{m}$ & a \\
\hline République tchèque & 12 & 12 & 17 & 9 & 10 & 5 & 8 & 8 & $x(13)$ & 1 & $2^{\circ}$ & $x(11)$ & $x(16)$ & a & $x(16)$ & $15^{4}$ & 100 & a \\
\hline Danemark & 18 & 13 & 13 & 8 & 8 & 8 & 5 & $x(15)$ & 2 & $\times(15)$ & $x(15)$ & 2 & 21 & a & $5^{\circ}$ & a & 100 & a \\
\hline Estonie & 13 & 14 & 21 & 11 & 10 & 10 & 6 & 6 & $x(16)$ & $x(16)$ & 5 & a & a & a & a & $4^{4}$ & 100 & a \\
\hline Finlande $^{2}$ & 12 & 13 & 16 & 8 & 8 & 5 & 12 & 7 & 4 & $x(17)$ & a & 6 & a & 6 & a & 4 & 100 & 11 \\
\hline France & 17 & 14 & 12 & $12^{\circ}$ & 12 & 7 & 12 & 8 & $x(4)$ & $x(17)$ & 4 & a & 1 & a & a & a & 100 & 20 \\
\hline Allemagne $^{3}$ & 13 & 13 & 11 & 11 & 12 & 5 & 9 & 9 & 5 & 1 & 2 & 2 & 2 & a & 6 & a & 100 & a \\
\hline Grece & 25 & 12 & 13 & 8 & 6 & 6 & 6 & 6 & 6 & 3 & 3 & 2 & a & a & a & 3 & 100 & 32 \\
\hline Hongrie & 13 & 11 & 11 & 9 & 10 & a & 17 & 7 & 3 & 3 & 3 & a & 3 & a & a & 10 & 100 & a \\
\hline Islande & 14 & 14 & 8 & $8^{\circ}$ & $19^{\circ}$ & $\times(5,15)$ & 8 & $8^{\circ}$ & $x(4)$ & 2 & a & $x(8)$ & a & a & $20^{\circ}$ & $\times(15)$ & 100 & a \\
\hline Irlande ${ }^{45}$ & 9 & 11 & $x(16)$ & 7 & 6 & $x(16)$ & 6 & $x(16)$ & $x(16)$ & $x(16)$ & $x(16)$ & $x(16)$ & 2 & a & a & $60^{\circ}$ & 100 & a \\
\hline Israël & 14 & 14 & 13 & 18 & 11 & 10 & 6 & 4 & 9 & a & a & a & a & a & a & 0 & 100 & a \\
\hline Italie & $33^{\circ}$ & $20^{\circ}$ & $x(2)$ & $x(1)$ & 10 & 7 & 7 & 13 & 3 & a & 7 & a & a & a & a & $x(17)$ & 100 & a \\
\hline Japon & 12 & 12 & 12 & 11 & 13 & a & 10 & 7 & 3 & a & 3 & a & 12 & 5 & a & a & 100 & a \\
\hline Corée & 13 & 11 & $20^{\circ}$ & $15^{\circ}$ & 10 & a & 8 & 8 & $x(4)$ & $x(3)$ & $x(12)$ & $x(3)$ & 9 & a & $x(16)$ & $5^{4}$ & 100 & a \\
\hline Lettonie & 15 & 16 & 10 & 14 & 8 & 6 & 6 & 6 & a & 1 & a & 4 & 7 & a & a & 9 & 100 & $\mathrm{~m}$ \\
\hline Lituanie & 18 & 13 & 13 & 15 & 10 & 5 & 5 & 7 & 3 & 3 & 5 & a & 1 & a & a & a & 100 & 15 \\
\hline Luxembourg ${ }^{4}$ & 19 & 13 & 8 & 11 & 12 & 13 & 8 & 9 & 7 & a & a & a & a & a & a & a & 100 & a \\
\hline Mexique & 14 & 14 & 17 & 12 & 9 & a & 6 & 6 & 8 & a & 11 & a & 3 & a & a & a & 100 & a \\
\hline Pays-Bas $^{5}$ & $x(14)$ & $x(14)$ & $x(14)$ & $x(14)$ & $x(14)$ & $x(14)$ & $x(14)$ & $x(14)$ & $x(14)$ & $x(14)$ & $x(14)$ & $x(14)$ & a & $100^{\circ}$ & a & a & 100 & a \\
\hline Nouvelle-Zèlande & $\mathrm{m}$ & m & $\mathrm{m}$ & $\mathrm{m}$ & m & $\mathrm{m}$ & m & m & m & m & m & m & m & m & $\mathrm{m}$ & $\mathrm{m}$ & m & m \\
\hline Norvège & 15 & 12 & 9 & 9 & 8 & $x(15)$ & 9 & 9 & 6 & $x(15)$ & $x(15)$ & 7 & $x(15)$ & a & $15^{\circ}$ & $x(15)$ & 100 & a \\
\hline Pologne ${ }^{6}$ & 15 & 12 & 16 & 13 & 11 & 4 & 12 & 3 & a & 3 & 1 & a & 5 & a & a & 4 & 100 & 8 \\
\hline Portugal' & 13 & 13 & $x(14)$ & $x(14)$ & $x(14)$ & $x(14)$ & 10 & $x(14)$ & a & $x(14)$ & $x(14)$ & a & $x(16)$ & $61^{d}$ & a & $3^{4}$ & 100 & 3 \\
\hline République slovaque & 16 & 14 & 12 & 11 & 10 & $x(16)$ & 7 & 6 & 3 & 3 & $x(16)$ & 3 & $x(16)$ & a & $x(16)$ & $13^{6}$ & 100 & a \\
\hline Slovénie & 13 & 13 & 17 & $15^{\circ}$ & 11 & $x(15)$ & 9 & 8 & $x(4)$ & $x(17)$ & 4 & a & 2 & a & $7^{4}$ & a & 100 & 23 \\
\hline Espagne & 17 & 13 & 11 & 10 & 11 & $x(16)$ & 7 & $x(16)$ & 4 & a & $x(16)$ & a & 3 & a & $x(16)$ & $23^{\circ}$ & 100 & a \\
\hline Suède ${ }^{2}$ & 12 & 12 & 11 & 14 & 8 & 11 & 8 & 7 & a & a & 4 & 9 & a & a & 5 & a & 100 & $\mathrm{~m}$ \\
\hline Suisse & $\mathrm{m}$ & $\mathrm{m}$ & $\mathrm{m}$ & m & m & $\mathrm{m}$ & $\mathrm{m}$ & m & $\mathrm{m}$ & m & m & m & a & a & $\mathrm{m}$ & a & m & m \\
\hline Turquie & 16 & 14 & 11 & 8 & 10 & $x(15)$ & 5 & 6 & 8 & 3 & 3 & 1 & a & a & $16^{4}$ & a & 100 & a \\
\hline États-Unis & $\mathrm{m}$ & m & $\mathrm{m}$ & m & $\mathrm{m}$ & m & $\mathrm{m}$ & m & m & $\mathrm{m}$ & $\mathrm{m}$ & $\mathrm{m}$ & m & $\mathrm{m}$ & m & m & m & m \\
\hline \multicolumn{19}{|l|}{ Economies } \\
\hline Comm. flamande (E & $x(14)$ & $x(14)$ & $x(14)$ & $x(14)$ & $x(14)$ & $x(14)$ & $x(14)$ & $x(14)$ & 6 & a & $x(14)$ & a & a & $73^{\circ}$ & a & 20 & 100 & a \\
\hline Comm. française (Belgique) & 17 & 14 & 9 & 13 & 13 & a & 9 & 3 & 6 & $x(16)$ & 3 & $x(16)$ & a & a & $x(16)$ & $13^{\circ}$ & 100 & a \\
\hline England (RU) $)^{5}$ & $x(14)$ & $x(14)$ & $x(14)$ & $x(14)$ & $x(14)$ & a & $x(14)$ & $x(14)$ & $x(14)$ & $x(14)$ & $x(14)$ & $x(14)$ & $x(14)$ & $100^{d}$ & a & a & 100 & a \\
\hline Ecosse (RU) & $\mathrm{m}$ & $\mathrm{m}$ & $\mathrm{m}$ & $\mathrm{m}$ & $\mathrm{m}$ & m & $\mathrm{m}$ & $\mathrm{m}$ & $\mathrm{m}$ & $\mathrm{m}$ & $\mathrm{m}$ & $\mathrm{m}$ & a & a & a & a & $\mathrm{m}$ & a \\
\hline Moyenne $\mathrm{OCDE}^{\prime}$ & 15 & 13 & 12 & 11 & 10 & 5 & 8 & 7 & 4 & 1 & 3 & 2 & 3 & 0 & 4 & 5 & 100 & 4 \\
\hline Moyenne UE235 & 15 & 13 & 12 & 11 & 10 & 6 & 8 & 7 & 3 & 1 & 3 & 2 & 3 & 0 & 1 & 5 & 100 & 6 \\
\hline \& Argentine & $\mathrm{m}$ & $\mathrm{m}$ & $\mathrm{m}$ & $\mathrm{m}$ & $\mathrm{m}$ & m & $\mathrm{m}$ & $\mathrm{m}$ & $\mathrm{m}$ & $\mathrm{m}$ & $\mathrm{m}$ & $\mathrm{m}$ & $\mathrm{m}$ & $\mathrm{m}$ & $\mathrm{m}$ & $\mathrm{m}$ & m & $\mathrm{m}$ \\
\hline Brésil & $\mathrm{m}$ & m & $\mathrm{m}$ & $\mathrm{m}$ & $\mathrm{m}$ & a & $\mathrm{m}$ & $\mathrm{m}$ & m & $\mathrm{m}$ & a & m & m & $\mathrm{m}$ & m & $\mathrm{m}$ & $\mathrm{m}$ & $\mathrm{m}$ \\
\hline Chine & $\mathrm{m}$ & $\mathrm{m}$ & $\mathrm{m}$ & m & m & m & $\mathrm{m}$ & $\mathrm{m}$ & $\mathrm{m}$ & m & m & m & m & m & $\mathrm{m}$ & m & $\mathrm{m}$ & m \\
\hline Costa Rica & 12 & 12 & 12 & 14 & 7 & 7 & 5 & 10 & 2 & 5 & a & 7 & 5 & a & a & 2 & 100 & a \\
\hline Inde & $\mathrm{m}$ & $\mathrm{m}$ & $\mathrm{m}$ & $\mathrm{m}$ & $\mathrm{m}$ & $\mathrm{m}$ & $\mathrm{m}$ & $\mathrm{m}$ & m & $\mathrm{m}$ & $\mathrm{m}$ & $\mathrm{m}$ & m & $\mathrm{m}$ & $\mathrm{m}$ & m & $\mathrm{m}$ & $\mathrm{m}$ \\
\hline Indonésie & $\mathrm{m}$ & $\mathrm{m}$ & $\mathrm{m}$ & $\mathrm{m}$ & $\mathrm{m}$ & m & $\mathrm{m}$ & $\mathrm{m}$ & $\mathrm{m}$ & $\mathrm{m}$ & $\mathrm{m}$ & m & m & $\mathrm{m}$ & $\mathrm{m}$ & $\mathrm{m}$ & $\mathrm{m}$ & $\mathrm{m}$ \\
\hline Fèdèration o & 22 & 16 & 17 & 9 & 10 & a & 7 & 5 & a & 2 & 5 & 1 & a & a & $\mathrm{m}$ & 7 & 100 & m \\
\hline Arabie saour & $\mathrm{m}$ & $\mathrm{m}$ & $\mathrm{m}$ & $\mathrm{m}$ & m & $\mathrm{m}$ & $\mathrm{m}$ & m & m & m & m & $\mathrm{m}$ & m & $\mathrm{m}$ & m & m & $\mathrm{m}$ & $\mathrm{m}$ \\
\hline Afrique du Sud & m & $\mathrm{m}$ & $\mathrm{m}$ & m & m & $\mathrm{m}$ & m & m & m & $\mathrm{m}$ & m & m & m & m & $\mathrm{m}$ & $\mathrm{m}$ & $\mathrm{m}$ & $\mathrm{m}$ \\
\hline
\end{tabular}

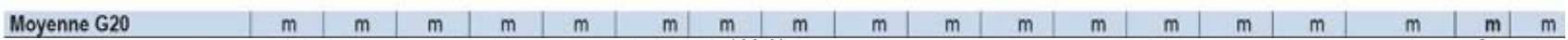

Remarque : Les moyennes ont été ajustées pour que leur somme soit égale à $100 \%$ et ne correspondent pas exactement à la moyenne de chaque colonne. Consulter les tableaux D1.5a à D1.5l, disponibles en ligne, pour la répartition du temps d'instruction par matière pour chaque âge (voir le StatLink à la fin de cet indicateur). Consulter les sections "Définitions » et « Méthodologie » pour de plus amples informations. Les données peuvent être consultées sur http://stats. oecd.orgl, Base de données de Regards sur l'éducation.

1. Les valeurs relatives au temps d'instruction prévu dérivées du programme scolaire australien partent du principe que certaines matières pouvant être considérées comme obligatoires en $7 \mathrm{e}$ et en $8^{\mathrm{e}}$ année peuvent être proposées aux élèves à titre optionnel en $9^{\mathrm{e}}$ et en $10^{\mathrm{e}}$ année.

2. Pour certaines matières, l'affectation du temps d'instruction est flexible entre les différentes années d'études.

3. Année de référence : 2018.

4. La première langue étrangère inclut les autres langues nationales enseignées.

5. L'Angleterre (Royaume-Uni), la Communauté flamande (Belgique), I'Irlande, les Pays-Bas et le Portugal ne sont pas inclus dans les moyennes.

6 . Le temps d'instruction des autres langues étrangères est inclus dans celui de la première langue étrangère en $9 e$ année.

Source : OCDE (2019). Consulter la section « Source » pour tout complément d'information et l'annexe 3 pour les notes (https://doi.org/10.1787/f8d7880d-en). Les symboles représentant les données manquantes et les abréviations figurent dans le Guide du lecteur. 


\section{Indicateur D2. Quels sont le taux d'encadrement et la taille des classes?}

\section{Faits marquants}

- Dans les pays de l'OCDE, les élèves sont, en moyenne, 15 par enseignant dans l'enseignement primaire et 13 par enseignant dans le premier cycle de l'enseignement secondaire. On compte en moyenne 21 élèves par classe dans l'enseignement primaire et 23 élèves par classe dans le premier cycle de l'enseignement secondaire.

- En moyenne, dans les pays de l'OCDE, les taux d'encadrement sont similaires dans les établissements publics et privés d'enseignement tertiaire, avec environ 15 étudiants par enseignant dans les établissements publics et 16 étudiants par enseignant dans les établissements privés. Les différences de taux d'encadrement entre établissements publics et privés sont plus marquées dans les pays partenaires.

- Dans les pays de l'OCDE, on compte en 2017 en moyenne 21 élèves par classe dans les établissements publics d'enseignement primaire et 20 élèves par classe dans les établissements privés pour le même niveau d'enseignement. Les différences de taille des classes dans les établissements publics et privés d'enseignement primaire varient sensiblement entre les pays de I'OCDE.

\section{Graphique D2.1. Taux d'encadrement dans l'enseignement tertiaire, selon le type d'établissement (2017)}

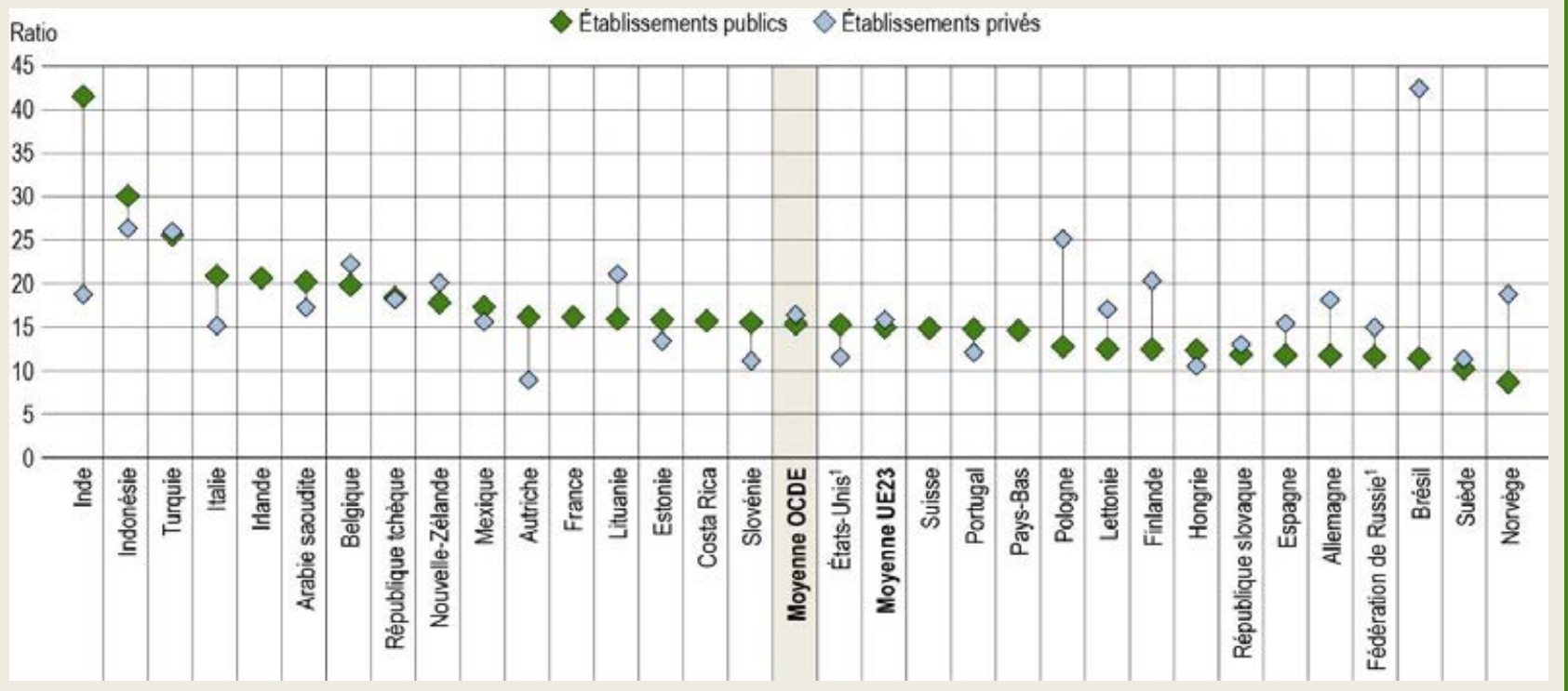

1. L'enseignement tertiaire inclut des programmes d'autres niveaux d'enseignement - voir l'annexe 3 pour plus de précisions. Les pays sont classés par ordre décroissant du nombre d'étudiants par élève dans les établissements publics d'enseignement tertiaire. Source : OCDE/ISU/Eurostat (2019), Base de données de Regards sur l'éducation, http://stats.oecd.org/. Consulter la section « Source » pour tout complément d'information et l'annexe 3 pour les notes (https://doi.org/10.1787/f8d7880d-en). 


\section{Contexte}

La taille des classes et les taux d'encadrement sont au cœur des débats sur l'éducation, car ils se conjuguent à d'autres facteurs pour déterminer la demande d'enseignants. Parmi ces facteurs, citons le temps d'instruction (voir l'indicateur D1), le temps de travail des enseignants et la répartition de leur temps de travail entre l'enseignement proprement dit et d'autres tâches (voir l'indicateur D4). Outre le salaire des enseignants (voir l'indicateur D3), la pyramide des âges du corps enseignant (voir l'indicateur D5) et le temps d'instruction (voir l'indicateur C7), la taille des classes et le taux d'encadrement ont aussi un impact considérable sur le niveau des dépenses de fonctionnement au titre de l'éducation (voir les indicateurs C6 et C7).

Il est courant de considérer que des effectifs plus réduits sont bénéfiques, car ils permettent aux enseignants de se concentrer davantage sur les besoins de chacun de leurs élèves et de passer moins de temps à gérer les perturbations pendant les cours. Pourtant, les effets de la variation de la taille des classes sur la performance des élèves ne sont pas étayés par des éléments probants (Fredriksson, Öckert et Oosterbeek, 2013[1] ; OCDE, 2017[2] ), même s'il apparaît que des effectifs plus réduits en classe pourraient être bénéfiques pour certains groupes spécifiques d'élèves, notamment les élèves défavorisés (Piketty et M. Valdenaire, 2006[3]).

Le taux d'encadrement, qui est dérivé du nombre d'élèves ou d'étudiants par enseignant, est également un indicateur important de la ventilation du budget de l'éducation. Des arbitrages s'imposent parfois entre certaines mesures telles que l'augmentation du taux d'encadrement (moins d'élèves/étudiants par enseignant) et la revalorisation du salaire des enseignants, l'investissement dans des activités de développement professionnel, l'augmentation des investissements dans le matériel pédagogique ou encore le recours plus généralisé à des auxiliaires d'éducation et autres paraprofessionnels dont les salaires sont souvent beaucoup moins élevés que ceux des enseignants.

\section{Autres faits marquants}

- Dans les pays de l'OCDE, le nombre d'enseignants et le nombre d'élèves ont augmenté à un rythme de l'ordre de $1 \%$ par an entre 2005 et 2017.

- En moyenne, dans les pays de l'OCDE, les taux d'encadrement dans le premier et le deuxième cycle de l'enseignement secondaire sont légèrement plus élevés dans les établissements privés que dans les établissements publics. L'écart est particulièrement frappant au Mexique où les établissements publics comptent plus du double d'élèves par enseignant que les établissements privés dans le premier cycle de l'enseignement secondaire.

- Dans l'enseignement primaire, la taille des classes varie sensiblement entre les pays, allant de 15 élèves par classe au Costa Rica à 31 élèves par classe au Chili. 


\section{Analyse}

\section{Taux d'encadrement}

Le taux d'encadrement est calculé comme suit : l'effectif d'élèves/étudiants (en équivalents temps plein) d'un niveau d'enseignement est divisé par le nombre d'enseignants (en équivalents temps plein), au même niveau d'enseignement et dans le même type d'établissement. Le taux d'encadrement ne tient pas compte du rapport entre le temps d'instruction des élèves/étudiants et le temps de travail quotidien des enseignants, ni de la part de ce temps que les enseignants consacrent à l'enseignement proprement dit. II ne peut donc pas être interprété en termes de taille des classes (voir l'encadré D2.1).

Dans les pays de l'OCDE, on compte en moyenne 15 élèves par enseignant dans l'enseignement primaire. Le nombre d'élèves par enseignant va de 10 en Norvège, à 27 au Mexique. Il est même encore plus élevé dans certains pays partenaires, avec jusqu'à 33 élèves par enseignant en Inde (voir le tableau D2.2).

En moyenne, le nombre d'élèves par enseignant est moins élevé dans l'enseignement secondaire (13 élèves par enseignant) que dans l'enseignement primaire. La diminution du taux d'encadrement entre l'enseignement primaire et l'enseignement secondaire peut être imputable à la variation du temps annuel d'instruction (qui tend à augmenter avec l'élévation du niveau d'enseignement, tout comme le nombre d'enseignants), ou à la variation du temps d'enseignement (qui diminue avec l'élévation du niveau d'enseignement, à mesure que la spécialisation des enseignants par matière s'accentue). Les pays présentent également des différences plus marquées dans l'enseignement secondaire que dans l'enseignement primaire : le nombre d'élèves par enseignant va de 8 en Lituanie à 29 au Mexique.

En moyenne, le taux d'encadrement ne varie guère dans les premier et deuxième cycles de l'enseignement secondaire (13 élèves par enseignant). Dans certains pays, toutefois, il varie fortement entre ces deux niveaux d'enseignement. C'est le cas en Finlande, où on compte au moins deux fois plus d'élèves par enseignant dans le deuxième cycle de l'enseignement secondaire que dans le premier cycle de l'enseignement secondaire.

Dans le deuxième cycle de l'enseignement secondaire, les différences de taux d'encadrement en filière professionnelle et en filière générale varient également entre les pays. En moyenne, dans le deuxième cycle de l'enseignement secondaire, le taux d'encadrement en filière professionnelle (14 élèves par enseignant) est similaire à celui en filière générale (13 élèves par enseignant). Bien que la différence entre les deux filières soit négligeable dans un petit nombre de pays, il y a en réalité autant de pays qui enregistrent un taux d'encadrement moins élevé en filière professionnelle que de pays qui enregistrent un taux plus élevé dans cette même filière. En Lettonie, on compte deux fois plus d'élèves (17) par enseignant en filière professionnelle qu'en filière générale (8 élèves par enseignant). Au Royaume-Uni, les établissements comptent 25 élèves par enseignant en filière professionnelle et seulement 14 élèves par enseignant en filière générale. Ces différences importantes peuvent s'expliquer par le fait que, dans certains pays, les formations en filière professionnelle sont largement dispensées en entreprise et que, par conséquent, les élèves passent énormément de temps en dehors des établissements d'enseignement. Dès lors, les établissements ont besoin de moins d'enseignants, ce qui peut se traduire par des taux d'encadrement moins élevés (OCDE, 2017 $[4]$ ). À l'inverse, dans d'autres pays tels que le Brésil - où l'écart est le plus marqué entre les deux filières, parmi tous les pays membres et partenaires de l'OCDE dont les données sont disponibles - les établissements comptent deux fois plus d'élèves (26) par enseignant en filière générale qu'en filière professionnelle (13 élèves par enseignant). Dans ce cas, ces chiffres peuvent refléter le fait qu'en filière professionnelle les élèves ont généralement besoin de davantage d'attention de la part de leurs formateurs, en particulier s'ils ont accès à des équipements plus sophistiqués. Les élèves en filière professionnelle nécessitent une supervision accrue à mesure que la spécificité des compétences à acquérir augmente. Cela peut alors avoir d'importantes implications en termes de coût de la formation professionnelle, puisque les formations à vocation professionnelle de haut niveau nécessitent à la fois des équipements spécialisés et davantage de ressources humaines (Klein, 2001 ${ }_{[5]}$ ). 
Dans l'enseignement tertiaire, on compte en moyenne 16 étudiants par enseignant. Le nombre d'étudiants par enseignant va de 9 en Norvège, à plus de 25 en Colombie, en Indonésie et en Turquie. Les différences de taux d'encadrement entre l'enseignement tertiaire de cycle court, la licence, le master, le doctorat ou une formation de niveau équivalent varient dans les pays dont les données sont disponibles. Ces résultats doivent toutefois être interprétés avec prudence puisque le taux d'encadrement reste une mesure limitée du niveau des ressources pédagogiques dans l'enseignement tertiaire (voir l'encadré D2.2). En outre, dans certains pays, le taux de scolarisation relativement faible dans l'enseignement tertiaire de cycle court limite la comparabilité entre les niveaux de l'enseignement tertiaire (voir l'indicateur B1)

\section{Encadré D2.1. Quelle est la relation entre la taille des classes et le taux d'encadrement ?}

La taille des classes, telle qu'elle est présentée dans le tableau D2.1, est calculée à partir du nombre d'élèves suivant un cours commun, sur la base du nombre le plus élevé de cours communs (il s'agit généralement des matières obligatoires), mais abstraction faite des cours donnés en sous-groupe. Elle est calculée en divisant les effectifs d'élèves/étudiants par le nombre de classes. Le taux d'encadrement d'un niveau d'enseignement, tel qu'il est présenté dans les tableaux D2.2 et D2.3, est calculé comme suit : l'effectif d'élèves en équivalents temps plein du niveau d'enseignement considéré est divisé par l'effectif d'enseignants, également en équivalents temps plein, du même niveau d'enseignement et dans le même type d'établissement.

Ces deux indicateurs mesurent, par conséquent, des caractéristiques propres aux systèmes d'éducation très différentes. Le taux d'encadrement décrit le niveau de ressources pédagogiques disponibles dans un pays, tandis que la taille des classes mesure le nombre moyen d'élèves par classe.

$\mathrm{Au}$ vu des différences entre les concepts de taux d'encadrement et de taille moyenne des classes, il est possible pour des pays présentant des taux d'encadrement similaires d'avoir toutefois des tailles de classe différentes. Dans l'enseignement primaire, par exemple, le taux d'encadrement est similaire aux États-Unis et en Israël (15 élèves par enseignant, voir le tableau D2.2), mais la taille moyenne des classes y est sensiblement différente : 21 élèves par classe aux États-Unis, contre 27 élèves par classe en Israël. Ce constat peut s'expliquer par le fait que le temps d'enseignement aux États-Unis est considérablement plus élevé qu'en Israël, ce qui signifie que les enseignants américains peuvent donner plus d'heures de cours durant une journée et, par conséquent, regrouper les élèves dans des classes plus petites (voir l'indicateur C7).

\section{Taux d'encadrement dans les établissements publics et privés}

Dans les pays de l'OCDE dont les données sont disponibles, les taux d'encadrement sont en moyenne un peu plus élevés dans les établissements privés que dans les établissements publics dans le premier cycle de l'enseignement secondaire et ne varient guère entre les deux types d'établissements dans le deuxième cycle de l'enseignement secondaire (voir le tableau D2.3).

Dans le premier cycle de l'enseignement secondaire, l'écart est particulièrement frappant au Mexique où les établissements publics comptent plus du double d'élèves par enseignant que les établissements privés. Toutefois, 10 \% seulement des élèves du premier cycle de l'enseignement secondaire sont scolarisés dans des établissements privés au Mexique (voir la Base de données de Regards sur l'éducation). Par contraste, dans certains pays, les taux d'encadrement sont plus élevés dans les établissements publics que dans les établissements privés. C'est au Chili que cette tendance est la plus marquée où les élèves sont 16 par enseignant dans les établissements publics, contre 24 par enseignant dans les établissements privés (voir le tableau D2.3). Au Chili, près de $60 \%$ des élèves du premier cycle de l'enseignement secondaire sont scolarisés dans des établissements privés (voir la Base de données de Regards sur l'éducation). 
Dans le deuxième cycle de l'enseignement secondaire, le taux d'encadrement est plus élevé dans les établissements privés que dans les établissements publics dans 14 pays, il est plus élevé dans les établissements publics dans 15 pays et est similaire dans les deux types d'établissements dans 4 pays. C'est au Mexique, une fois encore, que les écarts en matière de taux d'encadrement entre les établissements publics et privés sont les plus marqués à ce niveau d'enseignement : les établissements publics comptent 25 élèves par enseignant, et les établissements privés 16 élèves par enseignant seulement. (Voir le tableau D2.3). Dans le deuxième cycle de l'enseignement secondaire, cette tendance contrastée peut, en partie, refléter les différences de formations proposées par les établissements publics et privés. En Norvège, par exemple, peu d'établissements privés proposent des formations en filière professionnelle, filière qui affiche un taux d'encadrement légèrement plus élevé qu'en filière générale (voir la Base de données de Regards sur l'éducation et le tableau D2.2).

Dans l'enseignement tertiaire, les taux d'encadrement ne varient guère dans l'ensemble entre les établissements publics et les établissements privés dans les pays de l'OCDE, avec environ 15 étudiants par enseignant dans les établissements publics et 16 étudiants par enseignant dans les établissements privés (voir le graphique D2.1). Dans un petit nombre de pays de l'OCDE seulement, comme en Autriche et en Italie, les établissements publics comptent au moins cinq étudiants de plus par enseignant que les établissements privés. Dans ces pays toutefois, les établissements privés accueillent moins de $20 \%$ de l'effectif d'étudiants de l'enseignement tertiaire (voir l'indicateur B1). La différence entre les établissements publics et les établissements privés est plus marquée dans certains pays partenaires: en Inde par exemple, le nombre d'étudiants par enseignant passe du simple à plus du double entre les établissements publics (42) et les établissements privés (19). La différence la plus importante de taux d'encadrement entre établissements publics et établissements privés s'observe au Brésil, où le taux d'encadrement est nettement moins élevé dans les établissements privés qui accueillent $73 \%$ des étudiants dans l'enseignement tertiaire, que dans les établissements publics, qui sont plus sélectifs. Au Brésil, les étudiants sont confrontés soit à des exigences élevées de performance dans les établissements publics qui sont gratuits mais très sélectifs, soit à un obstacle d'ordre financier dans les établissements privés, ce qui peut limiter leurs possibilités d'apprentissage et suscite de sérieuses préoccupations concernant l'égalité des chances (voir le graphique D2.1).

\section{Encadré D2.2. Méthode d'estimation du taux d'encadrement dans l'enseignement supérieur}

Le taux d'encadrement évalue les moyens pédagogiques disponibles dans chaque pays. Si le taux d'encadrement est élevé, les enseignants sont plus susceptibles d'apporter un grand soutien et d'accorder une plus grande attention à chacun dans leur classe. Toutefois, dans l'enseignement tertiaire, l'interprétation de cet indicateur dépend de la définition et des fonctions du corps professoral. Certains enseignants ont parfois une charge d'enseignement limitée et consacrent l'essentiel de leur temps à la recherche. Dans ce cas, le taux d'encadrement n'est pas représentatif du niveau de soutien et d'attention dont les étudiants bénéficient en classe.

Les données disponibles ne permettent pas de faire la distinction entre les heures consacrées à l'enseignement et celles consacrées à la recherche. En fait, le manuel de l'ISU de l'UNESCO, de l'OCDE et d'Eurostat (UOE) définit le corps professoral comme le personnel en poste dans l'enseignement tertiaire dont la mission principale est l'enseignement ou la recherche, sans autre précision. D'autres sources faisant autorité, dont le manuel de Frascati (OCDE, 2016 $\left.6_{[6]}\right)$ et le Registre européen de l'enseignement supérieur $\left(E T E R_{[7]}\right)$, ne font pas non plus de distinction entre enseignement et recherche.

Le rapport sur le corps professoral de l'enseignement tertiaire en Europe publié par Eurydice en 2017 (Eurydice Report, 2017 $[8]$ ) est l'un des premiers à définir les attributs différents du corps académique en fonction d'une segmentation harmonisée. II est rédigé à partir de données de diverses sources, en grande partie des données recueillies par les Unités nationales d'Eurydice, d'un éventail de rapports de recherche et de bases de données d'autres organisations internationales. Conformément à la définition du corps professoral dans la collecte UOE de données, les données utilisées dans ce rapport se concentrent sur les 
enseignants et leurs auxiliaires en poste dans l'enseignement tertiaire et en charge de l'enseignement ou de la recherche. Cette collecte de données ne porte pas en particulier sur le nombre d'heures consacré à l'enseignement ou à la recherche, mais elle fournit des informations sur les responsabilités principales du corps enseignant et constitue une première tentative de faire la distinction entre l'enseignement et la recherche à ce niveau.

Outre les pays européens, d'autres pays de l'OCDE recueillent également des données sur la fonction des enseignants : l'enseignement ou la recherche, ou les deux. Toutefois, les définitions des deux concepts varient entre les pays. En Australie par exemple, les enseignants sont déclarés exclusivement enseignants si l'enseignement est leur seule fonction dans la description officielle de leur poste. Leur mission consiste uniquement à enseigner et à effectuer les activités y afférentes ou à gérer et à diriger les enseignants et le personnel d'appui, sans qu'il n'y ait d'exigences concernant des recherches à mener (Gouvernement australien[9]). Par contraste, la classification du personnel enseignant par fonction est plus large aux ÉtatsUnis. Le personnel enseignant inclut les enseignants dont la mission principale est l'enseignement ou est combinée avec la recherche ou une fonction publique (NCES National Center for Education Statistics, 2018[10] $)$. Ni le Canada, ni la Nouvelle-Zélande ne font la distinction entre les enseignants et les chercheurs. En Corée, les enseignants doivent uniquement enseigner, tandis que les professeurs doivent en principe non seulement donner des cours, mais aussi mener des recherches.

Dans l'ensemble, toutes ces tentatives restent limitées. Des travaux supplémentaires s'imposent pour recueillir des données plus précises sur le nombre d'heures consacré à l'enseignement et à la recherche afin de calculer plus précisément le taux d'encadrement dans l'enseignement tertiaire.

Les étudiants peuvent avoir à faire preuve de plus d'autonomie en matière d'apprentissage dans l'enseignement tertiaire que dans l'enseignement primaire et secondaire, certes, mais le taux d'encadrement demeure une préoccupation majeure. Les taux d'encadrement sont difficiles à estimer dans l'enseignement tertiaire, mais ils sont tout de même révélateurs du volume de ressources disponibles à ce niveau d'enseignement. En fait, le taux d'encadrement est considéré comme un indicateur de la qualité de l'enseignement supérieur (McDonald, 2013[11]), ce qui justifie d'améliorer la méthode d'estimation dans cet indicateur (voir l'encadré D2.2).

\section{Évolution de l'effectif d'étudiants et du corps professoral dans l'enseignement tertiaire}

Comparer les taux moyens d'évolution du nombre d'étudiants et du nombre d'enseignants par an dans l'enseignement tertiaire entre 2005 et 2017 permet de montrer l'ampleur de l'évolution des ressources humaines pendant cette période.

En moyenne, dans les pays de l'OCDE, le nombre d'étudiants et d'enseignants a augmenté à un taux moyen de $1 \%$ par an entre 2005 et 2017. Ces moyennes occultent toutefois de grandes différences entre les pays. Le nombre d'enseignants a le plus évolué en Norvège et en Estonie : le taux moyen de croissance du nombre d'enseignants par an a été le plus élevé en Norvège $(+6 \%)$ et le moins élevé en Estonie et en Grèce $(-3 \%)$. Le taux moyen de croissance du nombre d'étudiants par an a été le plus élevé au Mexique et aux Pays-Bas (+ $5 \%$ ) et le moins élevé en Lettonie (- $4 \%$ ) (voir le graphique D2.2).

Dans la majorité des pays dont les données sont disponibles, le nombre d'enseignants et le nombre d'étudiants ont évolué d'une façon similaire : tous deux ont soit augmenté, soit diminué entre 2005 et 2017. Le rythme auquel ils ont évolué varie toutefois fortement. En Norvège par exemple, le nombre d'enseignants a augmenté trois fois plus vite que le nombre d'étudiants. Par contraste, en Hongrie et en Lituanie, le nombre d'étudiants a diminué au moins trois fois de plus que le nombre d'enseignants. Dans d'autres pays, comme la Finlande et le Portugal, le nombre d'enseignants et d'étudiants a évolué à un rythme similaire. En Corée, en Lettonie, en Pologne et en Slovénie, le nombre d'enseignants a dans l'ensemble augmenté chaque année, alors que le nombre d'étudiants a diminué durant la même période (voir le graphique D2.2). Ce constat peut s'expliquer par les difficultés posées par la réduction du corps professoral à la suite d'une évolution démographique. 


\section{Graphique D2.2. Taux de croissance annuels moyens du nombre d'étudiants et d'enseignants dans} l'enseignement tertiaire (2005-17)

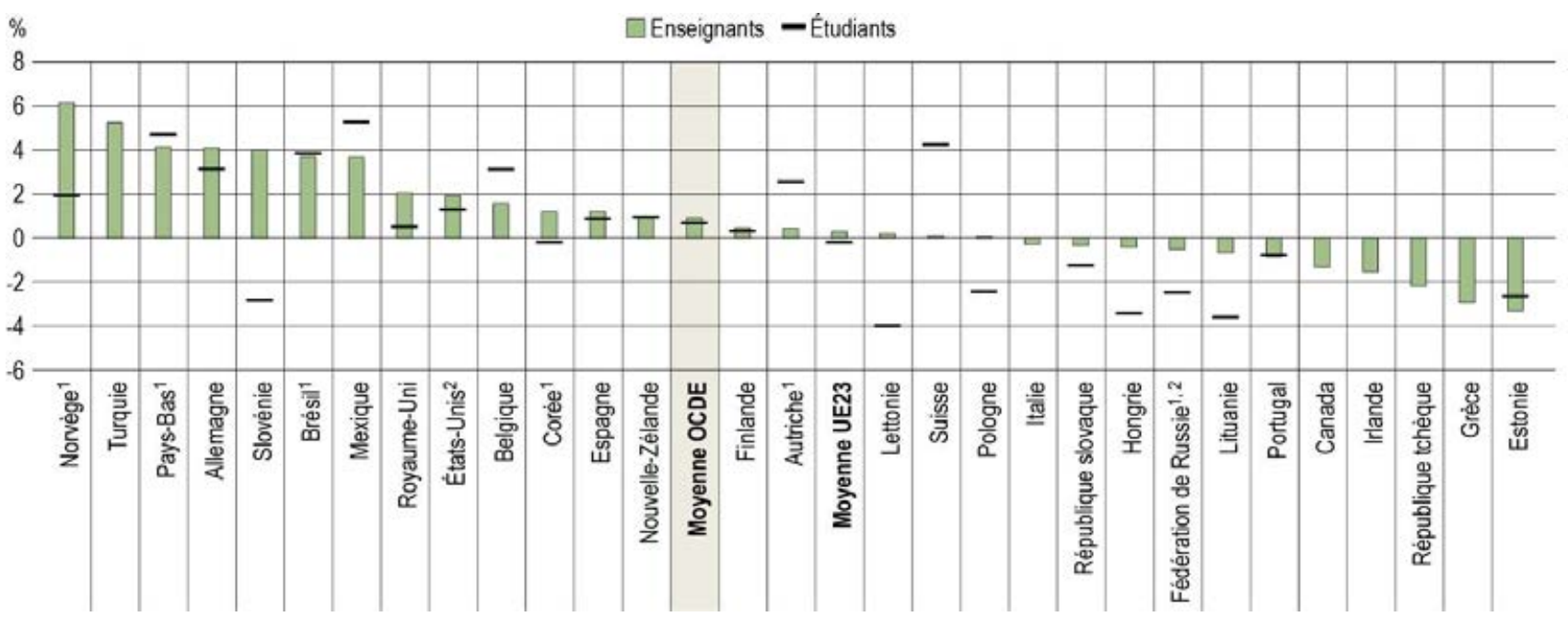

Remarque : Ces chiffres ne correspondent pas au taux d'encadrement. La couverture des effectifs n'est pas ajustée au personnel selon le niveau d'enseignement, la filière d'enseignement, le type d'établissement et l'intensité de la scolarisation comme c'est le cas pour le calcul du taux d'encadrement (voir la section « Méthodologie »).

1. Année de référence : 2010 , et non 2005.

2. L'enseignement tertiaire inclut des programmes d'autres niveaux d'enseignement - voir l'annexe 3 pour plus de précisions.

Les pays sont classés par ordre décroissant du taux de croissance annuel moyen du nombre d'enseignants dans l'enseignement tertiaire, entre 2005 et 2017.

Source : OCDE/ISU/Eurostat (2019), Base de données de Regards sur l'éducation, http://stats.oecd.org/. Consulter la section « Source » pour tout complément d'information et l'annexe 3 pour les notes (https://doi.org/10.1787/f8d7880d-en).

StatLink तiाst https://doi.org/10.1787/888933979823

Suivre l'évolution du nombre d'enseignants et d'étudiants dans l'enseignement tertiaire donnerait des informations précieuses sur la façon dont les systèmes d'éducation réagissent à l'évolution de la demande de cursus tertiaires. Dans l'ensemble des pays membres et partenaires de l'OCDE, l'enseignement tertiaire s'est développé ces deux dernières décennies et devrait continuer dans cette voie durant la prochaine décennie (OCDE, 2018[12]). Ce développement s'explique par l'augmentation de la demande de profils qualifiés, que l'on doit au progrès technologique (OCDE, 2017[13] $)$ et à l'action des gouvernements qui cherchent à promouvoir l'accès à l'enseignement tertiaire, par l'intermédiaire de diverses politiques de soutien financier (OCDE, 2017[4]). Dans les pays où l'augmentation de la demande est la plus forte (voir l'indicateur A1), l'enjeu est de limiter l'impact de la demande en hausse sur la qualité des systèmes d'enseignement tertiaire et d'investir en conséquence dans les ressources humaines.

\section{Taille des classes}

Taille moyenne des classes dans l'enseignement primaire et le premier cycle de l'enseignement secondaire

Cet indicateur sur la taille des classes se limite à l'enseignement primaire et au premier cycle de l'enseignement secondaire, car la taille des classes est difficile à définir et à comparer aux niveaux supérieurs d'enseignement, où les élèves/étudiants sont souvent répartis dans des classes différentes selon les matières.

Dans l'enseignement primaire, les élèves sont en moyenne 21 par classe dans les pays de l'OCDE. Les élèves sont moins de 28 par classe dans la quasi-totalité des pays dont les données sont disponibles, sauf au Chili où ils sont 31 par classe (voir le tableau D2.1). 
Dans le premier cycle de l'enseignement secondaire, les élèves sont en moyenne 23 par classe dans les pays de l'OCDE. Parmi les pays dont les données sont disponibles, ce chiffre va de moins de 20 élèves par classe en Estonie, en Fédération de Russie, en Finlande, en Lettonie, en Lituanie, au Luxembourg et en République slovaque, à plus de 30 élèves par classe au Costa Rica et au Japon (voir le tableau D2.1).

Les effectifs des classes tendent à augmenter entre l'enseignement primaire et le premier cycle de l'enseignement secondaire. Au Costa Rica, on compte près de 18 élèves de plus par classe dans les établissements du premier cycle de l'enseignement secondaire. Par contre, au Royaume-Uni et, dans une moindre mesure, en Australie, au Chili, en Estonie, en Fédération de Russie, en Finlande et en Hongrie, l'effectif d'élèves par classe diminue entre ces deux niveaux d'enseignement (voir le tableau D2.1).

\section{Taille des classes dans les établissements publics et privés}

La taille des classes est un facteur dont les parents peuvent tenir compte lorsqu'ils choisissent l'établissement où inscrire leur enfant. Par conséquent, les différences de taille de classe entre les établissements publics et privés (et entre les différents types d'établissements privés) peuvent influer sur leurs effectifs.

Les écarts en matière de taille des classes entre les établissements publics et privés sont similaires aux écarts observés entre ces deux types d'établissements en ce qui concerne le taux d'encadrement. Dans la plupart des pays de l'OCDE, la taille moyenne des classes ne varie pas de plus de deux élèves entre les établissements publics et privés dans l'enseignement primaire et le premier cycle de l'enseignement secondaire. En revanche, dans certains pays (comme au Brésil, en Colombie, en Fédération de Russie, en Lettonie, en Pologne et en République tchèque), on compte, dans l'enseignement primaire, en moyenne plus de cinq élèves de plus par classe dans les établissements publics que dans les établissements privés (voir le tableau D2.1). Toutefois, dans ces pays, le secteur privé est relativement peu important dans l'enseignement primaire et accueille au plus $5 \%$ des élèves, sauf au Brésil et en Colombie (voir la Base de données de Regards sur l'éducation). Par contraste, au Chili, en Corée, en Espagne, en Grèce et au Luxembourg, les établissements privés comptent, en moyenne, au moins quatre élèves de plus par classe que les établissements publics.

La comparaison de la taille des classes entre les établissements publics et les établissements privés révèle des tendances assez contrastées dans le premier cycle de l'enseignement secondaire, où les établissements privés sont plus nombreux. À ce niveau d'enseignement, les élèves sont en moyenne plus nombreux par classe dans les établissements privés que dans les établissements publics dans 9 pays. La situation inverse s'observe dans 16 pays, et les classes sont de même taille entre ces deux types d'établissements dans 7 pays. Les écarts sont toutefois moins marqués que dans l'enseignement primaire.

\section{Évolution de la taille moyenne des classes}

En moyenne, dans les pays de l'OCDE, la taille moyenne des classes n'a guère varié dans l'enseignement primaire mais a diminué dans le premier cycle de l'enseignement secondaire entre 2005 et 2017 (voir le graphique D2.1). La taille moyenne des classes a diminué dans 19 des 27 pays dont les données sont disponibles dans le premier cycle de l'enseignement secondaire, mais seulement dans 12 des 27 pays dans l'enseignement primaire (voir le graphique D2.3).

Dans le premier cycle de l'enseignement secondaire, la taille moyenne des classes a diminué de $6 \%$ entre 2005 et 2017. Ces moyennes occultent des variations très importantes dans certains pays. En Corée et en Estonie, par exemple, la taille moyenne des classes dans le premier cycle de l'enseignement secondaire a diminué d'environ $20 \%$ ces dix dernières années. En Corée, les effectifs des classes dans l'enseignement primaire sont également, en moyenne, $29 \%$ plus réduits qu'en 2005 - c'est la plus forte baisse enregistrée dans les pays de I'OCDE au cours de la dernière décennie. Ce constat pourrait refléter une diminution du nombre d'élèves. Dans d'autres pays, en revanche, la taille moyenne des classes dans l'enseignement primaire a augmenté : de $20 \%$ au Mexique, de $14 \%$ au Portugal et de $29 \%$ en Fédération de Russie. La taille moyenne des classes dans le 
premier cycle de l'enseignement secondaire a augmenté de $8 \%$ au Danemark - ce qui constitue la plus forte augmentation enregistrée dans les pays de l'OCDE au cours de cette période.

\section{Graphique D2.3. Taille moyenne des classes dans l'enseignement primaire (2005 et 2017)}

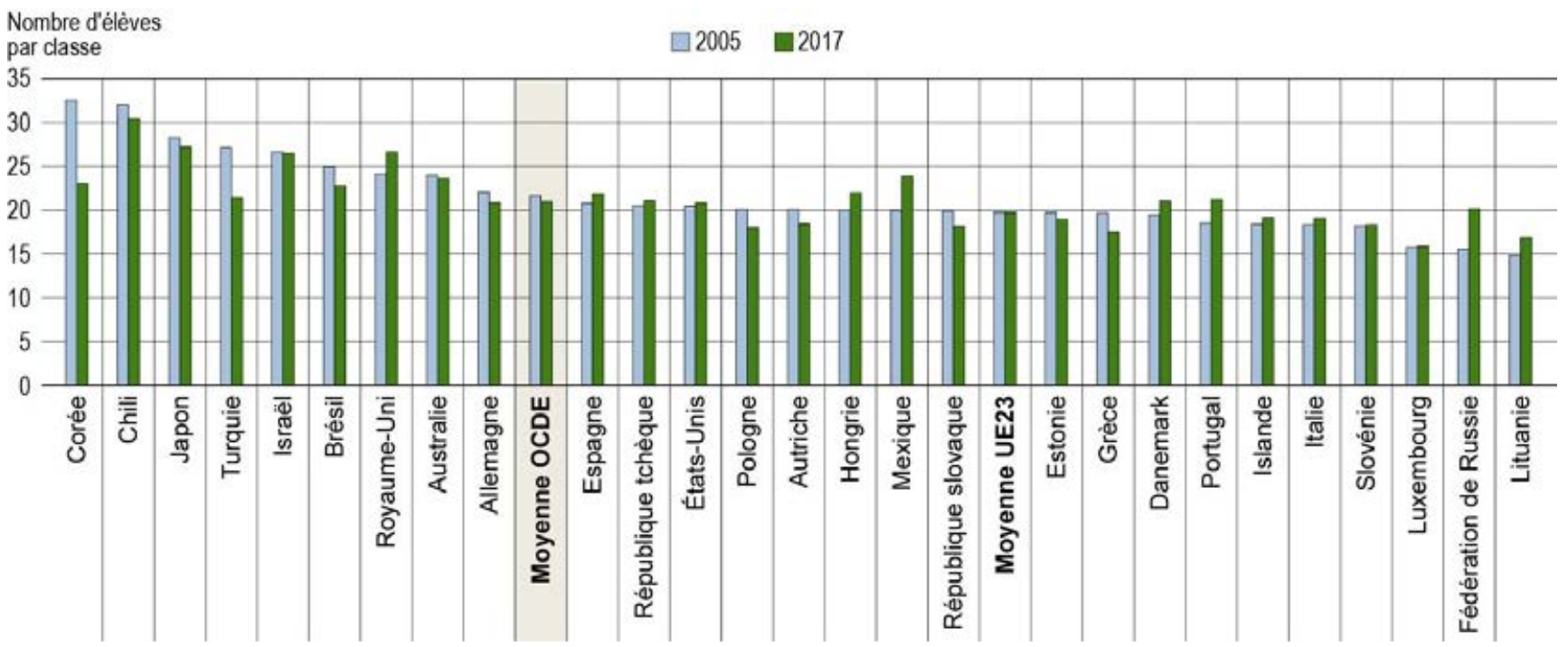

Les pays sont classés par ordre décroissant de la taille moyenne des classes dans l'enseignement primaire en 2005.

Source : OCDE/ISU/Eurostat (2019), tableau D2.1. Consulter la section « Source » pour tout complément d'information et l'annexe 3 pour les notes (https://doi.org/10.1787/f8d7880d-en).

StatLink 제프 https://doi.org/10.1787/888933979842

\section{Définitions}

Le personnel enseignant (enseignants) comporte deux catégories :

- La catégorie des auxiliaires d'éducation et des assistants de recherche inclut le personnel non certifié et les étudiants qui aident les enseignants à donner cours.

- La catégorie des enseignants inclut le personnel certifié directement impliqué dans l'instruction des élèves/étudiants. Elle englobe les enseignants qui ont une charge de cours, qui dispensent un enseignement spécialisé, qui prennent en charge des élèves/étudiants constituant une classe entière dans une salle de classe ou des élèves/étudiants réunis en petits groupes dans une salle spécialisée ou qui donnent des cours particuliers dans une salle de classe ou un autre local. Cette catégorie inclut également les chefs de département qui ont une charge de cours, mais exclut le personnel non certifié qui assiste les enseignants lors des cours auxétudiants, comme les auxiliaires d'éducation ou le personnel paraprofessionnel.

Dans l'enseignement tertiaire, le personnel académique inclut le personnel dont la mission principale relève de l'enseignement ou de la recherche.

\section{Méthodologie}

La taille des classes est calculée comme suit: les effectifs d'élèves/étudiants sont divisés par le nombre de classes. Les programmes d'enseignement spécial sont exclus afin de garantir la comparabilité internationale des données. Cet indicateur comprend uniquement les programmes normaux de l'enseignement primaire et du premier cycle de l'enseignement secondaire, et exclut les sous-groupes d'élèves constitués en dehors des classes normales. 
Le taux d'encadrement d'un niveau d'enseignement est calculé comme suit : l'effectif d'élèves en équivalents temps plein du niveau d'enseignement considéré est divisé par l'effectif d'enseignants, également en équivalents temps plein, du même niveau et dans le même type d'établissements. Dans l'enseignement tertiaire, le taux d'encadrement est calculé sur la base du corps professoral et non du corps enseignant.

Il faut des données harmonisées sur le corps professoral et l'effectif d'étudiants pour que les taux d'encadrement soient révélateurs. Par exemple, si les enseignants en poste dans des établissements confessionnels ne sont pas comptabilisés dans le corps professoral, les étudiants de ces établissements doivent être exclus.

Pour de plus amples informations, veuillez consulter le Guide de l'OCDE pour l'établissement de statistiques internationalement comparables dans le domaine de l'éducation 2018 : Concepts, normes, définitions et classifications (OCDE, 2019 $\left.{ }_{[14]}\right)$ et les notes spécifiques aux pays à l'annexe 3 (https://doi.org/10.1787/f8d7880d-en).

\section{Source}

Les données se rapportent à l'année académique 2016/17 et proviennent de l'exercice UNESCOISU/OCDE/Eurostat de collecte de données statistiques sur l'éducation réalisé par l'OCDE en 2018 (pour plus de précisions, voir l'annexe 3, https://doi.org/10.1787/f8d7880d-en).

\section{Remarque concernant les données fournies par Israël}

Les données statistiques concernant Israël sont fournies par et sous la responsabilité des autorités israéliennes compétentes. L'utilisation de ces données par l'OCDE est sans préjudice du statut des hauteurs du Golan, de Jérusalem-Est et des colonies de peuplement israéliennes en Cisjordanie aux termes du droit international.

\section{Références}

ETER (2019), ETER, https://eter-project.com/\#/home.

Eurydice Report (dir. pub.) (2017), Modernisation de l'enseignement supérieur en Europe : Personnel académique - 2017, Office des publications de l'Union européenne, Luxembourg, https://publications.europa.eu/en/publication-detail/-/publication/40f84414-683f-11e7-b2f201aa75ed71a1/language-fr (consulté le 18 octobre 2018).

Fredriksson, P., B. Öckert et H. Oosterbeek (2013), « Long-Term effects of class size », Quarterly Journal of Economics, vol. 128/1, pp. 249-285, http://dx.doi.org/10.1093/qje/qjs048.

Gouvernement australien (2019), HEIMSHELP, https://heimshelp.education.gov.au/resources/glossary/glossaryterm?title=Function.

Klein, S. (2001), Financing Vocational Education: A State Policymaker's Guide, RTI, http://www.rti.org/sites/default/files/resources/financing vocational education.pdf.

McDonald, G. (2013), « Does size matter? The impact of student-staff ratios », Journal of Higher Education Policy and Management, vol. 35/6, pp. 652-667, http://dx.doi.org/10.1080/1360080X.2013.844668.

NCES National Center for Education Statistics (2018), IPEDS 2017-18 Data Collection System, https://nces.ed.gov/ipeds/UseTheData/ArchivedSurveyMaterialPdf?year=2017\&fileName=package 1 43.pdf. 
OCDE (2019), Guide de l'OCDE pour l'établissement de statistiques internationalement comparables dans le domaine de l'éducation 2018: Concepts, normes, définitions et classifications, Éditions OCDE, Paris, https://dx.doi.org/10.1787/9789264305380-fr.

OCDE (2018), « Diplômés de l'enseignement tertiaire: Quelles évolutions ? », Les indicateurs de l'éducation à la loupe, $n^{\circ} 61$, Éditions OCDE, Paris, https://dx.doi.org/10.1787/1a4e9f01-fr.

OCDE (2017), "Future of works and skills », document présenté lors de la 2e réunion du Groupe de travail du G20 sur l'emploi, Hambourg, 15-17 février 2017, http://www.oecd.org/els/emp/wcms 556984.pdf.

OCDE (2017), Regards sur l'éducation 2017: Les indicateurs de l'OCDE, Éditions OCDE, Paris, https://dx.doi.org/10.1787/eag-2017-fr.

OCDE (2017), Résultats du PISA 2015 (Volume II): Politiques et pratiques pour des établissements performants, PISA, Éditions OCDE, Paris, https://dx.doi.org/10.1787/9789264267558-fr.

OCDE (2016), Manuel de Frascati 2015 : Lignes directrices pour le recueil et la communication des données sur la recherche et le développement expérimental, Éditions OCDE, Paris, https://doi.org/10.1787/9789264257252-fr.

Piketty, T. et M. Valdenaire (2006), «L'impact de la taille des classes sur la réussite scolaire dans les écoles, collèges et lycées français », Les Dossiers: Enseignement scolaire, No. 173, http://www.education.gouv.fr/cid3865//-impact-de-la-taille-des-classes-sur-la-reussite-scolaire-dansles-ecoles-colleges-et-lycees-francais.html\&xtmc=piketty\&xtnp=1\&xtcr=1 (consulté le 6 juin 2019).

\section{Tableaux de l'indicateur D2}

Tableau D2.1

Tableau D2.2

Tableau D2.3
Taille moyenne des classes, selon le type d'établissement (2017) et indice de variation entre 2005 et 2017

Taux d'encadrement dans les établissements d'enseignement, selon le niveau d'enseignement (2017)

Taux d'encadrement, selon le type d'établissement d'enseignement (2017)

Date butoir pour les données : 19 juillet 2019. Les mises à jour peuvent être consultées en ligne sur : http://dx.doi.org/10.1787/eag-data-en. D'autres données désagrégées sont également disponibles dans la Base de données de Regards sur l'éducation (http://stats.oecd.org/).

StatLink: https://doi.org/10.1787/888933981210 
Tableau D2.1. Taille moyenne des classes, selon le type d'établissement (2017) et indice de variation entre 2005 et 2017 Selon le niveau d'enseignement, calculs fondés sur l'effectif d'élèves et le nombre de classes

\begin{tabular}{|c|c|c|c|c|c|c|c|c|c|c|c|c|c|c|c|c|}
\hline & \multicolumn{5}{|c|}{ Primaire } & \multicolumn{5}{|c|}{ Premier cycle du secondaire } & \multicolumn{6}{|c|}{ Indice de variation entre 2005 et $2017(2005=100)$} \\
\hline & \multirow[b]{2}{*}{ 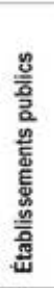 } & \multicolumn{3}{|c|}{ Etablissements privés } & \multirow[b]{2}{*}{ 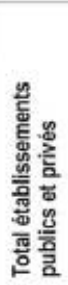 } & \multirow[b]{2}{*}{ 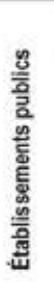 } & \multicolumn{3}{|c|}{ Etablissements privés } & \multirow[b]{2}{*}{ 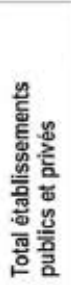 } & \multicolumn{3}{|c|}{ Primaire } & \multicolumn{3}{|c|}{$\begin{array}{l}\text { Premier cycle } \\
\text { du secondaire }\end{array}$} \\
\hline & & 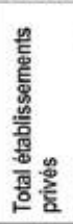 & 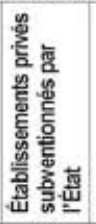 & 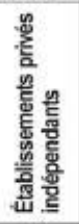 & & & 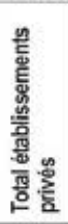 & 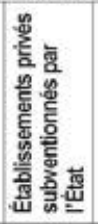 & 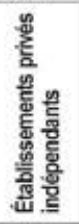 & & 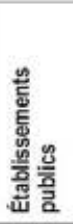 & 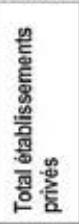 & 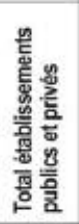 & 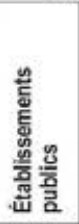 & 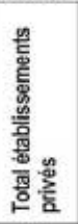 & 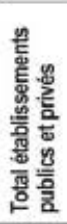 \\
\hline & (1) & (2) & (3) & (4) & (5) & (6) & (7) & (8) & (9) & $(10)$ & (11) & $(12)$ & (13) & $(14)$ & (15) & (16) \\
\hline \multicolumn{17}{|l|}{ шays } \\
\hline Ö Australie & 23 & 24 & 24 & a & 24 & 21 & 24 & 24 & a & 22 & 97 & m & 98 & 87 & m & 89 \\
\hline Autriche & 18 & 19 & $x(2)$ & $x(2)$ & 18 & 21 & 21 & $x(7)$ & $x(7)$ & 21 & 92 & 92 & 92 & 88 & 85 & 87 \\
\hline Belgique & $\mathrm{m}$ & $\mathrm{m}$ & $\mathrm{m}$ & $\mathrm{m}$ & $\mathrm{m}$ & $\mathrm{m}$ & $\mathrm{m}$ & $\mathrm{m}$ & $\mathrm{m}$ & m & $\mathrm{m}$ & $\mathrm{m}$ & $\mathrm{m}$ & $\mathrm{m}$ & $\mathrm{m}$ & m \\
\hline Canada & $\mathrm{m}$ & $\mathrm{m}$ & $\mathrm{m}$ & $\mathrm{m}$ & m & $\mathrm{m}$ & m & m & $\mathrm{m}$ & $\mathrm{m}$ & $\mathrm{m}$ & $\mathrm{m}$ & m & $\mathrm{m}$ & m & m \\
\hline Chili & 28 & 32 & 33 & 25 & 31 & 29 & 31 & 33 & 25 & 30 & 85 & 102 & 95 & 82 & 95 & 89 \\
\hline Colombie & 25 & 19 & a & 19 & 23 & 31 & 24 & a & 24 & 30 & $\mathrm{~m}$ & $\mathrm{~m}$ & m & $\mathrm{m}$ & $\mathrm{m}$ & m \\
\hline République tchèque & 21 & 15 & 15 & a & 21 & 22 & 18 & 18 & a & 22 & 103 & $\mathrm{~m}$ & 103 & 93 & m & 93 \\
\hline Danemark & 22 & 19 & 19 & a & 21 & 22 & 20 & 20 & a & 21 & 109 & $\mathrm{~m}$ & 108 & 109 & $\mathrm{~m}$ & 108 \\
\hline Estonie & 19 & 16 & a & 16 & 19 & 19 & 14 & a & 14 & 18 & 97 & $\mathrm{~m}$ & 96 & 81 & m & 81 \\
\hline Finlande & 20 & 18 & 18 & a & 20 & 19 & 19 & 19 & a & 19 & $\mathrm{~m}$ & $\mathrm{~m}$ & $\mathrm{~m}$ & $\mathrm{~m}$ & $\mathrm{~m}$ & $\mathrm{~m}$ \\
\hline France & 23 & 25 & 25 & a & 24 & 25 & 26 & 27 & 12 & 25 & m & m & m & 104 & 104 & 104 \\
\hline Allemagne & 21 & 21 & $\times(2)$ & $x(2)$ & 21 & 24 & 24 & $x(7)$ & $x(7)$ & 24 & 95 & 91 & 95 & 97 & 91 & 97 \\
\hline Gréce & 17 & 21 & a & 21 & 18 & 21 & 22 & a & 22 & 21 & 88 & $\mathrm{~m}$ & 89 & 85 & $\mathrm{~m}$ & 85 \\
\hline Hongrie & 22 & 21 & 22 & 17 & 22 & 21 & 21 & 22 & 16 & 21 & 110 & 110 & 110 & 96 & 96 & 96 \\
\hline Islande & 19 & 15 & 15 & a & 19 & 20 & 13 & 13 & a & 20 & 104 & 111 & 104 & 101 & 107 & 101 \\
\hline Irlande & 25 & $\mathrm{~m}$ & a & $\mathrm{m}$ & $\mathrm{m}$ & $\mathrm{m}$ & $\mathrm{m}$ & a & $\mathrm{m}$ & $\mathrm{m}$ & 101 & $\mathrm{~m}$ & $\mathrm{~m}$ & $\mathrm{~m}$ & $\mathrm{~m}$ & m \\
\hline Israèl & 27 & 25 & 25 & a & 27 & 29 & 24 & 24 & a & 28 & 98 & m & 96 & 94 & m & 91 \\
\hline Italic & 19 & 19 & a & 19 & 19 & 21 & 21 & a & 21 & 21 & 104 & $\mathrm{~m}$ & 104 & 101 & $\mathrm{~m}$ & 101 \\
\hline Japon & 27 & 28 & a & 28 & 27 & 32 & 33 & a & 33 & 32 & 96 & 83 & 96 & 96 & 92 & 96 \\
\hline Corée & 23 & 27 & a & 27 & 23 & 28 & 27 & 27 & a & 27 & 71 & 84 & 71 & 77 & 77 & 77 \\
\hline Lettonie & 17 & 9 & a & 9 & 16 & 16 & 13 & a & 13 & 16 & $\mathrm{~m}$ & $\mathrm{~m}$ & $\mathrm{~m}$ & m & $\mathrm{m}$ & m \\
\hline Lituanie & 17 & 15 & a & 15 & 17 & 18 & 19 & a & 19 & 18 & 114 & 149 & 114 & 83 & 123 & 83 \\
\hline Luxembourg & 15 & 20 & 20 & 20 & 16 & 19 & 19 & 19 & 20 & 19 & 99 & 105 & 101 & 100 & 93 & 98 \\
\hline Mexique & 24 & 20 & a & 20 & 24 & 28 & 24 & a & 24 & 28 & 123 & 91 & 120 & 94 & 89 & 93 \\
\hline Pays-Bas' & $23^{\circ}$ & m & m & $\mathrm{m}$ & m & m & m & m & m & m & $105^{d}$ & $\mathrm{~m}$ & $\mathrm{~m}$ & m & $\mathrm{m}$ & m \\
\hline Nouvelle-Zélande & $\mathrm{m}$ & $\mathrm{m}$ & $\mathrm{m}$ & $\mathrm{m}$ & $\mathrm{m}$ & m & $\mathrm{m}$ & $\mathrm{m}$ & $\mathrm{m}$ & $\mathrm{m}$ & $\mathrm{m}$ & m & $\mathrm{m}$ & $\mathrm{m}$ & $\mathrm{m}$ & m \\
\hline Norvège & m & $\mathrm{m}$ & m & $\mathrm{m}$ & m & m & m & $\mathrm{m}$ & $\mathrm{m}$ & $\mathrm{m}$ & $\mathrm{m}$ & $\mathrm{m}$ & $\mathrm{m}$ & $\mathrm{m}$ & $\mathrm{m}$ & m \\
\hline Pologne & 19 & 12 & 11 & 12 & 18 & 22 & 17 & 22 & 15 & 22 & 92 & 100 & 90 & 92 & 101 & 91 \\
\hline Portugal & 21 & 21 & 23 & 20 & 21 & 22 & 24 & 25 & 23 & 22 & 117 & 96 & 114 & 98 & 101 & 98 \\
\hline République slovaque & 18 & 18 & 18 & a & 18 & 19 & 18 & 18 & a & 19 & 92 & $\mathrm{~m}$ & 92 & 84 & $\mathrm{~m}$ & 84 \\
\hline Slovénie & 18 & 21 & 21 & a & 18 & 20 & 20 & 20 & a & 20 & 101 & $\mathrm{~m}$ & 101 & 97 & $\mathrm{~m}$ & 97 \\
\hline Espagne & 21 & 25 & 25 & 21 & 22 & 25 & 27 & 27 & 22 & 25 & 107 & 102 & 105 & 104 & 100 & 103 \\
\hline Suede & 20 & 18 & 18 & a & 19 & 21 & 22 & 22 & a & 21 & $\mathrm{~m}$ & $\mathrm{~m}$ & $\mathrm{~m}$ & $\mathrm{~m}$ & m & m \\
\hline Suisse & 19 & $\mathrm{~m}$ & $\mathrm{~m}$ & $\mathrm{~m}$ & m & 19 & $\mathrm{~m}$ & $\mathrm{~m}$ & m & $\mathrm{m}$ & m & m & m & $\mathrm{m}$ & $\mathrm{m}$ & $\mathrm{m}$ \\
\hline Turquie & 22 & 18 & a & 18 & 21 & 26 & 19 & a & 19 & 25 & 79 & $\mathrm{~m}$ & 79 & $\mathrm{~m}$ & m & m \\
\hline Royaume-Uni & 28 & a & 28 & 12 & 27 & 24 & a & 25 & 12 & 23 & 108 & m & 110 & 100 & m & 104 \\
\hline États-Unis & 21 & 18 & a & 18 & 21 & 27 & 20 & a & 20 & 26 & 102 & 99 & 102 & 101 & 95 & 100 \\
\hline $\begin{array}{l}\text { Moyenne OCDE } \\
\text { Moyenne des pays }\end{array}$ & 21 & 20 & m & m & 21 & 23 & 21 & m & m & 23 & 100 & m & 99 & 94 & m & 94 \\
\hline $\begin{array}{l}\text { dont les données des deux } \\
\text { années de référence sont } \\
\text { disponibles }\end{array}$ & 21 & 20 & $\mathrm{~m}$ & m & 21 & 23 & 22 & $\mathrm{~m}$ & m & 23 & 99 & $\mathrm{~m}$ & 99 & 94 & m & 94 \\
\hline Moyenne UE23 & 20 & 19 & $\mathrm{~m}$ & m & 20 & 21 & 20 & $\mathrm{~m}$ & $\mathrm{~m}$ & 21 & $\mathrm{~m}$ & $\mathrm{~m}$ & m & m & m & m \\
\hline A Argentine & $\mathrm{m}$ & m & m & m & $\mathrm{m}$ & $\mathrm{m}$ & m & m & $\mathrm{m}$ & m & $\mathrm{m}$ & m & $\mathrm{m}$ & m & m & $\mathrm{m}$ \\
\hline Brésil & 24 & 18 & a & 18 & 23 & 28 & 24 & a & 24 & 27 & 94 & $\mathrm{~m}$ & 91 & 84 & $\mathrm{~m}$ & 85 \\
\hline Chine & $\mathrm{m}$ & $\mathrm{m}$ & $\mathrm{m}$ & $\mathrm{m}$ & $\mathrm{m}$ & $\mathrm{m}$ & m & m & $\mathrm{m}$ & m & $\mathrm{m}$ & $\mathrm{m}$ & $\mathrm{m}$ & m & $\mathrm{m}$ & m \\
\hline Costa Rica & 15 & 17 & $x(2)$ & $x(2)$ & 15 & 35 & 21 & $x(7)$ & $x(7)$ & 33 & m & m & m & m & m & m \\
\hline Inde & $\mathrm{m}$ & $\mathrm{m}$ & $\mathrm{m}$ & $\mathrm{m}$ & $\mathrm{m}$ & $\mathrm{m}$ & $\mathrm{m}$ & $\mathrm{m}$ & $\mathrm{m}$ & $\mathrm{m}$ & $\mathrm{m}$ & $\mathrm{m}$ & $\mathrm{m}$ & $\mathrm{m}$ & $\mathrm{m}$ & $\mathrm{m}$ \\
\hline Indonésie & $\mathrm{m}$ & $\mathrm{m}$ & $\mathrm{m}$ & $\mathrm{m}$ & $\mathrm{m}$ & $\mathrm{m}$ & $\mathrm{m}$ & $\mathrm{m}$ & $\mathrm{m}$ & $\mathrm{m}$ & $\mathrm{m}$ & $\mathrm{m}$ & $\mathrm{m}$ & $\mathrm{m}$ & $\mathrm{m}$ & $\mathrm{m}$ \\
\hline Fedération de Russie & 20 & 13 & a & 13 & 20 & 20 & 12 & a & 12 & 19 & 130 & m & 129 & 103 & m & 103 \\
\hline Arabie saoudite & $\mathrm{m}$ & $\mathrm{m}$ & $\mathrm{m}$ & m & $\mathrm{m}$ & $\mathrm{m}$ & m & m & $\mathrm{m}$ & $\mathrm{m}$ & $\mathrm{m}$ & $\mathrm{m}$ & m & $\mathrm{m}$ & $\mathrm{m}$ & m \\
\hline Afrique du Sud & $m$ & m & m & m & m & $m$ & m & m & m & m & m & m & m & m & m & m \\
\hline Moyenne G20 & m & m & $\mathrm{m}$ & $\mathrm{m}$ & $\mathrm{m}$ & $\mathrm{m}$ & m & $\mathrm{m}$ & m & $\mathrm{m}$ & m & $\mathrm{m}$ & $\mathrm{m}$ & m & $\mathrm{m}$ & m \\
\hline
\end{tabular}

1. L'enseignement primaire inclut des programmes de l'enseignement préprimaire.

Source : OCDE/ISU/Eurostat (2019). Consulter la section « Source » pour tout complément d'information et l'annexe 3 pour les notes (https://doi.org/10.1787/f8d7880d-en). Les symboles représentant les données manquantes et les abréviations figurent dans le Guide du lecteur. 
Tableau D2.2. Taux d'encadrement dans les établissements d'enseignement, selon le niveau d'enseignement (2017) Calculs fondés sur des équivalents temps plein

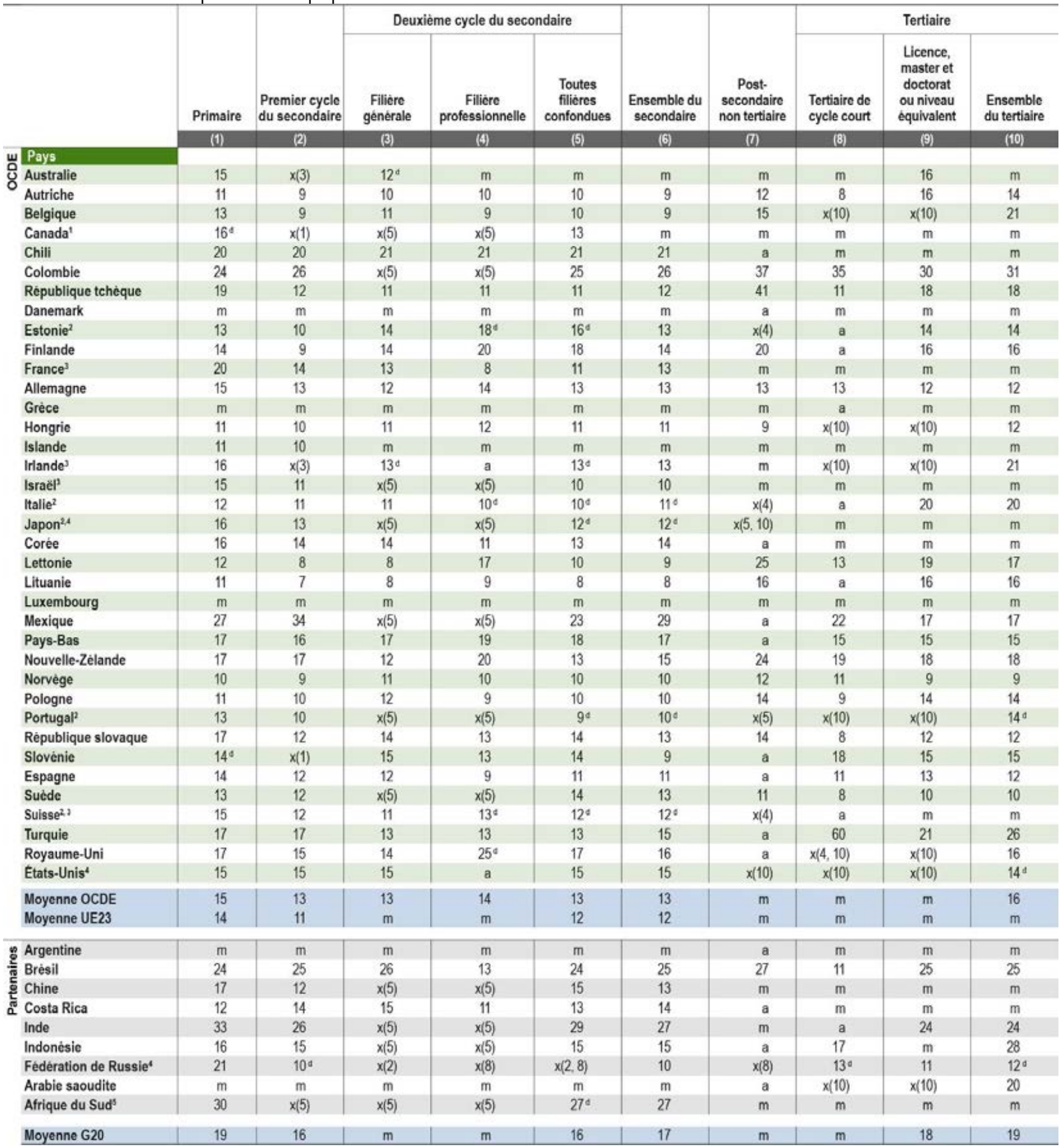

1. L'enseignement primaire inclut l'enseignement préprimaire.

2. Le deuxième cycle de l'enseignement secondaire inclut des programmes d'autres niveaux d'enseignement - voir l'annexe 3 pour plus de précisions.

3. Pour la France, établissements publics et privés subventionnés par l'État pour tous les niveaux d'enseignement. Pour l'Irlande et la Suisse, établissements publics uniquement pour tous les niveaux d'enseignement. Pour Israël, établissements publics uniquement pour le deuxième cycle du secondaire et l'ensemble du secondaire.

4. L'enseignement tertiaire inclut des programmes d'autres niveaux d'enseignement - voir l'annexe 3 pour plus de précisions.

5. Année de référence : 2016, et non 2017.

Source : OCDE/ISU/Eurostat (2019). Consulter la section « Source » pour tout complément d'information et l'annexe 3 pour les notes (https://doi.org/10.1787/f8d7880den).

Les symboles représentant les données manquantes et les abréviations figurent dans le Guide du lecteur. 
Tableau D2.3. Taux d'encadrement, selon le type d'établissement d'enseignement (2017)

Selon le niveau d'enseignement, calculs fondés sur des équivalents temps plein

\begin{tabular}{|c|c|c|c|c|c|c|c|c|c|c|c|c|}
\hline & \multicolumn{4}{|c|}{ Premier cycle du secondaire } & \multicolumn{4}{|c|}{ Deuxième cycle du secondaire } & \multicolumn{4}{|c|}{ Ensemble du secondaire } \\
\hline & \multirow[b]{2}{*}{ 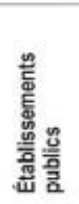 } & \multicolumn{3}{|c|}{ Établissements privés } & \multirow[b]{2}{*}{ 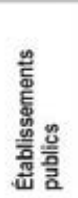 } & \multicolumn{3}{|c|}{ Ėtablissements privés } & \multirow[b]{2}{*}{ 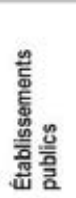 } & \multicolumn{3}{|c|}{ Établissements privès } \\
\hline & & 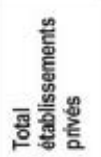 & 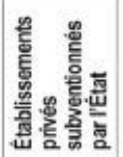 & 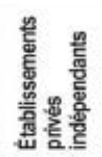 & & 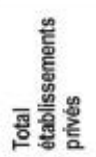 & 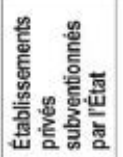 & 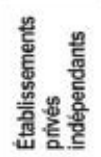 & & 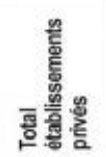 & 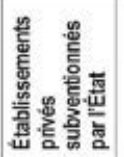 & 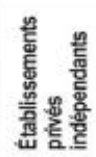 \\
\hline & (i) & (2) & (3) & (4) & (5) & (6) & (7) & (8) & (9) & (10) & (11) & (12) \\
\hline \multicolumn{13}{|l|}{ ш Pays } \\
\hline ¿' Australie' & $x(5)$ & $x(6)$ & $x(7)$ & a & $12^{\mathrm{d}}$ & $11^{\circ}$ & $11^{\circ}$ & a & $\mathrm{m}$ & $\mathrm{m}$ & m & $\mathrm{m}$ \\
\hline Autriche & 8 & 10 & $x(2)$ & $x(2)$ & 10 & 10 & $x(6)$ & $x(6)$ & 9 & 10 & $x(10)$ & $x(10)$ \\
\hline Belgique & 9 & 9 & 9 & 6 & 10 & 10 & 10 & 10 & 9 & 9 & 9 & 8 \\
\hline Canada & $\mathrm{m}$ & $\mathrm{m}$ & $\mathrm{m}$ & $\mathrm{m}$ & 13 & 14 & $x(6)$ & $x(6)$ & $\mathrm{m}$ & $\mathrm{m}$ & $\mathrm{m}$ & $\mathrm{m}$ \\
\hline Chill & 16 & 24 & 25 & 20 & 19 & 23 & 25 & 16 & 18 & 23 & 25 & 17 \\
\hline Colombie & 28 & 21 & a & 21 & 26 & 23 & a & 23 & 27 & 22 & a & 22 \\
\hline République tchèque & 12 & 11 & 11 & a & 11 & 12 & 12 & a & 12 & 12 & 12 & a \\
\hline Danemark & $\mathrm{m}$ & $\mathrm{m}$ & $\mathrm{m}$ & a & $\mathrm{m}$ & $\mathrm{m}$ & $\mathrm{m}$ & $\mathrm{m}$ & $\mathrm{m}$ & $\mathrm{m}$ & $\mathrm{m}$ & $\mathrm{m}$ \\
\hline Estonie ${ }^{2}$ & 10 & 9 & a & 9 & 16 & 13 & a & 13 & 13 & 11 & a & 11 \\
\hline Finlande & 9 & 9 & 9 & a & 18 & 20 & 20 & a & 13 & 17 & 17 & a \\
\hline France & 14 & 16 & 16 & $\mathrm{~m}$ & 11 & 12 & 12 & $\mathrm{~m}$ & 12 & 14 & 14 & $\mathrm{~m}$ \\
\hline Allemagne & 13 & 13 & $x$ (2) & $x(2)$ & 13 & 12 & $x(6)$ & $x(6)$ & 13 & 12 & $x(10)$ & $x(10)$ \\
\hline Grece & $\mathrm{m}$ & $\mathrm{m}$ & a & $\mathrm{m}$ & $\mathrm{m}$ & m & a & $\mathrm{m}$ & $\mathrm{m}$ & m & a & $\mathrm{m}$ \\
\hline Hongrie & 10 & 12 & 12 & 10 & 11 & 12 & 11 & 13 & 11 & 12 & 12 & 12 \\
\hline Islande & 10 & 5 & 5 & a & $\mathrm{m}$ & $\mathrm{m}$ & $\mathrm{m}$ & $\mathrm{m}$ & $\mathrm{m}$ & $\mathrm{m}$ & $\mathrm{m}$ & $\mathrm{m}$ \\
\hline Irlande & $\times(5)$ & $\mathrm{m}$ & a & $\mathrm{m}$ & $13^{\mathrm{d}}$ & m & a & $\mathrm{m}$ & 13 & m & a & m \\
\hline Israë| & 11 & $\mathrm{~m}$ & m & $\mathrm{m}$ & 10 & $\mathrm{~m}$ & $\mathrm{~m}$ & a & 10 & $\mathrm{~m}$ & $\mathrm{~m}$ & m \\
\hline Italie ${ }^{2}$ & 11 & 11 & a & 11 & 11 & 7 & a & 7 & 11 & 8 & a & 8 \\
\hline Japon $^{2}$ & 13 & 12 & a & 12 & $11^{\circ}$ & $14^{\circ}$ & a & $14^{4}$ & $12^{d}$ & $13^{\circ}$ & a & $13^{4}$ \\
\hline Coree & 14 & 15 & 15 & a & 12 & 14 & 14 & a & 13 & 14 & 14 & a \\
\hline Lettonie & 8 & 6 & a & 6 & 10 & 10 & a & 10 & 9 & 8 & a & 8 \\
\hline Lituanie & 7 & 9 & a & 9 & 8 & 8 & a & 8 & 7 & 9 & a & 9 \\
\hline Luxembourg & $\mathrm{m}$ & $\mathrm{m}$ & $\mathrm{m}$ & $\mathrm{m}$ & $\mathrm{m}$ & $\mathrm{m}$ & $\mathrm{m}$ & $\mathrm{m}$ & $\mathrm{m}$ & $\mathrm{m}$ & $\mathrm{m}$ & $\mathrm{m}$ \\
\hline Mexique & 38 & 18 & a & 18 & 25 & 16 & $\mathrm{a}$ & 16 & 32 & 17 & a & 17 \\
\hline Pays-Bas & 16 & 16 & a & 16 & 18 & 19 & a & 19 & 17 & 18 & a & 18 \\
\hline Nouvelle-Zélande & 17 & $\mathrm{~m}$ & $\mathrm{~m}$ & 13 & 13 & 12 & 13 & 11 & 15 & $\mathrm{~m}$ & $\mathrm{~m}$ & 12 \\
\hline Norvège & 9 & 8 & 8 & 8 & 10 & 11 & 11 & a & 10 & 10 & 10 & 8 \\
\hline Pologne & 10 & 9 & 11 & 8 & 10 & 11 & 11 & 11 & 10 & 10 & 11 & 10 \\
\hline Portuga ${ }^{2}$ & 9 & 15 & 15 & 15 & $g^{d}$ & $10^{\circ}$ & $12^{\circ}$ & $10^{d}$ & $9^{\mathrm{d}}$ & $12^{\circ}$ & $14^{\circ}$ & $11^{\mathrm{d}}$ \\
\hline République slovaque & 12 & 12 & 12 & a & 14 & 12 & 12 & a & 13 & 12 & 12 & a \\
\hline Slovénie & $\mathrm{m}$ & $\mathrm{m}$ & m & a & 14 & 17 & 28 & 13 & 9 & 15 & 17 & 13 \\
\hline Espagne & 11 & 15 & 15 & 14 & 10 & 14 & 15 & 13 & 10 & 15 & 15 & 13 \\
\hline Suede & 12 & 17 & 17 & a & 14 & 14 & 14 & a & 13 & 15 & 15 & a \\
\hline Suisse $^{2}$ & 12 & $\mathrm{~m}$ & $\mathrm{~m}$ & $\mathrm{~m}$ & $12^{d}$ & $\mathrm{~m}$ & $\mathrm{~m}$ & $\mathrm{~m}$ & $12^{\mathrm{d}}$ & $\mathrm{m}$ & $\mathrm{m}$ & $\mathrm{m}$ \\
\hline Turquie & 17 & 10 & a & 10 & 13 & 10 & $\mathrm{a}$ & 10 & 15 & 10 & a & 10 \\
\hline Royaume-Uni & 16 & 15 & 16 & 8 & 14 & 18 & 20 & 8 & 15 & 17 & 19 & 8 \\
\hline États-Unis & 16 & 10 & a & 10 & 16 & 10 & a & 10 & 16 & 10 & a & 10 \\
\hline Moyenne OCDE & 13 & 12 & $\mathrm{~m}$ & $\mathrm{~m}$ & 13 & 13 & $\mathrm{~m}$ & $\mathrm{~m}$ & 13 & 13 & $\mathrm{~m}$ & $\mathrm{~m}$ \\
\hline Moyenne UE23 & 11 & $\mathrm{~m}$ & m & m & 12 & 13 & m & $\mathrm{m}$ & 11 & m & m & m \\
\hline If Argentine & $\mathrm{m}$ & $\mathrm{m}$ & $\mathrm{m}$ & $\mathrm{m}$ & $\mathrm{m}$ & $\mathrm{m}$ & $\mathrm{m}$ & $\mathrm{m}$ & $\mathrm{m}$ & $\mathrm{m}$ & $\mathrm{m}$ & $\mathrm{m}$ \\
\hline Brésil & 26 & 20 & a & 20 & 25 & 18 & a & 18 & 26 & 19 & a & 19 \\
\hline Chine & 12 & 17 & $x(2)$ & $x(2)$ & 14 & 18 & $\times(6)$ & $x(6)$ & 13 & 17 & $x(10)$ & $x(10)$ \\
\hline Costa Rica & 14 & 9 & $\times(2)$ & $\mathrm{x}(2)$ & 14 & 9 & $x(6)$ & $x(6)$ & 14 & 9 & $x(10)$ & $x(10)$ \\
\hline Inde & 26 & 26 & $x \mid 27$ & $x(2)$ & $\mathrm{m}$ & $\mathrm{m}$ & $\mathrm{m}$ & $\mathrm{m}$ & $\mathrm{m}$ & $\mathrm{m}$ & $\mathrm{m}$ & $\mathrm{m}$ \\
\hline Indonésie & 16 & 14 & $x(2)$ & $x(2)$ & 15 & 16 & $x(6)$ & $x(6)$ & 16 & 15 & $x(10)$ & $x(10)$ \\
\hline Féderation de Russie & $11^{\circ}$ & $5^{\circ}$ & a & $5^{\circ}$ & $x(1)$ & $\times(2)$ & $a$ & $\times(4)$ & 11 & 5 & a & 5 \\
\hline Arabie saoudite & $\mathrm{m}$ & $\mathrm{m}$ & $\mathrm{m}$ & $\mathrm{m}$ & $\mathrm{m}$ & $\mathrm{m}$ & $\mathrm{m}$ & $\mathrm{m}$ & $\mathrm{m}$ & $\mathrm{m}$ & $\mathrm{m}$ & $\mathrm{m}$ \\
\hline Afrique du Sud & $x(5)$ & $x(6)$ & $x(7)$ & $x(8)$ & 28 & 14 & $x(6)$ & $\times(6)$ & 28 & 14 & $x(10)$ & $\times(10)$ \\
\hline Moyenne G20 & 17 & 14 & $\mathrm{~m}$ & $\mathrm{~m}$ & 15 & 14 & m & m & 16 & 13 & $\mathrm{~m}$ & m \\
\hline
\end{tabular}

1. Seule la filière générale est incluse dans les premier et deuxième cycles du secondaire.

2. Le deuxième cycle de l'enseignement secondaire inclut des programmes d'autres niveaux d'enseignement - voir l'annexe 3 pour plus de précisions.

3. Année de référence : 2016, et non 2017

Source : OCDE/ISU/Eurostat (2019). Consulter la section « Source » pour tout complément d'information et l'annexe 3 pour les notes (https://doi.org/10.1787/f8d7880d$\underline{\text { en). }}$

Les symboles représentant les données manquantes et les abréviations figurent dans le Guide du lecteur. 


\section{Indicateur D3. Quel est le niveau de salaire des enseignants et des chefs d'établissement?}

\section{Faits marquants}

- Le salaire statutaire et le salaire effectif des chefs d'établissement sont plus élevés que ceux des enseignants dans l'enseignement préprimaire et primaire, le premier cycle de l'enseignement secondaire et la filière générale du deuxième cycle de l'enseignement secondaire. En moyenne, dans les pays et économies de l'OCDE, le salaire effectif des chefs d'établissement est supérieur de $52 \%$ à celui des enseignants dans l'enseignement primaire et l'enseignement secondaire.

- Le salaire effectif des enseignants en poste dans l'enseignement préprimaire, l'enseignement primaire et la filière générale de l'enseignement secondaire représente en moyenne entre $78 \%$ et $93 \%$ de la rémunération des actifs occupés diplômés de l'enseignement tertiaire dans les pays de l'OCDE.

- En moyenne, dans les pays et économies de l'OCDE, les chefs d'établissement gagnent au moins $25 \%$ de plus que les actifs occupés diplômés de l'enseignement tertiaire, dans l'enseignement primaire et l'enseignement secondaire.

\section{Contexte}

Le salaire des personnels de l'éducation, en particulier des enseignants et des chefs d'établissement, représente le plus gros poste de dépenses dans l'enseignement institutionnel. Le salaire des enseignants a également un impact direct sur l'attractivité de la profession. II intervient dans la décision de choisir la formation d'enseignant, de devenir enseignant à la fin des études, de redevenir enseignant après une interruption de carrière ou de rester enseignant (dans l'ensemble, plus le salaire est élevé, moins les enseignants quittent la profession) (OCDE, 2006 $\left.{ }_{[1]}\right]$. Le niveau de salaire peut aussi intervenir dans la décision de devenir chef d'établissement.

L'accroissement de la dette publique, qui a résulté de l'action des gouvernements pendant la crise financière qui a éclaté à la fin de l'année 2008, a amené les responsables politiques à réduire les dépenses publiques, en particulier la rémunération dans la fonction publique. Comme le niveau de salaire et les conditions de travail sont des facteurs importants pour constituer, développer et entretenir un groupe d'enseignants et de chefs d'établissement compétents et de qualité, les responsables politiques doivent étudier de près leur salaire à l'heure où ils tentent à la fois de préserver la qualité de l'enseignement et de contenir le budget de l'éducation (voir les indicateurs C6 et C7).

Le salaire statutaire des enseignants et des chefs d'établissement n'est toutefois qu'une composante parmi d'autres de leur rémunération totale. Les enseignants peuvent par exemple bénéficier de primes au titre de l'affectation dans des régions reculées, d'allocations familiales, de réductions de tarif dans les transports publics ou de la détaxation de l'achat de matériel pédagogique. De plus, le régime fiscal et le système de prestations sociales varient énormément entre les pays de l'OCDE. II y a lieu de tenir compte de ces réserves et d'autres problèmes potentiels de comparabilité liés aux données recueillies (voir l'encadré D3.1et l'annexe 3) lors de la comparaison du salaire des enseignants entre les pays.

\section{Autres faits marquants}

- Dans la plupart des pays de l'OCDE, le salaire des enseignants et des chefs d'établissement augmente avec le niveau d'enseignement.

- Dans trois quarts au moins des pays et économies dont les données sont disponibles, les qualifications minimales requises pour exercer la profession d'enseignant sont également les plus courantes.

- En moyenne, le salaire statutaire des enseignants ayant les qualifications maximales au sommet de l'échelle barémique est entre $86 \%$ et $89 \%$ plus élevé que celui des enseignants ayant les qualifications minimales requises en début de carrière.

- Entre 2005 et 2018, dans les pays et économies de l'OCDE dont les données sont disponibles, le salaire statutaire des enseignants en exercice depuis 15 ans ayant les qualifications les plus courantes ont augmenté de $10 \%$ dans l'enseignement primaire, de $9 \%$ dans le premier cycle de l'enseignement secondaire (filière générale) et de $6 \%$ dans le deuxième cycle de l'enseignement secondaire (filière générale).

- Le salaire statutaire des enseignants ayant les qualifications minimales et 15 ans d'ancienneté a dépassé son niveau d'avant la crise dans l'enseignement primaire et dans le premier et deuxième cycle de l'enseignement secondaire. 
- Les chefs d'établissement sont moins susceptibles que les enseignants de recevoir des primes s'ils assument des responsabilités en plus de leur mission normale. Les chefs d'établissement et les enseignants en poste dans des régions défavorisées ou reculées reçoivent des primes dans la moitié des pays et économies de l'OCDE dont les données sont disponibles.

Graphique D3.1. Salaire des enseignants et des chefs d'établissement du premier cycle du secondaire par comparaison avec les revenus d'autres actifs occupés diplômés de l'enseignement tertiaire (2017) Salaire effectif (salaire annuel moyen [primes et allocations comprises]) des enseignants et des chefs d'établissement de la filière générale du premier cycle du secondaire dans les établissements publics

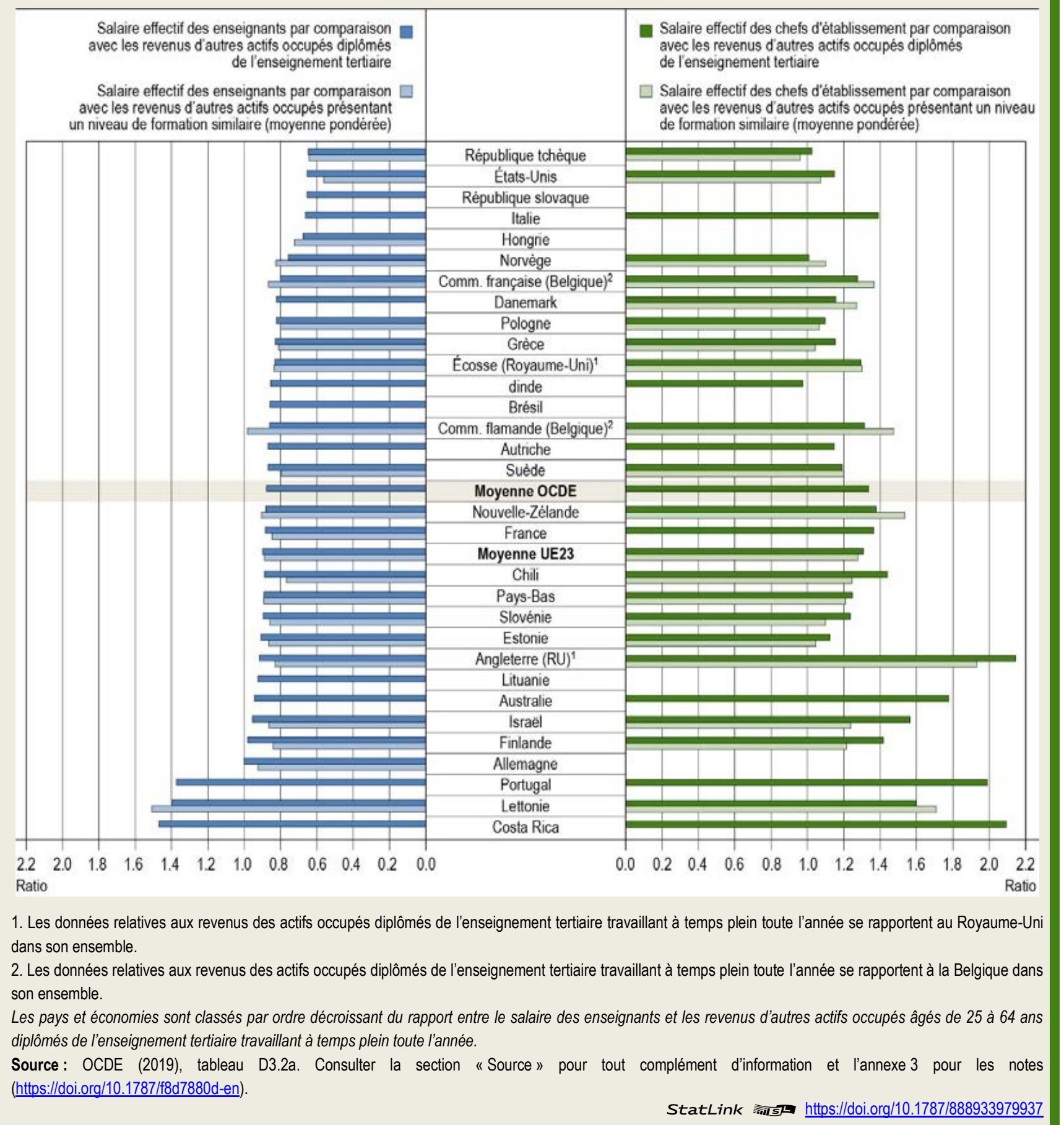




\section{Analyse}

\section{Salaire statutaire des enseignants}

Le salaire statutaire des enseignants varie en fonction d'un certain nombre de facteurs, dont le niveau d'enseignement où ils sont en poste, leur niveau de qualification, leur ancienneté ou le stade de leur carrière.

\section{Selon le niveau d'enseignement}

Le salaire des enseignants varie fortement entre les pays. Dans le premier cycle de l'enseignement secondaire, le salaire des enseignants en exercice depuis 15 ans ayant les qualifications les plus courantes (qui est assimilé au salaire des enseignants en milieu de carrière) est inférieur à 25000 USD en Hongrie, en Lituanie, en République slovaque et en République tchèque, mais est supérieur à 60000 USD en Allemagne, en Australie, au Canada, aux États-Unis, en Irlande et aux Pays-Bas; il passe même la barre des 100000 USD au Luxembourg (voir le tableau D3.1a).

Dans la plupart des pays et des économies dont les données sont disponibles, le salaire des enseignants augmente avec le niveau d'enseignement. En Communautés flamande et française de Belgique et en Norvège, les enseignants en exercice depuis 15 ans ayant les qualifications les plus courantes gagnent entre $25 \%$ et $30 \%$ de plus dans le deuxième cycle de l'enseignement secondaire que dans l'enseignement préprimaire ; ils gagnent entre $36 \%$ et $50 \%$ de plus en Finlande, en Lituanie et en République slovaque et même $89 \%$ de plus au Mexique. En Finlande et en République slovaque, cet écart s'explique essentiellement par la différence entre les niveaux de salaire des enseignants selon qu'ils sont en poste dans l'enseignement préprimaire ou dans l'enseignement primaire. En Communautés flamande et française de Belgique, le salaire des enseignants est nettement plus élevé dans le deuxième cycle de l'enseignement secondaire qu'aux autres niveaux d'enseignement (voir le tableau D3.1a).

L'augmentation du salaire des enseignants en exercice depuis 15 ans (ayant les qualifications les plus courantes) entre l'enseignement préprimaire et le deuxième cycle de l'enseignement secondaire est inférieure à $5 \%$ en Australie, au Chili, au Costa Rica, en France et en Slovénie et est identique quel que soit le niveau d'enseignement où ils sont en poste en Angleterre (Royaume-Uni), en Colombie, en Écosse (Royaume-Uni), en Grèce, en Pologne, au Portugal et en Turquie (voir le tableau D3.1a).

En Israël toutefois, le salaire des enseignants est plus élevé de $5 \%$ environ au moins dans l'enseignement préprimaire que dans le deuxième cycle de l'enseignement secondaire. Cette différence s'explique par la réforme « Nouvel Horizon » lancée en 2008 et pratiquement achevée en 2014 qui a entraîné l'augmentation du salaire des enseignants en poste dans l'enseignement préprimaire, l'enseignement primaire et le premier cycle de l'enseignement secondaire. Une autre réforme, lancée en 2012 et actuellement mise en œuvre, vise à augmenter le salaire des enseignants dans le deuxième cycle de l'enseignement secondaire.

\section{Selon le niveau de qualification}

Les qualifications minimales requises pour enseigner à un niveau d'enseignement donné dans le système scolaire public renvoient à la formation minimale à suivre et à sa durée minimale (selon les règlements officiels) pour commencer à enseigner. Les qualifications « les plus courantes » désignent le niveau de qualification et de formation qui caractérise le pourcentage le plus élevé d'enseignants. Elles peuvent être définies dans un niveau d'enseignement donné ou à un stade particulier de la carrière des enseignants (voir la description des niveaux de qualification à l'annexe 3).

Le niveau minimal de qualification exigé peut varier entre les niveaux d'enseignement selon les pays. Le niveau de formation exigé des enseignants est plus élevé (master ou diplôme équivalent) dans la filière générale du premier ou du deuxième cycle de l'enseignement secondaire que dans l'enseignement primaire en Autriche, au 
Danemark, en Espagne, en Hongrie, au Luxembourg, en Pologne et en Suisse. Cette exigence explique en partie le salaire plus élevé à ces niveaux d'enseignement dans ces pays.

Les différences de salaire entre les enseignants selon qu'ils ont les qualifications minimales ou les plus courantes sont loin d'être la règle : dans les pays où un pourcentage élevé des enseignants ont les qualifications minimales, celles-ci sont aussi les plus courantes. Dans trois quarts environ des pays et économies dont les données sont disponibles (voire dans un plus grand nombre de pays selon le niveau d'enseignement visé), les qualifications minimales requises pour commencer à enseigner sont aussi les qualifications les plus courantes au niveau d'enseignement considéré (par voie de conséquence, il n'y a pas de différence de salaire entre les enseignants selon qu'ils ont les qualifications minimales requises ou les qualifications les plus courantes durant leur carrière).

Dans les autres pays et économies, les qualifications les plus courantes des enseignants en poste à un niveau d'enseignement donné sont supérieures aux qualifications minimales exigées, ce qui est reconnu dans le système de rémunération. Parmi les 15 pays dont les données sont disponibles, le salaire des enseignants est supérieur de $10 \%$ au moins s'ils ont les qualifications les plus courantes plutôt que les qualifications minimales requises en Colombie (dans l'enseignement préprimaire et l'enseignement primaire), en Communauté flamande de Belgique (dans le deuxième cycle de l'enseignement secondaire), aux États-Unis (dans l'enseignement primaire et dans l'enseignement secondaire), en Norvège (dans le deuxième cycle de l'enseignement secondaire) et en Pologne (dans l'enseignement préprimaire, l'enseignement primaire et le premier cycle de l'enseignement secondaire); c'est le cas également à certains stades de la carrière uniquement au Canada, en Colombie, en Communauté française de Belgique, en Grèce, au Mexique, en Norvège (dans l'enseignement primaire et le premier cycle de l'enseignement secondaire) et en Nouvelle-Zélande. La différence de salaire entre les enseignants selon qu'ils ont les qualifications les plus courantes ou les qualifications minimales requises est supérieure à $75 \%$ au Costa Rica. Toutefois, le salaire des enseignants ayant les qualifications les plus courantes reste inférieur de $20 \%$ au moins à la moyenne de l'OCDE (à tous les stades de la carrière et à tous les niveaux d'enseignement). La prudence est de mise lors de l'interprétation de ces écarts de salaire, car dans certains pays, les enseignants ayant les qualifications minimales requises sont proportionnellement très peu nombreux (voir les tableaux D3.1b et D3.1c, disponibles en ligne).

Les qualifications les plus courantes des enseignants peuvent aussi varier selon leur ancienneté. C'est le cas dans quelques pays (les États-Unis, la Hongrie, l'Irlande, l'Islande, Israël, le Mexique et la Norvège), où la différence peut porter sur un ou plusieurs des quatre stades de la carrière à l'étude (en début de carrière, après 10 ans d'exercice, après 15 ans d'exercice et au sommet de l'échelle barémique). Cela est généralement lié à de récentes réformes du système de rémunération ou des qualifications exigées pour les enseignants. En Irlande par exemple, les modalités de rémunération ont changé pour les enseignants entrés en fonction à partir de 2011. Le salaire des enseignants ayant les qualifications les plus courantes après 10 ans au moins d'exercice concerne les enseignants entrés en fonction avant 2012 (l'écart de salaire varie entre $8 \%$ et $17 \%$ selon les niveaux d'enseignement et les stades de la carrière). En Norvège, les qualifications les plus courantes à l'entrée en fonction dans l'enseignement primaire et le premier cycle de l'enseignement secondaire correspondent aux qualifications minimales ; elles diffèrent des qualifications les plus courantes de tous les enseignants en poste à ces niveaux d'enseignement (voir le tableau D3.1a et le tableau D3.1b, disponible en ligne).

\section{Selon l'ancienneté}

Le régime salarial des enseignants donne la mesure des encouragements financiers qui leur sont accordés à différents stades de leur carrière. La compensation différée, qui incite les travailleurs à rester fidèles à leur employeur, à ne pas abandonner leur profession et à atteindre les objectifs de performance qui leur sont fixés, est également intégrée dans les barèmes salariaux des enseignants. Les indicateurs de l'OCDE sur le salaire des enseignants se limitent à quatre stades des barèmes salariaux : en début de carrière, après 10 ans d'exercice, après 15 ans d'exercice et à l'échelon maximal du barème. Dans certains pays, des qualifications supérieures au niveau minimal requis influent aussi sur les différences de salaire en début de carrière et à l'échelon maximal et peuvent valoir des augmentations de salaire. 
Dans les pays de l'OCDE, le salaire des enseignants progresse au cours de leur carrière (à un niveau donné de qualification), mais à un rythme différent selon les pays. Dans le premier cycle de l'enseignement secondaire, les enseignants ayant les qualifications les plus courantes gagnent en moyenne $30 \%$ et $38 \%$ de plus respectivement après 10 ans et 15 ans d'exercice qu'en début de carrière. En moyenne, ils gagnent en moyenne $67 \%$ de plus à l'échelon maximum du barème (qu'ils atteignent en moyenne après 25 ans d'exercice) qu'en début de carrière. Les enseignants en poste dans le premier cycle de l'enseignement secondaire ne parviennent au sommet de l'échelle barémique qu'après 35 années d'exercice au moins en Corée, en Espagne, en Grèce, en Hongrie, en Israël et en Italie. Par contraste, ils ne doivent enseigner que pendant six à sept ans pour y parvenir en Australie, en Écosse (Royaume-Uni) et en Nouvelle-Zélande (voir le tableau D3.1b et le tableau D3.3a, disponible en ligne).

À côté des barèmes, le nombre d'années d'exercice à cumuler pour atteindre l'échelon maximal donne une idée du rythme de l'évolution de la carrière et des perspectives professionnelles. En règle générale, plus l'écart est grand entre le salaire minimal et le salaire maximal, plus il faut cumuler d'années d'exercice pour atteindre le salaire maximal. En moyenne, les enseignants y parviennent après 6 ou 7 ans seulement en Australie, en Écosse (Royaume-Uni) et en Nouvelle-Zélande, mais le salaire n'est plus élevé que de $33 \%$ à $53 \%$ à l'échelon maximal qu'en début de carrière dans ces pays et économies, contre $66 \%$ en moyenne dans les pays de l'OCDE dont les dont les données sont disponibles pour les salaires en début de carrière et à l'échelon maximal du barème. Certains pays font toutefois figure d'exception. Ainsi, les enseignants ayant les qualifications les plus courantes atteignent le sommet de l'échelle barémique après environ 36 ans d'exercice en Israël et 32 ans en République tchèque, mais le salaire statutaire n'est plus élevé que de $32 \%$ seulement à l'échelon maximal qu'en début de carrière en République tchèque, contre $105 \%$ en Israël (voir le tableau D3.3a, disponible en ligne).

\section{Salaire statutaire par heure d'enseignement}

Comme le nombre d'heures de cours varie sensiblement entre les pays ainsi qu'entre les niveaux d'enseignement, les différences de salaire statutaire peuvent aussi donner lieu à des différences de salaire par heure d'enseignement. Après 15 ans d'exercice, le salaire statutaire par heure d'enseignement des enseignants ayant les qualifications les plus courantes s'établit en moyenne à 56 USD dans l'enseignement primaire, à 65 USD dans le premier cycle de l'enseignement secondaire et à 75 USD dans le deuxième cycle de l'enseignement secondaire (voir le tableau D3.3a, disponible en ligne).

Comme les enseignants en poste dans l'enseignement secondaire donnent moins d'heures de cours que ceux en poste dans l'enseignement primaire, le salaire par heure d'enseignement des premiers est généralement plus élevé que celui des seconds, même dans les pays où les salaires statutaires sont similaires (voir l'indicateur D4). En moyenne, dans les pays de l'OCDE, les enseignants gagnent environ $28 \%$ de plus par heure d'enseignement dans le deuxième cycle de l'enseignement secondaire que dans l'enseignement primaire. Cet écart de rémunération est nul en Écosse (Royaume-Uni), alors que les enseignants gagnent au moins $73 \%$ de plus par heure d'enseignement s'ils sont en poste dans le deuxième cycle de l'enseignement secondaire plutôt que dans l'enseignement primaire au Mexique. Au Costa Rica et en Lituanie, le salaire par heure d'enseignement est plus élevé dans l'enseignement primaire (voir le tableau D3.3a, disponible en ligne).

Toutefois, dans les pays où le salaire statutaire est similaire dans l'enseignement primaire et secondaire, les différences de salaire par heure d'enseignement peuvent se combler si la comparaison porte sur le salaire par heure de travail, car le temps de travail statutaire des enseignants est généralement similaire dans l'enseignement primaire et secondaire (voir l'indicateur D4).

\section{Salaire minimal et maximal des enseignants, selon l'ancienneté et les qualifications}

Les pays qui cherchent à étoffer leur corps enseignant, en particulier ceux où les enseignants sont vieillissants ou ceux dont la population en âge d'être scolarisée augmente, peuvent envisager de proposer des salaires plus attractifs en début de carrière et d'améliorer les perspectives de carrière. Ils doivent toutefois s'employer non 
seulement à recruter des enseignants, mais aussi à retenir les enseignants les plus qualifiés et les plus compétents pour préserver la qualité du corps enseignant.

Dans le premier cycle de l'enseignement secondaire, le salaire statutaire moyen des enseignants ayant les qualifications les plus courantes et 15 ans d'exercice à leur actif est supérieur de $40 \%$ à celui des enseignants ayant les qualifications minimales requises en début de carrière. Le salaire statutaire moyen des enseignants ayant les qualifications maximales au sommet de l'échelle barémique est supérieur de $85 \%$ à celui des enseignants ayant les qualifications minimales requises en début de carrière (voir le graphique D3.2).

\section{Graphique D3.2. Salaire statutaire des enseignants du premier cycle du secondaire à différentes étapes} de leur carrière (2018)

Salaire statutaire annuel des enseignants des établissements publics, en équivalents USD convertis sur la base des PPA

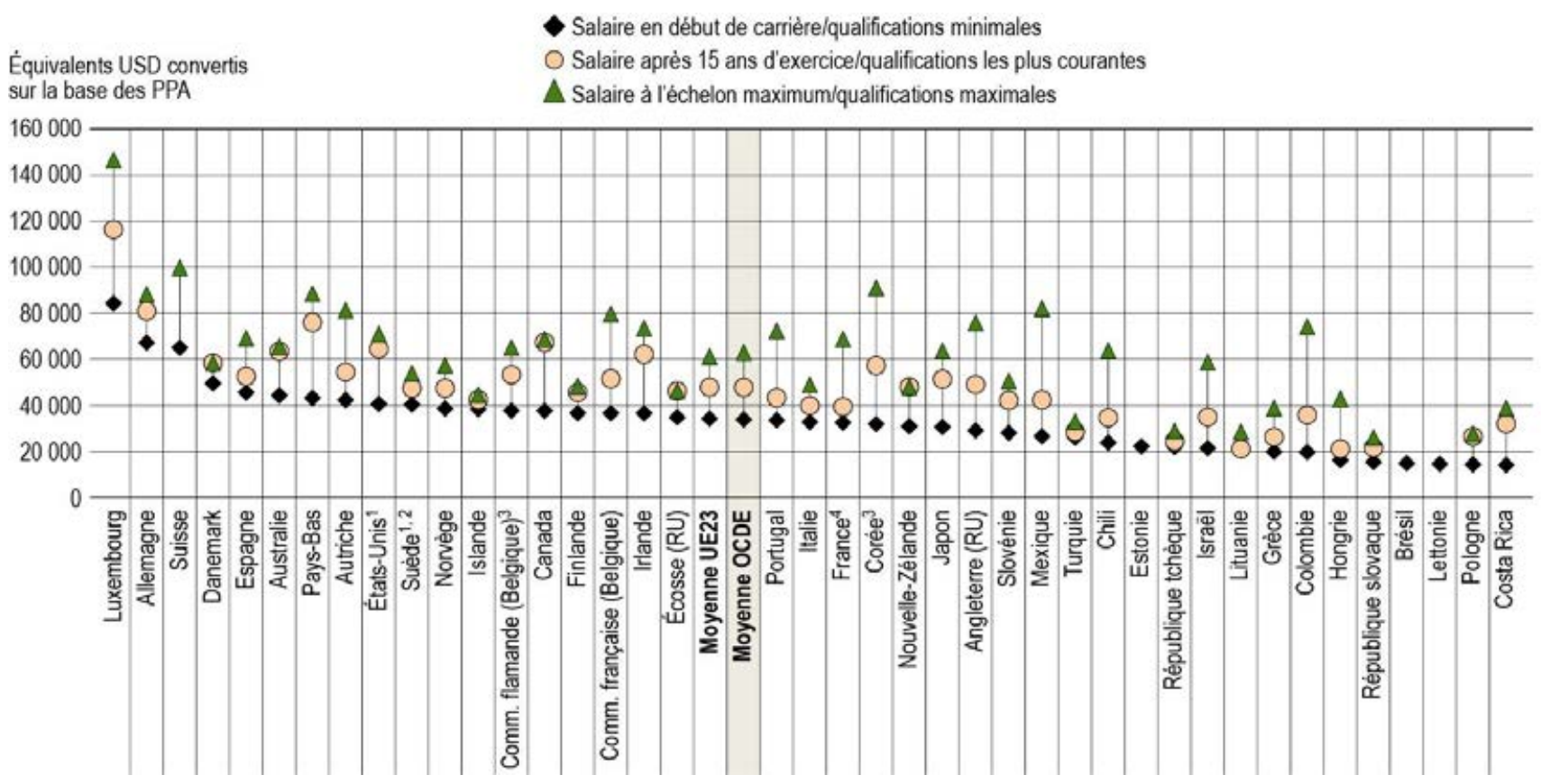

1. Salaire effectif de base.

2. Salaire à l'échelon maximum avec les qualifications minimales, et non les qualifications maximales.

3. Salaire à l'échelon maximum avec les qualifications les plus courantes, et non les qualifications maximales.

4. Inclut la moyenne des primes fixes au titre des heures supplémentaires.

Les pays et économies sont classés par ordre décroissant du salaire en début de carrière des enseignants du premier cycle du secondaire ayant les qualifications minimales.

Source : OCDE (2019), tableau D3.1a, et tableaux D3.1c et D3.6 disponibles en ligne. Consulter la section « Source » pour tout complément d'information et l'annexe 3 pour les notes (https://doi.org/10.1787/f8d7880d-en).

StatLink 가내 https://doi.org/10.1787/888933979956

Concernant l'étendue du barème salarial statuaire, c'est-à-dire l'ampleur de l'écart entre le salaire en début de carrière (avec qualifications minimales) et le salaire à l'échelon maximal (avec qualifications maximales), la plupart des pays et économies où le salaire est inférieur à la moyenne de l'OCDE en début de carrière sont aussi ceux où il est inférieur à la moyenne de l'OCDE à l'échelon maximal. Dans le premier cycle de l'enseignement secondaire, l'Angleterre (Royaume-Uni), la Colombie, la Corée et le Mexique font figure d'exception : le salaire des enseignants est inférieur de $5 \%$ au moins à la moyenne de l'OCDE en début de carrière, mais est supérieur de $18 \%$ à $45 \%$ à l'échelon maximal. Ces écarts pourraient s'expliquer par les différentes carrières disponibles dans ces pays pour les enseignants titulaires de qualifications différentes. L'inverse s'observe au Danemark, en 
Finlande, en Islande, en Norvège et en Suède : le salaire des enseignants est supérieur de $7 \%$ à $45 \%$ à la moyenne de l'OCDE en début de carrière, mais est inférieur de $5 \%$ au moins à la moyenne de l'OCDE à l'échelon maximal (inférieur de $7 \%$ à $29 \%$ ). Cela s'explique par le fait que le salaire progresse relativement peu dans un certain nombre de ces pays (voir les tableaux D3.1c et D3.6, disponibles en ligne).

À défaut de bonnes incitations financières, il risque d'être plus difficile de retenir les enseignants qui approchent du sommet de l'échelle barémique. Toutefois, resserrer l'échelle barémique peut présenter des avantages. Par exemple, dans les organisations où les écarts de salaire entre les membres du personnel sont moins grands, les informations circulent de manière plus fluide, les travailleurs se font davantage confiance et la collégialité est plus grande.

Par contraste, dans le premier cycle de l'enseignement secondaire, le salaire des enseignants ayant les qualifications maximales à l'échelon maximal du barème représente au moins le double de celui des enseignants ayant les qualifications minimales requises en début de carrière en Angleterre (Royaume-Uni), au Chili, en Communauté française de Belgique, en Corée au Costa Rica, en France, en Hongrie, en Irlande, en Israël, au Japon, aux Pays-Bas et au Portugal ; il en représente même plus du triple en Colombie et au Mexique (voir le graphique D3.2).

L'écart de salaire entre les enseignants ayant les qualifications maximales au sommet de l'échelle barémique et ceux ayant les qualifications les plus courantes après 15 ans d'exercice varie aussi entre les pays. Dans le premier cycle de l'enseignement secondaire, l'écart de salaire est inférieur à $10 \%$ dans un quart des pays et économies de l'OCDE, mais supérieur à $60 \%$ au Chili, en Colombie, en France, en Hongrie, en Israël, au Mexique et au Portugal (voir le tableau D3.6, disponible en ligne, et le graphique D3.2).

Lors de l'analyse du salaire en début de carrière (qualifications minimales requises) et à l'échelon maximal (qualifications maximales), il est important de garder plusieurs choses à l'esprit : en premier lieu, les qualifications minimales requises sont les plus courantes dans la majorité des pays ; en deuxième lieu, les enseignants n'atteignent pas tous le sommet de l'échelle barémique ou n'y aspirent pas tous et que les enseignants ayant les qualifications minimales requises ou les qualifications maximales sont peu nombreux dans certains pays (voir le tableau X2.5).

\section{Encadré D3.1. Problèmes de comparabilité relatifs aux données sur le salaire des enseignants et des chefs d'établissement}

Pour être probantes, les comparaisons internationales doivent porter sur des données recueillies dans le respect de définitions rigoureuses et reposer sur une méthodologie statistique sans faille. II n'est pas toujours possible de respecter les directives et la méthodologie ci-dessus à cause des différences dans les systèmes d'éducation et les barèmes de rémunération des enseignants entre les pays. Une certaine prudence s'impose donc lors de l'interprétation des données.

Les données sur le salaire des enseignants selon leur ancienneté sont recueillies en fonction de leur niveau de qualification. Les qualifications minimales et les plus courantes sont utilisées pour distinguer les barèmes salariaux. Le nombre de barèmes salariaux et le pourcentage d'enseignants rémunérés en fonction de ceuxci varient sensiblement entre les pays. Les barèmes salariaux sont nombreux dans certains pays, mais pas dans d'autres (où il n'en existe parfois qu'un seul). Dans les pays fédéraux tels que l'Allemagne, l'Australie, le Canada et les États-Unis, où les barèmes salariaux varient entre les États (parfois même entre les municipalités), les données fournies se rapportent aux barèmes salariaux moyens des entités infranationales (ou les salaires effectifs). Dans ces pays, les données sur les salaires statutaires ne se rapportent donc pas à un effectif particulier d'enseignants. Les données infranationales montrent l'ampleur de la variation entre les barèmes salariaux entre les pays (voir l'encadré D3.2). 
L'existence de divers barèmes salariaux implique parfois qu'un petit nombre d'enseignants sont rémunérés selon le barème correspondant aux qualifications les plus courantes. Par contraste, la qualification minimale est aussi la plus courante dans de nombreux pays, de sorte que les enseignants rémunérés en fonction du barème concerné sont majoritaires. Le nombre de barèmes salariaux tend à être plus élevé chez les chefs d'établissement que chez les enseignants, car plusieurs critères sont pris en compte pour déterminer le niveau de rémunération des chefs d'établissement. En d'autres termes, le salaire applicable à la qualification la plus courante risque d'être moins représentatif dans le corps des chefs d'établissement.

Le salaire des enseignants les plus et les moins qualifiés doit être comparé avec prudence, car les enseignants peuvent être très nombreux dans la catégorie des plus qualifiés ou des moins qualifiés dans certains pays, alors qu'ils sont très peu nombreux dans l'une et l'autre dans d'autres pays. Dans certains pays, le salaire statutaire des chefs d'établissement à l'échelon maximum du barème est théorique. Cet échelon existe, certes, mais il n'y a que très peu, voire pas de chefs d'établissement rémunérés à cet échelon maximum. Les données disponibles ne permettent pas de déterminer comment se répartissent les chefs d'établissement entre l'échelon minimum et l'échelon maximum du barème.

De plus, la répartition des années d'études entre les niveaux d'enseignement varie entre les pays. En Nouvelle-Zélande par exemple, l'enseignement secondaire n'est pas scindé en cycle. Les deux premières années du premier cycle de l'enseignement secondaire font partie de l'enseignement primaire et les deux années suivantes relèvent de l'enseignement secondaire. II s'ensuit que les salaires statutaires présentés par niveau d'enseignement sont parfois des moyennes dans des groupes spécifiques d'enseignants et ne se rapportent pas nécessairement strictement aux niveaux d'enseignement. En Norvège, les salaires comparables dans l'enseignement primaire et secondaire s'expliquent par le fait que les enseignants enseignent souvent aux deux niveaux et que leur salaire dépend davantage de leur niveau de formation que du niveau d'enseignement où ils sont en poste.

Les fonctions des enseignants et des chefs d'établissement et leur système de rémunération varient entre les pays. Les primes accordées aux enseignants en plus de leur salaire permettent de lever un coin du voile sur le sujet. Les enseignants en poste dans le premier cycle de l'enseignement secondaire reçoivent par exemple une prime au titre de l'orientation des élèves dans 13 pays, n'en reçoivent pas dans 18 pays et sont tenus de remplir cette mission sans prime dans 4 pays (en Grèce, en Lettonie, en Slovénie et en Suisse). Les différences de fonctions sont encore plus manifestes chez les chefs d'établissement ; les missions dont ils doivent ou sont censés s'acquitter varient entre les pays. L'importance de leurs responsabilités varie aussi, tout comme la taille de l'établissement qu'ils dirigent.

Pour plus de plus amples informations sur les problèmes de comparabilité, voir les notes spécifiques aux pays à l'annexe 3 .

\section{Évolution des salaires depuis 2000}

Entre 2000 et 2018, le salaire statutaire des enseignants ayant les qualifications les plus courantes (et 15 ans d'exercice à leur actif) a augmenté en valeur réelle dans la plupart des pays dont les données de cette période sont disponibles (sans interruption des séries chronologiques), soit la moitié des pays de l'OCDE. L'Angleterre (Royaume-Uni), la France et la Grèce font vraiment figure d'exception : le salaire des enseignants y a diminué de respectivement $3 \%$, jusqu'à $6 \%$ et $17 \%$. En Italie (dans l'enseignement primaire et secondaire), le salaire effectif a légèrement diminué aussi en valeur réelle (de moins de $2 \%$ ). Le salaire des enseignants en poste dans l'enseignement primaire et secondaire a augmenté de plus de $30 \%$ en Irlande et en Israël. Toutefois, dans certains pays, le salaire a augmenté dans l'ensemble entre 2000 et 2018, mais il a diminué (en valeur réelle) à certains moments, en particulier à partir de 2010 (voir le tableau D3.5a, disponible en ligne).

Entre 2005 et 2018, le salaire statutaire des enseignants ayant les qualifications les plus courantes et 15 ans d'exercice à leur actif a augmenté en valeur réelle dans plus de la moitié des pays à l'étude, à savoir les trois 
quarts des pays et économies de l'OCDE dont les données d'au moins un niveau d'enseignement sont comparables. En moyenne, dans les pays et économies de l'OCDE dont les données des deux années de référence, 2005 et 2018, sont disponibles, le salaire statutaire a augmenté de $10 \%$ dans l'enseignement primaire, de $9 \%$ dans le premier cycle de l'enseignement secondaire et de $6 \%$ dans le deuxième cycle de l'enseignement secondaire. II a augmenté de plus de $20 \%$ en Pologne dans l'enseignement préprimaire, primaire et secondaire (sous l'effet de la mise en œuvre en 2007 d'un programme gouvernemental visant à augmenter le salaire des enseignants progressivement entre 2008 et 2013 et à nouveau à partir de 2017 et à améliorer la qualité de l'enseignement en attirant les meilleurs enseignants par le biais d'incitations financières) ainsi qu'en Israël, au Luxembourg (dans l'enseignement préprimaire et primaire), en Norvège et en Suède.

\section{Graphique D3.3. Évolution du salaire des enseignants des pays de l'OCDE (2005 à 2018)}

Indice moyen de variation, dans les pays de l'OCDE disposant de données sur le salaire statutaire des enseignants pour toutes les années de référence, pour les enseignants ayant 15 ans d'exercice et les qualifications minimales $(2005=100$, prix constants)

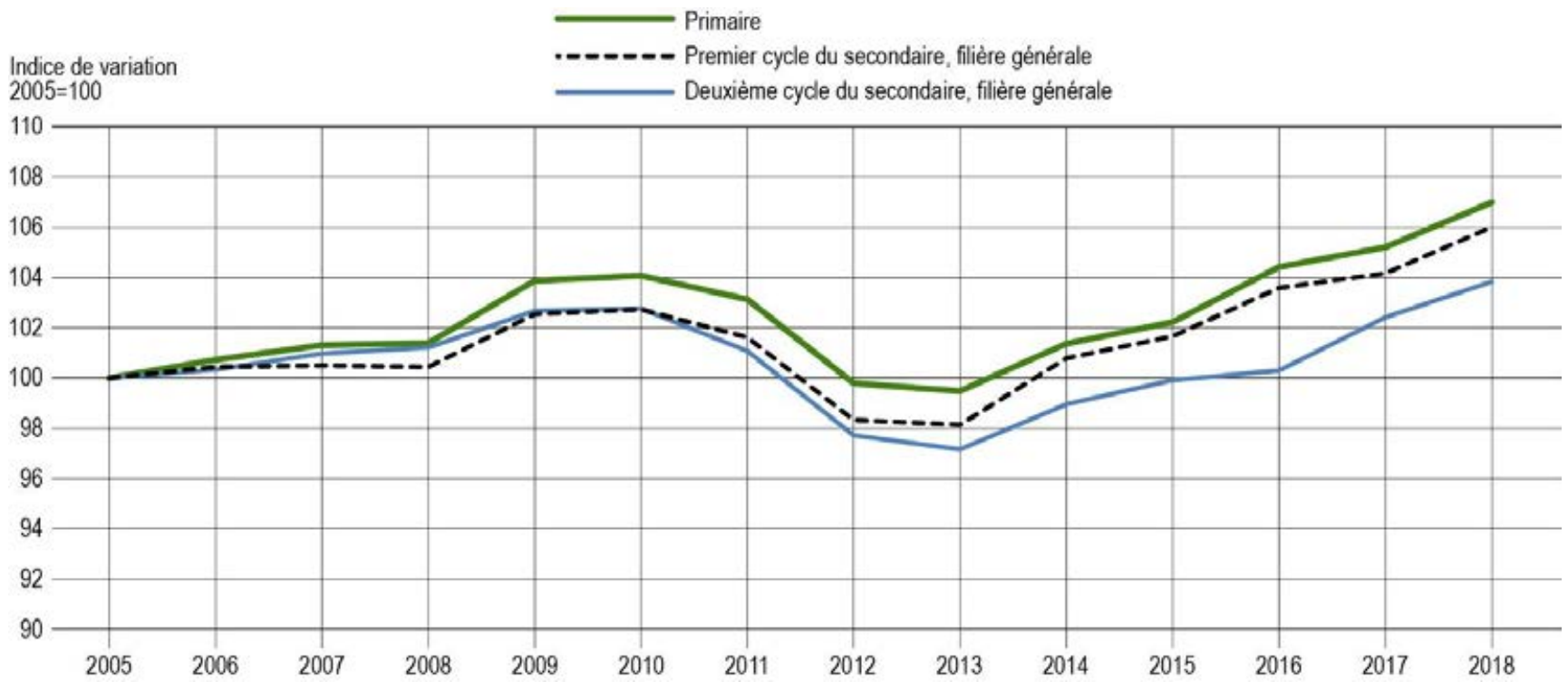

Source : OCDE (2019), tableau D3.5b, disponible en ligne. Consulter la section « Source » pour tout complément d'information et l'annexe 3 pour les notes (https://doi.org/10.1787/f8d7880d-en).

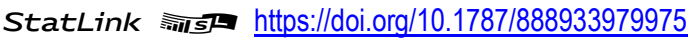

Entre 2005 et 2018, le salaire des enseignants a augmenté dans une mesure similaire dans l'enseignement primaire et le premier et le deuxième cycle de l'enseignement secondaire dans la plupart des pays. Ce n'est cependant pas le cas en Israël, où les salaires ont augmenté de plus de $56 \%$ dans l'enseignement préprimaire, de $40 \%$ dans l'enseignement primaire, de $52 \%$ dans le premier cycle de l'enseignement secondaire et de $50 \%$ dans le deuxième cycle de l'enseignement secondaire. En Israël, cela est dû en grande partie à la mise en œuvre progressive, à compter de 2008, de la réforme « Nouvel Horizon » faisant suite à un accord entre les autorités éducatives et le syndicat israélien des enseignants (dans l'enseignement primaire et le premier cycle de l'enseignement secondaire). Cette réforme prévoit l'augmentation du salaire des enseignants en contrepartie de l'augmentation de leur temps de travail (voir l'indicateur D4).

Par contraste, le salaire a légèrement diminué depuis 2005 dans quelques pays, à savoir au Danemark, en Écosse (Royaume-Uni), en Espagne, en France, en Italie et au Portugal ; il a diminué de $10 \%$ en Angleterre (Royaume-Uni) et au Japon et de plus de $25 \%$ en Grèce (à cause de la réduction des rémunérations, la mise en œuvre de nouvelles grilles salariales et du gel des salaires instauré en 2011) (voir le tableau D3.5a). 
Toutefois, cette variation globale du salaire des enseignants entre 2005 et 2018 occulte diverses variations ponctuelles sous l'effet de la crise économique qui a éclaté en 2008. En moyenne, dans les pays et économies de l'OCDE dont les données de toutes les années de la période à l'étude sont disponibles, le salaire a été soit gelé, soit réduit entre 2009 et 2013 avant de recommencer à augmenter (voir le graphique D3.3). En moyenne, dans les pays de l'OCDE disposant de données pour toutes les années de référence, le salaire statutaire des enseignants ayant les qualifications minimales qui sont en poste dans l'enseignement primaire et le premier et deuxième cycle de l'enseignement secondaire est supérieur à leur salaire d'avant la crise.

\section{Salaire statutaire des chefs d'établissement}

Les responsabilités des chefs d'établissement varient entre les pays et au sein même de ceux-ci, selon l'établissement qu'ils dirigent. Les chefs d'établissement peuvent avoir des responsabilités pédagogiques (une charge d'enseignement ainsi que la responsabilité du bon fonctionnement général de leur établissement, notamment les horaires, le respect des programmes et le choix du contenu des cours et du matériel et des méthodes pédagogiques). Ils peuvent aussi assumer des responsabilités administratives et financières et se charger de la gestion des ressources humaines.

Les différences dans la nature du travail des chefs d'établissements se reflètent dans le système de rémunération des pays. Les chefs d'établissement peuvent être rémunérés en fonction d'un barème spécifique et peuvent percevoir ou non une prime de chef d'établissement en plus de leur salaire statutaire. Toutefois, ils peuvent aussi être rémunérés en fonction du barème des enseignants ou de l'un de leurs barèmes et percevoir une prime de chef d'établissement. L'utilisation des barèmes des enseignants peut refléter le fait qu'initialement, les chefs d'établissement sont des enseignants ayant des responsabilités supplémentaires. Dans le premier cycle de l'enseignement secondaire, parmi les 33 pays dont les données sont disponibles, les chefs d'établissement sont rémunérés en fonction du barème des enseignants et perçoivent une prime de chef d'établissement dans 13 pays et en fonction d'un barème spécifique dans les autres pays, dont dans 12 pays sans percevoir de prime de chef d'établissement et dans 8 pays en en percevant une. La rémunération des chefs d'établissement (leur salaire statutaire et leur éventuelle prime de chef d'établissement) peut varier selon le type de leur(s) établissement(s), de l'endroit où il(s) se situe(nt) et de ses ou de leurs caractéristiques (importance de l'effectif scolarisé, nombre d'enseignants supervisés, etc.) ainsi que selon les spécificités des chefs d'établissement, notamment les fonctions à remplir, leur ancienneté (voir le tableau D3.9, disponible en ligne).

Comme le salaire statutaire des chefs d'établissement varie en fonction d'un grand nombre de critères, cet indicateur analyse leur salaire statutaire au niveau minimal de qualification exigé pour exercer leurs fonctions et le tableau D3.10 indique uniquement le salaire à l'échelon minimal et maximal. La prudence est de mise lors de l'interprétation de ces valeurs car les salaires dépendent souvent de nombreux critères et, par conséquent, peu de chefs d'établissement perçoivent effectivement ces montants.

Dans le premier cycle de l'enseignement secondaire, le salaire minimal s'établit en moyenne à 49629 USD dans les pays de l'OCDE et va de 19184 USD en Lettonie à 116560 USD au Luxembourg, et le salaire maximal s'établit en moyenne à 85700 USD dans les pays de l'OCDE et va de 29715 USD en République tchèque à 161200 USD au Luxembourg. La prudence est de rigueur lors de l'interprétation de ces chiffres, car le salaire minimal et le salaire maximal peuvent correspondre à des types différents d'établissements. Dans la moitié environ des pays de l'OCDE, les barèmes des chefs d'établissement sont similaires dans l'enseignement primaire et le premier cycle de l'enseignement secondaire, tandis que dans l'ensemble, leur salaire statutaire est plus élevé dans le deuxième cycle de l'enseignement secondaire.

En moyenne, dans les pays et économies de l'OCDE, le salaire statutaire maximal des chefs d'établissement ayant les qualifications minimales exigées est supérieur de $80 \%$ au salaire statutaire minimal dans l'enseignement primaire, de $77 \%$ dans le premier cycle de l'enseignement secondaire et de $74 \%$ dans le deuxième cycle de l'enseignement secondaire. Les chefs d'établissement au sommet de l'échelle barémique perçoivent le double de leur salaire statutaire à leur entrée en fonction dans au moins un de ces niveaux d'enseignement dans douze pays seulement ; ils en perçoivent plus que le triple au Costa Rica. 


\section{Graphique D3.4. Salaires statutaires minimum et maximum des enseignants et des chefs d'établissement du premier cycle du secondaire (2018)}

Calculs fondés sur les enseignants ayant les qualifications les plus courantes dans un niveau d'enseignement donné et les chefs d'établissement ayant les qualifications minimales

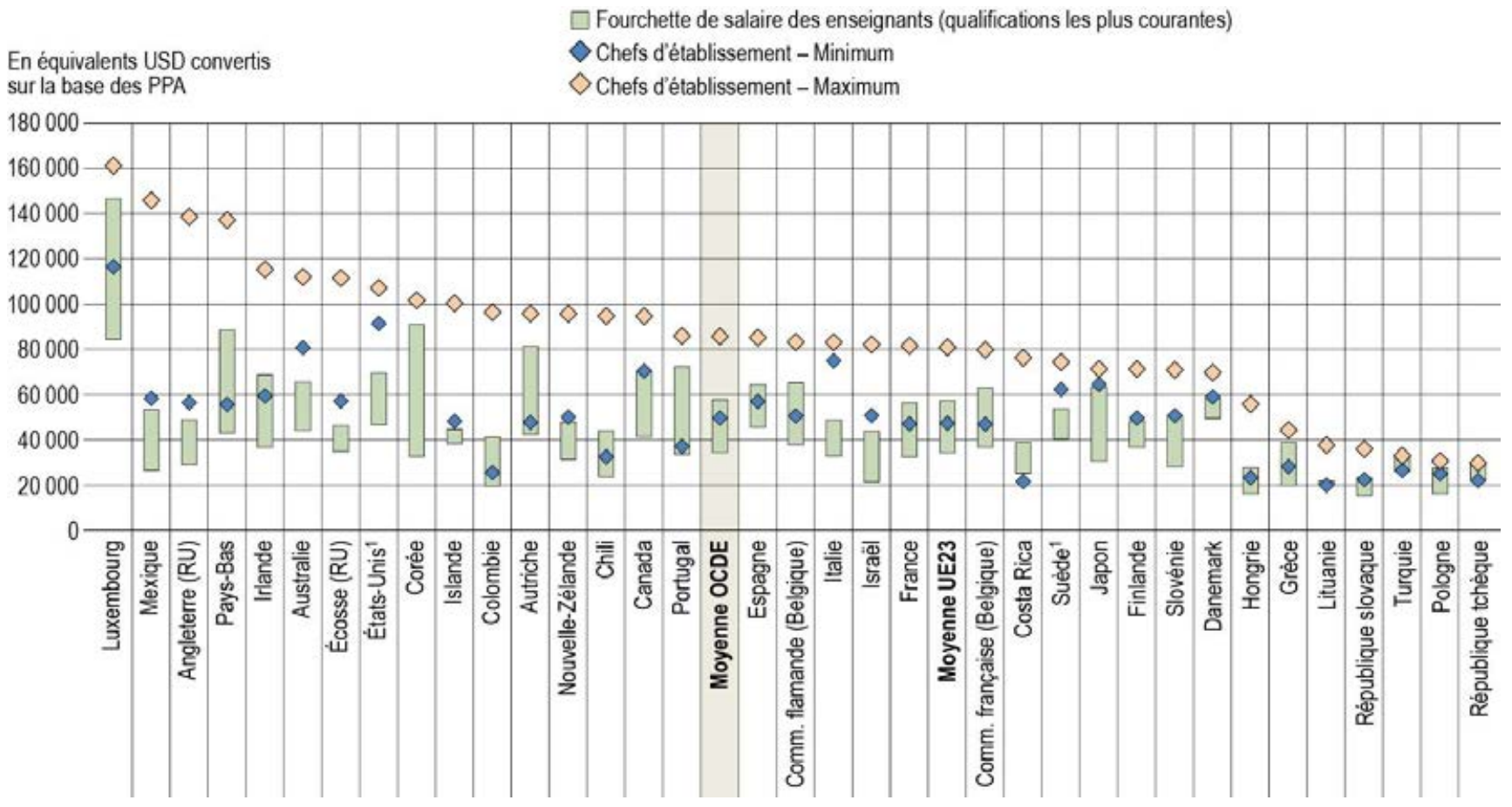

1. Salaire effectif de base.

Les pays et économies sont classés par ordre décroissant du salaire maximum des chefs d'établissement.

Source : OCDE (2019), tableau D3.1b disponible en ligne et tableau D3.10. Consulter la section « Source » pour tout complément d'information et l'annexe 3 pour les notes (https://doi.org/10.1787/f8d7880d-en).

Le salaire statutaire minimal des chefs d'établissement ayant les qualifications minimales requises est supérieur au salaire des enseignants en début de carrière sauf au Costa Rica et en Lituanie (enseignement primaire et secondaire). La différence entre le salaire minimal des chefs d'établissement (ayant les qualifications minimales requises) et le salaire des enseignants (ayant les qualifications les plus courantes) en début de carrière augmente avec le niveau d'enseignement : elle représente en moyenne $23 \%$ dans l'enseignement préprimaire, $33 \%$ dans l'enseignement primaire, $44 \%$ dans le premier cycle de l'enseignement secondaire et $45 \%$ dans le deuxième cycle de l'enseignement secondaire dans les pays et économies de l'OCDE. Dans quelques pays, le salaire statutaire minimal des chefs d'établissement est même supérieur au salaire maximal des enseignants. C'est le cas dans le premier cycle de l'enseignement secondaire en Angleterre (Royaume-Uni), en Australie, au Canada, au Danemark, en Écosse (Royaume-Uni), aux États-Unis, en Finlande, en Islande, en Israël, en Italie, au Japon, au Mexique, en Nouvelle-Zélande et en Slovénie (voir le graphique D3.4).

De même, le salaire statutaire maximal des chefs d'établissement est plus élevé que celui des enseignants dans tous les pays et économies de l'OCDE dont les données sont disponibles. Dans le premier cycle de l'enseignement secondaire, le salaire statutaire maximal des chefs d'établissement est supérieur de $48 \%$ en moyenne au salaire des enseignants (ayant les qualifications les plus courantes) au sommet de l'échelle barémique dans les pays et économies de l'OCDE. Toutefois, le salaire maximal des chefs d'établissement représente plus du double du salaire statutaire des enseignants au sommet de l'échelle barémique en Angleterre 
(Royaume-Uni), au Chili, en Colombie, en Écosse (Royaume-Uni), en Hongrie, en Islande et au Mexique (voir le graphique D3.4).

\section{Salaire effectif moyen des enseignants et des chefs d'établissement}

Contrairement au salaire statutaire, le salaire effectif des enseignants et des chefs d'établissement peut comprendre des avantages financiers tels que les primes annuelles, les primes au titre des résultats, ainsi que les montants versés pendant les vacances, les congés de maladie et d'autres avantages salariaux (voir la section «Définitions » à la fin de cet indicateur). Ces primes et avantages peuvent représenter un complément considérable au salaire de base. Le salaire effectif moyen est influencé par la mesure dans laquelle le système de rémunération prévoit le versement de primes et d'allocations, en plus d'autres facteurs tels que l'ancienneté ou le niveau de qualification. Les différences entre le salaire statutaire et le salaire effectif moyen sont également liées à la répartition des enseignants par ancienneté et niveau de qualification, ces deux facteurs ayant une incidence sur le niveau de salaire des enseignants.

\section{Graphique D3.5. Salaire effectif des enseignants et des chefs d'établissement du premier cycle du secondaire (2017)}

Salaire effectif annuel des enseignants et des chefs d'établissements dans le réseau public, en équivalents USD convertis sur la base des PPA

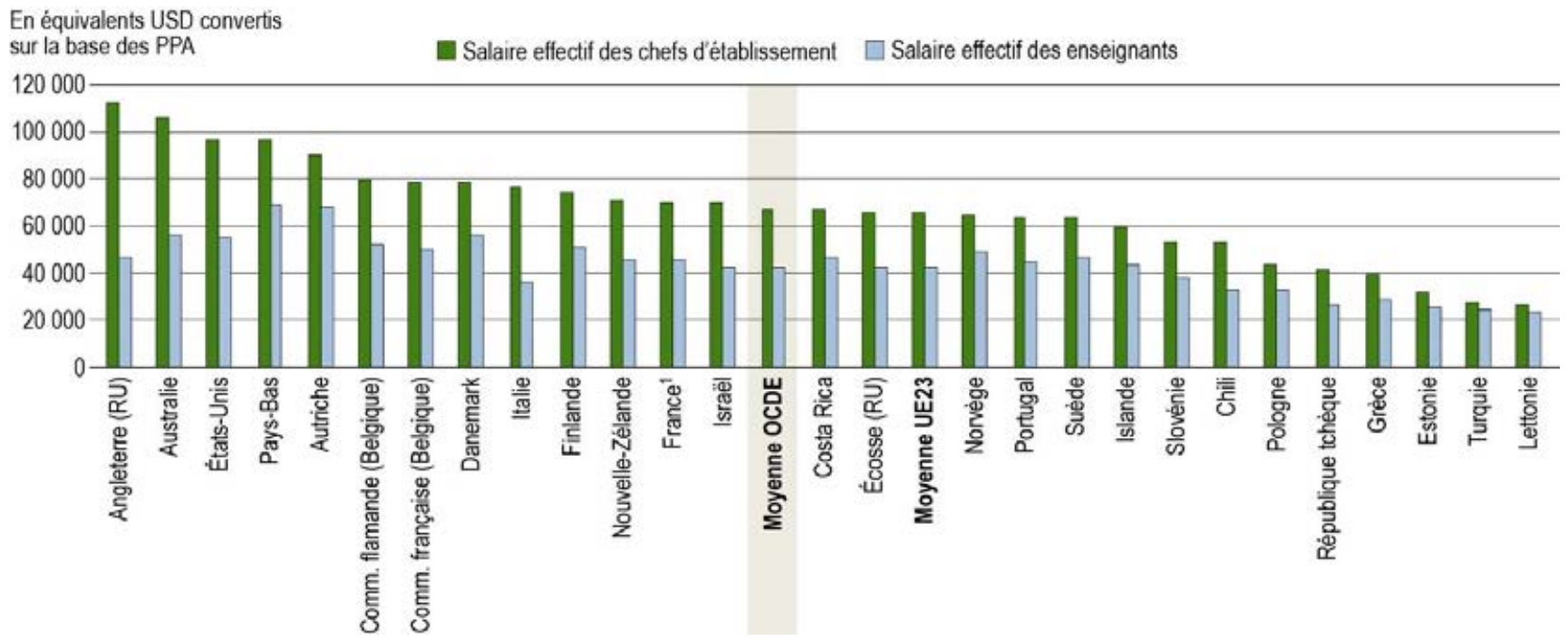

1. L'année de référence n'est pas 2017. Consulter le tableau D3.4 pour de plus amples informations.

Les pays et économies sont classés par ordre décroissant du salaire effectif des chefs d'établissement.

Source: OCDE (2019), tableau D3.4. Consulter la section «Source» pour tout complément d'information et l'annexe 3 pour les notes (https://doi.org/10.1787/f8d7880d-en).

StatLink 제내 https://doi.org/10.1787/888933980013

Dans les pays et économies de l'OCDE, le salaire effectif des enseignants âgés de 25 à 64 ans s'élève en moyenne à 36247 USD dans l'enseignement préprimaire, à 40580 USD dans l'enseignement primaire, à 42553 USD dans le premier cycle de l'enseignement secondaire et à 45803 USD dans le deuxième cycle de l'enseignement secondaire. Le salaire effectif des chefs d'établissement âgés de 25 à 64 ans s'élève en moyenne à 61791 USD dans l'enseignement primaire, à 66534 USD dans le premier cycle de l'enseignement secondaire et à 72081 USD dans le deuxième cycle de l'enseignement secondaire (voir le tableau D3.4) (voir la variation internationale dans l'encadré D3.2). 
Parmi les 28 pays et économies de l'OCDE dont les données sont disponibles dans au moins un niveau d'enseignement à la fois sur le salaire statutaire des enseignants ayant les qualifications les plus courantes et 15 ans d'exercice à leur actif et le salaire effectif des enseignants âgés de 25 à 64 ans, le salaire effectif est supérieur de $10 \%$ au salaire statutaire dans un sixième des pays dans l'enseignement préprimaire et dans un tiers des pays dans le deuxième cycle de l'enseignement secondaire.

Le salaire effectif des chefs d'établissement est plus élevé que celui des enseignants et la rémunération augmente avec le niveau d'enseignement. En moyenne, dans les pays et économies de l'OCDE, le salaire effectif des chefs d'établissement est supérieur de $52 \%$ à celui des enseignants dans l'enseignement primaire. La rémunération s'établit à $56 \%$ dans le premier cycle de l'enseignement secondaire et à $57 \%$ dans le deuxième cycle de l'enseignement secondaire. La différence de salaire effectif entre les chefs d'établissement et les enseignants varie fortement entre les pays et les niveaux d'enseignement. Les pays et les économies où la rémunération des chefs d'établissement est la plus élevée par comparaison avec les enseignants sont l'Angleterre (Royaume-Uni) (dans l'enseignement secondaire) et en Italie (dans l'enseignement primaire et secondaire), où les chefs d'établissement gagnent deux fois plus que les enseignants. Leur rémunération est la moins élevée par comparaison avec les enseignants, moins de $25 \%$ de plus, en Estonie (dans l'enseignement primaire et secondaire), en Finlande (dans l'enseignement préprimaire), en Lettonie (dans le premier cycle de l'enseignement primaire), en Norvège (dans l'enseignement préprimaire) et en Turquie. Dans d'autres pays, le salaire des chefs d'établissement est nettement plus élevé que celui des enseignants dans l'enseignement secondaire, tandis que la différence est plus modérée dans l'enseignement primaire. Au Danemark par exemple, le salaire effectif des chefs d'établissement est supérieur de $28 \%$ à celui des enseignants dans l'enseignement préprimaire, mais il y est supérieur de $40 \%$ dans le premier cycle de l'enseignement secondaire et de $59 \%$ dans le deuxième cycle de l'enseignement secondaire. En Lettonie, la différence entre les deux fonctions est nettement plus importante dans l'enseignement préprimaire et primaire que dans le premier et le deuxième cycle de l'enseignement secondaire (voir le tableau D3.4).

\section{Encadré D3.2. Variation infranationale du salaire des enseignants dans l'enseignement préprimaire, primaire et secondaire}

Les salaires statutaires des enseignants varient parfois en fonction du niveau d'enseignement et de l'ancienneté. Ils varient parfois aussi sensiblement entre les entités infranationales des pays, en particulier dans les pays fédéraux où les normes salariales sont définies à l'échelle infranationale. Cette variation est décrite dans quatre pays (la Belgique, le Canada, les États-Unis et le Royaume-Uni) dont les données infranationales sont disponibles.

Dans ces quatre pays, les salaires statutaires varient dans une mesure différente entre les entités infranationales en fonction de l'ancienneté des enseignants. Selon les chiffres de 2018 , le salaire des enseignants belges en poste dans l'enseignement primaire en début de carrière varie de $3 \%$ seulement (1 101 USD) : il s'élève à 36589 USD en Communauté française et à 37690 USD en Communauté flamande. À titre de comparaison, c'est au Canada que le salaire des enseignants en poste dans l'enseignement primaire en début de carrière varie le plus entre les entités infranationales : $80 \%$ (25 710 USD); il est compris entre 32279 USD au Québec et 57989 USD dans les Territoires du Nord-Ouest. Des tendances similaires s'observent au sujet du salaire des enseignants débutants dans le premier et le deuxième cycle de l'enseignement secondaire.

En Belgique, les différences de salaire statutaire entre les entités infranationales restent relativement uniformes à tous les niveaux d'enseignement et aux divers stades de la carrière des enseignants. Au Canada et au Royaume-Uni en revanche, les différences de salaire entre les entités infranationales sont plus importantes en début de carrière qu'à l'échelon maximum du barème. Au Royaume-Uni par exemple, le salaire dans le deuxième cycle de l'enseignement secondaire varie de $23 \%$ (6 583 USD) entre les entités 
infranationales en début de carrière, où il est compris entre 28186 USD et 34769 USD, mais de $6 \%$ (2 728 USD) à l'échelon maximal du barème, où il est compris entre 46227 USD et 48956 USD. Aux ÉtatsUnis, aucune tendance nette ne se dégage au sujet de la variation du salaire statutaire entre les entités infranationales selon les différents niveaux d'enseignement et stades de la carrière. Dans le premier cycle de l'enseignement secondaire, le salaire varie le moins en début de carrière, où il est compris entre 34243 USD et 59927 USD (soit une différence de $75 \%$ [25 684 USD]) et le plus à l'échelon maximal du barème, où il est compris entre 54081 USD et 110661 USD (soit une différence de $105 \%$ [56 580 USD]).

Le salaire effectif des enseignants et des chefs d'établissement varie sensiblement aussi entre les entités infranationales dans trois pays (en Belgique, aux États-Unis et au Royaume-Uni) dont les données de 2017 sont disponibles. Aux États-Unis et au Royaume-Uni, le salaire effectif varie nettement plus entre les entités infranationales chez les chefs d'établissement que chez les enseignants. Au Royaume-Uni, le salaire des enseignants en poste dans le deuxième cycle de l'enseignement secondaire est compris (dans les entités infranationales dont les données sont disponibles) entre 42474 USD en Écosse et 51307 USD en Irlande du Nord, soit une différence de $21 \%$ (8 832 USD). Par comparaison, le salaire des chefs d'établissement est compris entre 66023 USD en Écosse et 111801 USD en Angleterre, soit une différence de $69 \%$ (45 778 USD). Le salaire effectif des enseignants et des chefs d'établissement varie nettement moins entre les entités infranationales en Belgique. Le salaire des chefs d'établissement en poste dans le deuxième cycle de l'enseignement secondaire est compris entre 92707 USD en Communauté française et 94989 USD en Communauté flamande, soit une différence de 2 \% (2 283 USD).

La mesure dans laquelle le salaire effectif (des enseignants et des chefs d'établissement) varie entre les entités infranationales diffère aussi selon le niveau d'enseignement. Au Royaume-Uni (dans les entités infranationales dont les données sont disponibles), le salaire effectif des enseignants et des chefs d'établissement varie davantage entre les entités infranationales dans le premier et le deuxième cycle de l'enseignement secondaire que dans l'enseignement primaire. Aux États-Unis, le salaire effectif varie le plus entre les entités infranationales dans l'enseignement primaire chez les enseignants, mais dans le deuxième cycle de l'enseignement secondaire chez les chefs d'établissement.

Source : Base de données de Regards sur l'éducation, http://stats.oecd.org.

\section{Différences de salaire effectif entre les enseignants et les chefs d'établissement et les actifs occupés diplômés de l'enseignement tertiaire}

En matière de recrutement de profils hautement qualifiés, les systèmes d'éducation sont en concurrence avec d'autres secteurs d'activité. Selon une étude, le salaire et les débouchés influent considérablement sur l'attractivité de la profession d'enseignant (Johnes et Johnes, 2004[2]). Le salaire des enseignants par rapport à celui d'autres professions (requérant un niveau de formation similaire) et l'augmentation probable de la rémunération ont énormément d'influence sur la décision des diplômés de devenir enseignants et de le rester. Les perspectives professionnelles des chefs d'établissement et leur salaire relatif donnent aussi des indices sur les carrières qui s'offrent aux enseignants et sur la rémunération à laquelle ils peuvent s'attendre à plus long terme.

Dans la plupart des pays de l'OCDE, il faut un diplôme de l'enseignement tertiaire pour devenir enseignant, puis chef d'établissement à tous les niveaux d'enseignement ; en d'autres termes, l'alternative probable à la formation d'enseignant est une autre formation tertiaire. Pour comparer les niveaux de salaire et la situation sur le marché du travail entre les pays, le salaire effectif est donc rapporté à la rémunération des autres diplômés de l'enseignement tertiaire, en l'occurrence les diplômés du niveau 5, 6, 7 ou 8 de la CITE âgés de 25 à 64 ans qui travaillent à temps plein toute l'année (voir les données par groupe d'âge et par sexe dans l'encadré D3.3). Par ailleurs, pour garantir que la comparaison entre les pays n'est pas faussée par des différences de pourcentage de diplômés de l'enseignement tertiaire entre le corps enseignant et les autres professions, le salaire effectif des 
enseignants est rapporté à la moyenne pondérée de la rémunération des actifs occupés diplômés de l'enseignement tertiaire (la rémunération de ceux-ci est pondérée en fonction du pourcentage d'enseignants diplômés de l'enseignement tertiaire) (voir la répartition des enseignants et des chefs d'établissement entre les niveaux de formation dans les tableaux X2.11a et X2.11b à l'annexe 2).

\section{Encadré D3.3. Comparaison du salaire des enseignants et des actifs occupés à niveau égal de formation}

Les différences de salaire effectif entre les enseignants et les enseignantes sont minimes : elles sont favorables aux hommes et inférieures ou égales à $3 \%$ en moyenne dans l'enseignement primaire et secondaire. Des différences plus marquées entre les sexes ressortent cependant de la comparaison de la rémunération entre les enseignants et les actifs occupés diplômés de l'enseignement tertiaire dans le groupe d'âge des 25-64 ans. En moyenne, dans les pays et économies de l'OCDE, parmi les hommes âgés de 25 à 64 ans, les enseignants perçoivent un salaire effectif qui représente entre $73 \%$ (dans l'enseignement primaire) et $83 \%$ (dans le deuxième cycle de l'enseignement secondaire) de la rémunération d'autres diplômés de l'enseignement tertiaire travaillant à temps plein toute l'année. Par comparaison avec la rémunération des diplômés de l'enseignement tertiaire, le salaire effectif des enseignantes est supérieur de $31 \%$ à $40 \%$ à celui des enseignants dans l'enseignement préprimaire, primaire et secondaire. Ce ratio plus favorable aux enseignantes montre que par comparaison avec d'autres professions, la profession d'enseignant semble attirer plus les femmes que les hommes, mais il est aussi révélateur de la persistance des inégalités salariales entre les hommes et les femmes sur le marché du travail (voir les tableaux D3.2 et D3.4).

Des données sur la répartition des enseignants par niveau de formation qui sont ventilées par sexe (et par groupe d'âge) ont été recueillies lors d'une enquête en 2018. Elles ont permis de déterminer le salaire effectif des enseignants en pourcentage de la rémunération moyenne pondérée des actifs occupés ayant le même niveau de formation dans un petit nombre de pays. Cette comparaison montre la variation du salaire effectif des enseignants en pourcentage de la rémunération des actifs occupés diplômés de l'enseignement tertiaire par niveau de formation et selon le sexe.

Parmi les cinq pays dont les données sur le premier cycle de l'enseignement secondaire sont disponibles, les ratios pondérés révèlent un impact sur le salaire relatif, ce qui indique que la répartition entre les niveaux de formation ou les niveaux de salaire n'est pas la même chez les enseignants que chez les actifs occupés diplômés de l'enseignement tertiaire. Toutefois, cet impact peut entraîner l'augmentation ou la diminution du salaire relatif. Ces ratios montrent aussi que le salaire varie moins chez les femmes que chez les hommes entre les enseignants et les actifs occupés. Dans les pays à l'étude, les enseignantes en poste dans le premier cycle de l'enseignement secondaire gagnent en moyenne entre $73 \%$ et $121 \%$ de la rémunération des femmes ayant le même niveau de formation. Par contraste, les enseignants en poste dans le premier cycle de l'enseignement secondaire gagnent entre $53 \%$ et $78 \%$ de la rémunération des hommes ayant le même niveau de formation (voir le graphique D3.a).

En moyenne, le salaire effectif est plus élevé de $35 \%$ à $37 \%$ chez les enseignants plus âgés (les 55-64 ans) que chez les enseignants plus jeunes (les 25-34 ans) dans l'enseignement primaire et secondaire, mais la différence de salaire entre les groupes d'âge varie considérablement entre les pays et économies. La différence est inférieure à $20 \%$ à tous les niveaux d'enseignement en Australie, en Lettonie, en Norvège et en Suède, mais égale ou supérieure à $60 \%$ en Autriche, en Grèce, en Israël et au Portugal (voir le tableau D3.4).

La comparaison de la rémunération entre les enseignants et les actifs occupés diplômés de l'enseignement tertiaire montre qu'en dépit de l'accroissement du salaire chez les enseignants plus âgés, la rémunération évolue à un rythme moins soutenu dans ce corps de métier que dans les autres et que la profession 
d'enseignant perd de son attractivité l'âge venant. En moyenne, dans les pays et économies de l'OCDE, l'écart de salaire effectif entre les enseignants et les actifs occupés diplômés de l'enseignement tertiaire est plus élevé - de 10 points de pourcentage environ - chez les 25-34 ans que chez les 55-64 ans. Ce différentiel salarial varie toutefois fortement entre les pays. Au Chili, en Grèce, en Hongrie, en Israël et en Lettonie, les enseignants plus âgés en poste dans l'enseignement préprimaire, primaire et secondaire perçoivent un salaire effectif supérieur à la rémunération des actifs occupés diplômés de l'enseignement tertiaire.

\section{Graphique D3.a. Salaire effectif des enseignants par comparaison avec les revenus des actifs occupés diplômés de l'enseignement tertiaire, selon le sexe (2018)}

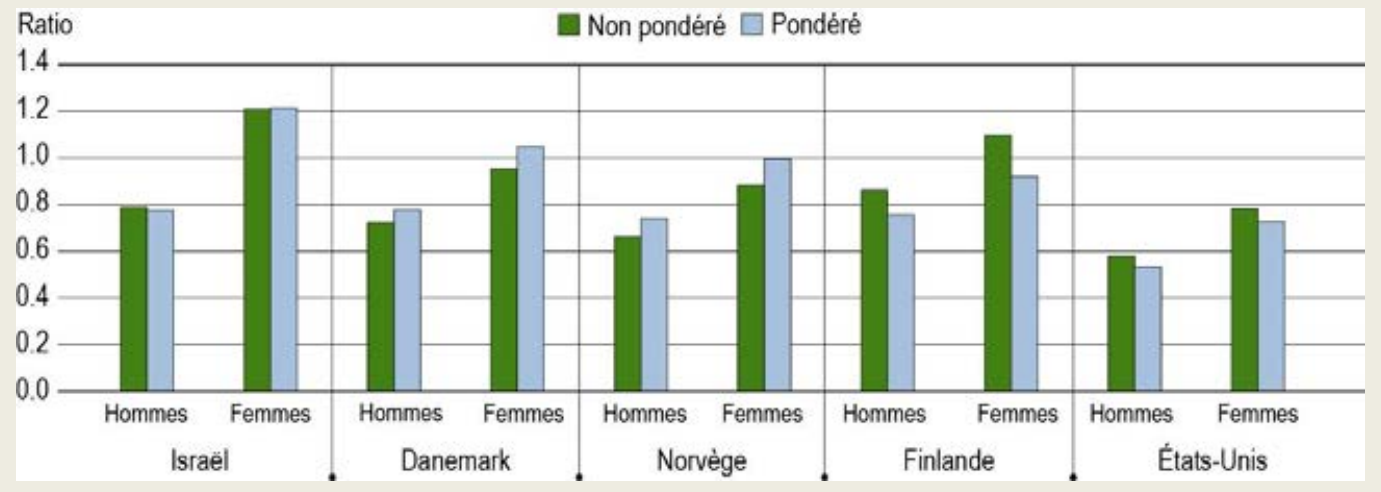

Les pays et économies sont classés par ordre décroissant du salaire relatif pondéré des enseignantes.

Source : OCDE (2019). Consulter la section «Source» pour tout complément d'information et l'annexe 3 pour les notes (https://doi.org/10.1787/f8d7880d-en).

StatLink 제패 https://doi.org/10.1787/888933980032

La comparaison du salaire entre les enseignants et les actifs occupés diplômés de l'enseignement tertiaire peut être biaisée par des différences de niveau de formation ou de salaire entre les deux groupes selon l'âge. Des données sur la répartition des enseignants entre les niveaux de formation par groupe d'âge sont disponibles dans quelques pays. Elles permettent de calculer le salaire relatif des enseignants par groupe d'âge, ce qui neutralise les différences dans la répartition des enseignants et des actifs occupés entre les niveaux de formation. Comme dans la comparaison entre les sexes, cela a un impact sensible sur le salaire relatif des enseignants par groupe d'âge. Cet impact peut entraîner l'augmentation ou la diminution du salaire relatif ; l'ampleur de la variation diffère entre les groupes d'âge. Dans les pays à l'étude, le salaire relatif des enseignants évolue de la même façon dans les groupes d'âge. Chez les jeunes (les 25-34 ans), les enseignants gagnent entre $66 \%$ et $110 \%$ de la rémunération des actifs occupés ayant le même niveau de formation. Chez les plus âgés (les $45-54$ ans), ils gagnent entre $52 \%$ et $89 \%$ de la rémunération des actifs occupés ayant le même niveau de formation.

Parmi les 22 pays et économies dont les données (d'au moins un niveau d'enseignement) sont disponibles, le salaire effectif des enseignants représente moins de $65 \%$ de la rémunération des actifs occupés aussi instruits aux États-Unis et en République tchèque (dans l'enseignement primaire et l'enseignement secondaire). Le salaire effectif des enseignants dépasse la rémunération des actifs occupés aussi instruits dans quelques pays seulement. Le salaire effectif des enseignants est équivalent à celui des actifs occupés aussi instruits en Communauté flamande de Belgique dans l'enseignement préprimaire et l'enseignement primaire et y est supérieur de $15 \%$ dans l'enseignement préprimaire et de 47 à $60 \%$ dans l'enseignement primaire et secondaire en Lettonie (voir le tableau D3.2a).

Comme peu de pays disposent de données sur le salaire relatif des enseignants, un second indicateur compare le salaire effectif de tous les enseignants à la rémunération des autres diplômés de l'enseignement tertiaire 
(niveau 5, 67 ou 8 de la CITE) qui travaillent à temps plein toute l'année (voir la section « Méthodologie »). Selon ce second indicateur, le salaire effectif des enseignants augmente avec le niveau d'enseignement par rapport aux actifs occupés diplômés de l'enseignement tertiaire. Les enseignants en poste dans l'enseignement préprimaire gagnent en moyenne $78 \%$ de la rémunération moyenne des diplômés de l'enseignement tertiaire âgés de 25 à 64 ans qui travaillent à temps plein toute l'année. Les enseignants gagnent $84 \%$ de cette rémunération de référence dans l'enseignement primaire, $88 \%$ dans le premier cycle de l'enseignement secondaire et $93 \%$ dans le deuxième cycle de l'enseignement secondaire (voir le tableau D3.2a).

Dans la quasi-totalité des pays et économies dont les données sont disponibles, le salaire effectif des enseignants est inférieur à la rémunération des actifs occupés diplômés de l'enseignement tertiaire, et ce, à tous les niveaux d'enseignement ou presque. Le salaire relatif des enseignants est le moins élevé dans l'enseignement préprimaire en République slovaque, où les enseignants gagnent $50 \%$ de la rémunération des actifs occupés diplômés de l'enseignement tertiaire, dans l'enseignement primaire aux États-Unis (où ils en gagnent $63 \%$ ) et dans l'enseignement primaire et secondaire en République tchèque (où ils en gagnent entre $64 \%$ et $66 \%$ ). Dans certains pays toutefois, les enseignants gagnent plus que les diplômés de l'enseignement tertiaire à tous les niveaux d'enseignement (au Costa Rica, en Lettonie et au Portugal) ou uniquement à certains niveaux enseignement (dans le deuxième cycle de l'enseignement secondaire en Communautés flamande et française de Belgique et en Finlande et dans le premier et le deuxième cycle de l'enseignement secondaire en Allemagne). En Lettonie et au Portugal, les enseignants gagnent au moins $30 \%$ de plus que les actifs occupés diplômés de l'enseignement tertiaire (voir le tableau D3.2a et le graphique D3.1).

Les chefs d'établissement gagnent plus que les enseignants, mais contrairement à ceux-ci, ils gagnent plus que les actifs occupés tous niveaux d'enseignement confondus. L'écart salarial tend à augmenter avec le niveau d'enseignement. Parmi les 17 pays économies dont les données sont disponibles (au sujet d'un niveau d'enseignement au moins), les chefs d'établissement n'accusent un salaire effectif inférieur en moyenne de $5 \%$ au moins à la rémunération des actifs occupés ayant le même niveau de formation s'ils sont en poste dans l'enseignement préprimaire qu'en Estonie, en Finlande et en Norvège. Par contraste, ils gagnent au moins $40 \%$ de plus que les actifs occupés en Communauté flamande de Belgique (dans l'enseignement préprimaire et primaire et le premier cycle de l'enseignement secondaire), en Angleterre (Royaume-Uni) (dans l'enseignement secondaire), en Lettonie et en Nouvelle-Zélande (dans l'enseignement primaire et secondaire). Les chefs d'établissement en poste dans le deuxième cycle de l'enseignement secondaire gagnent deux fois plus que les actifs occupés ayant le même niveau de formation en Lettonie.

Comme dans le cas des enseignants, les données sur le salaire relatif des chefs d'établissement ne sont disponibles que dans quelques pays. C'est pourquoi un deuxième indicateur rapporte le salaire effectif de tous les chefs d'établissement à la rémunération des diplômés de l'enseignement tertiaire occupés à temps plein toute l'année. En moyenne, dans les pays et économies de l'OCDE, les chefs d'établissement gagnent $25 \%$ de plus que les diplômés de l'enseignement tertiaire dans l'enseignement primaire, $34 \%$ de plus dans le premier cycle de l'enseignement secondaire et $43 \%$ de plus dans le deuxième cycle de l'enseignement secondaire. Les chefs d'établissement ne gagnent moins que les diplômés de l'enseignement tertiaire qu'au Danemark (dans l'enseignement préprimaire), en Estonie (dans l'enseignement préprimaire), en Finlande (dans l'enseignement préprimaire), en Norvège (dans l'enseignement préprimaire), en République tchèque (dans l'enseignement préprimaire) et en Turquie (dans l'enseignement préprimaire, l'enseignement primaire et le premier cycle de l'enseignement secondaire).

\section{Formation du salaire de base et autres compléments : incitations et allocations}

Le salaire statutaire des enseignants, qui est basé sur des barèmes, n'est qu'une composante de leur rémunération totale. Les systèmes d'éducation accordent aussi aux enseignants et aux chefs d'établissement des compléments, des primes, des incitations et autres. II peut s'agir d'avantages en espèces ou en nature, par exemple la réduction du temps d'enseignement ; les décisions relatives aux critères retenus dans la formation du salaire de base sont prises à des niveaux différents (voir les tableaux D3.8 et D3.12, disponibles en ligne). 
Les critères relatifs à ces avantages varient selon les pays. Dans la grande majorité des pays, les missions principales des enseignants (enseigner, préparer les cours, superviser les élèves et corriger leurs copies, participer aux travaux administratifs, communiquer avec les parents et collaborer avec des collègues) sont rarement prises en considération dans l'octroi de primes ou de compléments de salaire (voir le tableau D3.7, disponible en ligne). Les enseignants peuvent avoir à assumer certaines responsabilités ou à effectuer certaines tâches sans compensation (voir les tâches et responsabilités des enseignants dans l'indicateur D4). Les enseignants qui assument d'autres responsabilités peuvent toutefois souvent prétendre à une compensation sous une forme ou sous une autre.

Dans le premier cycle de l'enseignement secondaire, les enseignants qui participent à des activités relatives à la gestion de leur établissement en plus de leur charge d'enseignement ont droit à une compensation dans deux tiers des pays et économies dont les données sont disponibles.

Il est également courant d'accorder des compléments de salaire, annuels ou ponctuels, aux enseignants qui s'occupent de plus de classes ou qui donnent plus de cours que prévu dans leur contrat de travail à temps plein, qui sont professeurs principaux ou qui s'acquittent de missions spéciales, par exemple celles relatives à la formation des futurs enseignants (voir le tableau D3.7, disponible en ligne).

Des compléments de salaire ponctuels ou annuels ou une augmentation du salaire de base sont également accordés aux enseignants en poste dans le premier cycle de l'enseignement secondaire qui se distinguent par une performance remarquable dans la moitié environ des pays et économies de l'OCDE dont les données sont disponibles. Les enseignants peuvent aussi recevoir des primes s'ils enseignent dans des conditions particulières, par exemple s'ils prennent en charge des élèves ayant des besoins spécifiques d'éducation dans des établissements classiques ou qu'ils sont en poste dans des régions reculées ou dans des quartiers huppés ou défavorisés (voir le tableau D3.7, disponible en ligne).

Des compensations peuvent également être accordées aux chefs d'établissement en fonction de certains critères, mais dans un éventail de tâches et de responsabilités plus restreint que celui des enseignants. Dans le premier cycle de l'enseignement secondaire, quelques pays et économies seulement ne proposent pas de telles compensations aux chefs d'établissement : l'Autriche, la Communauté française de Belgique et le Portugal (voir le tableau D3.11, disponible en ligne).

Près d'un tiers des 31 pays dont les données sont disponibles accordent une compensation aux chefs d'établissement qui font des heures supplémentaires ou qui participent à des tâches de gestion en plus de leurs responsabilités normales de chef d'établissement. Dans la moitié environ des pays, à savoir en Angleterre (Royaume-Uni), en Australie, en Autriche, au Chili, en Communauté française de Belgique, en Corée, en Espagne, en Finlande, en France, en Irlande, en Italie, en Pologne au Portugal, en Slovénie et en Suisse, les enseignants qui assument des responsabilités supplémentaires reçoivent une compensation, contrairement aux chefs d'établissement qui ne peuvent prétendre à aucune compensation (voir le tableau D3.11, disponible en ligne). La compensation reçue par les enseignants qui assument des responsabilités supplémentaires varie entre ces pays. Dans certains pays, comme en Grèce, un certain nombre de ces responsabilités et tâches font partie intégrante de la fonction d'enseignant et de chef d'établissement et ne donnent droit à aucune forme de compensation supplémentaire.

Dans le premier cycle de l'enseignement secondaire, les chefs d'établissement qui se distinguent par une performance remarquable peuvent prétendre à une prime au même titre que les enseignants dans plus d'un tiers des pays et économies dont les données sont disponibles. Toutefois, la performance remarquable vaut une prime aux enseignants, mais pas aux chefs d'établissement en Angleterre (Royaume-Uni), en Autriche, au Chili, en Israël et en Turquie. C'est l'inverse en Colombie, en Espagne et en France, où les chefs d'établissement, mais pas les enseignants, peuvent recevoir une prime s'ils se distinguent par une performance remarquable. En France par exemple, les chefs d'établissement reçoivent tous les trois ans une partie de leur prime en fonction des résultats obtenus lors d'un entretien professionnel (voir les tableaux D3.11 et D3.7, disponibles en ligne). 
Le fait de travailler dans une région défavorisée, reculée ou chère peut valoir un complément de salaire aux enseignants et aux chefs d'établissement dans la moitié des pays; ce n'est pas le cas en Australie, où cette prime est réservée aux enseignants (voir les tableaux D3.11 et D3.7, disponibles en ligne).

\section{Définitions}

Par enseignants, on entend le personnel qualifié impliqué directement dans l'instruction des élèves. Cette catégorie englobe les enseignants, les enseignants dispensant un enseignement spécialisé et ceux qui prennent en charge des élèves constituant une classe entière dans une salle de classe ou des élèves réunis en petits groupes dans une salle spécialisée ou qui donnent des cours particuliers dans une salle de classe ou un autre local.

Par chefs d'établissement, on entend toutes les personnes dont la fonction principale ou majeure est de diriger un établissement d'enseignement ou un groupe d'établissements d'enseignement, seules ou au sein d'un organe administratif tel qu'un conseil de direction. Le chef d'établissement est le responsable principal de la direction, de la gestion et de l'administration d'un établissement d'enseignement.

Par salaire effectif des enseignants et chefs d'établissement âgés de 25 à 64 ans, on entend le salaire annuel moyen, avant impôt, que perçoivent les enseignants et chefs d'établissement âgés de 25 à 64 ans qui travaillent à temps plein. Du point de vue des salariés, il s'agit du salaire brut, car il inclut la part leurs cotisations de sécurité sociale et de retraire (même si elle est déduite automatiquement par l'employeur de leur salaire brut). Les cotisations patronales de sécurité sociale et de retraite ne sont en revanche pas incluses. Sont également inclus dans le salaire effectif les avantages financiers tels que les primes au titre de la fonction de chef d'établissement, les primes annuelles et les primes au titre des résultats ainsi que les montants versés pendant les vacances et les congés de maladie. Les revenus d'autres sources, tels que les prestations sociales, les revenus mobiliers et autres, qui sont sans rapport avec la profession d'enseignant ou de chef d'établissement, ne sont pas inclus.

La rémunération des diplômés de l'enseignement tertiaire correspond à la rémunération annuelle moyenne des diplômés du niveau 5, 6, 7 ou 8 de la CITE âgés de 25 à 64 ans qui travaillent à temps plein toute l'année.

Le salaire maximal correspond au salaire annuel prévu à l'échelon le plus élevé du barème applicable aux enseignants travaillant à temps plein (et ayant un niveau de qualification reconnu dans le système de rémunération).

Le salaire des enseignants après 15 ans d'exercice correspond au salaire annuel prévu des enseignants travaillant à temps plein. Le salaire statutaire correspond au salaire des enseignants ayant 15 ans d'exercice à leur actif dont le niveau de qualification est reconnu par le système de rémunération (qualifications minimales requises pour enseigner, qualifications les plus courantes ou qualifications maximales).

Le salaire des enseignants en début de carrière correspond au salaire annuel moyen brut en début de carrière des enseignants travaillant à temps plein qui ont un niveau de qualification reconnu par le système de rémunération (qualifications minimales requises pour enseigner ou qualifications les plus courantes).

Le salaire statutaire est la rémunération prévue dans les barèmes officiels. Le salaire indiqué est le salaire brut (soit la rémunération versée par l'employeur), hors cotisations patronales de sécurité sociale et de retraite, conformément aux barèmes salariaux en vigueur. Le salaire mentionné est celui dit « avant impôt », c'est-à-dire avant de l'impôt sur le revenu.

\section{Méthodologie}

Les données sur les salaires des enseignants en poste dans le premier et le deuxième cycle de l'enseignement secondaire se rapportent uniquement à la filière générale. 
Les salaires sont convertis sur la base des parités de pouvoir d'achat (PPA) de la consommation privée telles qu'elles figurent dans la Base de données de l'OCDE sur les comptes nationaux. La période de référence du salaire statutaire des enseignants s'étend du $1^{\text {er }}$ juillet 2017 au 30 juin 2018 et celle de leur salaire effectif, du 1er juillet 2016 au 30 juin 2017. Le salaire statutaire est converti sur la base des PPA de 2017/18 et le salaire effectif, sur la base des PPA de 2016/17, sauf dans quelques pays de l'hémisphère Sud (l'Australie et la NouvelleZélande, par exemple) où l'année scolaire va de janvier à décembre. Dans ces pays, l'année de référence est l'année civile (2018 ou 2017). Les tableaux indiquant les salaires en devise nationale figurent à l'annexe 2. Concernant l'évolution des salaires des enseignants présentée dans le tableau D3.5a et le tableau D3.5b (disponible en ligne), les salaires sont convertis aux prix de 2005 au moyen du déflateur de la consommation privée.

Dans la plupart des pays, les qualifications les plus courantes des enseignants sont déterminées sur la base du principe de la majorité absolue (et correspondent aux qualifications du pourcentage le plus élevé d'enseignants).

Dans le tableau $\mathrm{D} 3.2 \mathrm{a}$, les ratios entre le salaire des enseignants et la rémunération des diplômés de l'enseignement tertiaire âgés de 25 à 64 ans qui travaillent à temps plein toute l'année sont calculés sur la base de la rémunération annuelle moyenne pondérée des actifs occupés diplômés de l'enseignement tertiaire (les quatre premières colonnes contiennent des données concernant les enseignants et les quatre dernières concernant les chefs d'établissement). Le coefficient de pondération de chaque pays est déterminé sur la base du pourcentage d'enseignants et de chefs d'établissement diplômés de chaque niveau de l'enseignement tertiaire (voir les tableaux X2.11a et X2.11b à l'annexe 2). Les ratios sont calculés dans les pays dont ces données sont disponibles. La rémunération des actifs occupés qui se rapporte à une année de référence autre que 2017 à laquelle correspond le salaire des enseignants et des chefs d'établissement est ajustée à l'année de référence 2017 à l'aide d'un déflateur. Tous les autres ratios indiqués dans le tableau D3.2a et le tableau D3.2c (disponible en ligne) sont calculés sur la base de tous les actifs occupés diplômés de l'enseignement tertiaire, et non sur la base de moyennes pondérées. La rémunération des actifs occupés correspond à celle de tous les actifs occupés, y compris les enseignants, durant la période de référence. Comme les enseignants représentent une part importante des actifs occupés dans la plupart des pays, leur niveau de salaire peut affecter les revenus du travail moyens des actifs occupés. La même procédure a été utilisée dans le tableau D3.2b (disponible en ligne), mais les ratios ont été calculés sur la base du salaire statutaire des enseignants ayant 15 ans d'exercice à leur actif, et non sur la base de leur salaire effectif.

Voir le Guide de l'OCDE pour l'établissement de statistiques internationalement comparables dans le domaine de l'éducation 2018 (OCDE, 2019 $\left.{ }_{[3]}\right)$ pour de plus amples informations. Voir les notes spécifiques aux pays à l'annexe 3 (https://doi.org/10.1787/f8d7880d-en).

\section{Source}

Les données sur le salaire et les primes des enseignants et des chefs d'établissement proviennent de la collecte de données sur la rémunération des enseignants et des chefs d'établissement menée conjointement par l'OCDE et Eurydice en 2018. Elles se rapportent aux années scolaires 2017/18 (salaire statutaire) et 2016/17 (salaire effectif) et sont présentées dans le respect des politiques officielles appliquées dans les établissements publics. Les données sur la rémunération des actifs occupés proviennent de la collecte de données habituelle du réseau LSO (Labour Market and Social Outcomes of Learning) de l'OCDE, qui est chargé d'élaborer les données relatives aux retombées de l'enseignement sur l'économie, le marché du travail et la société.

\section{Note concernant les données d'Israël}

Les données statistiques concernant Israël sont fournies par et sous la responsabilité des autorités israéliennes compétentes. L'utilisation de ces données par l'OCDE est sans préjudice du statut des hauteurs du Golan, de Jérusalem-Est et des colonies de peuplement israéliennes en Cisjordanie aux termes du droit international. 


\section{Références}

Johnes, G. et J. Johnes (2004), International Handbook on the Economics of Education, Edward Elgar, Cheltenham, UK; Northampton, MA.

OCDE (2019), Guide de l'OCDE pour l'établissement de statistiques internationalement comparables dans le domaine de l'éducation 2018: Concepts, normes, définitions et classifications, Éditions OCDE, Paris, https://dx.doi.org/10.1787/9789264305380-fr.

OCDE (2006), Le rôle crucial des enseignants: Attirer, former et retenir des enseignants de qualité,

Politiques d'éducation et de formation, Éditions OCDE, Paris,

https://dx.doi.org/10.1787/9789264018051-fr.

\section{Tableaux de l'indicateur D3}

Tableau D3.1a

WEB Tableau D3.1b

WEB Tableau D3.1c

Tableau D3.2a

WEB Tableau D3.2b occupés diplômés de l'enseignement tertiaire (2018)

WEB Tableau D3.2c Salaire statutaire des enseignants par comparaison avec les revenus d'autres actifs occupés diplômés de l'enseignement tertiaire, selon le groupe d'âge et le sexe (2017)

WEB Tableau D3.2d Salaire statutaire des chefs d'établissement par comparaison avec les revenus d'autres actifs occupés diplômés de l'enseignement tertiaire (2018)

WEB Tableau D3.3a Comparaison du salaire statutaire des enseignants (sur la base des qualifications les plus courantes) à un niveau d'enseignement donné (2018)

WEB Tableau D3.3b Comparaison du salaire statutaire des enseignants, sur la base des qualifications minimales pour accéder à la profession d'enseignant pendant l'année de référence (2018)

Tableau D3.4

Salaire effectif moyen des enseignants et des chefs d'établissement, selon le groupe d'âge et le sexe (2017)

WEB Tableau D3.5a Évolution du salaire des enseignants entre 2000 et 2018, sur la base des qualifications les plus courantes à différentes étapes de leur carrière

WEB Tableau D3.5b Évolution du salaire des enseignants entre 2000 et 2018, sur la base des qualifications minimales pour accéder à la profession d'enseignant 
WEB Tableau D3.6 Salaire statutaire des enseignants en début de carrière/à l'échelon maximum, sur la base des qualifications minimales/maximales (2018)

WEB Tableau D3.7 Critères utilisés pour le calcul du salaire de base et de toute autre rémunération supplémentaire versés aux enseignants des établissements publics, à tous les niveaux d'enseignement (2018)

WEB Tableau D3.8 Niveau de l'exécutif statuant sur les critères retenus dans la formation du salaire de base et des compléments de salaire versés aux enseignants, selon le niveau d'enseignement (2018)

WEB Tableau D3.9 Structure du système de rémunération des chefs d'établissement (2018)

Tableau D3.10 Salaire statutaire minimum/maximum des chefs d'établissement, sur la base des qualifications minimales (2018)

WEB Tableau D3.11 Critères utilisés pour le calcul du salaire de base et de toute autre rémunération supplémentaire versés aux chefs d'établissement des établissements publics, selon le niveau d'enseignement (2018)

WEB Tableau D3.12 Niveau de l'exécutif statuant sur les critères retenus dans la formation du salaire de base et des compléments de salaire versés aux chefs d'établissement, selon le niveau d'enseignement (2018)

Date butoir pour les données : 19 juillet 2019. Les mises à jour peuvent être consultées en ligne sur: http://dx.doi.org/10.1787/eag-data-en. D'autres données désagrégées sont également disponibles dans la Base de données de Regards sur l'éducation (http://stats.oecd.org/).

StatLink : https://doi.org/10.1787/888933981229 
Tableau D3.1a. Salaire statutaire des enseignants (sur la base des qualifications les plus courantes) à différentes étapes de leur carrière (2018)

Salaire annuel des enseignants des établissements publics, en équivalents USD convertis sur la base des PPA pour la consommation privée

\begin{tabular}{|c|c|c|c|c|c|c|c|c|c|c|c|c|c|c|c|c|}
\hline & \multicolumn{4}{|c|}{ Préprimaire } & \multicolumn{4}{|c|}{ Primaire } & \multicolumn{4}{|c|}{$\begin{array}{l}\text { Premier cycle du secondaire, } \\
\text { filière générale }\end{array}$} & \multicolumn{4}{|c|}{$\begin{array}{l}\text { Deuxième cycle du secondaire, } \\
\text { filière générale }\end{array}$} \\
\hline & 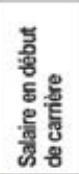 & 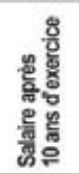 & 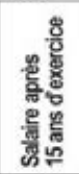 & 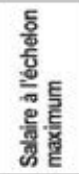 & 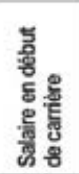 & 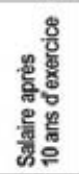 & 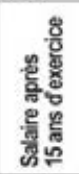 & 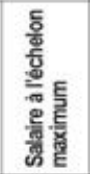 & 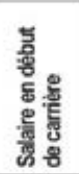 & 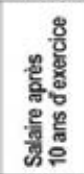 & 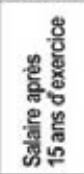 & 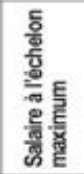 & 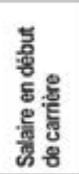 & 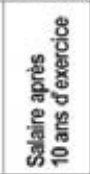 & 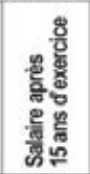 & 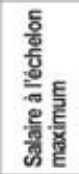 \\
\hline & (1) & (2) & (3) & (4) & (5) & (6) & (7) & (8) & (9) & (10) & (11) & (12) & (13) & (14) & (15) & (16) \\
\hline \multicolumn{17}{|l|}{ W Pays } \\
\hline Oustralie & 44729 & 63277 & 63277 & 65706 & 44287 & $632 \pi 7$ & 63098 & 65421 & 44247 & 63393 & 63393 & 65560 & 44247 & 63393 & 63393 & 65560 \\
\hline Autriche & $\mathrm{m}$ & $\mathrm{m}$ & $\mathrm{m}$ & $\mathrm{m}$ & 42702 & 46582 & 51788 & 76160 & 42277 & 48872 & 54406 & 81311 & 41918 & 52888 & 59626 & 86639 \\
\hline Canada & m & m & m & m & 39937 & 64561 & 67301 & 67301 & 39937 & 64561 & 67301 & 67301 & 39937 & 64561 & 67301 & 67301 \\
\hline Chili & 23747 & 29318 & 34577 & 44107 & 23747 & 29318 & 34577 & 44107 & 23747 & 29318 & 34577 & 44107 & 24555 & 30396 & 35763 & 45723 \\
\hline Colombie & 19624 & 35788 & 35788 & 41156 & 19624 & 35788 & 35788 & 41156 & 19624 & 35788 & 35788 & 41156 & 19624 & 35788 & 35788 & 41156 \\
\hline République tchèque & 20472 & 21250 & 21768 & 24273 & 21854 & 23236 & 24273 & 28678 & 21854 & 23323 & 24359 & 28851 & 21854 & 23323 & 24359 & 28765 \\
\hline Danemark & 44039 & 49675 & 49675 & 49675 & 48989 & 53943 & 57206 & 57206 & 49482 & 54756 & 58349 & 58349 & 46383 & 60278 & 60278 & 60278 \\
\hline Estonie & & & & & 22178 & & & & 22178 & a & & a & 22178 & a & a & \\
\hline Finlande' & 027 & 32651 & 32871 & 32871 & 33916 & 39525 & 42180 & 44711 & 36629 & 42688 & 45555 & 48288 & 38842 & 46966 & 49175 & 52126 \\
\hline France $^{2}$ & 30872 & 35290 & 37700 & 54503 & 30872 & 35290 & 37700 & 54503 & 32492 & 36910 & 39320 & 56283 & 32492 & 36910 & 39320 & 56283 \\
\hline Allemagne & & & & $\mathrm{m}$ & 60507 & 70678 & 74486 & 79355 & 67163 & 77499 & 80993 & 88214 & 70749 & 81584 & 85206 & 96736 \\
\hline Grèce & 19825 & 23638 & 26198 & 38804 & 19825 & 23638 & 26198 & 38804 & 19825 & 23638 & 26198 & 38804 & 19825 & 23638 & 26198 & 38804 \\
\hline Hongrie & 14545 & 19635 & 21090 & 27635 & 14545 & 19635 & 21090 & 27635 & 16161 & 19635 & 21090 & 27635 & 16161 & 21817 & 23433 & 30705 \\
\hline Islande & 37367 & 39324 & 41400 & 41400 & 38336 & 40293 & 42368 & 42368 & 38336 & 40293 & 42368 & 42368 & 37335 & 42029 & 46228 & 48379 \\
\hline Irlande & & & & & 36553 & 55755 & 61534 & 70967 & 36553 & 57748 & 62135 & 71568 & 36553 & 57748 & 62135 & 71568 \\
\hline Israē| & 24352 & 31149 & 35025 & 64096 & 21276 & 28132 & 31532 & 53639 & 21389 & 30099 & 34860 & 56000 & 22629 & 30132 & 33449 & 54969 \\
\hline Italie & 30403 & 33389 & 36604 & 44468 & 30403 & 33389 & 36604 & 44468 & 32725 & 36197 & 39840 & 48833 & 32725 & 37068 & 40952 & 51045 \\
\hline Japon & & & m & $\mathrm{m}$ & 30560 & 43658 & 51339 & 63562 & 30560 & 43658 & 51339 & 63562 & 30560 & 43658 & 51321 & 65238 \\
\hline $\mathrm{Co}_{0}$ & 32485 & 48959 & 57179 & 90911 & 32485 & 48959 & 57179 & 90911 & 32548 & 49021 & 57242 & 90973 & 31799 & 48273 & 56493 & 90225 \\
\hline Lettonie & 14494 & & & & 14494 & a & a & a & 14494 & a & a & a & 14494 & a & a & a \\
\hline Lituanie & 12930 & 13917 & 14236 & 14840 & 20255 & 20511 & 21084 & 21721 & 20255 & 20511 & 21084 & 21721 & 20255 & 20511 & 21084 & 21721 \\
\hline Luxembou & 74400 & 96224 & 108624 & 131440 & 74400 & 96224 & 108624 & 131440 & 84320 & 105400 & 116312 & 146568 & 84320 & 105400 & 116312 & 146568 \\
\hline Mexique & 20851 & 26364 & 33076 & 41693 & 20851 & 26364 & 33076 & 41693 & 26560 & 33598 & 42316 & 53262 & 50775 & 58726 & 62678 & 62678 \\
\hline Pays-Bas & 42133 & 53654 & 63413 & 67147 & 42133 & 53654 & 63413 & 67147 & 43132 & 66101 & 76006 & 88464 & 43132 & 66101 & 76006 & 88464 \\
\hline Nouvelle-Zélande ${ }^{4}$ & & & & & 30890 & 47311 & 47311 & 47311 & 31392 & 47950 & 47950 & 47950 & 31894 & 48589 & 48589 & 48589 \\
\hline Norvège & 34886 & 40645 & 40645 & 42333 & 38559 & 47387 & 47387 & 50883 & 38559 & 47387 & 47387 & 50883 & 46914 & 51838 & 51838 & 57374 \\
\hline Pologne & 16140 & 21639 & 26428 & 27549 & 16140 & 21639 & 26428 & 27549 & 16 & 21639 & 26428 & 27549 & 16 & 21639 & 26428 & 27549 \\
\hline Portugal & 33516 & 40791 & 43279 & 72369 & 33516 & 40791 & 43279 & 72369 & 335 & 40791 & 43279 & 72369 & & 40791 & 43279 & 72369 \\
\hline République slovaques & 13705 & 15084 & 15762 & 16995 & 15339 & 18418 & 21553 & 23242 & 15339 & 18418 & 21553 & 23242 & 15339 & 18418 & 21553 & 23242 \\
\hline Slovén & 28031 & 33333 & 40591 & 46922 & 28031 & 34563 & 42111 & 50539 & 28031 & 34563 & 42111 & 50539 & 28 & 34563 & 42111 & 50539 \\
\hline Espagr & 813 & 44121 & 47107 & 57983 & 40813 & 44121 & 47107 & 57983 & 45 & 49340 & 52506 & 64473 & 45 & 49340 & 52506 & 64473 \\
\hline Suéde & 38489 & 40655 & 41839 & 45315 & 39131 & 44135 & 45636 & 52346 & 40 & 44904 & 47323 & 53885 & & 46508 & 47470 & 54931 \\
\hline Suiss & 54388 & 67921 & & 82663 & 58017 & 72235 & & 88308 & 65010 & 82222 & & 99703 & 73250 & 94095 & $\mathrm{~m}$ & 112286 \\
\hline Turquil & 25955 & 26956 & 28545 & 32953 & 25955 & 26956 & 28545 & 32953 & 25955 & 26956 & 28545 & 32953 & 25955 & 26956 & 28545 & 32953 \\
\hline Etats-Unis ${ }^{6}$. & 39506 & 54044 & 65728 & 72886 & 40067 & 55040 & 62404 & 68712 & 40602 & 55796 & 64467 & 69586 & 41430 & 55840 & 64426 & 72498 \\
\hline \multicolumn{17}{|l|}{ Economies } \\
\hline Comm. flamande (Belgique) & 37690 & 47265 & 53213 & 65110 & 37690 & 47265 & 53213 & 65110 & 0 & 7265 & 3213 & 65110 & 024 & 59935 & 68350 & 82374 \\
\hline Comm. & 36589 & 45752 & 51511 & 63030 & 36589 & 45752 & 51511 & 63030 & 36589 & 45752 & 51511 & 63030 & 45518 & 58020 & 66167 & 79746 \\
\hline Anglet & 29040 & & 48956 & 48956 & 29040 & & 48956 & 48956 & 29040 & & 48956 & 48956 & 29040 & & 48956 & 48956 \\
\hline Ecosse ( $R$ & 34769 & 46227 & 46227 & 46227 & 34769 & 46227 & 46227 & 46227 & 34769 & 46227 & 46227 & 46227 & 34769 & 46227 & 46227 & 46227 \\
\hline Moyent & 276 & 39264 & 42078 & 51484 & 33058 & 42896 & 45947 & 55364 & 34230 & 44784 & 47675 & 57990 & 35859 & 47332 & 49804 & 60677 \\
\hline Moyen & & 589 & 354 & 806 & 32987 & 41590 & 748 & 54354 & & 43735 & 7772 & 57403 & & 45894 & 875 & 60005 \\
\hline \& Arge & & $\mathrm{m}$ & $\mathrm{m}$ & $\mathrm{m}$ & & $\mathrm{m}$ & ... & $\ldots$ & m & ... & in & $\mathrm{m}$ & . ... & $\mathrm{m}$ & $\mathrm{m}$ & $\mathrm{m}$ \\
\hline Bres & 14775 & $\mathrm{~m}$ & $\mathrm{~m}$ & $\mathrm{~m}$ & 14775 & $\mathrm{~m}$ & $\mathrm{~m}$ & $\mathrm{~m}$ & 14775 & $\mathrm{~m}$ & $\mathrm{~m}$ & $\mathrm{~m}$ & 14775 & $\mathrm{~m}$ & $\mathrm{~m}$ & $\mathrm{~m}$ \\
\hline Chin & & & & & & & & $\mathrm{m}$ & & m & m & & & m & m & \\
\hline Costa Rica & 24238 & 28552 & 30709 & 37179 & 24238 & 28552 & 30709 & 37179 & 25251 & 29746 & 31994 & 38736 & 25251 & 29746 & 31994 & 38736 \\
\hline Inde & $\mathrm{m}$ & $\mathrm{m}$ & $\mathrm{m}$ & $\mathrm{m}$ & $\mathrm{m}$ & $\mathrm{m}$ & $\mathrm{m}$ & $\mathrm{m}$ & $\mathrm{m}$ & $\mathrm{m}$ & $\mathrm{m}$ & $m$ & $m$ & $m$ & m & $\mathrm{m}$ \\
\hline Indonésie & $\mathrm{m}$ & $\mathrm{m}$ & $\mathrm{m}$ & $\mathrm{m}$ & $\mathrm{m}$ & $\mathrm{m}$ & $\mathrm{m}$ & $\mathrm{m}$ & $\mathrm{m}$ & $\mathrm{m}$ & $\mathrm{m}$ & $\mathrm{m}$ & $\mathrm{m}$ & $\mathrm{m}$ & $\mathrm{m}$ & $\mathrm{m}$ \\
\hline Federatio & $\mathrm{m}$ & $\mathrm{m}$ & $\mathrm{m}$ & $\mathrm{m}$ & m & m & m & m & $\mathrm{m}$ & $\mathrm{m}$ & m & mim & 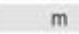 & $\mathrm{m}$ & $\mathrm{m}$ & $\mathrm{m}$ \\
\hline Arabie saoudite & $\mathrm{m}$ & $\mathrm{m}$ & $\mathrm{m}$ & $\mathrm{m}$ & $\mathrm{m}$ & $\mathrm{m}$ & $\mathrm{m}$ & $\mathrm{m}$ & $\mathrm{m}$ & $\mathrm{m}$ & $\mathrm{m}$ & $\mathrm{m}$ & $\mathrm{m}$ & $\mathrm{m}$ & $\mathrm{m}$ & $\mathrm{m}$ \\
\hline Afrique du Sud & $\mathrm{m}$ & $\mathrm{m}$ & $\mathrm{m}$ & $\mathrm{m}$ & $\mathrm{m}$ & $\mathrm{m}$ & $\mathrm{m}$ & m & $\mathrm{m}$ & $\mathrm{m}$ & $\mathrm{m}$ & m & $\mathrm{m}$ & & & $\mathrm{m}$ \\
\hline
\end{tabular}

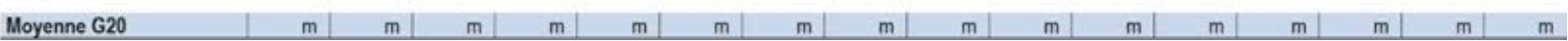

Remarque : La définition des qualifications les plus courantes parmi les enseignants se fonde sur une acception large, notamment le niveau de formation type dans la CITE et d'autres critères. Les qualifications les plus courantes sont définies pour chacune des quatre étapes de carrière incluses dans ce tableau. Consulter l'encadré D3.2, l'annexe 2 et les sections « Définitions » et « Méthodologie » pour de plus amples informations. Les données peuvent être consultées sur http://stats.oecd.org/, Base de données de Regards sur l'éducation.

1. Les données relatives aux enseignants du préprimaire incluent le salaire des enseignants des jardins d'enfants, qui sont majoritaires.

2. Inclut la moyenne des primes fixes au titre des heures supplémentaires pour les enseignants des premier et deuxième cycles du secondaire.

3. Inclut les cotisations de sécurité sociale et de retraite acquittées par l'employeur.

4. Exclut les cotisations de sécurité sociale et de retraite acquittées par le salarié

5. Dans le deuxième cycle du secondaire, inclut les enseignants de la filière professionnelle. (En Slovénie, inclut uniquement les enseignants de la filière professionnelle en charge de matières générales.)

6. Salaire effectif de base.

Source : OCDE (2019). Consulter la section « Source » pour tout complément d'information et l'annexe 3 pour les notes (https://doi.org/10.1787/f8d7880d-en)

Les symboles représentant les données manquantes et les abréviations figurent dans le Guide du lecteur. 
Tableau D3.2a. Salaire effectif des enseignants et des chefs d'établissement par comparaison avec les revenus d'autres actifs occupés diplômés de l'enseignement tertiaire (2017)

Rapport entre le salaire (sur la base du salaire annuel moyen [primes et allocations comprises]) des enseignants et des chefs d'établissements publics et les revenus d'autres actifs occupés présentant un niveau de formation similaire (moyenne pondérée) et ceux d'actifs diplômés de l'enseignement tertiaire occupés à temps plein toute l'année

\begin{tabular}{|c|c|c|c|c|c|c|c|c|c|c|c|c|c|c|c|c|c|}
\hline & \multirow{3}{*}{ 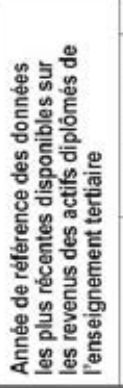 } & \multicolumn{8}{|c|}{ Ensemble des enseignants } & \multicolumn{8}{|c|}{ Ensemble des chefs d'etablissement } \\
\hline & & \multicolumn{4}{|c|}{$\begin{array}{l}\text { Salaire effectif par comparaison } \\
\text { avec les revenus d'autres actifs } \\
\text { occupes présentant } \\
\text { un niveau de formation similaire } \\
\text { et travaillant à temps plein toute } \\
\text { l'annee (moyenne pondéree, } \\
\text { adultes àges de } 25 \text { a } 64 \text { ans) }\end{array}$} & \multicolumn{4}{|c|}{$\begin{array}{l}\text { Salaire effectif par comparaison } \\
\text { avec les revenus d'autres actifs } \\
\text { occupés diplömés } \\
\text { de l'enseignement tertiaire } \\
\text { et travaillant a temps plein } \\
\text { toute lannée (CIIE } 5 \text { a } 8 \text {, } \\
\text { adultes âgés de } 25 \text { à } 64 \text { ans) }\end{array}$} & \multicolumn{4}{|c|}{\begin{tabular}{|c|} 
Salaire effectif par comparaison \\
avec les revenus d'autres actifs \\
occupes presentant \\
un niveau de formation similaire \\
et travaillant à temps plein toute \\
'lannee (moyenne pondéree, \\
adultes äges de 25 a 64 ans) \\
\end{tabular}} & \multicolumn{4}{|c|}{$\begin{array}{c}\text { Salaire effectif par comparaison } \\
\text { avec les revenus d'autres actifs } \\
\text { occupés diplömés } \\
\text { de l'enseignement tertiaire } \\
\text { et travaillant à temps plein } \\
\text { toute l'annee (CITEE } 5 \text { a } 8, \\
\text { adultes âgés de } 25 \text { à } 64 \text { ans) }\end{array}$} \\
\hline & & 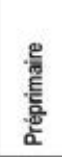 & 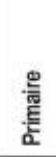 & 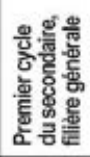 & 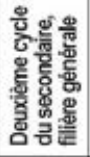 & 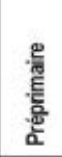 & 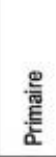 & 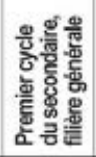 & 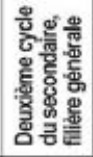 & 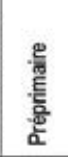 & 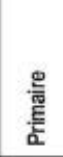 & 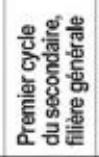 & 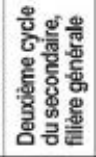 & 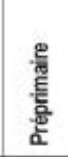 & 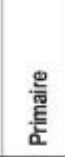 & 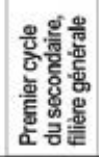 & 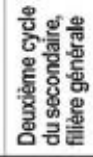 \\
\hline & (1) & (2) & (3) & (4) & (5) & (6) & (7) & (8) & (9) & (10) & (11) & (12) & (13) & (14) & (15) & (16) & (17) \\
\hline \multicolumn{18}{|l|}{ س Pays } \\
\hline Ô Australie & 2016 & m & $\mathrm{m}$ & m & $\mathrm{m}$ & 0.93 & 0.93 & 0.94 & 0.94 & m & $\mathrm{m}$ & m & $\mathrm{m}$ & 1.40 & 1.53 & 1.78 & 1.78 \\
\hline Autriche & 2017 & $\mathrm{~m}$ & $\mathrm{~m}$ & $\mathrm{~m}$ & $\mathrm{~m}$ & $\mathrm{~m}$ & 0.74 & 0.87 & 0.96 & a & $\mathrm{m}$ & $\mathrm{m}$ & $\mathrm{m}$ & $\mathrm{m}$ & 1.04 & 1.15 & 1.40 \\
\hline Canada & 2016 & m & $\mathrm{m}$ & $\mathrm{m}$ & $\mathrm{m}$ & $\mathrm{m}$ & $\mathrm{m}$ & $\mathrm{m}$ & $\mathrm{m}$ & m & $\mathrm{m}$ & m & m & $\mathrm{m}$ & $\mathrm{m}$ & m & $\mathrm{m}$ \\
\hline Chili & 2017 & 0.77 & 0.75 & 0.77 & 0.83 & 0.89 & 0.87 & 0.89 & 0.96 & 1.23 & 1.22 & 1.25 & 1.37 & 1.42 & 1.41 & 1.44 & 1.58 \\
\hline Colombie & m & m & $\mathrm{m}$ & $\mathrm{m}$ & m & m & m & $\mathrm{m}$ & $\mathrm{m}$ & m & $\mathrm{m}$ & $\mathrm{m}$ & $\mathrm{m}$ & $\mathrm{m}$ & $\mathrm{m}$ & m & $\mathrm{m}$ \\
\hline République & 2015 & 0.77 & 0.63 & 0.62 & 0.63 & 0.54 & 0.64 & 0.64 & 0.66 & 1.03 & 0.96 & 0.96 & 1.03 & 0.76 & 1.01 & 1.01 & 1.08 \\
\hline Danemark & 2017 & $\mathrm{~m}$ & $\mathrm{~m}$ & $m$ & 0.81 & 0.68 & 0.81 & 0.82 & 0.96 & 0.95 & 1.27 & 1.27 & 129 & 0.87 & 1.15 & 1.15 & 1.53 \\
\hline Estonie & 2017 & 0.68 & 0.88 & 0.86 & 0.86 & 0.63 & 0.91 & 0.91 & 0.91 & 0.90 & 1.05 & 1.05 & 1.04 & 0.95 & 1.12 & 1.12 & 1.12 \\
\hline Finlande & 2016 & 0.73 & 0.76 & 0.84 & 0.94 & 0.66 & 0.89 & 0.98 & 1.11 & 0.89 & 1.06 & 1.22 & 1.26 & 0.83 & 1.23 & 1.42 & 1.49 \\
\hline France & 2015 & 0.80 & 0.78 & 0.85 & 0.95 & 0.79 & 0.77 & 0.88 & 0.99 & m & $\mathrm{m}$ & $\mathrm{m}$ & $\mathrm{m}$ & 1.03 & 1.03 & 1.36 & 1.36 \\
\hline Allemagne & 2017 & $\mathrm{~m}$ & 0.84 & 0.93 & 0.98 & $\mathrm{~m}$ & 0.91 & 1.00 & 1.06 & $\mathrm{~m}$ & $\mathrm{~m}$ & m & $\mathrm{m}$ & $\mathrm{m}$ & $\mathrm{m}$ & $\mathrm{m}$ & $\mathrm{m}$ \\
\hline Grece & 2017 & 0.79 & 0.79 & 0.81 & 0.81 & 0.78 & 0.78 & 0.83 & 0.83 & 0.99 & 0.99 & 1.04 & 1.04 & 1.02 & 1.02 & 1.15 & 1.15 \\
\hline Hongrie & 2017 & 0.73 & 0.72 & 0.72 & 0.65 & 0.64 & 0.68 & 0.68 & 0.74 & m & m & $\mathrm{m}$ & $\mathrm{m}$ & $\mathrm{m}$ & m & m & m \\
\hline Islande & $\mathrm{m}$ & $\mathrm{m}$ & $\mathrm{m}$ & $\mathrm{m}$ & $\mathrm{m}$ & $\mathrm{m}$ & $\mathrm{m}$ & $\mathrm{m}$ & $\mathrm{m}$ & $\mathrm{m}$ & $\mathrm{m}$ & m & $\mathrm{m}$ & $\mathrm{m}$ & $\mathrm{m}$ & $\mathrm{m}$ & $\mathrm{m}$ \\
\hline Irlande & $\mathrm{m}$ & $\mathrm{m}$ & $\mathrm{m}$ & m & $\mathrm{m}$ & m & $\mathrm{m}$ & $\mathrm{m}$ & m & $\mathrm{m}$ & $\mathrm{m}$ & m & m & $\mathrm{m}$ & m & m & $\mathrm{m}$ \\
\hline |sraēl & 2017 & 0.83 & 0.83 & 0.86 & 0.87 & 0.85 & 0.88 & 0.96 & 0.94 & a & 1.29 & 1.24 & 1.39 & $\mathrm{~m}$ & 1.60 & 1.56 & 1.65 \\
\hline Italie & 2015 & $\mathrm{~m}$ & $\mathrm{~m}$ & m & $\mathrm{m}$ & 0.65 & 0.65 & 0.66 & 0.71 & a & $\mathrm{m}$ & $\mathrm{m}$ & $\mathrm{m}$ & $\mathrm{m}$ & 1.39 & 1.39 & 1.39 \\
\hline Japon & $\mathrm{m}$ & $\mathrm{m}$ & $\mathrm{m}$ & $\mathrm{m}$ & $\mathrm{m}$ & $\mathrm{m}$ & $\mathrm{m}$ & $\mathrm{m}$ & $\mathrm{m}$ & m & $\mathrm{m}$ & $\mathrm{m}$ & m & $\mathrm{m}$ & $\mathrm{m}$ & $\mathrm{m}$ & $\mathrm{m}$ \\
\hline Corée & $\mathrm{m}$ & $\mathrm{m}$ & $\mathrm{m}$ & $\mathrm{m}$ & $\mathrm{m}$ & $\mathrm{m}$ & & m & m & m & $\mathrm{m}$ & m & $\mathrm{m}$ & m & & $\mathrm{m}$ & $\mathrm{m}$ \\
\hline Lettonie & 2017 & 1.15 & 1.47 & 1.51 & 1.60 & 1.05 & 1.35 & 1.40 & 1.50 & 1.71 & 1.84 & 1.71 & 2.04 & 160 & 1.72 & 1.60 & 1.91 \\
\hline Lituanie & 2014 & $\mathrm{~m}$ & $\mathrm{~m}$ & $\mathrm{~m}$ & $\mathrm{~m}$ & 0.92 & 0.92 & 0.92 & 0.92 & $\mathrm{~m}$ & $\mathrm{~m}$ & $\mathrm{~m}$ & $\mathrm{~m}$ & $\mathrm{~m}$ & $\mathrm{~m}$ & m & $\mathrm{m}$ \\
\hline Luxembourg & 2016 & $\mathrm{~m}$ & $\mathrm{~m}$ & $\mathrm{~m}$ & $\mathrm{~m}$ & $\mathrm{~m}$ & $\mathrm{~m}$ & $\mathrm{~m}$ & $\mathrm{~m}$ & a & $\mathrm{m}$ & $\mathrm{m}$ & $\mathrm{m}$ & $\mathrm{m}$ & $\mathrm{m}$ & m & m \\
\hline Mexique & $\mathrm{m}$ & m & $\mathrm{m}$ & m & $\mathrm{m}$ & m & $\mathrm{m}$ & $\mathrm{m}$ & $\mathrm{m}$ & m & $\mathrm{m}$ & $\mathrm{m}$ & $\mathrm{m}$ & $\mathrm{m}$ & m & m & $\mathrm{m}$ \\
\hline Pays-Bas & 2017 & 0.75 & 0.75 & 0.89 & 0.89 & 0.71 & 0.71 & 0.89 & 0.89 & 0.99 & 0.99 & 1.21 & 1.21 & 1.00 & 1.00 & 1.25 & 1.25 \\
\hline Nouvelle-Zélande & 2017 & $\mathrm{~m}$ & 0.89 & 0.90 & 0.95 & $\mathrm{~m}$ & 0.86 & 0.88 & 0.95 & $\mathrm{~m}$ & 1.45 & 1.54 & 1.73 & m & 1 & 1.38 & 1.50 \\
\hline Norvège & 2017 & 0.75 & 0.83 & 0.83 & 0.80 & 0.68 & 0.76 & 0.76 & 0.82 & 0.89 & 1.10 & 1.10 & 1.19 & 0.81 & 1. & 1.01 & 1.21 \\
\hline Pologne & 2016 & 0.67 & 0.77 & 0.80 & 0.78 & 0.68 & 0.79 & 0.82 & 0.80 & 0.99 & 1.04 & 1.06 & 1.07 & 1.02 & 1.0 & 1.10 & 1.10 \\
\hline Portugal & 2017 & $\mathrm{~m}$ & $\mathrm{~m}$ & $\mathrm{~m}$ & $\mathrm{~m}$ & 1.53 & 14 & 1.37 & 150 & $\mathrm{~m}$ & $\mathrm{~m}$ & $\mathrm{~m}$ & $\mathrm{~m}$ & 199 & 199 & 1.99 & 199 \\
\hline République slovaque & 2017 & $\mathrm{~m}$ & $\mathrm{~m}$ & $\mathrm{~m}$ & $\mathrm{~m}$ & 0.50 & 0.65 & 0.65 & 0.67 & $\mathrm{~m}$ & m & m & $\mathrm{m}$ & $\mathrm{m}$ & $\mathrm{m}$ & m & $\mathrm{m}$ \\
\hline Slovénie & 2017 & 0.83 & 0.83 & 0.86 & 0.84 & 0.74 & 0.87 & 0.90 & 0.94 & 1.33 & 1.10 & 1.10 & 1.15 & 1.20 & 1.24 & 1.24 & 1.28 \\
\hline Espag & $\mathrm{m}$ & 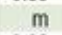 & & & & & & & $\mathrm{m}$ & $\mathrm{m}$ & $\mathrm{m}$ & $\mathrm{m}$ & $\mathrm{m}$ & $\mathrm{m}$ & & $\mathrm{m}$ & 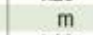 \\
\hline Suêde & 2017 & 0.82 & 0.86 & 0.80 & 0.79 & 0.74 & 0.84 & 0.87 & 0.89 & 1.21 & 1.20 & 1.20 & 1.17 & 1.08 & 1.19 & 1.19 & 1.23 \\
\hline Suisse & $\mathrm{m}$ & $\mathrm{m}$ & m & $\mathrm{m}$ & $\mathrm{m}$ & $\mathrm{m}$ & $\mathrm{m}$ & $\mathrm{m}$ & $\mathrm{m}$ & m & $\mathrm{m}$ & m & $\mathrm{m}$ & $\mathrm{m}$ & $\mathrm{m}$ & $\mathrm{m}$ & m \\
\hline Turquie & 2017 & & $\mathrm{~m}$ & m & m & 0.85 & 0.85 & 0.85 & 0.85 & m & $\mathrm{m}$ & $\mathrm{m}$ & $\mathrm{m}$ & 0.97 & 0.97 & 0.97 & 0.97 \\
\hline Etats-Unis & 2017 & 0.55 & 0.55 & 0.56 & 0.58 & 0.62 & 0.63 & 0.65 & 0.68 & 1.01 & 1.03 & 1.07 & 1.08 & 1.09 & 1.11 & 1.15 & 1.17 \\
\hline \multicolumn{18}{|l|}{ Economies } \\
\hline Comm. flamand & 2016 & 1.00 & 1.00 & 0.98 & 0.96 & 0.88 & 0.88 & 0.86 & 1.07 & 140 & 1.41 & 1.47 & 1.33 & 1.25 & 1.25 & 1.31 & 1.57 \\
\hline Comm. françai & 2016 & 0.95 & 0.93 & 0.87 & 0.88 & 0.83 & 0.82 & 0.80 & 1.02 & 1.33 & 1.33 & 1.37 & 1.34 & 1.17 & 1.19 & 1.28 & 1.50 \\
\hline Angleterre (RU) & 2017 & 0.76 & 0.76 & 0.83 & 0.83 & 0.81 & 0.81 & 0.92 & 0.92 & 1.39 & 1.39 & 1.93 & 1.93 & 1.47 & 1.47 & 2.14 & 2.14 \\
\hline Ecosse (RU) & 2017 & 0.84 & 0.84 & 0.84 & 0.84 & 0.83 & 0.83 & 0.83 & 0.83 & 1.30 & 1.30 & 1.30 & 1.30 & 1.29 & 1.29 & 1.29 & 1.29 \\
\hline Moyenne OCDE & & m & m & $\mathrm{m}$ & m & 0.78 & 0.84 & 0.88 & 0.93 & m & m & m & $\mathrm{m}$ & m & 1.25 & 1.34 & 1.43 \\
\hline Moyenne UE23 & & 0.82 & 0.85 & 0.88 & 0.89 & 0.78 & 0.85 & 0.89 & 0.95 & 1.17 & 121 & 1.28 & 1.30 & 1.16 & 1.24 & 1.34 & 1.43 \\
\hline Argentine & $\mathrm{m}$ & $\mathrm{m}$ & $\mathrm{m}$ & $\mathrm{m}$ & $\mathrm{m}$ & $\mathrm{m}$ & m & $\mathrm{m}$ & $\mathrm{m}$ & $\mathrm{m}$ & 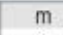 & $\mathrm{m}$ & $\mathrm{m}$ & $\mathrm{m}$ & $\mathrm{m}$ & $\mathrm{m}$ & $\mathrm{m}$ \\
\hline Brésil & 2015 & $\mathrm{~m}$ & $\mathrm{~m}$ & $\mathrm{~m}$ & $\mathrm{~m}$ & 0.82 & 0.84 & 0.86 & 0.87 & $\mathrm{~m}$ & $\mathrm{~m}$ & m & $\mathrm{m}$ & $\mathrm{m}$ & $\mathrm{m}$ & m & $\mathrm{m}$ \\
\hline inne & m & $\mathrm{m}$ & $\mathrm{m}$ & m & $\mathrm{m}$ & m & $\mathrm{m}$ & $\mathrm{m}$ & $\mathrm{m}$ & $\mathrm{m}$ & $\mathrm{m}$ & $\mathrm{m}$ & $\mathrm{m}$ & $\mathrm{m}$ & mil & $\mathrm{m}$ & $\mathrm{m}$ \\
\hline Costa Rica & 2017 & $\mathrm{~m}$ & $\mathrm{~m}$ & $\mathrm{~m}$ & $\mathrm{~m}$ & 1.15 & 1.21 & 1.47 & 1.47 & $\mathrm{~m}$ & $\mathrm{~m}$ & $\mathrm{~m}$ & $\mathrm{~m}$ & 1.96 & 1.83 & 2.09 & 2.09 \\
\hline Inde & m & $\mathrm{m}$ & $\mathrm{m}$ & $\mathrm{m}$ & $\mathrm{m}$ & m & m & $\mathrm{m}$ & m & $\mathrm{m}$ & m & m & $\mathrm{m}$ & $\mathrm{m}$ & $\mathrm{m}$ & m & $\mathrm{m}$ \\
\hline Indonésie & $\mathrm{m}$ & m & $\mathrm{m}$ & $\mathrm{m}$ & $\mathrm{m}$ & $\mathrm{m}$ & $\mathrm{m}$ & m & $\mathrm{m}$ & $\mathrm{m}$ & $\mathrm{m}$ & m & $\mathrm{m}$ & $\mathrm{m}$ & $\mathrm{m}$ & m & m \\
\hline Fédération de Russie & $\mathrm{m}$ & $\mathrm{m}$ & $\mathrm{m}$ & $\mathrm{m}$ & $\mathrm{m}$ & $\mathrm{m}$ & $\mathrm{m}$ & $\mathrm{m}$ & $\mathrm{m}$ & $\mathrm{m}$ & $\mathrm{m}$ & $\mathrm{m}$ & $\mathrm{m}$ & $\mathrm{m}$ & $\mathrm{m}$ & m & m \\
\hline Arabie saoudi & $\mathrm{m}$ & m & $\mathrm{m}$ & $\mathrm{m}$ & $\mathrm{m}$ & $\mathrm{m}$ & $\mathrm{m}$ & $\mathrm{m}$ & $\mathrm{m}$ & m & $\mathrm{m}$ & $\mathrm{m}$ & $\mathrm{m}$ & $\mathrm{m}$ & $\mathrm{m}$ & m & m \\
\hline Afrique du Sud & $\mathrm{m}$ & m & $\mathrm{m}$ & m & m & m & $\mathrm{m}$ & m & m & m & $\mathrm{m}$ & m & $\mathrm{m}$ & m & m & m & $\mathrm{m}$ \\
\hline Moyenne G20 & & $\mathrm{m}$ & $\mathrm{m}$ & $\mathrm{m}$ & $\mathrm{m}$ & $\mathrm{m}$ & $\mathrm{m}$ & $\mathrm{m}$ & $\mathrm{m}$ & $\mathrm{m}$ & $\mathrm{m}$ & $\mathrm{m}$ & $\mathrm{m}$ & $\mathrm{m}$ & $\mathrm{m}$ & $\mathrm{m}$ & $\mathrm{m}$ \\
\hline
\end{tabular}

Remarque : Consulter les sections « Définitions » et « Méthodologie » pour de plus amples informations. Les données peuvent être consultées sur http://stats.oecd.org/, Base de données de Regards sur l'éducation.

Source : OCDE (2019). Consulter la section « Source » pour tout complément d'information et l'annexe 3 pour les notes (https://doi.org/10.1787/f8d7880d-en). Les symboles représentant les données manquantes et les abréviations figurent dans le Guide du lecteur. 
Tableau D3.4. Salaire effectif moyen des enseignants et des chefs d'établissement, selon le groupe d'âge et le sexe (2017) Salaire annuel moyen (primes et allocations comprises) des enseignants et des chefs d'établissements publics, en équivalents USD convertis sur la base des PPA pour la consommation privée, selon le groupe d'âge et le sexe

\begin{tabular}{|c|c|c|c|c|c|c|c|c|}
\hline & \multicolumn{4}{|c|}{ Enseignants âgès de 25 a 64 ans } & \multicolumn{4}{|c|}{ Chefs d'ètablissement àgés de 25 a 64 ans } \\
\hline & Préprimaire & Primaire & $\begin{array}{l}\text { Premier cycle } \\
\text { du secondaire, } \\
\text { filière générale }\end{array}$ & $\begin{array}{l}\text { Deuxième cycle } \\
\text { du secondaire, } \\
\text { filière gènèrale }\end{array}$ & Prêprimaire & Primaire & $\begin{array}{l}\text { Premier cycle } \\
\text { du secondaire, } \\
\text { filière générale }\end{array}$ & $\begin{array}{l}\text { Deuxième cycle } \\
\text { du secondaire, } \\
\text { filière générale }\end{array}$ \\
\hline & (1) & (2) & (3) & (4) & (29) & (30) & (31) & (32) \\
\hline \multicolumn{9}{|l|}{ uس Pays } \\
\hline Ou Australic & 55283 & 55312 & 56196 & 56196 & 83169 & 90774 & 105703 & 105703 \\
\hline Autriche' ${ }^{1}$ & $\mathrm{~m}$ & 58130 & 67894 & 74920 & a & 81325 & 89618 & 109211 \\
\hline Canada & m & $\mathrm{m}$ & m & m & m & $\mathrm{m}$ & m & m \\
\hline Chill & 32837 & 31968 & 32690 & 35169 & 52108 & 51849 & 52922 & 58219 \\
\hline Colombie & $\mathrm{m}$ & $\mathrm{m}$ & $\mathrm{m}$ & m & $\mathrm{m}$ & $\mathrm{m}$ & m & m \\
\hline République tchèque & 22021 & 26318 & 26204 & 27039 & 31386 & 41358 & 41358 & 44184 \\
\hline Danemark & 45882 & 55227 & 55793 & 65272 & 58715 & 78304 & 78304 & 103525 \\
\hline Estonie & 17686 & 25333 & 25333 & 25333 & 26564 & 31328 & 31328 & 31328 \\
\hline Finlande ${ }^{2}$ & 34560 & 46300 & 51194 & 57779 & 43061 & 64366 & 73953 & 77650 \\
\hline France' & 40457 & 39426 & 45375 & 51007 & 52727 & 52727 & 70116 & 70116 \\
\hline Allemagne & $\mathrm{m}$ & 68747 & 75904 & 80483 & $\mathrm{~m}$ & $\mathrm{~m}$ & $\mathrm{~m}$ & $\mathrm{~m}$ \\
\hline Grece ${ }^{t}$ & 26453 & 26453 & 28292 & 28292 & 34751 & 34751 & 39331 & 39331 \\
\hline Hongrie & 23850 & 25393 & 25393 & 27648 & $\mathrm{~m}$ & $\mathrm{~m}$ & $\mathrm{~m}$ & $\mathrm{~m}$ \\
\hline Islande & 37873 & 43358 & 43358 & 56234 & 52408 & 59228 & 59228 & 82495 \\
\hline Irlande & $\mathrm{m}$ & $\mathrm{m}$ & $\mathrm{m}$ & $\mathrm{m}$ & $\mathrm{m}$ & $\mathrm{m}$ & $\mathrm{m}$ & $\mathrm{m}$ \\
\hline Israē| & 37734 & 39261 & 42476 & 41968 & a & 71123 & 69544 & 73578 \\
\hline Italie & 35647 & 35647 & 36363 & 38815 & a & 76184 & 76184 & 76184 \\
\hline Japon & $\mathrm{m}$ & $\mathrm{m}$ & $\mathrm{m}$ & $\mathrm{m}$ & $\mathrm{m}$ & $\mathrm{m}$ & m & $\mathrm{m}$ \\
\hline Corée & m & $\mathrm{m}$ & $\mathrm{m}$ & $\mathrm{m}$ & $\mathrm{m}$ & m & m & m \\
\hline Lettonie & 17638 & 22725 & 23488 & 25089 & 26811 & 28829 & 26819 & 32068 \\
\hline Lituaniet & 21264 & 21264 & 21264 & 21264 & m & $\mathrm{m}$ & m & m \\
\hline Luxembourg & m & $\mathrm{m}$ & $\mathrm{m}$ & $\mathrm{m}$ & a & a & $\mathrm{m}$ & m \\
\hline Mexique & $\mathrm{m}$ & $\mathrm{m}$ & $\mathrm{m}$ & m & m & $\mathrm{m}$ & $\mathrm{m}$ & m \\
\hline Pays-Bas & 54598 & 54598 & 68771 & 68771 & 77366 & 77366 & 96178 & 96178 \\
\hline Nouvelle-Zelande & $\mathrm{m}$ & 44339 & 45203 & 48452 & $\mathrm{~m}$ & 66711 & 70675 & 77079 \\
\hline Norvège & 43534 & 48820 & 48820 & 53120 & 51934 & 64921 & 64921 & 78125 \\
\hline Pologne & 27064 & 31535 & 32688 & 31796 & 40320 & 42572 & 43561 & 43669 \\
\hline Portugal & 49070 & 44856 & 44050 & 48035 & 63834 & 63834 & 63834 & 63834 \\
\hline Republique slovaque ${ }^{1,5}$ & 19053 & 25170 & 25170 & 25678 & $\mathrm{~m}$ & m & m & m \\
\hline Slovénie & 31701 & 37443 & 38453 & 40489 & 51313 & 53010 & 53010 & 55103 \\
\hline Espagne & $\mathrm{m}$ & $\mathrm{m}$ & $\mathrm{m}$ & $\mathrm{m}$ & $\mathrm{m}$ & $\mathrm{m}$ & m & $\mathrm{m}$ \\
\hline Suède' & 39265 & 44549 & 46156 & 47255 & 57534 & 63214 & 63214 & 65400 \\
\hline Suisse & $\mathrm{m}$ & $\mathrm{m}$ & $\mathrm{m}$ & $\mathrm{m}$ & $\mathrm{m}$ & $\mathrm{m}$ & $\mathrm{m}$ & $\mathrm{m}$ \\
\hline Turquie & 24187 & 24187 & 24187 & 24187 & 27561 & 27561 & 27561 & 27561 \\
\hline Etats-Unis' & 52239 & 53157 & 54993 & 57022 & 91867 & 93578 & 96518 & 98033 \\
\hline \multicolumn{9}{|l|}{ Economies } \\
\hline Comm. flamande (Belgique) & 53304 & 53093 & 52118 & 64756 & 75405 & 75931 & 79467 & 94989 \\
\hline Comm. française (Belgique) & 51530 & 50864 & 49426 & 62685 & 72193 & 73143 & 78703 & 92707 \\
\hline Angleterre (RU) & 41462 & 41462 & 46858 & 46858 & 76559 & 76559 & 111801 & 111801 \\
\hline Ecosse $(\mathrm{RU})^{6}$ & 42474 & 42474 & 42474 & 42474 & 66023 & 66023 & 66023 & 66023 \\
\hline Moyenne OCDE & 36247 & 40580 & 42553 & 45803 & $\mathrm{~m}$ & 61791 & 66534 & 72081 \\
\hline Moyenne UE23 & 34749 & 39864 & 42212 & 45534 & 53410 & 60046 & 65711 & 70739 \\
\hline \& Argentine & $\mathrm{m}$ & $\mathrm{m}$ & $\mathrm{m}$ & $\mathrm{m}$ & $\mathrm{m}$ & $\mathrm{m}$ & m & $\mathrm{m}$ \\
\hline Brésil' & 22544 & 22987 & 23526 & 23890 & $\mathrm{~m}$ & $\mathrm{~m}$ & $\mathrm{~m}$ & $\mathrm{~m}$ \\
\hline Chine & $\mathrm{m}$ & $\mathrm{m}$ & $\mathrm{m}$ & $\mathrm{m}$ & $\mathrm{m}$ & $\mathrm{m}$ & $\mathrm{m}$ & $\mathrm{m}$ \\
\hline Costa Rica & 36514 & 38410 & 46477 & 46477 & 61824 & 58020 & 66215 & 66215 \\
\hline${ }^{a}$ Inde & m & m & m & $\mathrm{m}$ & m & $\mathrm{m}$ & $\mathrm{m}$ & m \\
\hline Indonésie & m & $\mathrm{m}$ & $\mathrm{m}$ & $\mathrm{m}$ & $\mathrm{m}$ & $\mathrm{m}$ & $\mathrm{m}$ & m \\
\hline Féderation de Russie & $\mathrm{m}$ & $\mathrm{m}$ & $\mathrm{m}$ & $\mathrm{m}$ & $\mathrm{m}$ & $\mathrm{m}$ & $\mathrm{m}$ & $\mathrm{m}$ \\
\hline Arabie saoudite & $\mathrm{m}$ & m & $\mathrm{m}$ & $\mathrm{m}$ & m & $\mathrm{m}$ & $\mathrm{m}$ & m \\
\hline Afrique du Sud & m & m & m & m & m & m & m & m \\
\hline Moyenne G20 & $\mathrm{m}$ & $\mathrm{m}$ & $\mathrm{m}$ & $\mathrm{m}$ & $\mathrm{m}$ & $\mathrm{m}$ & $\mathrm{m}$ & $\mathrm{m}$ \\
\hline
\end{tabular}

Remarque : Les colonnes présentant le salaire effectif moyen des enseignants ventilé par groupe d'âge (soit les colonnes 5 à 28 ) peuvent être consultées en ligne. Consulter l'annexe 2 et les sections « Définitions » et « Méthodologie » pour de plus amples informations. Les données peuvent être consultées sur http://stats.oecd.orgl, Base de données de Regards sur l'éducation.

1. Dans le deuxième cycle du secondaire, inclut les enseignants de la filière professionnelle, (en Suède, inclut uniquement les enseignants des matières générales dans la filière professionnelle).

2. Inclut les données relatives à la majorité, c'est-à-dire uniquement les enseignants des jardins d'enfants pour l'éducation préprimaire.

3. Année de référence : 2016

4. Inclut les enseignants sans qualification.

5. Inclut le salaire des chefs d'établissement et des enseignants.

6 . Inclut tous les enseignants, indépendamment de leur âge.

7. Année de référence : 2015

Source : OCDE (2019). Consulter la section « Source » pour tout complément d'information et l'annexe 3 pour les notes (https://doi.org/10.1787/f8d7880d-en). Les symboles représentant les données manquantes et les abréviations figurent dans le Guide du lecteur. 
Tableau D3.10 Salaire statutaire minimum/maximum des chefs d'établissement, sur la base des qualifications minimales (2018) Salaire annuel des chefs d'établissements publics, en équivalents USD convertis sur la base des PPA pour la consommation privée (selon le niveau d'enseignement)

\begin{tabular}{|c|c|c|c|c|c|c|c|c|c|c|c|c|}
\hline & \multicolumn{3}{|c|}{ Préprimaire } & \multicolumn{3}{|c|}{ Primaire } & \multicolumn{3}{|c|}{$\begin{array}{l}\text { Premier cycle du secondaire, } \\
\text { filiere génerale }\end{array}$} & \multicolumn{3}{|c|}{$\begin{array}{l}\text { Deuxième cycle du secondaire, } \\
\text { filiere génerale }\end{array}$} \\
\hline & $\begin{array}{c}\text { Salaire } \\
\text { minimum }\end{array}$ & $\begin{array}{l}\text { Salaire } \\
\text { maximum }\end{array}$ & $\begin{array}{c}\text { Ratio } \\
\text { (maximin) }\end{array}$ & $\begin{array}{l}\text { Salaire } \\
\text { minimum }\end{array}$ & $\begin{array}{l}\text { Salaire } \\
\text { maximum }\end{array}$ & $\underset{\text { (maximin) }}{\text { Ratio }}$ & $\begin{array}{c}\text { Salaire } \\
\text { minimum }\end{array}$ & $\begin{array}{c}\text { Salaire } \\
\text { maximum }\end{array}$ & $\begin{array}{c}\text { Ratio } \\
\text { (maximin) }\end{array}$ & $\begin{array}{l}\text { Salaire } \\
\text { minimum }\end{array}$ & $\begin{array}{c}\text { Salaire } \\
\text { maximum }\end{array}$ & $\underset{\text { (maximin) }}{\text { Ratio }}$ \\
\hline & (1) & (2) & (3) & (4) & (5) & (6) & (a) & (8) & (9) & (10) & (11) & (12) \\
\hline \multicolumn{13}{|l|}{ w Pays } \\
\hline Oustralie & 71345 & 104807 & 1.47 & 71345 & 105761 & 1.48 & 80717 & 112073 & 1.39 & 80717 & 112073 & 1.39 \\
\hline Autriche & m & m & $\mathrm{m}$ & 47674 & 95799 & 2.01 & 47674 & 95799 & 2.01 & 62859 & 120319 & 1.91 \\
\hline Canada & $\mathrm{m}$ & m & $\mathrm{m}$ & 69384 & 94641 & 1.36 & 70498 & 94641 & 1.34 & 73998 & 94641 & 1.28 \\
\hline Chili & 32496 & 94717 & 2.91 & 32496 & 94717 & 2.91 & 32496 & 94717 & 2.91 & 33614 & 97950 & 2.91 \\
\hline Colombie & 21196 & 92674 & 4.37 & 21196 & 92674 & 4.37 & 25511 & 96381 & 3.78 & 25511 & 96381 & 3.78 \\
\hline République tchèque & 21077 & 24878 & 1.18 & 22027 & 29715 & 1.35 & 22027 & 29715 & 1.35 & 22027 & 29715 & 1.35 \\
\hline Danemark & 46925 & 54970 & 1.17 & 58961 & 69767 & 1.18 & 58961 & 69767 & 1.18 & 72940 & 82992 & 1.14 \\
\hline Estonie & $\mathrm{m}$ & $\mathrm{m}$ & $\mathrm{m}$ & $\mathrm{m}$ & m & $\mathrm{m}$ & $m$ & $\mathrm{~m}$ & $\mathrm{~m}$ & $\mathrm{~m}$ & $\mathrm{~m}$ & m \\
\hline Finlande' & 34164 & 37147 & 1.09 & 48060 & 63019 & 1.31 & 49645 & 71318 & 1.44 & 56792 & 69341 & 1.22 \\
\hline France & 39014 & 60305 & 1.55 & 39014 & 60305 & 1.55 & 47048 & 81524 & 1.73 & 47048 & 85540 & 1.82 \\
\hline Allemagne & $\mathrm{m}$ & $\mathrm{m}$ & $\mathrm{m}$ & $\mathrm{m}$ & m & $\mathrm{m}$ & m & m & $\mathrm{m}$ & $\mathrm{m}$ & $\mathrm{m}$ & $\mathrm{m}$ \\
\hline Grèce & 25453 & 40619 & 1.60 & 25453 & 44250 & 1.74 & 28177 & 44250 & 1.57 & 29084 & 45158 & 1.55 \\
\hline Hongrie & 23271 & 50179 & 2.16 & 23271 & 50179 & 2.16 & 23271 & 55754 & 2.40 & 25857 & 55754 & 2.16 \\
\hline Islande & 47302 & 68390 & 1.45 & 48195 & 100383 & 2.08 & 48195 & 100383 & 2.08 & 72638 & 104474 & 1.44 \\
\hline Irlande & $\mathrm{m}$ & $\mathrm{m}$ & $\mathrm{m}$ & 46017 & 101823 & 2.21 & 59450 & 115327 & 1.94 & 59450 & 115327 & 1.94 \\
\hline Israël & a & a & a & 50696 & 81901 & 1.62 & 50762 & 82126 & 1.62 & 39593 & 101683 & 2.57 \\
\hline Italie & a & a & a & 74984 & 83139 & 1.11 & 74984 & 83139 & 1.11 & 74984 & 83139 & 1.11 \\
\hline Japon & $\mathrm{m}$ & $\mathrm{m}$ & $\mathrm{m}$ & 64547 & 71354 & 1.11 & 64547 & 71354 & 1.11 & 66150 & 75139 & 1.14 \\
\hline Corée & a & 101886 & a & a & 101886 & a & a & 101699 & a & a & 100951 & a \\
\hline Lettonie & 19184 & a & a & 19184 & a & a & 19184 & a & a & 19184 & a & a \\
\hline Lituanie & 15860 & 34714 & 2.19 & 19936 & 37613 & 1.89 & 19936 & 37613 & 1.89 & 19936 & 37613 & 1.89 \\
\hline Luxembourg ${ }^{2}$ & a & a & a & a & a & a & 116560 & 161200 & 1.38 & 116560 & 161200 & 1.38 \\
\hline Mexique & 25840 & 75698 & 2.93 & 25840 & 75698 & 2.93 & 58320 & 145898 & 2.50 & 58851 & 76592 & 1.30 \\
\hline Pays-Bas & 50599 & 92651 & 1.83 & 50599 & 92651 & 1.83 & 55699 & 137147 & 2.46 & 55699 & 137147 & 2.46 \\
\hline Nouvelle-Zélande & $\mathrm{m}$ & $\mathrm{m}$ & $\mathrm{m}$ & 50802 & 95698 & 1.88 & 50086 & 95707 & 1.91 & 49371 & 95716 & 1.94 \\
\hline Norvège & $\mathrm{m}$ & $\mathrm{m}$ & $\mathrm{m}$ & $\mathrm{m}$ & $\mathrm{m}$ & $\mathrm{m}$ & $\mathrm{m}$ & $\mathrm{m}$ & $\mathrm{m}$ & $\mathrm{m}$ & $\mathrm{m}$ & $\mathrm{m}$ \\
\hline Pologne & 23972 & 26609 & 1.11 & 24686 & 27323 & 1.11 & 25014 & 30602 & 1.22 & 28247 & 34676 & 1.23 \\
\hline Portugal & 37125 & 85902 & 2.31 & 37125 & 85902 & 2.31 & 37125 & 85902 & 2.31 & 37125 & 85902 & 2.31 \\
\hline Rèpublique slovaque & 17629 & 28822 & 1.63 & 22475 & 35925 & 1.60 & 22475 & 35925 & 1.60 & 22475 & 36447 & 1.62 \\
\hline Slovènic & 50200 & 70938 & 1.41 & 50739 & 70938 & 1.40 & 50739 & 70938 & 1.40 & 49427 & 78371 & 1.59 \\
\hline Espagne & 47061 & 71659 & 1.52 & 47061 & 71659 & 1.52 & 57011 & 85170 & 1.49 & 57011 & 85170 & 1.49 \\
\hline Suède $^{3}$ & a & a & a & 62289 & 74413 & 1.19 & 62289 & 74413 & 1.19 & 65381 & 76337 & 1.17 \\
\hline Suisse & m & m & $\mathrm{m}$ & $\mathrm{m}$ & m & $\mathrm{m}$ & $\mathrm{m}$ & $\mathrm{m}$ & m & $\mathrm{m}$ & m & $\mathrm{m}$ \\
\hline Turquie & 26489 & 32955 & 1.24 & 26489 & 32955 & 1.24 & 26489 & 32955 & 1.24 & 26489 & 33157 & 1.25 \\
\hline Etats-Unis' 4 & 83427 & 104107 & 1.25 & 85798 & 105419 & 1.23 & 91386 & 107229 & 1.17 & 88481 & 117572 & 1.33 \\
\hline \multicolumn{13}{|l|}{ Economies } \\
\hline Comm. flamande (Belgique) & 49324 & 83226 & 1.69 & 49324 & 83226 & 1.69 & 50602 & 83226 & 1.64 & 61580 & 100490 & 1.63 \\
\hline Comm. française (Belgique) & 41698 & 77864 & 1.87 & 41698 & 77864 & 1.87 & 46892 & 79746 & 1.70 & 59613 & 95152 & 1.60 \\
\hline Angleterre (RU) & 56446 & 138588 & 2.46 & 56446 & 138588 & 2.46 & 56446 & 138588 & 2.46 & 56446 & 138588 & 2.46 \\
\hline Ecosse (RU) & 57164 & 111584 & 1.95 & 57164 & 111584 & 1.95 & 57164 & 111584 & 1.95 & 57164 & 111584 & 1.95 \\
\hline Moyenne OCDE & 38570 & 70636 & 1.85 & 44575 & 77538 & 1.80 & 49629 & 85700 & 1.77 & 52126 & 87420 & 1.74 \\
\hline Moyenne UE23 & 36454 & 64156 & 1.69 & 42009 & 71699 & 1.69 & 47321 & 80848 & 1.70 & 50299 & 84817 & 1.68 \\
\hline
\end{tabular}

\begin{tabular}{|c|c|c|c|c|c|c|c|c|c|c|c|c|}
\hline Argentine & m & m & m & $m$ & m & m & m & m & m & $\mathrm{m}$ & m & m \\
\hline Brésil & m & m & m & m & m & m & $\mathrm{m}$ & $m$ & m & $\mathrm{m}$ & $\mathrm{m}$ & $\mathrm{m}$ \\
\hline है Chine & m & m & m & $\mathrm{m}$ & m & $\mathrm{m}$ & m & m & m & $\mathrm{m}$ & m & m \\
\hline a Costa Rica & 21015 & 64689 & 3.08 & 20526 & 65297 & 3.18 & 21576 & 76268 & 3.53 & 21576 & 76268 & 3.53 \\
\hline Inde & m & m & m & m & m & m & m & m & m & m & m & m \\
\hline Indonésie & m & m & m & m & m & m & m & m & m & $\mathrm{m}$ & m & m \\
\hline Fédération de Russie & m & m & m & m & m & m & m & m & m & m & m & m \\
\hline Arabie saoudite & m & m & $m$ & m & m & m & $m$ & m & m & m & $m$ & m \\
\hline Afrique du Sud & m & m & $\mathrm{m}$ & $\mathrm{m}$ & m & $\mathrm{m}$ & m & m & m & $\mathrm{m}$ & $\mathrm{m}$ & m \\
\hline
\end{tabular}

Moyenne G20

Remarque : La définition des qualifications minimales des chefs d'établissement se fonde sur une acception large, notamment le niveau de formation type dans la CITE et d'autres critères. Consulter les sections "Définitions» et "Méthodologie» pour de plus amples informations. Les données peuvent être consultées sur http://stats.oecd.org/, Base de données de Regards sur l'éducation.

1. Inclut les données relatives à la majorité, c'est-à-dire uniquement les chefs d'établissement des jardins d'enfants pour l'éducation préprimaire.

2. Inclut les cotisations de sécurité sociale et de retraite acquittées par l'employeur.

3. Salaire effectif de base.

4. Le salaire minimum fait référence aux qualifications les plus courantes (titulaires d'un master) et le salaire maximum fait référence aux qualifications les plus élevées (spécialistes de l'éducation ou titulaires d'un doctorat).

Source : OCDE (2019). Consulter la section « Source » pour tout complément d'information et l'annexe 3 pour les notes (https://doi.org/10.1787/f8d7880d-en). Les symboles représentant les données manquantes et les abréviations figurent dans le Guide du lecteur. 


\section{Indicateur D4. Quel est le temps de travail des enseignants?}

\section{Faits marquants}

- D'après la réglementation ou les accords en vigueur dans les pays et économies de l'OCDE, les enseignants dans les établissements publics, donnent, en moyenne et par an, 1024 heures de cours dans l'enseignement préprimaire, 783 heures de cours dans l'enseignement primaire, 709 heures de cours dans le premier cycle de l'enseignement secondaire (filière générale) et 667 heures de cours dans le deuxième cycle de l'enseignement secondaire (filière générale).

- Dans la majorité des pays dont les données sont disponibles, le temps d'enseignement statutaire dans l'enseignement primaire, le premier cycle de l'enseignement secondaire et le deuxième cycle de l'enseignement secondaire dans les établissements publics est resté largement inchangé entre 2000 et 2018. Toutefois, dans quelques pays, le temps d'enseignement a varié de $10 \%$ ou plus dans un ou plusieurs niveaux d'enseignement durant cette période.

- La plupart des pays fixent un nombre d'heures par an pendant lesquelles les enseignants sont légalement tenus de travailler, tant pour effectuer leurs tâches d'enseignement que pour d'autres activités. Certains pays règlementent le nombre d'heures déterminé que les enseignants doivent passer dans leur établissement, tandis que d'autres établissent le temps de travail total des enseignants, qui comprend à la fois le temps de présence à l'école et le temps passé ailleurs.

Graphique D4.1. Nombre annuel d'heures d'enseignement en filière générale du premier cycle du secondaire $(2000,2005$ et 2018)

Temps statutaire net de contact dans les établissements publics

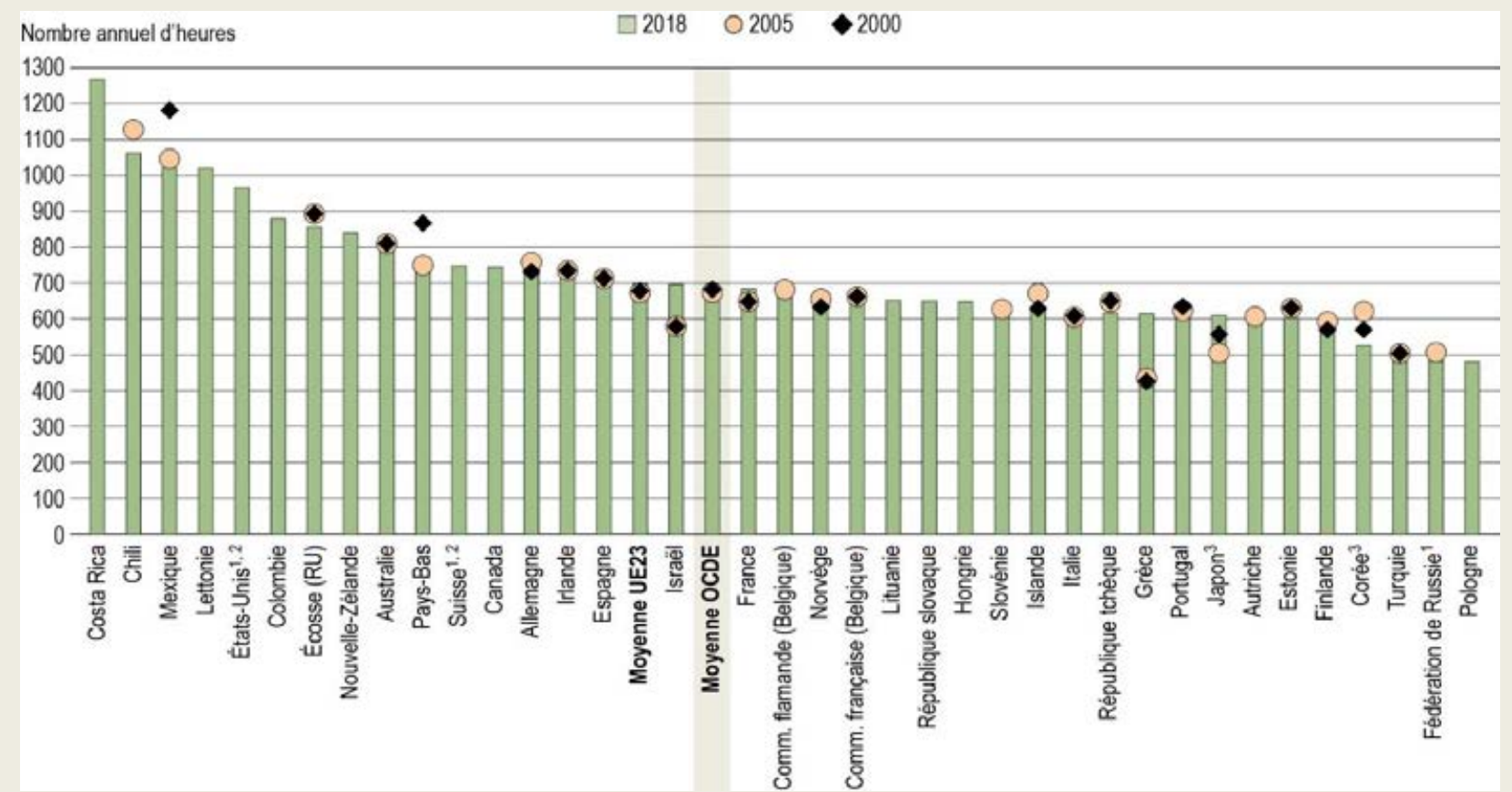

Remarque : Les moyennes OCDE et UE23 concernent uniquement les pays et économies de l'OCDE disposant de données pour 2000, 2005, 2010, 2015 et 2018. 1. Temps réel d'enseignement.

2. L'année de référence n'est pas 2018. Consulter le tableau source pour de plus amples informations.

3. Temps d'enseignement moyen planifié dans chaque établissement au début de l'année ou du semestre scolaire.

Les pays et économies sont classés par ordre décroissant du nombre annuel d'heures d'enseignement en filière générale du premier cycle de l'enseignement secondaire en 2018.

Source: OCDE (2019), tableau D4.2. Consulter la section "Source» pour tout complément d'information et l'annexe 3 pour les notes (https://doi.org/10.1787/f8d7880d-en). 


\section{Contexte}

Bien que le temps de travail et le temps d'enseignement réglementaires ne déterminent qu'en partie la charge de travail des enseignants, ils permettent de mieux comparer les exigences des pays envers leurs enseignants. Le nombre d'heures de cours et l'importance des activités autres que l'enseignement peuvent également être déterminants pour l'attractivité du métier d'enseignant. Combiné avec le salaire des enseignants (voir l'indicateur D3) et la taille moyenne des classes (voir l'indicateur D2), cet indicateur décrit plusieurs aspects essentiels de la vie professionnelle des enseignants.

La part du temps de travail statutaire consacrée à l'enseignement permet d'évaluer le temps réservé à d'autres activités, comme la préparation des cours, la correction des copies, la formation continue et les réunions de travail. Si les enseignants doivent passer une plus grande partie de leur temps de travail statutaire à donner cours, il est possible qu'ils aient moins de temps à consacrer à la préparation des leçons et à l'évaluation des élèves, par rapport au nombre d'heures fixé par la réglementation. Cela peut également indiquer que les enseignants doivent effectuer ces tâches pendant leur temps libre et donc travailler davantage que ce que prévoit leur temps de travail statutaire.

Comme la taille des classes et le taux d'encadrement (voir l'indicateur D2), le temps d'instruction des élèves (voir l'indicateur D1) et le salaire des enseignants (voir l'indicateur D3), le temps que les enseignants passent à enseigner a un impact sur le budget que les pays doivent consacrer à l'éducation (voir l'indicateur C7).

\section{Autres faits marquants}

- Le nombre d'heures de cours par an qu'est tenu de donner un enseignant type dans un établissement public varie considérablement selon les pays de l'OCDE, et ce, aux niveaux d'enseignement préprimaire, primaire et secondaire. II tend en outre à diminuer avec l'élévation du niveau d'enseignement.

- Dans l'enseignement préprimaire, le temps d'enseignement prévu dans les établissements publics varie davantage entre les pays qu'à tout autre niveau d'enseignement. Dans les pays et économies de l'OCDE, le temps d'enseignement statutaire dans les établissements publics d'enseignement préprimaire est, en moyenne, de 1024 heures de cours par an. II varie entre 519 heures d'enseignement au Mexique et 1755 heures en Allemagne.

- Les enseignants en poste dans l'enseignement primaire doivent donner, en moyenne, 783 heures de cours par an dans les pays et économies de l'OCDE. Ils en donnent 590 heures ou moins en Estonie, en Fédération de Russie et en Pologne, mais plus de 1050 au Chili et au Costa Rica.

- Dans le premier cycle de l'enseignement secondaire (filière générale), les enseignants donnent, en moyenne dans les pays et économies de l'OCDE, 709 heures de cours par an dans les établissements publics. Ce nombre varie entre 481 heures en Pologne et plus de 1050 heures au Chili et au Costa Rica.

- Dans le deuxième cycle de l'enseignement secondaire (filière générale), les enseignants donnent, en moyenne dans les pays et économies de l'OCDE, 667 heures de cours par an dans les établissements publics. Ils en donnent 405 au Danemark, mais plus de 1050 au Chili et au Costa Rica.

- Dans le premier cycle de l'enseignement secondaire, $43 \%$ du temps de travail des enseignants est consacré à l'enseignement proprement dit. Ce pourcentage va de $35 \%$ ou moins en Autriche, en Corée, en Islande, au Japon, en Pologne et en Turquie, à 63 \% en Écosse (Royaume-Uni). 


\section{Analyse}

\section{Temps d'enseignement}

Le nombre d'heures de cours par an que doit légalement donner un enseignant travaillant à plein temps dans un établissement public varie sensiblement selon les pays, et ce, dans l'enseignement préprimaire, primaire et secondaire (pour plus d'informations sur les variations infranationales du temps d'enseignement, voir l'encadré D4.1). Le fait que le temps d'enseignement soit réglementé et/ou signalé différemment selon les pays peut aussi expliquer en partie les variations du temps d'enseignement statutaire entre les pays (voir l'encadré D4.2).

Dans l'enseignement préprimaire, le temps d'enseignement statutaire dans les établissements publics varie davantage entre les pays qu'à tout autre niveau d'enseignement, dans les pays et économies dont les données sont disponibles. Le nombre de jours de cours est compris entre 159 jours en Communauté flamande de Belgique et 225 jours en Allemagne, en Islande et en Norvège. Les enseignants donnent entre 519 heures de cours par an au Mexique et 1755 en Allemagne. En moyenne, dans les pays et économies de l'OCDE, les enseignants en poste à ce niveau d'enseignement sont tenus de donner 1024 heures de cours par an, réparties sur 40 semaines ou 195 jours de cours (voir le tableau D4.1a et le graphique D4.2).

\section{Encadré D4.1. Temps de travail et temps d'enseignement au niveau infranational}

Des différences s'observent entre les régions en ce qui concerne le temps d'enseignement statutaire et le temps de travail des enseignants dans les quatre pays (la Belgique, le Canada, la Corée et le Royaume-Uni) qui ont fourni des données infranationales. En 2018, le nombre de semaines d'enseignement (dans l'enseignement préprimaire, primaire, ainsi que le premier et le deuxième cycle de l'enseignement secondaire) variait selon les régions dans deux de ces pays : d'une semaine en Belgique (de 36 à 37 semaines) et de deux semaines au Canada (de 36 à 38 semaines). En Corée et au Royaume-Uni, le nombre de semaines d'enseignement était identique dans toutes les entités infranationales. Toutefois, les données globales relatives au nombre de semaines d'enseignement occultent des écarts du temps d'enseignement en termes de nombre de jours ou d'heures d'enseignement au niveau infranational.

Les schémas de variations infranationales diffèrent entre les pays à l'étude. En Belgique, le nombre de jours d'enseignement varie bien plus (en valeur relative) entre les Communautés flamande et française que le nombre d'heures d'enseignement (sauf dans la filière professionnelle du deuxième cycle du secondaire). Par exemple, dans la filière générale du deuxième cycle de l'enseignement secondaire, le nombre de jours d'enseignement est $12 \%$ plus élevé en Communauté française qu'en Communauté flamande (179 jours contre 160 jours), en raison de différences entre les réglementations définissant le nombre de journées d'école, tandis que le nombre d'heures d'enseignement varie de $4 \%$ entre les deux communautés (622 heures en Communauté flamande contre 596 heures en Communauté française). Par contraste, le nombre de jours d'enseignement dans l'enseignement primaire et secondaire varie de $6 \%$ entre les différents territoires/provinces au Canada (entre 180 jours et 190 jours), mais le nombre d'heures d'enseignement varie bien davantage entre les entités infranationales. Dans l'enseignement primaire, la région où les enseignants donnent le plus d'heures de cours enregistre un temps d'enseignement $29 \%$ plus élevé que la région où les enseignants donnent le moins d'heures de cours (905 heures contre 700 heures). L'écart entre ces régions est de $58 \%$ dans la filière générale du premier cycle de l'enseignement secondaire (971 heures contre 615 heures), et de $52 \%$ dans la filière générale du deuxième cycle de l'enseignement secondaire (934 heures contre 615 heures). En Corée, les entités infranationales ne présentent aucune différence en termes de nombre de jours de cours, mais le nombre d'heures de cours dans la filière générale varie de $8 \%$ dans le deuxième cycle de l'enseignement secondaire (passant de 522 à 564 heures) et de $24 \%$ dans le premier cycle de l'enseignement secondaire (passant de 454 à 561 heures). 
Toutefois la prudence est de mise lors de la comparaison des données au niveau infranational, compte tenu des potentielles différences de réglementation entre les pays et entre les régions au sein même des pays, ainsi que de la façon dont les données sont communiquées pour les différentes entités infranationales. À titre d'exemple, les entités infranationales de Belgique rendent compte du temps d'enseignement typique des enseignants, tandis que les différentes entités infranationales du Canada rendent compte du temps d'enseignement maximal ou d'une estimation du temps d'enseignement (pour de plus amples informations sur les potentielles différences liées à la façon dont les données sont communiquées, voir l'encadré D4.2).

Source : Base de données de Regards sur l'éducation, http://stats.oecd.org.

\section{Graphique D4.2. Nombre annuel d'heures d'enseignement, selon le niveau d'enseignement (2018)}

Temps statutaire net de contact dans les établissements publics

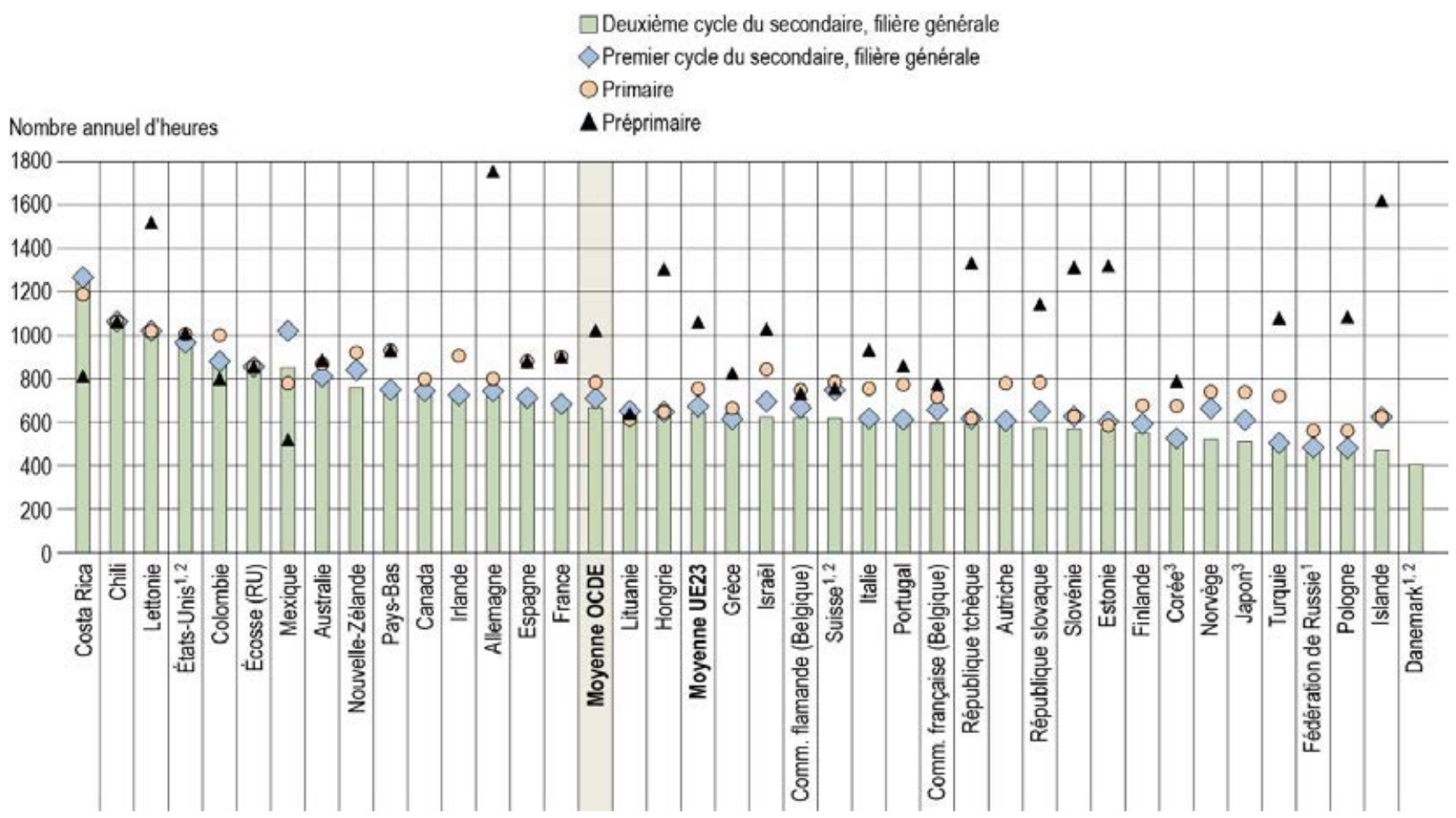

1. Temps réel d'enseignement.

2. L'année de référence n'est pas 2018. Consulter le tableau source pour de plus amples informations.

3. Temps d'enseignement moyen planifié dans chaque établissement au début de l'année ou du semestre scolaire.

Les pays et économies sont classés par ordre décroissant du nombre annuel d'heures d'enseignement en filière générale du deuxième cycle du secondaire.

Source : OCDE (2019), Table D4.1a. Consulter la section «Source» pour tout complément d'information et l'annexe 3 pour les notes (https://doi.org/10.1787/f8d7880d-en).

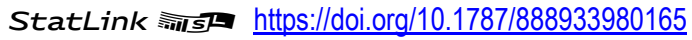

Dans les établissements publics d'enseignement primaire, les enseignants sont tenus de donner 783 heures de cours par an, en moyenne. Dans la plupart des pays dont les données sont disponibles, le temps d'enseignement quotidien varie entre trois et six heures, la moyenne de l'OCDE s'élevant à plus de quatre heures par jour. La répartition du temps d'enseignement au cours de l'année varie selon les pays. Au Costa Rica, par exemple, les enseignants doivent donner 1188 heures de cours par an dans l'enseignement primaire, soit 160 heures de plus 
qu'en Lettonie. Toutefois, comme le nombre de jours de cours au Costa Rica est plus élevé qu'en Lettonie (198 jours contre 170 jours), les enseignants de ces deux pays donnent en moyenne six heures de cours par jour (voir le tableau D4.1a).

Dans les pays de l'OCDE, les enseignants en poste dans la filière générale donnent, en moyenne, 709 heures de cours par an dans les établissements publics du premier cycle de l'enseignement secondaire. Le temps annuel d'enseignement va de moins de 600 heures de cours en Corée, en Fédération de Russie, en Finlande, en Pologne et en Turquie à plus de 1000 heures au Chili, au Costa Rica, en Lettonie et au Mexique. Cependant, les heures rapportées pour la Corée et la Finlande correspondent au nombre d'heures de cours minimum que les enseignants doivent donner (voir l'encadré D4.2); en Pologne, à la demande du chef d'établissement, les enseignants peuvent être contraints de donner jusqu'à $25 \%$ de leurs heures de cours statutaires à titre d'heures supplémentaires (dans le premier cycle de l'enseignement secondaire).

Dans la filière générale du deuxième cycle de l'enseignement secondaire, les enseignants qui enseignent dans des établissements publics donnent, en moyenne, 667 heures de cours par an. Le temps d'enseignement annuel varie de moins de 500 heures au Danemark, en Fédération de Russie, en Islande, en Pologne et en Turquie à plus de 1000 heures au Chili, au Costa Rica et en Lettonie. Les heures rapportées pour le Chili correspondent toutefois au temps de travail maximal que les enseignants sont tenus d'enseigner et non à leur temps d'enseignement typique (voir l'encadré D4.2). En moyenne, les enseignants donnent au plus trois heures de cours par jour en Corée, en Finlande, en Islande, au Japon, en Norvège, en Pologne, en République slovaque, en Slovénie et en Turquie, mais en donnent plus de six au Costa Rica et en Lettonie (voir le tableau D4.1).

\section{Variation du nombre d'heures de cours, selon le niveau d'enseignement}

Le temps d'enseignement a tendance à diminuer avec le niveau d'enseignement. Dans la plupart des pays, le temps d'enseignement statutaire est plus élevé dans l'enseignement préprimaire que dans le deuxième cycle de l'enseignement secondaire (filière générale). Échappent à ce constat le Chili et l'Écosse (Royaume-Uni) - où le temps d'enseignement que les enseignants sont tenus de donner est identique à tous les niveaux d'enseignement - et la Colombie, le Costa Rica, la Lituanie et le Mexique, où les enseignants en poste dans le deuxième cycle de l'enseignement secondaire doivent donner plus d'heures de cours que ceux en poste dans l'enseignement préprimaire (voir le tableau D4.1a et le graphique D4.2).

C'est entre l'enseignement préprimaire et l'enseignement primaire que le nombre légal d'heures de cours varie le plus. En moyenne, les enseignants en poste dans l'enseignement préprimaire sont tenus de donner près de $31 \%$ d'heures de cours de plus que ceux en poste dans l'enseignement primaire. En Allemagne, en Estonie, en Hongrie, en Islande, en République tchèque et en Slovénie, le temps d'enseignement annuel des enseignants en poste dans l'enseignement préprimaire représente au moins le double de celui des enseignants en poste dans l'enseignement primaire (voir le tableau D4.1a).

En Autriche, en Corée, en France, au Portugal et en Turquie, les enseignants donnent au moins $25 \%$ d'heures de cours de plus par an dans l'enseignement primaire que dans le premier cycle de l'enseignement secondaire, tandis qu'ils donnent le même nombre d'heures de cours par an à ces deux niveaux d'enseignement au Chili, en Écosse (Royaume-Uni), en Hongrie, en Islande, en Lettonie, en République tchèque et en Slovénie. Le nombre d'heures de cours est légèrement plus élevé dans le premier cycle de l'enseignement secondaire que dans l'enseignement primaire au Costa Rica, en Estonie et en Lituanie, et beaucoup plus élevé au Mexique (voir le tableau D4.1a).

Dans la plupart des pays, le nombre d'heures de cours par an est similaire dans le premier et le deuxième cycle de l'enseignement secondaire. Toutefois, en Islande, en Norvège et en Suisse, les enseignants donnent au moins $20 \%$ d'heures de cours de plus par an dans le premier cycle de l'enseignement secondaire que dans le deuxième cycle de l'enseignement secondaire (voir le tableau D4.1a). 


\section{Variation du nombre d'heures de cours, selon la filière d'enseignement}

Dans la plupart des pays, le temps d'enseignement statutaire ne varie pas entre la filière générale et la filière professionnelle. Si l'on se penche plus particulièrement sur le deuxième cycle de l'enseignement secondaire, qui dans la plupart des pays comprend à la fois des formations en filière générale et en filière professionnelle, il en ressort que le temps d'enseignement est similaire dans les deux filières dans près de deux tiers des pays dont les données sont disponibles. Toutefois, le temps d'enseignement est au moins $15 \%$ plus élevé en filière professionnelle qu'en filière générale en Finlande, en Lettonie et en Suisse, et au moins $40 \%$ plus élevé en Communauté flamande de Belgique (pour les cours pratiques dispensés dans le cadre des formations en filière professionnelle) et au Danemark. Le Canada et le Mexique sont les seuls pays où le temps d'enseignement est nettement moins élevé (d'au moins $15 \%$ ) en filière professionnelle qu'en filière générale (voir le graphique D4.3).

\section{Graphique D4.3. Nombre annuel d'heures d'enseignement en filières générale et professionnelle du deuxième cycle du secondaire (2018)}

Temps statutaire net de contact dans les établissements publics

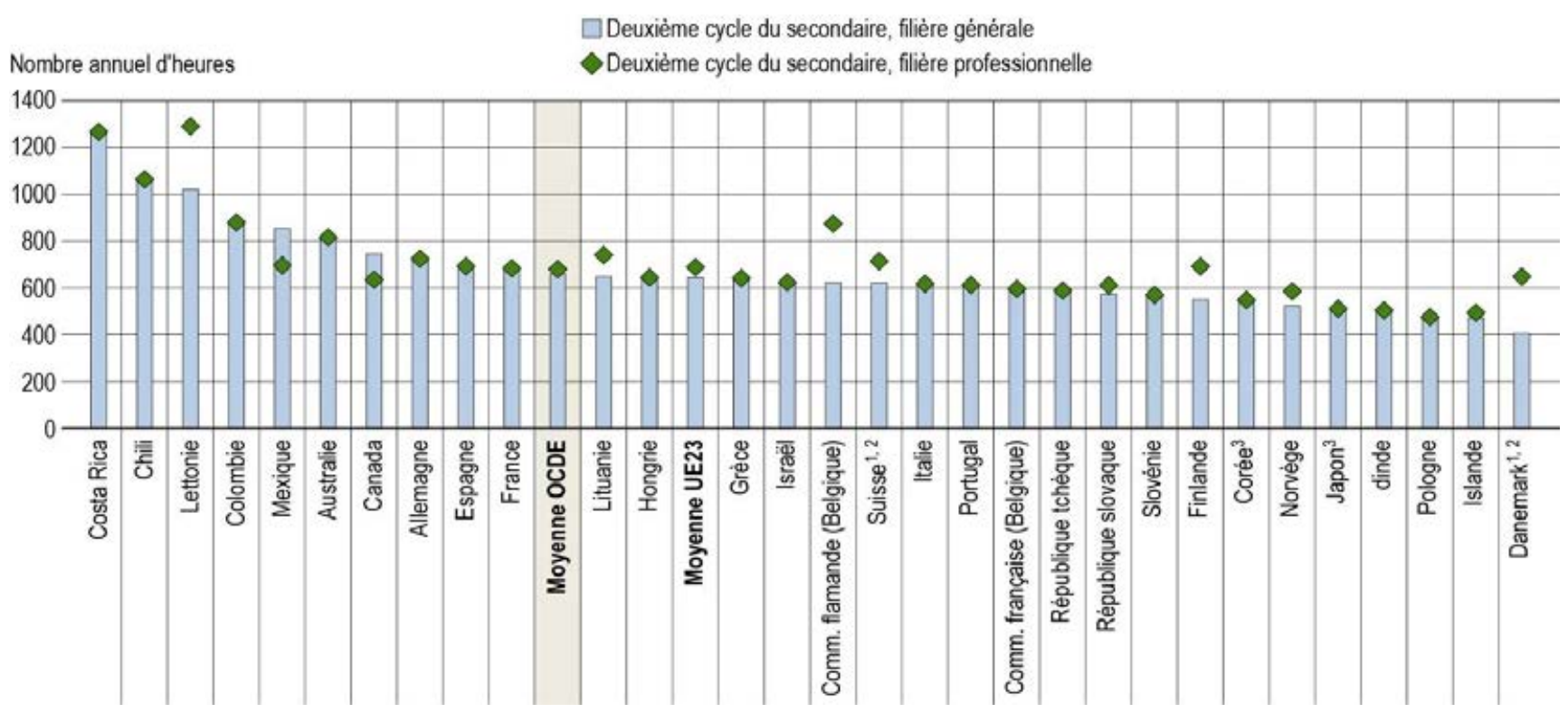

1. Temps réel d'enseignement.

2. L'année de référence n'est pas 2018. Consulter le tableau source pour de plus amples informations.

3. Temps d'enseignement moyen planifié dans chaque établissement au début de l'année ou du semestre scolaire.

Les pays et économies sont classés par ordre décroissant du nombre annuel d'heures d'enseignement en filière générale du deuxième cycle de l'enseignement secondaire en 2018.

Source : OCDE (2019), Table D4.1a. Consulter la section «Source» pour tout complément d'information et l'annexe 3 pour les notes (https://doi.org/10.1787/f8d7880d-en).

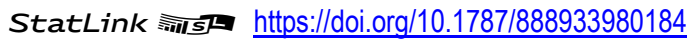

\section{Temps réel d'enseignement}

Le temps d'enseignement statutaire communiqué par la plupart des pays et mentionné dans cet indicateur correspond au nombre d'heures de cours tel qu'il est fixé par la réglementation. Toutefois, le nombre d'heures de cours données par les enseignants peut différer du temps fixé par la réglementation, notamment en raison des heures supplémentaires prestées. Le temps réel d'enseignement correspond au nombre d'heures de cours qu'un enseignant travaillant à temps plein donne par an à un groupe ou à une classe d'élèves, et tient compte 
des heures supplémentaires. II dresse donc un tableau exhaustif de la charge réelle d'enseignement incombant aux enseignants. Cependant, le temps réel d'enseignement ne tient pas compte du fait qu'une part du temps de travail des enseignants est consacrée à d'autres activités que l'enseignement, notamment le maintien de la discipline et les tâches administratives. En moyenne, dans les pays de l'OCDE ayant participé à l'Enquête internationale sur l'enseignement et l'apprentissage (TALIS), les enseignants du premier cycle de l'enseignement secondaire ont déclaré que l'apprentissage et l'enseignement représentaient $78 \%$ du temps passé en classe en 2018 (OCDE, 2019 $\left.{ }_{[1]}\right)$.

Seuls quelques pays ont communiqué le temps d'enseignement statutaire et le temps réel d'enseignement, mais ces données suggèrent que le temps réel d'enseignement peut parfois s'écarter des exigences statutaires. En Pologne, par exemple, le temps réel d'enseignement des enseignants du premier cycle de l'enseignement secondaire est $15 \%$ plus élevé que le temps d'enseignement statutaire. Ainsi, le temps réel d'enseignement des enseignants en poste dans le premier cycle de l'enseignement secondaire est supérieur de $6 \%$ au temps de travail statutaire en Slovénie, et jusqu'à $5 \%$ en Lettonie et en Lituanie. Par contraste, au même niveau d'enseignement, le temps réel d'enseignement des enseignants est inférieur d'environ $1 \%$ au temps statutaire d'enseignement au Portugal (voir le graphique D4.5, disponible en ligne).

Les variations entre le temps d'enseignement statutaire et le temps réel d'enseignement peuvent résulter en partie des heures supplémentaires imputables à l'absentéisme ou à la pénurie des enseignants. Elles peuvent également s'expliquer en partie par la nature des données. En effet, les chiffres concernant le temps statutaire d'enseignement correspondent aux normes et conventions officielles, alors que le temps réel d'enseignement est calculé sur la base de registres administratifs, de bases de données statistiques, d'enquêtes par échantillonnage représentatif ou d'autres sources de données représentatives.

\section{Évolution du temps d'enseignement}

Alors que le nombre moyen d'heures d'enseignement a peu évolué ces dix-huit dernières années, certains des pays dont les données sont disponibles (et sans ruptures dans les séries chronologiques) ont fait état d'une variation du temps d'enseignement de $10 \%$ au moins à la hausse ou à la baisse entre 2000 et 2018 (voir le tableau D4.2 et le graphique D4.1).

Entre 2000 et 2018, le temps d'enseignement a progressé d'au moins $15 \%$ (soit de plus de 100 heures) dans l'enseignement primaire en Israël et au Japon (voir le tableau D4.2). En Israël, cette augmentation du temps de travail et d'enseignement s'inscrit dans le cadre de la réforme "Nouvel horizon » qui a été mise en œuvre progressivement à partir de 2008. L'une des mesures phares de cette réforme a été d'allonger la semaine de classe des enseignants pour permettre la prise en charge des élèves en petits groupes, en échange d'une rémunération plus élevée. Le temps d'enseignement y est passé de 30 à 36 heures par semaine, et les enseignants doivent désormais donner cinq heures de cours à des petits groupes d'élèves dans l'enseignement primaire. Le salaire des enseignants a considérablement augmenté à titre de compensation (voir l'indicateur D3).

Dans le premier cycle de l'enseignement secondaire, le temps d'enseignement a également progressé de plus de $20 \%$ (soit 120 heures) en Israël durant cette période. Cette progression dans le premier cycle de l'enseignement secondaire est également notable au Japon, quoique dans une moindre mesure (plus de $9 \%$, soit 53 heures). Dans le deuxième cycle de l'enseignement secondaire, c'est en Israël que le temps d'enseignement a progressé le plus : en 2018, les enseignants devaient donner près de $19 \%$ d'heures de cours de plus (soit 99 heures de plus) qu'en 2000. Ces dernières années, le temps d'enseignement a aussi connu une forte hausse en Lettonie, où il a augmenté de $42 \%$ entre 2016 et 2018, en raison de modifications récemment apportées à la réglementation (voir le tableau D4.2).

Par contraste, dans certains pays et économies, le temps d'enseignement a diminué entre 2000 et 2018. Dans les quelques pays et économies dont les données de 2000 et 2018 sont disponibles, le temps d'enseignement a diminué dans l'enseignement préprimaire durant cette période de $10 \%$ ou plus (soit 95 heures ou plus) en Écosse (Royaume-Uni) et au Portugal. Aux autres niveaux d'enseignement, le temps d'enseignement a diminué 
de $10 \%$ ou plus en Écosse (Royaume-Uni) dans l'enseignement primaire (de 95 heures), au Mexique dans le premier cycle de l'enseignement secondaire (de 162 heures), aux Pays-Bas dans l'enseignement secondaire (de 117 heures) et en Turquie dans le deuxième cycle de l'enseignement secondaire (de 117 heures). Dans l'enseignement primaire, le temps d'enseignement a diminué de plus de $22 \%$ en Corée (de 190 heures). En Écosse (Royaume-Uni), la diminution du nombre d'heures de cours pour les enseignants en poste dans l'enseignement primaire s'inscrit dans le cadre de l'Accord « A teaching profession for the 21st century » adopté en 2001 : ce texte prévoit un temps de travail de 35 heures par semaine pour tous les enseignants et la réduction progressive du temps maximal d'enseignement à 22.5 heures par semaine dans l'enseignement primaire, secondaire et spécial. Malgré cette réduction, le temps maximal d'enseignement des enseignants en poste en Écosse (Royaume-Uni) demeure supérieur à la moyenne de l'OCDE (voir le tableau D4.2).

\section{Encadré D4.2. Comparabilité des données relatives au temps d'enseignement statutaire (2017)}

Les données relatives au temps d'enseignement utilisées dans cet indicateur portent sur le nombre d'heures de cours tel qu'il est défini dans la réglementation de chaque pays. La collecte de données internationale effectuée pour recueillir ces informations garantit l'utilisation des mêmes définitions et méthodologies pour compiler les données de l'ensemble des pays. Par exemple, le temps d'enseignement est converti en heures (de 60 minutes) afin d'éviter les différences résultant de la variation de la durée des périodes d'enseignement entre les pays. Le temps d'enseignement n'est cependant pas officiellement répertorié de la même manière selon les pays. Cela étant, l'impact sur la comparabilité des données a été minimisé autant que possible.

Dans cette comparaison internationale, le temps d'enseignement statutaire fait abstraction du temps de préparation et du temps officiellement réservé aux pauses entre les cours ou séries de cours. Toutefois, aux niveaux d'enseignement préprimaire et primaire, les courtes pauses (de dix minutes ou moins) sont incluses dans le temps d'enseignement si les enseignants sont responsables de leur classe pendant ce temps (voir la section « Définitions »).

D'autres activités des enseignants, telles que les journées consacrées aux activités de développement professionnel et à l'évaluation des élèves ainsi que la participation à des conférences, sont également exclues du temps d'enseignement calculé dans cet indicateur. Toutefois, la réglementation ne spécifie pas toujours le nombre de journées consacrées auxdites activités et il peut donc s'avérer difficile d'estimer ces heures et de les exclure du temps d'enseignement. À tous les niveaux d'enseignement, au moins deux pays et économies sur cinq sont en mesure d'exclure du temps d'enseignement statutaire la plupart ou la totalité des heures consacrées à ces activités. Toutefois, exclure les journées d'examen peut s'avérer plus complexe pour les pays. Dans le premier cycle de l'enseignement secondaire, près de $40 \%$ des pays ne sont pas en mesure de les exclure, et dans $10 \%$ des pays les données relatives à l'inclusion ou l'exclusion des journées d'examen ne sont pas disponibles. Ce constat peut avoir pour conséquence la surestimation du temps d'enseignement à raison de quelques jours dans ces pays.

Par ailleurs, les différentes réglementations officielles fixent un temps minimal, typique ou maximal pour le temps d'enseignement, ce qui peut expliquer en partie les différences entre les pays. La plupart des données se rapportent au temps d'enseignement typique, mais près d'un quart des pays fournissent des valeurs maximales ou minimales du temps d'enseignement.

Des informations plus détaillées concernant la manière dont les pays et économies participants fournissent des données sur le temps d'enseignement sont disponibles à l'annexe 3.

\section{Temps de travail des enseignants}

Dans la majorité des pays, le temps d'enseignement est déterminé en partie par le temps statutaire d'enseignement prévu par le règlement de travail. En outre, les enseignants sont légalement tenus de travailler 
sur une base annuelle pendant un nombre d'heures déterminé dans la plupart des pays, conformément au temps de travail annuel fixé dans des conventions collectives ou autres accords contractuels. Ce nombre d'heures peut concerner le temps de présence obligatoire des enseignants dans leur établissement, tant pour les tâches d'enseignement que pour d'autres activités, ou le nombre total d'heures de travail. Dans les deux cas, il s'agit du temps de travail officiel prévu dans les accords contractuels, et la répartition du temps de travail pour chaque activité varie selon les pays. En Israël, par exemple, de récentes réformes de l'enseignement prennent en compte des heures de travail supplémentaires au sein des établissements d'enseignement, en plus des heures d'enseignement. La règlementation spécifie désormais le temps que les enseignants doivent passer dans leur établissement, tant pour les tâches d'enseignement que pour d'autres activités. À la suite de la réforme, le nombre d'heures consacrées à des activités au sein des établissements autres que l'enseignement, telles que les réunions avec les élèves ou les parents, la préparation des cours et la correction des copies des élèves, a été élargi.

Plus de la moitié des pays et économies de l'OCDE spécifient le temps que les enseignants doivent passer dans leur établissement, tant pour les tâches d'enseignement que pour d'autres activités, à au moins un des niveaux d'enseignement. Dans plus de la moitié de ces pays, le temps de présence obligatoire des enseignants dans l'établissement ne varie pas de plus de $5 \%$ entre le deuxième cycle de l'enseignement secondaire et l'enseignement préprimaire. En revanche, en Hongrie, en Islande, en Lettonie, au Portugal, en Suède et en Turquie, le temps de présence obligatoire des enseignants dans l'établissement est $20 \%$ plus important dans l'enseignement préprimaire que dans le deuxième cycle de l'enseignement secondaire (bien que le temps de travail statutaire total soit identique à ces deux niveaux d'enseignement en Hongrie, en Lettonie et en Turquie) (voir le tableau D4.1b).

Dans certains autres pays, le temps de travail statutaire annuel total des enseignants est spécifié, mais la répartition entre le temps de présence dans l'établissement et le temps passé ailleurs ne l'est pas. C'est le cas en Allemagne, en Angleterre (Royaume-Uni), en Autriche (dans l'enseignement primaire et le premier cycle de l'enseignement secondaire), en Communauté française de Belgique (dans l'enseignement préprimaire et primaire), en Corée, au Danemark, en Estonie (dans l'enseignement primaire et secondaire) en France (dans le premier et le deuxième cycle de l'enseignement secondaire), au Japon, en Lituanie (dans l'enseignement primaire et secondaire), aux Pays-Bas, en Pologne, en République slovaque, en République tchèque et en Suisse (voir le tableau D4.1b). En Allemagne (dans certains Länder), en Corée, en France et au Japon, le même temps de travail statutaire total s'applique aux enseignants et aux fonctionnaires.

De plus, la charge de travail et d'enseignement peut évoluer tout au long de la carrière d'un enseignant. Certains pays accordent un horaire de cours réduit aux enseignants débutants dans le cadre de leur initiation. D'autres proposent aux enseignants plus âgés de diversifier leurs tâches et de réduire leur horaire de cours pour les encourager à rester dans la profession. Par exemple, au Portugal les enseignants peuvent se voir accorder un horaire de cours réduit en fonction de leur âge, du nombre d'années passées à enseigner, ou pour effectuer des activités périscolaires au sein de l'établissement. En Islande, les enseignants du deuxième cycle de l'enseignement secondaire peuvent également se voir accorder un horaire de cours réduit en fonction de leur âge : les enseignants âgés de 30 à 37 ans bénéficient d'un jour de congé supplémentaire par an, et ceux de 38 ans ou plus se voient accorder deux jours de congé supplémentaires par an. En outre, dans le deuxième cycle de l'enseignement secondaire, les enseignants âgés de 55 ans ou plus bénéficient d'une réduction de leur temps d'enseignement (de 58 heures pour les 55-59 ans jusqu'à 290 heures pour les enseignants âgés de 60 ans ou plus).

\section{Part du temps de travail consacrée à d'autres activités que l'enseignement}

Le temps d'enseignement est une composante importante de la charge de travail des enseignants, mais d'autres activités telles que l'évaluation des élèves, la préparation des cours, la correction des copies, la formation continue et les réunions pédagogiques doivent également être prises en considération pour bien comprendre ce que l'on attend des enseignants dans les différents pays. Le temps consacré à ces activités autres que 
l'enseignement varie entre les pays ; si les enseignants consacrent une plus grande partie du temps de travail statutaire à l'enseignement, il est possible qu'ils aient moins de temps à consacrer à d'autres activités.

\section{Graphique D4.4. Part du temps de travail des enseignants du premier cycle du secondaire consacrée à l'enseignement (2018)}

Temps net d'enseignement (nombre annuel typique d'heures) en pourcentage du temps de travail statutaire total, en filière générale, dans les établissements publics

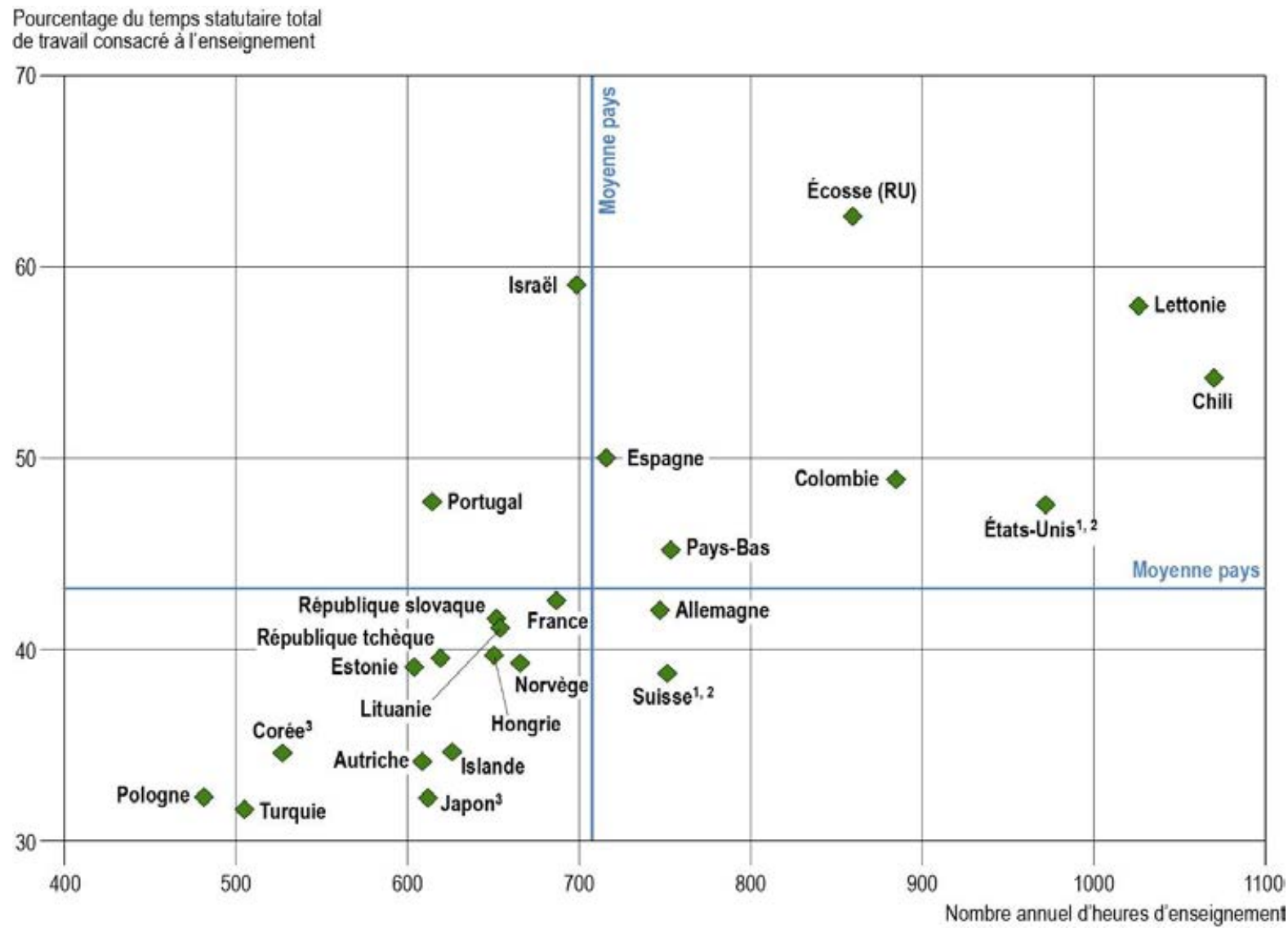

1. Temps réel d'enseignement.

2. L'année de référence n'est pas 2018. Consulter le tableau source pour de plus amples informations.

3. Temps d'enseignement moyen planifié dans chaque établissement au début de l'année ou du semestre scolaire.

Source : OCDE (2019), tableaux D4.1a et D4.1b. Consulter la section « Source » pour tout complément d'information et l'annexe 3 pour les notes (https://doi.org/10.1787/f8d7880d-en).

Bien que l'enseignement constitue l'activité principale des enseignants dans un grand nombre de pays, une grande part de leur temps de travail est consacrée à d'autres activités. Dans les 24 pays et économies ayant fourni des données sur le temps de travail total et le temps d'enseignement définis dans le premier cycle de l'enseignement secondaire, en moyenne $43 \%$ du temps de travail des enseignants est consacré à l'enseignement proprement dit. Ce pourcentage va de $35 \%$ ou moins en Autriche, en Corée, en Islande, au Japon, en Pologne et en Turquie, à 63 \% en Écosse (Royaume-Uni). La part du temps de travail consacrée à l'enseignement augmente avec le nombre annuel d'heures de cours, mais elle varie sensiblement entre les pays. À titre d'exemple, au Japon et au Portugal, les enseignants donnent presque le même nombre d'heures de cours (610 heures au Japon et 612 heures au Portugal) mais $32 \%$ du temps de travail est consacré à l'enseignement 
au Japon contre $48 \%$ au Portugal. En outre, dans certains pays, les enseignants consacrent une part quasi identique de leur temps de travail à l'enseignement même si le nombre d'heures de cours diffère nettement. En Espagne et aux États-Unis, par exemple, les enseignants du premier cycle de l'enseignement secondaire consacrent environ la moitié de leur temps de travail à l'enseignement mais donnent 713 heures de cours en Espagne, contre 966 heures aux États-Unis. Seuls les enseignants au Chili, en Écosse (Royaume-Uni), en Espagne, en Israël et en Lettonie consacrent au moins $50 \%$ de leur temps de travail statutaire à l'enseignement (voir le graphique D4.4).

Dans certains pays, le temps consacré à d'autres activités que l'enseignement n'est pas réglementé. C'est le cas en Autriche (dans le deuxième cycle de l'enseignement secondaire), au Costa Rica, dans les Communautés flamande et française de Belgique (dans l'enseignement secondaire) et en Italie. Cela ne signifie toutefois pas que les enseignants jouissent d'une liberté totale concernant ces autres tâches. En Communauté flamande de Belgique, le temps qui doit être consacré à la préparation des leçons, à la correction des copies et des devoirs des élèves et à diverses activités autres que l'enseignement, n'est pas réglementé, mais le nombre d'heures à consacrer à des activités autres que l'enseignement au sein de l'établissement est fixé par les établissements eux-mêmes. En Italie, la réglementation prévoit de consacrer jusqu'à 80 heures par an à des activités collégiales autres que l'enseignement dans les établissements. Sur ces 80 heures obligatoires par an, jusqu'à 40 doivent être consacrées aux réunions pédagogiques et de planification et aux rencontres avec les parents, et les 40 autres, aux conseils de classe (voir le tableau D4.1b).

\section{Encadré D4.3. Temps de travail et d'enseignement des chefs d'établissement}

Les chefs d'établissement constituent une ressource humaine précieuse pour les établissements, et participent à des activités d'enseignement en plus de leur charge de gestion de leur établissement. En moyenne, dans les pays de I'OCDE qui ont participé à l'enquête TALIS, les chefs d'établissement ont indiqué consacrer $16 \%$ de leur temps de travail à l'enseignement et à d'autres activités liées à l'enseignement en 2018 (OCDE, $\left.2019_{[1]}\right)$. Les chefs d'établissement peuvent être des enseignants qui ont décidé de prendre d'autres responsabilités dans l'établissement où ils travaillaient. Une récente enquête de l'OCDE s'est penchée sur la définition du temps de travail des chefs d'établissement. Les résultats de cette enquête pourraient permettre de mieux cerner les différences entre le temps de travail des enseignants et celui des chefs d'établissement.

Parmi les 27 pays participant à l'enquête, 21 ont déclaré que le même type de règlement officiel fixait le temps de travail des chefs d'établissement et celui des enseignants, pour au moins un niveau d'enseignement. Bien que le temps de travail des enseignants et celui des chefs d'établissement ne soient pas nécessairement définis par le même règlement officiel, cela peut suggérer que ces deux professions sont étroitement liées. Dans quatre pays et économies - l'Angleterre (Royaume-Uni), l'Espagne, Israël et la Slovénie -, les activités pédagogiques sont explicitement reprises comme faisant partie des responsabilités des chefs d'établissement dans la définition de leur temps de travail. En Pologne, les chefs d'établissement sont des enseignants à qui on a confié cette fonction et dont les heures d'enseignement ont été réduites voire supprimées. Le temps de travail des enseignants et celui des chefs d'établissement sont même similaires dans les quelques pays qui ont transmis des données comparables pour les enseignants et les chefs d'établissement.

Dans la plupart des 26 pays dont les données sont disponibles, il se peut que l'on demande aux chefs d'établissement de donner cours. Dans environ un tiers des pays, les chefs d'établissement sont obligés de donner cours ; dans un autre tiers, cette exigence ne s'applique que dans certaines conditions propres aux écoles. Par ailleurs, dans quelques pays, les chefs d'établissement ont la possibilité de prendre volontairement part à des activités d'enseignement (voir le graphique D4.a).

En général, les chefs d'établissement doivent participer à des activités d'enseignement à différents niveaux d'enseignement. Toutefois, dans quatre pays, ces activités varient d'un niveau d'enseignement à un autre. Le 
nombre de pays dans lesquels les chefs d'établissement prennent part à des activités d'enseignement est plus élevé pour l'enseignement primaire que pour l'enseignement préprimaire ou secondaire.

Dans la quasi-totalité des pays dont les données sur le temps d'enseignement des chefs d'établissement sont disponibles (16 pays sur 17), le temps consacré par les chefs d'établissement aux activités d'enseignement varie en fonction des caractéristiques des établissements ou selon les entités infranationales du pays. Dans 10 de ces pays, la taille et/ou la complexité des établissements affectent les activités d'enseignement des chefs d'établissement. En général, plus un établissement est grand et complexe (en termes de nombre d'élèves inscrits, de nombre d'enseignants qui y travaillent à temps plein ou de nombre de classes), moins les chefs d'établissement doivent prendre part aux activités d'enseignement. Cela implique que les chefs des établissements plus petits doivent parfois assumer la fonction d'enseignant supplémentaire et assister les enseignants qui travaillent à temps plein.

\section{Graphique D4.a. Charge d'enseignement assignée aux chefs d'établissement, selon le niveau d'enseignement (2018)}

Préprimaire

$\square$ Primaire

Q Secondaire

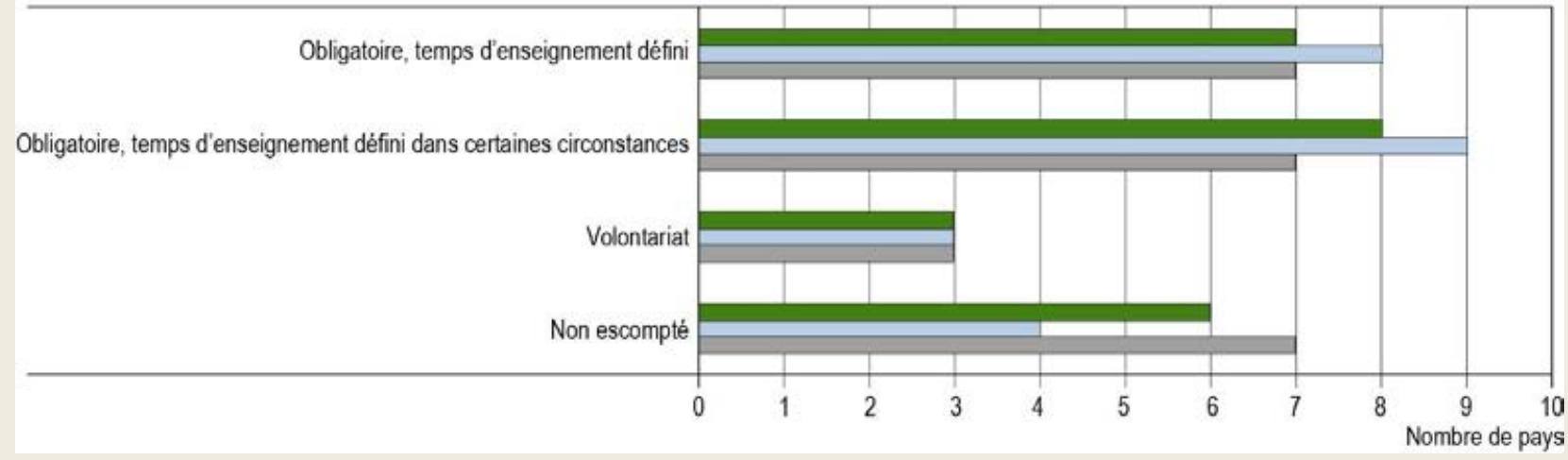

Remarque : Le secondaire inclut à la fois les filières générale et professionnelle des premier et deuxième cycles du secondaire.

Source: OCDE (2019). Consulter la section "Source» pour tout complément d'information et l'annexe 3 pour les notes (https://doi.org/10.1787/f8d7880d-en).

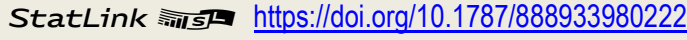

\section{Tâches et responsabilités autres que l'enseignement assignées aux enseignants}

Les tâches autres que les activités d'enseignement font partie intégrante de la charge et des conditions de travail des enseignants. Ces autres activités que l'enseignement prévues par la législation, la réglementation ou les accords entre les parties prenantes (syndicats d'enseignants, autorités locales, conseils d'établissement, etc.) ne reflètent pas nécessairement la participation effective des enseignants à ces activités. Cependant, elles offrent un aperçu de l'étendue et de la complexité du rôle des enseignants (voir l'encadré D4.3 pour des informations sur la charge de travail des chefs d'établissement).

Souvent, les enseignants n'ont pas de pouvoir de décision quant à la possibilité ou non d'effectuer certaines tâches, qui sont en général liées à l'enseignement. Conformément à la réglementation de plus de 31 des 39 pays et économies dont les données sont disponibles, parmi les autres activités comprises dans le temps de présence dans l'établissement ou dans le temps de travail total statutaires, la préparation individuelle des cours, la correction et la notation des copies et les relations avec les parents sont les plus courantes dans le premier cycle 
de l'enseignement secondaire (filière générale). Dans au moins 26 pays, le travail d'équipe et le dialogue entre collègues, ainsi que les tâches administratives générales, sont obligatoires pour les enseignants. Dans un cinquième des pays dont les données sont disponibles, cette décision reste à la discrétion des établissements scolaires. Dans 21 pays, la participation à des activités de développement professionnel est obligatoire pour les enseignants de tous les niveaux. Des contreparties incitatives telles qu'une réduction du temps d'enseignement ou une compensation financière sont rarement prévues pour la participation à ces tâches obligatoires (voir les tableaux D4.3a et D4.3b).

Les responsabilités venant s'ajouter à la charge de travail habituelle, telles que la fonction de professeur principal, la formation des futurs enseignants, la participation à la vie scolaire ou à d'autres activités de gestion, sont largement réparties entre les enseignants au sein des établissements. Les enseignants peuvent recevoir une compensation spéciale s'ils participent à la vie scolaire ou à d'autres activités de gestion. Dans certains pays, le temps d'enseignement peut être réduit pour que la charge de travail entre les tâches d'enseignement et de gestion soit équilibrée, et une compensation financière peut être octroyée. Une compensation financière et/ou une réduction du temps d'enseignement sont souvent accordées aux enseignants qui se sont acquittés volontairement de ces tâches (voir le tableau D4.3b).

Parmi les différentes tâches que les enseignants peuvent accomplir, les enseignants qui travaillent à temps plein sont souvent priés ou tenus d'orienter les élèves dans plus de deux tiers des pays et économies dont les données sont disponibles. Toutefois, en Israël, seuls les enseignants qui ont au moins un diplôme de master peuvent endosser cette responsabilité (voir le tableau D4.3b).

Les enseignants n'effectuent pas uniquement les tâches prévues par la réglementation ou les chefs d'établissement. En effet, ils effectuent souvent volontairement certaines tâches telles que s'occuper de plus de classes ou donner plus de cours que prévu dans leur contrat de travail à temps plein, participer à des activités périscolaires, superviser des enseignants stagiaires, exercer des fonctions de conseiller d'orientation et participer à des programmes de tutorat/soutien destinés aux nouveaux enseignants. Dans près de la moitié des pays, les enseignants décident d'effectuer ou non ces tâches. Jusqu'à deux tiers des pays proposent une compensation financière lorsque ces tâches sont effectuées volontairement (voir le tableau D4. 3b).

En général, les conditions à réunir pour pouvoir s'acquitter de certaines tâches et responsabilités ne varient pas entre les niveaux d'enseignement. Toutefois, des différences peuvent exister en fonction de l'évolution des besoins des élèves dans les différents niveaux d'enseignement. Par exemple, le nombre de pays où les enseignants sont tenus de surveiller les élèves pendant les pauses dans le premier cycle de l'enseignement secondaire (soit 16 pays) est moins élevé que pour l'enseignement préprimaire (22 pays) et l'enseignement primaire (20 pays) (voir le tableau D4.3a).

\section{Définitions}

Par temps réel d'enseignement, on entend le nombre d'heures de cours qu'un enseignant travaillant à temps plein donne, sur une base annuelle, à un groupe ou à une classe d'élèves, heures supplémentaires comprises. Les données peuvent provenir de registres administratifs, de bases de données statistiques, d'enquêtes par échantillonnage représentatif ou d'autres sources de données représentatives.

Le nombre de jours de cours correspond au nombre de semaines de cours multiplié par le nombre de jours de cours par semaine, déduction faite des jours de vacances pendant lesquels les établissements sont fermés.

Le nombre de semaines de cours correspond au nombre de semaines de cours, déduction faite des semaines de vacances.

Le temps d'enseignement statutaire correspond au nombre normal d'heures de cours qu'un enseignant travaillant à temps plein donne par an à un groupe ou à une classe d'élèves conformément à la réglementation, aux contrats de travail des enseignants ou à d'autres documents officiels. Le temps d'enseignement peut être 
défini sur une base hebdomadaire ou annuelle. En règle générale, le temps d'enseignement annuel est calculé comme suit : le nombre annuel de jours de cours est multiplié par le nombre d'heures de cours qu'un enseignant donne par jour (abstraction faite du temps réservé à la préparation des cours). II correspond au nombre d'heures de cours, abstraction faite du temps officiellement réservé aux pauses entre les cours ou séries de cours et des jours de vacances pendant lesquels les établissements sont fermés. Dans l'enseignement préprimaire et primaire, les courtes pauses entre les leçons sont incluses si les enseignants sont responsables de leur classe pendant ce temps.

Par temps de travail statutaire total, on entend le nombre réglementaire d'heures de travail d'un enseignant à temps plein. II peut être défini sur une base hebdomadaire ou annuelle. II ne comprend pas les heures supplémentaires rémunérées. Selon la réglementation en vigueur dans chaque pays, le temps de travail comprend :

- Les heures directement consacrées à l'enseignement ainsi qu'à d'autres activités concernant les élèves, notamment la correction des devoirs et des contrôles.

- D'une part, les heures directement consacrées à l'enseignement et, d'autre part, les heures consacrées à d'autres activités liées à l'enseignement, telles que la préparation des cours, l'orientation des élèves, la correction des devoirs et des copies, les activités de développement professionnel, les réunions avec les parents, les réunions de personnel et des tâches générales à caractère scolaire.

Par temps de présence obligatoire dans l'établissement, on entend le temps que les enseignants sont censés passer dans leur établissement, que ce soit pour enseigner ou pour se livrer à d'autres activités.

\section{Méthodologie}

Lors de l'interprétation de la variation du temps d'enseignement entre les pays, il faut tenir compte du fait que le nombre d'heures de cours, tel qu'il est défini dans le présent indicateur, ne correspond pas nécessairement à la charge d'enseignement. Le nombre d'heures de cours représente une composante importante de la charge d'enseignement, mais la préparation et le suivi des leçons (y compris la correction des copies) sont également à prendre en considération dans les comparaisons de la charge d'enseignement. D'autres éléments pertinents, comme le nombre de matières enseignées, le nombre d'élèves pris en charge et le nombre d'années pendant lesquelles les enseignants s'occupent des mêmes élèves, interviennent aussi.

Pour de plus amples informations, veuillez consulter le Guide de l'OCDE pour l'établissement de statistiques internationalement comparables dans le domaine de l'éducation 2018 (OCDE, 2019[2]) ainsi que l'annexe 3 pour les notes spécifiques aux pays (https://doi.org/10.1787/f8d7880d-en).

\section{Source}

Les données proviennent de l'Enquête OCDE-INES de 2018 sur les enseignants et les programmes et se rapportent à l'année scolaire 2017/18 (données statutaires) ou à l'année scolaire 2016/17 (données réelles).

\section{Note concernant les données d'Israël}

Les données statistiques concernant Israël sont fournies par et sous la responsabilité des autorités israéliennes compétentes. L'utilisation de ces données par l'OCDE est sans préjudice du statut des hauteurs du Golan, de Jérusalem-Est et des colonies de peuplement israéliennes en Cisjordanie aux termes du droit international. 


\section{Références}

OCDE (2019), Guide de l'OCDE pour l'établissement de statistiques internationalement comparables dans le domaine de l'éducation 2018: Concepts, normes, définitions et classifications, Éditions OCDE, Paris, https://dx.doi.org/10.1787/9789264305380-fr.

OCDE (2019), Résultats de TALIS 2018 (Volume I): Des enseignants et chefs d'établissement en formation à vie, TALIS, Éditions OCDE, Paris, https://dx.doi.org/10.1787/5bb21b3a-fr.

\section{Tableaux de l'indicateur D4}

Tableau D4.1a

Tableau D4.1b

Tableau D4.2

Tableau D4.3a

Tableau D4.3b

WEB Tableau D4.5
Organisation du temps d'enseignement des enseignants (2018)

Organisation du temps de travail des enseignants (2018)

Nombre annuel d'heures d'enseignement (2000, 2005 à 2018)

Tâches assignées aux enseignants, selon le niveau d'enseignement (2018)

Autres responsabilités assignées aux enseignants, selon le niveau d'enseignement (2018)

\section{secondaire (2017)}

Date butoir pour les données: 19 juillet 2019. Les mises à jour peuvent être consultées en ligne sur : http://dx.doi.org/10.1787/eag-data-en. D'autres données désagrégées sont également disponibles dans la Base de données de Regards sur l'éducation (http://stats.oecd.org/).

Statlink : https://doi.org/10.1787/888933981248 
Tableau D4.1a. Organisation du temps d'enseignement des enseignants (2018)

Nombre statutaire net de semaines, de jours et d'heures d'enseignement pendant l'année scolaire, dans les établissements publics

\begin{tabular}{|c|c|c|c|c|c|c|c|c|c|c|c|c|c|c|c|}
\hline & \multicolumn{5}{|c|}{ Nombre de semaines d'enseignement } & \multicolumn{5}{|c|}{ Nombre de jours d'enseignemen } & \multicolumn{5}{|c|}{ Temps net d'enseignement (en heures) } \\
\hline & 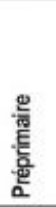 & 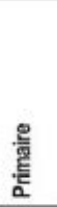 & 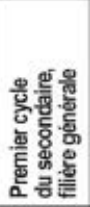 & 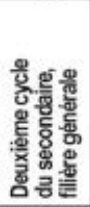 & 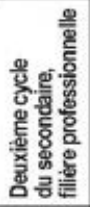 & 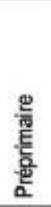 & 墨 & 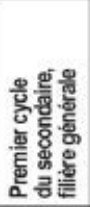 & 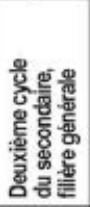 & 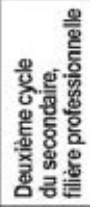 & 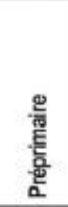 & $\begin{array}{l}\text { 量 } \\
\text { 硋 } \\
\end{array}$ & 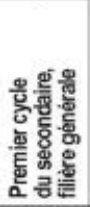 & 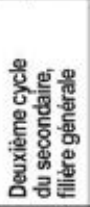 & 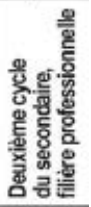 \\
\hline & (d) & (2) & (3) & (5) & (6) & (7) & (8) & (9) & (11) & (12) & (13) & (14) & (15) & (17) & (18) \\
\hline \multicolumn{16}{|l|}{ u Pays } \\
\hline Ô Australie' & 40 & 41 & 41 & 41 & 40 & 195 & 196 & 196 & 196 & 198 & 886 & 870 & 811 & 811 & 816 \\
\hline 'Autriche' & m & 38 & 38 & 38 & $\mathrm{~m}$ & $\mathrm{~m}$ & 180 & 180 & 180 & $\mathrm{~m}$ & m & 779 & 607 & 589 & $\mathrm{~m}$ \\
\hline Canada' & $\mathrm{m}$ & 37 & 37 & 37 & 40 & $\mathrm{~m}$ & 183 & 183 & 183 & 200 & $\mathrm{~m}$ & 797 & 744 & 746 & 635 \\
\hline Chill $^{2}$ & 38 & 38 & 38 & 38 & 38 & 178 & 178 & 178 & 178 & 178 & 1063 & 1063 & 1063 & 1063 & 1063 \\
\hline Colombie' & 40 & 40 & 40 & 40 & 40 & 200 & 200 & 200 & 200 & 200 & 800 & 1000 & 880 & 880 & 880 \\
\hline République tchèque' & 45 & 39 & 39 & 39 & 39 & 215 & 187 & 187 & 187 & 187 & 1333 & 617 & 617 & 589 & 589 \\
\hline Danemark ${ }^{34}$ & a & a & a & a & a & a & a & a & a & a & a & a & a & 405 & 648 \\
\hline Estonie' & 46 & 35 & 35 & 35 & 40 & 220 & 172 & 172 & 172 & 197 & 1320 & 585 & 602 & 568 & a \\
\hline Finlande $^{5}$ & $\mathrm{~m}$ & 38 & 38 & 38 & 38 & $\mathrm{~m}$ & 188 & 188 & 188 & 188 & $\mathrm{~m}$ & 677 & 592 & 550 & 692 \\
\hline France' & 36 & 36 & 36 & 36 & 36 & 162 & 162 & a & a & a & 900 & 900 & 684 & 684 & 684 \\
\hline Allemagne ${ }^{1}$ & 46 & 40 & 40 & 40 & 40 & 225 & 193 & 193 & 193 & 193 & 1755 & 800 & 744 & 717 & 724 \\
\hline Grèce $^{2}$ & 36 & 36 & 36 & 38 & 38 & 177 & 177 & 178 & 186 & 186 & 827 & 664 & 614 & 642 & 642 \\
\hline Hongrie $^{6}$ & 43 & 38 & 38 & 38 & 38 & 204 & 180 & 180 & 179 & 179 & 1306 & 648 & 648 & 644 & 644 \\
\hline Islande' & 46 & 37 & 37 & 36 & 36 & 225 & 180 & 180 & 175 & 175 & 1620 & 624 & 624 & 472 & 494 \\
\hline Irlande' & $\mathrm{m}$ & 37 & 33 & 33 & $\mathrm{~m}$ & $\mathrm{~m}$ & 181 & 165 & 165 & $\mathrm{~m}$ & $m$ & 905 & 726 & 726 & $\mathrm{~m}$ \\
\hline Israë|' & 38 & 38 & 36 & 36 & 36 & 182 & 182 & 174 & 172 & 172 & 1029 & 843 & 696 & 623 & 623 \\
\hline Italie & 42 & 39 & 39 & 39 & 39 & 187 & 172 & 172 & 172 & 172 & 933 & 755 & 617 & 617 & 617 \\
\hline $\mathrm{Japon}^{6}$ & $\mathrm{~m}$ & 40 & 40 & 39 & 39 & $\mathrm{~m}$ & 201 & 201 & 196 & 196 & $\mathrm{~m}$ & 739 & 610 & 511 & 511 \\
\hline Coree $^{6}$ & 36 & 38 & 38 & 38 & 38 & 180 & 190 & 190 & 190 & 190 & 789 & 675 & 526 & 547 & 549 \\
\hline Lettonie' & 39 & 35 & 35 & 35 & 44 & 190 & 170 & 170 & 170 & 215 & 1520 & 1020 & 1020 & 1020 & 1290 \\
\hline Lituanie' & a & 34 & 36 & 36 & a & a & 170 & 181 & 180 & a & 640 & 612 & 652 & 648 & 740 \\
\hline Luxembourg & $\mathrm{m}$ & $\mathrm{m}$ & $\mathrm{m}$ & $\mathrm{m}$ & $\mathrm{m}$ & $\mathrm{m}$ & $\mathrm{m}$ & $\mathrm{m}$ & $\mathrm{m}$ & $\mathrm{m}$ & $\mathrm{m}$ & $\mathrm{m}$ & $\mathrm{m}$ & $\mathrm{m}$ & $\mathrm{m}$ \\
\hline Mexique ${ }^{\prime}$ & 40 & 40 & 40 & 36 & 36 & 195 & 195 & 195 & 174 & 174 & 519 & 780 & 1021 & 853 & 696 \\
\hline Pays-Bas $^{2}$ & 40 & 40 & $\mathrm{~m}$ & $\mathrm{~m}$ & $\mathrm{~m}$ & 200 & 200 & $\mathrm{~m}$ & $\mathrm{~m}$ & $\mathrm{~m}$ & 930 & 930 & 750 & 750 & $\mathrm{~m}$ \\
\hline Nouvelle-Zélande' & $\mathrm{m}$ & 38 & 38 & 38 & $\mathrm{~m}$ & $\mathrm{~m}$ & 192 & 191 & 190 & $\mathrm{~m}$ & m & 922 & 840 & 760 & $\mathrm{~m}$ \\
\hline Norvegge $^{2}$ & a & 38 & 38 & 38 & 38 & 225 & 190 & 190 & 190 & 190 & a & 741 & 663 & 523 & 595 \\
\hline Pologne $^{2}$ & 45 & 37 & 37 & 37 & 37 & 217 & 178 & 178 & 176 & 176 & 1085 & 561 & 481 & 475 & 475 \\
\hline Portugal ${ }^{2}$ & 38 & 38 & 37 & 37 & 37 & 172 & 172 & 167 & 167 & 167 & 860 & 774 & 612 & 612 & 612 \\
\hline République slovaque' & 44 & 39 & 39 & 39 & 39 & 208 & 191 & 191 & 191 & 191 & 1144 & 783 & 649 & 573 & 611 \\
\hline Slovénie ${ }^{1}$ & 46 & 38 & 38 & 38 & 38 & 219 & 190 & 190 & 190 & 190 & 1314 & 627 & 627 & 570 & 570 \\
\hline Espagne' & 37 & 37 & 37 & 36 & 36 & 176 & 176 & 176 & 171 & 171 & 880 & 890 & 713 & 693 & 693 \\
\hline Suède & 47 & a & a & a & a & 224 & a & a & a & a & $\mathrm{m}$ & a & a & a & a \\
\hline Suisse $\mathrm{e}^{1,4}$ & 39 & 38 & 39 & 38 & 38 & 185 & 183 & 187 & 183 & 183 & 756 & 785 & 748 & 621 & 714 \\
\hline Turquie' & 38 & 38 & 38 & 38 & 38 & 180 & 180 & 180 & 180 & 180 & 1080 & 720 & 504 & 504 & 504 \\
\hline Etats-Unis $^{24}$ & 36 & 36 & 36 & 36 & a & 180 & 180 & 180 & 180 & a & 1011 & 1004 & 966 & 966 & a \\
\hline \multicolumn{16}{|l|}{ Economies } \\
\hline Comm. flamande (Belgique)' & 37 & 37 & 37 & 37 & 37 & 159 & 159 & 160 & 160 & 160 & 734 & 748 & 667 & 622 & 874 \\
\hline Comm. française (Belgique)' & 36 & 36 & 36 & 36 & 36 & 179 & 179 & 179 & 179 & 179 & 775 & 716 & 657 & 596 & 596 \\
\hline Angleterre (RU) & 38 & 38 & 38 & 38 & a & 190 & 190 & 190 & 190 & a & a & a & a & a & a \\
\hline Ecosse (RU) $)^{2}$ & 38 & 38 & 38 & 38 & a & 190 & 190 & 190 & 190 & a & 855 & 855 & 855 & 855 & a \\
\hline Moyenne OCDE & 40 & 38 & 38 & 37 & 38 & 195 & 183 & 183 & 182 & 185 & 1024 & 783 & 709 & 667 & 682 \\
\hline Moyenne UE23 & 41 & 37 & 37 & 37 & 38 & 195 & 180 & 179 & 179 & 183 & 1062 & 754 & 673 & 643 & 688 \\
\hline \& Argentine & $\mathrm{m}$ & $\mathrm{m}$ & $\mathrm{m}$ & m & $\mathrm{m}$ & $\mathrm{m}$ & $\mathrm{m}$ & $\mathrm{m}$ & $\mathrm{m}$ & $\mathrm{m}$ & $\mathrm{m}$ & $\mathrm{m}$ & $\mathrm{m}$ & $\mathrm{m}$ & $\mathrm{m}$ \\
\hline Brésil & 42 & 42 & 42 & 42 & 42 & 200 & 200 & 200 & 200 & 200 & m & $\mathrm{m}$ & $\mathrm{m}$ & m & $\mathrm{m}$ \\
\hline Chine & $\mathrm{m}$ & $\mathrm{m}$ & $\mathrm{m}$ & $\mathrm{m}$ & $\mathrm{m}$ & $\mathrm{m}$ & $\mathrm{m}$ & $\mathrm{m}$ & $\mathrm{m}$ & $\mathrm{m}$ & m & $\mathrm{m}$ & $\mathrm{m}$ & $\mathrm{m}$ & $\mathrm{m}$ \\
\hline Costa Rica' & 41 & 41 & 41 & 41 & 41 & 198 & 198 & 198 & 198 & 198 & 812 & 1188 & 1267 & 1267 & 1267 \\
\hline${ }^{a}$ Inde & $\mathrm{m}$ & $\mathrm{m}$ & m & m & $\mathrm{m}$ & m & $\mathrm{m}$ & m & $\mathrm{m}$ & $\mathrm{m}$ & m & $\mathrm{m}$ & $\mathrm{m}$ & $\mathrm{m}$ & $\mathrm{m}$ \\
\hline Indonésie & $\mathrm{m}$ & m & $\mathrm{m}$ & $\mathrm{m}$ & m & $\mathrm{m}$ & $\mathrm{m}$ & m & m & m & m & m & $\mathrm{m}$ & m & m \\
\hline Fédération de Russie ${ }^{3}$ & $\mathrm{~m}$ & 34 & 35 & 35 & $\mathrm{~m}$ & $\mathrm{~m}$ & 170 & 210 & 210 & $\mathrm{~m}$ & m & 561 & 483 & 483 & $\mathrm{~m}$ \\
\hline Arabie saoudite & $\mathrm{m}$ & $\mathrm{m}$ & m & $\mathrm{m}$ & $\mathrm{m}$ & $\mathrm{m}$ & $\mathrm{m}$ & m & $\mathrm{m}$ & $\mathrm{m}$ & m & $\mathrm{m}$ & $\mathrm{m}$ & $\mathrm{m}$ & $\mathrm{m}$ \\
\hline Afrique du Sud & $\mathrm{m}$ & m & m & $\mathrm{m}$ & $\mathrm{m}$ & m & m & m & $\mathrm{m}$ & $\mathrm{m}$ & m & m & m & $\mathrm{m}$ & $\mathrm{m}$ \\
\hline
\end{tabular}

Moyenne G20

Remarque : Consulter les sections « Définitions » et « Méthodologie » pour de plus amples informations. Les données sur la filière professionnelle du premier cycle du secondaire (soit les colonnes 4, 10 et 16) peuvent être consultées en ligne. Les données peuvent être consultées sur http://stats.oecd.orgl, Base de données de Regards sur l'éducation.

1. Temps typique d'enseignement (temps d'enseignement requis auprès de la plupart des enseignants lorsqu'aucune circonstance particulière ne s'applique).

2. Temps maximum d'enseignement.

3. Temps réel d'enseignement.

4. Année de référence : 2017 pour le Danemark et la Suisse, 2016 pour les États-Unis.

5. Temps minimum d'enseignement.

6. Temps d'enseignement moyen planifié dans chaque établissement au début de l'année ou du semestre scolaire.

Source : OCDE (2019). Consulter la section « Source » pour tout complément d'information et l'annexe 3 pour les notes (https://doi.org/10.1787/f8d7880d-en). Les symboles représentant les données manquantes et les abréviations figurent dans le Guide du lecteur. 
Tableau D4.1b. Organisation du temps de travail des enseignants (2018)

Temps de travail statutaire des enseignants au sein de l'établissement et temps total de travail pendant l'année scolaire, établissements publics

\begin{tabular}{|c|c|c|c|c|c|c|c|c|c|c|}
\hline & \multicolumn{5}{|c|}{ Temps de travail requis dans l'établissement (en heures) } & \multicolumn{5}{|c|}{ Temps de travail statutaire total (en heures) } \\
\hline & 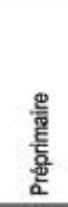 & $\begin{array}{l}\text { 兽 } \\
\text { हू } \\
\text { है }\end{array}$ & 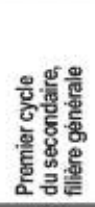 & 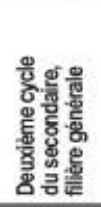 & 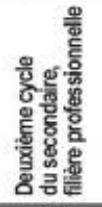 & 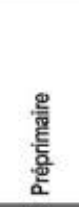 & 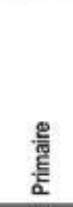 & 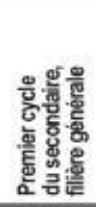 & 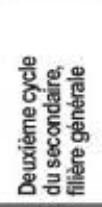 & 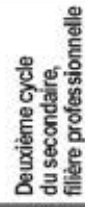 \\
\hline & (1) & (2) & (3) & (5) & (6) & (7) & (8) & (9) & (11) & (12) \\
\hline \multicolumn{11}{|l|}{ w Pays } \\
\hline Australie & $\mathrm{m}$ & $\mathrm{m}$ & m & $\mathrm{m}$ & m & $\mathrm{m}$ & $\mathrm{m}$ & m & m & m \\
\hline Autriche & $\mathrm{m}$ & a & a & a & a & a & 1776 & 1776 & a & a \\
\hline Canada & m & 1228 & 1233 & 1236 & 1280 & m & m & m & m & 1280 \\
\hline Chili & 1830 & 1830 & 1830 & 1830 & 1830 & 1962 & 1962 & 1962 & 1962 & 1962 \\
\hline Colombie & 1350 & 1350 & 1350 & 1350 & 1350 & 1800 & 1800 & 1800 & 1800 & 1800 \\
\hline République tchèque & a & a & a & a & a & 1800 & 1560 & 1560 & 1560 & 1560 \\
\hline Danemark & a & a & a & a & a & 1680 & 1680 & 1680 & 1680 & 1680 \\
\hline Estonie & 1610 & a & a & a & a & 1610 & 1540 & 1540 & 1540 & 1540 \\
\hline Finlande & $\mathrm{m}$ & 815 & 730 & 669 & 797 & a & a & a & a & a \\
\hline France & 954 & 954 & a & a & a & 1607 & 1607 & 1607 & 1607 & 1607 \\
\hline Allemagne & a & a & a & a & a & 1769 & 1769 & 1769 & 1769 & 1769 \\
\hline Grece & 1134 & 1134 & 1170 & 1170 & 1170 & a & a & a & a & a \\
\hline Hongric & 1476 & 1152 & 1152 & 1146 & 1146 & 1632 & 1632 & 1632 & 1632 & 1632 \\
\hline Islande & 1760 & 1610 & 1610 & 1440 & 1440 & 1800 & 1800 & 1800 & 1800 & 1800 \\
\hline Irlande & $\mathrm{m}$ & 1073 & 811 & 811 & $\mathrm{~m}$ & a & a & a & a & a \\
\hline Israël & 1066 & 1235 & 1178 & 1195 & 1195 & 1066 & 1235 & 1178 & 1195 & 1195 \\
\hline Italie & a & a & a & a & a & a & a & a & a & a \\
\hline Japon & a & a & a & a & a & 1891 & 1891 & 1891 & 1891 & 1891 \\
\hline Corée & a & a & a & a & a & 1520 & 1520 & 1520 & 1520 & 1520 \\
\hline Lettonie & 1560 & 1050 & 1050 & 1050 & 1320 & 1760 & 1760 & 1760 & 1760 & 1760 \\
\hline Lituanie & 1452 & a & a & a & a & 1584 & 1584 & 1584 & 1584 & 1584 \\
\hline Luxembourg & $\mathrm{m}$ & $\mathrm{m}$ & $\mathrm{m}$ & $\mathrm{m}$ & $\mathrm{m}$ & $\mathrm{m}$ & $\mathrm{m}$ & $\mathrm{m}$ & $\mathrm{m}$ & $\mathrm{m}$ \\
\hline Mexique & 772 & 800 & 1167 & a & a & a & a & a & a & a \\
\hline Pays-Bas & a & a & a & a & a & 1659 & 1659 & 1659 & 1659 & 1659 \\
\hline Nouvelle-Zélande & $\mathrm{m}$ & 1536 & 1243 & 950 & $\mathrm{~m}$ & a & 1616 & a & a & a \\
\hline Norvège & a & 1300 & 1225 & 1150 & 1150 & a & 1688 & 1688 & 1688 & 1688 \\
\hline Pologne & a & a & a & a & a & 1808 & 1488 & 1488 & 1472 & 1472 \\
\hline Portugal & 1021 & 935 & 810 & 810 & 810 & 1308 & 1308 & 1283 & 1283 & 1283 \\
\hline République slovaque & $\mathrm{m}$ & $\mathrm{m}$ & $\mathrm{m}$ & $\mathrm{m}$ & $\mathrm{m}$ & 1560 & 1560 & 1560 & 1560 & 1560 \\
\hline Slovénie & a & a & a & a & a & $\mathrm{m}$ & $\mathrm{m}$ & $\mathrm{m}$ & $\mathrm{m}$ & $\mathrm{m}$ \\
\hline Espagne & 1140 & 1140 & 1140 & 1140 & 1140 & 1425 & 1425 & 1425 & 1425 & 1425 \\
\hline Suède & 1792 & 1360 & 1360 & 1360 & 1360 & a & 1767 & 1767 & 1767 & 1767 \\
\hline Suisse & a & a & a & a & a & 1930 & 1930 & 1930 & 1930 & 1930 \\
\hline Turquie & 1160 & 980 & 836 & 836 & 836 & 1592 & 1592 & 1592 & 1592 & 1592 \\
\hline Etats-Unis ${ }^{1}$ & 1441 & 1443 & 1449 & 1446 & a & 1980 & 2016 & 2032 & 2047 & a \\
\hline \multicolumn{11}{|l|}{ Economies } \\
\hline Comm. flamande (Belgique) & 916 & 916 & a & a & a & a & a & a & a & a \\
\hline Comm. française (Belgique) & a & a & a & a & a & 962 & 962 & a & a & a \\
\hline Angleterre (RU) & a & a & a & a & a & 1265 & 1265 & 1265 & 1265 & a \\
\hline Ecosse (RU) & 1045 & 1045 & 1045 & 1045 & a & 1365 & 1365 & 1365 & 1365 & a \\
\hline $\begin{array}{l}\text { Moyenne OCDE } \\
\text { Moyenne UE23 }\end{array}$ & $\begin{array}{l}\mathrm{m} \\
\mathrm{m}\end{array}$ & $\begin{array}{l}\mathrm{m} \\
\mathrm{m}\end{array}$ & $\begin{array}{l}\mathrm{m} \\
\mathrm{m}\end{array}$ & m & $\begin{array}{l}\mathrm{m} \\
\mathrm{m}\end{array}$ & $\begin{array}{l}1613 \\
1550\end{array}$ & $\begin{array}{l}1612 \\
1539\end{array}$ & $\begin{array}{l}1634 \\
1572\end{array}$ & $\begin{array}{l}1629 \\
1558\end{array}$ & $\begin{array}{l}1623 \\
1593\end{array}$ \\
\hline
\end{tabular}

\begin{tabular}{|c|c|c|c|c|c|c|c|c|c|c|}
\hline \& Argentine & $\mathrm{m}$ & $\mathrm{m}$ & m & $\mathrm{m}$ & $\mathrm{m}$ & $\mathrm{m}$ & $\mathrm{m}$ & $\mathrm{m}$ & $\mathrm{m}$ & $\mathrm{m}$ \\
\hline Brésil & a & a & a & a & a & a & a & a & a & a \\
\hline Chine & m & $\mathrm{m}$ & $\mathrm{m}$ & $\mathrm{m}$ & $\mathrm{m}$ & m & $\mathrm{m}$ & m & $\mathrm{m}$ & $\mathrm{m}$ \\
\hline Costa Rica & a & a & a & a & a & a & a & a & a & a \\
\hline Inde & $\mathrm{m}$ & $\mathrm{m}$ & $\mathrm{m}$ & $\mathrm{m}$ & m & $\mathrm{m}$ & $\mathrm{m}$ & $\mathrm{m}$ & $\mathrm{m}$ & $\mathrm{m}$ \\
\hline Indonésie & $\mathrm{m}$ & $\mathrm{m}$ & $\mathrm{m}$ & $\mathrm{m}$ & $\mathrm{m}$ & $\mathrm{m}$ & $\mathrm{m}$ & $\mathrm{m}$ & $\mathrm{m}$ & $\mathrm{m}$ \\
\hline Federation de Russie & a & a & a & a & $\mathrm{m}$ & $\mathrm{m}$ & $\mathrm{m}$ & $\mathrm{m}$ & $\mathrm{m}$ & $\mathrm{m}$ \\
\hline Arabie saoudite & $\mathrm{m}$ & $\mathrm{m}$ & $\mathrm{m}$ & $\mathrm{m}$ & $\mathrm{m}$ & $\mathrm{m}$ & $\mathrm{m}$ & $\mathrm{m}$ & $\mathrm{m}$ & $\mathrm{m}$ \\
\hline Afrique du Sud & $\mathrm{m}$ & $\mathrm{m}$ & $\mathrm{m}$ & $\mathrm{m}$ & $\mathrm{m}$ & $\mathrm{m}$ & $\mathrm{m}$ & $\mathrm{m}$ & $\mathrm{m}$ & $\mathrm{m}$ \\
\hline
\end{tabular}

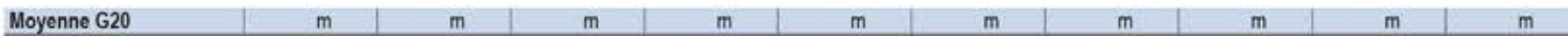

Remarque : Consulter les sections « Définitions » et « Méthodologie » pour de plus amples informations. Les données sur la filière professionnelle du premier cycle du secondaire (soit les colonnes 4 et 10) peuvent être consultées en ligne. Les données peuvent être consultées sur http://stats.oecd.org/, Base de données de Regards sur l'éducation.

1. Année de référence : 2016.

Source : OCDE (2019). Consulter la section « Source » pour tout complément d'information et l'annexe 3 pour les notes (https://doi.org/10.1787/f8d7880d-en).

Les symboles représentant les données manquantes et les abréviations figurent dans le Guide du lecteur. 
Tableau D4.2. Nombre annuel d'heures d'enseignement (2000, 2005 à 2018)

Temps statutaire net de contact dans les établissements publics, selon le niveau d'enseignement

\begin{tabular}{|c|c|c|c|c|c|c|c|c|c|c|c|c|c|c|c|}
\hline & \multicolumn{5}{|c|}{ Primaire } & \multicolumn{5}{|c|}{ Premier cycle du secondaire, filière gènèrale } & \multicolumn{5}{|c|}{ Deuxième cycle du secondaire, filière gènérale } \\
\hline & 2000 & 2005 & 2010 & 2015 & 2018 & 2000 & 2005 & 2010 & 2015 & 2018 & 2000 & 2005 & 2010 & 2015 & 2018 \\
\hline & (16) & (17) & (22) & (27) & (30) & (31) & (32) & (37) & (42) & (45) & (46) & $(47)$ & (52) & (57) & $(60)$ \\
\hline \multicolumn{16}{|l|}{ w Pays } \\
\hline Australic & 882 & 888 & 868 & 866 & 870 & 811 & 810 & 819 & 806 & 811 & 803 & 810 & 803 & 804 & 811 \\
\hline Autriche' & $\mathrm{m}$ & 774 & 779 & 779 & 779 & $\mathrm{~m}$ & 607 & 607 & 607 & 607 & $\mathrm{~m}$ & 589 & 589 & 589 & 589 \\
\hline Canada & m & $\mathrm{m}$ & 799 & 797 & 797 & $\mathrm{~m}$ & $\mathrm{~m}$ & 740 & 742 & 744 & $\mathrm{~m}$ & $\mathrm{~m}$ & 744 & 743 & 746 \\
\hline Chili & $\mathrm{m}$ & 1128 & 1105 & 1157 & 1063 & m & 1128 & 1105 & 1157 & 1063 & $\mathrm{~m}$ & 1128 & 1105 & 1157 & 1063 \\
\hline Colombie & m & 1000 & 1000 & 1000 & 1000 & m & 1200 & 1200 & 1200 & $880^{\circ}$ & $\mathrm{m}$ & 1200 & 1200 & 1200 & $880^{\circ}$ \\
\hline République tchéque ${ }^{1}$ & $\mathrm{~m}$ & 813 & 862 & 823 & 617 & 650 & 647 & 647 & 617 & 617 & 621 & 617 & 617 & 589 & 589 \\
\hline Danemark $^{2}$ & 640 & 640 & 650 & $784^{\circ}$ & a & 640 & 640 & 650 & $784^{\circ}$ & a & $\mathrm{m}$ & $\mathrm{m}$ & 377 & 386 & a \\
\hline Estonie & 630 & 630 & 630 & 619 & 585 & 630 & 630 & 630 & 619 & 602 & 578 & 578 & 578 & 568 & 568 \\
\hline Finlande & 656 & 677 & 680 & 677 & 677 & 570 & 592 & 595 & 592 & 592 & 527 & 550 & 553 & 550 & 550 \\
\hline France & 924 & 924 & 924 & 900 & 900 & 648 & 648 & 648 & 648 & 684 & 648 & 648 & 648 & 648 & 684 \\
\hline Allemagne & 783 & 808 & 805 & 799 & 800 & 732 & 758 & 756 & 750 & 744 & 690 & 714 & 713 & 714 & 717 \\
\hline Grèce & 609 & 604 & 589 & $630^{\circ}$ & 664 & 426 & 434 & 415 & $592^{\circ}$ & 614 & 429 & 430 & 415 & $600^{\circ}$ & 642 \\
\hline Hongrie & 583 & 583 & 604 & 652 & 648 & 555 & 555 & 604 & 652 & 648 & 555 & 555 & 604 & 648 & 644 \\
\hline Islande & 629 & 671 & 624 & $\mathrm{~m}$ & 624 & 629 & 671 & 624 & $\mathrm{~m}$ & 624 & 464 & 560 & 544 & $\mathrm{~m}$ & 472 \\
\hline Irlande & 915 & 915 & 915 & 915 & 905 & 735 & 735 & 735 & 735 & 726 & 735 & 735 & 735 & 735 & 726 \\
\hline Israë| & 731 & 731 & 820 & 864 & 843 & 579 & 579 & 598 & 704 & 696 & 524 & 524 & 521 & 587 & 623 \\
\hline Italie & 744 & 739 & 770 & 752 & 755 & 608 & 605 & 630 & 616 & 617 & 608 & 605 & 630 & 616 & 617 \\
\hline Japon ${ }^{3}$ & 635 & 578 & 707 & 742 & 739 & 557 & 505 & 602 & 610 & 610 & 478 & 429 & 500 & 511 & 511 \\
\hline Corée $^{3}$ & 865 & 883 & 807 & 658 & 675 & 570 & 621 & 627 & 548 & 526 & 530 & 605 & 616 & 551 & 547 \\
\hline Lettonie & 882 & 882 & 882 & $685^{\circ}$ & 1020 & 882 & 882 & 882 & $685^{\circ}$ & 1020 & 882 & 882 & 882 & $685^{\circ}$ & 1020 \\
\hline Lituanie & $\mathrm{m}$ & $\mathrm{m}$ & $\mathrm{m}$ & 565 & 612 & $\mathrm{~m}$ & $\mathrm{~m}$ & $\mathrm{~m}$ & 610 & 652 & m & $\mathrm{m}$ & $\mathrm{m}$ & 610 & 648 \\
\hline Luxembourg & $\mathrm{m}$ & 774 & 739 & 810 & $\mathrm{~m}$ & $\mathrm{~m}$ & 642 & 634 & 739 & $\mathrm{~m}$ & m & 642 & 634 & 739 & $\mathrm{~m}$ \\
\hline Mexique & 800 & 800 & 800 & 800 & 780 & 1182 & 1047 & 1047 & 1047 & 1021 & m & 848 & 843 & 848 & 853 \\
\hline Pays-Bas & 930 & 930 & 930 & 930 & 930 & 867 & 750 & 750 & 750 & 750 & 867 & 750 & 750 & 750 & 750 \\
\hline Nouvelle-Zelande & $\mathrm{m}$ & $\mathrm{m}$ & $\mathrm{m}$ & 922 & 922 & $\mathrm{~m}$ & $\mathrm{~m}$ & $\mathrm{~m}$ & 840 & 840 & $\mathrm{~m}$ & $\mathrm{~m}$ & $\mathrm{~m}$ & 760 & 760 \\
\hline Norvége & 713 & 741 & 741 & 741 & 741 & 633 & 656 & 654 & 663 & 663 & 505 & 524 & 523 & 523 & 523 \\
\hline Pologne & $\mathrm{m}$ & $\mathrm{m}$ & 586 & 573 & 561 & $\mathrm{~m}$ & $\mathrm{~m}$ & 497 & 486 & 481 & $\mathrm{~m}$ & $\mathrm{~m}$ & 494 & 481 & 475 \\
\hline Portugal & 779 & 765 & 779 & 743 & 774 & 634 & 623 & 634 & 605 & 612 & 577 & 567 & 634 & 605 & 612 \\
\hline Republique slovaque & $\mathrm{m}$ & $\mathrm{m}$ & 841 & 832 & 783 & $\mathrm{~m}$ & $\mathrm{~m}$ & 652 & 645 & 649 & $\mathrm{~m}$ & $\mathrm{~m}$ & 624 & 617 & 573 \\
\hline Slovénie & m & 627 & 627 & 627 & 627 & $\mathrm{~m}$ & 627 & 627 & 627 & 627 & m & 570 & 570 & 570 & 570 \\
\hline Espagne & 880 & 880 & 880 & 880 & 880 & 713 & 713 & 713 & 713 & 713 & 693 & 693 & 693 & 693 & 693 \\
\hline Suede & $\mathrm{m}$ & $\mathrm{m}$ & $\mathrm{m}$ & a & a & $\mathrm{m}$ & $\mathrm{m}$ & $\mathrm{m}$ & a & a & $\mathrm{m}$ & $\mathrm{m}$ & $\mathrm{m}$ & a & a \\
\hline Suisse $^{2}$ & $\mathrm{~m}$ & m & $\mathrm{m}$ & 810 & $\mathrm{~m}$ & $\mathrm{~m}$ & m & m & 765 & m & m & m & $\mathrm{m}$ & 656 & $\mathrm{~m}$ \\
\hline Turquie & 720 & 720 & 720 & 720 & 720 & 504 & 504 & 504 & 504 & 504 & 567 & 567 & 567 & 504 & 504 \\
\hline Etats-Unis ${ }^{2}$ & $\mathrm{~m}$ & m & m & 1004 & m & $\mathrm{m}$ & m & m & 966 & m & m & m & m & 966 & m \\
\hline \multicolumn{16}{|l|}{ Economies } \\
\hline Comm. flamande (Belgique) & 754 & 748 & 748 & 744 & 748 & $\mathrm{~m}$ & $682^{\circ}$ & 666 & 663 & 667 & m & $637^{\circ}$ & 622 & 618 & 622 \\
\hline Comm. française (Belgique) & 722 & 722 & 732 & 728 & 716 & 662 & 662 & 671 & 668 & 657 & 603 & 603 & 610 & 606 & 596 \\
\hline England $(R U)^{2}$ & $\mathrm{~m}$ & $\mathrm{~m}$ & 684 & m & a & $\mathrm{m}$ & $\mathrm{m}$ & 703 & m & a & $\mathrm{m}$ & $\mathrm{m}$ & 703 & $\mathrm{~m}$ & a \\
\hline Ecosse (RU) & 950 & 893 & 855 & 855 & 855 & 893 & 893 & 855 & 855 & 855 & 893 & 893 & 855 & 855 & 855 \\
\hline $\begin{array}{l}\text { Moyenne OCDE } \\
\text { Moyenne des pays }\end{array}$ & 765 & 782 & 779 & 788 & 776 & 680 & 702 & 698 & 717 & 700 & 626 & 671 & 662 & 674 & 668 \\
\hline $\begin{array}{l}\text { I'OCDE dont les donnees } \\
\text { de } 2000,2005,2010,2015 \\
\text { et } 2018 \text { sont disponibles }\end{array}$ & 771 & 769 & 775 & 769 & 783 & 682 & 673 & 681 & 685 & 695 & 634 & 632 & 640 & 635 & 656 \\
\hline $\begin{array}{l}\text { Moyenne des pays de } \\
\text { l'UE } 23 \text { dont les donnees } \\
\text { Ede } 2000,205,2010,2015 \\
\text { et } 2018 \text { sont disponibles }\end{array}$ & 774 & 71 & 773 & 768 & 790 & 678 & 673 & 676 & 680 & 697 & 660 & 655 & 661 & 657 & 684 \\
\hline of Argentine & m & m & m & $\mathrm{m}$ & m & $m$ & $\mathrm{~m}$ & m & m & $\mathrm{m}$ & $\mathrm{m}$ & $m$ & $\mathrm{~m}$ & $m$ & $m$ \\
\hline Brésil & $\mathrm{m}$ & $\mathrm{m}$ & $\mathrm{m}$ & $\mathrm{m}$ & $\mathrm{m}$ & $\mathrm{m}$ & $\mathrm{m}$ & $\mathrm{m}$ & m & $\mathrm{m}$ & $\mathrm{m}$ & $\mathrm{m}$ & $\mathrm{m}$ & m & $\mathrm{m}$ \\
\hline Chine & $\mathrm{m}$ & $\mathrm{m}$ & $\mathrm{m}$ & m & $\mathrm{m}$ & m & $\mathrm{m}$ & $\mathrm{m}$ & m & $\mathrm{m}$ & m & m & $\mathrm{m}$ & m & $\mathrm{m}$ \\
\hline Costa Rica & $\mathrm{m}$ & $\mathrm{m}$ & $\mathrm{m}$ & 1188 & 1188 & $\mathrm{~m}$ & $\mathrm{~m}$ & $\mathrm{~m}$ & 1267 & 1267 & $\mathrm{~m}$ & $\mathrm{~m}$ & $\mathrm{~m}$ & 1267 & 1267 \\
\hline Inde & $\mathrm{m}$ & $\mathrm{m}$ & $\mathrm{m}$ & $\mathrm{m}$ & $\mathrm{m}$ & $\mathrm{m}$ & $\mathrm{m}$ & $\mathrm{m}$ & m & $\mathrm{m}$ & m & $\mathrm{m}$ & m & m & m \\
\hline Indonésie & $\mathrm{m}$ & m & m & m & $\mathrm{m}$ & m & m & m & $\mathrm{m}$ & $\mathrm{m}$ & m & $\mathrm{m}$ & $\mathrm{m}$ & m & $\mathrm{m}$ \\
\hline Fèdération de Russie ${ }^{2}$ & $\mathrm{~m}$ & 615 & 615 & 561 & 561 & $\mathrm{~m}$ & 507 & 507 & 483 & 483 & m & 507 & 507 & 483 & 483 \\
\hline Arable saoudite & $\mathrm{m}$ & $\mathrm{m}$ & $\mathrm{m}$ & m & $\mathrm{m}$ & $\mathrm{m}$ & $\mathrm{m}$ & $\mathrm{m}$ & $\mathrm{m}$ & $\mathrm{m}$ & $\mathrm{m}$ & $\mathrm{m}$ & $\mathrm{m}$ & m & $\mathrm{m}$ \\
\hline Afrique du Sud & m & m & $\mathrm{m}$ & m & m & m & $\mathrm{m}$ & $\mathrm{m}$ & m & m & m & m & $\mathrm{m}$ & m & m \\
\hline
\end{tabular}

Remarque : Consulter les sections « Définitions » et « Méthodologie » pour de plus amples informations. Les données de 2000 à 2018 relatives à l'enseignement préprimaire (soit les colonnes 1-15) peuvent être consultées en ligne. Les données de 2006, 2007, 2008, 2009, 2011, 2012, 2013, 2014,2016 et 2017 relatives à l'enseignement primaire, et aux premier et deuxième cycles du secondaire (soit les colonnes $18-21 ; 23-26$; $28-29 ; 33-36$; 38-41; 43-44; 48-51;53-56; 58-59) peuvent être consultées sur http://stats.oecd.org/, Base de données de Regards sur l'éducation ou via le StatLink ci-dessous.

1. Les données relatives au niveau préprimaire font référence aux enseignants du primaire (dans des établissements d'enseignement primaire uniquement) enseignant dans des classes de niveau préprimaire.

2. Temps réel d'enseignement (au Danemark, à l'exception du niveau préprimaire)

3. Temps d'enseignement moyen planifié dans chaque établissement au début de l'année ou du semestre scolaire.

Source : OCDE (2019). Consulter la section « Source » pour tout complément d'information et l'annexe 3 pour les notes (https://doi.org/10.1787/f8d7880d-en). Les symboles représentant les données manquantes et les abréviations figurent dans le Guide du lecteur. 
Tableau D4.3a. Tâches assignées aux enseignants, selon le niveau d'enseignement (2018)

Tâches assignées aux enseignants dans les établissements publics, telles que définies explicitement dans la règlementation et/ou les directives

\begin{tabular}{|c|c|c|c|c|c|c|c|c|c|c|c|c|c|}
\hline & \multicolumn{13}{|c|}{ Premier cycle du secondaire, filière gènérale } \\
\hline & \multirow[b]{2}{*}{ 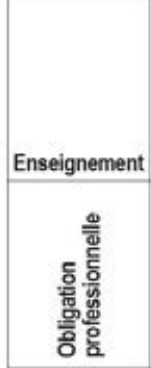 } & \multicolumn{2}{|c|}{$\begin{array}{l}\text { Planification } \\
\text { ou préparation } \\
\text { individuelle des } \\
\text { seances dans } \\
\text { Pétablissement } \\
\text { ou ailleurs }\end{array}$} & \multicolumn{2}{|c|}{$\begin{array}{l}\text { Correction des } \\
\text { copies des élèves }\end{array}$} & \multicolumn{2}{|c|}{$\begin{array}{l}\text { Travaux administratifs } \\
\text { d'ordre géneral (dont } \\
\text { communication et táches } \\
\text { administratives et de } \\
\text { secrétariat a effectuer dans } \\
\text { le cadre des fonctions } \\
\text { d'enseignant) }\end{array}$} & \multicolumn{2}{|c|}{$\begin{array}{c}\text { Communication et } \\
\text { coopération avec les } \\
\text { parents ou les tuteurs }\end{array}$} & \multicolumn{2}{|c|}{$\begin{array}{l}\text { Surveillance des } \\
\text { éleves durant les } \\
\text { pauses }\end{array}$} & \multicolumn{2}{|c|}{$\begin{array}{l}\text { Travail et dialogue } \\
\text { avec des collegues } \\
\text { au sein ou en dehors } \\
\text { de Pétablissement }\end{array}$} \\
\hline & & 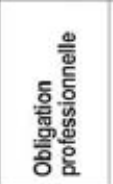 & 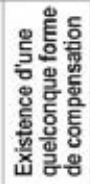 & 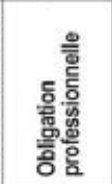 & 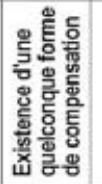 & 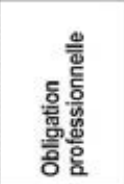 & 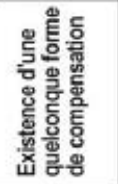 & 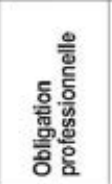 & 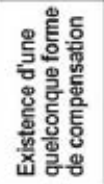 & 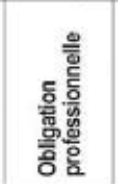 & 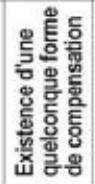 & 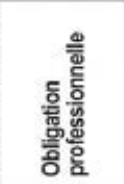 & 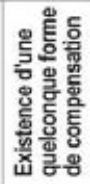 \\
\hline & (1) & (2) & (3) & (6) & (7) & (10) & (11) & (14) & (15) & (18) & (19) & (22) & (23) \\
\hline \multicolumn{14}{|l|}{ w Pays } \\
\hline Oustralie & Obl. & Obl. & Aucune & Obl. & Aucune & Obl. & Aucune & Obl. & Aucune & Od. & Aucune & Obl. & Aucune \\
\hline Autriche & Obl. & Obl. & Aucune & Obl. & Aucune & Obl. & Aucune & Obl. & Aucune & Obl. & Aucune & Obl. & Aucune \\
\hline Canada & $\mathrm{m}$ & m & m & $\mathrm{m}$ & $\mathrm{m}$ & m & m & m & m & m & m & $\mathrm{m}$ & m \\
\hline Chili & Obl. & Ob. & T & Obl. & T & Req ét. & T & Req et. & T & Req et. & T & Req. ét & T \\
\hline Colombie & Obl. & Obl. & Aucune & Obl. & Aucune & Obl. & Aucune & obl. & Aucune & obl. & Aucune & Obl. & Aucune \\
\hline Republique tchèque & Obl. & Volontariat & $\mathrm{m}$ & Volontariat & $\mathrm{m}$ & Req ét. & $\mathrm{m}$ & Volontariat & $\mathrm{m}$ & Req èt. & $\mathrm{m}$ & Req ét. & $\mathrm{m}$ \\
\hline Danemark & Obl. & Obl. & Aucune & obl. & Aucune & obl. & Aucune & obl. & Aucune & Req êt. & Aucune & Obl. & Aucune \\
\hline Estonic & Obl. & Obl. & Aucune & Obl. & Aucune & Obl. & Aucune & obl. & Aucune & Req est. & Aucune & Obl. & Aucune \\
\hline Finlande & Obl. & Obl. & Aucune & Obl. & Aucune & Obl. & Aucune & Obl. & Aucune & Req èt. & Aucune & Obl. & Aucune \\
\hline France & Obl. & Obl. & $\mathrm{F}$ & od. & $\mathrm{F}$ & obl. & $\mathrm{F}$ & obl. & $\mathrm{F}$ & Non req & Aucune & Obl. & $\mathrm{F}$ \\
\hline Allemagne & Obl. & Obl. & Aucune & Obl. & Aucune & Req ét. & Aucune & Obl. & Aucune & Req êt. & Aucune & Volontaniat & Aucune \\
\hline Grèce & Obl. & Obl. & Aucune & Obl. & Aucune & obl. & Aucune & Obl. & Aucune & obl. & Aucune & Obl. & Aucune \\
\hline Hongrie & Obl. & Obl. & Aucune & Obl. & Aucune & Obl. & Aucune & Obl & Aucine & Obl. & Aucune & Obl. & Aucune \\
\hline Islande & Obl. & Obl. & Aucune & Obl. & Aucune & Req ét. & Aucune & Req èt. & $\mathrm{T}$ & Volontariat & Aucune & Req. èt & Aucune \\
\hline Irlande & Obl. & Obl. & Aucune & Obl & Aucune & Obl. & Aucune & obl. & Aucune & Obl. & Aucune & Obl. & Aucune \\
\hline |sraē| & Obl. & Obl. & $F$ & Obl. & Aucune & Obl. & $\mathrm{F}$ & obl. & Aucune & Obl. & Aucune & Obl. & $F$ \\
\hline Italie & Obl. & obl. & Aucune & Obl. & Aucune & obl. & Aucune & Obl. & Aucune & Obl. & Aucune & Obl. & Aucune \\
\hline Japon & Obl. & Obl. & Aucune & Obl & Aucune & Obl. & Aucune & obl & Aucune & Req êt & Aucune & obl & Aucune \\
\hline Corée & Obl. & Obl. & Aucune & Obl. & Aucune & Obl. & $T$ & Obl. & Aucune & obl. & Aucune & Obl. & Aucune \\
\hline Lettonie & Obl. & Obl. & Aucune & obl. & Aucune & Obl. & Aucune & Obl. & Aucune & obl. & Aucune & Req. ét & Aucune \\
\hline Lituanie & Obl. & Obl. & $\mathrm{F}$ & obl. & $\mathrm{F}$ & Obl. & $\mathbf{F}$ & obl & Aucune & Req ét. & Aucune & Req èt & Aucune \\
\hline Luxembourg & $\mathrm{m}$ & $\mathrm{m}$ & $\mathrm{m}$ & $\mathrm{m}$ & $\mathrm{m}$ & $\mathrm{m}$ & $\mathrm{m}$ & $\mathrm{m}$ & $\mathrm{m}$ & $\mathrm{m}$ & $\mathrm{m}$ & $\mathrm{m}$ & m \\
\hline Mexique & Obl. & Obl. & Aucune & Obl. & Aucune & Req ét. & $T / F$ & Req ét. & Aucune & Non req. & Aucune & Obl. & Aucune \\
\hline Pays-Bas & Req ét & Req èt. & $\mathrm{m}$ & Req èt. & $\mathrm{m}$ & Req ét. & $\mathrm{m}$ & Req èt. & $\mathrm{m}$ & Req èt & $\mathrm{m}$ & Req èt & $\mathrm{m}$ \\
\hline Nouvelle-Zélande' & Obl. & obl. & $\mathrm{m}$ & Obl. & $\mathrm{m}$ & Obl. & $\mathrm{m}$ & obl. & m & Req et & $\mathrm{m}$ & Obl. & $\mathrm{m}$ \\
\hline Norvège & Obl. & Obl. & Aucune & Obl. & Aucune & obl. & Aucune & Req èt. & $T / F$ & Od. & Aucune & Obl. & Aucune \\
\hline Pologne & Obl. & Obl. & Aucune & Obl. & Aucune & obl. & Aucune & obl. & Aucune & Obl. & Aucune & Obl. & Aucune \\
\hline Portugal & Obl. & Obl. & Aucune & Obl. & Aucune & obl. & Aucune & Obl. & Aucune & Volontanat & Aucune & Obl. & Aucune \\
\hline Republique slovaque & Obl. & Obl. & Aucune & Obl & Aucune & obl. & Aucune & $\mathrm{Obl}$. & Aucune & Obl. & Aucune & Obl. & Aucune \\
\hline Slovénie & Obl. & Obl. & Aucune & Obl. & Aucune & obl. & Aucune & Od. & Aucune & Req et. & Aucune & Obl. & Aucune \\
\hline Espagne & Obl. & Obl. & Aucune & Obl. & Aucune & Obl. & Aucune & $\mathrm{Obl}$. & Aucune & obl. & Aucune & Obl. & Aucune \\
\hline Suéde & Obl. & Obl. & $\mathrm{m}$ & Obl. & $\mathrm{m}$ & Obl. & m & Obl. & m & Req êt. & $\mathrm{m}$ & Obl. & m \\
\hline Suisse & Obl. & Obl. & Aucune & Obl. & Aucune & Obl. & Aucune & Obl. & Aucune & Obl & Aucune & Obl. & Aucune \\
\hline Turquie & Obl. & Obl. & $\mathrm{F}$ & obl. & $T$ & Non req. & Aucune & Obl. & Aucune & Volontanat & Aucune & Obl. & Aucune \\
\hline Êtats-Unis & Obl. & Req ét. & T/F & Req.êt. & T/F & Req ét. & $T / F$ & Req êt. & $T / F$ & Req. ét. & T/F & Req. ét. & T/F \\
\hline \multicolumn{14}{|l|}{ Economies } \\
\hline Comm. flamande (Belgique) & Ob. & Obl. & Aucune & Req êt. & Aucune & Req, êt & Aucune & Req.êt. & Aucune & Req.ét. & Aucune & Req êt. & Aucune \\
\hline Comm. française (Belgique) & Obl. & Ob. & Aucune & obl. & Aucune & Obl. & Aucune & Obl. & Aucune & Volontariat & Aucune & Volontariat & Aucune \\
\hline Angleterre (RL & Obl. & obl. & T & obl. & T & Volontaniat & Aucune & obl. & T & Req. ét. & Aucune & Obl. & T \\
\hline Ecosse (RU) & Obl. & Obl. & Aucune & Ob. & Aucune & Volontariat & Aucune & Obl. & Aucune & Volontariat & Aucune & $\begin{array}{l}\text { Obl.! } \\
\text { Req.ét. }\end{array}$ & Aucune \\
\hline \& Argentine & in & 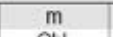 & $\mathrm{m}$ & $\mathrm{m}$ & $\mathrm{m}$ & m & $\mathrm{m}$ & m & $\mathrm{m}$ & m & $\mathrm{m}$ & $\mathrm{m}$ & $\mathrm{m}$ \\
\hline Brèsil & Obl. & Obl. & $\mathrm{m}$ & $\mathrm{m}$ & $\mathrm{m}$ & $\mathrm{m}$ & $\mathrm{m}$ & Obl. & $\mathrm{m}$ & $\mathrm{m}$ & $\mathrm{m}$ & $\mathrm{m}$ & $\mathrm{m}$ \\
\hline Chine & $\mathrm{m}$ & $\mathrm{m}$ & m & $\mathrm{m}$ & m & m & $\mathrm{m}$ & $\mathrm{m}$ & m & $\mathrm{m}$ & m & $\mathrm{m}$ & m \\
\hline Costa Rica & Obl. & Obl. & T & Obl. & T & Volontariat & $T / F$ & Obl. & T & Obl. & Aucune & Obl. & T \\
\hline Inde & m & m & m & $\mathrm{m}$ & $\mathrm{m}$ & m & $\mathrm{m}$ & $\mathrm{m}$ & m & m & m & m & m \\
\hline Indonésie & $\mathrm{m}$ & m & $\mathrm{m}$ & $\mathrm{m}$ & $\mathrm{m}$ & $\mathrm{m}$ & $\mathrm{m}$ & $\mathrm{m}$ & $\mathrm{m}$ & $\mathrm{m}$ & $\mathrm{m}$ & $\mathrm{m}$ & $\mathrm{m}$ \\
\hline Fédèration de Russie & $\mathrm{m}$ & m & m & $\mathrm{m}$ & $\mathrm{m}$ & m & m & m & m & m & m & m & m \\
\hline Arabie saoudite & $\mathrm{m}$ & $\mathrm{m}$ & $\mathrm{m}$ & $\mathrm{m}$ & $\mathrm{m}$ & $\mathrm{m}$ & $\mathrm{m}$ & $\mathrm{m}$ & $\mathrm{m}$ & m & $\mathrm{m}$ & $\mathrm{m}$ & $\mathrm{m}$ \\
\hline Afrique du Sud & $\mathrm{m}$ & $\mathrm{m}$ & m & $\mathrm{m}$ & m & $\mathrm{m}$ & $\mathrm{m}$ & $\mathrm{m}$ & $\mathrm{m}$ & $\mathrm{m}$ & $\mathrm{m}$ & $\mathrm{m}$ & m \\
\hline \multicolumn{2}{|c|}{$\begin{array}{l}\text { Ces täches/responsabilitès sont-elles } \\
\text { assignèes aux enseignants ? }\end{array}$} & \multicolumn{4}{|c|}{$\begin{array}{l}\text { Volontariat }=\text { Non, sur la base du volontariat, } \\
\text { à la discrétion des enseignants individuels } \\
\text { Non req. = Non, non requis } \\
\text { a : sans objet } \\
\text { m : données manquantes }\end{array}$} & \multicolumn{4}{|c|}{$\begin{array}{l}\text { À quel type de compensation l'enseignant } \\
\text { peut-il prétendre lorsquilis'acquitte de } \\
\text { cette táche/responsabilité ? } \\
\mathrm{T}=\text { Réduction du temps d'enseignement } \\
\mathrm{F}=\text { Octroi dune compensation financière spécfique }\end{array}$} & \multicolumn{4}{|c|}{$\begin{array}{l}\text { Aucune = Aucune } \\
\text { a: sans objet } \\
\mathrm{m} \text { : données manquantes }\end{array}$} \\
\hline
\end{tabular}

Remarque : Les données relatives aux niveaux préprimaire et primaire, ainsi qu'au premier cycle du secondaire (filière professionnelle) et au deuxième cycle du secondaire - présentées dans des lignes distinctes -, mais aussi celles relatives à la réduction du temps d'enseignement et aux compensations financières (soit les colonnes 4, 5, 8 , $9,12,13,16,17,20,21,24$ et 25) peuvent être consultées en ligne (voir le StatLink ci-dessous). Consulter les sections « Définitions » et « Méthodologie » pour de plus amples informations.

1. Les critères pour les deux premières années du premier cycle du secondaire (filière générale) suivent ceux pour l'enseignement primaire, et ceux pour les deux dernières années du premier cycle du secondaire (filière générale) suivent ceux du deuxième cycle du secondaire (filière générale).

Source : OCDE (2019). Consulter la section « Source » pour tout complément d'information et l'annexe 3 pour les notes (https://doi.org/10.1787/f8d7880d-en).

Les symboles représentant les données manquantes et les abréviations figurent dans le Guide du lecteur. 
Tableau D4.3b. Autres responsabilités assignées aux enseignants, selon le niveau d'enseignement (2018) Responsabilités assignées aux enseignants dans les établissements publics, telles que définies explicitement dans la règlementation et/ou les directives

\begin{tabular}{|c|c|c|c|c|c|c|c|c|}
\hline & \multicolumn{8}{|c|}{ Premier cycle du secondaire, filière génèrale } \\
\hline & \multicolumn{2}{|c|}{$\begin{array}{l}\text { Participation à la gestion de } \\
\text { l'établissement en sus de la charge } \\
\text { d'enseignement (par ex., assumer la } \\
\text { fonction de chef de département ou } \\
\text { de coordination des enseignants) }\end{array}$} & \multicolumn{2}{|c|}{$\begin{array}{l}\text { Dispense d'un enseignement pour } \\
\text { un nombre de classes ou d'heures } \\
\text { superieur à celui requis dans le } \\
\text { cadre d'un contrat à plein temps } \\
\text { (par ex., rémunération des heures } \\
\text { supplémentaires) }\end{array}$} & \multicolumn{2}{|c|}{$\begin{array}{c}\text { Conseil aux élèves } \\
\text { (dont supervision, aide en } \\
\text { ligne, orientation scolaire ou } \\
\text { professionnelle, et prévention } \\
\text { de la délinquance) }\end{array}$} & \multicolumn{2}{|c|}{$\begin{array}{l}\text { Participation à des activités } \\
\text { extrascolaires (par ex., activités } \\
\text { sportives, clubs de théâtre, } \\
\text { clubs de devoirs, cours d'été, etc.) }\end{array}$} \\
\hline & 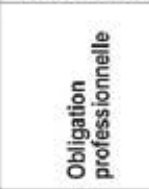 & 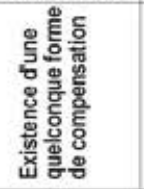 & 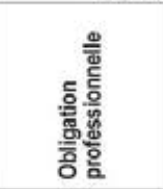 & 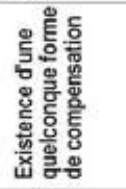 & 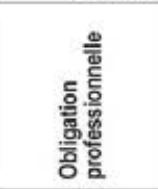 & 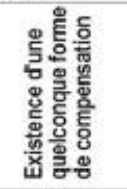 & 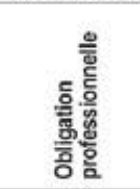 & 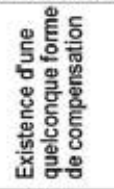 \\
\hline & (1) & (2) & (5) & (6) & (9) & (10) & (13) & (14) \\
\hline \multicolumn{9}{|l|}{ w Pays } \\
\hline Oustralie & $m$ & m & Non req. & Aucune & Volontariat & $\mathrm{F}$ & Volontaniat & Aucune \\
\hline Autriche & Req.ét & $\mathrm{T} / \mathrm{F}$ & Obl. & F & Req. ét. & $\mathrm{F}$ & Volontariat & Aucune \\
\hline Canada & m & m & $\mathrm{m}$ & m & m & m & m & m \\
\hline Chili & Volontaniat & $T / F$ & Req èt & $T / F$ & Req.êt. & $T / F$ & Volontariat & $T / F$ \\
\hline Colombie & Obl. & $F$ & Obl. & $F$ & Obl. & Aucune & Non req. & Aucune \\
\hline République tchèque & Volontariat & $F$ & Req. èt. & $\mathrm{F}$ & Volontanat & $T$ & Volontariat & $\mathrm{F}$ \\
\hline Danemark & Req. ét. & F & Req.èt & $\mathrm{F}$ & Req ét. & Aucune & Req.èt. & Aucune \\
\hline Estonie & Req.èt. & $T / F$ & Volontariat & $F$ & Obl. & Aucune & Req.ét. & $\mathrm{T} / \mathrm{F}$ \\
\hline Finlande & Volontanat & $T$ & Volontariat & $\mathrm{F}$ & Obl. & Aucune & Volontariat & $F$ \\
\hline France & Volontaniat & $T / F$ & Obl./Volontariat & $F$ & Obl. I Volontariat & $\mathrm{F}$ & Volontariat & Aucune \\
\hline Allemagne & Volontariat & $T$ & Volontariat & $\mathrm{T}$ & Volontariat & $\mathrm{T}$ & Volontariat & $T$ \\
\hline Grèce & Non req. & Aucune & Volontariat & $\mathrm{F}$ & Obl. & Aucune & Volontariat & Aucune \\
\hline Hongrie & Volontariat & TIF & Volontariat & $T / F$ & $\mathrm{Obl}$ & $T$ & Obl & Aucune \\
\hline Islande & Non req. & $F$ & Non req. & $F$ & Non req. & Aucune & Non req. & $\mathrm{F}$ \\
\hline Irlande & Req, et. & $F$ & Volontariat & Aucune & Non req. & Aucune & Volontariat & Aucune \\
\hline Israël & Volontanat & $\mathrm{F}$ & Volontariat & F & Req ét. & F & Non req. & $\mathrm{T}$ \\
\hline Italie & Req. ét. & $F$ & Volontariat & $\mathrm{F}$ & Volontariat & $\mathrm{F}$ & Volontariat & $\mathrm{F}$ \\
\hline Japon & Obl./Req. èt. & $\mathrm{F}$ & Obl./Req. ét. & $m$ & Obl. & Aucune & Obl./Req ét. & $\mathrm{F}$ \\
\hline Corée & Req. êt. & $T / F$ & Req. ot & $\mathrm{F}$ & Obl. & $T$ & Req èt. & $\mathrm{F}$ \\
\hline Lettonie & Obl. & $T$ & Req. èt. & $\mathrm{F}$ & Obl. & Aucune & Req. èt. & Aucune \\
\hline Lituanie & Req.èt. & $F$ & Req. èt. & $F$ & Req èt & $\mathrm{F}$ & Volontariat & $\mathrm{F}$ \\
\hline Luxembourg & m & $\mathrm{m}$ & m & $m$ & m & m & m & m \\
\hline Mexique & Req.èt. & $T / F$ & Non req. & Aucune & Non req. & Aucune & Non req. & Aucune \\
\hline Pays-Bas & Req.èt. & $\mathrm{m}$ & Volontariat & $F$ & Req.èt. & m & Req.èt. & m \\
\hline Nouvelle-Zèlande ${ }^{1}$ & Req, èt. & m & Non req. & m & Obl./Req. èt. & $m$ & Volontariat & m \\
\hline Norvège & Req èt & $\mathrm{T} / \mathrm{F}$ & Req ét & $\mathrm{F}$ & Req ét. & $\mathrm{T} / \mathrm{F}$ & Non req. & Aucune \\
\hline Pologne & Req.èt. & $T$ & Volontariat & $\mathrm{F}$ & Non req. & Aucune & Volontariat & Aucune \\
\hline Portugal & Obl. & $\mathrm{T}$ & Obl. & F & Obl. & Aucune & Obl. & Aucune \\
\hline République slovaque & Volontariat & $\mathrm{T} / \mathrm{F}$ & Req ét & $\mathrm{F}$ & Volontanat & $\mathrm{T} / \mathrm{F}$ & Volontariat & $\mathrm{T} / \mathrm{F}$ \\
\hline Slovenie & Req, èt & $F$ & Obl. & $F$ & Obl. & Aucune & Obl. & $\mathrm{F}$ \\
\hline Espagne & Obl. & $T / F$ & Non req. & F & Obl. & $\mathrm{F}$ & Volontariat & Aucune \\
\hline Suède & Volontariat & $\mathrm{m}$ & Volontanat & m & Req ét. & m & Volontariat & $\mathrm{m}$ \\
\hline Suisse & Volontanat & $\mathrm{T} / \mathrm{F}$ & Non req. & Aucune & $\mathrm{Obl}$ & Aucune & Non req. & $\mathrm{T} / \mathrm{F}$ \\
\hline Turquie & Obl. & Aucune & Volontaniat & F & Non req. & Aucune & Req.èt. & Aucune \\
\hline Etats-Unis & Req ét. & $\mathrm{T} / \mathrm{F}$ & Req èt & $\mathrm{T} / \mathrm{F}$ & Req ét. & $\mathrm{T} / \mathrm{F}$ & Req. êt. & $\mathrm{T} / \mathrm{F}$ \\
\hline \multicolumn{9}{|l|}{ Economies } \\
\hline Comm. flamande (Belgique) & Volontariat & Aucune & Volontariat & $\mathrm{F}$ & Non req & Aucune & Volontariat & Aucune \\
\hline Comm. française (Belgique) & Volontariat & Aucune & Volontariat & F & Volontariat & Aucune & Volontariat & Aucune \\
\hline Angleterre (RU) & Req.ét. & $T / F$ & Req èt & $T / F$ & Req èt. & $T / F$ & Req ét. & T/F \\
\hline Ecosse (RU) & a & a & Volontariat & Aucune & Obl. & Aucune & Volontariat & Aucune \\
\hline Argentine & $m$ & $\mathrm{~m}$ & $\mathrm{~m}$ & $\mathrm{~m}$ & $\mathrm{~m}$ & $\mathrm{~m}$ & $m$ & m \\
\hline 을 Brèsil & m & $m$ & $\mathrm{~m}$ & m & m & m & m & m \\
\hline č Chine & $m$ & m & $\mathrm{m}$ & $\mathrm{m}$ & $m$ & $m$ & $m$ & $\mathrm{~m}$ \\
\hline Costa Rica & Req. ét. & $\mathrm{F}$ & Volontariat & Aucune & Obl. & $\mathrm{T} / \mathrm{F}$ & Volontariat & $\mathrm{T}$ \\
\hline 2 Inde & m & $m$ & $\mathrm{~m}$ & m & $\mathrm{m}$ & $m$ & m & m \\
\hline Indonésie & $\mathrm{m}$ & $\mathrm{m}$ & $\mathrm{m}$ & $\mathrm{m}$ & $\mathrm{m}$ & $m$ & $\mathrm{~m}$ & $\mathrm{~m}$ \\
\hline Federation de Russie & $\mathrm{m}$ & $\mathrm{m}$ & $\mathrm{m}$ & $m$ & $m$ & $\mathrm{~m}$ & m & $m$ \\
\hline Arabie saoudite & m & $m$ & $m$ & $m$ & m & $m$ & m & m \\
\hline Afrique du Sud & $\mathrm{m}$ & $\mathrm{m}$ & m & m & $m$ & m & m & $\mathrm{m}$ \\
\hline \multicolumn{2}{|c|}{$\begin{array}{l}\text { Ces tãches/responsabilités sont-elles } \\
\text { assignées aux enseignants ? } \\
\text { Obl. = Oui, obligatoire } \\
\text { Req. èt. = Oui, à la discrétion } \\
\text { des établissements individuels }\end{array}$} & $\begin{array}{l}\text { ariat = Non, sur la } \\
\text { crétion des enseir } \\
\text { q. = Non, non re } \\
\text { is objet } \\
\text { nnées manquant }\end{array}$ & $\begin{array}{l}\text { base du volontariat, } \\
\text { nants individuels } \\
\text { quis }\end{array}$ & $\begin{array}{l}\text { A quel type } \\
\text { lorsqu'il s'a } \\
T=\text { Réductio } \\
\mathrm{F}=\text { Octroi d' }\end{array}$ & $\begin{array}{l}\text { compensation I } \\
\text { juitte de cette tác } \\
\text { du temps denseig } \\
\text { e compensation fi }\end{array}$ & $\begin{array}{l}\text { eignant peut-i } \\
\text { esponsabilité } \\
\text { ent } \\
\text { ière spécifique }\end{array}$ & étendre & $\begin{array}{l}\text { a : sans objet } \\
\mathrm{m} \text { : données } \\
\text { manquantes }\end{array}$ \\
\hline
\end{tabular}




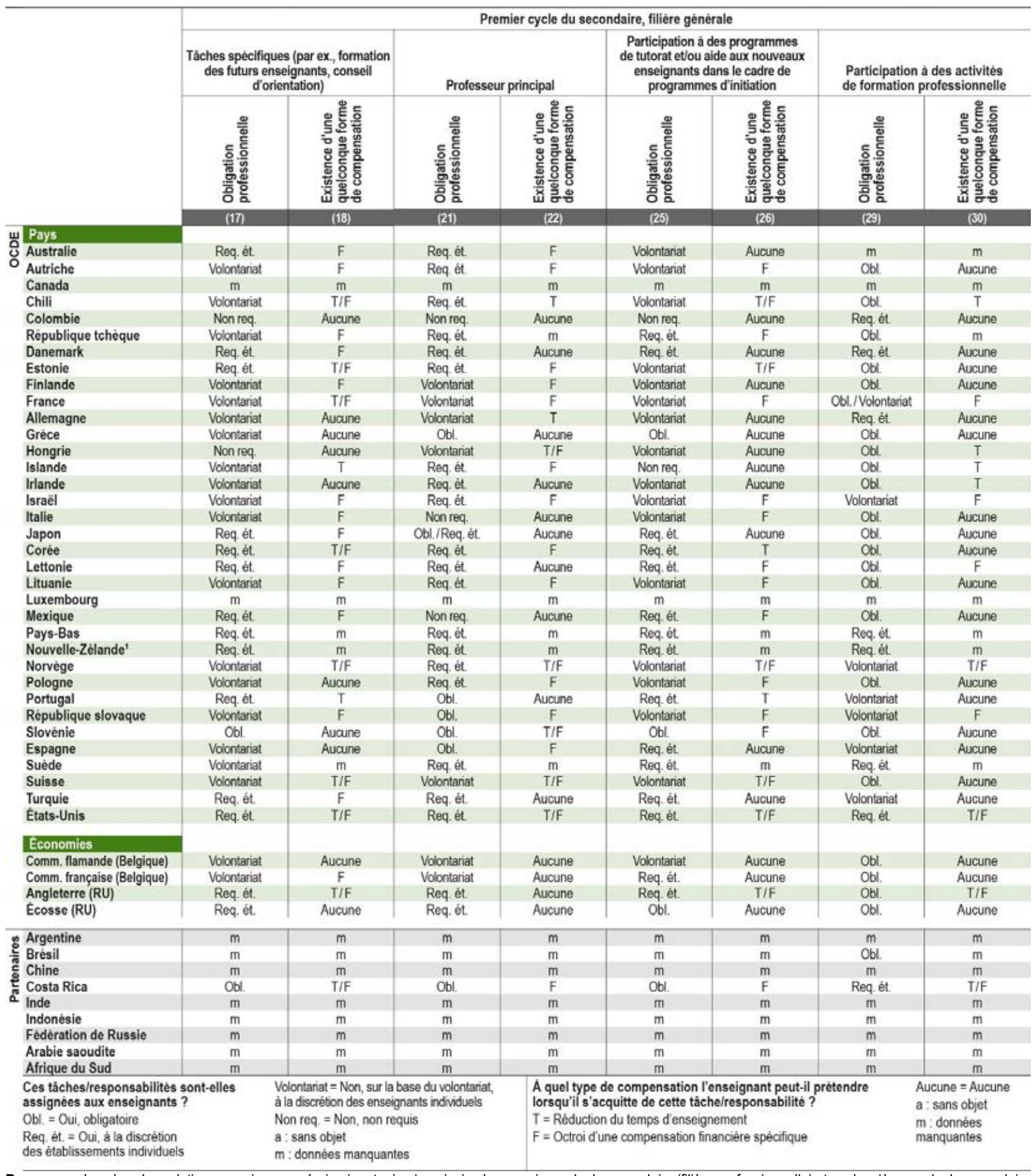

Remarque : Les données relatives aux niveaux préprimaire et primaire, ainsi qu'au premier cycle du secondaire (filière professionnelle) et au deuxième cycle du secondaire - présentées dans des lignes distinctes -, mais aussi celles relatives à la réduction du temps d'enseignement et aux compensations financières (soit les colonnes $3,4,7$, $8,11,12,15,16,19,20,23,24,27,28,31$ et 23) peuvent être consultées en ligne (voir le StatLink ci-dessous). Consulter les sections « Définitions » et « Méthodologie » pour de plus amples informations.

1. Les critères pour les deux premières années du premier cycle du secondaire (filière générale) suivent ceux pour l'enseignement primaire, et ceux pour les deux dernières années du premier cycle du secondaire (filière générale) suivent ceux du deuxième cycle du secondaire (filière générale).

Source : OCDE (2019). Consulter la section « Source » pour tout complément d'information et l'annexe 3 pour les notes (https://doi.org/10.1787/f8d7880d-en). Les symboles représentant les données manquantes et les abréviations figurent dans le Guide du lecteur. 



\section{Indicateur D5. Qui sont les enseignants?}

\section{Faits marquants}

- En moyenne dans les pays de l'OCDE, les enseignantes sont minoritaires dans l'enseignement tertiaire, mais majoritaires dans l'enseignement primaire et secondaire. Dans la plupart des pays dont les données sont disponibles, le pourcentage d'enseignantes est supérieur dans l'enseignement tertiaire en formation de cycle court qu'en licence, en master ou en doctorat.

- Dans la plupart des pays de l'OCDE, le pourcentage d'enseignants en poste dans l'enseignement primaire et secondaire est plus élevé chez les 50-59 ans que chez les 25-34 ans, ce qui peut faire craindre des pénuries d'enseignants à l'avenir.

- En moyenne, dans les pays de l'OCDE, moins de $15 \%$ des enseignants sont âgés de moins de 30 ans, quel que soit le niveau d'enseignement, de l'enseignement primaire au deuxième cycle de l'enseignement secondaire.

\section{Graphique D5.1. Répartition des enseignants selon le sexe dans l'enseignement tertiaire (2017)}

Pourcentage de femmes parmi les enseignants des établissements publics et privés

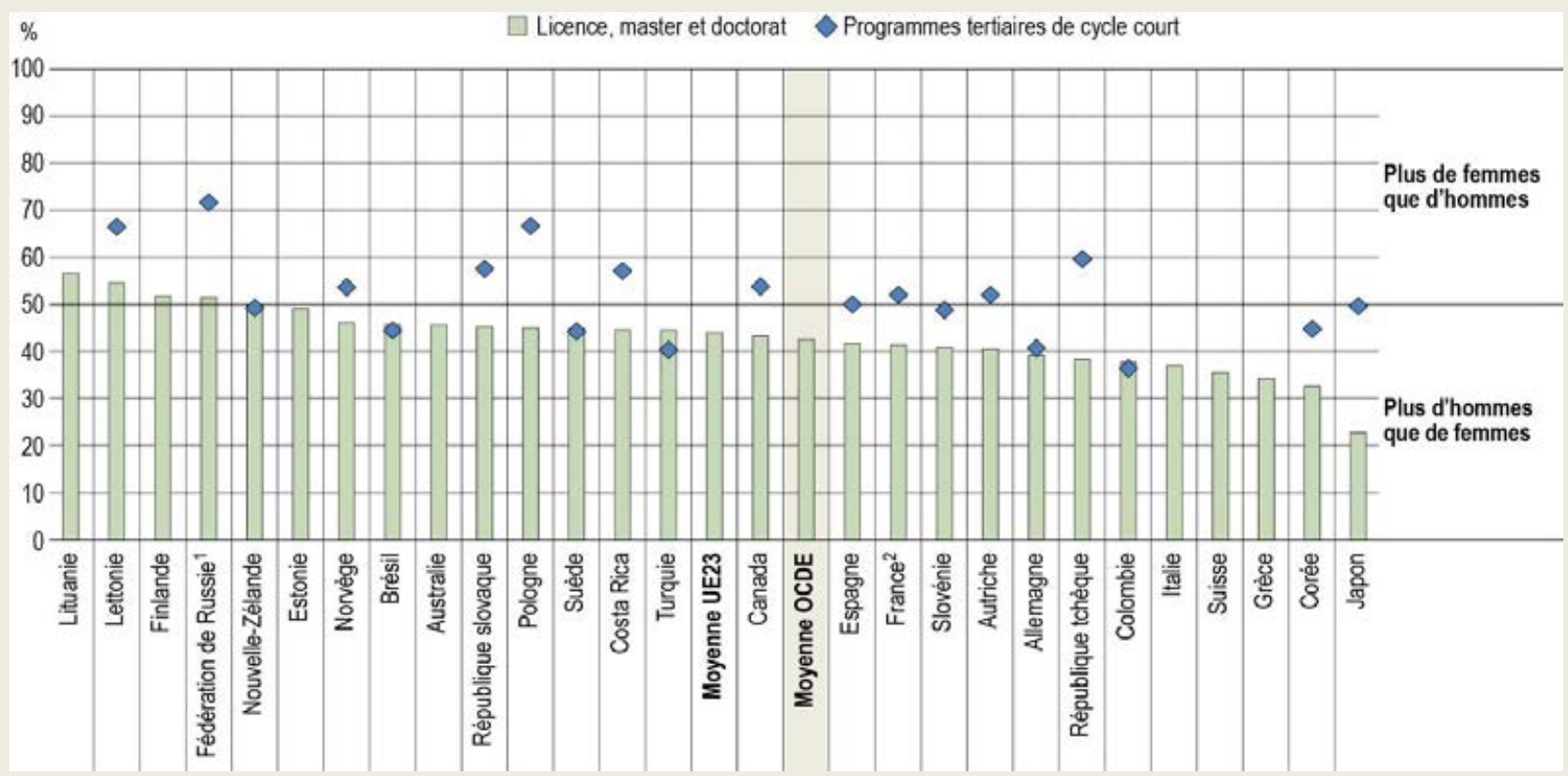

1. L'enseignement tertiaire inclut des programmes d'autres niveaux d'enseignement.

2. Établissements publics uniquement.

Les pays sont classés par ordre décroissant du pourcentage de femmes parmi les enseignants en licence, master et doctorat

Source : OCDE/ISU/Eurostat (2019), Base de données de Regards sur l'éducation, http://stats.oecd.org. Consulter la section « Source » pour tout complément d'information et l'annexe 3 pour les notes (https://doi.org/10.1787/f8d7880d-en). 


\section{Contexte}

La demande d'enseignants dépend d'un certain nombre de facteurs, dont la taille moyenne des classes, le temps d'instruction des élèves et étudiants, le recours aux auxiliaires d'éducation et aux personnels de l'éducation hors enseignants, les taux de scolarisation à chaque niveau d'enseignement et l'âge de début et de fin de la scolarité obligatoire. Comme un grand nombre d'enseignants partiront à la retraite dans les dix années à venir et que l'effectif scolarisé devrait augmenter dans certains pays de l'OCDE, les gouvernements concernés auront à former et à recruter de nouveaux enseignants. Comme il est de toute évidence établi que la qualité des enseignants est le facteur intra-établissement le plus déterminant de la performance de l'effectif scolarisé, des efforts concertés doivent être consentis pour inciter les meilleurs talents à embrasser la profession d'enseignant et proposer aux enseignants une formation de qualité (OCDE, 2015 [1] $)$.

Les politiques de maintien des enseignants dans la profession doivent promouvoir des environnements de travail qui encouragent les enseignants efficaces à rester dans la profession. Par ailleurs, la surreprésentation des enseignantes dans l'enseignement préprimaire et primaire et dans le premier cycle de l'enseignement secondaire est à l'origine d'un défaut de parité dans le corps enseignant dont l'impact potentiel sur l'apprentissage mérite une analyse approfondie (OCDE, 2018[2]).

\section{Autres faits marquants}

- En moyenne, dans les pays de l'OCDE, $70 \%$ des enseignants sont des femmes, tous niveaux d'enseignement confondus. Les pourcentages les plus élevés d'enseignantes s'observent dans les premières années de la scolarité et diminuent de niveau en niveau d'enseignement.

- En une décennie, le pourcentage d'enseignants de plus de 50 ans a augmenté de 3 points de pourcentage en moyenne dans l'enseignement primaire et secondaire dans les pays de l'OCDE. Le corps enseignant a toutefois a rajeuni dans un tiers des pays de l'OCDE. 


\section{Analyse}

\section{Répartition des enseignants selon le sexe}

En moyenne, dans les pays de l'OCDE, $70 \%$ des enseignants sont des femmes, tous niveaux d'enseignement confondus. Les pourcentages les plus élevés d'enseignantes s'observent dans les premières années de la scolarité et diminuent à chaque niveau supérieur d'enseignement. En moyenne, dans les pays de l'OCDE, les femmes représentent $97 \%$ du corps enseignant dans l'enseignement préprimaire et $83 \%$ dans l'enseignement primaire, mais $60 \%$ dans le deuxième cycle de l'enseignement secondaire et $44 \%$ seulement dans l'enseignement tertiaire (voir le tableau D5.2).

Les femmes représentent plus de $85 \%$ du corps enseignant dans l'enseignement préprimaire dans tous les pays de l'OCDE dont les données sont disponibles et représentent plus de $60 \%$ dans l'enseignement primaire dans tous les pays membres et partenaires de l'OCDE, sauf en Inde (51\%). Dans le premier et le deuxième cycle de l'enseignement secondaire, les enseignantes restent majoritaires, mais le pourcentage d'enseignants est plus élevé qu'aux niveaux inférieurs d'enseignement. Le pourcentage d'enseignantes va de $43 \%$ au Japon à $88 \%$ en Slovénie dans le premier cycle de l'enseignement secondaire. Dans le deuxième cycle de l'enseignement secondaire, les femmes représentent $31 \%$ du corps enseignant au Japon (y compris dans certaines formations post-secondaires non tertiaires) mais $80 \%$ du corps enseignant en Lettonie.

Pourquoi si peu d'hommes décident-ils d'enseigner aux niveaux d'enseignement préprimaire, primaire et secondaire ? L'une des raisons pourrait être d'ordre culturel : les perceptions sociales des liens entre le sexe et les professions pourraient influencer les choix de carrière des hommes et des femmes. Cette différenciation commence souvent très tôt, lorsque les parents nourrissent pour leurs enfants des ambitions professionnelles qui peuvent être basées sur des stéréotypes sexistes (Croft et al., 2014[3] ; Kane et Mertz, 2012[4] ; OCDE, 2015[1] $)$. Dans le corps enseignant, des différences de parité s'observent même entre les domaines d'études. Dans le premier cycle de l'enseignement secondaire, les femmes sont moins nombreuses parmi les professeurs de sciences, de mathématiques et de technologie que dans l'ensemble du corps enseignant (OCDE, 2018 ${ }_{[2]}$; OCDE, 2014[5]). Ce constat pourrait lui aussi s'expliquer par le fait que la science et les technologies sont perçues comme des domaines masculins, ce qui pourrait décourager les femmes d'entreprendre des études tertiaires scientifiques (voir l'indicateur B4 et (OCDE, 2014 $\left.{ }_{[5]}\right)$.

D'un point de vue économique, les jeunes choisissent aussi leur profession en fonction de leurs prétentions salariales. En moyenne, dans les pays de l'OCDE, les hommes diplômés de l'enseignement tertiaire gagnent moins s'ils sont enseignants que s'ils exercent d'autres professions, tandis que les femmes diplômées de ce niveau gagnent pratiquement autant : qu'elles enseignent dans l'enseignement primaire et le premier cycle de l'enseignement secondaire ou qu'elles exercent une autre profession (voir l'indicateur D3 et (OCDE, 2018[2])). À cause de ces différences salariales relatives, la profession d'enseignant est probablement plus attractive pour les femmes que pour les hommes, par rapport aux autres professions.

Les effets potentiels de ce défaut de parité dans le corps enseignant sur les résultats et la motivation des élèves et la rétention des enseignants méritent d'être étudiés, en particulier dans les pays où la profession d'enseignant attire peu les hommes (Drudy, 2008[6] ; OCDE, 2009 ${ }_{[7]}$; OCDE, 2006 $[8]$ ). II n'y a guère d'éléments à l'appui de la thèse selon laquelle le sexe des enseignants a un impact sur les résultats de leurs élèves (Antecol, Eren et Ozbeklik, 2012[9] ; Holmlund et Sund, 2008 $[10])$, mais promouvoir une plus grande parité pourrait avoir des effets positifs sur tous les élèves. Les enseignantes et les enseignants peuvent en particulier contribuer à tordre le cou à des stéréotypes sexistes et aider leurs élèves à développer une identité sexuelle positive (Hutchings et al., 2008[11]). Certains éléments montrent en particulier que les attitudes des enseignantes à l'égard de certaines matières, telles que les mathématiques, peuvent influer sur les résultats de leurs élèves de sexe féminin (Beilock et al., 2010 $[12]$; OCDE, 2014[13]). 


\section{Répartition des enseignants selon le sexe}

Dans l'enseignement tertiaire, le corps enseignant est majoritairement masculin dans les pays de l'OCDE. Les femmes représentent en moyenne $44 \%$ du corps enseignant de ce niveau dans les pays de l'OCDE, mais leur pourcentage varie entre $28 \%$ au Japon et $59 \%$ en Fédération de Russie.

Le degré de parité du corps enseignant varie entre les niveaux de l'enseignement tertiaire. Les enseignantes sont plus nombreuses en formation tertiaire de cycle court qu'en licence, en master et en doctorat. Plus précisément, les enseignantes sont minoritaires en licence, en master et en doctorat dans plus de quatre cinquièmes des pays dont les données sont disponibles, mais majoritaires en formation tertiaire de cycle court dans deux tiers environ de ces pays (voir le graphique D5.1).

Les domaines où les enseignantes sont majoritaires en formation tertiaire de cycle court sont aussi les domaines typiquement féminins. En Lettonie par exemple, les femmes représentent plus de $60 \%$ du corps enseignant en formation tertiaire de cycle court et près de $60 \%$ des cursus de ce niveau portent sur les services, la santé et la protection sociale, des domaines d'études où les femmes sont surreprésentées (voir l'indicateur B4 et la Base de données de Regards sur l'éducation). Au plus $20 \%$ de l'effectif total d'étudiants de l'enseignement tertiaire suit une formation de cycle court dans les pays de l'OCDE, sauf toutefois en Australie, en Canada, au Chili, en Corée, aux États-Unis, en Nouvelle-Zélande et en Turquie (voir l'indicateur B1 et la Base de données de Regards sur l'éducation). Les enseignantes sont surreprésentées en formation tertiaire de cycle court, mais restent sousreprésentées dans l'enseignement tertiaire (voir l'encadré D5.1).

Les enseignantes sont minoritaires en licence, en master et en doctorat dans tous les pays de l'OCDE dont les données sont disponibles, sauf en Finlande (52\%), en Lettonie (55\%), en Lituanie (57\%) et en NouvelleZélande (50\%). Elles représentent moins de $40 \%$ du corps enseignant dans un tiers des pays dont les données sont disponibles et représentent $23 \%$ seulement du corps enseignant en licence, en master et en doctorat au Japon. Toutefois, elles sont de plus en plus nombreuses dans l'enseignement tertiaire depuis 2005 dans la majeure partie des pays de l'OCDE pour lesquels les données sont disponibles (voir la Base de données de Regards sur l'éducation).

\section{Encadré D5.1. Présence des femmes dans le monde académique}

Malgré les progrès enregistrés ces derniers temps, le défaut de parité reste un problème dans la plupart des pays de l'OCDE ; il commence à s'observer chez les doctorants et se poursuit tout au long des carrières académiques (Winslow et Davis, 2016[14]]). Les femmes restent sous-représentées dans le monde académique. Dans les pays européens, elles représentent un tiers seulement des chercheurs et un quart seulement des professeurs de haut rang (Commission européenne, 2019 ${ }_{[15]}$ ), alors qu'elles représentent presque la moitié des doctorants (voir l'indicateur B7). Les chercheuses sont plus susceptibles que les chercheurs de travailler sous des contrats considérés comme précaires et un écart salarial important persiste entre les sexes dans la recherche scientifique et la recherche-développement (Commission européenne, 2019[15]). Les femmes sont pénalisées aussi dans d'autres pays, par exemple en Australie (Winchester et Browning, 2015[16] $)$ et aux États-Unis (Curtis, 2011 [17]). Le défaut de parité est encore plus frappant dans certains domaines, notamment en sciences, en technologie, en ingénierie et en mathématiques (STIM).

L'évolution de la carrière des femmes dans le monde académique est plus susceptible d'être freinée à cause des obligations familiales et du manque de politiques ou de programmes visant à réduire l'écart entre les sexes (Winslow et Davis, 2016[14]). Des pays de l'OCDE ont récemment entrepris de promouvoir un changement structurel en vue de féminiser le monde académique. L'Union européenne a par exemple massivement investi dans le projet « Institutional Transformation for Effecting Gender Equality in Research » (INTEGER) pour favoriser la carrière des femmes dans l'enseignement tertiaire et dans la recherche en Europe (Commission européenne, 2016 $\left.{ }_{[18]}\right)$. Aux États-Unis, la National Science Foundation a financé des 
recherches et des interventions en vue d'améliorer la représentation des femmes dans le monde de la science et de l'ingénierie, notamment dans le cadre du programme de bourses « ADVANCE Institutional Transformation » (Winslow et Davis, 2016[14]). En Australie, la Universities Australia Strategy for Women (2011-14) a été conçue pour encourager les universités à se fixer des objectifs chiffrés de parité dans leur programmation stratégique et à promouvoir les femmes dans le monde académique (Winchester et Browning, 2015[16]). Des universités australiennes ont récemment adopté des quotas de femmes et décidé de réserver aux femmes certains postes à pourvoir dans les facultés d'ingénierie, d'informatique et de mathématiques (Pyke et White ${ }_{[19]}$ ). Toutefois, le défaut de parité qui persiste dans le monde académique à divers égards, notamment la représentation des femmes, leurs conditions de travail et leur rémunération, justifie la poursuite des recherches et des investissements à l'avenir pour combler l'écart entre hommes et femmes.

\section{Pyramide des âges des enseignants}

Chez les enseignants, la pyramide des âges varie sensiblement entre les pays et les niveaux d'enseignement sous l'effet de différents facteurs, dont la taille et la pyramide des âges de la population et la durée de l'enseignement tertiaire ainsi que les conditions de travail et le salaire des enseignants. Ainsi, la régression des taux de natalité peut entraîner un tassement de la demande de nouveaux enseignants ; et des études tertiaires plus longues peuvent expliquer pourquoi les enseignants sont plus âgés lorsqu'ils entrent dans la vie active. Des salaires compétitifs, de bonnes conditions de travail et des perspectives professionnelles prometteuses peuvent inciter les jeunes à embrasser la profession d'enseignant dans certains pays et favoriser la rétention des enseignants efficaces dans d'autres pays.

Un pourcentage élevé d'enseignants ont au moins 50 ans. Leur pourcentage augmente avec le niveau d'enseignement: il s'établit à $33 \%$ dans l'enseignement primaire, à $37 \%$ dans le premier cycle de l'enseignement secondaire et à $40 \%$ dans le deuxième cycle de l'enseignement secondaire. Cette tendance est assez frappante dans le deuxième cycle de l'enseignement secondaire, où le pourcentage d'enseignants plus âgés est supérieur à $30 \%$ dans plus de deux tiers des pays dont les données sont disponibles. Ce pourcentage varie toutefois fortement entre les pays : de $15 \%$ en Turquie à $63 \%$ en Italie dans le deuxième cycle de l'enseignement secondaire. En moyenne, dans les pays de l'OCDE, plus de la moitié des enseignants en poste dans l'enseignement primaire et secondaire ont entre 30 et 49 ans.

Dans l'enseignement tertiaire, la plupart des enseignants ont plus de 40 ans dans tous les pays dont les données sont disponibles. En fait, $35 \%$ au moins des enseignants ont plus de 50 ans dans tous les pays, sauf en Allemagne (26\%), au Brésil (32\%), en Colombie (32\%), au Costa Rica (33\%), au Luxembourg (16\%), aux Pays-Bas (33\%) et en Turquie (19\%). Quant aux enseignants de moins de 30 ans, ils sont moins de $1 \%$ en Grèce, en Italie et en Slovénie, mais $24 \%$ en Allemagne (voir la Base de données de Regards sur l'éducation).

Par contraste, les jeunes - de moins de 30 ans - sont peu nombreux dans le corps enseignant : ils ne sont en moyenne que $13 \%$ dans l'enseignement primaire, $11 \%$ dans le premier cycle de l'enseignement secondaire et $8 \%$ dans le deuxième cycle de l'enseignement secondaire dans les pays de l'OCDE. Cette tendance est particulièrement frappante dans le deuxième cycle de l'enseignement secondaire : le pourcentage de jeunes enseignants est inférieur à $10 \%$ dans près de deux tiers des pays dont les données sont disponibles et à $5 \%$ dans un environ un tiers d'entre eux. Dans l'ensemble, les moins de 30 ans représentent moins de $25 \%$ du corps enseignant tous niveaux d'enseignement confondus dans tous les pays. Deux pays seulement font figure d'exception : le Royaume-Uni (où plus ils représentent plus de $30 \%$ du corps enseignant dans l'enseignement primaire) et la Turquie (où ils en représentent $27 \%$ dans le premier cycle de l'enseignement secondaire) (voir le tableau D5.1 et le graphique D5.2).

Le vieillissement du corps enseignant a un certain nombre d'implications pour les systèmes d'éducation des pays. De nouveaux enseignants devront être engagés pour remplacer ceux qui partiront à la retraite ces dix prochaines années, en particulier dans les pays où l'effectif à scolariser augmente (voir l'indicateur B1). Les 
gouvernements concernés pourraient devoir investir davantage dans la profession d'enseignant afin de renforcer son attractivité. Outre les efforts de formation et de recrutement à consentir pour remplacer les enseignants qui partent à la retraite, le vieillissement du corps enseignant pourrait aussi influer sur les décisions budgétaires. Dans la plupart des systèmes d'éducation, la rémunération des enseignants augmente avec l'ancienneté. Le vieillissement des enseignants entraîne donc une augmentation des coûts de l'éducation, laquelle réduit les marges budgétaires permettant de prendre de nouvelles initiatives (voir l'indicateur D3).

\section{Graphique D5.2. Pourcentage d'enseignants âgés de moins de 30 ans, selon le niveau d'enseignement (2017)}

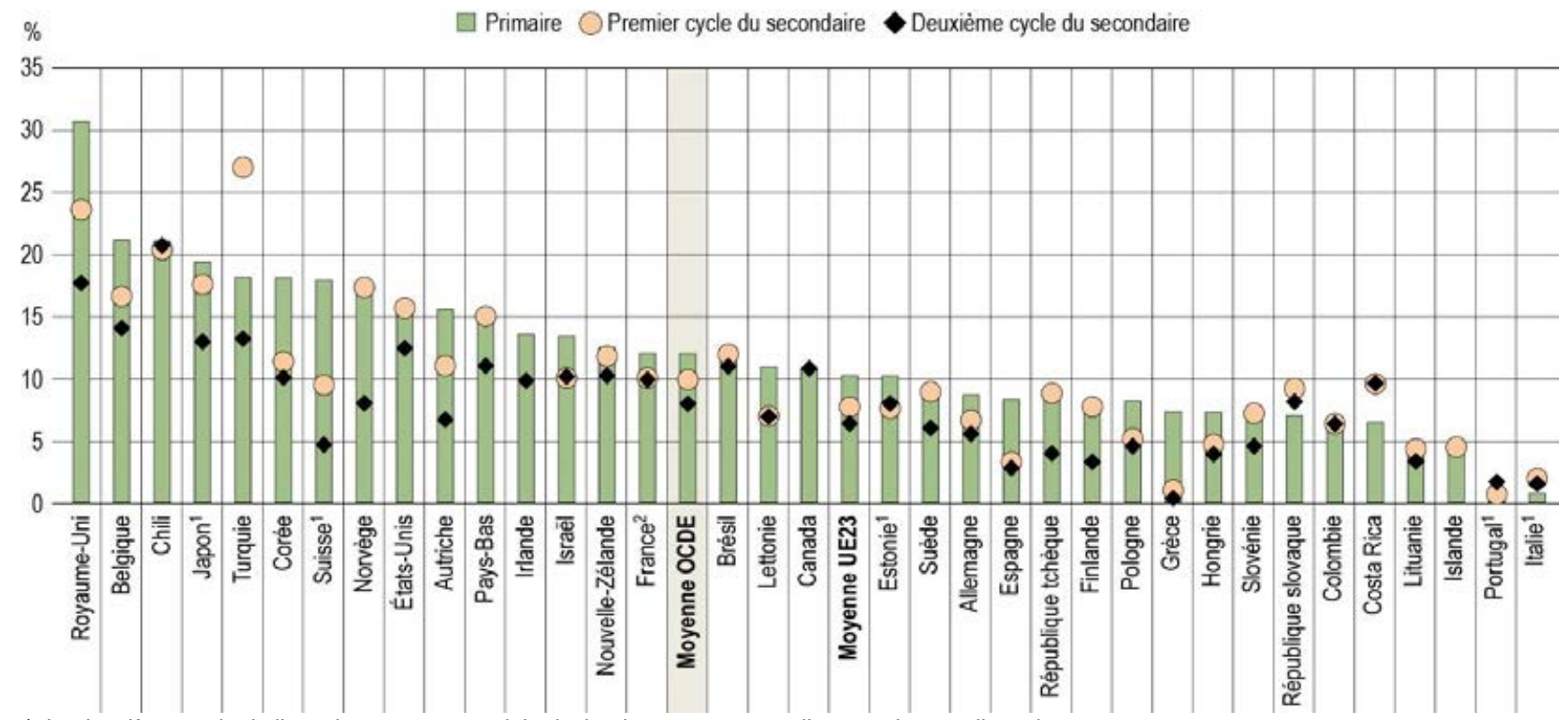

1. Le deuxième cycle de l'enseignement secondaire inclut des programmes d'autres niveaux d'enseignement.

2. Établissements publics et établissements privés subventionnés par l'État uniquement.

Les pays sont classés par ordre décroissant du pourcentage d'enseignants âgés de moins de 30 ans parmi les enseignants du primaire.

Source : OCDE/ISU/Eurostat (2019), tableau D5.3. Consulter la section « Source » pour tout complément d'information et l'annexe 3 pour les notes (https://doi.org/10.1787/f8d7880d-en).

StatLink 제픈 https://doi.org/10.1787/888933980317

\section{Évolution de la pyramide des âges des enseignants entre 2005 et 2017}

Les données tendancielles révèlent que le pourcentage d'enseignants âgés d'au moins 50 ans parmi ceux en poste dans l'enseignement primaire et secondaire a augmenté en moyenne de 5 points de pourcentage au cours des dix dernières années dans les pays de l'OCDE dont les données sont disponibles. Au cours de cette période, le pourcentage d'enseignants au moins quinquagénaires a augmenté d'au moins 13 points de pourcentage (voir la Base de données de Regards sur l'éducation) en Grèce, en Hongrie, en Lituanie, en Pologne, au Portugal et en Slovénie, bien que ce pourcentage reste inférieur à la moyenne de l'OCDE en Pologne. Par contraste, le pourcentage d'enseignants plus âgés est supérieur de plus de 10 points de pourcentage à la moyenne de l'OCDE en Italie, en Estonie, en Lettonie et en Lituanie où le vieillissement du corps enseignant se poursuit.

Le pourcentage d'enseignants plus âgés a diminué dans un tiers environ des pays dont les données sont disponibles - à savoir en Allemagne, au Chili, aux États-Unis, en France, en Irlande, au Luxembourg et au Royaume-Uni -, signe de la tendance opposée : le corps enseignant rajeunit. Cela s'explique en partie par les efforts déployés pour mettre en œuvre les politiques de recrutement d'enseignants. Le Royaume-Uni, où le pourcentage d'enseignants plus âgés a le plus diminué, a par exemple lancé une grande campagne de recrutement au début des années 2000 dans le but d'améliorer le statut des enseignants. La campagne a été rythmée par des slogans tels que "Use your head: teach » ou "Turn your talent to teaching », le but étant d'attirer des jeunes tentés par la profession d'enseignant, mais rebutés par plusieurs obstacles, dont le fardeau 
financier de la formation initiale. Le Royaume-Uni a également prévu d'accorder un soutien financier aux futurs enseignants en formation (OCDE, 2011 [20]). De même, le Chili a mis en œuvre en 2017 la Politique nationale relative aux enseignants, qui définit une nouvelle grille salariale et un système de développement professionnel pour les enseignants en poste dans les établissements publics. Le gouvernement chilien a aussi mis sur pied le programme d'octroi de bourses «Vocation d'enseignant », qui couvre les frais d'inscription des étudiants à l'université.

\section{Pourcentage d'enseignants dans la population}

Examiner le pourcentage d'enseignants par groupe d'âge est un autre moyen d'analyser l'évolution de la pyramide des âges dans le corps enseignant. Dans la plupart des pays de l'OCDE, les enseignants en poste dans l'enseignement primaire et secondaire sont plus nombreux chez les 50-59 ans que chez les 25-34 ans. Les différences les plus marquées s'observent en Grèce, en Italie, en Lituanie et au Portugal. Les jeunes enseignants sont plus nombreux que les enseignants plus âgés dans la population dans moins d'un quart des pays (voir le graphique D5.3).

La répartition des enseignants en poste dans l'enseignement primaire et secondaire entre les groupes d'âge fait aussi craindre des pénuries d'enseignants à l'avenir. En Italie et au Portugal, les enseignants ne représentent que $0.6 \%$ ou moins des 25-34 ans, mais près de $3 \%$ des 50-59 ans. Ces pourcentages sont similaires dans les deux groupes d'âge en Allemagne, au Brésil, au Canada, aux États-Unis, en France, en Israël, en Norvège, aux Pays-Bas et en Suisse (voir le graphique D5.3).

Graphique D5.3. Pourcentage d'enseignants du primaire et du secondaire dans la population, selon le groupe d'âge (2017)

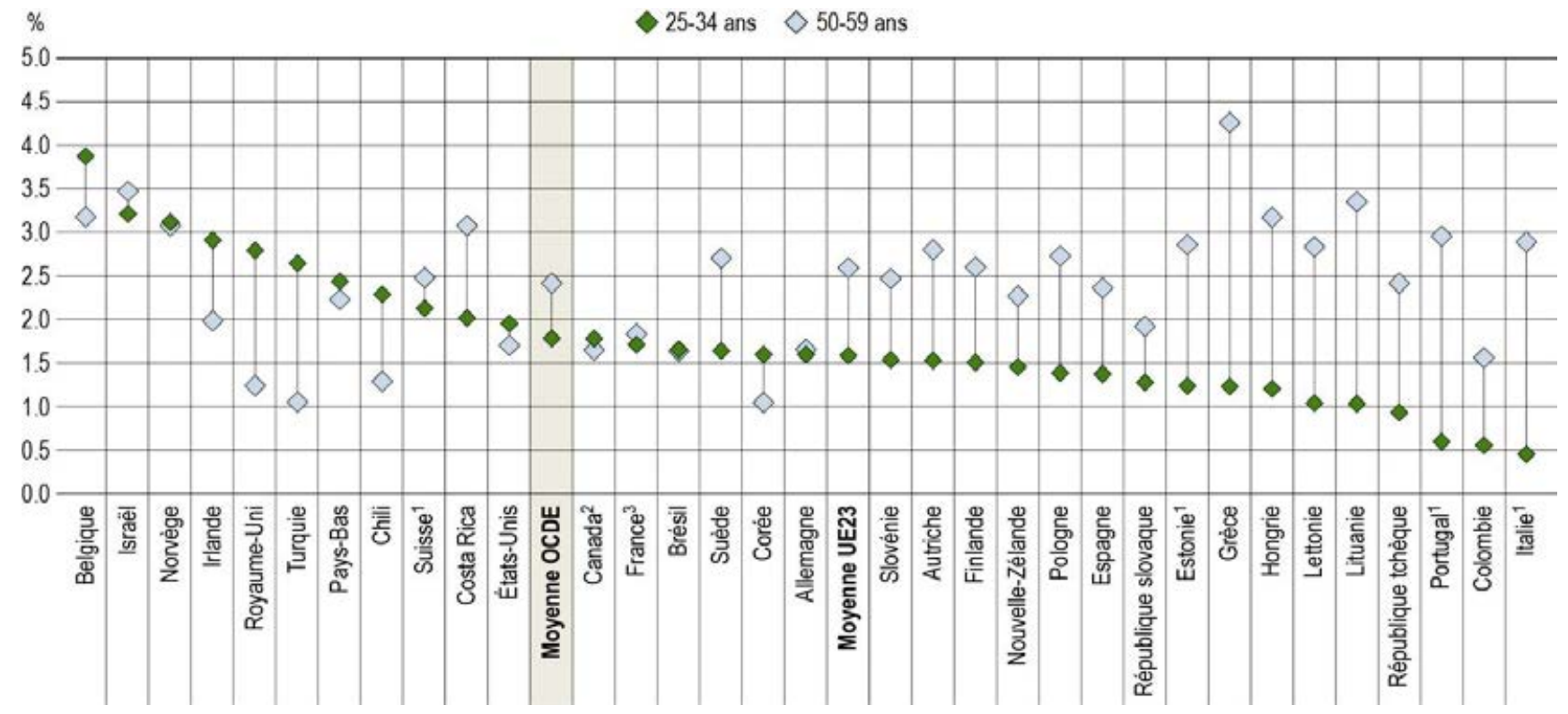

1. Le deuxième cycle de l'enseignement secondaire inclut des programmes d'autres niveaux d'enseignement.

2. L'enseignement primaire inclut l'enseignement préprimaire.

3. Établissements publics et établissements privés subventionnés par l'État uniquement.

Les pays sont classés par ordre décroissant du pourcentage d'enseignants parmi les 25-34 ans.

Source : OCDE/ISU/Eurostat (2019), Base de données de Regards sur l'éducation, http://stats.oecd.org. Consulter la section « Source » pour tout complément d'information et l'annexe 3 pour les notes (http://dx.doi.org/10.1787/eag-2019-36-fr). 
Dans la plupart des pays de l'OCDE, de nouveaux enseignants devront être engagés pour remplacer ceux qui partiront à la retraite ces dix prochaines années. Les gouvernements concernés pourraient avoir à développer la formation des enseignants et à inciter les étudiants à embrasser la profession d'enseignant (voir l'indicateur D6 (OCDE, 2014[21]). De plus, des difficultés budgétaires (en particulier celles résultant des régimes de retraite et des soins de santé des retraités) pourraient contraindre des gouvernements à réduire l'offre de formations, à augmenter la taille des classes ou à intégrer un apprentissage en ligne plus individualisé (Peterson, 2011 [22]).

\section{Définitions}

II existe deux catégories d'enseignants :

- La catégorie des auxiliaires d'éducation et des assistants de recherche inclut le personnel non certifié et les étudiants qui aident les enseignants à donner cours.

- La catégorie des enseignants inclut le personnel certifié directement impliqué dans l'instruction des élèves/étudiants. Elle englobe les enseignants qui ont une charge de cours, qui dispensent un enseignement spécialisé, qui prennent en charge des élèves/étudiants constituant une classe entière dans une salle de classe ou des élèves/étudiants réunis en petits groupes dans une salle spécialisée ou qui donnent des cours particuliers dans une salle de classe ou un autre local. Dans l'enseignement tertiaire, le personnel académique inclut le personnel dont la mission principale relève de l'enseignement ou de la recherche. Cette catégorie inclut également les chefs de département qui ont une charge de cours, mais exclut le personnel non certifié qui assiste les enseignants lors des cours auxétudiants, comme les auxiliaires d'éducation ou le personnel paraprofessionnel.

\section{Méthodologie}

Le pourcentage d'enseignants dans la population correspond au pourcentage d'enseignants par groupe d'âge (par exemple chez les 25-34 ans et les 50-59 ans) dans l'effectif total de la population du même âge.

Pour de plus amples informations, veuillez consulter le Guide de l'OCDE pour l'établissement de statistiques internationalement comparables dans le domaine de l'éducation 2018: Concepts, normes, définitions et classifications (OCDE, 2019[23]) et l'annexe A3 pour les notes spécifiques aux pays (https://doi.org/10.1787/f8d7880d-en).

\section{Source}

Les données se rapportent à l'année académique 2016/17 et proviennent de l'exercice UNESCOISU/OCDE/Eurostat de collecte de données statistiques sur l'éducation réalisé par l'OCDE en 2018 (pour plus de précisions, voir l'annexe 3, https://doi.org/10.1787/f8d7880d-en).

\section{Remarque concernant les données fournies par Israël}

Les données statistiques concernant Israël sont fournies par et sous la responsabilité des autorités israéliennes compétentes. L'utilisation de ces données par l'OCDE est sans préjudice du statut des hauteurs du Golan, de Jérusalem-Est et des colonies de peuplement israéliennes en Cisjordanie aux termes du droit international. 


\section{Références}

Antecol, H., O. Eren et S. Ozbeklik (2012), « The Effect of teacher gender on student achievement in primary school: Evidence from a randomized experiment », IZA Discusssion Papers, No.6453, http://ftp.iza.org/dp6453.pdf (consulté le 20 avril 2018).

Beilock, S. et al. (2010), " Female teachers' math anxiety affects girls' math achievement. », Proceedings of the National Academy of Sciences of the United States of America, vol. 107/5, pp. 1860-3, http://dx.doi.org/10.1073/pnas.0910967107.

Commission européenne (2019), She Figures 2018.

Commission européenne (2016), INTEGER Report Summary, http://www.integer-tools-for-action.eu.

Croft, A. et al. (2014), « The second shift reflected in the second generation », Psychological Science, vol. 25/7, pp. 1418-1428, http://dx.doi.org/10.1177/0956797614533968.

Curtis, J. (2011), Persistent Inequity: Gender and Academic Employment, American Association of University Professors, Washington, DC, https://www.aaup.org/NR/rdonlyres/08E023AB-E6D84DBD-99A0-24E5EB73A760/0/persistent inequity.pdf.

Drudy, S. (2008), « Gender balance/gender bias: the teaching profession and the impact of feminisation », Gender and Education, vol. 20/4, pp. 309-323, http://dx.doi.org/10.1080/09540250802190156.

Holmlund, H. et K. Sund (2008), " Is the gender gap in school performance affected by the sex of the teacher? ", Labour Economics, vol. 15/1, pp. 37-53, http://dx.doi.org/10.1016/j.labeco.2006.12.002.

Hutchings, M. et al. (2008), « Nice and kind, smart and funny: What children like and want to emulate in their teachers ", Oxford Review of Education, vol. 34/2, pp. 135-157, http://dx.doi.org/10.1080/03054980701663959.

Kane, J. et J. Mertz (2012), « Debunking myths about gender and mathematics performance », Notices of the AMS, vol. 59/1, http://dx.doi.org/10.1090/noti790.

OCDE (2019), Guide de l'OCDE pour l'établissement de statistiques internationalement comparables dans le domaine de l'éducation 2018: Concepts, normes, définitions et classifications, Éditions OCDE, Paris, https://dx.doi.org/10.1787/9789264305380-fr.

OCDE (2018), « Les déséquilibres entre les sexes dans la profession enseignante », Les indicateurs de l'éducation à la loupe, $\mathrm{n}^{\circ} 49$, Éditions OCDE, Paris, https://dx.doi.org/10.1787/026cb10b-fr.

OCDE (2015), « Comment expliquer l'inégalité entre les sexes dans l'éducation ? », PISA à la loupe, n 49, Éditions OCDE, Paris, https://dx.doi.org/10.1787/5js4xffc0pbr-fr.

OCDE (2014), Regards sur l'éducation 2014: Les indicateurs de l'OCDE, Éditions OCDE, Paris, https://dx.doi.org/10.1787/eag-2014-fr.

OCDE (2014), Résultats de TALIS 2013: Une perspective internationale sur l'enseignement et l'apprentissage, TALIS, Éditions OCDE, Paris, https://dx.doi.org/10.1787/9789264214293-fr. 
OCDE (2014), Résultats du PISA 2012 : Savoirs et savoir-faire des élèves (Volume I): Performance des élèves en mathématiques, en compréhension de l'écrit et en sciences, PISA, Éditions OCDE, Paris, https://dx.doi.org/10.1787/9789264208827-fr.

OCDE (2011), Lessons from PISA for the United States, Strong Performers and Successful Reformers in Education, Éditions OCDE, Paris, https://dx.doi.org/10.1787/9789264096660-en.

OCDE (2009), Creating Effective Teaching and Learning Environments: First Results from TALIS, Éditions OCDE, Paris, http://dx.doi.org/10.1787/9789264068780-en.

OCDE (2006), Le rôle crucial des enseignants: Attirer, former et retenir des enseignants de qualité, Politiques d'éducation et de formation, Éditions OCDE, Paris, https://dx.doi.org/10.1787/9789264018051-fr.

Peterson, P. (2011), Saving schools : from Horace Mann to virtual learning, Belknap Press of Harvard University Press.

Pyke, J. et K. White (s.d.), Are gender quotas in academia a good idea?, https://www.weforum.org/agenda/2018/09/gender-quotas-may-speed-up-equity-in-academia (consulté le 16 mai 2019).

Winchester, H. et L. Browning (2015), « Gender equality in academia: a critical reflection », Journal of Higher Education Policy and Management, vol. 37/3, pp. 269-281, http://dx.doi.org/10.1080/1360080X.2015.1034427.

Winslow, S. et S. Davis (2016), « Gender Inequality Across the Academic Life Course », Sociology Compass, vol. 10/5, pp. 404-416, http://dx.doi.org/10.1111/soc4.12372.

\section{Tableaux de l'indicateur D5}

Tableau D5.1

Tableau D5.2

Tableau D5.3
Pyramide des âges des enseignants (2017)

Répartition des enseignants selon le sexe (2017)

Répartition des enseignants par sexe selon le groupe d'âge (2017) et pourcentage de femmes parmi les enseignants, tous groupes d'âge confondus (2005 et 2017)

Date butoir pour les données : 19 juillet 2019. Les mises à jour peuvent être consultées en ligne sur : http://dx.doi.org/10.1787/eag-data-en. D'autres données désagrégées sont également disponibles dans la Base de données de Regards sur l'éducation (http://stats.oecd.org/).

StatLink : https://doi.org/10.1787/888933981267 
Tableau D5.1. Pyramide des âges des enseignants (2017)

Pourcentage d'enseignants dans les établissements publics et privés, selon leur niveau d'enseignement et leur groupe d'âge, calculs fondés sur le nombre d'individus

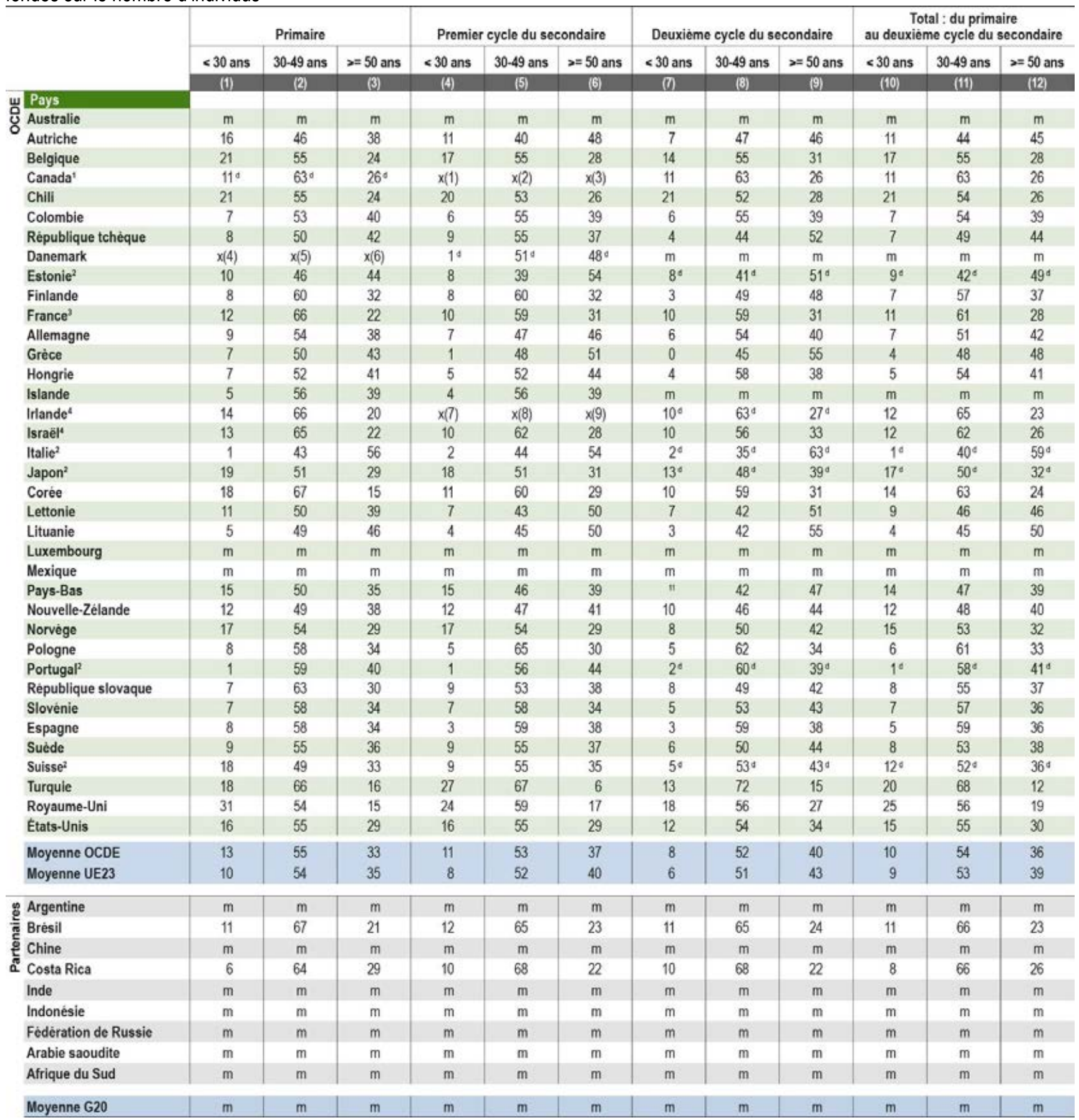

1. L'enseignement primaire inclut l'enseignement préprimaire.

2. Le deuxième cycle de l'enseignement secondaire inclut des programmes d'autres niveaux d'enseignement - voir l'annexe 3 pour plus de précisions.

3. Établissements publics et établissements privés subventionnés par l'État uniquement.

4. Pour l'Irlande, établissements publics uniquement. Pour Israël, les établissements privés sont inclus pour tous les niveaux d'enseignement à l'exception du préprimaire et du deuxième cycle du secondaire.

Source : OCDE/ISU/Eurostat (2019). Consulter la section « Source » pour tout complément d'information et l'annexe 3 pour les notes ((https://doi.org/10.1787/f8d7880den).

Les symboles représentant les données manquantes et les abréviations figurent dans le Guide du lecteur.

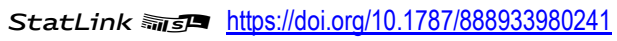


Tableau D5.2. Répartition des enseignants selon le sexe (2017)

Pourcentage de femmes parmi les enseignants des établissements publics et privés, selon le niveau d'enseignement, calculs fondés sur le nombre d'individus

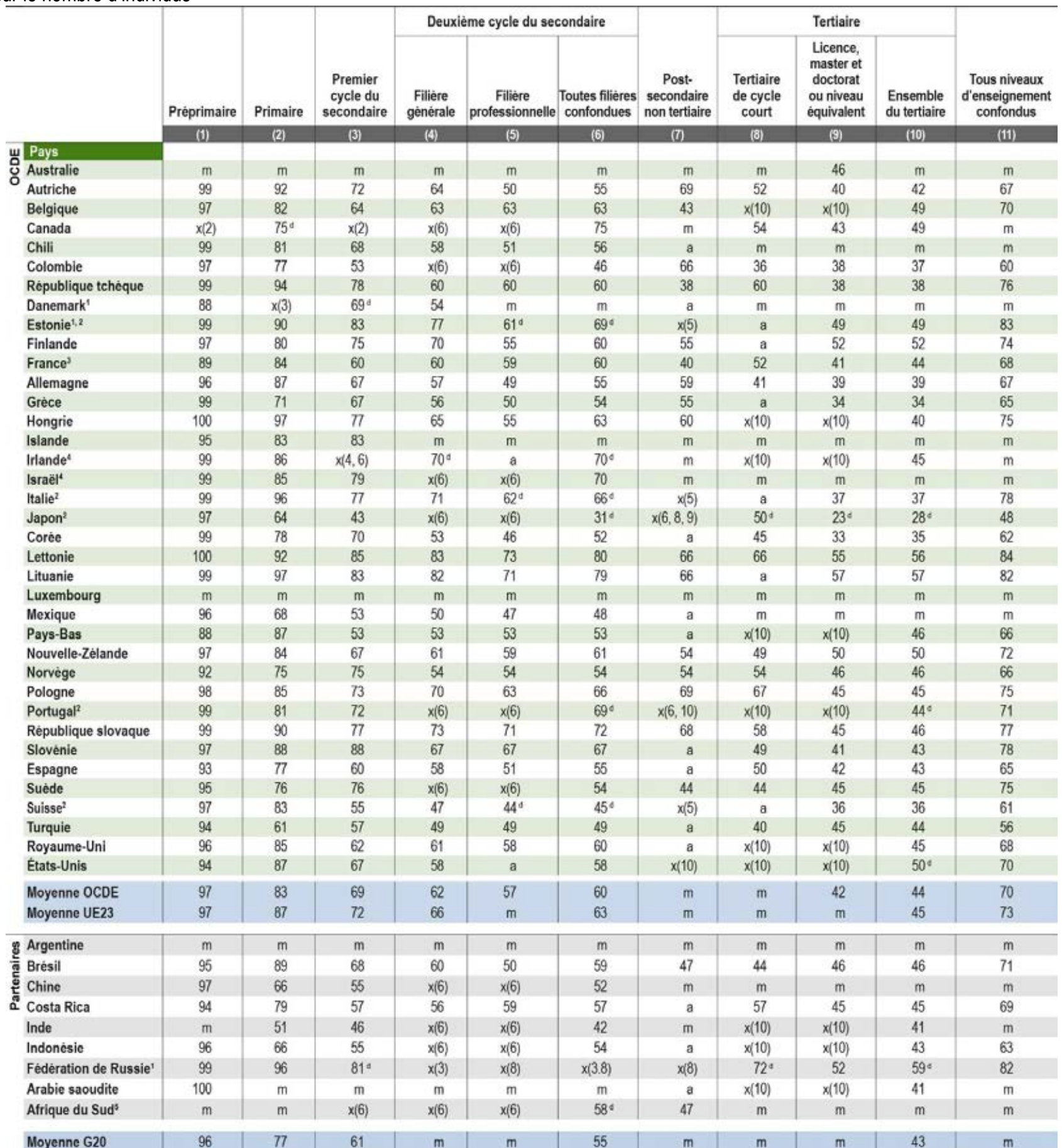

Remarque : Les données de la catégorie « Tous niveaux d'enseignement confondus » n'incluent pas les programmes de développement éducatif de la petite enfance (niveau 01 de la CITE).

1. Le préprimaire inclut les programmes de développement éducatif de la petite enfance.

2. Le deuxième cycle de l'enseignement secondaire inclut des programmes d'autres niveaux d'enseignement - voir l'annexe 3 pour plus de précisions.

3. Établissements publics et établissements privés subventionnés par l'Etat uniquement pour tous les niveaux sauf le tertiaire. Pour l'enseignement tertiaire, établissements publics uniquement.

4. Pour l'Illande, établissements publics uniquement pour tous les niveaux d'enseignement à l'exception du préprimaire, où les données incluent uniquement les établissements privés indépendants. Pour Israël, les établissements privés sont inclus pour tous les niveaux d'enseignement à l'exception du préprimaire et du deuxième cycle du secondaire.

5. Année de référence : 2016, et non 2017

Source : OCDE/ISU/Eurostat (2019). Consulter la section « Source » pour tout complément d'information et l'annexe 3 pour les notes (https://doi.org/10.1787/f8d7880d-en).

Les symboles représentant les données manquantes et les abréviations figurent dans le Guide du lecteur. 
Tableau D5.3. Répartition des enseignants par sexe selon le groupe d'âge (2017) et pourcentage de femmes parmi les enseignants, tous groupes d'âge confondus (2005 et 2017)

Pourcentage de femmes parmi les enseignants, selon le groupe d'âge et le niveau d'enseignement

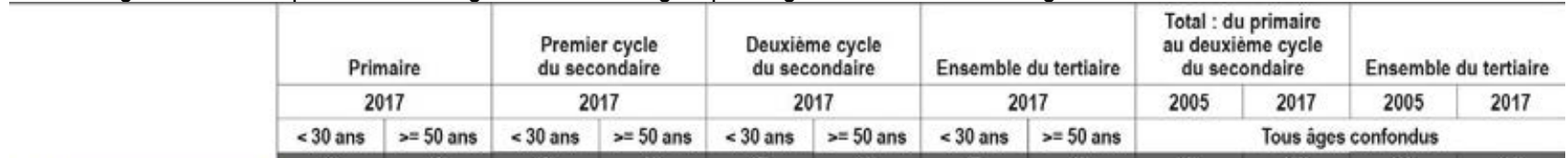

\begin{tabular}{|c|c|c|c|c|c|c|c|c|c|c|c|c|}
\hline \multirow{2}{*}{\multicolumn{13}{|c|}{ س. Pays }} \\
\hline & & & & & & & & & & & & \\
\hline Australie & $\mathrm{m}$ & $\mathrm{m}$ & $\mathrm{m}$ & $\mathrm{m}$ & $\mathrm{m}$ & m & $\mathrm{m}$ & $\mathrm{m}$ & $\mathrm{m}$ & m & m & m \\
\hline Autriche & 94 & 91 & 76 & 73 & 72 & 53 & 53 & 37 & $\mathrm{~m}$ & 74 & $\mathrm{~m}$ & 42 \\
\hline Belgique & 85 & 79 & 71 & 59 & 68 & 58 & 67 & 44 & $65^{\circ}$ & 70 & 41 & 49 \\
\hline Canada' & $83^{\circ}$ & $70^{\circ}$ & $x(1)$ & $x(2)$ & 83 & 70 & 60 & 44 & 73 & 75 & 48 & 49 \\
\hline Chill & 80 & 81 & 70 & 65 & 60 & 49 & $\mathrm{~m}$ & $\mathrm{~m}$ & 70 & 71 & $\mathrm{~m}$ & $\mathrm{~m}$ \\
\hline Colombie & 72 & 77 & 55 & 53 & 48 & 47 & 46 & 29 & $\mathrm{~m}$ & 64 & $\mathrm{~m}$ & 37 \\
\hline Rèpublique tchèque & 92 & 95 & 73 & 82 & 52 & 58 & $\mathrm{~m}$ & $\mathrm{~m}$ & $71^{.}$ & 76 & 40 & 38 \\
\hline Danemark & $x(3)$ & $x(4)$ & $69^{\circ}$ & $69^{\circ}$ & $\mathrm{m}$ & $\mathrm{m}$ & $\mathrm{m}$ & $\mathrm{m}$ & $\mathrm{m}$ & $\mathrm{m}$ & $\mathrm{m}$ & $\mathrm{m}$ \\
\hline Estonic ${ }^{2}$ & 84 & 92 & 75 & 85 & $60^{\circ}$ & $72^{\circ}$ & 50 & 46 & $\mathrm{~m}$ & $83^{4}$ & 48 & 49 \\
\hline Finlande & 81 & 76 & 77 & 73 & 68 & 56 & 45 & 52 & 69 & 72 & 47 & 52 \\
\hline France $^{3}$ & 89 & $\pi$ & 64 & 57 & 63 & 56 & 56 & 38 & 65 & 68 & 38 & 44 \\
\hline Allemagne ${ }^{4}$ & 92 & 85 & 79 & 67 & 72 & 50 & 45 & 30 & 65 & 70 & 32 & 39 \\
\hline Grece & 88 & 60 & 78 & 62 & 75 & 48 & 47 & 32 & 59 & 66 & 36 & 34 \\
\hline Hongrie & 92 & 97 & 71 & 76 & 61 & 59 & 44 & 35 & 79 & 78 & 39 & 40 \\
\hline Islande & 73 & 84 & 73 & 84 & m & m & $\mathrm{m}$ & $\mathrm{m}$ & $\mathrm{m}$ & $\mathrm{m}$ & $\mathrm{m}$ & $\mathrm{m}$ \\
\hline Irlande ${ }^{5}$ & 81 & 86 & $x(5)$ & $x(6)$ & $66^{\circ}$ & $69^{\circ}$ & m & m & 72 & 79 & 39 & 45 \\
\hline Israế| $\left.\right|^{5}$ & 91 & 83 & 86 & 76 & 83 & 65 & m & $\mathrm{m}$ & 79 & 80 & $\mathrm{~m}$ & $\mathrm{~m}$ \\
\hline Italie ${ }^{2}$ & 92 & 96 & 64 & $\pi$ & $66^{\circ}$ & $66^{\circ}$ & 51 & 33 & 78 & $79^{4}$ & 34 & 37 \\
\hline Japon $^{2}$ & 65 & 68 & 45 & 40 & $38^{\circ}$ & $23^{\circ}$ & $49^{\circ}$ & $25^{\circ}$ & 46 & $49^{\circ}$ & 18 & $28^{\circ}$ \\
\hline Corée & 73 & 88 & 72 & 58 & 69 & 30 & 67 & 22 & 61 & 67 & 31 & 35 \\
\hline Lettonie & 84 & 94 & 69 & 85 & 60 & 82 & 58 & 54 & m & 87 & $\mathrm{~m}$ & 56 \\
\hline Lituanie & 89 & 97 & 74 & 81 & 67 & 79 & 58 & 53 & $84^{\circ}$ & 85 & 53 & 57 \\
\hline Luxembourg & $\mathrm{m}$ & $\mathrm{m}$ & $\mathrm{m}$ & $\mathrm{m}$ & $\mathrm{m}$ & $\mathrm{m}$ & $\mathrm{m}$ & $\mathrm{m}$ & $\mathrm{m}$ & $\mathrm{m}$ & $\mathrm{m}$ & $\mathrm{m}$ \\
\hline Mexique & $\mathrm{m}$ & $\mathrm{m}$ & $\mathrm{m}$ & $\mathrm{m}$ & $\mathrm{m}$ & $\mathrm{m}$ & $\mathrm{m}$ & $\mathrm{m}$ & 56 & 58 & $\mathrm{~m}$ & $\mathrm{~m}$ \\
\hline Pays-Bas & 88 & 84 & 62 & 45 & 65 & 46 & 51 & 36 & $66^{\circ}$ & 69 & 35 & 46 \\
\hline Nouvelle-Zélande & 87 & 86 & 74 & 66 & 64 & 60 & 50 & 48 & 69 & 72 & 50 & 50 \\
\hline Norvege & 69 & 78 & 69 & 78 & 60 & 48 & 45 & 43 & $\mathrm{~m}$ & 69 & $\mathrm{~m}$ & 46 \\
\hline Pologne & 82 & 87 & 65 & 74 & 62 & 62 & $\mathrm{~m}$ & $\mathrm{~m}$ & 76 & 77 & 41 & 45 \\
\hline Portugal ${ }^{2}$ & 85 & 79 & 60 & 72 & $56^{4}$ & $69^{\circ}$ & 44 & 39 & 74 & $74^{\circ}$ & $42^{4}$ & 44 \\
\hline République slovaque & 86 & 93 & 77 & 79 & 78 & 72 & 58 & 42 & 77 & 79 & 42 & 46 \\
\hline Slovénie & 88 & 88 & 88 & 88 & 70 & 62 & 63 & 38 & 78 & 83 & 33 & 43 \\
\hline Espagne & 80 & 76 & 66 & 58 & 61 & 52 & 50 & 37 & 62 & 66 & 39 & 43 \\
\hline Suéde & 70 & 77 & 70 & 77 & 53 & 51 & 47 & 43 & $\mathrm{~m}$ & 70 & $\mathrm{~m}$ & 45 \\
\hline Suisse $e^{2}$ & 89 & 79 & 68 & 49 & $58^{\circ}$ & $41^{\circ}$ & 56 & 30 & 62 & $65^{\circ}$ & 32 & 36 \\
\hline Turquie & 73 & 39 & 65 & 35 & 64 & 32 & 53 & 31 & $\mathrm{~m}$ & 55 & 38 & 44 \\
\hline Royaume-Uni & 83 & 89 & 65 & 58 & 63 & 55 & 50 & 41 & 68 & 72 & 40 & 45 \\
\hline Etats-Unis ${ }^{6}$ & 88 & 88 & 69 & 68 & 62 & 56 & $\mathrm{~m}$ & $\mathrm{~m}$ & 74 & 75 & $44^{\circ}$ & $50^{\circ}$ \\
\hline Moyenne OCDE & 83 & 82 & 70 & 68 & 64 & 56 & 52 & 39 & 69 & 72 & 39 & 44 \\
\hline $\begin{array}{l}\text { Moyenne des pays dont } \\
\text { les donnees des deux } \\
\text { annees de reférence sont } \\
\text { disponibles }\end{array}$ & - & - & - & - & - & - & - & - & 68 & 72 & 39 & 44 \\
\hline Moyenne UE23 & 86 & 86 & 71 & 71 & 65 & 61 & $\mathrm{~m}$ & $\mathrm{~m}$ & $\mathrm{~m}$ & 75 & m & 45 \\
\hline
\end{tabular}

\begin{tabular}{|c|c|c|c|c|c|c|c|c|c|c|c|c|}
\hline Argentine & m & m & m & m & m & m & m & m & m & m & m & $\mathrm{m}$ \\
\hline Brésil & 82 & 92 & 61 & 71 & 55 & 60 & 50 & 42 & m & 73 & m & 46 \\
\hline Chine & m & $\mathrm{m}$ & $\mathrm{m}$ & $\mathrm{m}$ & $\mathrm{m}$ & m & $\mathrm{m}$ & m & m & 60 & m & $\mathrm{m}$ \\
\hline Costa Rica & 67 & 81 & 56 & 58 & 56 & 58 & 46 & 40 & $\mathrm{~m}$ & 69 & $\mathrm{~m}$ & 45 \\
\hline Inde & m & m & m & m & m & m & $\mathrm{m}$ & m & m & 48 & m & 41 \\
\hline Indonésie & m & m & m & $\mathrm{m}$ & $\mathrm{m}$ & m & m & $\mathrm{m}$ & m & 61 & $\mathrm{~m}$ & 43 \\
\hline Fédération de Russie ${ }^{6}$ & m & m & $\mathrm{m}$ & m & $\times(3,7)$ & $x(4,8)$ & $64^{\circ}$ & $54^{\circ}$ & 86 & 85 & $51^{4}$ & $59^{\circ}$ \\
\hline Arabie saoudite & $m$ & $\mathrm{~m}$ & m & m & m & $m$ & $\mathrm{~m}$ & m & m & $\mathrm{m}$ & $m$ & 41 \\
\hline Afrique du Sud & $\mathrm{m}$ & m & m & m & m & $\mathrm{m}$ & m & m & m & $\mathrm{m}$ & $\mathrm{m}$ & $m$ \\
\hline
\end{tabular}

\begin{tabular}{l|c|c|c|} 
Moyenne $\mathrm{G} 20$ & $\mathrm{~m}$ & $\mathrm{~m}$ & $\mathrm{~m}$ \\
1. L'enseignement primaire inclut l'enseignement préprimaire.
\end{tabular}

2. Le deuxième cycle de l'enseignement secondaire inclut des programmes d'autres niveaux d'enseignement - voir l'annexe 3 pour plus de précisions.

3. Établissements publics et établissements privés subventionnés par l'État uniquement pour tous les niveaux sauf le tertiaire. Pour l'enseignement tertiaire, établissements publics uniquement.

4. Année de référence : 2006 , et non 2005 .

5. Pour l'Irlande, établissements publics uniquement. Pour Israël, les établissements privés sont inclus pour tous les niveaux d'enseignement à l'exception du préprimaire et du deuxième cycle du secondaire.

6. L'enseignement tertiaire inclut des programmes d'autres niveaux d'enseignement - voir l'annexe 3 pour plus de précisions.

Source : OCDE/ISU/Eurostat (2019). Consulter la section « Source » pour tout complément d'information et l'annexe 3 pour les notes (https://doi.org/10.1787/f8d7880d-en). Les symboles représentant les données manquantes et les abréviations figurent dans le Guide du lecteur. 



\section{Indicateur D6. Quels sont les systèmes d'admission dans l'enseignement tertiaire?}

\section{Faits marquants}

- Dans plus de la moitié des pays et économies dont les données sont disponibles, l'admission est libre (tous les candidats ayant le niveau minimal de qualification requis sont admis) dans au moins certains des établissements publics ou privés. Des critères de sélection peuvent toutefois s'appliquer dans des établissements ou domaines d'études spécifiques dans ces pays.

- Les examens centraux ou nationaux organisés vers la fin du deuxième cycle de l'enseignement secondaire et les examens d'entrée organisés par les établissements d'enseignement tertiaire sont les épreuves les plus largement utilisées pour sélectionner les candidats admissibles dans les premiers cursus de l'enseignement tertiaire.

- Dans la plupart des pays, d'autres critères que les résultats aux examens centraux ou nationaux sont également pris en compte par les établissements qui exercent une forme de sélection, mais à des degrés divers. L'admission dans les établissements publics d'enseignement tertiaire est le plus souvent décidée sur la base des résultats scolaires moyens des candidats, de leur expérience professionnelle et d'entretiens avec eux.

\section{Graphique D6.1. Limitation de la capacité d'accueil dans certains domaines d'études et établissements dans les pays à régime ouvert ou sélectif (2017)}

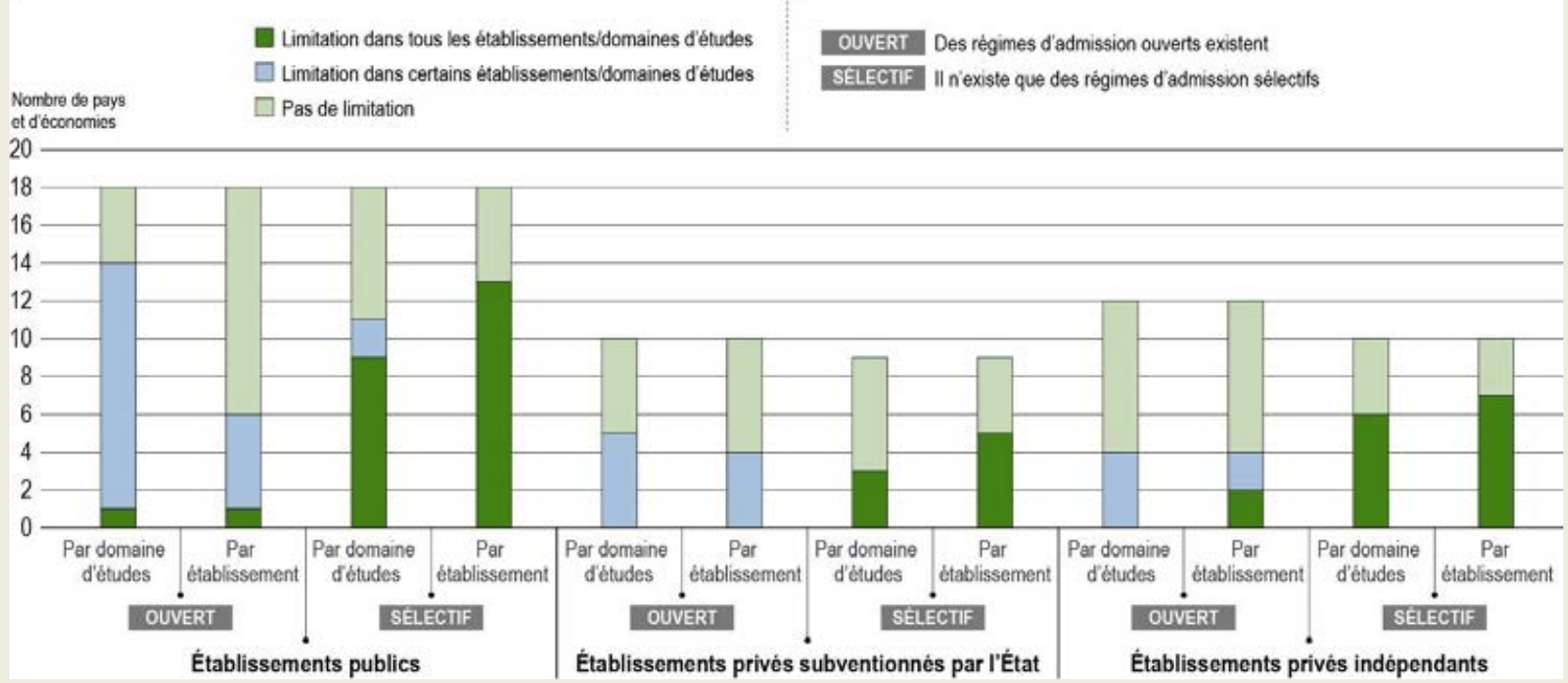

\section{Lecture du graphique}

Dans les pays et économies à régime d'admission ouvert, la capacité d'accueil en premiers cursus tertiaires peut néanmoins être limitée, soit par domaine d'études, soit par établissement. Elle peut être limitée dans tout ou partie des domaines d'études et types d'établissements ou ne l'être dans aucun d'entre eux. De même, elle peut être limitée dans des domaines d'études ou établissements dans les pays à régime sélectif. C'est pourquoi elle n'est pas nécessairement limitée dans l'une de ces dimensions dans les pays à régime sélectif.

Remarque : Ce graphique n'inclut pas les pays dont les données sont manquantes ou non applicables parmi les 38 pays qui ont participé à l'enquête. Source : OCDE (2017), tableaux D6.1a, D6.1b et D6.1c. Consulter la section « Source » pour tout complément d'information et l'annexe 3 pour les notes (https://doi.org/10.1787/f8d7880d-en). 


\section{Contexte}

Le taux de scolarisation de l'enseignement tertiaire augmente dans les pays de l'OCDE sous l'effet de différents facteurs. En premier lieu, l'augmentation de l'effectif diplômé du niveau d'enseignement minimal requis à l'admission dans l'enseignement tertiaire entraîne l'accroissement de la demande potentielle de cursus tertiaires (voir l'indicateur B3). Parallèlement, la relation positive entre le niveau de formation et les débouchés sur le marché du travail peut aussi contribuer à accroître la demande en particulier dans les pays accusant des taux de chômage élevés ou en proie à une crise économique, car le bon rendement financier de l'investissement dans l'élévation du niveau de formation incite les diplômés de l'enseignement secondaire à poursuivre leurs études (voir les indicateurs A4 et A5).

Le taux de scolarisation dans l'enseignement tertiaire dépend aussi de la capacité d'accueil des établissements de ce niveau. En raison de l'accroissement de la demande de formations tertiaires, les établissements et les responsables politiques ont de nouveaux défis à relever pour que la capacité d'accueil soit suffisante. L'accroissement de la demande pourrait aussi intensifier la concurrence entre les candidats aux études tertiaires. Dans certains pays plus que dans d'autres, les décisions sur la capacité d'accueil de domaines d'études tertiaires donnés dépendent davantage des besoins sur le marché du travail. Cette mise en adéquation de la production de profils tertiaires avec la demande de compétences sur le marché du travail pourrait avoir un impact sur les taux de scolarisation et la sélectivité de l'admission dans différents domaines d'études tertiaires.

Dans l'enseignement tertiaire, les systèmes d'admission peuvent être conçus pour combiner des objectifs différents. Des critères d'admission peuvent être utilisés pour garantir que les candidats possèdent les compétences requises pour réussir la formation qu'ils souhaitent entreprendre (voir l'indicateur B5). Toutefois, réduire le nombre de critères d'admission peut contribuer à améliorer l'accès à l'enseignement tertiaire et à remédier à des problèmes d'équité.

L'analyse des systèmes et des critères nationaux d'admission en premiers cursus tertiaires révèle des différences entre les régimes ouverts et sélectifs des pays et montre les pourcentages de candidats satisfaisant aux critères applicables et admis à l'issue du processus d'admission. Elle ne porte toutefois pas sur la sélectivité qui peut s'observer pendant les études (par exemple, des étudiants qui arrêtent leurs études parce qu'ils ne réussissent pas des épreuves intermédiaires ou qui ne progressent pas au rythme voulu).

\section{Autres faits marquants}

- L'exécutif central définit le niveau minimal de performance académique requis à l'accès en premiers cursus tertiaires en plus du niveau minimal de qualification requis par domaine d'études ou par établissement d'enseignement tertiaire dans la moitié environ des pays et économies dont les données sont disponibles. Ce niveau de performance requis est le plus souvent déterminé sur la base du diplôme ou du bulletin de fin d'études secondaires, lequel mentionne les notes obtenues, ou des résultats des examens centraux ou nationaux administrés dans le deuxième cycle de l'enseignement secondaire.

- Pour être admis dans certains au moins des domaines d'études, les candidats à une formation tertiaire dans les établissements publics doivent impérativement réussir un examen central ou national ou autre test standardisé dans le deuxième cycle de l'enseignement secondaire ou un examen d'entrée dans plus de deux tiers des pays et économies dont les données sont disponibles.

- Les candidats doivent envoyer leur candidature directement aux établissements publics d'enseignement tertiaire dans près de la moitié des pays et économies, tandis que le système d'admission est centralisé ou hybride dans les autres pays. Les dossiers de candidature adressés aux établissements privés sont moins susceptibles d'être traités de manière centralisée.

- Le processus de candidature et d'admission en premiers cursus tertiaires (dans les établissements publics et privés) ne varie guère entre les ressortissants nationaux et les étudiants étrangers ou en mobilité internationale dans la moitié environ des pays et économies dont les données sont disponibles. 


\section{Analyse}

\section{Organisation du système d'admission : régimes ouverts versus régimes sélectifs}

Les régimes d'admission en premiers cursus tertiaires reflètent la manière dont l'enseignement tertiaire est organisé et structuré dans les pays. Les établissements publics sont caractéristiques de l'enseignement tertiaire dans la quasi-totalité des pays et économies dont les données sont disponibles. Dans les pays de l'OCDE, ils accueillent dans l'ensemble la plupart des étudiants (voir le graphique B1.3). Les établissements privés sont presque aussi nombreux à ce niveau d'enseignement, sauf au Danemark et en Grèce, les deux seuls pays où aucun établissement privé subventionné par l'État ou indépendant ne propose de premiers cursus tertiaires. Dans la moitié environ des pays et économies dont les données sont disponibles, les établissements privés subventionnés par l'État font partie du paysage de l'enseignement tertiaire (voir le tableau D6.1 et les tableaux D6.1b et D6.1c, disponibles en ligne).

En premiers cursus tertiaires, l'admission libre, sans sélection, de tous les candidats diplômés du niveau d'enseignement requis pour y accéder est assez courante dans les établissements tant publics que privés ; ces régimes d'admission sont souvent dits " ouverts" (par opposition aux régimes « sélectifs »). Dans la moitié des pays et économies dont les données sur les établissements publics sont disponibles, il existe au moins quelques établissements à régime d'admission ouvert. Les régimes ouverts sont aussi courants dans les établissements privés : près de la moitié des pays et économies où il existe des établissements privés subventionnés par l'État et près de la moitié de ceux où il existe des établissements privés indépendants qualifient d'ouvert le régime d'admission dans certains au moins de ces établissements d'enseignement tertiaire. Toutefois, les régimes ouverts peuvent comporter certaines restrictions à cause de la limitation de la capacité d'accueil en premiers cursus tertiaires (voir le graphique D6.1). Dans l'enseignement tertiaire, le nombre de nouveaux inscrits peut être limité dans certains domaines ou établissements, auquel cas divers critères de sélection sont utilisés pour décider de l'admission des candidats (voir le tableau D6.1 et les tableaux D6.1b et D6.1c, disponibles en ligne).

\section{Limitation de la capacité d'accueil dans des domaines d'études spécifiques}

Dans les établissements publics d'enseignement tertiaire, le régime d'admission est ouvert dans la moitié (18) des 36 pays et économies dont les données sont disponibles, dont la plupart appliquent toutefois des restrictions à l'admission dans certains au moins des domaines d'études. En Allemagne par exemple, des quotas limitent l'admission dans quelques domaines d'études si le nombre total de candidats est supérieur à la capacité d'accueil de tous les établissements d'enseignement supérieur. Les candidats à l'admission dans ces domaines sont sélectionnés en fonction de leurs notes à l'Abitur (l'examen de fin d'études secondaires qui ouvre l'accès à l'enseignement tertiaire en Allemagne). En Nouvelle-Zélande, la capacité d'accueil est limitée dans certains domaines, notamment en médecine humaine et vétérinaire, en dentisterie et en aéronautique. II est d'usage de limiter le nombre d'étudiants en médecine ainsi que dans d'autres disciplines en rapport avec la santé dans des établissements publics d'enseignement tertiaire dans plusieurs autres pays (voir le tableau D6.1a). II en va de même dans des établissements privés subventionnés par l'État ou indépendants (voir les tableaux D6.1b et D6.1c, disponibles en ligne).

Le système d'admission en premiers cursus tertiaires est sélectif dans les établissements publics dans la moitié des pays dont les données sont disponibles. Ces pays sont, par comparaison avec les pays où le régime est ouvert, moins nombreux à limiter la capacité d'accueil par domaine d'études. Toutefois, lorsque des restrictions y existent, elles s'appliquent généralement à tous les domaines d'études plutôt qu'à certains d'entre eux. Dans les établissements privés subventionnés par l'État et indépendants, la capacité d'accueil est restreinte dans tous les domaines d'études si les systèmes sont sélectifs et dans certains domaines seulement si les systèmes sont ouverts (voir le graphique D6.1). La limitation de la capacité d'accueil peut influer sur la sélectivité des différents domaines (voir l'encadré D6.1). 


\section{Limitation de la capacité d’accueil dans des établissements spécifiques}

Les pays où les régimes sont sélectifs sont plus susceptibles de limiter les effectifs des établissements d'enseignement tertiaire que ceux des domaines d'études. Ces restrictions s'appliquent alors à tous les établissements publics et privés (subventionnés par l'État et indépendants).

En premiers cursus tertiaires, 13 des 18 pays où le régime est sélectif limitent les effectifs de tous les établissements publics d'enseignement tertiaire. En Turquie par exemple, les autorités centrales décident des limites de l'effectif de tous les établissements publics. Toutefois, des pays où le système d'admission est ouvert limitent parfois aussi l'effectif des établissements d'enseignement tertiaire. Aux États-Unis par exemple, ce sont les établissements d'enseignement tertiaire qui décident eux-mêmes de la limitation de leur effectif et le degré de sélectivité varie fortement entre eux, puisque les décisions d'admission sont de leur ressort. L'admission est libre dans de nombreux établissements, mais est sélective, voire très sélective dans d'autres (voir le graphique D6.1).

Des tendances similaires s'observent dans les systèmes d'admission des établissements privés subventionnés par l'État et indépendants. Toutefois, les décisions relatives à la limitation des effectifs de ces établissements sont moins souvent prises exclusivement par les autorités centrales. Les décisions relatives à la limitation des effectifs sont du seul ressort des autorités centrales en Israël (dans les établissements privés subventionnés par l'État) et en Turquie (dans tous les établissements privés indépendants) (voir les tableaux D6.1b et D6.1c, disponibles en ligne).

\section{Encadré D6.1. Attractivité et sélectivité de différents domaines d'études}

En 2017, l'OCDE a mené une enquête sur le nombre de candidats et de candidatures à l'admission en premiers cursus tertiaires, en complément de la collecte des données sur les systèmes d'admission à ces formations. La moitié environ des 30 pays et économies qui ont participé à l'enquête ont fourni des données ventilées jusqu'à un certain point par domaine d'études sur les candidats ou les candidatures.

Seuls 11 pays ont fourni les données requises pour calculer le nombre de candidatures par candidat dans les différents domaines d'étude. Le nombre de candidatures par candidat varie fortement entre les pays et entre les domaines d'études dans ces pays. Toutefois, il est difficile à interpréter, car son importance dépend des caractéristiques du système d'admission. Les candidats peuvent par exemple indiquer plusieurs options qui ne sont pas nécessairement comptabilisées chacune comme une candidature dans les pays où le système d'admission est centralisé, mais présenter une candidature par option dans les pays où le système d'admission n'est pas centralisé. De plus, le montant des frais de scolarité et leur variation entre les domaines d'études peuvent aussi influer sur les candidatures.

Les suites données aux candidatures permettent aussi d'évaluer l'attractivité et la sélectivité des domaines d'études, mais pas de distinguer l'attractivité de la sélectivité. Comme les candidats peuvent présenter plusieurs candidatures, cette analyse porte sur la candidature à l'issue la plus favorable. Soit les candidats sont admis et inscrits, soit ils sont admis et non inscrits, soit ils ne sont pas admis, car aucune de leurs candidatures n'aboutit. Parmi les 30 pays qui ont rempli le questionnaire, 14 seulement ont réparti les candidats entre tous les domaines d'études en fonction de leur candidature à l'issue la plus favorable, de sorte que les candidats ne sont comptabilisés qu'une seule fois (voir le graphique D6.a). Le fait que cette répartition n'est pas disponible dans certains pays peut s'expliquer par l'existence d'un système d'admission ouvert, qui permet aux étudiants de choisir leur domaine d'études librement, sans devoir en passer par un processus spécifique de candidature. C'est le cas en Communauté flamande et en Communauté française de Belgique. 


\section{Graphique D6.a. Candidats à un premier cursus tertiaire selon le statut de la demande, par domaine d'études (2016)}

Domaines d'études où le pourcentage de candidats admis et inscrits est le plus et le moins élevé.

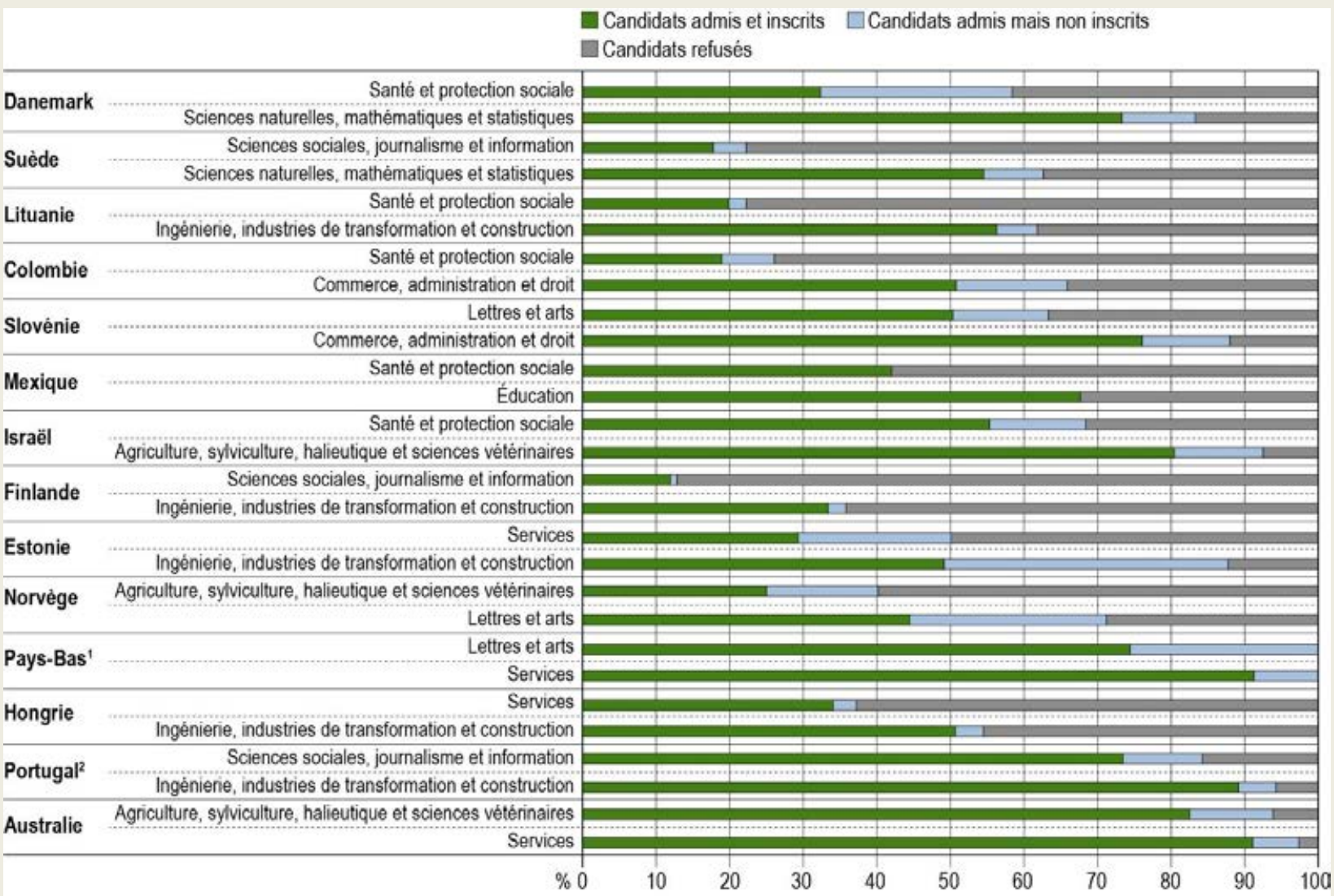

1. Les candidats non admis sont comptabilisés dans la catégorie des candidats admis, mais non inscrits.

2. Année de référence : 2017.

Les pays sont classés par ordre décroissant de la différence de pourcentage de candidats admis et inscrits entre les deux domaines d'études sélectionnés.

Source : Enquête 2017 de l'OCDE-INES NESLI sur les candidats et les candidatures dans l'enseignement tertiaire.

StatLink त्गाज् https://doi.org/10.1787/888933980450

La répartition des candidats en fonction de leur candidature à l'issue la plus favorable varie entre les pays dont les données sont disponibles ainsi qu'entre les domaines d'études dans les pays. Le pourcentage de candidats admis et inscrits varie par exemple entre les domaines d'études de moins de 10 points de pourcentage en Australie, de $83 \%$ (en agriculture, en sylviculture, en halieutique et en sciences vétérinaires) à $91 \%$ (en technologies de l'information et de la communication), mais de 40 points de pourcentage environ au Danemark, de $32 \%$ (en santé et en protection sociale) à $73 \%$ (en sciences naturelles, en mathématiques et en statistiques). Les domaines d'études où le nombre de candidats admis et inscrits est le plus ou le moins élevé varient aussi entre les 14 pays à l'étude. Le pourcentage de candidats admis et inscrits est le moins élevé dans le domaine de la santé et la protection sociale dans cinq pays, mais le plus élevé dans le domaine de l'ingénierie, des industries de transformation et de la construction dans cinq pays. Le pourcentage peu élevé de candidats admis et inscrits peut s'expliquer par la forte attractivité ou sélectivité des domaines d'études (voir le graphique D6.a). 
Les pourcentages de candidats non admis et de candidats admis, mais non inscrits varient aussi entre les pays et les domaines d'études. Toutefois, le pourcentage de candidats admis, mais non inscrits est dans l'ensemble nettement inférieur dans tous les pays et dans tous les domaines d'études.

Ces différences dans les pourcentages de candidats admis et inscrits, de candidats admis et non inscrits et de candidats non admis par domaine d'études donnent des informations sur la sélectivité ou l'attractivité des domaines d'études. Toutefois, ces chiffres doivent être interprétés avec prudence, car ils s'inscrivent dans le contexte des tendances plus générales des systèmes d'admission des pays. Les comparaisons peuvent par exemple être affectées par les étudiants en mobilité internationale : le pourcentage élevé d'étudiants en mobilité internationale candidats à l'admission dans l'enseignement tertiaire peut biaiser les comparaisons, en particulier si leur candidature concerne des domaines d'études différents de ceux prisés par les autres étudiants.

\section{Qualification et performance exigées à l'admission en premiers cursus tertiaires}

Dans tous les pays, l'admission en premiers cursus tertiaires (dans les établissements publics et privés) est subordonnée à un niveau minimal de qualification, équivalent en général au deuxième cycle de l'enseignement secondaire. Les pouvoirs publics peuvent également imposer un niveau minimal de performance aux diplômés du deuxième cycle de l'enseignement secondaire candidats à l'admission en premiers cursus tertiaires (voir le tableau D6.3).

Dans la moitié (19) des 38 pays et économies dont les données sont disponibles, l'exécutif fixe aussi des critères de performance minimale pour être admis dans au moins certains premiers cursus tertiaires ou établissements d'enseignement tertiaire. Ces critères de performance minimale sont plus souvent fixés dans des domaines d'études spécifiques que dans des établissements spécifiques. Ils s'appliquent à tout ou partie des domaines d'études dans 14 pays, mais à tout ou partie des établissements d'enseignement dans 8 pays seulement. Ils s'appliquent à la fois à des domaines d'études et à des établissements d'enseignement en Colombie, en Grèce et au Portugal (voir le tableau D6.3).

Les mécanismes utilisés pour évaluer le niveau minimal de performance des étudiants varient selon les pays, mais ils portent le plus souvent sur le diplôme de fin d'études secondaires (et les notes obtenues) et les résultats aux examens centraux ou nationaux organisés à ce niveau d'enseignement (voir le tableau D6.3).

\section{Examens et tests utilisés par les établissements publics pour décider de l'admission en premiers cursus tertiaires}

Le système d'admission impose parfois en plus des examens d'entrée des examens centraux, nationaux ou infranationaux (standardisés ou non) aux diplômés du deuxième cycle de l'enseignement secondaire candidats à l'admission dans l'enseignement tertiaire. La combinaison des différents types d'examens et la façon d'en utiliser les résultats comme critère d'admission dans l'enseignement tertiaire varient fortement entre les pays. La Lettonie est le seul des pays dont les données sont disponibles à administrer tous les types d'examens (mais ceux-ci ne sont pas tous utilisés pour décider de l'admission dans l'enseignement tertiaire). Par contraste, dans des pays comme le Brésil, la Colombie, le Danemark, l'Espagne, la Hongrie, l'Italie et le Portugal, il n'existe que des examens centraux ou nationaux (qui sont utilisés dans certains de ces pays pour décider de l'admission dans l'enseignement tertiaire).

Réussir les examens centraux ou nationaux vers la fin du deuxième cycle de l'enseignement secondaire ou les examens d'entrée dans l'enseignement tertiaire (qui ne sont pas organisés par les établissements d'enseignement secondaire) peut faire partie des conditions à réunir impérativement pour être admis en premier cursus tertiaire. Dans plus de la moitié des pays, il est obligatoire de passer des examens centraux ou nationaux (des tests standardisés officiellement suivis de conséquence pour les candidats) pour être admis dans la plupart ou la totalité des établissements publics d'enseignement tertiaire. Il est obligatoire de passer un examen d'entrée 
pour être admis dans un établissement public d'enseignement tertiaire dans certains domaines d'études dans un tiers des pays. Dans certains pays, comme en Estonie, en Fédération de Russie, en Lettonie, en Lituanie, au Luxembourg, en Norvège, en Slovénie et en Suisse, les candidats doivent passer les deux types d'épreuves pour être admis dans certains domaines d'études. D'autres épreuves (standardisées ou non, ni centrales ni nationales) sont obligatoires dans quelques rares pays (voir le tableau D6.2a).

\section{Graphique D6.2. Finalité des examens centraux ou nationaux et utilisation de leurs résultats comme critère d'admission dans les établissements d'enseignement tertiaire (2017)}

Par examens nationaux/centraux, on entend ceux administrés aux élèves au terme du deuxième cycle du secondaire.

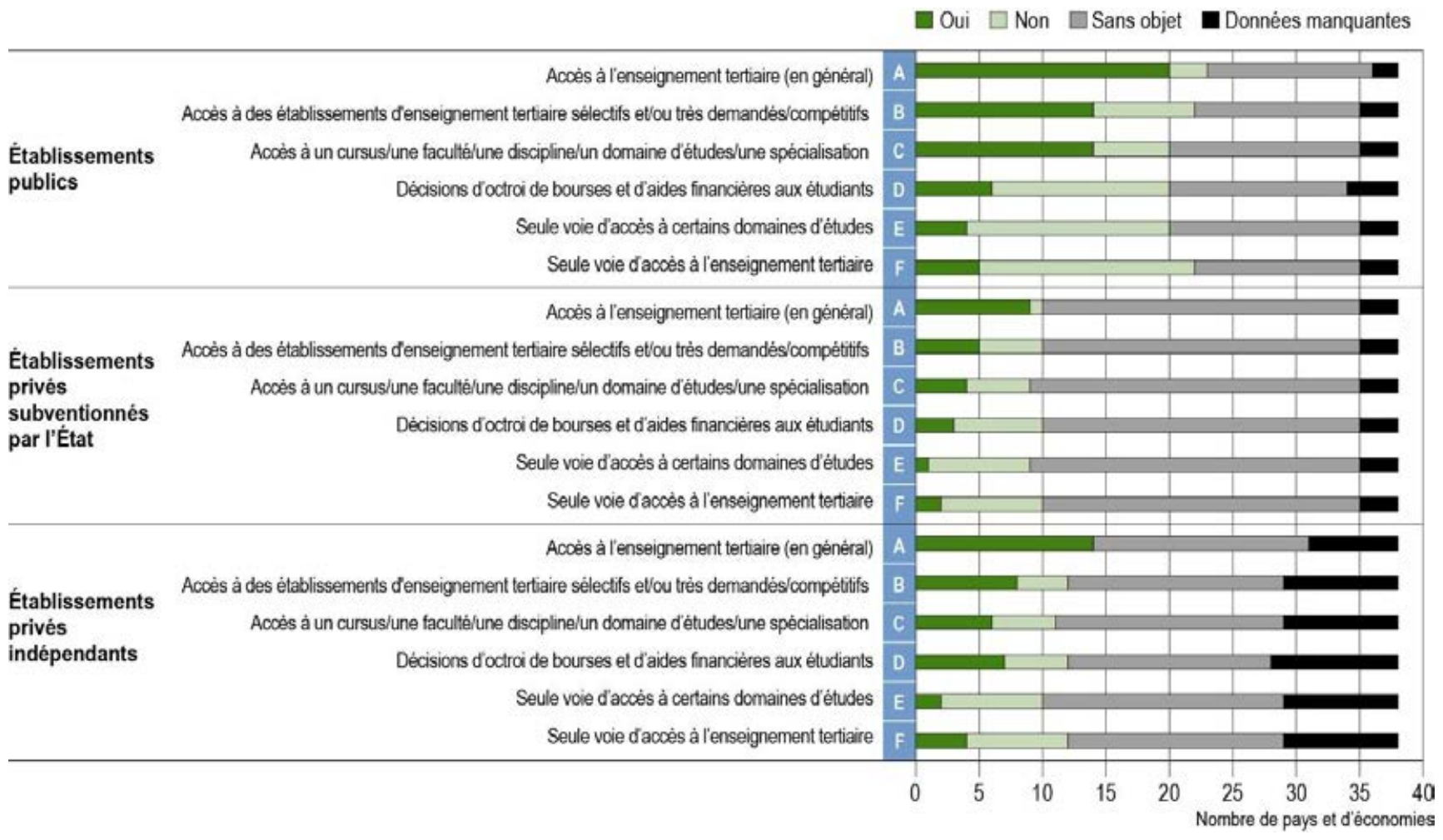

Source : OCDE (2019), tableaux D6.5a, D6.5b et D6.5c. Consulter la section « Source » pour tout complément d'information et l'annexe 3 pour les notes (https://doi.org/10.1787/f8d7880d-en).

Ces examens et épreuves peuvent intervenir dans le processus d'admission même lorsqu'ils ne sont pas obligatoires. Les examens centraux ou nationaux administrés à la fin du deuxième cycle de l'enseignement secondaire sont déterminants pour l'admission dans des domaines d'études dans les établissements publics dans la plupart des pays dont les données sont disponibles (23 pays). Des examens d'entrée dans les établissements publics sont organisés pour décider de l'admission dans certains au moins des domaines d'études dans la moitié environ des pays dont les données sont disponibles (17 pays) (voir le tableau D6.5a).

Dans les établissements publics, ces deux types d'épreuves concernent en particulier les candidats à l'admission dans des établissements, des domaines d'études ou des spécialisations très sélectifs ou très demandés dans l'enseignement tertiaire. Dans six pays, les établissements publics prennent les résultats de ces épreuves en considération lors des décisions relatives aux bourses et à d'autres aides financières (voir le graphique D6.2). 


\section{Autres critères d'admission en premiers cursus tertiaires}

Il y a d'autres critères d'admission en premiers cursus tertiaires que les résultats des candidats aux examens et aux épreuves. Les notes moyennes dans le deuxième cycle de l'enseignement secondaire interviennent dans les décisions d'admission dans les établissements publics d'enseignement tertiaire dans un tiers des pays (que le régime d'admission soit ouvert ou sélectif), tandis qu'elles sont utilisées librement par les établissements dans un quart des pays. Toutefois, ces notes sont d'une importance modérée à élevée dans la décision d'admettre ou non les candidats dans plus de la moitié de ces pays. Dans plus de deux tiers des pays, les entretiens avec les candidats interviennent, soit dans tous les établissements publics d'enseignement tertiaire (dans un quart des pays), soit à leur discrétion (dans plus d'un tiers des pays) (voir le tableau D6.2a).

Dans un nombre assez élevé de pays, les établissements publics se basent sur d'autres facteurs pour admettre les candidats en première année (l'expérience professionnelle antérieure, les revenus de leur famille, leurs recommandations, etc.). Le plus souvent, ces facteurs sont combinés. La Hongrie fait figure d'exception : le seul critère utilisé en plus de la réussite des examens nationaux est la moyenne des notes dans l'enseignement secondaire (voir le tableau D6.2a).

Les notes moyennes dans l'enseignement secondaire, les entretiens et l'expérience professionnelle antérieure sont les critères d'admission en premiers cursus tertiaires les plus souvent retenus par les établissements privés (subventionnés par l'État ou indépendants). Toutefois, par contraste avec les systèmes d'admission dans les établissements publics d'enseignement tertiaire, la prise en considération de ces critères est largement laissée à l'appréciation des établissements (voir les tableaux D6.2b et D6.2c, disponibles en ligne).

Plus généralement, le nombre de critères utilisés dans les systèmes d'admission combiné à la difficulté d'y satisfaire peut accroître la sélectivité des systèmes d'admission. Le pourcentage de candidats non admis est également révélateur du degré de sélectivité. Les systèmes les plus sélectifs sont vraisemblablement ceux où le pourcentage de candidats dont les candidatures sont refusées est le plus élevé (voir l'encadré D6.2).

\section{Encadré D6.2. Variation du pourcentage de candidats non admis}

Parmi les 19 pays dont les chiffres sur le nombre de candidats sont disponibles, 13 seulement peuvent répartir les candidats en fonction des suites données à leurs candidatures, en l'espèce en fonction de leur candidature à l'issue la plus favorable (voir le graphique D6.b). Dans ce graphique, le pourcentage de candidats non admis correspond au pourcentage des candidats dont aucune des candidatures n'a abouti.

Le pourcentage de candidats non admis est inférieur à $5 \%$ en Australie, mais supérieur à $60 \%$ en Finlande et en Suède, deux pays où les admissions sont limitées dans tous les cursus et domaines d'études et où le nombre de candidats admis est décidé lors de négociations entre les établissements d'enseignement tertiaire et le gouvernement central. Le pourcentage de candidats non admis est inférieur à $15 \%$ en Australie, en France, au Portugal et en République slovaque, mais le système d'admission varie fortement entre ces pays. En France, le système d'admission est ouvert et la sélection concerne uniquement quelques domaines d'études et établissements publics (qui accueillent la plupart des étudiants). En Australie, au Portugal et en République slovaque, la limitation de la capacité d'accueil varie. En Australie, la capacité d'accueil n'est pas limitée dans les établissements et domaines d'études (sauf en médecine) ; au Portugal, elle l'est dans tous les établissements et domaines d'études; et en République slovaque, elle l'est uniquement dans certains établissements publics.

Ces différences entre pays montrent l'existence de limites, mais pas nécessairement le degré de sélectivité de l'ensemble du système. II faut des informations plus détaillées sur la capacité d'accueil pour évaluer le degré de sélectivité des systèmes d'enseignement tertiaire. De plus, lorsque la sélection des étudiants s'effectue principalement dans l'enseignement secondaire, une forte sélectivité ne s'impose pas nécessairement, mais le processus d'admission peut malgré tout être sélectif. 


\section{Graphique D6.b. Candidats à un premier cursus tertiaire selon le statut de la demande (2016)}

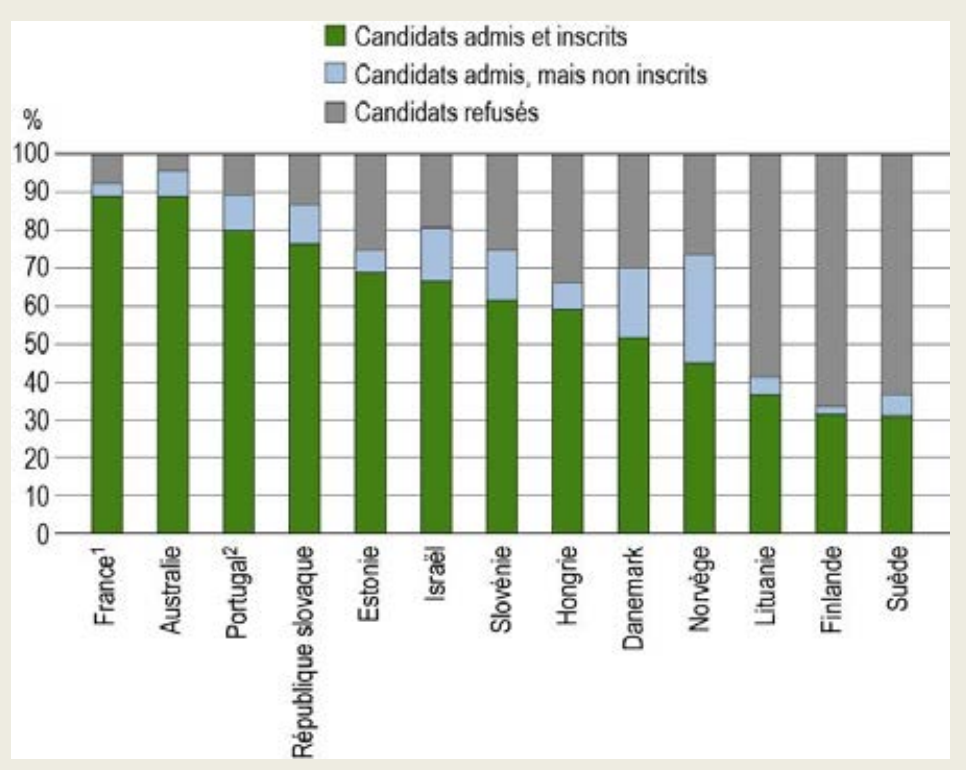

1. Inclut les candidats à une formation tertiaire de cycle court.

2. Année de référence : 2017.

Les pays sont classés par ordre décroissant du pourcentage de candidats admis et inscrits.

Source : Enquête 2017 de l'OCDE-INES NESLI sur les candidats et les candidatures dans l'enseignement tertiaire.

StatLink त्ताज् https://doi.org/10.1787/888933980469

Les candidats admis ne s'inscrivent pas nécessairement dans le cursus où ils ont été admis. Dans les 13 pays dont les données sont disponibles, le pourcentage de candidats admis, mais pas inscrits est supérieur à $10 \%$ au Danemark, en Israël, en République slovaque et en Slovénie et à $25 \%$ en Norvège. Le report de l'inscription peut expliquer les différences entre le nombre de candidats admis et le nombre de nouveaux inscrits.

\section{Processus de candidature et d'admission dans les établissements d'enseignement tertiaire}

Le processus de candidature et d'admission en premiers cursus tertiaires varie sensiblement entre les pays dans les établissements publics. Les candidats doivent envoyer leur dossier directement aux établissements publics dans près de la moitié des pays dont les données sont disponibles, mais doivent l'enregistrer dans un système centralisé dans un quart environ des pays. Dans les autres pays, le système est centralisé, mais les candidats doivent envoyer directement leur candidature dans les établissements publics d'enseignement tertiaire.

Si le système est centralisé, qu'il se double ou non d'un système décentralisé (c'est-à-dire avec envoi direct des candidatures aux établissements), le nombre d'options que les candidats peuvent indiquer peut être limité, tout comme le nombre de propositions qu'ils reçoivent en réponse à leurs candidatures. Les candidats à l'admission dans un établissement public peuvent indiquer au plus deux options au Brésil et trois options au Canada, en Fédération de Russie, aux Pays-Bas et en Slovénie, mais peuvent en indiquer une vingtaine, voire davantage en France et en Turquie. Le nombre de candidatures n'est pas plafonné en Italie et en Nouvelle-Zélande. En Grèce, le nombre d'options n'est pas limité, mais les candidats ne peuvent choisir que deux domaines scientifiques sur les cinq possibles. Quel que soit le nombre maximum de candidatures, les candidats ne reçoivent qu'une seule proposition dans la plupart des pays où le système est centralisé. Le nombre de propositions est toutefois illimité en Australie, au Canada, en Corée et en Italie, où le processus d'admission est 
hybride (les candidats enregistrent leur dossier dans un système centralisé d'admission dans l'enseignement tertiaire et l'envoient aux établissements de leur choix) (voir le tableau D6.1a).

Les dossiers de candidature adressés aux établissements privés sont moins susceptibles d'être traités de manière centralisée. Le système d'admission centralisé est le seul ou le principal système d'admission dans les établissements privés dans quelques pays - au Chili, en Finlande et en Suède (dans les établissements privés subventionnés par l'État) et en Hongrie et en Turquie (dans les établissements privés indépendants). Les candidats doivent adresser leur candidature directement aux établissements privés dans près de la moitié des pays où il existe des établissements privés subventionnés par l'État et dans la plupart des pays où il existe des établissements privés indépendants. Toutefois, le système d'admission est hybride puisqu'il est centralisé, mais prévoit l'envoi direct des candidatures dans un tiers des pays où ce type d'établissements d'enseignement tertiaire existe (voir les tableaux D6.1b et D6.1c, disponibles en ligne).

\section{Processus de candidature et d'admission des étudiants étrangers ou en mobilité internationale}

Dans l'enseignement tertiaire, la mobilité internationale des étudiants a fortement augmenté ces dernières années (voir l'indicateur B6) et les systèmes d'admission à ce niveau d'enseignement peuvent contribuer à promouvoir (ou non) cette tendance. Comme l'indique l'édition de 2017 de Regards sur l'éducation (OCDE, 2017[1]), le système d'admission applicable aux étudiants étrangers ou en mobilité internationale est comparable à celui applicable aux ressortissants nationaux (ou résidents permanents) dans la moitié environ des pays et économies à l'étude. Dans un quart des pays, le système applicable aux ressortissants nationaux ne s'applique aux ressortissants étrangers que s'ils sont originaires de certains pays. C'est généralement le cas pour les ressortissants de pays membres de l'Union européenne (UE) qui souhaitent s'inscrire dans un établissement d'enseignement tertiaire dans un autre pays membre de l'UE ; il en va de même en Norvège par exemple pour les ressortissants des autres pays nordiques. Dans un quart des pays, le processus de candidature et d'admission diffère entre les ressortissants nationaux et les étudiants étrangers ou en mobilité internationale.

Des critères supplémentaires ou spécifiques s'appliquent aux étudiants en mobilité internationale même dans les pays où le système de candidature ne varie guère entre les ressortissants nationaux et étrangers (voir le tableau D6.9 dans OCDE $\left(2017_{[1]}\right)$. Ces différences, combinées à des différences de frais de scolarité et à d'autres facteurs, peuvent influer sur les candidatures des étudiants en mobilité internationale ou sur les suites qui y sont données (voir l'encadré D6.3).

\section{Encadré D6.3. Candidats et candidatures à l'admission dans l'enseignement tertiaire : le cas des étudiants en mobilité internationale}

Sur les 30 pays et économies qui ont répondu à l'enquête de 2017 sur les candidats et les candidatures en premiers cursus tertiaires, un tiers environ ont fourni des données distinguant les étudiants en mobilité internationale des autres étudiants.

Neuf pays ont fourni des données qui distinguent les étudiants en mobilité des autres étudiants dans les données relatives aux suites données aux candidatures (candidats admis et inscrits, candidats admis et non inscrits et candidats non admis). Dans ces pays, le nombre de candidatures par candidat est du même ordre chez les étudiants en mobilité internationale que chez les autres étudiants (voir le graphique D6.c). Le pourcentage de candidatures refusées ne varie guère entre les étudiants en mobilité internationale et les autres étudiants en Finlande, en Hongrie et en Israël (moins de 10 points de pourcentage de différence). La différence de pourcentage atteint toutefois 20 points de pourcentage au Danemark (où les candidats en mobilité internationale représentent $18 \%$ de l'effectif total de candidats) et en Slovénie (où les candidats en mobilité internationale représentent $6 \%$ de l'effectif total de candidats). 


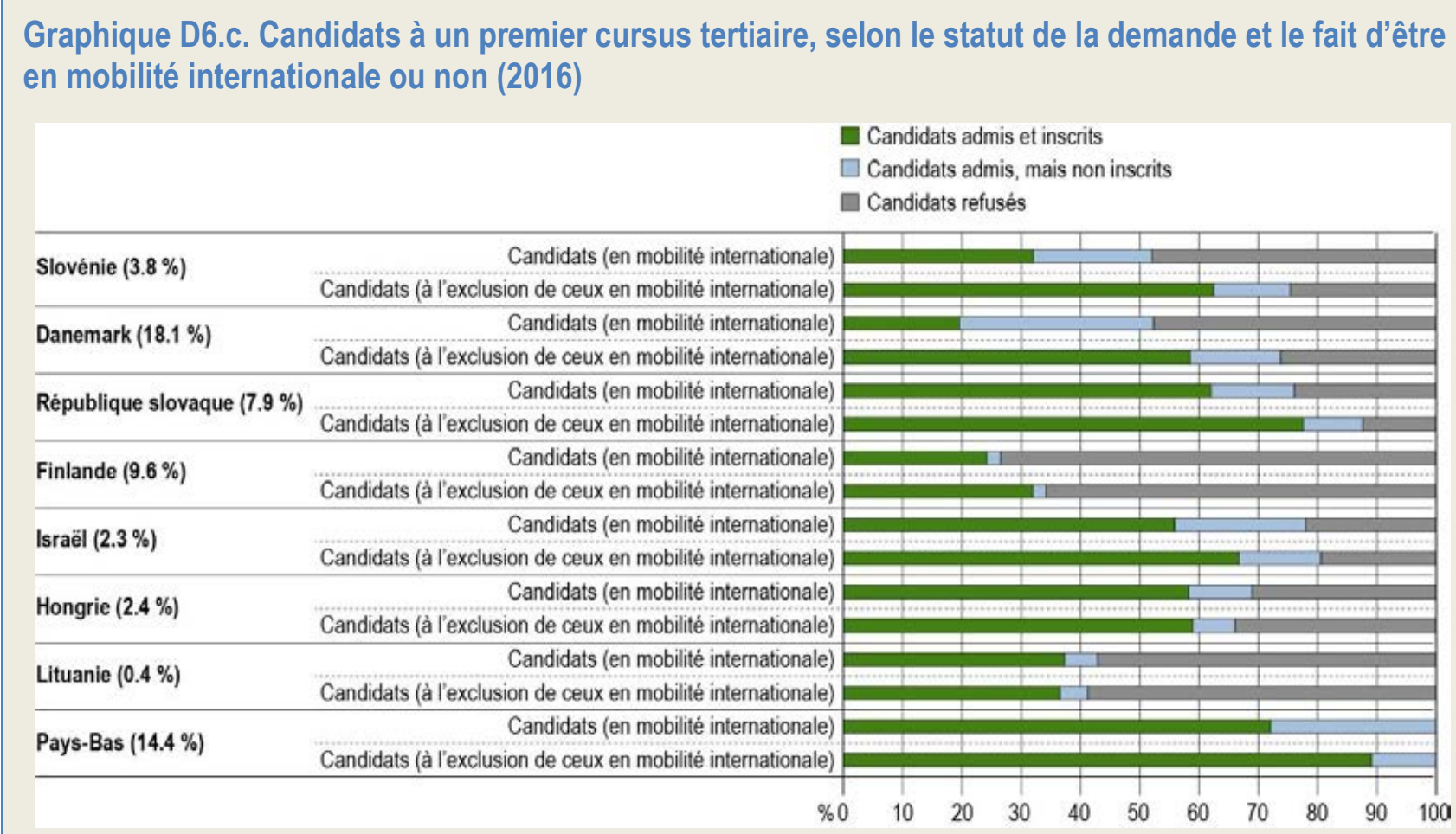

Remarque : Le chiffre entre parenthèses indique le pourcentage de candidats en mobilité internationale parmi l'ensemble des candidats. Les pays sont classés par ordre décroissant de la différence de pourcentage de candidats refusés entre les candidats en mobilité internationale et les autres.

Source : Enquête 2017 de l'OCDE-INES NESLI sur les candidats et les candidatures dans l'enseignement tertiaire.

StatLink 젶ㄴ https://doi.org/10.1787/888933980488

Le système d'admission à l'enseignement tertiaire ne diffère pas vraiment entre les étudiants en mobilité internationale et les autres étudiants dans ces pays, contrairement à certains pays, où des procédures spécifiques d'admission s'appliquent aux ressortissants étrangers ou en mobilité internationale. De plus, des critères supplémentaires ou spécifiques s'appliquent aux candidats en mobilité internationale dans tous ces pays, sauf au Danemark (les données concernant cet aspect ne sont pas disponibles en République slovaque). Les sept pays dont les données sont disponibles exigent la réussite des études dans le pays d'origine et un certificat délivré par le système scolaire du pays d'origine. La plupart d'entre eux exigent également une qualification internationale et des compétences linguistiques entre autres critères. Aucun de ces pays n'exige la preuve d'un budget suffisant (voir le tableau D6.9 (OCDE, 2017[1])).

\section{Définitions}

Par examens ou tests standardisés, on entend les épreuves administrées et corrigées dans les mêmes conditions dans différents établissements, de sorte que les résultats des élèves sont directement comparables entre établissements. Dans certains cas, il s'agit d'épreuves constituées d'items à choix multiple ou à réponse fermée, ce qui permet de les corriger de manière uniforme. Toutefois, il est possible d'administrer des épreuves constituées aussi d'items à réponse ouverte si des consignes précises et des échelles de référence sont fournies aux correcteurs (les personnes qui codent les réponses ouvertes). 
Par examens centraux ou nationaux, on entend les épreuves normalisées officiellement suivies d'effets pour les élèves, c'est-à-dire dont les résultats déterminent s'ils sont admis en classe supérieure ou s'ils ont réussi un niveau d'enseignement officiellement reconnu. Ces épreuves évaluent une grande partie des connaissances et compétences que les élèves sont censés avoir acquises dans une matière donnée. Les examens n'ont pas la même finalité que les évaluations. Les évaluations nationales sont obligatoires, mais leurs résultats n'ont pas d'impact sur le passage en classe supérieure ou la délivrance du diplôme, contrairement aux examens.

Par examens infranationaux standardisés, on entend les épreuves conçues à l'échelle d'entités fédérées, de provinces ou de collectivités territoriales ou municipales qui sont administrées et corrigées dans les mêmes conditions dans différents établissements de sorte que les résultats des élèves sont directement comparables.

Par examens d'entrée, on entend les épreuves qui ne sont pas administrées par les établissements d'enseignement secondaire et dont les résultats sont utilisés, seuls ou en combinaison avec d'autres critères, pour admettre les candidats dans l'enseignement tertiaire. Ces épreuves peuvent être conçues et corrigées par les établissements d'enseignement tertiaire (seuls ou en consortium) ou par des agences privées.

Par premiers cursus tertiaires, on entend au sens de la CITE 2011 les licences et les masters sanctionnés par un premier diplôme dans l'enseignement supérieur.

Par régime ouvert d'admission, on entend les systèmes d'admission non sélectifs ( $v s$ sélectifs), selon lesquels tous les candidats ayant le niveau de formation minimal requis peuvent s'inscrire dans l'enseignement tertiaire, sans avoir à satisfaire à d'autres critères.

Les établissements publics d'enseignement tertiaire sont ceux dont la gestion et le contrôle relèvent directement : 1) d'autorités en charge de l'éducation ou d'une agence publique dans le pays où ils se situent; ou 2) d'un conseil de direction dont la plupart des membres sont soit nommés par une instance publique du pays où ils se situent, soit élus au suffrage public.

Les établissements d'enseignement tertiaire sont des établissements privés subventionnés par l'État si au moins $50 \%$ de leur budget principal est financé par les pouvoirs publics ou que leur personnel enseignant est rémunéré par une instance publique - soit directement, soit indirectement.

Les établissements d'enseignement tertiaire sont des établissements privés indépendants si moins de $50 \%$ de leur budget principal est financé par les pouvoirs publics ou que leur personnel enseignant n'est pas rémunéré par une instance publique.

\section{Méthodologie}

Cet indicateur est basé sur une enquête relative aux systèmes nationaux de candidature et d'admission en premiers cursus tertiaires qui porte davantage sur les conditions officielles que sur les pratiques concrètes. Comme les pratiques varient considérablement entre les individus et les établissements d'enseignement tertiaire, cet indicateur ne peut rendre compte de leur diversité.

Voir l'annexe 3 (https://doi.org/10.1787/f8d7880d-en) pour de plus amples informations et les remarques spécifiques aux pays.

\section{Source}

Les données proviennent de deux enquêtes du Réseau de I'INES chargé de recueillir des données sur les structures, les politiques et les pratiques en matière d'éducation (NESLI) de l'OCDE : l'enquête de 2016 sur les systèmes nationaux d'admission en premiers cursus tertiaires (dont les données se rapportent à l'année académique 2016/17) et l'enquête de 2017 sur les candidats et les candidatures dans l'enseignement tertiaire (dont les données se rapportent à l'année académique 2015/16). 


\section{Note concernant les données d'Israël}

Les données statistiques concernant Israël sont fournies par et sous la responsabilité des autorités israéliennes compétentes. L'utilisation de ces données par l'OCDE est sans préjudice du statut des hauteurs du Golan, de Jérusalem-Est et des colonies de peuplement israéliennes en Cisjordanie aux termes du droit international.

\section{Références}

OCDE (2017), Regards sur l'éducation 2017: Les indicateurs de l'OCDE, Éditions OCDE,

Paris, https://dx.doi.org/10.1787/eag-2017-fr.

\section{Tableaux de l'indicateur D6}

Tableau D6.1a

WEB Tableau D6.1b cursus tertiaire dans un établissement privé subventionné par l'État (2017)

WEB Tableau D6.1c Organisation du système d'admission et du processus de candidature pour un premier cursus tertiaire dans un établissement privé indépendant (2017)

Tableau D6.2a

WEB Tableau D6.2b Examens et autres critères utilisés pour l'admission en premier cursus tertiaire dans un établissement établissement privé subventionné par l'État (2017)

WEB Tableau D6.2c Examens et autres critères utilisés pour l'admission en premier cursus tertiaire dans un établissement privé indépendant (2017))

Tableau D6.3

Niveau minimal de qualification et de performance académique requis à l'accès à l'enseignement tertiaire (selon les autorités) (2017)

WEB Tableau D6.4 Autorités en charge des systèmes d'examen d'accès/d'admission en premier cursus tertiaire (2017)

WEB Tableau D6.5a Finalité des examens et utilisation de leurs résultats comme critère d'accès/d'admission en premier cursus tertiaire dans les établissements publics (2017)

WEB Tableau D6.5b Finalité des examens et utilisation de leurs résultats comme critère d'accès/d'admission en premier cursus tertiaire dans les établissements privés subventionnés par l'État (2017)

WEB Tableau D6.5c Finalité des examens et utilisation de leurs résultats comme critère d'accès/d'admission en premier cursus tertiaire dans les établissements privés indépendants (2017)

Date butoir pour les données: 19 juillet 2019. Les mises à jour peuvent être consultées en ligne sur : http://dx.doi.org/10.1787/eag-data-en.

StatLink : $\underline{\text { https://doi.org/10.1787/888933981286 }}$ 
Tableau D6.1a. Organisation du système d'admission et du processus de candidature pour un premier cursus tertiaire dans un établissement public (2017)

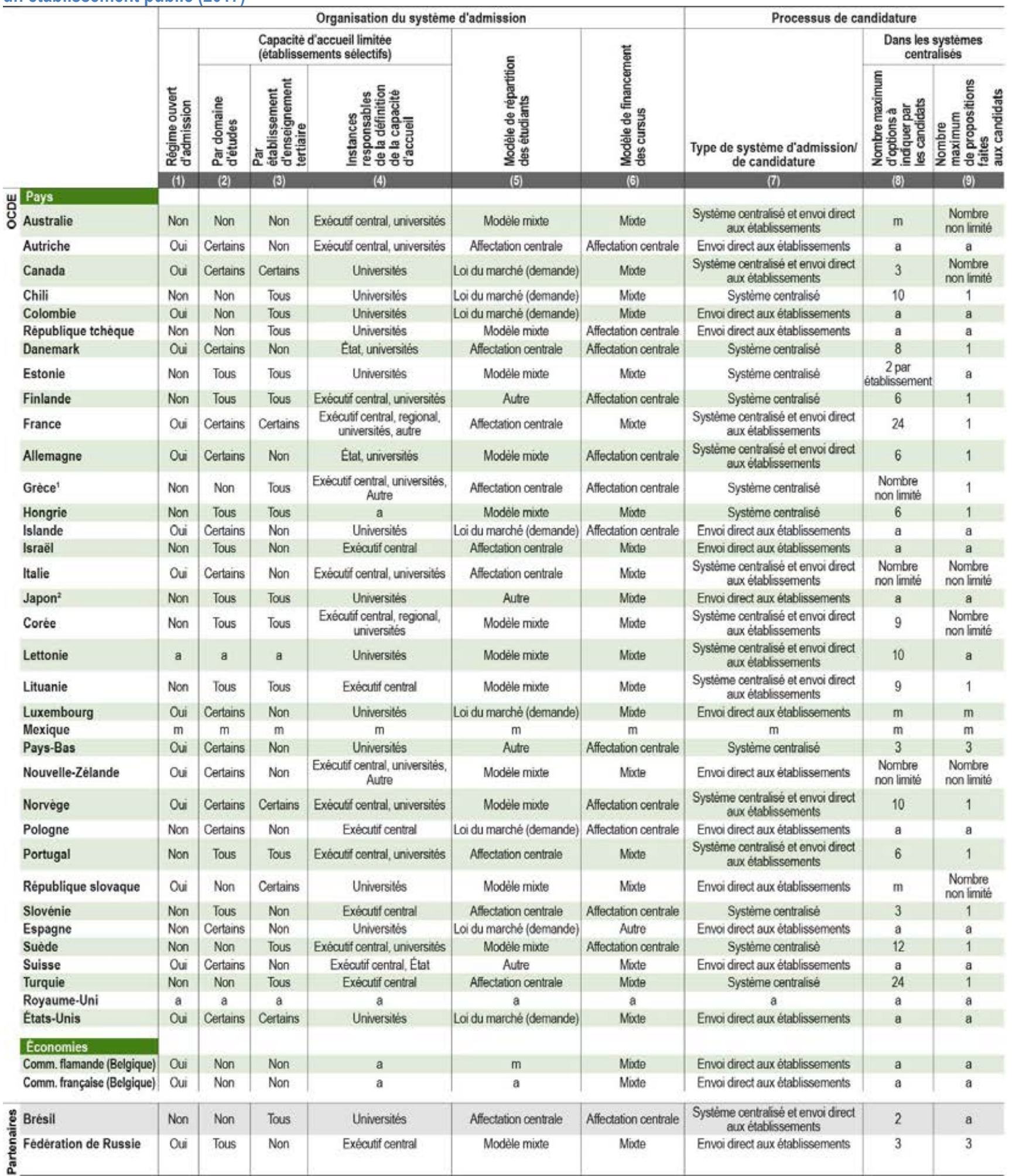

Remarque : Voir les sections « Définitions » et « Méthodologie » pour de plus amples informations.

1. Dans quelques domaines, le nombre d'options qu'un candidat peut indiquer n'est pas limité. Dans d'autres, certaines limitations peuvent s'appliquer.

2. Pour les universités nationales, la capacité d'accueil est fixée par chaque université nationale et soumise pour approbation, dans le cadre de son plan à moyen terme, au ministère de l'Éducation, de la Culture, des Sports, de la Science et de la Technologie.

Source : OCDE (2017). Consulter la section « Source » pour tout complément d'information et l'annexe 3 pour les notes (https://doi.org/10.1787/f8d7880d-en) Les symboles représentant les données manquantes et les abréviations figurent dans le Guide du lecteur. 
Tableau D6.2a. Examens et autres critères utilisés pour l'admission en premier cursus tertiaire dans un établissement public (2017)

\begin{tabular}{|c|c|c|c|c|c|c|c|c|}
\hline & \multicolumn{4}{|c|}{ Utilisation d'examens/de tests pour déterminer l'accés/l'admission } & \multicolumn{3}{|c|}{$\begin{array}{c}\text { Utilisation d'autres critères ou de circonstances particulières } \\
\text { dans les systemes d'admission }\end{array}$} \\
\hline & & \multicolumn{4}{|c|}{$\begin{array}{c}\text { Les examens/tests sont-ils obligatoires pour l'accès à un cursus } \\
\text { dans un établissement d'enseignement tertiaire public? }\end{array}$} & \multicolumn{3}{|c|}{$\begin{array}{l}\text { D'autres critères sont-ils utilisés, quel est leur niveau d'importance } \\
\text { et quel est le degré d'autonomie des établissements á leur égard? }\end{array}$} \\
\hline & & $\begin{array}{l}\text { Examens } \\
\text { centraux/ } \\
\text { nationaux }\end{array}$ & $\begin{array}{c}\text { Examens } \\
\text { standardisés } \\
\text { non nationaux } / \\
\text { centraux }\end{array}$ & $\begin{array}{c}\text { Examens non } \\
\text { standardisès } \\
\text { non nationaux } / \\
\text { centraux }\end{array}$ & \begin{tabular}{|c|} 
Examens \\
d'entrée en \\
premier cursus \\
tertiaire'
\end{tabular} & $\begin{array}{l}\text { Moyenne des notes dans } \\
\text { P'enseignement secondaire }\end{array}$ & Entretiens & $\begin{array}{l}\text { Origine ethnique } \\
\text { du candidat }\end{array}$ \\
\hline & & (1) & (2) & (3) & (4) & (5) & (6) & (7) \\
\hline \multicolumn{9}{|c|}{$\ddot{\omega}$ Pays } \\
\hline & Australie & a & Non & Non & Ou (dans certains) & Non & Oui & Oui \\
\hline & Autriche & a & a & a & a & Non & Non & Non \\
\hline & Canada & a & Oui (dans certains) & Oui (dans certains) & a & Oui-Niveau dimportance élevé & A la discrétion de létablissement & A la discrétion de létablissernent \\
\hline & Chili & $\mathrm{m}$ & m & m & Oui (dans tous) & $\begin{array}{l}\text { Oui - Niveau dimportance } \\
\text { modere }\end{array}$ & Non & Non \\
\hline & Colombie & Oui (dans tous) & a & a & a & Non & Oui-Niveau dimportance faible & Non \\
\hline & République tchèque & Oui (dans la phupart) & Non & a & a & $\begin{array}{l}\text { Á la discrétion de fétablissement } \\
\text { - Utlisé, mais dans une mesure } \\
\text { inconnue }\end{array}$ & $\begin{array}{l}\text { Á la discrétion de lètablissement } \\
\text { - Utilisé, mais dans une mesure } \\
\text { inconnue }\end{array}$ & Non \\
\hline & Danemark & Oui (dans la plupart) & a & a & a & Oui- Niveau dimportance ellevé & $\begin{array}{l}\text { Ou - Niveau dimportance } \\
\text { modére }\end{array}$ & Non \\
\hline & Estonie & Oui (dans la plupart) & a & a & Oui (dans la plupart) & $\begin{array}{l}\text { Ȧla discrétion de fétablissement } \\
\text { - Utlisé, mais dans une mesure } \\
\text { inconnue }\end{array}$ & $\begin{array}{l}\text { Ála discrétion de létablissement } \\
\text { - Utilisé, mais dans une mesure } \\
\text { inconnue }\end{array}$ & Non \\
\hline & Finlande & Non & Non & a & $\mathrm{m}$ & A la discrétion de fétablissement & A la discrétion de lètablissement & Non \\
\hline & France & Oui (dans la phupart) & a & a & Non & Ou - Niveau dimportance élevé & Oui - Niveau dimportance élevé & a \\
\hline & Allemagne & a & Oui (dans tous) & Oui (dans tous) & a & $\begin{array}{l}\text { Oui- Niveau dimportance } \\
\text { modéré }\end{array}$ & $\begin{array}{l}\text { A la discrétion de létablissement } \\
\text { - Utilisé, mais dans une mesure } \\
\text { inconnue }\end{array}$ & Non \\
\hline & Grèce & Oui (dans tous) & a & $\mathrm{m}$ & a & Non & Non & Non \\
\hline & Hongrie & Oui (dans tous) & Non & a & a & Oui - Niveau dimportance èlevé & Non & Non \\
\hline & Islande & a & a & a & Non & Non & Non & Non \\
\hline & IsraëI & Oui (dans tous) & Non & Non & Non & Non & Oui - Niveau dimportance élevé & $\begin{array}{l}\text { Ala discrétion } \\
\text { de fétablissement - Niveau } \\
\text { dimportance modéré }\end{array}$ \\
\hline & Italie & Oui (dans tous) & a & a & a & $\begin{array}{l}\text { Oui - Niveau dimportance } \\
\text { modéré }\end{array}$ & Oui - Nvegu dimportance élevê & $\begin{array}{l}\text { Oui- Niveau dimportance } \\
\text { modéré }\end{array}$ \\
\hline & Japon $^{2}$ & a & a & a & Non & $\begin{array}{l}\text { Oui - USissé, mais dans } \\
\text { une mesure inconnue }\end{array}$ & $\begin{array}{l}\text { Ou - Ublisé, mais dans } \\
\text { une mesure inconnue }\end{array}$ & m \\
\hline & Corée & a & a & a & Oui (dens la plupart) & Oui-Niveau dimportance élevé & $\begin{array}{l}\text { A la discrétion de l'ètablissement } \\
\text { - Utilisé, mais dans une mesure } \\
\text { inconnue }\end{array}$ & $\begin{array}{l}\text { Oui- Utilsé, mais dans } \\
\text { une mesure inconnue }\end{array}$ \\
\hline & Lettonie & Oui (dans tous) & Non & Non & Oui (dans cortains) & $\begin{array}{l}\text { Oui - Nveau dimportance } \\
\text { modéré }\end{array}$ & $\begin{array}{l}\text { A la discrétion de létablissement } \\
\text { Niveau dimportance modéré }\end{array}$ & Non \\
\hline & Lituanie & Oui (dans tous) & Oui (dans certains) & a & Oui (dans certains) & Non & Non & Non \\
\hline & Luxembourg & Oui (dans certains) & a & a & Oui (dans certains) & A la discrétion de fétablissement & A la discrétion de l'établissement & Non \\
\hline & Mexique & $\mathrm{m}$ & $m$ & $m$ & $m$ & $m$ & $\mathrm{~m}$ & $m$ \\
\hline & Pays-Bas & Oui (dans tous) & a & Oui (dans tous) & Non & A la discrétion de fétablissement & A la discrétion de létablissement & Non \\
\hline & Nouvelle-Zëlande & Non & Non & Non & a & $\begin{array}{l}\text { A la discrétion de fétablissement } \\
\text { - Utilisé, mais dans une mesure } \\
\text { inconnue }\end{array}$ & $\begin{array}{l}\text { A la discrétion de létablissement } \\
\text { - Utilisé, mais dans une mesure } \\
\text { inconnue }\end{array}$ & $\begin{array}{l}\text { Á la discrétion de fétablissement } \\
\text { - Utísé, mais dans une mesure } \\
\text { inconnue }\end{array}$ \\
\hline & Norvège & Oui (dans la plupart) & Non & Non & Oui (dans certains) & Non & Ou - Niveau dimportance faible & Oui-Niveau dimportance fable \\
\hline & Pologne & Oui (dans tous) & a & a & m & Oui & $\begin{array}{l}\text { Oui - Utilisé, mais dans } \\
\text { une mesure inconrue }\end{array}$ & Non \\
\hline & Portugal & Oui (dans tous) & a & a & a & Oui - Niveau dimportance èlevé & $\begin{array}{l}\text { Ou- Niveau dimportance } \\
\text { modéré }\end{array}$ & Non \\
\hline & République slovaque & m & m & m & a & $\begin{array}{l}\text { Á la discrétion de fètablissement } \\
\text { - Nveau dimportance modéré }\end{array}$ & $\begin{array}{l}\text { A la discrétion de l'établissement } \\
\text { - Niveau dimportance modéré }\end{array}$ & Non \\
\hline & Slovènie & Oui (dans tous) & a & a & Oui (dans certains) & a & a & a \\
\hline & Espagne & Oui (dans tous) & a & a & a & $\begin{array}{l}\text { A la discrétion de létablissement } \\
\text { - Niveau dimportance élevé }\end{array}$ & $\begin{array}{l}\text { À la discrétion de létablissement } \\
\text { - Niveau dimportanoe modéré }\end{array}$ & Non \\
\hline & Suéde & a & a & a & Non & Oui - Niveau d'mportance elevé & $\begin{array}{l}\text { A la discrétion de l'établissement } \\
\text { - Niveau d'importance modéré }\end{array}$ & Non \\
\hline & Suisse & Oui (dans tous) & a & a & Ou (dans tous) & Non & Ála discrétion de l'établissement & Non \\
\hline & Turquie & Oui (dans tous) & a & Non & a & $\begin{array}{l}\text { Qui - Nveau dimportance } \\
\text { modéré }\end{array}$ & Non & Non \\
\hline & Royaume-Uni & a & a & a & a & a & a & $a$ \\
\hline & Etats-Unis & Non & Non & a & Non & $\begin{array}{l}\text { A la discrétion de fétablissement } \\
\text { - Uttisé, mais dans une mesure } \\
\text { inconnue }\end{array}$ & $\begin{array}{c}\text { A la discrétion de l'établissement } \\
\text { - Utilisé, mais dans une mesure } \\
\text { inconnue }\end{array}$ & $\begin{array}{l}\text { A la discrétion de rétablissement } \\
\text { - Utísé, mais dans une mesure } \\
\text { inoonnue }\end{array}$ \\
\hline \multicolumn{9}{|c|}{ Economies } \\
\hline & Comm. flamande (Belgique) & a & a & a & Oui (dans certains) & a & a & a \\
\hline & Comm. trançaise (Belgique) & a & a & $\mathrm{a}$ & Oui (dans certains) & a & a & a \\
\hline है & Brèsil & m & m & m & Non & Ả la déscrétion de Iétablissement & À la discrétion de l'établissement & $\begin{array}{l}\text { Oui- Utilisé, mais dans } \\
\text { une mesure nconnue }\end{array}$ \\
\hline 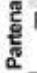 & Fedération de Russie & Oui (dans tous) & Oui (dans tous) & a & Oui (dans certains) & Non & Oui-Niveau dimportance élevé & Non \\
\hline
\end{tabular}




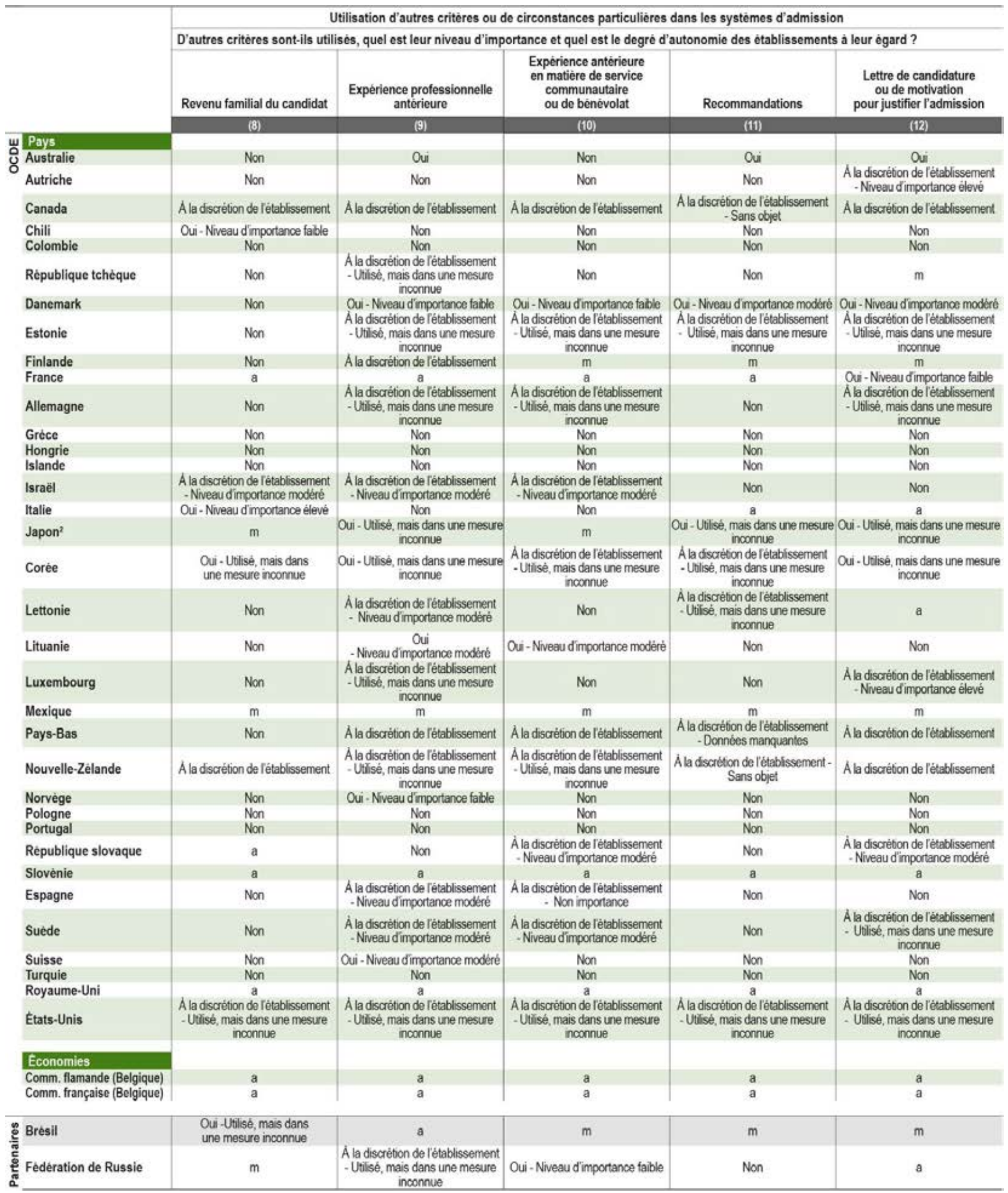

Remarque : Voir les sections « Définitions » et « Méthodologie » pour de plus amples informations.

1. À l'exception des examens d'entrée en premier cursus tertiaire administrés par les établissements d'enseignement tertiaire, ces examens/test sont administrés par les établissements du deuxième cycle du secondaire (aux élèves arrivés au terme de ce niveau).

2. Pour les universités nationales, la capacité d'accueil est fixée par chaque université nationale et soumise pour approbation, dans le cadre de son plan à moyen terme, au ministère de l'Éducation, de la Culture, des Sports, de la Science et de la Technologie.

Source : OCDE (2017). Consulter la section « Source » pour tout complément d'information et l'annexe 3 pour les notes (https://doi.org/10.1787/f8d7880d-en).

Les symboles représentant les données manquantes et les abréviations figurent dans le Guide du lecteur. 
Tableau D6.3. Niveau minimal de qualification et de performance académique requis à l'accès à l'enseignement tertiaire (selon les autorités) (2017)

\begin{tabular}{|c|c|c|c|c|c|c|c|c|c|c|}
\hline & \multirow[b]{2}{*}{$\begin{array}{l}\text { Niveau CITE } \\
\text { minimal } \\
\text { geneneralement } \\
\text { requis a l'accés } \\
\text { en premiers } \\
\text { cursus tertiaires } \\
\text { (par type de filiere } \\
\text { du deuxieme cycle } \\
\text { de l'enseignement } \\
\text { secondaire) }\end{array}$} & \multicolumn{2}{|c|}{$\begin{array}{l}\text { Performance academique } \\
\text { minimale requise à laccés } \\
\text { à lenseignement tertiaire } \\
\text { (fixée par les autorités) }\end{array}$} & \multicolumn{6}{|c|}{ Modes d'évaluation de la performance académique minimale requise } & \multirow[b]{2}{*}{$\begin{array}{c}\text { Matières prèrequises } \\
\text { pour l'accès à des } \\
\text { domaines d'ètudes } \\
\text { spécifiques }\end{array}$} \\
\hline & & $\begin{array}{l}\text { Par domaine } \\
\text { d'études }\end{array}$ & $\begin{array}{c}\text { Par } \\
\text { ètablissement } \\
\text { d'enseignement } \\
\text { tertiaire }\end{array}$ & 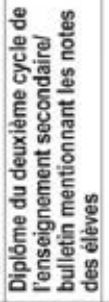 & 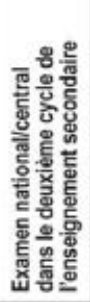 & 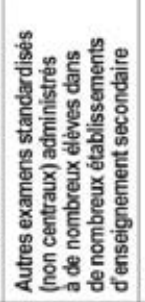 & 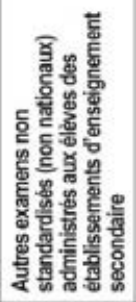 & 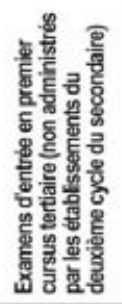 & 晕 & \\
\hline & (1) & (2) & (3) & (4) & (5) & (6) & (7) & (8) & (9) & (10) \\
\hline \multicolumn{11}{|l|}{ 崩 Pays } \\
\hline Ô Australie & Filère générale & Non & Non & a & a & a & a & a & a & Dans certains domaines \\
\hline 'Autriche' & a & Non & Non & a & a & a & a & a & a & Non \\
\hline Canada & Tous & Non & Non & a & a & a & a & a & a & Dans certains domaines \\
\hline Chili & Tous & Non & Oui (dans certains) & Oui & Non & Non & Non & Oui & Oui & Non \\
\hline Colombie & Tous & Oui (dans lous) & Oui (dans certains) & Non & oui & Non & Non & Non & Non & a \\
\hline Rèpublique tcheque ${ }^{2}$ & $\begin{array}{l}\text { Filière générale ou } \\
\text { professionnelle }\end{array}$ & Non & Non & a & a & a & a & a & a & Non \\
\hline Danemark & Filière générale & Non & Non & a & a & a & a & a & a & $\begin{array}{l}\text { Dans la plupart des } \\
\text { domaines }\end{array}$ \\
\hline Estonie & Tous & Non & Non & a & a & a & a & a & a & a \\
\hline Finlande & Tous & Non & Non & $\mathbf{a}$ & a & a & a & a & a & $\mathbf{a}$ \\
\hline France & Tous & Non & Oui (dans certains) & Oui & Non & Non & Non & Oui & Non & Dans certains domaines \\
\hline Allemagne & Tous & Non & Non & a & a & a & a & a & a & Non \\
\hline Grèce & Tous & Oui (dans tous) & Oui (dans tous) & Non & Oui & a & a & a & Non & Dans tous les domaines \\
\hline Hongrie & Tous & Oui (dans lous) & Non & Oui & Oui & Non & Non & Non & Non & Dans tous les domaines \\
\hline Islande & Tous & Non & Non & a & a & a & a & a & a & m \\
\hline Israẹl & Filière professionnelle & Non & $\begin{array}{l}\text { Ou } \\
\text { (dans la plupart) }\end{array}$ & a & Oui & a & $\mathbf{a}$ & Oui & Oui & Dans certains domaines \\
\hline Italie & Tous & Non & Non & a & a & a & a & a & a & Non \\
\hline Japon & Tous & Non & Non & a & a & a & a & a & a & Non \\
\hline Corée & Tous & Non & Non & a & a & a & a & a & a & Dans certains domaines \\
\hline Lettonie & Tous & Oui (dans tous) & Non & Non & Oui & Non & Non & Non & $\mathrm{Ou}$ & Dans certains domaines \\
\hline Lituanie $^{3}$ & Tous & Oui (dans lous) & Non & Oui & Oui & Oui & Non & Oui & Non & Dans certains domaines \\
\hline Luxembourg & Tous & Non & Non & a & a & a & a & a & a & $\mathrm{m}$ \\
\hline Mexique & m & m & m & m & m & $\mathrm{m}$ & m & m & m & $\mathrm{m}$ \\
\hline Pays-Bas & Tous & Oui (dans tous) & Non & Oui & Oui & Non & Non & Oui & Non & Dans certains domaines \\
\hline Nouvelle-Zèlande & Filère générale & $\begin{array}{l}\text { Oui } \\
\text { (dans la plupart) }\end{array}$ & Non & Oui & Oui & Non & Non & Non & Non & Dans certains domaines \\
\hline Norvège & Filère générale & Oui (dans certains) & Non & a & Oui & Non & Non & Oui & Non & Dans certains domaines \\
\hline Pologne & $\begin{array}{l}\text { Filère gènérale } \\
\text { cu professionnelle }\end{array}$ & Oui (dans tous) & Non & Oui & Oui & Non & Non & Non & Non & Non \\
\hline Portugal & Tous & Oui (dans lous) & Oui (dans tous) & Oui & Oui & Non & Non & Non & Non & Dans certains domaines \\
\hline République slovaque & Tous & Oui (dans tous) & Non & Oui & $\mathrm{m}$ & $m$ & m & m & Non & Non \\
\hline Slovénie & $\begin{array}{l}\text { Filère gènérale } \\
\text { ou professionnelle }\end{array}$ & Oui (dans tous) & Non & Oui & Oui & Non & Non & Non & Oui & Dans certains domaines \\
\hline Espagne & Fítère générale & Non & Oui (dans tous) & m & Oui & m & m & $m$ & Non & Dans tous les domaines \\
\hline Suède & Filière gónérale & Non & Non & a & a & a & a & a & a & Dans tous les domaines \\
\hline Suisse & Tous & Non & Non & a & a & a & a & a & a & Dans certains domaines \\
\hline Turquie & Tous & Oui (dans tous) & Non & Oui & Oui & Non & Oui & Non & m & Non \\
\hline Royaume-Uni ${ }^{4}$ & Filière générale & Non & Oui (dans tous) & Non & Oui & Non & Non & Non & Non & Dans certans domaines \\
\hline Etats-Unis & Tous & Non & Non & a & a & a & a & a & a & Non \\
\hline \multicolumn{11}{|l|}{ Economies } \\
\hline Comm. flamande (Belgique) & Tous & Non & Non & a & a & a & a & a & a & a \\
\hline Comm. française (Belgique) & Tous & Non & Non & a & a & a & a & a & a & Non \\
\hline Brésil & Tous & Non & Non & a & a & a & a & a & a & Non \\
\hline 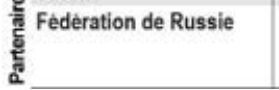 & Tous & Oui (dans lous) & Non & Non & Oui & a & Non & Non & Oui & Non \\
\hline
\end{tabular}

Remarque : La qualification minimale généralement requise à l'accès en premiers cursus tertiaires correspond au niveau de la CITE, mais les qualifications de ce niveau n'ouvrent pas toutes l'accès en premiers cursus tertiaires. Voir les sections « Définitions » et « Méthodologie » pour de plus amples informations.

1. La qualification minimale requise est le diplôme de fin d'études secondaires (appelé MATURA), mais il existe d'autres voies d'accès.

2. Dans le deuxième cycle de l'enseignement secondaire, certaines filières donnent accès à l'enseignement tertiaire, mais d'autres n'y donnent pas accès.

3. En Lituanie, il est possible d'accéder à l'enseignement tertiaire avec une qualification du deuxième cycle du secondaire (toutes filières) ou avec une qualification de l'enseignement post-secondaire non tertiaire (filières professionnelles).

4. Les données portent sur les quatre systèmes séparés qui existent au Royaume-Uni. Dans chaque cas, « oui » signifie que le dispositif est en place dans un des quatre systèmes au moins.

Source : OCDE (2017). Consulter la section « Source » pour tout complément d'information et l'annexe 3 pour les notes (https://doi.org/10.1787/f8d7880d-en). Les symboles représentant les données manquantes et les abréviations figurent dans le Guide du lecteur. 


\section{Annexe 1. Caractéristiques des systèmes d'éducation}

Tous les tableaux de l'annexe 1 sont disponibles en ligne sur :

StatLink: https://doi.org/10.1787/888933981305

\section{Note concernant les données d'Israël}

Les données statistiques concernant Israël sont fournies par et sous la responsabilité des autorités israéliennes compétentes. L'utilisation de ces données par l'OCDE est sans préjudice du statut des hauteurs du Golan, de Jérusalem-Est et des colonies de peuplement israéliennes en Cisjordanie aux termes du droit international. 
Tableau X1.1a. Âge typique d'obtention des diplômes, selon le niveau d'enseignement (2017)

L'âge typique correspond a『l'âge de l'élève/étudiant au début de l'année scolaire ; les élèves/étudiants ont généralement un an de plus que l'âge indiquel lorsqu'ils obtiennent leur diplôme en fin d'année scolaire. L'âge typique est utilisé dans le calcul du taux brut d'obtention des diplômes.

\begin{tabular}{|c|c|c|c|c|c|c|c|c|c|c|c|c|c|}
\hline & \multicolumn{2}{|c|}{$\begin{array}{l}\text { Deuxième cycle du } \\
\text { secondaire }\end{array}$} & \multicolumn{2}{|c|}{$\begin{array}{l}\text { Post-secondaire } \\
\text { non tertiaire }\end{array}$} & \multicolumn{9}{|c|}{ Tertiaire } \\
\hline & \multirow[b]{2}{*}{ 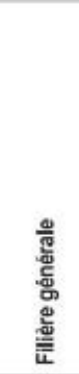 } & \multirow[b]{2}{*}{ 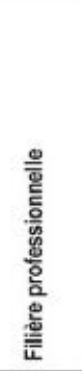 } & \multirow[b]{2}{*}{ 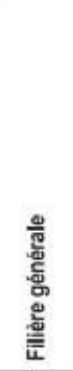 } & \multirow[b]{2}{*}{ 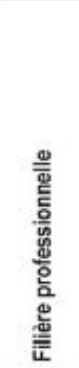 } & \multicolumn{2}{|c|}{$\begin{array}{l}\text { Tertiaire de cycle court } \\
\text { (CITE 5) }\end{array}$} & \multicolumn{3}{|c|}{$\begin{array}{l}\text { Licence ou niveau équivalent } \\
\text { (CITE 6) }\end{array}$} & \multicolumn{3}{|c|}{$\begin{array}{l}\text { Master ou niveau équivalent } \\
\text { (CITE 7) }\end{array}$} & \multirow[b]{2}{*}{ 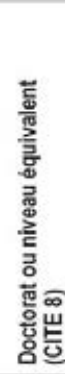 } \\
\hline & & & & & 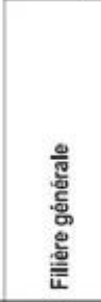 & 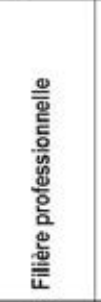 & 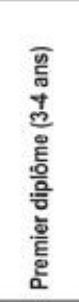 & 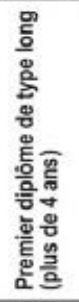 & 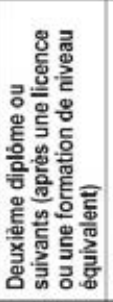 & 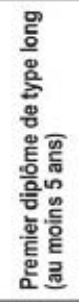 & 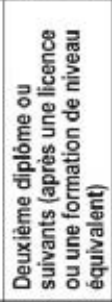 & 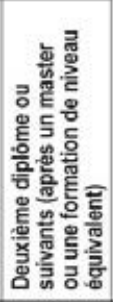 & \\
\hline & (1) & (2) & (3) & (4) & (5) & (6) & (7) & (8) & (9) & (10) & (11) & (12) & (13) \\
\hline \multicolumn{14}{|l|}{ س. Pays } \\
\hline Oustralie & $17-18$ & 18.32 & a & 18.37 & $19-24$ & 18.30 & $20-23$ & $22-25$ & 22.34 & a & $22-30$ & $29-44$ & 26.35 \\
\hline Autriche & $17-18$ & $16-18$ & a & 19.32 & a & 18.19 & $21-24$ & a & a & $23-27$ & 24.28 & a & 28.33 \\
\hline Belgique & $18-18$ & 18-19 & a & $20-22$ & a & $21-25$ & $21-23$ & a & $22-24$ & a & $22-24$ & $23-32$ & $27-31$ \\
\hline Canada & $17-18$ & 19.33 & $\mathrm{~m}$ & $\mathrm{~m}$ & a & $20-24$ & 22.24 & $23-24$ & 22.29 & $22-24$ & 24.29 & $26-29$ & 29.34 \\
\hline Chili & $17-17$ & $17-17$ & a & a & a & $21-26$ & $22-27$ & $22-28$ & $23-26$ & 24.26 & $26-35$ & $\mathrm{~m}$ & 29.35 \\
\hline Colombie & $16-17$ & $16-17$ & $18-20$ & a & a & $19-24$ & a & $22-27$ & $22-27$ & a & $26-36$ & $26-39$ & $29-41$ \\
\hline République tchèque & $\mathrm{m}$ & $\mathrm{m}$ & $\mathrm{m}$ & $\mathrm{m}$ & $\mathrm{m}$ & $\mathrm{m}$ & $\mathrm{m}$ & $\mathrm{m}$ & $\mathrm{m}$ & $m$ & $\mathrm{~m}$ & m & $\mathrm{m}$ \\
\hline Danemark & $18-19$ & 19.25 & a & 23.35 & a & $20-25$ & 22.25 & a & $32-44$ & $30-31$ & $25-28$ & a & 28.32 \\
\hline Estonic & $18-19$ & $18-20$ & a & $20-28$ & a & a & $21-25$ & a & a & $24-26$ & $23-28$ & a & $29-34$ \\
\hline Finlande & $19-19$ & 19.25 & a & $32-46$ & a & a & 23.26 & a & a & $26-28$ & $25-30$ & $30-41$ & 29.37 \\
\hline France & $17-18$ & $16-19$ & m & $m$ & m & $\mathrm{m}$ & $m$ & $m$ & $m$ & $m$ & m & m & $26-30$ \\
\hline Allemagne & $18-19$ & $19-21$ & $20-23$ & $21-24$ & a & $21-25$ & 22.25 & a & 24.30 & $24-27$ & $24-27$ & $24-27$ & $28-32$ \\
\hline Grèce & $17-17$ & $17-17$ & a & $20-22$ & a & a & $\mathrm{m}$ & m & $\mathrm{m}$ & a & $\mathrm{m}$ & m & $\mathrm{m}$ \\
\hline Hongrie & $17-19$ & $17-19$ & a & $19-21$ & a & $20-22$ & $21-24$ & a & $27-41$ & $23-26$ & $23-26$ & a & $27 \cdot 32$ \\
\hline Islande & m & m & $\mathrm{m}$ & $\mathrm{m}$ & $\mathrm{m}$ & $\mathrm{m}$ & $\mathrm{m}$ & $\mathrm{m}$ & $\mathrm{m}$ & $\mathrm{m}$ & $\mathrm{m}$ & m & m \\
\hline Irlande & $18-19$ & 18.24 & a & $20-26$ & $20-35$ & 20.35 & $21-23$ & 23.25 & $23-33$ & 22.30 & $22-30$ & $30-22$ & 27.32 \\
\hline Israë| & $17-17$ & $17-17$ & $\mathrm{~m}$ & $\mathrm{~m}$ & $\mathrm{~m}$ & $\mathrm{~m}$ & 24.28 & 27.29 & 24.32 & $\mathrm{~m}$ & $27-34$ & $\mathrm{~m}$ & 31.37 \\
\hline Italie & $18-19$ & $18-19$ & a & $20-20$ & a & $20-22$ & 22.25 & m & $\mathrm{m}$ & $\mathrm{m}$ & 24.27 & $\mathrm{~m}$ & 27.35 \\
\hline Japon & $17-17$ & $17-17$ & $18-18$ & $18-18$ & $19-19$ & $19-19$ & $21 \cdot 21$ & m & $\mathrm{m}$ & $23-23$ & $23-23$ & m & $26-26$ \\
\hline Corèe & $18-18$ & $18-18$ & a & a & a & $20-22$ & $23-25$ & $x(7)$ & a & a & $25-31$ & a & $29-38$ \\
\hline Lettonic & $18-18$ & $20-21$ & a & $20-24$ & a & $21-25$ & $22-24$ & $23-25$ & 24.33 & $25-29$ & 2427 & a & 28.36 \\
\hline Lituanie & $18-18$ & $19-24$ & a & $19-25$ & a & a & $21-22$ & a & $23-29$ & $23-24$ & 24.25 & 27.29 & 28.31 \\
\hline Luxembourg & $17-19$ & $17-20$ & a & 23.29 & a & $21-23$ & 22.24 & a & a & a & $24-27$ & 25.30 & 28.32 \\
\hline Mexique & $17-18$ & $17-18$ & a & a & a & $20-24$ & $20-24$ & $\mathrm{~m}$ & a & a & $23-26$ & a & 24.28 \\
\hline Pays-Bas & $16-18$ & $18-21$ & a & a & a & $21-27$ & $21 \cdot 23$ & a & a & a & $23-26$ & $24-27$ & $28-31$ \\
\hline Nouvelle-Zèlande & $17-18$ & $16-30$ & $17-26$ & $17-26$ & $18-24$ & $18-25$ & $20-23$ & $22-24$ & $21-28$ & a & $23-30$ & a & $27-35$ \\
\hline Norvège & $18-18$ & $18-22$ & a & 19.30 & 22.28 & $21-27$ & $21-24$ & a & 27.30 & $24-26$ & $24-28$ & $25-29$ & 28.35 \\
\hline Pologne & $19-19$ & $19-20$ & a & $21-25$ & a & $22-37$ & $22-24$ & a & 25.35 & $24-25$ & 24.25 & a & $29-32$ \\
\hline Portugal & $17-17$ & $17-18$ & a & 19.23 & a & $20-22$ & $21-23$ & a & 33.39 & $23-24$ & $23-26$ & a & 26.36 \\
\hline République slovaque & $18-19$ & $18-19$ & a & $19-24$ & a & $20-22$ & $21-22$ & a & a & $23-24$ & $23-24$ & $24-28$ & $26-29$ \\
\hline Slovénie & $18-18$ & $17-19$ & a & a & a & 21.25 & $21-24$ & a & a & $24-25$ & $24-26$ & a & 27.32 \\
\hline Espagne & $17-17$ & $17-21$ & a & $25-45$ & a & $20-23$ & $21-23$ & a & a & $22-25$ & $22-26$ & $28-32$ & $28-38$ \\
\hline Suède & $18-19$ & $18-19$ & a & 19.31 & 21.28 & $22 \cdot 30$ & $22-26$ & a & a & 24.28 & 24,30 & a & 28.34 \\
\hline Suisse & $18-22$ & $18-24$ & 21.23 & a & a & 23.36 & $23-28$ & a & $30-39$ & 24.29 & 25.32 & $26-33$ & 28.34 \\
\hline Turquie & $17-17$ & $17-17$ & a & $22-20$ & $23-24$ & $19-21$ & $21-23$ & a & a & $23-25$ & $25-30$ & a & $30-35$ \\
\hline Royaume-Uni & $15-17$ & $16-19$ & a & a & $19-25$ & 18.30 & $20-22$ & $22-24$ & 21.28 & a & $23-28$ & $24 \cdot 34$ & 25.32 \\
\hline États-Unis & $17-17$ & $17-17$ & $19-22$ & $19-22$ & $20-21$ & $20-21$ & $21-23$ & a & a & a & 2431 & 24.31 & 2632 \\
\hline If Argentine' & $18-20$ & $18-20$ & $\mathrm{~m}$ & $\mathrm{~m}$ & $22-24$ & $22-24$ & $22-24$ & $22-24$ & $\mathrm{~m}$ & a & 24.26 & m & $27-29$ \\
\hline 商 Brésil & $16-17$ & $16-18$ & $a$ & $18-26$ & $19-27$ & $19-32$ & $20-27$ & a & $\mathrm{m}$ & a & $25-31$ & a & $29-37$ \\
\hline Chine & $18-20$ & $18-20$ & m & $\mathrm{m}$ & $20-22$ & $20-22$ & $22-24$ & $22-24$ & $\mathrm{~m}$ & a & 2426 & m & 27.29 \\
\hline a Costa Rica & $16-17$ & $17-18$ & a & a & $18-20$ & m & $18-21$ & $22-23$ & a & 24.26 & a & a & 27 \\
\hline Inde & $16-18$ & $16-18$ & m & $m$ & $21-23$ & $21-23$ & $21-23$ & $21-23$ & m & $23-25$ & $23-25$ & m & $28-30$ \\
\hline Indonésie & $19-21$ & $19-21$ & $\mathrm{~m}$ & $\mathrm{~m}$ & $20-22$ & 20.22 & $23-25$ & $23-25$ & $\mathrm{~m}$ & a & $25-27$ & $\mathrm{~m}$ & $28 \cdot 30$ \\
\hline Fedération de Russie & $17-18$ & $17-18$ & a & $18-22$ & a & $19-20$ & $21-23$ & a & a & $22-25$ & $22-25$ & a & $25-27$ \\
\hline Arabie saoudite & 18.20 & $18-20$ & $\mathrm{~m}$ & $\mathrm{~m}$ & $20-22$ & $20-22$ & $22-24$ & $22-24$ & $\mathrm{~m}$ & 24.26 & 24.26 & $\mathrm{~m}$ & 28.30 \\
\hline Afrique du Sud' & $19-21$ & 19.21 & m & m & 21.23 & $21-23$ & $22-24$ & $22-24$ & $m$ & a & $24-26$ & m & $27-29$ \\
\hline
\end{tabular}

1. Année de référence : 2016.

Source : OCDE (2019). Consulter la section « Source » pour tout complément d'information et l'annexe 3 pour les notes (https://doi.org/10.1787/f8d7880d-en). Les symboles représentant les données manquantes et les abréviations figurent dans le Guide du lecteur. 
Tableau X1.1b. Âge typique d'accès, selon le niveau d'enseignement (2017)

L'âge typique correspond al l'âge de l'étudiant au début de l'année scolaire.

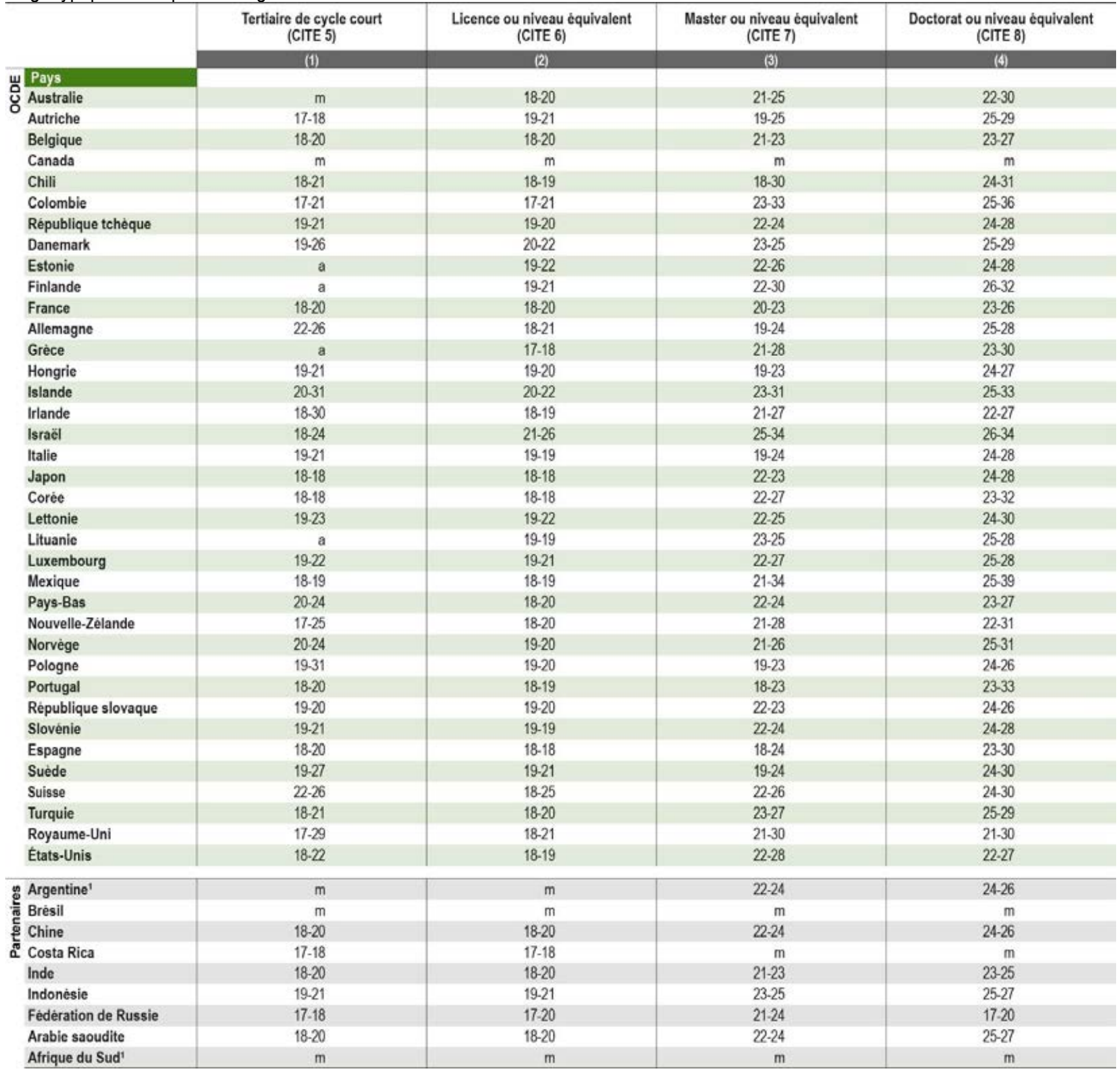

1. Année de référence : 2016.

Source : OCDE (2019). Consulter la section « Source » pour tout complément d'information et l'annexe 3 pour les notes (https://doi.org/10.1787/f8d7880d-en). Les symboles représentant les données manquantes et les abréviations figurent dans le Guide du lecteur.

StatLink 게프 https://doi.org/10.1787/888933980526 
Tableau X1.2a. Année scolaire et année budgétaire utilisées pour le calcul des indicateurs, pays membres de l'OCDE

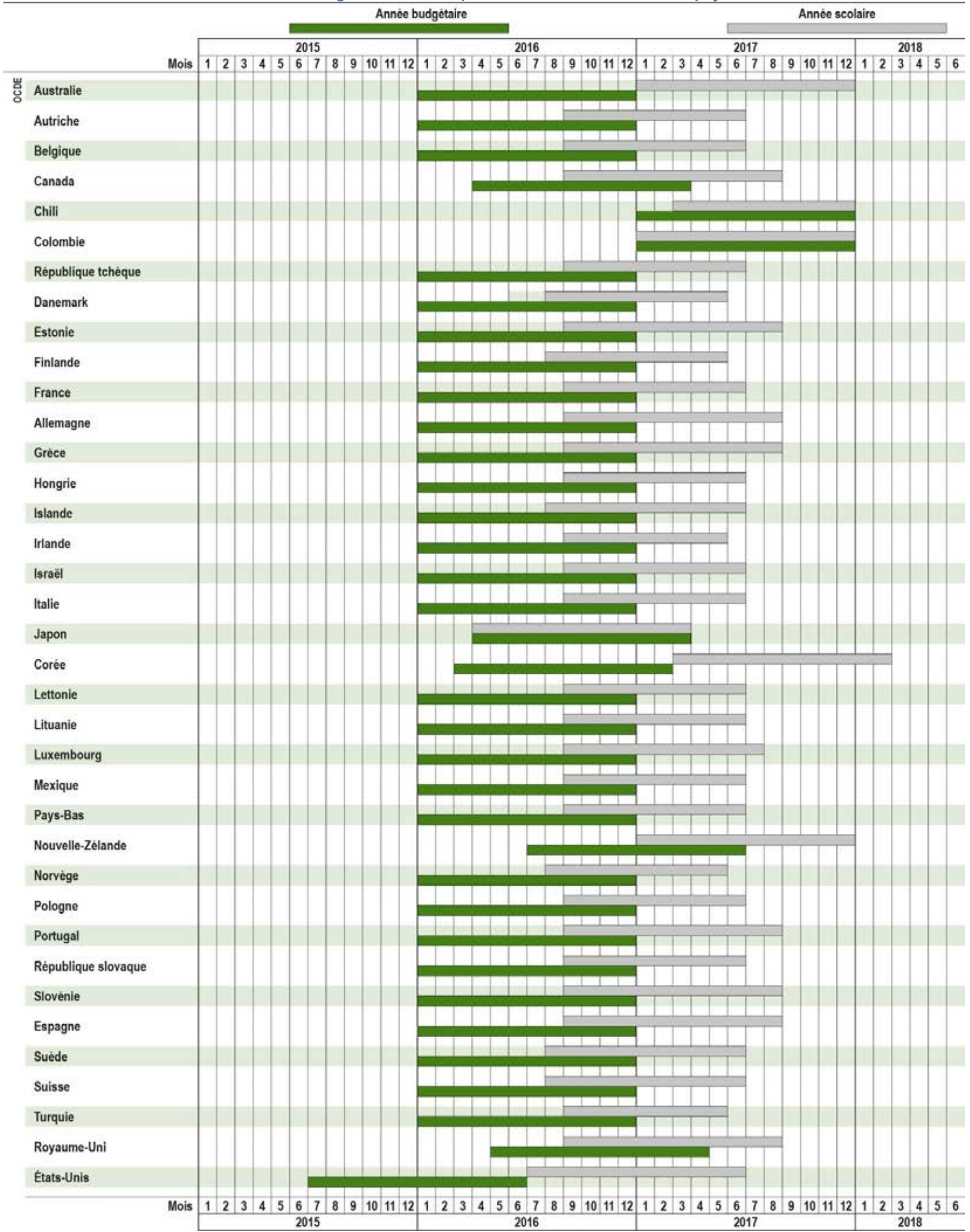

Source : OCDE (2018). Consulter la section « Source » pour tout complément d'information et l'annexe 3 pour les notes (https://doi.org/10.1787/f8d7880d-en). StatLink 部穴 https://doi.org/10.1787/888933980545 
ANNEXE 1. CARACTÉRISTIQUES DES SYSTĖMES D'ÉDUCATION | 503

Tableau X1.2b. Année scolaire et année budgétaire utilisées pour le calcul des indicateurs, pays partenaires

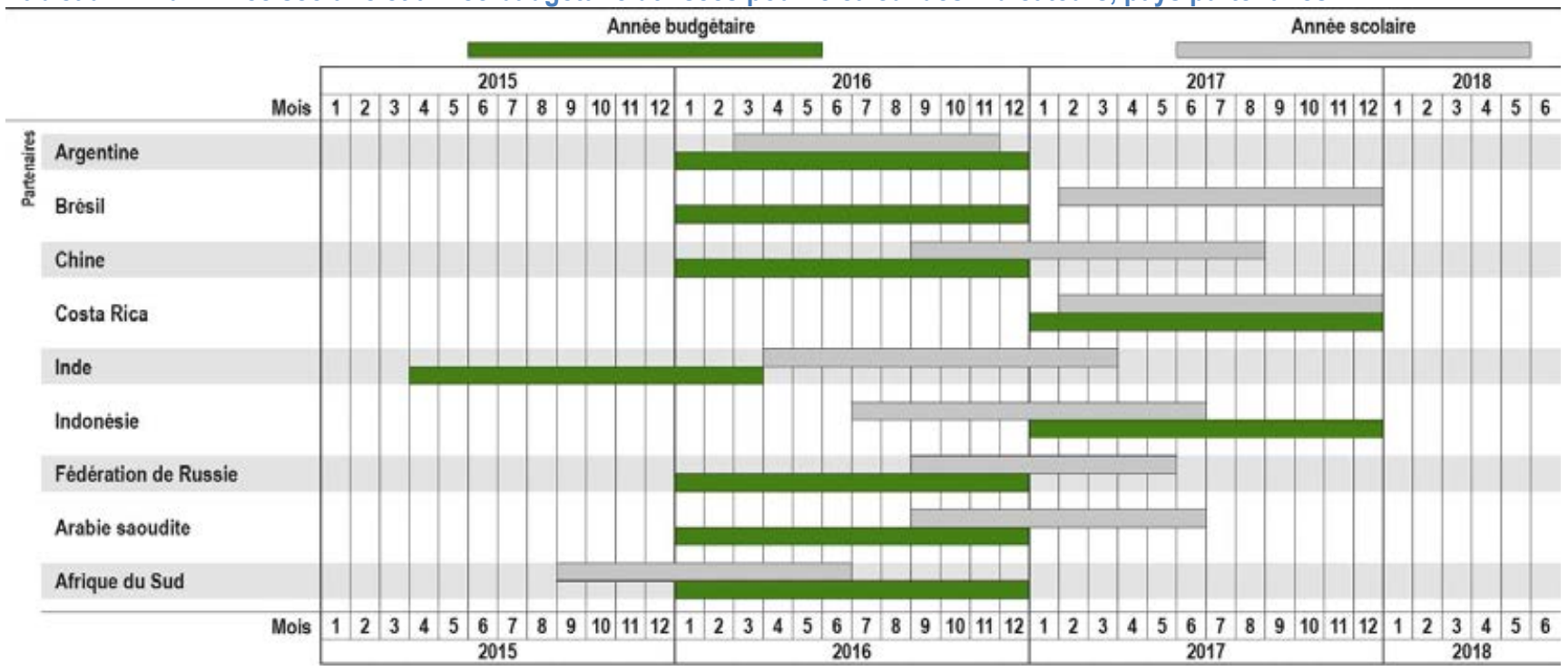

Source : OCDE (2018). Consulter la section « Source » pour tout complément d'information et l'annexe 3 pour les notes (https://doi.org/10.1787/f8d7880d-en).

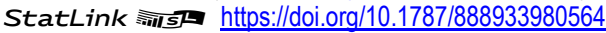


Tableau X1.3. Âge de début et de fin de la scolarité obligatoire, selon le niveau d'enseignement (2017) L'âge typique correspond à l'âge de l'élève au début de l'année scolaire

\begin{tabular}{|c|c|c|c|c|c|c|c|c|c|}
\hline & \multicolumn{2}{|c|}{ Scolarité obligatoire } & \multicolumn{2}{|c|}{ Enseignement primaire } & \multicolumn{2}{|c|}{$\begin{array}{c}\text { Premier cycle } \\
\text { de l'enseignement secondaire }\end{array}$} & \multicolumn{2}{|c|}{$\begin{array}{c}\text { Deuxième cycle } \\
\text { de l'enseignement secondaire }\end{array}$} \\
\hline & & Åge de début & Age de fin & Åge de début & Áge de fin & Âge de début & Áge de fin & Áge de début & Áge de fin \\
\hline & & (1) & (2) & (3) & (4) & (5) & (6) & $(7)$ & (8) \\
\hline \multirow{38}{*}{ 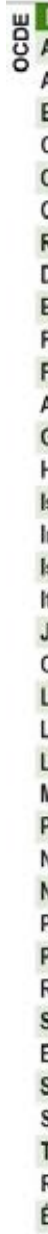 } & Pays & & & & & & & & \\
\hline & Australie & 6 & 17 & 5 & 11 & 12 & 15 & 16 & 17 \\
\hline & Autriche & 6 & 15 & 6 & 9 & 10 & 13 & 14 & 17 \\
\hline & Belgique & 6 & 18 & 6 & 11 & 12 & 13 & 14 & 17 \\
\hline & Canada & 6 & $16-18$ & 6 & 11 & 12 & 14 & 15 & 17 \\
\hline & Chili & 6 & 18 & 6 & 11 & 12 & 13 & 14 & 17 \\
\hline & Colombie & 5 & 15 & m & m & $\mathrm{m}$ & $\mathrm{m}$ & $\mathrm{m}$ & $\mathrm{m}$ \\
\hline & République tchèque & 6 & 15 & 6 & 10 & 11 & 14 & 15 & 18 \\
\hline & Danemark & 6 & 16 & 6 & 12 & 13 & 15 & 16 & 18 \\
\hline & Estonic & 7 & 16 & 7 & 12 & 13 & 15 & 16 & 18 \\
\hline & Finlande & 7 & 16 & 7 & 12 & 13 & 15 & 16 & 18 \\
\hline & France & 6 & 16 & 6 & 10 & 11 & 14 & 15 & 17 \\
\hline & Allemagne & 6 & 18 & 6 & 9 & 10 & 15 & 16 & 18 \\
\hline & Grèce & 5 & $14-15$ & 6 & 11 & 12 & 14 & 15 & 17 \\
\hline & Hongrie & 3 & 16 & 7 & 10 & 11 & 14 & 15 & 18 \\
\hline & Islande & 6 & 16 & 6 & 12 & 13 & 15 & 16 & 19 \\
\hline & Irlande & 6 & 16 & 5 & 12 & 13 & 15 & 16 & 17 \\
\hline & |sraē| & 3 & 17 & 6 & 11 & 12 & 14 & 15 & 17 \\
\hline & Italie & 6 & 16 & 6 & 10 & 11 & 13 & 14 & 18 \\
\hline & Japon & 6 & 15 & 6 & 11 & 12 & 14 & 15 & 17 \\
\hline & Corée & 6 & 14 & 6 & 11 & 12 & 14 & 15 & 17 \\
\hline & Lettonie & 5 & 16 & 7 & 12 & 13 & 15 & 16 & 18 \\
\hline & Lituanie & 7 & 16 & 7 & 10 & 11 & 16 & 17 & 18 \\
\hline & Luxembourg & 4 & 16 & 6 & 11 & 12 & 14 & 15 & 18 \\
\hline & Mexique & 3 & 17 & 6 & 11 & 12 & 14 & 15 & 17 \\
\hline & Pays-Bas & 5 & 18 & 6 & 11 & 12 & 14 & 15 & 17 \\
\hline & Nouvelle-Zélande & 5 & 16 & 5 & 10 & 11 & 14 & 15 & 17 \\
\hline & Norvège & 6 & 16 & 6 & 12 & 13 & 15 & 16 & 18 \\
\hline & Pologne & 6 & 16 & 7 & 12 & 13 & 15 & 16 & 18 \\
\hline & Portugal & 6 & 18 & 6 & 11 & 12 & 14 & 15 & 17 \\
\hline & République slovaque & 6 & 16 & 6 & 9 & 10 & 14 & 15 & 18 \\
\hline & Slovénie & 6 & 14 & 6 & 11 & 12 & 14 & 15 & 18 \\
\hline & Espagne & 6 & 16 & 6 & 11 & 12 & 14 & 15 & 17 \\
\hline & Suede & 6 & 16 & 7 & 12 & 13 & 15 & 16 & 18 \\
\hline & Suisse & $4-5$ & 15 & 7 & 12 & 13 & 15 & 16 & 19 \\
\hline & Turquie & $5-6$ & 17 & 6 & 9 & 10 & 13 & 14 & 17 \\
\hline & Royaume-Uni & $4-5$ & 16 & $4-5$ & 10 & 11 & 13 & 14 & 17 \\
\hline & États-Unis & 46 & 17 & 6 & 11 & 12 & 14 & 15 & 17 \\
\hline \multirow{9}{*}{ 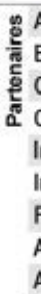 } & Argentine & 5 & 17 & m & m & $\mathrm{m}$ & $\mathrm{m}$ & $\mathrm{m}$ & $\mathrm{m}$ \\
\hline & Brèsil & 4 & 17 & 6 & 10 & 11 & 14 & 15 & 17 \\
\hline & Chine & $\mathrm{m}$ & $\mathrm{m}$ & m & m & $\mathrm{m}$ & $\mathrm{m}$ & $\mathrm{m}$ & $\mathrm{m}$ \\
\hline & Costa Rica & $\mathrm{m}$ & m & m & m & $\mathrm{m}$ & $\mathrm{m}$ & $\mathrm{m}$ & $\mathrm{m}$ \\
\hline & Inde & $\mathrm{m}$ & $\mathrm{m}$ & m & $\mathrm{m}$ & m & $\mathrm{m}$ & m & $\mathrm{m}$ \\
\hline & Indonésie & 7 & 15 & m & m & $\mathrm{m}$ & m & $\mathrm{m}$ & $\mathrm{m}$ \\
\hline & Fédèration de Russie & 7 & 17 & 7 & 10 & 11 & 15 & 16 & 17 \\
\hline & Arabie saoudite & 6 & 11 & m & m & $\mathrm{m}$ & $\mathrm{m}$ & $\mathrm{m}$ & $m$ \\
\hline & Afrique du Sud & 7 & 15 & $\mathrm{~m}$ & $\mathrm{~m}$ & $\mathrm{~m}$ & $\mathrm{~m}$ & m & $\mathrm{m}$ \\
\hline
\end{tabular}

Remarque : Par âge de fin de la scolarité obligatoire, on entend l'âge à partir duquel l'obligation d'être scolarisé prend fin. Par exemple, lorsque l'âge de fin de la scolarité obligatoire est fixé à 18 ans, tous les élèves de moins de 18 ans sont légalement tenus d'être scolarisés.

Source : OCDE (2019). Consulter la section « Source » pour tout complément d'information et l'annexe 3 pour les notes (https://doi.org/10.1787/f8d7880d-en. Les symboles représentant les données manquantes et les abréviations figurent dans le Guide du lecteur.

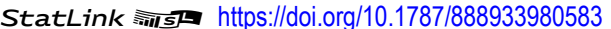




\section{Annexe 2. Statistiques de référence}

Tous les tableaux de l'annexe 2 sont disponibles en ligne sur:

StatLink: https://doi.org/10.1787/888933981324

\section{Note concernant les données d'Israël}

Les données statistiques concernant Israël sont fournies par et sous la responsabilité des autorités israéliennes compétentes. L'utilisation de ces données par l'OCDE est sans préjudice du statut des hauteurs du Golan, de Jérusalem-Est et des colonies de peuplement israéliennes en Cisjordanie aux termes du droit international. 
Tableau X2.1. Statistiques de référence en prix courants (période de référence : années civiles 2005, 2010, 2011, 2016)

\begin{tabular}{|c|c|c|c|c|c|c|c|c|}
\hline & \multicolumn{4}{|c|}{$\begin{array}{c}\text { Produit intérieur brut } \\
\text { (ajusté suivant l'année budgétaire, } \\
\text { en millions de la devise nationale, prix courants) }\end{array}$} & \multicolumn{4}{|c|}{$\begin{array}{l}\text { Dépenses publiques totales } \\
\text { (en millions de la devise nationale, prix courants) }\end{array}$} \\
\hline & 2005 & 2010 & 2011 & 2016 & 2005 & 2010 & 2011 & 2016 \\
\hline & (1) & (2) & (3) & (4) & (5) & (6) & (7) & (8) \\
\hline \multicolumn{9}{|l|}{ س Pays } \\
\hline Ô Australie & 959401 & 1358917 & 1458040 & 1713425 & 348130 & 523104 & 557755 & 648215 \\
\hline Autriche & 254075 & 295897 & 310129 & 356238 & 129973 & 156351 & 157846 & 179094 \\
\hline Belgique & 311481 & 365101 & 379106 & 424605 & 160811 & 194750 & 206680 & 225423 \\
\hline Canada & 1357185 & 1595012 & 1693051 & 1999885 & 559532 & 731454 & 751910 & 838733 \\
\hline Chill & 68831705 & 111508611 & 122006090 & 169469507 & 13864130 & 26009860 & 27805330 & 42810200 \\
\hline Colombie & 336940938 & 543187690 & 618117721 & 863782000 & $\mathrm{~m}$ & $\mathrm{~m}$ & $\mathrm{~m}$ & 374673000 \\
\hline République tchèque & 3264931 & 3962464 & 4033755 & 4767990 & 1380188 & 1724241 & 1735916 & 1882525 \\
\hline Danemark & 1585984 & 1810926 & 1846854 & 2100216 & 812682 & 1026310 & 1042167 & 1106069 \\
\hline Estonie & 11262 & 14717 & 16668 & 21683 & 3827 & 5962 & 6238 & 8557 \\
\hline Finlande & 164387 & 187100 & 196869 & 216073 & 81002 & 102446 & 107066 & 120820 \\
\hline France & 1765905 & 1995289 & 2058369 & 2228568 & 941123 & 1134956 & 1158670 & 1264297 \\
\hline Allemagne & 2300860 & 2580060 & 2703120 & 3159750 & 1062999 & 1219219 & 1208565 & 1396760 \\
\hline Grèce & 199242 & 226031 & 207029 & 176488 & 90778 & 118616 & 111973 & 86313 \\
\hline Hongrie & 22559880 & 27224599 & 28304938 & 35474186 & 11132603 & 13424928 & 14017434 & 16598403 \\
\hline Islande & 1058882 & 1672719 & 1757695 & 2490936 & 437351 & 799305 & 777342 & 1108713 \\
\hline Irlande & 170187 & 167721 & 171140 & 273238 & 56795 & 109160 & 79696 & 75354 \\
\hline Israēl & 639099 & 873922 & 936457 & 1226592 & 284159 & 359197 & 378563 & 473332 \\
\hline Italie & 1489726 & 1604515 & 1637463 & 1689824 & 702315 & 800494 & 808562 & 828676 \\
\hline Japon & 521757250 & 492214225 & 498117550 & 532486450 & 186153000 & 198817500 & 199698900 & 210431700 \\
\hline Corée & 919797300 & 1265308000 & 1332681000 & 1641786000 & 271192000 & 392264100 & 431075500 & 529717400 \\
\hline Lettonie & 13597 & 17938 & 20303 & 25038 & 4647 & 8148 & 8219 & 9259 \\
\hline Lituanic & 21002 & 28028 & 31275 & 38849 & 7157 & 11855 & 13284 & 13253 \\
\hline Luxembourg & 30031 & 40178 & 43165 & 53303 & 13087 & 17729 & 18287 & 22354 \\
\hline Mexique & 9562648 & 13366377 & 14665576 & 20116689 & 2025090 & 3400765 & 4222624 & 5210880 \\
\hline Pays-Bas & 550883 & 639187 & 650359 & 708337 & 232712 & 305938 & 304320 & 308695 \\
\hline Nouvelle-Zèlande & 156652 & 196547 & 205886 & 258048 & 61359 & 96359 & 92703 & 105287 \\
\hline Norvège ${ }^{1}$ & 1514364 & 2077604 & 2161617 & 2712752 & 836626 & 1165716 & 1223285 & 1583600 \\
\hline Pologne & 990468 & 1445298 & 1566824 & 1861112 & 439719 & 662055 & 687518 & 765040 \\
\hline Portugal & 158653 & 179930 & 176167 & 186480 & 74054 & 93237 & 88112 & 83564 \\
\hline République slovaque & 50415 & 67577 & 70627 & 81226 & 20053 & 28480 & 28828 & 33669 \\
\hline Slovénie & 29227 & 36252 & 36896 & 40357 & 13127 & 17858 & 18448 & 18292 \\
\hline Espagne & 930566 & 1080935 & 1070449 & 1118743 & 356547 & 493202 & 490592 & 472155 \\
\hline Suède & 2910683 & 3523824 & 3661043 & 4385497 & 1522630 & 1788623 & 1839773 & 2183866 \\
\hline Suisse & 508900 & 608831 & 621256 & 660393 & 171949 & 200808 & 204384 & 226036 \\
\hline Turquie & 673703 & 1160014 & 1394477 & 2608526 & 214120 & 422734 & 477070 & 940469 \\
\hline Royaume-Uni & 1331829 & 1549776 & 1601736 & 1914260 & 573371 & 755010 & 755199 & 815182 \\
\hline États-Unis & 12625184 & 14720492 & 15267317 & 18463243 & 4818229 & 6471661 & 6535453 & 7147629 \\
\hline of Argentine & 582538 & 1661721 & 2179024 & 8228160 & 142284 & 554305 & 760502 & 3411230 \\
\hline Brésil & 2170585 & 3885847 & 4376382 & 6267205 & $\mathrm{~m}$ & 2285508 & 2670879 & 4173293 \\
\hline Chine & 18731890 & 41303030 & 48930060 & 74358550 & 3427930 & 10251180 & 13128590 & 23809550 \\
\hline ¿ Costa Rica & 9532875 & 19596937 & 21370733 & 31136211 & 3130228 & 7651628 & 8330952 & 10427743 \\
\hline Inde & 35812963 & 75479115 & 87363287 & 152537135 & 9761840 & 21365300 & 24147720 & 41912890 \\
\hline Indonésie & 3035611121 & 6864133100 & 7831726000 & 12401728500 & 526114280 & 1159098280 & 1387241120 & 2086438830 \\
\hline Fèdération de Russie & 23275971 & 49879129 & 60282540 & 86043649 & 6820650 & 17616660 & 19994650 & 31323680 \\
\hline Arabie saoudite & 1230771 & 1980777 & 2517146 & 2418508 & 346471 & 653896 & 826700 & 935516 \\
\hline Afrique du Sud & 1639254 & 2748008 & 3023659 & 4359061 & 461829 & 864157 & 933613 & 1423820 \\
\hline
\end{tabular}

Remarque : Pour les pays dont le PIB ne correspond pas à la même période de référence que les données sur les dépenses d'éducation, le PIB est calculé comme suit : wt-1 (GDPt - 1) + wt (GDPt), où wt et wt-1 sont les pondérations attribuées aux fractions respectives des deux périodes de référence qui serviront à estimer le PIB pour la période de référence concernée. Dans le chapitre C, des ajustements ont été faits pour l'Australie, le Canada, les États-Unis, le Japon, la Nouvelle-Zélande et le Royaume-Uni.

1. Le PIB continental aux prix du marché est utilisé pour la Norvège.

Source : OCDE (2019). Consulter la section « Source » pour tout complément d'information et l'annexe 3 pour les notes (https://doi.org/10.1787/f8d7880d-en). Les symboles représentant les données manquantes et les abréviations figurent dans le Guide du lecteur.

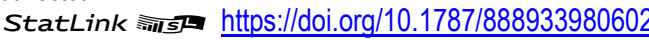


Tableau X2.2. Statistiques de référence en prix constants (période de référence : années civiles 2005, 2010, 2011, 2016)

\begin{tabular}{|c|c|c|c|c|c|c|c|c|}
\hline & \multicolumn{4}{|c|}{$\begin{array}{c}\text { Produit intérieur brut } \\
\text { (ajusté suivant l'année budgétaire, } \\
\text { en millions de la devise nationale, prix constants) }\end{array}$} & \multicolumn{4}{|c|}{$\begin{array}{l}\text { Dépenses publiques totales } \\
\text { (en millions de la devise nationale, prix constants) }\end{array}$} \\
\hline & 2005 & 2010 & 2011 & 2016 & 2005 & 2010 & 2011 & 2016 \\
\hline & (1) & (2) & (3) & (4) & (5) & (6) & (7) & (8) \\
\hline \multicolumn{9}{|l|}{ س Pays } \\
\hline Australie & 1188603 & 1358917 & 1431227 & 1620385 & 431299 & 523104 & 547498 & 613017 \\
\hline Autriche & 277307 & 295897 & 304545 & 318621 & 141858 & 156351 & 155004 & 160183 \\
\hline Belgique & 340164 & 365101 & 371666 & 390131 & 175619 & 194750 & 202624 & 207121 \\
\hline Canada & 1502080 & 1595012 & 1640002 & 1847876 & 619268 & 731454 & 728350 & 774982 \\
\hline Chili & 92687960 & 111508611 & 118322811 & 137242154 & 18669273 & 26009850 & 26965906 & 34669152 \\
\hline Colombie & 436603893 & 543187690 & 583180051 & 697449737 & $\mathrm{~m}$ & $\mathrm{~m}$ & $\mathrm{~m}$ & 302524926 \\
\hline République tchèque & 3512515 & 3962464 & 4032910 & 4412049 & 1484849 & 1724241 & 1735552 & 1741990 \\
\hline Danemark & 1791959 & 1810926 & 1835134 & 1977045 & 918227 & 1026310 & 1035553 & 1041202 \\
\hline Estonie & 15018 & 14717 & 15835 & 18268 & 5103 & 5962 & 5926 & 7210 \\
\hline Finlande & 179646 & 187100 & 191910 & 192684 & 88521 & 102446 & 104369 & 107742 \\
\hline France & 1915414 & 1995289 & 2039040 & 2124590 & 1020802 & 1134956 & 1147789 & 1205309 \\
\hline Allemagne & 2426546 & 2580060 & 2674490 & 2870575 & 1121066 & 1219219 & 1195765 & 1259846 \\
\hline Gréce & 229784 & 226031 & 205389 & 184421 & 104693 & 118616 & 111086 & 90193 \\
\hline Hongrie & 27533349 & 27224599 & 27675890 & 30677114 & 13586856 & 13424928 & 13705911 & 14353848 \\
\hline Islande & 1582786 & 1672719 & 1704193 & 2049623 & 653739 & 799305 & 753681 & 912285 \\
\hline Irlande & 163842 & 167721 & 173962 & 252407 & 54677 & 109160 & 81010 & 69609 \\
\hline |sraë| & 706274 & 873922 & 918926 & 1085943 & 314026 & 359197 & 371476 & 419057 \\
\hline Italie & 1629932 & 1604515 & 1613766 & 1574604 & 768414 & 800494 & 796861 & 772173 \\
\hline Japon & 495657667 & 492214225 & 506599680 & 525432959 & 176841168 & 198817500 & 203099447 & 207644252 \\
\hline Corée & 1034337497 & 1265308000 & 1311892696 & 1509754997 & 304962903 & 392264100 & 424351214 & 487117987 \\
\hline Lettonie & 18380 & 17938 & 19083 & 21768 & 6282 & 8148 & 7725 & 8050 \\
\hline Lituanie & 26436 & 28028 & 29721 & 34530 & 9009 & 11855 & 12624 & 11780 \\
\hline Luxembourg & 35606 & 40178 & 41198 & 47232 & 15517 & 17729 & 17454 & 19808 \\
\hline Mexique & 12417875 & 13366377 & 13855989 & 15906837 & 2629744 & 3400765 & 3989521 & 4120391 \\
\hline Pays-Bas & 596863 & 639187 & 649102 & 677999 & 252135 & 305938 & 303732 & 296474 \\
\hline Nouvelle-Zélande & 181378 & 196547 & 201705 & 233658 & 71044 & 96359 & 90821 & 95336 \\
\hline Norvége ${ }^{1}$ & 1882831 & 2077604 & 2024914 & 2487412 & 1040190 & 1165716 & 1145923 & 1452055 \\
\hline Pologne & 1145116 & 1445298 & 1517813 & 1728973 & 508375 & 662056 & 666012 & 710722 \\
\hline Portugal & 174509 & 179930 & 176643 & 175505 & 81455 & 93237 & 88350 & 78646 \\
\hline République slovaque & 53590 & 67577 & 69482 & 79132 & 21316 & 28480 & 28361 & 32800 \\
\hline Slovénie & 33274 & 36252 & 36488 & 38116 & 14945 & 17858 & 18244 & 17276 \\
\hline Espagne & 1025389 & 1080935 & 1070139 & 1106948 & 392878 & 493202 & 490450 & 467177 \\
\hline Suède & 3257173 & 3523824 & 3618235 & 4019179 & 1703885 & 1788623 & 1818261 & 2001449 \\
\hline Suisse & 546591 & 608831 & 619137 & 671837 & 184684 & 200808 & 203687 & 229953 \\
\hline Turquie & 969036 & 1160014 & 1288932 & 1686911 & 314341 & 422734 & 440962 & 608193 \\
\hline Royaume-Uni & 1491645 & 1549776 & 1571572 & 1741278 & 642174 & 755010 & 740977 & 741518 \\
\hline États-Unis & 13880146 & 14720492 & 14954921 & 16751024 & 5297169 & 6471651 & 6401726 & 6484782 \\
\hline \& Argentine & 1308651 & 1661721 & 1761490 & 1750824 & 319636 & 554305 & 614778 & 725857 \\
\hline Brésil & 3122228 & 3885847 & 4040287 & 3975948 & $\mathrm{~m}$ & 2285508 & 2465763 & 2647559 \\
\hline Chine & 24169862 & 41303030 & 45242989 & 64365398 & 4423077 & 10251180 & 12139299 & 20609751 \\
\hline$\AA^{\circ}$ Costa Rica & 15532812 & 19596937 & 20440997 & 24499179 & 5100375 & 7651628 & 7968513 & 8204953 \\
\hline Inde & 50628809 & 75479115 & 80489685 & 112364435 & 13800319 & 21365300 & 22247816 & 30874568 \\
\hline Indonèsie & 5181384705 & 6864133100 & 7287635302 & 9434613430 & 898007147 & 1159098280 & 1290865814 & 1587258083 \\
\hline Fèdération de Russie & 41911235 & 49879129 & 52006063 & 53590944 & 12281415 & 176166000 & 17249489 & 19509465 \\
\hline Arabie saoudite & 1492242 & 1980777 & 2178793 & 2587758 & 420077 & 653896 & 715575 & 1000984 \\
\hline Afrique du Sud & 2359099 & 2748008 & 2838258 & 3076467 & 664632 & 864157 & 876367 & 1004880 \\
\hline
\end{tabular}

Remarque : Pour les pays dont le PIB ne correspond pas à la même période de référence que les données sur les dépenses d'éducation, le PIB est calculé comme suit : wt-1 (GDPt - 1) + wt (GDPt), où wt et wt-1 sont les pondérations attribuées aux fractions respectives des deux périodes de référence qui serviront à estimer le PIB pour la période de référence concernée. Dans le chapitre C, des ajustements ont été faits pour l'Australie, le Canada, les États-Unis, le Japon, la Nouvelle-Zélande et le Royaume-Uni.

1. Le PIB continental aux prix du marché est utilisé pour la Norvège.

Source : OCDE (2019). Consulter la section « Source » pour tout complément d'information et l'annexe 3 pour les notes (https://doi.org/10.1787/f8d7880d-en). Les symboles représentant les données manquantes et les abréviations figurent dans le Guide du lecteur. 
Tableau X2.3. Statistiques de référence (période de référence : années civiles 2005, 2007, 2012, 2016, 2017)

\begin{tabular}{|c|c|c|c|c|c|c|}
\hline & \multicolumn{3}{|c|}{$\begin{array}{l}\text { Parités de pouvoir d'achat pour le PIB (PPA) } \\
\qquad(U S D=1)\end{array}$} & \multirow{2}{*}{$\begin{array}{c}\text { Produit intérieur brut utilisé } \\
\text { dans l'indicateur B2 } \\
\text { (ajusté suivant l'année } \\
\text { budgétaire, en millions } \\
\text { de la devise nationale, } \\
\text { prix courants) } \\
2012 \\
\end{array}$} & \multirow{2}{*}{$\begin{array}{l}\text { Produit intéricur brut } \\
\text { par habitant (ajuste suivant } \\
\text { l'annee budgetaire, en } \\
\text { equivalents USD convertis } \\
\text { sur la base des PPA) }\end{array}$} & \multirow{2}{*}{$\begin{array}{c}\begin{array}{c}\text { Produit intérieur brut } \\
\text { par habitant (en equivalents } \\
\text { USD convertis sur la base } \\
\text { des PPA) }\end{array} \\
2017\end{array}$} \\
\hline & 2007 & 2016 & 2017 & & & \\
\hline & (1) & (2) & (3) & (4) & (5) & (6) \\
\hline \multicolumn{7}{|l|}{ س Pays } \\
\hline Oustralie & 1.4 & 1.5 & 1.4 & 1517883 & 48767 & 52000 \\
\hline Autriche & 0.9 & 0.8 & 0.8 & 318653 & 51870 & 54031 \\
\hline Belgique & 0.9 & 0.8 & 0.8 & 387500 & 47299 & 49514 \\
\hline Canada & 12 & 1.2 & 1.3 & 1787348 & 44205 & 46930 \\
\hline Chili & 323.9 & 406.9 & 402.4 & 129947342 & 22927 & 24316 \\
\hline Colombie & 1000.4 & 1241.2 & 1278.0 & 665883659 & 14276 & 14607 \\
\hline Rèpublique tchèque & 14.3 & 12.8 & 12.5 & 4059912 & 35272 & 38076 \\
\hline Danemark & 82 & 72 & 7.0 & 1895002 & 50879 & 54510 \\
\hline Estonie & 0.6 & 0.5 & 0.5 & 17935 & 30894 & 33492 \\
\hline Finlande & 0.9 & 0.9 & 0.9 & 199793 & 43794 & 46385 \\
\hline France & 0.9 & 0.8 & 0.8 & 2088804 & 42082 & 44231 \\
\hline Allemagne & 0.8 & 0.8 & 0.8 & 2758260 & 50026 & 52660 \\
\hline Grece & 0.7 & 0.6 & 0.6 & 191204 & 27254 & 28544 \\
\hline Hongrie & 134.2 & 134.6 & 136.1 & 28781064 & 26807 & 28770 \\
\hline Islande & 107.5 & 141.9 & 137.7 & 1841729 & 52792 & 56156 \\
\hline Irlande & 1.0 & 0.8 & 0.8 & 175216 & 71362 & 77177 \\
\hline Israë| & 3.7 & 3.8 & 3.8 & 992649 & 37879 & 39249 \\
\hline Italie & 0.8 & 0.7 & 0.7 & 1613265 & 39021 & 40946 \\
\hline Japon & 120.4 & 102.6 & 102.5 & 492295675 & 40817 & 41910 \\
\hline Corée & 7702 & 862.5 & 866.0 & 1377456700 & 37143 & 38839 \\
\hline Lettonie & 0.6 & 0.5 & 0.5 & 21886 & 25716 & 28248 \\
\hline Lituanie & 0.5 & 0.4 & 0.4 & 33348 & 30087 & 33025 \\
\hline Luxembourg & 0.9 & 0.9 & 0.9 & 44112 & 106133 & 108674 \\
\hline Mexique & 7.4 & 8.7 & 9.0 & 15817755 & 19143 & 19830 \\
\hline Pays-Bas & 0.9 & 0.8 & 0.8 & 652966 & 51493 & 54581 \\
\hline Nouvelle-Zèlande & 1.5 & 1.5 & 1.5 & 214299 & 37411 & 40438 \\
\hline Norvège ${ }^{1}$ & 8.9 & 10.2 & 10.1 & 2298445 & 50792 & 52842 \\
\hline Pologne & 1.9 & 1.8 & 1.8 & 1629425 & 27737 & 29932 \\
\hline Portugal & 0.6 & 0.6 & 0.6 & 168398 & 30994 & 32525 \\
\hline République slovaque & 0.6 & 0.5 & 0.5 & 72704 & 30922 & 32394 \\
\hline Slovénie & 0.6 & 0.6 & 0.6 & 36076 & 33198 & 36162 \\
\hline Espagne & 0.7 & 0.7 & 0.6 & 1039815 & 36750 & 39092 \\
\hline Suède & 8.9 & 9.0 & 8.9 & 3688871 & 49443 & 51726 \\
\hline Suisse & 1.5 & 12 & 1.2 & 626414 & 64572 & 66554 \\
\hline Turquie & 0.9 & 1.2 & 1.4 & 1569672 & 26509 & 28328 \\
\hline Royaume-Uni & 0.7 & 0.7 & 0.7 & 1657014 & 41910 & 44469 \\
\hline Ėtats-Unis & 1.0 & 1.0 & 1.0 & 15869795 & 57419 & 60126 \\
\hline \& Argentine & 1.3 & 9.3 & 11.5 & 2637914 & 20139 & 20957 \\
\hline Brésil & 1.1 & 2.0 & 2.0 & 4814760 & 15375 & 15649 \\
\hline Chine & 30 & 35 & 3.5 & 54036740 & 15256 & 16531 \\
\hline ¿ Costa Rica & 269.9 & 390.0 & 390.7 & 23371406 & 16324 & 17079 \\
\hline Inde & 11.8 & 17.5 & 17.7 & 99440131 & 6574 & 7065 \\
\hline Indonésie & 2415.7 & 40922 & 4190.5 & 8615704500 & 11606 & 12282 \\
\hline Fédération de Russie & 14.0 & 244 & 24.3 & 68163883 & 24102 & $\mathrm{~m}$ \\
\hline Arabie saoudite & 1.5 & 1.4 & 1.4 & 2759906 & 54379 & 54219 \\
\hline Afrique du Sud & 3.8 & 5.9 & 6.1 & 3253852 & 13277 & 13503 \\
\hline
\end{tabular}

Remarque : Pour les pays dont le PIB ne correspond pas à la même période de référence que les données sur les dépenses d'éducation, le PIB est calculé comme suit : wt-1 (GDPt - 1) + wt (GDPt), où wt et wt-1 sont les pondérations attribuées aux fractions respectives des deux périodes de référence qui serviront à estimer le PIB pour la période de référence concernée. Dans le chapitre C, des ajustements ont été faits pour l'Australie, le Canada, les États-Unis, le Japon, la Nouvelle-Zélande et le Royaume-Uni.

1. Le PIB continental aux prix du marché est utilisé pour la Norvège.

2. Ces données sont utilisées dans l'indicateur $\mathrm{C} 1$ pour le calcul des dépenses au titre des établissements d'enseignement par élève/étudiant en équivalents temps plein en pourcentage du PIB par habitant.

3. Ces données sont utilisées dans l'indicateur $\mathrm{C} 7$ pour le calcul du coût salarial des enseignants par élève en pourcentage du PIB par habitant.

Source : OCDE (2019). Consulter la section « Source » pour tout complément d'information et l'annexe 3 pour les notes (https://doi.org/10.1787/f8d7880d-en). Les symboles représentant les données manquantes et les abréviations figurent dans le Guide du lecteur.

StatLink *iाls https://doi.org/10.1787888933980640 
Tableau X2.4a. Salaire statutaire des enseignants du préprimaire et du primaire ayant les qualifications les plus courantes, à différentes étapes de leur carrière (2018)

Salaire annuel des enseignants ayant les qualifications les plus courantes, en poste dans des établissements publics (en devises nationales)

\begin{tabular}{|c|c|c|c|c|c|c|c|c|}
\hline & \multicolumn{4}{|c|}{ Préprimaire } & \multicolumn{4}{|c|}{ Primaire } \\
\hline & $\begin{array}{c}\text { Salaire en début } \\
\text { de carriere }\end{array}$ & $\begin{array}{c}\text { Salaire après } \\
10 \text { ans d'exercice }\end{array}$ & $\begin{array}{c}\text { Salaire après } \\
15 \text { ans d'exercice }\end{array}$ & $\begin{array}{c}\text { Salaire a l'echelon } \\
\text { maximum }\end{array}$ & $\begin{array}{c}\text { Salaire en début } \\
\text { de carriere }\end{array}$ & $\begin{array}{c}\text { Salaire après } \\
10 \text { ans d'exercice }\end{array}$ & $\begin{array}{c}\text { Salaire apress } \\
15 \text { ans d'exercice }\end{array}$ & $\begin{array}{l}\text { Salaire a P'echelon } \\
\text { maximum }\end{array}$ \\
\hline & (1) & (2) & (3) & (4) & (5) & (6) & (7) & (8) \\
\hline \multicolumn{9}{|l|}{ س Pays } \\
\hline Oustralie & 68801 & 97330 & 97330 & 101066 & 68120 & 97330 & 97054 & 100627 \\
\hline Autriche & $\mathrm{m}$ & $\mathrm{m}$ & $\mathrm{m}$ & $\mathrm{m}$ & 35863 & 39122 & 43494 & 63963 \\
\hline Canada' & $\mathrm{m}$ & m & m & $\mathrm{m}$ & 53518 & 86516 & 90188 & 90188 \\
\hline Chili & 10953276 & 13522845 & 15948689 & 20343948 & 10953276 & 13522845 & 15948689 & 20343948 \\
\hline Colombie & 27571090 & 50281719 & 50281719 & 57823942 & 27571090 & 50281719 & 50281719 & 57823942 \\
\hline République tchèque & 284400 & 295200 & 302400 & 337200 & 303600 & 322800 & 337200 & 398400 \\
\hline Danemark & 351876 & 396900 & 396900 & 396900 & 391419 & 431003 & 457080 & 457080 \\
\hline Estonie & a & a & a & a & 13400 & a & a & a \\
\hline Finlande ${ }^{2}$ & 28433 & 30917 & 31126 & 31126 & 32115 & 37427 & 39941 & 42337 \\
\hline France & 26140 & 29881 & 31922 & 46149 & 26140 & 29881 & 31922 & 46149 \\
\hline Allemagne & $\mathrm{m}$ & $\mathrm{m}$ & $\mathrm{m}$ & $\mathrm{m}$ & 48698 & 56884 & 59948 & 63867 \\
\hline Grèce & 13104 & 15624 & 17316 & 25648 & 13104 & 15624 & 17316 & 25648 \\
\hline Hongrie & 2192400 & 2959740 & 3178980 & 4165560 & 2192400 & 2959740 & 3178980 & 4165560 \\
\hline Islande & 5787490 & 6090556 & 6412064 & 6412064 & 5937490 & 6240556 & 6562064 & 6562064 \\
\hline Irlande & $\mathrm{m}$ & m & $\mathrm{m}$ & m & 35958 & 54848 & 60533 & 69813 \\
\hline Israël & 103186 & 131988 & 148414 & 271596 & 90154 & 119203 & 133612 & 227285 \\
\hline Italie & 23729 & 26058 & 28568 & 34706 & 23729 & 26058 & 28568 & 34706 \\
\hline Japon & $\mathrm{m}$ & $\mathrm{m}$ & $\mathrm{m}$ & $\mathrm{m}$ & 3318000 & 4740000 & 5574000 & 6901000 \\
\hline Corée & 31250880 & 47098680 & 55006680 & 87456600 & 31250880 & 47098680 & 55006680 & 87456600 \\
\hline Lettonie & 8160 & a & a & a & 8160 & a & a & a \\
\hline Lituanie & 6455 & 6948 & 7107 & 7409 & 10112 & 10240 & 10526 & 10844 \\
\hline Luxembourg ${ }^{3}$ & 72437 & 93685 & 105758 & 127972 & 72437 & 93685 & 105758 & 127972 \\
\hline Mexique & 212094 & 268169 & 336437 & 424081 & 212094 & 268169 & 336437 & 424081 \\
\hline Pays-Bas & 36533 & 46522 & 54984 & 58222 & 36533 & 46522 & 54984 & 58222 \\
\hline Nouvelle-Zélande & m & m & m & m & 49588 & 75949 & 75949 & 75949 \\
\hline Norvège & 376200 & 438300 & 438300 & 456500 & 415800 & 511000 & 511000 & 548700 \\
\hline Pologne & 30109 & 40369 & 49302 & 51394 & 30109 & 40369 & 49302 & 51394 \\
\hline Portugal & 22290 & 27128 & 28783 & 48129 & 22290 & 27128 & 28783 & 48129 \\
\hline Rèpublique slovaque & 7398 & 8142 & 8508 & 9174 & 8280 & 9942 & 11634 & 12546 \\
\hline Slovénie & 18161 & 21597 & 26299 & 30401 & 18161 & 22394 & 27284 & 32745 \\
\hline Espagne & 29188 & 31554 & 33689 & 41467 & 29188 & 31554 & 33689 & 41467 \\
\hline Suède ${ }^{1,4}$ & 360000 & 380256 & 391326 & 423840 & 366000 & 412800 & 426840 & 489600 \\
\hline Suisse & 74783 & 93390 & $\mathrm{~m}$ & 113660 & 79772 & 99322 & $\mathrm{~m}$ & 121422 \\
\hline Turquie & 43633 & 45315 & 47987 & 55397 & 43633 & 45315 & 47987 & 55397 \\
\hline Etats-Unis & 39506 & 54044 & 65728 & 72886 & 40067 & 55040 & 62404 & 68712 \\
\hline \multicolumn{9}{|l|}{ Economies } \\
\hline Comm. flamande (Belgique) & 32304 & 40511 & 45609 & 55805 & 32304 & 40511 & 45609 & 55805 \\
\hline Comm. française (Belgique) & 31361 & 39214 & 44151 & 54023 & 31361 & 39214 & 44151 & 54023 \\
\hline Angleterre (RU) & 22917 & a & 38633 & 38633 & 22917 & a & 38633 & 38633 \\
\hline Ecosse (RU) & 27438 & 36480 & 36480 & 36480 & 27438 & 36480 & 36480 & 36480 \\
\hline \& Argentine & $\mathrm{m}$ & m & m & $\mathrm{m}$ & $\mathrm{m}$ & m & m & $\mathrm{m}$ \\
\hline Brésil & 32737 & $\mathrm{~m}$ & $\mathrm{~m}$ & $\mathrm{~m}$ & 32737 & $\mathrm{~m}$ & $\mathrm{~m}$ & $\mathrm{~m}$ \\
\hline E़ㄴ Chine & $\mathrm{m}$ & m & m & $\mathrm{m}$ & $\mathrm{m}$ & m & $\mathrm{m}$ & $\mathrm{m}$ \\
\hline ¿ Costa Rica & 9111375 & 10732855 & 11543595 & 13975815 & 9111375 & 10732855 & 11543595 & 13975815 \\
\hline Inde & m & m & m & m & $\mathrm{m}$ & m & $\mathrm{m}$ & $\mathrm{m}$ \\
\hline Indonésie & $\mathrm{m}$ & $\mathrm{m}$ & $\mathrm{m}$ & $\mathrm{m}$ & $\mathrm{m}$ & $\mathrm{m}$ & $\mathrm{m}$ & $\mathrm{m}$ \\
\hline Féderation de Russie & m & m & $\mathrm{m}$ & $\mathrm{m}$ & $\mathrm{m}$ & m & $\mathrm{m}$ & m \\
\hline Arabie saoudite & $\mathrm{m}$ & $\mathrm{m}$ & $\mathrm{m}$ & $\mathrm{m}$ & $\mathrm{m}$ & $\mathrm{m}$ & $\mathrm{m}$ & $\mathrm{m}$ \\
\hline Afrique du Sud & $\mathrm{m}$ & $\mathrm{m}$ & $\mathrm{m}$ & $\mathrm{m}$ & $\mathrm{m}$ & $\mathrm{m}$ & $\mathrm{m}$ & $\mathrm{m}$ \\
\hline
\end{tabular}

Remarque : La définition des qualifications les plus courantes parmi les enseignants se fonde sur une acception large, notamment le niveau de formation type dans la CITE et d'autres critères. Les qualifications les plus courantes sont définies pour chacune des quatre étapes de carrière incluses dans ce tableau. Dans nombre des cas, les qualifications minimales équivalent aux qualifications les plus courantes (voir le tableau X3.D3.2 à l'annexe 3). Consulter l'annexe 2 et les sections " Définitions » et « Méthodologie » pour de plus amples informations. Les données peuvent être consultées sur http://stats.oecd.org/, Base de données de Regards sur l'éducation.

1. Exclut les cotisations de sécurité sociale et de retraite acquittées par le salarié

2. Les données relatives aux enseignants du préprimaire incluent le salaire des enseignants des jardins d'enfants, qui sont majoritaires.

3. Inclut les cotisations de sécurité sociale et de retraite acquittées par l'employeur.

4. Salaire effectif de base.

Source : OCDE (2019). Consulter la section « Source » pour tout complément d'information et l'annexe 3 pour les notes (https://doi.org/10.1787/f8d7880d-en). Les symboles représentant les données manquantes et les abréviations figurent dans le Guide du lecteur.

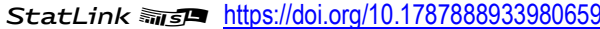


Tableau X2.4b. Salaire statutaire des enseignants du secondaire ayant les qualifications les plus courantes, à différentes étapes de leur carrière (2018)

Salaire annuel des enseignants ayant les qualifications les plus courantes, en poste dans des établissements publics (en devises nationales)

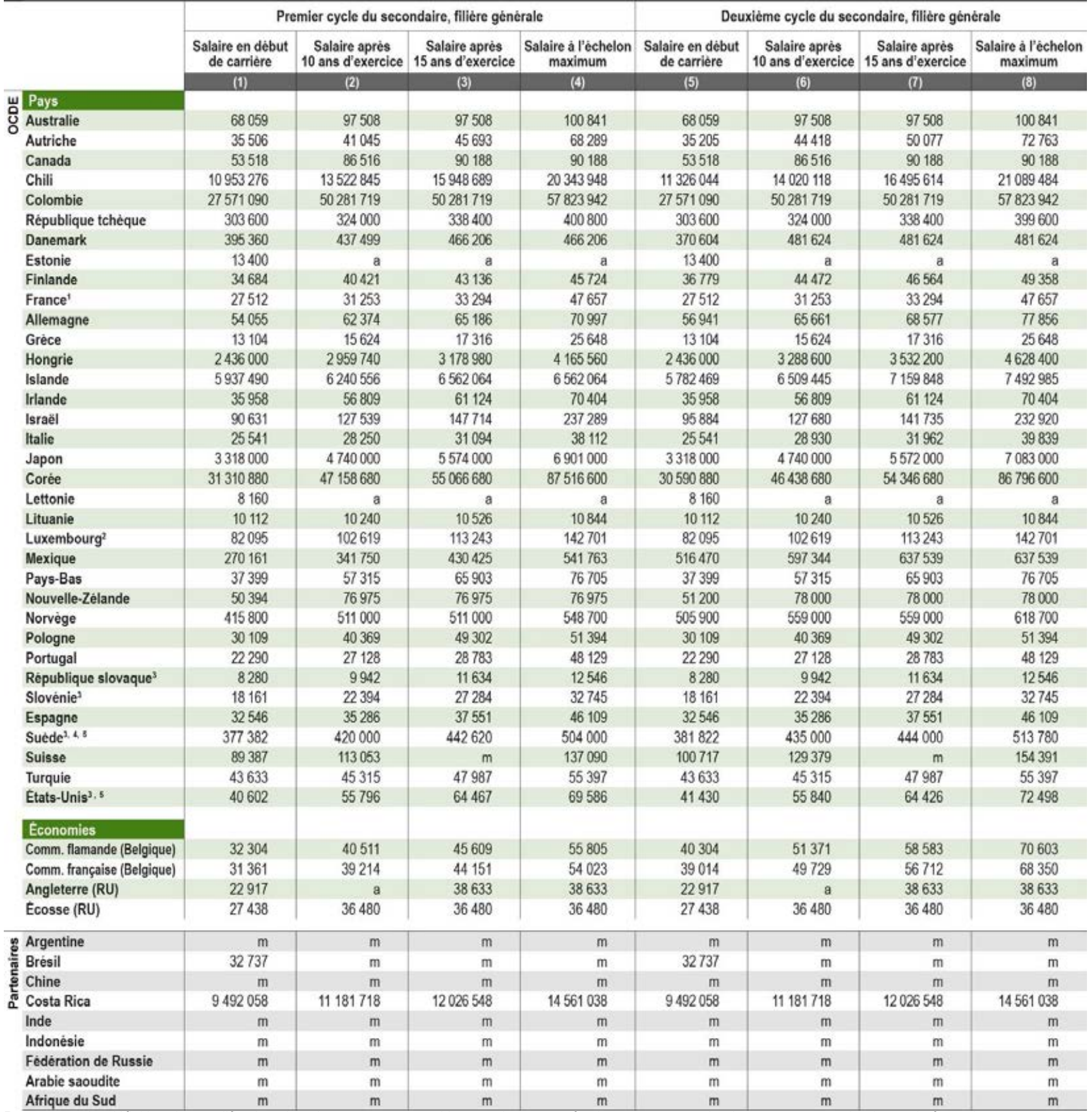

Remarque : La définition des qualifications les plus courantes parmi les enseignants se fonde sur une acception large, notamment le niveau de formation type dans la CITE et d'autres critères. Les qualifications les plus courantes sont définies pour chacune des quatre étapes de carrière incluses dans ce tableau. Dans nombre des cas, les qualifications minimales équivalent aux qualifications les plus courantes (voir le tableau X3.D3.2 à l'annexe 3). Consulter l'annexe 2 et les sections « Définitions » et « Méthodologie » pour de plus amples informations. Les données peuvent être consultées sur http://stats.oecd.org/, Base de données de Regards sur l'éducation.

1. Inclut la moyenne des primes fixes au titre des heures supplémentaires pour les enseignants des premier et deuxième cycles du secondaire.

2. Inclut les cotisations de sécurité sociale et de retraite acquittées par l'employeur.

3. Dans le deuxième cycle du secondaire, inclut les enseignants de la filière professionnelle. (En Slovénie, inclut uniquement les enseignants de la filière professionnelle en charge de matières générales.)

4. Exclut les cotisations de sécurité sociale et de retraite acquittées par le salarié.

5. Salaire effectif de base.

Source : OCDE (2019). Consulter la section « Source » pour tout complément d'information et l'annexe 3 pour les notes (https://doi.org/10.1787/f8d7880d-en). Les symboles représentant les données manquantes et les abréviations figurent dans le Guide du lecteur.

StatLink : 
Tableau X2.8. Statistiques de référence utilisées pour le calcul du salaire des enseignants (2000, 2005 à 2018)

\begin{tabular}{|c|c|c|c|c|c|c|c|c|c|c|c|c|c|c|c|c|c|c|c|c|c|c|}
\hline & \multicolumn{5}{|c|}{$\begin{array}{c}\text { Parités de pouvoir d'achat } \\
\text { pour la consommation privee (PPA)' }\end{array}$} & \multicolumn{15}{|c|}{ Déflateurs de la consommation privée $(2005=100)$} & \multirow{2}{*}{ 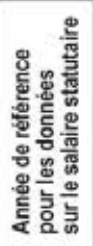 } & \multirow{2}{*}{ 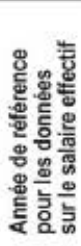 } \\
\hline & 2016 & 2017 & 2018 & 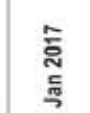 & $\begin{array}{l}\text { ֻ } \\
\text { స్ } \\
\text { 贸 }\end{array}$ & 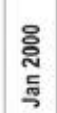 & స్ & 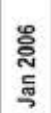 & $\begin{array}{l}\text { స్ } \\
\text { స్ } \\
\text { స }\end{array}$ & $\begin{array}{l}\text { స్๊ } \\
\text { స్ల్ }\end{array}$ & 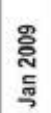 & $\begin{array}{l}\text { ํ్ㅊ } \\
\text { స్ }\end{array}$ & $\begin{array}{l}\overline{\text { స్ }} \\
\text { స్ల్ }\end{array}$ & 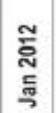 & $\begin{array}{l}\text { స్ల్ } \\
\text { స్ల్ }\end{array}$ & 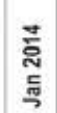 & $\begin{array}{l}\text { 心 } \\
\text { స్ } \\
\text { 品 }\end{array}$ & 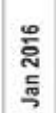 & 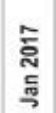 & 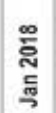 & & \\
\hline & (1) & (2) & (3) & (4) & (5) & (6) & (7) & (8) & (9) & (10) & (11) & (12) & (13) & (14) & (15) & (16) & (17) & (18) & (19) & (20) & (21) & (22) \\
\hline \multicolumn{23}{|c|}{ 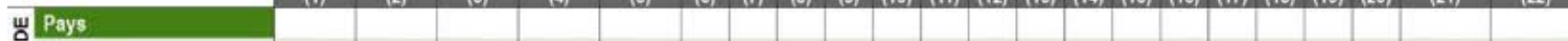 } \\
\hline Australie & 1.56 & 1.54 & 1.54 & 1.55 & 1.54 & 88 & 100 & 103 & 106 & 110 & 113 & 116 & 118 & 121 & 124 & 127 & 130 & 131 & 131 & 130 & 2018 & 2017 \\
\hline Autriche & 0.85 & 0.84 & 0.84 & 0.84 & 0.84 & 91 & 100 & 102 & 105 & 107 & 108 & 110 & 112 & 115 & 118 & 121 & 123 & 124 & 126 & 129 & $2017 / 18$ & $2016 / 17$ \\
\hline Canada & 1.34 & 1.34 & 1.34 & 1.34 & 1.34 & 91 & 100 & 101 & 103 & 105 & 105 & 106 & 108 & 110 & 111 & 113 & 115 & 116 & 117 & 119 & 2017/18 & $2016 / 17$ \\
\hline Chili & 463.37 & 461.25 & 461.25 & 462.31 & 46125 & 86 & 100 & 104 & 107 & 113 & 118 & 121 & 125 & 129 & 133 & 138 & 146 & 153 & 148 & 140 & 2018 & 2017 \\
\hline Colombie & 1371,39 & 1404.99 & 140499 & 1388.19 & 1404.99 & 72 & 100 & 104 & 109 & 115 & 120 & 124 & 128 & 133 & 136 & 140 & 147 & 156 & 138 & 115 & 2017 & 2017 \\
\hline République tchèque & 14.13 & 13.89 & 13.89 & 14.01 & 13.89 & 90 & 100 & 101 & 104 & 108 & 111 & 112 & 113 & 115 & 117 & 117 & 118 & 118 & 120 & 123 & $2017 / 18$ & $2016 / 17$ \\
\hline Danemark & 8.32 & 7.99 & 7.99 & 8.16 & 7.99 & 92 & 100 & 102 & 104 & 106 & 109 & 111 & 113 & 116 & 118 & 119 & 120 & 120 & 121 & 122 & $2017 / 18$ & $2016 / 17$ \\
\hline Estonie & 0.60 & 060 & 0.60 & 0.60 & 0.60 & 82 & 100 & 105 & 112 & 121 & 126 & 128 & 134 & 141 & 145 & 148 & 148 & 149 & 152 & 158 & $2017 / 18$ & $2016 / 17$ \\
\hline Finlande & 0.97 & 0.95 & 0.95 & 0.96 & 0.95 & 93 & 100 & 101 & 103 & 106 & 108 & 110 & 113 & 116 & 119 & 121 & 122 & 123 & 124 & 125 & 2017/18 & 2016/17 \\
\hline France & 0.86 & 0.85 & 0.85 & 0.85 & 0.85 & 92 & 100 & 102 & 104 & 107 & 107 & 107 & 109 & 111 & 112 & 112 & 112 & 112 & 111 & 110 & $2017 / 18$ & 2016 \\
\hline Allemagne & 0.82 & 0.80 & 0.80 & 0.81 & 0.80 & 93 & 100 & 101 & 103 & 104 & 105 & 106 & 108 & 110 & 111 & 112 & 113 & 114 & 115 & 117 & $2017 / 18$ & $2016 / 17$ \\
\hline Grèce & 0.67 & 0.66 & 0.66 & 0.67 & 0.66 & 87 & 100 & 103 & 107 & 111 & 114 & 116 & 120 & 121 & 121 & 118 & 115 & 114 & 114 & 114 & $2017 / 18$ & $2016 / 17$ \\
\hline Hongrie & 149.08 & 150.74 & 150.74 & 149.91 & 150.74 & 73 & 100 & 103 & 108 & 115 & 121 & 125 & 130 & 136 & 142 & 144 & 144 & 144 & 146 & 150 & $2017 / 18$ & 2017 \\
\hline Islande & 159.80 & 154.88 & 154.88 & 157.34 & 154.88 & 82 & 100 & 104 & 110 & 121 & 139 & 150 & 154 & 161 & 169 & 174 & 177 & 179 & 180 & 182 & $2017 / 18$ & 2016/17 \\
\hline Irlande & 0.99 & 0.98 & 0.98 & 0.99 & 0.98 & 83 & 100 & 102 & 105 & 107 & 105 & 100 & 100 & 101 & 102 & 104 & 105 & 106 & 106 & 107 & 2017/18 & $2016 / 17$ \\
\hline Israël & 4.35 & 4.24 & 4.24 & 4.29 & 4.24 & 93 & 100 & 102 & 104 & 107 & 111 & 114 & 118 & 121 & 123 & 124 & 124 & 123 & 119 & 116 & $2017 / 18$ & $2016 / 17$ \\
\hline Italie & 0.80 & 0.78 & 0.78 & 0.79 & 0.78 & 87 & 100 & 102 & 105 & 108 & 109 & 110 & 112 & 115 & 117 & 118 & 118 & 118 & 119 & 121 & 2017/18 & 2016/17 \\
\hline Japon & 109.25 & 108.57 & 108.57 & 108.91 & 108.57 & 105 & 100 & 100 & 99 & 99 & 98 & 96 & 94 & 94 & 93 & 94 & 95 & 95 & 98 & 101 & 2017/18 & $2016 / 17$ \\
\hline Corée & 961.14 & 962.00 & 962.00 & 961.57 & 962.00 & 84 & 100 & 102 & 104 & 107 & 111 & 114 & 117 & 121 & 123 & 124 & 125 & 126 & 128 & 130 & 2018 & 2017 \\
\hline Lettonie & 0.57 & 0.56 & 0.56 & 0.57 & 0.56 & 77 & 100 & 110 & 122 & 137 & 143 & 139 & 141 & 148 & 150 & 152 & 153 & 152 & 156 & 160 & $2017 / 18$ & $2016 / 17$ \\
\hline Lituanie & 0.50 & 0.50 & 0.50 & 0.50 & 0.50 & 99 & 100 & 104 & 109 & 118 & 127 & 131 & 134 & 139 & 142 & 142 & 142 & 142 & 145 & 149 & $2017 / 18$ & $2016 / 17$ \\
\hline Luxembou & 0.98 & 0.97 & 0.97 & 0.98 & 0.97 & 90 & 100 & 103 & 105 & 108 & 109 & 110 & 112 & 115 & 117 & 118 & 118 & 118 & 119 & 122 & $2017 / 18$ & $2016 / 17$ \\
\hline Mexique & & 10.17 & 10.17 & 9.93 & 10.17 & 80 & 100 & 104 & 109 & 115 & 121 & 127 & 132 & 137 & 142 & 147 & 153 & 159 & 151 & 143 & $2017 / 18$ & $2017 / 18$ \\
\hline Pays-Bas & 0.89 & 0.87 & 0.87 & 0.88 & 0.87 & 88 & 100 & 102 & 105 & 107 & 107 & 107 & 109 & 111 & 113 & 115 & 115 & 116 & 113 & 111 & $2017 / 18$ & $2016 / 17$ \\
\hline Nouvello- $Z$ & 1.62 & 1.61 & 1.61 & 1.61 & 1.61 & 92 & 100 & 102 & 105 & 108 & 111 & 113 & 116 & 118 & 119 & 119 & 120 & 121 & 122 & 124 & 2018 & 2017 \\
\hline Norvège & 10.86 & 10.78 & 10.78 & 10.82 & 10.78 & 91 & 100 & 101 & 103 & 106 & 109 & 111 & 113 & 114 & 116 & 118 & 121 & 125 & 124 & 123 & $0.017 / 18$ & $2016 / 17$ \\
\hline Pologne & 1.87 & 1.87 & 1.87 & 1.87 & 1.87 & 84 & 100 & 102 & 104 & 107 & 111 & 113 & 118 & 122 & 125 & 125 & 124 & 123 & 124 & 127 & $2017 / 18$ & $2016 / 17$ \\
\hline Portugal & 0.67 & 0.67 & 0.67 & 0.67 & 0.67 & 85 & 100 & 104 & 107 & 111 & 111 & 111 & 113 & 115 & 116 & 117 & 118 & 119 & 120 & 122 & $2017 / 18$ & $2016 / 17$ \\
\hline Rèpublique & 0.54 & 0.54 & 0.54 & 0.54 & 0.54 & 76 & 100 & 104 & 108 & 111 & 114 & 115 & 117 & 122 & 125 & 125 & 125 & 125 & 126 & 128 & $2017 / 18$ & $2016 / 17$ \\
\hline Slovénie & 0.67 & 0.65 & 0 & 0.66 & 0.65 & 76 & 100 & 102 & 106 & 111 & 114 & 116 & 117 & 119 & 121 & 121 & 121 & 120 & 122 & 125 & $2017 / 18$ & $2016 / 17$ \\
\hline Espagne & 0.73 & 0.72 & 0 & 0. & 0.72 & 85 & 100 & 104 & 107 & 111 & 112 & 113 & 115 & 118 & 120 & 121 & 121 & 121 & 122 & 124 & $2017 / 18$ & $2016 / 17$ \\
\hline Suède & 9.50 & 9.35 & 9.35 & 9.4 & 9.35 & 93 & 100 & 101 & 102 & 105 & 108 & 110 & 111 & 113 & 113 & 114 & 115 & 117 & 117 & 117 & 2017 & 2017 \\
\hline Suisse & 1.41 & 1.3 & 1.3 & 1. & 1.37 & 97 & 100 & 101 & 102 & 104 & 105 & 105 & 105 & 105 & 104 & 103 & 103 & 102 & 102 & 103 & $0.017 / 18$ & $2016 / 17$ \\
\hline Turquie & 1. & 1 & 1. & 1. & 1. & 28 & 100 & 109 & 118 & 128 & 138 & 145 & 156 & 169 & 179 & 190 & 205 & 220 & 240 & 270 & $017 / 18$ & $2016 / 17$ \\
\hline Etats-Unis & 1.00 & 1.00 & 1.00 & 1.00 & 1.00 & 90 & 100 & 103 & 105 & 108 & 110 & 111 & 113 & 116 & 117 & 119 & 120 & 121 & 119 & 118 & $2017 / 18$ & $2016 / 17$ \\
\hline \multicolumn{23}{|l|}{ Economics } \\
\hline Comm. flamande (Belgique) & 0.87 & & & 0.86 & 0.86 & 90 & 100 & 103 & 106 & 109 & 111 & 111 & 114 & 117 & 119 & 120 & 120 & 121 & 122 & 123 & $2017 / 18$ & $2016 / 17$ \\
\hline Comm. française (Belgique) ${ }^{2}$ & 0.87 & 0.86 & 0.86 & 0.86 & 0.86 & 90 & 100 & 103 & 106 & 109 & 111 & 111 & 114 & 117 & 119 & 120 & 120 & 121 & 122 & 123 & $2017 / 18$ & $2017 / 18$ \\
\hline Angleterr & 0.80 & 0.79 & 0.79 & 0.79 & 0.79 & 95 & 100 & 102 & 105 & 108 & 111 & 112 & 115 & 119 & 121 & 124 & 125 & 126 & 126 & 126 & $2017 / 18$ & $2016 / 17$ \\
\hline Ecosse (RU) ${ }^{3}$ & 0.80 & 0.79 & 0.79 & 0.79 & 0.79 & 95 & 100 & 102 & 105 & 108 & 111 & 112 & 115 & 119 & 121 & 124 & 125 & 126 & 126 & 126 & 2017/18 & $2016 / 17$ \\
\hline \& Argentine & Ii & in & II & $\mathrm{m}$ & Ii & $\mathrm{m}$ & $\mathrm{m}$ & $\mathrm{m}$ & $\mathrm{m}$ & $m$ & $m$ & $\mathrm{~m}$ & $\mathrm{~m}$ & $m$ & $\mathrm{~m}$ & $\mathrm{~m}$ & $\mathrm{~m}$ & $\mathrm{~m}$ & $\mathrm{~m}$ & $m$ & III & \\
\hline Brésil & 2.19 & 2.22 & 2.22 & 2.04 & 2.22 & 65 & 100 & 106 & 112 & 118 & 126 & 135 & 144 & 156 & 168 & 179 & 194 & 213 & 227 & 234 & 2018 & 2015 \\
\hline Chine & $\mathrm{m}$ & $\mathrm{m}$ & $\mathrm{m}$ & $\mathrm{m}$ & $\mathrm{m}$ & $\mathrm{m}$ & $\mathrm{m}$ & $\mathrm{m}$ & $\mathrm{m}$ & $\mathrm{m}$ & $\mathrm{m}$ & $\mathrm{m}$ & $\mathrm{m}$ & m & m & $\mathrm{m}$ & $\mathrm{m}$ & $\mathrm{m}$ & m & $\mathrm{m}$ & $\mathrm{m}$ & $\mathrm{m}$ \\
\hline ¿ Costa Rica & 373.21 & 375.91 & 375.91 & 374.56 & 375.91 & 56 & 100 & 115 & 129 & 144 & 154 & 159 & 167 & 173 & 178 & 185 & 189 & 188 & 193 & 200 & 2018 & 2018 \\
\hline Inde & $\mathrm{m}$ & $\mathrm{m}$ & $\mathrm{m}$ & $\mathrm{m}$ & $\mathrm{m}$ & $\mathrm{m}$ & $\mathrm{m}$ & $\mathrm{m}$ & $\mathrm{m}$ & $\mathrm{m}$ & $\mathrm{m}$ & $\mathrm{m}$ & $\mathrm{m}$ & $\mathrm{m}$ & $\mathrm{m}$ & $\mathrm{m}$ & $\mathrm{m}$ & $\mathrm{m}$ & m & $\mathrm{m}$ & $\mathrm{m}$ & m \\
\hline Indonésie & $\mathrm{m}$ & $\mathrm{m}$ & m & $\mathrm{m}$ & $\mathrm{m}$ & $\mathrm{m}$ & $\mathrm{m}$ & $\mathrm{m}$ & $\mathrm{m}$ & $\mathrm{m}$ & $\mathrm{m}$ & m & $\mathrm{m}$ & $\mathrm{m}$ & $\mathrm{m}$ & $\mathrm{m}$ & $\mathrm{m}$ & $\mathrm{m}$ & $\mathrm{m}$ & m & $\mathrm{m}$ & $\mathrm{m}$ \\
\hline Fèdération de Russie & 26.02 & 26.18 & 26.18 & 26.10 & 26.18 & 48 & 100 & 110 & 120 & 132 & 148 & 160 & 172 & 185 & 196 & 210 & 235 & 264 & 230 & 187 & $\mathrm{~m}$ & m \\
\hline Arabie saoudite & m & $\mathrm{m}$ & $\mathrm{m}$ & m & $\mathrm{m}$ & $\mathrm{m}$ & $\mathrm{m}$ & $\mathrm{m}$ & $\mathrm{m}$ & $\mathrm{m}$ & $\mathrm{m}$ & m & m & m & m & $\mathrm{m}$ & $\mathrm{m}$ & m & m & m & $\mathrm{m}$ & m \\
\hline Afrique du Sud & m & m & m & m & m & m & m & m & $\mathrm{m}$ & $\mathrm{m}$ & m & $\mathrm{m}$ & $\mathrm{m}$ & $\mathrm{m}$ & $\mathrm{m}$ & $\mathrm{m}$ & $\mathrm{m}$ & $\mathrm{m}$ & $\mathrm{m}$ & $\mathrm{m}$ & $\mathrm{m}$ & $\mathrm{m}$ \\
\hline
\end{tabular}

Remarque : Consulter les sections «Définitions » et «Méthodologie » pour de plus amples informations. Les données peuvent être consultées sur http://stats.oecd.org/, Base de données de Regards sur l'éducation.

1. Les données sur les PPA et le PIB des pays désormais dans la zone euro sont exprimées en euros.

2. Les données sur les PPA et les déflateurs se rapportent à la Belgique dans son ensemble.

3. Les données sur les PPA et les déflateurs se rapportent au Royaume-Uni dans son ensemble.

Source : OCDE (2019). Consulter la section « Source » pour tout complément d'information et l'annexe 3 pour les notes (https://doi.org/10.1787/f8d7880d-en). Les symboles représentant les données manquantes et les abréviations figurent dans le Guide du lecteur.

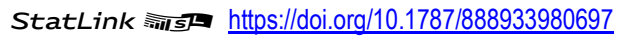


Tableau X2.9. Évolution du salaire effectif moyen des enseignants, en devises nationales (2000, 2005, 2010 à 2017) Salaire annuel moyen (primes et allocations comprises) des enseignants âgés de 25 à 64 ans

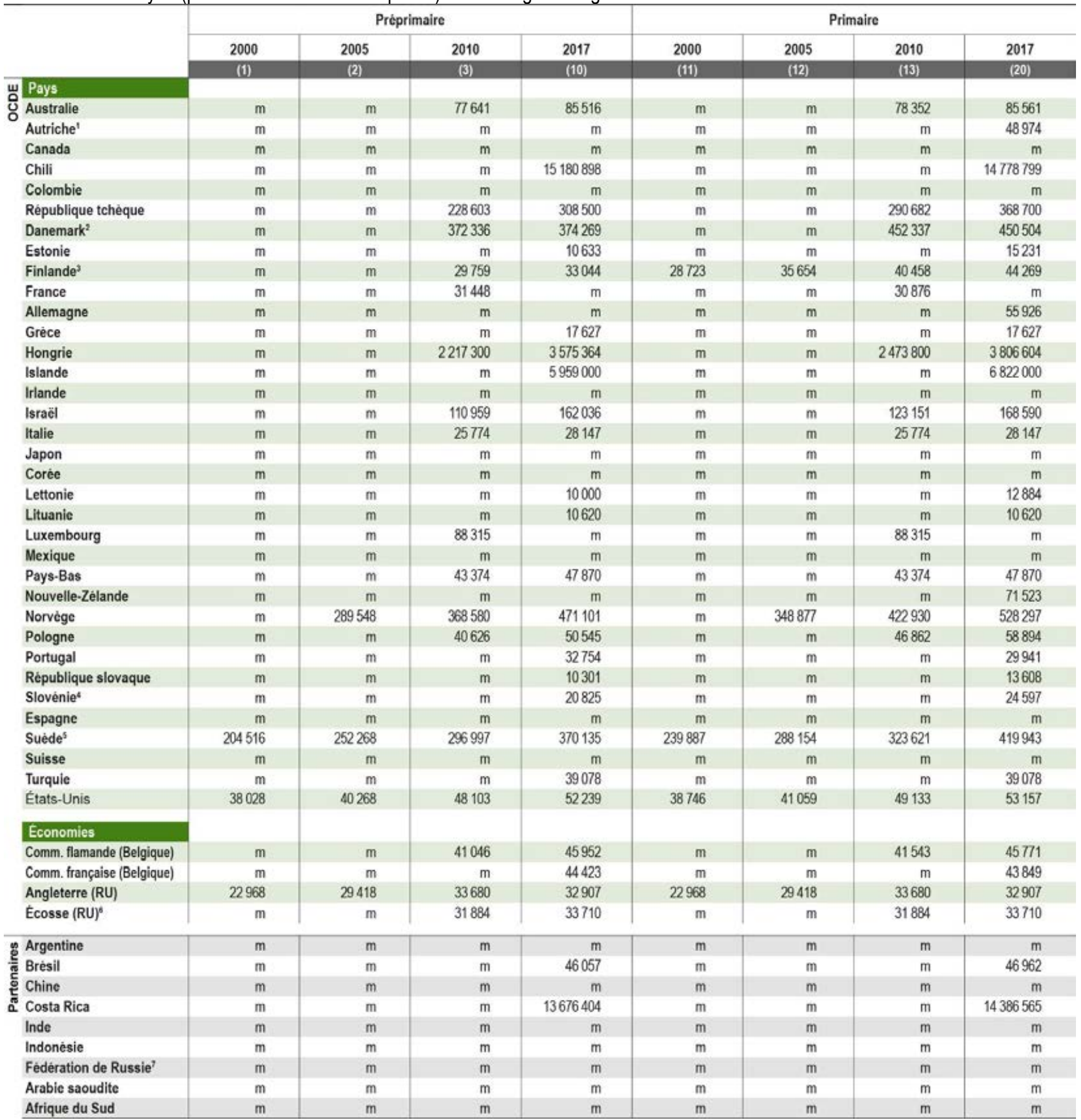


ANNEXE 2. STATISTIQUES DE RÉFÉRENCE | 513

\begin{tabular}{|c|c|c|c|c|c|c|c|c|}
\hline & \multicolumn{4}{|c|}{ Premier eycle du secondaire } & \multicolumn{4}{|c|}{ Deuxième cycle du secondaire } \\
\hline & 2000 & 2005 & 2010 & 2017 & 2000 & 2005 & 2010 & 2017 \\
\hline & (21) & (22) & (23) & (30) & (31) & (32) & (33) & (40) \\
\hline \multicolumn{9}{|l|}{ एuays. } \\
\hline Australie & m & $\mathrm{m}$ & 78221 & 86928 & $\mathrm{~m}$ & $\mathrm{~m}$ & 78225 & 86928 \\
\hline Autriche' & $\mathrm{m}$ & $\mathrm{m}$ & $\mathrm{m}$ & 57200 & m & m & $\mathrm{m}$ & 63119 \\
\hline Canada & $\mathrm{m}$ & $\mathrm{m}$ & $\mathrm{m}$ & $\mathrm{m}$ & $\mathrm{m}$ & $\mathrm{m}$ & m & $\mathrm{m}$ \\
\hline Chili & m & $\mathrm{m}$ & $\mathrm{m}$ & 15112928 & $\mathrm{~m}$ & m & m & 16258651 \\
\hline Colombie & $\mathrm{m}$ & $\mathrm{m}$ & $\mathrm{m}$ & $\mathrm{m}$ & $\mathrm{m}$ & $\mathrm{m}$ & $\mathrm{m}$ & $\mathrm{m}$ \\
\hline République tchèque & m & $\mathrm{m}$ & 289771 & 367100 & $\mathrm{~m}$ & $\mathrm{~m}$ & 313534 & 378800 \\
\hline Danemark ${ }^{2}$ & $\mathrm{~m}$ & $\mathrm{~m}$ & 457728 & 455123 & $\mathrm{~m}$ & $\mathrm{~m}$ & m & 532445 \\
\hline Estonie & $\mathrm{m}$ & $\mathrm{m}$ & $\mathrm{m}$ & 15231 & $\mathrm{~m}$ & $\mathrm{~m}$ & $\mathrm{~m}$ & 15231 \\
\hline Finlande ${ }^{3}$ & 32919 & 39519 & 44421 & 48948 & 37728 & 44051 & 49808 & 55245 \\
\hline France & m & $\mathrm{m}$ & 37198 & $\mathrm{~m}$ & $\mathrm{~m}$ & $\mathrm{~m}$ & 41789 & $\mathrm{~m}$ \\
\hline Allemagne & $\mathrm{m}$ & $\mathrm{m}$ & $\mathrm{m}$ & 61748 & $\mathrm{~m}$ & $\mathrm{~m}$ & $\mathrm{~m}$ & 65473 \\
\hline Grèce & m & $\mathrm{m}$ & $\mathrm{m}$ & 18853 & $\mathrm{~m}$ & $\mathrm{~m}$ & $\mathrm{~m}$ & 18853 \\
\hline Hongrie & m & $\mathrm{m}$ & 2473800 & 3806604 & $\mathrm{~m}$ & $\mathrm{~m}$ & 2814100 & 4144680 \\
\hline Islande & $\mathrm{m}$ & $\mathrm{m}$ & $\mathrm{m}$ & 6822000 & $\mathrm{~m}$ & $\mathrm{~m}$ & 5172300 & 8848000 \\
\hline Irlande & $\mathrm{m}$ & $\mathrm{m}$ & $\mathrm{m}$ & $\mathrm{m}$ & $\mathrm{m}$ & $\mathrm{m}$ & $\mathrm{m}$ & $\mathrm{m}$ \\
\hline Israël & $\mathrm{m}$ & $\mathrm{m}$ & 126309 & 182398 & $\mathrm{~m}$ & $\mathrm{~m}$ & 133790 & 180215 \\
\hline Italle & $\mathrm{m}$ & $\mathrm{m}$ & 27170 & 28713 & $\mathrm{~m}$ & $\mathrm{~m}$ & 28986 & 30649 \\
\hline Japon & $\mathrm{m}$ & $\mathrm{m}$ & $\mathrm{m}$ & $\mathrm{m}$ & $\mathrm{m}$ & $\mathrm{m}$ & $\mathrm{m}$ & $\mathrm{m}$ \\
\hline Corée & m & $\mathrm{m}$ & $\mathrm{m}$ & m & m & m & m & $\mathrm{m}$ \\
\hline Lettonie & m & $\mathrm{m}$ & $\mathrm{m}$ & 13317 & $\mathrm{~m}$ & $\mathrm{~m}$ & $\mathrm{~m}$ & 14225 \\
\hline Lituanie & $\mathrm{m}$ & $\mathrm{m}$ & $\mathrm{m}$ & 10620 & $\mathrm{~m}$ & $\mathrm{~m}$ & $\mathrm{~m}$ & 10620 \\
\hline Luxembourg & m & m & 101471 & m & $\mathrm{m}$ & $\mathrm{m}$ & 101471 & m \\
\hline Mexique & $\mathrm{m}$ & $\mathrm{m}$ & m & m & $\mathrm{m}$ & $\mathrm{m}$ & $\mathrm{m}$ & $\mathrm{m}$ \\
\hline Pays-Bas & $\mathrm{m}$ & $\mathrm{m}$ & 52831 & 60297 & $\mathrm{~m}$ & $\mathrm{~m}$ & 52831 & 60297 \\
\hline Nouvelle-Zèlande & $\mathrm{m}$ & $\mathrm{m}$ & $\mathrm{m}$ & 72917 & $\mathrm{~m}$ & $\mathrm{~m}$ & $\mathrm{~m}$ & 78158 \\
\hline Norvège & $\mathrm{m}$ & 348877 & 422930 & 528297 & $\mathrm{~m}$ & 372694 & 449704 & 574825 \\
\hline Pologne & $\mathrm{m}$ & $\mathrm{m}$ & 47410 & 61047 & $\mathrm{~m}$ & $\mathrm{~m}$ & 46147 & 59381 \\
\hline Portugal & m & $\mathrm{m}$ & m & 29403 & $\mathrm{~m}$ & $\mathrm{~m}$ & m & 32063 \\
\hline Rèpublique slovaque & m & m & $\mathrm{m}$ & 13608 & m & $\mathrm{m}$ & m & 13823 \\
\hline Slovènie & $\mathrm{m}$ & $\mathrm{m}$ & $\mathrm{m}$ & 25260 & $\mathrm{~m}$ & $\mathrm{~m}$ & m & 26598 \\
\hline Espagne & m & $\mathrm{m}$ & m & m & m & m & m & $\mathrm{m}$ \\
\hline Suède ${ }^{5}$ & 247793 & 290058 & 324639 & 435096 & 265488 & 315592 & 347967 & 445457 \\
\hline Suisse & $\mathrm{m}$ & $\mathrm{m}$ & $\mathrm{m}$ & $\mathrm{m}$ & $\mathrm{m}$ & $\mathrm{m}$ & $\mathrm{m}$ & $\mathrm{m}$ \\
\hline Turquie & $\mathrm{m}$ & $\mathrm{m}$ & $\mathrm{m}$ & 39078 & $\mathrm{~m}$ & $\mathrm{~m}$ & $\mathrm{~m}$ & 39078 \\
\hline États-Unis & 39500 & 41873 & 50158 & 54993 & 41124 & 43588 & 52188 & 57022 \\
\hline \multicolumn{9}{|l|}{ Economics } \\
\hline Comm. flamande (Belgique) & m & m & 41277 & 44930 & $\mathrm{~m}$ & $\mathrm{~m}$ & 54381 & 55825 \\
\hline Comm. française (Belgique) & $\mathrm{m}$ & $\mathrm{m}$ & $\mathrm{m}$ & 42609 & $\mathrm{~m}$ & $\mathrm{~m}$ & $\mathrm{~m}$ & 54039 \\
\hline Angleterre (RU) & 25347 & 32355 & 36173 & 37189 & 25347 & 32355 & 36173 & 37189 \\
\hline Ecosse (RU) & $\mathrm{m}$ & m & 31884 & 33710 & m & m & 31884 & 33710 \\
\hline of Argentine & $\mathrm{m}$ & $\mathrm{m}$ & $\mathrm{m}$ & $\mathrm{m}$ & $\mathrm{m}$ & $\mathrm{m}$ & $\mathrm{m}$ & $\mathrm{m}$ \\
\hline Brésil & $\mathrm{m}$ & $\mathrm{m}$ & $\mathrm{m}$ & 48065 & $\mathrm{~m}$ & $\mathrm{~m}$ & $\mathrm{~m}$ & 48807 \\
\hline Shine & $\mathrm{m}$ & $\mathrm{m}$ & $\mathrm{m}$ & $\mathrm{m}$ & $\mathrm{m}$ & $\mathrm{m}$ & $\mathrm{m}$ & $\mathrm{m}$ \\
\hline ฮू Costa Rica & $\mathrm{m}$ & m & m & 17408159 & $\mathrm{~m}$ & $\mathrm{~m}$ & m & 17408159 \\
\hline Inde & m & $\mathrm{m}$ & $\mathrm{m}$ & m & m & $\mathrm{m}$ & m & $\mathrm{m}$ \\
\hline Indonésie & m & m & m & $\mathrm{m}$ & $\mathrm{m}$ & m & m & $\mathrm{m}$ \\
\hline Fédération de Russie ${ }^{7}$ & m & $\mathrm{m}$ & m & m & $\mathrm{m}$ & $\mathrm{m}$ & m & m \\
\hline Arabie saoudite & m & $\mathrm{m}$ & $\mathrm{m}$ & $\mathrm{m}$ & $\mathrm{m}$ & $\mathrm{m}$ & $\mathrm{m}$ & $\mathrm{m}$ \\
\hline Afrique du Sud & $\mathrm{m}$ & $\mathrm{m}$ & $\mathrm{m}$ & $\mathrm{m}$ & $\mathrm{m}$ & $\mathrm{m}$ & $\mathrm{m}$ & $\mathrm{m}$ \\
\hline
\end{tabular}

Remarque : Les données de 2011 à 2016 (soit les colonnes 4 à 9,14 à 19, 24 à 29 et 34 à 39) peuvent être consultées en ligne. Les données peuvent être consultées sur http://stats.oecd.org/, Base de données de Regards sur l'éducation.

1. Avant 2015, inclut également des données sur le salaire effectif des chefs d'établissement, adjoints et assistants.

2. Inclut également des données sur le salaire effectif des enseignants des programmes de développement éducatif de la petite enfance pour l'enseignement préprimaire.

3. Inclut les données relatives à la majorité, c'est-à-dire uniquement les enseignants des jardins d'enfants pour l'éducation préprimaire.

4. Inclut également des données sur le salaire effectif des assistants d'enseignement préscolaire pour l'enseignement préprimaire pour la période 2011-15.

5. Salaire effectif moyen des enseignants, primes et allocations non comprises.

6. Inclut tous les enseignants, indépendamment de leur âge.

7. Salaire effectif moyen de tous les enseignants, indépendamment du niveau auquel ils enseignent.

Source : OCDE (2019). Consulter la section « Source » pour tout complément d'information et l'annexe 3 pour les notes (https://doi.org/10.1787/f8d7880d-en). Les symboles représentant les données manquantes et les abréviations figurent dans le Guide du lecteur.

StatLink Ainls https://doi.org/10.1787/888933980716 
Tableau X2.10. Proportion d'enseignants, selon leur niveau de qualification (2018)

Enseignants ayant les qualifications minimales ou des qualifications supérieures (et les plus courantes)

\begin{tabular}{|c|c|c|c|c|c|c|c|c|c|c|c|c|}
\hline & \multicolumn{3}{|c|}{ Préprimaire } & \multicolumn{3}{|c|}{ Primaire } & \multicolumn{3}{|c|}{ Premier cycle du secondaire } & \multicolumn{3}{|c|}{ Deuxième cycle du secondaire } \\
\hline & 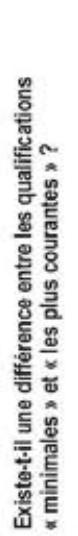 & 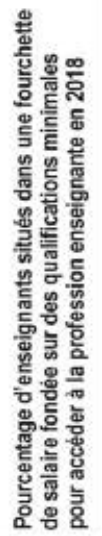 & 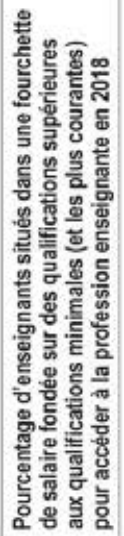 & 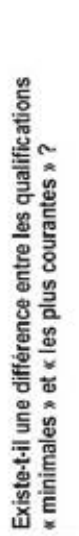 & 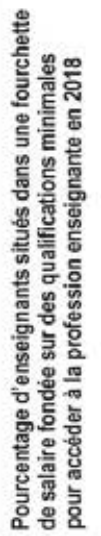 & 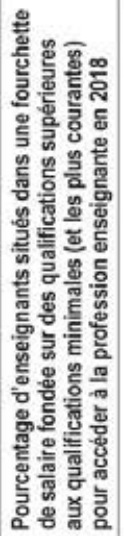 & 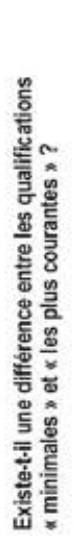 & 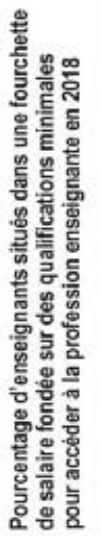 & 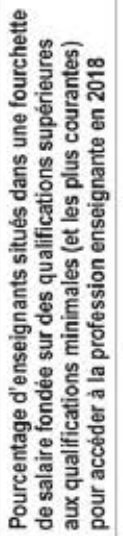 & 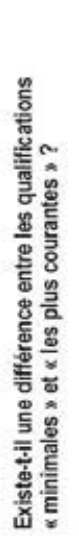 & 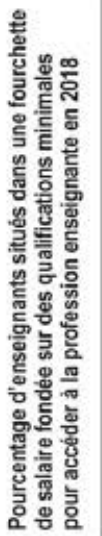 & 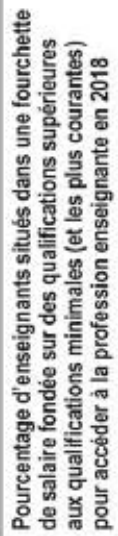 \\
\hline & (1) & (2) & (3) & (4) & (5) & (6) & (7) & (8) & (9) & (10) & (11) & (12) \\
\hline \multicolumn{13}{|l|}{ ш Pays } \\
\hline Uustralic & $\mathrm{m}$ & 100 & m & $\mathrm{m}$ & 100 & $\mathrm{~m}$ & $\mathrm{~m}$ & 100 & $\mathrm{~m}$ & $\mathrm{~m}$ & 100 & $\mathrm{~m}$ \\
\hline Autriche & $\mathrm{m}$ & $\mathrm{m}$ & $\mathrm{m}$ & No & 100 & a & № & 100 & a & No & 100 & a \\
\hline Canada & a & $\mathrm{m}$ & $\mathrm{m}$ & Yes & $\mathrm{m}$ & $\mathrm{m}$ & Yes & $\mathrm{m}$ & $\mathrm{m}$ & Yes & $\mathrm{m}$ & $\mathrm{m}$ \\
\hline Chili & No & $\mathrm{m}$ & a & No & $\mathrm{m}$ & $\mathrm{m}$ & No & $\mathrm{m}$ & $\mathrm{m}$ & No & $\mathrm{m}$ & $\mathrm{m}$ \\
\hline Colombie & $\mathrm{m}$ & $\mathrm{m}$ & $\mathrm{m}$ & $\mathrm{m}$ & $\mathrm{m}$ & $\mathrm{m}$ & $\mathrm{m}$ & 4 & 35 & $\mathrm{~m}$ & $x(8)$ & $\times(9)$ \\
\hline République tchéque & No & 92 & a & No & 100 & a & No & 100 & a & No & 100 & a \\
\hline Danemark & No & 100 & a & No & 100 & a & No & 100 & a & No & 100 & a \\
\hline Estonie & a & a & a & a & a & a & a & a & a & a & a & a \\
\hline Finlande & No & 90 & a & No & 99 & a & No & 96 & a & No & 91 & a \\
\hline France & No & 98 & a & No & 98 & a & № & 87 & a & No & 66 & a \\
\hline Allemagne & No & $\mathrm{m}$ & m & No & 100 & a & No & 100 & a & No & 100 & a \\
\hline Grèce & No & 100 & a & No & 100 & a & № & 100 & a & No & 100 & a \\
\hline Hongrie & No & $\mathrm{m}$ & $\mathrm{m}$ & No & $\mathrm{m}$ & m & No & $\mathrm{m}$ & $\mathrm{m}$ & No & $\mathrm{m}$ & $\mathrm{m}$ \\
\hline Islande & No & $\mathrm{m}$ & a & № & m & a & No & $\mathrm{m}$ & a & No & m & a \\
\hline Irlande & No & m & m & No & 20 & a & No & 18 & a & No & 18 & a \\
\hline Israēl & No & 70 & a & № & 60 & a & № & 49 & a & No & 47 & a \\
\hline Italie & No & 100 & a & No & 100 & a & № & 100 & a & No & 100 & a \\
\hline Japon & $\mathrm{m}$ & $\mathrm{m}$ & m & No & $\mathrm{m}$ & $\mathrm{m}$ & № & $\mathrm{m}$ & $\mathrm{m}$ & No & $m$ & $\mathrm{~m}$ \\
\hline Corée & Yes & $\mathrm{m}$ & $\mathrm{m}$ & No & $\mathrm{m}$ & a & Yes & $\mathrm{m}$ & $\mathrm{m}$ & Yes & $\mathrm{m}$ & $\mathrm{m}$ \\
\hline Lettonie & No & 100 & a & No & 100 & a & No & 100 & a & No & 100 & a \\
\hline Lituanie & No & $\mathrm{m}$ & a & No & $\mathrm{m}$ & a & № & $\mathrm{m}$ & a & No & $\mathrm{m}$ & a \\
\hline Luxembourg & No & 76 & a & No & 83 & a & No & 69 & a & No & 84 & a \\
\hline Mexique & No & $\mathrm{m}$ & $\mathrm{m}$ & No & $\mathrm{m}$ & m & № & $\mathrm{m}$ & $\mathrm{m}$ & No & $\mathrm{m}$ & $\mathrm{m}$ \\
\hline Pays-Bas & No & 100 & a & № & 100 & a & № & 100 & a & No & 100 & a \\
\hline Nouvelle-Zélande & Yes & m & $\mathrm{m}$ & Yes & $\mathrm{m}$ & $\mathrm{m}$ & Yes & a & $\mathrm{m}$ & Yes & $\mathrm{m}$ & $\mathrm{m}$ \\
\hline Norvège & No & $\mathrm{m}$ & $\mathrm{m}$ & Yes & 41 & 45 & Yes & 41 & 45 & Yes & 13 & 44 \\
\hline Pologne & Yes & $\mathrm{m}$ & $\mathrm{m}$ & Yes & $\mathrm{m}$ & $\mathrm{m}$ & Yes & $\mathrm{m}$ & $\mathrm{m}$ & Yes & $\mathrm{m}$ & a \\
\hline Portugal & No & 100 & a & No & 100 & a & No & 100 & a & No & 100 & a \\
\hline Rèpublique slovaque & No & $\mathrm{m}$ & a & No & $\mathrm{m}$ & a & No & $\mathrm{m}$ & a & No & $\mathrm{m}$ & a \\
\hline Slovénic & No & 100 & a & No & 100 & a & No & 100 & a & No & 100 & a \\
\hline Espagne & No & 100 & a & No & 100 & a & No & 100 & a & No & 100 & a \\
\hline Suède & No & 100 & a & No & 100 & a & № & 100 & a & No & 100 & a \\
\hline Suisse & No & $\mathrm{m}$ & m & No & $\mathrm{m}$ & $\mathrm{m}$ & No & $\mathrm{m}$ & $\mathrm{m}$ & No & $\mathrm{m}$ & $\mathrm{m}$ \\
\hline Turquie & No & $\mathrm{m}$ & a & No & $\mathrm{m}$ & a & No & $\mathrm{m}$ & a & No & $\mathrm{m}$ & a \\
\hline États-Unis & No & 49 & a & Yes & 44 & 46 & Yes & 40 & 48 & Yes & 35 & 50 \\
\hline \multicolumn{13}{|l|}{ Economies } \\
\hline Comm. flamande (Belgique) & No & 100 & a & No & 100 & a & No & 96 & a & Yes & 38 & 62 \\
\hline Comm. française (Belgique) & No & 99 & a & No & 96 & a & No & 86 & a & Yes & 8 & 81 \\
\hline Angleterre (RU) & Yes & 99 & a & Yes & 99 & a & Yes & 98 & a & Yes & 98 & a \\
\hline Ecosse (RU) & No & 100 & a & № & 100 & a & No & 100 & a & No & 100 & a \\
\hline \& Argentine & $\mathrm{m}$ & $\mathrm{m}$ & $\mathrm{m}$ & $\mathrm{m}$ & m & $\mathrm{m}$ & $\mathrm{m}$ & $\mathrm{m}$ & $\mathrm{m}$ & $\mathrm{m}$ & $\mathrm{m}$ & $\mathrm{m}$ \\
\hline Brésil & No & $\mathrm{m}$ & a & No & $\mathrm{m}$ & a & № & $\mathrm{m}$ & a & No & $\mathrm{m}$ & a \\
\hline Chine & $\mathrm{m}$ & $\mathrm{m}$ & $\mathrm{m}$ & $\mathrm{m}$ & $\mathrm{m}$ & $\mathrm{m}$ & $\mathrm{m}$ & m & $\mathrm{m}$ & $\mathrm{m}$ & m & $\mathrm{m}$ \\
\hline Costa Rica & Yes & 0 & 94 & Yes & 0 & 77 & Yes & 0 & 49 & Yes & 0 & 49 \\
\hline${ }^{a}$ Inde & $\mathrm{m}$ & $\mathrm{m}$ & $\mathrm{m}$ & $\mathrm{m}$ & $\mathrm{m}$ & $\mathrm{m}$ & $\mathrm{m}$ & m & $\mathrm{m}$ & m & m & $\mathrm{m}$ \\
\hline Indonèsie & $\mathrm{m}$ & $\mathrm{m}$ & $\mathrm{m}$ & $\mathrm{m}$ & $\mathrm{m}$ & m & m & $\mathrm{m}$ & $\mathrm{m}$ & $\mathrm{m}$ & $\mathrm{m}$ & $\mathrm{m}$ \\
\hline Fèderation de Russie & $\mathrm{m}$ & $\mathrm{m}$ & m & $\mathrm{m}$ & $\mathrm{m}$ & $\mathrm{m}$ & m & $\mathrm{m}$ & $\mathrm{m}$ & m & $\mathrm{m}$ & $\mathrm{m}$ \\
\hline Arabie saoudite & $\mathrm{m}$ & $\mathrm{m}$ & $\mathrm{m}$ & $\mathrm{m}$ & $\mathrm{m}$ & $\mathrm{m}$ & m & m & $\mathrm{m}$ & $\mathrm{m}$ & $\mathrm{m}$ & $\mathrm{m}$ \\
\hline Afrique du Sud & $\mathrm{m}$ & $\mathrm{m}$ & $\mathrm{m}$ & $\mathrm{m}$ & $\mathrm{m}$ & $\mathrm{m}$ & $\mathrm{m}$ & $\mathrm{m}$ & $\mathrm{m}$ & $\mathrm{m}$ & $\mathrm{m}$ & $\mathrm{m}$ \\
\hline
\end{tabular}

Remarque : Consulter les sections "Définitions » et "Méthodologie» pour de plus amples informations. Les données peuvent être consultées sur http://stats.oecd.org/, Base de données de Regards sur l'éducation.

Source : OCDE (2019). Consulter la section « Source » pour tout complément d'information et l'annexe 3 pour les notes (https://doi.org/10.1787/f8d7880d-en). Les symboles représentant les données manquantes et les abréviations figurent dans le Guide du lecteur. 


\section{Annexe 3. Sources, méthodes et notes techniques}

L'annexe 3 consacrée aux sources et méthodes est uniquement

disponible en anglais et en version électronique. Elle peut être consultée en ligne sur :

https://doi.org/10.1787/f8d7880d-en 



\section{Liste des participants à cette publication}

De nombreuses personnes ont participé à cette publication.

La liste qui suit indique les noms des représentants nationaux qui ont pris une part active aux réunions de I'INES et aux travaux préparatoires de cette édition de Regards sur l'éducation 2019 : Les indicateurs de I'OCDE.

L'OCDE tient à les remercier pour leur précieuse collaboration.

\section{Groupe de travail INES}

Mme Ana COPES (Argentine)

Mme Inés CRUZALEGUI (Argentine)

M. Juan Manuel CORVALAN ESPINA (Argentine)

M. Karl BAIGENT (Australie)

M. Edward HARVEY (Australie)

M. Stuart FAUNT (Australie)

M. Steve NERLICH (Australie)

Mme Rebecca SMEDLEY (Australie)

M. Andreas GRIMM (Autriche)

Mme Sabine MARTINSCHITZ (Autriche)

M. Mark NÉMET (Autriche)

M. Wolfgang PAULI (Autriche)

Mme Helga POSSET (Autriche)

Mme Natascha RIHA (Autriche)

M. Philippe DIEU (Belgique)

Mme Isabelle ERAUW (Belgique)

Mme Nathalie JAUNIAUX (Belgique)

M. Guy STOFFELEN (Belgique)

M. Raymond VAN DE SIJPE (Belgique)

Mme Ann VAN DRIESSCHE (Belgique)

M. Pieter VOS (Belgique)

M. Carlos Augusto DOS SANTOS ALMEIDA (Brésil)

Mme Juliana MARQUES DA SILVA (Brésil)

Mme Rachel RABELO (Brésil)

M. Patric BLOUIN (Canada)
M. Gregory BYLINSKI (Canada)

M. Richard FRANZ (Canada)

Mme Amanda HODGKINSON (Canada)

Mme Robin Liu HOPSON (Canada)

M. David McBRIDE (Canada)

Mme Klarka ZEMAN (Canada)

Mme Rosario DEL VILLAR (Chili)

M. Ignacio LARRAGUIBEL (Chili)

Mme Paola LEIVA (Chili)

Mme Francisca MÜLLER (Chili)

M. Fabián RAMÍREZ (Chili)

M. Juan SALAMANCA (Chili)

Mme Constanza VIELMA (Chili)

Mme Claudia DÍAZ (Colombie)

Mme Helga Milena HERNÁNDEZ (Colombie)

M. Javier Andrés RUBIO (Colombie)

Mme Azucena Paola VALLEJO (Colombie)

Mme Elsa Nelly VELASCO (Colombie)

M. Wilfer VALERO (Colombie)

Mme Erika VILLAMIL (Colombie)

Mme Carolina CHAVES (Costa Rica)

M. Andrés FERNÁNDEZ (Costa Rica)

M. Vladimír HULíK (République tchèque)

Mme Michaela MARŠíKOVÁ (République tchèque)

M. Lubomír MARTINEC (République tchèque) 
M. Jens ANDERSEN (Danemark)
M. Jens BJERRE (Danemark)

Mme Susanne Irvang NIELSEN (Danemark)

Mme Signe Tychsen PHILIP (Danemark)

Mme Tiina ANNUS (Estonie)

Mme Katrin REIN (Estonie)

Mme Kadi SERBAK (Estonie)

M. Arnaud DESURMONT (Eurostat, Commission européenne)

Mme Malgorzata STADNIK (Eurostat, Commission européenne)

M. Mika TUONONEN (Finlande)

Mme Kristiina VOLMARI (Finlande)

Mme Nathalie CARON (France)

Mme Marion DEFRESNE (France)

Mme Emmanuelle FERARD (France)

Mme Roselyne KERJOSSE (France)

Mme Isaure LEFEUVRE (France)

Mme Pascaline FEUILLET (France)

Mme Stéphanie LEMERLE (France)

Mme Valérie LIOGIER (France)

Mme Clotilde LIXI (France)

Mme Pascale POULET-COULIBANDO (France)

M. Robert RAKOCEVIC (France)

Mme Julie SOLARD (France)

M. Boubou TRAORE (France)

Mme Pia BRUGGER (Allemagne)

M. Andreas SCHULZ (Allemagne)

M. Hans-Werner FREITAG (Allemagne)

M. Benny SCHNEIDER (Allemagne)

M. Martin SCHULZE (Allemagne)

Mme Eveline VON GAESSLER (Allemagne)

Mme Susanne ZIEMEK (Allemagne)

M. Michael LENZEN (Allemagne)

Mme Maria FASSARI (Grèce)

M. Vasileios KARAVITIS (Grèce)

Mme Athena PLESSA-PAPADAKI (Grèce)

Mme Magda TRANTALLIDI (Grèce)

M. Georgios VAFIAS (Grèce)

M. László LIMBACHER (Hongrie)
M. István BUCSI SZABÓ (Hongrie)

Mme Dóra GÉCZI (Hongrie)

Mme Sára HATONY (Hongrie)

M. Tibor KÖNYVESI (Hongrie)

M. László LIMBACHER (Hongrie)

Mme Hedvig SZABÓ (Hongrie)

M. Gunnar J. ÁRNASON (Islande)

Mme Ásta M. URBANCIC (Islande)

Mme Swapna BHATTACHARYA (Inde)

M. Tayyab MOHAMMAD (Inde)

Mme Deirdre CULLEN (Irlande)

M. Pádraig MAC FHLANNCHADHA (Irlande)

Mme Violeta MOLONEY (Irlande)

Mme Sophie ARTSEV (Israël)

M. Yoav AZULAY (Israël)

Mme Orit BARANY (Israël)

M. Matan CHOCRON (Israël)

Mme Hana COHEN (Israël)

M. Yosef GIDANIAN (Israël)

Mme Merav KATZ (Israël)

Mme Osnat LANDAU (Israël)

M. Daniel LEVI-MAZLOUM (Israël)

Mme Silvia LIPLEWSKI (Israël)

Mme Iris Avigail MATATYAHU (Israël)

M. Dov NATAN (Israël)

M. Haim PORTNOY (Israël)

Mme Michal SALANSKI (Israël)

Mme Naama STEINBERG (Israël)

Mme Einat WEISS (Israël)

M. Roman ZILBERSHLAG (Israël)

M. Massimiliano CICCIA (Italie)

Mme Gemma DE SANCTIS (Italie)

Mme Daniela DI ASCENZO (Italie)

Mme Paola DI GIROLAMO (Italie)

Mme Maria Teresa MORANA (Italie)

Mme Claudia PIZZELLA (Italie)

M. Paolo TURCHETTI (Italie)

Mme Etsuko AOYAMA (Japon)

M. Takashi FURUDATE (Japon) 


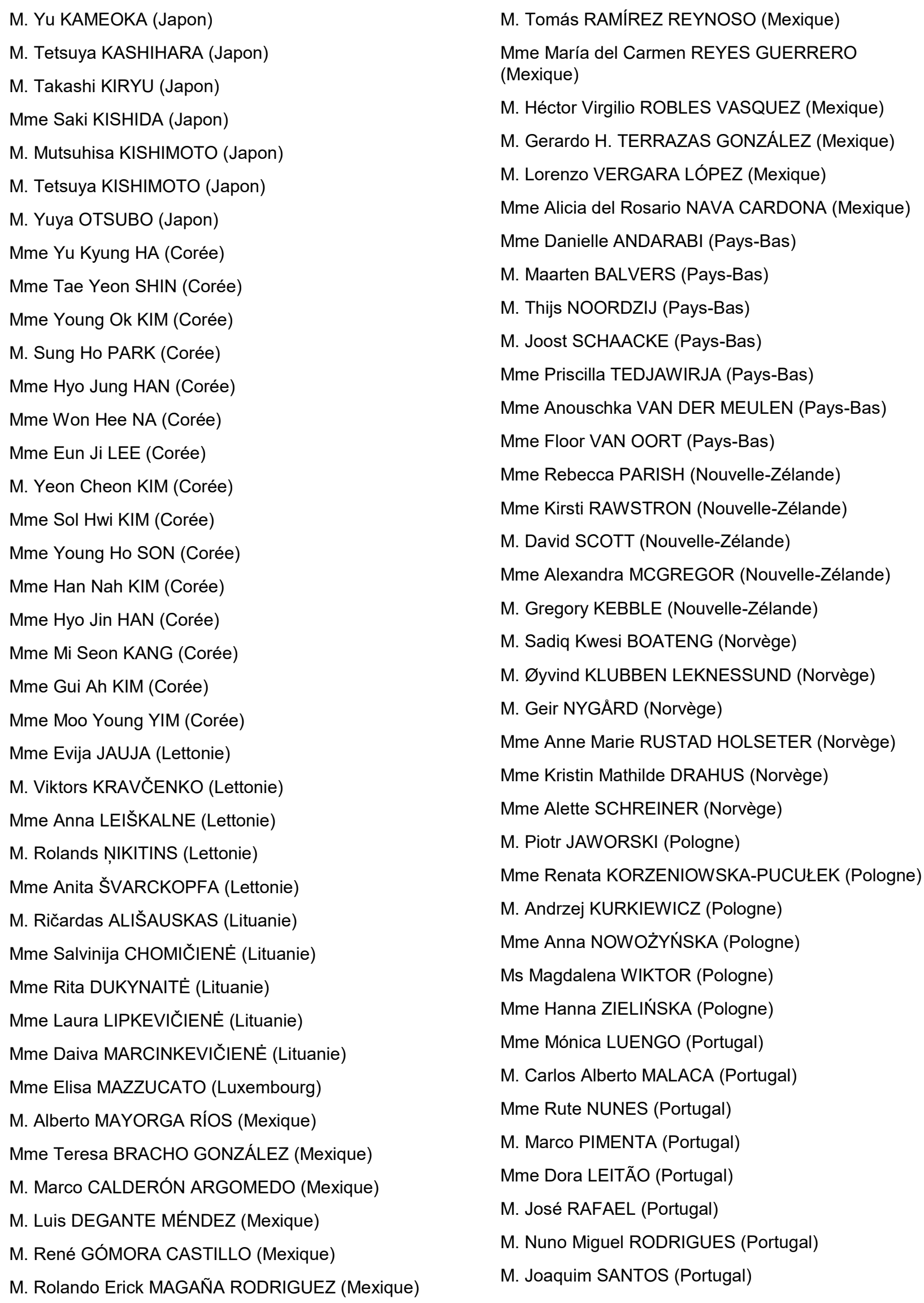

M. Tomás RAMÍREZ REYNOSO (Mexique) Mme María del Carmen REYES GUERRERO (Mexique)

M. Héctor Virgilio ROBLES VASQUEZ (Mexique)

M. Gerardo H. TERRAZAS GONZÁLEZ (Mexique)

M. Lorenzo VERGARA LÓPEZ (Mexique) Mme Alicia del Rosario NAVA CARDONA (Mexique) Mme Danielle ANDARABI (Pays-Bas)

M. Maarten BALVERS (Pays-Bas)

M. Thijs NOORDZIJ (Pays-Bas)

M. Joost SCHAACKE (Pays-Bas)

Mme Priscilla TEDJAWIRJA (Pays-Bas)

Mme Anouschka VAN DER MEULEN (Pays-Bas)

Mme Floor VAN OORT (Pays-Bas)

Mme Rebecca PARISH (Nouvelle-Zélande)

Mme Kirsti RAWSTRON (Nouvelle-Zélande)

M. David SCOTT (Nouvelle-Zélande)

Mme Alexandra MCGREGOR (Nouvelle-Zélande)

M. Gregory KEBBLE (Nouvelle-Zélande)

M. Sadiq Kwesi BOATENG (Norvège)

M. Øyvind KLUBBEN LEKNESSUND (Norvège)

M. Geir NYGÅRD (Norvège)

Mme Anne Marie RUSTAD HOLSETER (Norvège)

Mme Kristin Mathilde DRAHUS (Norvège)

Mme Alette SCHREINER (Norvège)

M. Piotr JAWORSKI (Pologne)

Mme Renata KORZENIOWSKA-PUCUŁEK (Pologne)

M. Andrzej KURKIEWICZ (Pologne)

Mme Anna NOWOŻYŃSKA (Pologne)

Ms Magdalena WIKTOR (Pologne)

Mme Hanna ZIELIŃSKA (Pologne)

Mme Mónica LUENGO (Portugal)

M. Carlos Alberto MALACA (Portugal)

Mme Rute NUNES (Portugal)

M. Marco PIMENTA (Portugal)

Mme Dora LEITÃO (Portugal)

M. José RAFAEL (Portugal)

M. Nuno Miguel RODRIGUES (Portugal)

M. Joaquim SANTOS (Portugal) 
M. Amaro VIEIRA (Portugal)

M. Mark AGRANOVICH (Fédération de Russie)

Mme Julia ERMACHKOVA (Fédération de Russie)

Mme Irina SELIVERSTOVA (Fédération de Russie)

M. Abdulrahman S. AL-ANGARI (Arabie saoudite)

M. Saad ALBAIZ (Arabie saoudite)

M. Michal REVAK (République slovaque)

Mme Eva HLADIKOVA (République slovaque)

Mme Danica OMASTOVA (République slovaque)

M. Roman SAJBIDOR (République slovaque)

Mme Gabriela SLODICKOVA (République slovaque)

Mme Nina ČEŠEK VOZEL (Slovénie)

Mme Andreja KOZMELJ (Slovénie)

Mme Barbara KRESAL STERNIŠA (Slovénie)

Mme Nada POŽAR MATIJAŠIČ (Slovénie)

Mme Duša MARJETIČ (Slovénie)

Mme Karmen SVETLIK (Slovénie)

Mme Tatjana ŠKRBEC (Slovénie)

Mme Jadranka TUŠ (Slovénie)

Mme Tanja DOMIJAN (Slovénie)

Mme Rirhandzu BALOYI (Afrique du Sud)

Mme Mamphokhu KHULUVHE (Afrique du Sud)

Mme Letho MAPASEKA (Afrique du Sud)

Mme Bheki MPANZA (Afrique du Sud)

Mme Hersheela NARSEE (Afrique du Sud)

Mme Matome SEKGOTA (Afrique du Sud)

Mme Nthabiseng TEMA (Afrique du Sud)

M. Miguel Ángel ÁLVAREZ ESPINOSA (Espagne)

Mme Elena BANDA LÓPEZ (Espagne)
M. José María GALLEGo ALONSO-COLMENARES (Espagne)

M. Jesús IBAÑEZ MILLA (Espagne)

M. Ricardo MARTÍNEZ ZAMORANO (Espagne)

Mme Ana REVILLA TRUJILLO (Espagne)

Mme Carmen TOVAR SÁNCHEZ (Espagne)

M. Jaime VAQUERO JIMÉNEZ (Espagne)

Mme Isabel YUN MORENO (Espagne)

Mme Anna ERIKSSON (Suède)

Mme Maria GÖTHERSTRÖM (Suède)

Mme Marie KAHLROTH (Suède)

M. Alexander GERLINGS (Suisse)

Mme Hasnie HANNO WEBER (Suisse)

Mme Katrin HOLENSTEIN (Suisse)

Mme Nicole SCHÖBI (Suisse)

M. Emanuel VON ERLACH (Suisse)

Mme Hatice Nihan ERDAL (Turquie)

Mme Fatma Filiz ÇiçEK (Turquie)

Mme Gülçin ÖZ (Turquie)

M. Turgay ALTUN (Turquie)

M. Friedrich HUEBLER (UNESCO)

M. Said Ould Ahmedou VOFFAL (UNESCO)

Mme Aliki PAREAS (Royaume-Uni)

Mme Melissa DILIBERTI (États-Unis)

Mme Rachel DINKES (États-Unis)

Mme Jana KEMP (États-Unis)

Mme Lauren MUSU (États-Unis)

Mme Ashley ROBERTS (États-Unis)

M. Thomas SNYDER (Président du Groupe de travail INES, États-Unis)

\section{Réseau chargé d'élaborer des données relatives aux retombées de} l'enseignement sur l'économie, le marché du travail et la société (LSO)

\author{
M. Karl BAIGENT (Australie) \\ M. Stuart FAUNT (Australie) \\ M. Steve NERLICH (Australie) \\ Mme Rebecca SMEDLEY (Australie) \\ M. Mark NÉMET (Autriche) \\ Mme Isabelle ERAUW (Belgique)
}

Mme Geneviève HINDRYCKX (Belgique)

M. Kasper OSSENBLOK (Belgique)

Mme Naomi WAUTERICKX (Belgique)

Mme Christyne CARVALHO DA SILVA (Brésil)

Mme Camila NEVES SOUTO (Brésil)

Mme Rachel PEREIRA RABELO (Brésil) 
M. Patric BLOUIN (Canada)

Mme Dallas MORROW (Canada)

Mme Annik FOREMAN (Canada)

M. Marco SERAFINI (CEDEFOP)

M. Daniel SCHEUREGGER (CEDEFOP)

M. Ignacio LARRAGUIBEL (Chili)

Mme Paola LEIVA (Chili)

M. Fabián RAMÍREZ (Chili)

M. Roberto SCHURCH (Chili)

Mme Constanza VIELMA (Chili)

M. Vladimír HULÍK (République tchèque)

Mme Michaela MARŠíKOVÁ (République tchèque)

Mme Carolina CHAVES (Costa Rica)

M. Andrés FERNÁNDEZ (Costa Rica)

M. Jens ANDERSEN (Danemark)

Mme Tiina ANNUS (Estonie)

Mme Kristel BANKIER (Estonie)

Mme Ingrid JAGGO (Estonie)

M. Priit LAANOJA (Estonie)

Mme Marianne LEPPIK (Estonie)

M. Marti LILLEMÄGI (Estonie)

Mme Kaire RAASIK (Estonie)

Mme Aune VALK (Estonie)

M. Jens FISHER-KOTTENSTEDE (Commission européenne)

M. Mantas SEKMOKAS (Commission européenne)

Mme Elodie CAYOTTE (Eurostat, Commission européenne)

Mme Sabine GAGEL (Eurostat, Commission européenne)

Mme Irja BLOMQVIST (Finlande)

M. Mika WITTING (Finlande)

Mme Nathalie CARON (France)

Mme Pascale POULET-COULIBANDO (France)

M. Hans-Werner FREITAG (Allemagne)

Mme Sylvia SCHILL (Allemagne)

Mme Susanne ZIEMEK (Allemagne)

Mme Dimitra FARMAKIOTOU (Grèce)

Mme Maria FASSARI (Grèce)

Mme Eudokia KARDAMITSI (Grèce)
M. Georgios MALLIOS (Grèce)

M. Stylianos MERKOURIS (Grèce)

M. Konstantinos PAPACHRISTOS (Grèce)

Mme Athena PLESSA-PAPADAKI (Grèce)

Mme Magda TRANTALLIDI (Grèce)

M. László LIMBACHER (Hongrie)

M. István BUCSI SZABÓ (Hongrie)

Mme Rita JAKUBOVICS (Hongrie)

Mme Ásta M. URBANCIC (Islande)

Mme Sarah CRILLY (Irlande)

Mme Deirdre CULLEN (Irlande)

Mme Helen MAXWELL (Irlande)

Mme Violeta MOLONEY (Irlande)

Mme Tracey SHANKS (Irlande)

Mme Sophie ARTSEV (Israël)

Mme Hana COHEN (Israël)

Mme Lior DUPAZ (Israël)

M. Mark FELDMAN (Israël)

M. Yonatan HAYUN (Israël)

M. Haim PORTNOY (Israël)

Mme Hagit SARID (Israël)

Mme Raffaella CASCIOLI (Italie)

M. Gaetano PROTO (Italie)

Mme Liana VERZICCO (Italie)

Mme Yu Kyung HA (Corée)

Mme Tae Yeon SHIN (Corée)

Mme Young Ok KIM (Corée)

Mme Hea Jun YOON (Corée)

Mme Sook Weon MIN (Corée)

M. Sung Ho PARK (Corée)

Mme Hye Ja KIM (Corée)

M. Yeon Cheon KIM (Corée)

Mme Ruta BEINĀRE (Lettonie)

Mme Sandra CERIN̦A (Lettonie)

M. Viktors KRAVČENKO (Lettonie)

Mme Zaiga PRIEDE (Lettonie)

M. Ričardas ALIŠAUSKAS (Lituanie)

M. Eduardas DAUJOTIS (Lituanie)

Mme Regina DEVEIKYTĖ (Lituanie) 
M. Gintautas JAKŠTAS (Lituanie)

Mme Julija UMBRASAITÉ (Lituanie)

Mme Elisa MAZZUCATO (Luxembourg)

M. Héctor Virgilio ROBLES VÁSQUEZ (Mexique)

M. Gerardo H. TERRAZAS GONZÁLEZ (Mexique)

M. Ted REININGA (Pays-Bas)

Mme Francis VAN DER MOOREN (Pays-Bas)

Mme Antoinette VAN WANROIJ (Pays-Bas)

Mme Rebecca PARISH (Nouvelle-Zélande)

Mme Kirsti RAWSTRON (Nouvelle-Zélande)

M. David SCOTT (Nouvelle-Zélande)

Mme Alexandra MCGREGOR (Nouvelle-Zélande)

M. Gregory KEBBLE (Nouvelle-Zélande)

Mme Hild Marte BJøRNSEN (Norvège)

M. Sadiq Kwesi BOATENG (Norvège)

M. Piotr JAWORSKI (Pologne)

M. Jacek MAŚLANKOWSKI (Pologne)

Mme Anna NOWOŻYŃSKA (Pologne)

Mme Hanna ZIELIŃSKA (Pologne)

M. Carlos Alberto MALACA (Portugal)

M. Joaquim SANTOS (Portugal)

M. Mark AGRANOVICH (Fédération de Russie)
Mme Elena SABELNIKOVA (Fédération de Russie)

M. Frantisek BLANAR (République slovaque)

Mme Nina ČEŠEK VOZEL (Slovénie)

M. Matej DIVJAK (Slovénie)

Mme Melita SELJAK Tina OSVALD ZALETELJ

(Slovénie)

M. Marko TOMAŽıČ (Slovénie)

Mme Barbara KRESAL STERNIŠA (Slovénie)

M. Miguel Ángel ÁLVAREZ ESPINOSA (Espagne)

M. Jesús IBAÑEZ MILLA (Espagne)

M. Raúl SAN SEGUNDO (Espagne)

Mme Ann-Charlott LARSSON (Suède)

M. Mattias FRITZ (Suède)

Mme Anna BENGTSSON (Suède)

Mme Wayra CABALLERO LIARDET (Suisse)

M. Emanuel VON ERLACH (Président du réseau LSO, Suisse)

M. Davut OLGUN (Turquie)

M. Cengiz SARAÇOĞLU (Turquie)

M. Thomas LOCKHART (Royaume-Uni)

Mme Rachel DINKES (États-Unis)

Mme Ashley ROBERTS (États-Unis)

M. Thomas SNYDER (États-Unis)

\section{Réseau chargé de collecter et de diffuser des informations descriptives sur les} structures, les politiques et les pratiques en matière d'éducation à l'échelon des systèmes (NESLI)

M. Karl BAIGENT (Australie)

M. Stuart FAUNT (Australie)

M. Steve NERLICH (Australie)

Mme Antonella SALPIETRO (Australie)

Mme Rebecca SMEDLEY (Australie)

M. Andreas GRIMM (Autriche)

M. Stefan POLZER (Autriche)

M. Philippe DIEU (Belgique)

Mme Nathalie JAUNIAUX (Belgique)

Mme Bernadette SCHREUER (Belgique)

M. Raymond VAN DE SIJPE (Belgique)

Mme Ann VAN DRIESSCHE (Belgique)
Mme Christyne CARVALHO DA SILVA (Brésil)

Mme Camila NEVES SOUTO (Brésil)

Mme Rachel PEREIRA RABELO (Brésil)

Mme Jennifer CHEW LEUNG (Canada)

M. Brett WILMER (Canada)

Mme Klarka ZEMAN (Canada)

M. Ignacio LARRAGUIBEL (Chili)

Mme Paola LEIVA (Chili)

M. Fabián RAMÍREZ (Chili)

M. Roberto SCHURCH (Chili)

Mme Constanza VIELMA (Chili)

M. Vladimír HULÍK (République tchèque) 
Mme Michaela MARŠíKOVÁ (République tchèque)

M. Lubomír MARTINEC (République tchèque)

M. Jorgen Balling RASMUSSEN (Danemark)

Mme Tiina ANNUS (Estonie)

Mme Hanna KANEP (Estonie)

Mme Kristel VAHER (Estonie)

Mme Hille VARES (Estonie)

Mme Lene MEJER (Commission européenne)

Mme Nathalie BAIDAK (Eurydice)

Mme Arlette DELHAXHE (Eurydice)

Mme Petra PACKALEN (Finlande)

Mme Kristiina VOLMARI (Finlande)

Mme Emmanuelle FERARD (France)

M. Louis MEURIC (France)

M. Robert RAKOCEVIC (France)

M. Thomas ECKHARDT (Allemagne)

M. Benny SCHNEIDER (Allemagne)

M. Marco MUNDELIUS (Allemagne)

Mme Dimitra FARMAKIOTOU (Grèce)

Mme Maria FASSARI (Grèce)

Mme Vassilliki MAKRI (Grèce)

M. Panagiotis PASSAS (Grèce)

Mme Sára HATONY (Hongrie)

M. István BUCSI SZABÓ (Hongrie)

M. Gunnar J. ÁRNASON (Islande)

Mme Asta URBANCIC (Islande)

Mme Deirdre CULLEN (Irlande)

M. Pádraig MAC FHLANNCHADHA (Irlande)

Mme Violeta MOLONEY (Irlande)

M. Yoav AZULAY (Israël)

M. Pinhas KLEIN (Israël)

M. Aviel KRENTZLER (Israël)

M. Daniel LEVI-MAZLOUM (Israël)

M. David MAAGAN (Israël)

M. Rakan MORAD SHANNAN (Israël)

M. Dov NATAN (Israël)

Mme Gianna BARBIERI (Italie)

Mme Lucia DE FABRIZIO (Italie)

Mme Annarita Lina MARZULLO (Italie)
M. Takashi FURUDATE (Japon)

M. Yu KAMEOKA (Japon)

Mme Saki KISHIDA (Japon)

Mme Yu Kyung HA (Corée)

Mme Tae Yeon SHIN (Corée)

Mme Young Ok KIM (Corée)

M. Sung Ho PARK (Corée)

Mme Hyo Jung HAN (Corée)

Mme Han Nah KIM (Corée)

Mme Modra JANSONE (Lettonie)

M. Viktors KRAVČENKO (Lettonie)

M. Ričardas ALIŠAUSKAS (Lituanie)

M. Evaldas BAKONIS (Lituanie)

M. Eduardas DAUJOTIS (Lituanie)

Mme Ingrida ŠIAUČIULIENĖ (Lituanie)

Mme Rima ZABLACKE் (Lituanie)

Mme Charlotte MAHON (Luxembourg)

Mme Elisa MAZZUCATO (Luxembourg)

M. Alberto MAYORGA RÍOS (Mexique)

M. Marco CALDERÓN ARGOMEDO (Mexique)

M. Juan Martín SOCA DE IÑIGO (Mexique)

M. Thijs NOORDZIJ (Pays-Bas)

M. Hans RUESINK (Président du réseau NESLI, Pays-Bas)

M. Jerry STRATEN (Pays-Bas)

M. Dick VAN VLIET (Pays-Bas)

Mme Rebecca PARISH (Nouvelle-Zélande)

Mme Kirsti RAWSTRON (Nouvelle-Zélande)

M. David SCOTT (Nouvelle-Zélande)

Mme Alexandra MCGREGOR (Nouvelle-Zélande)

M. Gregory KEBBLE (Nouvelle-Zélande)

M. Øyvind KLUBBEN LEKNESSUND (Norvège)

Mme Barbara ANTOSIEWICZ (Pologne)

Mme Renata KARNAS (Pologne)

Mme Renata KORZENIOWSKA-PUCUŁEK (Pologne)

Mme Anna NOWOŻYŃSKA (Pologne)

M. Joaquim SANTOS (Portugal)

M. Mark AGRANOVICH (Fédération de Russie)

Mme Julia ERMACHKOVA (Fédération de Russie) 
Mme Eva HLADIKOVA (République slovaque)

Mme Gabriela SLODICKOVA (République slovaque)

Mme Barbara KRESAL-STERNIŠA (Slovénie)

Mme Duša MARJETIČ (Slovénie)

Mme Karmen SVETLIK (Slovénie)

Mme Tanja TAŠTANOSKA (Slovénie)

Mme Inmaculada CABEZALÍ MONTERO (Espagne)

M. Juan Carlos GIRÓN ORTEGA (Espagne)

M. Jaime VAQUERO JIMÉNEZ (Espagne)

M. David VARAS DEL PESO (Espagne)

\section{Autres participants à cette publication}

BRANTRA SPRL (traduction française)

Mme Sally Caroline HINCHCLIFFE (édition)
M. Christian LOVERING (Suède)

M. Tomas GUSTAVSSON (Suède)

Mme Katrin MÜHLEMANN (Suisse)

M. Osman Yıldırım UĞUR (Turquie)

Mme Fatma Filiz ÇiçEK (Turquie)

Mme Gülçin ÖZ (Turquie)

Mme Sarah CROSS (Royaume-Uni)

Mme Jana KEMP (États-Unis)

Mme Lauren MUSU (États-Unis)

Mme Fung Kwan TAM (mise en page) 


\section{Les indicateurs de l'éducation à la loupe}

Les indicateurs de l'éducation à la loupe est une série de notes de synthèse mettant en lumière des indicateurs spécifiques de la publication de l'OCDE Regards sur l'éducation qui présentent un intérêt particulier pour les décideurs et les professionnels du secteur de l'éducation. Ils présentent une analyse détaillée de questions d'actualité concernant les niveaux d'enseignement préprimaire, primaire, secondaire et supérieur, et des résultats des adultes dans une perspective internationale.

Combinant un ensemble attrayant de textes, tableaux et graphiques, ils décrivent le contexte international des questions les plus pressantes en matière de politiques et pratiques dans le domaine de l'éducation.

La série complète peut être consultée sur :

En anglais : http://dx.doi.org/10.1787/22267077

En français : http://dx.doi.org/10.1787/22267093

" How can the comparability of early childhood education and care statistics be improved? ", Les indicateurs de l'éducation à la loupe, $n^{\circ} 70$ (2019) https://doi.org/10.1787/9ac255e5-en

"Influence du milieu socio-économique sur l'accès à l'enseignement tertiaire », Les indicateurs de l'éducation à la loupe, $\mathrm{n}^{\circ} 69$ (2019) https://doi.org/10.1787/9ac255e5-en

«Caractéristiques de la filière professionnelle du deuxième cycle de l'enseignement secondaire », Les indicateurs de l'éducation à la loupe, $n^{\circ} 68$ (2019)

https://doi.org/10.1787/a1a7e2f1-en

"L'importance de l'Objectif de développement durable relatif à l'éducation (ODD 4) pour les pays de l'OCDE ", Les indicateurs de l'éducation à la loupe, $n^{\circ} 67$ (2019) https://doi.org/10.1787/cdc2482b-en

"Quel serait le coût induit par une réduction de la taille des classes d'un élève ? ", Les indicateurs de l'éducation à la loupe, $\mathrm{n}^{\circ} 66$ (2019) https://doi.org/10.1787/d773f268-en

« Niveau de formation et résultats sur le marché du travail : Comment se situent les adultes nés à l'étranger par rapport à leurs pairs nés dans le pays ? ", Les indicateurs de l'éducation à la loupe, $n^{\circ} 65$ (2018) https://doi.org/10.1787/b952a74a-fr

"Quel est le degré de décentralisation des systèmes d'éducation et son incidence pour les établissements d'enseignement ? ", Les indicateurs de l'éducation à la loupe, $n^{\circ} 64$ (2018) https://doi.org/10.1787/b3b6fcc4-fr

"Quelle est l'incidence des régimes d'admission sur les taux de scolarisation dans l'enseignement tertiaire public ? ", Les indicateurs de l'éducation à la loupe, $n^{\circ} 63$ (2018)

https://doi.org/10.1787/ae2cd9b3-fr

" Avantage salarial des actifs occupés diplômés de l'enseignement tertiaire : Quelle évolution entre les générations ? ", Les indicateurs de l'éducation à la loupe, ${ }^{\circ} 62$ (2018) https://doi.org/10.1787/48ce83ae-fr

"Diplômés de l'enseignement tertiaire : Quelles évolutions ? ", Les indicateurs de l'éducation à la loupe, $n^{\circ} 61(2018)$

https://doi.org/10.1787/1a4e9f01-fr 
"Quels liens entre dépression et éducation ? ", Les indicateurs de l'éducation à la loupe, $n^{\circ} 60$ (2018) https://doi.org/10.1787/4cfd84c9-fr

" Accès aux services d'éducation et d'accueil des jeunes enfants : Quel impact sur la participation des femmes au marché du travail ? », Les indicateurs de l'éducation à la loupe, $n^{\circ} 59$ (2018) https://doi.org/10.1787/197fe9c5-fr

"Enseignants du primaire et du premier cycle du secondaire : Quelles similitudes et différences ? ", Les indicateurs de l'éducation à la loupe, $n^{\circ} 58$ (2018)

https://doi.org/10.1787/c65867d6-fr

« La demande du marché du travail suit-elle le rythme de l'élévation du niveau de formation de la population ? ", Les indicateurs de l'éducation à la loupe, $n^{\circ} 57$ (2017)

https://doi.org/10.1787/b7cb619b-fr

"Qui assume réellement les coûts de l'éducation ? », Les indicateurs de l'éducation à la loupe, $\mathrm{n}^{\circ} 56$ (2017) https://doi.org/10.1787/67d4d9e0-fr

"Quelles disparités entre les sexes et quels débouchés professionnels dans les différents domaines d'études ? ", Les indicateurs de l'éducation à la loupe, $n^{\circ} 55$ (2017)

https://doi.org/10.1787/db2f011c-fr

"Transition des études au marché du travail : Une étape aussi difficile pour tous les groupes d'âge ? ", Les indicateurs de l'éducation à la loupe, $n^{\circ} 54$ (2017)

https://doi.org/10.1787/e30b1bf2-fr

« Salaire des enseignants : Évolution et position par rapport aux revenus du travail d'autres actifs occupés diplômés de l'enseignement tertiaire ", Les indicateurs de l'éducation à la loupe, $n^{\circ} 53$ (2017)

https://doi.org/10.1787/077eb4d0-fr

«Éducation de la petite enfance : Qui en assume les coûts et quelle incidence sur les taux de scolarisation ? ", Les indicateurs de l'éducation à la loupe, $n^{\circ} 52$ (2017)

https://doi.org/10.1787/1d0c1a0e-fr

" Réforme des frais de scolarité et mobilité internationale ", Les indicateurs de l'éducation à la loupe, $\mathrm{n}^{\circ} 51$ (2017)

https://doi.org/10.1787/8351e555-fr

"Niveau de formation et investissement dans l'éducation dans les pays ibéro-américains », Les indicateurs de l'éducation à la loupe, $\mathrm{n}^{\circ} \mathbf{5 0}$ (2017)

https://doi.org/10.1787/4a6e0d1f-fr

«Les déséquilibres entre les sexes dans la profession enseignante », Les indicateurs de l'éducation à la loupe, $\mathrm{n}^{\circ} 49$ (2017)

https://doi.org/10.1787/026cb10b-fr

"Niveau de formation : Aperçu de 50 ans d'évolution et d'expansion de l'éducation », Les indicateurs de l'éducation à la loupe, $\mathrm{n}^{\circ} \mathbf{4 8}$ (2017)

https://doi.org/10.1787/354a08db-fr

"Santé et satisfaction à l'égard de la vie : Quels liens avec l'éducation ? », Les indicateurs de l'éducation à la loupe, $\mathrm{n}^{\circ} 47$ (2016)

https://doi.org/10.1787/073b3012-fr

«Quels facteurs influent sur les dépenses d'éducation ? ", Les indicateurs de l'éducation à la loupe, n 46 (2016)

https://doi.org/10.1787/d1f76bb9-fr

"Domaines d'études et marché du travail : Où en sont les hommes et les femmes ? ", Les indicateurs de l'éducation à la loupe, $\mathrm{n}^{\circ} 45$ (2016)

https://doi.org/10.1787/5jlpgh1gb824-fr

" Diplômés de l'enseignement tertiaires : Niveau de formation et débouchés professionnels », Les

indicateurs de l'éducation à la loupe, $\mathrm{n}^{\circ} 44$ (2016)

https://doi.org/10.1787/4ebdf69f-fr 
"Niveau de formation et débouchés professionnels : Quelles variations infranationales ? ", Les indicateurs de l'éducation à la loupe, $\mathrm{n}^{\circ} \mathbf{4 3}$ (2016)

https://doi.org/10.1787/22e126f3-fr

"Quels sont les bénéfices de l'éducation de la petite enfance ? ", Les indicateurs de l'éducation à la loupe, $\mathrm{n}^{\circ} 42$ (2016)

https://doi.org/10.1787/67bb28ec-fr

«Combien les étudiants paient-ils et de quelles aides publiques bénéficient-ils ? », Les indicateurs de l'éducation à la loupe, $\mathrm{n}^{\circ} 41$ (2016)

https://doi.org/10.1787/5j|z9zk4rnbx-fr

"Compétences en TIC et en résolution de problèmes : Où en sont les enseignants ? ", Les indicateurs de l'éducation à la loupe, $\mathrm{n}^{\circ} \mathbf{4 0}$ (2016)

https://doi.org/10.1787/5jm0pkjr7qq8-fr

"L'internationalisation des études de doctorat et de master ", Les indicateurs de l'éducation à la loupe, $\mathrm{n}^{\circ} 39$ (2016) https://doi.org/10.1787/5jm2f6whlm0s-fr

"Comment s'organise le temps d'apprentissage dans l'enseignement primaire et secondaire ? », Les indicateurs de l'éducation à la loupe, $n^{\circ} 38$ (2015)

https://doi.org/10.1787/5jm3tqh48ljc-fr

« Diplômés de licence et de master : qui sont-ils ? ", Les indicateurs de l'éducation à la loupe, ${ }^{\circ} 37$ (2016) https://doi.org/10.1787/5jm5hlOr7cf5-fr

"Quels sont les avantages de la classification CITE 2011 pour les indicateurs de l'éducation ? », Les indicateurs de l'éducation à la loupe, $\mathrm{n}^{\circ} 36$ (2015)

https://doi.org/10.1787/5jraf114gis7-fr

"Quelle incidence les différences de milieu social et culturel ont-elles sur l'accès à l'enseignement supérieur et la réussite des études ? ", Les indicateurs de l'éducation à la loupe, n 35 (2015) https://doi.org/10.1787/5jrs70389bxn-fr

"Quels avantages offre aujourd'hui un diplôme du deuxième cycle du secondaire ? ", Les indicateurs de l'éducation à la loupe, $\mathrm{n}^{\circ} 34$ (2015)

https://doi.org/10.1787/5jits3mv6llp-fr

"Zoom sur l'enseignement et la formation professionnels (EFP) ", Les indicateurs de l'éducation à la loupe, $\mathrm{n}^{\circ} 33$ (2015) https://doi.org/10.1787/5jirtk43b246-fr

"Éducation et compétences : Vers une distribution plus inclusive ? ", Les indicateurs de l'éducation à la loupe, $\mathrm{n}^{\circ} 32$ (2015)

https://doi.org/10.1787/5js082cj7jmr-fr

"Vivier mondial de talents : Quelles évolutions $(2013,2030)$ ? », Les indicateurs de l'éducation à la loupe, $n^{\circ} 31$ (2015)

https://doi.org/10.1787/5js008vjzwwd-fr

"Éducation et emploi : Quelles différences entre les sexes ? ", Les indicateurs de l'éducation à la loupe, $\mathrm{n}^{\circ} 30$ (2015)

https://doi.org/10.1787/5js4pkjmfnnp-fr

"Combien de temps les enseignants consacrent-ils aux tâches d'enseignement et autres ? ", Les indicateurs de l'éducation à la loupe, $\mathrm{n}^{\circ} 29$ (2015)

https://doi.org/10.1787/5js008vmqphj-fr

"Les jeunes atteignent-ils un niveau de formation supérieur à celui de leurs parents ? ", Les indicateurs de l'éducation à la loupe, $\mathrm{n}^{\circ} 28$ (2015)

https://doi.org/10.1787/5js7kk4dn7wg-fr

"Éducation et emploi : Quel avantage salarial le niveau de formation procure-t-il ? ", Les indicateurs de l'éducation à la loupe, $n^{\circ} 27$ (2014)

https://doi.org/10.1787/5jxrcljnrzr2-fr 
«L'envie d'apprendre vient en apprenant : Participation des adultes à la formation tout au long de la vie », Les indicateurs de l'éducation à la loupe, $n^{\circ} 26$ (2014)

https://doi.org/10.1787/5jxss/w21qkd-fr

" Titulaires de doctorats : Qui sont-ils et que deviennent-ils après l'obtention de leur diplôme ? », Les indicateurs de l'éducation à la loupe, $\mathrm{n}^{\circ} 25$ (2014)

https://doi.org/10.1787/5jxt470gm6g4-fr

"L'éducation : Un secteur innovant ? ", Les indicateurs de l'éducation à la loupe, n 24 (2014) https://doi.org/10.1787/5jz10nzggxkh-fr

" À quel âge les étudiants obtiennent-ils leur premier diplôme universitaire ? », Les indicateurs de l'éducation à la loupe, $\mathrm{n}^{\circ} 23$ (2014)

https://doi.org/10.1787/5jz3wks7nq26-fr

"Combien de temps les élèves du primaire et du premier cycle du secondaire passent-ils en classe ? ",

Les indicateurs de l'éducation à la loupe, $\mathrm{n}^{\circ} 22$ (2014)

https://doi.org/10.1787/5jz44fngi6vk-fr

"Le salaire des enseignants : Bien plus qu'une simple affaire de chiffres », Les indicateurs de l'éducation à la loupe, $\mathrm{n}^{\circ} 21$ (2014)

https://doi.org/10.1787/5jz6wn8w720q-fr

"Quel âge ont les enseignants ? ", Les indicateurs de l'éducation à la loupe, n 20 (2014)

https://doi.org/10.1787/5jz72pjk5af8-fr

"Que choisissent d'étudier les nouveaux inscrits de l'enseignement tertiaire ? », Les indicateurs de

l'éducation à la loupe, $\mathrm{n}^{\circ} 19$ (2014)

https://doi.org/10.1787/5jz8ssmnn1wc-fr

"Quel est l'impact de la crise économique sur les dépenses publiques d'éducation ? ", Les indicateurs de l'éducation à la loupe, $\mathrm{n}^{\circ} 18$ (2013)

https://doi.org/10.1787/5jz8ssmrbbhb-fr

"Les filières professionnelles du deuxième cycle du secondaire améliorent-elles les perspectives d'emploi des jeunes adultes ? ", Les indicateurs de l'éducation à la loupe, $\mathrm{n}^{\circ} 17$ (2013)

https://doi.org/10.1787/5js008vr1zhk-fr

"Quelles sont les bonnes politiques pour former des jeunes actifs hautement qualifiés ? ", Les indicateurs de l'éducation à la loupe, $\mathrm{n}^{\circ} 16$ (2013)

https://doi.org/10.1787/5jz8qjd542lv-fr

« Comment le profil des étudiants de l'enseignement supérieur évolue-t-il ? », Les indicateurs de l'éducation à la loupe, $\mathrm{n}^{\circ} 15$ (2015)

https://doi.org/10.1787/5js008vx53wl-fr

"Quels facteurs influencent la mobilité internationale des étudiants ? ", Les indicateurs de l'éducation à la loupe, $\mathrm{n}^{\circ} 14$ (2013)

https://doi.org/10.1787/5k40hdc1cmth-fr

"Transition des études à la vie active : Quelles difficultés ? ", Les indicateurs de l'éducation à la loupe, $n^{\circ} 13(2013)$ https://doi.org/10.1787/5k40hdc378wj-fr

"Quels facteurs influent sur le niveau des dépenses au titre du personnel enseignant ? ", Les indicateurs de l'éducation à la loupe, $\mathrm{n}^{\circ} 12$ (2013)

https://doi.org/10.1787/5k4818h0klr5-fr

«En quoi les politiques, les systèmes et la qualité de l'éducation et de l'accueil des jeunes enfants (EAJE) se différencient-ils dans les pays de l'OCDE ? ", Les indicateurs de l'éducation à la loupe, $n^{\circ} 11$ (2013) https://doi.org/10.1787/5k49czkvxr0w-fr

"Quelles sont les retombées sociales de l'éducation ? ", Les indicateurs de l'éducation à la loupe, n 10 (2013)

https://doi.org/10.1787/5k4c78m89ng0-fr 
" Dans quelle mesure la taille des classes varie-t-elle d'un pays à l'autre ? ", Les indicateurs de l'éducation à la loupe, $n^{\circ} 9$ (2012)

https://doi.org/10.1787/5k8x7gvill77d-fr

"L'augmentation des dépenses privées affecte-t-elle le niveau des dépenses publiques et l'équité de l'accès à l'éducation, en particulier dans l'enseignement tertiaire ? ", Les indicateurs de l'éducation à la loupe, $n^{\circ} 8$ (2012)

https://doi.org/10.1787/5k8zs4317b9p-fr

« Dans quelle mesure les pays parviennent-ils à former les jeunes au niveau requis pour trouver un emploi et gagner leur vie ? ", Les indicateurs de l'éducation à la loupe, $\mathrm{n}^{\circ} 7$ (2012)

https://doi.org/10.1787/5k91d4fmc8tc-fr

«Quel est le rendement de l'investissement dans l'enseignement supérieur pour les individus et la société ? ", Les indicateurs de l'éducation à la loupe, $n^{\circ} 6$ (2012)

https://doi.org/10.1787/5k91d4fpzk5c-fr

"Quelle est l'évolution du vivier mondial de talents ? ", Les indicateurs de l'éducation à la loupe, n $^{\circ} 5$ (2012) https://doi.org/10.1787/5k97b07r4f7g-fr

"Quelle est l'ampleur des inégalités de revenus dans le monde - et comment l'éducation peut-elle aider à les réduire ? ", Les indicateurs de l'éducation à la loupe, $n^{\circ} 4$ (2012)

https://doi.org/10.1787/5k97jv7/466l-fr

"Comment les filles réussissent-elles dans leurs études - et les femmes au travail - dans le monde ? ", Les indicateurs de l'éducation à la loupe, $\mathrm{n}^{\circ} 3$ (2012)

https://doi.org/10.1787/5k9crhnx265c-fr

"Quelles aides les pays apportent-ils aux étudiants de l'enseignement supérieur dans le monde ? ", Les indicateurs de l'éducation à la loupe, $\mathrm{n}^{\circ} 2$ (2012)

https://doi.org/10.1787/5k9d5v70pOla-fr

"Quel est l'impact de la crise économique mondiale sur les individus en fonction de leur niveau de formation ? ", Les indicateurs de l'éducation à la loupe, $\mathrm{n}^{\circ} 1$ (2012)

https://doi.org/10.1787/5k9d5v71tskb-fr 


\section{Regards sur l'éducation 2019}

\section{LES INDICATEURS DE L'OCDE}

Regards sur l'éducation est la publication de référence sur l'état de l'éducation dans le monde. Elle fournit des données clés sur la structure, le financement et la performance des systèmes d'éducation des pays de l'OCDE, ainsi que d'un certain nombre de pays partenaires. Avec plus de 100 tableaux et graphiques - et des liens vers de nombreuses données supplémentaires sur notre base de données consacrée à l'éducation - cette publication présente des données clés sur les résultats des établissements d'enseignement ; l'impact de l'apprentissage dans les différents pays ; l'accès, la participation et la progression au sein des systèmes d'éducation ; les ressources financières investies dans l'éducation ; et les enseignants, l'environnement d'apprentissage et l'organisation scolaire.

L'édition 2019 inclut un éclairage spécifique sur l'enseignement tertiaire, avec de nouveaux indicateurs sur le taux de réussite à ce niveau, sur les doctorants et leurs perspectives sur le marché du travail, sur les systèmes d'admission dans l'enseignement tertiaire, ainsi qu'un chapitre dédié au quatrième Objectif de développement durable.

Les fichiers Excel ${ }^{\mathrm{TM}}$ qui ont servi à l'élaboration des tableaux et graphiques de Regards sur l'éducation sont disponibles via les liens StatLinks fournis tout au long de la publication. Les tableaux et graphiques ainsi que la base de données complète de l'OCDE sur l'éducation sont disponibles sur le site de l'OCDE dédié à l'éducation (www.oecd.org/education/education-at-a-glance-19991487.htm). Les données actualisées peuvent être consultées en ligne à l'adresse http://dx.doi.org/10.1787/eag-data-fr.

Veuillez consulter cet ouvrage en ligne : https://doi.org/10.1787/6bcf6dc9-fr.

Cet ouvrage est publié sur OECD iLibrary, la bibliothèque en ligne de l'OCDE, qui regroupe tous les livres, périodiques et bases de données statistiques de l'Organisation.

Rendez-vous sur le site www.oecd-ilibrary.org pour plus d'informations.

\section{éditionsOCDE}

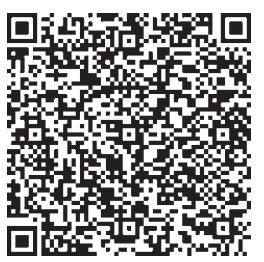

ISBN 978-92-64-67749-4

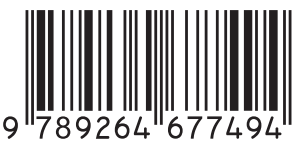

